\title{
Archéologie de la montagne européenne
}

Actes de la table ronde internationale de Gap, 29

septembre- $1^{\text {er }}$ octobre 2008

\section{Stéfan Tzortzis et Xavier Delestre (dir.)}

DOI : 10.4000/books.pccj. 143

Éditeur : Publications du Centre Camille Jullian, Éditions Errance

Année d'édition : 2010

Date de mise en ligne : 13 février 2020

Collection : Bibliothèque d'archéologie méditerranéenne et africaine

EAN électronique : 9782957155736

\section{Q OpenEdition}

\section{Books}

https://books.openedition.org

\section{Édition imprimée}

Date de publication : 1 juin 2010

EAN (Édition imprimée) : 9782877724234

Nombre de pages : 333

\section{Référence électronique}

TZORTZIS, Stéfan (dir.) ; DELESTRE, Xavier (dir.). Archéologie de la montagne européenne : Actes de la table ronde internationale de Gap, 29 septembre-7er octobre 2008. Nouvelle édition [en ligne]. Aix-en-

Provence : Publications du Centre Camille Jullian, 2010 (généré le 08 décembre 2022). Disponible sur Internet : <http://books.openedition.org/pccj/143>. ISBN : 9782957155736. DOI : https://doi.org/ 10.4000/books.pccj.143. 


\section{RÉSUMÉS}

Depuis quelques années, l'archéologie de la montagne connaît un indéniable regain d'intérêt.

Les problématiques liées au statut des espaces d'altitude irriguent des programmes pluridisciplinaires, actuellement menés ou projetés dans les différents massifs européens. Dans ce contexte, les approches diachroniques et géoarchéologiques permettent désormais de mieux connaitre des territoires qu'une absence de recherche et certains présupposés maintenaient encore naguère dans un état proche de la terra incognita. Cette dynamique est rythmée par toute une série de rencontres internationales dans laquelle s'inscrit la table ronde qui s'est déroulée au Musée-Muséum départemental de Gap entre le 29 septembre et le 1er octobre 2008. Les vingtneuf contributions rassemblées dans le présent volume reflètent à la fois la diversité des zones étudiées et l'interdisciplinarité des recherches.

Avec cette publication, nous espérons contribuer de façon significative au dialogue et à la coordination nécessaires entre les équipes de recherche se vouant à l'étude de la présence et de l'activité de l'homme au coeur des écosystèmes de moyenne et de haute montagne en Europe, des milieux bien particuliers, parfois difficiles à appréhender et trop longtemps restés en marge des terrains d'investigation de l'archéologie.

\section{NOTE DE L'ÉDITEUR}

Textes réunis par Stéfan Tzortzis et Xavier Delestre avec la collaboration de Jennifer Greck. 


\section{Bibliothèque d'Archéologie \\ Méditerranéenne et Africaine \\ 4}


Dans la lignée des anciens Travaux de Centre Camille Jullian, la Bibliothèque d'Archéologie Méditerranéenne et Africaine (BiAMA) regroupe des travaux (monographie, actes de colloques, ouvrages collectifs) en relation avec les programmes scientifiques du Centre Camille Julian, sur l'histoire et l'archéologie de la Gaule méridionale, de l'Afrique du Nord et du bassin méditerranéen. La BiAMA peut comprendre des sous-séries, comme la collection Études massaliètes (EtMassa).

Responsable légal :

Dominique Garcia, Directeur du CCJ

Directeur de la publication :

Henri Tréziny

Comité de pilotage :

Xavier Delestre, Dominique Garcia, Henri Tréziny

Conception graphique et mise en page :

Virginie Teillet

Comité de lecture :

Ph. Borgard (CCJ, CNRS), M.-Br. Carre (CCJ, CNRS), X. Delestre (DRAC PACA), D. Garcia (CCJ, Université de Provence), M. Griesheimer (CCJ, Université de Provence), A. Hermary (CCJ, Université de Provence), Ph. Jockey (CCJ, Université de Provence), M. Lombardo (Professeur à l'Université de Lecce), T. S. Loseby (Professeur à l'Université de Sheffield), J.-M. Mignon (Service archéologique départemental du Vaucluse), P. Pomey (CCJ, CNRS), L. Rivet (CCJ, CNRS), J. Sanmarti (professeur à l'Université de Barcelone), H. Tréziny (CCJ, CNRS), C. Virlouvet (CCJ, Université de Provence), E. Voutiras (Professeur à l'Université de Thessalonique).

(C) 2010 pour tous pays,

Édition Errance, éditeur du groupe Actes Sud,

7, rue Jean Du Bellay 75004 Paris

Tél. : 0443268582

Fax : 0143293488

Courriel : contact@editions-errance.fr

http://www.librairie-epona.fr

Centre Camille Jullian

Maison Méditerranéenne des Sciences de l'Homme

5 rue du Château de l'Horloge. BP 647, 13094 Aix-en-Provence Cedex 2

ISBN : 978-2-87772-423-4

Illustration de couverture : La haute vallée de la Durance et le massif des Écrins, au premier plan, la citadelle de Montdauphin (cliché Christian Hussy, DRAC SRA de Provence Alpes-Côte d'Azur).

Illustration 4ème de couverture: Gravures rupestres du val de Fontanalba, Alpes-Maritimes (cliché Michel Olive, DRAC SRA de Provence-Alpes-Côte d'Azur).

\section{Publications du Centre Camille-Jullian}

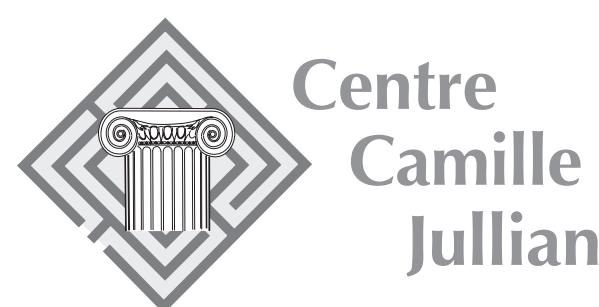

Ouvrage financé par le

Ministère de la Culture et de la Communication

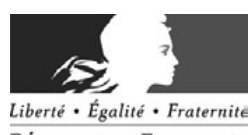

RÉPUBLIQUE FRANÇAISE

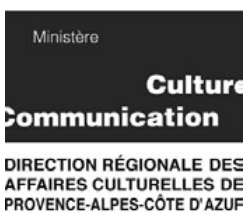

Envoyer les manuscrits à :

Henri Tréziny

Bibliothèque d'Archéologie Méditerranéenne et Africaine

Centre Camille Jullian

Maison Méditerranéenne des Sciences de l'Homme

5 rue du Château de l'Horloge. BP 647,

13094 Aix-en-Provence Cedex 2 


\section{Archéologie de la montagne européenne}

Actes de la table ronde internationale de Gap 29 septembre- $1^{\text {er }}$ octobre 2008

Textes réunis par

Stéfan TZORTZIS et Xavier DELESTRE

avec la collaboration de Jennifer GRECK 


\section{Sommaire}

\section{PREMIÈRE PARTIE : \\ MÉTHODOLOGIES DES ENQUÊTES ARCHÉOLOGIQUES EN MOYENNE ET HAUTE MONTAGNE}

Thomas HUET

Utilisation de l'outil SIG dans l'étude des gravures protohistoriques de la région du mont Bego (Alpes-Maritimes, France)

Use of GIS tool to study protohistorical rock engravings in the Mont Bego region (Alpes-Maritimes, France)

\section{Philippe DELLA CASA}

Recherche interdisciplinaire en archéologie et écologie humaine dans la vallée centre-alpine de la Léventine, Tessin (Suisse) Interdisciplinary research on archaeology and human ecology in the Central Alpine valley of Leventina,Ticino (Switzerland) ....

Ermengol GASSIOT, Albert PÈLACHS, Marie-Claude BAL, Virginia GARCIA, Ramon JULIÀ, Ramon PÉREZ, David RODRÍGUEZ et Anne-Charlotte ASTROU

Dynamiques des activités anthropiques sur un milieu montagnard dans les Pyrénées occidentales catalanes durant la Préhistoire: une approche multidisciplinaire

Dynamics of human activities on a mountain site in Western Catalan Pyrenees during the prehistoric period:

a multidisciplinary approach

\section{Franck SUMÉRA et Henri GEIST}

Exploitation de la haute montagne du Mercantour et impact sur l'environnement depuis l'âge du Fer. Étude de cas:

l'exemple du vallon de Millefonts, commune de Valdeblore (Alpes-Maritimes)

Exploitation of the high mountain of Mercantour and impact on environment since the Iron age. Study of case:

the example of the dale of Millefonts, village of Valdeblore (Alpes-Maritimes)

\section{Nathalie MAGNARDI et Silvia SANDRONE}

Les premiers résultats de la prospection-inventaire dans la haute vallée de la Roya (Alpes-Maritimes, France)

The first results of the prospection-inventory in the upper Roya valley (Alpes-Maritimes, France)

\section{Laurent FAU}

Approche méthodologique de l'étude du peuplement montagnard médiéval: l'exemple des plateaux d'Aubrac et du Cézallier dans le Massif Central

Methodological approach of the study of mountain mediaeval settlement: the example of Aubrac et Cezallier plateaus

in the Massif Central

Diego MORENO, Carlo MONTANARI, Anna Maria STAGNO et Chiara MOLINARI

A plea for a (New) Environmental Archaeology: the use of the geographical historical microanalitical approach in mountain areas of NW Italy

Pour une archéologie des ressources de l'environnement de montagne : l'apport de la microanalyse historique et géographique du site

Juliette LASSALLE et Béatrice PALMERO

L'exploitation pastorale des territoires de confins de la haute vallée de la Roya à travers les sources écrites (XII ${ }^{e}-\mathrm{XVIII}^{\mathrm{e}} \mathrm{s}$.). 
Contribution à une approche pluridisciplinaire

Pastoral use of lands at the confines of upper Roya valley, based on written $12^{\text {th }}$ to $17^{\text {th }}$ century documents.

Contribution to a pluridisciplinary study

Ada ACOVITSIOTI-HAMEAU

Une montagne à vivre et à partager: le territoire de Montegrosso-Pian-Latte en Ligurie

A mountain for living and sharing: the montegrosso-Pian-Latte territory in Liguria

\section{Véronique LALLEMAND et Hélène BREICHNER}

L'archéologie en milieu montagnard en Languedoc-Roussillon : études de cas en Cerdagne (Pyrénées-Orientales) et sur les causses lozériens (Lozère)

Mountain archaeology in Languedoc-Roussillon region: studies of cases in Cerdagne (Pyrénées-Orientales) and

on the lozerian limestone plateaus (Lozère)

Xavier MARGARIT et Carine DEAL

Quelle archéologie préventive pour l'espace montagnard ? Pratiques et enjeux dans l'Arc alpin et le département des Hautes-Alpes

Preventive archaeology in moutain environments? Practices and issues in the Alpsand the "Hautes-Alpes" County ......

\section{DEUXIÈME PARTIE :}

\section{CHRONOLOGIES, PALÉO-ENVIRONNEMENT, MODALITÉS DE FRÉQUENTATION ET D'EXPLOITATION DE LA MOYENNE ET DE LA HAUTE MONTAGNE}

\section{Fernand DAVID}

Diversité des paléo-paysages dans les Alpes françaises depuis la dernière glaciation

Diversity of the palaeo-landscapes in the French Alps since the last glacial retreat

Xavier MANGADO, Maria MERCÈ BERGADÀ, Mathieu LANGLAIS, Xavier ESTEVE, José Miguel TEJERO, Alicia ESTRADA $(\dagger)$, Jordi NADAL, Oriol MERCADAL et Josep Maria FULLOLA

Montlleó: un gisement des chasseurs magdaléniens dans la plaine de la Cerdagne. L'occupation d'un espace montagnard dans les Pyrénées de la Catalogne?

Montlleó: a Magdalenian hunter's site in the Cerdagne valley. Evidences of mountain environments occupation by humans in the Catalan Pyrenees?

Oscar BELVEDERE et Vincenza FORGIA

Prehistoric settlement and population in the Madonie mountains: new data from the archaeological survey

Occupation et population préhistoriques dans les montagnes de Madonie: nouvelles données archéologiques

\section{Walter LEITNER}

Traces to the oldest flint and rock crystal mining places int the Austrian Alps

Les plus anciens sites d'extraction de silex et de cristal de roche dans les Alpes autrichiennes

Michel MARTZLUFF, Jorge MARTINEZ MORENO, Joel CASANOVA et Rafael MORA

La montagne comme modèle d'enregistrement des mutations « culturelles » précoces : les cas de l'Azilien et du Sauveterrien en Pyrénées catalanes

The role of the moutain in the pioneer "cultural" mutations: the Azilian and the Sauveterrian in the Catalan Pyrenees

Gilles MONIN, Christophe GRIGGO, Julia FOURNIER et Christine OBERLIN

Exploitation d'un écosystème alpin au Tardiglaciaire: les chasseurs de marmottes (Marmota marmota) du Vercors.

Données environnementales, culturelles et économiques

Management of an alpine ecosystem during the late glacial: marmot hunters in the Vercors.

Environmental, economic and cultural findings

Philippe CURDY, Jérôme BULLINGER, Pierre CROTTI, Veruska VALSECCHI et Willy TINNER

Recherches archéologiques dans les régions du Simplon et de l'Albrun (Valais et Piémont), du Mésolithique à l'époque romaine Archaeological survey around the Simplon and Albrun passes (Valais, Piemont), from Mesolihic to Roman period 
Pierre-Jérôme REY, Cécile BATIGNE-VALLET, Julien COLLOMBET, Claire DELHON, Lucie MARTIN, Bernard MOULIN, Jérôme POULENARD, Nicolas SCOCCIMARRO, Dominique SORDOILLET, Stéphanie THIÉBAULT et Jean-Michel TREFFORT

Approche archéologique et environnementale des premiers peuplements alpins autour du col du Petit-Saint-Bernard (Savoie, vallée d'Aoste): un bilan d'étape

Archaeological and environmental approaches to the first alpine settlements around the Petit-Saint-Bernard pass

(Savoie - Aoste valley): first results

Kevin WALSH, Florence MOCCI, Stéfan TZORTZIS, Céline BRESSY et Brigitte TALON

avec la collaboration de Suzi Richer, Mona COURT-PICON, Vincent DUMAS et Josep PALET-MARTINEZ

Les Écrins, un territoire d'altitude dans le contexte des Alpes occidentales de la Préhistoire récente jusqu'à l'âge du Bronze (Hautes-Alpes, France)

The Ecrins: a high altitude territory in the context of the Southern Alps, from the later prehistoric periods to the Bronze Age (Hautes-Alpes, France)

Alexandre MORIN, Loïc SERRIÈRES, Régis PICAVET avec la collaboration de Pierre-Yves CARRON, Jean-Pascal JOSPIN, Yannick TEYSSONNEYRE, Christophe GRIGGO, Fabrice MOUTHON

Structures pastorales sur les Hauts Plateaux du Vercors et les Hauts de Chartreuse

Frédéric SURMELY, Violaine NICOLAS, Stéfan TZORTZIS, Yannick MIRAS, Aurélie SAVIGNAT, Pascal GUENET,

Gabriel SERVERA et Stéphane PETIT

Recherches sur l'histoire de l'occupation humaine sur la planèze sud du Plomb du Cantal

Historical survey about the human settlement on the "south Planèze" of the Plomb du Cantal

Andreas LIPPERT

Late Bronze Age helmets with crests on transalpine long-distance trade routes

Découvertes de casques à crête du Bronze final sur des routes commerciales transalpines

Laurent CAROZZA, Pierre ROSTAN, David BOURGARIT, Benoît MILLE, Yvan COQUINOT, Albane BURENS, Nicolau Escanilla ARTIGAS

Un site métallurgique du Bronze ancien dans le vallon du Longet à Molines-en-Queyras (Hautes-Alpes) : caractérisation du contexte archéologique et des déchets liés aux activités de métallurgie extractive An Early Bronze Age metallurgic site in the longet dale (Molines-en-Queyras, Hautes-Alpes):

characterization of the archaeological context and the extractive metallurgy waste

Vanessa PY et Aline DURAND

Évolution des écosystèmes et des pratiques agrosylvopastorale et minière pour la production de bois de feu dans le Haut-Champsaur et la Haute-Durance (France) de l'âge du Bronze ancien au xvie s.

Evolution of the ecosystems and forestry, pastoral and mining practices for the production of firewood in the upper Champsaur and upper Durance valleys (France) from the Late Bronze Age to the 16th century AD

Bruno ANCEL

Les anciennes mines métalliques des Alpes du Sud: bilan diachronique

Ancient metal mining activity in the southern Alps: diachronic review

\section{LÖ̈c SERRIÈRES}

Les Alpes françaises du Nord à l'âge du Fer

The French Northern Alps during the Iron age period (800-0)

Florence MOCCI, Maxence SEGARD, Kevin WALSH et Raphaël GOLOSETTI avec la collaboration de Vincent DUMAS, Carine CENZON-SALVAYRE et Brigitte TALON

Données récentes sur l'occupation humaine dans les Alpes méridionales durant l'Antiquité

Recent research on human settlement in the Southern Alps during Antiquity 309

Jean-Louis ÉDOUARD

Longue chronologie de cernes du mélèze et occupation humaine depuis plus de mille ans dans la vallée de la Clarée

(Briançonnais, Alpes françaises)

The long chronology of larch trees and human settlement during more than a thousand years in the Clarée valley

(Briançonnais, french Alps) 


\title{
Avant-propos
}

\author{
Stéfan TZORTZIS*, Xavier DELESTRE**, Jennifer GRECK***
}

$\mathrm{D}$ epuis quelques années, les recherches archéologiques menées en milieu montagnard sont marquées par un indéniable regain d'intérêt. Les problématiques liées au statut des territoires d'altitude, en particulier les questions de chronologies et de modalités du peuplement ainsi que d'exploitation des écosystèmes de moyenne et de haute montagne, constituent le fondement de plusieurs programmes de recherche pluridisciplinaire actuellement menés ou projetés dans les différents massifs européens. Dans ce contexte, les approches diachroniques et géoarchéologiques ont récemment permis de documenter des zones parfois quasiment vierges de toute référence.

En région Provence-Alpes-Côte d'Azur, les investigations se sont longtemps concentrées sur une petite série de sites emblématiques dont la très célèbre vallée des Merveilles et le val de Fontanalba dans le département des AlpesMaritimes. À ces acquis s'ajoutaient des trouvailles fortuites et des fouilles de sauvetage ponctuelles. À partir du début des années 1990, c'est à Jean-Paul Jacob, alors Conservateur Régional de l'Archéologie, que l'on doit le renouveau de l'activité scientifique sur ces territoires par le lancement d'un programme d'étude sur les mines et la métallurgie. Un thème qui est aujourd'hui illustré par les recherches menées sur deux sites importants du département des Hautes-Alpes: la mine de cuivre préhistorique des Clausis à Saint-Véran, et la mine de plomb argentifère médiévale et contemporaine du Fournel à L'Argentière-la-Bessée. Depuis lors, de nouveaux programmes ont été lancés sur le pastoralisme par le biais de prospections et de fouilles et, plus généralement, sur l'histoire du peuplement de la moyenne et haute montagne: haute vallée de l'Ubaye (Alpes-de-Haute-Provence), massif des Écrins (Champsaur, hautes vallées de Freissinières et du Fournel, Hautes-Alpes) massif du Mercantour (AlpesMaritimes)... Au cours de la dernière décennie, des données nouvelles ont été acquises sur le paléoenvironnement. Enfin, des fouilles ont livré des données archéologiques de première importance scientifique. Parmi celles-ci on citera le tertre des Sagnes (Jausiers, Alpes-de-Haute-Provence) sur les pratiques funéraires protohistoriques ou le cimetière de pestiférés de Lariey (Puy-Saint-Pierre, Hautes-Alpes) contemporain de la grande épidémie de 1629-1630. Dans le même temps, des travaux universitaires ont permis de revoir l'ensemble de la documentation et la préciser. Ainsi, d'année en année, l'archéologie dans les Alpes du Sud s'est organisée et structurée avec pour principale caractéristique une approche alliant prospections et fouilles. Suite à ce renouvellement des connaissances, au développement économique des départements alpins avec notamment la restructuration des sites de stations de ski et les modifications climatiques qui ouvrent pour la recherche, dans un avenir proche, de nouveaux espaces, il semblait important d'établir un premier bilan et d'échanger avec les collègues œuvrant dans d'autres territoires de montagne, à l'échelle européenne.

Forts de ces constats, il nous est ainsi apparu opportun et pertinent d'organiser une rencontre permettant aux acteurs de ces recherches novatrices d'exposer, d'évaluer et de comparer leurs choix méthodologiques ainsi que les résultats les plus récents de leurs travaux. Cette rencontre se voulait également un lieu d'échange sur les stratégies et

\footnotetext{
* Ingénieur d'étude, Ministère de la Culture et de la Communication, Direction Régionale des Affaires Culturelles de PACA, Service Régional de l'Archéologie, 23 bd du Roi René, 13617 Aix-en-Provence cedex 1. Chercheur associé, Unité d'anthropologie bioculturelle, UMR 6578 CNRS-EFSUniversité de la Méditerranée, faculté de médecine, secteur Nord, 27 bd Pierre Dramard, 13916 Marseille cedex 20.

** Conservateur général du patrimoine, Conservateur Régional de l'Archéologie de Provence-Alpes-Côte d'Azur, 23 bd du Roi René, 13617 Aixen-Provence cedex 1. Chercheur au Centre Camille Jullian, UMR 6573 CNRS-Université de Provence, Maison Méditerranéenne des Sciences de l'Homme, 5 rue du Château de l'Horloge, BP 647, 13094 Aix-en-Provence cedex 2.

*** Étudiante en anthropologie biologique, Dynamique de l'évolution humaine: individus, populations, espèces, UPR 2147 CNRS, 44 rue de l'Amiral Mouchez, 75014 Paris.
} 
les priorités générales à mettre en œuvre pour assurer la poursuite et l'approfondissement des études relatives à la présence et à l'action de l'homme en montagne. Par cette initiative, nous espérions contribuer de façon significative aux nécessaires dialogue et coordination entre les équipes de recherche travaillant sur ces milieux bien particuliers, parfois difficiles à appréhender et trop longtemps restés en marge des terrains d'investigation de l'archéologie.

Cette manifestation, qui s'inscrivait dans une dynamique internationale ( $c f$. la rencontre du printemps 2008 à Tarragone en Espagne et celle de l'année suivante à Toulouse), a rencontré un écho très favorable, comme en témoignent les vingt-neuf contributions regroupées dans ce volume. Un vaste champ chronologique de la Préhistoire ancienne à l'Époque moderne, est ainsi scruté. Les articles concernent des territoires européens échelonnés entre les étages végétatifs «montagnard», à partir de 800-1200 m, et «alpin», jusqu'à environ $3000 \mathrm{~m}$ d'altitude, selon la terminologie française traditionnelle. Les réflexions diachroniques sur le peuplement et les dynamiques naturelles et sociales sont bien représentées. À leur lecture, on peut constater qu'un vaste ensemble de massifs est abordé, avec d'ouest en est, les Pyrénées catalanes, le Massif Central en France, les Alpes françaises, italiennes, suisses, autrichiennes, les montagnes de Sicile, les Apennins ligures.

Sans chercher à compartimenter outre mesure les différentes approches des écosystèmes de montagne, lesquelles participent de toute façon d'une dynamique scientifique commune, nous avons toutefois fait le choix de dégager deux thématiques principales afin de structurer le présent recueil de textes :

- méthodologies des enquêtes archéologiques en moyenne et haute montagne;

- chronologies, paléo-environnement, modalités de fréquentation et d'exploitation de la moyenne et de la haute montagne.
Nous ne saurions omettre, dans ce propos introductif, d'adresser nos plus vifs remerciements à toutes celles et à tous ceux qui par leur engagement ou leur aide ont contribué de façon décisive, d'une part au succès de la table ronde de Gap et d'autre part à la publication du présent volume d'actes. Ce projet n'aurait pu se concrétiser sans le soutien de l'État (Ministère de la Culture et de la Communication - Direction Régionale des Affaires Culturelles de Provence-Alpes-Côte d'Azur) ainsi que celle du Conseil Général des Hautes-Alpes. Notre entreprise n'aurait pu voir le jour sans le soutien attentif de Monsieur Jean-Yves Dusserre, Président, et celui de Monsieur Richard Siri, Vice-Président chargé de la culture, du patrimoine, de la vie associative et des relations avec les groupes, toujours à nos côtés pour favoriser le développement des travaux de recherches archéologiques dans le département. Nous sommes également redevables à l'équipe du Musée-Muséum départemental de Gap, en particulier à sa directrice, Madame Frédérique Verlinden, ainsi qu'à l'archéologue départementale, Mademoiselle Carine Deal. Nos remerciements s'adressent également à la ville de Gap et à son Maire, Monsieur Roger Didier, au directeur du Centre d'Études Préhistoire Antiquité, Moyen Âge (CEPAM, UMR 6130 CNRS-Université de Nice Sophia Antipolis), Monsieur Didier Binder, au directeur du Centre Camille Jullian (CCJ, UMR 6573 CNRS-Université de Provence), Monsieur Dominique Garcia, ainsi qu'aux partenaires de la table ronde.

L'ensemble des différentes contributions a fait l'objet d'une relecture par Hugues Savay-Guerraz, conservateur du patrimoine, responsable scientifique des musées gallo-romains de Lyon-Fourvière ainsi que par Franck Perrin, maître de conférences en archéologie à l'université Lumière Lyon 2, tout deux membres de la Commission Interrégionale de la Recherche Archéologique Sud-Est. Qu'ils soient, eux aussi, chaleureusement remerciés. 


\section{Première Partie}

\section{MÉTHODOLOGIES DES ENQUÊTES ARCHÉOLOGIQUES EN MOYENNE ET HAUTE MONTAGNE}
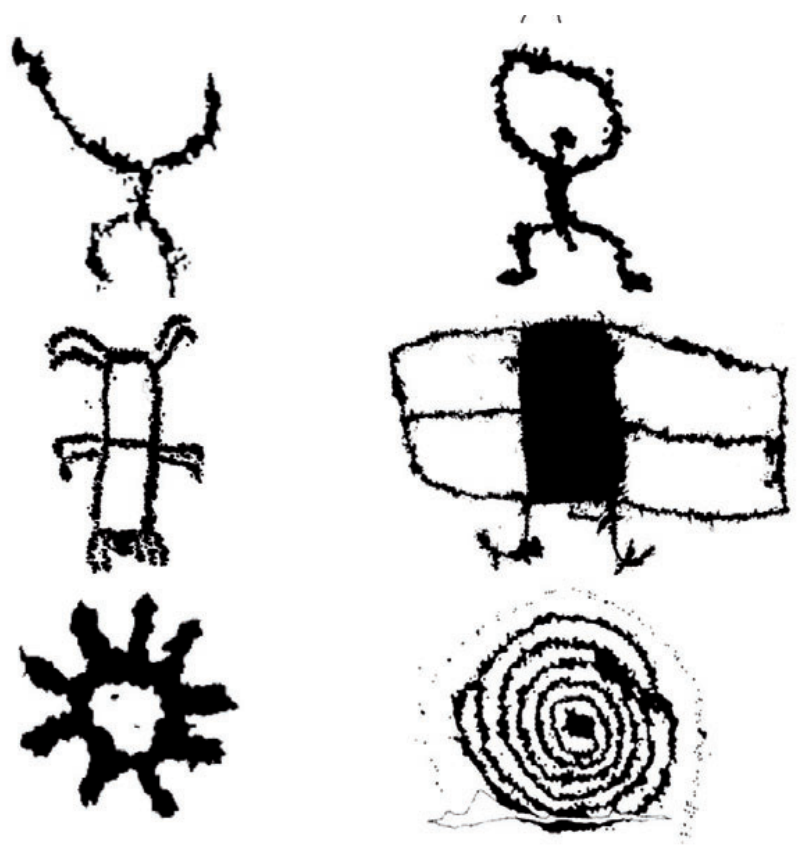
ARCHÉOLOGIE DE LA MONTAGNE EUROPÉENNE

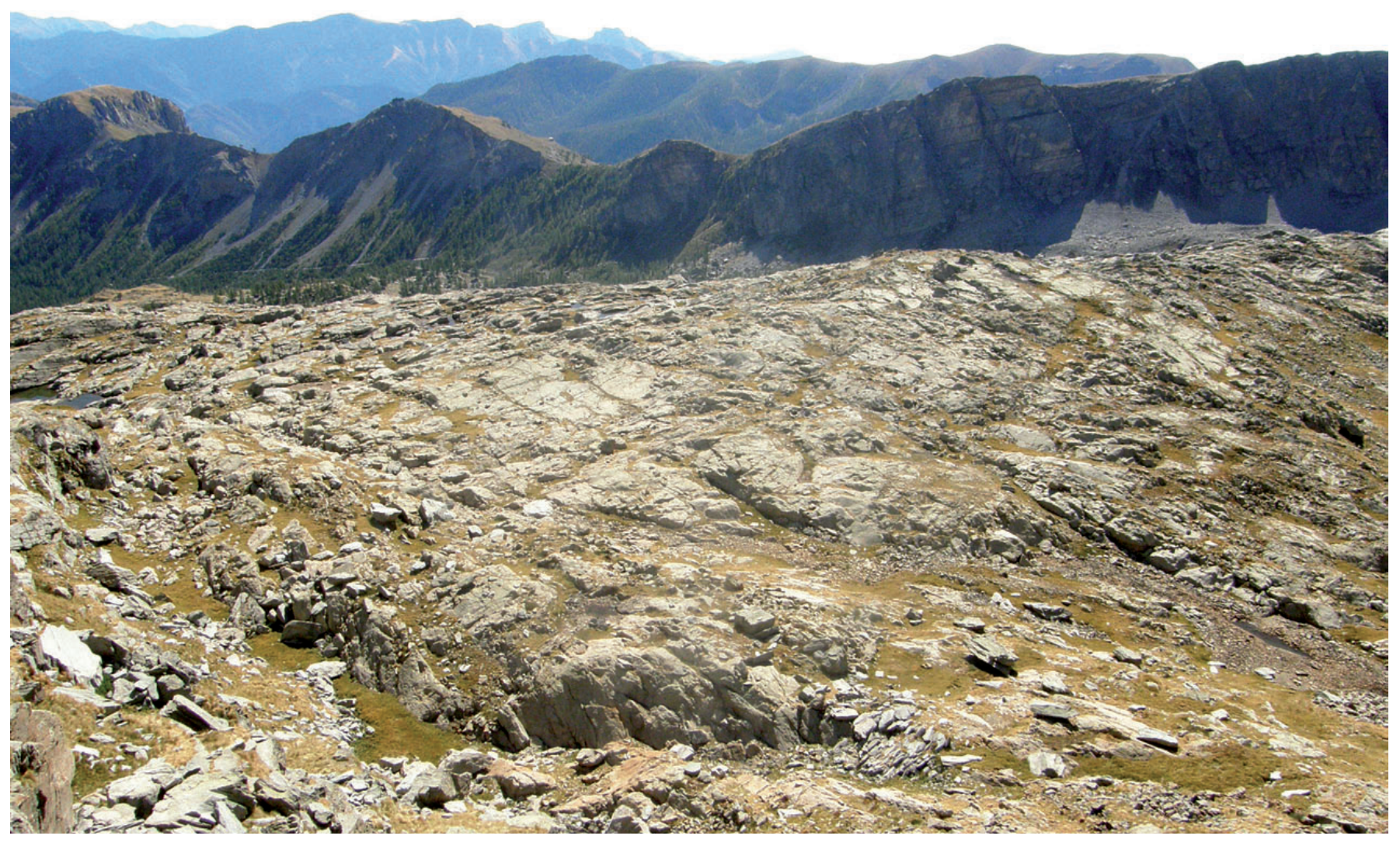

Fig. 1. Vue des ciappes de Fontanalba (zone XVIII, secteur de Fontanalba, mont Bego). 


\title{
Utilisation de l'outil SIG dans l'étude des gravures protohistoriques de la région du mont Bego (Alpes-Maritimes, France)
}

\author{
Thomas HUET*
}

\begin{abstract}
Résumé. L'avancée des recherches sur les gravures protohistoriques (relevés, base de données) dans la région du mont Bego, et le développement des outils d'analyse géographique (GPS, SIG) permettent de mettre en relation les roches gravées et leur contexte géographique. Cette démarche, si elle n'est pas tout à fait nouvelle, reste originale au vu de l'importance du corpus à traiter: 20000 gravures figuratives et 4200 roches gravées. Après leur intégration dans une base de données liée à un SIG, la spatialisation des données montre différents regroupements de gravures. Il restera encore à introduire dans l'analyse le critère chronologique pour distinguer une succession de systèmes graphiques (diachronie) d'une structuration symbolique de l'espace (synchronie). Ces résultats devraient pouvoir trouver un écho dans l'évolution des systèmes symboliques à la fin du Néolithique en Méditerranée occidentale.
\end{abstract}

Use of GIS tool to study protohistorical rock engravings in the Mont Bego region (Alpes-Maritimes, France)

Abstract. The advance of researches for the study of protohistorical engravings (drawings and database) in the mont Bego region, and the development of geographical analysis tools (GPS, GIS) allow to relate engraved rocks with their geographic context. This approach, if not totally new, is at least original given the corpus to work with: 20000 figurative engravings and 4200 engraved rocks. After their integration into a database link with a GIS, the spatial projection of data shows different groups of engravings. It stays to introduce in the analysis the chronologic criterion to distinguish between evolutions of graphical systems (diachronic) from the symbolical structuring of the site (synchronic). These results would probably found comparisons with the evolution of symbolic systems during later Neolithic in occidental Mediterranean.

\section{Introduction}

$\mathrm{L}$ a région du mont Bego, dans les Alpes du Sud, regroupe une concentration de quelques 35000 gravures piquetées (dont environ 20000 figuratives) réalisées probablement pour la plupart à la fin du Néolithique (De Lumley et al. 2003a, p. 585-626; 2003b, p. 441-471). Ces dernières sont regroupées sur 900 ha et étagées entre 2000 et 2700 m d'altitude, le site n'ayant certainement été occupé que de manière saisonnière durant les mois d'été (fig. 1).

Depuis 1967, Henry De Lumley et son équipe mènent l'inventaire systématique des gravures en centralisant l'ensemble des données et en développant une étude essentiellement tournée vers l'iconographie prenant notamment en compte les associations de signes. Plus de $95 \%$ des gravures peuvent être classées dans une dizaine de catégories (thèmes, fig. 2).

L'analyse spatiale des roches gravées, des thèmes figurés et des associations était restée relativement marginale ou implicite dans l'étude des gravures et s'arrêtait au niveau de la zone (De Lumley et al. 2003a, p. 312-317; 2003b, p. 246-254) malgré des essais précédents de définition d'ensembles géo-archéologiques. Nous avons développé un SIG qui a permis de conduire et de multiplier les observations dans un horizon de travail mitoyen entre l'analyse iconographique (associations de signes au niveau de la face gravée) et géo-statistique (regroupements géographiques de gravures).

\section{Mise en place du corpus d'étude}

La méthodologie actuelle d'enregistrement des gravures est celle mise en place par De Lumley avec un classement hiérarchique des gravures en secteur/zone/groupe/roche/ face/gravure.

Les roches et les faces gravées sont renseignées par plusieurs critères (nature, type, dimensions, orientation des faces...) pouvant être intégrés dans l'analyse. Pour les gravures, leur technologie (taille, forme, espacement des

* Centre d'Études Préhistoire Antiquité Moyen Âge (CEPAM), UMR 6130 CNRS - Université de Nice Sophia Antipolis, 250 avenue Albert Einstein, 06560 Valbonne cedex et Laboratoire départemental de Préhistoire du Lazaret, Boulevard Franck Pilatte, 06000 Nice. 
enlèvements ayant servi à la réalisation des gravures, patine) et leurs dimensions sont également enregistrées. La reconnaissance de leur caractère schématique et normalisé a conduit rapidement à la réalisation d'un lexique descriptif pour leur codification (De Lumley, Fontvieille, Abenalet 1976).

\subsection{Intégration des données dans le SIG}

Le niveau d'intégration des données repose sur les relations existant entre trois corpus: les données iconographiques, l'enregistrement dans la base de données et la situation de la roche gravée. Après digitalisation de l'ensemble des plans et millimétrés, la base de données liée au SIG regroupe plus de 4200 roches gravées, 3600 plans de roches liés et l'enregistrement de 35000 gravures. Ce corpus de données peut être considéré comme représentatif de l'ensemble des gravures présentes dans le site.

\subsection{Positionnement des roches}

Le secteur des Merveilles, sur lequel se concentrent les campagnes de vérification depuis 1998, est le plus prospecté et le mieux documenté, alors que celui de Fontanalba montre des disparités d'une zone à l'autre. Les zones périphériques (Veil del Bouc, Col du Sabion, Zone 0, Zone XXIII) restent encore mal connues. Ces différences dans la qualité des données se retrouvent dans le positionnement des roches gravées (fig. 3).

Carte des cheminements (1803 roches): les roches qui avaient été positionnées sur les cartes des cheminements par triangulation et chaînage sur un agrandissement du fond de carte IGN (1970) dès le début des recherches (id.) ont été intégrées dans le SIG après géoréférencement des cartes. La vérification sur la BD Ortho (cf. ci-dessous) montre des écarts moyens de $10 \mathrm{~m}$ entre ces positions et la position estimée sur la photographie aérienne. Des différences importantes existent en fonction de l'éloignement de ces roches à des points remarquables ou aux autres roches mieux positionnées (BD Ortho ou GPS différentiel). BD Ortho (1243 roches): sur le terrain, la BD Ortho de l'IGN (1999) fournit un bon référentiel pour le positionnement des roches avec une résolution d'un pixel pour un carré de terrain de $50 \mathrm{~cm}$ de côté (Huet, Davtian 2009): les pélites patinées orange et les grès violets qui ont été préférentiellement choisis pour être gravés sont généralement facilement repérables entre les bandes vertes de la pelouse alpine. Si le repérage est jugé difficile un indice '-' est noté (BD Ortho-). Après vérification au GPS, l'imprécision du positionnement sur la BD Ortho est généralement inférieure à $3 \mathrm{~m}$.

GPS différentiel (1 103 roches): dans le secteur des Merveilles, le positionnement GPS des roches gravées a été réalisé avec un GPS différentiel. Le contrôle-qualité effectué sur un même point par différents GPS (Leica 9500, Trimble PROXRS, Trimble R8) montre une précision généralement submétrique des coordonnées.

Description Françoise Villain (23 roches) : le cheminement décrivant le moyen d'accéder à chacune des roches gravées a également été utilisé lorsque les roches n'apparaissaient pas sur les cartes. Les écarts estimés avec les positions réelles sont de l'ordre d'une dizaine de mètres.

Position arbitraire (44 roches): dans le cas où aucune information géographique n'était disponible, les roches ont été positionnées par proximité de leur numéro d'identifiant (par ex. ZXVIII.GII.R $52 \eta$ proche de la roche ZXVIII. GII.R 52 ع). L’imprécision du positionnement est évaluée à environ $20 \mathrm{~m}$.

\subsection{Modélisation du terrain}

La modélisation numérique du terrain (MNT), associée à la qualité de la position de la roche gravée, doit permettre d'effectuer des analyses sur les correspondances entre les roches gravées et leur environnement: accès, visibilité, proximité pondérée aux lacs, cours d'eau, sentiers, gias. Elle a débuté avec la digitalisation des courbes de niveaux de la carte SCAN 25 de l'IGN (intervalle: $10 \mathrm{~m}$ ). Les courbes altitudinales du territoire italien ont été extrapolées à partir du SRTM de la Nasa (intervalle: 90 m). La lecture des photographies en stéréoscopie et la reconnaissance des volumes sur la BD Ortho ont permis d'approcher une précision altitudinale de l'ordre de $10 \mathrm{~m}$ avec, encore une fois, de grands écarts en fonction de l'éloignement des points remarquables.

Le contrôle des courbes de niveau avec les altitudes des roches relevées au GPS a permis de réduire les approximations. Le lac Long Supérieur a été restitué dans sa forme ancienne par digitalisation des courbes de niveau relevées par l'EDF avant l'édification du barrage (fig. 4). Il restera à faire de même pour les lacs Fourca et du Trem dans lesquels des roches gravées avaient été relevées.

Une partie du site, 47 ha, de l'ouest du lac Long Supérieur à l'entrée de la vallée des Merveilles ainsi que le fond de la vallée des Merveilles, a fait l'objet d'une modélisation précise avec une topographie GPS en continu avec un relevé tous les 3-5 m.

Le levé GPS en topographie continue a également concerné les environs de deux roches: «l'Homme aux bras en zigzag » (ZIV.GIII.R 16D) et « l'Autel» (ZXI.G0.R 1), 1 ha chacun, avec 1 point pris tous les 2-3 m. Finalement, ces deux roches ont été entièrement modélisées au GPS Trimble R8.

Pour l'affleurement de «l'Autel» 334 points ont été pris pour environ de $1000 \mathrm{~m}^{2}$ de superficie, soit 1 point tous les $3 \mathrm{~m}^{2}$, pour «l'Homme aux bras en zigzag », 27 points 


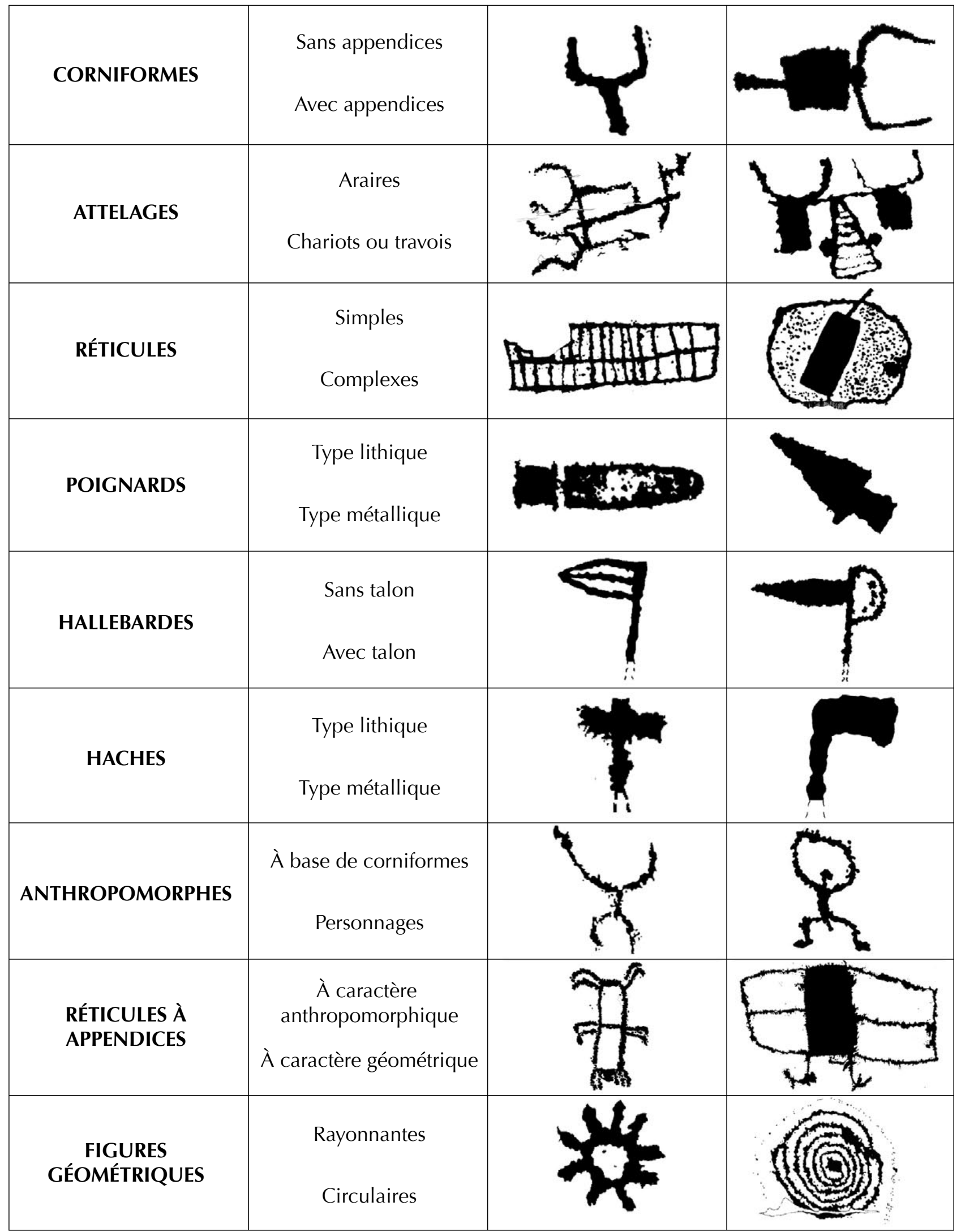

Fig. 2. Classement des principaux thèmes gravés dans le site du mont Bego. La colonne de gauche rend mieux compte des gravures du secteur des Merveilles, celle de droite des gravures du secteur de Fontanalba. 


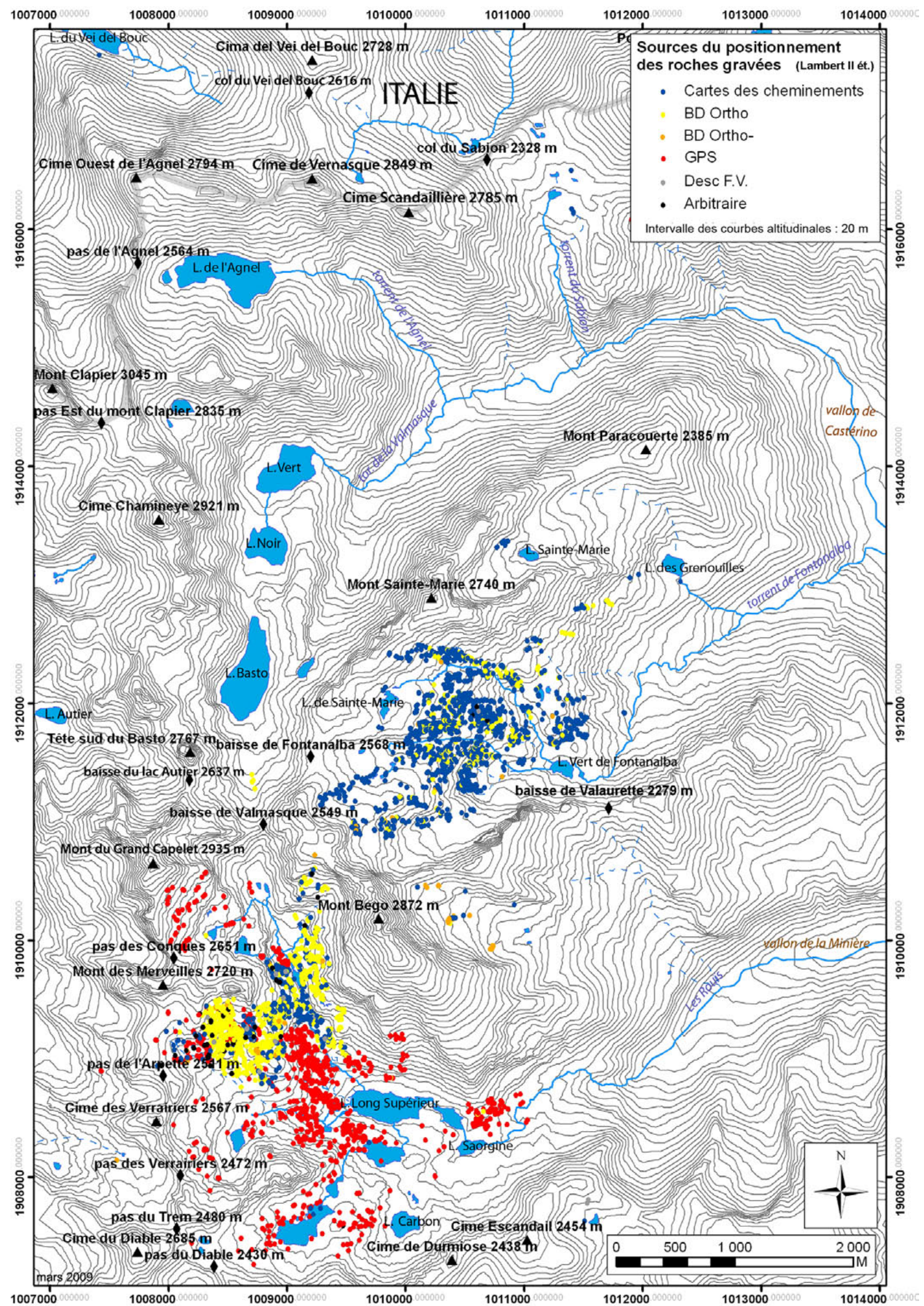

Fig. 3. Sources du positionnement des 4236 roches protohistoriques du site du mont Bego (mars 2009). Les principaux secteurs: celui des Merveilles se situe au sud et à l'ouest du mont Bego, celui de Fontanalba au nord du mont Bego. Il existe également plusieurs petits secteurs jusqu'au Vei del Bouc en Italie. 

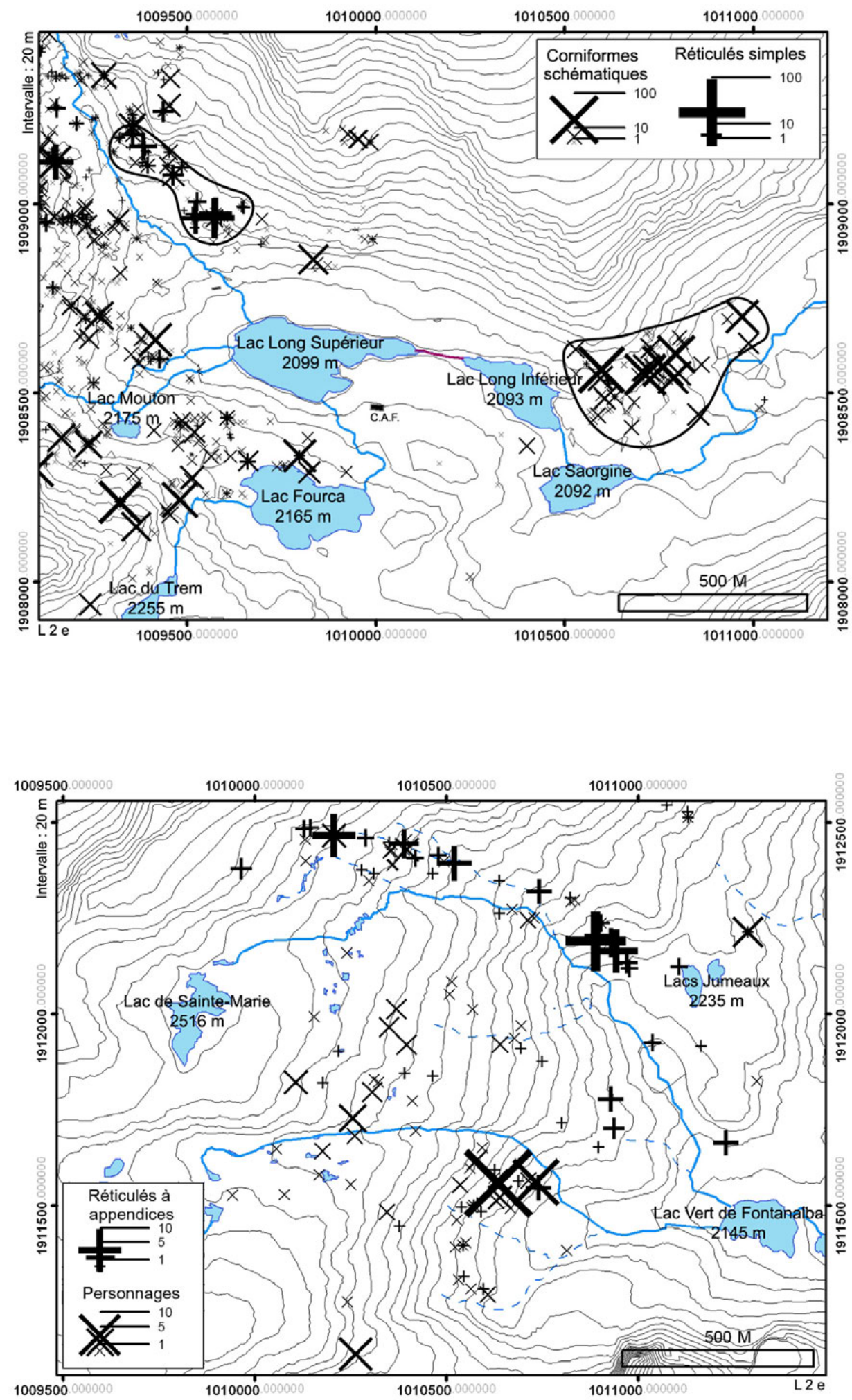

Fig. 4. Répartition des corniformes schématiques et des réticulés simples dans le secteur des Merveilles. Les corniformes constituent le «bruit de fond» du site avec plus de $60 \%$ des gravures figuratives. Dans le bas du secteur, leur proportion atteint $80 \%$. Les réticulés se concentrent à l'entrée et sur les flans de la vallée des Merveilles.
Fig. 5. Répartition des personnages et des réticulés à appendices à caractère géométrique dans le secteur de Fontanalba. Les premiers sont régulièrement associés à des attelages ou des hallebardes, moins souvent à des zigzags. Les seconds montrent une filiation iconologique avec les réticulés complexes (surtout Fontanalba) d'une part, et les réticulés à appendices à caractère anthropomorphique (surtout Merveilles) de l'autre. 
ont été pris pour $8,5 \mathrm{~m}^{2}$ de superficie, soit 1 point tous les $30 \mathrm{~cm}^{2}$. Dans les deux cas la précision en $x, y, \mathrm{z}$ est jugée inférieure à $10 \mathrm{~cm}$. À noter toutefois que pour les grands ensembles gravés (roche de «l'Autel $»$ ZXI.G0.R 1 , roche du « défilé Rivière » ZVII.GII.R 8, roche du « dos de baleine » ZVIII.GI.R 1...), un décalage peut apparaître entre le positionnement des relevés de gravures (fait par assemblage de calques) et le relevé GPS de leur contour.

\section{Analyse géospatiale}

Pour mettre en évidence des regroupements géographiques de gravures, nous avons donc privilégié une approche géostatistique qui prend en compte la proximité des thèmes qu'ils soient sur une même roche ou dans un ensemble régional. Nous présentons ici deux exemples. D'une part, au niveau régional ou local: la répartition des concentrations de corniformes schématiques et des réticulés simples (bas du secteur des Merveilles) et la répartition des personnages et des réticulés à appendices à caractère géométrique (secteur de Fontanalba). D'autre part, au niveau de la roche: la répartition des gravures sur les différentes faces de la roche de «l'Autel ».

\subsection{Les regroupements de corniformes schématiques et de réticulés simples dans le bas secteur des Merveilles}

Dans le bas secteur des Merveilles, la répartition des regroupements de corniformes et de réticulés montre une disjonction géographique (fig. 4).

Pour les corniformes, en aval du lac Long Inférieur (zone I groupe I), une forte proportion d'entre eux (290), sur les 780 que totalise l'ensemble des roches de cette partie du site, se retrouvent alignés dans des gouttières naturelles à l'exclusion des autres thèmes. Il est possible d'opposer ce premier regroupement à celui du replat rocheux au nord-ouest du lac Long Supérieur où l'on retrouve presqu'exclusivement des réticulés. Ces répartitions pourraient être liées à deux facteurs différents: d'une part la présence des gias (abris pastoraux) dans le bas de la zone liée à la réalisation de file de corniformes et de l'autre d'une analogie entre la topographie locale (espace plat) et la réalisation de réticulés sur des roches au pendage luimême relativement plat.

\subsection{Les regroupements de personnages et réticulés à appendices à caractère géométrique dans le secteur de Fontanalba}

Dans le secteur de Fontanalba, Clarence Bicknell avait noté l'existence d'une concentration de gravures: «Une autre forme rectangulaire très répandue - et presque uniquement dans le Val de Fontanalba - semble représenter une peau de bête. On la trouve principalement près du Lac Vert et dans la partie inférieure de Skin Hill » (Bicknell 1913 [1971]).

Ces gravures correspondent aux « réticulés à appendices à caractère géométrique » de notre classification (fig. 2). La spatialisation des données vient confirmer et compléter l'observation de Bicknell. Par ailleurs, mise en confrontation avec la répartition des personnages, elle fait ressortir deux concentrations distinctes au nord du secteur (ZXVII. GII) pour les réticulés à appendices et au sud (ZXIX.GIV) pour les personnages (fig. 5).

Lorsqu'une ligne de cupule est ajoutée aux réticulés à appendices à caractère géométrique ou aux réticulés complexes (fig. 2) celle-ci part systématiquement du petit côté de la plage rectangulaire. Sur la base de ces régularités iconographiques il est donc possible de considérer ces deux types de gravures comme se référant à un même signifié probablement lié aux techniques d'irrigation des champs. L'hypothèse la plus probable étant celle d'une évolution graphique d'une forme vers l'autre.

\subsection{La roche de « l'Autel » (ZXI.G0.R 1)}

Ce large affleurement de pélite patinée orange, situé à une centaine de mètres au nord du lac des Merveilles est la plus grande concentration de gravures du site avec 1371 gravures. Long de $54 \mathrm{~m}$ et orienté approximativement est-ouest, il affecte une forme triangulaire. La surface de la roche a été divisée en différents ensembles, ou faces, qui montrent des répartitions thématiques différentes. Les poignards et les réticulés forment deux regroupements disjoints. Les premiers formant une concentration, sur le haut de la roche et au nord de la roche, les seconds une concentration sur les faces sud, en aval des premiers (De Lumley et al. 1995 ; fig. 6).

L'analyse statistique des critères reconnus comme intervenant dans le choix des roches gravées (nature géologique, aspect de la surface, proximité aux chemins, inclinaison, dimension, De Lumley et al. 2003a ; 2003b) montrera certainement qu'ils ne suffisent pas, seuls, à expliquer une telle concentration. Des éléments de comparaisons viennent par ailleurs étayer l'hypothèse d'un choix prédéterminé de cette roche pour la réalisation de nombreux poignards (en opposition à un choix opportuniste). Il est probable que sa forme triangulaire (fig. 7) ait été la principale raison de l'importance des accumulations de gravures et plus particulièrement des représentations d'armes.

Cette hypothèse s'appuie sur les similitudes formelles existantes avec les podiums triangulaires M VI et M XII du Petit-Chasseur à Sion et T II de Saint-Martin-de-Corléans en Aoste ainsi que sur les représentations du poignard de 
type Remedello 2 des stèles anthropomorphiques érigées devant ces podiums. Cette période correspondrait au maximum de diffusion des poignards lithiques du Monti Lessini (Mottes 2006) et de Forcalquier (Renault 1998; Honegger 2006). La majorité des représentations de poignards du mont Bego montrant des similitudes avec les lames des poignards de type Remedello 2 (De Lumley et al. 2003a, p. $585-626$; 2003b, p. 441-471), la date de 2700 av. J.-C. (Heyd, Harrison 2004 pour la datation des podiums triangulaires; De Marinis, Pedrotti 1999 pour celle des poignards Remedello 2) peut donc être raisonnablement avancée.

\section{Conclusion}

Nous souhaiterions finalement orienter notre conclusion vers la fonction pastorale du site. Dans le secteur des Merveilles (zone I groupe I), les carottages effectués dans la tourbière du lac Long Inférieur (De Beaulieu 1977) et plus tard confirmés par l'étude des fossiles d'insectes (Ponel, Parchoux 1999) montrent des indices de pâturage dès l'âge du Bronze ancien (De Beaulieu, Goeury 2004). Dans une autre zone, au col du Sabion (2328 m) à $8 \mathrm{~km}$ au nord des lacs Longs, on retrouve des représentations de corniformes associées à des structures pastorales (Geist 2001) ainsi que des indices de pâturage dès le Bronze ancien (De Beaulieu, Goeury 2004). D'autres indices d'anthropisation (Kharbouch 1996; Ponel et al. 2001) et d'occupation saisonnière du site (Conti 1972 ; Machu et al. 2007) permettraient de reculer ces dates jusqu'au Néolithique moyen.

Ces éléments placeraient les gravures dans le phénomène plus général de prise de possession des alpages reconnu pour la Ligurie (Maggi 2000) et de spécialisation croissante des métiers exprimée ici par quelques 13000 représentations de bovinés (corniformes).

\section{Bibliographie}

Bicknell 1913 [1971]: BICKNELL (C.) - Guide des gravures rupestres préhistoriques dans les Alpes-Maritimes, Bordihera, Institut International d'Études Ligures, 1972, 138 p., 46 pl. h.t.

Conti 1972: CONTI (C.) - Corpus delle incisioni rupestri di Monte Bego, fascicolo I. Zone I. Regione dei Laghi Lunghi. Prefazione di Piero Barocelli, Bordighera, Istituto Internazionale di Studi Liguri (1971), 1972, 122 p., 32 fig.

De Beaulieu 1977: DE BEAULIEU (J.-L.) - Contribution pollenanalytique à l'histoire tardiglaciaire et holocène de la végétation des Alpes méridionales françaises, Thèse de doctorat d'État ès-sciences, Université d'Aix-Marseille III, 18 mars $1977,358 \mathrm{p}$.

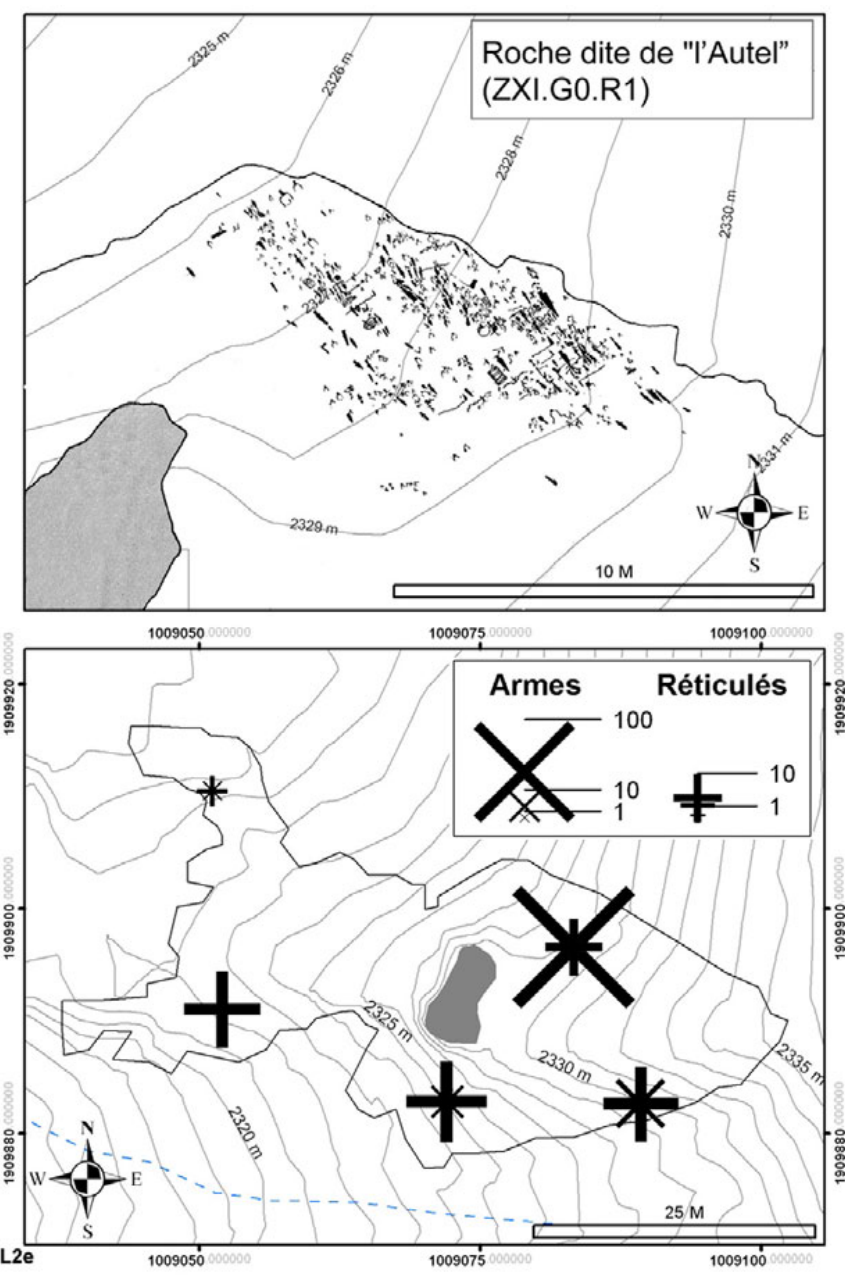

Fig. 6. Répartition des gravures d'armes et de réticulés simples sur la roche de l'Autel. Parmi les armes, les poignards sont les plus nombreux (164 ex.). Parmi les poignards, les lames triangulaires (90\%) et les bases rectilignes (46\%) sont les mieux représentées et se rapprochent des modèles italiques de Remedello 2 (2900-2400 av. J.-C.).

De Beaulieu, Goeury 2004 : DE BEAULIEU (J.-L.), GOEURY (C.) - Les premiers signes d'anthropisation des Alpes françaises d'après l'analyse pollinique. In: RICHARD (H.) dir., Néolithisation précoce. Premières traces d'anthropisation du couvert végétal à partir des données polliniques: résultats du programme CNRS «Paléoenvironnement, évolution des Hominidés », Besançon, Presses universitaires de FrancheComté (Collection Annales Littéraires), 2004, p. 163-171.

De Lumley, Fontvieille, Abenalet 1976: DE LUMLEY (H.), FONTVIELLE (M.-E.), ABENALET (J.) - Livret-guide de l'excursion C1: Vallée des Merveilles, 1976. Préface de José Balarello, IXe Congrès de l'Union Internationale des Sciences Préhistoriques et Protohistoriques, Nice 13-18 sept. 1976, publié avec le concours du secrétariat d'État à la culture, service des fouilles et antiquités, 1976, 185 p., 51 fig., dont 1 planche en couleurs. 
De Lumley et al. 1995 : DE LUMLEY (H.), BEGIN-DUCORNET (J.), ÉCHASSOUX (A.), FOURNIER (A.), GUISTOMAGNARDI (N.), LAVIGNE (G.), DE LUMLEY (M.-A.), MACHU (P.), MANO (L.), MESLIN (L.), YOUNG-HEE (P.), REY (M.), ROMAIN (O.), ROMAIN (S.), SAGUEZ (S.), SERRES (T.), VILLAIN-RINIERI (F.) - Le Grandiose et le Sacré, Édisud, 1995, 400 p., 265 fig.

De Lumley et al. 2003a: DE LUMLEY (H.), ARCHILOQUE (A.), ÉCHASSOUX (A.), FOUCAUT (L.), MAGNARDI (N.), LE BRETON (G.), MACHU (P.), MANO (L.), RADULESCO (N.), ROMAIN (O.), SERRES (T.), STARNGI (J.-M.), VIERS (R.), VILLAIN-RINIERI (F.) - Gravures protohistoriques et historiques de la région du mont Bego. Tende, Alpes-Maritimes, Secteur des Merveilles, Zone de la cime des Lacs, Zone III, Groupes I et II, t. 5, Édisud, 2003, 796 p.

De Lumley et al.2003b: DE LUMLEY (H.), ARCHILOQUE (A.), ÉCHASSOUX (A.), FOUCAUT (L.), MAGNARDI (N.), LE BRETON (G.), MACHU (P.), MANO (L.), RADULESCO (N.), ROMAIN (O.), SERRES (T.), STARNGI (J.-M.), VIERS (R.), VILLAIN-RINIERI (F.) - Gravures protohistoriques et historiques de la région du mont Bego. Tende, Alpes-Maritimes, Secteur des Merveilles, Zone du Grand Capelet, Zone XII, Groupes I à VI, t. 14, Édisud, 2003, 750 p.

De Marinis, Pedrotti 1999: DE MARINIS (R.), PEDROTTI (A.) - L'età del Rame nel versante italiano delle Alpi centrooccidentali. In: La Valle d'Aosta nel quadro della preistoria e protohistoria dell'arco alpino centro-occidentale, Atti della XXXI Riunione Scientifica dell'Istituto Italiano di preistoria e protohistoria (Courmayeur, 2-5 giugno 1994), Firenze, 1999, p. 247-300.

Geist 2001 : GEIST (H.) - Les enclos pastoraux de la Valette du Sabion. ARCHÉAM, 9, 2001-2002, p. 37-38.

Heyd, Harrison 2004: HEYD (V.), HARRISON (R.) - Sion, Aosta e la transformazioni nell' Europa del terzo millenio a.C. NAB, 12, 2004, p. 143-173.

Honegger 2006: HONEGGER (M.) - Grandes lames et poignards dans le Néolithique final du nord des Alpes. In: D'ANNA (A.), BINDER (D.) dir., Production et identité culturelle. Actualité de la recherche. Rencontres méridionales de préhistoire récente. Actes de la deuxième session, Antibes, APCDA, 1998, p. 43-56.

Huet, Davtian 2009: HUET (T.), DAVTIAN (G.) - Organisation spatiale des gravures protohistoriques d'un grand site d'art rupestre: le mont Bego. Géomatique Expert, décembre-janvier 2009, p. 46-49.

Kharbouch 1996: KHARBOUCH (M.) - Paléoenvironnement végétal de la région du mont Bego (Tende, Alpes-Maritimes) depuis 15000 ans. Contributions palynologiques et interprétations paléoclimatiques, Muséum National d'Histoire Naturelle, Thèse doctorale, 1996, 252 p.

Machu et al. 2007 : MACHU (P.), MANO (L.), PLISSON (H.), BRESSY (C.) - Provenance et utilisation du silex dans les

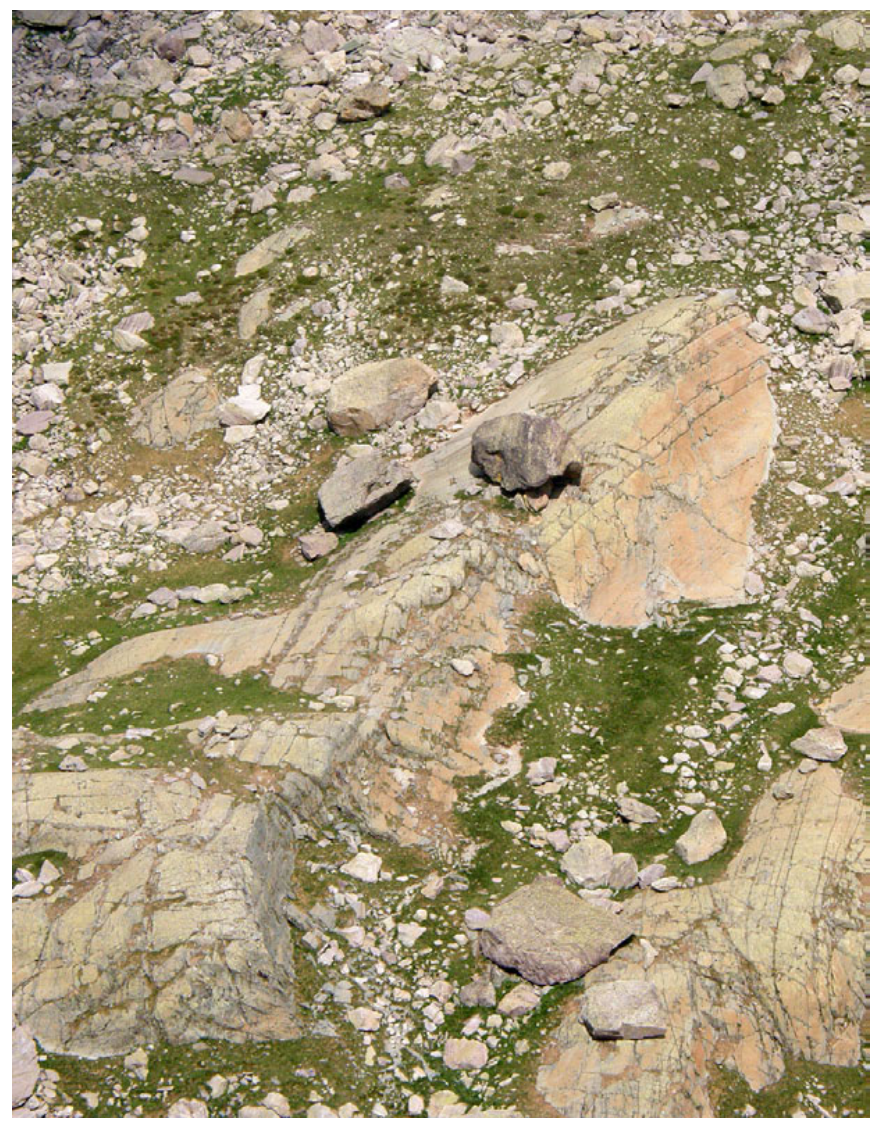

Fig. 7. La roche de «l'Autel» vue depuis le versant ouest de la vallée des Merveilles.

Alpes-Maritimes, l'exemple de la région du mont Bego, Actes du XI ${ }^{\text {e }}$ colloque sur les Alpes dans l'Antiquité, Champsec / Val de Bagnes / Valais-Suisse, 15-17 septembre 2006. Bulletin d'étude préhistoriques et archéologiques alpines, XVIII, Aoste, Société Valdôtaine de Préhistoire et d'Archéologie, 2007, p. 432-437.

Maggi 2000: MAGGI (R.) - Aspetti di archeologia del territorio in Liguria: la formazione del paesaggio dal Neolitico all' Età del Bronzo. In: Ambienti e storia della Liguria. Studi in ricolo di Emilio Sereni, Annali dell'Istituto «Alce Cervi», 1997, p. 143-162.

Mottes 2006: MOTTES (E.) - Les lames de poignards bifaciaux en silex d'Italie septentrionale: sources d'approvisionnement, technologie et diffusion. In : VAQUER (J.), BRIOIS (F.) dir., La fin de l'Âge de Pierre en Europe du Sud, Toulouse, Éditions des Archives d'Écologie Préhistorique, 2006, p. 25-42.

Ponel, Parchoux 1999: PONEL (P.), PARCHOUX (F.) - Une succession d'assemblages d'insectes fossiles depuis la fin du Würm jusqu'à l'Actuel dans la vallée des Merveilles. Étude Géographique Physique, ${ }^{\circ}$ XXVIIII, p. 57-60. 
Ponel et al. 2001: PONEL (P.), ANDRIEU-PONEL (V.), PARCHOUX (F.), JUHASZ (I.), DE BEAULIEU (J.-L.) Late-glacial and Holocene high-altitude environmental changes in Vallée des Merveilles (Alpes-Maritimes, France): insect evidence. Journal of Quaternary Science, vol. 16 (8), 2001, p. $795-812$.
Renault 1998: RENAULT (S.) - Économie de la matière première. L'exemple de la production au Néolithique final en Provence de grandes lames en silex oligocène du bassin de Forcalquier (Alpes-de-Haute-Provence). In: D'ANNA (A.), BINDER (D.) dir., Production et identité culturelle. Actualité de la recherche. Rencontres méridionales de préhistoire récente. Actes de la deuxième session, Antibes, APCDA, 1998, p. 145-162. 


\title{
Recherche interdisciplinaire en archéologie et écologie humaine dans la vallée centre-alpine de la Léventine, Tessin (Suisse)
}

\author{
Philippe DELla CASA*
}

\begin{abstract}
Résumé. Le Département d'Archéologie Préhistorique de l'Université de Zurich conduit depuis une trentaine d'années des fouilles archéologiques dans les Alpes. Les chercheurs s'intéressent en particulier aux modes d'occupation et aux paysages, élaborant de nouvelles techniques de recherche et, notamment, des approches interdisciplinaires de l'écologie humaine. Un nouveau projet intitulé «Léventine - paysage de l'occupation préhistorique» vise à retracer l'histoire du peuplement aux âges du Bronze et du Fer dans la Léventine (vallée alpine du Tessin) grâce à des études archéologiques et paléo-environnementales menées à différentes altitudes. Pour ce projet, il a fallu développer une méthodologie de prospection et de recherches éco-archéologiques, avec modélisation prédictive fondée sur des cartes archéologiques, étude systématique ou aléatoire du terrain, carottages, sondages et fouilles de moyenne ampleur. Les données sont modélisées en SIG à partir de la base de données du projet et de données spatiales mises à l'échelle.
\end{abstract}

Interdisciplinary research on archaeology and human ecology in the Central Alpine valley of Leventina, Ticino (Switzerland) Abstract. The department of Prehistoric Archaeology at the University of Zurich has been engaged in archaeological Alpine research for the last 30 years. This research focuses on themes of settlement and landscape archaeology mainly, developing new research methods, and in particular interdisciplinary approaches to human ecology. A new project entitled "Leventina - Prehistoric Settlement Landscape" aims at reconstructing the Bronze and Iron Age settlement history of the Leventina (Alpine Ticino valley) through archaeological and paleo-environmental studies in its different altitudinal zones. A comprehensive strategy of survey and eco-archaeological research has been designed for the project, including predictive modeling using archaeological maps, systematic and random field survey, coring, sub-surface testing, and medium-scale excavation. Data are modeled in GIS using the project database along with scaled geodata.

\section{Introduction}

$\mathrm{L}$ e Département d'Archéologie Préhistorique de l'Uni$\Lambda_{\text {versité de Zurich conduit depuis une trentaine d'années }}$ des fouilles archéologiques dans les Alpes. Les chercheurs s'intéressent en particulier aux modes d'occupation et aux paysages, élaborant de nouvelles techniques de recherche et, notamment, des approches interdisciplinaires de l'écologie humaine. Leurs travaux couvrent toutes les périodes préhistoriques et protohistoriques postglaciaires, avec une préférence pour les âges des Métaux.

Un nouveau projet sur l'histoire de la culture et de l'environnement, lancé en 2004 et intitulé «Léventine - paysage de l'occupation préhistorique», a obtenu en 2006 un financement sur trois ans du Fonds National Suisse de la Recherche Scientifique (FNS). Ce projet vise à retracer l'histoire du peuplement aux âges du Bronze et du Fer dans la Léventine (vallée alpine du Tessin) grâce à des études archéologiques et paléo-environnementales menées à différentes altitudes - depuis le fond de vallée et les premières terrasses (altitude 800-1250 m) aux prairies alpines (1800-2300 m) en passant par la Moyenne montagne (1400-1700 m).

La zone d'intervention, située dans les cantons du Tessin (TI) et d'Uri (UR), a été choisie en fonction d'un certain nombre de recherches déjà effectuées dans les Alpes centrales (fig. 1), notamment dans la vallée du Rhin alpin et sur la voie transalpine du San Bernardino reliant le sud des Alpes au Lac de Constance, et sur le versant nord du Saint-Gotthard dans la vallée de la Reuss (Primas, Della Casa, SchmidSikimic 1992; Della Casa, Bass, Fedele 1996; Della Casa 2000 ; Primas et al. 2004). De par la morphologie du terrain, la proximité des passages primordiaux des Alpes centrales et le peu de données archéologiques connues au préalable, la vallée de la Léventine nous a semblé fort bien placée pour

\footnotetext{
* Université de Zurich, Dept de Pré-/Protohistoire, Karl-Schmid-Str.4, CH8006 Zürich (Suisse).
} 


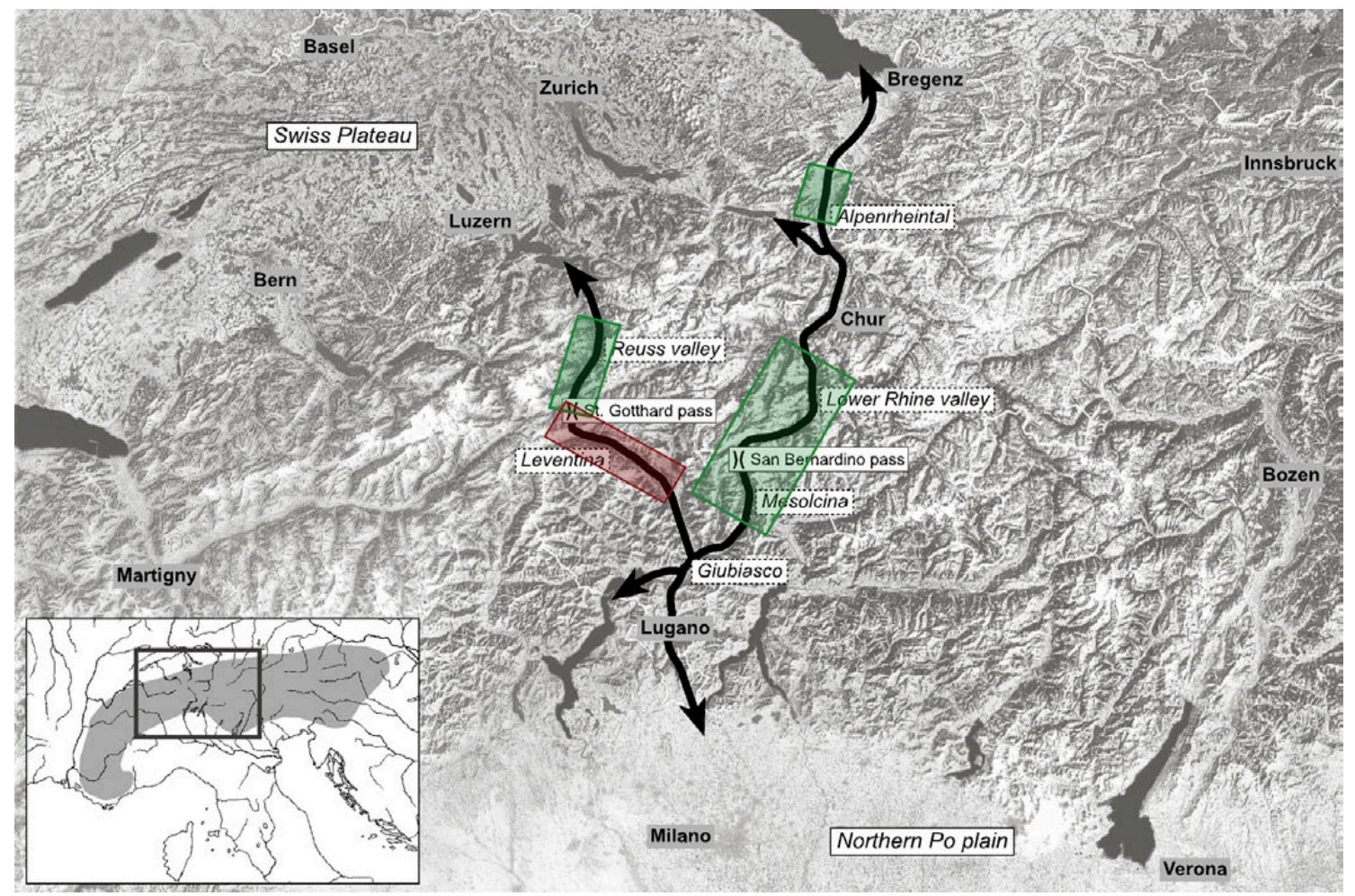

Fig. 1. Recherches archéologiques de l'Université de Zurich dans les Alpes centrales, 1985-2008.

l'emplacement d'une recherche ciblée et innovatrice, visant aussi bien les aspects écologiques qu'économiques et culturels du peuplement précoce des Alpes. En même temps, nous avons cherché une réflexion approfondie de la problématique de la recherche archéologique en milieu alpin, en particulier en ce qui concerne la localisation de sites à différentes altitudes et à fonctions diverses et leur interprétation socio-culturelle (Della Casa 2002).

Le climat, le sol et la sédimentation varient profondément d'une zone altitudinale à l'autre dans les Alpes, de même que les conditions de préservation et la mise au jour de sites archéologiques. Les stratégies et les méthodes de recherche doivent donc être adaptées aux facteurs environnementaux et culturels, passés et contemporains. Pour ce projet, il a donc fallu développer toute une méthodologie de prospection et de recherches éco-archéologiques, avec modélisation prédictive fondée sur des cartes archéologiques, étude systématique ou aléatoire du terrain, carottages, sondages et fouilles de moyenne ampleur.

\section{Le fond de vallée et les terrasses : Airolo-Madrano, Osco (altitude 1100-1200 m)}

La grande majorité des villages et hameaux contemporains se situe dans la zone du fond de vallée et sur les terrasses de l'étage montagnard inférieur. La découverte du site d'Airolo-Madrano (TI) (fig. 2 et 3), unique habitat protohistorique à vocation agropastorale connu dans toute la vallée alpine du Tessin, est due d'une part à la morphologie prononcée et la situation stratégique caractéristique de la colline «In Grop» (Della Casa 2007), mais d'autre part aussi au hasard d'un tesson isolé, retrouvé à la base d'un petit sondage effectué en 2003. Ce n'est que par la suite qu'un décapage de $50-100 \mathrm{~cm}$ de profondeur sur une surface de plusieurs dizaines de mètres carrés a permis de reconnaitre l'importance de cette implantation humaine au cœur des Alpes. Deux phases d'occupation, bien attestées par du mobilier et des datations ${ }^{14} \mathrm{C}$, marquent l'histoire de ce lieu: une première débute vers la fin du Bronze ancien et dure jusqu' au début du Bronze final, une deuxième, vraisemblablement moins marquée, se situe au second âge du Fer.

Grâce à un carottage systématique du sous-sol, il a été possible de cerner l'étendue du site d'habitat, malgré les dimensions réduites de la fouille de seulement $100 \mathrm{~m}^{2}$. Celui-ci recouvre le plateau exposé de la colline «In Grop » ainsi que le vallon à l'ouest du plateau - d'ailleurs ajouté d'un mur de fortification aux âges du Bronze et du Fer - sur une surface d'environs $2400 \mathrm{~m}^{2}$ (fig. 4). Les carottages montrent en outre bien que les sédiments et couches archéologiques se sont conservés sur le plateau dans les 


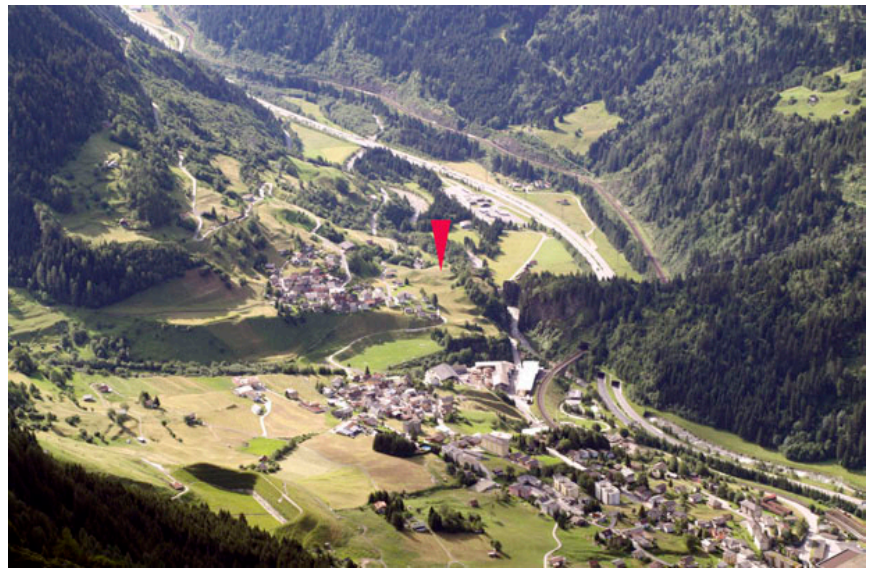

Fig. 2. Emplacement du site d'Airolo-Madrano en HauteLéventine (canton du Tessin), direction sud-est (photo: UZH).

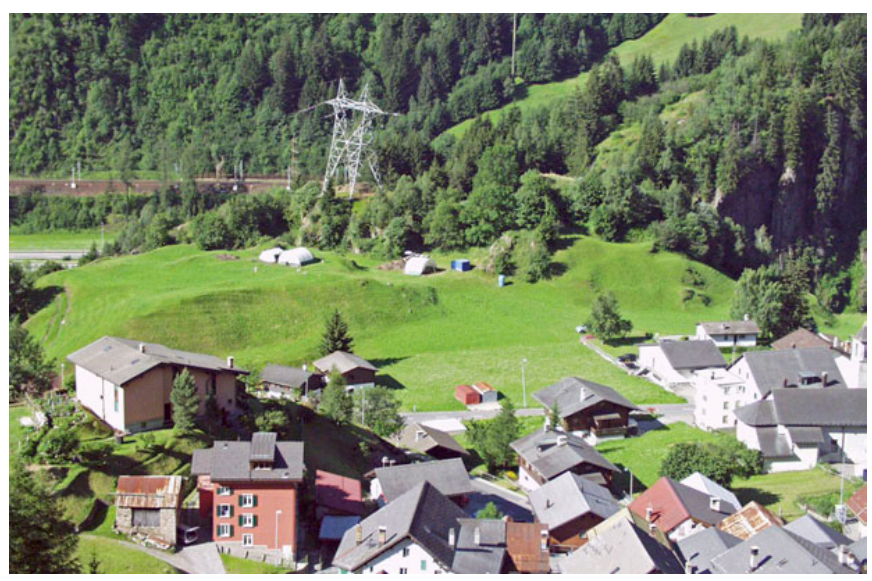

Fig. 3. La colline «In Grop» de Madrano avec la zone de fouille (photo: UZH).

rainures de la roche uniquement, alors que dans le vallon, ils peuvent être recouverts de plus de $150 \mathrm{~cm}$ de terre.

Cette situation apparaît tout à fait caractéristique des sites de fond de vallée et de terrasse, fortement exposés à l'érosion, au colluvionnement et à la sédimentation locale. Dans les vallées ceux-ci peuvent rapidement atteindre plusieurs mètres d'épaisseur (Della Casa 2000, p. 158). Comme il s'agit souvent de sédiments grossiers - argiles mélangées à des graviers ou cailloutis - il est pratiquement exclu d'y reconnaître des situations archéologiques avec les moyens classiques de la prospection visuelle, manuelle (tarrière) ou géophysique, les sondages mécaniques se heurtant par contre à l'ampleur des zones potentielles. D'ailleurs, l'unique autre site de type «terrasse» que nous ayons pu localiser lors de nos prospections, au lieu-dit «Mugniei» à Osco, a été découvert dans l'excavation d'un chantier de construction sous un colluvionnement important (fig. 5). À proximité de ce site, une datation ${ }^{14} \mathrm{C}$ du Bronze récent/final effectué sur un carottage à $150 \mathrm{~cm}$ de profondeur dans une terrasse agraire aménagée, et correspondant fort bien avec les dates de la base de la couche archéologique, indique la présence d'un paysage protohistorique enseveli sous les colluvionnements et bouleversements successifs et donc extrêmement difficile à retracer.

\section{La Moyenne montagne: Monti di Airolo, Prati di Cé (altitude 1500-1700 m)}

En suivant l'étagement altitudinal des implantations agropastorales des périodes historiques et contemporaines, l'étage montagnard supérieur est la zone des mayens (Curdy 2007). Suite aux déboisements importants, cette zone est aujourd'hui également exposée aux activités d'érosion et d'accumulation, bien que la sédimentation naturelle n'y soit pas très prononcée (fig. 6).

Aucun site archéologique n'a pu être localisé lors de nos prospections dans cette zone de la Haute-Léventine. Il faut cependant avouer que, encore une fois, le terrain est très vaste et que les situations caractéristiques (par exemple les promontoires) et les «fenêtres géomorphologiques» (rainures, talus érodés etc.) y sont très peu nombreuses. Nous avons effectué des séries de carottages et avons à deux reprises, notamment aux Monti en amont d'Airolo, obtenu des datations au radiocarbone du $\mathrm{X}^{\mathrm{e}}-\mathrm{XII}{ }^{\mathrm{e}}$ s. ap. J.-C. à des profondeurs d'environ $100 \mathrm{~cm}$, correspondant d'une part à une phase tardive d'aménagement du territoire attestée aussi sur le site d'Airolo-Madrano et, d'autre part, à la période des plus anciens écrits faisant état du peuplement médiéval de la vallée.

\section{Les alpages : Alpe di Pinett, Alpe di Tom, Alpe di Rodono, Alpe di Pontino (altitude 2000-2300 m)}

Comme presque partout dans les Alpes, les alpages historiques et contemporains se situent à la limite supérieure de la forêt, parfois dans des zones déboisées, ou alors dans des prairies à mélèzes. En un premier temps, ce sont souvent des vestiges d'activités économiques sub-récentes, tels des fonds de cabane ou des enclos en pierres encore visibles en surface, qui nous ont orienté dans nos recherches. Les blocs et abris sous roche sont également nombreux dans ces zones. Finalement, promontoires et terrasses exposées avec vues panoramiques surplombant les accès aux alpages ont attiré notre attention (fig. 7).

Dans la zone alpine, la sédimentation naturelle est quasiment inexistante dans les zones protégées par une couverture végétale : les prospections à la tarrière, voire sondages à la truelle, sont là très efficaces. Elles permettent d'échantillonner une 


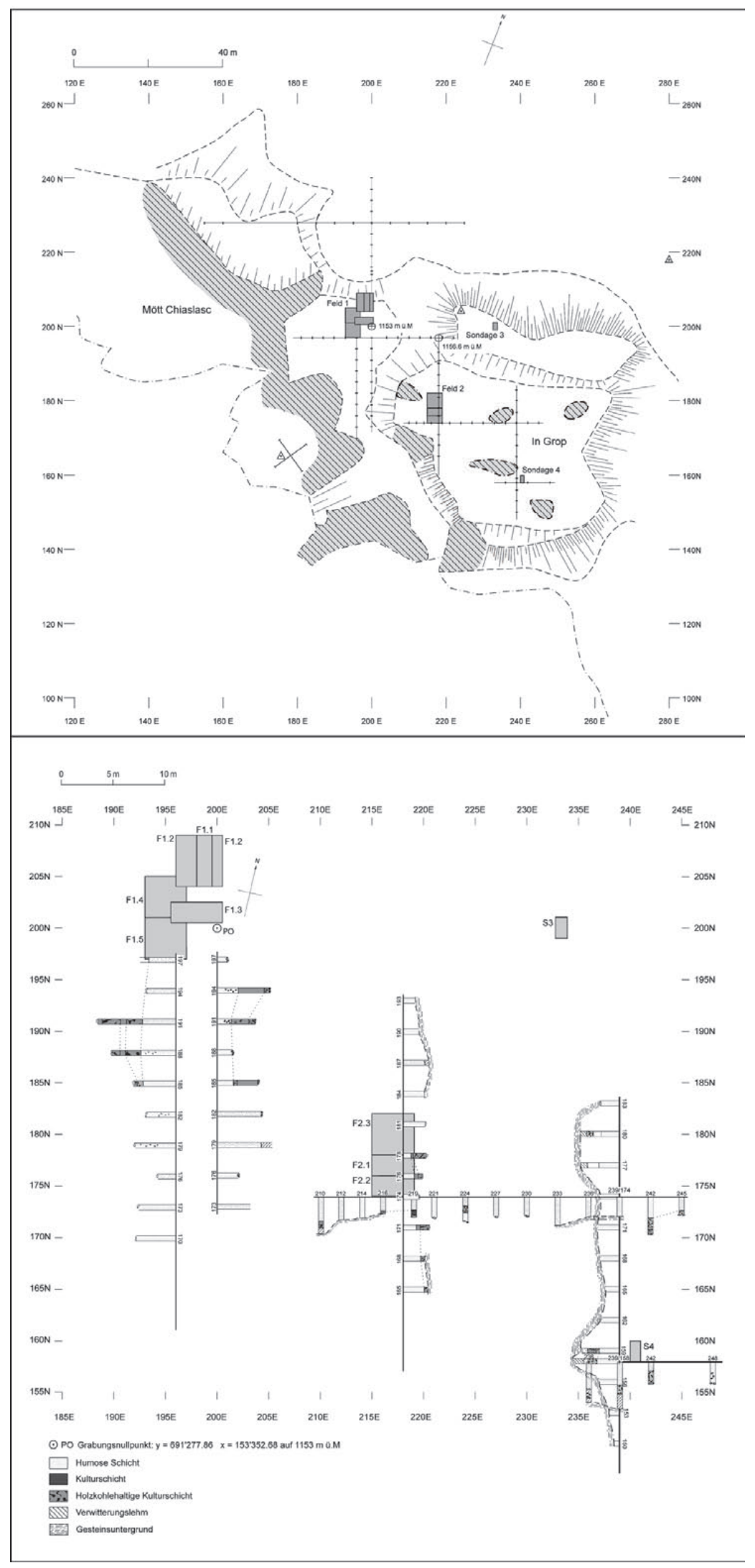

Fig. 4. Airolo-Madrano: secteurs de fouille, carottages et étendue du site (graphique: UZH). 
panoplie de situations géomorphologiques en relativement peu de temps. Grâce à cette méthode, nous avons pu localiser une quinzaine de sites pré- et protohistoriques dans la zone du Lac du Ritom (Alpe di Pinett, Alpe di Tom), en amont d'Airolo (Alpe di Pontino) et à proximité du col du Saint-Gotthard (Alpe di Rodont).

L'abri de l'Alpe di Rodont, situé à quelques dizaines de mètres au-dessus d'un petit lac à proximité immédiate du col du Saint-Gotthard et du sentier historique, est emblématique (fig. 8). Un petit sondage mené à une profondeur d'environ un mètre a révélé une succession stratigraphique de quatre foyers, dont deux datés du Mésolithique (VIII'-VII mill. av. J.-C.) et un du Bronze ancien/moyen (XVII $-\mathrm{XV}^{\mathrm{e}} \mathrm{s}$. av. J.-C.). Le mobilier archéologique, composé essentiellement de cristal de roche, n'est pas abondant, mais montre quelques éléments typiques tels que des petits grattoirs et des géométriques ainsi que des artefacts de production.

Cependant, un certain nombre des situations sous abri n'ont livré aucun mobilier archéologique, mais uniquement des foyers, parfois aménagés en fosse ou avec quelques pierres. Seuls les charbons de bois et les dates chronométriques que nous avons pu en extraire attestent ici des activités anthropiques. C'est le cas à l'abri de l'Alpe di Pinett (fig. 7) où une succession de foyers datant de l'âge du Bronze final, du premier et du second âge du Fer démontre une certaine continuité de fréquentation -bien que discrète - du site.

Juste à côté, longeant les abords d'un petit promontoire naturel, des sondages à la tarrière ont permis de reconnaître immédiatement sous le gazon alpin toute une série de petits foyers protohistoriques super- et juxtaposés les uns aux autres (fig. 7, 9). Là aussi, le mobilier est extrêmement rare: quelques lamelles et éclats de cristal uniquement. Les datations ${ }^{14} \mathrm{C}$ nous rapportent au milieu du $\mathrm{II}^{\mathrm{e}}$ et au $\mathrm{I}^{\mathrm{er}}$ mill. av. J.-C. Il est vraisemblable que la fréquentation répétée de la région soit à mettre en relation avec des activités pastorales et/ou cynégétiques aux âges du Bronze et du Fer. Malheureusement, les sols acides de presque toute la zone cristalline du sud des Alpes ne permettent pas la conservation des ossements.

À plusieurs reprises, finalement, nous avons localisé des situations archéologiques à proximité ou même à l'intérieur de structures architecturales appartenant à des alpages sub-récents, indiquant une fois de plus la longue durée de fréquentation de certains sites. À l'Alpe di Tom, c'est tout un petit hameau d'alpage avec enclos qui est enseveli dans un vallon évacuant le petit lac du même nom (fig. 10). Les dates les plus récentes obtenues sur ce site sont du XVIII ${ }^{\text {- }}$ $X^{\mathrm{e}}$ s., d'autres sont du Moyen Âge, alors que dans une petite grotte à proximité, le niveau inférieur d'une succession d'occupations remonte au haut Moyen Âge. Un sondage sous le sol d'une des cabanes du hameau a permis d'identifier un foyer protohistorique de l'âge du Fer avec mobilier de cristal de roche, notamment un grattoir macrolithique et des éclats de préparation.

À l'Alpe di Pontino finalement, des sondages à l'intérieur d'un vaste enclos en pierre sèche de date inconnue ont permis de mettre à jour une couche médiévale, un petit abri contre bloc avec de la céramique et un foyer du premier âge du Fer, ainsi que, en profondeur, des charbons de bois datant du Mésolithique.

\section{L'approche interdisciplinaire : carpologie, anthracologie, palynologie}

Dès le lancement du projet, il était convenu d'accompagner les fouilles et prospections archéologiques d'une série d'analyses écologiques et archéo-biologiques dans les milieux sur-site et hors-site, ciblées sur les questions de l'évolution du milieu naturel, de l'impact humain, et des activités économiques.

À ces buts, nous avons réalisé trois carottages palynologiques à l'étage montagnard de la vallée en collaboration avec l'Institut de Botanique de l'Université de Berne: dans la mare de Roncascio face à Airolo, ainsi qu'à Foppe et dans la tourbière de la Bedrina près de Dalpe, où de premières recherches avaient été menées dans les années soixante par Zoller (1960). Pour l'étage alpin, d'anciennes analyses polliniques dans les tourbières d'alpage de Pinett et du lac de Cadagno peuvent servir de référence.

Lors des fouilles à Madrano, les couches et anomalies archéologiques (fosses, foyers) ont été systématiquement échantillonnées afin d'y extraire des macrorestes sous forme de charbons, d'os calcinés (les seuls à être préservés) ainsi que de graines et fruits fossilisés. La préparation des échantillons a permis d'identifier environs 3000 restes carpologiques issus de plantes cultivées et sauvages. Dans les sondages de prospection, se sont essentiellement des charbons de bois que l'on a pu récolter.

Dans les alentours du site d'Airolo-Madrano et des Monti di Airolo, un petit nombre de profils pédologiques viennent compléter les données intra-site des fouilles et sondages.

Ces différentes analyses permettent de suivre certains facteurs décisifs de l'évolution du paysage anthropisé dans le temps et l'espace, mais surtout de mettre en relation des données indirectes (palynologiques) et directes (carpologiques, issues de fouilles archéologiques). On citera dans ce contexte les changements de la végétation naturelle dus au déboisement et autres formes de mise en valeur du territoire, les modes d'exploitation de la forêt, l'apparition des cultures céréalières et de la flore adventive, et la transformation des milieux naturels aux alentours des sites d'habitat. Pour l'instant encore, seul des données partielles peuvent être discutées. Dans le profil palynologique de la Bedrina, l'impact humain sous forme de déboisements actifs et 


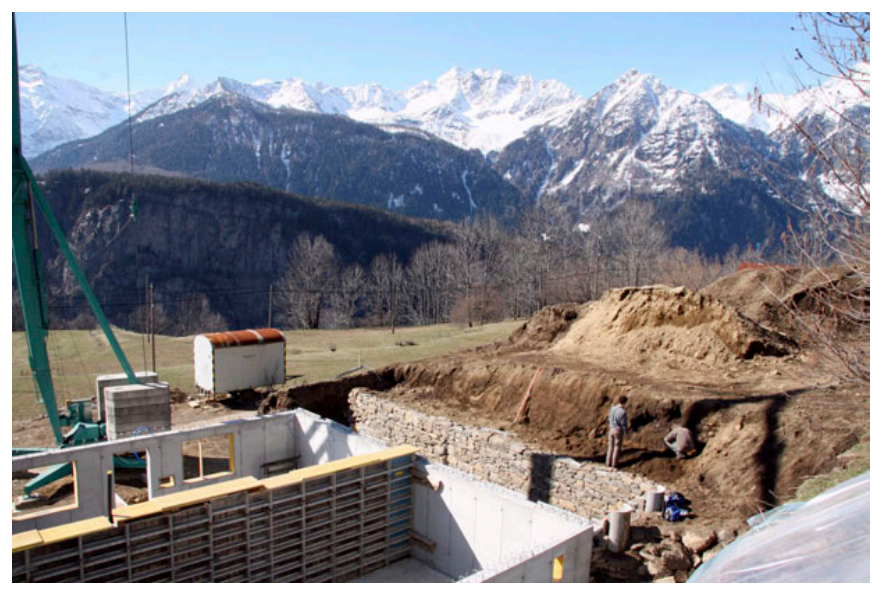

Fig. 5. Découverte d'un site protohistorique dans un chantier à Osco, Mugniei (Photo: UZH).

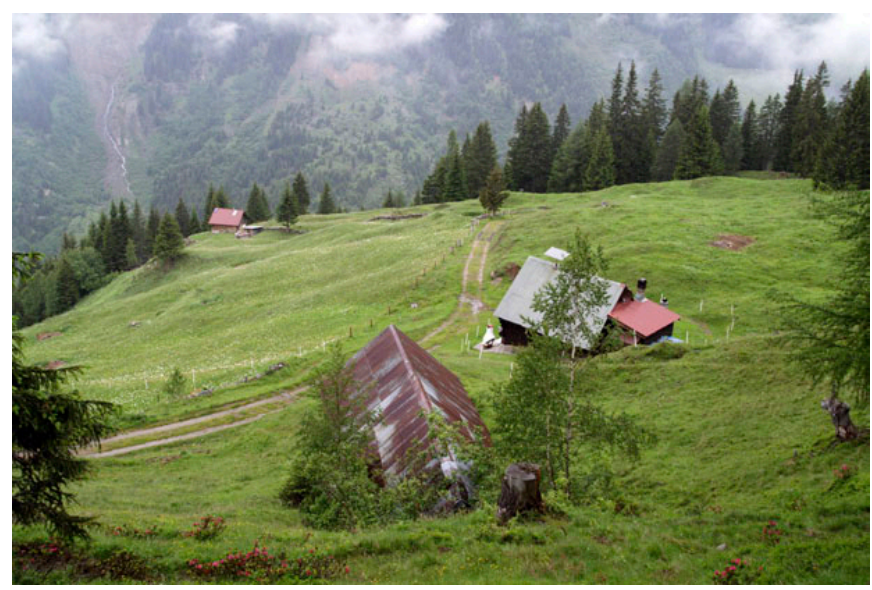

Fig. 6. Mayens des Prati di Cé, altitude 1700 m (photo: UZH).

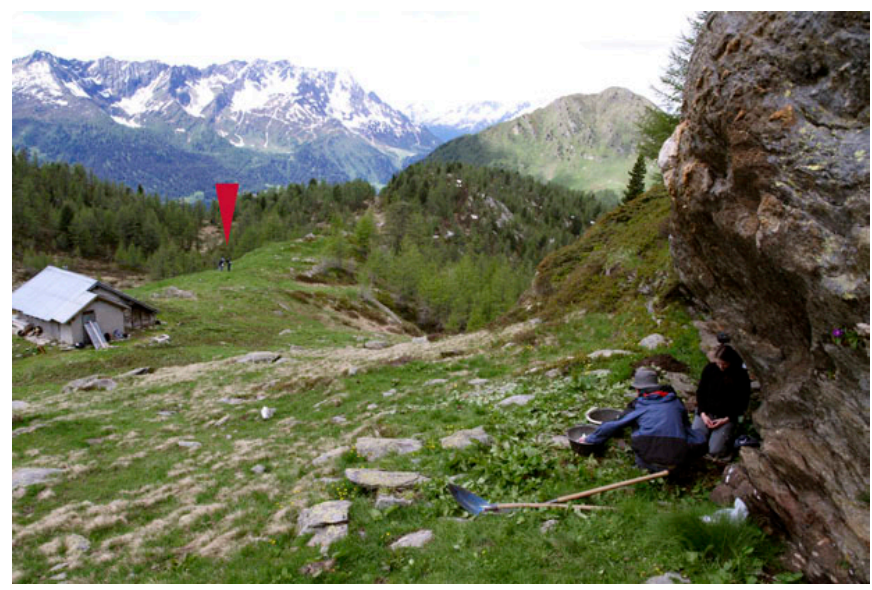

Fig. 7. Alpage de l'Alpe di Pinett, altitude $2050 \mathrm{~m}$. À droite: sondage $d^{\prime}$ un petit abri, à gauche en arrière-plan: promontoire avec emplacement de foyers protohistoriques (photo: UZH).

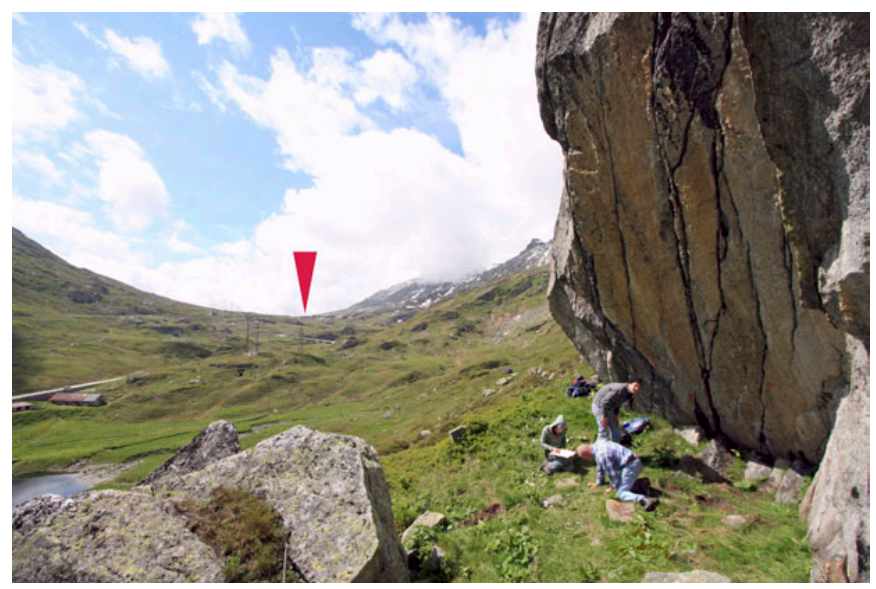

Fig. 8. Abri sous roche en amont du Lago di Rodont à proximité du col du Saint-Gotthard (photo: UZH).

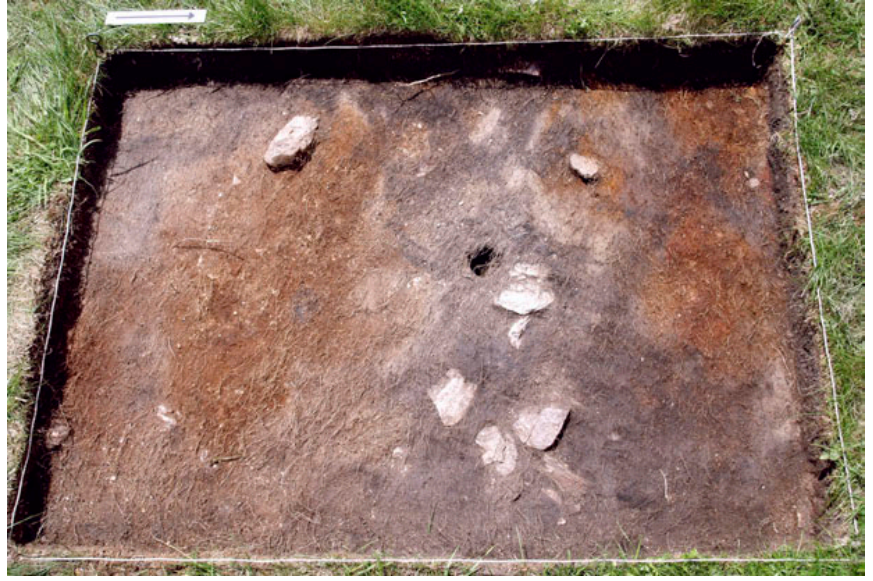

Fig. 9. Petits foyers protohistoriques sous le gazon alpin de I'Alpe di Pinett (photo: UZH).

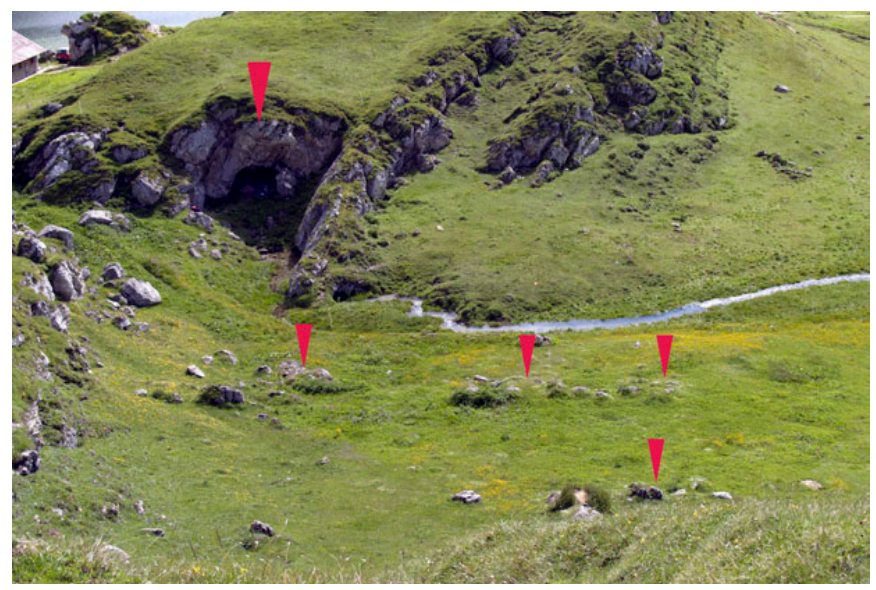

Fig. 10. Vallon, vestiges et grotte de l'Alpe di Tom (photo: UZH). 


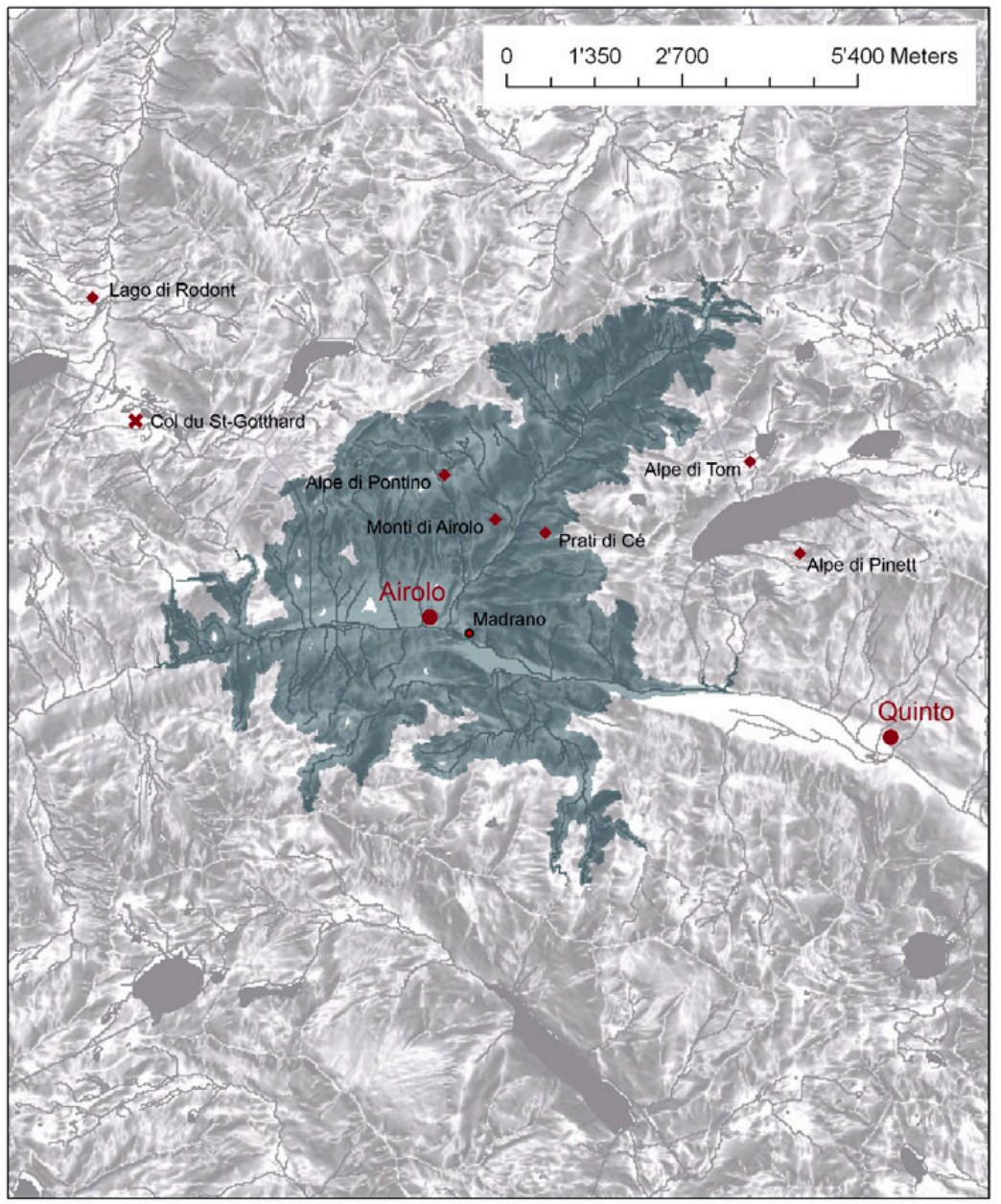

Fig. 11. Analyse de la zone attenante de l'habitat protohistorique d'Airolo-Madrano (graphique: Martin Sauerbier ETHZ).

cultures céréalières est tangible à partir de la zone BED-3 qui débute avec le Bronze ancien (Steinhauser 2008). Bien qu'aucun vestige archéologique ne soit connu pour cette période dans la zone de Dalpe, ces données sont compatibles avec la situation à Airolo-Madrano à une douzaine de kilomètres en amont de la vallée. Les cultures vivrières y sont attestées dès le début du site d'habitat vers 1650 av. J.-C. (dates calibrées), alors que l'analyse anthracologique montre fort bien que cet habitat vient s'installer dans un environnement déjà sensiblement anthropisé (Jacquat, Della Casa, Studer en prép.; Dufraisse 2009).

Dans l'absence de données directes, nous ne pouvons qu'émettre des hypothèses quant à la nature d'une occupation humaine pionnière en Haute-Léventine. Parmi les quarante-trois datations au radiocarbone réalisées sur des charbons provenant de situations archéologiques (sur-site) ou de terrasses aménagées (hors-site), deux seulement tombent dans la fourchette chronologique 2300-2000 av. J.-C. - le Chalcolithique et Néolithique ne sont pas représentés.
Cependant, il est important de rappeler ici que l'atelier de taille de cristal de roche à l'abri sous roche du lac de Rossplatten fouillé par M. Primas en 1990, à 2170 m d'altitude au-dessus de Hospental (UR) au nord du col du Saint-Gotthard, a livré trois dates ${ }^{14} \mathrm{C}$ entre 2500 et 1800 av. J.-C. (Primas, Della Casa, Schmid-Sikimic 1992, p. 307). L'exploitation de cette zone alpine est donc mise en évidence dès la fin du Chalcolithique. Plus au sud, dans la vallée de la Mesolcina, le petit habitat de terrasse de Castaneda-Pian del Remit (GR) est illustré par de la céramique, de l'industrie rocheuse et des datations de la période 3200-2700 av. J.-C. (Della Casa 2000, p. 97, 140).

Il nous semble envisageable de voir dans ces traces les indices d'une première colonisation, plus ou moins durable, de la zone interne des Alpes centrales au III $^{\mathrm{e}}$ millénaire. Colonisation qui d'ailleurs se manifeste à plusieurs reprises dans les profils polliniques de la région du San Bernardino (Della Casa 2000, p. 152) et peut-être, de manière plus discrète, par de premières transformations anthropiques dans le profil de la Bedrina (Steinhauser 2008). 
En ce qui concerne les occupations agropastorales du $\mathrm{II}^{\mathrm{e}}$ et $\mathrm{I}^{\mathrm{er}}$ millénaire, elles sont maintenant attestées aussi bien par les résultats des fouilles d'Airolo-Madrano que par les données indirectes de la palynologie. Ce sont là plutôt les détails qui intéressent: l'occupation de la vallée est-elle continue dès la fin du Bronze ancien? Comment se confirme-t-elle à travers la dépression climatique de Löbben? Y a-t-il des phases d'abandon, notamment dans la transition âge du Bronze final/premier âge du Fer, pour laquelle nous constatons une lacune importante de données archéologiques? Il faudra attendre les résultats complets des analyses polliniques et anthracologiques afin de pouvoir s'exprimer de manière fondée sur ces aspects bien particuliers de l'histoire de la colonisation alpine (Della Casa 2000, p. 172; Jacquat, Della Casa, Studer en prép.).

\section{Modélisation : base de données et SIG}

Afin de pouvoir visualiser de manière cohérente les résultats de nos recherches et de permettre des analyses éco-dynamiques ultérieures, les données de terrain et leurs compléments issus de l'étude bibliographique ont été intégrés à une base de données d'un SIG (MS-Access et ArcGIS d'ESRI). Pour les modélisations, nous employons des modèles de terrain conventionnels de swisstopo (C) à plusieurs échelles de résolution (Sauerbier, Fasler, Della Casa en prép.), complétés par des informations climatiques (précipitations, ensoleillement, température) et géomorphologiques (déclivité, sous-sol et sols) digitalisées à partir de cartes spécialisées, comme les cartes des aptitudes climatiques pour l'agriculture en Suisse (1977) ou les cartes des aptitudes des sols de la Suisse (1980). Également, un certain nombre de documents historiques tels que d'anciennes photographies du XIX et début du $\mathrm{XX}^{\mathrm{e}} \mathrm{s}$. illustrant les techniques agraires traditionnelles peuvent servir d'arrière-plan à l'interprétation des données.

Dans le cas présent, nous avons choisi d'illustrer une modélisation issue de l'analyse de la zone attenante (site catchment analysis) du site d'Airolo-Madrano (fig. 11). Ce genre d'analyse qui remonte à des concepts méthodiques élaborés dans les années soixante-dix du siècle dernier (Vita-Finzi, Higgs 1970; Roper 1979) a depuis été amplement utilisé en archéologie pré- et protohistorique (Pignat, Crotti 1984 pour un exemple alpin). De par leur capacité à traiter une multitude de données simultanément, les SIG peuvent sensiblement augmenter les sophistications méthodologiques de l'analyse de la zone attenante (Wheatley, Gillings 2002, p. 159).

En milieu alpin, où les zones attenantes sont beaucoup plus complexes à définir que dans la plaine, l'analyse demande un certain nombre d'adaptations à la démarche. Le fort découpage topographique et altitudinal des régions alpines, où les zones potentielles d'exploitation agricole et les pentes raides et inaccessibles peuvent se côtoyer très étroitement, nécessite l'élaboration méticuleuse d'un fond de carte faisant lieu de la morphologie du terrain, de la qualité des sols et des conditions microclimatiques (cf. supra). Afin de rester dans une logique «alpine» des exploitations du territoire, il nous a semblé utile de remplacer les critères de définition des différentes unités à l'intérieur de la zone - habituellement des rayons de distance $(1 \mathrm{~km}, 5 \mathrm{~km})$ - par des unités de temps parcouru. Dans l'exemple illustré (fig. 11), la zone attenante est limitée par un temps de marche de 2 heures aux alentours du site en fonction de la morphologie du terrain (Tobler 1993), notamment en tenant compte des eaux courantes en tant que barrières naturelles; ce périmètre peut être modifié à tout instant en fonction des besoins de l'analyse.

On y reconnaît d'ors et déjà quelques éléments importants: l'étroite corrélation entre dénivellement et temps parcouru par exemple est bien visible dans l'extension de la zone attenante le long de rivières et ruisseaux. Là où les pentes sont particulièrement raides, peu de terrain reste accessible. En ce qui concerne la localisation de nos lieux d'intervention, on constate que les mayens (Prati di Cé, Monti di Airolo) et alpages (Alpe di Pontino) au-dessus d'Airolo y sont intégrés. Par contre, les alpages du Ritom (Alpe di Tom, Alpe di Pinett) se trouvent en dehors de la zone définie, et pourraient se rattacher à une zone attenante voisine, d'un site d'habitat à proximité du village de Quinto - comme c'est encore le cas aujourd'hui. Quelques tombes de l'âge du Fer sont d'ailleurs connues dans cette région. Pour le site du Lago di Rodont, la situation est peut-être encore différente : il semblerait que ce soit plutôt le passage du col du Saint-Gotthard qui ait dirigé le choix de son emplacement.

À l'intérieur de la zone délimitée en tant que zone attenante, il est possible de calculer - pour chaque cellule du modèle digital de terrain - une probabilité d'aptitude aux différentes activités de subsistance (notamment agriculture, pâturage et élevage, et exploitation forestière) à l'aide d'une analyse factorielle tenant compte des éléments altitude, déclivité, exposition et irradiation solaire (pour un exposé de la démarche complète: Fasler 2008; Sauerbier, Fasler, Della Casa en prép.). La totalité des surfaces potentielles à une activité particulière - telle que la culture céréalière par exemple - pourra par la suite être utilisée pour calculer des taux de rendement, ce qui devrait nous fournir une estimation pondérée de la production vivrière aux alentours du site d'habitat. Ces algorithmes n'ont cependant pas encore été mis en place. 


\section{Perspectives}

Une approche méthodique transdisciplinaire, telle que nous l'avons présentée dans cette contribution, nous semble bien représenter pour l'instant une démarche prometteuse face à l'envergure des questions archéologiques et écologiques qui se posent par rapport à la colonisation précoce du milieu alpin. Notamment, elle permet d'adapter les processus de prospection sur terrain aux différentes situations géomorphologiques, et par cela, d'intégrer les différents étages altitudinaux si caractéristiques au domaine des Alpes. L'intégration de données provenant de toute sorte de situations sur-site et hors-site élargit amplement notre base de discussion pour ce qui touche à l'exploitation du territoire et à l'impact humain. Grâce aux possibilités techniques et mathématiques des SIG, il devient possible de proposer des simulations éco-dynamiques étroitement appuyées sur des données environnementales et économiques réelles.

\section{Remerciements}

Nos remerciements vont au FNS pour son soutien fondamental au projet (10-111987/1). Nous tenons également à remercier l'Ufficio dei beni culturali, l'Ufficio della natura e del paesaggio, l'Ufficio dell'agricultura ainsi que le centro di dialettologia e di etnografia de Bellinzona et la Pro Natura Ticino. Analyses et discussions nous ont été fournies par Werner Schoch et Alexa Dufraisse (anthracologie), Jacqueline Studer (archéozoologie), Christiane Jacquat (carpologie), Willy Tinner, Elisa Vescovi, Ursula Steinhauser et Lucia Wick (palynologie), Eileen Eckmeier et Daniela Kauf (pédologie), Martin Sauerbier (SIG) et Mario Fransioli (historien). Les datations au radiocarbone ont été effectuées en collaboration avec Irka Hajdas et Georges Bonani au laboratoire AMS de l'EPF de Zurich.

\section{Bibliographie}

Curdy 2007: CURDY (P.) - Prehistoric settlement in middle an high altitudes in the Upper Rhone Valley (Valais-Vaud, Switzerland): a summary of twenty years of research. Preistoria Alpina, 42, 2007, p. 99-108.

Della Casa 2000 : DELLA CASA(P.) - Mesolcina Praehistorica. Mensch und Naturraum in einem Bündner Südalpental vom Mesolithikum bis in römische Zeit (Universitätsforschungen zur Prähistorischen Archäologie 67), Bonn, Habelt, 2000.

Della Casa 2002 : DELLA CASA (P.) - Landschaft, Siedlungen, Ressourcen. Langzeitszenarien menschlicher Aktivität in ausgewählten alpinen Gebieten der Schweiz, Italiens und
Frankreichs (Préhistoires, 6), Montagnac, Mergoil, 2002, $124 \mathrm{p}$.

Della Casa 2007: DELLA CASA (P.) - Transalpine pass routes in the Swiss Central Alps and the strategic use of topographic resources. Preistoria Alpina, 42, 2007, p. 109-118.

Della Casa, Bass, Fedele 1996: DELLA CASA (P.), BASS (B.), FEDELE (F.) - The Grisons Alpine Valleys Survey 1995-97: methods, results and prospects of an interdisciplinary research program. In: DELLA CASA (P.) ed., Prehistoric alpine environment, society, and economy. Papers of the international colloquium PAESE '97 in Zurich (Universitätsforschungen zur prähistorischen Archäologie 55), Bonn, Habelt, 1996, p. $151-172$.

Dufraisse 2009: DUFRAISSE (A.) - Airolo-Madrano „In Grop“", Haute-Léventine: analyses anthracologiques. Rapport de projet UZH, 2009.

Fasler 2008 : FASLER (D.) - Entwicklung von Analysemethoden zur Untersuchung bronzezeitlicher Landnutzungen. ETH Zurich, Master Thesis, unpublished, 2008.

Jacquat, Della Casa, Studer en prép. : JACQUAT (C.), DELLA CASA (P.), STUDER (J.) - Airolo-Madrano "In Grop", Haute-Léventine (TI): Première esquisse de l'espace archéologique et du paléoenvironnement d'un site montagnard aux ages du Bronze et du Fer. Proceedings of the conference "Paysage-Landschaft-Paesaggio" in Geneva 2007 (Cahiers d'Archéologie Romande), Genève, en prép.

Pignat, Crotti 1984 : PIGNAT (G.), CROTTI (P.) - Rarogne. Une économie néolithique en milieu alpin (Valais). Archéologie Suisse, 7, 1984, p. 7-15.

Primas, Della Casa, Schmid-Sikimic 1992: PRIMAS (M.), DELLA CASA (P.), SCHMID-SIKIMIC (B.) - Archäologie zwischen Vierwaldstättersee und Gotthard. Siedlungen und Funde der ur- und frühgeschichtlichen Epochen (Universitätsforschungen zur Prähistorischen Archäologie 12), Bonn, Habelt, 1992, 366 p.

Primas et al. 2004: PRIMAS (M.), DELLA CASA (P.), JOCHUM-ZIMMERMANN (E.), HUBER (R.) - Wartau Ur- und frühgeschichtliche Siedlungen und Brandopferplatz im Alpenrheintal (Kanton St. Gallen, Schweiz) II. Bronzezeit, Kupferzeit, Mesolithikum (Universitätsforschungen zur prähistorischen Archäologie 108), Bonn, Habelt, 2004, 311 p.

Roper 1979: ROPER (D.C.) - The method and theory of site catchment analysis: a review. In: SCHIFFER (M.B.) ed., Advances in archaeological method and theory 2, New York, Academic Press, 1979, p. 120-140.

Sauerbier, Fasler, Della Casa en prép.: SAUERBIER (M.), FASLER (D.), DELLA CASA (P.) - Bronze Age land use in the Central Alps: GIS-based investigation of influencing environmental and economic factors. Proceedings of the 36th CAA conference in Budapest 2008, en prép.

Steinhauser 2008: STEINHAUSER (U.) - Pollenanalytische Untersuchungen in der Leventina TI. Die Bedrina bei Prato. 
Semesterarbeit, Abt. Ur- und Frühgeschichte der Universität Zürich, unpubliziert, 2008.

Tobler 1993: TOBLER (W.) - Nonisopic Modeling. Three Presentations on Geographical Analysis and Modeling. National Center for Geographic Information and Analysis. Technical Report, 93 (1), 1993.

Vita-Finzi, Higgs 1970: VITA-FINZI (C.), HIGGS (E.) Prehistoric economy in the Mount Carmel area of Palestine: site catchment analysis. Proceedings of the Prehistoric Society, 36, 1970, p. 1-37.
Wheatley, Gillings 2002 : WHEATLEY (D.), GILLINGS (M.) Spatial Technology and Archaeology. The archaeological applications of GIS. London, New York, Taylor \& Francis, 2002.

Zoller 1960 : ZOLLER (H.) - Pollenanalytische Untersuchungen zur Vegetationsgeschichte der insubrischen Schweiz. Denkschriften der Schweizerischen Naturforschenden Gesellschaft, 83, Abh. 2, 1960, p. 46-156. 


\title{
Dynamiques des activités anthropiques sur un milieu montagnard dans les Pyrénées occidentales catalanes durant la Préhistoire : une approche multidisciplinaire
}

\author{
Ermengol GASSIOT*, Albert PÈLACHS**, Marie-Claude BAL**, Virginia GARCIA*, \\ Ramon JULIÀ***, Ramon PÉREZ****, David RODRÍGUEZ*, \\ Anne-Charlotte ASTROU*****
}

\begin{abstract}
Résumé. Les recherches archéologiques menées depuis l'an 2000 dans le Noguera Pallaresa et le Noguera Ribagorçana ont permis de documenter les habitats humains dans les zones alpines et subalpines depuis le début du Néolithique jusqu'à aujourd'hui. Généralement, les données archéologiques montrent des modèles d'habitats et d'exploitations de l'environnement variables dans le temps et dans l'espace. De nombreux sites sont répertoriés pour la période allant de 3400 à 2450 cal BC, alors que les évidences archéologiques décroissent brusquement après cette période et jusqu'à la fin du Premier Millénaire calBC. Cet article présente premièrement une synthèse des données archéologiques sur les habitats humains répertoriés dans la zone d'étude depuis le début de l'Holocène jusqu'à la période romaine. Deuxièmement, la comparaison avec les données paléoécologiques met en évidence les changements environnementaux passés pour lesquels nous tentons de distinguer les origines climatiques ou anthropiques de ces dynamiques. Finalement, notre approche multidisciplinaire fait ressortir de nouvelles interrogations issues des données archéologiques comme la chute du nombre de sites à la fin de la Préhistoire. Cela suscite de nouvelles hypothèses qui conduiront vers des recherches futures.
\end{abstract}

Dynamics of human activities on a mountain site in Western Catalan Pyrenees during the prehistoric period:

a multidisciplinary approach

Abstract. The archaeological researches done since the year 2000 in the header of the watersheds of the Noguera Pallaresa and Noguera Ribagorçana rivers permitted to document a broad the human settlement in alpine and subalpine areas since the Early Holocene until the present. Current archaeological data shows a settlement pattern and exploitation of the environment mode variable in time and space. There are, for example, a relatively high number of sites for the period between 3400 to 2450 cal BC, whereas the archaeological evidences decreases sharply after that time until the end of the First Millenium calBC and their typology varies. This paper presents, firstly, a synthesis of the archaeological data on the human settlement in the study area from the Early Holocene until the Roman times. Secondly, the contributions of the paleoecological analyses states the changes in past environments trying to distinguish both the derived from climatic issues from those linked to human factors. Finally, this multidisciplinary approach allow to bring up again some questions that arise from the archaeological record, like the decreases in site number during the Late Prehistory and to advance some new hypotheses that will conduce future researches.

\section{Introduction}

$\mathrm{T}$ raditionnellement, les Pyrénées ont joué un rôle important dans une bonne partie des paradigmes explicatifs des différentes périodes de la préhistoire du nord de la Péninsule Ibérique. Elles ont été pensées aussi bien comme lieu de passage des groupes humains et des pratiques culturelles, que comme lieu central dans la configuration des réseaux de transhumance de certaines sociétés préhistoriques à partir du Néolithique (Estéban et al. 2003; Llovera et al. 1994; Martín, Vaquer 1995; Ruíz Zapatero 1995). Cependant, à la fin du XX $X^{\mathrm{e}}$ s., la connaissance du peuplement préhistorique du massif était pratiquement nulle. Il existait notamment un véritable désert de preuves dans les zones hautes de la chaîne, là même, paradoxalement, où les milieux alpins ou subalpins auraient pu accueillir un possible élevage saisonnier préhistorique. Ces dernières années, ce panorama a commencé à changer, grâce à la

\footnotetext{
* Departament de Prehistoria, Facultat de Filosofia i Lletres - Edifici B, Universitat Autonoma de Barcelona, Bellatera, E08193 Barcelona (Espagne). ** Departament de Geografia, Facultat de Filosofia i Lletres - Edifici B, Universitat Autonoma de Barcelona, Bellatera, E08193 Barcelona (Espagne). *** Institute de Ciences de la Terra Jaume Almera, Consejo Superior de Investigaciones Cientificas, C/Lluis Sole Sabanis s/n, E08028 Barcelona (Espagne).

**** Departament de Biologia Animal, de Biologia Vegetal i d'Ecologia, Facultat de Ciències - Edifici C, Universitat Autonoma de Barcelona, Bellatera, E08193 Barcelona (Espagne).

***** Université de Toulouse II-Le Mirail, 5 allées Antonio Machado, 31058 Toulouse cedex 9.
} 
consolidation de travaux archéologiques en Andorre et au développement de programmes de recherche orientés vers la documentation des activités humaines et de leurs changements au cours du temps en haute montagne (Gassiot, Jiménez 2006; Gassiot, Jiménez, Picón 2006; Miras et al. 2007 ; Palet-Martinez et al. 2008).

Ce travail présente les résultats des recherches archéologiques qui, complétées par des données paléo-écologiques, sont conduites depuis 2001 dans les Pyrénées occidentales de Catalogne. Parmi les objectifs spécifiques qui sous-tendent cette recherche, se détachent en particulier les processus de colonisation postglaciaire de ces espaces, l'introduction des pratiques pastorales et leur évolution au cours du temps, l'apparition de nouvelles activités de production (telles que les activités minières), enfin, la façon dont les relations entre les communautés humaines de haute montagne et celles d'autres zones géographiques ont structuré différentes formes de territorialité.

\section{Problématique}

Il est établi aujourd'hui, pour une partie de l'archéologie, que les hautes montagnes, lieux peu propices à l'établissement d'un peuplement humain, ont hébergé des groupes relativement marginaux par rapport aux évolutions sociales de leur époque, en grande partie réticents au changement et fortement conditionnés par les caractéristiques du milieu physique (Llovera et al. 1994; Pons 1994; Ruiz Zapatero 1995). On a en outre souvent recouru aux sources indirectes - principalement à la documentation historique et ethnographique - pour valider certaines représentations de la vie sociale durant la Préhistoire. Ces interprétations ont pu induire des erreurs telles, par exemple, que l'affirmation du fait que les pratiques pastorales saisonnières de la fin du $\mathrm{XIX}^{\mathrm{e}}$ s. reflétaient, comme fossilisées dans le temps, la gestion des troupeaux et de la faune domestique, quasiment depuis le Néolithique (Gardes 1996).

Les recherches présentées dans cet article se proposent d'échapper à ces a priori :

- en redéfinissant les potentialités, pour l'être humain, des milieux alpins et subalpins, notamment par l'analyse des façons dont les différents écosystèmes de montagne ont changé sur la longue durée, tant du point de vue climatique que de celui des perturbations naturelles et humaines du paysage.

- en partant de l'hypothèse que les populations des zones de montagnes possèdent, elles aussi, des modes de vie changeants au cours du temps, que ce soit sous l'effet de processus locaux ou de phénomènes de plus grande ampleur géographique.

En ce sens, il faut souligner le travaille novateur de Rendu (2003) en Cerdagne du Nord, qui démontre la nécessité de recourir aux données archéologiques quand cela s'avère possible. Le recours à l'analogie ethnographique ou aux sources historiques récentes doit s'effectuer en revanche avec précaution, et plutôt dans le but de poser des questions ou justifier la définition d'indicateurs archéologiques, que dans celui de représenter des pratiques d'une période différente de celle dont ces sources procèdent.

\section{Cadre de la recherche}

Les résultats exposés ici sont issus des recherches archéologiques réalisées dans le Parc Nacional d'Aigüestortes i Estany de Sant Maurici, ainsi que dans sa zone périphérique et ses adjacences. C'est une zone de montagne dont les sommets atteignent jusqu'à $3000 \mathrm{~m}$ d'altitude. Elle est de façon générale assez rocheuse et abrupte, avec des variations selon le substrat dominant (granite ou schiste). Elle comprend principalement les hautes vallées, une toute petite partie de ce territoire se situant en dessous de la cote des 1800 m d'altitude (fig. 1).

Le climat est caractéristique de la haute montagne pyrénéenne et fortement conditionné par l'altitude, avec des contrastes très marqués entre les parties les plus basses et les plus hautes du territoire. Dans ces dernières, le taux de précipitation oscille entre 1000 et $1300 \mathrm{~mm}$ par an, atteignant jusqu'à 2000 mm/an dans la zone de l'Estany Gento. Dans les fonds de vallée en revanche, les précipitations peuvent être inférieures à $700 \mathrm{~mm}$ par an. La température moyenne annuelle est comprise entre 2 et 9 degrés sur les hauteurs et entre 9 et 12 degrés dans les vallées (Martín Vide 1992).

La végétation reflète également les contrastes du relief: la partie haute associe zones rocheuses et pelouses alpines tandis que l'aval est peuplé d'importantes forêts de pin noir (Pinus mugo subsp. uncinata), de sapin (Abies alba) et de pin sylvestre (Pinus sylvestris).

\section{Matériel et méthodes de recherches}

\subsection{Archéologie}

La recherche archéologique réalisée depuis 2001 a consisté en une prospection systématique du territoire entre 1500 et $2900 \mathrm{~m}$ d'altitude sans exclure aucun type d'espace en raison de sa morphologie tant qu'il était accessible à pied. Cette prospection s'est effectuée à partir de transects au sein desquels ont été enregistrées toutes les traces d'occupation humaine observées, à l'exception de celles du XX $\mathrm{X}$. déjà cartographiées.

La documentation de certains contextes a été complétée par le nettoyage de structures et par la réalisation de sondages 
stratigraphiques. Ces sondages, d'extension réduite, ont été réalisés selon deux objectifs: évaluer le potentiel archéologique de certains secteurs (comme par exemple des grottes), et obtenir du mobilier afin de dater les contextes documentés, la prospection de surface ne permettant que très rarement un diagnostic chronologique pertinent ${ }^{1}$.

Parallèlement, des fouilles extensives ont été réalisées sur trois des gisements préalablement repérés : le Dolmen de la Font dels Coms, l'abri de l'Estany de la Coveta I et la Cova del Sardo (fig. 1).

\subsection{Paléoécologie}

Les données archéologiques obtenues ont été confrontées avec d'autres données, paléoécologiques, provenant des sites archéologiques eux-mêmes mais aussi de trois sondages sédimentaires réalisés à l'étang de Burg, un paléolac fonctionnant aujourd'hui comme une tourbière (fig. 2). Dans le premier sondage (CMB-I) 6,57 m de sédiment ont été recueillis au moyen d'un carottier «Eijkelkamp». Les deux autres sondages (CMB-8 et CMB-9) ont été réalisés postérieurement, avec un carottier mécanique Rolatec RL 48-L de $10 \mathrm{~cm}$ de diamètre qui a permis d'extraire $16,5 \mathrm{~m}$ de matériel.

Outre le diagramme pollinique issu de ces sondages (Pèlachs et al. 2007), on a utilisé, pour l'interprétation de la dynamique paléoenvironnementale, celui issu du sondage de l'Estany Redó dans la vallée de Sant Nicolau (Catalán, Pérez Obiol, Pla 2001). Ces données ont été comparées avec celles d'autres diagrammes polliniques proches (Montserrat 1992; Estéban et al. 2003; Miras et al. 2007).

Les données palynologiques ont été complétées par l'analyse des macrocharbons sédimentaires $(>150 \mu \mathrm{m})$ et l'analyse sédimentaire (lithologie, teneur en matière organique, LOI et composition géochimique) des sondages CMB-8 et CMB-9 issus de l'étang de Burg.

\section{Résultats et interprétations}

\subsection{Les gisements répertoriés}

Plus de 200 gisements ${ }^{2}$ archéologiques ont été identifiés dans l'ensemble des zones prospectées. Peu de secteurs

1. Il est intéressant, de ce point de vue, de souligner la présence d'outils sur éclats silex et d'autres matières tant dans des contextes d'époque romaine que médiévale, et même du XVI $\mathrm{s}$.

2. Le qualificatif de site est difficile à appliquer, dans ces contextes marqués par l'absence de sites agglomérés, par un modèle diffus de peuplement et d'usage de l'espace, par une dispersion de petits vestiges d'activités humaines et, souvent, par un usage récurrent des mêmes sont restés vides de découvertes archéologiques, mis à part ceux de très forte pente ou d'accès difficiles, certains non prospectés, ou ceux où les processus géologiques récents ont altéré le relief.

La typologie de ces traces archéologiques est très variable: elle va de vestiges architecturaux de morphologies et de grandeurs diverses (de cabanes ou enclos isolés à de grands ensembles composés de dizaines de structures qui peuvent couvrir plus de 0,35 ha d'extension), à des épandages de surface d'artefacts, en passant par de petits abris et cavités avec traces archéologiques d'occupation humaine, par des tranchées minières, et enfin, ponctuellement, par des panneaux d'art rupestre. Cette diversité de formes et, semble-t-il, de fonctions des vestiges découverts se traduit par une grande diversité des emplacements. Bien que la plupart des sites composés de vestiges architectoniques se trouvent principalement en fond de vallées et dans les cirques glaciaires, certains ont été découverts sur des crêtes, des lieux proches des sommets, ou encore sur des versants boisés et rocheux. La chronologie des ensembles archéologiques documentés a été essentiellement établie à partir de datations absolues, et ponctuellement, non sans précautions, à partir des caractéristiques du mobilier trouvé. 38 datations, documentant 20 sites, ont ainsi été obtenues sur la marge ouest de la vallée de la Noguera Pallaresa (tabl. 1).

\subsubsection{La colonisation mésolithique des espaces de haute montagne}

La séquence archéologique mise au jour dans la zone étudiée laisse apparaître des indices, ténus, de peuplement humain dès le début de l'Holocène. Les données proviennent de deux sites. Le premier est celui du Dolmen de la Font dels Coms, une sépulture mégalithique, située à 1830 m d'altitude dans la vallée de Baiasca et qui fut réutilisée postérieurement, à l'époque romaine, pour y installer un four de réduction du fer. Sous le tumulus funéraire, est apparu, dans un petit sondage, un possible trou de poteau entouré de pierres, dont les restes de charbons ont été datés entre 8745 et 8560 cal BC (Rapalino et al. 2007; tabl. 1). Bien que l'ensemble ne soit pas des plus évidents, il faut noter que c'est dans le niveau stratigraphique où s'ouvre le creusement correspondant au trou de poteau qu'est apparu un des deux fragments de silex taillés du gisement. La présence du tumulus, couvert d'un pavement de pierres plates, écarte l'hypothèse d'une intrusion.

Les données provenant de l'Abric de l'Estany de la Coveta I sont plus détaillées et plus fiables. Le gisement est un petit abri rocheux, formé par l'accumulation naturelle de grands blocs de granite, qui ménage un petit espace habitable de

emplacements. D'autres chercheurs, dans les Pyrénées, se sont heurtés au même problème (Palet-Martinez et al. 2006; Rendu 2003). 


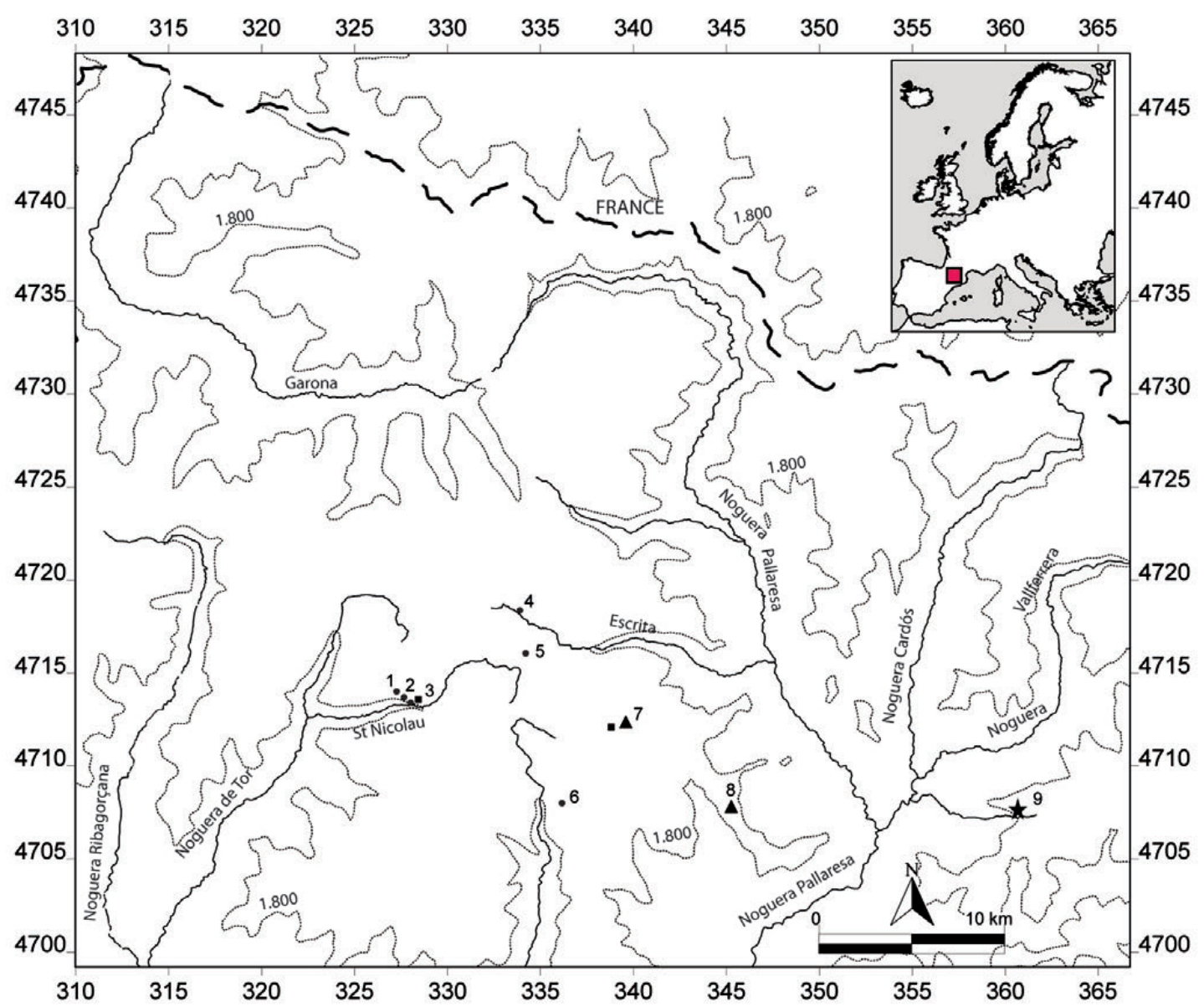

Fig. 1. Carte de la zone de la recherche avec l'indication des sites mentionnés et sa chronologie (triangle: 9000-6000 cal BC ; carré: 6000-3000 cal BC; cercle: 3000-2300 cal BC): 1- Cova de Sarradé, 2- Covetes, 3- Cova del Sardo, 4- Obagues de Ratera, 5- Portarró, 6- Coma d'Escós, 7- Abric de I'Estany de la Coveta I, 8- Dolmen de la Font dels Coms, 9- étang de Burg.

$5,8 \mathrm{~m}^{2}$. Comme bien d'autres abris similaires, celui-ci est aujourd'hui délimité sur certaines de ses ouvertures par des murs, et contient des indices d'activités humaines. Cet abri se situe à $2425 \mathrm{~m}$ d'altitude, entre l'étang de la Coveta et l'étang Negre.

La cavité a été fouillée en extension en 2005 après la découverte, entre ses fissures internes, d'un récipient céramique attribué, par sa typologie, au $\mathrm{II}^{\mathrm{e}}$ millénaire cal BC. L'intervention a permis de documenter trois phases d'occupation. En dessous d'une phase datant possiblement du haut Moyen Âge, fut fouillé un grand foyer de la fin du Néolithique, situé près de l'entrée et chronologiquement placé, à partir d'un charbon entre 3340 et 3328 cal BC. L'occupation précédente, séparée de celle-ci par un niveau stérile, a livré une autre aire de combustion de $0,5 \mathrm{~m}^{2}$, située elle aussi près de l'entrée. La datation obtenue, à nouveau sur un fragment de Pinus sp. brûlé, est placée cette fois entre 7001 et 6572 calBC. Associées au foyer, trois petites lames de silex allochtone ont été prélevées, ainsi qu'une lamelle de quartz très altérée par le feu.

Les pièces sont de petite taille, aucune ne dépasse $17 \mathrm{~mm}$ de large. Une des lames de silex est marquée, sur son tranchant distal, par de petites ébréchures et un poli propres au travail de la peau séchée. Ces traces signent un maniement transversal que l'on peut associer à un dégrossissement du cuir.

Bien que rares et encore fragmentaires, les données actuelles indiquent donc que ces espaces de hautes montagnes ont fait l'objet d'un intérêt de la part des populations humaines dans une chronologie pré-néolithique. En l'absence d'assemblages faunistiques conservés, qui s'explique par l'acidité des sols granitiques à l'Abric de l'Estany de la Coveta, il est difficile de soutenir la fonction cynégétique de ce premier peuplement. Les traces d'activité présentes sur une des pièces lithiques de ce site illustrent néanmoins un processus de production dérivé de cette activité. 


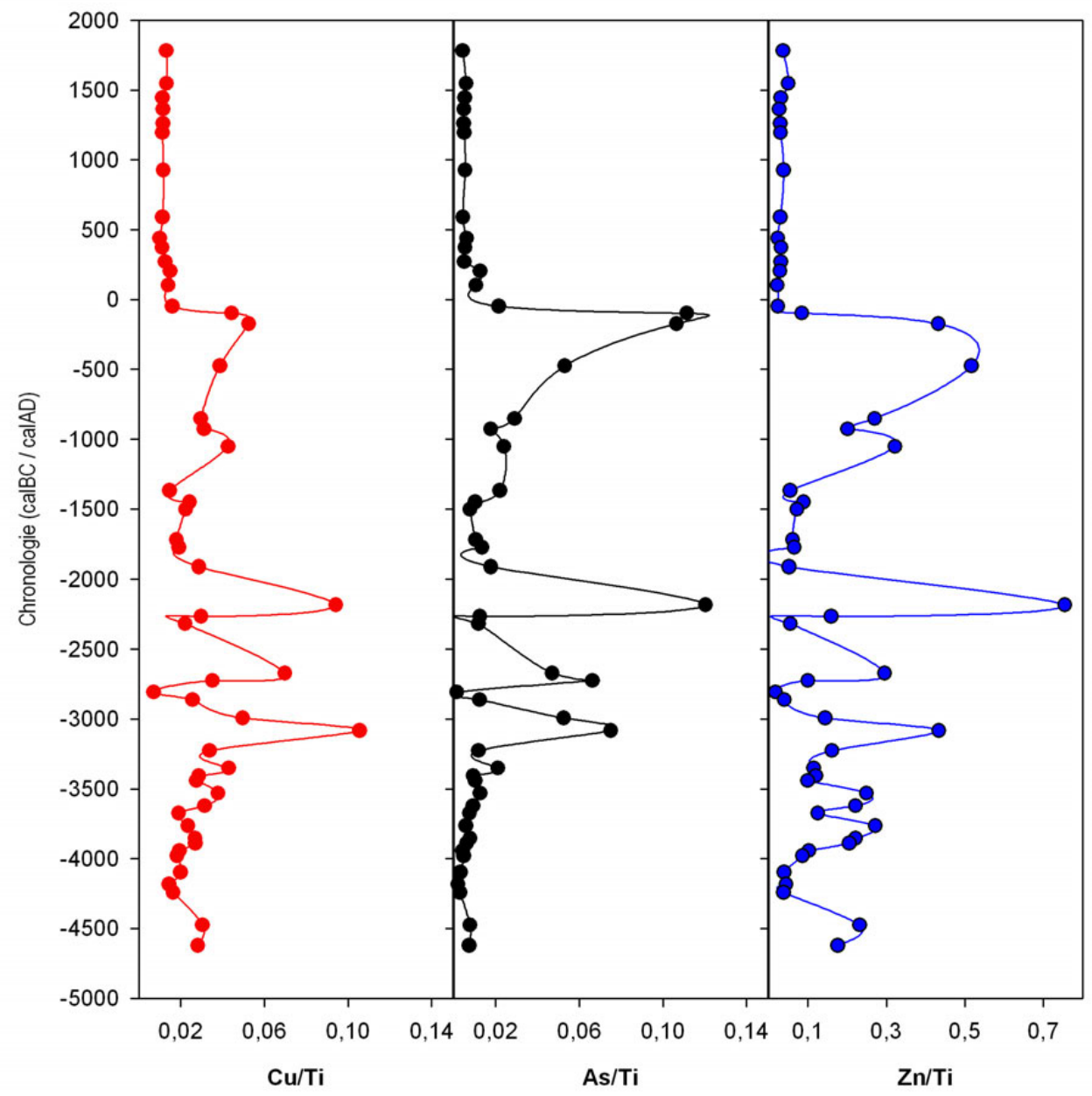

Fig. 2. Présence de métaux lourds (cuivre, zinc, arsénique) dans le registre sédimentaire de Burg. Les données pour chaque métal sont calibrées avec un élément stable (titanium) pour éliminer les oscillations résultants des changements dans la dynamique de sédimentation.

\subsubsection{Les occupations de la première moitié du Néolithique (5800-3400 cal BC)}

Une grande partie des occupations néolithiques suivantes sont circonscrites à la Cova del Sardo, un petit baume situé à $1820 \mathrm{~m}$ sur la partie basse de l'un des versants de la vallée de Sant Nicolau. Orientée est-ouest, cette vallée, l'une des principales de la zone d'étude, et constitue l'une des voies d'accès les plus faciles pour passer du bassin de la rivière Noguera Ribagorçana à celui de la Noguera Pallaresa.

En 2004, un sondage de $1 \mathrm{~m}^{2}$ effectué sur ce site a livré une phase du haut Moyen Âge et permis d'obtenir deux dates préhistoriques pour les niveaux stratigraphiques sous-jacents. Une fouille en extension fut donc entreprise en 2006 et complétée en 2008, atteignant une surface totale de 74,1 $\mathrm{m}^{2}$, dont 19,2 $\mathrm{m}^{2}$ correspondent à l'intérieur de la cavité, le reste à la terrasse frontale. Au cours des trois campagnes, quatre phases d'époque historique $\left(\mathrm{XVIII}^{\mathrm{e}}, \mathrm{XVI}^{\mathrm{e}}, \mathrm{X}^{\mathrm{e}}\right.$ et $\mathrm{II}^{\mathrm{e}} \mathrm{s}$.) ont été mises au jour ainsi que diverses occupations d'époque préhistorique qui se situent entre 2570 et 5540 cal BC.

La Cova del Sardo contient les seuls contextes archéologiques documentés sur la zone d'étude, entre 6500 et 3500 calBC. À la base de la séquence archéologique apparaissent, sur un sédiment stérile, les vestiges de trois structures de combustion. Deux de ces structures sont des cuvettes de plan circulaire et de section concave, la troisième, également fouillée, est formée de trois cercles concentriques de pierres de chant, qui délimitent une petite cuvette centrale pourvue d'un pavement de pierres plates. Comme pour les époques postérieures, cette disposition résulte plus vraisemblablement d'une succession d'occupations humaines au cours d'un certain laps de temps, difficile à estimer, que d'une occupation unique. La datation d'un charbon provenant d'une des cuvettes à permis la seule mesure ${ }^{14} \mathrm{C}$, 


\begin{tabular}{|c|c|c|c|c|}
\hline Code laboratoire & Site & Âge BP & Âge cal (1 sigma) & Âge cal (2 sigma) \\
\hline KIA-23142 & Dolmen Font dels Coms & $9375+/-35$ & $8712-8609 \mathrm{cal} \mathrm{BC}$ & 8745-8560 cal BC \\
\hline KIA-29818 & Abric Estany Coveta I & $7845+/-45$ & 6749-6606 cal BC & 7000-6571 cal BC \\
\hline KIA-37689 & Cova del Sardo & $6525+/-45$ & 5539-5391 calBC & 5607-5374 calBC \\
\hline KIA-37690 & Cova del Sardo & $5850+/-40$ & $4784-4685 \mathrm{cal} \mathrm{BC}$ & 4825-4600 cal BC \\
\hline KIA-36935 & Cova del Sardo & $5695+-/ 35$ & $4552-4461$ cal BC & 4666-4452 cal BC \\
\hline KIA-32340 & Cova del Sardo & $5245+/-40$ & 4221-3979 cal BC & 4228-3969 cal BC \\
\hline KIA-26248 & Cova del Sardo & $5060+/-40$ & 3941-3798 cal BC & 3961-3765 cal BC \\
\hline KIA-32342 & Cova del Sardo & $4945+/-35$ & 3764-3661 cal BC & $3790-3650 \mathrm{cal}$ BC \\
\hline KIA-36934 & Cova del Sardo & $4765+/-40$ & $3634-3520 \mathrm{calBC}$ & $3640-3379 \mathrm{cal} \mathrm{BC}$ \\
\hline KIA-37691 & Cova del Sardo & $4715+/-35$ & 3625-3378 cal BC & 3631-3373 cal BC \\
\hline KIA-32351 & Cova del Sardo & $4555+/-30$ & 3364-3125 calBC & 3482-3102 cal BC \\
\hline KIA-29816 & Abric Estany Coveta I & $4475+/-30$ & 3326-3093 calBC & 3338-3026 cal BC \\
\hline KIA-28276 & Portarró & $4255+/-40$ & 2913-2777 calBC & 3006-2694 cal BC \\
\hline KIA-26251 & Cova del Sardo & $4210+/-35$ & 2890-2704 calBC & 2900-2675 cal BC \\
\hline KIA-36936 & Coma d'Escós & $4180+/-30$ & 2878-2697 cal BC & 2885-2665 cal BC \\
\hline KIA-28280 & Obagues de Ratera & $4160+/-35$ & 2871-2677 calBC & 2879-2625 cal BC \\
\hline KIA-32348 & Cova del Sardo & $4090+/-35$ & 2838-2572 cal BC & 2862-2493 cal BC \\
\hline KIA-32341 & Covetes & $3960+/-30$ & 2564-2457 cal BC & 2570-2345 cal BC \\
\hline KIA-32335 & Cova de Sarradé & $3945+/-25$ & 2558-2347 calBC & 2568-2306 cal BC \\
\hline KIA-28279 & Fangassals & $2115+/-30$ & 190-97 cal BC & $340-47$ calBC \\
\hline KIA-32349 & Estany Xic de Subenuix & $1875+/-30$ & $78-210 \mathrm{cal} A D$ & $70-225$ cal AD \\
\hline KIA-32347 & Cova del Sardo & $1845+/-25$ & $130-215$ cal AD & 86-239 calAD \\
\hline KIA-28278 & Abric de l'Estany de la Ribera & $1725+/-30$ & $256-380 \mathrm{cal} A D$ & 243-394 cal AD \\
\hline KIA-28277 & Pletiu de Subenuix II & $1715+/-30$ & 259-383 cal AD & $250-401 \mathrm{cal} A D$ \\
\hline KIA-26469 & Abric de l'Estany Llebreta & $1530+/-30$ & $440-580 \mathrm{cal} A D$ & $432-601 \mathrm{cal} A D$ \\
\hline KIA-28281 & Pletiu de la Coveta & $1425+/-35$ & 606-651 cal AD & $570-661 \mathrm{cal} A D$ \\
\hline KIA-28086 & Abric de I'Estany Gran de Colieto II & $1155+/-30$ & $783-962 \mathrm{calAD}$ & 778-972 cal AD \\
\hline KIA-37688 & Cova del Sardo & $1105+/-30$ & $896-981 \mathrm{cal} A D$ & $885-1014$ cal AD \\
\hline KIA-32339 & Cova del Sardo & $1050+/-25$ & $982-1019 \mathrm{cal} A D$ & $898-1036 \mathrm{cal} A D$ \\
\hline KIA-32336 & Abric del Bosc del Cantó & $650+/-25$ & 1290-1387 calAD & $1282-1393 \mathrm{calAD}$ \\
\hline KIA-32337 & Estany Gémena de Dalt & $545+/-25$ & 1329-1423 calAD & 1319-1433 calAD \\
\hline KIA-32350 & Cova de Serradé & $395+/-30$ & 1445-1616 calAD & $1439-1629 \mathrm{calAD}$ \\
\hline KIA-37692 & Estanys Vidals de Dalt & $385+/-30$ & 1449-1617 calAD & 1442-1632 calAD \\
\hline KIA-28272 & Vall de Tallada Llarga & $365+/-30$ & 1458-1621 calAD & 1448-1635 calAD \\
\hline KIA-32363 & Cova del Sardo & $350+/-30$ & $1481-1631 \mathrm{cal} A D$ & $1457-1636 \mathrm{cal} A D$ \\
\hline KIA-32352 & Cova del Sardo & $150+/-25$ & 1674-1942 calAD & 1667-1951 calAD \\
\hline KIA-32338 & Abric de l'Estany de Castieso & $135+/-25$ & 1681-1939 calAD & 1675-1942 calAD \\
\hline
\end{tabular}

Tabl. 1. Datations radiocarbone des sites du Parc Nacional d'Aigüestortes i Estany de Sant Maurici et du niveau mésolithique du Dolmen de la Font dels Coms. 
située entre 5609 et 5376 calBC. Si la fouille de ces foyers a livré divers fragments lithiques taillés, actuellement en cours d'étude, elle n'a en revanche livré aucun matériel céramique.

À partir de 4500 calBC, les occupations de la cavité deviennent progressivement plus intenses, comme le montre l'augmentation du volume de restes (innombrables charbons dispersés sur l'ensemble de la surface, fragments de diaphyses brûlées, augmentation des vestiges lithiques, apparition des fragments céramiques, principalement de petits bols hémisphériques ainsi que des jarres globulaires). On continue à trouver des aires de combustion, certaines aménagées dans des cuvettes circulaires, d'autres simplement délimitées par un cercle, d'autres enfin dépourvues de toute préparation apparente de l'espace.

Autour de 4667-4454 cal BC, est également documenté l'un des deux seuls contextes préhistoriques connus au-dessus de la cavité. Il consiste en un petit terrassement contenu par un mur frontal et un soubassement postérieur disposé parallèlement à l'entrée de la grotte. Fouillé partiellement, cet espace a livré un dépôt de $9 \mathrm{~cm}$ d'épaisseur couvrant une surface de $20 \mathrm{~m}^{2}$, qui contenait une grande quantité de charbons et de cendres. Les artefacts archéologiques sont en revanche quasiment absents. Dans l'attente des résultats d'analyses chimiques du sédiment, on ne connaît toujours pas la fonction de cet espace, qui paraît lié à une activité spécifique, différente de celles observées à l'intérieur de la grotte.

En raison de la très mauvaise conservation des restes osseux et de leur forte fragmentation, il est difficile d'inférer des activités d'élevage à partir des seuls assemblages faunistiques. Les vestiges lithiques offrent en revanche quelques indices préliminaires très suggestifs. On observe en effet, tout au long de la séquence, la présence de lames de silex et de pièces géométriques (principalement des trapèzes), qui ont été apportés sur le site déjà manufacturés. Les matières premières dont elles sont issues semblent provenir de sites d'extraction assez distants (les chaînes des Pré-Pyrénées, nord et sud et, peut-être, de plus long).

L'analyse tracéologique des deux lames issues des ensembles datés entre 4000 et 3500 calBC a révélé une utilisation pour couper l'herbe fraîche au ras du sol, activité qui, de manière hypothétique, pourrait être mise en relation avec l'approvisionnement de fourrage. Parallèlement, les deux pièces géométriques analysées, de même chronologie, présentent une utilisation comme pointes de projectiles. Bien qu'il soit nécessaire de confirmer ces interprétations par des études tracéologiques plus poussées, ces indices semblent révéler une combinaison des pratiques pastorales et de chasse (tabl. 1).

\subsubsection{L'augmentation des sites à la fin du Néolithique (3400-2400 cal BC)}

À partir de 3400 calBC et au cours des mille ans qui suivent, le nombre de gisements datés augmente de manière significative. Ce phénomène est particulièrement net pour la seconde moitié de la période. L'autre phénomène marquant réside dans l'absence de niveaux d'occupation datés de la seconde moitié du $\mathrm{III}^{\mathrm{e}}$ millénaire cal BC, lacune qui se prolonge jusqu'au début de l'époque romaine. À la Cova del Sardo, entre 3370 et 3104 cal BC les occupations de l'intérieur de la cavité semblent s'interrompre, tandis que s'établit à l'extérieur une construction de bois dont le toit s'appuie sur la corniche. C'est à peu près de la même époque que date la deuxième occupation de l'Abric de l'Estany de la Coveta, mentionnée plus haut.

À partir de 2900 calBC se dessine un net accroissement du nombre d'occupations en grottes qui se matérialisent par des aires de combustions et leurs vestiges respectifs (petits ensembles céramiques et lithiques). Ce sont l'Abric del Portarró (3007-2696 calBC), l'Abric d'Obagues de Ratera (2886-2667 calBC), l'occupation préhistorique la plus récente de la cavité de Covetes (2571-2347 cal BC), la grotte de Sarradé (2569-2348 calBC), ainsi que la Cova del Sardo (2864-2495 cal BC), qui continue d'abriter des occupations humaines, comme le montrent la datation d'une aire de combustion (2864-2495 calBC) et celle issue du sondage. Une chronologie similaire (2886-2667 cal BC) a été obtenue à partir de la datation d'une poutre provenant du toit effondré d'une construction de plan rectangulaire de 8 x $5 \mathrm{~m}$, dont la base est formée d'un mur de pierre d'1 m de large, située à 2290 m d'altitude dans la vallée de Coma d'Escós. Certains ensembles sans datation absolue s'inscrivent en outre très probablement dans cette période et / ou dans la précédente. Le premier est celui de l'Abric de la Girada Gran de Monestro, dans lequel un sondage a livré un niveau avec du débitage laminaire de silex. Les deux autres occurrences correspondent aux découvertes d'une lame et d'un fragment de lame en deux points de la même crête, à 2755 m d'altitude.

Ainsi les preuves recueillies montrent une augmentation de la présence humaine à la fin du Néolithique, avec un modèle de peuplement caractérisé principalement par des occupations relativement étendues et intensives au sein de cavités de grandes dimensions situées relativement bas sur les versants des vallées principales (Covetes et Cova del Sardo), et complété par l'utilisation extensive de petits abris situés à la source des réseaux hydriques, qui accueillent des occupations de plus faible ampleur. Dans les deux cas l'outillage lithique, essentiellement sur silex, se compose d'éclats et de supports laminaires et géométriques (ainsi que d'une pointe foliacée à la Cova del Sardo) et les vestiges céramiques sont marqués par la 
I. MÉTHODOLOGIES DES ENQUÊTES ARCHÉOLOGIQUES EN MOYENNE ET HAUTE MONTAGNE

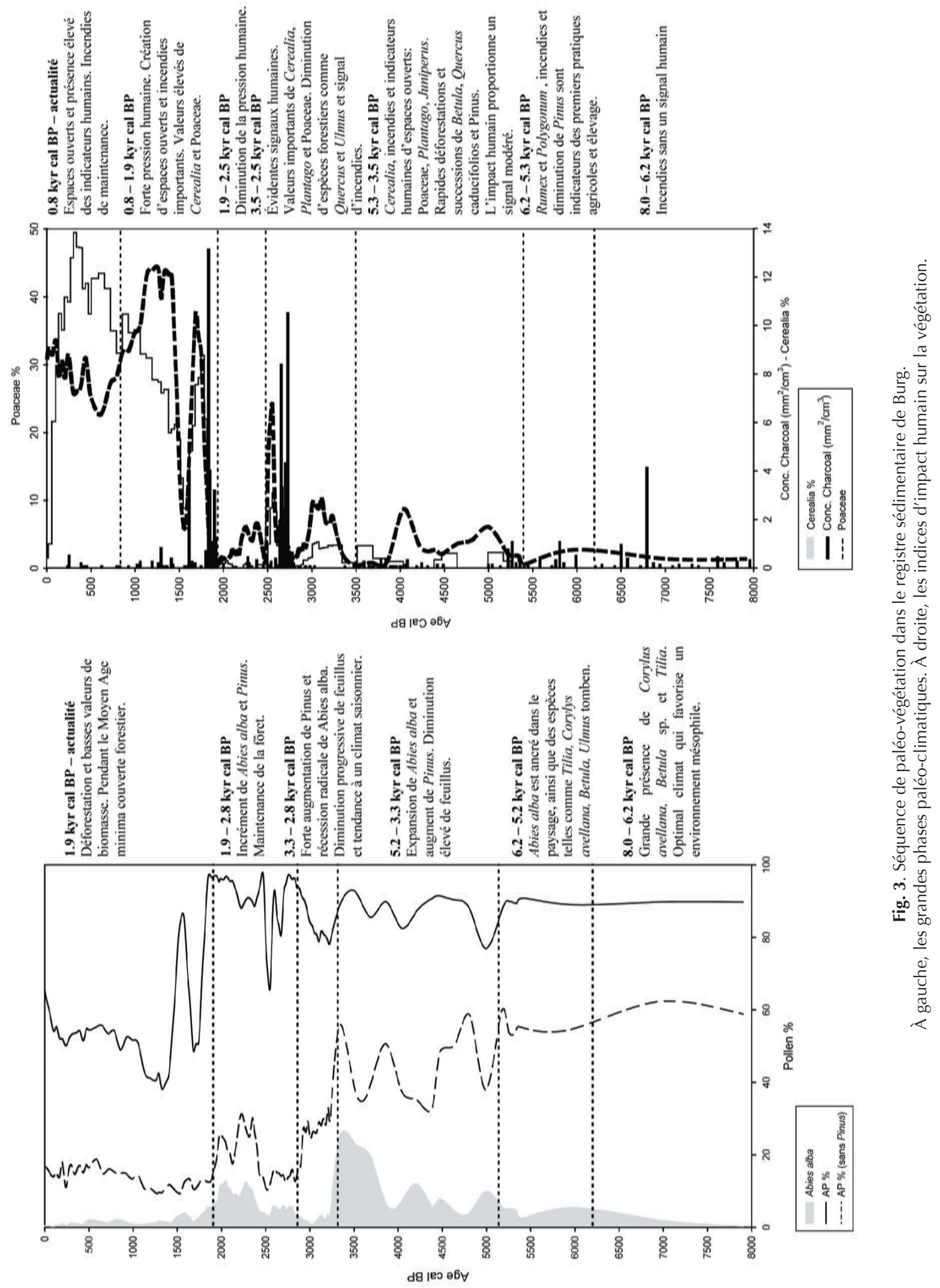


prédominance de grands récipients. La construction de la Coma d'Escós illustre d'autre part la présence d'habitats de plein air partiellement construits en pierre, fait nouveau à la fin du Néolithique en Catalogne. La découverte de vestiges d'outillage lithique dans certaines zones très hautes où il ne semble pas y avoir de traces d'habitat, signale que ces parages furent fréquentés certainement comme des aires de travail (chasse ou contrôle des troupeaux), et de circulation. L'ensemble de ces indices archéologiques dessine donc un processus d'anthropisation croissante du territoire. Ce tableau concorde avec les données des autres travaux réalisés dans la partie méridionale des Pyrénées (Palet-Martinez et al. 2008; Rendu 2003).

\subsubsection{L'absence de contextes d'habitat entre le milieu du III ${ }^{e}$ millénaire et la fin du $I^{\text {er }}$ millénaire calBC}

À partir de 2400 cal BC, les traces d'occupations disparaissent de toute la zone d'étude. Étonnement, les abris et les cavités échantillonnés qui pourtant seront à nouveau occupés aux périodes romaines et médiévales, n’ont livré aucun contexte de cette époque. Il en est de même pour les sites de plein air à architecture de pierre, dont les datations les plus anciennes, exception faite du cas cité précédemment, sont d'époque tardo-romaine. Ce phénomène interroge, dans la mesure où il est traditionnellement admis que les Pyrénées connurent, aux second et premier millénaire cal BC, un certain accroissement démographique et une intensification des activités pastorales (Maluquer 1979; Maya 1977 ; Ruiz Zapatero 1995).

Les seuls vestiges qui, pour l'instant, dans la zone d'étude qui nous concerne, s'inscrivent dans cet intervalle chronologique, sont trois découvertes de céramiques attribuées typologiquement au $\mathrm{II}^{\mathrm{e}}$ millénaire cal BC (Gassiot, Jiménez 2006). Il s'agit de récipients entiers (deux vases de grandes dimensions avec des cordons appliqués dans les deux premiers cas et trois récipients dans le troisième). Dans tous les cas, ces découvertes proviennent de lieux protégés, à l'écart, amas rocheux, failles ou fissures de petits abris. La fuille d'un d'eux, l'Abric de l'Estany de la Coveta, n'a livré aucune autre trace d'occupation susceptible d'être mise en relation avec l'époque théoriquement indiquée par la typologie céramique. Dans les autres cas, le lieu de découverte ne contenait pas de sédiment permettant le même jeu d'association.

Une lecture exclusive du registre archéologique conduirait donc à formuler l'hypothèse que les zones hautes des Pyrénées Occidentales Catalanes, postérieurement à 2400 calBC, ont connu un processus de dépeuplement. Les petits dépôts de matériel répertoriés suggèrent cependant que cette décrue du nombre des sites ne peut être corrélée à une absence de fréquentation du territoire. La présence de récipients de stockage, a priori liés à des activités de production ou de consommation d'aliments, pose, quant à elle, des questions difficiles à résoudre dans l'état actuel des données.

\subsection{Les indices paléoécologiques comme complément du registre archéologique}

\subsubsection{Les traces de contamination des métaux lourds}

La géochimie des 5 premiers mètres du registre sédimentaire des sondages CMB-2 et CMB-3 (fig. 2) montre trois épisodes de croissance marquée et soutenue des taux de certains métaux lourds (cuivre, zinc, arsénique, chrome, cadmium) entre 3100 et 2000 cal BC. Deux de ces épisodes se situent entre 3100 et 2500 cal BC, période qui coïncide avec celle du maximum de gisements d'époque pré-médiévale. Ce fait ne peut être attribué uniquement à l'effet réservoir de la matière organique puisque d'autres niveaux caractérisés par des taux élevés de matière organique ne présentent pas ce type d'anomalie et que certaines de ces anomalies correspondent à des limons (silts). Par conséquent, cette augmentation doit être attribuée à un processus de mobilisation des accumulations d'arsénopyrite décrites dans la région (Soler et al. 1995). À ce fait s'ajoute celui que la combinaison $\mathrm{Cu}, \mathrm{Zn}$ et $\mathrm{As}$ est à mettre en relation avec la pollution générée par la métallurgie de cuivre et de bronze. Ce phénomène ouvre sur la possibilité d'expliquer, ou du moins de corréler l'augmentation de sites observée entre 3000 et 2500 cal BC avec une hypothétique métallurgie du cuivre naissante qui aurait pu être combinée à d'autres activités, comme le pastoralisme.

Cette hypothèse devra cependant être confrontée avec des recherches orientées vers la documentation de contextes directement liés à ces activités, pour l'heure encore inconnus.

\subsubsection{Végétation et intervention humaine}

La figure 3 synthétise l'évolution de la végétation, elle a été élaborée à partir des données paléoécologiques provenant de l'étang de la Coma de Burg et complétée par les informations provenant d'autres sites des zones proches (Catalan et al. 2001 ; Estéban et al. 2003). Pour faire bref, nous ne signalerons ici que les indices d'influence anthropique. Quelques sources disponibles signalent la possibilité d'un impact humain durant les années 5850-6400 cal BC. Elles se fondent sur le signal incendie issu de l'analyse des macrocharbons (Bal, inédit) et sur l'augmentation de différentes espèces caractéristiques des milieux ouverts (Poaceae, herbacées héliophiles, Ericaceae, Fabaceae, etc.), qui auraient été colonisés postérieurement par Betula et Corylus (Miras et al. 2007). L'identification de Cerealia dans certaines séquences du secteur occidental de la zone 
d'étude antérieurement à 6000 calBC pourrait appuyer cette hypothèse. Cette identification a toutefois été discutée (Estéban et al. 2003) et l'on ne dispose pour l'instant d'aucune donnée supplémentaire.

Il n'y a aucune polémique en revanche sur l'apparition ponctuelle de céréales sur toute la zone d'étude entre 4200 et 3600 calBC et sur la relation qu'entretient ce phénomène avec la mise en oeuvre de pratiques agricoles. L'hypothèse est en outre corroborée par la présence de Rumex et Polygonum et la baisse simultanée de Pinus (Estéban et al. 2003). Cette activité a été détectée aussi dans d'autres séquences proches des deux extrémités de la zone d'étude: l'étang Redon (Estéban et al. 2003) et la vallée du Madriu (Miras et al. 2007). L'occupation archéologique de la Cova del Sardo à cette période, celle de quelques sites andorrans, ainsi que le signal incendie de l'étang de Burg confirment encore le phénomène, qui ne paraît toutefois pas avoir eu un fort impact sur le paysage (Bal et al. soumis).

Cet impact augmente en revanche nettement à partir de 3300 calBC dans le secteur oriental quand, résultant de l'activité humaine, Cerealia apparaît clairement dans le diagramme pollinique, en association avec d'autres indicateurs caractéristiques des espaces ouverts par les déforestations (Poaceae, Plantago, Juniperus, etc.). Betula, Qercus caducifolié et Pinus baissent alors momentanément. Ces indices de l'impact anthropique concordent avec une augmentation des vestiges archéologiques et avec les indices d'incendie que livre le comptage des macro-charbons dans l'étang de Burg. Cette phase a également été décrite dans des secteurs proches, comme la vallée Madriu (Miras et al. 2007), l'étang Redo et l'étang Redon (Estéban et al. 2003). Cet impact anthropique sur le paysage se maintient jusque vers 1300 calBC. Si certaines phases plus marquées sont suivies par une succession rapide de formations végétales, les indicateurs dénotent toujours une activité humaine relativement modérée.

La transition d'Abies à Pinus (1500-850 cal BC) coïncide avec un nouvel impact anthropique, sensible à l'échelle de toute la région. Les zones de pâturage s'étendent de façon significative, tandis que disparaissent certaines espèces forestières propres à l'étage montagnard, telles que le chêne et l'orme (Estéban et al. 2003). L'augmentation des valeurs de Cerealia, Poaceae et Plantago et le fort impact détecté sur Pinus et Abies autour de 700-650 cal BC sont contemporains d'un pic très net du signal incendie (Pèlachs et al. 2007). Comparable en intensité à celui du Moyen Âge, celui-ci n'est en revanche pas aussi durable, puisqu'il ne se prolonge pas au-delà de 550 cal BC. Cette forte pression humaine, et l'extension des pâturages qui l'accompagne, ont également été détectées dans la vallée du Madriu (Miras et al. 2007).

\section{Discussion et conclusions}

Les données archéologiques récentes révèlent une présence humaine dans les zones d'altitude de l'aire d'étude depuis pratiquement le début de l'Holocène. Elles soulignent tout autant l'accroissement des contextes datés du Néolithique final / Chalcolithique que l'absence de lieux d'habitat entre 2400 cal BC et le début de notre ère. Cette lacune coïncide cependant avec la découverte, en divers points, de petits dépôts de céramiques attribués, par la typologie, à l'âge du Bronze. De leur côté, les données paléoécologiques montrent que l'impact anthropique sur la végétation, déjà sensible tout au long du Néolithique, se renforce précisément durant certaines des phases correspondant à cette période de vide de sites archéologiques: traces de déforestation dans les diagrammes polliniques, apparition de Cerealia et signal incendie marqué. Cette dichotomie dans les données interroge sur le caractère potentiellement biaisé de la vision que délivre le registre archéologique. Elle pourrait être le fruit d'un changement du modèle d'occupation, qui s'orienterait plus nettement vers des habitats de plein air à la fin du $\mathrm{III}^{\mathrm{e}}$ millénaire cal $\mathrm{BC}$.

L'espace disponible pour cette communication limite à une simple énumération les conclusions du travail en cours. Les matières premières lithiques, majoritairement allochtones, interrogent sur l'existence de réseaux de circulation de biens et de personnes durant les différentes phases documentées. L'étude tracéologique en cours, en suggérant, de manière encore préliminaire, l'utilisation de lames de silex pour couper l'herbe autour de 3600 cal BC, soulève de nouvelles interrogations sur de probables pratiques d'affouragement des troupeaux. Il faut enfin souligner les traces de pollution de métaux lourds à l'étang de Burg. Contemporaines de la période de densité maximale des sites entre 3000 et 2400 cal BC, elles orientent les hypothèses vers l'existence d'une métallurgie du cuivre assez ancienne dans la zone d'étude. 


\section{Bibliographie}

Bal et al. soumis: BAL (M.C.), PÈLACHS (A.), PÉREZ OBIOL (R.), JULIÀ (R.), CUNILL (R.) - Fire history and human activities during the last 3300 cal yr. BP in Spain's central Pyrenees: the case of Estany de Burg. Palaeogeography, Palaeoclimatology, Palaeoecology (soumis 2009).

Catalán, Pérez Obiol, Pla 2001 : CATALÁN (J.), PÉREZ OBIOL (R.), PLA (S.) - Canvis climàtics a Aigüestortes durant els darrers 15000 anys. In: V Jornades sobre Recerca al Parc Nacional d'Aigüestortes i Estany de Sant Maurici (2000), Lleida, Departament de Medi Ambient, 2001, p. 45-51.

Estéban et al. 2003: ESTÉBAN (A.) coord., OLIVER (J.), CÒTS (P.), PÈLACHS (A.), MENDIZÀBAL (E.), SORIANO (J.M.), NASARRE (E.), MATAMALA (N.) La humanización de las altas cuencas de la Garona y las Nogueras (4500 aC-1955 dC). Madrid, Servicio Nacional de Parques Nacionales, 2003, p. 469.

Gardes 1996: GARDES (P.) - La néolithisation des piémonts pyrénéens occidentaux: un phénomène de longue durée? Rubricatum 1(2), Actes del $\mathrm{I}^{\text {er }}$ Congrés del Neolític a la Península Ibèrica, 1996, p. 863-877.

Gassiot, Jiménez 2006: GASSIOT (E.), JIMÉNEZ (J.) - El poblament prefeudal de l'alta muntanya dels Pirineus occidentals catalans. Tribuna d'arqueologia 2004-2005, 2006, p. $89-122$.

Gassiot, Jiménez, Picón 2006: GASSIOT (E.), JIMÉNEZ (J.), PICÓN (A.) - Nuevas Aportaciones al Estudio de la Prehistoria y la Protohistoria en las Zonas Altas del Pallars Sobirà: Planteamientos, Resultados y Potencialidad. In : Oliverira (N.) ed., Simbolismo, Arte e Espaços Sagrados na Pré-história da Península Ibérica. Actas do IV Congreso de Arqueología Peninsular. Faro, Universidade do Algarve, 2006, p. 169-179.

Llovera et al. 1994: LLOVERA (X.), LLUELLES (M.J.), MARTÍN (A.), MARTLUFF (M.), ROVIRA (J.) - Atles històric d'Andorra. Introducció general, la Prehistòrica (12000-1000 aC), Andorra la Vella, Govern d'Andorra, 1994.

Maluquer 1979: MALUQUER (J.) - L'economia i les estrtuctures sòcio-polítiques del Neolític. In: SALVAT (J.) dir., Història de Catalunya, vol. 1, Barcelona, Salvat ed., 1979, p. 105-118.

Martín Vide 1992: MARTÍN VIDE (J.) - "El Clima". In: Geografia General dels Països Catalans, 1, Barcelona, Enciclopèdia Catalana, 1992, p. 1-110.

Martín, Vaquer 1995: MARTÍN (A.), VAQUER (J.) - El poblament dels Pirineus a l'Holocè, del Mesolític a l'Edat del Bronze. In : BERTRANPETIT (J.), VIVES (E.) ed., Muntanyes i población. El passat dels Pirineus des d'una perspectiva multidisciplinària. I Simposi dels Pirineus, Andorra la Vella, Centre de Trobada de les Cultures Pirinenques, 1995, p. 35-73.

Maya 1977 : MAYA (J.L.) - Lérida prehistórica, Lleida, Dilagro S.A., 1977.

Miras et al. 2007: MIRAS (Y.), EJARQUE (A.), RIERA (S.), PALET (J.M.), ORENGO, (H.), EUBA (I.) - Dynamique holocène de la végétation et occupation des Pyrénées andorranes depuis le Néolithique ancien, d'après l'analyse pollinique de la tourbière de Bosc dels Estanyons (2180 m, Vall del Madriu, Andorre). Comptes rendus. Palévol, 6 (4), 2007, p. 291-300.

Montserrat 1992 : MONTSERRAT (J.M.) - Evolución glaciar y postglaciar del clima y la vegetación en la vertiente sur del Pirineo : Estudio Palinológico, Zaragoza, Instituto Pirenaico de Ecología - C.S.I.C., 1992.

Palet-Martinez et al. 2008: PALET-MARTINEZ (J.M.), EJARQUE (A.), MIRAS (Y.), RIERA (S.), EUBA (I.), ORENGO (H.) - Formes d'ocupació d'alta muntanya a la vall de la Vansa (Serra del Cadí-alt Urgell) i a la valldel Madriu-Perafita-Claror (Andorra) : estudi diacrònic de paisatges cuturals pirinencs. Tribuna d' arqueologia, 2006-2007, 2008, p. 229-253.

Pèlachs et al. 2007: PÈLACHS (A.), SORIANO (J.M.), NADAL (J.), ESTEBAN (A.) - Holocene environmental history and human impact in the Pyrenees. Contributions to Science 3 (3), 2007, p. 423-431.

Pons 1994: PONS (J.) - Territori i societat romana a Catalunya (dels inicis al Baix Imperi), Barcelona, Edicions 62, 1994.

Rapalino 2007: RAPALINO (V.), MARIGAN (C.M.), GASSIOT (E.), FONT (J.), CAZANEUVE (X.), CASES (LL.), BRINGUÉ (J.M.), ADELL (J.A.) - Un passeig per la història de Llavorsí. Lleida, Ajuntament de Llavorsí i Pagès Editors, 2007.

Rendu 2003: RENDU (C.) - La montagne d'Enveig, une estive pyrénéenne dans la longue durée. Canet, Trabucaire eds, 2003.

Ruiz Zapatero 1995: RUIZ ZAPATERO (G.) - El poblamiento del primer milenio a.c. en los Pirineos. In: Muntanyes i población. El passat dels Pirineus des d'una perspectiva multidisciplinària. I Simposi dels Pirineus, 1995, p. 85-106.

Soler et al. 1995 : SOLER (A), DELGADO (J.), ARCOS (D.), CARDELlACH, (E.), AYORA (C.) - The diverse types of $\mathrm{Au}$ mineralization in the Pyrenees and their significace in the evolution of Hercynian orogen. In: PASAVA (J.), KRIBEK (B.), ZAK (K.) ed., Mineral Deposits : From their origin to environmental impacts, Rotterdam, Balkema, 1995, p. 71-74. 


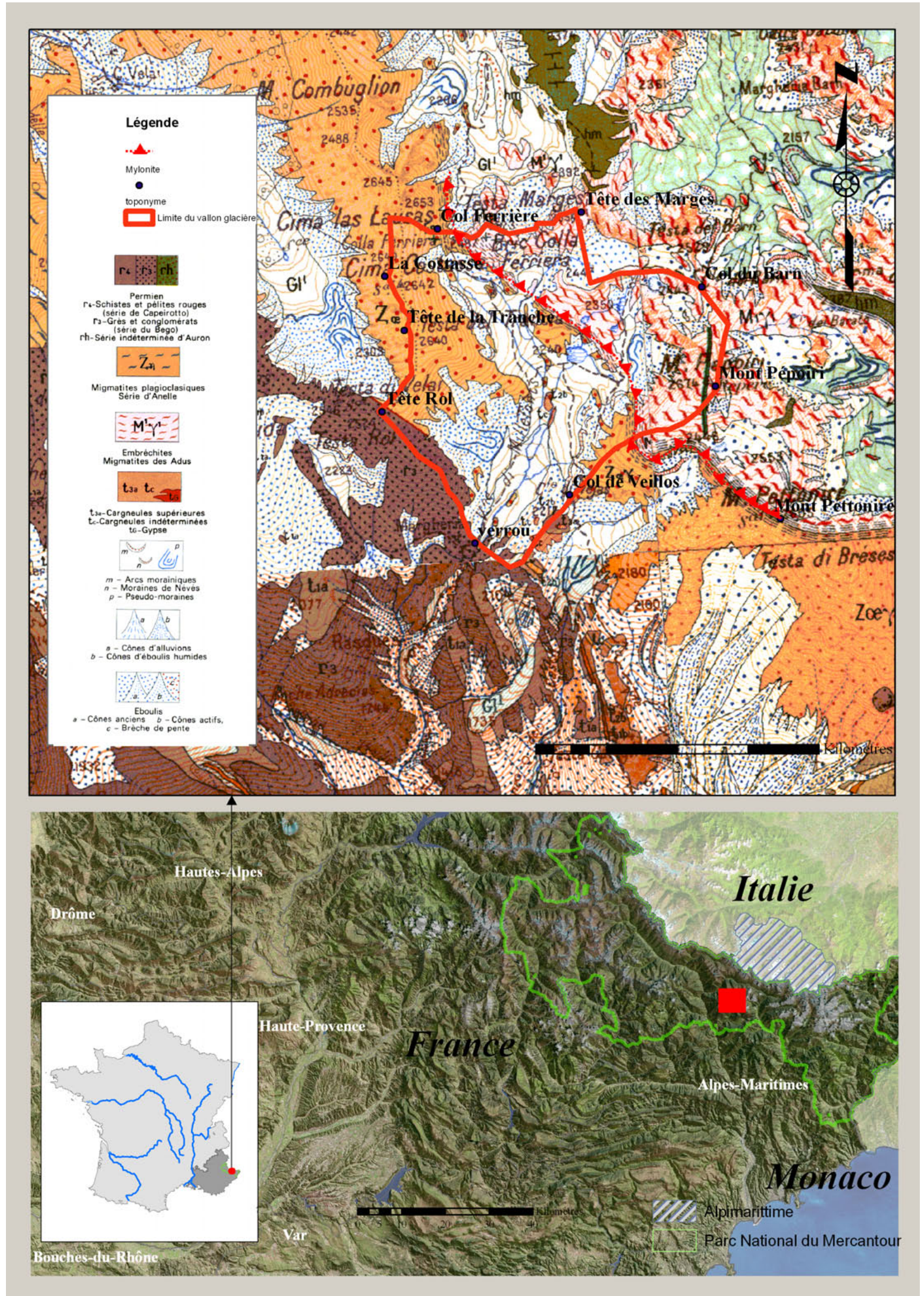

Fig. 1. Contexte géologique et géographique du Vallon de Millefonts (commune de Valdeblore). Extrait de la carte géologique (BD Scan-Géol50. Dalle 10230 @ BRGM mai 2004). 


\title{
Exploitation de la haute montagne du Mercantour et impact sur l'environnement depuis l'âge du Fer. Étude de cas : l'exemple du vallon de Millefonts, commune de Valdeblore (Alpes-Maritimes)
}

\author{
Franck SUMÉRA*, Henri GEIST**
}

\begin{abstract}
Résumé. Les études archéologiques réalisées sur le vallon de Millefonts s'inscrivent dans le programme d'un Projet Collectif de Recherches dont l'un des objectifs est d'évaluer l'évolution des modes d'exploitation de la haute montagne du Mercantour et leurs impacts sur l'environnement depuis les âges des Métaux jusqu'à l'Époque moderne. Le croisement des données archéologiques, avec les observations paléoenvironnementales, et des datations radiocarbone laisse ici entrevoir une dynamique de défrichement qui ne correspondrait pas à une conquête progressive de la haute montagne mais se traduirait par une exploitation des fonds de vallons, laquelle ne tiendrait pas compte des étages végétatifs.
\end{abstract}

Exploitation of the high mountain of Mercantour and impact on environment since the Iron age. Study of case: the example of the dale of Millefonts, village of Valdeblore (Alpes-Maritimes)

Abstract. Archaeological studies of the date of Millefonts are in line with a collective program of research that one of the objectives is to estimate the evolution of the exploitation modes of the high mountain of Mercantour and their impact on the environment, since the ages of metals to modern period. The combination of archaeological data, paleoenvironmental observations and ${ }^{14} \mathrm{C}$ analysis let glimpse a process of clearing which would not correspond to a progressive conquest of the high mountain, but would be translated by an exploitation of the bottoms of the valleys, which would note take into account mountain floors.

$\mathrm{S}$ ans aucune singularité, le questionnement de ce programme d'étude repose sur l'identification des témoins liés au pastoralisme et/ou à la transhumance, à l'impact du pastoralisme sur l'environnement, à l'identification de la diversité des activités économiques développées, à l'enregistrement de l'évolution de l'environnement naturel (Suméra 2008a, b, c et d). L'enquête de terrain s'appuie sur tous les marqueurs d'anthropisation, tels que les constructions en pierres sèches, les terrasses, les itinéraires, sur l'identification des ressources naturelles organiques ou minérales mais aussi sur le recensement des marqueurs paléoenvironnementaux. À ce stade de l'étude, les données paléoenvironnementales sont à peine exploitées; néanmoins les premières observations géomorphologiques et anthracologiques viennent, grâce à l'appui d'une première série de datations radiocarbone, apporter un éclairage complémentaire sur les données archéologiques. Le vallon de
Millefonts a été retenu comme premier terrain d'étude d'expérimentation parce qu'il bénéficiait d'un important potentiel archéologique lié à la quantité d'enclos recensés par Henri Geist (Geist 1999; 2001), à la présence de gisements et d'exploitations métallifères identifiés depuis le XIX $^{\mathrm{e}}$ s. (Vérany 2001; Lambert 2005) ${ }^{1}$, ayant récemment fait l'objet de nouvelles prospections réalisées par l'équipe de Denis Morin et Patrick Rosenthal (Morin, Rosenthal $2002 \mathrm{a}$ et b) et, enfin, à l'existence de tourbières et de lacs qui constituent de bon capteurs de données paléoenvironementales. Précédée par une analyse des orthophotographies qui a permis de relever et localiser les principaux enclos, l'intervention archéologique a consisté sur le terrain en la réalisation d'une prospection systématique du vallon (360 ha) et en la fouille d'une dizaine de cabanes $\left(200 \mathrm{~m}^{2}\right.$,

1. http://sigminesfrance.brgm.fr/sig.asp

\footnotetext{
* Ministère de la Culture et de la Communication, DRAC de Provence-Alpes-Côte d'Azur, Service Régional de l'Archéologie, 21-23, boulevard du Roi René, 13617 Aix en Provence cedex 1 et Centre Camille Jullian (CCJ), UMR 6573 CNRS - Université de Provence, Maison Méditerranéenne des Sciences de l'Homme, 5 rue du château de l'Horloge, BP 647, 13094 Aix-en-Provence cedex 2.

* Cercle d'Histoire et d'Archéologie des Alpes-Maritimes, 51 bd Stalingrad, 06000 Nice.
} 
Suméra 2008b). Elle se poursuit aujourd'hui et intègre maintenant des études paléoenvironementales approfondies $^{2}$ ainsi qu'un programme sur la réduction des minerais ${ }^{3}$.

\section{Contexte géographique et géologique}

Situé à l'immédiate périphérie du socle cristallin qui constitue le cœur du massif du Mercantour, le vallon de Millefonts correspond à une empreinte glaciaire qui s'est formée à l'interface entre différentes formations géologiques. Localisée entre 1800 et $2400 \mathrm{~m}$, cette unité paysagère, très fermée, occupe une superficie de 370 ha. Son contour est matérialisé par une ligne de crêtes qui part d'un verrou glaciaire localisé à $2160 \mathrm{~m}$ NGF et qui passe d'est en ouest par une série de sommets et de cols: Tête Rol (2225 m), Tête de la Tranche (2628 m), La Costasse $(2639 \mathrm{~m})$, Le Col Ferrière $(2516 \mathrm{~m})$, Tête des Marges (2550 m), Tête du Barn (2529 m), Col du Barn (2452 m), Mont Pepoiri (2674 m), Col du Veillos (2 194 m) (fig. 1) ${ }^{4}$. Le vallon orienté nord-nord-est, sud-sud-ouest prend naissance dans des terrains cristallins appartenant au socle du massif de l'Argenterra-Mercantour et vient buter sur des terrains sédimentaires du permien constitués de grès et de conglomérats (série du Bégo). L'ablation glaciaire a porté sur une zone de compression entre les complexes cristallins de La Tinée et de Chastillon Valmasque qui est jalonnée par la mylonite de la Valletta-Molière. Cette formation, qui suit un axe passant par le Col Ferrière et le Mont Pettonire, a été soumise à de fortes pressions qui ont provoqué la création de diaclases de part et d'autre de cet axe. Ces fractures ont été cimentées par les filons d'hématite $\left(\mathrm{Fe}_{2} \mathrm{O}_{3}\right)$ exploitables dans le cadre d'une production métallurgique.

Au nord du vallon, un chapelet de cinq lacs de surcreusement recueille et alimente le réseau hydrique qui s'écoule dans le fond du vallon par l'intermédiaire d'un réseau de ruisseaux qui alimentent et drainent les pâturages. Les profils en travers du vallon, plus marqués à l'est qu'à l'ouest, montrent que ses versants se referment progressivement vers le verrou glaciaire. Un léger épaulement de part et d'autre témoigne d'une phase de retrait qui a laissé un cordon de

2. Un programme d'études paléoenvironnementales du vallon a été engagé en 2009. Il associe des géomorphologues (Fabien Arnaud, EDYTEM, Chambéry; Cécile Miramont et Élodie Brisset, IMEP, Aix-en-Provence), une anthracologue (Claire Delhon, CEPAM, SophiaAntipolis), un palynologue (Frédéric Guité, IMEP), un entomologue (Philippe Ponel, IMEP), un dendrologue (Jean-Louis Édouard, CCJ, Aix-en-Provence).

3. Gaspard Pagès (Université de Liège) a entrepris en 2009, au lieu-dit Le Clouté, la fouille d'un atelier de réduction situé dans la zone sensible identifiée en 1982 par le BRGM et reprise en 2001 par D. Morin et P. Rosenthal.

4. Toutes les altitudes sont données en référence au NGF. dépôts morainiques. D'importants blocs erratiques occupent la partie située immédiatement au-dessus du verrou. Sur le versant ouest, la carte du BRGM indique la présence de pseudo-moraines liées à la fonte de névés. Enfin, on observe conjointement aux phénomènes de dépôts morainiques latéraux la présence d'importants dépôts de pente provenant de l'activité érosive des versants. Ces derniers sont particulièrement actifs sur le versant est du vallon. La pelouse qui occupe la partie basse du vallon couvre une superficie de 37 ha.

\section{Un paysage asylvatique}

Sur les deux versants de la vallée qui est située en amont du verrou glaciaire on observe la présence d'une forêt de conifères dont le développement devient épars à partir de la côte d'altitude des $1960 \mathrm{~m}$. Le centre de la vallée est occupé par des terres pâturables. Au-delà du verrou, le vallon de Millefont présente un couvert herbacé ras dans lequel aucun arbre n'est présent (fig. 2). Néanmoins, sur le sommet du versant est du vallon, on remarque la présence de rebord du vallon d'un petit bosquet épars constitué de mélèzes et dont le développement s'arrête vers le Col du Veillos autour de la cote d'altitude des $2151 \mathrm{~m}$. Le dernier mélèze a été identifié à $2315 \mathrm{~m}$. Le fond et les versants du vallon occupent donc des altitudes comprises entre 1800 et $2400 \mathrm{~m}$. Ce paysage, où seuls quelques jeunes mélèzes subsistent de façon éparse, correspond à l'interface entre les zones alpines interne et intermédiaire. Ces altitudes, qui correspondent à la transition entre les étages subalpin et alpin, sont donc théoriquement occupées par des formations à mélèzes, à arolles (pin cembro) et à pins à crochet.

Le vallon de Millefonts correspond à un paysage dont l'état asylvatique actuel a une origine anthropique illustrée par de nombreux témoignages archéologiques d'activités pastorales et sidérurgiques. Les prospections et fouilles ont permis de recenser une vingtaine d'enclos pastoraux, mais également des sites d'extraction et de réduction de minerai de fer. Leur répartition spatiale est fortement conditionnée par ce cadre géophysique mais aussi par leurs fonctions et l'adaptation à l'évolution des ressources végétales.

\section{L'impact de la métallurgie}

Dès le $\mathrm{XIX}^{\mathrm{e}} \mathrm{s}$. la présence au Col Ferrière de minerai de fer, mais également celle de vestiges paléo-métallurgiques, était identifiée. Dans le cadre d'un inventaire des ressources géologiques des Alpes-Maritimes et de l'ancien Comté de Nice, le naturaliste Jean-Baptiste Vérany recensait la présence de vestiges liés à la réduction du fer mais 
aussi celle d'un important filon métallifère (Vérany 2001). $\mathrm{Au}$ détour d'une note, ce dernier envisage même l'implantation d'usines dans la montagne de Millefonts pour alimenter les arsenaux et signale l'existence de veines de fer oligistes qui auraient eu «plusieurs décimètres de puissance». Il mentionne la présence autour du col de restes de fourneaux «à la Catalane», témoins d'une activité effacée de la mémoire collective. Probablement intrigué par cette présence alors que la montagne est déjà dénuée de couvert forestier, il précise : «la tradition du pays porte même qu'elle était couverte de forêts [...] et qu'elle fut dépeuplée par suite des usines qui s'y formèrent». En 1982, l'existence de cet important potentiel sidérurgique, au demeurant déjà soulignée par la toponymie, a été confirmée par le BRGM qui a effectué une campagne de prospection

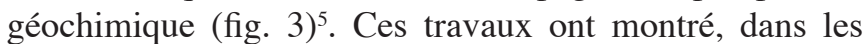
prélèvements analysés, une teneur en fer située autour de $6 \%$. Entre 2000 et 2004, Bruno Ancel, puis Denis Morin et Patrick Rosenthal ont repris les investigations dans ce vallon dans le cadre du PCR «Mines et métallurgies du fer dans les Alpes du Sud». Ils ont pu ainsi confirmer la présence d'une zone d'extraction située entre le Lac Petit (2225 m) et le Col Ferrière $(2484 \mathrm{~m})$ et découvert une zone de réduction située en contrebas du verrou glaciaire. La zone d'extraction correspond au secteur de la bande de mylonite où le substrat a subi des déformations qui ont créé des fissurations et diaclases, lesquelles ont été cimentées par des remplissages ferrugineux d'hématite. À l'intérieur d'une zone couvrant 12 ha, Morin et Rosenthal ont identifié une dizaine de gisements où le minerai affleure. La plupart suivent les lignes de crêtes qui délimitent le bassin de Millefonts, mais on note, à proximité du Lac Petit, la présence d'un site sortant de cette configuration topographique et qui est localisé en bas du petit vallon menant au Col Ferrière. En 2009, un autre site d'extraction par abattage au feu associé à une aire de concassage a été découvert au nord du Lac Petit (fig. 4) ${ }^{6}$.

Ce mode d'exploitation, attesté dès la Protohistoire, nécessite l'emploi de combustible et pose donc la question de la provenance de ce dernier (Py 2002). Concernant la datation de l'exploitation de ces différents gisements, on ne dispose pas d'indicateurs chronologiques directs. On doit toutefois faire le lien avec la zone de réduction située en contrebas. Ainsi, à $1300 \mathrm{~m}$ de distance, immédiatement sous le verrou glaciaire, une zone sidérurgique s'étendant sur 12 ha a

5. Ces prospections on été réalisées dans le cadre d'un programme du BRGM appelé «Inventaire des ressources minérales du territoire national» qui s'est déroulée entre 1975 et 1991. Les données sont consultables sur le réseau Internet (http://sigminesfrance.brgm.fr/sig. asp) et dans Lambert 2005.

6. Prospection Alain Morand, Joséphine Lopez, Franck Suméra. Le site n'a pas encore été étudié et n'est pas encore daté. pu être identifiée. À l'occasion de prospections pédestres menées en 2001, six implantations supposées de fours liés à la réduction du fer ont été localisées grâce à la présence de scories, de parois de four et de charbon de bois. Les analyses paléo-métallurgiques indiqueraient que ces fours étaient entièrement dédiés au traitement du minerai issu du Col Ferrière. Les sites F1, F2 et F4 sont localisés autour de la cote altimétrique des $2000 \mathrm{~m}^{7}$ et portent respectivement les cotes d'altitudes suivantes 1990, 1973, 1977. Les sites F3, F7, F8 et F9 sont localisés autour de 1800 m, soit $200 \mathrm{~m}$ en contrebas. F5 et F6 se détachent un peu du groupe et sont respectivement localisés à $1640 \mathrm{~m}$ et $1590 \mathrm{~m}$. La distance à vol d'oiseau entre les points extrêmes de l'ensemble est d'exactement $1000 \mathrm{~m}$. Il faut cependant relativiser la valeur de la précision, topographique de ces informations: les derniers travaux, réalisés en 2009 par Gaspard Pagès (Pagès 2009), indiquent en effet que les différents locus découverts à l'occasion des prospections de Morin et Rosenthal semblent correspondre à des zones de colluvionnement et provenir de complexes métallurgiques moins nombreux et situés en amont des zones de découvertes. Ces précisions géographiques sur le contexte des découvertes ont été rendues possibles grâce à la réalisation des sondages et fouilles qui n'avaient pu être entrepris par les inventeurs des résidus de fours.

Grâce à la collecte de charbons de bois, les indices de fours ont pu être datés. Les structures F1, F2 et F4 seraient ainsi attribuables à la période antique et le four F3 serait, quant à lui, antérieur et inclus dans une fourchette correspondant à la fin de l'âge du Fer et au début de l'époque romaine. L'ensemble s'étend sur un laps de temps compris entre le $\mathrm{II}^{\mathrm{e}}$ s. av. J.-C. et le VI ${ }^{\mathrm{e}}$ ap. J.-C. ${ }^{8}$. Ces datations s'appuient sur les résultats d'analyses radiocarbone réalisées par le laboratoire de Gif-sur-Yvette sur des charbons de bois issus de ramassages de surface. Elles nécessitent donc d'être confirmées par de nouvelles analyses qui devraient être réalisées, cette fois-ci, sur des prélèvements issus de contextes archéologiques bien établis et sur des charbons de bois sélectionnés. En effet, dans le contexte des étages subalpin et alpin où se développent mélèzes et pins cembrons à l'espérance de vie pluri-séculaire, il importe de précéder les analyses radiocarbones par une reconnaissance anthracologique destinée à identifier les espèces à faible espérance de

7. Les altitudes mentionnées dans cet article sont issues d'un report de données à partir du MNT de l'IGN. Ce choix est lié à un souci d'homogénéiser les données altimétriques. Les résultats différent quelque peu des données de D. Morin et P. Rosenthal établies par GPS. 8. Toutes les datations concernant la paléo-métallurgie présentées dans cet article sont issues des travaux de D. Morin et P. Rosenthal et reposent sur des ramassages de surface. Les références des fours sont celles utilisées par les auteurs des articles cités. 


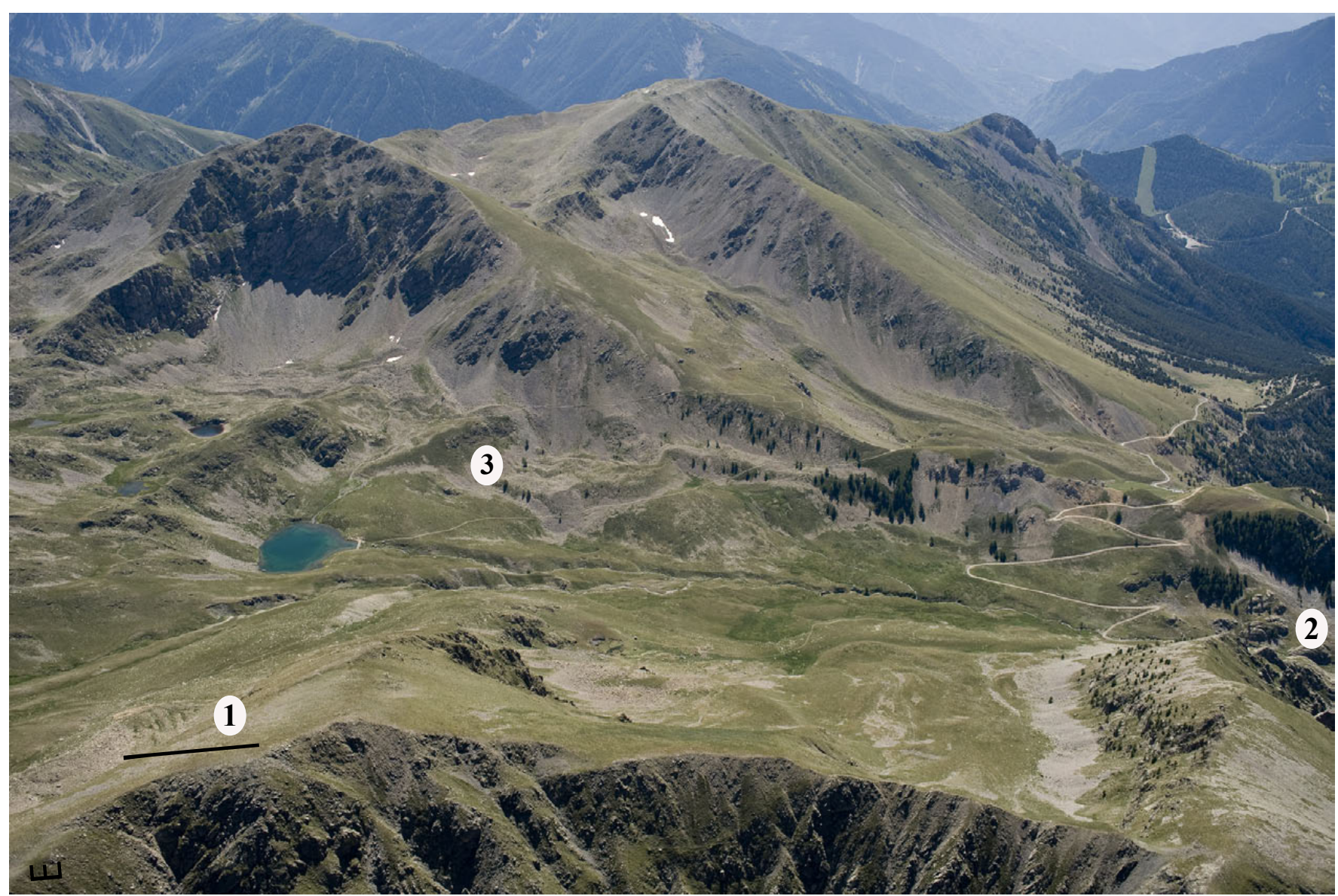

Fig. 2. Vue aérienne du Vallon de Millefonts. Le paysage asylvatique témoigne de l'impact de l'homme sur le paysage. Au premier plan à droite, le col de Ferrière (1) correspond à une zone d'extraction du minerai de fer; à droite de l'image, sous la zone du verrou glacier, se situe la zone de réduction du minerai de fer (2); quelques mélèzes préservés dans les zones d'éboulis témoignent des possibilités de reconquête forestière dans cet étage alpin (3). C C. Hussy, SRA PACA.

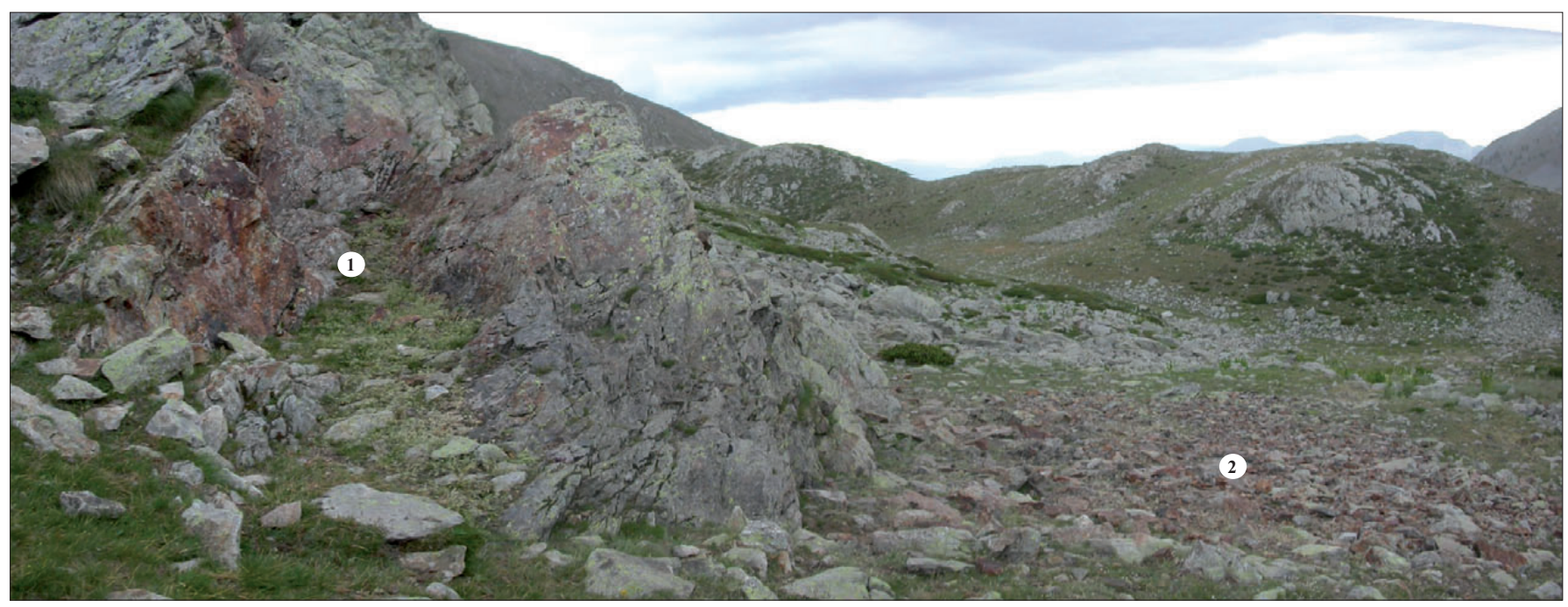

Fig. 4. Indices d'abattage au feu (1) associés à une zone de concassage liée à une activité métallurgique (2). Cliché J. Lopez. 


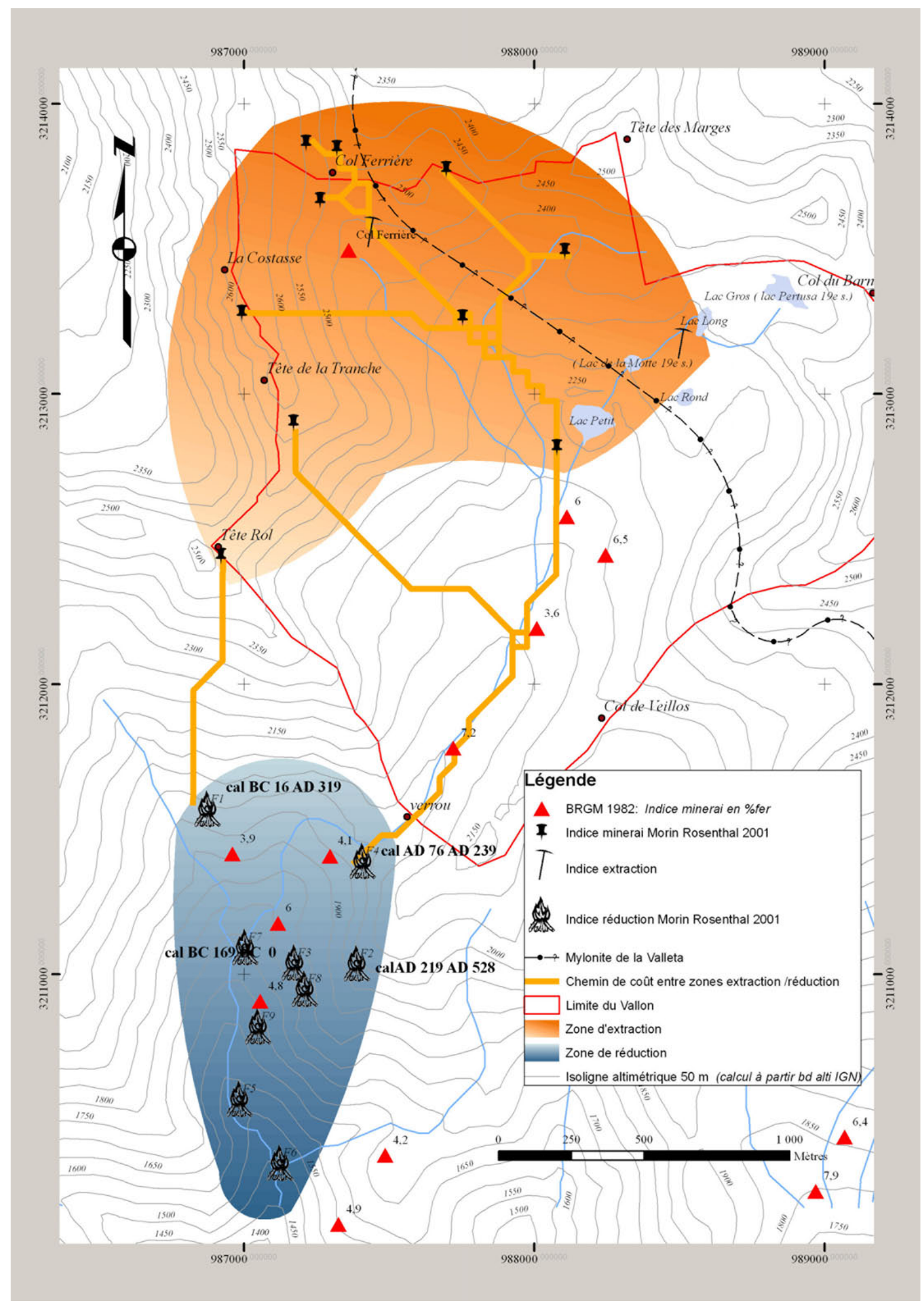

Fig. 3. Répartition des vestiges liés à la métallurgie et des indices de minerai. 
vie ou les jeunes brindilles ${ }^{9}$. De même il est important de privilégier les datations radiocarbone AMS qui portent sur des échantillons plus ciblés car les datations traditionnelles peuvent créer un nouveau biais lorsqu'elle repose sur des échantillons pouvant s'inscrire dans la diachronie ${ }^{10}$.

\section{L'impact du pastoralisme}

Concernant les vestiges liés au pastoralisme, on note la présence d'une vingtaine d'enclos disposés en anneaux au pied des cônes d'éboulis et en périphérie externe de la zone pâturable la mieux drainée et la plus herbeuse (fig. 5).

Cinq séries d'enclos associés aux vestiges de cabanes ont été fouillées à proximité du Lac Petit. L'une des cabanes fouillée en 1995 a livré deux niveaux de sols associés à des foyers (Geist 2001). Les charbons de bois issus du premier niveau de sol de la cabane ont été analysés par la société Archéolab et ont livré une datation située entre le $\mathrm{XV}^{\mathrm{e}}$ et XVII ${ }^{\mathrm{e}} \mathrm{s} .{ }^{11}$. Le deuxième foyer a été découvert dans un niveau archéologique situé $0,20 \mathrm{~m}$ en dessous du dernier état d'occupation. Les études radiocarbone réalisées sur ce deuxième niveau de foyer livrent une datation qui se situe entre le début du XII et la fin du XIII ${ }^{\mathrm{e}} \mathrm{s} .{ }^{12}$. Les fouilles réalisées par Henri Geist ont été reprises en 2004 et ont permis la fouille de cinq autres cabanes dont l'une présentait trois niveaux de foyers. Les relations stratigraphiques, qui laissaient penser que ces foyers étaient liés à un ensemble de structures plus anciennes que le foyer du XIII ${ }^{\mathrm{e}} \mathrm{s}$. fouillé en 1995, ont été globalement confirmées. Les datations obtenues sont toutefois à peine antérieures. Ainsi, une couche cendreuse (US65), stratigraphiquement antérieure à la cabane de Geist, a livré une datation située autour de l'an mil $^{13}$. À une quinzaine de mètres au nord de cette structure, une seconde cabane comportant trois états a livré deux foyers datés entre le milieu du $\mathrm{XI}^{\mathrm{e}}$ et le milieu du XIII ${ }^{\mathrm{e}} \mathrm{s}$. (fig. 6). Plus au sud, dans un second enclos, une cabane

9. Rappelons que le ${ }^{14} \mathrm{C}$ date la mort du prélèvement analysé et que, dans un arbre, seul l'aubier et l'écorce sont vivants. Or il existe en haute montagne des arbres qui peuvent atteindre 1000 ans d'âge, si bien qu'une analyse provenant de ce type d'individu est susceptible de provoquer une erreur de même amplitude dans le cas où le prélèvement est issu du cœur ou de l'aubier de l'arbre.

10. Dans un contexte où des charbons de bois de différentes périodes ont pu être brassés se pose aussi la question de la méthode utilisée pour l'analyse radiocarbone. L'utilisation d'une datation traditionnelle, par comptage, à la place d'une datation AMS a pour effet de livrer un résultat qui n'est qu'une moyenne des datations des différents éléments analysés.

11. Arc-1572: 1450-1665 cal AD à 2 sigma.

12. Arc-1778: $1125-1280$ cal AD à 2 sigma.

13. Ly-5683 : 983-1033 cal AD à 2 sigma. Datation sur Pinus sylventrisPinus uncinata (C. Delhon CEPAM). a livré un autre foyer (US76) confirmant une occupation médiévale de ce complexe, soit au XI ${ }^{\mathrm{e}} \mathrm{s} .{ }^{14}$. À $150 \mathrm{~m}$ au sud, un second complexe d'enclos a livré un foyer issu d'une petite structure quadrangulaire qui a pu être datée, grâce à la présence d'un foyer, entre le début du $\mathrm{II}^{\mathrm{e}}$ et le milieu du I ${ }^{\text {er }}$ s. av. J.-C. ${ }^{15}$. Le contexte de cette structure, qui n'a fait l'objet que d'un sondage stratigraphique, reste à étudier et il n'est pas certain que cette dernière soit liée à une activité pastorale. Hormis cette dernière construction, l'ensemble des structures situées autour du Lac Petit à plus de $2500 \mathrm{~m}$ d'altitude, témoigne ainsi d'une occupation récurrente entre le $\mathrm{XI}^{\mathrm{e}}$ et le $\mathrm{XVII}{ }^{\mathrm{e}} \mathrm{s}$., avec, certes, des glissements d'implantations mais, néanmoins, un maintien de l'assiette du site à vocation pastorale. Une autre intervention, réalisée à la limite inférieure de ce même étage alpin, a montré la présence de structures médiévales datées autour de l'an mil. Ainsi un petit enclos situé autour du verrou glaciaire a livré deux niveaux de foyers datés respectivement $\mathrm{du} \mathrm{XI}^{\mathrm{e}}$ et du XII ${ }^{\mathrm{e}}{ }^{16}$.

Signalons enfin que la fouille de ces sites n'a livré que très peu de mobilier et, en particulier, aucun vestige céramique datable. Tous les sondages et fouilles réalisés sur les sites se sont révélés pratiquement stériles en mobilier, les seuls artefacts rencontrés en fouille correspondant aux foyers qui furent trouvés dans chacune des cabanes associées aux enclos. Néanmoins, parallèlement aux opérations de fouille, une reconnaissance au détecteur de métaux a été engagée sur les enclos afin de rechercher d'une part les vestiges liés à d'éventuelles activités métallurgiques et d'autre part ceux permettant d'identifier les espèces animales présentes: éléments de sellerie, briderie, harnarchement, ferrage etc... Cette prospection a permis de mettre en évidence des battants de sonnailles, clous de selleries, rivets d'harnachement et fers de sabots. Les fonctions liées à ces objets, pour la plupart indatables, témoignent de la spécialisation de ce lieu manifestement dédié à l'élevage et à la chasse. On remarque que la présence du fer à sabot évoque les asiniens et que les clous transformés en sonnailles sont à associer, par leur taille, à l'élevage des ovi-caprinés et non à celui des bovins. Concernant les activités cynégétiques, on note la présence de balles de plomb mais également celle d'un carreau d'arbalète quoique ce dernier soit plutôt associé à une arme de guerre. Enfin, il faut signaler que la présence immédiate du gisement de minerai de fer au Col Ferrière n'a pas débouché sur une économie annexe de la

14. Ly-5681: 1026-1180 cal AD à 2 sigma. Datation sur Pinus sylventris-Pinus uncinata (C. Delhon CEPAM).

15. Ly-5682: 196-43 cal BC à 2 sigma. Datation sur Vaccinium iliginosum (C. Delhon CEPAM) issu du foyer FY 106.

16. Poz-27041 : 970-1050 cal AD à 2 sigma et Poz 27042: 1020-1160 cal $\mathrm{AD}$ à 2 sigma. 
métallurgie. L'intérieur des enclos ou des cabanes ne recèle ainsi ni scorie, ni le minerai qui aurait pu être ramassé à l'occasion des estives.

\section{Synthèse}

\subsection{Des activités cloisonnées dans l'espace}

La distribution spatiale des sites dessine quatre zones qui semblent constituer des facteurs d'exclusion si l'on considère qu'il n'y a pratiquement pas de superposition dans la typologie des activités du vallon. De haut en bas, on distingue un premier groupe qui s'étend sur une douzaine d'hectares et qui est lié à l'extraction du minerai. On ne dispose pas directement d'éléments de datation concernant les activités d'extraction, néanmoins on sait qu'elle est au moins pour part contemporaine du fonctionnement de la zone de réduction située sous le verrou, laquelle a fonctionné entre la fin de l'âge du Fer et le début du haut Moyen Âge. En contrebas des sites d'extraction, une zone constituant un anneau autour de l'alpage central est matérialisée par l'implantation des enclos et structures de pierres sèches. Situés immédiatement sur le pourtour de la pelouse alpine, ils sont principalement installés sur des dépôts morainiques ou des éboulis de pente, souvent en situation perchée. Les datations réalisées sur ces structures montrent une continuité ou du moins une forte récurrence d'occupation entre le $\mathrm{X}^{\mathrm{e}} \mathrm{s}$. et la période contemporaine. Seuls deux indices de datation montrent l'existence d'une occupation antérieure à l'époque médiévale dans l'anneau de structure qui entoure la zone de pâturage central. Ainsi, au niveau du verrou, la découverte d'un sesterce de Gordianus III $^{17}$ trouvé hors structure mais sur un chemin dont le tracé est contraint par le relief, atteste, sans autre précision, une fréquentation du vallon au cours du $\mathrm{III}^{\mathrm{e}}$ s. ap. J.-C. Par ailleurs, un foyer (FY106) découvert dans la zone du Lac Petit, indiquerait une occupation pastorale au second âge du Fer. Ces deux éléments de datation constituent cependant des marqueurs éloignés du bloc de datations médiévales et modernes mais il est très probable, en l'état, que cela soit un effet de distorsion lié à l'enquête archéologique au cours de laquelle $20 \%$ seulement des structures ont été explorés. Les analyses paléoenvironnementales et notamment la palynologie corrigeront probablement cette perception. Nous n'avons toutefois à ce jour aucune trace liée à des pratiques pastorales antérieures à l'âge du Fer.

La troisième zone, celle du pâturage central du vallon, semble jouer un rôle répulsif et n'a livré aucun site. Cela

17. Découverte en prospection au détecteur de métaux. $\mathrm{N}^{\circ}$ inv. DT 2008-7. Lambert II: X 988010, 472; Y 1911934 Z = 1993 m. Enfouissement à $5 \mathrm{~cm}$. évoque bien entendu un problème de taphonomie. Les observations réalisées sur les enclos situés sur les pentes ou sur les bas de pentes semblent néanmoins indiquer une relative stabilité des phénomènes d'érosion et de recouvrement. Il semblerait, plus vraisemblablement, que cette zone ait été délaissée du fait de sa pauvreté en blocs de construction au profit des zones bien mieux pourvues situées à l'interface avec les pierriers provenant des éboulis de pente.

La dernière zone, qui est essentiellement caractérisée par la présence des ateliers de réduction du minerai offre une plus grande mixité puisqu'elle intègre aussi des enclos et des sites qui correspondent à de l'habitat. Elle se situe sous le verrou glaciaire entre 1600 et $2000 \mathrm{~m}$.

\section{2. Évolution du couvert forestier au cours des deux derniers millénaires}

Le croisement de ces données altimétriques, topographiques, archéologiques et dans une moindre mesure environnementales, permet de construire une hypothèse de restitution du schéma d'évolution de la végétation. Le couvert forestier actuel ne traduisant pas le potentiel naturel puisque la timberline se situe autour de 2400 et $2500 \mathrm{~m}$, la question posée est celle de l'époque de la déforestation du massif entre 2000 et $2500 \mathrm{~m}$ d'altitude. Or, on observe que les activités métallurgiques ont généré la création d'une zone consacrée à l'extraction du fer qui se situant dans l'étage de la cembraie-mélézin (encore attestée aujourd'hui par la présence de quelques individus isolés). Cette activité n'est associée à aucune trace de réduction de minerai ou de charbonnière. En revanche, une zone consacrée à la réduction de ce même minerai a été localisée $140 \mathrm{~m}$ en en contrebas. On peut donc penser que si le minerai a été transporté pour être réduit à un kilomètre de distance, c'est qu'il n'y avait déjà plus de combustible au niveau du Col Ferrière et que, dès le $\mathrm{II}^{\mathrm{e}}$ s. av. J.-C., la partie du vallon de Millefonts située au-dessus du verrou était entièrement déboisée. La découverte, en 2009, d'une zone d'extraction par abattage au feu vient toutefois pondérer ce constat. En considérant que cette activité est avant tout contrainte par la localisation du gîte métallifère, on peut envisager que le bois ait été acheminé sur place. Mais il se peut également que l'extraction corresponde à une première phase d'activité constituant l'une des causes du déboisement. Les fouilles à venir permettront, grâce à l'analyse des charbons de bois, de définir si les essences sont endogènes. Elles livreront par ailleurs les éléments de datation qui font aujourd'hui défaut.

Les jalons chronologiques obtenus par les datations radiocarbone des fours de réduction, permettent aussi de déduire qu'il n'y a pas eu de reprise de la forêt à l'intérieur du vallon entre ce terminus post quem et le VII ${ }^{\mathrm{e}} \mathrm{s}$. ap. J.-C. puisque 


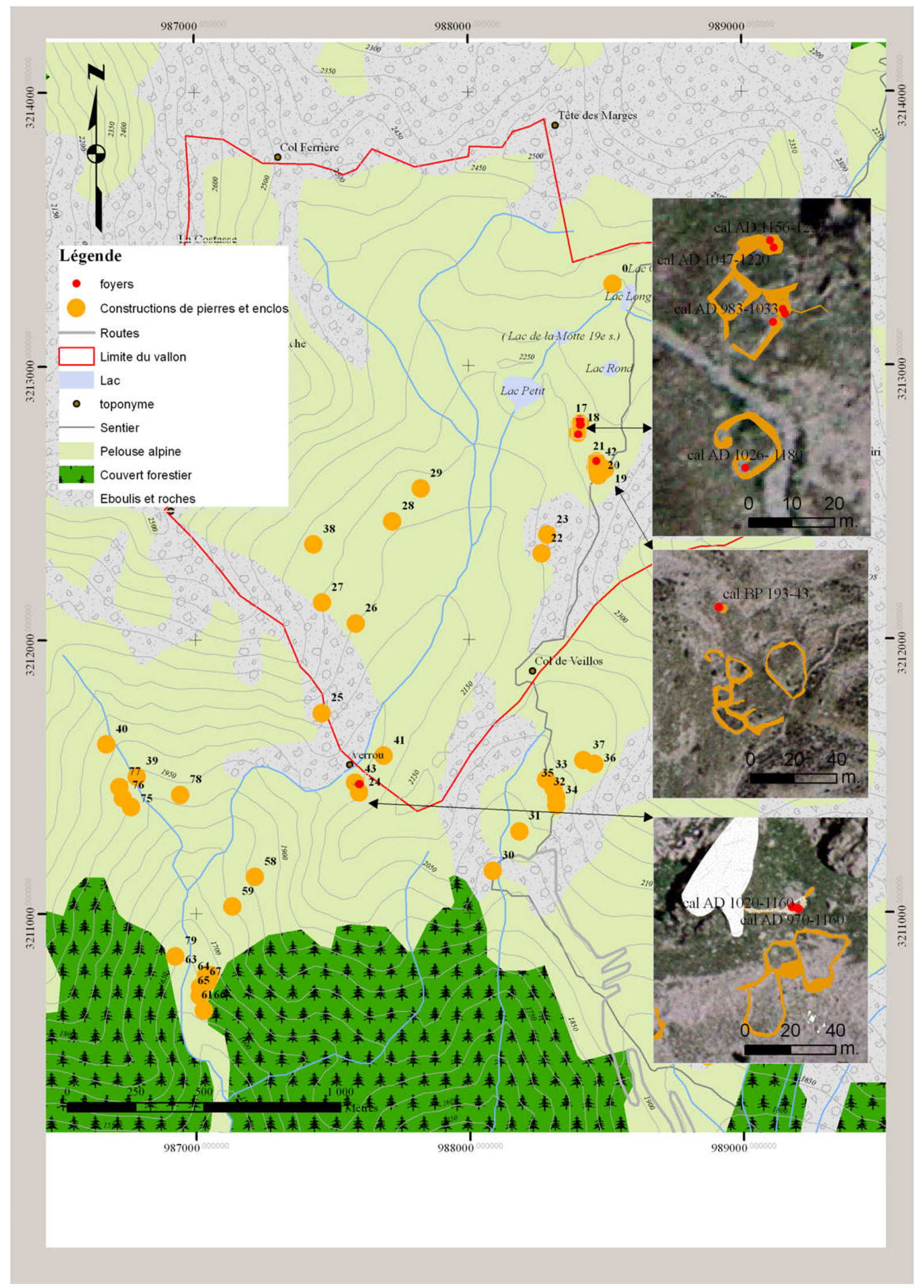

Fig. 5. Répartition des vestiges liés aux activités pastorales. 


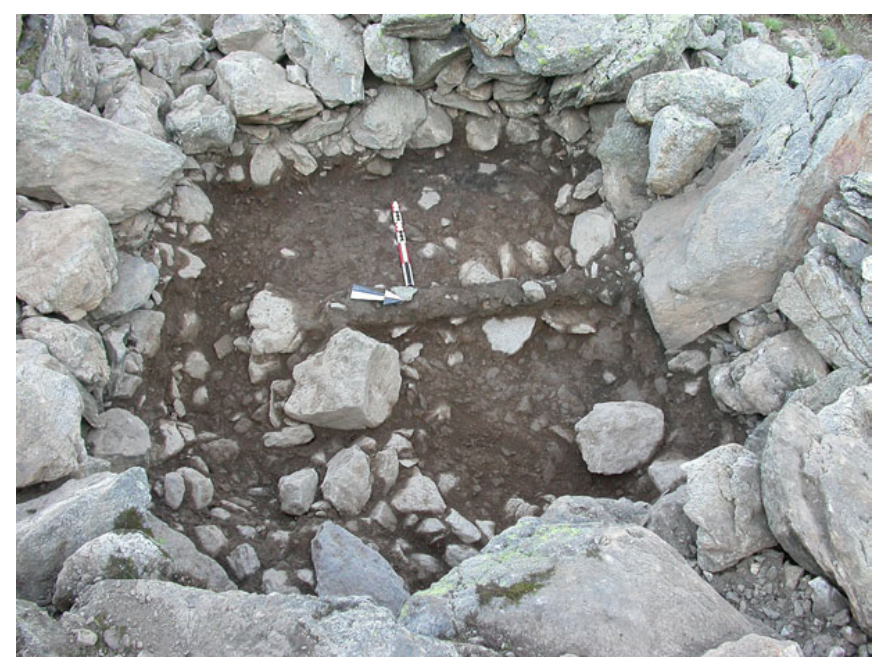

Fig. 6. Cabane associée à un groupe d'enclos situé à proximité du Lac Petit et ayant livré deux niveaux de foyers datés entre le $\mathrm{XI}^{\mathrm{e}}$ s. et le début XIII $\mathrm{e}$. (cf. fig. 5, site 17). cette date correspond à la dernière période où une activité métallurgique est attestée en contrebas. À l'opposé, ces mêmes constatations indiquent que la forêt était présente sur les versants du vallon situé sous le verrou glaciaire alors qu'actuellement cette zone est entièrement dénuée d'arbres. Se dégage ainsi un schéma qui semble montrer ici une stabilité de l'implantation de la forêt entre l'âge du Fer et le haut Moyen Âge. Ainsi, sans être parvenue à reconquérir l'étage, celle-ci offrirait néanmoins toujours des ressources de ligneux dans le vallon situé en contrebas et sur les versants correspondants.

On observe donc que la déforestation ne s'est pas faite simplement du bas vers le haut. L'étage de la cembraie-mélézin est ainsi détruit alors qu'en contrebas, les ressources forestières sont encore disponibles pendant l'Antiquité et le haut Moyen Âge. Il faut cependant souligner que la régénérescence de la forêt de mélèzes est très difficile alors que celle du pin sylvestre est rapide. Il se peut donc que cette dernière ait connu des épisodes de déprise et de reprise.

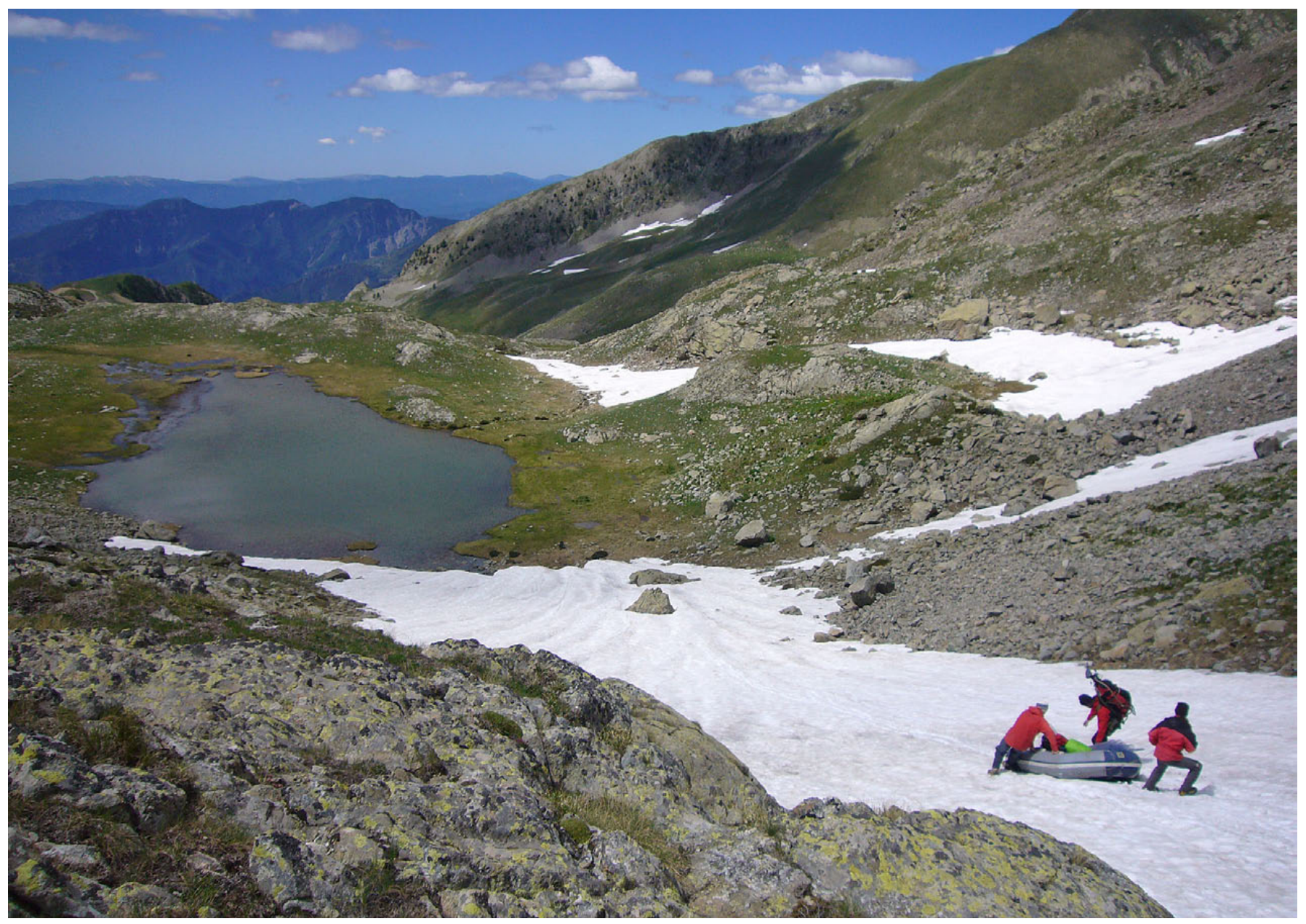

Fig. 7. Campagne de carottage réalisée en 2009 par le laboratoire EDYTEM dans les lacs du Vallon de Millefonts. (C) J.-M. Sivrine. 
Les datations des fours pourraient dans ce cas n'indiquer que les pics de reprise de la forêt dans la partie inférieure de l'étage subalpin. La répartition des fours pourrait aussi donner une indication sur l'évolution de lisière de la forêt. Il semblerait ainsi que le déboisement se soit engagé avant l'âge du Fer et qu'il ait concerné principalement le fond des vallées, c'est-à-dire les espaces avec une couverture sédimentaire suffisante pour qu'une prairie puisse se développer. À l'inverse, les versants rocheux situés en amont du verrou semblent avoir été épargnés jusqu'au VII ${ }^{\mathrm{e}} \mathrm{s}$. Cela semble indiquer que la motivation principale de la déforestation soit la création de prairies et non l'exploitation du bois. La carte géologique montre par ailleurs que la dynamique d'exploitation du bois semble conditionnée par la qualité des terrains et leur aptitude à permettre le développement d'une couverture herbacée. Ainsi, les flancs rocheux sont épargnés, mais il s'agit peut-être là aussi d'une question d'accessibilité de la coupe. Concernant la question de l'évolution du couvert forestier, l'analyse spatiale des sites montre l'existence d'une déprise forestière du territoire avant la fin de l'âge du Fer. L'impact des défrichements antérieurs semble si considérable qu' on peut estimer que la forêt est déjà détruite au-dessus du verrou lorsque les premiers métallurgistes de l'âge du Fer s'implantent au $\mathrm{II}^{\mathrm{e}} \mathrm{s}$. av. J.-C. Sur le fond, cette constatation confirme le schéma selon lequel l'ouverture définitive du paysage se réalise au cours de la Protohistoire. Mais, c'est de manière tout à fait exceptionnelle que nous percevons l'existence d'une déforestation aussi aboutie à plus de $2000 \mathrm{~m}$ d'altitude alors que l'on pouvait penser que celle-ci était le fruit des activités du Moyen Âge et de l'Époque moderne.

L'étude de Millefonts laisse entrevoir une dynamique de défrichement qui ne correspondrait pas à une conquête progressive de la haute montagne mais se traduirait par une exploitation des fonds de vallons conduisant à des zones pâturables de haute montagne et une exploitation immédiate des zones boisées les plus hautes. Ainsi, les premières terres de conquêtes pastorales ne correspondraient pas seulement à la moyenne montagne mais affecteraient très tôt les fonds de vallons situés en haute montagne, créant ainsi des couloirs qui mènent à des zones pâturables en épargnant les coteaux arides. Ce mécanisme de déprise forestière aurait affecté prioritairement les zones à recouvrement sédimentaire et, de ce fait, ne peut avoir qu'une origine anthropique, car des incendies naturels auraient suivi une propagation plus aléatoire sans liens avec le substrat. D'une manière générale, les mécanismes de déprise forestière en haute montagne reposent beaucoup sur des enregistrements palynologiques. Aussi, considérant que De Beaulieu et Goeury (2004) ont déjà attiré l'attention sur les difficultés à lire la présence de clairière dans les études palynologiques, si le schéma que nous entrevoyons se confirme, il faudrait probablement revisiter certaines études qui concluent à l'existence de milieu fermé en haute montagne pour des périodes récentes de l'Holocène. Pour être perçues, la présence de grandes clairières étendues sur l'axe des vallées nécessite donc des études entomologiques, malacologiques et géoanthracologiques livrant une vision plus localisée de l'environnement. La réalisation de transects paléoenvironnementaux perpendiculaires au vallon est probablement une réponse à ces questions.

\subsection{Perspectives}

Concernant la suite immédiate de ce programme, signalons que des carottages ont été réalisés en 2009 dans le Lac Petit afin d'engager une première vague d'étude (fig. 7). Les premières carottes extraites ont livré des séquences sédimentaires couvrant les quatre derniers millénaires et présentent suffisamment de macrorestes organiques pour envisager un bon enregistrement paléo environnemental. Des analyses palynologiques, géoanthracologiques, géomorphologiques et entomologiques, prévues dans le cadre du programme paléoenvironnemental lancé en 2009, permettront, au cours de l'année 2010, d'apporter une autre lecture sur ce dossier. Des études géochimiques ont aussi été engagées dans l'objectif de préciser la chronologie des grandes périodes d'activité minière, grâce à la mesure des pollutions métallifères.

\section{Bibliographie}

De Beaulieu, Goeury 2004: DE BEAULIEU (J.-L.), GOEURY (C.) - Les premiers signes de l'anthropisation dans les Alpes françaises d'après l'analyse pollinique. In: RICHARD (H.) dir., Néolithisation précoce. Premières traces d'anthropisation du couvert végétal à partir des données polliniques, Besançon, Presses universitaires de Franche-Comté, n 777, série Environnement, sociétés et archéologie, 7, 2004, p. 163-172.

Geist 1995: GEIST (H.) - Groupes de structures en pierres sèches des lacs des Millefonts. Archéam, 6, 1994-1995, p. 17-20.

Geist 1999: GEIST (H.) - Valdeblore, les Millefonts (06) : coord. Lambert: $\mathrm{x}=988,200-\mathrm{y}=3212$. Archéam, 8, 1998-1999, p. $40-41$.

Geist 2001 : GEIST (H.) - Structure pastorale en pierres sèches de Millefonts (06- Valdeblore). Archéam, 8, 2000-2001, p. 51.

Morin, Rosenthal 2002a: MORIN (D.), ROSENTHAL (P.) Mines et métallurgie du fer en Provence et dans les Alpes du Sud, département des Alpes-Maritimes. Commune de SaintDalmas, Valdeblore. Etude diachronique des vestiges d'exploitation minière et de métallurgie du fer, prospection au sol.DFS Opération PCR 2001, Aix-en-Provence, SRA PACA, 2002.

Morin, Rosenthal 2002b: MORIN (D.), ROSENTHAL (P.) Valdeblore, Col Ferrière/ vallon de Margès et de Molières. Vestiges d'exploitation minière et de métallurgie du fer. Bilan 
Scientifique de la Région Provence-Alpes-Côtes d'Azur 2003. Aix-en-Provence, SRA PACA, 2003, p.73-74.

Pagès 2009: PAGÈS (G.) - Le Clouté Valdeblore 2009, rapport de fouilles programmées. Aix-en-Provence, SRA PACA, 2009, 42 p.

Py 2002: PY (V.) - Modalités d'exploitation forestière dans la haute vallée de la Durance au Moyen Âge. Approche croisée des données historiques, archéologiques et anthracologiques. Mémoire de DEA sous la direction de M. Fixot, Aix-enProvence, Université de Provence, 2002, 2 vol., 215 et 80 p.

Lambert 2005: LAMBERT (A.) - Les données géochimiques et alluvionnaires de l'inventaire minier du territoire national. Constitution d'une base de données exhaustives. Rapport final. Janvier 2005. BRGM/RP-53546-FR, 2005.

Suméra 2008a: SUMÉRA (F.) - Antiquité espace Rural. Projet Collectif de recherche «peuplement et occupation du sol dans le Mercantour au cours de l'Holocène». Bilan scientifique de la Région Provence-Alpes-Côtes d'Azur 2008. Aix-en-Provence, SRA PACA, 2008, p. 88-89.

Suméra 2008b : SUMÉRA (F.) dir., BLANC (F.), CAVANA (E.),
GILI (E.), HUSSY (C.), MIRAMONT (C.), SIVAN (O .) Rapport de prospection thématique, communes de Valdeblore et Saint-Martin de Vésubie Campagne 2008. Rapport Final d'Opération 2008. Aix-en-Provence, SRA PACA, 2008, 52 p.

Suméra 2008c: SUMÉRA (F.) dir., GOURDON (G), HUSSY (C.), LASSALE (J.), PALMERO (B.), THOMASSIN (P.), TINNELI (B .) - Rapport intermédiaire d'opération correspondant à la première année d'exercice, campagne 2008. Projet Collectif de recherche "Peuplement et occupation du sol du massif du Mercantour et de l'Argenterra au cours de l'Holocène. Rapport. Final d'Opération 2008. Aix-enProvence, SRA PACA, 2008, 105 p.

Suméra 2008d : SUMÉRA (F.) dir., BLANC (F.), CAVANA (E.), CHOLET (V.), DELHON (C.), GAULTIER (M.), MARTIN (L.) - Rapport de sondage, commune de Valdeblore. Campagne 2008. Rapport Final d'Opération 2008. Aix-enProvence, SRA PACA, 2008, 30 p.

Vérany 2001 : VÉRANY (J.-B.) - Millefonte. In: Vérany J.-B. (1800-1865), Annales du Museum d'Histoire naturelle de Nice, t. 16, Nice, 2001, p. 24-25. 


\title{
Les premiers résultats de la prospection-inventaire dans la haute vallée de la Roya (Alpes-Maritimes, France)
}

\author{
Nathalie MAGNARDI*, Silvia SANDRONE*
}

\begin{abstract}
Résumé. Depuis 2002 des campagnes de prospection-inventaire ont été systématiquement menées dans la haute vallée de la Roya par l'équipe scientifique du musée départemental des Merveilles de Tende, service du Conseil général des Alpes-Maritimes, avec comme but la vérification des données de la carte archéologique nationale et comme conséquence la découverte de nombreux nouveaux sites, datés de la Pré-Protohistoire au siècle dernier. Ces opérations permettent d'ores et déjà de mettre en avant la richesse du patrimoine archéologique et historique local.
\end{abstract}

\section{The first results of the prospection-inventory in the upper Roya valley (Alpes-Maritimes, France)}

Abstract. Since 2002 prospecting and inventory campaigns have been carried out systematically in the high valley of the Roya river by the archaeological team of the Museum of Merveilles in Tende (service of the General Council of the Alpes-Maritimes Department). These campaigns allow to check data of the National Archaeological Map and discover several new sites dated from Pre-Protohistory to the 20th century. This work has already highlighted the great richness of the archaeological and historical local heritage.

\section{Les campagnes de prospection-inventaire dans la haute vallée de la Roya}

Située à $80 \mathrm{~km}$ au nord de Nice, à la frange orientale du Parc National du Mercantour, non loin de la Ligurie et du Piémont italien, la haute vallée de la Roya (AlpesMaritimes) présente un contexte géographique, géologique et historique tout à fait particulier.

D'un point de vue géographique, la Roya est un fleuve qui prend sa source en France, au col de Tende, et rejoint la Méditerranée en Italie, à Ventimiglia, à travers de hautes gorges calcaires et de superbes forêts. D'un point de vue géologique (Borchiellini 2002, p. 36-39), la vallée de la Roya se situe à l'extrême sud-est du massif de l'ArgenteraMercantour, partie la plus ancienne du département des Alpes-Maritimes, datée d'il y a environ 280 millions d'années. Elle est formée de roches magmatiques plus ou moins métamorphisées (migmatites, granites, gneiss...), véritable socle cristallin à la périphérie duquel se sont déposées des formations sédimentaires (schistes, grés et conglomérats). D'un point de vue historique, la vallée de la Roya a représenté depuis toujours un axe très important de fréquentation et de passage entre la côte ligure-provençale et la plaine du
Pô par la route dénommée par la suite «Route du Sel» puis «Grand chemin ducal» puis «Route Royale», à travers le col de Tende. À partir du Moyen Âge, de nombreuses seigneuries se disputent le territoire, qui va appartenir tour à tour au Comté de Vintimille, au Comté de Provence, au Comté Angevin, à la République de Gênes et, enfin, à la Maison de Savoie. Française pour une brève période durant la Révolution, la haute vallée de la Roya a été intégrée au royaume de Sardaigne puis à l'État italien jusqu'après la Deuxième Guerre Mondiale et, enfin, définitivement rattachée à la France en 1947.

Dans la littérature locale nous lisons que la haute vallée de la Roya et le col de Tende ont servi de voie de passage «depuis l'aube de l'humanité» (Beltrutti 1987, p. 6). Cependant ces affirmations, qui ne sont pas basées sur des données certaines, n'ont pas de valeur au niveau archéologique et historique. C'est aussi pour cela que depuis 2002 l'équipe scientifique du musée départemental des Merveilles, service du Conseil général des AlpesMaritimes, mène des campagnes de prospection-inventaire dans ce territoire, dans le but de vérifier l'état des lieux et d'élargir la connaissance du patrimoine archéologique et historique local.

* Musée départemental des Merveilles, avenue du 16 septembre 1947, 06430 Tende. 


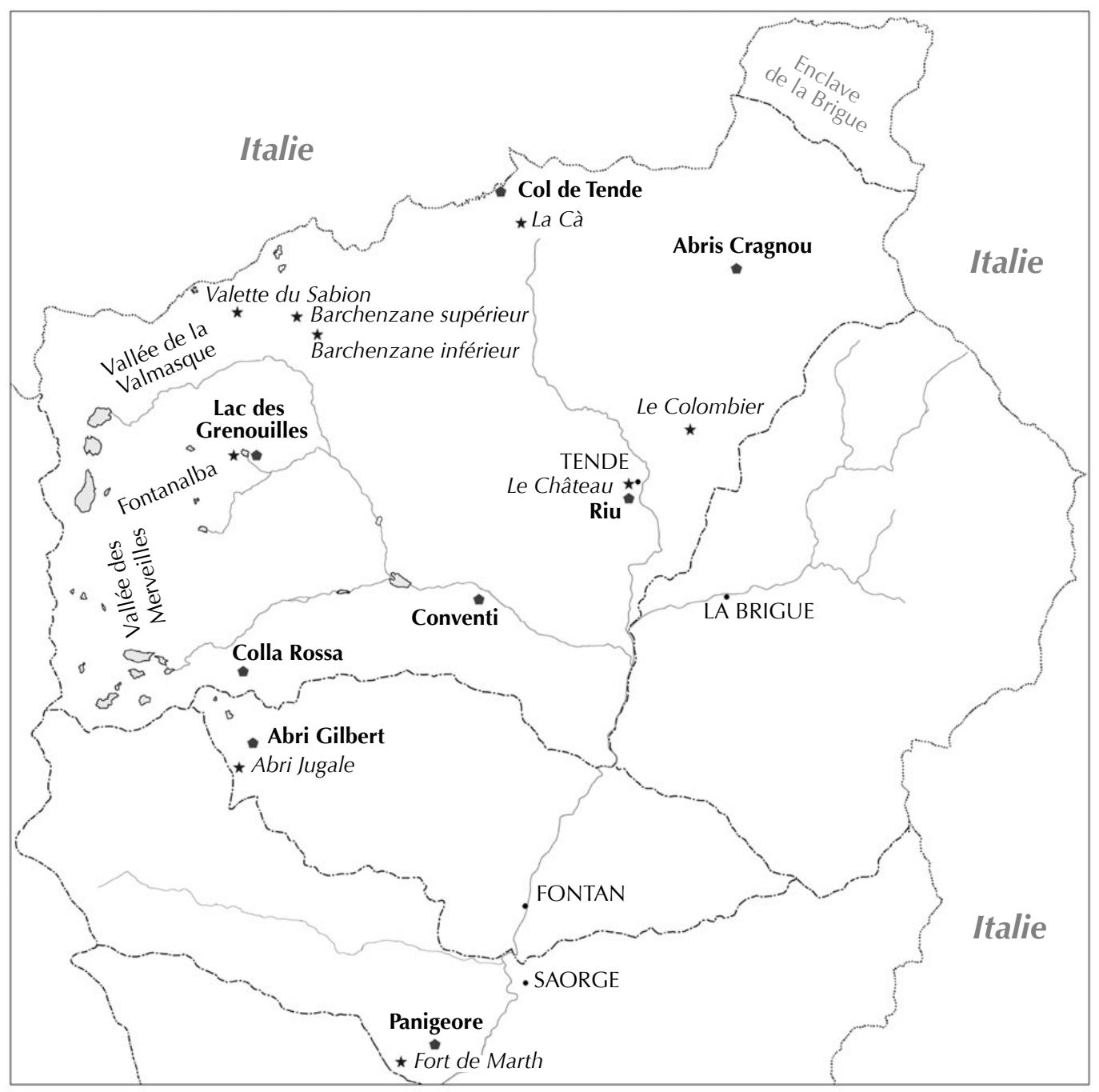

Fig. 1. Carte des sites archéologiques $(\bullet)$ et historiques $(\star)$ prospectés.

En 2002 et en 2003, deux premières campagnes de prospection-inventaire ont été effectuées dans la haute vallée de la Roya (responsable scientifique: Pierre Machu; BSR PACA 2002, p. 67; BSR PACA 2003, p. 83-84). Celles-ci avaient pour but de réviser les données de la carte archéologique nationale, laquelle mentionnait alors seize sites (dont dix pour les seuls secteurs à gravures rupestres de la région du mont Bego), et ont permis le recensement de vingt-cinq nouveaux sites dont douze protohistoriques, deux antiques, deux médiévaux, six modernes ou contemporains, deux diachroniques et un indéterminé.

En 2007 et en 2008, deux nouvelles campagnes de prospection-inventaire ont été menées sur ce territoire ${ }^{1}$ (res-

1. Le Conseil général des Alpes-Maritimes, à travers le musée départemental des Merveilles de Tende, a été l'organisme de rattachement dans ces opérations archéologiques. Membres de l'équipe scientifique ponsable scientifique: Silvia Sandrone; BSR PACA 2007, p. 108-109; BSR PACA 2008a, p. 85-86) et récemment insérées dans un projet collectif de recherche titré «Peuplement et occupation du sol du massif du Mercantour au cours de l'Holocène» (coordination scientifique: Franck Suméra, DRAC-SRA Aix-en-Provence) ayant pour objectifs de caractériser les modes d'occupation du territoire depuis les âges des métaux, d'en renouveler l'état des connaissances archéologiques et historiques et, enfin, d'offrir un bilan documentaire.

Ce sont les résultats majeurs de ces dernières opérations archéologiques qui font tout particulièrement l'objet de cette communication (fig. 1).

du musée départemental des Merveilles participant aux actions de terrain (outre le responsable scientifique) : N. Magnardi et J.-M. Strangi. 


\section{Les sites pré-protohistoriques et antiques}

En partant des témoignages les plus anciens et en procédant par ordre chronologique, nous avons étudié un site très intéressant, déjà connu en 2003 (BSR PACA 2003, p. 83) : l'abri Gilbert, sur la commune de Fontan. Il s'agit d'un abri sous roche qui se situe au-dessous du lac Jugale, dans le Parc National du Mercantour, et qui a livré quatre-vingt-sept tessons de céramique à pâte gris rougeâtre, assez grossière et sans dégraissants, avec d'évidents coups de feu. Les bords soulignés d'une rangée de perforations traversières et équidistantes, au-dessus d'un cordon horizontal le plus souvent à section triangulaire, et les fonds plats situent ces tessons dans l'horizon de la céramique d'accompagnement au Campaniforme: ils s'inscrivent ainsi dans une typologie bien spécifique qui se concentre principalement dans le sud de la France au début de l'âge du Bronze ancien en s'associant aux habitats (Besse 1996, p. 23), sans doute ici un abri saisonnier fréquenté très probablement par des bergers transhumants (fig. 2).

D'autres traces d'occupation humaine ont été repérées dans la zone du Lac des Grenouilles, sur la commune de Tende (BSR PACA 1994, p. 71-72; Mano 1994). Parmi les cent soixante tessons de céramiques modelées relevés, quelques fragments de bords toujours accompagnés par un cordon lisse appliqué, deux morceaux de fond plat légèrement débordant ainsi que deux fragments d'anses en ruban illustrent l'assez grande homogénéité d'une culture matérielle datée de la fin du Chalcolithique à l'âge du Bronze ancien. Peuvent être datés de la même époque les nombreux tessons de céramique modelée, à pâte grossière et

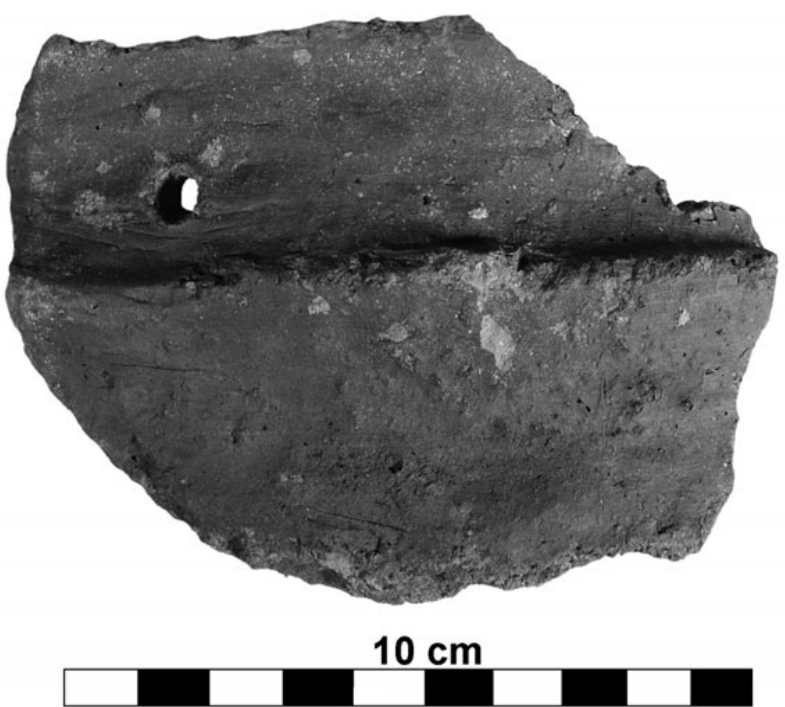

Fig. 2. Fragment de céramique à trous passants. Abri Gilbert, commune de Fontan. Cliché J.-M. Strangi. gros dégraissant ou à pâte plus fine et bien lustrée, repérés et récupérés en surface dans des abris-sous-roche appelés «Abris Cragnou», dans le vallon de Réfrei, sur la commune de Tende (fig. 3).

Sur la base de ce matériel archéologique il est possible d'affirmer que l'espace montagnard de la haute vallée de la Roya était déjà fréquenté de façon saisonnière entre la fin de la préhistoire et le début de la protohistoire, très probablement dans un but pastoral.

Aucune évidence archéologique concernant l'âge du Bronze moyen et final n'a été repérée à présent, alors que deux pièces très intéressantes de l'âge du Fer ont été fortuitement trouvées et nous ont été signalées.

La première, découverte dans une anse du torrent du Riu, au cœur du village de Tende, est une pointe de javelot en fer de $21 \mathrm{~cm}$ de long. Le métal, assez raffiné et bien conservé, était emmanché sur la hampe en bois par une douille perforée de trous pour les rivets, dont un est encore bien visible. La pointe, massive et légèrement courbée au bout, se révèle de section rhomboïdale. La deuxième pièce, trouvée face à un petit chalet en ruine dans le hameau de Conventi, le long de la route pour Castérino, sur la commune de Tende, est une pointe de lance en fer de $19,5 \mathrm{~cm}$ de long. La douille, moins bien conservée que la précédente, est très abîmée, même si deux trous de rivets aux formes irrégulières sont encore visibles le long de son bord. Par contre, la pointe foliacée à nervure médiane, assez fine, est en très bon état (fig. 4). L'analyse typologique et la comparaison avec des pièces similaires trouvées dans la Ligurie italienne (De Marinis, Spadea 2004, p. 267 et 383) situent ces deux pièces dans l'horizon ligure du deuxième âge du

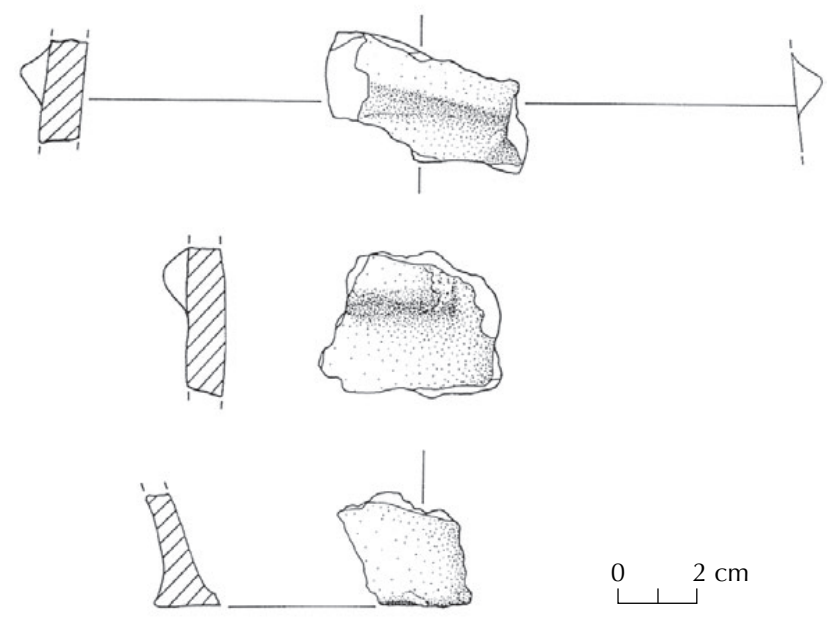

Fig. 3. Fragments de céramique modelée. Abris Cragnou, commune de Tende. Dessin F. Bongni. 


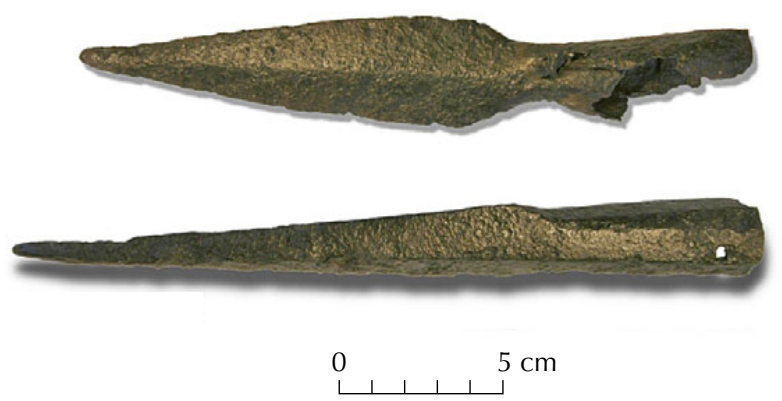

Fig. 4. Pointes de lance et de javelot. Conventi et Le Riu, commune de Tende. Cliché J.-M. Strangi.

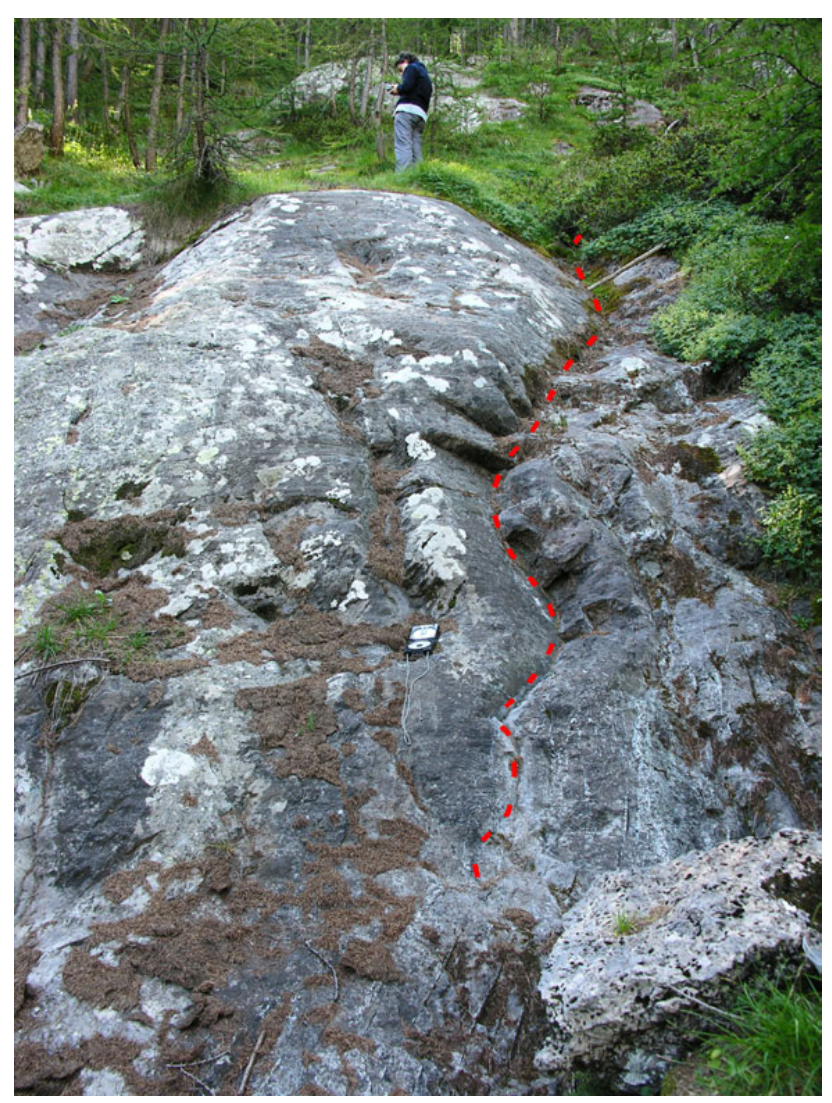

Fig. 5. Filon de chalcopyrite et de malachite. Colla Rossa, commune de Tende. Cliché J.-M. Strangi.

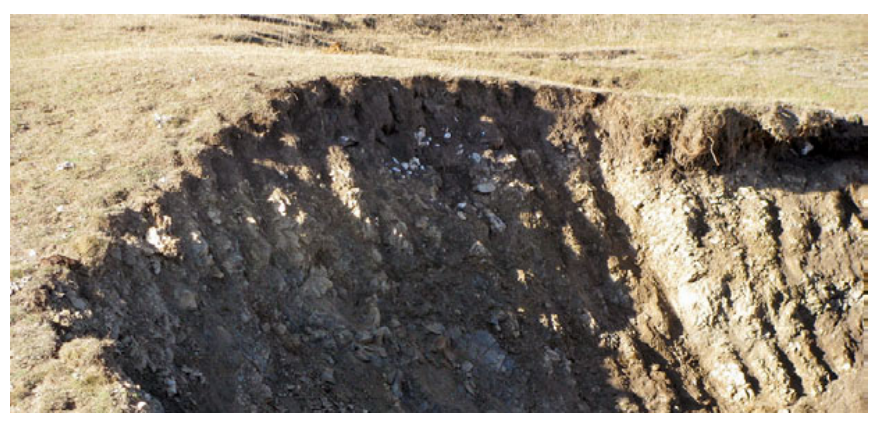

Fig. 6. Traces de destruction issue de l'action d'une pelle mécanique. Col de Tende, commune de Tende. Cliché S. Sandrone.

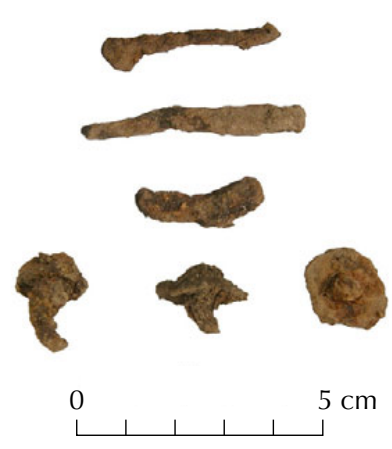

Fig. 7. Clous en fer de forme allongée et à tête arrondie. Col de Tende, commune de Tende. Cliché J.-M. Strangi.

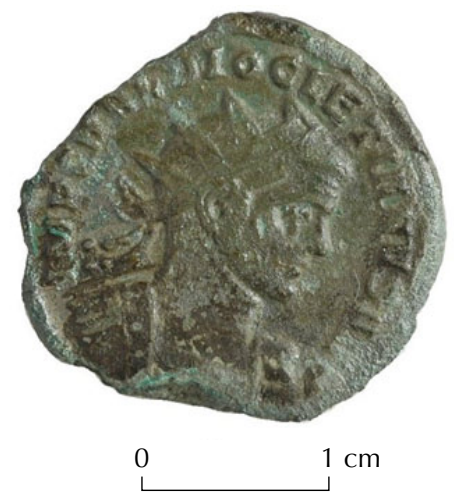

Fig. 8. Pièce de monnaie de Dioclétien. Col de Tende, commune de Tende. Cliché J.-M. Strangi.

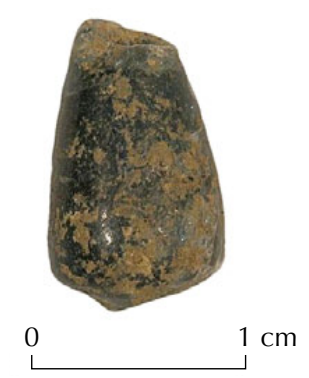

Fig. 9. Perle en verre bleu. Col de Tende, commune de Tende. Cliché J.-M. Strangi. 
Fer. Avec l'ensemble funéraire de Saint-Dalmas-de-Tende ${ }^{2}$ et les tessons de poterie découverts au Golf de Viévola, sur la commune de Tende (BSR PACA 2000, p. 60-62), elles enrichissent la carte archéologique de la haute vallée de la Roya à la fin de la Protohistoire.

Enfin, deux indices probables d'utilisation de matières premières ont été repérés: des affleurements de silex noir à Panigeore, sur la commune de Saorge, et des filons de chalcopyrite et de malachite à Colla Rossa, sur la commune de Tende (fig. 5).

\section{Un site majeur : le col de Tende}

En 1994, dans le cadre d'une recherche sur les voies de passage entre la Ligurie et le Piémont italien, L. Mano (Museo Civico de Cuneo, Italie) découvrit dans les déblais de travaux routiers au sommet de l'ancien col de Tende (cote 1871) de nombreux tessons de céramiques modelées et tournées, datant de l'âge du Fer à l'antiquité tardive, ainsi qu'une dizaine de pièces de monnaie romaines. Une opération de sondage au sommet de la butte d'où provenaient les déblais fut menée en 1997 par A. Echassoux, archéologue départementale, avec la collaboration du découvreur (BSR PACA 1997, p. 52-53). Ce sondage permit de situer le niveau archéologique à $3 \mathrm{~m}$ au-dessus de la route actuelle et à $30 \mathrm{~cm}$ au-dessous de la pelouse alpine et de relever une puissance de la couche de 10 à $15 \mathrm{~cm}$.

Dès lors, quatre campagnes de prospection-inventaire ont été conduites par l'équipe scientifique du musée des Merveilles de Tende et un matériel archéologique consistant a été récupéré et déposé dans les réserves du musée, où il est actuellement en cours d'étude. Le 7 octobre 2008, lors d'un passage de vérification du site, d'importantes destructions de nature anthropique, issues probablement de l'action d'une pelle mécanique, ont été constatées (fig. 6). La gravité des dégâts a permis d'envisager une opération de fouille préventive nécessitée par l'urgence absolue ${ }^{3}$ (BSR $P A C A$ 2008b, p. 79-80). L'action de terrain, très restreinte dans le temps et par la météorologie de l'hiver approchant, a été limitée au tamisage des déblais et à la régularisation des coupes créées par l'action de la pelle mécanique et l'érosion du terrain.

2. Originaux au musée archéologique de Cimiez de Nice; moulages au musée départemental des Merveilles de Tende.

3. Le Conseil général des Alpes-Maritimes, à travers le musée départemental des Merveilles de Tende, a été l'organisme de rattachement dans la fouille préventive nécessitée par l'urgence absolue (responsable scientifique: Silvia Sandrone). Membres de l'équipe scientifique du musée départemental des Merveilles participant aux opérations de terrain (outre le responsable scientifique): N. Magnardi, J.-M. Strangi et S. Sarda.
De nombreux tessons de céramique modelée protohistorique ont été récoltés : les bords sont peu évasés et souvent décorés par incision de traits et de dents de loup, les fonds sont généralement plats et la pâte, dont la couleur varie du rougeâtre au gris ou au noir, se révèle généralement fine, à dégraissant micacé petit et peu évident, à parois assez épaisses. Les formes et les décors se rapprochent parfois des vases-situles de la culture dite «Ligure III », bien attestée dans le Piémont sud-occidental italien au deuxième âge du Fer (Ferrero, Giaretti, Padovan 2004, p. 51-80). Sur la base de l'analyse de ce matériel, le site protohistorique pourrait être interprété comme une halte temporaire sur un chemin transalpin de transhumance, située dans un des cols les plus bas des Alpes-Maritimes.

En ce qui concerne la période romaine, de nombreux tessons de céramiques modelées et tournées ont été récoltés. Parmi la céramique modelée, différents bords évasés, parfois décorés de traits et soulignés d'un ou plusieurs sillons, se rapprochent d'une imitation de la précédente production «ligure» très répandue dans la plaine piémontaise du Pô au $\mathrm{I}^{\mathrm{er}}$ S. ap. J.-C. ${ }^{4}$. Dans ce cas, la pâte se révèle assez grossière, à dégraissant peu évident et à parois assez épaisses. Par contre, en ce qui concerne les exemplaires tournés, la pâte est généralement fine et dépurée, à la couleur variant du rouge à l'orange, du gris au noir. Il s'agit pour la plupart de céramique commune et à paroi fine. Quelques rares tessons de céramique à vernis noir et un tesson fragmentaire en terre sigillée ont été trouvés. Ce dernier peut contribuer à soutenir l'hypothèse d'un commerce même à longue distance à travers le col de Tende.

Lors des actions de tamisage, différents éléments métalliques ont ainsi été récupérés: des petits clous en fer de forme allongée et irrégulière (clouage de petites structures en bois ?), des clous très courts à tête arrondie (clouage de bottes ferrées?) et trois pièces de monnaie, dont une de Dioclétien (Ticinum, 286-288), qui vont enrichir la collection des trente-quatre monnaies romaines ${ }^{5}$ provenant du site et conservées au musée des Merveilles (fig. 7 et 8).

Enfin, pièce unique dans notre territoire, un élément de parure en verre bleu complète le cadre de la culture matérielle romaine recueillie lors de cette opération archéologique d'urgence (fig. 9).

Concernant cette époque, l'interprétation la plus valide à présent serait celle d'un dépôt votif lié à une aire cultuelle située au sommet d'un col, comme au mont Genèvre ou à Caprauna, dans la vallée Pennavaire entre la Ligurie et le Piémont italien (Gandolfi, Gervasini 1983, p. 85-167).

4. Des exemplaires similaires sont exposés dans la section romaine du Museo Civico de Cuneo (Italie).

5. Catalogue au musée départemental des Merveilles de Tende, rédigé par le numismate G. Fea (Cuneo, Italie). 


\section{Les sites médiévaux et modernes}

Dans le cadre de ces prospections, l'étude du pastoralisme d'altitude se poursuit avec la découverte ou la révision de sites d'altitude et saisonniers. Ainsi de nouvelles constructions ont-elles été localisées au-dessus du lac Jugale, sur la commune de Fontan: il s'agit d'un vaste complexe pastoral rassemblant des enclos plus ou moins quadrangulaires, associés à des ruines sans doute des celliers, et des ruines d'abri autour d'un bloc: on appelle ces ensembles «gias». Quatre structures de vastes dimensions sont visibles: les murs, tous en pierres sèches, sont très épais, bas et arrondis vers la toiture. Pour supporter le poids de la neige et résister aux avalanches, deux des bâtisses sont à demi enterrées dans le sol et la porte, située au ras du sol, oblige l'usager à ramper. Groupées par deux, ces bâtisses ont dû être des celles à fromage communes aux bergers utilisant le même alpage Trois fragments de céramique moderne ont été retrouvés dans l'une d'elles (fig. 10).

Vers le col du Sabion, sur la commune de Tende, deux complexes pastoraux sans doute d'époque historique (Barchenzane inférieur et Barchenzane supérieur) ont été remarqués. L'ensemble dit «Barchenzane supérieur» propose plusieurs structures: fond de cabane circulaire, enclos compartimentés, ruines d'abris qui pourraient dater des premières époques historiques... Des remaniements, avec différentes phases de construction semblent indiquer un prolongement ou une continuité de la destination de ce pâturage estival et de son emploi régulier dans le temps (fig. 11). Un peu plus loin, à la Vallette du Sabion (BSR PACA 2001, p. 78-79), nous avons vérifié l'état de conservation des structures pastorales saisonnières composées d'enclos associés aujourd'hui à des cabanes en ruines d'époque historique. La présence de gravures protohistoriques assimilables à celles de la région du mont Bego atteste de l'utilisation ancienne de ces structures et de leur pérennité (fig. 12).

Dans la région de Fontanalbe, sur la commune de Tende, à proximité du Lac des Grenouilles, plusieurs «gias» d'époque historique ont été localisés. Ces «gias» offrent des enclos de forme variée, des abris et des ruines d'annexes, de mystérieux couloirs dallés, dont un couloir de traite, ainsi qu'un long mur de pierres sèches destiné peut-être à éviter la dispersion des troupeaux vers la pente qui descend à Castérino. Certaines de ces constructions posent problème quant à leur usage et leur interprétation. Cependant ces enclos, ruines et « gias » permettent de compléter nos connaissances quant à la destination des alpages et leur pratique aux époques historiques.

En ce qui concerne la période historique, le fort de Marth, sur la commune de Saorge, a été prospecté. Il s'agit d'une longue enceinte ovale en pierres sèches de $34 \mathrm{~m}$ de long dominant et ceignant un promontoire à $1150 \mathrm{~m}$ d'altitude. L'appareillage des murs en pierres sèches, environ de $1 \mathrm{~m}$ de haut, utilise de très gros blocs. Une entrée est marquée dans le mur, au nord, précédée de quelques marches. Incontestablement ce type de construction fortifiée a dû avoir un usage de défense ou d'observation militaire et semble d'époque médiévale (fig. 13).

À l'entrée du vallon de Réfrei (cote $851 \mathrm{~m}$ ), sur la commune de Tende, se situe «le Colombier», très intéressant habitat troglodytique composé d'une cavité bouchée contre une falaise par un mur haut d'une dizaine de mètres et large d'une quinzaine. À l'intérieur, sur presque toute la surface du mur des niches à pigeons (entre 300 et 500) sont disposées irrégulièrement tandis qu'une source jaillissante est canalisée par des renflements maçonnés. La technique de maçonnerie daterait peut-être du XIX ${ }^{\mathrm{e}}$ s. (fig. 14).

Sur l'ancienne route menant au col de Tende, la prospection du bâtiment dit «La Cà », a révélé une situation très préoccupante: la toiture monumentale s'effondre, les ronces envahissent la cour, les encadrements de pierres vertes ont été volés... Ce bâtiment, ancien relais de poste à fonction d'auberge et d'hospice, qui aurait été rebâti au XVII ${ }^{\mathrm{e}} \mathrm{s}$. sur les ruines d'une chapelle du XIII ${ }^{\mathrm{e}}$, à la valeur historique et patrimoniale indéniable, est malheureusement en état de délabrement et d'abandon (fig. 15).

\section{Un site majeur : le château de Tende}

Appelé aussi château des Lascaris, il s'agit d'un monument très intéressant et peu étudié (Astro 1992, p. 45; Beltrutti 1954, p. 107-109, 231-232, 237-238, 272; Durante 1847, p. 165). Reconstruit plusieurs fois, sa lisibilité au cours des siècles s'est opacifiée. De plus, au début du XIX ${ }^{\mathrm{e}}$ s., le cimetière a pris place dans les ruines du château, empêchant toutes prospections sérieuses ou fouilles, même si une parcelle de terre pourrait être aisément sondée sous la tour ronde occidentale. Le jardin attenant au château, appelé «vignes du seigneur», aurait été par la suite agrandi et entouré d'un mur de protection. Au centre du celui-ci, un système très ingénieux et peu courant d'escaliers à double volées a été découvert: peut-être avaient-ils été construits pour faciliter le ramassage des vendanges? Depuis le jardin, il est aussi possible d'observer que la base d'une des tours propose une maçonnerie différente et plus ancienne que celle visible aujourd'hui; il s'agit sans doute de la base d'une tour de l'ancienne citadelle lorsqu'elle a été transformée en palais seigneurial. Grâce aux lithographies, la porte principale originelle du château ${ }^{6}$ ainsi que l'emplacement de l'ancien pont-levis ont pu être localisés (fig. 16).

6. Signalons en outre que l'ancienne porte en pierre verte, ou portail monumental, avec les armoiries de René de Savoie, «le Grand 
Au-dessus du palais, à plusieurs centaines de mètres, domine la Citadelle, un des premiers édifices fortifiés de Tende; à l'ouest, s'écoule le torrent du Riu. Dans ce torrent, ainsi que dans les parages de l'actuel cimetière, dans le jardin attenant et tout autour du château, de nombreux tessons moyenâgeux et modernes ont été trouvés.

\section{Conclusion}

Étagés de la Protohistoire au XIX ${ }^{\mathrm{e}}$ s., les sites pré-protohistoriques et antiques et les constructions historiques recensés lors des prospections dans la haute vallée de la Roya, quoi qu'assez nombreux, se caractérisent par des occupations saisonnières (abris-sous-roche ou campements en plein air), des lieux de passage ou des constructions légères (bois et pierre) ayant laissées peu de traces au sol et un mobilier souvent peu abondant et peu varié.

Certains d'entre eux sont malheureusement soumis à des dégradations et à des destructions de nature anthropique très importantes. C'est le cas notamment des sites du Col de Tende et du Lac des Grenouilles, dont la disparition semble inéluctable à moyen terme du fait de la fréquentation touristique et des travaux d'aménagements routiers. Le bâtiment du Colombier, acheté par un privé, voit sa destination changer et la Cà, abandonnée par son propriétaire, subit des dommages irréversibles.

Cependant ces opérations permettent d'ores et déjà de mettre en avant la richesse du patrimoine archéologique et historique local ainsi que l'importance de la vallée de la Roya comme lieu de communication et de contact entre le littoral méditerranéen et la plaine du Pô.

Les prospections à venir devront permettre de compléter et d'enrichir considérablement ce tableau de connaissances afin d'élargir l'état des connaissances et d'apporter d'importantes informations et compléments à la carte archéologique nationale.

\section{Bibliographie}

Astro 1992: ASTRO (C.) - L'ardoise. Arts et techniques en sculpture et peinture de la Ligurie au Pays de Nice. Nice, Action Culturelle municipale, 1992, 68 p.

Beltrutti 1954: BELTRUTTI (G.) - Tende et la Brigue. Breilsur-Roya, Éditions du Cabri, 1988, 352 p.

Besse 1996: BESSE (M.) - Le Campaniforme en France. Analyse de la céramique d'accompagnement. Oxford, 1996, 56 p., 115 fig., 26 planches (BAR International Series 635).

Bâtard", écartelées avec celles des Lascaris-Vintimille, datée d'environ 1509/1525, se trouve en dépôt au musée départemental des Merveilles de Tende.
Borchiellini 2002 : BORCHIELLINI (S.) - Géologie des AlpesMaritimes. Nice, Serre Éditeur, 2002, 117 p.

BSR PACA 1997: ECHASSOUX (A.), MANO (L.), FEA (G.) - Tende. Col de Tende. Bilan scientifique régional de Provence-Alpes-Côte d'Azur, 1997. Service régional de l'Archéologie, Aix-en-Provence, Ministère de la Culture Direction du Patrimoine, 1998.

BSR PACA 2000: MACHU (P.), MANO (L.), STRANGI (J.M.) - Tende. Golf de Vievola. Bilan scientifique de la région Provence, Alpes, Côte d'Azur, 2000. Service régional de l'Archéologie, Aix-en-Provence, Ministère de la Culture Direction du Patrimoine, 2001.

BSR PACA 2002 : MACHU (P.), MANO (L.), MAGNARDI (N.), STRANGI (J.-M.) - Tende. Commune. Bilan scientifique de la région Provence, Alpes, Côte d'Azur, 2002. Service régional de l'Archéologie, Aix-en-Provence, Ministère de la Culture - Direction du Patrimoine, 2003.

BSR PACA 2003: MACHU (P.), MANO (L.), MAGNARDI (N.), SANDRONE (S.), STRANGI (J.-M.) - Tende. Commune. Bilan scientifique de la région Provence, Alpes, Côte d'Azur, 2003. Service régional de l'Archéologie, Aix-en-Provence, Ministère de la Culture - Direction du Patrimoine, 2004.

BSR PACA 2007: SANDRONE (S.), MAGNARDI (N.), MACHU (P.) - Tende. Commune. Bilan scientifique de la région Provence, Alpes, Côte d'Azur, 2007. Service régional de l'Archéologie, Aix-en-Provence, Ministère de la Culture Direction du Patrimoine, 2008.

BSR PACA 2008a: SANDRONE (S.), MAGNARDI (N.), STRANGI (J.-M.) - Haute vallée de la Roya (communes de Tende, La Brigue, Fontan et Saorge), Bilan scientifique de la région Provence, Alpes, Côte d'Azur, 2008. Service régional de l'Archéologie, Aix-en-Provence, Ministère de la Culture Direction du Patrimoine, 2009.

BSR PACA 2008b: SANDRONE (S.), MAGNARDI (N.), STRANGI (J.-M.) - Col de Tende (commune de Tende), Bilan scientifique de la région Provence, Alpes, Côte d'Azur, 2008. Service régional de l'Archéologie, Aix-en-Provence, Ministère de la Culture - Direction du Patrimoine, 2009.

De Marinis, Spadea 2004: DE MARINIS (R.C.), SPADEA (G.) dir. - I Liguri. Un antico popolo europeo tra Alpi e Mediterraneo, Catalogue de l'exposition (Genova, Commenda di San Giovanni di Pré, 23 octobre 2004-23 janvier 2005). Genova, Skira, 2004, 655 p.

Durante 1847: DURANTE (L.) - Chorographie du Comté de Nice. Torino, Tipografia dei fratelli Favale, 1847, 475 p.

Ferrero, Giaretti, Padovan 2004: FERRERO (L.), GIARETTI (M.), PADOVAN (S.) - Gli abitati della Liguria interna: la ceramica domestica. In: VENTURINO GAMBARI (M.), GANDOLFI (D.) dir., Ligures Celeberrimi. La Liguria interna nella seconda età del Ferro, Actes du Colloque International (Mondovì, 26-28 avril 2002). Bordighera, Istituto Internazionale di Studi Liguri, 2004, 438 p.

Gandolfi, Gervasini 1983: GANDOLFI (D.), GERVASINI (L.) - La stipe votiva di Caprauna. Rivista di Studi Liguri, XLIX. Bordighera, Istituto Internazionale di Studi Liguri, 1983.

Mano 1994: MANO (L.) - Note preliminari su reperti archeologici di età preistorica emersi in località della regione del monte Bego. Fontanalba, Lac des Grenouilles (GR); Berghe, Vallon de Torrent Ceva $(\mathrm{CV})$, document inédit conservé au musée départemental des Merveilles de Tende, 1994. 


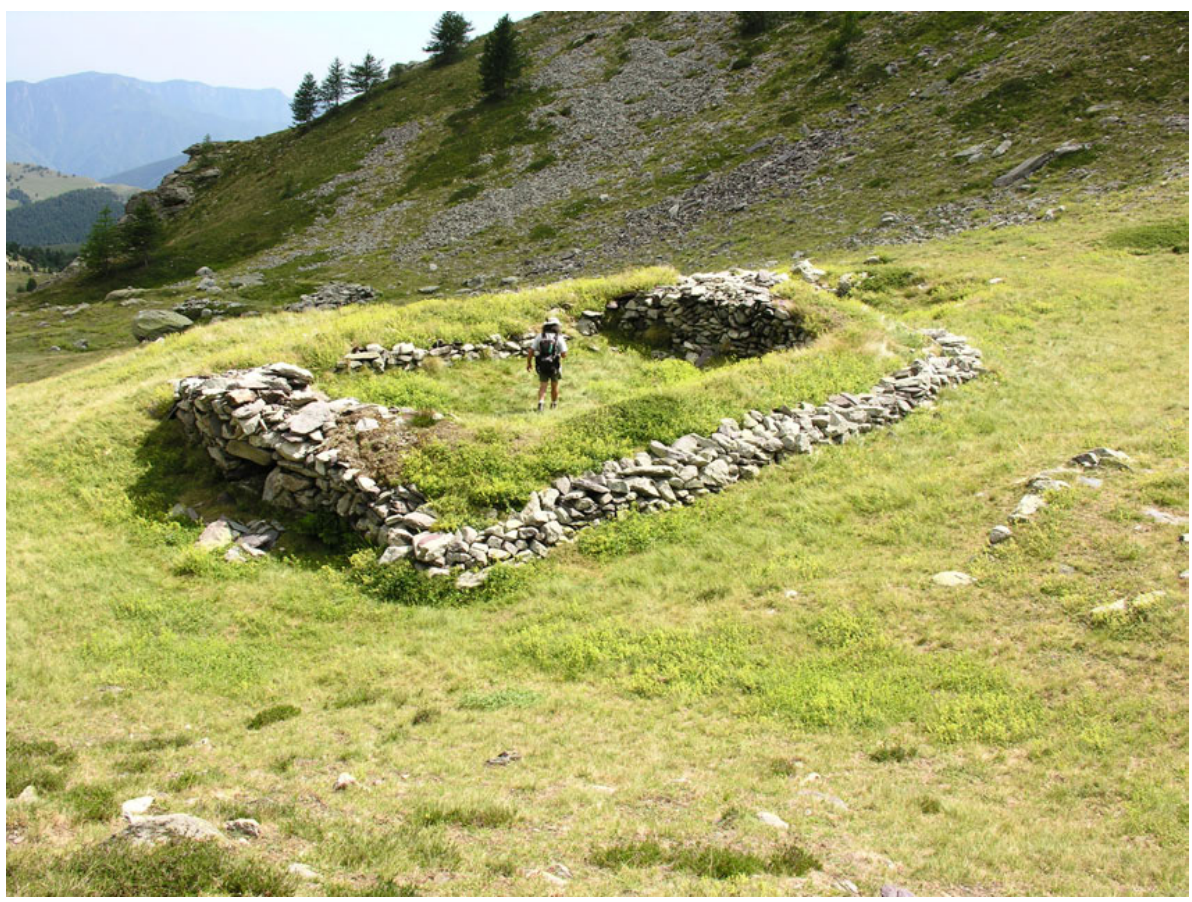

Fig. 10. Ruines d'une celle à fromage. Enclos Jugale, commune de Fontan. Cliché S. Sandrone.

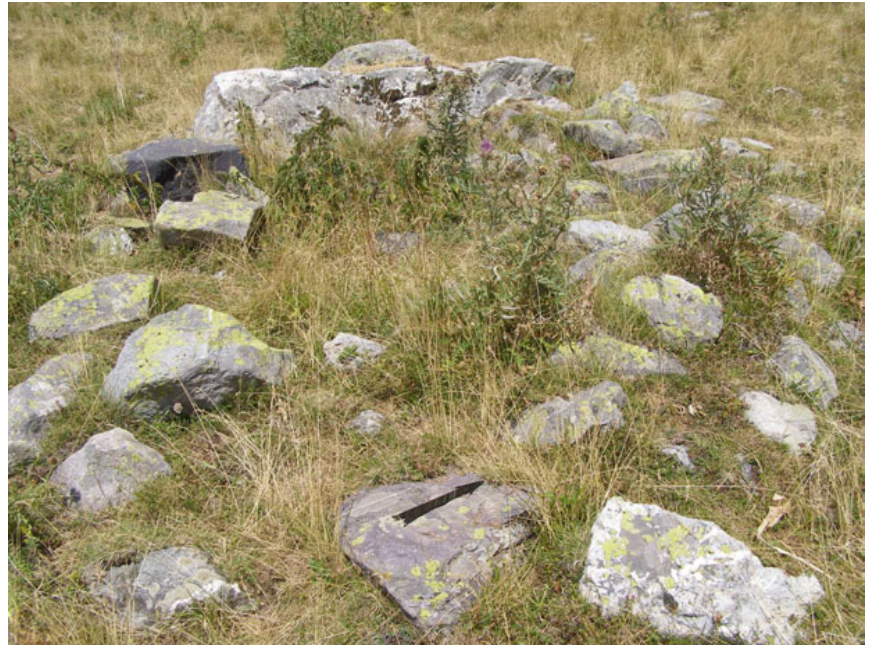

Fig. 11. Fond de cabane (?). Barchenzane supérieur, commune de Tende. Cliché S. Sandrone.

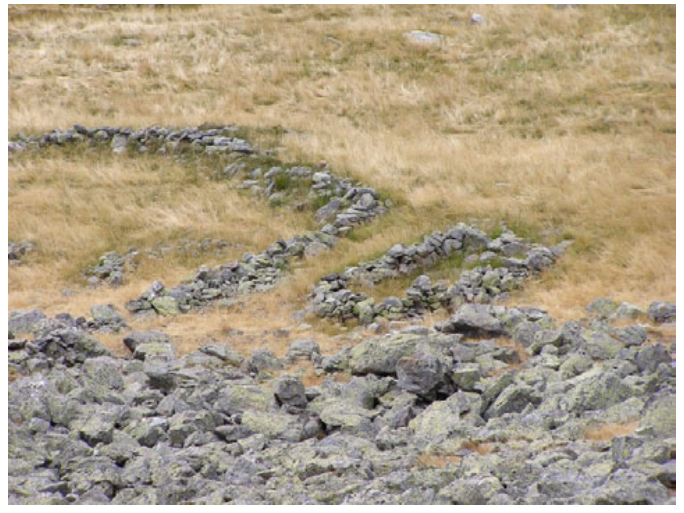

Fig. 12. Ruines d'enclos et de cabane. Vallette du Sabion, commune de Tende. Cliché N. Magnardi. 


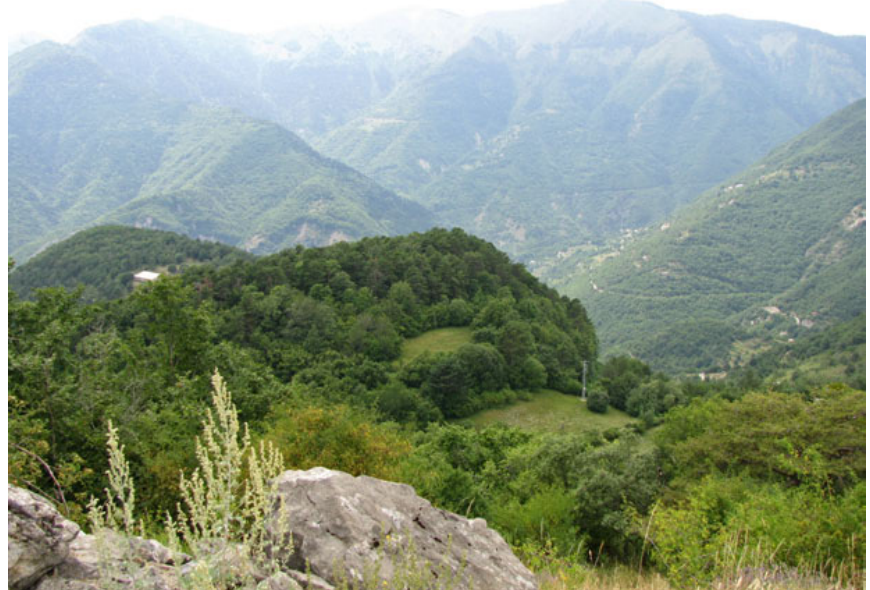

Fig. 13. Mur de l'enceinte. Fort de Marth, commune de Saorge. Cliché S. Sandrone.

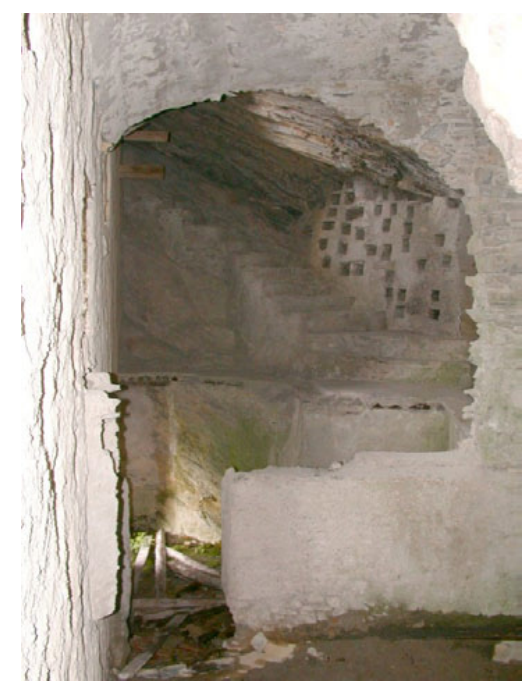

Fig. 14. Vue des niches intérieures. Le Colombier, commune de Tende. Cliché N. Magnardi.

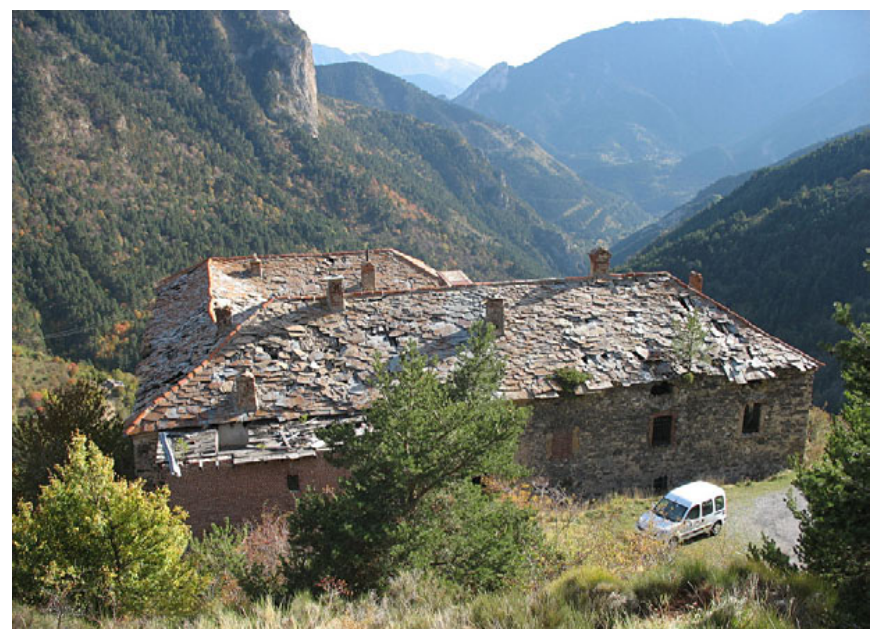

Fig. 15. La Cà, commune de Tende. Cliché J.-M. Strangi.

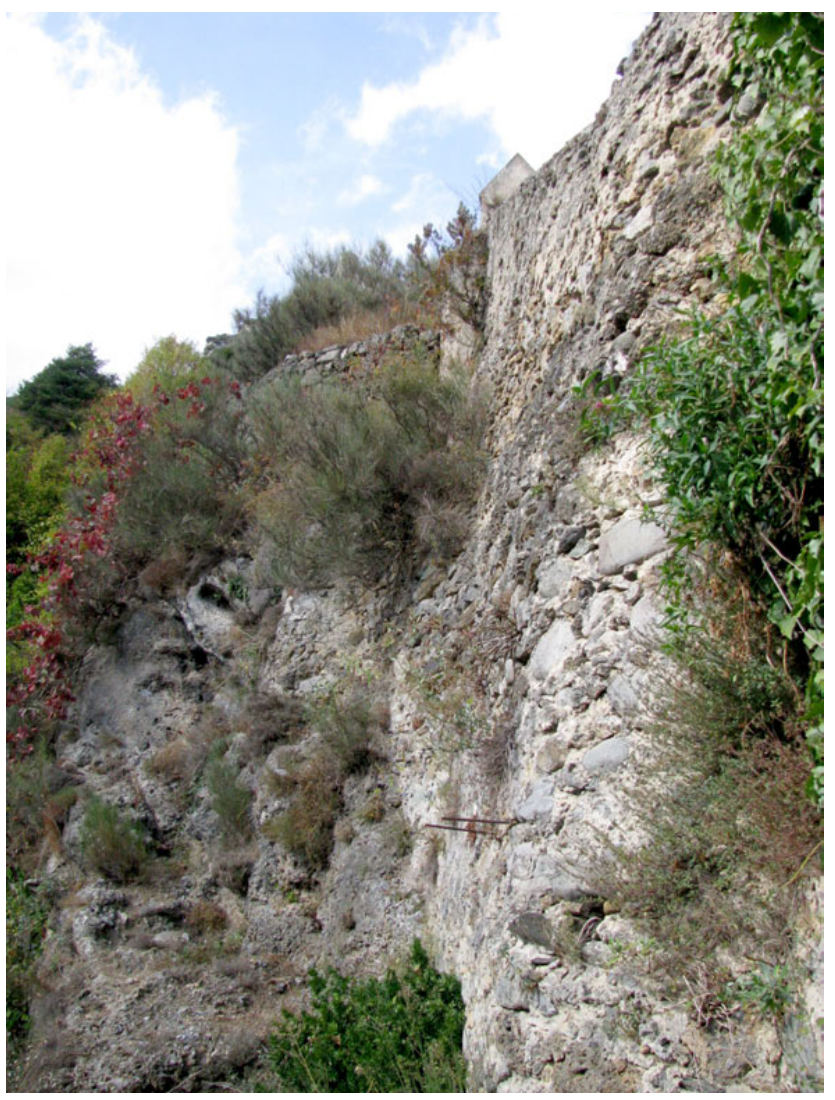

Fig. 16. Différence de maçonnerie dans l'enceinte. Château des Lascaris, commune de Tende. Cliché N. Magnardi. 


\title{
Approche méthodologique de l'étude du peuplement montagnard médiéval : l'exemple des plateaux d'Aubrac et du Cézallier dans le Massif Central
}

\author{
Laurent FAU*
}

\begin{abstract}
Résumé. Les recherches archéologiques menées sur les vastes plateaux basaltiques et granitiques du sud-ouest du Massif Central ont permis de révéler un fort potentiel archéologique, notamment en Aubrac et en Cézallier. Une équipe regroupant archéologues, historiens, ethnologues et paléoenvironnementalistes s'est intéressée à la dynamique de peuplement de ces plateaux sur la longue durée. Elle a pu notamment appréhender le mode d'habitat, temporaire ou permanent suivant les époques, de cette zone d'altitude charnière, située entre 1000 et $1500 \mathrm{~m}$. Après une phase de prospection et de sondages archéologiques, la problématique de ce programme de recherche s'est orientée vers l'habitat agropastoral médiéval avec notamment la fouille extensive d'une habitation mixte des $\mathrm{XI}^{\mathrm{e}}-\mathrm{XII}^{\mathrm{e}} \mathrm{s}$. L'analyse comparée des résultats concernant la période médiévale en Aubrac et en Cézallier laisse supposer que les conclusions esquissées en Aubrac pourraient également avoir des correspondances dans d'autres massifs montagnards.
\end{abstract}

\begin{abstract}
Methodological approach of the study of mountain mediaeval settlement: the example of Aubrac et Cezallier plateaus in the Massif Central

Abstract. Archaeological findings obtained on the broad basaltic and granitic plateaus in the south-western Massif Central have shown the great archaelogical potential of the plateaus, especially those formed by the Aubrac and Cézallier mountains. A group of archaelogists, historians, ethnologists and paleoenvironmentalists have been studying the long-term dynamics of human settlement on these plateaus. The results obtained have shed light on the types of habitat(temporary or permanent, depending on the period) present in this key belt located at altitudes of 1000 to $1500 \mathrm{~m}$. After a time of prospecting and archaeologicals survey, it was decided to focus this research project on the theme of the medieval agro-pastoral habitat. For this purpose, extensive excavations were conducted on a dwelling dating back to the $11^{\text {th }}$ and $12^{\text {th }}$ centuries. Comparisons between the results obtained on the mediaeval period in the Aubrac and Cézallier mountains suggest that some of the conclusions tentatively reached in Aubrac may well apply to other plateaus areas.
\end{abstract}

$\mathrm{L}$ es hauts plateaux du sud-ouest du Massif Centrall'Aubrac et le Cézallier - constituent de vastes territoires recouverts aujourd'hui de pâturages accueillant chaque été des troupeaux de bovins. Situés à une altitude comprise entre 1000 et $1500 \mathrm{~m}$, ces grands espaces naturels, réputés pour leur climat hivernal rigoureux, ont une densité d'habitants très faible.

L'enquête archéologique que nous avons entreprise a été confrontée à ses débuts à une image de pays inhospitalier qui sous-entendait une absence d'occupation humaine continue, image qui s'est avérée totalement fausse au fur et à mesure de l'avancée de notre recherche.

L'Aubrac est en premier lieu symbolisé par son hôpital médiéval qui venait au secours des pèlerins se rendant à Saint-Jacques-de-Compostelle. Les rares vestiges archéologiques antérieurs à cette époque sont représentés par une voie antique reliant Lyon à l'Espagne avec, au cœur du plateau, un relais routier accueillant les voyageurs dans un pays froid et dépeuplé. Le parallèle entre les périodes médiévale et antique est troublant, il renforce l'image d'un pays que l'on ne fait que traverser au plus vite.

Dans un tel contexte, il est facilement compréhensible que les archéologues n'aient pas trouvé d'intérêt à entreprendre des recherches dont les résultats ne pouvaient guère concerner que de rares étapes routières ou d'anciennes cabanes de berger. Un précurseur essaiera pourtant dès le XIX $\mathrm{s}$. de percer le mystère de ce pays, le docteur Prunières. Vers 1860-70, il va chercher inlassablement le moindre indice de présence humaine sur le plateau de l'Aubrac. Il ira jusqu'à sonder le fond du lac de Saint-Andéol dans l'espoir de

\footnotetext{
* Ministère de la Culture et de la Communication, DRAC de Midi-Pyrénées, Service Régional de l'Archéologie, 32 rue de la Dalbade, BP 811 , 31080 Toulouse cedex 6 et Travaux et Recherches Archéologiques sur les Cultures, les Espaces et les Sociétés (TRACES), UMR 5608 CNRS - Université de Toulouse-Le-Mirail, 5 allées Antonio Machado, 31058 Toulouse cedex 9.
} 
repêcher les vestiges du village disparu. Les résultats sont au rendez-vous, avec la découverte de «nombreux villages gaulois » qui datent en fait du Moyen Âge (Prunières 1867). Si le docteur Prunières a pu se méprendre sur la datation de certains sites, il a très vite compris que les vestiges recensés pouvaient correspondre à des centres d'exploitation d'un terroir et que, par conséquent, le pays avait fait l'objet d'une véritable occupation humaine.

Le contexte environnemental bien spécifique du milieu montagnard peut être considéré aujourd'hui comme un atout pour la recherche archéologique. Avant de présenter dans le détail la méthodologie appliquée dans le cadre de notre recherche sur les hauts plateaux du Massif Central, il est important de préciser que ces grands espaces se situent à des altitudes susceptibles d'accueillir une population à l'année. Cependant, les conditions climatiques ne permettent pas des conditions de vie et d'exploitation agricole optimales. Contrairement donc aux étages montagnards élevés comme on peut les rencontrer dans les massifs alpins et destinés au pacage du bétail, nous nous situons ici à une altitude charnière qui permet d'accueillir un habitat dispersé permanent ou un habitat temporaire lié à l'estive. Il s'agit donc d'un phénomène de balancier: habitat permanent/habitat temporaire qui, en fonction des critères climatiques, économiques ou politiques va, selon les périodes, pencher d'un côté ou de l'autre.

Cette caractéristique est un bon indicateur pour qui veut étudier la dynamique du peuplement. Elle révèle l'évolution et l'adaptation de l'homme à ce milieu mais également donne à travers elle, des informations précieuses sur la société de plaine.

Ce constat représente en fait non pas l'introduction à notre enquête mais sa conclusion. Ce n'est, en effet, qu'après une longue étude d'une décennie sur ce secteur que nous avons pu analyser ce phénomène grâce à la mise en place d'une équipe de recherche pluridisciplinaire. Au vu des résultats obtenus, la problématique de cette recherche a progressivement évolué vers l'étude de la dynamique de peuplement.

\section{Méthodologie de l'enquête}

Lors du démarrage de nos recherches en 1994 sur le plateau de l'Aubrac et ses contreforts, nous nous sommes très vite rendu compte de l'extraordinaire conservatoire environnemental que représentait cette région.

Ce paysage, constitué essentiellement de pâturages et de forêts, n'a quasiment pas évolué depuis le bas Moyen Âge, obéissant ainsi à des critères économiques toujours d'actualité : l'élevage et la gestion forestière. Le climat de ces hauts plateaux est bien évidemment à l'origine de cette tradition et a poussé l'homme, comme dans tout pays de montagne, à exploiter les animaux et les arbres.
Contrairement aux régions de plaine, où les travaux d'aménagement ont souvent détruit au cours des dernières décennies les sites archéologiques et leur environnement, les «montagnes » d'Aubrac ont livré un patrimoine admirablement conservé. De plus, les bâtiments agricoles d'époque contemporaine conservent des spécificités intéressantes, dont l'étude se révèle riche d'enseignements pour la compréhension des vestiges archéologiques médiévaux. Pour cela, nous nous sommes appuyé sur l'exceptionnelle étude ethnologique menée par G.H. Rivière et son équipe du CNRS durant une vingtaine d'années. La publication en sept volumes issue de cette enquête a servi pendant longtemps de référence (Collectif 1970-1986).

La présence de nombreuses tourbières sur le plateau est aussi un atout d'importance pour l'étude du paysage, l'approche palynologique a permis de suivre l'évolution de ce dernier pour les périodes préhistorique et surtout historique.

Le patrimoine de l'Aubrac ne se limite cependant pas à son paysage, ses tourbières, son architecture ou ses vestiges, il est aussi présent à travers une très riche documentation historique. D'époque médiévale ou moderne, les textes provenant de l'Hôpital d'Aubrac sont nombreux et constituent un fonds archivistique précieux (Rigal, Verlaguet 1913-1917; Rigal 1934).

Face aux fortes potentialités archéologiques, ethnologiques, écologiques et historiques de l'Aubrac, il nous est apparu indispensable de travailler de façon pluridisciplinaire en constituant une équipe associant archéologues, ethnologues, environnementalistes et historiens. Il a fallu par la suite définir un cadre cohérent dans lequel nous pouvions insérer les données tout en fixant des limites chronologiques, géographiques et thématiques. Nous avons développé dans le même temps une méthode de prospection et d'inventaire pour recenser le plus de gisements possible. Cette approche de travail nous a permis d'aborder les sites archéologiques de cette région non seulement de façon monographique mais également en tenant compte de leur contexte environnemental et historique.

Enfin, l'apport de la documentation écrite pour les périodes médiévale et moderne nous a incités à privilégier ce cadre chronologique, sans pour autant délaisser une approche diachronique.

Le cadre géographique était quant à lui relativement facile à établir dans la mesure où la région de l'Aubrac, située aux confins des départements de l'Aveyron, du Cantal et de la Lozère est une entité en soi ; son territoire nous est apparu cependant trop vaste pour une enquête archéologique. La carte des possessions de la Domerie (Hôpital) au XIV ${ }^{\mathrm{e}} \mathrm{s}$, restée inchangée jusqu'à la Révolution, paraissait constituer une bonne base puisque, d'une part, elle limitait notre étude à la partie est de l'Aubrac et, d'autre part, elle correspondait aux zones renfermant la grande majorité des premiers sites repérés. En outre, ceux-ci devaient certainement 


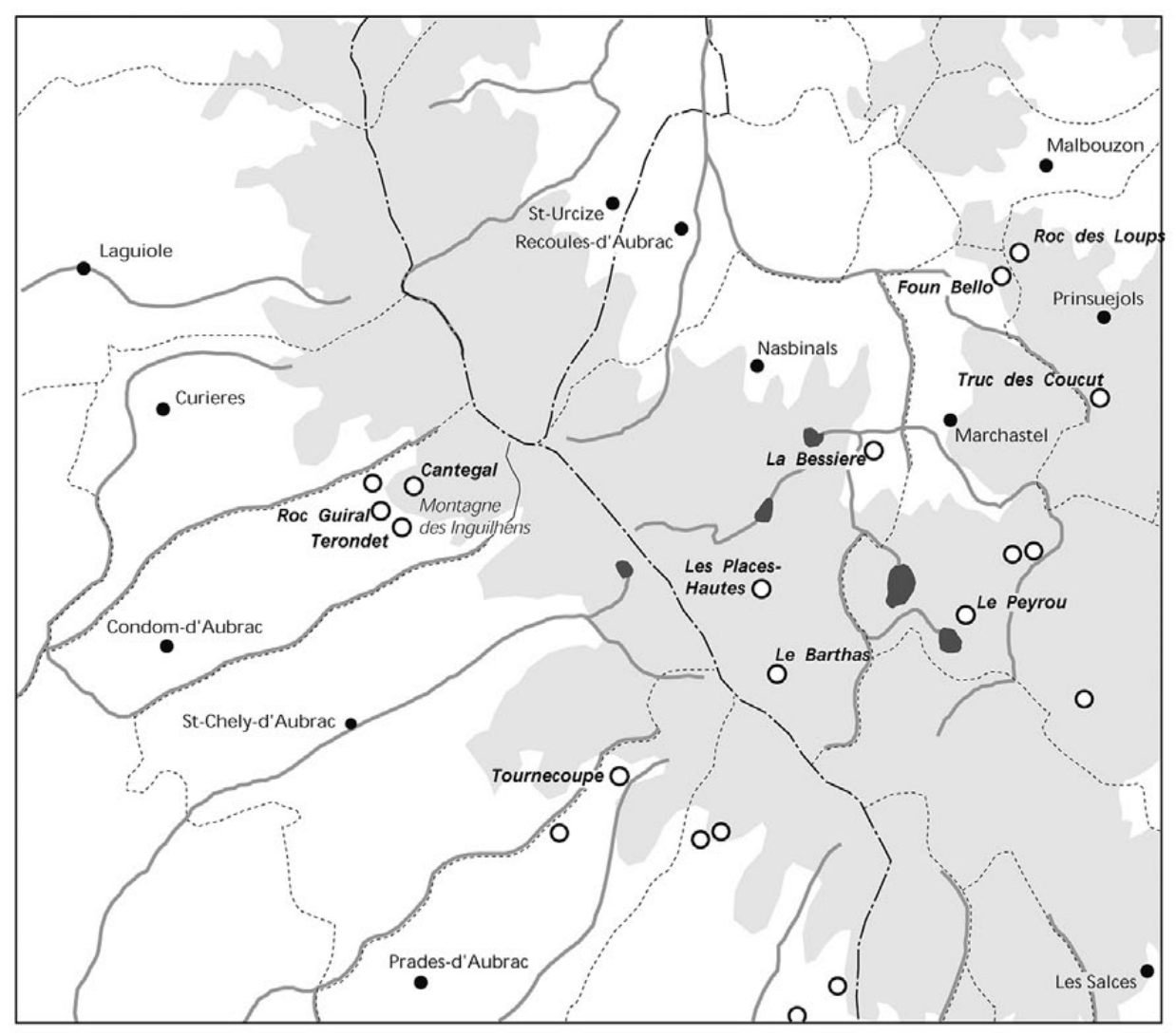

Fig. 1. Carte de situation des mas médiévaux découverts en Aubrac.

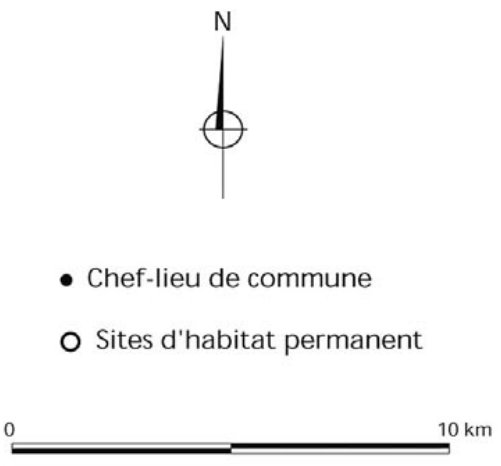

dépendre de l'Hôpital; le titre retenu pour le projet collectif de recherche fut donc «Approche de l'habitat et de l'activité économique en moyenne montagne: les dépendances de la Domerie d'Aubrac». Depuis lors, nous savons que la plupart des sites d'habitat permanent ne dépendaient pas de la Domerie puisqu'ils ont été datés, dans leur majorité, du $\mathrm{XI}^{\mathrm{e}}$ et du début du $\mathrm{XII}^{\mathrm{e}} \mathrm{s}$., période antérieure à l'établissement de l'Hôpital (Fau 2006).

Ces limites territoriales restent néanmoins tout à fait valables pour notre enquête, car elles présentent le double avantage d'englober la majeure partie du plateau et de nombreuses vallées boisées - paysages bien représentatifs de la topographie de l'Aubrac -, et de rassembler la majorité des sites (fig. 1).

Les cadres géographique et chronologique retenus, nous avons mis en place plusieurs équipes de travail. En premier lieu les membres du projet collectif ont défini différents thèmes à étudier: le paysage, la relation entre le milieu naturel et l'homme, le patrimoine archéologique avant l'arrivée des moines, le cadre seigneurial, la création et le mode de fonctionnement de la Domerie, le système d'estive.

Si les sujets sélectionnés par l'équipe étaient relativement documentés, les résultats ont été quant à eux largement tributaires des enquêtes de terrain, organisées méthodiquement pour servir au mieux la problématique. Cette application sur le terrain a par ailleurs été très diverse puisqu'elle consistait à la fois à prospecter, à sonder certains sites, ainsi qu'à effectuer des carottages palynologiques ou des études géomorphologiques.

Les méthodes d'approche se devaient d'être multiples pour tenter d'enregistrer un maximum de données. Nous avons donc eu recours à la méthode dite d' "archéologie extensive» définie par Jean-Marie Pesez (Pesez 1988). Il s'agit d'une série de moyens d'investigation qui, présentés séparément ont tous leurs limites mais qui, utilisés de manière concomitante, apportent les informations les plus performantes pour l'étude d'un terroir. Cette notion de terroir permet en outre une approche des sites dans leur ensemble et non pas isolés de leur contexte.

L'étude historique a révélé une vingtaine de sites d'habitats; plusieurs mentions d'anciens mas désignent en effet «les montagnes » au bas Moyen Âge. La difficulté majeure concernait cependant, comme c'est malheureusement le cas bien souvent, l'attribution d'une mention à un site précis sur le terrain; sept d'entre eux toutefois ont pu être repérés avec certitude. Les recherches sont allées bien au-delà de la simple identification de site. Nous avons également pris en compte le contexte historique en définissant les limites de paroisses, la voirie, la cadastration, pour resituer les gisements dans leur environnement. 
En liaison directe avec l'étude des sources, la toponymie a permis d'obtenir des indications précieuses pour la prospection, dans un pays d'une grande permanence linguistique. L'exemple du Barthas, terme définissant un endroit envahi par les ronces ou les buissons, facilement repérables dans un contexte de pâturage, a ainsi révélé très souvent des vestiges de bâtiments dans lesquels ce type de végétation s'est aisément développé.

L'enquête orale s'est également avérée très fructueuse, notamment auprès des érudits locaux et des anciens bergers qui connaissent à merveille la région et dont la mémoire du pays est fortement ancrée.

La prospection pédestre a donné, elle aussi, de très bons résultats sur les pâturages ainsi qu'en forêt; il va de soi que sur des superficies aussi importantes les prospections systématiques n'ont pu être que ciblées, en particulier grâce aux informations toponymiques ou orales.

Enfin, la prospection aérienne a certainement constitué le moyen le plus spectaculaire de repérer un grand nombre de sites archéologiques. Pratiquée exclusivement au-dessus des pâturages, elle a rapidement permis de localiser quantité de nouveaux gisements, alors que les prises de vue réalisées sur des sites préalablement connus ont révélé des structures illisibles au sol.

À l'issue de la phase de prospection, il s'est avéré nécessaire de classer les dizaines d'indices de site recensés. Un tri thématique a été effectué en les regroupant en trois grands groupes: l'habitat permanent, c'est-à-dire le hameau ou la ferme, l'habitat temporaire, lié au système d'estive et enfin la proto-industrie. À l'intérieur de chaque thème, nous avons établi un ordre hiérarchique allant de la simple mention au site attesté par les textes et dont les vestiges sont encore visibles.

Dès la première année de travail, allant de pair avec la prospection, des campagnes de relevés de terrain ont été programmées. Nous avons choisi par la suite les gisements les plus prometteurs révélés par la prospection pour effectuer des sondages archéologiques. Même ponctuels, ces sondages ont souvent permis d'émettre des hypothèses sur les fonctions des différents sites et surtout de les dater grâce aux analyses radiocarbones ainsi qu'à l'étude du rare mobilier découvert. Les spécificités de l'habitat temporaire furent ainsi facilement identifiées, la forme rectangulaire des creusements à flanc de colline ainsi que la concentration des structures ne laissant pas de doute sur leurs fonctions. Dans une certaine mesure, les vestiges concernant l'artisanat étaient eux aussi aisément reconnaissables grâce à leur situation géographique, puisqu'ils se situent tous dans les vallées boisées, au plus près des matières premières indispensables à leur activité.

Ce type de démarche pourrait être qualifié de recherche sélective, dans la mesure où tous les sites ont été recensés et où de nombreuses pistes de travail ont été lancées les premières années pour ensuite se concentrer, au fur et à mesure de l'avancée de la recherche, vers un sujet fédérateur. Pour autant, les thèmes de départ n'ont pas été délaissés; renonçant à une étude exhaustive irréalisable, nous avons choisi de sélectionner pour chacun d'eux un site assez révélateur et exemplaire, à savoir la montagne de Cammejane (commune de Saint-Chély-d'Aubrac, Aveyron) pour l'habitat temporaire et la Verrière (commune de Saint-Chély-d'Aubrac également), illustrant la protoindustrie dans les forêts des vallées.

Les séries de sondages effectués sur les sites d'habitats permanents nous ont permis, dans le même esprit, de sélectionner le plus intéressant d'entre eux à nos yeux, celui de la montagne des Inguilhens, pour y entreprendre de 1999 à 2002 la fouille extensive d'un habitat mixte.

Les résultats liés à cette méthodologie sont à la fois extrêmement riches et très rapides. Citons l'exemple de la prospection aérienne où en quelques heures de survol des pâturages apparaissent les vestiges livrant le plan des bâtiments et des structures qui les entourent: le gain de temps et de compréhension est considérable puisqu'avant même d'avoir fouillé, nous connaissons l'emprise du site et l'essentiel de son plan. Il est alors possible de se limiter à quelques sondages d'évaluation pour obtenir une coupe stratigraphique et un peu de mobilier pour dater le site, notamment grâce à la présence de charbons de bois qui font l'objet de datations radiocarbones.

Nous voyons donc que cette méthode permet de couvrir des territoires importants et de dresser un inventaire archéologique pertinent sans qu'il vise par ailleurs à l'exhaustivité.

\section{Une problématique retenue: l'habitat agro-pastoral}

Ce thème a ainsi permis de faire évoluer la problématique tout en renforçant l'aspect interdisciplinaire du projet. Les campagnes de prospection se sont par ailleurs poursuivies en conservant leur aspect "généraliste », prenant donc en compte tous les gisements découverts.

La multiplication des interventions sur le terrain a facilité une étude comparative entre les sites d'habitats sondés, qui sont au nombre de six, et ceux simplement recensés (une vingtaine au total). Alors que les vestiges d'habitat temporaire, voire de proto-industrie, semblaient relativement homogènes, il n'en allait pas de même pour l'habitat permanent aux aspects fort variés.

L'habitat dispersé présentait en effet de nombreux sites au potentiel archéologique très prometteur. Plusieurs éléments laissaient entrevoir tout l'intérêt qu'il y avait à approfondir l'étude de cette question. La documentation historique nous indiquait que ces vestiges avaient été fossilisés par 


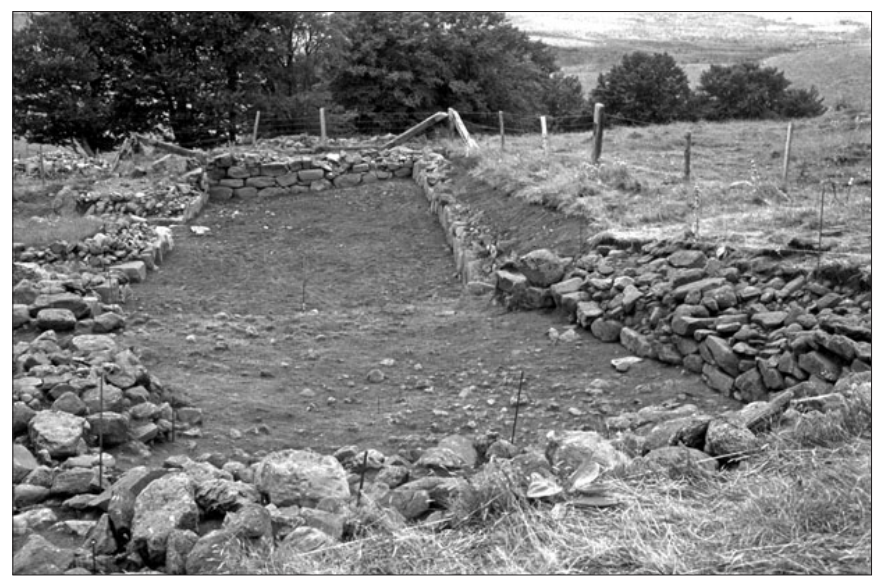

Fig. 2. Fouille extensive d'un habitat agro-pastoral: plan de la maison mixte de Cantegal (Condom-d'Aubrac, 12).

les pâturages dès le Moyen Âge et pouvaient correspondre aux unités agro-pastorales des mas; les données archéologiques proposaient des datations s'échelonnant du $\mathrm{XI}^{\mathrm{e}} \mathrm{au}$ $\mathrm{XIII}^{\mathrm{e}} \mathrm{s}$., enfin la présence de tourbières permettait d'étudier l'environnement paysager des sites.

Le choix s'est porté sur un mas des $\mathrm{XI}^{\mathrm{e}}-\mathrm{XII}{ }^{\mathrm{e}} \mathrm{s}$. comportant une dizaine de bâtiments parmi lesquels une maison mixte correspondant à l'une des habitations du hameau. Cette maison mesure $35 \mathrm{~m}$ de long pour 8 de large et est divisée entre l'habitation et l'aire de stabulation, reprenant un plan bien connu dans les pays anglo-saxons: the long house (fig. 2). La fouille extensive de cette bâtisse a permis d'étudier les critères d'implantation, le mode de construction et le mode de vie à travers la culture matérielle. Ces données de terrain étaient indispensables pour progresser sur la connaissance de ce type d'habitat, elles viennent en complément de la prospection liée au projet collectif de recherche.

Après l'enquête sur l'habitat dispersé médiéval de l'Aubrac et la bonne identification de la présence de ce réseau de mas médiévaux, il est apparu important de savoir si ce phénomène était propre à ce pays ou pouvait correspondre à un schéma général applicable à tout autre pays de montagne comparable. Le patrimoine découvert en Aubrac pouvait ainsi avoir des correspondances dans d'autres régions, à commencer par les autres secteurs du Massif Central.

C'est ce que nous avons voulu vérifier en investissant un autre plateau du Massif Central : le Cézallier, situé au nord du Cantal et au sud du Puy-de-Dôme.

Bénéficiant dans ce secteur d'un précieux travail de prospection archéologique (Vinatié, Baillargeat 2002), nous avons pu réaliser une nouvelle étude sur un panel d'une dizaine de sites pouvant correspondre à un habitat permanent comparable à celui rencontré en Aubrac.

Après une première année d'étude et de relevés des plans de ces habitats, nous avons engagé des sondages sur l'un d'eux: le site de Troucou dans la commune de Vèze
(Cantal) (fig. 3). Les résultats semblent être identiques à ceux obtenus dans l'Aubrac dans la mesure où les sites présentent des critères d'implantation et surtout des plans de bâtiments similaires. La campagne de fouilles entreprise à Troucou a permis de constater une même technique de construction ainsi qu'un mobilier et des datations identiques à celles pratiquées sur l'habitat de l'Aubrac: $\mathrm{XI}^{\mathrm{e}}-\mathrm{XII}^{\mathrm{e}} \mathrm{s}$. Tout en restant prudent, il semble donc que les sites d'habitat du Cézallier correspondent à ceux de l'Aubrac (Fau 2004 et 2005).

\section{Limites de la méthode}

Il convient, avant de conclure, de signaler les limites de notre étude et aussi de pondérer nos propos après ce résumé quelque peu idyllique de notre enquête. Pour ce faire, l'exemple le plus révélateur est celui de l'opération d'archéologie subaquatique menée dans le lac de Saint-Andéol sur le plateau de l'Aubrac. En effet, cette intervention renseigne plusieurs phases chronologiques qui n'avaient pas été repérées lors de la prospection pédestre ou aérienne.

Le lac de Saint-Andéol, situé dans la commune de Marchastel en Lozère, a attiré depuis plus d'un siècle les chercheurs dans la mesure où il correspond vraisemblablement à un lieu de culte remontant à la période antique qui aurait perduré jusqu'au XIX ${ }^{\mathrm{e}} \mathrm{s}$. Face aux données archéologiques présentes aux abords du site et à quelques découvertes fortuites, nous avons décidé en 2006 de programmer une opération de fouilles subaquatiques. Les données ethnologiques, historiques et archéologiques permettent de dire aujourd'hui que ce site a bien fait l'objet d'un culte: il a livré une vaisselle d'époque protohistorique spécifique; un temple gallo-romain puis une église du haut Moyen Âge s'implantent par la suite à ses abords; un texte attribué à Grégoire de Tours (De Gloria Confessorum, Kruch 1885) le cite et décrit précisément les rites pratiqués sur ses rives. Enfin des données ethnologiques livrent à la fois des légendes et des récits mentionnant que le culte s'est maintenu jusqu'à la période contemporaine. Nous voyons donc que, même si les découvertes de mobilier dans le lac ont été limitées, ce site exceptionnel a livré des informations sur la longue durée.

Le présent article n'est pas le cadre pour un compte rendu détaillé de cette recherche mais l'apport de ces informations est fondamental pour mettre en perspective et relativiser notre enquête en Aubrac.

En effet, l'Aubrac n'avait jusqu'alors rien livré de l'époque protohistorique, pas plus que pour la période du haut Moyen Âge, les données archéologiques restaient absentes des résultats de notre enquête. Étant donné l'aspect très complémentaire de notre enquête pluridisciplinaire ainsi que l'efficacité de la prospection archéologique, nous aurions 


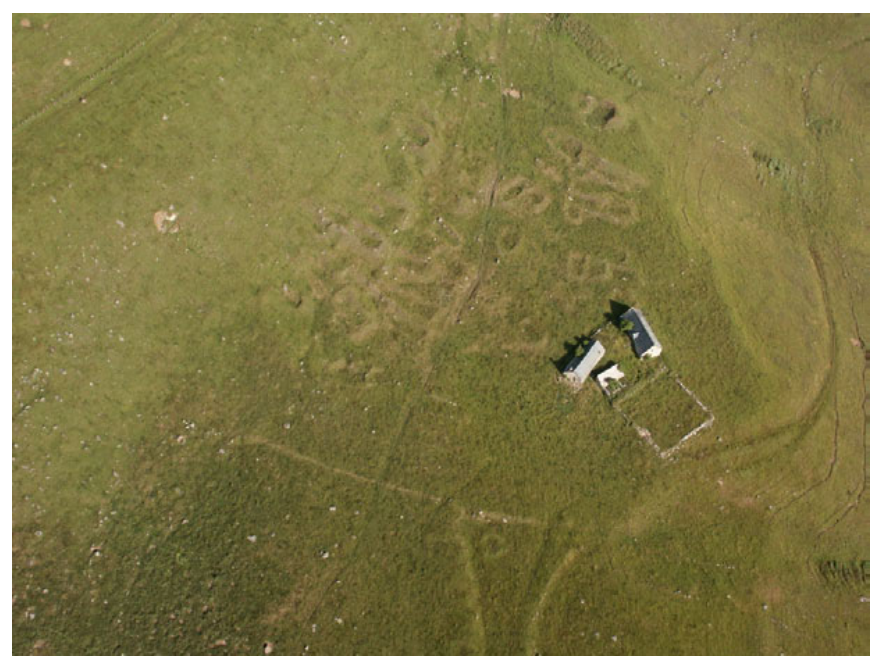

Fig. 3. Vue aérienne du site d'habitat de Troucou en Cézallier (Vèze, 15).

été tentés de conclure que ces périodes étaient absentes de cette région.

L'étude du lac de Saint-Andéol, au-delà du grand intérêt de ce site, nous apporte la preuve-par le mobilier pour la période protohistorique et par les textes pour le haut Moyen Âge - que l'activité humaine peut, à un moment donné, ne laisser que très peu de traces, voire pas du tout sur le terrain, alors qu'elle est bien présente.

L'exemple d'une étude issue de l'enquête ethnologique est riche d'enseignement à ce propos: il s'agit d'une pratique de gardiennage de troupeau nommée l'asegado. Le berger fait paître son troupeau de bovins en établissant un système rotatif sur une parcelle donnée pour mieux la fumer. Pour cela, il fixe une limite imaginaire dans le pâturage audelà de laquelle le troupeau ne peut aller; dès qu'une bête dépasse cette limite, il projette son bâton qui vient frapper l'animal. Au bout de quelques jours, le bétail a intégré cette «clôture virtuelle» et attend sagement que le berger décide de déplacer son troupeau. Cet exemple, parmi tant d'autres, illustre comment une intense activité humaine, en l'occurrence l'élevage, ne peut laisser aucune trace sur le terrain, pas même une simple clôture.

Tout ceci ne fait que souligner une évidence qu'il est bon de formuler lorsque l'on entreprend une enquête archéologique dans un contexte montagnard: l'inexistence de données archéologiques concernant une période ne signifie en rien une absence d'occupation humaine. Il est donc important de veiller à ne pas conclure hâtivement que certaines périodes sont absentes, ou même sous-représentées, lorsque l'on travaille sur le long terme et la dynamique de peuplement sous prétexte que les résultats archéologiques sont absents.
Les données environnementales et notamment palynologiques sont certainement les seules aujourd'hui à apporter des éléments d'anthropisation sur toutes les périodes. Elles sont de ce fait incontournables pour qui étudie un terroir montagnard sur le long terme.

\section{Résultats et perspectives de recherche}

À l'issue de plusieurs années de prospection, de nombreuses découvertes archéologiques ont notamment permis de révéler l'existence de noyaux d'habitat permanent médiéval totalement ignoré, et distincts du traditionnel habitat temporaire (burons). Une vingtaine de mas médiévaux ont été mis en évidence en Aubrac, une dizaine en Cézallier. Plusieurs de ces sites ont été datés des $\mathrm{XI}^{\mathrm{e}}-\mathrm{XII}^{\mathrm{e}}$ s. grâce à la réalisation de sondages archéologiques ayant fourni du mobilier céramique ainsi que des fragments de charbons de bois qui ont fait l'objet d'analyses radiocarbones.

Face aux découvertes de sites archéologiques correspondant à ces habitats permanents d'époque médiévale, nous nous sommes légitimement posé la question de savoir quelles sont les raisons de leur établissement et de leur abandon. Après avoir énuméré les réponses liées au contexte historique ou événementiel, nous avons réalisé que c'est très certainement pour des raisons économiques que des paysans se sont installés sur ces hautes terres. En effet, l'explosion démographique du $\mathrm{XI}^{\mathrm{e}} \mathrm{s}$. a suscité de nouveaux fronts de colonisation, les terres froides du Massif Central ont donc vu arriver une vague de paysans qui ont maillé le territoire en construisant des fermes: les mas, pour exploiter ces terrains plus ou moins vacants. Un siècle plus tard, ces mas sont abandonnés laissant la place à une exploitation du bétail d'estive, les vestiges étant fossilisés par les pâturages. À partir de la fin du Moyen Âge, l'habitat temporaire lié à une transhumance de grande envergure organisée par l'Hôpital d'Aubrac succède aux mas. Cet habitat, les burons donc, est totalement différent du précédent: il est reconstruit à chaque saison d'estive, laissant d'innombrables traces dans les «montagnes» de l'Aubrac et du Cézalier, sous forme de dépressions rectangulaires accolées les unes aux autres, la pierre étant pratiquement absente de la construction. Enfin, il est intéressant de noter que nous retrouvons le même type de ferme, adoptant un plan tout à fait similaire à ceux des mas du Moyen Âge, dans la deuxième moitié du XIX ${ }^{\mathrm{e}} \mathrm{s}$. Poussés par une forte démographie, de nombreux paysans se sont expatriés à cette époque. Certains ont choisi de traverser l'Atlantique ou de partir s'installer à Paris, d'autres ont investi à nouveau les rudes plateaux du Massif Central. Tout en restant très prudent dans l'interprétation, les fortes similitudes des données relatives aux deux périodes sont remarquables et semblent correspondre à des mouvements de population 
liés à une vague de colonisation de terres vacantes lors des phénomènes de surpopulation.

Les paysages de l'Aubrac et du Cézallier, constitués de grands plateaux situés entre 1000 et $1500 \mathrm{~m}$ d'altitude, ont de nombreux parallèles en France comme à l'étranger. Le patrimoine découvert dans ces secteurs et notamment l'habitat dispersé médiéval, pourrait donc avoir des correspondances dans d'autres régions. Si cette hypothèse se confirmait, un axe de recherche particulièrement intéressant pourrait être alors développé à grande échelle.

\section{Bibliographie}

\section{Sources publiées}

Kruch 1885: Grégoire de Tours - De gloria confessorum. In: Kruch (B.) éd. - Monumenta Germaniae Historica: scriptores rerum merovingicarum, I, 2, Hanovre, 1885, p. $749-750$.

Rigal, Verlaguet 1913-1917: RIGAL (J.-L.), VERLAGUET (P-A.) - Documents sur l'ancien hôpital d'Aubrac, Tome I (1108-1341), Rodez, Imp. Carrère, 1913-1917, 686 p.

Rigal 1934: RIGAL (J.-L.) - Documents sur l'ancien hôpital d'Aubrac, Tome II 1342-1416, Millau, impr. Artières et Maury, 1934, 778 p.

\section{Imprimés}

Collectif 1970-1986: L'Aubrac - étude ethnologique, linguistique, agronomique, et économique d'un établissement humain, R.C.P. du CNRS, Paris, éd. du CNRS, 1970-1986, 7 vol., 3 annexes.

Fau 2004: FAU (L.) - L'habitat intercalaire médiéval en Cézallier, Document Final de Synthèse de Prospection Thématique, Archives Service Régional d'archéologie d'Auvergne, Clermont-Ferrand, 2004.

Fau 2005: FAU (L.) - L'habitat médiéval de Troucou, Document Final de Synthèse de Prospection Thématique, Archives Service Régional d'archéologie d'Auvergne, ClermontFerrand, 2005.

Fau 2006: FAU (L.) dir. - Les Monts d'Aubrac au Moyen Âge: genèse d'un monde agro-pastoral. Paris, MSH, Daf $\mathrm{n}^{\circ} 101$, 2006, 216 p.

Pesez 1988: PESEZ (J.-M.) - Les méthodes et l'apport de l'archéologie extensive, dans Structures de l'habitat et occupations du sol dans les pays méditerranéens, Castrum 2, Rome-Madrid, 1988, p. 129-135.

Prunières 1867 : PRUNIÈRES (Dr.) - Notes sur quelques découvertes archéologiques faites dans les montagnes d'Aubrac (Lozère), Revue archéologique du Midi de la France, Toulouse, 1867, vol. 2, 14 e liv., p. 17-30.

Vinatié, Baillargeat 2002: VINATIÉ (A.), BAILLARGEAT (C.) - Archéologie en Cézallier, Les amis du vieil Allanche, Aurillac, 2002, 277 p. 


\title{
A plea for a (New) Environmental Archaeology: the use of the geographical historical microanalitical approach in mountain areas of NW Italy
}

\author{
Diego Moreno*, Carlo MonTANARI*, Anna Maria StAGNO*, Chiara MOLINARI*
}

\begin{abstract}
Here are proposed different studies carried out by the Laboratorio di Archeologia e Storia Ambientale of Genoa University through the use of a geographical historical microanalitical approach to documentary, field and sedimentary sources. The main aim is the reconstruction of different agri-silvo-pastoral practices and of environmental processes connected to the management of mountain resources widespread in the past in the Eastern Ligurian Apennines and now completely disappeared. In particular, we focused our attention on one of the access points to pastoral resources of the upper Aveto valley connected to transhumance systems involving mainly sheep until the end of $19^{\text {th }}$ century. This study was carried out in the perspective of the identification of different agri-silvopastoral practices concerning the common-land use system since the $16^{\text {th }}$ century. In this particular case, the comparison of different sources allowed the reconstruction of the relationship between settlement development, environmental resources management systems and the abandonment of these practices.
\end{abstract}

Pour une archéologie des ressources de l'environnement de montagne : l'apport de la microanalyse historique et géographique du site

Résumé. Sont ici exposés différents cas d'étude conduits par le Laboratorio di Archeologia e Storia Ambientale de l’Université de Gênes avec l'apport de la microanalyse historique et géographique du site. Le but principal de notre groupe est la reconstruction de différentes pratiques agro-selvi-pastorales et de procès liés à la gestion des ressources de l'environnement de montagne sur les Apennins de la Ligurie orientale durant les époques passées. Nous avons en particulier focalisé notre attention sur le hameau rural de Ventarola, un des points d'accès aux ressources pastorales de la haute vallée d'Aveto en lien avec le système de transhumance principalement dédié aux ovins jusqu'à la fin du XIX ${ }^{e}$ s. Cette étude a été conduite dans la perspective d'une identification de différentes pratiques agro-selvi-pastorales qui ont alimenté un usage de terre commune depuis le $\mathrm{XVI}^{\mathrm{e}} \mathrm{s}$. Dans ce cas particulier, le croisement de différentes sources a permis de reconstruire les relations existantes entre le développement de l'agglomération, le système de gestion des ressources environnementales et les effets induits par l'abandon de ces pratiques de gestion.

\section{Introduction}

Cince its foundation (1995), the Laboratorio di Archeologia e Storia Ambientale (L.A.S.A., Di.SMeC. - Dip.Te.Ris.) has involved a group of researchers and teachers of both the Faculties of Humanities and of Sciences at Genoa University. Presently it is mainly concerned with the activities of the Doctoral School of Historical Geography for the Valorisation of Historical and Environmental Heritage, and many local, national and European research projects are in progress.

Each project is based on many different types of evidence: written and oral sources, archaeological excavation and survey, sedimentary investigations (geoarchaeological, archaeobotanical, archaeozoological) and in-site and extrasite historical ecology analysis of existing landscapes.

The study of past dynamics and functions affecting the environmental resource ecology is the main focus of the teamwork. Our perspective starts from the standard field techniques of palaeoecology and aims to develop methods based on the analysis of precise local case studies at a topographical scale that can suggest a more complex historical generalisation. In our view, dynamics and modelling of resources systems need a high resolution geographical historical microanalytical approach to the sites for producing and employing field evidences. The main methodological

\footnotetext{
* Laboratorio di Archeologia e Storia Ambientale (LASA Dismec-Diptéris), Università degli studi di Genova, Via Balbi, 6, I16126 Genova (Italie) et Doctoral School on Historical Geography for the Valorisation of Historical - Environmental Heritage, Laboratory of Environmental Archaeology and History
} 


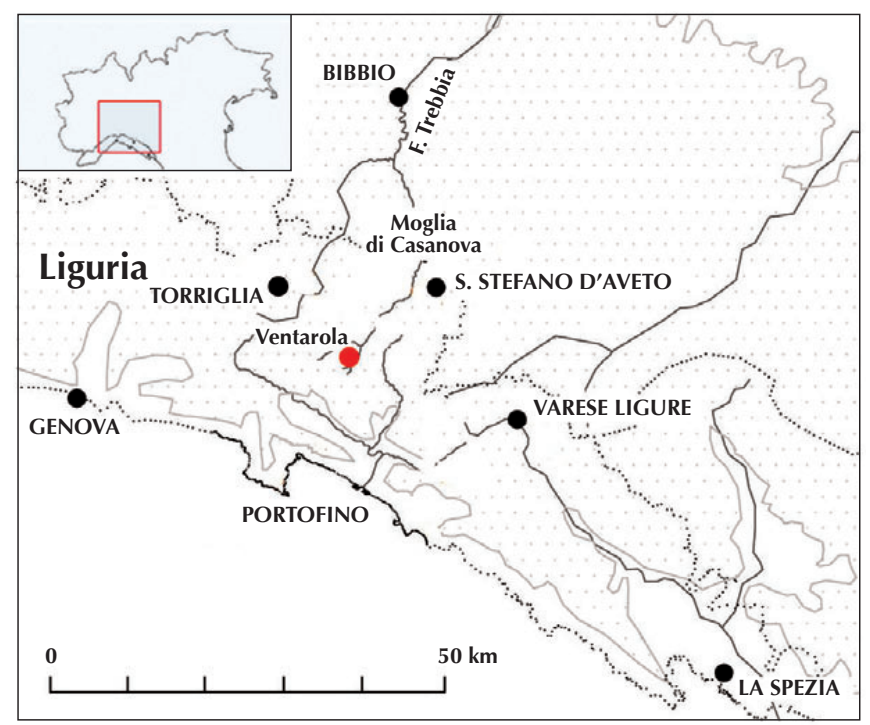

Fig. 1. Ventarola hamlet localization.

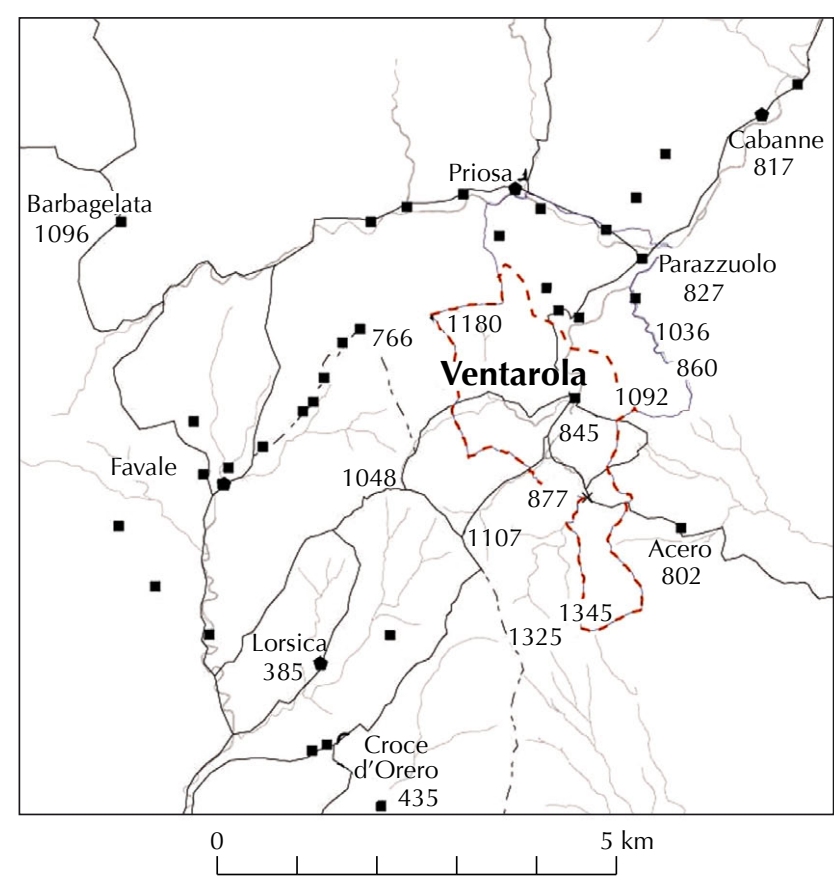

Fig. 2. Ventarola hamlet "boundaries" in 1822.

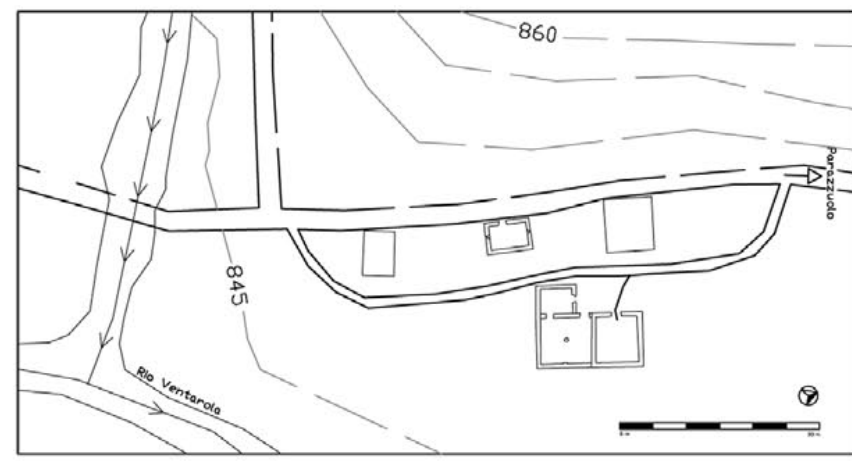

1630 circa

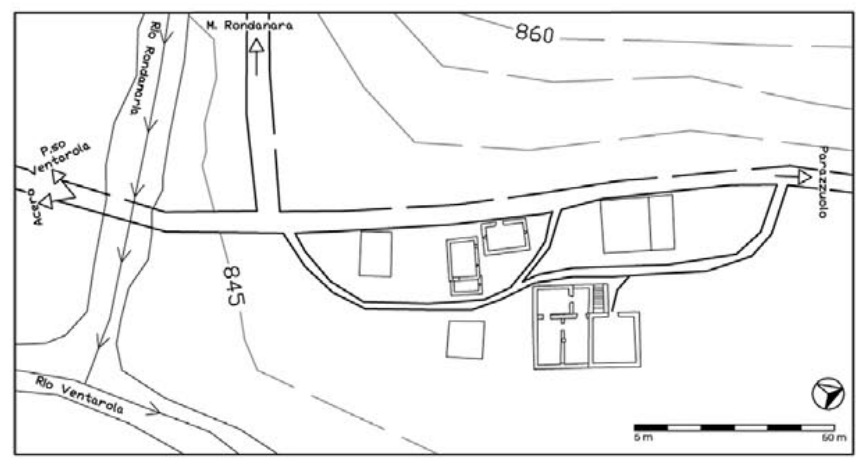

1720 circa

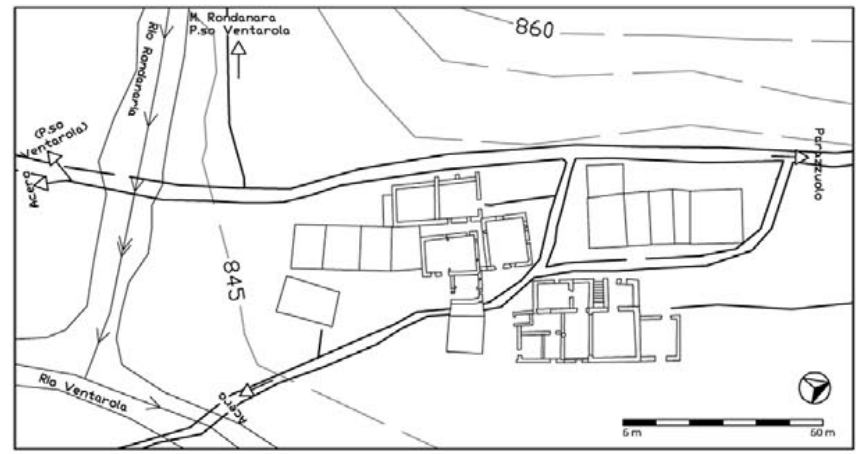

1820 circa

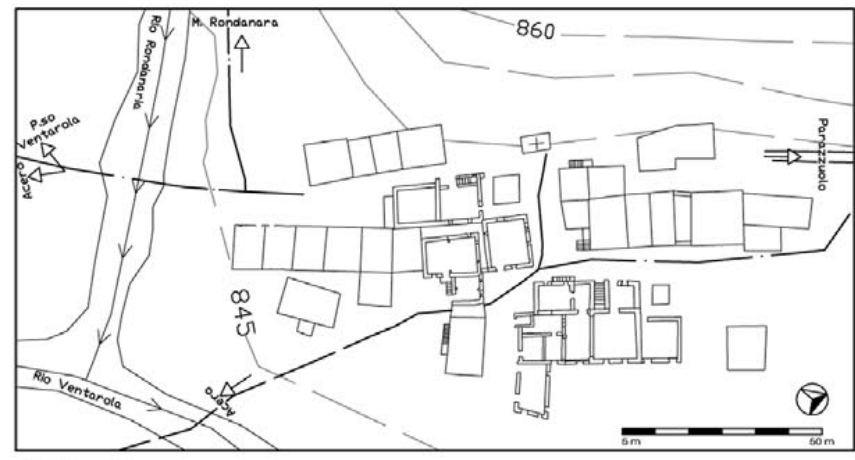

1940 circa

Fig. 3. Ventarola hamlet and road transformations between $1630 \mathrm{ca}$. and $1940 \mathrm{ca}$. 


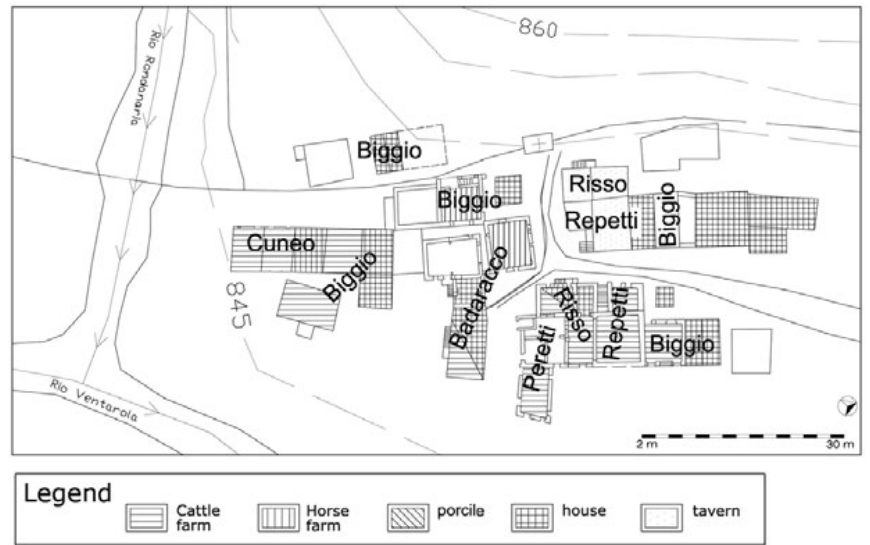

Fig. 4. Ventarola hamlet. Chronology of the construction of livestock spaces (stables and hay-barns) documented for 1870 .

The last modification is considered for restored buildings.

features of this approach can be listed as follows: 1) reexamining the importance of interdisciplinary fieldwork; 2) combining present local environmental knowledge and outside (academic) knowledge; 3 ) pointing out the crucial role of different (and changing) management and activation practices on the ecology of environmental resources; 4) adopting a regressive method in the historical approach to the different sources; 5) producing high resolution studies on sedimentary evidence (pollen, charcoal, etc.); 6) combining archaeological survey with vertical stratigraphy for the study of standing rural buildings (and ruins); 7) cross-comparing evidences and contextualization of textual and iconographical evidences.

The choice of a detailed scale of reconstruction of historical management and activation practices allows the identification of the processes which have produced past cultural (rural) landscapes and exploring the historical relationship with the related rural settlement distribution.

Researches carried on by our group deal mainly with the Western Apennines, but a number of different sites of interest are distributed in the North Western Italian Mountain area, reaching the Maritime Alps (Cevasco, Poggi 1999; 2000; Maggi et al., 2006; Moreno 1997; Moreno, Cevasco 2006; Moreno et al., 1992; 2004; 2005).

\section{Ventarola case study}

Ventarola (Rezzoaglio, Genoa) is a mountain hamlet (today composed by seven houses, two of them still inhabited) located at about $845 \mathrm{~m}$ a.s.l. in the upper Aveto valley (Eastern Ligurian Apennines, Northern Italy, fig. 1).

This rural hamlet is one of the widespread nucleated settlements in Eastern Ligurian mountain areas (referred as

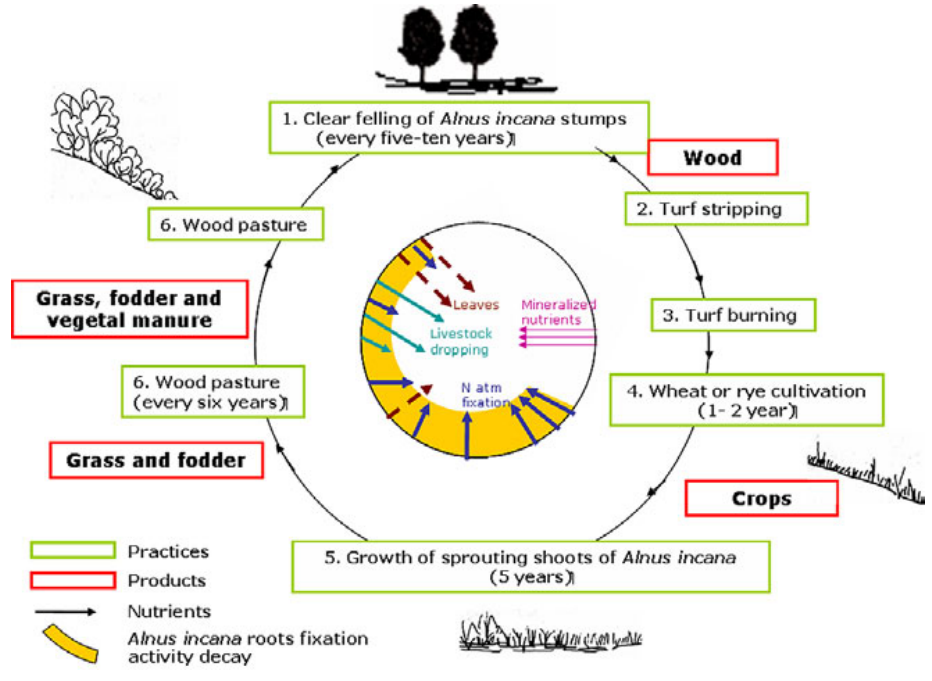

Fig. 5. Prevailing economic products (in the outer circle), management practices (in the middle circle) and nutrient sources/ecological basis (in the inner circle) in the

"alnocoltura" cycle according to 1820 Consegne dei Boschi and to 1896 Relazioni (after Moreno et al. 1998).

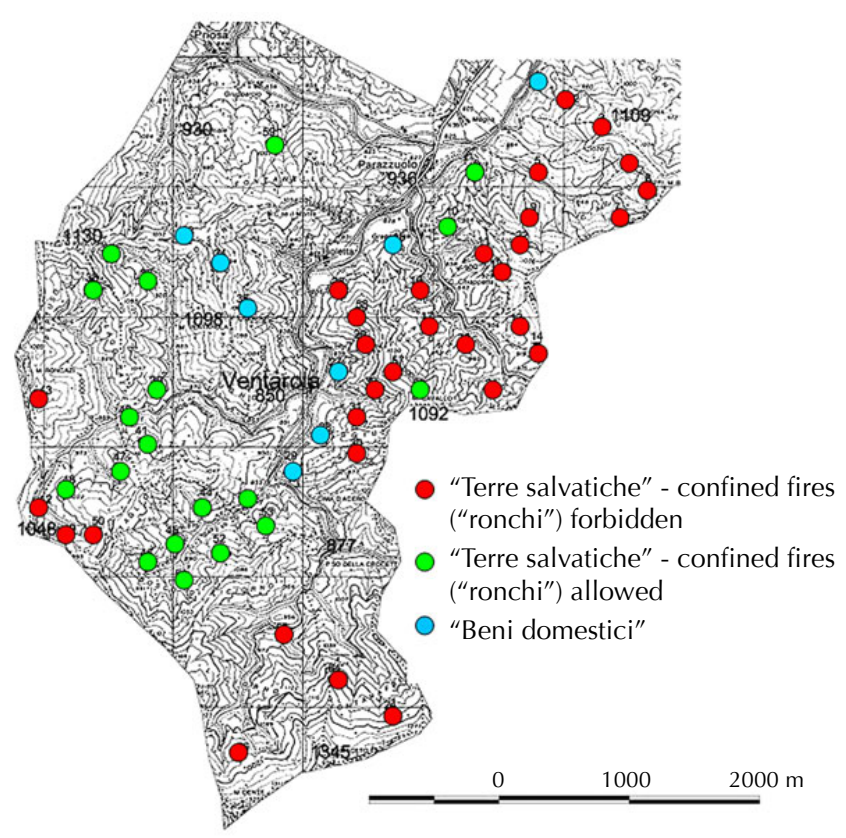

Fig. 6. Localization of parcels where, according to Relazioni of 1720, confined fires were forbidden or allowed (after Cevasco et al. 2008). 
ville in post-medieval texts, Scarin 1957, Raggio 1990). As testified by cartographical and textual documentation, during the past Ventarola was an important access point to the upper Aveto Valley, within a network of commercial and transhumance routes linking coastal winter pastures of Riviera di Levante to mountain summer pastures of the Po valley (fig. 2).

Today the area is part of the Aveto Regional Natural Park. For what concerns climatic and geological features, the climate is sub-oceanic, the mean 2006 temperature is $9.8^{\circ} \mathrm{C}$ and the annual rainfall is $1351 \mathrm{~mm}$ p.a. (as recorded at the Santo Stefano d'Aveto meteorological station, APAT 2007). The local bedrock consists mainly of sandstone, fine limestone, marlstone and clayey schists ${ }^{1}$.

The present vegetation of the area is characterized by coppiced mixed woodlands, mainly dominated by turkey oak (Quercus cerris L.) and beech (Fagus sylvatica L.). Cultivated fields, meadows and wooded-pastures are present in the surroundings of the hamlet, while alders (Alnus glutinosa (L.) Gaertner) and willows (Salix caprea L.) grow around wetlands.

The study of the Ventarola rural settlement started as a rescue archaeological campaign carried out since 2005 in the frame of the restoration of one of the hamlet buildings, in order to obtain a new hiking refuge for the Aveto Regional Natural Park ${ }^{2}$. These investigations showed that part of the transformations documented in the building (dated to 1630 A.D.) were due to inner social changes affecting the rural families that used (or held) the dwellings. Moreover, they seem also in connection with general changes affecting agri-silvo-pastoral practices in which the settlement and this building were involved (Cevasco et al. 2008). After this first campaign, the research has developed, by means of a multidisciplinary approach, into a micro-analytical study focused on the reconstruction of the functional organization of the productive space inside and outside the hamlet. The relationships between the settlement and the agri-silvo-pastoral resources management (system of practices) carried out since the $16^{\text {th }}$ century onwards were also investigated.

During 2007, the archaeological investigation was extended on the standing walls of the hamlet buildings to better understand different transformations documented during the rescue campaign, and to validate them in the rural peopling geography perspective: individual strategies were distinguished from changes related to the whole hamlet (inhabitants collectivity). Historical cartographical and archival analyses were focused on changes of vegetation

1. Regione Liguria, Carta Geologica Regionale, scala 1:25 000, 2006. 2. DOCUP Obiettivo 2 (2000-2006), "attività di supporto alla gestione ambientale",- componente b, "realizzazione della Rete Natura 2000" "Parco dell'Aveto e Rete Natura 2000: boschi e biodiversità". between the $18^{\text {th }}$ and $20^{\text {th }}$ century. In this case, a specific interest was lead to the transformations of environmental resources management and to changes in the use of spaces by inhabitants of Ventarola through time. This method also allowed validating the archaeological approach to the reconstructive analysis of the building (Stagno in press). The outcomes of the archaeological research have been compared with those from bio-stratigraphic evidence. In particular, palynological analyses conducted on a soil profile from the surroundings of the Ventarola hamlet clearly showed the strict correlation between environmental resources management, rural buildings (space distribution) and changes of vegetation cover (Molinari, Stagno 2009).

\subsection{Archaeological investigations}

Archaeological investigations were conducted with the methodology of architecture archaeology (stratigraphic analysis of the standing walls and configurational analysis, Mannoni 1984, 1998) on the hamlet buildings and allowed to underline different periods of settlement development. In order to date the walls, a chrono-typology of doors and windows was defined on the base of the presence of dated doors and on the comparison with other previous archaeological studies on buildings in Eastern Liguria.

Hypotheses on functions and changes of buildings spaces were based on the characteristic of the last function at present recognizable. Moreover, by comparing dimensions and distribution of rooms, doors and windows, a grid of interpretation was built for the use of spaces through time. The results hypothesized that since the end of $15^{\text {th }}$ century a number of the documented transformations could have been connected to general changes affecting local agrisilvo-pastoral practices.

The study of this settlement's transformations, in connection with modifications of the road network, showed that during the $18^{\text {th }}$ and the first half of the $19^{\text {th }}$ century Ventarola was transformed from a scattered (1630) into a linear nucleated settlement. Since the second half of $19^{\text {th }}$ century a disjointed hamlet has developed, by constructing buildings in all direction (fig. 3). These changes were probably due to the progressive decrease of Ventarola road network importance during the $19^{\text {th }}$ century, that also induced the decrease of inhabitant number, as testified by archival documents. For these reasons it can be argued that the "economic success of Ventarola" was fed by social and geographical long-distance relationships, connected to trades, seasonal migrations and to transhumance systems. For what concerns the stabling structures, archaeological investigations underlined the first occurrence, at the beginning of the $19^{\text {th }}$ century, of a clear differentiation among houses and spaces 
devoted to the livestock and a general increase of hay-barns (both dimensionally and numerically, fig. 4).

In buildings used only for stabling and feeding animals (locally called cascine) the new stables have windows instead of slits used formerly; at the first floor there is a hay-barn with a lot of windows and an external door for the hay transportation, as previously. Since this period, the construction of the second floor for the old buildings was documented and the new buildings were constructed with three floors. Such variations could be correlated to a change from a transhumant sheep-goat breeding to a resident bovine breeding ${ }^{3}$ (and consequent need of more space) and to a change from a multiple to a monocultural management system of agri-silvo-pastoral resources. During the rescue campaign, the construction of a pebble floor with drainage system, serving the two livestock shelters, was documented at the end of the $18^{\text {th }}$ century. A similar pebble floor is also found in another stable built in the same period. It is not clear if the "drainage system" is a solution adopted in all hamlet stables: if it is true, the shift of stables to the south-eastern part of the hamlet, near the rivers, during the $19^{\text {th }}$ century, could be explained.

\subsection{Historical ecology, cartographical and documentary sources}

In order to study the composition, structure and ecological function of Alnus incana (L. Moench) actual plots in the upper Aveto valley, previous researches were carried out by L.A.S.A. teamwork, based on historical ecology investigations, archival documents and historical cartographical studies.

Through these researches (Bertolotto, Cevasco 2000a; 2000b; Moreno et al. 1998; Cevasco 2007) a particular local type of multiple agricultural practice called ronco was documented in this area, between the $18^{\text {th }}$ and the $19^{\text {th }}$ century (and now completely disappeared). This system is part of a cyclical soil workmanship for cereals seeding (rye and oat) through the use of controlled fire in woodland and shrubland parcels populated by alder (and for this reason called alnocoltura, fig. 5). Soil fertilization of the parcel was due to grazing and to the particular fertilizing capacity of alder (Daniere et al. 1986).

For the reconstruction of different local practices involved in this common-land use system during the $18^{\text {th }}$ century, a series of six manuscript topographical maps drawn between 1714 and 1726 by Marc'Antonio Fossa (a judge acting as agent in the mountain estates of the DoriaPamphilj seigneurial family) were analysed. The richness

3. This transformation was documented during the same period in the nearby Fontanabuona Valley and in the "Montagna di Fascia" near Genoa city (Moreno 1990, p. 116-119). of place-names and the detailed description annexed to each map (Relazione) allowed to document the permission or prohibition to make ronchi (roncare) at the level of the individual properties (terreno) of each villa (Cevasco, Tigrino 2008). The information collected from these maps, once plotted on a GIS platform, allowed to localize each site with the indication of ronco on a recent topographical map. Moreover, the comparison between these maps and a woodland enquiry promoted by Regno di Sardegna (Consegne dei Boschi) ${ }^{4}$ underlined that between 1720 and 1822 Ventarola agricoltural system was based on the division between beni domestici (subjected to permanent cultivation) and terre salvatiche (forested, grazed, temporarily cultivated with different practices of ronco (including the alnocoltura) and almost covered with scattered trees [fig. 6]).

After that, in order to point out the most important vegetation and land use changes between the $18^{\text {th }}$ and the $19^{\text {th }}$ century, the methodology of the so called "cartographic filtration" on a GIS platform was employed. This method consists in a comparison among a series of cartographic documents from the same area in different periods ${ }^{5}$ (fig. $7 \mathrm{a}, \mathrm{b}, \mathrm{c}, \mathrm{d}$ ).

As it can be seen from the maps, the most important change between the 1818 Minute di campagna and the 1854 Gran Carta degli Stati Sardi di Terraferma consists in the representation of most of the parcels with scattered trees into woodlands. In these maps it is not possible to recognize the alnocoltura sites, while the space devoted to permanent grassland and pasture is evident. This could be a first trace of an agro-sylvi-pastoral resource management transformation, from a multiple to a monocoltural system. This element can be connected to the increase of space devoted to haybarns, also documented during archaeological investigations.

In the 1936 map the increase of open areas is probably connected to the cattle breeding expansion, while the 1999 map documents a post-cultural situation, with the spreading of woodlands as a consequence of the abandonment of agro-sylvi-pastoral practices.

\subsection{Biostratigraphical analysis}

In the frame of previous historical ecology and environmental archaeology investigations, the possibility to identify in a pollen diagram some traces of the local agro-sylvi-pastoral

4. Archivio di Stato di Genova, Prefettura Sarda, pacco 207, Consegne dei boschi e foreste, mandamento di S. Stefano d'Aveto, 1822-1824.

5. In particular, for the reconstruction of Ventarola "agricultural system" the following sequence of maps have been employed: Minute di campagna (1818), scale 1:9450; Gran Carta degli Stati Sardi di Terraferma (1854), scale 1:50.000; Istituto Geografico Militare, F. 83NE, Favale di Malvaro (1936), scale 1:25.000; Carta Tecnica Regionale (1999-2000), scale 1:10.000. 

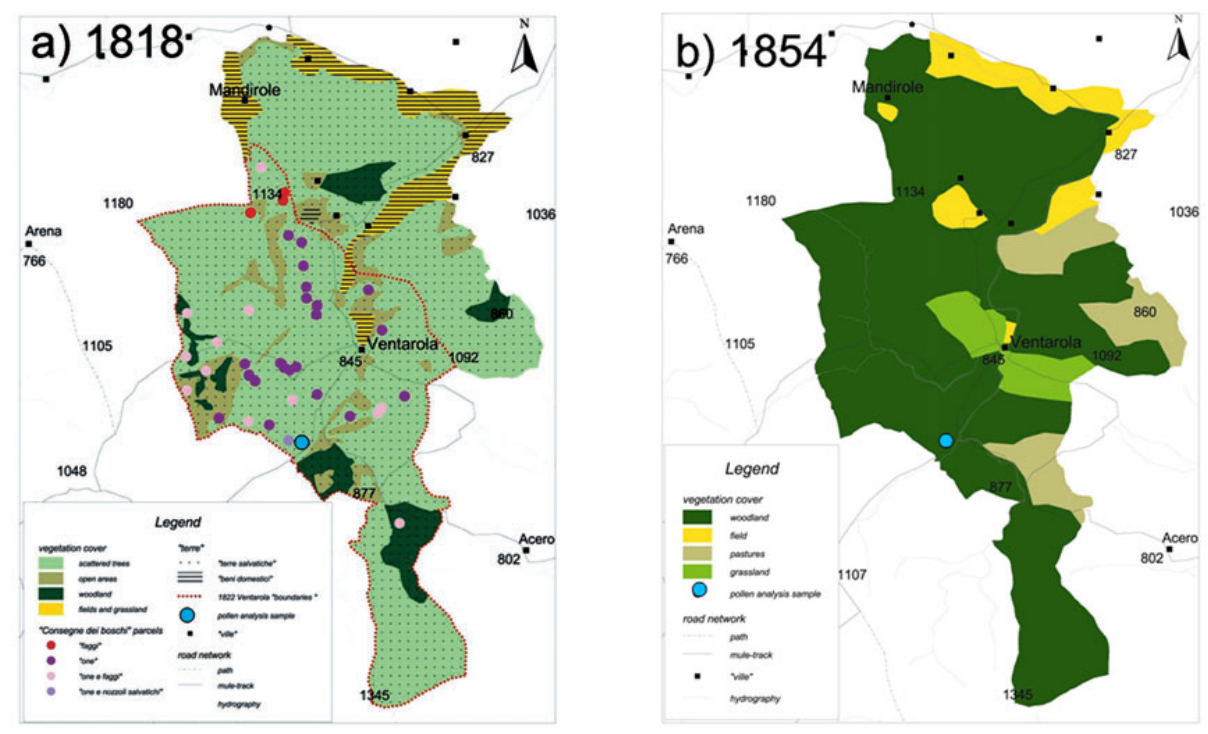

Fig. 7. a-d). Maps outcome from the cartographic filtration.
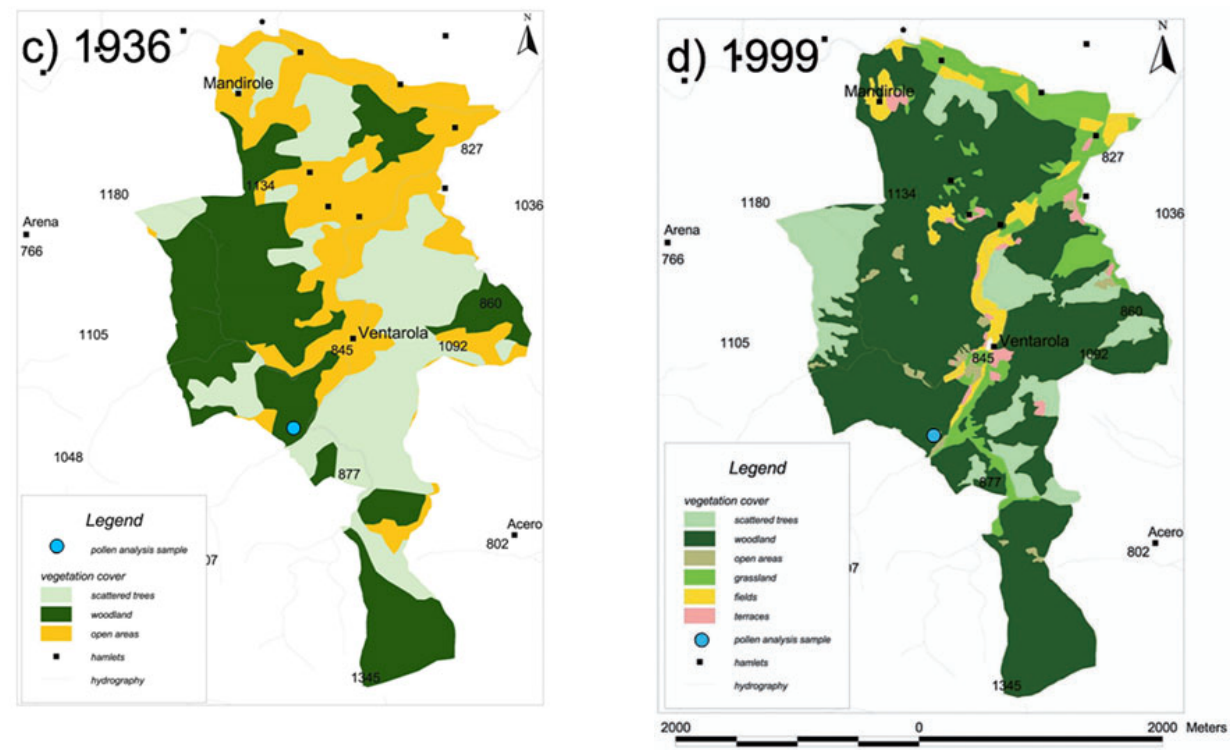

practices in which the settlement and the surrounding areas were involved through time has been tested.

For this reason, in November 2007 a soil profile $40 \mathrm{~cm}$ deep was sampled every $5 \mathrm{~cm}$ in a historically documented site of alnocoltura in the surroundings of Piaggia di San Rocco, at $867 \mathrm{~m}$ a.s.l. (UTM: $4922409 \mathrm{~N}$; 0524510E), close to the rural hamlet of Ventarola (fig. 8a, b). Today the sampled parcel is an abandoned coppiced alder wood, mixed with turkey oaks (Quercus cerris L.) and hawthorns (Crataegus monogyina Jacq.). The herb layer is characterised by bracken (Pteridium aquilinum (L.) Kuhn) and bramble (Rubus hirtus W. et K.). Wooded pastures are present in the surroundings.

Lithology, stratigraphy and Munsell soil colors of the different layers of the soil profile were described in the field. Sub-samples of $2 \mathrm{~cm}^{3}$ were taken for pollen and microcharcoal analysis throughout the soil profile and one surface moss sample was collected and analyzed for the study of the recent pollen rain ${ }^{6}$. Soil $\mathrm{pH}\left(\mathrm{H}_{2} \mathrm{O}\right)$ was measured with standard technique (Thunjai, Boyd 2001).

According to Davidson et al. (1999), despite problems due to bioturbation, percolation, preservation and anthropogenic disturbance, pollen assemblages in soils can be useful indicators for environmental and land-use reconstruction

6. Lycopodium tablets were added to the samples (Stockmarr 1971), which were processed using standard laboratory preparation (Moore, Webb, Collinson 1991). Pollen grains and spores were identified with a binocular microscope at $400 \mathrm{x}$ magnification and a minimum of 200 pollen grains (due to their low concentration) was counted at each level. Nomenclature follows Reille (1992). The number of micro-charcoal fragments bigger than $10 \mu \mathrm{m}$ was counted in the slides prepared for pollen analysis. 

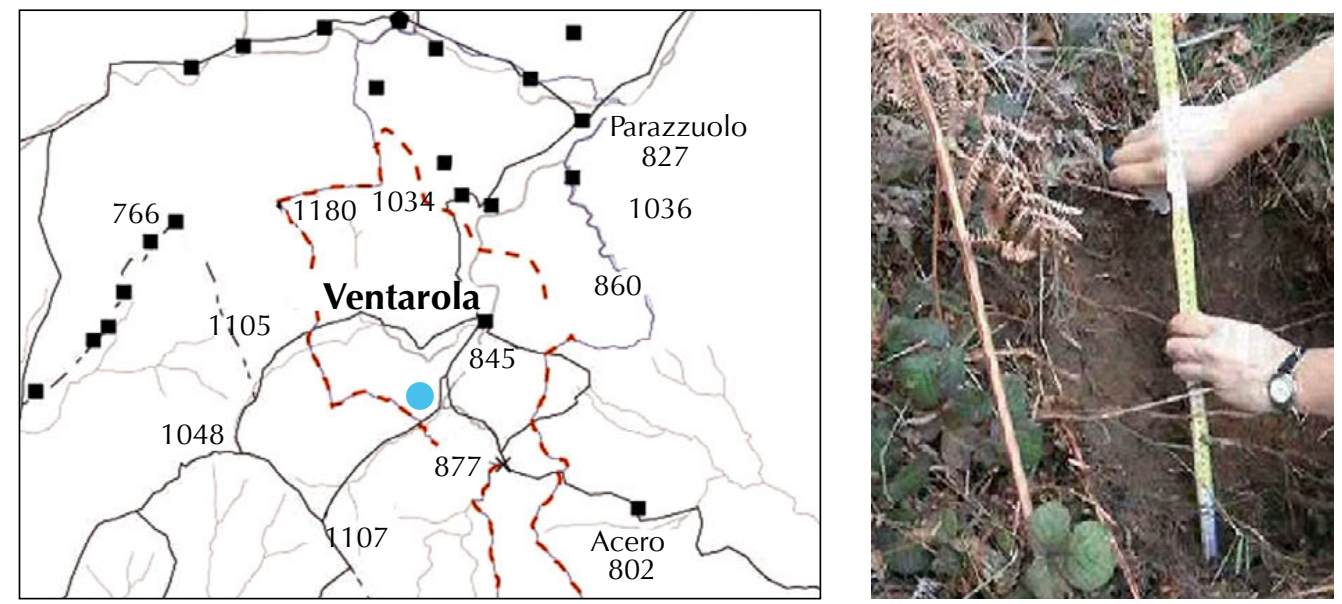

Sampled parcel for pollen analysis

a

Fig. 8. a) Localization of the parcel sampled for pollen analysis and b) picture of the soil profile.

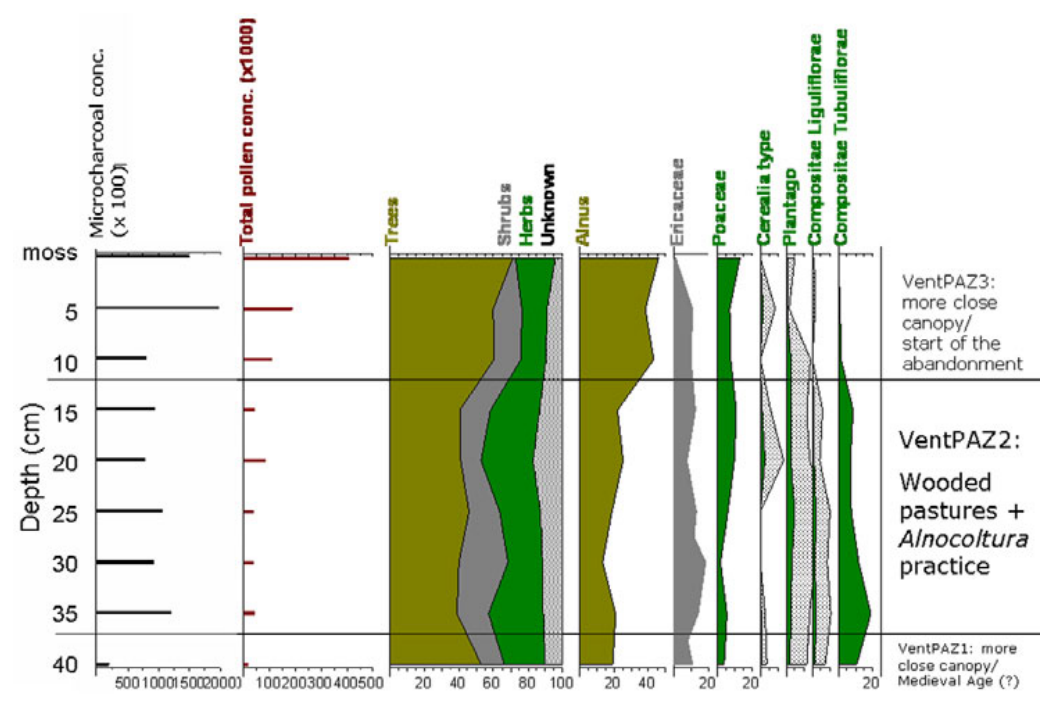

Fig. 9. Synthetic pollen diagram showing the most important taxa characterizing vegetation composition dynamics and land-use changes near Ventarola during the time period recorded. from small, defined catchments at least over the last few centuries. Although different opinions on soil palynology, Dijkstra \& van Mourik (1995) and Segerström (1991) stressed that pollen extracted from acid forest soils can be stratified and provide a record of vegetation history.

At the Ventarola site, pollen data suggest that a sort of stratigraphy of the acid brown/light yellowish brown soil analyzed can be assumed. At the moment, the lack of radiocarbon dating prevents a chronologically control. However, the presence of some pollen markers, together with historical and archaeological information, allowed an indirect dating of the pollen diagram.

The diagram has been divided into three pollen zones on the base of the most important vegetation and land-use changes (fig. 9).
In particular, in the more ancient pollen zone, palynological data show a quite open arboreal canopy dominated by Alnus, while Ericaceae (mainly Erica) and Compositae tubuliflorae, followed by Poaceae undiff. represent the non arboreal pollen component. The steady presence throughout the profile of quite high percentages undifferentiated pollen grains, could be due to an high soil oxidation which causes degradation of botanical plant remains (Dimbleby 1957). In spite of the current lack of radiocarbon dating, according to the presence of Abies (still persistent locally within the Liguria mountains in the Middle Ages, Macphail 1988, Branch 2004, Gentile et al. 1988, Lowe et al. 1994), and to the low microcharcoal concentration (suggesting the absence of any form of burning practices), this phase could be set at the Medieval times. 
In the second phase, the landscape is even more open and it is dominated by non-arboreal components, suggesting the presence of wooded-pastures with scattered trees. The higher and quite constant microcharcoal concentration indicates an increased use of fire, probably connected to the spreading of temporary agricultural practices (ronchi), testified by the archival documents between 1720 and 1822 . Due to the Alnus dominance (but with moderate percentages showing the absence of a forest cover), the practice of the alnocoltura can be argued. Another possible indicator of the use of this particular system is testified by the presence of taxa connected to mowing, grazing and cultivation practices (Behre 1986; Hjelle 1998, 1999). The increase of Calluna and Erica could be due to their greater spreading after fires, but also to the fact that Ericaceae are normally favored by mowing.

Finally, the most recent zone of the pollen diagram, in accordance with the historical cartography, shows a postcultivation picture, with the progressive closure of the forest canopy due to the abandonment of temporary agricultural practices, also testified by the lower microcharcoal concentration in the first part of this phase.

\subsection{Conclusion}

Reconstructing techniques for the exploitation of environmental resources, even not far in the past, it is always difficult and complex. Nonetheless, documentary or observational sources can be hard to decipher singularly. Therefore, a multidisciplinary approach, according to the method of historical ecology, can result successful.

In this case, encouraging results have been obtained by matching, the results of building archaeology and soil pollen analysis, in a historical frame based upon documentary sources.

Different kind of sources that singularly could seem inadequate, when put together can allow a more precise description of the past management of the environmental resources. Actually, it has been pointed out the strict correlation between changes in vegetation cover, modifications in the past management practices and variations in exploiting buildings and in the organization of small rural settlements.

\section{References}

Apat 2007: APAT - Gli indicatori del clima in Italia nel 2006. Rapporto stato dell'ambiente APAT 11/2007.

Behre 1986: BEHRE (K.E.) - Anthropogenic indicators in pollen diagrams. Rotterdam/Vienna, A.A. Balkema, 1986, 232 p.
Bertolotto, Cevasco 2000a: BERTOLOTTO (S.), CEVASCO (R.) - Fonti osservazionali e fonti testuali. Le "consegne dei boschi” ed il sistema dell'“alnocoltura" nell'Appennino ligure orientale (1822). Quaderni Storici, 103, a. XXXV, n.1, 2000, p. 87-108.

Bertolotto, Cevasco 2000b: BERTOLOTTO (S.), CEVASCO (R.) - The "Alnoculture" System in the Ligurian Eastern Apennines: Archive Evidence. In: AGNOLETTI (M.), ANDERSON (S.) dir., Methods and Approaches in Forest History, Wallingford, CAB International 2000, p. 169-182.

Branch 2004: BRANCH (N.) - Late Würm Lateglacial and Holocene environmental History of the Ligurian Apennines, Italy. In: BALZARETTI (R.), WATKINS (C.), PEARCE (M.) dir., Ligurian landscapes, studies in archeology, geography \& history, Accordia Research Institute, University of London, Vol. 10, 2004, p. 7-69.

Cevasco 2007 : CEVASCO (R) - Memoria verde. Nuovi spazi per la geografia, Reggio Emilia, Edizioni Diabasis, 2007, 300 p.

Cevasco, Moreno, Stagno 2008: CEVASCO (R.), MORENO (D.), STAGNO (A.M.) - Geographie historique et archeologie environnementale des bâtiments ruraux: quelques notes de terrain sur l'habitat animal dans un site des Apennins ligures (Nord-Ouest de l'Italie) du XVII ${ }^{\mathrm{e}}$ au $\mathrm{XX}^{\mathrm{e}}$ siecle. In: TROCHET (J.-R.) dir., Les maisons paysannes en Europe occidentale $X V^{e}-X X^{e} s$., Paris, Presses de l'Université ParisSorbonne, 2008, p. 71-80.

Cevasco, Poggi 1999: CEVASCO (R), POGGI(G.) - Per una definizione storica del patrimonio rurale delle Valli Monregalesi: alpeggi della "raschera". In: GALANTE GARRONE (G.), GRISERI (A.), LOMBARDINI (S.), MAMINO (L.), TORRE (A.) dir., Le risorse culturali delle valli monregalesi e la loro storia, Savigliano, L'Artistica Savigliano, 1999, p. 9-29.

Cevasco, Poggi 2000: CEVASCO (R), POGGI (G.) - L'alpe, l'arbre et le lait. Pour une valorisation environnementale et culturelle des produits de terroir de la montagne ligure (Italie). Sud-Ouest Europèen, 7, Toulouse, Presses Universitaires du Mirail, 2000, p. 35-47.

Cevasco, Tigrino 2008: CEVASCO (R.), TIGRINO (V.) - Lo spazio geografico: una discussione tra storia politico-sociale ed ecologia storica. Quaderni Storici n. 127, a. XLIII, 1, 2008, p. 207-242.

Daniere, Capellano, Moirud 1986: DANIERE (C.), CAPELLANO (A.), MOIRUD (A.) - Dynamique de l'azote dans un peuplement natural d'Alnus incana L., Moench. Acta Oecologia/Oecologia Plant, 7, 1986, p. 165-175.

Davidson et al. 1999: DAVIDSON (D.A.), CARTER (S.), BOAG (B.), LONG (D.), TIPPING, (R.), TYLER (A.) Analysis of pollen in soils: processes of incorporation and redistribution of pollen in five soil profile types. Soil Biology \& Biochemistry, 31, 5, 1999, p. 643-653.

Dijkstra, Van Mourik 1995 : DIJKSTRA (E.F.), VAN MOURIK (J.M.) - Palynology of young acid forest soils in the 
Netherlands. Mededelingen Rijks Geologiche Dienst, 52, 1995, p. 283-295.

Dimbleby 1957: DIMBLEBY (G.W.) - Pollen analysis of terrestrial soils. New Phyytol., 56 1957, p. 12-28.

Gentile et al. 1988: GENTILE (S.), GUIDO (M.A.), MONTANARI (C.), PAOLA(G.), BRAGGIO MORUCCHIO (G.), PETRILLO (M.) - Ricerche geobotaniche e saggi di cartografia della vegetazione del piccolo bacino di lago Riane (Liguria). Braun-Blanquette, 2, 1988, p. 77-104.

Hjelle 1998: HJELLE (K.L.) - Herb pollen representation in surface moss samples from mown meadows and pastures in western Norway. Veget Hist Archaeobot 7, 1998, p. 79-96.

Hjelle 1999: HJELLE (K.L.) - Modern pollen assemblages from mown and grazed vegetation types in western Norway. Rev. Palaeobot. Palynol., 107, 1999, p. 55-81.

Lowe et al. 1994 : LOWE (J.J.), DAVITE (C.), MORENO (D.), MAGGI (R.) - Holocene pollen stratigraphy and human interference on the woodlands of the northern Apennines, Italy. The Holocene. An International Journal focusing on recent environmental change, 4, 2, 1994, p.153-164.

Macphail 1988: MACPHAIL (G.M.) - Pollen Stratigraphy of Holocene peat sites in eastern Liguria, northern Italy. $\mathrm{PhD}$ Thesis, City of London Polytechnic (unpublished), $202 \mathrm{p}$.

Maggi et al. 2006: MAGGI (R.), DE PASCALE (A.), GUIDO (M.A.), MANNONI (T.), MONTANARI (C.), MORENO (D.) - Per un'archeologia delle Cinque Terre. In MUSSO (S.F.), FRANCO (G.) ed., Guida agli interventi di recupero dell'edilizia diffusa nel Parco Nazionale delle Cinque Terre. Venezia, Marsilio, 2006, p. 45-59.

Mannoni 1984 : MANNONI (T.) - Metodi di datazione dell'edilizia storica. Archeologia Medievale, XI, 1984, p. 396-403.

Mannoni 1998: MANNONI (T.) - Analisi archeologiche degli edifici con strutture portanti non visibili. Archeologia dell'Architettura III, 1998, p. 81-86.

Molinari, Stagno 2009: MOLINARI (C.), STAGNO (A.M.) Agro-sylvi-pastoral resources at Ventarola (Rezzoaglio, GE) between the 16th and the 20th century A.D. Poster submitted at the International Meeting Wetlands as archives of the cultural landscapes: from research to management, Genoa, 29-30 January 2009. http://www.dismec.unige.it/zum/.

Moore, Webb, Collinson 1991 : MOORE (P.D.), WEBB (J.A.), COLLINSON (M.E.) - Pollen Analysis. Oxford, Blackwell, 1991, 216 p.

Moreno 1990: MORENO (D.) - Dal documento al terreno. Storia e archeologia dei sistemi agro-silvo-pastorali, Il Mulino-Ricerche, Bologna, 1990, p. 276.

Moreno 1996 [1997] : MORENO (D.) - Pastori e serpi nelle Alpi Liguri (1890-1990). In: MORNET (E.), MORENZONI (F.) dir., Milieux naturels, espaces sociaux. Études offertes à $R$. Delort, Paris, Publications de la Sorbonne, Histoire ancienne et médiévale, 47, 1997, p. 313-325.
Moreno et al. 1992: MORENO (D.), CROCE (G.E.), GUIDO (M.A.), MONTANARI (C.) - Pine Plantations on Ancient Grassland: Ecologoical Changes in the Mediterranean Mountains of Liguria, Italy During the 19th and 20th centuries. In WATKINS (C.) (Editor) The Ecological Effects of Afforestation. Oxford C.A.B., cap. VII, 1992, p. 93-110.

Moreno et al. 1998: MORENO (D.), CEVASCO (R.), BERTOLOTTO (S.), POGGI (G.) - Historical ecology and post-medieval management practices in alder woods (Alnus incana (L.) Moench) in the northern Apennines, Italy. In: KIRBY (K.), WATKINS (C.) dir., The Ecological History of European Forests, CAB International, vol. 2, 1998, p. $185-201$.

Moreno et al. 2004: MORENO (D.), MONTANARI (C.), GUIDO (M.A.), POGGI (G.) - Historical vegetation dynamics: archive and pollen evidence for ancient grassland and plantations in nineteenth century Liguria (NW-Italy). In: MAZZOLENI (S.), DI PASQUALE (G.), MULLIGAN (M.), DI MARTINO (P.), REGO (F.). (Ed.), Recent Dynamics of the Mediterranean Vegetation and Landscape, Chichester, Wiley, 2004, p. 179-187.

Moreno et al. 2005 : MORENO (D.), CEVASCO (R.), GUIDO (M.A.), MONTANARI (C.) - L'approccio storico archeologico alla copertura vegetale: il contributo dell'Archeologia ambientale e dell'Ecologia storica. In CANEVA (G.) (Ed.), La Biologia vegetale per $i$ Beni Culturali. Vol. II Conoscenza e Valorizzazione. Firenze, Cardini Editore, 2005, p. 463-498.

Moreno, Cevasco 2006: MORENO (D.), CEVASCO (R.) Un territorio alimentare da ricomporre. In: CASSINI (G.) dir., L'identità perduta. I musei contadini della provincia di Imperia, Torino, Allemandi, 2006, p. 41-47.

Raggio 1990 : RAGGIO (O.) - Faide e parentele. Lo stato genovese visto dalla Fontanabuona, Einaudi, Torino, 1990, 260 p.

Reille 1992: REILLE (M.) - Pollen and spores D'Europe et D'Afrique du Nord, Marseille, Laboratoire de Botanique Historique et Palynologie, 1992, 520 p.

Scarin 1957: SCARIN (E.) - La casa rurale nella Liguria, Genova, Fratelli Pagano, 1957, 205 p.

Sergerström 1991: SERGERSTRÖM (U.) - Soil pollen analysis: an application for tracing ancient arable fields. Journal of Archaeological Science, 18, 1991, p. 165-175.

Stagno in press: STAGNO (A. M.) - Geografia degli insediamenti e risorse ambientali: un percorso tra fonti archeologiche e documentarie (Ventarola, Val d'Aveto, Rezzoaglio GE). In: MACCHI JANICA (G.) dir., Geografie del Popolamento. Casi di studio, metodi e teorie, Actes des colloques de Grosseto (2008).

Stockmarr 1971 : STOCKMARR (J.) - Tablets with spores used in absolute pollen analysis. Pollen et Spores 13, p. 615-621.

Thunjai, Boyd 2001: THUNJAI (T.), BOYD (C.E.) - Pond soil $\mathrm{pH}$ measurement. Journal of the World Aquaculture Society, 32, 2001, p. 141-152. 


\title{
L'exploitation pastorale des territoires de confins de la haute vallée de la Roya à travers les sources écrites ( $\mathrm{XII}^{\mathrm{e}}$-XVIII ${ }^{\mathrm{e}} \mathrm{S}$.). Contribution à une approche pluridisciplinaire
}

\author{
Juliette LASSALLE*, Béatrice PALMERO**
}

\begin{abstract}
Résumé. Nous livrons les résultats des recherches menées sur les pâturages de confins de la haute vallée de la Roya (France/Italie) à partir des sources écrites (périodes médiévale et moderne) et cartographiques. Cette démarche s'inscrit dans une approche diachronique et dans une dynamique pluridisciplinaire visant à confontrer les résultats tirés de l'archéologie et de l'histoire à travers l'analyse spatiale des données livrées par les textes et par le terrain. Les territoires choisis ici se situent en altitude (Parc du Mercantour/Parco regionale Alta Valle Pesio e Tanaro), zone délaissée par les récentes publications consacrées à la transhumance dans les Alpes. Ils se définissent avant tout par l'exploitation des ressources, tant coutumière que commerciale, à travers une série de droits d'usage dans le cadre d'une économie montagnarde fondée sur l'élevage (pâturages de proximité), la transhumance à courte, moyenne et longue distances et l'exploitation du bois. Entre le milieu du XII et la fin du XVII ${ }^{e}$ s., ces territoires ont été dotés de structures liées à l'économie pastorale qui ont laissé une empreinte plus ou moins pérenne sur le territoire (enclos, cabanes pour la fabrication des fromages, abris des bergers, vayles). Les limites de juridiction et de droits d'exploitation des différents ayants-droits ont été matérialisées sur le terrain par l'implantation de bornages successifs associant des éléments anthropiques (bornes de pierre, chemins) et naturels (cours d'eau, croix gravées dans les rochers). Le déplacement des troupeaux et des hommes a également été codifié selon un ensemble d'itinéraires autorisés (drailles), parfois selon les saisons en fonction de la montée ou de la descente des alpages. Ces itinéraires associent l'accessibilité, la proximité de l'eau pour le bétail et les hommes ainsi que celle des zones boisées (branchages pour la construction des enclos, des cabanes et des abris, bois de chauffage, nourriture des troupeaux). Cette contribution se conçoit donc comme un point d'appui au référentiel chronologique de l'exploitation des écosystèmes des pâturages d'altitude par les communautés d'habitants locales.
\end{abstract}

Pastoral use of lands at the confines of upper Roya valley, based on written $12^{\text {th }}$ to $17^{\text {th }}$ century documents.

Contribution to a pluridisciplinary study

Abstract. We present the results of studies carried out on pastures at the confines of the upper Roya valley (between France and Italy), based on both mediaeval and contemporary documents and maps. This study was part of diachronic project involving the use of a dynamic multidisciplinary approach, in which it was proposed to compare the results of archaeological and historical studies and to perform spatial analyses on data based on written texts and obtained on the field. The territories selected for this purpose were located at high altitudes (in the Parc du Mercantour and the Parco regionale Alta Valle Pesio e Tanaro), regions somewhat neglected by recent studies on Alpine patterns of transhumance. It was proposed in particular to describe the use made of traditional and trading resources during various periods by examining a set of customary rights and practices in the framework of a mountain economy mainly involving sheep-raising activities (due to the availibily of pastures), including short, medium and long-distance transhumance movements and woodworking activities. Between themed-1 $12^{\text {th }}$ century and the late $17^{\text {th }}$ century, these territories were equipped with typically pastoral structures leaving variably durable traces (enclosures, cheese-making huts, shelters for sheperds, vayles). The legal boundaries and the rights of various heirs were materialized on the field by series of boundary markers consisting of both man-made signs (stones, paths) and natural features (streams, crosses engraved on rocks). The movements of herds and men were also codified in the form of a set of authorized itineraries (sheep parts), sometimes depending on the seasons, according to the wether the sheep were being driven up to their Alpine pastures or down again. These itineraries were selected on the basis of characteristics such as their accessibility of water for the herds and shepherds and the proximity of woodlands areas (providings branches for building enclosures, huts and shelters, firewood and food for the herds). This paper therefore sets the foundations for chronological description of how local communities of inhabitants used high-altitude pasture ecosystems.

\footnotetext{
* Laboratoire de Médiévistique Occidentale de Paris, UMR 8589 CNRS - Université de Paris I Panthéon Sorbonne, 1 rue Victor Cousin, 75005 Paris. ** Laboratoire d'Histoire des Alpes USI-Academia di Architettura, LabiSAlp Mendrisio (Suisse), Via ville 30, I18039 Ventimiglia, Imperia (Italie).
} 
$\mathrm{L}$ e travail que nous présentons ici livre les résultats d'une enquête menée sur les pâturages de confins que constitue le territoire de Malaberga, situé dans la haute vallée de la Roya (Alpes-Maritimes). Cette enquête s'appuie sur une importante production documentaire qui provient essentiellement des procédures de règlement des conflits sur les confins de territoire qui ont opposé les communautés de Tende et de La Brigue selon une fourchette chronologique qui s'étend du milieu du XII ${ }^{\mathrm{e}}$ au milieu du XVIII ${ }^{\mathrm{e}} \mathrm{s}$. Cette documentation, essentiellement écrite, livre, dans le cadre de procédures judiciaires (sentences seigneuriales, procès) ou infrajudiciaires (compromis et arbitrages), les étapes successives de délimitations territoriales et permet d'en reconstituer la chronologie au cours du Moyen Âge puis de la période moderne. Ces délimitations s'appuient sur de nombreux micro-toponymes qui permettent de les restituer dans l'espace et qui fixent le territoire juridique au sein duquel chaque communauté, ensemble ou alternativement, est autorisée à exploiter les ressources locales. Les modalités de cette exploitation s'appuient sur une codification précise des droits d'usages et de leurs conditions d'exercice. Ces droits d'exploitation relèvent essentiellement du domaine pastoral et concernent à la fois le déplacement des troupeaux dans le cadre de simples remues des troupeaux de la vallée ou des vallées voisines, le développement de la transhumance sur de moyennes ou de longues distances, l'exploitation des pâturages et du bois. L'organisation territoriale de ces deux communes à l'époque moderne (fin $\mathrm{XVI}^{\mathrm{e}}$ s.-moitié XVII ${ }^{\mathrm{e}} \mathrm{s}$.) nous fournit d'autres données descriptives à partir de la réglementation et de l'enregistrement des lieux de pâturage au cadastre savoyard (début du $\mathrm{XVIII}^{\mathrm{e}} \mathrm{s}$.). Les toponymes lient alors droits d'appartenance, de possession et d'usage du territoire de l'époque moderne à une exploitation strictement pastorale de l'espace qui relevait d'accords remontant au Moyen Âge. Le croisement des données textuelles et cartographiques nous permet de proposer une analyse spatiale du territoire qu'il reste à confronter à des données archéologiques de terrain fiables dont nous ne disposons pas encore dans cette région. C'est donc essentiellement à travers les sources écrites issues de l'administration communale ou judiciaire que nous tenterons de suivre les transformations de l'espace pastoral alpin situé aux confins des terres de La Brigue et de Tende.

Le toponyme de Malaberga est employé dès la seconde moitié du XII ${ }^{\mathrm{e}}$ s. sous la forme plastra Madalberga par les hommes de Tende et de La Brigue. Cette forme toponymique désigne un plateau qui constitue un espace de confins à vocation pastorale entre les deux communautés. Cet espace est aujourd'hui encore défini comme une «enclave de la commune de La Brigue » qui se trouve séparée du territoire communal de La Brigue par celui de Tende. Il confine désormais avec les crêtes qui constituent aujourd'hui la frontière franco-italienne entre le département français des
Alpes-Maritimes et le Piémont italien. Il s'agit donc d'une terre d'altitude dévolue au pastoralisme depuis des siècles, même si l'ensemble de la vallée de la Roya reste absente des récentes publications consacrées à la transhumance dans les Alpes (Jourdain-Annequin, Duclos 2006). Partant de la formation du territoire de Malaberga, cette étude se propose dans un premier temps de décrire la méthodologie sur laquelle s'appuie la reconstitution topographique de l'organisation des terres pastorales qui constituent les confins de haute vallée de la Roya.

\section{La reconstruction topographique des limites de pâturages de confins : de la micro-toponymie à la délimitation territoriale}

La première étape de ce travail réside dans la constitution d'un corpus documentaire cohérent qui permet de suivre la formation de l'espace pastoral de Malaberga sur une longue période historique (milieu du XII -début du $\mathrm{XVIII}^{\mathrm{e}} \mathrm{s}$.). Les premiers documents qui mentionnent explicitement le territoire de Malaberga remontent aux années centrales du XII ${ }^{\mathrm{e}}$ s. Il s'agit de cinq sentences judiciaires rendues entre 1162 et 1169 pour régler les différends territoriaux qui opposent alors Tende et La Brigue au sujet de leurs confins ${ }^{1}$. On peut probablement rattacher à ce dossier documentaire une notice de plaid de 1149 qui fait état d'une guerre qui aurait alors opposé les habitants de Tende

1. Parmi ces cinq documents, deux sont les parchemins originaux des sentences rendues le 15 octobre 1162 sous l'autorité du légat impérial de Frédéric I ${ }^{\text {er }}$ Barberousse en Italie du Nord pour régler le conflit territorial qui oppose les deux communautés. Ces originaux d'un contenu identique sont conservés au Musée des Merveilles de Tende et dans les archives privées de la famille Alberti della Briga. On en trouve une copie complète et un extrait dans le recueil d'actes du notaire Guidi de Tende (seconde moitié du XVe s., circa 1470-1472), Archives Départementales des Alpes-Maritimes (désormais A.D.A.M.), $1 \mathrm{Mi}$ 12 R 12 (micro-films), document n. 136, fol. 25 v., document n. 2, 15 octobre 1162 (copie intégrale) et fol. 26 r., document n. 3, extrait. Deux autres sentences sont rendues en 1163. Nous n'en conservons que des copies médiévales issues de l'inventaire cité précédemment (seconde moitié du XV ${ }^{e} s$.). L'un de ces deux documents est une sentence arbitrale qui reprend la délimitation du territoire attribué à Tende par le tribunal féodal qui se réunit à Borgo San Dalmazzo le 5 juillet 1163 . La seconde sentence reprend les dispositions de l'année précédente au sujet des territoires de Malaberga et des Bois. A.D.A.M.), 1 Mi 12 R 12, document n. 136, fol. 26 r.-v., document n. 4, 5 juin 1163. Acte de division territoriale entre Tende et La Brigue, validée par le tribunal féodal le 5 juin 1163, A.D.A.M., idem, fol. 26 v. -27 r., document n. 5,5 juin 1163 . Le dernier document est une sentence arbitrale rendue par l'évêque de Vintimille dans le litige opposant Tende et La Brigue au sujet des territoires de Malaberga et De Bosco en 1169, A.D.A.M., idem, fol. 27 v.-28 r., document n. 8, 23 avril 1169, copie médiévale. L'original de cet inventaire est conservé à l'Archivio di Stato di Torino (désormais A.S.T.), fonds "Città e Contado di Nizza », mazzo 51, « Tende, Limone e Vernante », document n. 1. 
et de La Brigue ${ }^{2}$. Ces sentences fixent à la fois les limites territoriales des deux communautés dans la partie la plus septentrionale de la vallée de la Roya et les droits que les hommes de La Brigue pouvaient ou non exercer sur les terres tendasques lorsqu'ils traversaient ces dernières pour rejoindre leurs terres de Malaberga. Après 1169, nous ne trouvons plus de litiges territoriaux concernant le territoire de Malaberga qui semble être passé sous le contrôle exclusif de La Brigue. C'est l'accès à ce territoire, qui impose aux Brigasques de traverser le territoire de Tende, qui suscite de nouvelles querelles dans les dernières années du XIII $\mathrm{S} .^{3}$. Les sentences rendues en 1282 et confirmées 1284 par les comtes de Vintimille réaffirment les droits de passage de La Brigue sur le territoire de Tende pour rejoindre Malaberga et exigent des syndics qui représentent la communauté de Tende qu'ils s'engagent à ne plus perturber, ni inquiéter les hommes de La Brigue lors de ces déplacements. Les deux communautés s'accordent ensuite sur les modalités de l'exploitation des ressources des territoires traversés par les Brigasques pour rejoindre Malaberga à travers une codification complexe, notamment dans le domaine pastoral et forestier ${ }^{4}$. Au cours du premier tiers du XIV s., le territoire tendasque de Trevellega puis ceux de Bachiolo et d'Orno sont institués en «bandites » par la communauté : ce sont désormais des territoires de pâturages réservés et bornés, que la communauté de Tende cède en adjudication à des particuliers avec les droits attachés à ces territoires pour une période donnée ${ }^{5}$ Ces terres se localisent en deçà de la fraction territoriale attribuée à La Brigue sur l'adret du vallon de Bachialon actuel ${ }^{6}$. Dès lors les conditions de traversée des troupeaux de La Brigue s'en trouvent modifiées

2. Ce document n'est conservé que sous la forme d'un extrait qui fut copié au cours de la seconde moitié du $\mathrm{XV}^{\mathrm{e}} \mathrm{s}$. par le notaire Guidi de Tende. Cet extrait ne précise pas l'objet de la querelle. A.D.A.M., $1 \mathrm{Mi}$ 12 R 12 (micro-films), document n. 136, fol. 25 v., document n. 1, 1149, extrait et A.S.T., fonds « Città e Contado di Nizza », mazzo 51, « Tende, Limone e Vernante », document n. 1 (original), fol. 25 v., document n. 1 . L'analyse de cet inventaire et son contenu étudié par Lassalle, 2008, p. 204-252 et p.324-348 sont en cours de publication.

3. Archives Municipales de Tende (désormais A.M.T.), Catégorie VII, dossier n. 8, « Recueil Lanteri », fol. 5-38 et 41-44 (1282-1284).

4. Jugement prononcé par Guido de Susaria, docteur en loi, en faveur de Tende sur les controverses entre Tende et La Brigue au sujet des litiges territoriaux sur le territoire dit « Des Bois » ou Nemorum et sur le territoire de Malaberge. A.D.A.M., 1 Mi 12 R 12, document n. 136, fol. 29 r., document n. 13, circa 1291, extrait. Au cours de la même période, plusieurs contentieux opposent les communautés de Tende et de Limone sur les terres situées à l'Ouest de Malaberga.

5. A.M.T., Catégorie I -Parchemins, document n. 26, 17 mars 1326, adjudication de la bandite de Trevellega à Jean Jordana pour neuf ans en échange de l'extinction d'une dette que la communauté avait envers lui. A.D.A.M., 1 Mi 12 R 12, document n. 136, fol. 31 r., document n. 20, sans date (document de procédure du $X^{e}$ s. qui rappelle les adjudications du début du XIV ${ }^{\mathrm{e}} \mathrm{s}$.).

6. Le vallon de Bachialon actuel correspond au vallon de Celle Vieilles de la période napoléonienne et au vallon Pertegale antérieur. ce qui suscite de nouveaux conflits au cours des XIV et $\mathrm{XV}^{\mathrm{e}} \mathrm{s}$. dont le détail s'est malheureusement perdu. Au cours de la période moderne, dans le cadre de la réorganisation des pouvoirs territoriaux orchestrée par l'administration piémontaise, les communautés se dotent d'instruments pour maîtriser le territoire local ${ }^{7}$. Les statuts communaux de La Brigue ${ }^{8}$ et de Tende ${ }^{9}$ de la fin du XVI ${ }^{\mathrm{e}}$ s. ainsi que le règlement des bandites de la communauté datant de $1645^{10}$ nous fournissent les données toponymiques qui permettent la localisation des terres de pâturage et des passages sur lesquels s'appuient le fonctionnement et la gestion des confins en fonction des différents droits de pâturage qui grèvent le territoire de Malaberga. Le cadastre de La Brigue, réalisé entre 1698 et $1702^{11}$, nous permet de compléter le dossier descriptif de ce territoire et des pâturages de confins à travers l'analyse des micro-toponymes sur lesquels reposent l'articulation des droits d'usage et la possession de terres de pâturage que les villages maîtrisent en tant que finage intercommunautaire. Enfin, les procès-verbaux de délimitations territoriales de la période napoléonienne, qui traçaient les limites de finage entre Tende et La Brigue dans le cadre de la réorganisation administrative et fiscale des départements et des communes, complètent le dossier documentaire de Malaberga $^{12}$. À partir de cette documentation écrite, nous avons procédé à un relevé systématique de toutes les données spatiales sur lesquelles s'appuyaient les règlements des litiges territoriaux opposant Tende et La Brigue dans cette partie de la vallée: micro-toponymes désignant une terre, une couverture végétale, un cours d'eau, un torrent, une zone de pâturage, un col, un sommet ou une draille.

7. Les perspectives des études historiques actuelles appréhendent les statuts des communautés comme des sources à part entière pour 1'histoire des territoires. Ferrières, 2001. La production des statuts de l'ancien «comté de Tende" dans les éditions du XVI $\mathrm{s}$. fait l'objet d'une recherche menée par Casana, 2000. En outre, les statuts des communautés du XVI ${ }^{\mathrm{e}} \mathrm{s}$. reproduisent l'organisation de l'espace local à travers la codification des accords médiévaux et la reprise d'anciennes réglementations. Palmero 2005, p. 431-436.

8. A.D.A.M., 02Mi 039, Statuts de La Brigue (1585), ch. 160, « Confins de la bandite Malberga »; ch. 170, « Confins bandite Seneca » ; ch. 67 «passage pour venir des alpes aux bandites... ». Le manuscrit, dont il n'existe aucune version imprimée, est composé entre 1707 et 1711 . Palmero 2005, p. 731-749.

9. Istituto internazionale Studi Liguri Bordighera (desormais I.I.S.L.) Fondo Rossi, Statuti di Tenda (1579), ch. 62 et 67. Ce manuscrit se termine sur la délibération du conseil communal pour sa publication (20 décembre 1620). Une copie imprimée des statuts de Tende, datée 1621, est conservée à la Bibliothèque royale de Turin.

10. A.D.A.M., Insinuation de Tende, C 3271, c. 483 r.-485 v. « Capitoli in forme ai quali la comunità di Tenda da a suoi creditori in pagamento le bandite et pascui », 7 septembre 1645 , ch 12 et 13 .

11. A.S.T. sezione riunite, Camerale-Estimi e misure catastali, Catasto antico della Briga (1702). Palmero 2005, annexe H, p. 764-774.

12. A.D.A.M., Fonds Consulat et Empire, Délimitation des communes, p. 155, Tende, un cahier, 19 folios, An XI; Idem, p. 117, La Brigue, un cahier, 18 folios, 1806. Lassalle 2008, p. 74-83. 


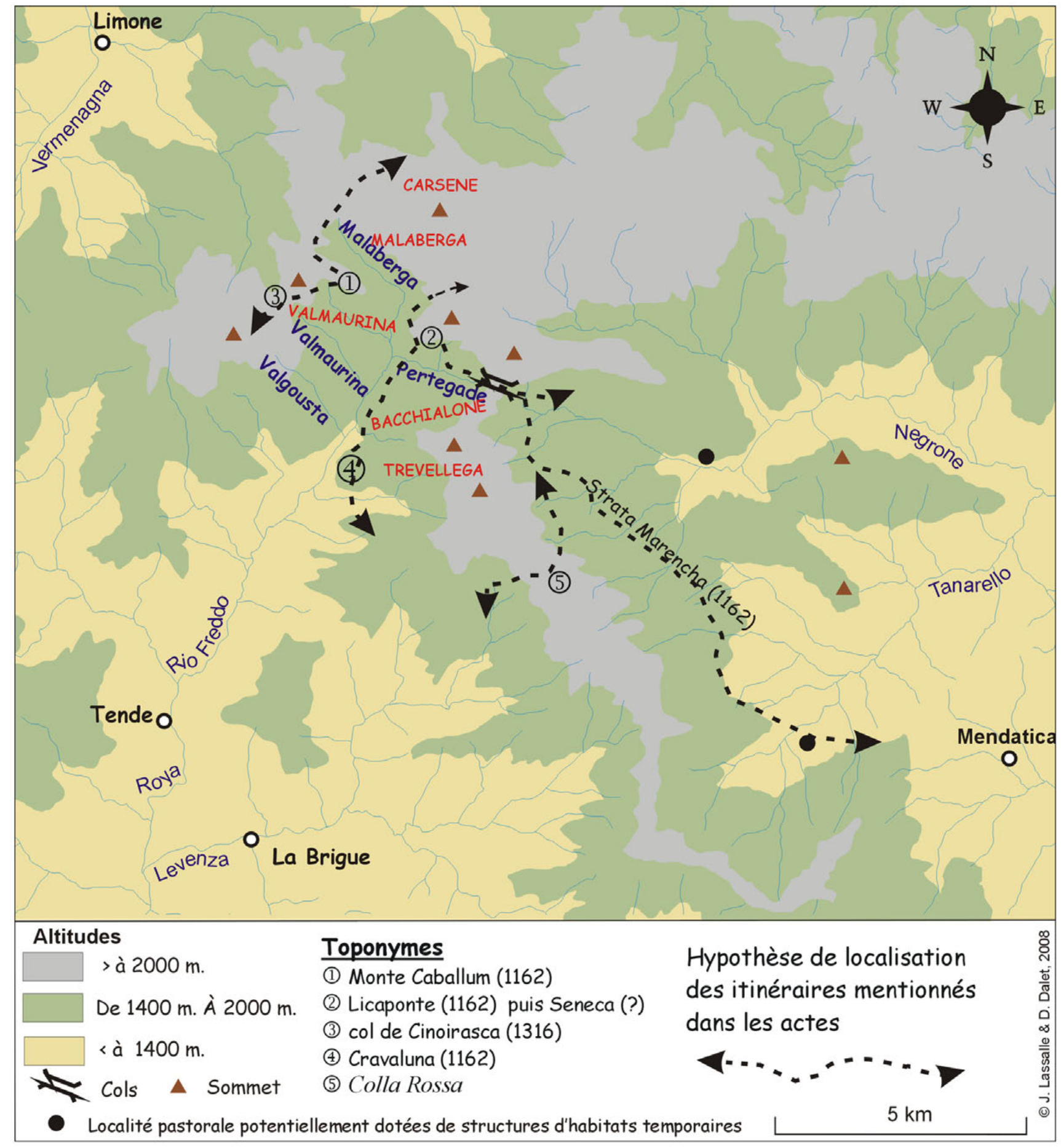

Fig. 1. Localisation des toponymes servant de support aux délimitations territoriales entérinées par les sentences judiciaires de 1162-1169. Les itinéraires représentés sur cette carte ne sont pour le moment que des hypothèses de travail que la confrontation avec d'autres sources et les données de terrain devraient pouvoir préciser. 


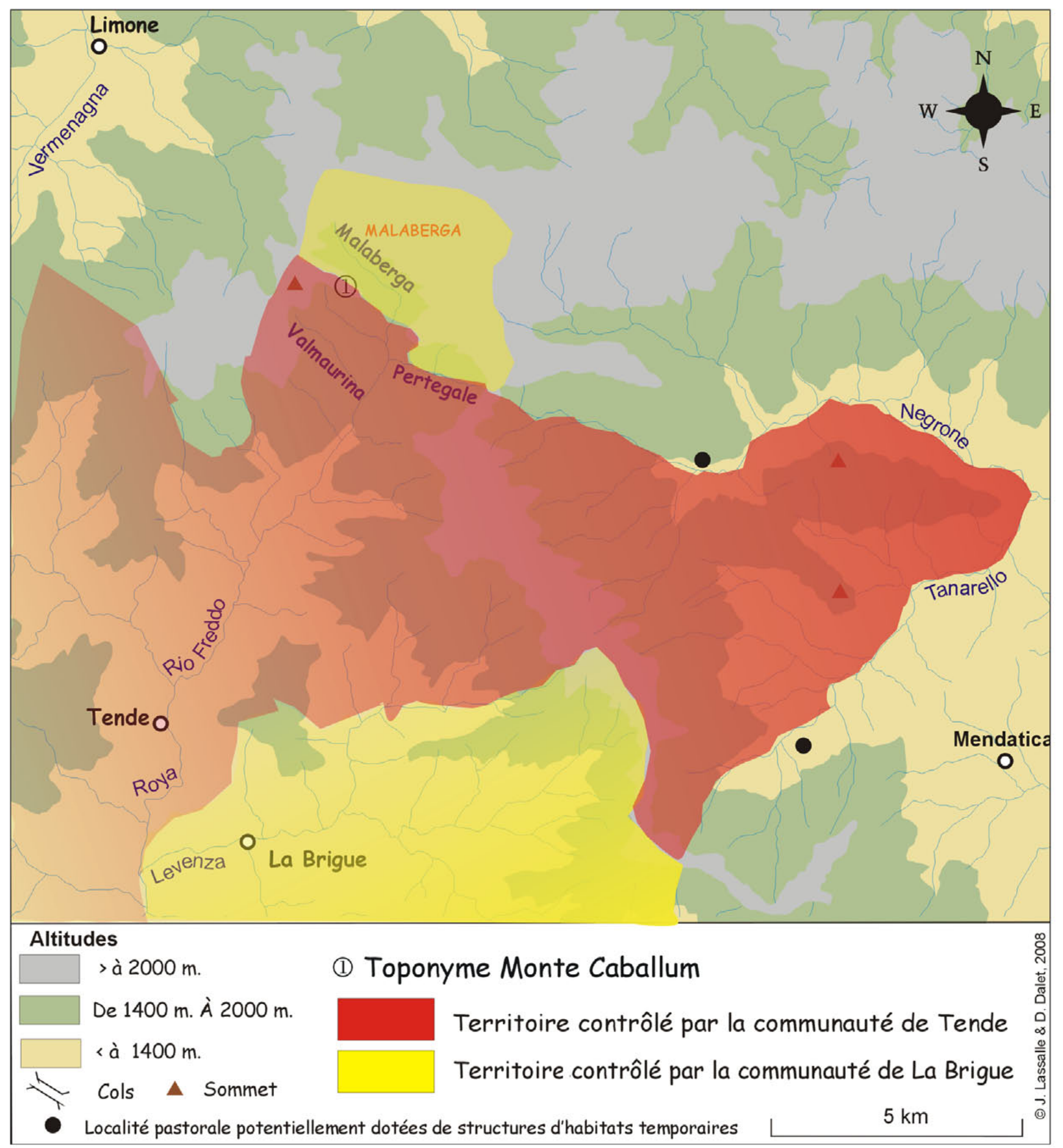

Fig. 2. Proposition de reconstruction territoriale des confins de Tende et de La Brigue à l'issue des délimitations de 1163. 
Dans un troisième temps, l'ensemble de ces données toponymiques a été confronté aux données cartographiques actuelles ${ }^{13}$.

Les données toponymiques révélées par les procédures de règlement des litiges territoriaux du Moyen Âge constituent donc la base documentaire d'une approche micro-analytique des territoires de confins à travers la réglementation et l'organisation territoriale de ces communes à l'époque moderne. En l'absence de représentation cartographique ancienne, la première étape de cette reconstitution consistait à relever les différents micro-toponymes fournis comme support des délimitations territoriales médiévales puis à en retrouver la localisation grâce aux données fournies par les procès-verbaux de délimitation territoriale de la période napoléonienne, puis par les cartes topographiques actuelles. Cette seconde phase du travail a été facilitée par la relative stabilité de la toponymie constatée dans l'ensemble de cette région (Lassalle 2008) ${ }^{14}$. Les divisions territoriales de 1163, reprises en 1266 puis en 1285 fixent la limite territoriale des deux communautés au col de Pertigale dans la zone orientale. La limite suit ensuite le vallon de Pertigade jusqu'à une route qui traverse le plateau de Licaponte et rejoint ensuite le plateau de Maderberga. Puis, la délimitation conduit vers Laschina et vers l'alma de Maderberga, puis on suit la crête de Monte Caballum jusqu'au col de Ciceraste. La confrontation de cette délimitation territoriale médiévale et de celles issues des procédures de délimitation napoléonienne permet d'identifier et de localiser un certain nombre de toponymes: le versant nord de cette colline, le Monte Caballum médiéval, jouxte le vallon de Malaberga. La limite médiévale partait donc du col de Pertigale puis suivait le cours du vallon et remontait probablement la route de Cravaluna citée dans les sentences judiciaires de 1162 pour rejoindre

13. Cartes topographiques italiennes: Limone Piemonte - valle delle Meraviglie - Saint Dalmas de Tende, n. 114, 1/25000, Istituto Geografico Centrale (désormais IG.C.), 1989; Alpi Marittime e Liguri, carta dei sentieri e dei rifugi, n. 8, 1/50000, I.G.C., 1973. Cartes topographiques françaises: Viévola, série orange, n. 3840, 1/50000, I.G.N., n.1991; Vallée de la Roya - vallée des Merveilles, promenades et randonnées balisées, n. 3, 1/25000, I.G.N. et Conseil Général des Alpes-Maritimes, 1990; Marguareis-Mongioie, Alpes sans frontières, les spéciales de l'I.G.N, n. 3, 2002.

14. Il n'est cependant pas rare de trouver plusieurs toponymes proches voire identiques dans les vallées voisines. Ainsi, on trouve sur le versant oriental de la ligne de crête qui sépare La Brigue de la Ligurie actuelle les toponymes «Rocche del Piano Cavallo» et « Cima di Piano Cavallo». Seules la transcription cartographique des délimitations territoriales et une vision globale des litiges territoriaux des communautés de la haute Roya et de ces communautés avec celles des versants voisins permettent de s'assurer de la localisation correcte de ces micro-toponymes. la crête de Monte Caballum qui constituait la limite territoriale des deux communautés dans cette zone ${ }^{15}$ (fig. 1 et 2 ). Cette reconstitution cartographique met en évidence la situation de confins du territoire de Malaberga qui occupe le versant méridional de la ligne de crête qui permet la jonction entre la haute vallée de la Roya et la haute vallée du Pesio mettant ainsi en relation les itinéraires qui permettent de se rendre du Piémont méridional actuel à la Provence orientale d'une part, à la Ligurie occidentale d'autre part. Ce territoire est irrigué de plusieurs itinéraires qui permettent de passer d'un versant alpin à un autre: via Cravaluna, via de Pertigale, viae de Terre Rosse, Strata Marencha, bien que la continuité et la précision de leur tracé nous échappent encore. L'enjeu du litige du XII $\mathrm{S}$. semble résider dans le nécessaire contrôle des cols alpins pour permettre aux communautés de rejoindre leurs terres de pâturage. Alors que la commune de Tende réalise la continuité territoriale vers l'Est où elle dispose de droits territoriaux et juridictionnels, celle de La Brigue est obligée de traverser le territoire de Tende pour rejoindre ses terres de pâturages de Malaberga et peut-être déjà celles de la haute vallée du Pesio ${ }^{16}$.

\section{Formation d'une enclave pastorale}

Les délimitations territoriales médiévales créaient un espace de pâturage qui s'appuyait sur les cours d'eau et des itinéraires de déplacement des troupeaux qui se prolongeaient au-delà des lignes de crête. Dès 1162, les hommes de La Brigue avaient obtenu l'autorisation de traverser les terres de Tende pour rejoindre les terres pastorales sur lesquelles leurs troupeaux «montaient » durant la période estivale. La route qui traversait le plateau de Licaponte et supportait la limite méridienne de l'enclave de Malaberga,

15. La limite napoléonienne suivait le vallon du col de Pertigale appelé Celles Vieilles et rejoignait ensuite le vallon de Malaberga. Sur les cartes topographiques françaises actuelles, le vallon de Bachialon mène au col de Celle Vieille (colle de Selle Vecchie sur les cartes italiennes). La réunion de ces deux torrents donne naissance au vallon de Réfréi correspondant au vallon de Rio Freddo dans la délimitation de 1805. Colle Selle Vecchie sur les cartes itailennes (n. 114, 1/25000, 1989) ou col de la Celle Vieille sur les cartes françaises (voir supra), 2098 m. Un autre dossier de conflits territoriaux opposant cette fois la commune de Tende à celles des Châtellenies (Cosio et Pornassio, en Ligurie actuelle, dans la haute vallée de l'Arroscia) permet d'identifier le col de Pertigale médiéval comme celui de Celles Vieilles. Lassalle 2008, p. 483-500.

16. Un breve recordationis de la seconde moitié du XII ${ }^{\mathrm{e}} \mathrm{s}$. révèle en effet les liens entretenus entre les seigneurs de Morozzo qui contrôlent la haute vallée du Pesio et notamment la localité de Chiusa, et les Tendasques. En échange du contrôle militaire des populations alpines éloignées du cœur patrimonial des Morozzo, les hommes de Tende avaient obtenu le remboursement d'une dette probablement gagée sur l'usufruit de pâturages de la haute vallée du Pesio. Lassalle 2008, p. 317-362 et p. 556-557. 
entre le vallon de Pertigale et le monte Caballum, constituait probablement déjà un passage intercommunautaire qui se trouve réaffirmé par le règlement tendasque de 1645. Cet itinéraire qui jouxte alors les limites des pâturages tendasques se constitue comme un droit brigasque de passage à propos duquel il est précisé que les troupeaux de La Brigue peuvent rejoindre leurs pâturages de Malaberga et ainsi ceux de Carsene, situés sur le versant septentrional, à l'opposé de la ligne de crête formée par les Monts Carsene, dans la haute vallée du Pesio. Comme au XII ${ }^{\mathrm{e}}$ s., les troupeaux brigasques pouvaient à nouveau l'emprunter pour revenir des estives et regagner leur village, mais il leur était cependant interdit de pâturer en deçà de Malaberga. Seul le passage était donc autorisé, comme l'avaient établi les sentences de la seconde moitié du XII ${ }^{\mathrm{e}} \mathrm{s}$. afin de relier les alpages éloignés au village créant ainsi un espace pastoral de proximité. Il s'agit donc en d'autres termes d'un espace qui reproduit dans la longue durée des relations de pâturage entre villages alpins limitrophes sous forme des statuts, règlements ou de nouvelles sentences qui interviennent pour conserver la circulation des troupeaux entre les versants opposés des montagnes (Palmero 2005, p. 47-68). L'étude du territoire de Malaberga sur une longue période historique met donc en évidence la formation d'un alpage séparé du finage communautaire que les remaniements frontaliers entre France et Italie établis en 1947 ne remettent pas en question. Malgré le démembrement du territoire de la commune de La Brigue de part et d'autre de la ligne de crête en 1948, la délimitation médiévale départage encore aujourd'hui les finages de Tende et La Brigue.

Le territoire de Malaberga réapparaît dans les statuts des communautés rédigés à la fin du $\mathrm{XVI}^{\mathrm{e}} \mathrm{s}$. en tant que bandite. Ces terres particulières que constituent les bandites se définissent à la fois comme un type d'organisation spatiale des zones pastorales du village et comme un droit de pacage exclusif des bandiotes, titulaires des bandites. On retrouve dans ces descriptions modernes l'organisation médiévale des confins intercommunautaires du territoire de Malaberga qu'elles définissent alors comme une bandite brigasque, sur laquelle s'exercent des droits de pâturage des troupeaux de La Brigue. Ces statuts définissent en effet à la fois les confins du pâturage des communautés, les limites du pacage des troupeaux sur les «alpes » des villages, les droits de passage du bétail et la description topographique du finage des « bandites », c'est-à-dire un espace réservé au pâturage des troupeaux des ayants droit. Les statuts de La Brigue, particulièrement attentifs à la toponymie des localités de pâturage, consacrent un chapitre entier aux « confins de la bandite de Malberga », réservée toute l'année aux pâturages. Dans sa partie orientale, l'étendue de la bandite de Malaberga est délimitée par des croix sur les confins d'une autre bandite brigasque nommée Seneca, et par le territoire alpin du village piémontais de Limone à l'Ouest.
Dans sa partie méridionale, elle jouxte une autre bandite, celle de Valmaurina, relevant depuis le début du XIV $\mathrm{s}$. au moins du territoire de Tende (in districtu Tendae). En 1316, la valle Maurina avaient en effet été vendue par une famille brigasque à un notable de Tende, Audoin Cassio. Trente ans plus tard, son fils renonce à tous ses droits en faveur de la communauté de Tende ${ }^{17}$. L'acte de vente précise alors que cette vallée est composée de prés, de bois et d'alpes et que ses limites jouxtent les terres de la commune et des hommes de La Brigue là où se trouve la division de territoire établie entre les deux communautés, dans la partie inférieure du vallon qui sort de Malaberga. Le territoire médiéval de la valle Maurina s'étend jusqu'au vallon du même nom, puis rejoint la Vallée Gosta plus au Sud (Valgosta actuel), remonte en direction des cimes, puis jusqu'à une draille qui conduit au col de Cinoirasca situé sur la crête et de là à la cime du Monte Caballeto (Monte Caballum). La limite de la bandite brigasque de Malaberga et de la bandite tendasque de Valmaurina se superpose ici à celle des confins des territoires des deux communautés et rencontrent celles du village de Limone au Nord-Ouest. L'utilisation de la bandite dans le sens de confins de pacage s'articule dans l'organisation du territoire communal, soit en fonction des locations de pâturage, soit en fonction de l'assignation des bandites comme rente aux créanciers de la commune, selon un calendrier qui distinguait la période et les ayants droit au pâturage. La bandite de Malaberga s'inscrit donc dans une vaste organisation territoriale, qui repose sur l'articulation de plusieurs bandites situées aux confins des deux communautés de Tende et de La Brigue. Ceux-ci apparaissent comme des territoires maîtrisés, constitués d'espaces de pacage réservés et délimités par des bornes au sein de l'organisation spatiale des zones de pâture des villages. Le finage intercommunautaire se consolide alors sur le tracé de passages médiévaux et les bornes-frontières de certaines bandites selon la codification des droits de pâturage et la règlementation de l'espace local des deux villages. L'enclave de Malabergue définit ainsi une «frontière des estives de la communauté » qui se consolide sur les confins des alpes entre Tende et La Brigue.

\section{La « fouille juridictionnelle » du droit depâturage sur les confins des deux communautés à l'époque moderne}

17. A.M.T., Catégorie I - Parchemins, document n. XX, 25 juillet 1316 et A.D.A.M., 1 Mi 12 R 12, document n. 136, fol. 30, document n. 15 , extrait médiéval du parchemin original. A.M.T., idem, document n. XXXIV, 11 avril 1344 et A.D.A.M., Idem, fol. 31 v., document n. 23, extrait. Lassalle 2008. 


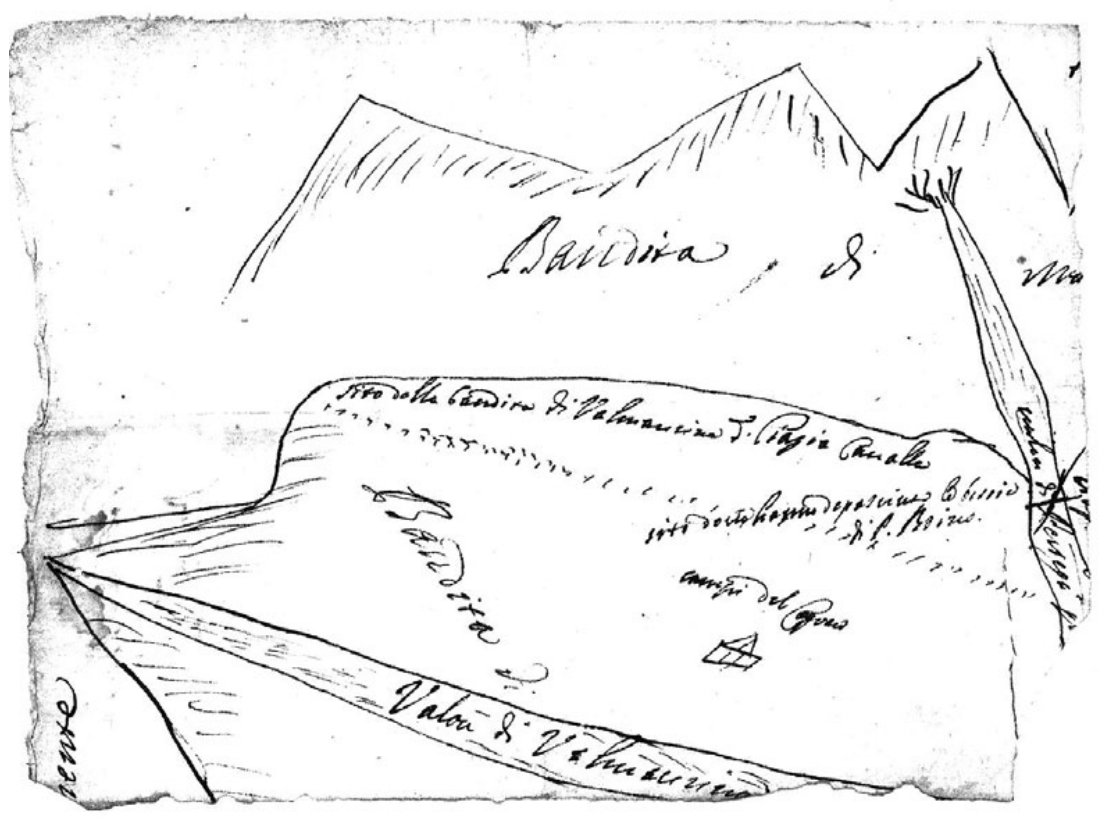

Fig. 3. Dessin de l'abus de pâturage réalisé au cours de la procédure (XVIIII $\mathrm{s}$.).

C'est le règlement d'un abus de pâturage ${ }^{18}$ du troupeau brigasque sur le territoire de Tende que nous permet de mieux comprendre la complexité de ce site de pâturage par rapport à l'exploitation moderne de cet espace pastoral. Nous proposons d'abord une lecture juridictionnelle des actes de procédures et des témoignages produits à l'occasion de ce procès (1700-1703). L'abus de pâturage, reproché par les Tendasques au troupeau brigasque entre la fin du XVII et le début du XVIII ${ }^{\mathrm{e}}$ s. identifie trois discours des ayants-droit : celui des campiers de Tende sur la juridiction communale; celui du troupeau brigasque sur le droit de passage; celui des bergers d'Entracque qui louent une bandite tendasque. Ces discours dévoilent les pratiques coutumières des bergers sur ces lieux de pâturage et détaillent les droits qu'ils pouvaient y exercer d'après la codification des juridictions en vigueur sur ces terres de confins. Ces actes conservent en outre les témoignages des différents ayants droit au pâturage avec leurs titres et possessions. Nous proposons donc la lecture de ce dossier comme une « fouille juridictionnelle » du droit de pâturage sur les confins des deux communautés à l'époque moderne.

En premier lieu, les troupeaux brigasques traversaient le territoire de Tende pour rejoindre la bandite de Malaberga selon un droit de passage codifié dans le règlement des

18. A.M.T., Catégorie VIII, carton n. 9, pièces 11 et 12 (1701-1703). À la fin du XVII s., le prêtre Boino et d'autres de La Brigue conduisaient leurs troupeaux à proximité du vallon de Malaberga. Ils sont accusés par le garde champêtre de Tende de pâturer sur un lieu qui se trouve sur la bandite tendasque qui jouxte celle de La Brigue. Le prêtre Boino fait appel de sa condamnation par la justice tendasque auprès du tribunal du Sénat de Nice. Une lecture en terme de la procédure judiciaire des campiers de Tende est réalisée par Ortolani 1991, p. 69-71. bandites de 1645, comme nous l'avons déjà souligné. En outre, les troupeaux brigasques pouvaient rejoindre les alpes « au-delà des cols » durant l'été, selon les anciens statuts ${ }^{19}$. En revanche, les gardes champêtres (campari ou campiers) de Tende s'appuyaient sur le règlement des bandites pour justifier plusieurs saisies des troupeaux brigasques dans le lieu nommé Piagia Cavalla situé sur la bandite de Valmaurina. La production de deux chapitres extraits des règlements champêtres de Tende (datés du 28 septembre 1598) venait à l'appui du procès : «Que les bandites soient interdites au bétail » et «que les campari soient tenus d'en interdire l'accès ». Un chapitre des statuts de Tende consacré à «l'observation des bandites » nous permet de mieux expliciter l'exercice d'un droit exclusif de pâturage des troupeaux à travers le calendrier des adjudications des bandites établi par la commune de Tende. Les troupeaux issus de la communauté pouvaient s'y rendre dès le 15 avril. Ils étaient rejoints par les troupeaux étrangers le $1^{\mathrm{er}}$ mai et tous pouvaient y rester jusqu'au 8 septembre. Les campiers de Tende pouvaient donc interdire le pâturage de ces bandites, qui pouvaient être assignées comme rente aux créanciers de la communauté ou dont la location aux éleveurs était mise aux enchères par la communauté de Tende ${ }^{20}$. Les bandites de Tende constituaient ainsi un «marché des pâturages » qui était ouvert à des adjudicataires étrangers, notamment

19. A.D.A.M., Insinuation Tende C3271, cc.483r-485v. Palmero 2005, p. 723-729. Statuts La Brigue (1585), cit., chap. 224.

20. A.M.T., Registres de l'adjudication des bandites, années 1645-1675: nous retrouvons les bandiotes d'Entracque qui participent aux enchères des bandites de Tende depuis 1650 et qui deviennent bandiotes de la Valmaurina une fois dans l'année en 1657 et en 1664. Palmero 2005, p. 489-497. 


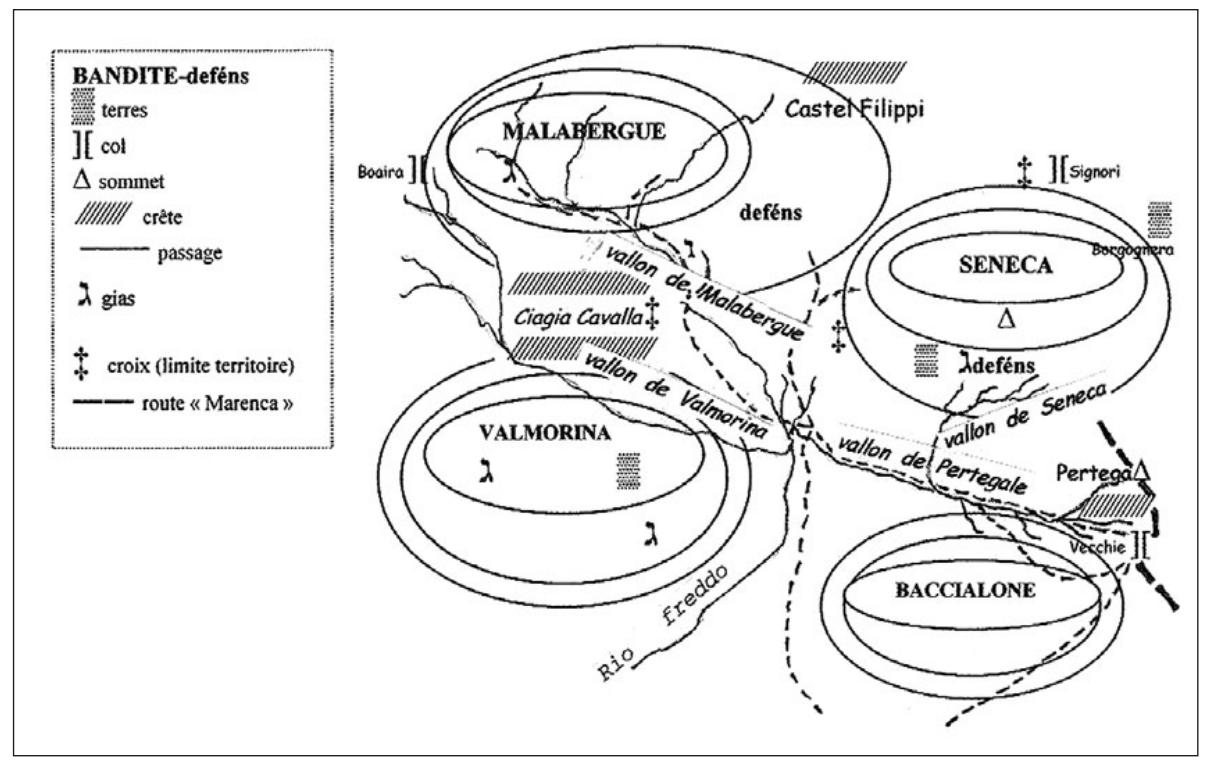

Fig. 4. Malaberga : bandites, passage et structures d'élevage (début du XVII $\mathrm{s}$.). aux bergers d'Entracque (valle Gesso-Cuneo). Selon les témoignages de la procédure de l'abus de pâturage du début du XVIII s., ces derniers avaient obtenu l'adjudication de la bandite de la Valmaurina depuis 1694 et y retrouvaient le bétail brigasque. L'analyse juridictionnelle de ces témoignages permet donc de recomposer les entrelacs des droits de pâture selon une «stratification » des pratiques pastorales sur ce site de pâturage pendant l'été. L'ancien droit de pacage des grands troupeaux issus des communautés sur les alpes communales « au-delà des cols » durant l'été (droit de vayle) se superpose à l'assignation de terres de pacage à des créanciers de la communauté ou à leur location à des adjudicataires étrangers (droit de bandite) et croise la fréquentation « au-delà du col » par les vaches des voisins. De même, le droit de passage s'entrelace avec les confins intercommunautaires et se superpose aux pâturages réservés aux différents ayants droit en concurrence avec le troupeau communautaire. Puisque la fréquentation de cet espace de proximité remonte à des «temps immémoriaux », comme le soutiennent les témoins brigasques, la solution du conflit conduit en premier lieu à une nouvelle visite des lieux pour réaffirmer les bornes des confins et les passages intercommunaux. La contestation des droits d'exploitation et d'usages qui s'élève entre les deux communautés conduit ainsi à la redéfinition des lieux de pâture modernes et de leurs limites en raison de la concurrence entre estives communautaires et pâturages de bandites. C'est un dessin réalisé au cours de la procédure ${ }^{21}$ qui nous permet de mieux comprendre l'articulation du territoire de

21. A.M.T., catégorie VIII, carton n. 9 , pièce 12 , dessin s.d., réalisé au cours du débat judiciaire sur la base de l'audition du capitaine Giovanni
Malaberga avec les différentes pratiques pastorales de cette région (fig. 3). Cette illustration replace dans l'espace, à l'appui des toponymes, les éléments et droits disputés par les différents protagonistes du procès. Le schéma que nous avons réalisé transpose les discours des différents droits sur les relevés altimétriques de la carte militaire de $1879^{22}$ et des cartes actuelles ${ }^{23}$ (fig. 4) et nous donne une idée de l'exploitation de cet espace pastoral au début du XVIII ${ }^{\mathrm{e}} \mathrm{s}$. Le lieu de la saisie des deux vaches du prête Boino et d'autres bêtes brigasques illustré dans le dessin du XVIII ${ }^{\mathrm{e}} \mathrm{s}$. réalisé au cours du procès (fig. 3 ) se concentre sur le vallon de Pertega (ou Pertegale) situé dans la bandite de Valmaurina. On y repère également l'existence d'une structure d'élevage construite au lieu-dit «Campo del capraro », tandis que la «Piagia Cavalla » est indiquée en amont de la bandite tendasque. Le toponyme Monte Caballum médiéval désigne la colline dont la Piagia Cavalla moderne désigne l'adret. La crête de cette colline porte encore aujourd'hui le nom de Cima Malaberga. À l'arrière-plan, on peut voir la bandite brigasque de Malaberga, avec ses trois alpes, qui jouxte la bandite tendasque de Valmaurina. C'est le long du vallon de Pertega que les campiers de Tende avaient arrêté plusieurs fois à la mi-juin les troupeaux brigasques en vertu de ce qu'ils jugeaient comme un abus de pâturage.

Francesco Chianea qui a lieu le 29 juillet 1703. Ce fragment se trouve actuellement détaché et intégré dans le dossier fasc. 11.

22. Istituto Geografico Militare di Firenze, chargé de la cartographie du royaume d'Italie depuis 1865, desormais IGM 1879-1895, F. 91 III Carta d'Italia. Tenda.

23. I.G.C., « Alpi Marittime e Liguri » 1/50000, Torino, 1953 et 2005. 
Selon eux, ce bétail ne se trouvait pas le long du passage intercommunal coutumier pour monter à Malaberga.

En revanche, pour les Brigasques, les troupeaux longeaient le parcours vers les alpages brigasques de Malaberga, faisaient paître leur bétail sur les sprescie (terrasses occupent l'ubac ou les côtes en amont d'une bandite) de Seneca et sur le plateau de Piagia Cavalla, que nous pouvons localiser entre 1600 et $1850 \mathrm{~m}$ d'altitude au nord-est du vallon de Valmaurina ${ }^{24}$ (fig. 4). Le développement des constructions destinées à l'élevage, suggéré par l'exercice des droits d'usage lié à la fabrication du fromage dès le Moyen Âge (ius cellandi) est attestée par la confrontation cartographique. Les témoignages des procédures modernes permettent même supposer une concurrence entre bovins et ovins pour l'utilisation des stations d'élevage d'altitude à l'époque moderne.

\section{Limites des bandites et droits de passage entre Moyen Âge et époque moderne}

La dispute des droits locaux de pâturage avait conduit les autorités à visiter les lieux. Elles confirmaient les limites de pâturages. Pour rejoindre les alpes de Malaberga, les troupeaux brigasques ne devaient pas traverser le territoire de Tende, mais se contenter de suivre le parcours formé par les limites des bandites. L'un des passages connus touche les confins des bandites de Baccialone et de Seneca; il se situe à $1600 \mathrm{~m}$ d'altitude.

L'autre jouxte les limites des bandites de Malaberga et de Seneca, mais aussi de Valmaurina à $1750 \mathrm{~m}$ d'altitude environ. La transposition cartographique de ces passages révèle l'organisation des bandites et les quatre itinéraires que pouvaient emprunter les troupeaux brigasques pour traverser le territoire de la commune de Tende. Le premier traversait les terres de Tende par le chemin inférieur de Velega qui correspondait probablement à la Via Cravaluna médiévale. Le second, dit chemin supérieur de Velega suivait les crêtes et permettait aux Brigasques de contourner les bandites tendasques de Velega et de Baccialone. Il correspondait probablement aux viae de Terre Rosse médiévales et permettait de rejoindre la Strata Marencha citée dans les sentences juridiciaires de 1162 et dont un tronçon est toujours visible sur les cartes actuelles ${ }^{25}$. Le

24. "Gias de Vermorina" 1851 m d'altitude et 1600 bâti (IGM1879); « vacherie de Valmorine » $1848 \mathrm{~m}$ d'altitude et 1600 environ bâti (IGC1953).

25. Les sentences judiciaires du XII $\mathrm{s}$. et la codification des bandites et des passages relevées dans les statuts de l'époque moderne montrent que la route Marenca reliait deux cols (col de Pertigale et col de Carezio- actuel Garezzo) mais aussi la haute vallée de la Roya à celle du Tanaro en direction des plaines piémontaises et à celle de l'Arroscia en direction des plaines ligures. chemin supérieur de Velega desservait également la forêt de Baccialone et permettait de rejoindre directement le chemin de Pertigale qui longeait une partie du vallon du même nom et conduisait à Tende. S'il n'est pas désigné sous cette forme toponymique dans la documentation médiévale, cet itinéraire permettait pourtant déjà de relier la haute vallée de la Roya à celles du Tanaro et de l'Arroscia par le col de Pertigale. La transposition cartographique des litiges territoriaux du Moyen Âge et leur confrontation avec les sources de la période moderne suggèrent dans cette zone un déplacement des passages vers le Sud et une exploitation des estives élevée dans la seconde moitié du XII ${ }^{\mathrm{e}}$ s., à 2500 m d'altitude environ. Au cours de la période moderne, les limites de Malaberga prennent appui sur les bandites et les passages conventionnels hérités en partie du Moyen Âge. Ces itinéraires irriguaient le réseau de pâturages situés à distance des villages, sur les terres de confins situées de part et d'autres des crêtes et fréquentées par les bergers de la Haute-Roya. Au cours de la période moderne, les limites du territoire de Malaberga se renforcent sur les règlements et les statuts des bandites. L'analyse de l'abus de pâturage brigasque illustre la consolidation du finage entre les deux communautés sur un espace de pâturage de confins doté de stations d'élevage.

\section{Conclusion : confins des alpes et « pâturages de proximité », un site archéologique?}

Nous avons vu qu'entre les $\mathrm{XIV}^{\mathrm{e}}$ et $\mathrm{XVI}^{\mathrm{e}}$ s., les sociétés pastorales de la haute Roya mettent en place un réseau de bandites situé sur les passages conventionnels qui longent les confins des finages de Tende et de La Brigue: Baccialone, Seneca, Valmaurina, qui assurent les mouvements des troupeaux locaux. Les témoignages des bergers d'Entracque, de Tende et de La Brigue qui fréquentent ces bandites entre 1694 et 1703 précisent les droits d'usages dont la pratique est autorisée sur ces pâturages de proximité. Le berger d'Entracque, qui avait loué la bandite de Valmaurina à Tende, affirme notamment que les margari (gardien des troupeaux de gros bétail) du prêtre Boino, montaient jusqu'au gias d'en haut (gias soprano) durant le mois de juillet. Ce gias, identifié comme le jas de Valmaurina localisé sur les cartes actuelles à $1846 \mathrm{~m}$ d'altitude, est localisé par le témoin dans la bandite tendasque du même nom (fig. 4). Néanmoins, le fait que la commune de Tende ne soit jusqu'alors jamais intervenue contre le prêtre Boino et ses margari depuis 1694 compromet de fait pour les Tendasques l'utilisation et la possession des gias de ces bandites que les Brigasques semblent s'être appropriées. La bandite de Malaberga avait également un « gias d'en haut », mais la carte de l'année 1879 révèle qu'il existe alors au moins deux autres structures à l'intérieur 
du territoire brigasque. Seule celle qui se trouve à $1743 \mathrm{~m}$ d'altitude apparaît sur la carte de 1953 sous la dénomination de « vacherie de Malaberga », tout comme l'on trouve une vacherie dans la bandite de la Valmaurina. Enfin, sur la bandite de Seneca qui appartenait à La Brigue, il existait également des structures pastorales, les celle de Pertegale, dont la propriété revenait aux Brigasques ${ }^{26}$. C'est dans le vallon de Seneca que nous avons localisé un bâti à 1699 m d'altitude nommé la Sella tandis qu'une autre construction est identifiée à $1935 \mathrm{~m}$ d'altitude, au nord de Cima Pertega, sous le nom de «le Selle» (fig. 4). La construction de structures liées à l'élevage - enclos, cabanes pour la fabrication du fromage, abri de bergers - sur les alpages relevait de la juridiction de la communauté. Ces constructions, en principe temporaires, avaient été consolidées par la fréquentation des alpes et l'exploitation de l'espace selon différentes altitudes, comme l'atteste la cartographie du XIX ${ }^{\mathrm{e}} \mathrm{s}$. Les pâturages de proximité se définissent donc comme des lieux de dépaissance dotés de structures d'élevage alpines, situés sur les alpes des communautés, loin des villages, et délimités par un réseau de passages conventionnels formés par les confins des terres communales de villages limitrophes.

La contextualisation des sources médiévales et modernes sur la base de données toponymiques et sur une «longue durée historique » permet d'identifier l'existence d'un site sur les confins des terres de pâturages des communautés. Il s'agit d'un espace de pâturage complexe codifié par un ensemble de règles de compascuité pesant à la fois sur le territoire et sur les passages utilisés par les bergers et les troupeaux entre le Moyen Âge et l'époque moderne sur les confins intercommunautaires de Tende et La Brigue. La confrontation cartographique du discours juridique des litiges médiévaux et de celui des bergers de la fin du $\mathrm{XVII}^{\mathrm{e}}$ s. montre un changement de perspective dans la mâ̂trise de l'espace pastoral. L'enjeu repose sur le contrôle des cols pour permettre le passage des troupeaux, en direction des pâturages d'altitude ou dans le cadre du développement de la transhumance avec les Alpes ligures d'une part. De l'autre, les pratiques pastorales et les droits d'usage sur un système de pâturages de proximité sont bien évidents à l'époque moderne. Cette évolution tend à une spécialisation territoriale des pâturages communautaires soit en tant que bandites, soit en tant que pâturages communautaires à travers les règles d'accès qui les définissent. Elle révèle

26. Le prêtre, don Antonio Boino, l'un des Brigasques accusé d'abus de pâturage, possédait la moitié de la montagne de Seneca où se trouvaient les celle (celle de Pertegale), tandis que l'autre moitié était déclarée au cadastre par le syndic de La Brigue. A.S.T., Catasti antichi, Briga 1702, dichiarazione Antonio Boino fu Marc'Antonio, c. 132; dichiarazione del sindaco Pietro Alberti, c. 167. Les celles sont codifiées dans les statuts de La Brigue (1585), comme appartenance de la bandite homonyme de Seneca (cit., chap. 170). également une concurrence sur l'accès aux alpages entre différents ayants droit. Les sources écrites soulèvent également l'hypothèse d'une concurrence de l'élevage entre ovins et bovins et dans l'utilisation des stations de pâturage d'altitude $(>1600,>1800,>2000 \mathrm{~m})$ sans qu'il soit possible de préciser à quel moment celle-ci se développe. Les pratiques pastorales, la codification locale des droits et des règles ainsi que les discours juridictionnels construisent ici un territoire de confins sur la «longue durée», traversé par des itinéraires et sur lequel se développent des structures d'exploitation pastorale différenciées. La documentation écrite permet d'identifier des indices importants de l'exploitation des écosystèmes des pâturages d'altitude par les communautés d'habitants que nous livrons ici aux problématiques développées par l'archéologie des sites de montagne.

\section{Bibliographie}

Casana 2000 : CASANA (P.) - Gli Statuti di Vernante e il diritto locale nella contea di Tenda. Cuneo, Società degli Studi Storici, Archeologici e Artistici di Cuneo, fonti VI, 2000.

Ferrières 2001: FERRIÈRES (M.) - Une enquête sur les statuts du Vaucluse. Les Statuts de Gigondas (1592). Histoire des Sociétés Rurales, 16, 2001, p. 177-204.

Jourdain-Annequin, Duclos 2006: JOURDAIN-ANNEQUIN (C.), DUCLOS (J.-C.) dir. - Aux origines de la transhumance. Les Alpes et la vie pastorale d'hier à aujourd'hui, Paris, Picard, 2006, $315 \mathrm{p}$.

Lassalle 2008: LASSALLE (J.) - Entre Provence, Ligurie et Piémont. Litiges territoriaux et conflits d'alpages de la haute vallée de la Roya (XII ${ }^{e}-X V^{e} s$.), thèse de doctorat de $3^{\mathrm{e}}$ cycle, sous la direction de Monique Bourin, Université de Paris-I/ Panthéon-Sorbonne - LAMOP, décembre 2008.

Ortolani 1991: ORTOLANI (M.) - Tende 1699-1792. Destin d'une autonomie communale. Breil, 1991.

Palmero 2005 : PALMERO (B.) - Communautés, enjeux de pouvoir et maîtrise de l'espace pastoral aux confins du comté de Nice (Tende, La Brigue et Triora) à l'époque moderne. Une approche micro-historique : les alpes de proximité, thèse de doctorat de $3^{\text {e }}$ cycle, sous la direction de George Comet, Université de Provence, Aix-Marseille I - TELEMME, novembre 2005. 


\title{
Une montagne à vivre et à partager : le territoire de Montegrosso-Pian-Latte en Ligurie
}

\author{
Ada ACOVITSIOTI-HAMEAU*
}

\begin{abstract}
Résumé. La commune de Montegrosso se situe dans la haute vallée d'Arroscia en Ligurie italienne. Elle s'étage entre 700 et $2500 \mathrm{~m}$ d'altitude, en une succession de terrains discontinus, qui relient le fond du talweg aux cimes alpines. Cette disposition assure la complémentarité des terroirs (cultures, bois et pâtures) et facilite les communications à travers la montagne. La mise en valeur traditionnelle de ce territoire morcelé nécessite des déplacements saisonniers qui servent tant l'élevage que l'agriculture. Les rotations s'organisent entre l'habitat principal et les hameaux de mi-saison et d'estive. Les relevés et l'analyse du bâti et l'enquête ethnographique et historique sur l'organisation des espaces et la circulation des biens et des personnes permettent de comprendre l'intrication et le partage des terroirs ainsi que les motivations qui impulsent l'occupation de hautes terres. Économiques à première vue, ces motivations procèdent aussi des sentiments d'appartenance des groupes humains. Les gens de Montegrosso affirment cet ancrage territorial à travers l'entretien des aménagements techniques et le maintien du calendrier festif de leurs «terres au loin », malgré le recul spectaculaire de l'activité agropastorale. Ces observations engagent une réflexion archéologique et ethnoarchéologique sur la mise en place des territoires montagnards, sur leurs modes d'occupation et sur les représentations qui influencent l'évolution de leurs usages.
\end{abstract}

\begin{abstract}
A mountain for living and sharing: the montegrosso-Pian-Latte territory in Liguria
Abstract. The town of Montegrosso is located in the upper Arroscia valley in the Italian part of Liguria. It extends at a height of 700 to $2200 \mathrm{~m}$ in successive discontinuous pieces of land that connect the valley bottom to the Alpine summits. This arrangement ensures soil complementarities (fields, woods and pastures) and facilitates communications through mountain ranges. The traditional method of working in this highly divided territory makes necessary seasonal move as much for pastoral than for agricultural purposes. Rotations are organized between the main settlement and the mid-season and summer hamlets. The catalogue and analysis of constructions and the ethnographical and historical study on space organization and circulation of goods and persons allows us to understand the interference and the partition of spaces as well as the reasons that drive inhabitants to occupy the high lands. Economical at first sight, these reasons include also the sense of belonging. People of Montegrosso confirm their territorial anchorage by the maintenance of the built technical equipment and of the feast calendar of their « remote earths», in spite of the inexorable decline of agricultural and pastoral activities. These observations engage archaeological and ethno-archaeological reflection on the founding of mountain territories, on the models of their occupation and on representations that have an effect on the evolution of their use.
\end{abstract}

\section{Problématique et approche(s) du sujet}

$\mathrm{P}$ arler de l'espace montagnard revient à traiter d'un espace diversement défini et partagé, un espace pluriel où l'altitude, la configuration des lieux et les spécificités sociales et culturelles jouent un rôle primordial pour la perception, la fréquentation et l'exploitation de chaque terroir. La haute montagne ${ }^{1}$, exempte de végétation arborée, s'im-

1. Cf. pour la perception sociale, culturelle et économique de l'espace montagnard, le volume de 1988/1-2 de la revue Monde alpin et rhodanien (Monde alpin et rhodanien 1988), et plus particulièrement pose comme un espace hors de l'humain et le reste dans les mentalités paysannes malgré l'essor, à partir du XIX ${ }^{\mathrm{e}} \mathrm{s}$., d'une économie touristique centrée sur la conquête ou la contemplation des cimes. Même la moyenne montagne pleine de richesses, ce mittelberg qui fait tampon entre le bas « civilisé » et le haut « sauvage », n'est pas viable et vivable tout au long de l'année sur toute son étendue: se rendre à certains chalets ou hameaux l'hiver relève, par

les contributions de Philippe Joutard, de Christian Abry, Alice Joistens et Jacques Berlioz, de Claude Macherel, de Françoise Loux et de Bernard Debarbieux.

* ASER du Centre Var, Maison de l'archéologie, 21, rue de la République, 83143 Le Val. 
exemple, du défi et de l'exploit, tant à cause de conditions climatiques qu'à cause des êtres surnaturels ou des âmes de défunts qui y descendent pendant la mauvaise saison. De plus, bêtes et végétation ne peuvent pas s'épanouir dans de tels contextes. Donc, pour chaque étage montagnard, la saisonnalité de la présence humaine est une donnée incontournable qui induit l'existence d'autres lieux où les mêmes hommes évoluent à d'autres moments de l'année. Autrement dit, le temps en montagne étant cyclique et l'espace évolutif, il serait vain de chercher des permanences sans interruptions dans les évolutions des activités et des habitats. Une autre constante dans la perception de l'espace montagnard est la dominance de la gestion collective, diversement structurée certes, mais ayant une prégnance forte. Ce n'est pas un hasard, par exemple, si les Chamoniards organisent le tourisme comme s'il s'agissait d'un estivage (guides locaux qui encadrent les touristes dans un espace géré par la communauté) et si les différends autour des taxes pour les refuges rappellent étrangement les différends autour des taxes pour les herbages. Nous retrouverons cette attitude dans la confrontation de deux logiques (agropastorale/collective versus touristique/libérale) de mise en valeur du territoire de la commune de Montegrosso, qui nous servira d'exemple pour discuter sur les usages économiques et sociaux des terres d'altitude.

L'étude se centre plus particulièrement sur l'organisation des espaces, la circulation des biens et des personnes et les mécanismes d'appropriation des territoires. Elle se fonde sur les relevés et l'analyse des constructions agropastorales, sur l'enquête ethnographique à leur sujet et au sujet des modes et des rythmes de vie au village et aux hameaux, sur les données environnementales et les données d'histoire locale. Elle a été effectuée entre 1996 et 2003, en trois missions saisonnières (fin de l'hiver, automne et été) et plusieurs visites ponctuelles. Pendant ces missions et visites, nous avons pu apprécier l'efficacité des enquêtes participantes lors des activités du quotidien, des réunions amicales et des fêtes instituées. Résulte de ce travail une riche documentation qui concerne les locaux et les pratiques, ainsi que les besoins et les représentations qui ont un impact sur les statuts et les usages des terres. Dans les faits, il s'agit de l'exercice d'une ethnoarchéologie des restes et des gestes, discipline qui questionne les traces matérielles tout en étant aussi attentive aux permanences non matérielles. Nous entendons par là les structures, dynamiques et processus qui sont ancrés dans la mémoire des hommes et du milieu et qui sont réactivés chaque fois que les contextes font appel aux éléments constitutifs du groupe humain. Dans ce cadre, nous sollicitons plusieurs notions clés des sciences humaines : celle de «mémoire longue» qui, selon l'ethnologue Françoise Zonabend, structure les sociétés en dépit du temps historique (Zonabend 1999), celle d' «espace culturel» qui, selon le géographe Joël Bonnemaison, précède et fonde le territoire physique (Bonnemaison 2000), celle de «fonctions en puissance des lieux» qui, selon Gérard Chouquer, géographe longuement investi en archéologie, sont immanentes et réapparaissent dans le paysage même si aucun indice matériel ne les annonce (Chouquer 2001). Ces notions nous servent de trame pour l'analyse des données de terrain et guident leur interprétation.

\section{2. État des lieux: Montegrosso et ses voisins}

Le village de Montegrosso (fig. 1) occupe un plateau court et étroit, qui se dresse à $721 \mathrm{~m}$ d'altitude dans la haute vallée d'Arroscia dans les Alpes ligures, à la frontière des provinces de Imperia (Ligurie) et de Cuneo (Piémont). Le territoire de la commune s'étire du fond de la vallée aux sommets les plus élevés. Il est composé de terrains discontinus, disposés en lanière, circonscrits d'éléments naturels (cours d'eau, cols, crêtes) et dont chacun comprend des cultures, des bois et des pâtures. Ces ensembles constituent autant d'unités d'habitat et d'exploitation : village principal, hameau de mi-saison, hameau d'estive. Seuls les lieux d'hivernage près de la mer (pratique suivie par les propriétaires des plus gros troupeaux) n'appartiennent pas de droit à la communauté. Dans la configuration actuelle, Montegrosso possède un hameau de mi-saison, Case Fascei, situé au sud du village, à une heure de marche et à environ $1300 \mathrm{~m}$ d'altitude et, vers la même direction, un alpage, Pian del Latte, que la commune loue à des éleveurs extérieurs, situé à deux heures de marche du village et à une altitude d'environ 1600 à $1800 \mathrm{~m}$. L'estive, éloignée de $36 \mathrm{~km}$, se trouve au nord-ouest, dans le Bosco delle Navette, à six heures de marche du village par des raccourcis et à une altitude d'environ 1300 à $1500 \mathrm{~m}$. La route qui y mène ne date que des années 1960. Cette estive est enclavée dans le territoire de la localité de Upega (commune de Briga Alta). Elle se compose d'un hameau avec ses terres adjacentes (environ 1000 ha) et se prolonge avec des pâturages, qui montent, côté nord, jusqu'à la localité de Nivorina et, côté ouest, jusqu'au Mont Bertrand et l'alpage de Colla Rossa à plus de $2000 \mathrm{~m}$ d'altitude. Le hameau d'estive est annoncé par le sanctuaire de la Madonna della Neve, réputé d'avoir été fondé au XIV ${ }^{\mathrm{e}} \mathrm{s}$. La chapelle mariale se dresse en sentinelle sur la limite avec Upega, se présentant comme un «géosymbole $»^{2}$ qui marque, protège et singularise l'enclave. Les communes alentours - avec qui Montegrosso compose, selon l'époque, soit une seule châtellenie, soit des groupements rivaux - montrent aussi un parcellaire fractionné, échelonné entre la moyenne et la haute montagne. Ces parcellaires sont intercalés les uns dans les autres. Les

2. Selon la définition de J. Bonnemaison (2000). 


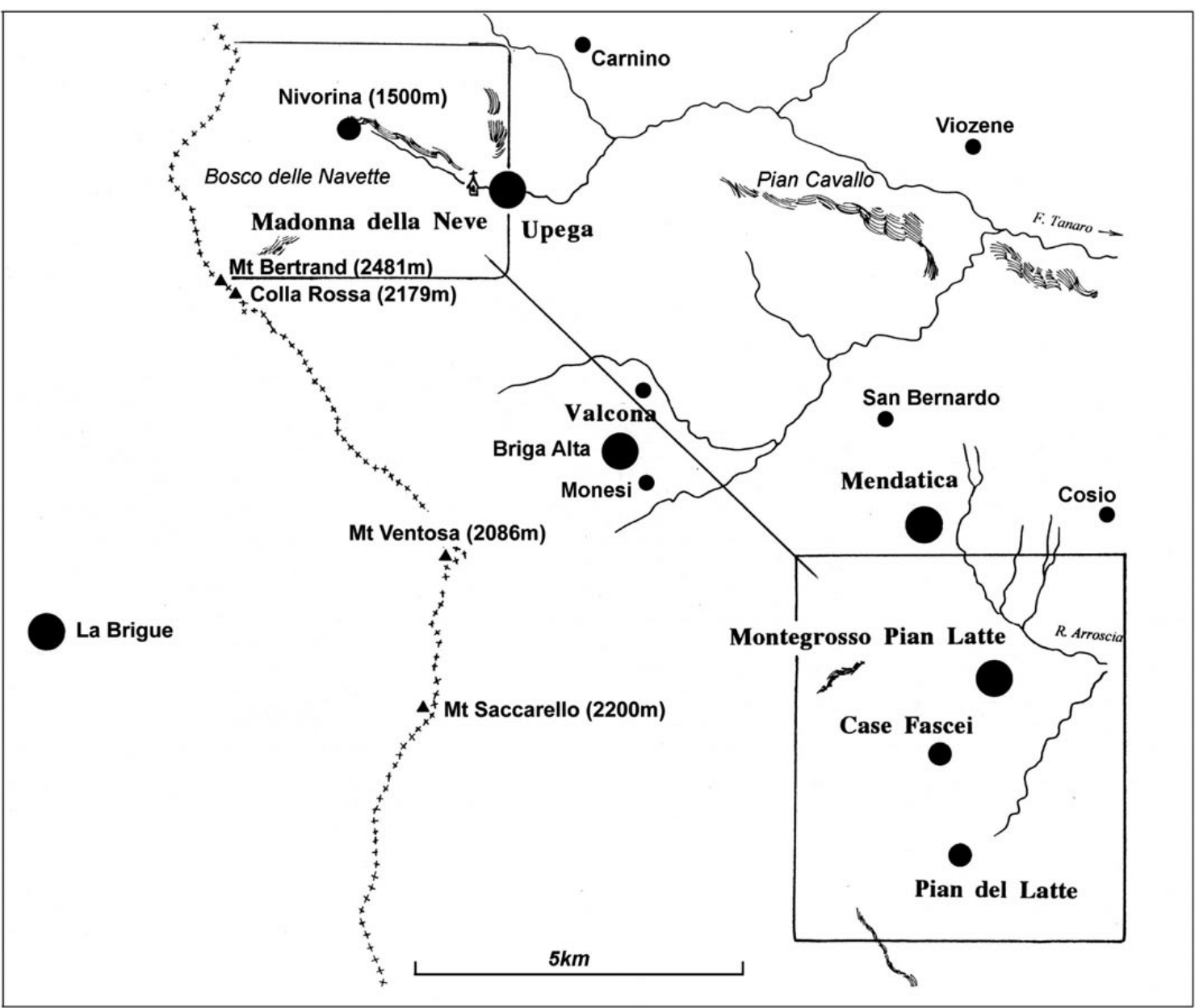

Fig. 1. Le territoire de Montegrosso et les terres de ses communes voisines.

alpages de Briga Alta s'étendent parallèlement à ceux de Montegrosso, de Upega à la cime de Montjoio (2630 m), en passant par la localité de Carnino, notoire pour la sévérité de ses hivers ${ }^{3}$. Les villages de Cosio et de Mendatica, limitrophes de Montegrosso, détiennent aussi des terrains à Navette et d'autres prés et pâturages plus bas et plus haut que cette forêt. Le hameau de Viozene à l'est de Upega et les grands plans qui l'encadrent sont, par exemple, affiliés à Cosio, tandis que Mendatica possède les deux hameaux de Valcona et les alpages à l'ouest de la zone, qui culminent au Monte Saccarello (2200 m). Sur ce sommet, la statue du Redentore (le Christ Sauveur) constitue un autre «géosymbole» qui réunit les pèlerins de tous côtés et rappelle les liens entre les versants. D'autres communes (Carpasio, Pornasio, Ormea) sont concernées aussi par cette même grande région qui est drainée par le Tanaro, affluent du Pô, et ses cours d'eau secondaires. Une partie de ces alpages a le

3. «Qui veut voir l'Enfer, va à Carnino l'hiver », précise le dicton. statut de malghe ou margherie (lieux destinés au séjour des bergers et des troupeaux, en premier celui des vaches mais, par extension, de tout troupeau), tandis que d'autres sont désignés comme bandie (terres louées pour l'estivage ou pour l'hivernage et sont donc, soustraites à la libre pâture $)^{4}$. Contrairement aux paysans de Cosio et de Mendatica, ceux de Montegrosso n'utilisent pas ces termes; ils vont simplement aux prairies: ai prati.

La stabilisation de ces territoires date de la fin du Moyen Âge. Les cessions, échanges et annexions qui ont lié ou divisé ces communes, les associant, tour à tour et diversement, à Tende, à Vintimille, à la Savoie ou à Gênes,

4. Ces termes, connus depuis le XIII $\mathrm{s}$. au moins, sont discutés pour les vallées proches d'Arroscia (Tanarello, Argentina, Roya) par Juliette Lassalle et Béatrice Palmero, qui signalent des variations sémantiques suivant les lieux et les périodes chronologiques. Au fil du temps et avec l'essor de la « grande » transhumance, les règles sur les passages et les haltes des troupeaux deviennent plus strictes, sans que cela n'enraye les acceptions locales des mots. Lassalle 1997, 2001, 2003 et Palmero 2001. 

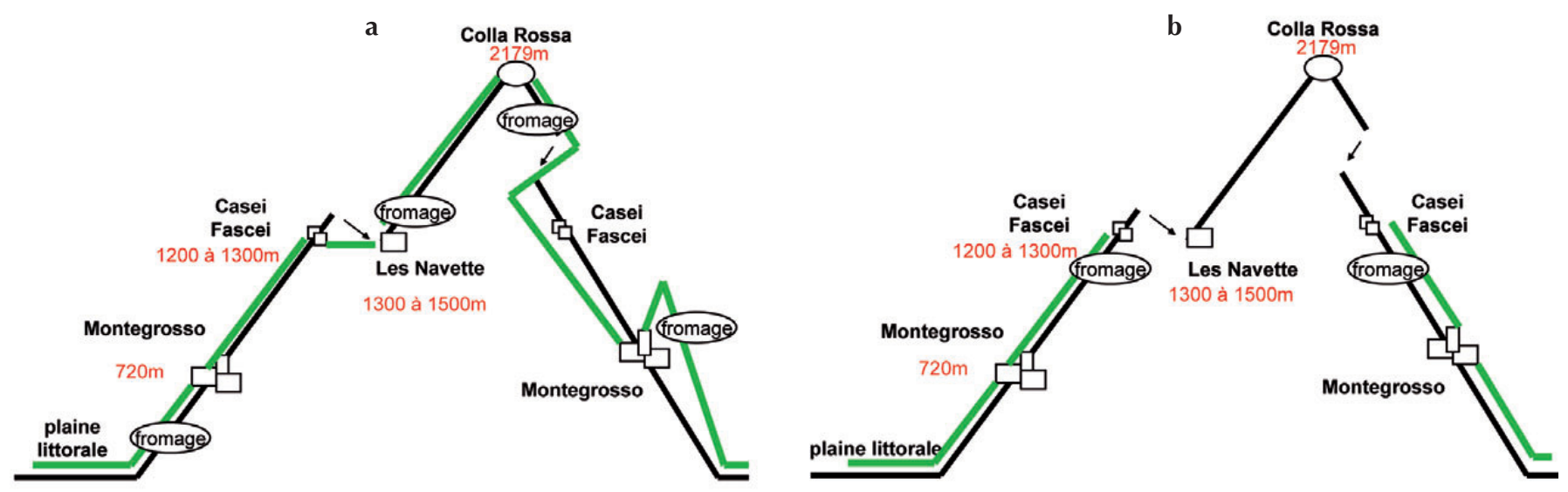

Fig. 2. Les déplacements a) des ovins et b) des bovins.

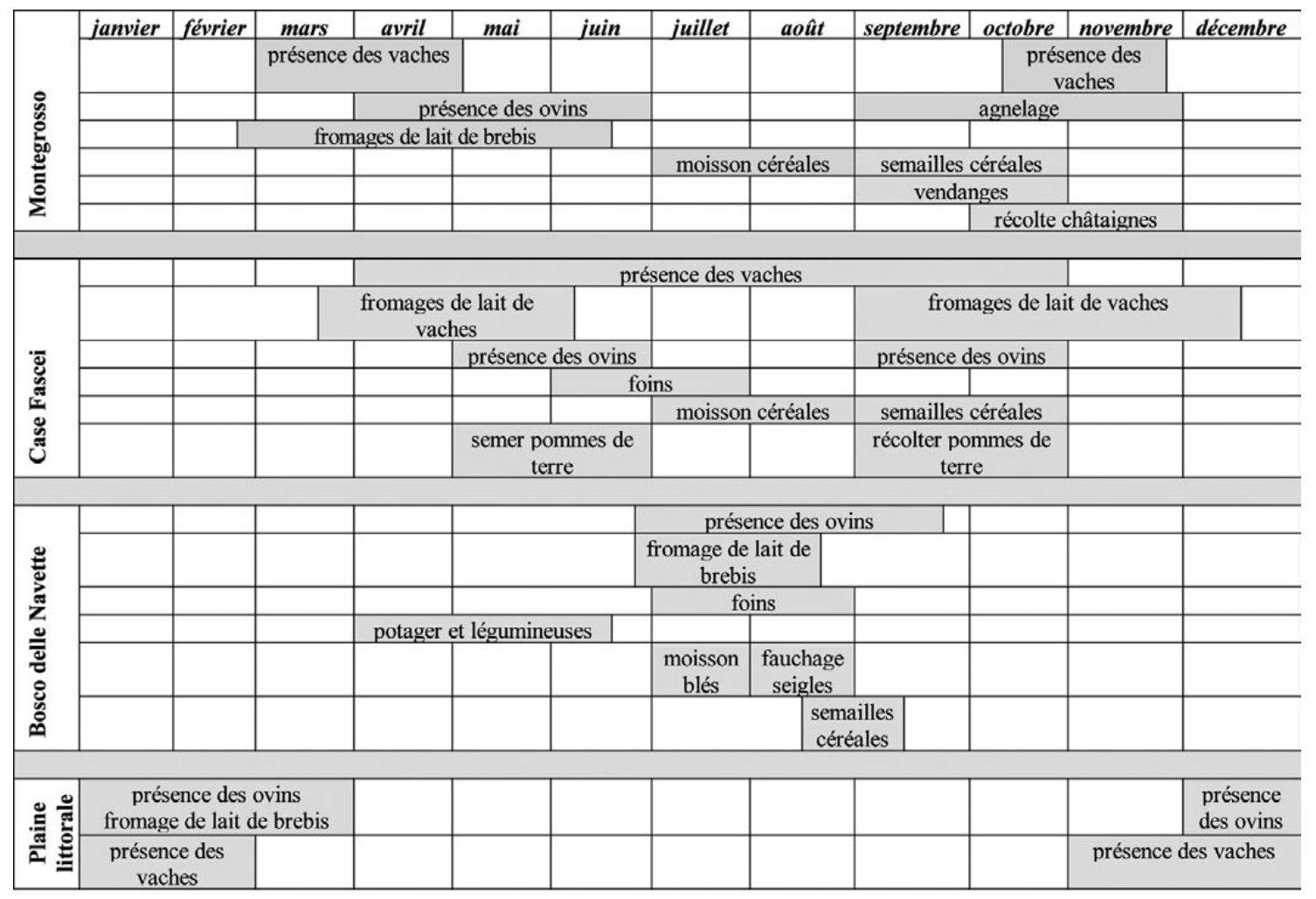

Fig. 3. Le calendrier agropastoral traditionnel.

s'étalent du XIII ${ }^{e}$ au XVIII ${ }^{\mathrm{e}}$ s. ${ }^{5}$. Elles seraient trop longues à exposer ici et sans vrai intérêt pour notre sujet, si ce n'est le poids social de la tradition et du passé historique, qui transparaissent dans les droits d'usage, dans les affinités

5. Les sources explicitant ces événements se trouvent dispersées entre Nice, Turin et Gênes et les synthèses existantes (de rigueur inégale) sont contenues dans des revues et publications locales (par exemple: Moriani 1994, Laiolo 2001). Le territoire de Montegrosso trouve sa forme définitive après son affiliation aux Lascaris de Tende en 1445. et les inimitiés entre communautés, dans les rapports avec l'espace et dans les sentiments d'appartenance des habitants. L'existence de rivalités et de petites frictions ne met pas en cause la nécessité et la pertinence de l'agencement territorial en lanières composées de terroirs dispersés et contrastés. L'exploitation de ces finages se résume longtemps par l'exercice d'un agropastoralisme de subsistance, fondé sur la complémentarité des saisons, des terres et des productions. Toutefois, ce type d'économie ne cesse de décliner. Ce déclin se produit en même temps que le 


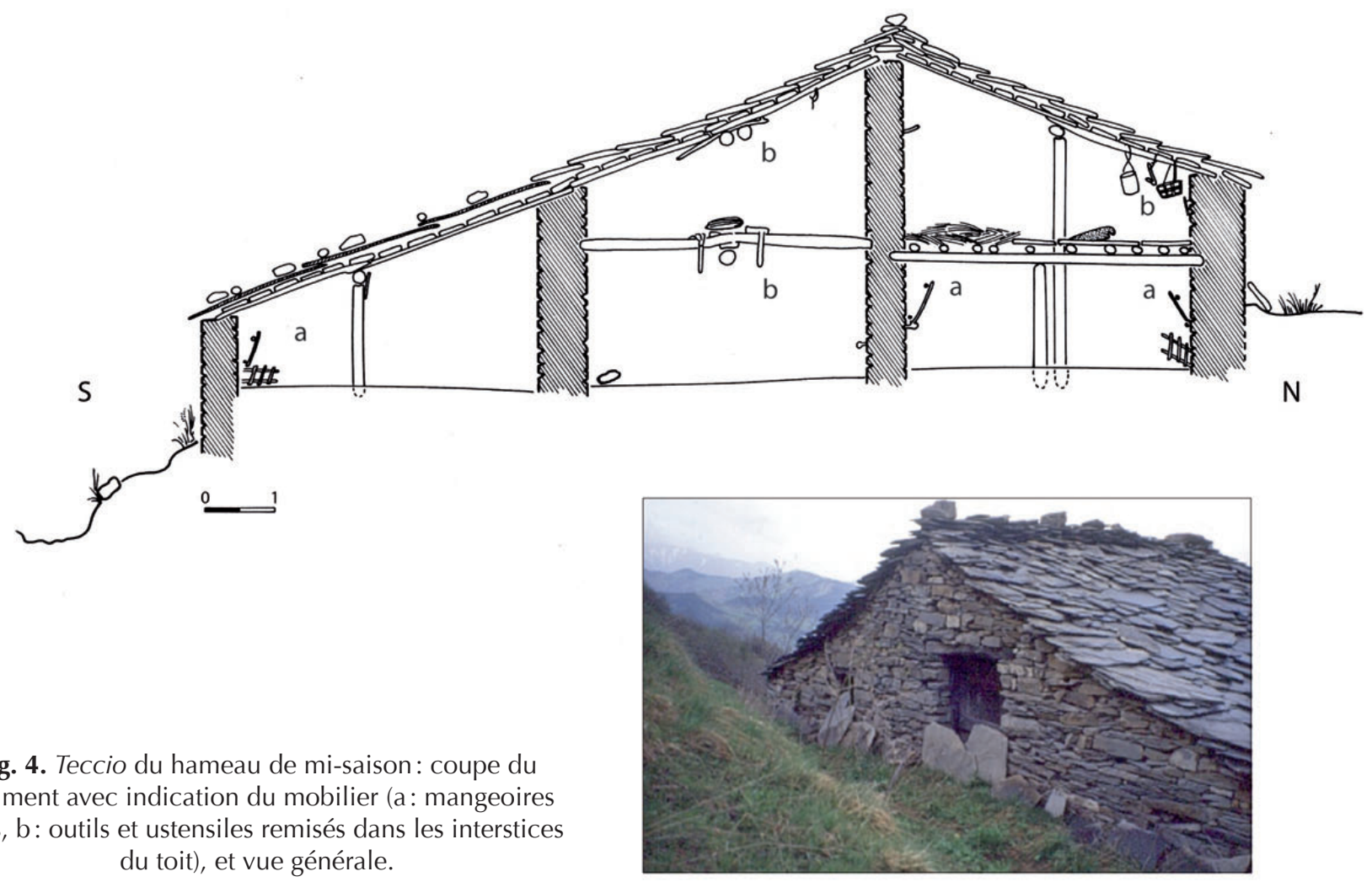

changement du statut de propriété des terres et des locaux (les fermes-bergeries de montagne) qui est de nos jours, achevé ou en cours. Ce statut évolue du collectif (usage commun des terres indivises: arrangements entre familles et rotations entre les différents lots de champs et de prairies) vers le communal (usage réglementé des terres publiques: transactions avec l'autorité communale) et vers le privé (possession des terres et des locaux par les particuliers, qui peuvent les transmettre et les vendre). Cette évolution passe par la mise en place de cadastres qui facilitent la privatisation des terres et leur transformation en lieux de villégiature ${ }^{6}$.

\section{L'agropastoralisme traditionnel}

Montegrosso pratique un agropastoralisme traditionnel, à caractère plutôt vivrier que commercial, jusque dans les années 1970. À cette époque, son cheptel compte une

6. C'est, par exemple, le cas pour Mendatica, qui a procédé à l'encadastrement de ses terres pastorales dès 1925. Pour Montegrosso, cette procédure n'avait pas encore abouti en 1996/1997. À cette date, la plupart des fermettes du hameau de Case Fascei avaient un statut privé mais pas les hauts pâturages mis en location, ni les lots familiaux de l'estive de Navette où la commune entend se réserver la propriété des prés et des pâtures. vingtaine de troupeaux d'ovins et un peu moins de bovins. Le troupeau-type moyen est de 80 à 100 têtes pour les ovins, mêlés à quelques chèvres et de 10 à 20 têtes pour les bovins. Des chèvres sont aussi gardées à l'année au village. Labours, vergers, vignes et potagers s'étendent au-delà de l'agglomération. Un moulin à farine fonctionne au fond de la vallée. Entre la zone agricole, qui ceinture le village et la forêt spontanée de mélèzes et de pins sylvestres, qui borde les prés de Case Fascei, s'étend la forêt cultivée des châtaigniers. C'est dans les châtaigniers et les terres boisées proches, c'est-à-dire dans le «sale », que l'on mène paître les chèvres. L'élevage caprin est comparable à celui des volailles et des lapins. Pratiqués au village, ces élevages induisent une séparation des tâches féminines et masculines: les femmes restent moins longtemps à l'estive à cause des soins réclamés par la basse-cour et par les jardins. Contrairement aux chèvres, ovins et bovins sont menés paître dans le «propre »: sous-bois nettoyés et prairies. Ils se déplacent sur des distances comprises entre quelques heures et une journée de marche pratiquant des parcours journaliers, des transhumances de proximité et des transhumances inverses. Ces remues du bétail rythment la vie rurale et vont de pair avec d'autres opérations majeures pour l'approvisionnement des habitants: cycle cultural des céréales et des fourrages, production fromagère, récolte et séchage des châtaignes. De plus, avec ses 
rotations, le bétail assure le fumage des terres, que celles-ci soient semées ou laissées en prairies.

Bovins et ovins suivent des circuits parallèles qui se croisent aux mi-saisons (fig. 2). Vaches et veaux séjournent à Case Fascei de la mi-avril à la fin octobre. C'est à Case Fascei que l'on transforme, traditionnellement, le lait de vache, entre le fort de l'été et le tout début de l'hiver. Ces fromages, des tommes, sont autant vendus qu'autoconsommés. Entre avril et juin et en septembre/ octobre, les ovins sont aussi admis dans les prés les plus bas où les bovins sont déjà passés. Les vaches, qui ne mangent pas l'herbe trop rase et imbibée de salive acide laissée par les brebis, montent alors journellement plus haut, jusqu'aux limites des pâturages de Pian del Latte, les terres communales louées pendant l'été à des éleveurs «étrangers ». Toutes ces pâtures se touchent mais vaches et brebis ou vaches locales et vaches étrangères ne se mêlent pas. Les anciens éleveurs sont formels à ce sujet: « les vaches de Pian Latte allaient d'un côté et celles de Montegrosso d'un autre » ou « à Pian Rosso, là-haut, c'était seulement des montagnes à moutons, parce que eux ils allaient sur les cimes, non au-dessous, parce que en bas il y avait les vaches ». Les parcours des bêtes représentent donc des espaces-temps parallèles mais différenciés. Les troupeaux au complet font leur dernière apparition solennelle (« se montrent ») à la foire annuelle de Mendatica le 29 septembre (Saint-Michel), seul moment où «vaches et brebis se rencontrent ». En novembre, quelques vachers partent hiverner près du littoral tandis que les moins fortunés rentrent leurs bêtes au village et les nourrissent à l'étable avec du son et le foin engrangé pendant l'été.

Les déplacements des ovins connaissent plusieurs étapes. $\mathrm{Au}$ printemps, ceux-ci circulent entre le village et le hameau de mi-saison. Fin juin, ils montent aux Navette. Tous les troupeaux doivent être partis pour la Saint-Pierre (29 juin). À l'estive, ils font plusieurs paliers entre les herbages autour de la Madonna della Neve et les hauts prés au nord et à l'ouest de la zone. Leur garde est le plus souvent collective ainsi que le transport de vivres, de produits agricoles, de produits laitiers. L'estivage est particulièrement lié à la fabrication des fromages, la saison de cette production pouvant s'allonger de janvier (après l'agnelage) à août. Toutefois, ce dernier mois est moins propice: la lactation s'épuise et le lait devient «épais », à odeur forte. En vérité donc, le lait de brebis est transformé tant à l'estive qu'à l'hiverne ou au village (mi-saisons) mais le prestige va à la tomme préparée aux Navette et affinée sur place 2 à 3 mois. Ces tommes (le vrai formaggio: lait caillé mis en forme) sont majoritairement vendues contrairement à la ricotta et surtout, au brussu, qui sont régulièrement consommés par les ménages 7 . Le fromage d'hiver est souvent commercialisé frais, dans les 15-20 jours après la fabrication. Le moment fort de l'estivage est la fête de la Madonna della Neve, qui se tient le dimanche le plus proche du 5 août et rassemble les ressortissants de Montegrosso, les estivants et les riverains. La descente coïncide avec une autre fête mariale: celle de la Madonna delle Grazie (8 septembre), célébrée au village. Baignés, tondus et «toilettés » avant leur départ, les ovins sont conduits directement vers Case Fascei d'où ils descendent au village pour le jour de la fête. L'hivernage près du littoral se passe généralement dans des oliveraies, la fumature des vergers payant en partie la location des terres.

Malgré l'importance attribuée socialement et économiquement à l'élevage, la production agricole est présente partout (fig. 3). Case Fascei, le hameau des mi-saisons, fournit le foin mais aussi le blé et les pommes de terre. L'activité agricole coïncide avec le séjour des vaches (avril à octobre) et avec les parcours journaliers des ovins au début et à la fin de la belle saison. Pendant cette période, les prés naturels sont fauchés plusieurs fois, le foin remisé pour l'hiver et les céréales battues au fléau dans les granges. En début de période, on sème les pommes de terre, en fin de période, on sème le blé. Le hameau n'est pas fréquenté de novembre à mars. À l'estive des Navette, où l'on cultive le blé, le seigle, les légumineuses (lentilles, pois) sans oublier les coupes des foins pour revigorer les prés, la saison d'occupation intense est encore plus concentrée. L'activité agricole démarre avant la montée des ovins, dès la mi-avril, avec de courts séjours en famille ou en solitaire et des déplacements journaliers pour les différents transports. Elle bat son plein en juillet/août, à la période de l'estivage des ovins qui est aussi le moment de la moisson du blé et de la fauchaison du seigle. Une aire à battre collective à côté de la grange/bergerie communautaire sert pour le dépiquage. Les semailles des céréales ont lieu juste avant la descente, début septembre. Le court séjour automnal des éleveurs dans et autour du village permet de finir les labours et les semailles au hameau de mi-saison et de préparer l'hiver (rentrer le foin et autres provisions). La récolte des châtaignes marque la période entre la mi-octobre et la mi-décembre. Hormis quelques « castagnades » où ils sont consommés rôtis, ces fruits sont stockés après avoir été séchés au-dessus d'un feu doux dans des édifices ou des pièces spécifiques (les casun). Ainsi préparées, les châtaignes sont, selon leurs qualités, soit préparées en soupes et bouillies, soit données comme nourriture d'appoint aux animaux tenus au village. Portée essentiellement par le groupe familial, cette économie agropastorale relie donc le haut et le bas dans un

7. Les fromages des estives de la zone (la ricotta notamment) sont mentionnés dès le $\mathrm{XIV}^{\mathrm{e}} \mathrm{s}$. et jouissent d'une réputation de nourriture saine et savoureuse au XVII' ${ }^{\mathrm{e}}$. (Palmero 2001, p. 473). 
va-et-vient complexe mais organisé, qui fonde un système de dépendances réciproques, où saisons et quartiers se caractérisent par un calendrier d'activités et par des productions et cueillettes propres. Dans ce système, aucun module spatial ne fonctionne seul, ni ne garde le même statut (terre agricole ou terre pastorale, prés en friche ou prés travaillés, bois exploité ou bois laissé sauvage, etc.) à longueur d'année ou d'une année à l'autre. La variabilité, la réversibilité même des fonctions des lieux préservent in fine la fonctionnalité générale du territoire.

\section{Le haut et le bas : constructions, objets et pratiques}

L'habitat principal et les hameaux de mi-saison et d'estive montrent tout un cortège d'aménagements et de bâtiments résidentiels et techniques où la trame architecturale traditionnelle est encore visible et lisible malgré la désaffection ou la restructuration de plusieurs locaux. Le village est bâti en ordre serré tandis que les hameaux sont occupés en ordre dispersé : les tecci (petites fermes-bergeries) y sont disposés isolés ou en petits groupes détachés les uns des autres. Implantés sur les terrains de la communauté, ces tecci sont édifiés par les familles qui utilisent les terres et ils restent leur propriété tant que lieux et locaux sont fréquentés et entretenus. La plupart des familles ont généralement un pied-à-terre dans chacun de deux hameaux. Les tecci se distinguent des maisons du village par l'agencement et l'extension des locaux et par les techniques de construction. Aux hameaux, l'espace pour les hommes se réduit pour laisser la place à l'espace destiné au parcage et au stockage. Au village, les locaux de service se subordonnent aux locaux résidentiels occupant des soubassements, des soupentes ou des ailes latérales. Aux hameaux, la maçonnerie est au liant de terre et les toitures exclusivement en lauzes ou en végétal. Au village, dominent la maçonnerie à la chaux et les toitures en lauzes et/ou en tuiles. Sur les hautes terres et dans la forêt, quelques cabanes isolées et certains aménagements (murettes, abreuvoirs) sont en pierres sèches, quoiqu'une grande partie des terrasses des alpages présente un front gazonné. Les types des locaux pastoraux et leur hiérarchisation au sein des établissements sont comparables à ce qui se passe, généralement, dans d'autres régions méditerranéennes, dans le Var par exemple (Acovitsióti-Hameau 2005, p. 275-280) ou en Aragon (Rivas 2006). L'usage préférentiel de la technique de construction à sec dans l'espace sauvage et pour certains types de locaux est aussi un principe régulièrement observé dans le monde rural (Acovitsióti-Hameau 2000; 2005, p. 302-304).

Entre les deux hameaux, les différences concernent 1'organisation de l'espace occupé par le bâti, les matériaux de construction et les fonctions des locaux. Case Fascei est composé de trois groupements de tecci contigus ou juxtaposés. Certains sont accompagnés par des selle (caves d'affinage pour les fromages $)^{8}$, qui se trouvent en soubassement ou accolés au bâti principal. Les murs sont en pierres brutes ou équarries et les toitures constituées de robustes charpentes en mélèze et châtaignier, avec un couvrement de lauzes de schiste (ciappe) sur un treillis de noisetier (fig. 4). Chaque ensemble comprend des étables, des parcs couverts, des granges, souvent une pièce à feu qui sert d'habitation et de laiterie. Sur l'estive, les tecci occupent la croupe qui surplombe la chapelle de la Madonna en un semis plus ou moins lâche. Leurs toitures ont des charpentes en mélèze et sapin et sont, traditionnellement, recouvertes de paille de seigle. Les tecci sont accompagnés de grandes cours à ciel ouvert, puisque l'été, le troupeau se repose à l'extérieur. Les selle, à un cas près, sont collectives. D'autres lieux spécifiques caractérisent l'estive, tels le bassin arrangé dans un torrent et qui sert pour baigner les brebis avant la tonte, la bergerie/grange communale avec son aire de battage ou les deux selle isolées, placées en arrière de la chapelle, qui s'imposent comme les bâtiments les plus emblématiques (fig. 5). Les détails de forme et de construction de ces dernières ont tous leur importance. Basses (on y entre courbé) et en partie enterrées, ces caves ont des murs en pierres sèches qui laissent un interstice vide au-dessus de l'entrée et un toit charpenté recouvert de quelques lauzes et de terre herbeuse. Le but est d'assurer de façon constante une aération légère, une humidité modérée et une fraîcheur égale. Dans ces locaux, les fromages sont stockés au fur et à mesure de leur fabrication. Les comptes et le partage sont faits à la fin de la saison, à côté de la chapelle. Les murs des selle gardent les traces de ces pratiques (décomptes de tommes avec les noms des éleveurs). Les faisselles gravées de monogrammes en réfèrent aussi.

Les hameaux de mi-saison et d'estive sont actuellement en une phase qui oscille entre abandon et restauration, ce qui favorise les relevés et l'enquête tout en les rendant urgents. Les autorités et la population locales en sont conscientes et désirent palier cette urgence. Cette situation permet une étude détaillée du bâti qui relance la réflexion ethnoarchéologique sur plusieurs points: les modes de construction et les aménagements (récupération de matériaux ou dispositifs inattendus, tels les semelles non bâties pour les poteaux

8. Le terme sella/selle est à rapprocher à celui de cella/cellae rencontré dans les archives de Tende/La Brigue dès 1169 et signifiant le local « où les bergers entreposaient le fromage » (Lassalle 2001, p. 448-449). Le terme est lié aux pratiques de l'estive. Le droit de construire ce type de local accompagne le droit d'estivage. Ce droit (comme celui d'établir des parcs pour les animaux et des cabanes pour les bergers) se négocie entre propriétaires et usagers des pâturages. Un impôt en nature (le cellagio) en découle. Les éleveurs de Montegrosso racontent encore que leurs aïeux payaient $1 / 16$ de la production par cave. 

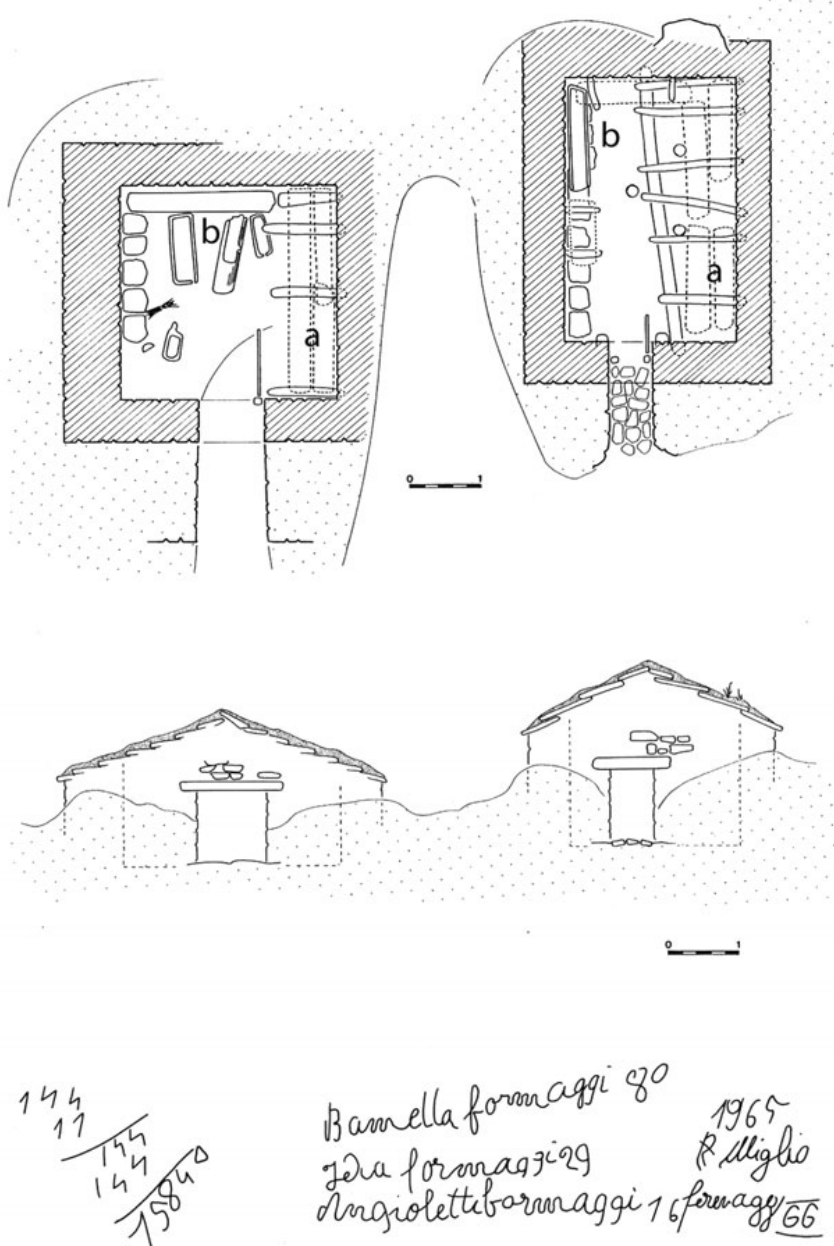

Fig. 5. Les caves d'affinage collectives au hameau d'estive: plans, élévations, indication du mobilier (a: étagères,

$b$ : planches et bancs à égoutter) - en dessous : décompte des fromages par producteur (graffiti sur le mur).

porteurs ou les foyers à plat sur des planchers à l'étage [fig. 6], par exemple), les modes de parcage et de nourrissage (mangeoires fixes et mobiles, barrières qui bougent), les modes de rangement (suspensions à diverses hauteurs, étagères amovibles, usage des interstices de la charpente), l'agencement des propriétés (dispersion des composantes d'un même établissement, manque de certains types de locaux et fusion d'autres), etc. La place des objets du quotidien donne aussi matière à réflexion, par exemple, quand nous nous trouvons devant des positions qui paraissent aberrantes mais qui sont dues simplement au rangement du local avant l'évacuation saisonnière. Dans ce cas, dans la pièce d'habitation, les mangeoires mobiles sont remisées à l'envers sur les couchages, les matelas enlevés et enroulés, les paniers et autres récipients suspendus aux poutres et solives. Dans la cave d'affinage, seules les grosses pièces (tel un demi-tronc servant de table à égoutter) sont laissées en place. Les autres ustensiles sont suspendus ou retournés
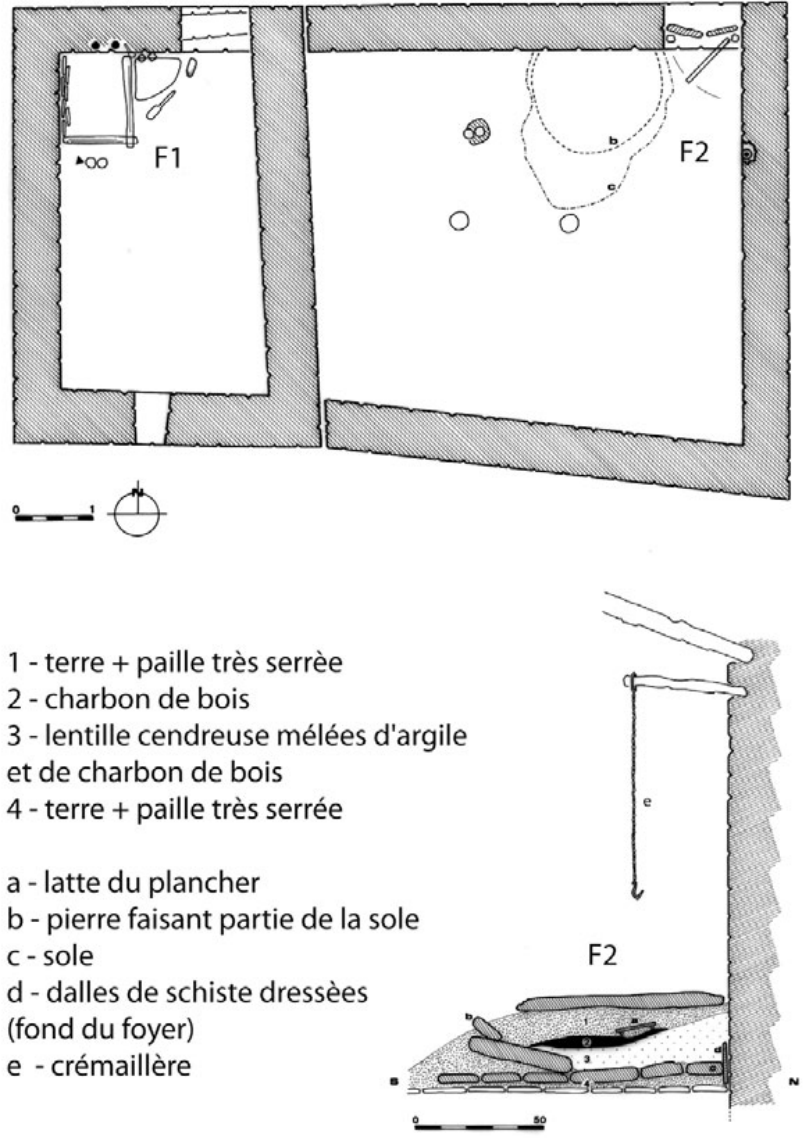

Fig. 6. L'étage d'un teccio au hameau d'estive avec foyers à plat sur le plancher: plans, coupe du foyer F2, indication du mobilier.

et la plupart des étagères enlevées. Comme plusieurs locaux se trouvent actuellement entre usage effectif et patrimonialisation familiale, leur mobilier est soit mis au rebut en tant qu'inutile, soit mis de côté en vue de sa réutilisation en tant que témoin du passé. Dans les deux cas, seule une enquête fine et patiente peut nous renseigner sur le contexte technique de ce mobilier.

Au-delà du hameau de la Madonna della Neve, les locaux bâtis se raréfient. Les séjours sur les hauts alpages se concentrent entre la mi-juillet et la fin août. Pendant ce temps, bêtes et hommes vivent à la dure. Pas de parc couvert pour les premiers mais juste des enclos de fortune dont celui de traite est le seul indispensable. Les hommes s'accommodent de quelques baracche en pierres sèches ou en matériaux hétéroclites, parfois d'un simple rocher qui forme abri, souvent d'un arbre ou d'un gros buisson, naturellement présent ou transplanté, qui sert pour se protéger et pour suspendre ses affaires (un vrai « arbre à merveilles » 

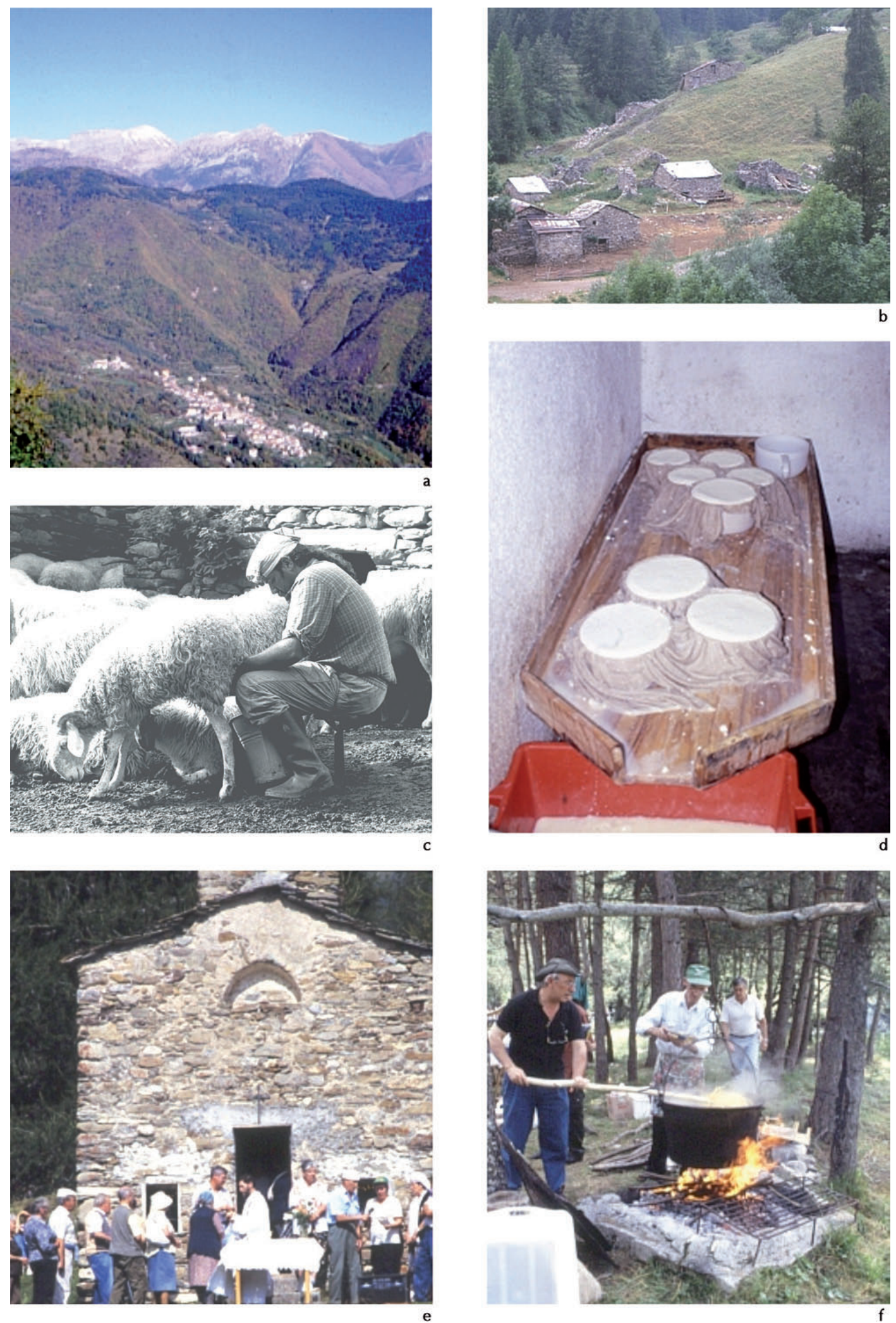

Fig. 7. a) Le village de Montegrosso au sein de ses montagnes. b) Vue générale du hameau d'estive à Upega. c) Traite des brebis à l'estive (été 1997). d) Planche à égoutter et fromages qui sèchent à I'estive (été 1997). e) La fête du mois d'août à la Madonna della Neve: messe devant la chapelle et communion. f) La fête du mois d'août à la Madonna della Neve: préparation du repas commun (spagettata et grillades). 
aux dires des usagers). Le lait est transformé sur place dans des aménagements de fortune et les fromages transportés quotidiennement aux selle de la chapelle. C'est depuis le hameau que sont aussi emmenés le pain et autres denrées de base pour les gardiens des troupeaux qui évoluent près des sommets.

Les constructions et les pratiques qui s'y rattachent relient donc le haut et le bas. Elles ordonnent le territoire plus qu'elles ne le divisent, puisque la singularité de chaque lieu fait partie intégrante de leur complémentarité. Les locaux pastoraux sont par excellence les témoins de cette unité transversale entre bas pays et haut pays. Leur implantation exprime les besoins du troupeau en parcours, ambiances de parcage et nourritures variées et variables. Ces besoins sont satisfaits par la diversité des terroirs investis et s'établissent pour la journée, pour la saison ou pour l'année à travers les variations d'altitudes, d'expositions, de particularités géomorphologiques, hydrographiques et climatiques. Ainsi, le territoire pastoral exprime l'extension et la cohérence du territoire dans son ensemble, tout en dévoilant la ténacité des sentiments d'appartenance envers les espaces où l'homme passe, stationne, réside et travaille.

\section{5. Évolutions et permanences}

Dès le début des années 1990, l'économie fondée sur l'agropastoralisme traditionnel devient un modèle obsolète. En effet, depuis 1993-1994, aucun troupeau d'ovins de Montegrosso n'est monté aux Navette où la forêt commence à gagner les alpages. En 1995 et jusqu'en 2000, un seul troupeau villageois d'une douzaine de vaches a passé la belle saison à Case Fascei où l'étendue des prés fauchés décroît d'année en année. Parallèlement, les tecci et leurs terrains deviennent des propriétés privées et les paysans acquièrent le droit de les léguer et de les transformer. Ils ne sont plus les usagers de terres communes, périodiquement remises en cause et redistribuées. "Nous avons changé les règles, nous avons fait chacun pour soi », nous dit une agricultrice septuagénaire, soulignant ainsi le sens social du changement. Entamé dans les années 1950-1960, ce processus arrive à terme. De plus, une grande partie de la population active travaille actuellement dans la vallée et sur la côte où quelques ménages ont déjà leur résidence principale. Pour faire face à ces mutations économiques et sociales, la commune loue les alpages destinés aux gens du pays à des éleveurs venant de la côte. Ceux-ci effectuent, dès lors, une transhumance directe ou estivale et à distance et introduisent de plus en plus la cohabitation des ovins et des bovins sur des lieux où autrefois ces espèces s'excluaient mutuellement. Ces éleveurs produisent du beurre et du fromage qu'ils écoulent aux randonneurs et aux vacanciers. Ainsi, la transformation des règles de propriété et d'utilisation des espaces s'accompagne du développement d'une économie de marché, d'une monétarisation des échanges, qui fait une place non négligeable au tourisme de proximité. Nous assistons donc à des changements en cascade qui marquent la fin d'un système.

Toutefois, si le système de production ancien n'est plus viable, les constructions, les pratiques et les produits liés à ce système structurent encore la mémoire collective. Ainsi, plusieurs tecci et leur environnement sont entretenus par les familles, tant pour y aller à la belle saison que pour être loués à l'occasion. Les séjours aux tecci sont mis à profit pour cueillir herbes, salades, champignons mais aussi pour se procurer les produits laitiers locaux qui expriment la vocation pastorale des lieux. La volonté de perpétuer cette vocation et de conserver ses droits d'usage s'exprime symboliquement par l'occupation des tecci pendant les fêtes des hameaux (mai-juin à Case Fascei, début août aux Navette). Le rappel et l'accomplissement de rites au cours de ces fêtes sont des moments culminants de cycles d'affirmation identitaire. Les réinvestissements périodiques des locaux correspondent à la réaffirmation périodique de l'identité de paysan/éleveur montagnard, même si cette identité ne repose plus sur des réalités matérielles et qu'elle ne réfère qu'aux ancêtres. Ces sentiments d'appartenance s'expriment aussi à travers une valorisation des savoir-faire et des aliments traditionnels, soit festifs (viandes grillées, spagettata), soit quotidiens (pains, fromages, tourtes aux végétaux sauvages). C'est le cas à la Madonna della Neve (fig. 7) où l'appartenance territoriale et culturelle (le fait d'être berger de Montegrosso) s'exprime par la participation à la messe et à la communion, par la préparation et le partage du repas champêtre, par l'exécution de chants de façon improvisée mais solennelle (on chante debout, en cercle, en se regardant). La descente (fictive) des troupeaux de l'estive pour le 8 septembre donne lieu à des réjouissances qui se passent au village (messe, défilés, danses, jeux, buvettes). Depuis une trentaine d'années, au mois d'octobre, une autre fête célèbre les mêmes sentiments d'appartenance. Réunis au village, les habitants deviennent acteurs et mettent le territoire en scène (fig. 7). Pendant que rôtissent les châtaignes, plusieurs activités agropastorales sont reconstituées dans les rues: séchage des châtaignes, vannage des céréales, préparation et vente de fromages, cuisson et vente de pain, confection de paniers dont la cavanetta pour la ricotta, etc. Ces pratiques théâtralisées et codifiées fournissent la trame d'un essor touristique qui n'a, pour le moment, qu'une notoriété locale. En même temps, elles ne cessent d'indiquer une identité locale revendiquée 9 .

9. À ce sujet, Béatrice Palmero fait une remarque intéressante concernant le poids de la tradition pastorale dans la même grande région entre le XIII ${ }^{\mathrm{e}}$ et le XVIII ${ }^{\mathrm{e}} \mathrm{s}$. Elle a le net sentiment que les gestes de 
D'autres permanences sont beaucoup plus implicites quoique visibles au jour le jour. Il y a une transmission indéniable des techniques du corps (portage de charges sur la tête, par exemple), des comportements (lieux et heures de réunions de voisins) ou de l'image de marque rattachée à certains actes (faire défiler des brebis à certains moments et à certains endroits). En fait, c'est tout un ensemble de profils spatio-temporels, de relations humaines, d'agissements, de gestes qui s'héritent et qui se transforment de concert à partir de quelques principes qui gèrent l'occupation et l'exploitation des terres d'altitude. Nous comptons parmi eux la nécessaire complémentarité avec un bas pays, l'inévitable variabilité des statuts des lieux et des locaux, la complexité évolutive des déplacements des hommes et des bêtes, les spécificités, les discontinuités et les réversibilités possibles du bâti selon les lieux et les saisons, la multiplicité des motivations pour la présence des hommes. Économiques à première vue, ces motivations renvoient aussi aux mécanismes de construction de la personnalité individuelle, de la mémoire collective, de la dynamique sociale et des territoires en réseau où centres et périphéries sont interchangeables suivant les circonstances. Montegrosso est un territoire en réseau, un ensemble d'espaces vécus où le matériel et l'idéel revêtent, assez classiquement devrait-on dire, une importance égale. Aucune prospection ne pourrait restituer la cohérence de ce territoire dispersé sans l'apport des témoignages écrits et oraux et sans la compréhension des schèmes qui sous-tendent les rapports de l'homme avec la haute et moyenne montagne.

\section{Bibliographie}

Acovitsióti-Hameau 2000 : ACOVITSIÓTI-HAMEAU (A.) - La pierre sèche et le berger dans le domaine nord-méditerranéen. In: Pierres sèches. Regards croisés. Actes du VI Congrès international sur la pierre sèche, Carcès-Le Val, septembre 1998, Supplément n 8 au Cahier de l'ASER, 2000, p. 175-187.

Acovitsióti-Hameau 2005: ACOVITSIÓTI-HAMEAU (A.) Côté colline. Pratiques et constructions de l'espace sylvopastoral en Centre-Var. Aix-en-Provence, Publications de l'Université de Provence, 2005, 340 p.

Bonnemaison 2000: BONNEMAISON (J.) - La géographie culturelle. Cours de l'Université Paris I, Paris, CTHS, 2000, $152 \mathrm{p}$.

Chouquer 2001: CHOUQUER (G.) - Le parcellaire dans le temps et dans l'espace. In : GUILAINE (J.) dir., La très longue durée, Études Rurales, 153-154, 2001, p. 39-58.
Laiolo 2001 : LAIOLO (G.) - La via Marenca. Imperia, Associazone Comuni dei Lascaris, 2001, 55 p.

Lassalle 1997 : LASSALLE (J.) - Quelques données sur les pratiques pastorales dans la vallée de la Roya aux $\mathrm{XIV}^{\mathrm{e}}-\mathrm{XV}^{\mathrm{e}} \mathrm{s}$. In: L'élevage en Provence. Actes des $7^{\mathrm{e}}$ journées d'étude d'histoire régionale de Mouans-Sartoux, avril 1995, 1997, p. 135-151.

Lassalle 2001 : LASSALLE (J.) - Terres communes et delimitation de territoires à partir des litiges sur la transhumance dans la haute vallée de la Roya (XII $-\mathrm{XV}^{\mathrm{e}} \mathrm{s}$.). Provence historique, LI/206, 2001, p. 445-465.

Lassalle 2003: LASSALLE (J.) - Strata, via et drayra: tracés et enjeux des voies de circulation dans la vallée de la Roya au moyen Âge à travers les itinéraires des transhumances (XIV ${ }^{\mathrm{e}}-\mathrm{XVI}^{\mathrm{e}} \mathrm{s}$.). In : La forêt et le bois en Provence. Actes des $11^{\mathrm{e}}$ journées d'étude de l'espace provençal, Mouans-Sartoux, mai 2000, 2003, p. 181-210.

Monde alpin et rhodanien 1988: CENTRE ALPIN ET RHODANIEN D'ETHNOLOGIE (Musée Dauphinois) - La haute montagne. Vision et représentations. Grenoble, Monde alpin et rhodanien, 1-2, 1988, $258 \mathrm{p}$.

Moriani 1994: MORIANI (R.) - Le Alpi Maritime incrocio de civiltá. In: Pontedassio e la valle Impero. Conferenze 1992/1993, Imperia, 1994, p. 103-132.

Palmero 2001 : PALMERO (B.) - Les vaili à Tende et à la Brigue: une activité pastorale traditionnelle au sein des pratiques de l'époque moderne. Provence historique, LI/206, 2001, p. 467-491.

Rivas 2006: RIVAS (F.) - Construcciones pastoriles en la comarca de Monzón, Monzón (Huesca), CEHIMO, coll. Tolous, 15, 2006, $292 \mathrm{p}$.

Zonabend 1999: ZONABEND (F.) - La mémoire longue. Temps et histoires au village. Paris, Les cahiers de Gradhiva 31, éd. Jean-Michel Place, 1999, 294 p. 


\title{
L'archéologie en milieu montagnard en Languedoc-Roussillon : études de cas en Cerdagne (Pyrénées-Orientales) et sur les causses lozériens (Lozère)
}

\author{
Véronique LALLEMAND*, Hélène BREICHNER**
}

\begin{abstract}
Résumé. Cet article présente, à travers quelques cas, comment dans une même région et dans deux départements, la mise en œuvre administrative des opérations archéologiques, la pratique de terrain et les résultats qui en découlent sont différents alors même que les vestiges archéologiques sont similaires.
\end{abstract}

Mountain archaeology in Languedoc-Roussillon region: studies of cases in Cerdagne (Pyrénées-Orientales) and on the lozerian limestone plateaus (Lozère)

Abstract. This article presents, throughout a few cases, how, within one region and two districts, the administrative implementation of archeological operations, the consequent field practice and results are different, although that the archeological remains are alike.

$\mathrm{Q}$ uand on parle du Languedoc-Roussillon, on ne l'associe pas d'emblée à la montagne. On pense d'abord à la vaste plaine languedocienne et roussillonnaise, au littoral, aux garrigues ou aux Cévennes, mais on oublie que cette région dispose d'espaces montagnards dont certains à étage alpin. Si l'archéologie de cette région s'est concentrée sur la plaine, la montagne en a été longtemps le parent pauvre. Les approches archéologiques de ces territoires d'altitude, si elles ont heureusement bénéficié du travail pionnier d'archéologues bénévoles, ont mis du temps à trouver leur place et ce n'est que récemment, grâce aux opérations d'archéologie programmée menées en Cerdagne à partir des années 1990 et en Lozère à partir des années 2000 sur le Mont Lozère, qu'elles se sont fait jour.

Aujourd'hui, les espaces montagnards du Languedoc et du Roussillon sont l'objet de travaux agricoles, forestiers, d'exploitation de carrière, d'aménagements et d'urbanisme qui impactent les vestiges archéologiques et nécessitent une prise en compte spécifique. Si la loi sur l'archéologie préventive permet, pour partie, cette prise en compte, certains types de travaux échappent à cette législation (notamment les travaux agricoles et forestiers) alors qu'ils sont tout aussi destructeurs que les travaux d'aménagement.

\section{Un cadre géographique spécifique pour chacun des massifs (fig. 1)}

Le département des Pyrénées-Orientales, d'une superficie de $4116 \mathrm{~km}^{2}$, a un développement économique et une population (440000 hab., 106 hab. $/ \mathrm{km}^{2}$ ) inégalement répartis sur le territoire, avec une forte polarisation autour de Perpignan, de la bande côtière et de la plaine du Roussillon. La Cerdagne, plaine d'altitude (entre 1150 et $1500 \mathrm{~m}$ ) orientée est-ouest, a une faible densité d'occupation (24 hab./ $\left.\mathrm{km}^{2}\right)$ et une activité essentiellement tournée vers l'agriculture (élevage) et le tourisme. Ce bassin sédimentaire est situé entre le massif métamorphique du Carlit (2921 m) au nord et le massif sédimentaire du CadiPuigmal (2600/2900 m) au sud. Le versant granitique est orienté au sud et descend en pente douce vers le fond de vallée. Le versant sédimentaire forme une barrière continue et raide particulièrement spectaculaire dans la sierra del Cadi. La vallée, au relief accidenté, est drainée par le Sègre qui s'écoule vers l'est pour rejoindre l'Ebre. Le climat est de type méditerranéen montagnard avec un fort ensoleillement avec des aspects plus rudes et plus marqués dans les étages alpins du Carlit et du Cadi-Puigmal.

\footnotetext{
* Ministère de la Culture et de la Communication, DRAC de Languedoc-Roussillon, Service Régional de l'Archéologie, 5 rue Salle l'Evêque, 34967 Montpellier cedex 02 .

** Ministère de la Culture et de la Communication, DRAC de Languedoc-Roussillon, Service Régional de l'Archéologie, 5 rue Salle l’Evêque, 34967 Montpellier cedex 02 et Laboratoire d'Archéologie Médiévale Méditerranéenne (LAMM), UMR 6572 CNRS - Université de Provence, Maison Méditerranéenne des Sciences de l'Homme, 5 rue du château de l'Horloge, BP 64713094 Aix-en-Provence cedex 2.
} 


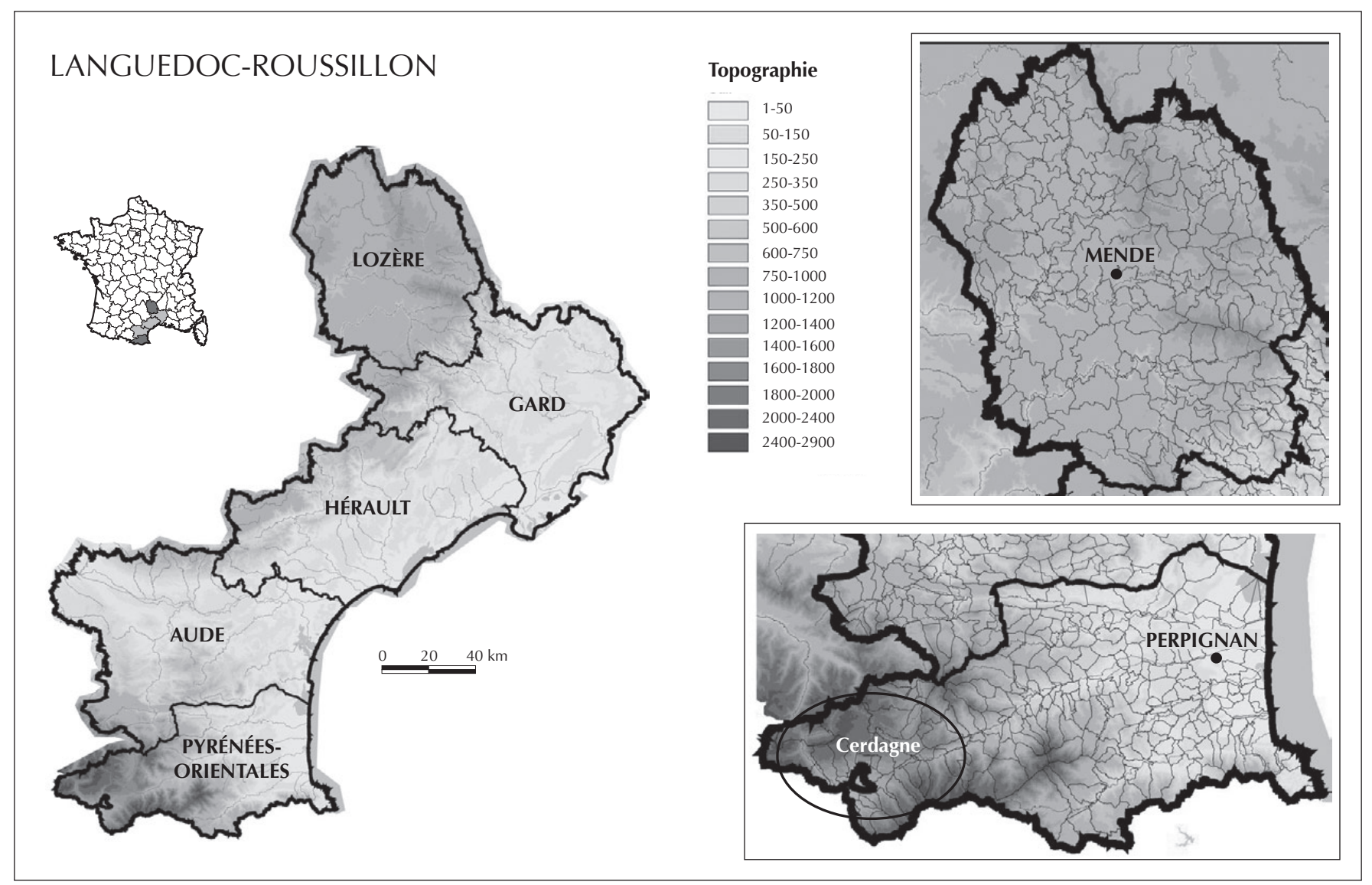

Fig. 1. Localisation des départements de la Lozère et des Pyrénées-Orientales en Languedoc-Roussillon.

La Lozère est un département montagnard qui comptait 145000 habitants en 1851 et n'a cessé de se dépeupler depuis (actuellement 76000 habitants pour un territoire de $5167 \mathrm{~km}^{2}$ ). Il est le moins peuplé en valeur absolue et en valeur relative ( $14 \mathrm{hab} . / \mathrm{km}^{2}$ en moyenne) des départements métropolitains. C'est également le département présentant l'altitude moyenne de zone habitable la plus élevée de France (environ $1100 \mathrm{~m}$ ). D'une grande variété de paysages, il englobe: au nord, les montagnes cristallines de la Margeride, au nord-ouest, les plateaux volcaniques de l'Aubrac; au sud-est, les Cévennes, avec le mont Lozère (1699 m) et le Bougès (1424 m). Au sud-ouest, les Grands Causses introduisent un paysage totalement différent de plateaux calcaires karstifiés (Sauveterre, Méjean) et de gorges profondes (Lot, Tarn). L'occupation du sol est surtout dominée par l'omniprésence du couvert forestier (environ $45 \%$ du territoire lozérien).

On observe donc, dans ces deux entités, un paysage de moyenne montagne mais avec des spécificités propres à chacun des massifs.

\section{Le cadre de l'archéologie de ces deux départements}

L'archéologie des Pyrénées-Orientales, ce sont de nombreux archéologues bénévoles qui ont œuvré, à partir des années 1960 et jusqu'au développement de l'archéologie professionnelle, en effectuant des prospections, des fouilles de sauvetages et des fouilles programmées. C'est aussi, un potentiel important de chercheurs du CNRS, de l'Université, du SRA, de l'Afan puis de l'Inrap qui s'est investi sur le département depuis des dizaines d'années. C'est un inventaire archéologique, initié par Pierre-Yves Genty avec la collaboration des archéologues bénévoles et des archéologues professionnels en devenir, qui a été soigneusement élaboré et qui est une base de décision pour l'archéologie même s'il est assez faible pour ce qui concerne le milieu montagnard. Actuellement, c'est un département qui est géré par deux agents du service régional de l'archéologie, qui a une archéologie préventive développée et qui bénéficie d'opérateurs institutionnels (Inrap et Pôle archéologique 
départemental des Pyrénées-Orientales), d'un service de collectivité non agréé (Ville de Perpignan) et d'un opérateur privé (SARL ACTER) dont le siège social est situé dans le département.

En Lozère, l'éloignement des pôles de recherches régionaux (Montpellier, Clermont-Ferrand, Toulouse...) explique l'investissement très modéré des études universitaires sur ce département. Le tissu associatif est également très faible. Enfin, l'archéologie lozérienne pâtit encore de l'absence d'appui d'un service de collectivité local.

Les données disponibles sur ce département relèvent d'une tradition fortement ancrée par les érudits chercheurs du siècle passé et se traduisent par une forte mobilisation autour du mégalithisme. Plus récemment, une équipe pluridisciplinaire menée par Alain Ferdière (Université de Tours) s'est penchée sur le cas de Javols (Anderitum), chef-lieu de la cité gallo-romaine en contexte de montagne. Enfin, il faut noter l'investissement d'I. Darnas et d'I. Rémy, médiévistes et castellologues qui explorent les castra du Gévaudan depuis plus de 20 ans.

La gestion de ce département est confiée de manière transversale à un agent du service régional de l'archéologie (prescription, suivi des documents d'urbanisme, carte archéologique nationale...) qui se charge également de l'établissement de la carte archéologique nationale sur un autre secteur de la région ainsi que de dossiers relevant de son domaine de compétence chronologique.

\section{Des vestiges similaires}

Malgré les différences géographiques et géomorphologiques de ces deux massifs, les vestiges archéologiques rencontrés sont très similaires. Ils sont les témoins des activités qui, de tout temps, ont été pratiquées en montagne et que l'on pratique encore aujourd'hui, pour certaines. Roches gravées, mégalithes, villages désertés médiévaux, exploitations des ressources naturelles de toutes périodes (carrières, mines et métallurgie, charbonnières...), aménagements vernaculaires et systèmes agropastoraux... sont le lot de l'archéologie montagnarde. D'un point de vue taphonomique, les sites ont les mêmes caractéristiques: leur conservation est généralement très bonne. Ils peuvent présenter des élévations importantes et des recouvrements sédimentaires parfois faibles à nuls. C'est un réservoir patrimonial qui n'a pas, ou peu, été touché par l'agriculture mécanisée: la base de la pelouse alpine ou de la prairie peut être en contact direct avec les vestiges archéologiques de chronologie différente dans un même horizon d'humus. La base de données Patriarche est peu alimentée sur ces espaces faute d'investissement; de prospecteurs locaux et de réelles enquêtes archéologiques; mais aussi en raison des contraintes propres au milieu : étage alpin, altitude importante, accès difficile qui rebute, enrésinement couvrant, prairies à la lisibilité nulle. Mais, lorsque le milieu s'ouvre, par exemple lors d'un incendie, et que l'on choisit de s'investir, les travaux de prospection-inventaire sont révélateurs d'un nombre de sites et d'indices largement insoupçonnés (exemple des travaux d'O. Passarrius après l'incendie de Rodès, 66). Ainsi, les menaces sur ce patrimoine sont donc plus sensibles par tous types de travaux d'aménagement, même hors du sol, alors que les plaines alluviales constituent ponctuellement une forme de protection naturelle pour les vestiges enfouis.

\section{Les types d'aménagements et d'archéologie de l'espace montagnard}

Les deux départements, aux antipodes de la région, divergent dans leur organisation sociale et démographique et surtout dans l'investissement en matière de recherche archéologique.

La Cerdagne a été, jusqu'à une date récente, peu investie par l'archéologie préventive. Seules les prospections, les recherches (notamment sur les roches gravées) et les fouilles menées par Pierre Campmajo et les opérations d'archéologie programmées récentes engagées par Christine Rendu ont jeté les bases de nouvelles méthodes d'approche et développé des problématiques. Elles ont apporté un éclairage nouveau sur ces espaces de montagne, longtemps délaissés par la recherche. Au cours des six dernières années, l'urbanisation et les projets d'aménagements touristiques en lien avec les sports d'hiver, ont connu un important développement sous la forte impulsion de la clientèle espagnole. Cette pression urbanistique sur des superficies importantes, dans des espaces non investis par les prospections systématiques et sans données archéologiques, a nécessité une prise en compte de la part du service régional de l'archéologie. En effet, si l'archéologie préventive s'était, jusque-là, principalement développée dans la plaine du Roussillon en raison de son développement économique, c'est parce qu'elle bénéficiait aussi de données tangibles apportées par les prospections systématiques qui avaient largement investi la plaine. Une première démarche a donc été entreprise auprès des services de l'Équipement, afin que le service régional de l'archéologie soit destinataire, de l'ensemble des dossiers de lotissements, d'UTN (Unité Touristique Nouvelle) et de tout autre projet d'importance en Cerdagne, ce qui n'était pas le cas. À la faveur des nouvelles dispositions législatives sur l'archéologie préventive, à partir de 2004, ce fut chose faite. Aujourd'hui, de nombreux dossiers qui ont, ou vont générer des opérations d'archéologie préventive en montagne, sont adressés au service régional de l'archéologie et l'on se retrouve ainsi dans la même situation d'approche administrative qu'en 
plaine avec des choix à faire en matière de prescriptions, au regard de l'ensemble de l'archéologie préventive régionale. Le contraste est fort en Lozère où la superficie des aménagements est rarement très étendue pour des demandes soumises à autorisation d'urbanisme (sauf pour les carrières et les éoliennes). Avec un solde migratoire beaucoup plus faiblement positif que dans le reste du Languedoc, le nombre de lotissements n'a pas crû de manière exponentielle ces dernières années. En revanche, les aménagements agricoles et forestiers, qui ne répondent pas aux critères du cadre du Code du Patrimoine, sont prépondérants et affectent tout autant les vestiges archéologiques. Ce type d'aménagement est d'ailleurs encouragé par des mesures incitatives telles que les subventions européennes (FEADER: Fond Européen Agricole pour le Développement Rural, PER: Pôle d'Excellence Rural, LEADER : Liaisons Entre Actions de l'Économie Rurale). Des zones encore préservées de tout aménagement destructeur sont désormais menacées par l'extension des exploitations agricoles mécanisées qui grignotent peu à peu les flancs des dolines, les coteaux et les crêtes en réduisant les constructions vernaculaires à l'état de gravier sous la lame des broyeurs-concasseurs. Il est d'autant plus difficile de prévenir ce genre de destructions que les sites ne sont souvent visibles et reconnaissables qu'une fois éventrés.

La perception de la protection du patrimoine archéologique s'avère donc plus sensible que dans un cadre législatif clairement applicable.

Le traitement de ces différents dossiers est donc d'ordre différent, quels sont les outils à mettre en œuvre?

\subsection{Les cas cerdans en moyenne montagne à étage alpin: une archéologie préventive}

Plusieurs opérations d'archéologie préventive ont été menées ou vont être menées en Cerdagne au cours des prochaines années.

La première opération d'archéologie préventive a été réalisée en 2005 dans le cadre d'un projet de lotissement sur la commune d'Angoustrine (1350 m d'altitude). Le diagnostic a été mené par l'Inrap sur une parcelle comportant de nombreuses boules de granit issues de l'activité fluvio-glaciaire et sans doute employées en aménagements parcellaires. Peu formé à ce type de terrain chahuté, où des éléments naturels sont potentiellement des aménagements rupestres de datation indéterminée, peut-être en lien avec des vestiges protohistoriques découverts en sous-sol, le responsable d'opération a eu beaucoup de difficultés à mener son diagnostic, en raison du manque d'expérience dans l'approche du milieu montagnard et de ses spécificités et de la contrainte de la banalisation des tranchées mécaniques. Ce diagnostic a livré une occupation sur environ $1000 \mathrm{~m}^{2}$ appartenant au premier âge du Fer. Une structure fossoyée contenait un mobilier très abondant de céramique modelée généralement liée à un habitat. Une collaboration s'est établie avec Pierre Campmajo pour l'étude de ce mobilier dit à « décor cerdan ». La présence de ces vestiges archéologiques justifiait la mise en œuvre d'une fouille préventive compte tenu de l'impact des travaux. Toutefois, le coût de la fouille archéologique préventive, qui remettait en cause l'économie du projet, a été très mal vécu par la municipalité. Aussi, c'est en travaillant avec l'architecte du projet que des solutions techniques ont été trouvées afin de préserver le site. Ainsi, aujourd'hui seules les données du diagnostic permettent de documenter ce site.

La seconde opération d'archéologie préventive (2006) concernait un projet de construction immobilière à Bolquère au lieu-dit Pla de la Creu (1780 m). Le diagnostic archéologique, qui a bénéficié d'une collaboration entre l'Inrap et le CNRS, portait sur un terrain, en limite de la station de ski de Pyrénées 2000, non soumis à l'agriculture mécanisée et couvert d'une pelouse alpine émaillée de blocs ou amas de blocs granitiques. Une prospection préalable a été menée. Ses résultats ont permis de guider l'ouverture des sondages mécaniques qui par la suite ont été étendus à la parcelle dans le sens de la pente. Un site protohistorique avec des aménagements parcellaires de blocs de granit, lié à une zone humide a été mis en évidence. Le projet d'aménagement était porté par la mairie avec deux cabinets d'architectes. Sur une partie du site, où les vestiges étaient peu importants, un des architectes, a proposé une modification des fondations, sous forme de pieux, pour assurer leur conservation. Le second cabinet d'architecte, peu sensibilisé à l'archéologie, a poursuivi son projet sans proposer de solution technique. La fouille préventive s'est donc révélée nécessaire. Toutefois, suite à diverses embûches administratives, la fouille de cette partie du site, réalisée par l'Inrap, n'a eu lieu qu'en juin 2008. Elle a été menée par un responsable d'opération protohistorien, qui a été parfois dérouté par ce type de site, où les amas de granit directement à l'air libre, peuvent faire partie intégrante des structures protohistoriques.

En 2008, trois opérations archéologiques préventives ont été prescrites : un projet de station de ski avec urbanisation et pistes (62,5 ha), un projet d'UTN (Unité Touristique Nouvelle) avec urbanisation et golf (91 ha) et un projet d'aménagement touristique autour de l'ancienne centrale solaire Thémis (9,75 ha). Pour les deux premiers, il s'agit de dossiers d'UTN, dossiers longs en terme administratif et à enjeux politiques importants: c'est dans ce type de dossiers qu'on mesure le millefeuille administratif, l'État intervient souvent avec beaucoup de casquettes et les différentes politiques sectorielles ne sont pas toujours compatibles.

Le projet d'aménagement du domaine skiable de «Porte des Neiges » avec son espace résidentiel (fig. 2) porte sur 


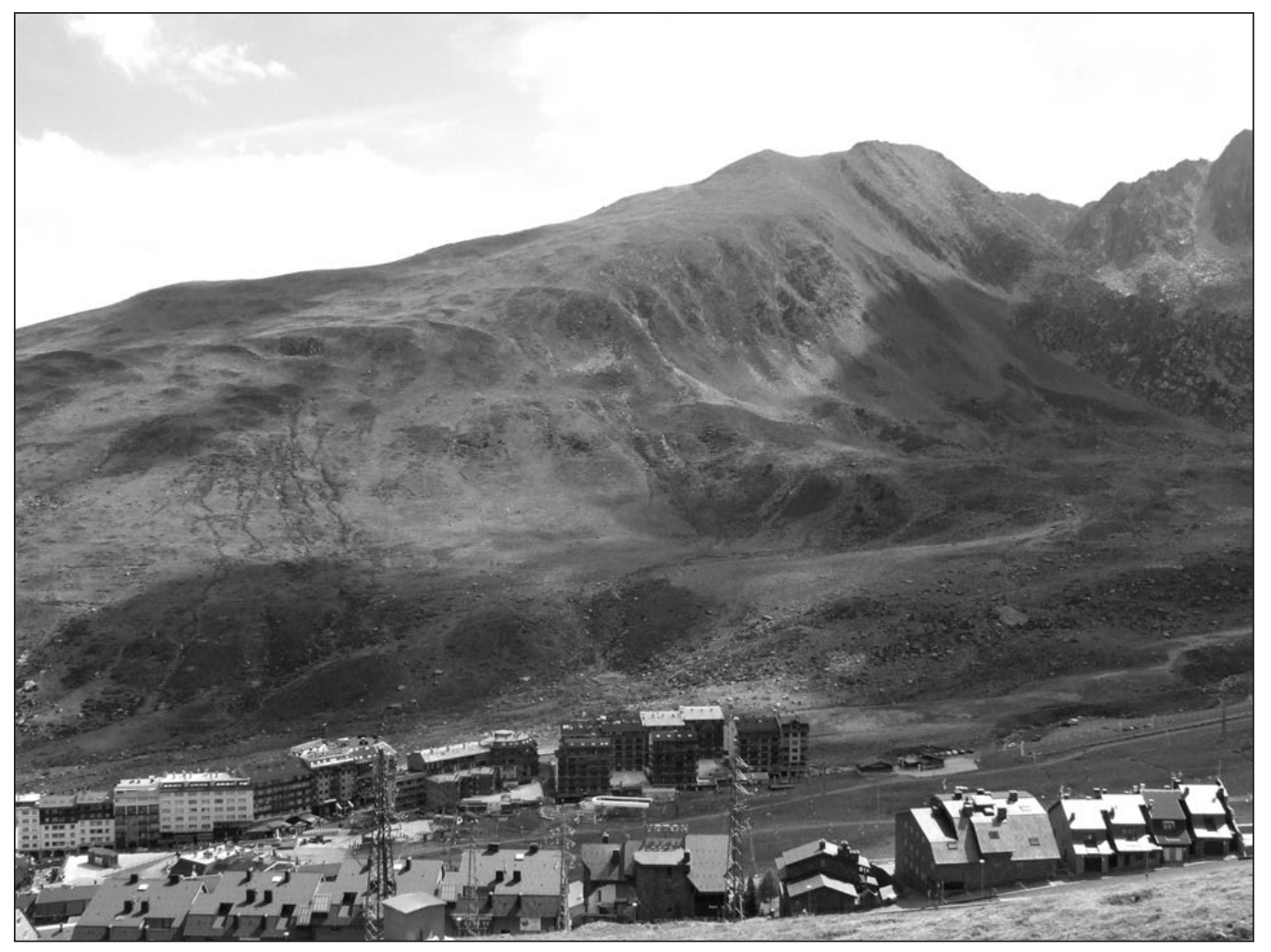

Fig. 2. Porta (PyrénéesOrientales): vue de la zone où doit être implantée la future urbanisation et la station de ski. Cliché V. Lallemand. un site actuellement vierge de tout aménagement, en vis à vis du Pas de la Case (Andorre) fortement urbanisé et aménagé pour la pratique du ski. Ce projet a bénéficié d'une autorisation d'UTN en 1996. Il se place au cœur d'un cirque glaciaire au fond duquel coule l'Ariège, qui constitue la frontière entre la France et l'Andorre. Le projet s'étage de $1850 \mathrm{~m}$ au nord à $2715 \mathrm{~m}$ au sud et touche des terrains couverts par la pelouse alpine et des zones d'éboulis. Ce projet privé, qui bénéficie de capitaux venus d'Espagne et d'Andorre, était alors soutenu par la municipalité de l'époque (avant 2008).

Le projet d'UTN de Porté-Puymorens, se situe en zone frontalière avec l'Espagne, au pied du col du Puymorens. Il prévoit une urbanisation sous forme d'hôtels, de résidences hôtelières et secondaires (11 ha), la création d'un golf (70 ha) et l'agrandissement et la modernisation de la station de ski (10 ha). Si l'urbanisation porte sur les abords ouest et nord du village actuel occupé par des prairies dégradées, le golf porte sur des espaces agricoles et naturels sans aménagements qui comportent de nombreuses formations quaternaires d'origine glaciaire (blocs, moraines), à une altitude comprise entre 1600 et $1800 \mathrm{~m}$. Ce projet est pour l'instant porté par la commune de Porté-Puymorens.

Le dernier projet concerne un aménagement touristique de la reconversion du site de la centrale électro-solaire Thémis sur la commune de Targasonne. Ce projet, soutenu par le Conseil Général des Pyrénées-Orientales, est localisé à une altitude comprise entre 1600 et 1700 m, sur un versant exposé au sud, dominé par le Pic dels Moros (2135 m) qui surplombe le haut plateau cerdan. Les terrains sont occupés par la prairie et des espaces boisés dans les talwegs.

Pour les deux premiers projets, aucun site archéologique n'est actuellement enregistré dans la base de données Patriarche. Pour le troisième, les parcelles recèlent, d'ores et déjà, des sites archéologiques enregistrés. Il s'agit d'un village occupé durant tout le Moyen Âge avec son église et son cimetière, ceinturé de parcelles agricoles. À l'ouest du projet, des zones renfermant des tumuli ont été observées. Enfin, au sud, le chaos de Targasonne a livré de nombreux sites archéologiques de l'âge du Bronze et de l'âge du Fer. Ces trois projets offrent l'opportunité d'engager, dans le cadre de diagnostics, une recherche archéologique qui vient s'intégrer pleinement dans les programmes sur l'histoire de l'anthropisation de la haute montagne de la préhistoire jusqu'à nos jours (travaux de C. Rendu pour la Cerdagne, de J. Palet-Martinez, Y. Miras et S. Riera Mora de l'Université de Barcelone et de l'Institut Catalan d'Archéologie Classique de Tarragonne pour l'Andorre, prospection thématique dans le Cantal de Y. Miras et F. Surmely). Pour appréhender ces espaces montagnards dans le cadre de l'archéologie préventive, il faut s'appuyer sur une approche pluridisciplinaire (archéologie du paysage, agropastorale, approche environnementale, géographie physique et paléo-écologie, palynologie, anthracologie...), qui associe les opérateurs d'archéologie préventive (Inrap et Pôle Archéologique Départemental des Pyrénées-Orientales) 
aux équipes du CNRS œuvrant sur les mêmes terrains. Ainsi, pour la préparation des projets d'opérations, chacun des opérateurs (Inrap et PADPO) s'est rapproché des équipes du FRAMESPA UMR 5136 afin de formaliser des partenariats par le biais de conventions et d'élaborer des projets de diagnostic prenant en compte ce milieu spécifique, s'appuyant sur des méthodes déjà rodées, s'intégrant aux problématiques générales sur l'espace cerdan et mettant en commun les connaissances.

Mais dans le cadre de ces dossiers, il faudra se plier aux contraintes extérieures liées au milieu, aux législations environnementales fortes et aux questions scientifiques spécifiques à ces espaces. Les contraintes naturelles du milieu montagnard sont prégnantes. Topographie et climat imposent leur poids. Les prospections vont être menées sur des parcelles en fort dénivelé ne permettant pas de couvrir les mêmes surfaces qu'en plaine. La période d'intervention sur le terrain est bornée par les chutes de neiges laissant une fenêtre d'intervention comprise entre le début du mois de juin et le milieu du mois d'octobre. Les contraintes environnementales sont fortes. Ces projets portent sur des sites protégés au titre de l'environnement et pratiquer, par exemple, un sondage dans une tourbière nous paraît, à nous archéologue indispensable, pour avoir une approche du paléo-environnement; mais la DDAF (Direction Départementale de l'Agriculture et de la Forêt) et la DIREN (Direction Régionale de l'Environnement) ne voient pas la chose du même œil quand le site est protégé (NATURA 2000, Zone Naturelle d'Intérêts Écologiques Faunistiques et Floristiques, Zone Importante pour la Conservation des Oiseaux...). La mise en œuvre de sondages demande donc des validations préalables de ces services. De même, le défrichement et le déboisage d'une zone pour la réalisation du diagnostic, ne sont pas forcément conformes aux préconisations de ces services. Il ne faut pas perdre de vue que les archéologues interviennent dans un milieu naturel protégé et fragile, où toute action peut avoir des conséquences sur l'environnement (perturbation ou disparition d'espèces végétales ou animales, modification des écosystèmes, érosion des sols...).

Ici, le diagnostic va devoir prendre obligatoirement une forme différente et originale pour s'adapter à ces contraintes et répondre au mieux aux questions scientifiques spécifiques posées par cet espace : le diagnostic « classique », tel qu'on le pratique depuis des années sous forme de tranchées systématiques, ne peut répondre à toutes ces exigences.

Dans tous les cas, le diagnostic doit avoir pour objectif de définir les « marqueurs » archéologiques liées à l'anthropisation du territoire concerné. En cela, le but est d'identifier les types de sites rencontrés (cabanes, enclos, couloirs à traire, voies pastorales et de transhumance, charbonnières, structures minières et métallurgiques, roches gravées).

Il doit d'abord passer par une étude documentaire prenant en compte la documentation textuelle et cadastrale des époques médiévales, modernes et contemporaines, la photo-interprétation et carto-interprétation avec localisation des structures ainsi découvertes. Dans un second temps, il doit être suivi d'une prospection pédestre de toute la zone d'étude avec une géolocalisation des sites et vestiges archéologiques (GPS). La réalisation des sondages manuels ou à l'aide d'engin mécanique spécialisé dans les zones de forte pente (type «pelle-araignée »), en zone difficile ou écologiquement sensible, doit nécessairement bénéficier de l'accord des services compétents en matière d'environnement quant à leur implantation. Ces sondages doivent permettre d'obtenir une stratigraphie (phases d'abandon, d'occupation, de construction), les fonctions supposées des structures expertisées et d'effectuer des prélèvements pour des études paléo-environnementales et des datations radiocarbone.

À l'issue du diagnostic, ces données doivent être formalisées pour être un outil d'aide à la décision, pour le SRA et l'aménageur qui auront à discuter sur la compatibilité du projet avec les vestiges archéologiques et qui décideront des suites à donner, notamment par la mise en œuvre de fouilles préventives, de mesures conservatoires ou la modification du projet sur les sites. Ainsi, ces diagnostics sont une première étape essentielle car, bien souvent dans le cadre de vastes projets, les modifications ou les mesures conservatoires (quand ce n'est pas l'abandon du projet pour des raisons extérieures) sont souvent retenues. Elles permettent d'éviter l'engagement de fouilles préventives considérées comme onéreuses par les aménageurs, qui n'en tiennent pas compte lors de l'établissement en amont des projets et contraignantes en matière de calendrier.

À l'heure où nous rédigeons cet article, le projet de Porta essuie de nombreux refus administratifs alors que le diagnostic devait être engagé en juin 2009 et le projet de Porté-Puymorens est encore en instruction administrative. Seul le projet de diagnostic concernant l'aménagement touristique sur l'ancienne centrale Thémis devrait être engagé à partir d'avril 2009, par une équipe du Pôle Archéologique Départemental de Pyrénées-Orientales et du FRAMESPA UMR 5136, selon le schéma de diagnostic précédemment défini. Ici enfin, nous pourrons avoir un retour d'expérience sur une prescription d'archéologie préventive en espace montagnard.

\subsection{Les cas lozériens en moyenne montagne: une archéologie programmée « palliative »}

L'archéologie préventive sur le territoire lozérien est rare: en 2007, sur 22 dossiers parvenus au SRA, 7 ont été prescrits (en 2008: 12 dossiers arrivés, 3 prescrits). Qu'il s'agisse des dossiers de carrières ou de lotissements, les aménagements concernés peuvent être remis en question d'un point de vue économique par les travaux archéologiques. C'est 
le cas notamment d'une carrière où le montant de la fouille sera égal au chiffre d'affaires d'une année entière d'exploitation. Les enjeux d'emploi à l'échelon local dépassent largement le seul domaine de l'archéologie. Récemment, un arrêté de diagnostic a dû être abrogé pour ces raisons sur la commune de La Canourgue où les données historiques et archéologiques sont pourtant riches en informations. La viabilité du lotissement étant en péril et le préfet de Région ne souhaitant pas aggraver la perception des effets de la crise financière sur le secteur du BTP, des solutions « palliatives » ont permis de s'assurer de l'absence de vestiges menacés. Il faut souligner que ce cas risque de se reproduire à très court terme et pas uniquement sur des secteurs ruraux.

À ces maigres exemples d'archéologie préventive, il faut ajouter deux initiatives particulières à ces milieux ruraux et forestiers, qui comme on l'a déjà évoqué, échappent en théorie à notre législation.

La première concerne une découverte réalisée sur un terrain agricole au lieu-dit « les Aouzerals » sur la commune de La Malène. Bien que le site soit connu et publié, les vestiges d'un habitat du haut Moyen Âge ont été bouleversés par l'exploitant de la parcelle qui s'est contenté de pousser un pierrier au bulldozer. Les arases de murs en pierres sèches d'une ferme du haut Moyen Âge y ont été mises au jour, associées à de très abondants lots de céramiques (fig. 3).

L'agriculteur étant dans l'impossibilité de prendre en charge le coût d'une fouille archéologique d'urgence, il a été décidé de mettre en place une fouille pluriannuelle programmée dirigée par un agent du SRA. On pourrait arguer du fait de l'existence du Fonds National pour l'Archéologie Préventive pour répondre à ce genre de sollicitations mais sans rentrer dans des détails complexes, ce type de cas ne peut être intrinsèquement considéré comme répondant aux critères d'éligibilité de prise en charge. La solution conservatoire a dû également être écartée car les vestiges étaient

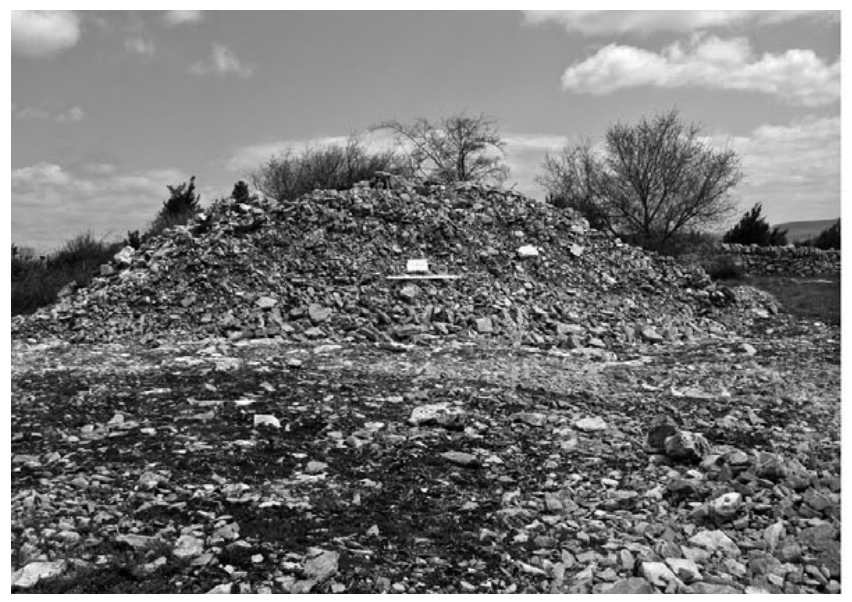

déjà fortement érodés et leur intérêt scientifique justifiait une documentation plus complète. L'agriculteur a accepté de surseoir aux travaux mais devait pouvoir récupérer la partie de la parcelle concernée. Au terme des trois années engagées, c'est chose faite.

Parallèlement à ces missions ponctuelles de sauvetages programmés, d'autres actions de sensibilisation en amont de travaux ont été effectuées auprès du plus gros aménageur lozérien: l'ONF.

Cet établissement public établit régulièrement des cartes d'inventaires de chaque forêt domaniale dont il a la charge. À cette occasion, le service régional de l'archéologie a été sollicité pour obtenir la carte des sites archéologiques localisés dans ces aires de plusieurs hectares (forêts domaniales du Bramont et de Mende). Ces documents constituent des références pour une dizaine d'années. Une simple réponse cartographique ne pouvait suffire à établir un contact durable et faire comprendre à ces partenaires privilégiés les enjeux de conservation de zones aujourd'hui peu ou pas prospectées. En effet, les agents de terrain n'ont pas forcément les moyens de savoir à quoi correspondent les pastilles de la carte. C'est pourquoi, une journée de formation a permis de réunir, sur le terrain, les agents chargés de l'établissement de ces inventaires, les gardes forestiers et un agent du SRA. Cette journée avait pour but de donner des clefs de lecture afin de détecter d'éventuels vestiges et surtout de déterminer quelles mesures de précaution adopter en cas de doute. Par prudence, chaque zone suspecte fera l'objet d'une protection d'office et ne sera pas sujette à l'exploitation forestière. Ces contacts permettent également de faire remonter des informations qui ne parviennent pas forcément aux services archéologiques. De même, cette sensibilisation a démontré qu'une forêt pourtant bien connue par ses gestionnaires, recelait des témoignages anthropiques insoupçonnés. C'est donc sur la base d'un échange de données SIG puis d'une formation sur place des

Fig. 3. La Malène (Lozère): site des Aouzerals vu avant et après l'intervention archéologique. Clichés H. Breichner.

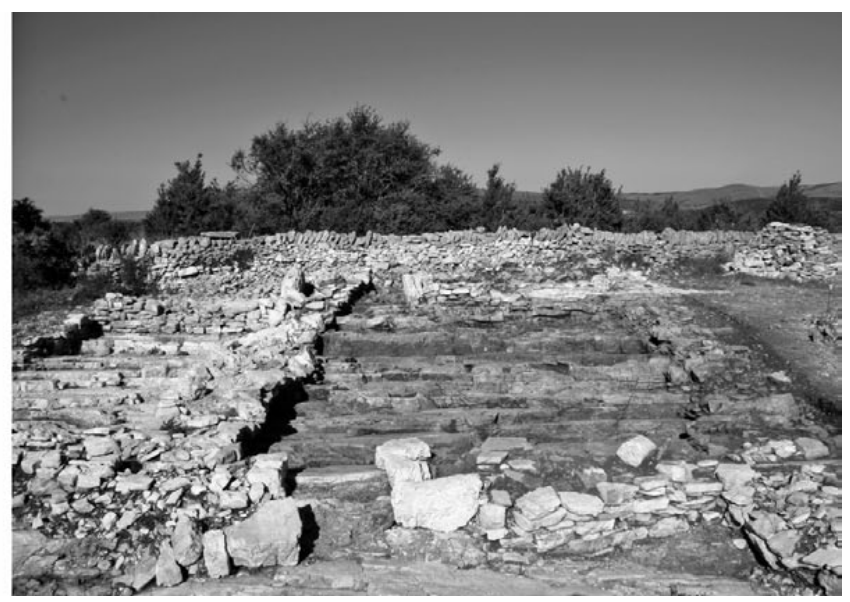


techniciens, que cette collaboration va se poursuivre par le biais d'une convention et d'un système d'alerte de vigilance, de propositions de mise en place de zones « gelées », pour éviter les destructions des sites majeurs (oppidum, champ de tumulus) ou simplement en cas de présomption de vestiges. En revanche, une nouvelle fois dans ce genre de dossiers nous sommes amenés à renoncer à effectuer des diagnostics préalables aux coupes ou à l'ouverture de pistes. Les surfaces sont trop importantes et inaccessibles (lisibilité des sols, dénivelés...).

En conclusion, le contexte montagnard cumule donc des spécificités archéologiques et des problématiques particulières permettant de les aborder tout en composant avec des contraintes extérieures assez lourdes. Dans les deux cas, la gestion des dossiers implique de nombreux partenaires institutionnels, avec des implications fortes dans le domaine environnemental: DIREN, DDAF, Parc National des Cévennes, ou Parc Naturel Régional des Pyrénées Catalanes.

D'un point de vue méthodologique, nous tenons à souligner l'importance de la première approche de terrain (prospection et diagnostic) qu'il faut considérer comme une opération archéologique globale et fondamentale, qui sera souvent la seule façon d'explorer sur une petite fenêtre une problématique très large qui est celle de l'occupation des espaces d'altitude sur la longue durée. Il convient donc de tenter d'explorer le maximum du champ d'investigation lors de la première phase de diagnostic en promouvant une synergie avec les forces en présence (CNRS, Collectivités, Inrap).

En effet, pour des raisons de viabilité économique, ces projets soumis parfois à des diagnostics ou explorés en sondages ne seront jamais étudiés par des fouilles archéologiques. 


\title{
Quelle archéologie préventive pour l'espace montagnard? Pratiques et enjeux dans l'Arc alpin et le département des Hautes-Alpes
}

\author{
Xavier MARGARIT*, Carine DEAL**
}

\begin{abstract}
Résumé. Les espaces de moyenne et surtout de haute montagne connaissent un développement récent des recherches et des découvertes archéologiques, mais demeurent presque toujours en marge de l'archéologie préventive. Cette situation paradoxale pose la question de la nature et de l'impact des travaux en zone d'altitude et de l'intérêt de leur suivi archéologique. Dans cette perspective a été réalisé un bilan typologique et méthodologique centré sur la région Provence-Alpes-Côte d'Azur (France), et plus particulièrement sur le département des Hautes-Alpes. Il a permis de mettre en évidence un certain nombre de caractéristiques qui motivent l'adaptation et le développement d'une archéologie préventive spécifiquement dévolue au milieu montagnard.
\end{abstract}

Preventive archaeology in moutain environments ? Practices and issues in the Alps and the "Hautes-Alpes" County

Abstract. Preventive archaeology has contributed considerably in France during the last twenty years to extending our scientific knowledge, although this applies to some geographical sectors more than others: these advances, which have benefited from the economic factors involved in territorial development, have focused mainly so far on urban areas and plains to the detriment of other places such as mountain regions. Despite their considerable potential in terms of the numbers of unexplored archaeological sites they harbour, mountain regions have given rise to very few efforts on preventive archaeological lines. In this context, it was proposed to perform a typological and methodological survey in the Provence-Alpes-Côte d'Azur region, focusing in particular on the "HautesAlpes" County. Studies were therefore carried out on the characteristics of the sites, how they were set up and developed, and what preventive archaeological policies had been applied, such as those based on "archaeological zoning" rules, in particular. The results of this study show the existence of a number of similarities and differences between sites, which suggests that further efforts are now required to specifically adapt and develop the preventive archaeological approach for dealing with mountain regions.

$\mathrm{L}$ 'archéologie préventive a considérablement contribué ces vingt dernières années au développement de nos connaissances scientifiques, de façon néanmoins inégale selon les secteurs géographiques considérés. Ainsi, en France, cet essor, principalement conditionné par le facteur économique de l'aménagement du territoire, a-t-il surtout concerné les noyaux urbains et les secteurs de plaines périphériques ou situés sur les axes de circulation, au détriment, par exemple, des zones de montagnes. Parallèlement, sous l'impulsion de recherches archéologiques programmées, ont été récemment mis en évidence de nombreux témoignages d'occupations du milieu montagnard, pour des périodes et des secteurs encore mal ou jamais documentés. Ce double constat, d'un milieu montagnard à la fois potentiellement riche en sites et néanmoins peu investi par l'archéologie préventive, pose donc la question de l'impact des travaux en zone d'altitude, et de la pertinence de leur suivi archéologique.

Dans cette perspective, a été engagé un bilan typologique et méthodologique centré sur la région Provence-AlpesCôte d'Azur, et plus particulièrement le département des Hautes-Alpes. Ainsi, ont été respectivement analysés dans ce cadre, la nature des sites, les types de travaux d'aménagement, et, à une échelle plus large, les politiques d'archéologie préventive en vigueur fondées notamment sur le concept réglementaire de «zonage archéologique ». Il ressort de cette étude un certain nombre de caractéristiques qui motivent l'adaptation et le développement d'une archéologie préventive spécifiquement dévolue au milieu montagnard.

\footnotetext{
* Ministère de la Culture et de la Communication, DRAC de Provence-Alpes-Côte d'Azur, Service Régional de l'Archéologie, 21-23, boulevard du Roi René, 13617 Aix en Provence cedex 1 et Laboratoire Méditerranéen de Préhistoire Europe Afrique (LAMPEA), UMR 6636 CNRS - Université de Provence, Maison Méditerranéenne des Sciences de l'Homme, 5 rue du château de l'Horloge, BP 647, 13094 Aix-en-Provence cedex 2. ** Conseil Général des Hautes-Alpes, Musée Muséum Départemental, 6 Avenue Maréchal Foch, 05000 Gap.
} 


\section{La montagne, milieu spécifique, archéologie spécifique}

\subsection{Un espace archéologique marginal?}

L'espace montagnard, principalement caractérisé par son altitude et l'ampleur de son dénivelé, concerne différents ensembles topographiques circonscrits en massifs, et hiérarchisés en étages, qui couvrent, respectivement, $20 \%$ et $25 \%$ des territoires français et européen. Dans son acception large, il est notamment constitué de sommets, de versants, de plateaux et de vallées, auxquels s'attachent différentes spécificités naturelles, notamment climatiques, parfois rigoureuses. Ces particularités ont largement influencé les modalités de circulation, d'occupation ou d'exploitation de ces territoires.

Eu égard à l'histoire de ces peuplements, on rappellera que, dès le XIX ${ }^{\mathrm{e}} \mathrm{s}$., la découverte et l'exploitation de sites montagnards, en l'occurrence lacustres, ont joué un rôle fondamental dans le développement de l'archéologie comme discipline scientifique (Coye 1998, p. 193). Pourtant, à l'exception de fonds de vallées et de certains sites emblématiques, comme par exemple ceux de roches gravées du Mont Bégo ou du Valcamonica (De Lumley 1995), force est de constater que, jusqu'à la fin du XXe s., l'archéologie programmée a relativement peu investi les secteurs montagneux. Plus précisément, et selon un ratio quantitatif inversement proportionnel au développement de l'altitude, elle s'est davantage attachée à l'étude des plaines, des plateaux et des vallées plutôt qu'à celle des versants et des sommets. Ce désintérêt de l'archéologie pour les zones de haut et de très hauts reliefs, a concerné, tant, le milieu forestier, considéré lui-même encore récemment comme archéologiquement peu attractif, que les espaces de prairie et de pelouse alpine. Cette désaffection résulte de la perception particulière de ces milieux, réputés, à tort, à la fois comme peu favorables à l'occupation et comme inadaptés à la conservation des sites en raison de leur déclivité. En somme, si de vastes zones d'altitude ont été assimilées à des déserts archéologiques, c'est en raison, d'une part, de l'absence présumée de sites, et d'autre part de l'idée d'une probable destruction de ceux qui y aurait malgré tout été implantés. Ce constat d'une désaffection traditionnelle pour l'archéologie de moyenne et de haute montagne jusqu'à la fin du $\mathrm{XX}^{\mathrm{e}} \mathrm{s}$., résulte donc davantage d'une lacune de la recherche plutôt que de l'absence avérée de sites.

\subsection{Les acquis récents de l'archéologie programmée}

Au-delà des aspects précédemment évoqués, la prise en compte des territoires de montagne dans les problématiques archéologiques est relativement récente. Elle s'est appuyée, tant depuis les années 1970 et 1980 sur l'étude de sites spécifiques, que depuis les années 1990 et 2000 sur la multiplication et le développement de projets de recherche pluridisciplinaires et de prospections. Ainsi peut-on citer, pour les Alpes, les exemples du colloque d'Aoste $^{1}$ en 2006, des programmes CIRCALP ${ }^{2}$, JurAlp ${ }^{3}$, et d'étude sur l'Ubaye (Garcia 2007), ou sur le pastoralisme alpin ${ }^{4}$ (Leveau 2008). Les recherches de terrains, pour leur part, ont permis la mise au jour d'une documentation inédite considérable dans de nombreux massifs, tel que les Alpes (Mocci et al. 2005), les Pyrénées (Carozza et al. 2005), ou le Massif Central (Miras et al. 2006). Ainsi, de 1998 à 2005, 260 sites ont, par exemple, été recensés entre $1600 \mathrm{~m}$ et $2700 \mathrm{~m}$ d'altitude, dans le cadre des prospections des massifs du Champsaur et de l'Argentièrois (Hautes-Alpes, Walsh et al. 2005).

Bien que les problématiques ayant présidé à ces travaux soient diversifiées, notamment en fonction des périodes ou des régions considérées, on y retrouve des thèmes récurrents, qui constituent des spécificités de l'archéologie de montagne. Parmi ceux-ci, notamment, l'art rupestre, l'archéologie minière ou relative à l'exploitation des ressources naturelles, et l'archéologie agropastorale. Dans la plupart des cas, cependant, ces recherches participent à l'étude des interactions culturelles ou économiques, voire paléo-environnementales, entre différents territoires. Ainsi, la montagne, entité géomorphologique ou paysagère parmi d'autres, participe-t-elle à la compréhension des espaces qui lui sont périphériques.

Sous l'impulsion de ces travaux ont donc été découverts de nombreux sites d'altitude, qui constituent un apport à la fois quantitatif et qualitatif. Ces résultats comblent des lacunes sur des secteurs encore mal ou jamais documentés, et concernent, d'une façon générale, toutes les périodes depuis la Préhistoire. Ils montrent également que la montagne peut être un secteur d'étude privilégié, notamment pour l'exploitation du milieu naturel. Ils présentent également des spécificités sur la forme et les modalités d'implantation. Ainsi, convient-il de noter, par exemple, une certaine propension à l'utilisation de la technique de la pierre sèche pour les structures agropastorales. Quant aux logiques d'implantation, on notera une certaine prédilection pour l'occupation des zones de replat et de moindre déclivité (Walsh et al. 2005, p. 28), voire celle en situation d'abri sous roche. Enfin, ces sites présentent des formes

1. Alpis Graia, Archéologie sans frontières au Col du Petit Saint-Bernard. 2. Circulations et identités culturelles alpines à la fin de la Préhistoire. 3. GDR JurAlp, Du climat à l'Homme. Dynamique holocène de l'environnement dans le Jura et les Alpes.

4. Projet collectif de recherche «Occupation du sol et pastoralisme de la Préhistoire au Moyen Âge dans le sud du massif alpin». 
caractéristiques, qui résultent des processus taphonomiques propres à ces milieux montagnards. Outre la relative rareté des mobiliers céramiques ou ostéologiques recueillis lors des fouilles ou des prospections, on constate, en effet, que les stratigraphies y sont naturellement très peu développées, et que les structurations archéologiques sont, de ce fait, souvent perceptibles en simple affleurement, voire en relief ou en microrelief (fig. 1). Ces différents aspects, dont cette assez bonne perception des structures en surface, fait de cet environnement de prairies d'altitudes et de pelouse alpine un milieu archéologique spécifique : à la fois dégagé comme en plaine, mais relativement conservateur d'élévations, comme en foret. Ainsi, par la mise en évidence de nombreux témoignages de fréquentations, d'occupations et d'exploitations, l'archéologie programmée a-t-elle permis de renouveler notre vision de ce milieu montagnard.

\subsection{La particularité des buttes d'empierrements}

Caractéristique de nombreux milieux ruraux et agricoles, et donc également d'un certain nombre de secteurs de montagne, les buttes d'empierrements, autrement qualifiées de pierriers, de clapiers ou de murgers, correspondent à des accumulations anthropiques de pierres (fig. 2). Ces structures, rarement isolées, de formes et de tailles variées, généralement linéaires, subcirculaires ou oblongues, mesurent plusieurs mètres, voire plusieurs dizaines de mètres de dimensions (fig. 3). Parfois abusivement assimilées à des tumulus, elles correspondent plus généralement à des tas d'épierrement de champ, et à l'aménagement de limites parcellaires agropastorales dont la datation est malaisée. Pourtant, de nombreuses découvertes de vestiges ou de structure archéologique en leur sein témoignent de la complexité et de la diversité du phénomène. Certaines de ces buttes correspondent assurément, à l'origine, à des ruines archéologiques de bâtiments, comme par exemple sur les sites haut-alpins, respectivement gallo-romain et médiéval, du Clapier des Monge à Baratier et du Prieuré Saint-Laurent à Barret-sur-Méouge (fig. 4). Elles constituent, d'ailleurs, dans ces cas comme dans d'autres, des milieux particulièrement favorables à la conservation des murs en élévations. Le phénomène de buttes d'empierrement, correspond donc a des réalités vraisemblablement très diverses, voire mixtes, de périodes variées, pour partie récentes et stériles, et pour partie archéologiques. Cette problématique d'étude demeure peu investie par l'archéologie programmée en raison des importants moyens de terrassement nécessaires à l'investigation de ces structures. En revanche, compte tenu de leur démantèlement fréquent dans le cadre de travaux ruraux (fig. 3), comme réserves naturelles de pierre pour la réalisation de dalles de fondation en béton, ces buttes d'empierrement constituent des objets d'étude particulièrement adaptés à l'archéologie préventive.

\section{Les politiques d'archéologie préventives}

Réalisée dans un cadre réglementaire préalablement aux travaux d'aménagement du territoire, l'archéologie préventive a largement contribué, depuis la fin du XX⿳⺈ s., au développement de nos connaissances scientifiques. En 1992, la convention de Malte, relative à la protection du patrimoine archéologique, en a constitué un jalon fondamental au niveau européen. En France, depuis la création en 1974 de l'association pour les fouilles archéologiques nationales (Afan), l'archéologie préventive a été principalement structurée par le décret du 5 février 1986, relatif à sa prise en compte dans le cadre des procédures d'urbanisme, et surtout par la loi du 17 janvier 2001. Cette dernière, qui a fait l'objet de modifications ultérieures, a notamment permis d'en préciser le cadre financier et opérationnel, notamment par la création de l'institut national de recherche en archéologie préventive (Inrap).

Ainsi, les opérations d'archéologie préventive sont réalisées, en France, par une première phase de détection, dite de diagnostic, et une éventuelle seconde phase d'étude, dite de fouille. Elles sont prescrites par les services du Ministère de la Culture ${ }^{5}$, sur la base de l'instruction de dossiers d'urbanismes, eux-mêmes transmis en fonction de seuils de superficies des travaux projetés. Ces seuils s'inscrivent principalement dans le cadre de «zones de présomption de prescription», communément qualifiées de «zonages archéologiques » (fig. 5).

Ce sont donc ces zones, définies le plus souvent en fonction de la présence avérée ou supposée de sites, ou en raison d'une pression particulière de l'aménagement, qui constituent un rouage essentiel de l'exercice de l'archéologie préventive nationale. Leur analyse permet donc de dégager un certain nombre de tendances sur les orientations locales ou régionales du développement de cette archéologie préalable aux travaux.

La définition des zonages présente un certain nombre de disparités régionales qui tiennent davantage à des distinctions méthodologiques dans l'exercice des missions, plutôt qu'à de réelles discordances dans l'application de la loi de 2001. Ainsi, selon que le tri des dossiers d'urbanisme soit réalisé en amont ou en aval de la chaîne administrative, le zonage ne concerne que quelques communes du département montagneux du Cantal (Auvergne), un nombre plus important de celles de Haute-Savoie (Rhône-Alpes) et des Hautes-Alpes (Provence-Alpes-Côte d'Azur), et la totalité de celles du département des Vosges (Lorraine).

Par ailleurs, au niveau national, les zonages sont plus spécialement développés sur les centres villes anciens et d'une

5. Services régionaux de l'archéologie, des Directions régionales des affaires culturelles. 


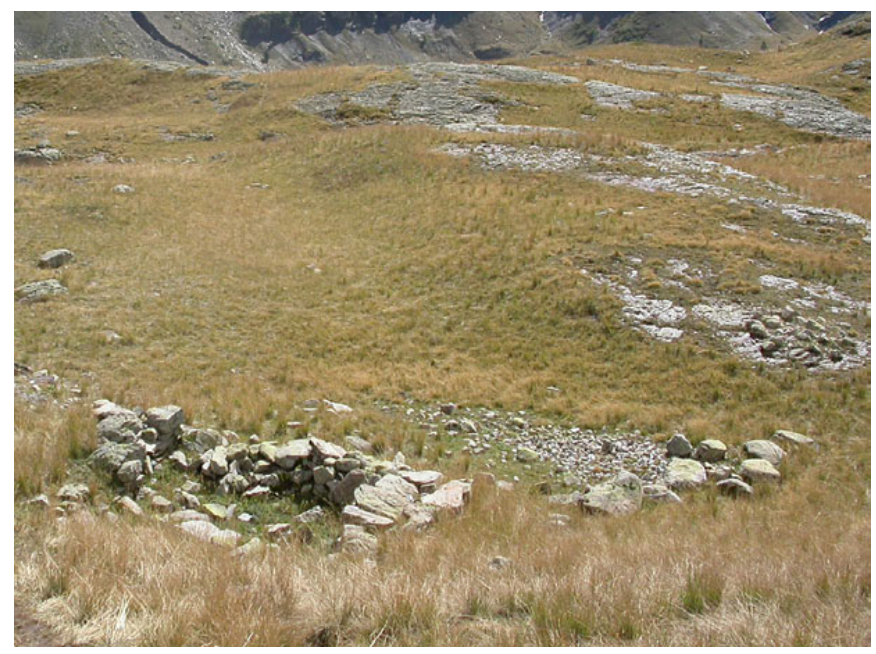

Fig. 1. Freissinières (Hautes-Alpes) : structures agropastorales $d^{\prime}$ altitudes en pierre sèche (X. Margarit 2005).

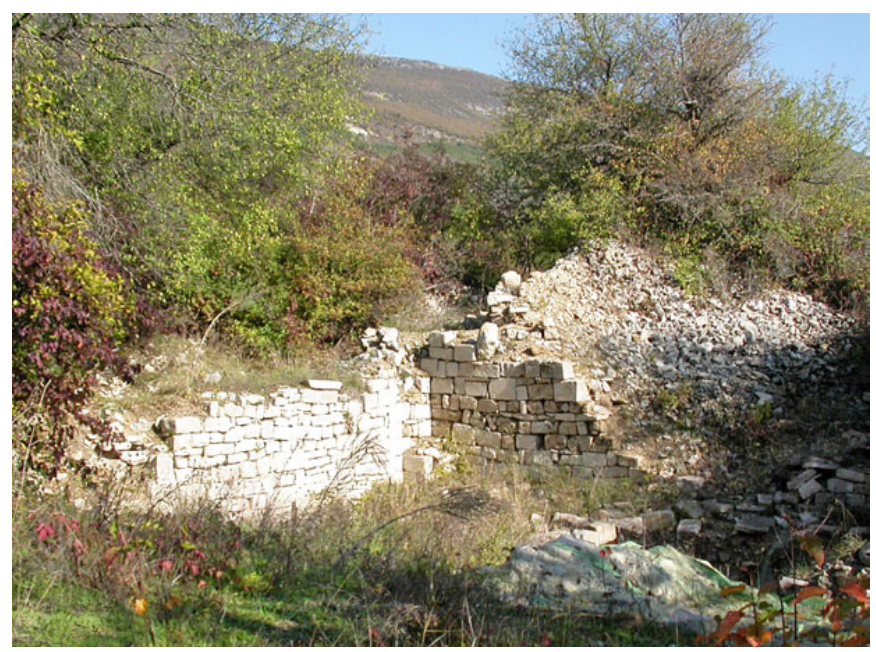

Fig. 4. Barret-sur-Méouge (Hautes-Alpes): mise en évidence de murs médiévaux de l'église du prieuré Saint-Laurent, lors du dégagement intempestif d'une butte d'empierrement à

I'occasion de travaux ruraux (M.-P. Estienne 2005).
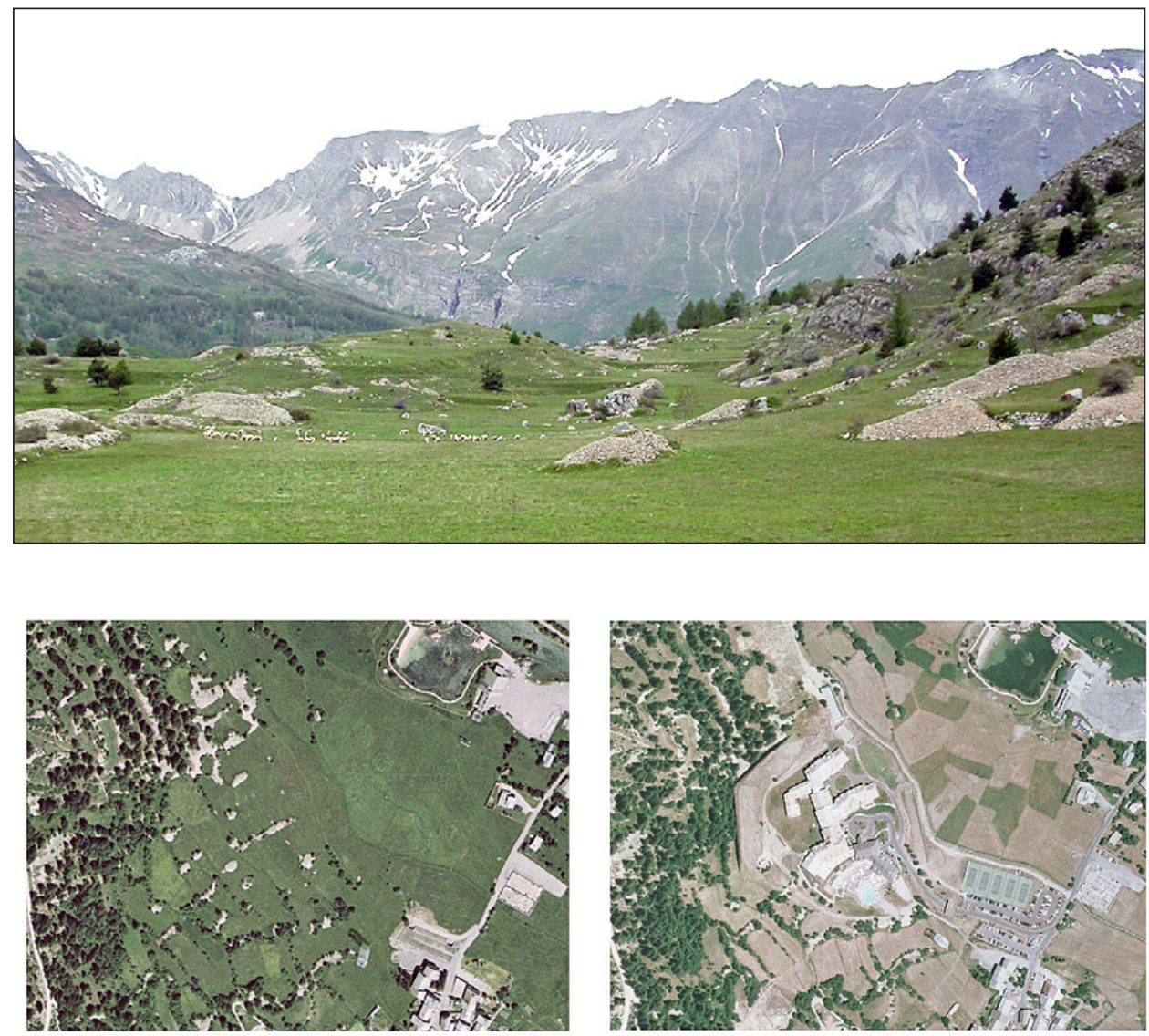

Fig. 2. Réallon (Hautes-Alpes): buttes d'empierrements, ou " clapiers », en milieu rural d'altitude (X. Margarit 2006).

Fig. 3. La Salle-les-Alpes (Hautes-Alpes) : à gauche, structures agraires de buttes d'empierrement (orthophoto 1999), affectées, à droite, par le développement d'un lotissement (orthophoto 2003) dans le secteur touristique de Serre-Chevalier (Orthophotos, copyright IGN 1999-2003). façon générale sur les grandes communes urbaines, en raison de la double densité, de vestiges et de travaux, que celles-ci concentrent. Les secteurs ruraux sont également concernés, mais prioritairement sur les axes de passage naturels. L'exemple du département des Hautes-Alpes, pour lequel le zonage reprend le tracé de la vallée de la
Durance, voie de circulation privilégiée, illustre bien ce dernier point (fig. 5). À l'inverse, dans les Hautes-Alpes comme dans la plupart des autres départements d'altitude, les massifs montagneux se dessinent en négatif, comme contournés mais peu concernés par les zonages d'archéologie préventive (fig. 5). Pourtant, si les travaux en montagne 


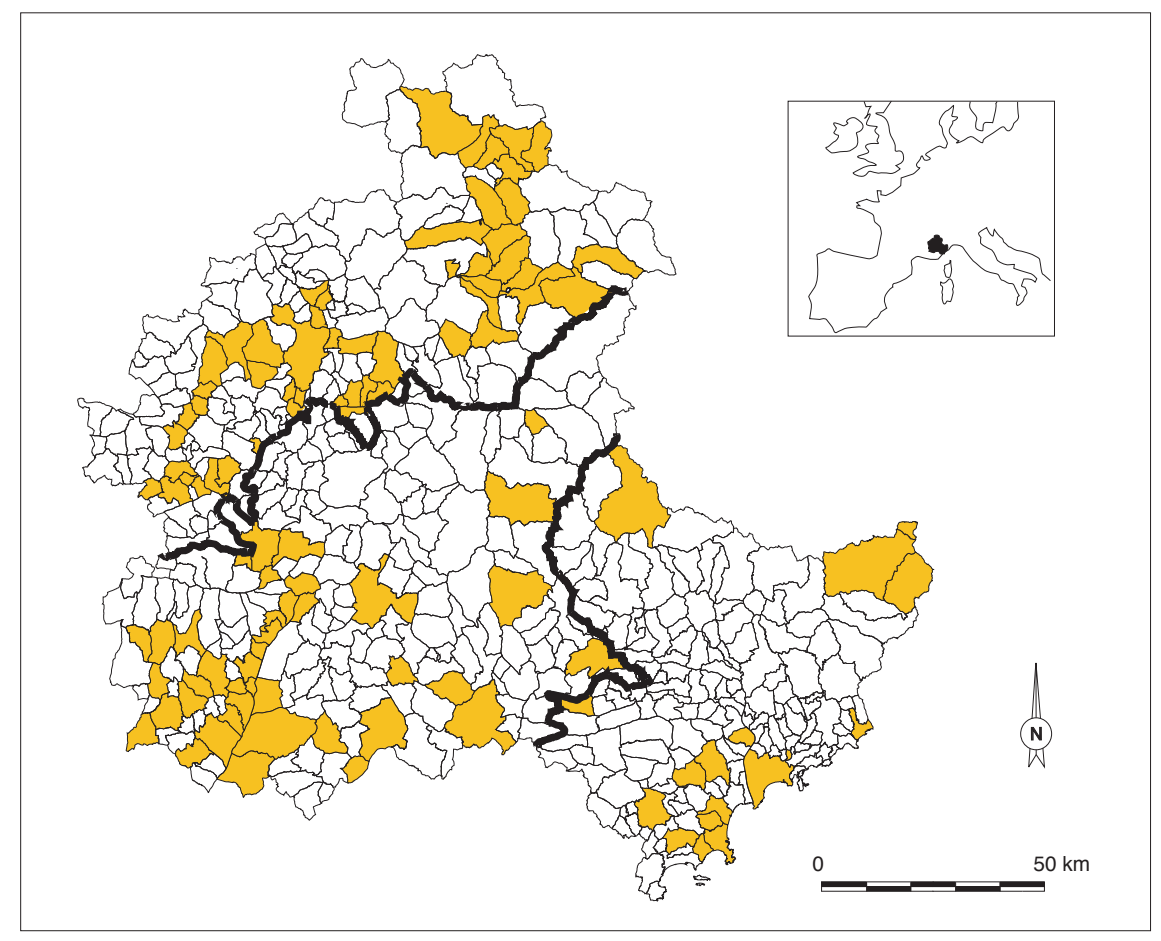

Fig. 5. Plan des communes (en jaune) des départements alpins de la région Provence-Alpes-Côte d'Azur ayant fait l'objet d'un arrêté de zones de présomption de prescription archéologique ou « zonage » en 2007 (de haut en bas, les Hautes-Alpes, les Alpes-de-Haute-Provence, et les Alpes-Maritimes). À I'exception de certains secteurs de vallées, les massifs montagneux sont peu intégrés à ce système de transmission de dossiers de travaux.

sont moins nombreux qu'en plaine, ils présentent pourtant des caractéristiques d'implantations et d'impacts qui légitiment leur suivi spécifique.

\section{Le département des Hautes-Alpes et les spécificités des travaux d'aménagement de montagne}

Les aménagements de l'espace montagnard ont une spécificité que nous proposons d'analyser dans le département des Hautes-Alpes ${ }^{6}$. Il s'agit de comprendre quels types de travaux peuvent avoir un impact sur le sous-sol, de spécifier leur étendue et leur localisation, et de faire le parallèle nécessaire avec les informations offertes par les résultats de la recherche programmée sur les sites d'altitude.

\subsection{Un département montagnard}

Les Hautes-Alpes sont le département le plus haut de France, avec une altitude variant entre $430 \mathrm{~m}$ (vallée du Buëch) et $4102 \mathrm{~m}$ d'altitude (Barre des Écrins). Un tiers de son territoire se trouve au-dessus de $2000 \mathrm{~m}$, et son réseau routier est le plus élevé du pays. Il est peu

6. Nous remercions particulièrement Patrice Cea et Alain Mars (agents du Conseil général des Hautes-Alpes, AD-DE Tourisme) pour les explications et détails techniques donnés sur ces aménagements. peuplé (130752 habitants $)^{7}$ et la densité de population y est faible; 22 habitants au $\mathrm{km}^{2}$ contre 112 de moyenne pour la France métropolitaine. On compte trois agglomérations principales: Gap, Briançon et Embrun ${ }^{8}$. Un petit nombre de communes autour de Gap voient leur population s'accroître particulièrement ces dernières années ; ainsi Veynes compte aujourd'hui 3204 habitants.

L'examen de ces chiffres appelle deux remarques. Il apparaît, d'une part, que la population haute-alpine nécessite moins d'infrastructures, de moindre superficie, que dans des départements plus densément peuplés. Ainsi très peu de Zones d'aménagements concertés (ZAC) o nt été réalisées ces dernières années dans les Hautes-Alpes ${ }^{9}$, alors qu'en raison de leurs vastes étendues, les dossiers de ce type sont toujours susceptibles de faire l'objet d'une prescription d'archéologie préventive. D'autre part, tous les aménagements sont nécessairement guidés par les contraintes du relief. La commune de Gap rencontre des difficultés révélatrices de cette problématique d'aménagement: comment fluidifier le trafic routier dans le centre, lorsque la construction d'une déviation est rendue malaisée en raison des hauteurs entourant la ville?

Ces constats préliminaires pourraient laisser penser que l'archéologie préventive a un rôle moindre à jouer dans l'espace montagnard en raison d'aménagements plus rares

7. Chiffre au $1^{\text {er }}$ janvier 2009.

8. 39136 habitants à Gap, 11851 à Briançon, et 6700 à Embrun.

9. Moins d'une par an. 
ou a plus faible impact sur le sous-sol. Pourtant deux raisons principales montre qu'une telle conclusion serait trop hâtive. La première est directement liée à l'activité touristique, qui tient une place essentielle dans l'économie du département ${ }^{10}$. En effet celui-ci voit saisonnièrement sa population fortement augmenter, en particulier pour la pratique des sports d'hiver. L'affluence de ces touristes implique la construction de logements, de structures d'accueil et de loisirs, l'aménagement et la sécurisation des routes, ainsi que l'aménagement des domaines skiables (fig. 6). La seconde concerne la population permanente. Le développement économique du département et l'augmentation progressive de sa population demandent de nouveaux aménagements. La construction de deux collèges périurbains autour de Gap $^{11}$ en est l'exemple le plus récent. Parallèlement à ces constats, il convient de mentionner le désenclavement du département par l'amélioration du réseau routier.

\subsection{Des infrastructures liées à l'activité touristique et aux sports d'hiver}

L'analyse des types d'ouvrages construits en altitude, et de leurs lieux d'implantation, permet d'évaluer leur éventuel impact sur le sous-sol. Les stations de sports d'hiver, qui comprennent le domaine skiable (ensemble des pistes et des remontées mécaniques) et la station proprement dite (hébergements, commerces, etc.) constituent de ce point de vue des infrastructures à la fois représentatives et privilégiées. Si l'on connaît l'impact géo-écologique de ces travaux, en revanche, l'étude des effets sur les vestiges archéologiques n'en est qu'aux prémices.

L'aménagement des domaines skiables comprend principalement la construction de télésièges et de retenues d'eau. L'établissement d'un télésiège nécessite d'effectuer une coupe de bois sur un tracé correspondant à l'implantation des pylônes, entre une gare de départ et d'arrivée à chaque extrémité. Ces dernières sont installées sur des replats naturels, ou demandent un terrassement plus ou moins important. Dans un cas comme dans l'autre des vestiges archéologiques sont susceptibles d'être affectés, puisque d'après les résultats de l'archéologie programmée ${ }^{12}$ ceux-ci sont présents sur les replats ou à une très faible profondeur. Il faut mentionner aussi la vulnérabilité des vestiges archéologiques liés à la roche, gravures ${ }^{13}$, mais aussi traces

10. $80 \%$ du PIB des Hautes-Alpes provient du tourisme.

11. Il s'agit des collèges de la Bâtie-Neuve et de Tallard, dont l'ouverture est prévue pour la rentrée scolaire de septembre 2009.

12. Cf. notamment Palet-Martinez 2003; 2004; 2005; Py 2006; Walsh, Mocci 2003, 2004, 2006

13. Cf. notamment Ricou 2006 et Rossi 2003. d'exploitation minières et carrières ${ }^{14}$. Outre ces zones directement concernées par des travaux, il ne faut pas négliger la circulation de gros engins de construction sur des pistes d'accès aménagées spécifiquement dans ce but. Tout vestige présent en surface est donc dans ce cas aussi susceptible d'être détruit. Par contre, l'installation des pylônes semble avoir peu d'impact sur le sous-sol : les creusements effectués sur des zones de pente sont ponctuels et de faible surface. Quant à la création de nouvelles pistes, elle peut nécessiter des terrassements importants, qui peuvent donc avoir les mêmes effets que l'installation des gares, avec notamment des destructions de buttes naturelles pour la cohérence du tracé. Enfin, les pistes déjà existantes peuvent faire l'objet de réaménagements afin de faciliter le travail des dameuses et maintenir la neige au sol plus longtemps; ce sont des travaux d'aplanissement, de concassage et de drainage, dont il nous est difficile de mesurer l'impact.

La prise en compte de l'ensemble de ces travaux est encore d'actualité, puisque nous sommes dans un contexte où grandes et petites stations de ski sont toujours dans une perspective d'améliorer, agrandir et moderniser leurs tracés et leurs accès. Depuis quelques années, les HautesAlpes, comme d'autres départements, remplacent ainsi leurs infrastructures parfois devenues vétustes pour des remontées mécaniques appelées Télémix. Ces dispositifs, qui ont la particularité d'allier télésièges et cabines, demandent entre autres de rectifier les tracés, d'agrandir les zones de gares de départ et d'arrivée, et nécessitent l'accès d'engins de construction de plus en plus imposants, avec des effets sur le patrimoine archéologique qu'il nous est désormais possible d'appréhender. Par exemple, dans la vallée de la Guisane, la grande station de Serre Chevalier (1200-2830 m d'altitude) s'est équipée en 2006 de trois nouveaux télésièges, a revu son aménagement en terme de neiges de culture et a fait l'objet de création de nouvelles pistes connexes à un remodelage des autres tracés. L'hiver 2008-2009 a vu l'ouverture d'un nouveau Télémix, dont les vingt-trois pylônes se répartissent sur un tracé de $2,8 \mathrm{~km}$. D'autre part, à Orcières (1174-3117 m d'altitude), l'année 2008 a vu le démontage de trois télésièges pour l'installation d'un nouveau Télémix (Drouvet 1$)^{15}$; ces travaux ont engendré un terrassement de $25000 \mathrm{~m}^{3}$. Un premier Télémix (Drouvet 2) avait été installé dans la station en 2005.

Le deuxième type d'aménagement lié aux stations de sports d'hiver concerne la construction des retenues d'eau (fig. 7). Celles-ci, appelées aussi réserves collinaires, constituent

14. Cf. notamment Ancel 2007; Barge 2003; Rostan 2003; 2005 ; Py 2006 ; Rostan, Thirault 2007.

15. Le levage des éléments du Télémix du Drouvet a été effectué par héliportage, ce qui a donc limité le passage des gros engins sur les pentes. 
une réponse au réchauffement climatique, par la fabrication de neige artificielle, afin de prolonger les débuts et fins de saisons ${ }^{16}$. Elles se multiplient ces dernières années, et ont un impact déjà bien connu (Hassid 2004) sur le milieu naturel, ainsi que potentiellement important sur le patrimoine archéologique.

Ces réserves sont en effet des lacs artificiels, souvent rectilignes ou ovales, qui nécessitent, d'une part, un emplacement en un endroit plat, et d'autre part le plus en altitude possible, afin de faciliter la circulation de l'eau par gravité. L'implantation d'une future réserve collinaire demande donc de trouver un moyen terme entre ces deux contraintes topographiques. Force est de constater que la recherche d'un replat naturel pour une installation en altitude n'est pas un fait nouveau, et qu'un aménagement de ce type est susceptible de recouvrir, d'endommager ou de détruire des établissements humains antérieurs. Le décaissement nécessaire à ces constructions varie selon l'importance de la réserve, les volumes sont donc très variables. Par exemple, la réserve collinaire construite à Molines-en-Queyras en 2007 a une profondeur d'environ $15 \mathrm{~m}$ et un volume de $22000 \mathrm{~m}^{3}$. Il s'agit d'une construction aux dimensions relativement modestes, comparées aux plus grandes réserves de France $^{17}$ dont le volume atteint les $300000 \mathrm{~m}^{3}$ et $400000 \mathrm{~m}^{3}$.

Un dernier type d'aménagement en altitude, lié aussi à l'activité touristique, est la réalisation de structures d'accueil dans les stations. Le souci de diversification des activités hivernales engendre, en effet, l'installation d'équipements nouveaux. Ainsi un vaste programme d'équipements destiné aux activités de l'après-ski a été inauguré en 2008 aux Orres (1650-2720 m d'altitude); celui-ci représente plusieurs milliers de mètres carrés d'aménagement et comprend la construction d'une patinoire, d'une salle de spectacles de six cents places et une zone de résidences de tourisme (ZAC) avec la construction de deux mille cinq cents nouveaux lits.

Dans les zones d'altitude, les travaux d'équipement des domaines skiables comportent donc des aménagements sur des secteurs topographiques correspondant eux-mêmes à ceux de certains sites archéologiques : travaux sur les zones planes, d'occupation privilégiés, mais aussi sur les zones de pentes avec un bouleversement possible des vestiges affleurant.

16. Pour donner un aperçu de l'ampleur du phénomène, remarquons qu'à la station des Orres (1650-2720 m d'altitude), l'enneigement artificiel représente $60 \%$ du domaine skiable.

17. Il s'agit, dans l'ordre, de la réserve collinaire du Grand-Bornand (Haute-Savoie), et de celle de la station des Arcs à Bourg-Saint-Maurice (Savoie) mise en service pour l'hiver 2008-2009.

\subsection{Aspects administratifs et réglementaires des travaux en altitude}

La spécificité des aménagements de domaines skiables fait référence à des applications réglementaires spécifiques. Ainsi la construction de remontées mécaniques nécessite la réalisation d'un dossier d'autorisation d'exécution des travaux $^{18}$, demande qui est soumise au Préfet. Les coupes et abattages d'arbres consécutifs à la préparation des pistes relèvent du code forestier ${ }^{19}$. Pour la construction de réserves collinaires, est constitué un dossier Loi sur l'eau ${ }^{20}$, transmis en Préfecture. L'installation de ces réserves s'accompagne de la construction de postes de conduite pour alimenter ces réserves et d'adductions, lesquelles ne font pas l'objet de demandes spécifiques, sauf dans le cas d'une protection patrimoniale de la zone concernée. Enfin, le droit de l'urbanisme en montagne règle, désormais de manière pré$\operatorname{cise}^{21}$, un certain nombre d'aménagements liés à l'accueil touristique. Ceux-ci nécessitent la création d'Unités touristiques nouvelles (UTN) qui sont soumises à une étude d'impact (Blaise et al. 2003). Aménagements de pistes et parkings par exemple, devraient donc faire l'objet d'une consultation réglementaire auprès des Services régionaux de l'archéologie du Ministère de la Culture. Néanmoins, en 2003, une mission interministérielle a révélé des problèmes de mise en pratique de la loi, en l'absence de document intermédiaire d'application, et les «pratiques d'évitement de la procédure et donc de contournement de la loi $»^{22}$.

Comme l'illustre les exemples de zonages précédemment évoqués, les conditions de transmission des dossiers d'aménagement conformes code du patrimoine peuvent paraître parfois peu adaptées à la spécificité des zones de relief. Aussi, l'application scrupuleuse des réglementations particulières liées à la montagne devrait permettre une meilleure prise en compte de la surveillance archéologique des travaux d'altitude ${ }^{23}$.

\section{Conclusion}

Le constat d'une archéologie préventive relativement peu développée dans l'espace montagnard, voire quasi absente

18. Code de l'urbanisme: version consolidée du 6 août 2008, Livre IV, Titre VII, Chapitre II, Section I, articles R472-1 à R472-13

19. Articles L.-311-1 et 312-1 du code forestier.

20. Loi $n^{\circ} 92-3$ du 3 janvier 1992.

21. La procédure administrative d'autorisation des Unités touristiques nouvelles a pour cadre l'instruction interministérielle du 4 janvier 1977. Cf. les articles L145-3 et L145-9 du code de l'urbanisme. Le décret d'application date du 22 décembre 2006: décret n²006-1683 relatif à l'urbanisme en montagne et modifiant le code de l'urbanisme.

22. Cf. Blaise et al. 2003, p. 26.

23. Avec la collaboration de Pierre Rostan 


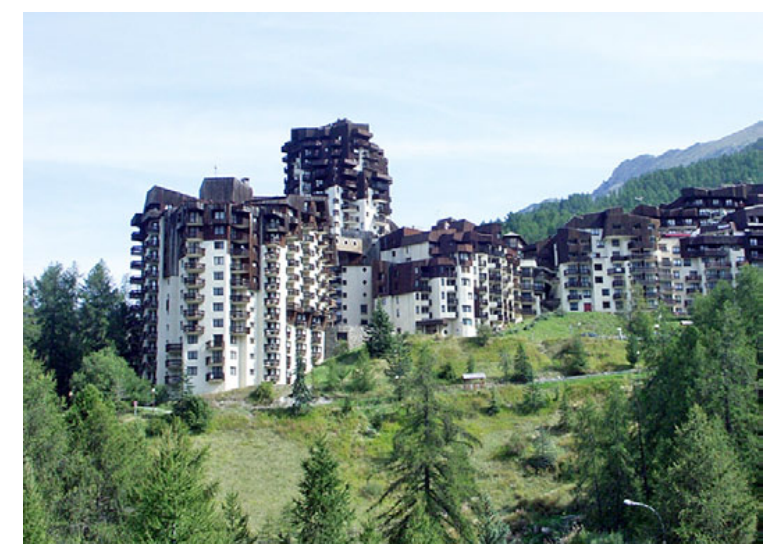

Fig. 6. Les Orres (Hautes-Alpes): exemple d'infrastructures touristiques aménagées sur un secteur d'altitude de moindre déclivité (X. Margarit 2008).

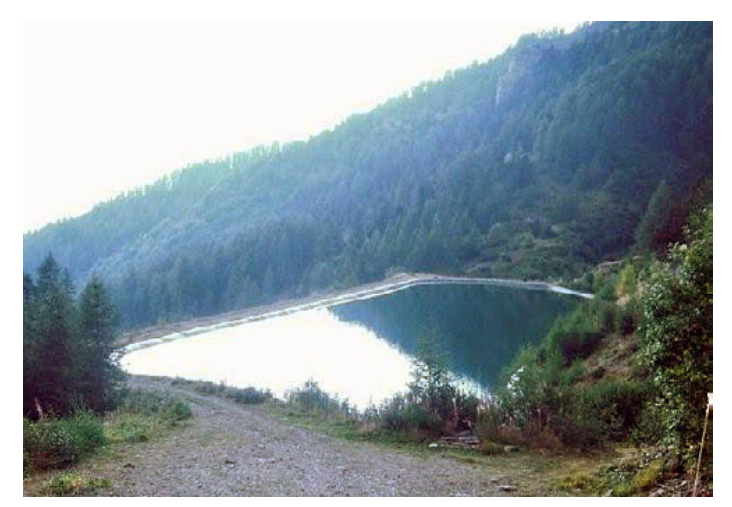

Fig. 7. Chaillol (Hautes-Alpes) : lac artificiel de retenue d'eau, ou réserve collinaire, relatif à la fabrication de neige artificielle pour les stations de sport d'hiver (C. Deal 2008).

des zones de relief de moyenne et de haute montagne, est d'autant plus déconcertante, qu'une analyse précise de ce milieu témoigne d'un intéressant potentiel. Les sites et vestiges archéologiques y sont en effet nombreux, et les travaux d'aménagements destructifs, bien que moins abondant que dans les zones de plaine, peuvent y être néanmoins relativement extensifs. Ces travaux, plus qu'ailleurs, ont même la particularité de rechercher des configurations de terrain qui les font vraisemblablement se superposer à certains sites archéologiques. En outre, de part leur faible enfouissement, voire leur conservation en relief ou en microrelief, les sites d'altitude présentent une grande fragilité qui les rend particulièrement sensibles à de faibles impacts. Pour l'ensemble de ces raisons, il nous paraît important de développer le suivi archéologique des travaux d'altitude, en ciblant notamment de grands travaux à vocation touristique. Dans le département des Hautes-Alpes, où un travail de signalement a déjà été ponctuellement engagé avec le Parc National des Écrins et sur la commune de Molines en Queyras, cette démarche doit être appelée a se développer, notamment pour les aménagements liés au domaine skiable, selon une méthodologie de reconnaissance de terrain par prospection préalable. Tout comme l'archéologie programmée, avec laquelle elle doit être d'ailleurs complémentaire, l'archéologie préventive doit en effet pouvoir développer son champ de compétence au bénéfice de notre connaissance de l'espace montagnard.

\section{Bibliographie}

Ancel 2007: ANCEL (B.) - L'Argentière-la-Bessée, Mines d'argent du Fournel. Bilan scientifique régional 2006 de la région Provence-Alpes-Côte d'Azur, Ministère de la Culture et de la Communication, DRAC-SRA, 2007, p. 54.

Barge 2003: BARGE (H.) - Saint-Véran, Mine de cuivre des Clausis. Bilan scientifique régional 2002 de la région Provence-Alpes-Côte d'Azur, Ministère de la Culture et de la Communication, DRAC-SRA, 2003, p. 45.

Blaise et al. 2003 : BLAISE (L.), WAUTERS (A.), ROUSSEAU (B.), Rapport sur l'adaptation de la procédure des unités touristiques nouvelles, février 2003, (IGE/01/031, CGPC $\mathrm{n}^{\circ}$ 2001-0164-01).

Carozza et al. 2005: CAROZZA (L.), GALOP (D.), MAREMBERT (F.), MONNA (F.) - Quel statut pour les espaces de montagne durant l'âge du Bronze ? regards croisés sur les approches société-environnement dans les Pyrénées occidentales. Documents d'Archéologie Méridionale, 28, 2005, p. 7-23.

Coye 1998: COYE (N.) - La Préhistoire en parole et en acte. Méthodes et enjeux de la pratique archéologique (18301950), Paris, L'Harmattan, Histoire des sciences humaines, $340 \mathrm{p}$.

De Lumley 1995 : DE LUMLEY (H.) - Le grandiose et le sacré. Gravures rupestres protohistoriques et historiques de la région du Mont Bégo. Nice, Éditions Edisud, 1995.

Garcia 2007: GARCIA (D.) - Archéologie de la vallée de l'Ubaye (Alpes-de-Haute-Provence, France) : premiers résultats d'un Projet Collectif de Recherche.). Preistoria Alpina, 42, 2007, p. 23-48.

Hassid 2004: HASSID (M.-J.) - Gestion de la ressource en eau et contrainte touristique en montagne: alimenter et entretenir le manteau neigeux, 2004.

Leveau 2008: LEVEAU (P.) - Le pastoralisme dans les Alpes, de l'identité à la constitution des savoirs. In: JOSPIN (dir.), Premiers bergers des Alpes, de la Préhistoire à l'Antiquité. Grenoble, 2008, catalogue d'exposition du Musée Dauphinois, p. 15-21. 
Miras et al. 2006: MIRAS (Y.), SURMELY (F.), VANNIERE (B.), WALTER-SIMONET (A.-V.), TZORTZIS (S.) Dynamiques d'occupation et histoire de l'environnement d'un terroir de moyenne montagne: La Tourbière de Peyre (Lacapelle-Barrès, Cantal, Massif Central) et ses alentours. Premiers résultats. In: MIRAS (Y.), SURMELY (F.) dir., Environnement et peuplement de la moyenne montagne $d u$ tardiglaciaire à nos jours. Actes de la Table ronde internationale de Pierrefort (Cantal) juin 2003. Presses universitaires de Franche-Comté, 2006, 210 p.

Mocci et al. 2005: MOCCI (F.), PALET-MARTINEZ (J.), SEGARD (M.), TZORTZIS (S.), WALSH (K.) - Peuplement, pastoralisme et modes d'exploitation de la moyenne et haute montagne depuis la Préhistoire dans le Parc National des Écrins (vallées du Haut-Champsaur et de Freissinières, Hautes-Alpes). In: BOUET (A.), VERDIN (F.) dir. - Territoires et paysages de l'âge du Fer au Moyen Âge, Mélanges offerts à Ph. Leveau. Université de Bordeaux III, éd. Ausonius, 16, 2005, 218 p.

Palet-Martinez 2003 : PALET-MARTINEZ (J.-P.) - Archéologie et pastoralisme dans le Haut-Champsaur, Bilan scientifique régional 2002 de la région Provence-Alpes-Côte d'Azur, Ministère de la Culture et de la Communication, DRACSRA, 2003, p. 52.

Palet-Martinez 2004 : PALET-MARTINEZ (J.-P.) - Archéologie pastorale dans le Champsaur, Parc National des Ecrins. Bilan scientifique régional 2003 de la région Provence-Alpes-Côte d'Azur, Ministère de la Culture et de la Communication, DRAC-SRA, 2004, p. 51-52.

Palet-Martinez 2005 : PALET-MARTINEZ (J.-P.) - Archéologie pastorale dans le Champsaur, Parc National des Ecrins. Bilan scientifique régional 2004 de la région Provence-Alpes-Côte d'Azur, Ministère de la Culture et de la Communication, DRAC-SRA, 2005, p. 66-67.

Py 2006a: PY (V.) - Freissinières, Les Mines métalliques de Faravel et de Fangeas. Bilan scientifique régional 2005 de la région Provence-Alpes-Côte d'Azur, Ministère de la Culture et de la Communication, DRAC-SRA, 2006, p. 39.

Py 2006b: PY (V.) - Freissinières, structures agropastorales de Fangeas. Bilan scientifique régional 2005 de la région Provence-Alpes-Côte d'Azur, Ministère de la Culture et de la Communication, DRAC-SRA, 2006, p. 58.
Ricou 2006: RICOU (F.) - Ancelle, Faudon. Bilan scientifique régional 2005 de la région Provence-Alpes-Côte d'Azur, Ministère de la Culture et de la Communication, DRACSRA, 2006, p. 49.

Rossi 2003: ROSSI (M.) - Molines-en-Queyras, Vallon du Longis. Bilan scientifique régional 2002 de la région Provence-Alpes-Côte d'Azur, Ministère de la Culture et de la Communication, DRAC-SRA, 2003, p. 40.

Rostan 2003 : ROSTAN (P.) - La Grave, Cristallières, anciennes exploitations de cristaux de quartz hyalin. Bilan scientifique régional 2002 de la région Provence-Alpes-Côte d'Azur, Ministère de la Culture et de la Communication, DRACSRA, 2003, p. 39

Rostan 2005: ROSTAN (P.) - La Grave et Villar-d'Arêne, anciennes exploitation de cristaux du quartz hyalin dans la haute Romanche. Bilan scientifique régional 2004 de la région Provence-Alpes-Côte d'Azur, Ministère de la Culture et de la Communication, DRAC-SRA, 2005, p. 68-69.

Rostan, Thirault 2007: ROSTAN (P.), THIRAULT (E.) - La Grave, Plateau d'Emparis. Bilan scientifique régional 2006 de la région Provence-Alpes-Côte d'Azur, Ministère de la Culture et de la Communication, DRAC-SRA, 2007, p. 64.

Walsh et al. 2005: WALSH (K.), MOCCI (F.), COURT-PICON (M.), TZORTZIS (S.), PALET-MARTINEZ (J.-M.) Dynamique du peuplement et activités agropastorales durant l'âge du Bronze dans les massifs du Haut-Champsaur et de l'Argentierois (Hautes-Alpes). Documents d'Archéologie méridionale, 28, 2005, p. 25-44.

Walsh, Mocci 2003 : WALSH (K.), MOCCI (F.) - Freissinières, Vallée de Chichin. Bilan scientifique régional 2002 de la région Provence-Alpes-Côte d'Azur, Ministère de la Culture et de la Communication, DRAC-SRA, 2003, p. 37-38.

Walsh, Mocci 2004: WALSH (K.), MOCCI (F.) - Freissinières, Vallée de Chichin. Bilan scientifique régional 2003 de la région Provence-Alpes-Côte d'Azur, Ministère de la Culture et de la Communication, DRAC-SRA, 2004, p. 38-41.

Walsh, Mocci 2006: WALSH (K.), MOCCI (F.) - Haute vallée d'Entre-les-Aygues (Vallouise) et Haute vallée du Fournel (L'Argentière-la-Bessée), Parc National des Écrins. Bilan scientifique régional 2005 de la région Provence-Alpes-Côte d'Azur, Ministère de la Culture et de la Communication, DRAC-SRA, 2006, p. 66-67. 


\section{Deuxième Partie}

\section{Chronologies, PaléO-ENVIRONNEMENT,}

MODALITÉS DE FRÉQUENTATION ET D'EXPLOITATION DE LA MOYENNE ET DE LA HAUTE MONTAGNE
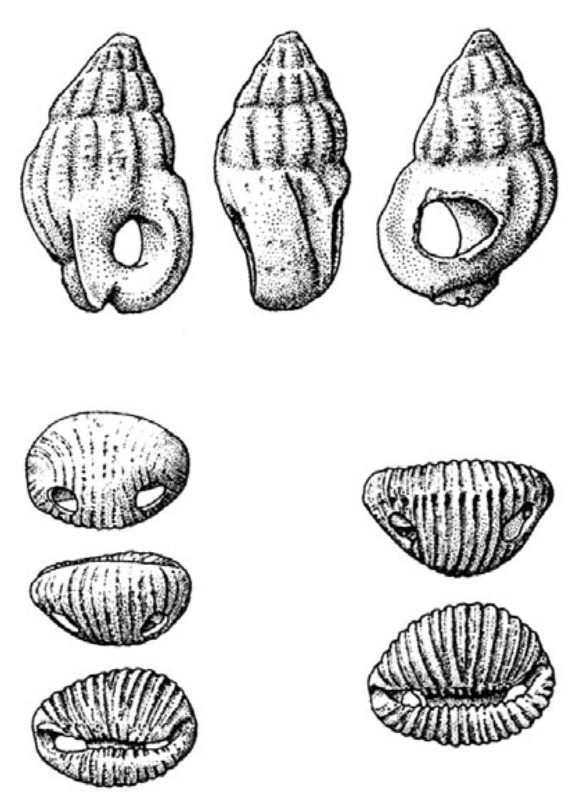


\title{
Diversité des paléo-paysages dans les Alpes françaises depuis la dernière déglaciation
}

\author{
Fernand DAVID*
}

\begin{abstract}
Résumé. Ce travail rappelle dans un premier volet les contraintes méthodologiques incontournables pour la reconstitution des paléopaysages à partir de l'analyse pollinique et dans un second volet une synthèse des acquis dans les Alpes françaises. En milieu de montagne, l'uniformisation potentielle de l'image pollinique par le brassage des masses d'air impose la localisation des études dans des aires restreintes écologiquement homogènes et le choix de sites enregistrant au mieux l'image de la végétation locale. C'est ainsi qu'a émergé la notion de massif clé, constitué de sites de faible dimension dans les différents étages de végétation et à différentes expositions. La synthèse des acquis s'effectue par intégration des résultats de proche en proche. Une revue des données des cinquante dernières années est passée au crible de cette méthodologie qui met en évidence une uniformisation artificielle de l'image des paléopaysages et un biais dans les datations. Pendant l'Holocène, l'étage subalpin était plus diversifié et majoritairement boisé avec des espèces dont la limite supérieure était plus élevée qu'actuellement. La mise en évidence de diachronismes des évolutions des paysages liés au relief contrasté constitue l'apport fondamental de cette méthodologie.
\end{abstract}

\section{Diversity of the palaeo-landscapes in the French Alps since the last glacial retreat}

Abstract. In this paper, some mandatory methodological precautions which have to be taken when reconstituting palaeo-landscapes are discussed, and the results obtain on these lines will be presented. The possibility that the pollen collected in mountain habitats may have been homogenized due to the mixing effects of the wind led the present author to develop a method of studying local differences in plant cover. This method consists in performing highly localized studies on small ecologically homogeneous areas and selecting sites closely reflecting local patterns of vegetation. This approach led to the concept of the "key clump", consisting of small sites located in several vegetation zones with various exposures. All the data obtained during the last fifty years were systematically screened using this method, and the results showed that an falsely uniform picture of palaeo-landscapes has been drawn. During the Holocene period, the sub-alpine vegetation was highly diversified and the woodland species grew up to higher altitudes than they do nowadays. The main finding obtained using the present method is that landscape changes which occurred showed a diachronic pattern due to the differences in the relief of the land.

\section{Introduction}

$\mathrm{L}$ 'analyse pollinique reste la discipline fondamentale pour reconstruire les changements de végétation passée à différentes échelles spatiales (Birks, Birks 1980; Delcourt, Delcourt, Webb 1983; Berglund 1991 ; Punning, Koff 1997). Les contraintes méthodologiques de l'analyse pollinique relèvent à la fois de l'écologie, à savoir production et capacité de transport du pollen et de la géologie, à savoir l'incorporation et la conservation du pollen dans les sédiments, le tout en fonction des différentes variables environnementales. En conséquence, la finalité d'une étude paléo-écologique doit conditionner le choix des sites (Jacobson, Bradshaw 1981).

\section{Choix des sites}

En milieu de montagne, l'uniformisation potentielle de l'image pollinique par le brassage des masses d'air implique la recherche de sites dont le contenu pollinique des sédiments est dominé par l'apport local. Néanmoins la composante régionale dans les sites d'altitude n'est jamais négligeable (Coûteaux 1981; Barthelemy, Jolly 1989). Ce flux pollinique régional peut être détecté par l'étude des sites

* Centre Européen de Recherche et d'Enseignement des Géosciences de l'Environnement (CEREGE), UMR 6635 CNRS - Université Paul Cézanne IRD - Collège de France - Université de Provence, BP 80, Europôle Méditerranéen de l’Arbois, 13545 Aix-en-Provence Cedex 4. 

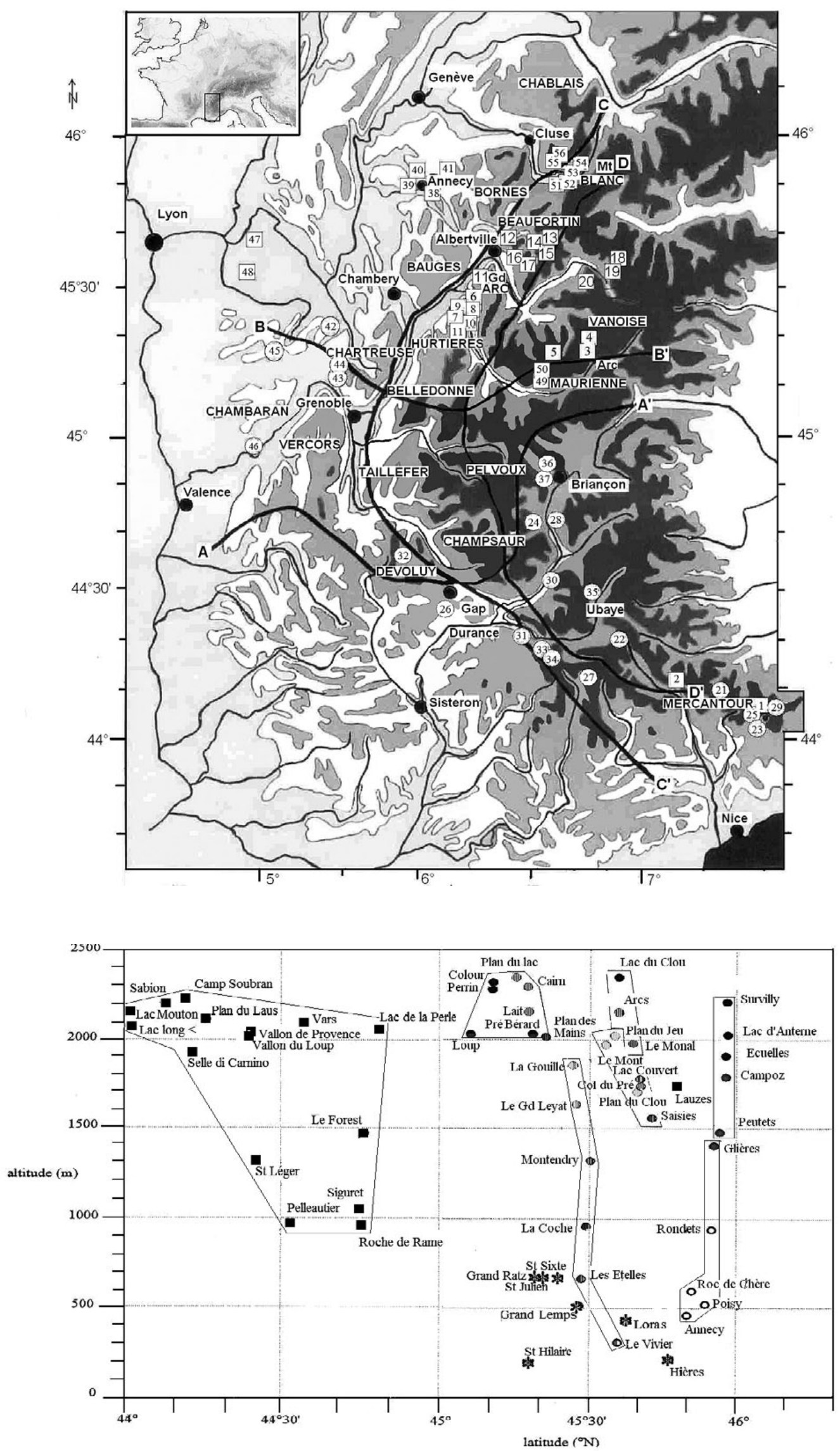

Fig. 1. Répartition des sites étudiés et zonation écologique ( $d$ 'après Ozenda 1966). AA' limite des cols entre domaine méridional et septentrional, $\mathrm{BB}^{\prime}$ limites de la zone de transition, $\mathrm{CC}^{\prime}$ limite entre domaine externe et intermédiaire, DD' limite entre domaine intermédiaire et interne. Altitudes $500 \mathrm{~m}, 1000 \mathrm{~m}$, $2000 \mathrm{~m}$.

Fig. 2. Répartition altitudinale et latitudinale des sites étudiés. Les sites sont regroupés par massif ou bassin. 


\begin{tabular}{|c|c|c|c|c|c|c|}
\hline Massif & Site & Numéro & Altitude & Longitude & Latitude & Références \\
\hline \multirow[t]{2}{*}{ Mercantour } & Lac des Grenouilles & 1 & $1994 \mathrm{~m}$ & 0672905 & 440556 & Kharbouch 1996 \\
\hline & Terres Rouges & 2 & $2160 \mathrm{~m}$ & 071014 & 441101 & Gelloz 1995 \\
\hline \multirow[t]{3}{*}{ Vanoise } & Lac du Lait & 3 & $2210 \mathrm{~m}$ & 064856 & 451851 & David 1993a \\
\hline & Plan du Lac & 4 & $2360 \mathrm{~m}$ & 065000 & 452022 & " \\
\hline & Cairn & 5 & $2315 \mathrm{~m}$ & 063324 & 451953 & $"$ \\
\hline \multirow[t]{6}{*}{ Hurtières } & Le Vivier & 6 & $345 \mathrm{~m}$ & 061831 & 453208 & $"$ \\
\hline & Les Etelles & 7 & $715 \mathrm{~m}$ & 060920 & 452822 & " \\
\hline & La Coche & 8 & $980 \mathrm{~m}$ & 061515 & 452904 & $"$ \\
\hline & Montendry & 9 & $1325 \mathrm{~m}$ & 061551 & 453055 & $"$ \\
\hline & Le Grand Leyat & 10 & $1660 \mathrm{~m}$ & 061334 & 452804 & \\
\hline & La Gouille & 11 & $1825 \mathrm{~m}$ & 061253 & 452623 & David 2001a \\
\hline \multirow[t]{9}{*}{ Beaufortin } & Les Saisies & 12 & $1570 \mathrm{~m}$ & 062833 & 454409 & David 1993a \\
\hline & Col du Pré & 13 & $1730 \mathrm{~m}$ & 063638 & 454121 & " \\
\hline & Plan du Clou & 14 & $1690 \mathrm{~m}$ & 063220 & 454153 & " \\
\hline & Lac Couvert & 15 & $1805 \mathrm{~m}$ & 063203 & 454142 & $"$ \\
\hline & Plan du Jeu & 16 & $2010 \mathrm{~m}$ & 063156 & 453626 & $"$ \\
\hline & Le Mont & 17 & $1995 \mathrm{~m}$ & 063256 & 453305 & $"$ \\
\hline & Lac du Clou & 18 & $2375 \mathrm{~m}$ & 065602 & 453402 & $"$ \\
\hline & Le Monal & 19 & $1975 \mathrm{~m}$ & 065543 & 453325 & $"$ \\
\hline & Plan Déchaud & 20 & $2175 \mathrm{~m}$ & 064951 & 453402 & " \\
\hline Mercantour & Clapeyret & 21 & $2260 \mathrm{~m}$ & 071420 & 440850 & De Beaulieu 1977 \\
\hline Ubaye & Clapouse & 22 & $2100 \mathrm{~m}$ & 0647 & 4422 & " \\
\hline \multirow{3}{*}{ Mercantour } & Lac long & 23 & $2093 \mathrm{~m}$ & 072726 & 440328 & $"$ \\
\hline & Lac des Lauzes & 24 & $1784 \mathrm{~m}$ & 063217 & 454609 & " \\
\hline & Lac Mouton & 25 & $2175 \mathrm{~m}$ & 072661 & 440328 & $"$ \\
\hline Gapençais & Pelleautier & 26 & $975 \mathrm{~m}$ & 061100 & 443102 & $"$ \\
\hline Haut-Verdon & Plan du Laus & 27 & $2122 \mathrm{~m}$ & 064208 & 441430 & $"$ \\
\hline Embrunnais & Roche de Rame & 28 & $950 \mathrm{~m}$ & 063500 & 444449 & $"$ \\
\hline Mercantour & Sabion & 29 & $2216 \mathrm{~m}$ & 072824 & 440748 & $"$ \\
\hline Embrunnais & Siguret & 30 & $1308 \mathrm{~m}$ & 063300 & 444730 & $"$ \\
\hline Gapençais & Saint-Léger & 31 & $1308 \mathrm{~m}$ & 062011 & 442512 & " \\
\hline Bassin d'Annecy & Forest en Devoluy & 32 & $1460 \mathrm{~m}$ & 055400 & 444515 & $"$ \\
\hline \multirow[t]{2}{*}{ Ubaye } & Vallon du Loup & 33 & $2010 \mathrm{~m}$ & 062420 & 442351 & $"$ \\
\hline & Val de Provence & 34 & $2075 \mathrm{~m}$ & 062415 & 442328 & $"$ \\
\hline Embrunnais & Vars & 35 & $2070 \mathrm{~m}$ & 064300 & 443300 & " \\
\hline \multirow[t]{2}{*}{ Briançonnais } & Plaine Alpe & 36 & $1800 \mathrm{~m}$ & 053539 & 445750 & Muller et al. 2000 \\
\hline & Pré Rond & 37 & $1850 \mathrm{~m}$ & 063539 & 445508 & “ \\
\hline \multirow[t]{4}{*}{ Bassin d'Annecy } & Lac d'Annecy & 38 & $450 \mathrm{~m}$ & 061010 & 455257 & David et al. 2006 \\
\hline & Poisy & 39 & $510 \mathrm{~m}$ & 060352 & 455532 & \\
\hline & Les Rondets & 40 & $940 \mathrm{~m}$ & 061134 & 460402 & $"$ \\
\hline & Les Glières & 41 & $1390 \mathrm{~m}$ & 062053 & 455832 & $"$ \\
\hline \multirow[t]{2}{*}{ Chartreuse } & Saint-Sixte & 42 & $650 \mathrm{~m}$ & 053730 & 452530 & Clerc 1988 \\
\hline & Grand Ratz & 43 & $650 \mathrm{~m}$ & 053630 & 452530 & \\
\hline Chartreuse & Saint-Julien & 44 & $650 \mathrm{~m}$ & 072400 & 452100 & \\
\hline Terres froides & Grand Lemps & 45 & $500 \mathrm{~m}$ & 052500 & 452824 & \\
\hline Vercors & Saint-Hilaire & 46 & $190 \mathrm{~m}$ & 051900 & 450845 & $"$ \\
\hline \multirow[t]{2}{*}{ Crémieu } & Loras & 47 & $410 \mathrm{~m}$ & 051440 & 453950 & $"$ \\
\hline & Hières sur Amby & 48 & $212 \mathrm{~m}$ & 051700 & 454727 & " \\
\hline \multirow[t]{2}{*}{ Vanoise } & Pré Bérard & 49 & $2030 \mathrm{~m}$ & 062959 & 451425 & David, Barbero 2001 \\
\hline & Plan des Mains & 50 & $2050 \mathrm{~m}$ & 063520 & 452050 & David 1997 \\
\hline \multirow[t]{4}{*}{ Haute-Arve } & Prarion & 51 & $1600 \mathrm{~m}$ & 064754 & 455939 & De Beaulieu et al. 1993 \\
\hline & Granges Chavants & 52 & $1290 \mathrm{~m}$ & 064554 & 455345 & \\
\hline & La Flatière & 53 & $1430 \mathrm{~m}$ & 064725 & 455435 & $"$ \\
\hline & Aiguillette Houches & 54 & $2210 \mathrm{~m}$ & 064833 & 455524 & \\
\hline
\end{tabular}

Tabl. I. Coordonnées des sites étudiés. 


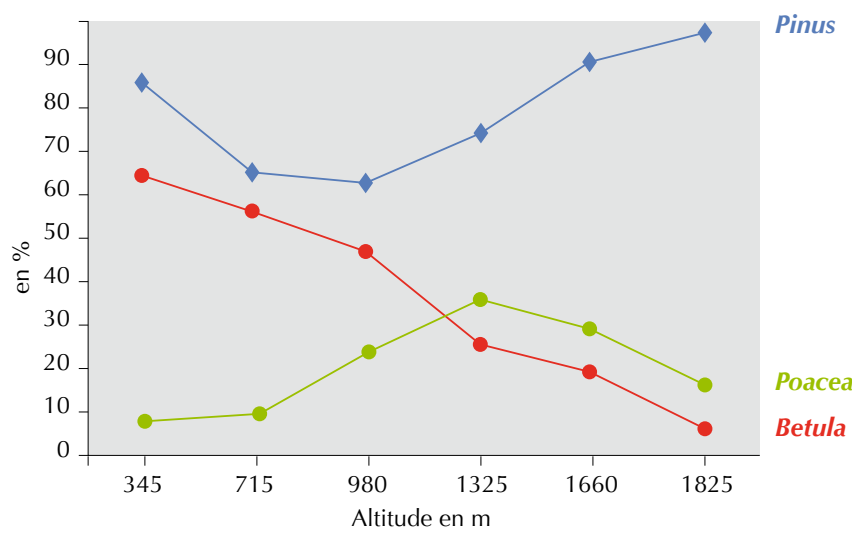

Fig. 3. Évolution des pourcentages polliniques de Pinus, Betula, Poaceae en fonction de l'altitude au Tardiglaciaire dans le massif des Hurtières (d'après David 1993a). régulièrement étagés sur une aire restreinte. C'est ainsi que Beug (1975) a préconisé le choix de sites étagés pour mettre en évidence la mise en place des étages de végétation dans ses travaux sur les montagnes méditerranéennes. De nombreux travaux ont mis en évidence la relation entre pluie pollinique et caractéristiques morphométriques des sites (Crowder, Cuddy 1973 ; Peck 1973 ; Currier, Knapp 1974; Bonny 1976; Pennington 1979; Jacobson, Bradshaw 1981; Jackson 1990 ; etc.). Sur ces bases, l'auteur a préconisé le choix de petits sites de taille inférieure à l'hectare dans des bassins fermés i.e. sans apport de rivières (David 1993a; 1995). L'influence des divers paramètres sédimentaires sur l'image pollinique implique également une approche par sondage multiple pour chaque site (Whittington, Edwards, Cundill 1991).

Dans les Alpes françaises, la définition de zones écologiques homogènes (fig. 1) repose sur les travaux de l'équipe du laboratoire de biologie végétale de Grenoble qui définissent quatre frontières délimitant neuf zones écologiques (Ozenda 1966; 1985). La recherche de sites de
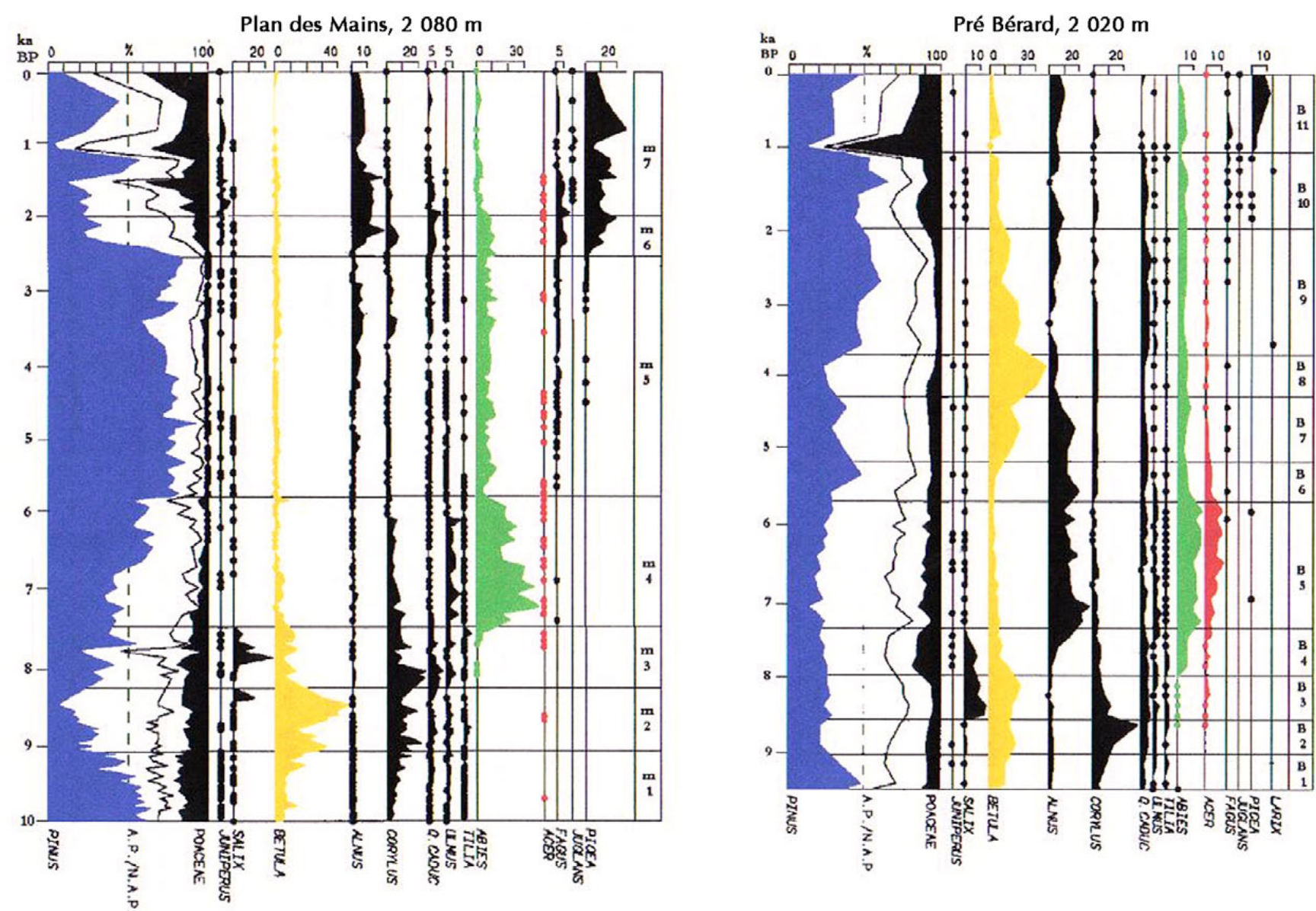

Fig. 4. Diagrammes polliniques simplifiés de Plan des Mains (2080 m) et Pré Bérard (2020 m). 
faible dimension dans les différents étages de végétation et à différentes expositions (fig. 2) a conduit à la notion de massif clé (David 1993a; 1995; 2001a). La synthèse des données s'effectue par intégration des résultats de proche en proche. La comparaison entre sites d'altitude variable n'a de sens que dans une zone restreinte et la comparaison de sites d'altitude comparable est la seule à même de mettre en évidence une variation du couvert végétal de l'étage considéré. C'est dans ce cadre méthodologique, qu'a été abordée une revue des travaux polliniques antérieurs à 1990 (tabl. I). Deux exemples de réinterprétation des données anciennes montrent le changement de paradigme qui a conduit d'une histoire de la végétation à une reconstitution des paléopaysages (David 2001a).

\section{Mise en évidence de la surreprésentation des pins}

La démonstration de la surreprésentation des pins en altitude a été apportée en suivant (fig. 3) l'évolution des pourcentages des pins des bouleaux et des poacées en fonction de l'altitude pendant l'optimum de la phase des pins à l'époque tardiglaciaire dans le massif des Hurtières (David

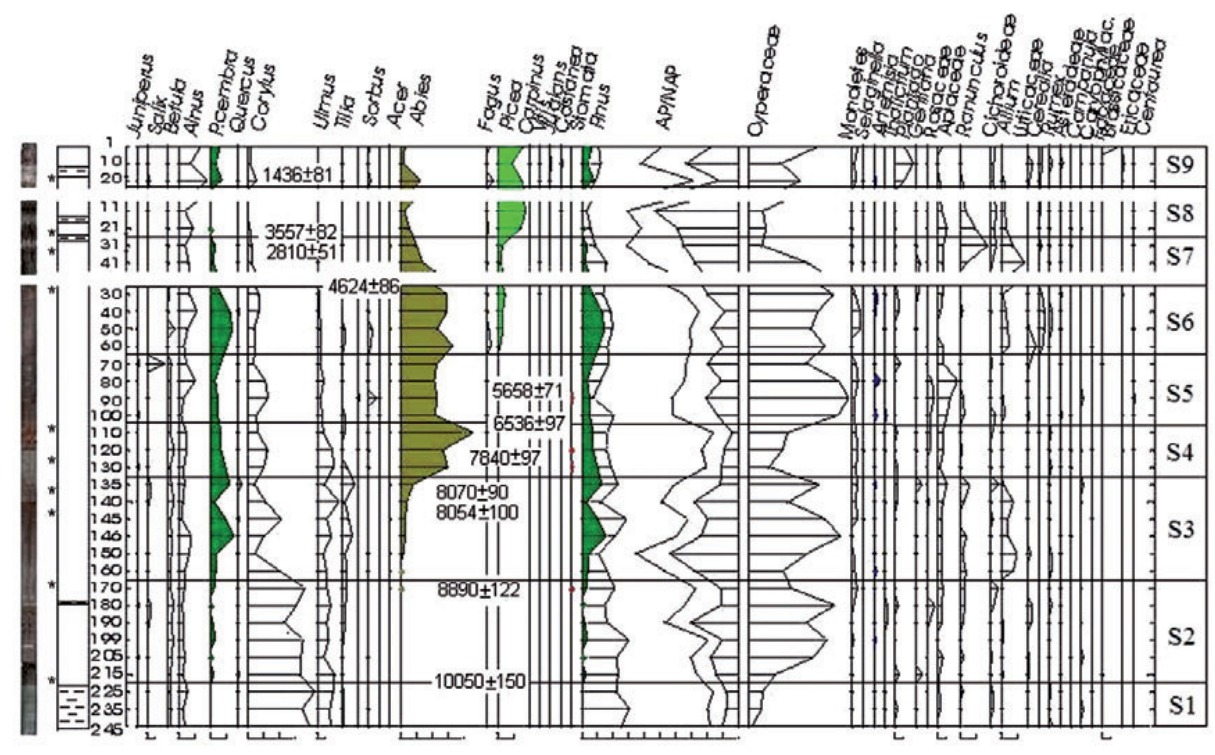

Survilly, $2235 \mathrm{~m}$

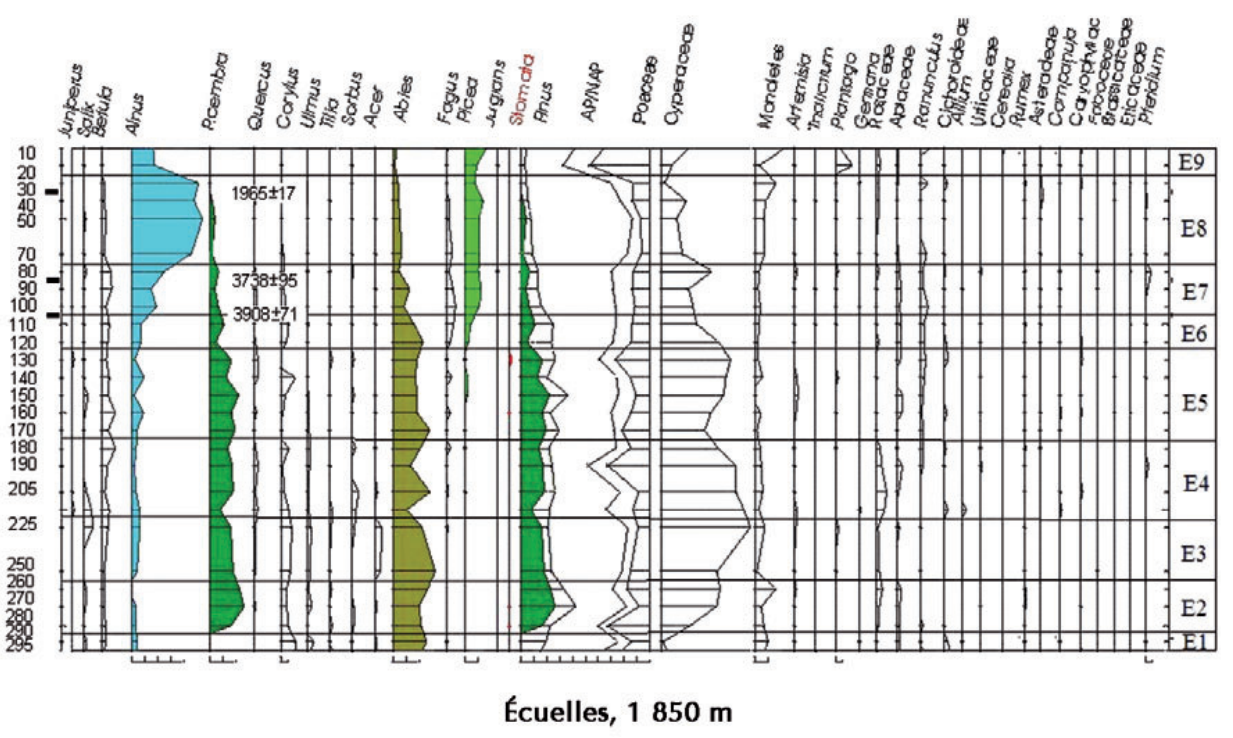

Fig. 5. Diagramme pollinique simplifié de Survilly (2 235 m).

Fig. 6. Diagramme pollinique simplifié des Écuelles (1850 m). 
1993a). Les pourcentages de pin décroissent de la plaine vers les altitudes intermédiaires (entre $700 \mathrm{~m}$ et $1600 \mathrm{~m}$ ), là où les bouleaux et les poacées dominent. Au dessus de mille six cents mètres, les pourcentages de pins atteignent des niveaux équivalents ou supérieurs aux pourcentages de basse altitude. L'observation concomitante des stomates de Pinus aux altitudes les plus basses confirme la localisation des pinèdes tardiglaciaires aux étages collinéen et montagnard (David 1993b; 2001b). Les pourcentages élevés aux altitudes supérieures résultent de l'incorporation de pollen de taxons très fortement producteurs par rapport aux plantes arctico-alpines faibles productrices. Cela infirme l'existence des pinèdes d'altitude au Tardiglaciaire décrites par J.-L. De Beaulieu (1977). Cette interprétation résultait de l'approche consistant à traduire des pourcentages polliniques en termes de couvert végétal sur des sites d'altitude supérieure à $1000 \mathrm{~m}$ où les pins sont surreprésentés. Dans les Alpes françaises, l'étage subalpin a été colonisé par les ligneux seulement au cours de l'holocène. Les erreurs d'interprétation conséquences de la traduction directe des pourcentages polliniques en termes de couvert végétal se retrouvent également à plus basse altitude (David 1993c). Ainsi l'homogénéité de la répartition des sites dans le BasDauphiné favorable à une interprétation écologique (Clerc 1988) a conduit à une vision incomplète de l'histoire tardiglaciaire en raison de l'absence de site d'altitude supérieure à $700 \mathrm{~m}$ (fig. 2). La résilience des peuplements de pins à basse altitude au cours du Dryas récent s'est traduite par le maintien de pourcentages élevés. Seule l'observation d'une chute des concentrations polliniques et de marqueurs polliniques tels que l'aulne et quelques taxons herbacés steppiques a permis de déceler une rétraction des peuplements forestiers du Dryas récent (David 1993c ; 2001b).

Ces deux exemples montrent l'importance de la prise en compte de l'altitude dans l'interprétation des spectres polliniques. Ainsi la comparaison de sites aux caractéristiques proches dans une même tranche altitudinale permet d'évaluer les différences entre sites et de mettre en évidence la diversité des paysages. Les résultats présentés dans ce papier montrent la diversité des paysages anciens de l'étage subalpin actuellement dominé par les pelouses. Ils résultent d'une première étude de deux sites en Maurienne Pré Bérard $(2020 \mathrm{~m})$ et Plan des Mains $(2080 \mathrm{~m})$ et d'une seconde étude de deux sites en haute vallée de l'Arve, Survilly (2230 m) et Écuelles (1980 m) (programme ANR Pygmalion en cours). En Maurienne, l'analyse pollinique a été complétée par une analyse de macrorestes et la chronologie est étayée par onze datations AMS (David 1997; David, Barbero 2001; Chalier 2001). En Haute-Arve, la chronologie est étayée par quatorze datations AMS. Une précédente étude avait souligné la difficulté à établir une chronologie précise malgré la multiplication des dates ${ }^{14} \mathrm{C}$ (De Beaulieu et al. 1993).

\section{Résultats}

Les résultats sont présentés sous forme de diagrammes polliniques simplifiés. Les diagrammes de la vallée de la Maurienne ont été juxtaposés pour mettre en évidence les variations significatives des principaux taxons dans deux sites proches à même altitude (fig. 4). Les diagrammes des sites de la haute vallée de l'Arve sont présentés séparément: Survilly 2240 m (fig. 5), Écuelles 1980 m (fig. 6).

\section{Discussion}

Comparaison des enregistrements polliniques des deux sites de Maurienne, Pré Bérard (2020 m) et Plan des Mains (2080 m) (fig. 4).

Cette comparaison met en évidence le rôle qu'ont pu jouer certains taxons généralement sous estimés en raison de leur faible représentation pollinique et la différence d'enregistrements polliniques dans deux sites proches.

Le site de Pré Bérard montre un peuplement mixte et original de sapins érables et aulnes entre 7,5 et 5,5 ka (fig. 4, B3). Les taux proches de $10 \%$ pour les érables sont inhabituellement élevés pour ce taxon dans cette région. La présence de ces taxons a été confirmée par l'étude des macrorestes (Chalier 2001). L'étude conjointe des macrorestes a montré que d'autres taxons tels que peupliers, sorbiers voire aulnes ont pu être sous estimés dans les diagrammes polliniques (David 2001b).

Les peuplements ligneux constitués d'érables et sapins régressent en premier (fig. 4, B6-7). La présence de charbons indique que cette régression est consécutive à des incendies qui en se rapprochant du site affectent ensuite les aulnes (fig. 4, B7). Ces événements favorisent un développement exceptionnel des bouleaux (fig. 4, B8) marqué par un retour de taux polliniques élevés équivalents à ceux indiquant la colonisation par le bouleau de cette tranche altitudinale au début de l'holocène (David, Barbero 1995). On enregistre dans ce site un développement moindre du pin cembro (fig. 4, B9-10) par rapport au site du Plan des Mains (fig. 4, M5) où les stomates sont enregistrés de façon discontinue dans la séquence sédimentaire et montrent le maintien d'une cembraie sur plusieurs millénaires (David 1997). Cet exemple souligne l'efficacité de cette méthodologie dans la mise en évidence d'une variation locale du couvert végétal. C'est sur le même principe qu'avait pu être mis en évidence le rôle de l'opposition adret/ubac sur l'évolution de la couverture végétale holocène dans la vallée de la Guisane, en Briançonnais (Müller, David, Wicha 2000). 


\section{Comparaison des enregistrements polliniques de deux sites de la haute vallée de l'Arve}

La sédimentation organique dans l'étage subalpin débute dans cette vallée également au début de l'holocène, autour de $10000 \mathrm{BP}$ dans le site le plus élevé (Survilly $2230 \mathrm{~m}$, fig. 5, S2). De plus l'enregistrement des premiers stomates de pins vers 8900 BP (fig. 5, S2) confirme le schéma général de l'installation des pins à l'holocène dans l'étage subalpin des Alpes françaises (David 1993c).

L'analyse comparée (fig. 5, 6) des diagrammes polliniques des deux sites montre une évolution semblable tendant au recul des arbres. Néanmoins ce recul des arbres ( $P$. cembra) permet un établissement plus précoce des pelouses peu après 4600 ans BP en altitude à 2235 m (fig. 5, S7-S8). À plus basse altitude (Écuelles $1850 \mathrm{~m}$ ), les arbres reculent au profit des aulnes verts entre 3900 et 3700 ans BP (fig. 6, S8) alors que ce n'est que vers 1960 ans BP que l'on observe une rétraction des aulnaies au profit des pelouses actuelles. Le développement des brousses subalpines à aulne vert constitue dans cette zone une étape intermédiaire de la déforestation intense menant aux pelouses subalpines. De plus les taux de l'épicéa dans les deux sites sont faibles (inférieurs à $20 \%$ ) alors que dans des sites voisins à altitude équivalente les taux dépassent les $70 \%$ (De Beaulieu et al. 1993). Cela montre que l'épicéa n'a jamais pu s'installer en peuplements denses autour des sites étudiés. La localisation actuelle des quelques arbres sur des falaises inaccessibles montre qu'il n'y a pas d'obstacle écologique à la croissance de ces arbres et confirme l'origine anthropique du retrait des arbres et l'intensité de la déforestation dans cette zone localisée.

\section{Conclusion}

En montagne l'étude de sites étagés dans un massif permet de pallier l'homogénéisation potentielle des spectres polliniques et de suivre les évolutions altitudinales des écotones et notamment celles de la limite supérieure des arbres. Les différents exemples présentés illustrent la capacité de la méthodologie des massifs clés à mettre en évidence les variations locales du couvert végétal. Elle s'avère particulièrement utile dans les approches pluridisciplinaires notamment quand il s'agit d'évaluer l'impact local des activités anthropiques sur l'environnement. Le développement de cette méthodologie permet d'aborder la reconstruction des paléopaysages qui s'avèrent beaucoup plus diversifiés dans l'étage subalpin qui de nos jours est majoritairement constitué de landes et pelouses. La synthèse des données par intégration dans une zone écologique définie (massif ou bassin-versant) doit nous permettre de cerner les éventuelles variations dans l'usage des territoires en fonction des paramètres locaux et d'aborder ces questions à la même échelle spatiale et temporelle que les archéologues.

\section{Remerciements}

Je remercie particulièrement Guillaume Buchet pour le traitement chimique des échantillons polliniques au CEREGE. L'étude des sites de la Haute Vallée de L'Arve est financée dans le cadre du programme ANR PYGMALION.

\section{Bibliographie}

Barthelemy, Jolly 1989: BARTHELEMY (L.), JOLLY (M.C.) - Milieux de montagne et palynologie. Acta biologica montana, IX, 1989, p. 325-332.

Berglund 1991: BERGLUND (B.E.) - The cultural landscape during 6000 years in southern Sweeden- The Ystad Project. Ecological Bulletins 41, 1991, p. 1-495.

Beug 1975: BEUG (H.J.) - Changes of climate and vegetation belts in the mountains of Mediterranean Europe during the Holocene. Bull. Geol. Warsawa 19, 1975, p. 101-110.

Birks, Birks 1980 : BIRKS (H.J.B)., BIRKS (H.H.) - Quaternary palaeoecology. Edward Arnold, London, 1980, 289 p.

Bonny 1976: BONNY (A.P.) - The effect of the pollen recruitment processes on pollen distribution over the sediment surface of a small lake in Cumbria. Journal of Ecology, 66, 1976, p. 385-416.

Chalier 2001: CHALIER (O.) - Contribution des macrorestes végétaux à la connaissance de l'évolution holocène de la végétation dans l'étage subalpin (Pré Bérard, 2020 m, Alpes françaises du Nord). Mémoire de Maîtrise, Aix-Marseille III, 2001, 17 p.

Clerc 1988: CLERC (J.) - Recherches pollenanalytiques sur la paléoécologie tardiglaciaire et holocène du Bas Dauphiné. Thèse es Sciences, Aix-Marseille III, 1988, 179 p.

Coûteaux 1981: COÛTEAUX (M.) - Caractérisation pollenanalytique en Oisans des milieux forestiers et des milieux supraforestiers dans l'actuel et dans le passé. Actes du colloque de Perpignan, 16-4 (1981). La limite supérieure de la forêt et sa valeur de seuil, 1981, p. 139-159.

Crowder, Cuddy 1973: CROWDER (A.A.), CUDDY (D.G.) - Pollen in a small river basin: Wilton Creek, Ontario. In : BIRKS (H.J.), WEST (R.J.) ed., Quaternary Plant Ecology, Blackwell Scientific Publications, Oxford, 1973, p. 43-60.

Currier, Knapp 1974 : CURRIER (P.J.), KNAPP (R.D.) - Local and regional pollen rain components at Dairs lake, Montcalm County, Michigan. The Michigan Academian, 7, 1974, p. 211-225. 
David 1993a: DAVID (F.) - Évolutions de la limite supérieure des arbres dans les Alpes françaises du Nord. Thèse es Sciences, Aix-Marseille III, 1993, 94 p.

David 1993b : DAVID (F.) - Altitudinal variation in the response of the vegetation to Late-Glacial climatic events in the northern French Alps. The New Phytologist, 205, 1993, p. 203-220.

David 1993c: DAVID (F.) - Extension tardiglaciaire des pins dans les Alpes du Nord. C. R. Acad. Sci., Paris, 317, Série II, 1993, p. 123-129.

David 1995: DAVID (F) - Vegetation dynamics in the northern French Alps. Historical Biology, 9, 1995, p. 269-295.

David 1997: DAVID (F.) - Holocene tree limit in the northern French Alps: Stomata and pollen evidence. Review of Palaeobotany and Palynology, 97, 1997, p. 227-237.

David 2001a: DAVID (F.) - Établissement des étages de végétation holocène: vers la modélisation complete d'un massif. C. R. Acad. Sci. Paris, 324, 2001, p. 273-278.

David 2001b: DAVID (F.) - Le tardiglaciaire des Etelles: Instabilité climatique et dynamique de la végétation. $C . R$. Acad. Sci. Paris, 324, 2001, p. 373-380.

David, Barbero 1995: DAVID (F.), BARBERO (M.) - De l'histoire du genre Betula dans les Alpes françaises du Nord. Review of Palaeobotany and Palynology, 89, 1995, p. 455-467.

David, Barbero 2001: DAVID (F.), BARBERO (M.) - Les érables dans l'étage subalpin: une longue histoire. C. R. Acad. Sci. Paris, 324, 2001, p. 159-164.

De Beaulieu 1977: DE BEAULIEU (J.-L.) - Contribution pollenanalytique à l'histoire tardiglaciaire et holocène de la végétation des Alpes méridionales françaises, Thèse univ. Marseille, 1977, 285 p.

De Beaulieu et al. 1993 : DE BEAULIEU (J.-L.), KOSTENZER (J.), REICH (K.) - Dynamique forestière holocène dans la Haute vallée de l'Arve (Haute Savoie) et migrations de Abies et Picea dans les Alpes occidentales. Dissertationes Botanicae, 196, 1993, p. 387-398.
Delcourt, Delcourt, Webb 1983: DELCOURT (H.R)., DELCOURT (P.A.), WEBB (T.) - Dynamic plant ecology : the spectrum of vegetation change in space and time. Quaternary Science Reviews, 1983, p. 153-175.

Jackson 1990 : JACKSON (S.T.) - Pollen source area and representation in small lakes of the northern Unites States. Review of Palaeobotany and Palynology, 63, 1990, p. 53-76.

Jacobson, Bradshaw 1981: JACOBSON Jr(G.L.), BRADSHAW (R.H.W.) - The selection of sites for palaeovegetational studies. Quaternary Research, 16, 1981, p. 80-96.

Müller, David, Wicha 2000: MÜLLER (S.D.), DAVID (F.), WICHA (S.) - Impact de l'exposition et de l'anthropisation sur la dynamique forestière dans les Alpes du Sud (France). Revue de Géographie Physique et Quaternaire, 54 (2), 2000, p. 227-239.

Ozenda 1966: OZENDA (P.) - Perspectives nouvelles pour l'étude phytogéographique des Alpes du Sud. Doc. Carte Végét. Alpes, VI, 1966, p. 71-88.

Ozenda 1985: OZENDA (P.) - La végétation de la chaîne alpine dans l'espace montagnard européen, Masson, 1985, $331 \mathrm{p}$.

Peck 1973: PECK (R.M.) - Pollen budget studies in a small Yorkshire catchment. In: BIRKS (H.J.), WEST (R.J.) ed., Quaternary Plant Ecology, Blackwell Scientific Publications, Oxford, 1973, p. 43-60.

Pennington 1979: PENNINGTON (W.) - The origin of pollen in lake sediments. An enclosed lake compared with receiving in flow streams. New Phytologist, 83, 1979, p. 189-213.

Punning, Koff 1997: PUNNING (J.M.), KOFF (T.) - The landscape factor in the formation of pollen records in lake sediments, Journal of Paleolimnology 18, 1997, p. 33-44.

Whittington, Edwards, Cundill 1991: WHITTINGTON (G.), EDWARDS (K.J.), CUNDILL (P.R.) - Late and Post glacial vegetational change at Black Loch, Fife, eastern Scotland. A multiple core approach. New Phytologist, 118, 1991, p. $147-166$. 


\title{
Montlleó : un gisement des chasseurs magdaléniens dans la plaine de la Cerdagne. L'occupation d'un espace montagnard dans les Pyrénées de la Catalogne?
}

\author{
Xavier MANGADO*, Maria Mercè Bergadì*, Mathieu LANGLAIS*, Xavier EsTEVE*, \\ José Miguel TEJERO*, Alicia ESTRADA (†), Jordi NADAL*, Oriol MERCADAL**, \\ Josep Maria FULLOLA*
}

\begin{abstract}
Résumé. Le site de Montlleó se trouve en plein air à $1140 \mathrm{~m}$ dans un endroit privilégié avec une large visibilité sur toute la plaine cérétane au cœur des Pyrénées. Il fut découvert en 1998 sur une petite colline près de la rivière Sègre. La fouille depuis 2000 a mis au jour un campement sûrement saisonnier datant du XVI e millénaire BP. La faune est bien représentée par le cheval. L'outillage lithique montre comme matière première principale le silex, toujours d'origine externe à la vallée. La parure marine nous permet d'envisager des contacts ou des échanges avec la Méditerranée, voire au-delà.
\end{abstract}

\begin{abstract}
Montlleó: a Magdalenian hunter's site in the Cerdagne valley. Evidences of mountain environments occupation by humans in the Catalan Pyrenees?

Abstract. The open air site of Montlleó is located at $1140 \mathrm{~m}$ in a place with broad visibility across the Ceretan plain in the heart of the Catalan Pyrenees. It was discovered in 1998 on a small hill near the river Segre. The search since 2000 has brought to light a camp, probably seasonal, dating from the XVI millennium BP. The fauna is well represented by the horse. Lithic remains show chert, as main raw material.This has a non local origin. The perforated marine shells allow us to consider contacts or exchanges with the Mediterranean or further.
\end{abstract}

\section{Emplacement du site}

Le site de plein air de Montlleó se trouve au Col de Saig, dans la commune de Prats i Sansor (Cerdagne, Pyrénées de Lleida, Espagne) (fig. 1). Ce gisement fut découvert en 1998, par la mise en évidence de plusieurs éléments lithiques et de restes de faune dans une coupe d'érosion provoquée par l'exploitation en plein air d'une mine de lignite aujourd'hui abandonnée. L'érosion étant encore active, la fouille fut organisée sur trois secteurs, afin d'étudier le mobilier archéologique in situ.

L'endroit s'insère dans un petit affleurement rocheux de conglomérats d'âge post-miocène situé à $1140 \mathrm{~m}$ d'altitude. Le site est placé sur une petite colline, lieu privilégié au cœur de la vallée, près de la rivière Sègre, et avec une large visibilité sur toute la plaine cérétane (Mangado et al. 2006).
Une molaire de cheval, découverte en 1998 dans la coupe stratigraphique, a fait l'objet d'une première datation par ${ }^{14} \mathrm{C}$ (OxA-9017: 15440 $\left.\pm 80 \mathrm{BP} / \mathrm{CalPal}: 18535 \pm 287 \mathrm{cal} \mathrm{BP}\right)$ (Bronk Ramsey et al. 2000; Weninger, Jöris, Danzeglocke 2007), datation en accord avec les données de la typologie lithique rattachant le site au Magdalénien, comme nous le verrons.

\section{Géologie du site}

Du point de vue géologique le site fait partie de la dépression néogène recoupant l'axe de la chaîne pyrénéenne. Le remplissage de la dépression résulte de sédiments lacustres du Miocène. Ces derniers (argiles) ont ensuite été recouverts par des alluvions plio-pléistocènes en provenance des versants nord occidentaux des chaînes du Cadí et du

\footnotetext{
* Seminari d'Estudis i Recerques Prehistòriques (SERP). Departament de Prehistòria, Història Antiga i Arqueologia. Facultat de Geografia i Història. Universitat de Barcelona. C/ Montalegre 6. 08001 Barcelona. España.

** Museu Cerdà de Puigcerda. Apartat de correus 177. c\Higini de Rivera,4. 17520 Puigcerdà. España.
} 

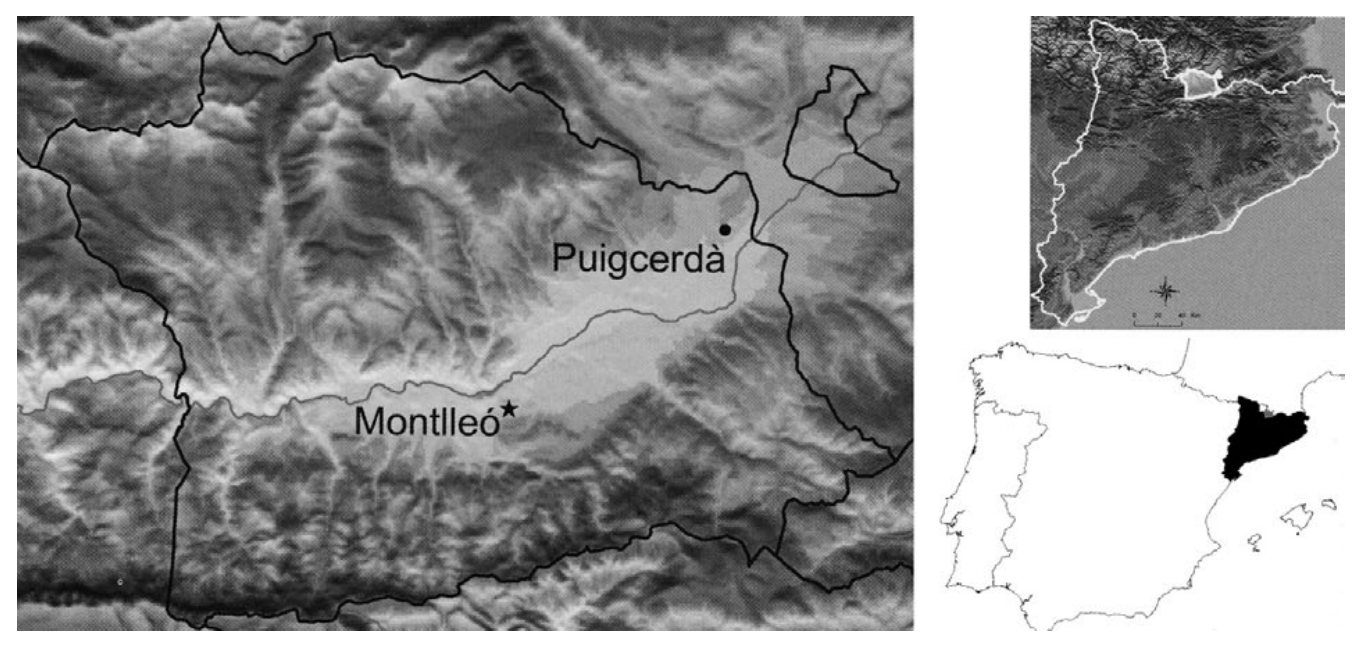

Fig. 1. Emplacement du site.

Moixeró. Par la suite, l'érosion quaternaire, liée dans cette zone à l'encaissement du Sègre, a été conditionnée par changements climatiques, principalement du fait de l'activité des glaciers des reliefs qui encadrent la dépression de la Cerdagne (Roca 1986; Llac 1991).

Pendant le Pléistocène supérieur l'activité glaciaire des Pyrénées orientales a, en effet, connu une évolution en trois étapes:

1. Un maximum d'englacement (entre 60000 et 50000 BP).

2. Une période de stabilisation jusqu' aux $30000 \mathrm{BP}$.

3. Une déglaciation rapide depuis $20000 \mathrm{BP}$. L'effet de cette dernière $a$ du être très marqué dès le début, du fait de la faible importance des glaciers (Fullola et al. 1995).

C'est dans ce contexte, avec des épisodes froids et secs qui donnent naissance, autour de $2000 \mathrm{~m}$, à de petits glaciers couverts, et surtout de nombreux glaciers pierreux, que s'inscrit l'occupation du site de Montlleó.

\section{Principales données et interprétations}

Les recherches menées sur ce gisement se sont déclinées en plusieurs axes.

\subsection{L'état de conservation du site}

Les travaux archéologiques sur le gisement de Montlleó ont débuté l'année 2000.

L'étude comparative entre les cartes topographiques, les rapports des travaux miniers, et les photos anciennes, montre que l'érosion provoquée par l'abandon à la fin des années 1980, de la mine de lignites en plein air «Mine Lourdes», située à moins de $100 \mathrm{~m}$ du gisement, a fortement diminué le potentiel du site. Dans un souci de sauvegarde du patrimoine, la priorité a donc été donnée à l'étude in situ des mobiliers archéologiques menacés par l'érosion active de

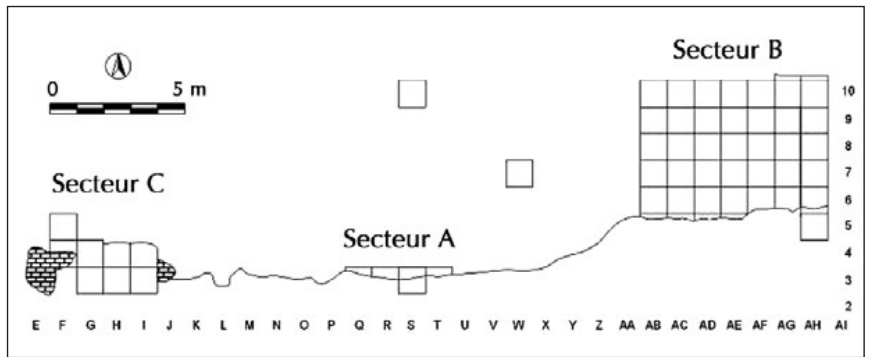

Fig. 2. Plan du site.

la coupe. Dans ce but, trois secteurs de fouille ont été établis (A, B et C) (fig. 2).

Le secteur A, au milieu de la coupe, a été rapidement abandonné car il s'est avéré presque stérile d'un point de vue archéologique. Il présentait des traces évidentes de lessivage du sédiment et de remaniement du matériel conservé (orientation contrainte). Les fouilles ont par conséquent été concentrées dans un premier temps sur le secteur B, représentant une surface de $36 \mathrm{~m}^{2}$, du côté est de la coupe. À partir de 2003, le secteur C vers l'Ouest, représentant quant à lui une surface de $11 \mathrm{~m}^{2}$ dans la partie ouest de la coupe, a été investi à son tour.

\subsection{Données climatiques (secteur C)}

La chute d'un gros bloc de conglomérat pendant l'hiver 2002 a permis l'étude de la coupe stratigraphique du secteur $\mathrm{C}$. La séquence sédimentaire étudiée correspond au profil des carrées $4 \mathrm{H} / 4 \mathrm{I}$ dont la puissance est de $175 \mathrm{~cm}$ (Mangado et al. 2005).

D'un point de vue strictement macro-sédimentaire, trois niveaux ont été identifiés. Le dernier (niveau III) a été daté par ${ }^{14} \mathrm{C}$ à partir de charbons (OxA-14034: 15550 $140 \mathrm{BP} /$ 18636-19025 Cal BP. Calib 5.0.1 (100 \%). Calcurbe: intcal 04.14c). Cette date situe l'occupation dans le Glacial 


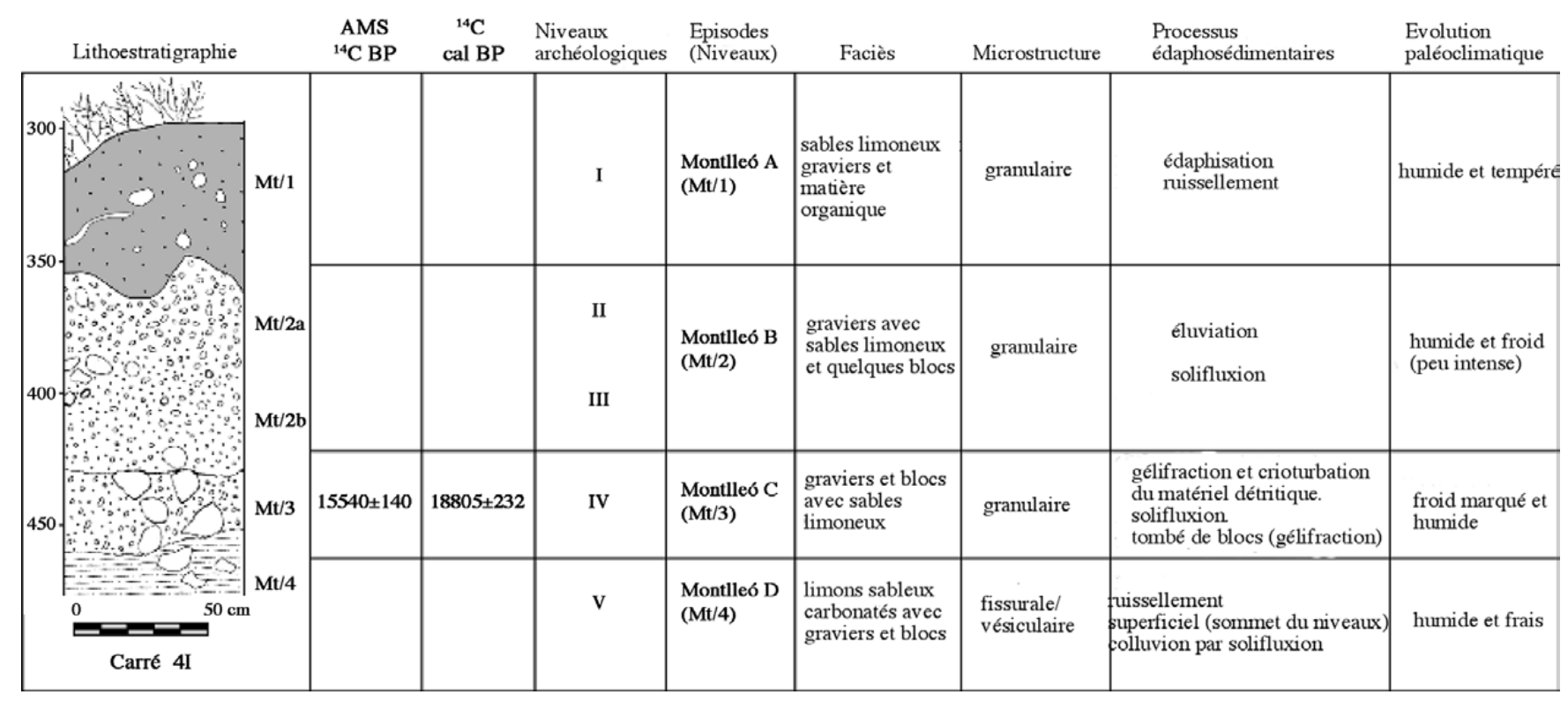

Fig. 3. Schéma de la séquence sédimentaire étudiée dans le secteur C (d'après : M.M. Bergadà).

stade $2 \mathrm{~b}$, ce qui correspond au moins froid des stades glaciaux, avec une présence de gel en surface mais sans permafrosts.

Les niveaux I et II sont constitués de blocs et de graviers dispersés dans une matrice de sables limoneux. Leur évolution est la conséquence de solifluxions, ce qui correspond à des conditions climatiques d'humidité et de froid. Cet épisode est postérieur aux 15000 BP et affecte tout le gisement. Le registre sédimentaire du niveau III est différent des précédents. S'il est constitué d'une matrice de graviers et de blocs avec également des sables limoneux, cet horizon n'a manifestement jamais été affecté par les processus de solifluxion.

Du point de vue micromorphologique, l'étude de cette séquence sédimentaire permet de distinguer 4 niveaux (Mt 1 à 4, fig. 3).

\section{Niveau IV (Mt4)}

L'origine de ce niveau est un colluvionnement à caractère solifluidal dans un environnement très humide et frais, comme le montre la microstructure de type vésiculaire (A). Après la déposition, il y aurait une période de stabilisation édaphique mise en évidence par l'activité biologique et les accumulations secondaires de micrite et sparite (B) avec un processus de fissuration lié à l'humectation et dessiccation du sédiment $(\mathrm{C})$. Cet horizon est resté en surface suffisamment de temps pour que s'y développe une couverture végétale à l'origine des circulations hydriques qui ont favorisé la formation de croûtes sédimentaires au sommet du niveau (D). Le contact avec le niveau suivant est bien marqué.

\section{Niveau III (Mt/3)}

Ce niveau a une puissance moyenne de $35 \mathrm{~cm}$. Il est formé par des graviers et des blocs avec des sables limoneux (A). La fraction grossière montre des morphologies sub-anguleuses et sub-arrondies avec des traces de dissolution et l'apparition en abondance de fissures liées à des périodes successives de gel et de dégel (B). Certains graviers ont une position verticale et l'on constate la présence de vestiges charbonneux (2\%).

Les phénomènes à l'origine de ce remplissage sont certainement la chute de blocs et une légère solifluxion. Ils correspondent à un environnement à la fois plus froid et plus humide que celui qui caractérise le niveau précédent. Le contact avec le niveau suivant est, cette fois-ci, diffus.

\section{Niveau II Mt/2}

Ce niveau est divisé en deux sub-niveaux distincts : $\mathrm{Mt} / 2 \mathrm{a}$ et $\mathrm{Mt} / 2 \mathrm{~b}$. Le premier $(\mathrm{Mt} / 2 \mathrm{a})$ a une puissance moyenne de $52 \mathrm{~cm}$ et le seconde (Mt/2b), une puissance de $28 \mathrm{~cm}$. Il est constitué de graves, de sables limoneux et de quelques blocs. La différence entre ces deux sub-niveaux réside dans une réduction considérable de la matrice au sein de $\mathrm{Mt} / 2 \mathrm{a}$. Sa formation est liée à un phénomène solifluidal. Le contact avec le niveau supérieur est, dans ce cas également, diffus.

\section{Niveau I (Mt/1)}

Ce niveau a une puissance maximale de $66 \mathrm{~cm}$ qui diminue vers l'Ouest. Les sables y limoneux prédominent. Des graviers sont également présents ainsi que de la matière organique caractéristique du développement édaphique de cet horizon. Il a été formé par ruissellement. 
L'étude micromorphologique montre clairement que le niveau d'occupation (niveau III) dans le secteur C, n'a pas subi des problèmes de solifluxion importants et se trouve par conséquent en place. Leur datation (Glacial Stade 2b) révèle un climat glacial, avec du gel en surface mais, en revanche, sans permafrost. Nous envisageons donc des conditions de vie certes très dures mais pas extrêmes.

\subsection{Données archéologiques (secteur B)}

Le secteur B, à l'est du gisement, permet d'appréhender les modes de vie des préhistoriques de Montlleó. Les horizons superficiels décapés ont livré de nombreux vestiges osseux ainsi qu'un abondant mobilier lithique. Ces pièces apparaissent dans l'ensemble assez mal conservées du fait du développement édaphique. En revanche, passés les premiers cm de la fouille, les vestiges, qu'ils soient faunistiques ou lithiques, sont très bien conservés, d'aspect frais et non patiné.

Ces vestiges préhistoriques, répandus sur toute l'extension de la fouille, sont toutefois davantage concentrés aux abords des gros blocs de conglomérat, qui ont certainement joué un rôle dans l'organisation de l'espace du campement. Dans ce secteur, ont également été identifiés des restes d'un petit foyer plat, légèrement altéré par solifluxion, avec un grand nombre de petits vestiges d'os brûlés à l'intérieur. Ces os devaient être employés comme combustible. À partir de l'étude micromorphologique, la meilleure hypothèse semble être celle d'un foyer à fonction principalement culinaire, dont la température a pu atteindre 300 à $400{ }^{\circ} \mathrm{C}$ environ. Une deuxième accumulation d'ossements brûlés, localisée à proximité du foyer, pourrait correspondre à une zone de vidange (Mangado et al. 2005).

Aucune structure d'habitat ou de cabane n'a encore pu être clairement identifiée. Il est possible que ces structures aient été présentes dans la partie la plus plate du gisement et ne se soient pas conservées.

Une nouvelle datation ${ }^{14} \mathrm{C}$ obtenue sur une autre molaire de cheval (OxA-X-2234-52) a donné pour résultat: 16900 \pm 110 BP / CalPal: 20134 \pm 276 Cal BP (Weninger, Jöris, Danzeglocke 2007).

Les restes de faune sont très abondants dans ce secteur. La présence de trois taxons a pu être établie. L'espèce la plus représentée est le cheval (Equus caballus), avec divers éléments du crane mais également postcraniens, suivi par le bouquetin des Pyrénées (Capra pyrenaica) et le cerf (Cervus elaphus). Il y a aussi quelques restes de petits bovidés indéterminés (chevreuil, Capreolus capreolus ?). La présence du renne, pourtant très abondant dans plusieurs gisements magdaléniens du versant nord-pyrénéen (Nadal 1998), n'a pas pu être démontrée.

Le cheval indique un approvisionnement en ressources biotiques en relation avec les espaces ouverts de la plaine de Cerdagne. Le bouquetin se rencontraient sans doute les secteurs escarpés proches du site (versants du Cadí et du Moixeró). Le cerf devait quant à lui fréquenter les petits espaces boisés environnant le Sègre.

\subsection{L'outillage lithique}

\section{Provenance des matières premières lithiques}

Cette analyse est encore partiellement en cours. Les premiers résultats montrent qu'une grande variété de roches en provenance du fossé de Cerdagne a été utilisée (rhyolite, lydienne, quartz, quartzites, schistes, cornéennes). À côté de ces matières premières locales, le silex domine largement le spectre lithologique dans le corpus des produits de débitage. Il est exogène à la région mais plusieurs origines géologiques et géographiques ont pu être identifiées.

Une partie provient ainsi du versant méridional de la chaîne pyrénéenne; il s'agit de silex éocènes du Cadí, originaires des formations calcaires du Cuisien inférieur, localisées dans la haute vallée du Llobregat, dans la région de l'Alt Bergadà (Terradas 1995).

Une autre partie a pour origine le nord de la chaîne pyrénéenne. Il faut signaler ici la présence des silicifications ferrugineuses de contact, que la littérature archéologique nomme jaspes du Canigou.

D'autres matériaux siliceux peuvent provenir des deux versants de la chaîne des Pyrénées. Il s'agit des silex à characées, localisés, en ce qui concerne le versant méridional, dans les niveaux marne-calcaires du Sannoisien de la vallée de l'Èbre, (Mangado et al. 2005 ) et, pour le versant nord, au sein de plusieurs niveaux calcaires des Corbières ainsi qu'à proximité des étangs de Bages-Sigean, (Grégoire 2000). Les études menées sur l'identification des algues characées, confirme, sur les deux versants, la présence du genre Chara, ce qui empêche pour l'instant une identification plus précise de l'origine des silex à characées mis au jour sur le site.

Nous avons reconnu enfin des silex tertiaires d'origine sédimentaire continentale, connus dans les secteurs des Petites Pyrénées (Simonnet 1985) ainsi que des Pré-Pyrénées de Lleida (Mangado 2005; fig. 4).

\section{Productions lithiques}

De nombreux outils sont réalisés sur éclats. Ces supports proviennent essentiellement, d'une part d'une récupération de sous-produits d'un débitage lamellaire (tablettes, produits de flancs) et d'autre part, d'un débitage d'éclats minces effectué sur place (Langlais 2003).

Si les éclats récupérés sont utilisés de manière aléatoire pour des grattoirs, burins ou perçoirs, les éclats minces sont dévolus préférentiellement aux outils latéraux (éclats 


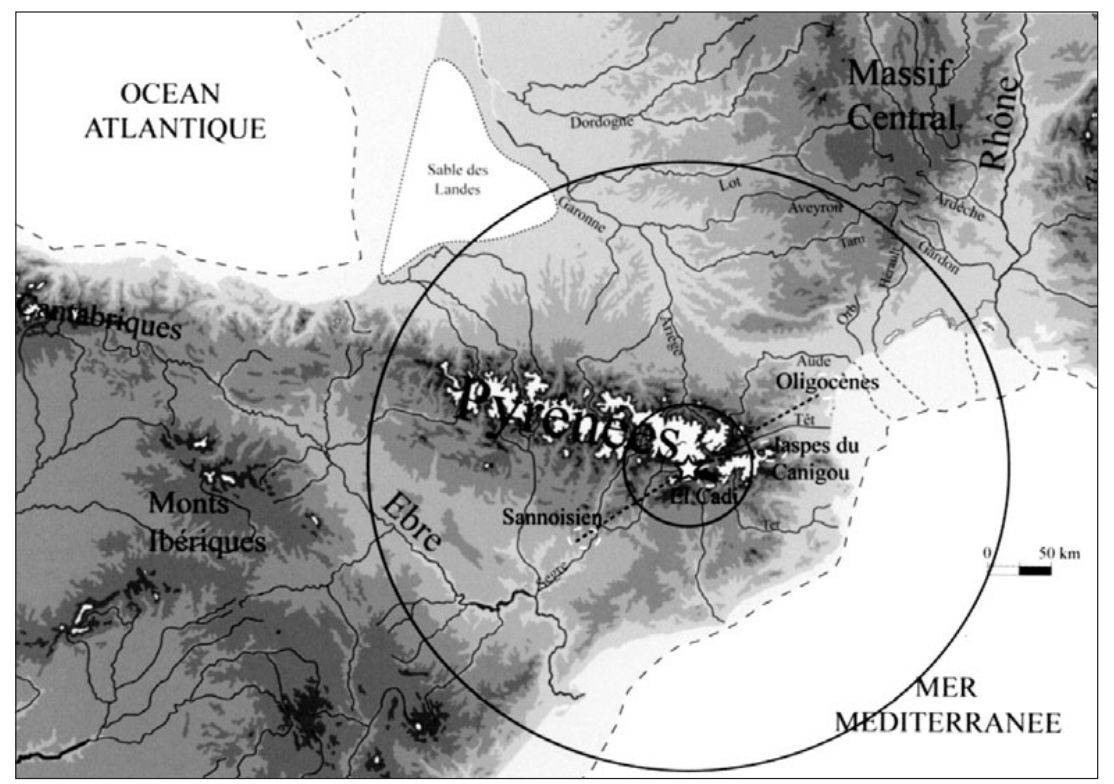

Fig. 4. Aires potentielles d'approvisionnement en silex (d'après Langlais 2007).

retouchés, denticulés). La chaîne opératoire de ces supports correspond à une production de type «facial à enlèvements superposés-juxtaposés ». À côté de ces éclats minces, une production d'éclats épais a également été mise en œuvre afin de fournir des supports de nucléus à microlamelles. Les lames tiennent une place relativement importante dans l'outillage (38\%). Aucun élément n'indique une réduction progressive des nucléus à lames vers les lamelles dans le cadre d'un même schéma. Il s'agit donc d'objectifs disjoints. La plupart des supports laminaires est importée, mais quelques déchets indiquent une production unipolaire simplifiée mise en œuvre in situ.

D'autre part, les lames régulières importées témoignent d'un schéma élaboré de type unipolaire «semi-tournant». Les rares talons de lames conservés indiquent un plan de frappe lisse abrasé et l'utilisation d'un percuteur en pierre selon un geste tangentiel. Ces supports se retrouvent parmi les outils (grattoirs et burins, notamment). Une fragmentation volontaire de lames est envisageable à partir de la présence de fragments mésiaux portant les stigmates d'une segmentation par percussion.

L'outillage domestique est réalisé sur des lames, des éclats et quelques lamelles. Les outils d'extrémité sont composés essentiellement de grattoirs, perçoirs et becs, burins et d'éléments tronqués. Les outils latéraux sont dominés par les lames et éclats retouchés, des denticulés et encoches auxquels il faut ajouter quelques pièces présentant des tranchants utilisés bruts ou peu modifiés (couteaux). Notons également la place relative des pièces esquillées. Aucune pointe à cran n'a été mise au jour.

Les lamelles constituent l'essentiel des supports produits sur place et sont principalement destinées aux microlithes. Trois types de supports bruts ont été distingués.
- Des lamelles antéro-latérales à pan revers. Leur profil est rectiligne à torse et leur section souvent triangulaire.

- Des lamelles de profil rectiligne à section trapézoïdale (3 pans) ou triangulaire (2 pans) correspondent à des extractions effectuées au centre de la table de débitage dans le cadre d'un débitage sur une face étroite («sur tranche») ou large (enveloppant).

- Des microlamelles de profil courbe à tors issues de nucléus carénés.

Deux schémas de débitage déclinés en différentes modalités peuvent être proposés.

La production de supports de profil rectiligne et de module assez grand est mise en œuvre à partir de rognons et d'éclats. Les rognons sont exploités selon un schéma enveloppant (architecture pyramidale). Dans d'autres cas, un plan de frappe opposé est ouvert à la suite de réfléchissements (architecture prismatique). Des éclats épais sont exploités «sur tranche», de manière frontale.

Les débitages microlamellaires sont effectués marginalement «sur tranche» longitudinale ou transversale et l'essentiel des nucléus à microlamelles sont de type «sur front dorsal» (Langlais 2007).

\section{Les microlithes}

La présence de stigmates d'impact macroscopiques atteste de l'utilisation d'au moins une partie de ces pièces comme éléments de projectiles. Selon la typologie de G. Laplace (1974), les armatures sont dominées par les lamelles à dos à retouche abrupte marginale ou profonde (LD11-LD21). Selon la liste typologique de D. de Sonneville-Bordes et J. Perrot (1954-56), les lamelles à dos simples et tronqués sont majoritaires. 

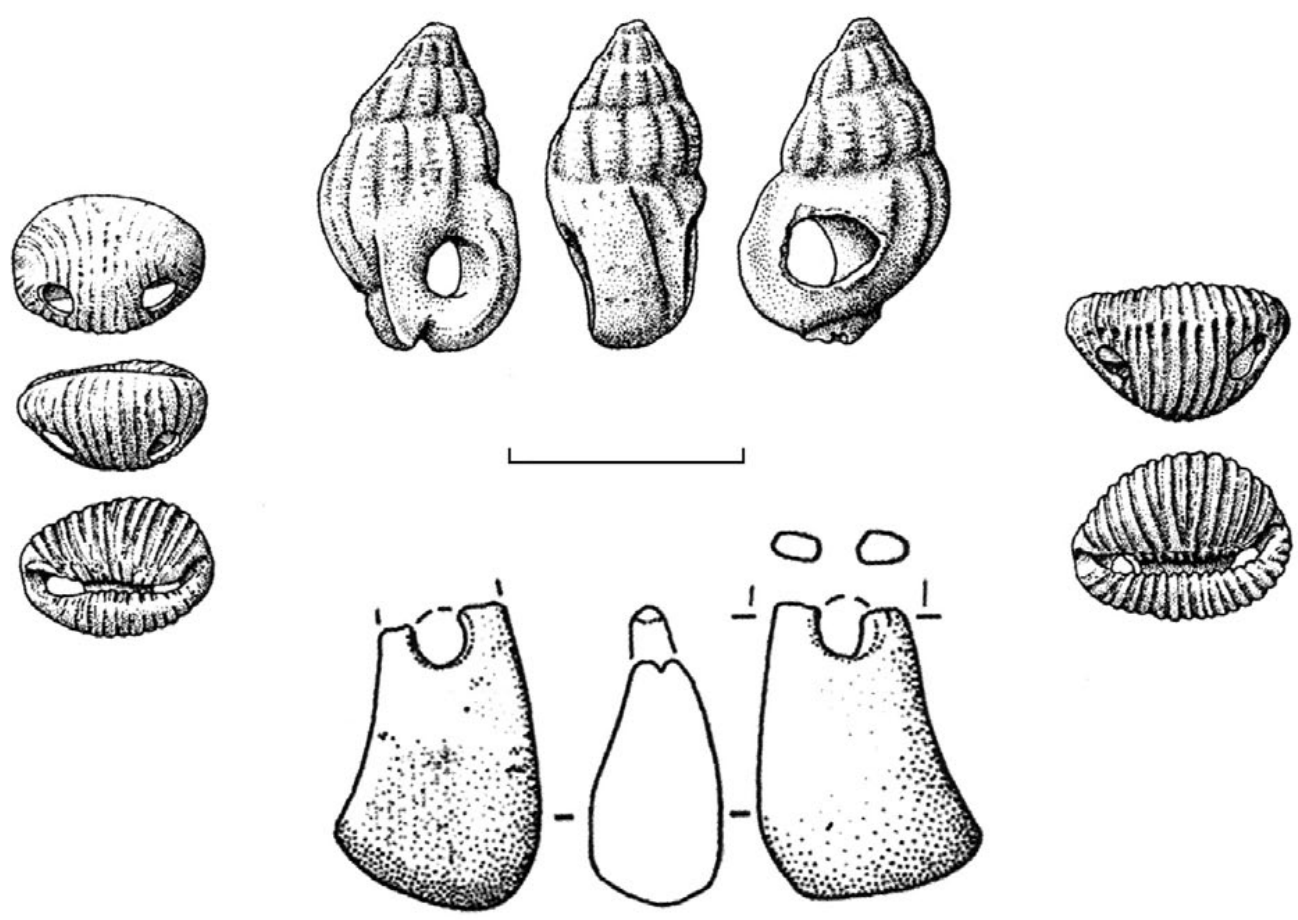

Fig. 5. Quelques éléments perforés de Montlleó, parmi lesquels une crèche de cervidé (dessin R. Álvarez).

Du point de vue strictement typologique, le groupe des armatures semble donc homogène. Toutefois, à partir d'observations technologiques, deux groupes distincts ont pu être identifiés:

Les lamelles à dos de profil rectiligne et de gabarits assez grands montrent une relative diversité typologique, avec des lamelles à dos simples, tronquées, appointées ou denticulées. Les dos ne sont pas latéralisés préférentiellement Le second groupe d'armatures est formé par les microlamelles à dos marginal. Par rapport au groupe précédent, ces pièces témoignent d'une forte monotonie typologique. En outre, une véritable norme de fabrication peut être définie. Les microlamelles de Montlleó sont munies d'un dos semi-abrupt réalisé à partir d'une retouche inverse généralement totale et latéralisée quasi-exclusivement sur le bord droit. En résumé, l'industrie et les productions lithiques de Montlleó peuvent être rapprochées du Magdalénien inférieur (Ladier 2000 ; Langlais 2007).

\subsection{La parure}

A Montlleó, les restes malacofauniques d'origine marine ne sont pas très abondants. Il s'agit de plusieurs exemplaires de bivalve, gastéropodes et scaphopodes pour la plupart perforés (fig. 5). Ces éléments sont sans intérêt du point de vue alimentaire, mais en revanche potentiellement de grande portée symbolique, que ce soit au niveau individuel (habillement), ou collectif (éléments de représentation sociale). Ils nous permettent également d'envisager l'existence d'un flux direct avec la côte, que ce soit vers le Golfe du Lion à travers la vallée de la Têt, ou vers la côte catalane à travers les vallées de l'Ebre et du Sègre. Ils autorisent enfin de poser l'hypothèse de réseaux d'échanges régionaux de produits à forte valeur sociale entre plusieurs groupes du magdalénien.

La plupart des espèces répertoriées à Montlleó ont une origine méditerranéenne (Dentalium sp., Cyclope pellucida, Homalopoma sanguineum...).

Seulement un exemplaire parmi les éléments répertoriés a une provenance plus lointaine; il s'agit de Littorina obtusata, espèce d'origine atlantique. Il n'est cependant pas possible de déterminer avec certitude s'il provient du Bassin Aquitain ou s'il est parvenu à Montlleó par la vallée de l'Èbre depuis la zone cantabrique (Fullola, Mangado, Estrada 2007).

\section{Conclusion}

La découverte récente du site de Montlleó, gisement de plein air à 1140 m d'altitude, est un argument en faveur de la colonisation précoce, par les magdaléniens, des espaces pyrénéens.

La possibilité d'un passage entre les versants nord et sud de la chaîne avait été déjà envisagée par des études sur le glacialisme des Pyrénées orientales. Le site de Montlleó 
confirme la présence humaine dans cette région, et donc la possibilité d'un passage par les hautes vallées du Sègre et de la Têt vers la Méditerranée, permettant le contact avec les espaces côtiers, comme l'indique la présence des parures sur coquilles marines collectées pendant la fouille. En dépit de conditions climatiques très rudes, l'emplacement du site sur une petite hauteur au milieu de la vallée de Cerdagne offre aux magdaléniens un point de repaire stratégique pour mener l'exploitation des ressources fauniques de la région, principalement le cheval de la plaine et le bouquetin des secteurs rocheux voisins.

Malgré la destruction partielle du gisement provoquée par les phénomènes d'érosion et l'altération d'une partie de la stratigraphie liée aux processus de solifluxion, nous avons pu mettre en évidence et étudier un certain nombre de structures archéologiques. Il s'agit pour l'instant de deux foyers, dont l'un au moins avait une fonction culinaire.

La structuration de l'espace et des aires d'activités, probablement organisées en fonction de la présence des gros blocs de conglomérat, tout comme la présence d'une gamme variée de matières premières lithiques autochtones, montre que les chasseurs du Magdalénien étaient des bons connaisseurs de cet espace géographique. L'importation de supports déjà débités en silex exogène ainsi que le débitage intensif des petits nucleus tirés ce type de matière première, confirment à nos yeux cette hypothèse. D'autre part, la variabilité des activités pratiquées par les magdaléniens de Montlleó dont semblent témoigner la diversité typologique des outillages (éléments à finalité cynégétique et domestique) indiquerait une occupation inscrite dans la durée, cette dernière demeurant bien entendu à évaluer. On pourrait donc envisager Montlleó comme un campement implanté au sein d'un territoire économique marqué par les déplacements saisonniers des Magdaléniens des Pyrénées.

\section{Remerciements}

Ce travail a reçu les soutiens économiques des projets: HAR 2008-00103 du MICINN, SGR 2005-00299 DURSI de la Generalitat de Catalunya et le PGIR de l'Université de Barcelone.

\section{Bibliographie}

Bronk Ramsey et al. 2000 : BRONK RAMSEY (C.), PETTITT (P.B.), HEDGES (R.E.M.), HARDINGS (G.W.L.), OWEN (D.C.) - Radiocarbon dates from the Oxford AMS system: Archaeometry datelist 30. Archaeometry, 42 (2), 2000, p. 459-479.

Fullola et al. 1995 : FULLOLA (J.M.), GARCIA-ARGÜELLES (P.), SERRAT (D.), BERGADÀ (M.M) - El paleolític i l'Epipaleolític al vessant meridional dels Pirineus catalans. Vint anys de recerca a la franja pirinenca sud; interrelacions amb les àrees circundants. In: Cultures i Medi, de la Prehistòria a l'Edat Mitjana. Vint anys d'Arqueologia pirinenca. Actes del Xè Col-loqui Internacional d'Arqueologia de Puigcerdà. Éd. Institut d'Estudis Ceretans, Puigcerdà, 1995, p. 159-176.

Fullola, Mangado, Estrada 2007: FULLOLA (J.M.), MANGADO (J.), ESTRADA (A.) - Circulation des matières premières lithiques et des coquillages dans le Paléolithique supérieur du nord-est ibérique. In: GOMEZ DE SOTO (J.) dir., La notion de mobilité dans les sociétés préhistoriques, Paris, 2007, Actes du 130 Congrès National des Sociétés Historiques et Scientifiques, La Rochelle, Éd. du CTHS, 2005, p. 57-66.

Grégoire 2000: GRÉGOIRE (S.) - Origine des matières premières des industries lithiques du Paléolithique pyrénéen et méditerranéen. Contribution à la connaissance des aires de circulations humaines. Thèse de Doctorat, Université de Perpignan, 2000.

Ladier 2000 : LADIER (E.) - Le Magdalénien ancien à lamelles à dos de l'abri Gandil à Bruniquel (Tarn-et-Garonne) : étude préliminaire de l'industrie de la C.20. In: PION (G.) dir., Le Paléolithique supérieur récent: nouvelles données sur le peuplement et l'environnement, table ronde de Chambéry, 1999, Mém. SPF, 28, 2000, p. 191-200.

Langlais 2003: LANGLAIS (M.) - Réflexions sur la place des productions lamellaires au sein de la culture magdalénienne du Languedoc méditerranéen et pyrénéen de l'est. Etude typo-technologique de quatre assemblages leptolithiques: Montlleó (Prats i Sansor, Lleida), Le Crès (Béziers, Hérault), Belvis (Aude) et Les Piles Loins (Vauvert, Gard). Mémoire de DEA, Université de Toulouse-Le Mirail, 2003.

Langlais 2007: LANGLAIS (M.) - Dynamiques culturelles des sociétés magdaléniennes dans leurs cadres environnementaux. Enquête sur 7000 ans d'évolution de leurs industries lithiques entre Rhône et Èbre. Thèse de Doctorat. Université de Toulouse II, 2007.

Llac 1991: LLAC (F.) - Histoire géologique de la Cerdagne. Ceretania, 1, 1991, p. 7-17.

Mangado, 2005: MANGADO (J.) - La caracterización y el aprovisionamiento de los recursos abióticos en la prehistoria de Cataluña. Oxford, BAR Intermational Series, $\mathrm{n}^{\circ} 1420$, 2005, 205 p.

Mangado et al. 2005: MANGADO (J.), MERCADAL (O.), FULLOLA (J.M.), ESTEVE (X.), LANGLAIS (M.), NADAL (J.), ESTRADA (A.), BERGADÀ (M.M.) - Montlleó (La Cerdanya, Lleida). Un yacimiento magdaleniense de alta montaña al aire libre en los Pirineos catalanes. In : FERREIRA (N.) dir., O Paleolitico, Actas do IV Congresso de Arqueologia Peninsular, 2004, Ed universidade do Algarve, Promontoria Monografica, Faro, 2005, p. 471-480.

Mangado et al. 2006: MANGADO (J.), MERCADAL (O.), FULLOLA (J.M.), ESTEVE (X.), LANGLAIS (M.), NADAL (J.), ESTRADA (A.), SANCHEZ (E.), LACRUZ (S.), GRIMAO (J.) - Montlleó (Prats i Sansor, La Cerdanya). 
El primer jaciment magdalenià a l'aire lliure en altitud al cor dels pirineus. Tribuna d'Arqueologia, 2003-2004, 2006, p. 23-44.

Nadal 1998: NADAL (J.) - Les faunes del Plistocè final-Holocè a la Catalunya méridional $i$ de Ponent. Interpretacions tafonomiques $i$ paleoculturals. Tesi Doctoral, Universitat de Barcelona, 1998.

Roca 1986: ROCA (E.) - Estudi geològic de la fossa de la Cerdanya. Tesi doctoral inèdita, Universitat de Barcelona, 1986.

Simonnet 1985: SIMONNET (R.) - Le silex du Magdalénien final de la grotte des Eglises dans le bassin de Tarascon-sur- Ariège.
Bulletin de la Société Préhistorique de l'Ariège, 40, 1985, p. 71-97.

Terradas 1995: TERRADAS (X.) - Las estrategias de gestión de los recursos liticos del Prepirineo catalan en el $\mathrm{XI}^{\mathrm{e}}$ milenio BP: el asentamiento prehistórico de la Font del Ros (Berga, Barcelona). Treballs d'Arqueologia, 3, 1995, 206 p.

Weninger, Jöris, Danzeglocke 2007 : WENINGER (B.), JÖRIS (O.), DANZEGLOCKE (U.) - CalPal-University of Cologne Radiocarbon Calibration Program Package CalPal2007_ HULU. Institut der Ur-und Frühgeschite, Universität zu Köln. köln (http://www.calpal.de). 


\title{
Prehistoric settlement and population in the Madonie mountains: new data from the archaeological survey
}

\author{
Oscar BELVEDERE*, Vincenza FORGIA*
}

\begin{abstract}
The aim of the Madonie research project is to analyse mobility strategies and the use of a mountainous territory by relating geomorphologic features, raw material sources and landscape to the prehistoric settlement. For this purpose we planned an intensive and systematic survey of sample areas, selected on geo-morphological, altimetric and archaeological criteria, correlated to a palaeoenvironmental investigation based on the study of palynological sequence samples coming from wet areas of the Madonie territory and from archaeological deposits.
\end{abstract}

Occupation et population préhistoriques dans les montagnes de Madonie : nouvelles données archéologiques

Résumé. Le projet de recherche sur la Madonie analyse les stratégies de mobilité et l'exploitation du territoire de montagne, en reliant les caractéristiques géomorphologiques, les sources de matières premières et le paysage aux modes d'occupation préhistoriques. Pour ce faire, nous avons mis en œuvre l'étude systématique de certains secteurs sélectionnés suivant des critères géomorphologiques, altimétriques et archéologiques, en parallèle à une recherche paléoenvironnementale fondée sur l'analyse d'échantillons palynologiques en provenance de zones humides et de sites archéologiques du territoire de la Madonie.

$I^{n}$

n 1928, R. Vaufrey discovered and excavated several Upper Palaeolithic deposits founded into caves, along the Northern coastline of Sicily (Vaufrey 1928). After the publication of the results of his investigations, further archaeological researches were focused upon sites into caves instead to be devoted to archaeological surveys and the identification of open-air sites. Therefore, a misunderstanding occurred: it was emphasised by the students a settlement strategy by prehistoric people based on the almost exclusive use of natural caves. Besides, there was no knowledge of territory exploitation and of a probable seasonality between the coastal sites and the mountainous ones, especially for the period of the first (surely documented) "colonization" of the island, during the late Upper Palaeolithic (Epigravettian). Our study would like to analyze the territorial organization during prehistoric periods, considering also high altitudes areas, which surely played a key role in some specific economic systems (that of Upper Palaeolithic hunters-gatherers societies, for example).

\section{Aim of the project and methodological approach}

Our project is the next stage of a larger research project which investigated the hinterland of the Greek colony of Himera, carried out since the ' 80 as a systematic and intensive survey of the territory of three main rivers valleys, Imera, Torto and San Leonardo valleys, with a chronological range from prehistory until the medieval period. The results have been published in two volumes (Belvedere et al. 1988; 2002) which inform us about the archaeological landscapes, the human land use history and exploitation of the natural resources, in relation to palaeoenvironmental data.

Survey interested more than 120 sq. km, including (starting from the South):

- The high Southern Imera (Salso) and Platani rivers basin; - The southern upper hilly watershed zone;

- The Eastern coastline area, between the Northern Imera River and the Roccella Stream.

\footnotetext{
* Università di Palermo, Dipartimento di Beni Culturali, Viale delle Scienze, Palermo (Italie).

The project was designed by O. Belvedere and V. Forgia together. O. Belvedere is responsible for the methodological approach; V. Forgia conducted the work on the field, collected the data and wrote this report.
} 
About 400 new archaeological points of interest (sites, potsherd scatter areas, sporadics, tombs, and so on...) have been detected and positioned with high precision using the regional topographic map at the scale of 1:10000 (CTR). All the data are stored in a GIS, now to some extent available to the students as web-Gis.

The last stage of the Himera project is the study of the Madonie Mountains bordering the Eastern part of its territory. Even if we don't forget the long chronological range and recorded the protohistoric, classical and medieval archaeological sites and scatters, the main aim of the Madonie research project is to analyse mobility strategies and the use of a mountain territory by prehistoric people, by relating geomorphologic features, raw material sources and landscape to human behaviour and prehistoric settlement. To that end we planned an archaeological survey and a palaeoenvironmental investigation based on the study of palynological sequence samples, coming from wet areas of the Madonie territory and from different archaeological test pits.

Our research started out with the investigation of four sample areas chosen with altimetric and geomorphologic criteria. In a second time we planned some targeted inspections, so we focused on the investigation of main river terraces slopes, rock-shelters and caves.

\section{Geo-topographic context}

Madonie Natural Park lies on the northern coast of Sicily, near Palermo, in the surrounding of the Greek colony of Himera (fig. 1).

The Madonie system is the second of Sicily in terms of altitude and extent. The highest peaks are over $1900 \mathrm{~m}$ above sea level (Pizzo Carbonara 1979 m, Monte Ferro 1907 m). The Madonie Mountains are bordered by three main rivers: Northern Imera on the West, Pollina on the East, while Southern Imera starts from the South. The northern border is marked by the Mediterranean (Tirreno) Sea.

\section{Archaeological data coming from the systematic survey}

In the Uplands our interest has been focused on two areas: the first one is marked by the presence of chert sources, while the second one is characterised by a karstic geomorphology, with many dolines, dry valleys, polje, sinkholes and caves. Both areas are located between 1400 and $1900 \mathrm{~m}$ of altitude.

The Lowlands are also marked by karstic phenomena which are responsible for the presence of several natural caves frequented during the prehistoric periods (mainly

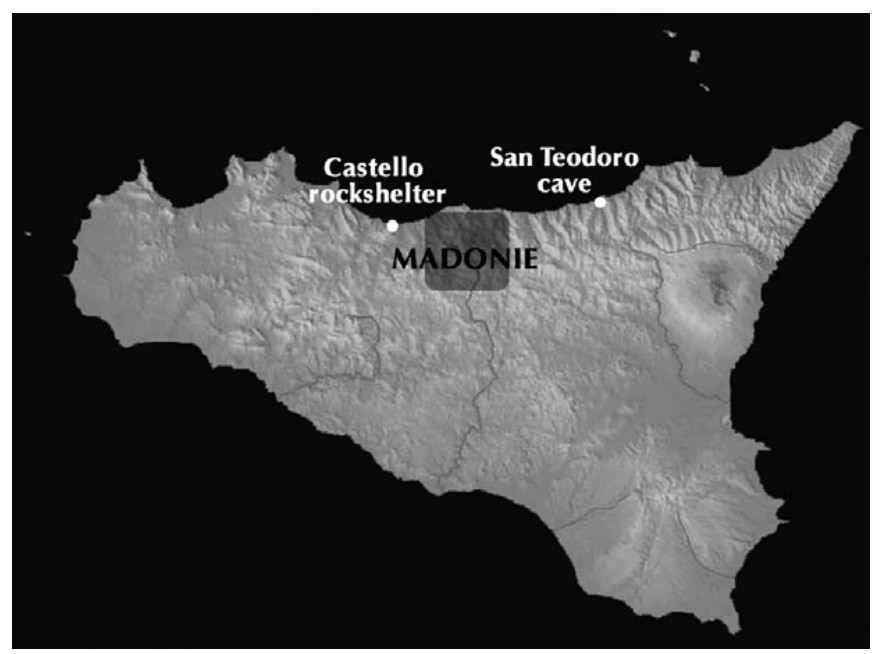

Fig. 1. Localization of the Madonie mountains system.

during the Copper Age). Our research testifies for the first time the presence of open-air settlement and prehistoric human activity out of the caves.

The lowest area, looking at the Greek colony of Himera, presents a hilly or flat landscape with different Classic and Late Roman potsherd scatters.

\subsection{Upland sample area - I}

In the first high altitude area, between 1400 and $1800 \mathrm{~m}$ above the sea level, the systematic survey lets us recognize a lot of lithic scatters mainly localized along valleys (karstic dry valleys), on the few plane zones (also of karstic origin) and in association with rock-shelters. One of this areas, characterized for the presence of natural flint nodules, revealed different Topographic Units (sites) constituted mainly by flint cores and unretouched flakes.

\subsection{Upland sample area - II}

On the other hand, the second area, with a different geological substratum showing the presence of quartz-arenitic rocks, lets us identify a significant open-air site where we were able to collect typical Upper Palaeolithic implements as quartzite blades and bladelets.

\subsection{Battaglietta site}

Karstic area reveals the presence of different Upper Palaeolithic stations. The Topographic Unit 24, a possible débitage area where laminar blanks were produced, is located in the middle of one of the main polje of the Madonie complex at the altitude of $1600 \mathrm{~m}$ above the sea level, close to the Battaglietta sinkhole (fig. 2). 
Finds are represented by unretouched and retouched blades, made up of quartz-arenite. Blanks are generally long (between 8 and $12 \mathrm{~cm}$ ) (fig. 3).

A small number of flint tools were also found. We suppose that the place is a lithic workshop mainly because of the presence in-situ of the raw material constituted by quartzarenitic rocks included in an isolated bed of Numidian Flysch (while the area is characterised by carbonates of the Panormide Unit). The place was probably exploited during the final period of Upper Palaeolithic, when more favourable climate conditions should have allowed hunters-gatherers groups to reach highest altitudes. New inspections of the area revealed also the presence of microlithic blanks, which could testify a frequentation of the site during Mesolithic.

Investigation of the Battaglietta site could represent a good opportunity to solve open questions about the local transition to Holocene and about seasonality between coastal and mountainous areas. A first analysis detected that the reduction sequences of quartz-arenitic implements are akin to those observed in the Upper Palaeolithic complexes coming from coastal cave sites, as Grotta Natale (Sebasti 1998, p. 27-28), Castello rock-shelter (Gabrici 1930, tav. 1; Zampetti 1987) and Grotta San Teodoro (Vigliardi 1968), with respect to the final phase of local Epigravettian (upper level of San Teodoro deposit, without geometrics - Palma di Cesnola 1993).

The Madonie Mountains lie just in front of the Castello rockshelter and their core is about $60 \mathrm{~km}$ far from this coastal Epigravettian site (fig. 1); the systematic survey of mountainous areas lets us suggest the presence of a complex use of Sicilian territory by Upper Palaeolithic hunter-gatherers groups, involving likely seasonal displacements, whose ways have to be analysed by the ongoing research (intensified field survey and planned excavations).

The presence in a site at high altitude $(1740 \mathrm{~m}$ above sea level) of obsidian tools with some other flint implements indicates the use of the uplands during more recent periods, like Neolithic or Copper Age.

\subsection{Middle altitude sample area}

The archaeological survey in the middle area, the valley of Isnello (between 700 and $1100 \mathrm{~m}$ above the sea level), already known in literature for the presence of Copper Age tombs into natural caves (Fico, Chiusilla and Vento caves), allowed us to recognize some lithic and potsherds scatters, that actually confirm the use and occupation of open-air sites besides the use of the caves. Most of the caves of this area show modern and ancient pastoral use, which it is possible to recognize by the presence of spherulites, layers of burnt manure and rock polish (Brochier et al. 1992). We suppose that the interest of prehistoric people for this close valley was linked to pastoral practice and to the possibility to walk up to higher places, where today we can observe abandoned or still in use stock pens and pagliari (we remind the case of few obsidian implements founded close to one of these modern pens at an altitude of $1700 \mathrm{~m}$ above the sea level, that could give evidence of a later use of the same places for pastoral activities).

Recently discovered open air-sites are located over small plane surfaces surrounded by (or predominant over) a hilly district. Common pottery, associated to lithic tools, testify the occupation and the use of this narrow valley area, which looks quite different from the Imera river valley (as we shall see further), where we are recording evidences of human presence since Middle Neolithic and where there are signs also of another kind of cultural approach, more open and dynamic, during the following Copper and Bronze Ages.

\subsection{Lowland sample area}

In the lowest area situated between the western slopes of the Madonie Mountains and the Imera River, we recorded many sites of classic and Late Roman age (this area looks at the ancient Greek town of Himera). In this area we can also find the significant Vallone Inferno rock-shelter deposit -where we collected samples for palaeoenvironmental investigation- which links directly this lower area to the top of the Madonie mountains.

\section{Inspections focused on specific questions}

The investigation of single places of interest (river terraces slopes, caves and sinkholes), outside from the sample areas, provided other data attesting that the human interest for the low and middle altitude areas of Madonie mountains has to be linked at least to the Middle Neolithic (Late Neolithic human presence was already testify by Diana pottery coming from Vecchiuzzo cave, in the Southern Madonie), as attested by the presence of Middle Neolithic painted pottery into a cave (Bommartino cave) and in a rock-shelter (Vallone Inferno).

\subsection{Early human presence in Sicily in the contest of European early peopling}

Investigations particularly looked at:

- Exploration of section and slopes of marine and river terraces

- New caves recording

- Exploration of karstic sinkholes in order to verify the presence of ancient deposits.

This second step of the research was developed in order to clarify basic questions about early human presence 


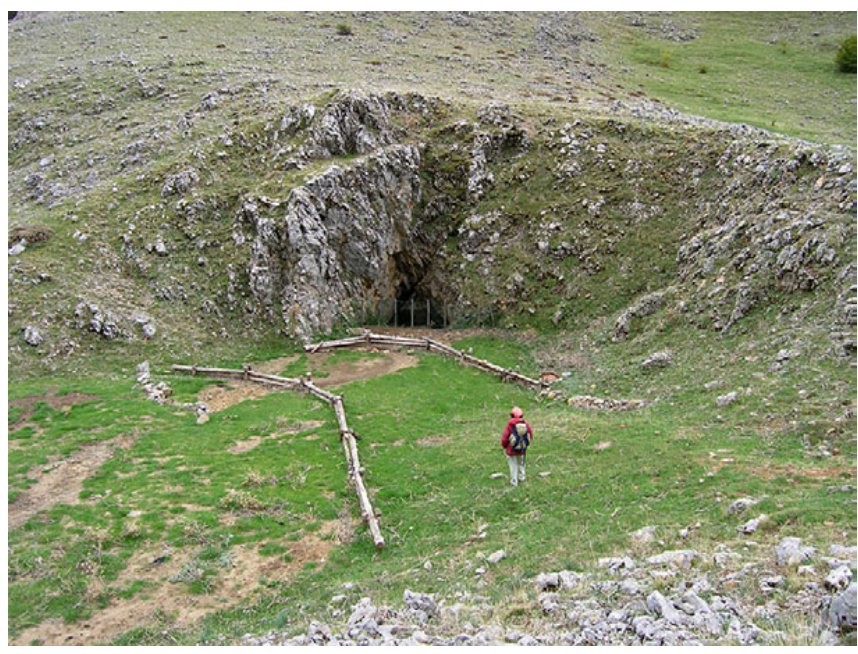

Fig. 2. Detail of Battaglietta sinkhole (Photo: A. Ollè).

in Sicily, which is strictly linked to the first peopling of Europe (Carbonell, Rodríguez 2006; Peretto 2006; Mishra et al. 2007, p. 3005; De Lumley et al. 2009).

An important issue in relation to the early phases of human displacement from Africa ("out-of-Africa" I) concerns the possibility of migrations across the central Mediterranean Sea from Tunisia into Sicily and Southern Italy. Considering that "river terraces are well established as an important source of Lower and Middle Palaeolithic artefacts in Europe" (Mishra et al. 2007) and that main Early Palaeolithic European sites have been individuated into deep sinkholes (Atapuerca karst system), the research included an accurate control of river terraces and local sinkholes in order to find some evidence of pre-Homo sapiens people. At present we recorded some lithic assemblage of
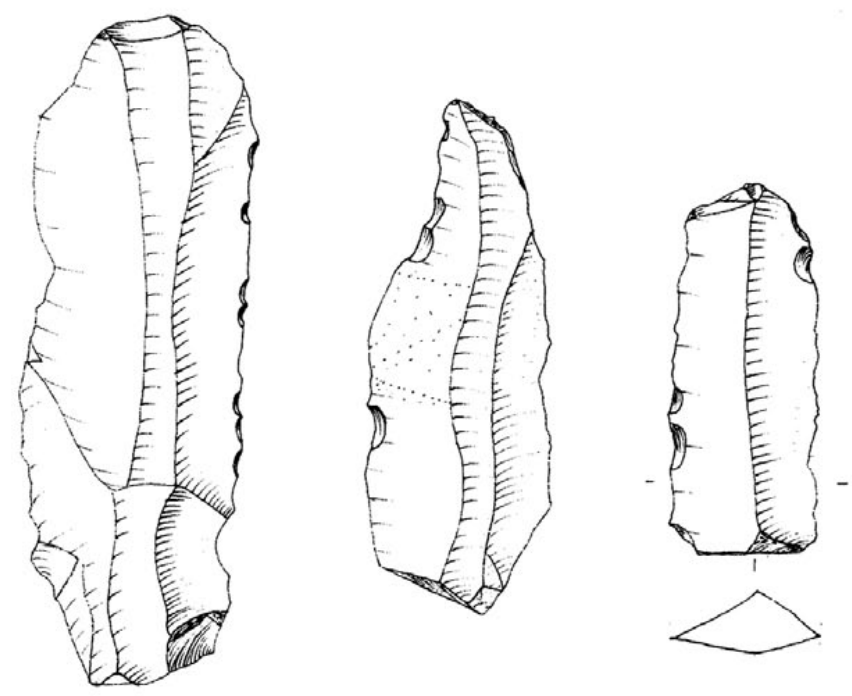

undefined chronology and an isolated faunal remain of an extinct dwarf elephant (Forgia 2008).

\subsection{Giancaniglia (Early Palaeolithic site?)}

The last discovery is linked to an old information (Meli 1961) about the presence of quartzite flakes ("une sorte de Clacto-Levalloisien..." - Graziosi 1968) in the same river terrace section, that, if the reciprocal association will be confirmed by further investigations, could give a first contribute to the understanding of early peopling of the island.

\subsection{Caves and rockshelters of Madonie territory}

More then 20 caves have been recorded by survey. Most of the caves present important deposits which could reveal an archaeological interest.

\subsubsection{Vallone Canna caves system}

Vallone Canna is a natural canyon characterized by the presence of many horizontal caves opened into its sides. Three of these caves have been explored in order to detect an eventual ancient deposit. The first one, starting from the East, is interested by the stream of Canna River, which cut its deposit, characterized by horizontal and sub-horizontal layers. Inside the section it was possible to identify some faunal remains but no evidence of anthropic presence.

The other two caves, both opening on the left side of the river, show a deep deposit (as it looks like by the natural shape of karstic caves), interested by presence of modern pottery, which testify the use of the caves in modern time and could hide an earlier and really probable frequentation. Not far from the river and caves system there is a shepherd

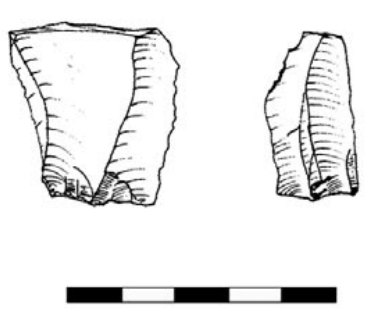

Fig. 3. Lithic artefacts from Battaglietta (UT 24). 
modern site (Case Sambuchi). Further researches could link the modern use of this place with the potential archaeological and palaeoenvironmental record here preserved.

\subsubsection{Vallone Inferno rock-shelter}

In 2008 University of Palermo, in cooperation with Institut Català de Paleoecologia Humana i Evolució Social -Universitat Rovira i Virgili, Tarragona- started out an investigation of the Vallone Inferno prehistoric rock-shelter, located in the latest survey season. First preliminary data will be given in a further communication. The main aim of the investigation is to collect new information about palaeoenvironmental holocenic changes of the area and to obtain new radiocarbon dates of all the phases of occupation in this multi-stratified deposit.

\subsubsection{Bommartino cave (Middle Neolithic-Early Bronze age site)}

The cave is located in the territory of Sclafani Bagni, on the western side of the Imera River. Local farmers call the place with the name of Bommartino, so we gave to the cave the same name.

The cave is formed by a rock-shelter, an open chamber and an underground cavity.

The rock-shelter is interested by the presence of prehistoric potsherds of undefined chronology; the open chamber has no deposit (the rock bottom appears); the underground cavity, which presents a deposit with an important inclination

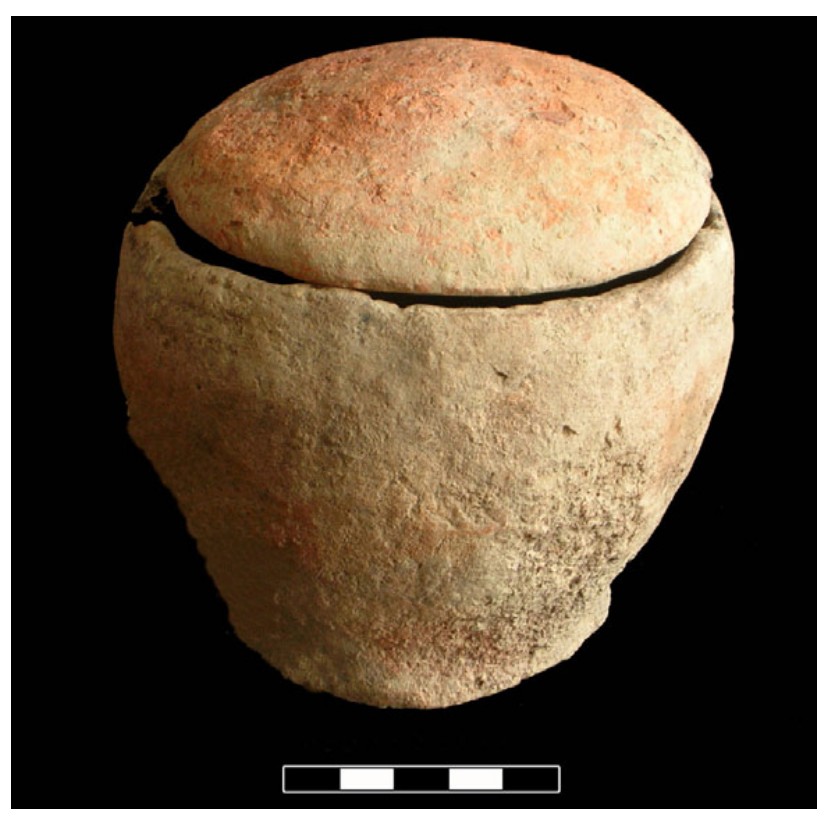

Fig. 4. Prehistoric pot from Bommartino cave. (about $35^{\circ}$ ), is rich of prehistoric pottery and lithic industry scattered on the surface. A lateral recess seems to be used as burial place (human bones and one probable cinerary pot were found), but only future investigation could clarify the functions of the inner chamber during several phases of prehistory (fig. 4).

The human presence inside the cave, is attested, up to now, since the Middle Neolithic, by the typical painted pottery (called tricromica), which we also found on the opposite side of the valley, at Vallone Inferno rock-shelter (at the same altitude). Other prehistoric periods are represented by Copper and early Bronze Age pottery. The presence of Castelluccio pottery (early Bronze Age), almost unknown in this part of Sicily, has to be explained. It could represent an isolated introduction of some items or implies the interest of Castelluccio groups for this specific territory, maybe linked to the thermal activity and the sulphurous water source of Sclafani.

\section{Preliminary palaeoenvironmental data}

During last years scientific community has looked with a renovate interest to palaeoenvironmental topics of Sicily. Some pilot researches have been carried out in order to define different aspects of the Quaternary environment (Belvedere et al. 2002) with a special focus about Pleistocene-Holocene transition (Frisia et al. 2006; Sadori 2001; 2007a, b).

A work in progress in the hinterland of the Greek town of Himera is sampling different ancient lacustrine deposits situated in the Southern part of the Imerese territory, between the hills and the Madonie Mountains.

The research of the University of Palermo, in cooperation with the Free University of Amsterdam ${ }^{1}$, is giving first preliminary results. Some interesting data come from a core (C7) from Gorgo di Pollicino Lake, located at the altitude of $1300 \mathrm{~m}$ a.s.l., in Petralia Sottana territory.

Pollen is common through the cores and the variety of pollen-assemblage shows that the core envelops a long period. Moreover olive pollen has been found only at the top of the core. Between tree pollens, when Quercus (oak) pollen decreases Fagus and Juglans are present. These are not quite typical for Mediterranean communities, although they do occur at high altitudes with low temperatures and humidity. At 104-110 cm depth Gelasinospora have been found, indicating burned wood. In the core, dark layers present at $110 \mathrm{~cm}$ probably indicates forest fire events.

Waiting for radio-carbon dating of the core, we can turn our attention to the data coming from the research lead in Lago

1. TROELSTRA (S.) - Relazione preliminare della campagna di rilevamento paleoambientale del territorio di Himera, preprint, 2004. 
di Pergusa (667 m a.s.1.), the main inland lake of Sicily (Sadori, Giardini 2007).

The comparison between micro-charcoal and pollen data coming from the sediment core of Lago di Pergusa indicated the linkages between fire, vegetation, and climate at local and regional scale.

Results about vegetation of the inland, as revealed by this research can be summarized as follows: "[...] The transition period related to the present interglacial reforestation, characterized by slowly increasing humidity, started about 10700 years BP. The onset of the wettest conditions of the Holocene occurred from about 9000 years BP until about 7200 years BP. Then a trend towards aridification began, leading to very dry conditions at about 3000 years BP. An unquestionable human impact on vegetation is found since 2800 years BP, when dry conditions are still however clear, although earlier land use traces are visible in the last four millennia." (Sadori, Giardini 2007, p. 176).

From the comparison between fire events at a regional scale (testified by micro-charcoal remains between 50 and $125 \mathrm{~mm}$ in diameter) and vegetation, the authors identify two regional fire events at 8200 and 7700 years BP, after a few hundred years since the emergence of Fagus.

Looking at Madonie core C7, we can note the emergence of Fagus and, soon after, two fire events attested by the presence of Gelasinospora (which means burned wood), and by two dark layers.

In the absence of radiocarbon dating, we do not suggest identifying these two fire events as the same events, but only the possibility that Madonie samples could cover a long period and be useful for a more detailed palaeoecological reconstruction.

New data, coming from Vallone Inferno rock shelter, will be shortly available. The information will regard vegetation, fauna and climate since the middle Neolithic age until modern age (probably with some lack in the data). Analyses of seasonality and function of the site are also in progress. Knowledge of the palaeoenvironment of Vallone Inferno rock shelter will be a useful asset in order to value the origin and development of some central activities of Holocene cultures of the region, as breeding or agriculture. In addiction to palaeobotanic and archaeozoological analysis our research will be supported by functional studies of lithic tools based on use wear analysis that will increase the knowledge of the economy of the site during different chrono/cultural stages.

\section{Perspectives and conclusions}

Our excursus about Madonie Mountains lets us make some remarks and leave many open questions.

The most ancient phases of prehistory, not only of Madonie, but of the entire island, are not sufficiently documented; surface finds should attest the presence of Lower Palaeolithic culture, but there are no evidences coming from excavated sites. During our research, we discovered a quaternary faunal remain, pertinent to an extinct dwarf elephant, in the section of an alluvial terrace where many years ago probable Lower Palaeolithic tools were founded (site of Giancaniglia, Termini Imerese). Some other lithic implements (quartz-arenitic and flint flakes, UT 20) have been founded, during our survey, in a section of another terrace (an Imera river terrace), in a place called Capraria, near the modern small town of Scillato.

The first peopling of the island is still an interesting and open question to investigate.

Going on with prehistoric occupation and use of the mountainous territory we can observe the presence at higher altitude of final Upper Palaeolithic groups probably interested not only to wild fauna, but also to raw materials, as flint sources of Monte Cervi zone.

With respect to raw material it's possible to note some differences in exploitation ways.

The survey we conducted on highest areas had pointed out that lithic scatters of the flint source zone are mainly constituted by flint tools, while the area with no flint and some quartz-arenitic beds is interested by the presence of a site with a predominant quartz-arenitic assemblage.

Next stage of our research should consider settlement strategies and seasonality taking into account also the already known sites (as Castello rock shelter) of the plane, near the coast.

One of the main topics of the Madonie research is the study of the origin and development of pastoralism in the island. The possibility to cross archaeological, archaeo-zoological and palaeobotanic record will give an idea of the development of pastoralism maybe since its establishment in Sicily. Many archaeological sites are interested by the presence of middle Neolithic phases. The absence of earlier phases of Neolithic in the mountainous territory could be itself an information about land use. On the contrary the considerable presence of middle Neolithic phases in the same area could testify an interest for middle altitude places, maybe linked to the earliest exploitation of summer pastures. More information about local fire events could clarify the chronology and the use of mountainous territory with respect to pastoral activities, as in the case of Alpine region (Marzatico 2007, p. 165; Mottes, Nicolis 2002, p. 249).

Some cultural phenomena in Alpine region are actually linked to pastoral practice development. It seems to be realistic that contact between Northern and Southern Alps become stronger during the first half of IV millennium in correspondence of the beginning of pastoral activity at higher altitudes (Marzatico 2007, p. 164 and previous 
bibliography). It will be an asset of our research to clarify the relationship between pastoral farming development in the mountains and the main prehistoric cultural aspects concerning this part of the island.

\section{Bibliography}

Belvedere et al. 1988: ALLIATA (V.), BELVEDERE (O.), CANTONI (A.), CUSIMANO (G.), MARESCALCHI (P.), VASSALLO (S.) - Himera III.1. Prospezione archeologica nel territorio, Roma, 1988.

Belvedere et al. 2002: BELVEDERE (O.), BERTINI (A.), BOSCHIAN (G.), BURGIO (A.), CONTINO (A.), CUCCO (R.M.) LAURO (D.) - Himera III.2. Prospezione archeologica nel territorio, Roma, 2002.

Brochier et al. 1992: BROCHIER (J.-E.), VILLA (P.), GIACOMARRA (M.), TAGLIACOZZO (A.) - Shepherds and sediments: Geo-ethnoarchaeology of Pastoral Sites. Journal of Anthropological Archaeology, 11, 1992, p. 47-102.

Carbonell, Rodrìguez 2006 : CARBONELL (E.), RODRÌGUEZ (X. P.) - The first human settlement of Mediterranean Europe. Comptes rendus - Palevol, 1-2, 2006, p. 291-298.

De Lumley 2009: DE LUMLEY (H.) et al. - Les premières étapes de la colonisation de l'Europe et l'arrivée de l'Homme sur les rives de la Méditerranée. L'Anthropologie, 113, 2009, p. 1-46.

Forgia 2008: FORGIA (V.) - Mountain environment and landscape in prehistoric Sicily: the Madonie region (Palermo, Italy). In: GRIMALDI (S.), PERRIN (T.), GUILAINE (J.) ed., Mountain environments in prehistoric Europe: settlement and mobility strategies from Palaeolithic to the Early Bronze Age, Proceedings of the XV UISPP World Congress (Lisbon, 4-9 September 2006), Vol. 26, Session C31, Oxford, BAR International Series, 1885, 2008, p. 160-169.

Frisia 2006: FRISIA (S.), BORSATO (A.), MANGINI (A.), SPÖTL (C.), MADONIA (G.), SAURO (U.) - Holocene climate variability in Sicily from a discontinuous stalagmite record and the Mesolithic to Neolithic transition. Quaternary Research, 66, 2006, p. 388-400.

Gabrici 1930: GABRICI (E.) - Scavo stratigrafico al «Ricovero sotto roccia» di Termini Imerese. Bullettino di Paletnologia italiana, 1930-1931.

Graziosi 1968: GRAZIOSI (P.) - Découverte d'outils du Paléolithique inférieur en Sicile. L'Anthropologie, 72, 1968, p. $39-48$.

Marzatico 2007: MARZATICO (F.) - La frequentazione dell'ambiente montano nel territorio atesino fra l'età del Bronzo e del Ferro: alcune considerazioni sulla pastorizia transumante e l'economia di “malga". Preistoria Alpina, 42, 2007, p. 163-182.
Meli 1961 : MELI (M.) - Nuove facies del paleolitico in Sicilia. Quaternaria, 5, 1961, p. 322-323.

Mishra 2007: MISHRA (S.), WHITE (M.J.), BEAUMONT (P.), ANTOINE (P.), BRIDGLAND (D.R.), LIMONDINLOZOUET (N.), SANTISTEBAN (J.I.), SCHREVE (D.C.), SHAW (A.D.), WENBAN-SMITH (F.F.), WESTAWAY (R.W.C.), WHITE (T.S.) - Fluvial deposits as an archive of early human activity. Quaternary Science Reviews, 26, 2007, p. 2996-3016.

Mottes, Nicolis 2002: MOTTES (E.), NICOLIS (F.) - Il territorio del Trentino tra Neolitico recente ed età del Rame: analisi ed interpretazione dei dati. Il declino del mondo neolitico. Ricerche in Italia centro-settentrionale fra aspetti peninsulari, occidentali e nord-alpini. In: FERRARI (A.), VICENTINI (P.) (a cura di), Atti Convegno (Pordenone 5-7 aprile 2001), Museo delle Scienze, Comune di Pordenone (Quaderni del Museo Archeologico del Friuli occidentale, 4), 2002, p. 237-256.

Palma di Cesnola 1993 : PALMA DI CESNOLA (A.) - Il Paleolitico Superiore in Italia. Introduzione allo studio, Firenze, Garlatti \& Razzai, 1993, 575 p.

Peretto 2005 : PERETTO (C.) - The first peopling of southern Europe: the Italian case. Comptes Rendus Palevol, 5, 2005, p. 283-290.

Sadori, Giardini 2007 : SADORI (L.), GIARDINI (M.) - Charcoal analysis, a method to study vegetation and climate of the Holocene: The case of Lago di Pergusa (Sicily, Italy). Geobios, 40, 2007, p. 173-180.

Sadori, Narcisi 2001: SADORI (L.), NARCISI (B.M.) - The Postglacial record of environmental history from Lago di Pergusa, Sicily. The Holocene, 11,6, 2001, p. 655-670.

Sebasti 1995: SEBASTI (F.) - Riparo del Castello a Termini Imerese (PA): analisi di una collezione del Paleolitico superiore. Bullettino di Paletnologia italiana, 86, 1995, p. 59-96.

Sebasti 1998: SEBASTI (F.) - L'Epigravettiano della grotta Natale a Termini Imerese (PA): analisi di una collezione del Museo “L. Pigorini”. Bullettino di Paletnologia italiana, 89, 1998, p. 19-30.

Vaufrey 1928: VAUFREY (R.) - Le Paléolithique italien. Archives de l'Institut de Paléontologie Humaine, Mémoire 3, Paris, 1928.

Vigliardi 1968: VIGLIARDI (A.) - L'industria litica della Grotta S. Teodoro in provincia di Messina. Rivista di Scienze Preistoriche, 23, 1968, p. 1-2.

Zampetti 1984: ZAMPETTI (D.) - Il Paleolitico superiore del Riparo del Castello a Termini Imerese (Palermo): analisi di una collezione. Origini, XIII, p. 59-97. 


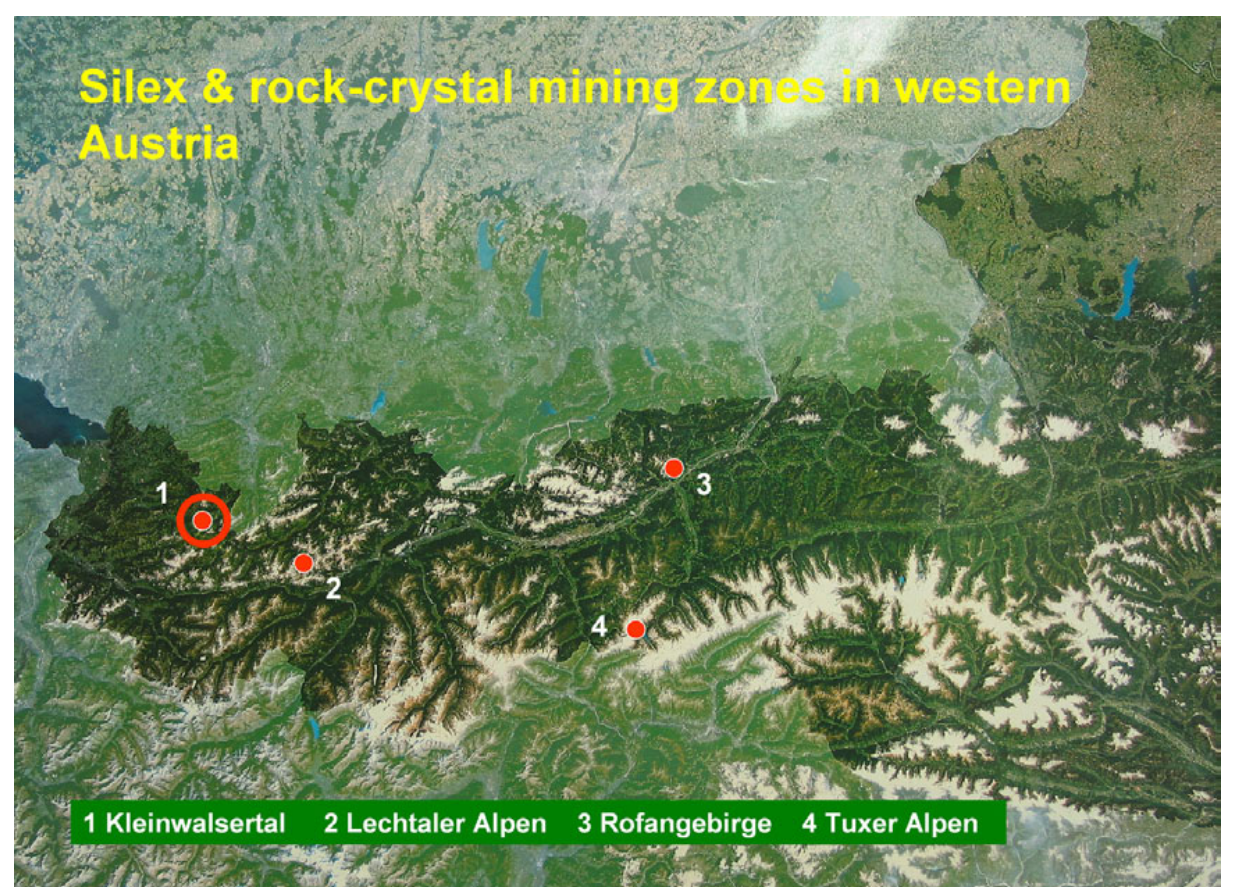

Fig. 1. Map of Western Austria with the four find-spots in the investigation area (Landsat/ESA (C).

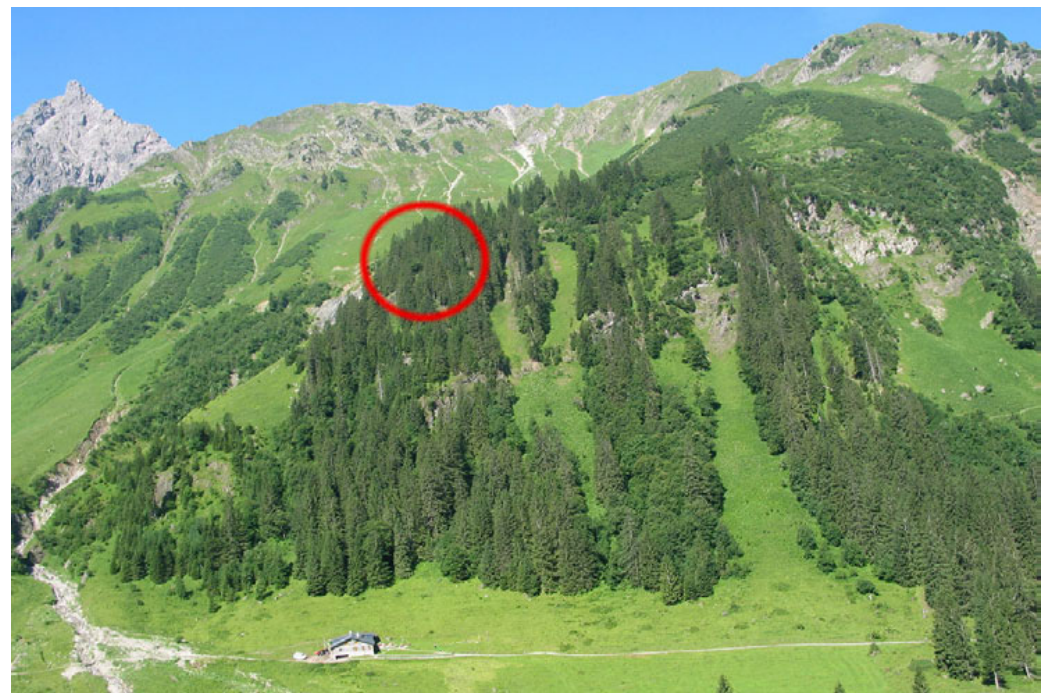

Fig. 2. The wooded hilltop of the Bärenkopf in the Gemsteltal. The red circle marks the mining area (○ Walter Leitner).

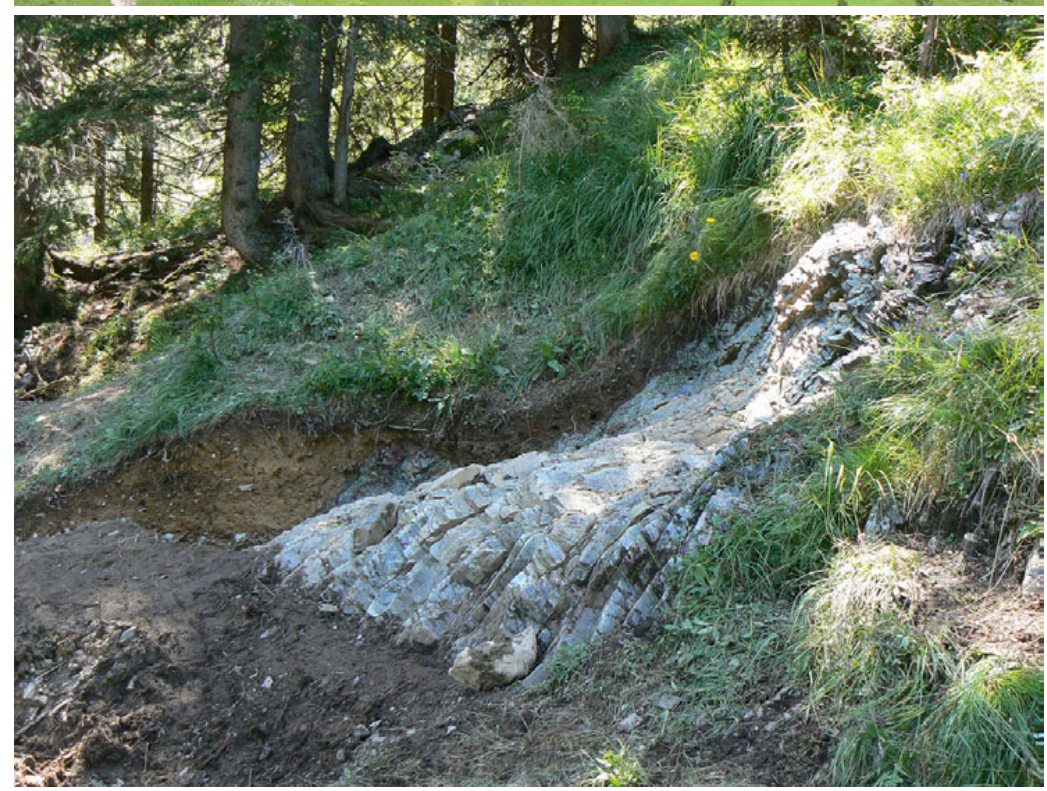

Fig. 3. Stepped formation of the radiolarite layers as a result of man-made reduction (C) Walter Leitner). 


\title{
Traces to the oldest flint and rock crystal mining places in the Austrian Alps
}

\author{
Walter LEITNER*
}

\begin{abstract}
Recently the Institute of Archaeology (Dep. of Pre- and Protohistory) of the University of Innsbruck has undertaken excavation work in the Kleinwalsertal (Vorarlberg). Actually all sites and finds belong to the Mesolithic period. The lithic artefacts are made to a large extend from a red and green radiolarite which has been mined in the very close surroundings. Finds of corresponding raw material in the river gravel of the valley led to the primary layers on precipitous slopes in an altitude of 1600 meters. This place can therefore be defined as the oldest and highest mining site in the Alps. From the actual explorations we can deduce that the so called fresh raw material was stroken off in form of steps. In 2007 a mining tool corresponding to a stonehammer could be found. The raw-material is of good quality and the localized rich natural deposits in this area permits a kind of small supplying center for the western region of Austrian Alps in the Mesolithic age. Other studies were conducted in the Lechtaler Alps and in the Rofan Mountains in the upper and respectively in the lower Inn Valley of the Tyrol. There Silex resources appear in great quantities so that prehistoric mining is to be expected. Further exploration work is done in the Tuxer Alps where big quartz clefts show traces of prehistoric extractions of rock-crystal.
\end{abstract}

Les plus anciens sites d'extraction de silex et de cristal de roche dans les Alpes autrichiennes

Résumé. Les travaux de ces dernières décennies ont révélé ques les chasseurs-cueilleurs de l'époque postglaciaire avaient occupé de manière intensive toute la région des Alpes, que ce soit dans les vallées, en moyenne altitude ou vers les sommets. Pour fabriquer leurs outils en pierre, ils puisaient alors dans les différents types de chert. Les outils de meilleure qualité parcouraient souvent de longues distances avec leur propriétaire. Mais où trouver des mines où extraire ces précieux matériaux? Contrairement aux excavations néolithiques que l'on retrouve dans toutes les Alpes, il n'y a pratiquement pas de traces datant du Mésolithique dans cette région des Alpes autrichiennes. Les travaux récents conduisent à s'intéresser aux zones calcaires du Tyrol et du Vorarlberg. L'institut d'archéologie (département de pré- et protohistoire) de l'Université d'Innsbruck vient de commencer une campagne de fouilles dans le Kleinwalsertal (Vorarlberg). Tous les sites et les objets trouvés remontent de fait à la période mésolithique. Les artefacts lithiques sont pour la plupart fabriqués à partir d'une radiolarite rouge et verte, extraite dans des mines voisines. Les matériaux bruts correspondants trouvés dans le gravier de rivière de la vallée nous ont conduits aux couches primaires présentes sur les pentes escarpées, à $1600 \mathrm{~m}$ d'altitude. Un outil de mineur (maillet en pierre) a été mis au jour sur place en 2007, ce qui pourrait permettre de conclure à la présence, à l'époque Mésolithique, d'un petit centre d'approvisionnement pour la partie occidentale des Alpes autrichiennes. D'autres études ont été effectuées dans les Alpes du Lechtal ainsi que dans les Montagnes du Rofan, se situant dans la vallée supérieure et inférieure de l'Inn au Tyrol. Dans ces régions, des affleurements de silex sont fréquents, une exploitation préhistorique est très probable. D'autres recherches ont lieu dans les Alpes de Tux, où des failles alpines avec présence de cristal de roche démontrent aussi l'évidence d'une exploitation préhistorique.

$\mathrm{T}$ his work is part of a special international research project of the university of Innsbruck called HIMAT (History of mining activity in the Tyrol and adjacent areas), supported by FWF, Austria.

Silex belongs to the most important raw materials for the Stone Age tool production, and we know many exploitation zones in the whole of Europe. But looking at the alpine arch we notice a big gap. The few verified exploitation zones

* Institute of Archaeologies, Langer Weg 11, A6020 Innsbruck (Autriche). can be found on the outermost outskirts of the Alps, like for example in the area of Vaucluse in the Provence and in the area of Olten and Lägern in Switzerland. Mauer, a small exploitation site near Vienna (Austria), lies basically outside already. In the south we have the most obvious traces in the mountains of Lessini near Verona (Italy).

All these features mainly indicate to be Neolithic in date. We know, that hunters and gatherers have already heavily populated the inner alpine region during the postglacial period and used the higher alpine regions as their hunting areas at regular intervals. 
Where did they get their silex material from?

What about the spatial distribution?

Were they dependent on imports?

Has silex already been systematically exploited in the Mesolithic?

In connection with the special research program mentioned before investigations have started in the western Austria in the provinces Tyrol and Vorarlberg, where Silex from the point of geological view is frequently found in the northern limestone Alps (Leitner 2006-2007).

The archaeological investigations on that topic are in an initially phase. The situation will be lifted up on the base of by four site-examples (fig. 1).

Only in case 1 clear statements can be made. Concerning the sites 2, 3 and 4 the preconditions for the exploitation of silex and rock crystal are given, but need to be further investigated.

\section{Site 1 (Bärenkopf, Kleinwalsertal, Vorarlberg)}

Between 1999 and 2004 several Mesolithic camp-sites have been excavated in this region.

In nearly up to $100 \%$ red and green radiolarite was used for the production of the stone tools. The material is of good quality and can be found as secondary deposits in the gravels of the main stream of the valley. So, looking for the primary deposits, the prehistoric hunters only needed to walk upstream because the material has been transported down into the valley via rock slides ending in the streams (Binsteiner 2008; Leitner 2008a).

Close to the top of the valley rises a rocky hill formation, the so-called Bärenkopf. It forms the centre of the radiolarite occurrences. The research area is located on a very steep and wooded hilltop. Typically enough, this formation is called Flintstone-hill by local people (fig. 2).

At this point the layers of radiolarite appear at the surface at several spots.

One could recognize small terraces, which in contrast to the surrounding steep incline, did not seem to be natural. After digging away the soil, the stepped structure of the radiolarite formation surfaced at several points and gave proof of an intentional knocking out of the silex material relevant to a mining activity (fig. 3 ).

The main colours of the exploited radiolarite are red and green, in very few cases with fine black lines. At the other side of the valley dark grey to black material can also be found. Knapping experiments indicated, that the green raw material is of best quality. The geological/petrographical report proofed a particularly qualitative radiolarite variety. It is a recoverable material. Concerning the age of this mining site we have some indirect, but also some direct indications: It is significant that all the stone tools excavated in the valley till now, are just a few kilometres remote of the exploitation area and they are all Mesolithic in date. Important is also the fact that there is no historical tradition of mining activity on silex in the whole valley. Among the direct indications of age determination are several finds of stone artefacts of the mining site with characteristic marks of prehistoric flint knapping technique (Leitner 2008b).

Tools are rare. In most cases we have some fragmentary small blades, rarely retouched on the edges. Not without reason. Precisely said, people came up here, but just to exploit the raw material and not to produce tools. One could suppose it was levered by antlers. Apart from the fact that there were no relevant finds, the space between the layers is surely too narrow to fit in an antler pick.

We don't have even traces of wooden wedges to crack the silex layers. And even no indications of the oftentimes used method of heating to crack the rock easier.

According to experiments this material can be mined best by continuously hammering the lateral surfaces. Finally the so obtained chunks were reduced to smaller pieces. So plentiful flakes and angular debris were produced while the material was tested on the spot in order to take only the best cores away finally. The most decisive finds of the excavation came out in summer 2007.

At a depth of $1,10 \mathrm{~m}$ in the investigation area 5 three spherical objects appeared. Without any doubt one of these was shaped intentionally by picking the surface. Traces of splintered parts make clear that the tool was used as a stone-hammer to knock out silex from the rock.

The finding spot also corresponds with the most planar situation in the steep terrain. Only this one point corresponds to the position where mining tools could have been laid down (fig. 5).

While the material of the hammer-stone is radiolarite two other spherical stone-tools consist of sandstone and limestone. They seem to be a kind of grinding stones based on the fact that on the surface some very flat and rubbed off areas can be seen (fig. 4).

All these circumstances approve the mining activity in this section. Around 16000 survey points were taken in the area of investigation to get a three dimensional model of the situation.

On fig. 6 the seven excavation areas are charted. Note the long stripe of exploitation and the red spot where the mining tools were found.

Relating to several surveys in the surroundings of the Kleinwalsertal it turned out, that there are, as far as quantity and quality are concerned, no comparable radiolarite deposits. Of course stone tools made of comparable radiolarite are present in the immediate vicinity, but also in the alpine Rhine valley and in the southern region of the Lake Constance. Due to its quality it is quite possible, that the radiolarite had a certain circulation. In summary we can 
say that the Bärenkopf is not a big mine with tunnelling and shafts like we know from the Neolithic. But the exploitation of the quarry-site in the Kleinwalsertal certainly represents a small supply centre in the west of Austria and is up to now at an altitude of $1600 \mathrm{~m}$ above sea level the highest and oldest silex exploitation site in the Alps.

\section{Site 2 (Schafgufl, Tyrol)}

Indications of radiolarite exploitation are given also in the Lechtaler Alpen in Tyrol (fig. 1,2).

A big cave of particular interest is located in a side valley of the river Lech at $2000 \mathrm{~m}$ above sea level. The so-called Schafgufl gives actually permanent shelter to a modern shepherd, and we can suppose that it also offered ideal preconditions for a Stone Age hunter-camp with a nice forecourt, for which we could list many comparable examples in the alpine region. Why does this cave site attract our attention? The chalk formation of the overhang is streaked by beds of radiolarite (fig. 7).

Bigger unnatural hollows remind on artificial exploitation (arrow). In a manner of speaking the raw material - apart from the fact that it was not of best quality - was in front of the hut.

Excavations, that could illuminate those circumstances, unfortunately could not take place, because it was not possible to evacuate the shepherd and destroy his cosy summer camp.

\section{Site 3 (Rofangebirge, Tyrol)}

The Rofan-mountains in the northern limestone Alps (fig. 1,3) form a big silex resource as the geological situation shows. Corresponding to these circumstances numerous Mesolithic silex tools were found in this area, mostly at altitudes between 1800 and $2000 \mathrm{~m}$ above sea level. One of these sites is the so-called Grubalacke (fig. 8). Numberless debris, flakes, chips and also small exhausted cores and bigger nodules of red radiolarite are spread over the entire area.

Evidences suggest, that people have spent time here to test the surrounding raw material, a material which most of all reaches the quality that is required for the production of stone tools. Investigations started in summer 2008 on the western lakeside area (fig. 9).

First results show that red radiolarite formation is overlaying the white limestone in this area. The radiolarite layers are very weathered and not good enough for use (fig. 9). But here and there bigger nodules of best quality were integrated in these layers, ready to be picked up or easily be quarried out of the weathered layers directly beneath the top soil. So mining in regular sense was not really necessary. The best nodules were collected, battered and then the best pieces were used for the production of flint blades. First results verify the quantitative and qualitative significant flint resources in the entire Rofan Mountains and their earliest usage by Mesolithic hunters-gatherers. The area around the Grubalacke proves to have notably abundant finds and possibly resembles a central site for the prehistoric utilization of flint resources in the lower Inn valley.

\section{Site 4 (Riepenkar, Zillertal, Tyrol)}

Finally a site should be presented, which is important for the earliest rock crystal exploitation. It is located in the Tuxer Alps in the very back Zillertal in Tyrol. This region belongs to the crystalline zone of the Alps. The area encircles the so-called "Tauernfenster", a sector with an extremely rich rock crystal occurrence. The research area lies at an altitude of $2800 \mathrm{~m}$ above sea level at the so-called Riepenkar on the southern foot of the mount Olperer (fig. 10).

Here one of the biggest quartz clefts in the Zillertaler Alps we know of was discovered. Based on mineralogical investigations the biggest amount of the material is of an incredible and incomparable transparency and purity.

Amongst these pieces we find flakes with traces of retouching and percussion negatives indicating a prehistoric technique. That proves that this zone has obviously already been prospected for rock crystal by the post-glacial hunters (fig. 11).

Besides the usual chert varieties rock crystal provided an additional source for the production of stone tools for the prehistoric hunters in the high-Alpine terrain. Even though the material may be pretty difficult to work, the effort is obviously compensated by the optic qualities of the stone. Shape, transparency and sparkle make these crystals a sought-after material within the hunters-society.

Amidst the finds a piece of black chert must be noted. This material does not occur in-situ and was therefore must have been brought here by the hunters. Referring to the slightly convex outline of the stone and pick-marks on the surface it can be suggested that it might have served as an oval hammer stone to quarry out the crystals.

Predominantly they are the product of on-site flaking attempts on the rock crystal. A stationary camp at this altitude is not to be expected. The site has rather been visited on purpose for sourcing the treasured raw material. The actual tool-manufacturing took place at respective base camps.

It is to be assumed that this site probably played a significant role in the early countertrade across the Alps based on its central geographical position on the main ridge of the Alps. 

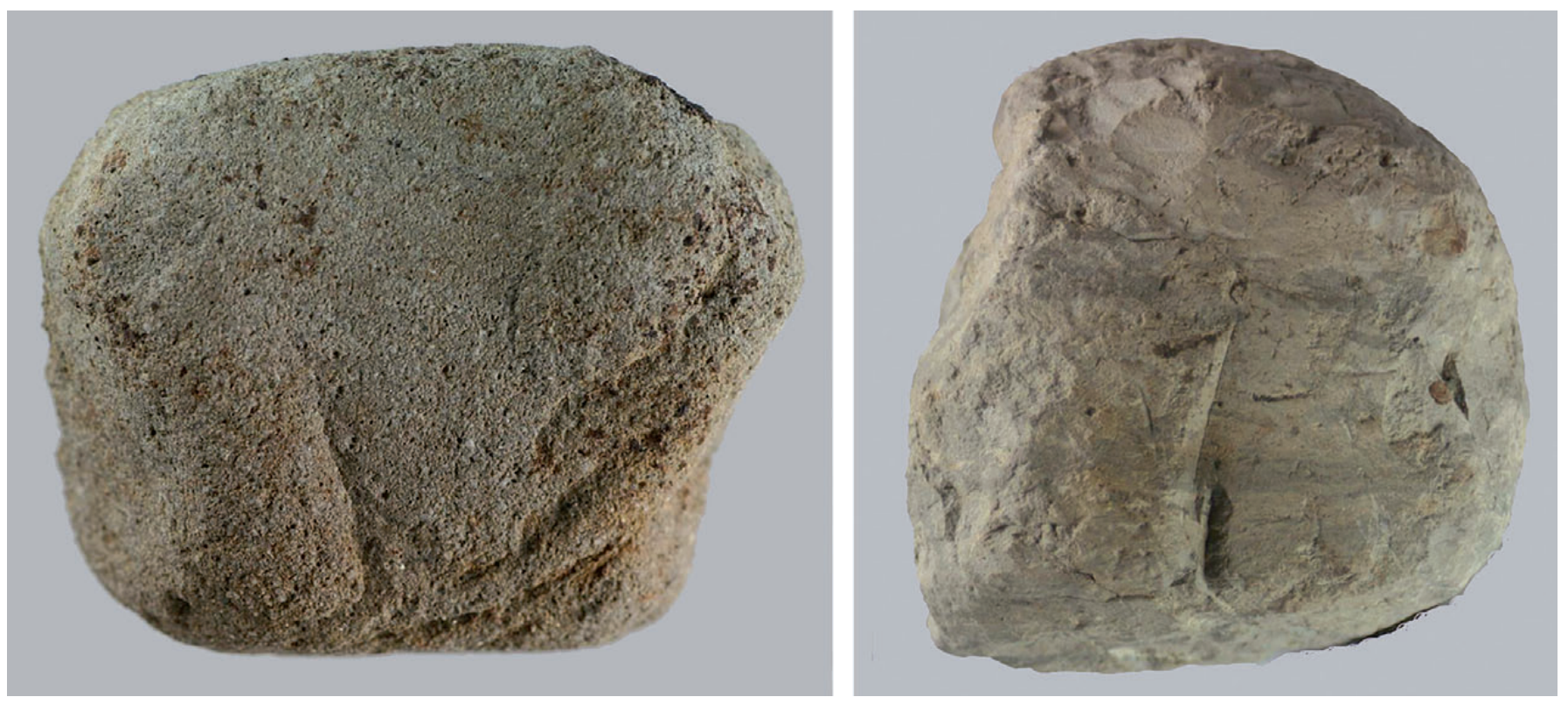

Fig. 4. Grinding or rubbing stone-tools from section 5 (@ Walter Leitner).

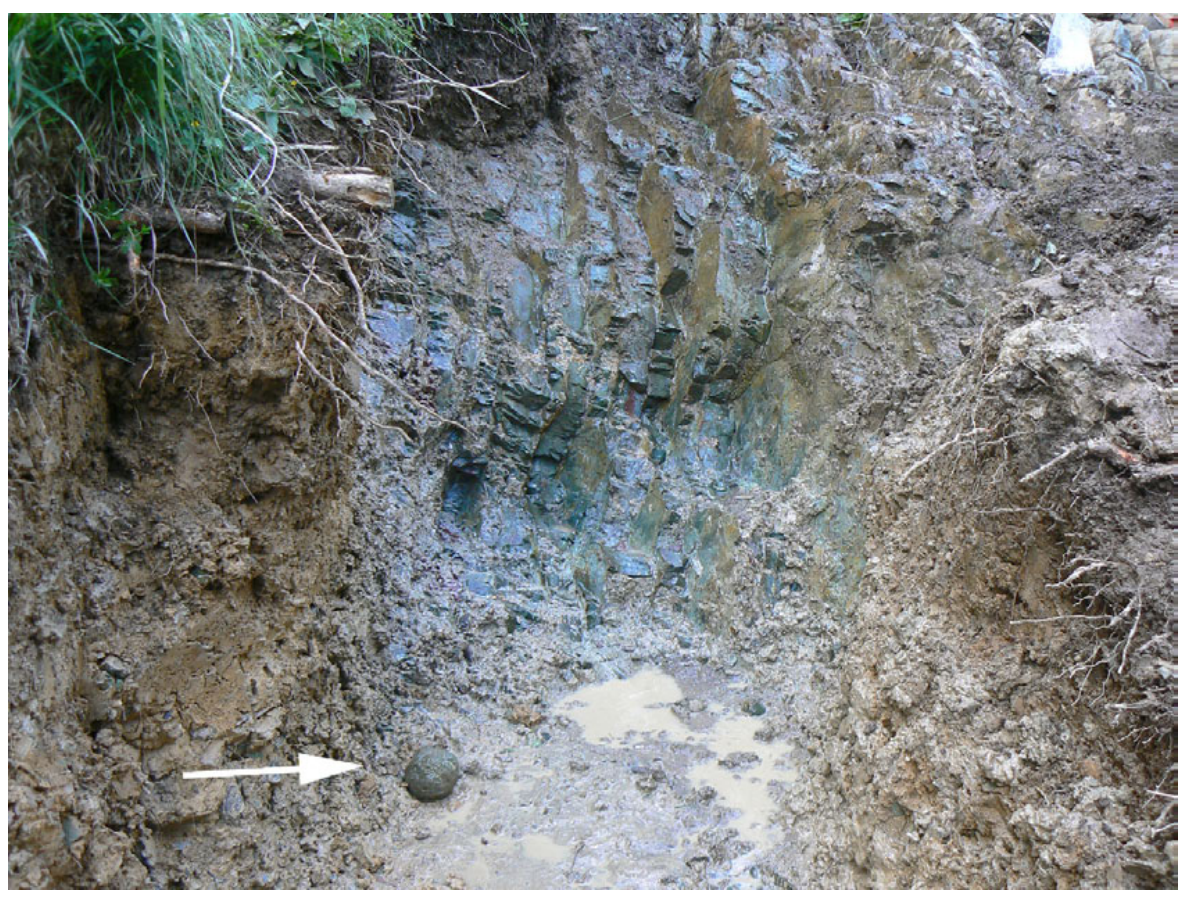

Fig. 5. Spherical hammer tool in "in situ" position (arrow) with the very proximate and clear traces of mining extraction in the radiolarite layers behind (@ Walter Leitner). 

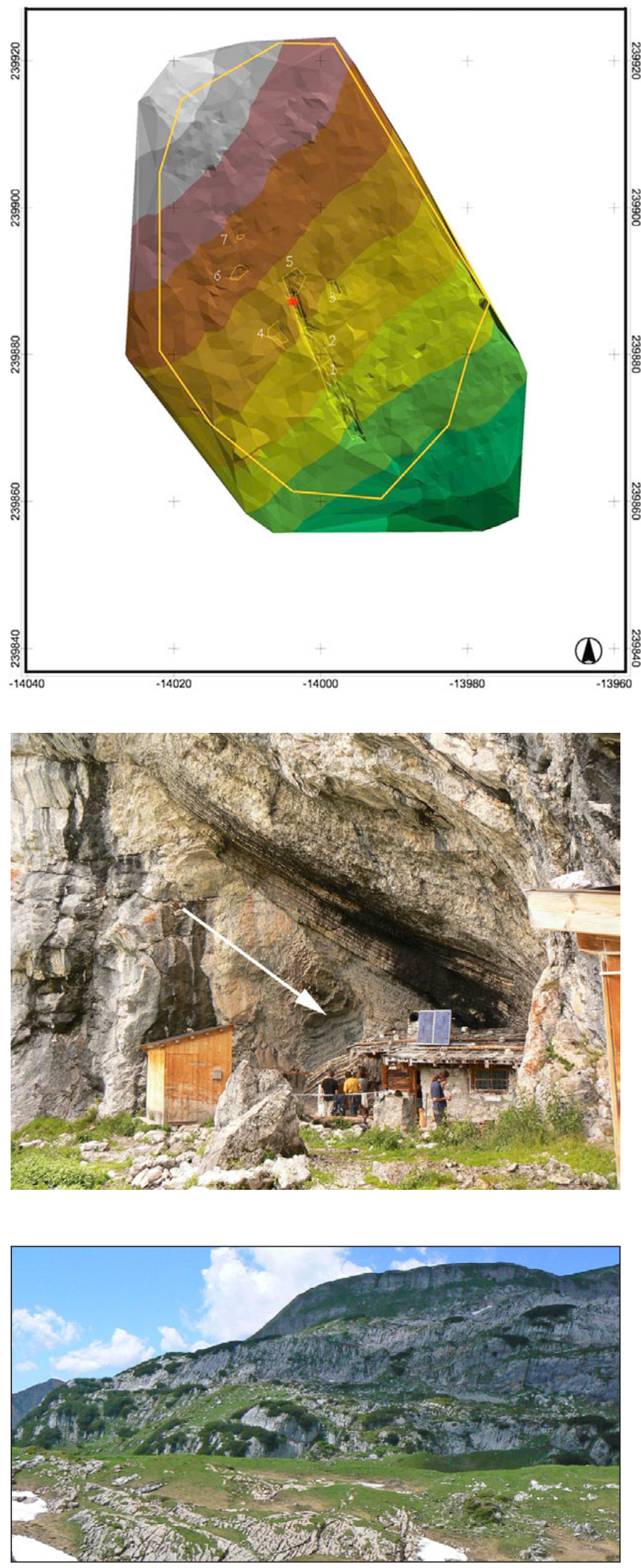

Fig. 8. The excavation area of the Grubalacke in the Rofan mountains (@ Walter Leitner).
Fa. ARDIS

Innsbruck

\begin{tabular}{|c|}
\hline 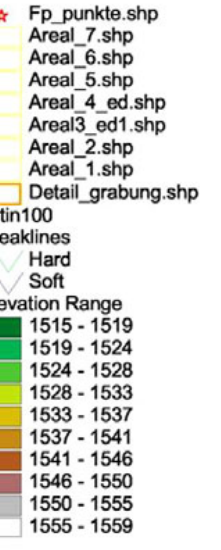 \\
\hline
\end{tabular}

Fig. 6. Three-dimensional plan of the silex mining area on the Bärenkopf with the excavated sections (C Ardis).
Fig. 7. The Schafgufel abri shows traces of silex exploitation on the arched slab (arrow) (@ Walter Leitner).

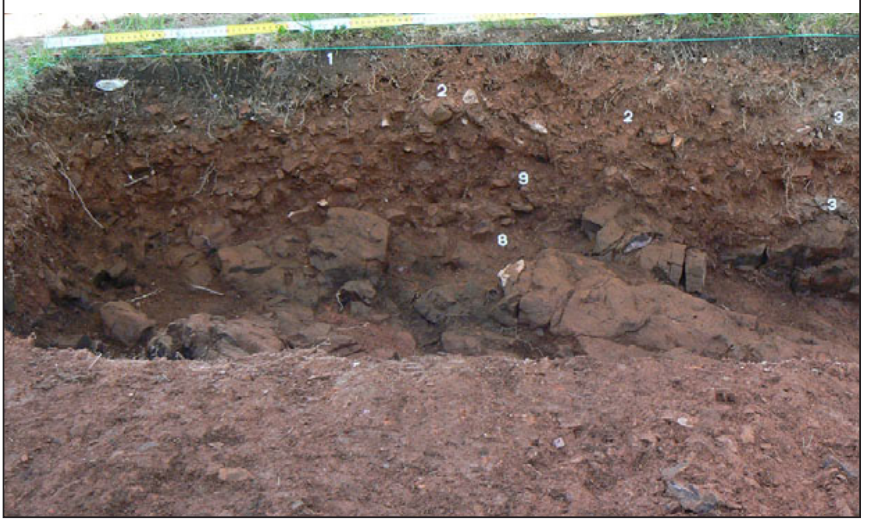

Fig. 9. Section with weathered red radiolarite layers near the Grubalacke (@ Walter Leitner). 


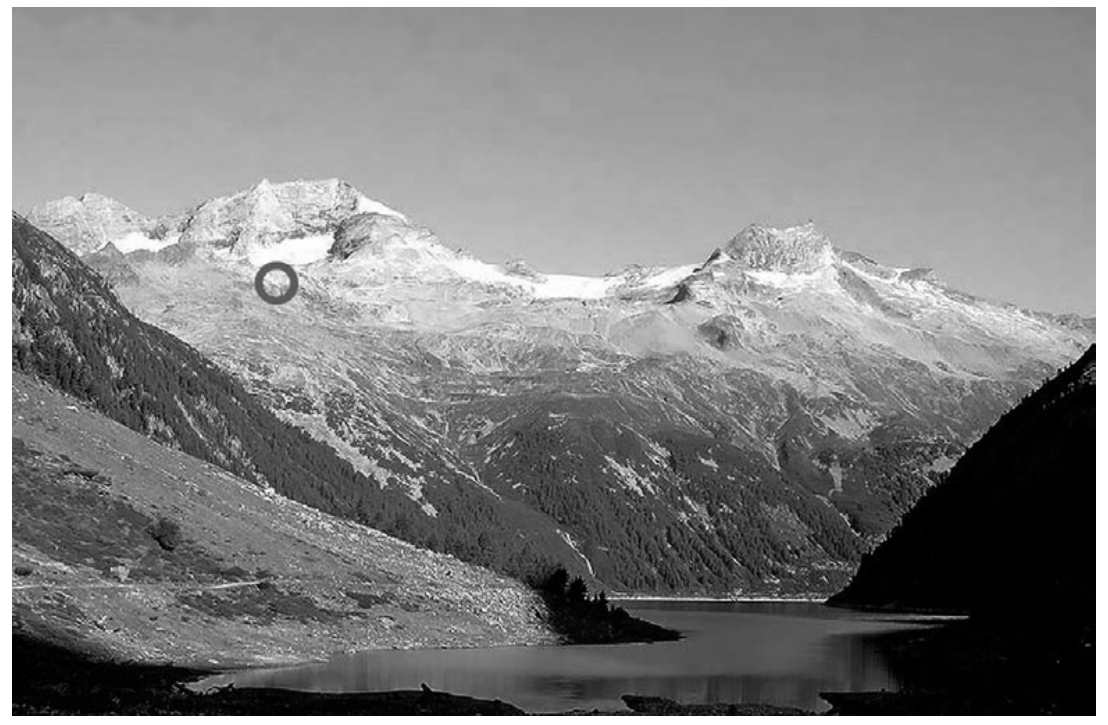

Fig. 10. On the southern inclination of the mount Olperer several quarz-clefts are situated (red circle) (C Walter Ungerank).

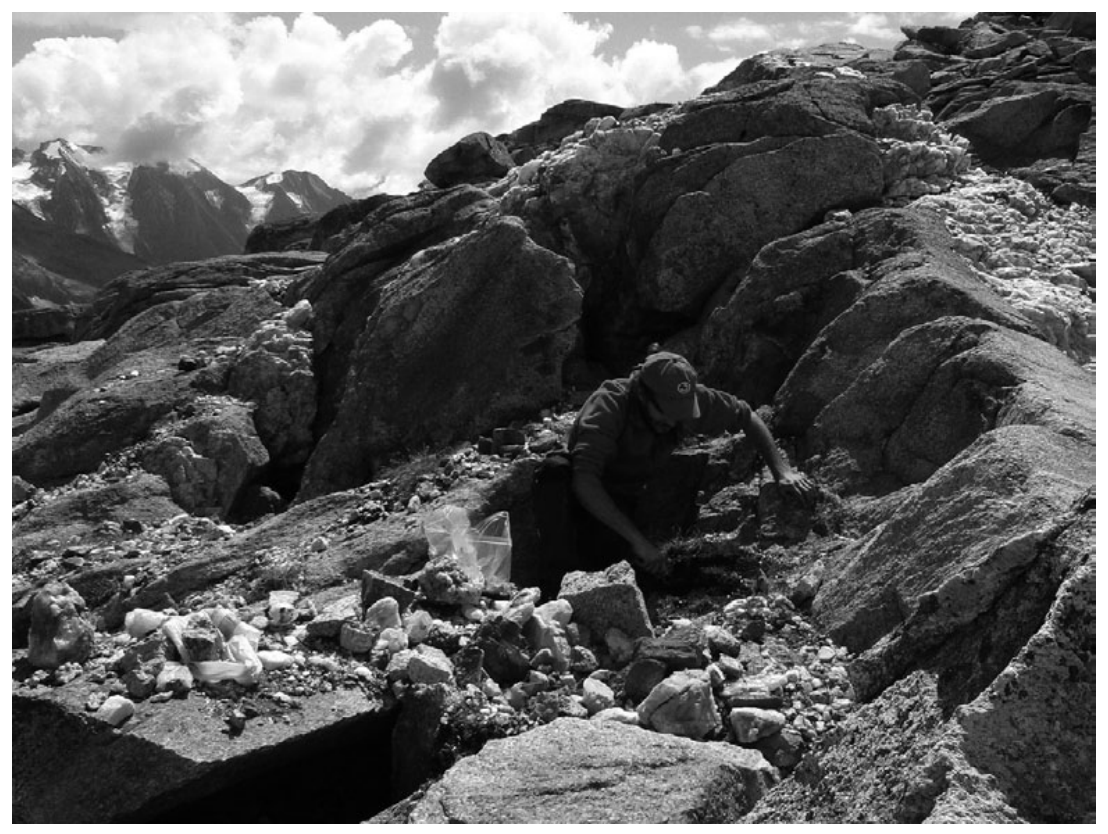

Fig. 11. Excavation site of a prehistoric mining place of rock crystal at the Riepenkar (2800 m) (@ Walter Leitner). 
Both northwards and southwards of this place several Middle Stone Age sites with artefacts of rock crystal are known andsuggest a north-south running connection. It seems pretty obvious that the Riepenkar plays a certain key role concerning the raw material and it's exploitation. From this point of view we can reconstruct a possible prehistoric transalpine rock-crystal route leading to the northern and southern areas, where the valuable and beautiful rock crystal material does not exist and needed to be imported.

\section{Bibliography}

Binsteiner 2008: BINSTEINER (A.) - Steinzeitlicher Bergbau auf Radiolarit im Kleinwalsertal, Vorarlberg (Österreich). Rohstoff und Prospektion. Archäologisches Korrespondenzblatt, 38/2, 2008, p. 185-190.

Leitner 2006-2007: LEITNER (W.) - Spuren zum ältesten Bergwerk in den Alpen. Jahrbuch des Vorarlberger Landesmuseumsvereins, 151, 2006/07, p. 71-77.

Leitner 2008a: LEITNER (W.) - Steinzeitlicher Bergbau auf Radiolarit im Kleinwalsertal, Vorarlberg (Österreich). Archäologische Ausgrabungen. Archäologisches Korrespondenzblatt, 38/2, 2008, p. 175-183.

Leitner 2008b: LEITNER (W.) - Steinzeitlicher Silexabbau im Kleinwalsertal. Archäologie in Deutschland, 4, 2008, p. 28-29. 


\title{
La montagne comme modèle d'enregistrement des mutations «culturelles» précoces : les cas de l’Azilien et du Sauveterrien en Pyrénées catalanes
}

\author{
Michel MARTZLUFF*, Jorge MARTINEZ MORENO**, \\ Joel CASANOVA I MARTI**, Rafael MORA TORCAL***
}

\begin{abstract}
Résumé. Les Pyrénées ne comptent que quatre sites établis autour de $1000 \mathrm{~m}$ qui peuvent témoigner de l'occupation de l'étage montagnard avant le Néolithique ancien. À partir des vallées d'Andorre et sur le flanc sud de la chaîne orientale, les abris de Guilanya et Margineda permettent d'analyser les mutations environnementales et les évolutions dans la culture matérielle et spirituelle des groupes de chasseurs-collecteurs de la fin du Tardiglaciaire à l'Holocène ancien. Au côté d'originalités culturelles (incursion d'Aziliens du versant nord pendant l'Alleröd, Sauveterriens sans microlithes cantonnés dans les Pyrénées sèches), les innovations techniques bien cernées en stratigraphie sont plus précocement attestées au cœur de la chaîne axiale qu'en bordure du littoral et dans les piémonts où certains décalages techno-typologiques, tel l’Épimagdalénien, ont été individualisés.
\end{abstract}

The role of the mountain in the pioneer "cultural" mutations: the Azilian and Sauveterrian in the catalan Pyrenees

Abstract. In the Pyrenees, mountain settlements higher than $1000 \mathrm{~m}$ are scarce before the Early Neolithic. Balma Guilanyà and Balma Margineda, rock-shelters located in the south-eastern face of the Pyrenees, allow analyzing the ecological and the huntergatherer adaptations along the limit Late Glacial/Early Holocene. In this area, some cultural processes (like the sudden apparition of the Azilian from the north Pyrenees in the Allerød, or the development of a Sauveterrien stage without standardized microlithic artifacts in the south Pyrenees) suggest that these technical innovation are detected sooner in the core of the mountain chain than in peripheral areas as the piedmont or the coast, where some techno-typological endurances (Epimagdalenian) has been recognized.

\section{Introduction}

$\mathrm{L}$ a configuration de la chaîne des Pyrénées est assez particulière en cela qu'elle sépare deux aires climatiques très contrastées. L'une est baignée par les influences océaniques, depuis son épigone occidental, sur la corniche cantabrique, jusqu'aux contreforts aquitains du bassin de la Garonne, tandis que l'autre, depuis son extrémité nord et orientale, à partir des Corbières et du littoral méditerranéen, puis tout au long du versant sud drainé par l'Èbre, est marquée par l'alternance entre de longues sécheresses et de brusques abats d'eau. Relayée par la continentalité ibérique, l'aridité se prolonge loin dans les confins du bassin de l'Èbre. Le contraste entre Pyrénées atlantiques et Pyrénées sèches correspond à de fortes disparités dans les écosystèmes, surtout accentués lors des épisodes froids à cause du régime nival, la sphère méridionale étant privée du renne (et du saumon dans le vaste réseau hydrographique méditerranéen). Mais ce contraste correspond aussi à des différences relevées dans les équipements techniques et les manifestations idéologiques des groupes de chasseurs-collecteurs établis sur les deux versants, originalités plus particulièrement sensibles à partir de la fin des temps glaciaires.

Les sites archéologiques situés au cœur du massif représentent donc en principe de bons postes d'observation pour pouvoir estimer, non seulement la propagation de fronts de peuplement pionniers en direction de l'alpe ${ }^{1}$, mais encore d'éventuelles frontières ou - au contraire - des échanges avérés entre groupes culturels individualisés dans les piémonts. Cependant, en termes d'appartenance « culturelle », la valeur réelle des différences observées dans les outillages

1. La colonisation de l'étage alpin en Pyrénées n'est attestée pour l'instant qu'au Néolithique final et dans les Pyrénées-Orientales (travaux de C. Rendu 2003: La montagne d'Enveigt. Une estive pyrénéenne sur la longue durée, Trabucaïre éd., 601 p.).

\footnotetext{
* Université de Perpignan, 52 avenue Paul Alduy, 66860 Perpignan cedex et Travaux et Recherches Archéologiques sur les Cultures, les Espaces et les Sociétés (TRACES), UMR 5608 CNRS - Université de Toulouse-Le-Mirail, 5 allées Antonio Machado, 31058 Toulouse cedex 9.

** Centró de Estudios del Patrimonio Arqueológico de la Prehistoria (CEPAP), Facultat de Filosofia i Lletres - Edifici B, Universitat Autonoma de Barcelona, Bellatera, E08193 Barcelona (Espagne)

*** Departament de Prehistoria, Facultat de Filosofia i Lletres - Edifici B, Universitat Autonoma de Barcelona, Bellatera, E08193 Barcelona (Espagne).
} 
(armatures microlithiques et en matières dures animales), mais aussi dans l'acquisition des ressources alimentaires (abondance des petites proies, collecte de mollusques et de baies) ou dans les manifestations artistiques (galets peints et gravés), nous échappe en grande partie. Ainsi la présence de fossiles directeurs est-elle souvent surestimée, en particulier pour les harpons magdaléniens et aziliens dont la répartition est clairement associable à la sphère du saumon, avec quelques débordements mineurs à la marge (Martzluff 2009 [à paraître]). C'est également le cas pour les microlithes géométriques dont la quasi-absence au fond des tamis pour la séquence archéologique du plein Boréal dans le bassin de l'Èbre ne signifie nullement un abandon de la chasse aux grands mammifères. D'autre part, la piste des échanges transpyrénéens n'est pas aisée à suivre en raison de l'ubiquité de certaines ressources biotiques - par exemple les coquillages marins utilisés pour la parure - et celle des ressources minérales, avec la difficile identification des silexites présentes au sein des mêmes étages géologiques dans les nappes de charriages sur les deux versants (Fullola et al. 2006).

Mais surtout, l'état de la recherche en Pyrénées met en avant la rareté globale des sites attestant d'une fréquentation de l'étage montagnard au Paléolithique supérieur et pendant l'Épipaléolithique-Mésolithique ${ }^{2}$. Ce sont quatre gisements logés autour de $1000 \mathrm{~m}$ d'altitude dans les Pyrénées sèches: la grotte de Zatoya (Navarre) à $900 \mathrm{~m}$, l'abri sous roche de Guilanyà (Lleida) à 1157 m (Martinez Moreno, Mora Torcal, Casanova i Marti 2006a; 2007; Casanova i Marti, Martinez Moreno, Mora Torcal 2007) et celui de la Margineda (Andorre) à 970 m (Martzluff 1994; Guilaine, Martzluff 1996; Guilaine et al. 2007), ainsi que la station de plein air du Magdalénien ancien de Montlleó (Cerdagne) à 1130 m (Mangado et al. 2005). Dans les Pyrénées catalanes, où se trouve l'essentiel de la documentation (fig. 1), les sites les plus proches de la zone montagnarde en altitude sont également rarissimes. $\mathrm{Ne}$ sont attestés, un peu au-dessus de 700 m, que les gravures d'obédience magdaléniennes sur le rocher de FornolsHaut, en Conflent (Sacchi 2003) ainsi qu'un petit site de plein air de l'Alta Garrotxa, Can Menera, qui a livré une poignée d'artefacts rapportables au Paléolithique supérieur, au sens large (Buixo 1982).

Tous les autres gisements, en particulier ceux qui ont servi de références pour établir le cadre d'une évolution entre le Paléolithique supérieur et le Néolithique ancien, se trouvent dans les piémonts, certains étant toutefois assez près de la zone axiale, au fond de grandes vallées pyrénéennes, mais à des altitudes n'excédant que rarement et de peu 500 m (zone de Lourdes dans les Pyrénées occidentales et de Tarascon-sur-Ariège, sur le flanc nord, secteur de

2. Un seul site antérieur connu : le gisement moustérien final de la Grotte de Peyrère 1 ou du Noisetier (alt. 825 m, Hautes-Pyrénées, France).
Villefranche-de-Conflent dans les Pyrénées-Orientales et, vers le sud, la Noguera pallaresa au niveau des derniers défilés du Sègre dans les barres calcaires, avant la plaine). C'est dire l'importance des abris de Guilayà et Margineda qui, au cœur du massif, offrent des stratigraphies bien développées permettant une approche diachronique des peuplements depuis l'amélioration climatique Bölling-Alleröd - une séquence peu individualisée dans les Pyrénées - jusqu'à la fin du Boréal. Malgré leurs lacunes et l'absence de raccord avec le Magdalénien supérieur classique in situ, les données issues de ces deux gisements se complètent.

\section{Le site de Guilanyà}

Ouvert vers l'est, l'abri est logé au bas flanc d'une vallée étroite, près d'un ruisseau tributaire du Riu Cardener, torrent qui débouche sur la plaine du Solsonès Dans un milieu très pentu qui, aujourd' hui encore, se montre rude en hiver, le site se trouve donc à l'écart d'un passage qui conduirait vers les sommets en suivant les berges d'un fleuve. Vers l'amont cependant, le ravin de Ventoldrà permet d'accéder à des replats perchés (Pla de Busa) et, par des cols faciles, il donne aussi accès à de hautes vallées qui, le long des barres calcaires culminant ici à $2000 \mathrm{~m}$, suivent l'axe transverse des plissements synclinaux jusqu'à la vallée du Sègre et au bassin de la Seu d'Urgell (fig. 1). Les falaises, tout comme le relief plus aéré par des formes tabulaires et de larges trouées synclinales, offrent en principe sur les hauts des milieux favorables aux animaux rupicoles, tel le bouquetin, mais aussi à des ongulés de milieux ouverts, comme le cheval, alors que les alentours de l'abri sont plus propices aux mammifères qui se satisfont de pentes encombrées de halliers, tels le cerf, le sanglier ou le chevreuil. L'absence de lac ou de ruisseau pérenne à proximité du site le prive de ressources halieutiques.

Dans un contexte marqué par un couvert forestier de pins sylvestre (Casanova i Marti, Martinez Moreno, Mora Torcal 2007), les premières occupations témoignent d'un peuplement du haut bassin du Llobregat dès la fin du Tardiglaciaire en plusieurs niveaux (de bas en haut: unités $\mathrm{K}, \mathrm{Ej}, \mathrm{E}$ ). La base est datée du début de l'amélioration climatique Bölling-Alleröd (EJ : 12180 ( \pm 50) BP; 14200-13880 cal. $\mathrm{BP})$. L'étude de la culture matérielle est en cours, mais il est clair que l'équilibre typologique des industries, en associant pointes à bord abattu, petits grattoirs et divers processus expédients, dont la pièce esquillée, trahit un engagement précoce dans l'azilianisation qui correspondrait tout à fait à la séquence Rhodes II - F5/6, en Ariège (Simonnet 1976; 1983).

C'est du moins ce que laisse penser l'équipement des chasseurs de bouquetins (surtout), de sangliers, de cerfs et plus occasionnellement de petites proies (léporidés) qui 
prolonge ces premières occupations dans l'unité E (11460 $( \pm 230) \mathrm{BP} ; 13800-12920$ cal. BP) et qui illustre bien l'Azilien classique au plein Alleröd. L'absence d'industrie osseuse, en particulier de harpons, n'est pas surprenante.

La provenance de silexites variées est indéterminée, mais les processus de débitage sont bien engagés dans une moindre exigence pour les produits lamellaires étroits et standardisés au bénéfice de larges lamelles ou de courtes lames à profil rectiligne extraites au percuteur de pierre dure. L'usage de produits proches de la chute de burin issus du débitage d'éclats et une plus grande tolérance pour l'utilisation d'outils sur éclats (nucleus bifaces centripètes) sont attestés. La simplification du débitage laminaire pour des productions moins contraignantes dans les processus de débitage et dans l'approvisionnement en matière première, c'est-à-dire ce qui correspond à une plus faible planification des besoins, est une tendance lourde par la suite, mais elle est déjà nettement perceptible entre le Magdalénien ancien et moyen de part et d'autre des Pyrénées (Langlais 2007). En réalité, dès les premiers moments de l'occupation saisonnière de cette montagne, les restes de la culture matérielle témoignent d'une sorte d'éclectisme dans la maîtrise des techniques antérieurement connues, avec une récurrence d'archaïsmes qui trahissent le déplacement d'investissements sociaux-économiques vers des activités qui nous échappent et sans doute sous l'effet de probables changements dans les modes d'approvisionnement en ressources alimentaires, processus cynégétiques compris. Dans ce contexte, la découverte d'une trentaine de restes humains épars rapportables à un minimum de trois individus dans l'unité stratigraphique E est exceptionnelle puisqu'elle traduit la présence de femmes et d'enfants (Ruiz Ventura et al. 2005).

L'abri est déserté au Dryas récent et au tout début du Préboréal, soit pendant deux millénaires environ (Martinez Moreno, Mora Torcal, Casanova i Marti 2007). Cet hiatus, souligné par une forte chute de blocs tombés de l'auvent rocheux, scellant les niveaux épipaléolithiques inférieurs, a été mis au compte de la péjoration climatique confrontée à la position secondaire éventuelle du site dans les parcours de chasse. Mais il questionne aussi sur la recomposition culturelle que suppose au même moment l'apparition du Sauveterrien d'un bout à l'autre du bassin de l'Èbre dans des territoires moins enclavés (Atxoxe, Parco, Margineda, Gaï, Filador, Martzluff 2009 [à paraître]).

Les occupations du Mésolithique moyen de l'unité C se développent par une série prolongée de brefs séjours jusqu'en plein Boréal avec une dispersion des dates sur un millénaire (entre $9410 \mathrm{BP}( \pm 60)$ et $8680 \mathrm{BP}( \pm 50)$, soit entre 10810-10490 et 9790 et 9510 cal. BP). Alors que la chasse est plus diversifiée (avec le cheval et le chevreuil) dans un environnement déjà fermé par la forêt tempérée et que la collecte de semences sauvages est avérée grâce aux macrorestes végétaux et celle de dépôts sur les nombreux galets ayant eu des usages plurifonctionnels (percussion, broyage...), l'industrie lithique est marquée par la quasiabsence des armatures microlithiques et par l'inflation d'outils de fortune, dont de minuscules éclats utilisés qui proviennent de la pièce esquillée. Ce faciès « à coches et denticulés », particulier aux Pyrénées sèches, puisqu'il ne déborde pas la limite de l'Aude dans les Corbières, sur le flanc septentrional des Pyrénées, est bien représenté dans le bassin de l'Èbre avant l'apparition tardive des armatures larges dérivées des trapèzes, à la fin du Boréal. Comme à la Font del Ros, gisement de plein air de la plaine proche où il fut le mieux identifié dans son aspect opportuniste (Martinez Moreno, Mora Torcal, Casanova i Marti 2006b; Martinez Moreno et al. 2006), il est ici marqué par l'omniprésence d'outils denticulés épais dont la retouche est souvent opposée à un dos de préparation ou à une cassure, outils probablement tenus en main qui ont été obtenus par un débitage expéditif à la pierre sur des matériaux locaux. Dans un milieu déjà très fermé par la forêt, il s'agit là du paroxysme d'un comportement conduisant à l'extrême simplification des gestes techniques dans la gestion de la taille des pierres, sans doute relayée par d'autres investissements dans d'autres domaines et déjà pressenti bien en amont, dès le Tardiglaciaire.

\section{La Balma de la Margineda}

L'Azilien d'Andorre est plus récent, dans son stade ancien, que celui de Guilanyà. Les datations radiométriques qui l'encadrent s'étalent de $11870( \pm 110)$ BP (14030-13510 cal. BP) à 10340 ( \pm 130$)$ BP (12740-11660 cal. BP), soit depuis la charnière conventionnelle Bölling-Alleröd jusqu'au Dryas récent. Les dépôts naturels (C11, C9 et C7) se rejoignent sur les marges de la zone occupée dans un amas graveleux et pierreux stérile, quasi indivis. Ils servent très heureusement de tampon stratigraphique pour les niveaux plus fortement humanisés (C8 et C6). Dans les interfaces, chacune de ces couches géologiques a mobilisé dans ses horizons inférieur ou supérieur stériles, de menus éléments anthropogènes antérieurs ou postérieurs (Le sommet de la couche 7 occupe une position chronologique plus haute que la cuvette de C6LB qui s'y enfonçait, par exemple).

Un calcul statistique sur les dates calibrées fait apparaître, dans un intervalle global 12120-10300 BC, trois périodes intenses d'occupation au rythme séculaire (11640-1106010470 BC), séparées par des phases d'abandon de même ampleur (Brochier 2007). L'analyse des lits de suie piégés dans les spéléothèmes pariétaux (calcite) issus de la desquamation de la voûte après les écoulements de printemps conclut à des stations saisonnières continues dans l'abri, soit au moins une trentaine pour la première occupation $(\mathrm{C} 10)$. 


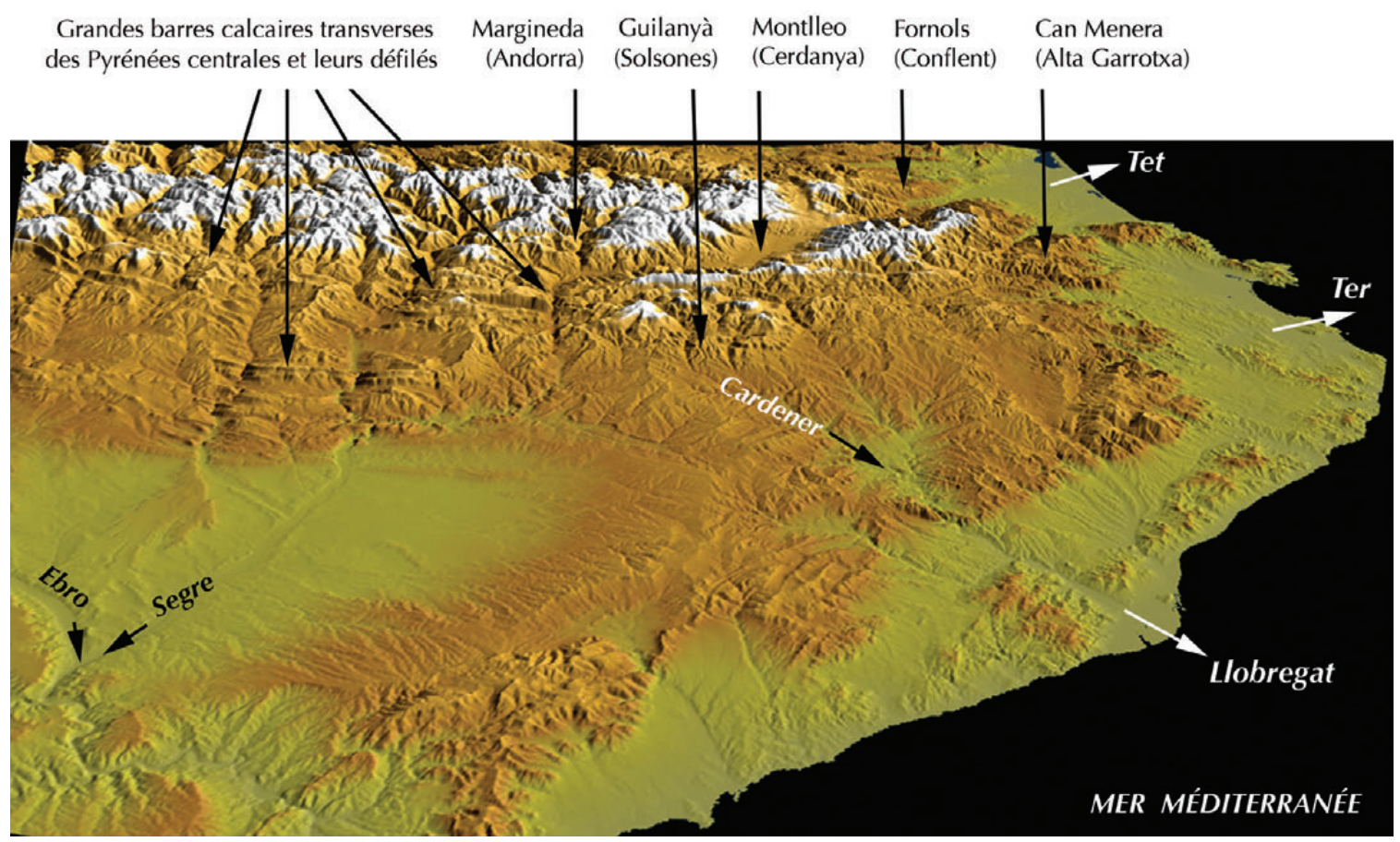

Fig. 1. Situation des gisements montagnards dans les Pyrénées catalanes.

Cela se traduit dans l'industrie lithique par 781 taxons, dont 9 nucléus et 296 déchets de taille mesurables (hors cassons), 43 outils, pour moitié des armatures (17 pointes à bord abattu), dont 5 grattoirs et 1 pièce esquillée. Ainsi la périodicité de ces occupations et la rapidité du remplissage représentent-elles en quelque sorte un avantage des sites montagnards au niveau des enregistrements « culturels ». La présence de harpons de type azilien et de pointes triédriques (fig. 2), typiques de la zone éponyme, autour du Mas d'Azil, évoque nettement une incursion de ces groupes vers le sud pendant l'Alleröd (C8).

L'évolution paléo-envrironnementale entre C10 et C6 montre la dégradation d'un paysage végétal pionnier de type montagnard installé lors de l'optimum Bölling-Alleröd, soit une forêt claire à pin sylvestre et fruticée épineuse à genévriers. La péjoration, marquée par un retour à la forêt claire subalpine de pins à crochets établie aujourd'hui $1000 \mathrm{~m}$ plus haut, est accomplie au Dryas récent. Dans un paysage relativement ouvert, le bouquetin constitue la part quasi absolue des proies chassées à l'Azilien, parmi lesquelles apparaissent quelques isards, des sangliers et de plus rares cerfs. Ce fait constitue une permanence remarquable jusqu'au Néolithique et illustre sans doute une traque opportuniste de la proie dominante associée au relief très abrupt du lieu.

Des signes de comportements éclectiques dans la diète sont attestés avec les premiers ramassages d'escargots en C8 et la collecte de baies de prunellier dès la couche 10 , alors que d'autres espèces, largement représentées dans le spectre
Sauveterrien en C6, sont déjà attestées dans l'Azilien de la couche 8 . Il n'y a cependant pas de véritables accumulations d'escargots (Cepea nemoralis) dans les foyers avant la fin de couche 4 (début de l'optimum Atlantique) et les truites sont quasiment toutes capturées à la fin de la belle saison.

Le Sauveterrien à microlithes géométriques pygmées est attesté au Dryas récent (fig. 3) et s'étale dans sa phase ancienne jusqu'au début du Boréal en plusieurs niveaux qui témoignent de fréquentations répétitives (C7 sup., C6 et C5) datés entre $10640( \pm 260)$ BP; 13160-11760 cal. BP et $8960( \pm 120)$ BP; $10320-9520$ cal. BP. Globalement, nous pouvons diagnostiquer qu'il n'y a pas eu de véritable déperdition dans la culture technologique. Les principes d'extraction lamellaire observés pour les nucléus bien formés de l'Azilien ancien se poursuivent, par exemple dans les exemplaires prismatiques à deux plans de frappe orthogonaux opposés et reprise croisée des corniches. Ce type de débitage est présent en C6 sous une forme diminutive mimant le berlingot. Mais il y a bien eu progression d'un opportunisme associable à l'exploitation des ressources minérales locales, à la mise en jeu de techniques archaïques (pièce esquillée) pour profiter au maximum des roches exogènes les plus isotropes (silexites, cristal de roche) et à une baisse des exigences lamelliformes dans la confection des armatures. Apparaissent aussi les denticulés épais qui envahiront la panoplie des outillages par la suite.

Une partie seulement du nouvel équipement sauveterrien de chasse est géométrique, l'autre résulte d'une manie de la troncature des minuscules éclats allongés pour réaliser des 

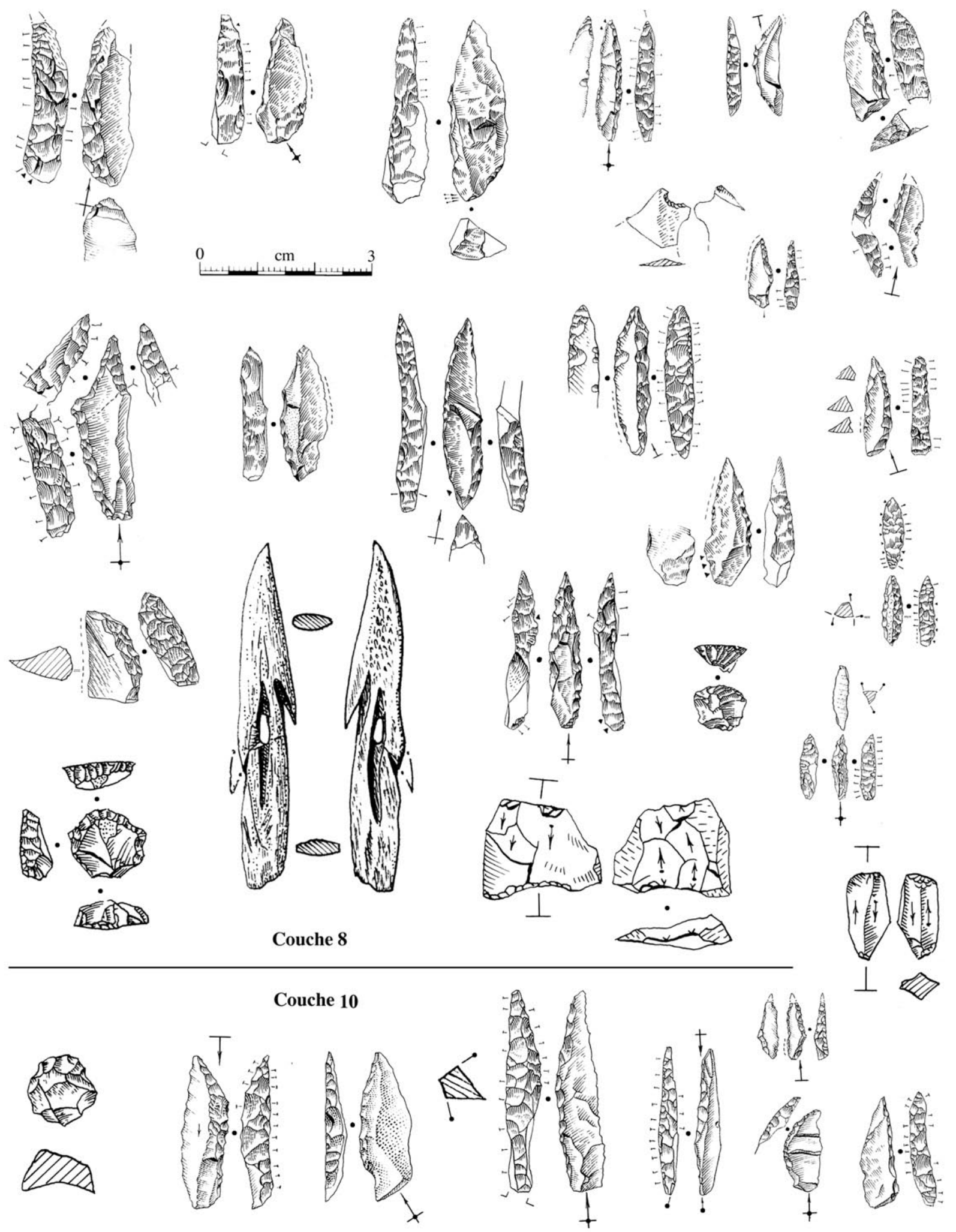

Fig. 2. Industries de l'Azilien ancien et classique à la Margineda. On remarquera les microlithes, en particulier les pointes trièdriques, à partir de C9 (à droite). 

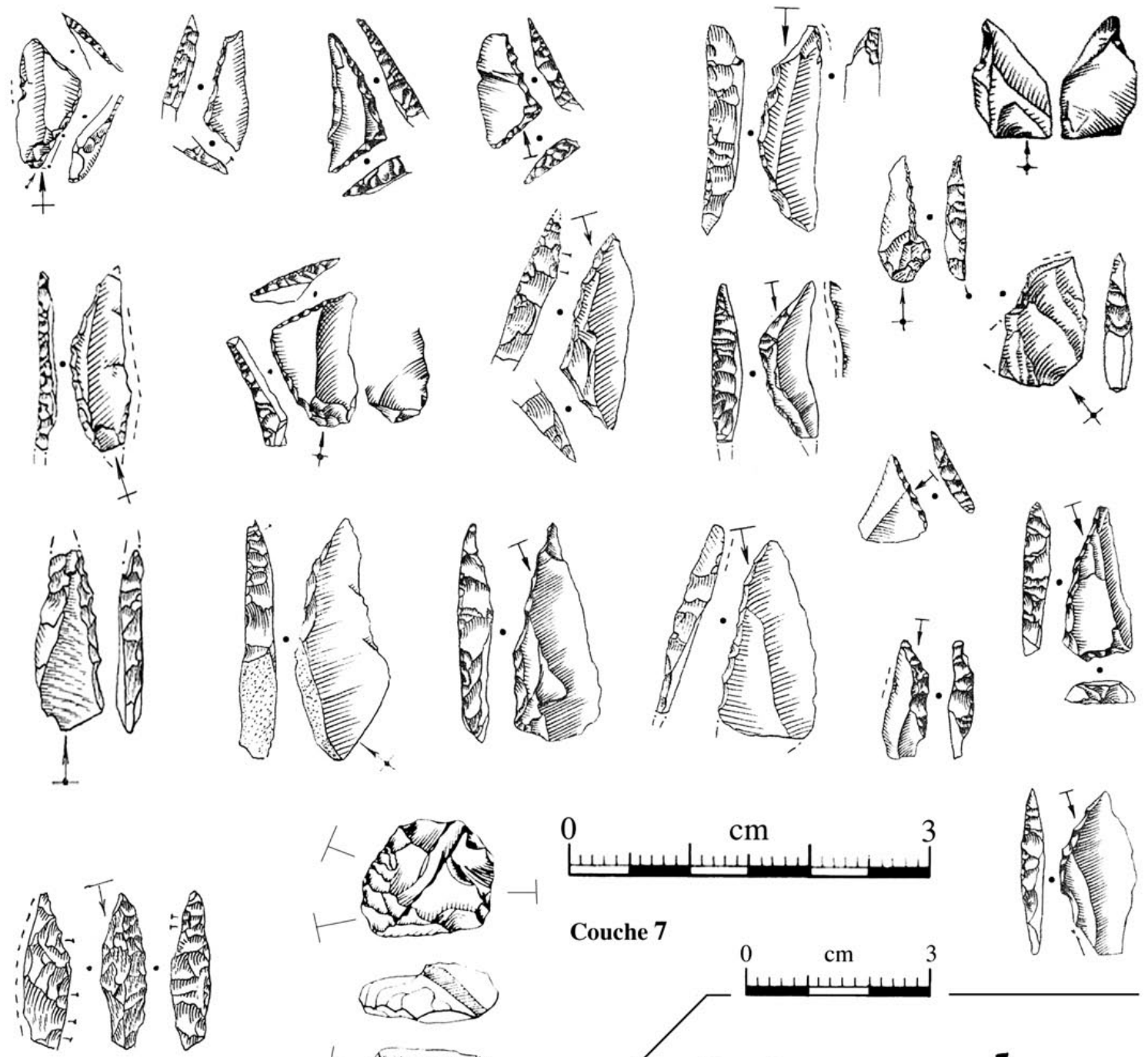

Couche 7
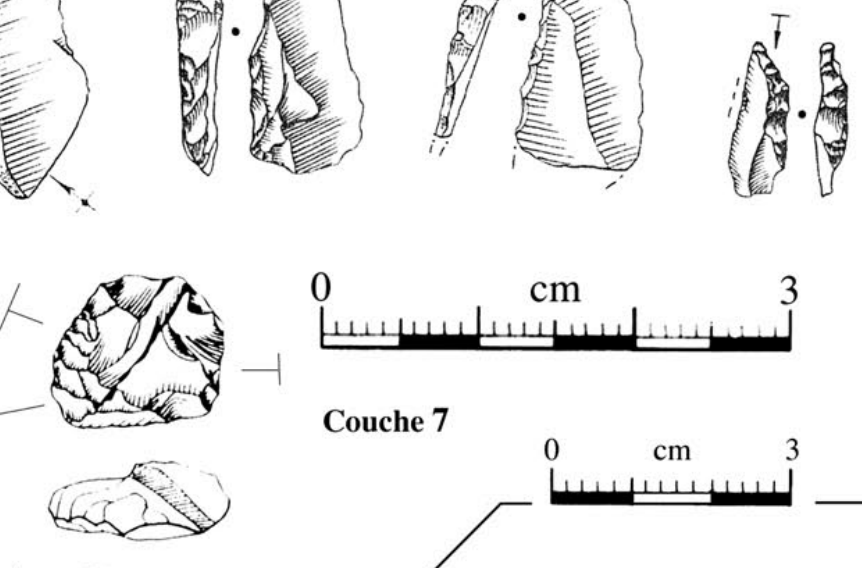

3
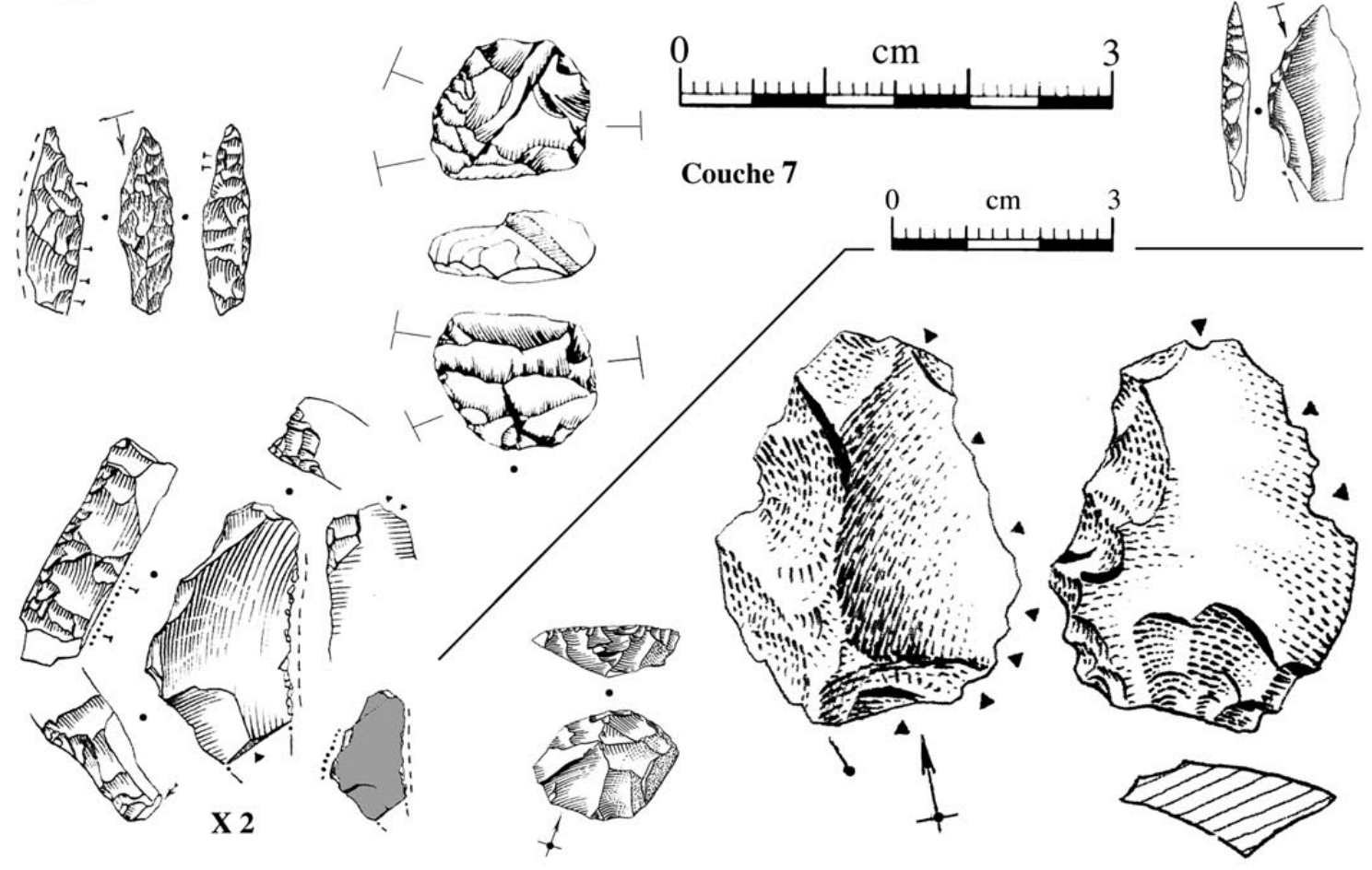

Fig. 3. Industrie du Sauveterrien ancien à la Margineda. Sauf pour le denticulé en quartzite et le grattoir, l'échelle est doublée pour les microlithes géométriques et les pointes à troncature oblique (au-dessus de la mire). La pièce esquillée minuscule au centre provient de la couche 6 , le reste de la couche 7 sup. 

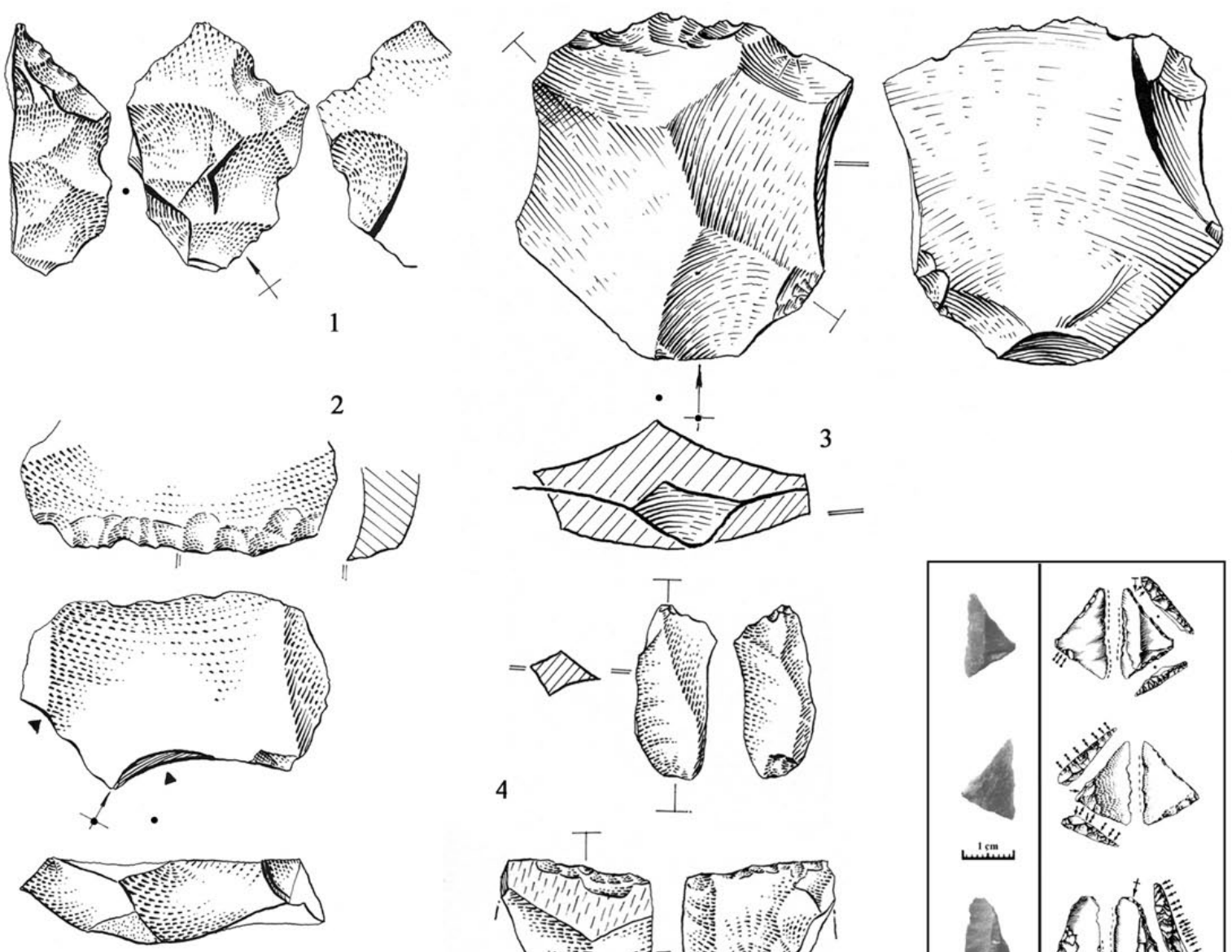

$\mathrm{cm}$
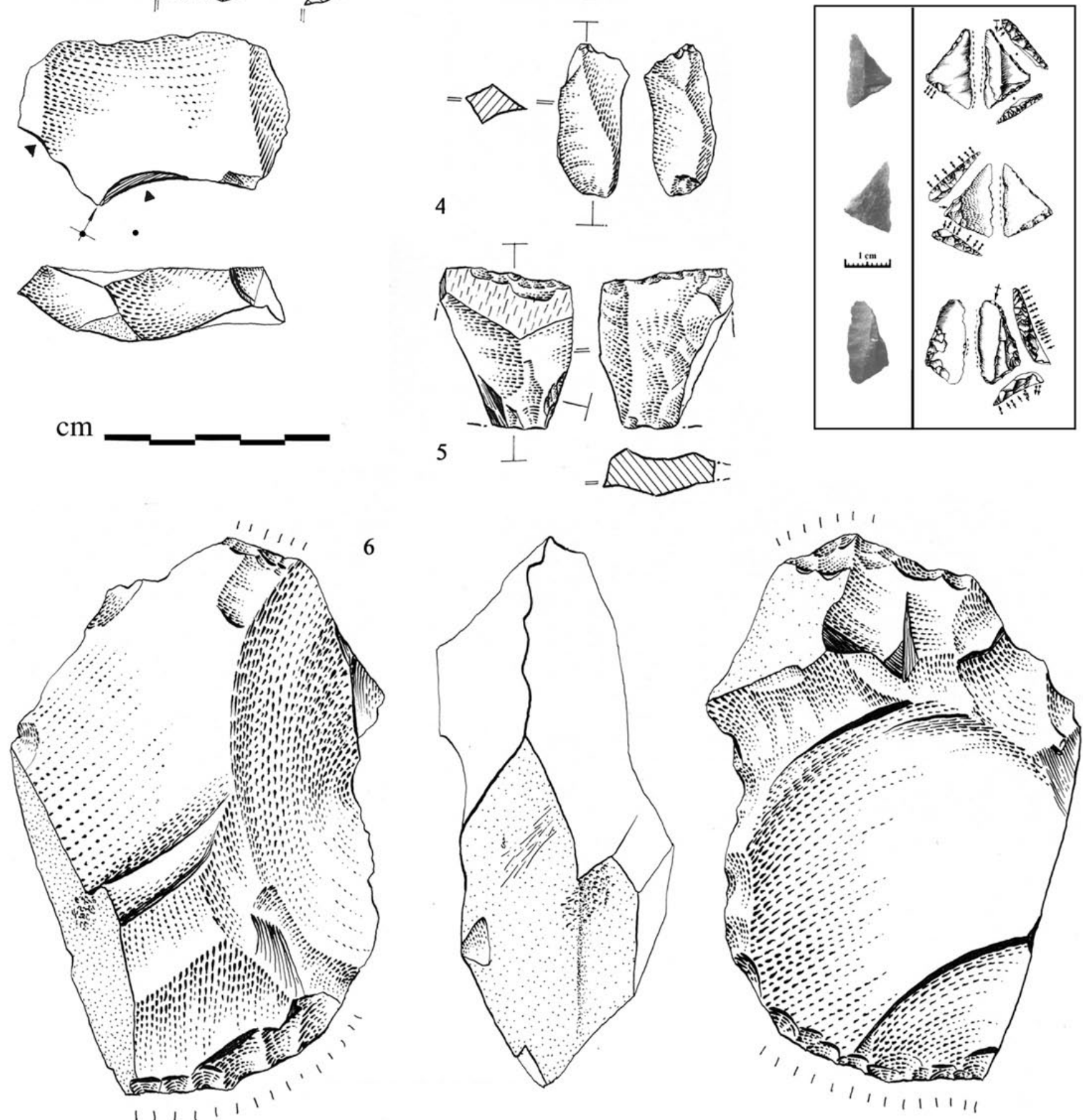

Fig. 4. Industrie du Mésolithique moyen du Boréal à la Margineda. Armature larges tardives et intrusives dans la couche 4 à droite. 
pointes. Cette « manie » de la troncature est déjà faiblement présente à l'Azilien ancien (fig. 2). En l'absence totale de vraies micropointes de Malaurie, abondantes au même moment dans les cultures aziloïdes d'Aquitaine, les pointes à troncatures pygmées semblent donc remplacer les pointes aziliennes et caractériser le Sauveterrien précoce sur ce versant méditerranéen de la chaîne. Elles sont sans doute le fruit d'une tradition ancienne liée à l'utilisation de produits de débitage peu normalisés.

Par contre, force est de constater que la présence de galets peints et gravé « aziliens » est tardive (C6 sup. et C5/6). Nettement séparés de l'Azilien typique sous-jacent depuis la couche 7 , ces objets occupent strictement la même position chronologique au Préboréal que ceux du Filador (Garcia-Argüelles et al. 1998). Le contexte chrono-stratigraphique, et l'environnement typologique « sauveterrien » des galets « aziliens » catalans, impliquent par conséquent une indépendance certaine entre cet art et les marqueurs de la culture matérielle.

Précédée au Préboréal par l'arrivée du sapin, une forêt de feuillus colonise les pentes autour de l'abri dès la couche 4 , soit un millénaire avant l'optimum climatique, avec des assemblages mésoméditerranéens qui, à la limite de l'olivier, influencent actuellement le secteur de la Margineda. La fermeture de l'espace est bien enregistrée par l'ordonnance sédimentaire de la couche 4, affectée par l'affaiblissement des apports terrigènes et par une part cendreuse anthropogène plus importante. Elle est également marquée dans sa partie supérieure par des phénomènes érosifs mal identifiés (épisode 6200 BC ?). En effet, dans les horizons de la couche 4 précédant le Néolithique ancien, alors que le fonds commun de l'industrie est encore typique du faciès du Mésolithique moyen «à muescas y denticulados » exprimé au Boréal en l'absence d'armatures, se trouvent quelques têtes de projectiles larges, déjà pourvues de retouches amincissantes complexes et généralement associées au Mésolithique pré-Néolithique (fig. 4) où elles apparaissent en association avec un débitage de lames en silex réalisé au punch. Ces niveaux n'ont pourtant pas de décalage chronologique important avec la base de C4 (8970 ( \pm 120$)$; 104009680 cal. BP et $8530( \pm 420) ; 10640-8480$ cal. BP $)$.

\section{Conclusion}

Bien curieusement, ce sont aussi des sites spécialisés dans l'exploitation des ressources de montagne qui offrent les lointaines références à la précocité des changements observés à Guilanyà et Margineda dans la culture matérielle, tant au niveau de l'azilianisation des groupes du Paléolithique supérieur que lors du passage avancé au SauveterrienMontadien. Le site du Poeymaü (500 m) dans les Pyrénées atlantiques (Livache et al. 1984), celui de l'Abeurador près d'une crête, sur la frange méridionale du Massif Central (Vaquer 1986), celui de La Fru (560 m), dans le nord des Alpes (Pion 1997), semblent avoir été le réceptacle d'innovations dont on ne trouve pas le même écho dans les habitats pyrénéens proches des grandes plaines. Comme si cette évolution s'y trouvait décalée dans un temps plus récent, par exemple à la grotte-abri de Troubat, en piémont nord-pyrénéen (Barbaza 1999), mais aussi au Filador, à proximité de l'embouchure de l'Èbre en Méditerranée (Garcia-Argüelles et al. 1998).

Les longues occupations des bons repaires de basse altitude n'écrasent-elles pas les différenciations constatées en altitude lors d'occupations plus brèves dans des séquences que nourrissent de plus forts dépôts stériles? Alors que rien ne permet de dire qu'il existe un biais dans les valeurs des datations isotopiques, notre appréciation des cultures n'est-elle pas faussée par la spécialisation cynégétique qu'impliquent ces habitats ? S'agit-il d'une colonisation de niches vides sous l'effet de déplacements lointains, eux-mêmes motivés par des influx que nous avons de la peine à définir, dont celui de la remontée rapide du niveau marin? Autant de problèmes que la découverte de sites à brève occupation en plaine et en montagne pourraient tenter de résoudre sur cette aire géographique.

\section{Bibliographie}

Barbaza 1999: BARBAZA (M.) - Les civilisations postglaciaires. La vie dans la grande forêt tempérée, Paris, La Maison des Roches éd., 1999, 126 p. et ill.

Brochier 2007: BROCHIER (J.-É.) - Estudi geoarqueològic dels depòsits tardiglacials de la Balma de la Margineda (capes de la 6 a la 11), In: GUILAINE (J.), BARBAZA (M.), MARTZLUFF (M.) dir., (texte bilingue), Les escavacions a la Balma de la Margineda. 1979-1991, T. 4, Ministeri d'Afers Socials i Cultura éd., Principat d'Andorra, 2007, p. 34-60.

Buixo 1982 : BUIXO i CAPDEVILLA (R.) - Analisi de la industria litica localitzada al bac de Can Mernera, Alta Garotxa. Revista de Girona, 99, 1992, p. 131-133, 2 fig.

Casanova i Marti, Martinez Moreno, Mora Torcal 2007: CASANOVA I MARTI (J.), MARTINEZ MORENO (J.), MORA TORCAL (R.) - Traçant l'occupació dels Pirineus : la Balma de Guilanyà i els caçadors recol.lectors del Tardiglacial i l'Holocè antic al Pirineu Oriental. Tribuna d'Arqueologia, Barcelona, 2007, p. 59-83, 9 fig.

Fullola et al. 2006 : FULLOLA I PERICOT (J. M.), MANGADO (X.), ESTRADA (P.), NADAL (J.) - Comunidades humanas y circulación de recursos bióticos i abióticos, en lel Paleolítico superior del noreste de la península ibérica. Zephyrus, vol. LIX, Universidad de Salamanca éd., 2006, p. 89-96. 
Garcia-Argüelles et al. 1998: GARCIA-ARGÜELLES ANDREU (P.), NADAL i LLORENZO (J.), FULLOLA i PERICOT (J. M.), 1998-1999 - Vingt anys d'excavacions a l'abric del Filador (Margalef de Montasant, Priorat, Tarragona). Tribuna d'Arqueologia, Generalitat de Catalunya éd., Barcelona, 1998, p. 71-95, 3 fig.

Guilaine, Martzluff 1996: GUILAINE (J.), MARTZLUFF (M.) dir. - Les escavacions de la Balma a la Margineda. 1979-1991, monographie du site, T. 1-2-3 (Néolithique et Mésolithique, textes bilingues catalan/français), Ministeri d'Afers Socials i Cultura éd., Principat d'Andorra, 1996, 1034 p., nombreuses ill. au trait, cartes, clichés.

Guilaine, Barbaza, Martzluff 2007: GUILAINE (J.), BARBAZA (M.), MARTZLUFF (M.) dir. - Les escavacions a la Balma de la Margineda. 1979-1991, monographie du site, Vol. 4 (Azilien, textes bilingues catalan/français), Ministeri d'Afers Socials i Cultura éd., Principat d'Andorra, 2007, 598 p., nombreuses ill. au trait, cartes, clichés.

Langlais 2007: LANGLAIS (M.) - Dynamiques culturelles des sociétés magdaléniennes dans leurs cadres environnementaux. Enquête sur 7000 ans d'évolution de leurs industries lithiques entre Rhône et Èbre, Thèse de Doctorat, Université Toulouse II et Universitat de Barcelona, 2007, t. 1: 500 p., 107 tab., 369 fig. et t. $2: 250$ p., 315 pl.

Livache et al. 1984 : LIVACHE (M.), LAPLACE (G.), ÉVIN (J.), PASTOR (G.) - Stratigraphie et datations par le radiocarbone des charbons, os et coquilles de la grotte du Poeymau à Arudy, Pyrénées-Atlantiques. L'Anthropologie, 88-3, 1984, p. 367376, 5 fig. 1 tab.

Mangado et al. 2005: MANGADO (X.), MERCADAL (O .), FULLOLA i PERICOT (J.-M.), ESTEVE (X.), LANGLAIS (M.), NADAL (J.), ESTRADA (A.), BERGADA (M.M.) Montlleó (La Cerdanya, Lleida), un yacimiento Magdaleniense de alta montaña al aire libre en los Pirineos catalanes, In: FERRIERA (N.) dir., O Paleolítico, Actas do congresso de arqueologia peninsular de Faro, Universidade de Algarve éd., 2005, p. 471-480, 4 fig.

Martzluff 1994 : MARTZLUFF (M.) - Filiations et mutations des industries lithiques au début de l'Holocène dans les Pyrénées catalanes: Épipaléolithique-Mésolithique et Néolithique ancien à la Balma de la Margineda (Andorre) et en Roussillon (France, Pyrénées-Orientales), Université de Perpignan, 1994, 1040 p, 535 fig.

Martzluff (à paraître en 2009) : MARTZLUFF (M.) - L'azilien pyrénéen entre Garonne et Èbre:un état de la question. In: FULLOLA i PERICOT (J.M.), VALDEYRON (N.), LANGLAIS (M.) dir., Les Pyrénées et leurs marges durant le Tardiglaciaire. Mutations et filiations techno-culturelles, évolutions paléo-environnementales, actes du XIV colloqui internacional d'archéologia de Puigcerda, novembre 2006, Hommages à Georges Laplace, Puigcerda, Institut d'Estudis Ceretans, à paraître, 28 p. dactyl., 9 fig.

Martinez Moreno, Mora Torcal, Casanova i Marti 2006a: MARTINEZ MORENO (J.), MORA TORCAL (R.),
CASANOVA i MARTI (J.) - Balma Guilanyà y la ocupación de la vertiente sur del Prepirineo del noreste de la Península iberica durante el Tardiglaciar. In: SANCHIRIDÍAN TORTI (J.L.), MÁRQUEZ ALCÁNTARA (A.M.), FULLOLA i PERICOT (J.M.) dir., La cuenca mediterránea durante el Paleolítico superior, U.I.S.P.P. 2004, Fundación Cueva de Nerja éd., 2006, p. 444-457, 6 fig.

Martinez Moreno, Mora Torcal, Casanova i Marti 2006b : MARTINEZ MORENO (J.), MORA TORCAL (R.), CASANOVA i MARTI (J.) - El Mesolítico de los Pirineos suborientales: una reflexión sobre el significado de las facis de fortuna » del Postglaciar. In: ALDAY (A.) dir., El Mesolítico de muecas i denticulados, col. De Vitoria, Memorias de yacimientos alaveses 11, Museo de arqueologia de Álava éd., 2006, p. 161-188, 10 fig.

Martinez Moreno, Mora Torcal, Casanova i Marti 2007: MARTINEZ MORENO (J.), MORA TORCAL (R.), CASANOVA i MARTI (J.) - El contexto cronométrico y tecno-tipólogico durante el Tardiglaciar y Postglaciar de la verdiente sur de los Pirineos orientales. Revista d'arqueologia de Ponent, 16-17, 2007, p. 7-44, 9 fig.

Martinez Moreno et al. 2006: MARTINEZ MORENO (J.), MARTZLUFF (M.), MORA (R.), GUILAINE (J.) - D'une pierre deux coups: entre percussion posée et plurifonctionnalité, le poids des comportements « opportunistes » dans l'Épipaléolithique-Mésolithique pyrénéen. In: ASTRUC (L.), BON (F.), LÉA (V.), MILCENT (P.-Y.), PHILIBERT (S.) dir., Normes techniques et pratiques sociales. De la simplicité des outillages pré- et protohistoriques, $\mathrm{XXVI}^{\mathrm{e}}$ rencontres internationales d'Antibes, APCDCA-CNRS, Antibes, 2006, p. 147-160, 6 fig., 1 tab.

Pion 1997: PION (G.) - L'abri de La Fru à Saint-Christophe-laGrotte (Savoie) : l'Azilien ancien du début d'Alleröd. Bulletin de la Société Préhistorique Française, 94-3, 1997, p. 319326, 6 fig.

Ruiz Ventura et al. 2005: RUIZ VENTURA (J.), GARCÍA SIVOLI (C.), MARTINEZ MORENO (J.), SUBIRÀ DE GALDÁÇANO (M.E.) - Los restos humanos del Tardiglaciar de Balma Guilanyà. In: SANCHIRIDÍAN TORTI (J.L.), MÁRQUEZ ALCÁNTARA (A.M.), FULLOLA i PERICOT (J.M.) dir., La cuenca mediterránea durante el Paleolítico superior, U.I.S.P.P., Fundación Cueva de Nerja éd., 2005, p. 458-466, 7 fig., 2 tab.

Sacchi 2003: SACCHI (D.) - Le Magdalénien. Apogée de l'art quaternaire, Coll. Histoire de la France préhistorique (de -17000 à -11000 ans), La Maison des Roches éd., 2003, 127 p. et ill.

Simonnet 1976: SIMONNET (R.) - Les civilisations de l'Épipaléolithique et du Mésolithique dans les confins Pyrénéens de la Gascogne et du Languedoc. La Préhistoire française, t. 1-2, Paris, CNRS éd., 1976, p. 1412-1419, 4 fig.

Simonnet 1983 : SIMONNET(R.) - Stratigraphie du Magdalénien final et de l'Azilien à Rhodes II, commune d'Arignac, Ariège. 
Bulletin de la Société Préhistorique Française, 80-1, 1983, p. 12-13, 1 fig.

Vaquer et al. 1986: VAQUER (J.), GEDDES (D), BARBAZA

(M.), EROUX (J.) - Mesolithic plant exploitation at the
Balma Abeurador (France). Oxford Journal of Archaeology, 5-1, 1986, p. 1-18, 4 fig. 


\title{
Exploitation d'un écosystème alpin au Tardiglaciaire : les chasseurs de marmottes (Marmota marmota) du Vercors. Données environnementales, culturelles et économiques
}

\author{
Gilles MONIN*, Christophe GrIGGO**, Julia FOURNIER**, Christine OBERLIN***
}

\begin{abstract}
Résumé. Les sites tardiglaciaires d'altitude du Vercors montrent une exploitation préférentielle de la marmotte alpine (Marmota marmota) dans des horizons archéologiques présentant des mélanges magdaléniens et épipaléolithiques. Une série de dates ${ }^{14} \mathrm{C}$ AMS sur marmotte met en évidence une pratique diachronique liée à la dynamique végétale tardiglaciaire et à l'évolution de la limite supérieure de la forêt dans les vallées synclinales du massif. Cette activité est reconnue entre la fin du Dryas ancien et le début du Préboréal, mais n'est pas attestée à l'Alleröd phase d'extension maximale de la forêt en altitude. L'étude de saisonnalité indique pour tous les sites une exploitation préférentielle ( $70 \%$ des prises) intervenant en septembre, juste avant l'hibernation de la marmotte, période ou cette activité est quantitativement et qualitativement la plus rentable. Les produits alimentaires (viande, graisse) et techniques (fourrure, graisse) de cette chasse étaient destinés à une consommation différée en plaine. Ces modalités d'exploitation de la marmotte sont proches de celles pratiquées par les Amérindiens d'Amérique du Nord suivant le modèle des collecteurs.
\end{abstract}

\begin{abstract}
Management of an alpine ecosystem during the late glacial: marmot hunters in the Vercors.
Environmental, economic and cultural findings

Abstract. In the Vercors mountain (Northern french Alps) the high altitude lateglacial settlements (near $1000 \mathrm{~m}$ a.s.1.) show a preferential exploitation of alpin marmot (Marmota marmota). This animal frequently reach $90 \%$ of the faunal remains in the archeological layers. Nevertheless most of these layers are palimpsestes of diachronical cultural settlements between Magdalenian and Epipaleolithic. The AMS radiocarbon dating of marmot samples with cut marks shows that this activity was diachronical pluricultural and correlated to the vegetable dynamic and the upper tree limit. It occurs in the synclinal Vercors valleys from the end of the Older Dryas to the beginning of the Preboreal. But it is not attested during the Alleröd when the upper tree limit reach the higher altitude. The seasonal study of marmots dental remains shows that most catchs $(70 \%)$ occured just before hibernation which appears as a maximisation of profitability for furs meat and fat. The archeozoological study shows that these products were not used and eaten in the Vercors valleys but were transported to lower altitude settlments. This economic behavior is close to the collector strategies of the north american amerindian marmot hunters.
\end{abstract}

\section{Introduction}

$\mathrm{L}$ e massif du Vercors, en tant qu'unité géographique montagnarde, présente un ensemble remarquable d'occupations d'altitude du Paléolithique supérieur récent. Ces sites de grotte ou abri sont associés à une exploitation préférentielle de la Marmotte alpine (Marmota marmota), qui atteint fréquemment $90 \%$ des restes de faune chassée. Le fait qu'au Tardiglaciaire, des groupes humains se soient prioritairement focalisés sur un petit gibier tel que la marmotte n'est pas exclusif au Vercors. Cette pratique est connue dans d'autres zones de montagne, notamment à la grotte de la Chenelaz, dans le Jura méridional (Cartonnet, Naton 2000; Tomé, Chaix 2003), ou à la grotte del Clusantin, dans le Frioul (Peresani 2008). Néanmoins, par son extension à l'ensemble des sites d'altitude du massif où la faune est conservée, ce phénomène des «chasseurs de marmottes » (Müller 1914), illustre la mise en place d'une véritable stratégie d'exploitation de l'étage alpin par les hommes du Tardiglaciaire.

\footnotetext{
* Association pour la Valorisation et la Diffusion de la Préhistoire Alpine et UMR 6636 LAMPEA, ERPPA, Institut Dolomieu, 15 rue Maurice Gignoux, 38031 Grenoble cedex.

** Université Joseph Fourier, UMR 6636 LAMPEA, Institut Dolomieu, 15 rue Maurice Gignoux, 38031 Grenoble cedex.

*** Centre de Datation par le Radiocarbone, «Archéométrie et archéologie : Origine, datation et technologie des matériaux », UMR 5138 CNRS Université Claude Bernard, 40 boulevard Niels Bohr, 69622 Villeurbanne cedex.
} 
Une précédente étude (Monin, Griggo, Tomé 2006), d'une part, avait dressé un bilan descriptif actualisé de ces gisements, en soulignant les problèmes de mélanges tardiglaciaires diachroniques (Magdalénien et Épipaléolithique), conséquence des conditions de sédimentations en altitude, et, d'autre part, en s'appuyant sur une approche taphonomique et archéozoologique renouvelée des assemblages de marmotte, avait mis en évidence que les produits recherchés (viande, fourrure, graisse) ne l'avaient pas été pour une consommation de subsistance immédiate, mais afin d'être exportés et consommés à basse altitude, en dehors du massif. Nous avions alors dressé deux hypothèses. La première, en nous référant aux données paléoenvironnementales sur l'évolution de la limite supérieure de la forêt, envisageait une continuité diachronique de la chasse à la marmotte entre Magdalénien et Épipaléolithique. La seconde privilégiait une acquisition des ressources lors de la fin de période d'activité de la marmotte, juste avant l'hibernation (septembre-octobre), alors qu'elle a atteint sa masse maximale, qu'elle possède une importante couche de graisse sous cutanée et une fourrure très fournie en prévision de l'hibernation. Cette hypothèse d'une chasse intervenant au moment de l'optimum de rentabilité de la marmotte, était en accord avec les données ethnographiques concernant les Amérindiens, principalement d'Alaska et des Montagnes Rocheuses.

Cette contribution va présenter les résultats d'une série de datations directes de la marmotte par le radiocarbone, ainsi qu'une étude de saisonnalité, afin de tester la validité de nos hypothèses chronologiques et économiques.

\section{Présentation des sites}

\subsection{Une homogénéité géographique}

Le corpus des sites à marmottes concernés par cette étude, l'abri de l'Olette (950 m, Lans-en-Vercors, Isère), les grottes voisines de Colomb et la Passagère $(1050$ m, Méaudre, Isère), la grotte des Freydières (820 m, SaintAgnan-en-Vercors, Drôme), et, dans une moindre mesure, car ayant fourni des séries fauniques moins documentées, l'abri des Pierres (1040 m, Villard-de-Lans, Isère) et l'abri de Bobache (700 m, La Chapelle-en-Vercors, Drôme), présente une unité en terme de position géographique (fig. 1). Tous sont établis dans les fonds des vallées synclinales et subhorizontales d'altitude du massif, à proximité des cours d'eau. Actuellement ces sites appartiennent à l'étage montagnard. Les gisements installés autour de 1000 m d'altitude dans les vallées du Nord Vercors sont à proximité de l'isotherme annuel $5^{\circ} \mathrm{C}$ (Delannoy 1986). Un fort dénivelé associé aux contreforts rocheux qui ceinturent et délimitent le Vercors, les isole des sites tardiglaciaires de piémont de la basse vallée de l'Isère.

L'autre facteur géographique essentiel est la proximité d'un contexte géomorphologique favorable à l'établissement d'importantes populations de marmotte. Ce gros rongeur requiert des sols profonds pour s'installer et creuser son terrier principal. Dans celui-ci, l'hibernaculum est généralement implanté à plus de $2 \mathrm{~m}$ de la surface. Il est ainsi isolé du froid hivernal. Aussi en montagnes les éboulis et les dépôts fluvioglaciaires sont une des caractéristiques des biotopes à marmotte (Perrin 2001). Les vallées synclinales du Vercors présentent de vastes surfaces couvertes par ces deux types de formations superficielles: des dépôts fluvioglaciaires (moraines, terrasses glacio-lacustres, cônes de déjections) hérités des glaciers quaternaires locaux, et des éboulis de gravité issus des escarpements.

Dès lors, le territoire d'acquisition des chasseurs paléolithiques apparaît concentré à proximité des sites, dans les principales vallées du massif. Les zones de plateaux qui s'étendent au sud, bien qu'à plus haute altitude, n'ont pas le potentiel géomorphologique propice pour accueillir de grandes populations de marmottes, en raison de faibles pentes (risque d'ennoiement des terriers, et fonte moins rapide des neiges; Perrin 2001), et d'une faible couverture superficielle (le substrat calcaire affleurant fréquemment dans ces secteurs très karstifiés).

\subsection{Historique des découvertes}

La découverte du phénomène des « chasseurs de marmottes » revient à Hippolyte Müller, pionnier de la Préhistoire dauphinoise du début du $\mathrm{XX}^{\mathrm{e}} \mathrm{s}$., qui fouilla la majorité de ces sites: l'Olette, Colomb, la Passagère, Bobache (Müller 1912; 1914 ; Monin, Griggo, Tomé 2006). Malgré cette activité de terrain ancienne, les travaux de Müller, tant au niveau de la fouille que de l'interprétation des vestiges, n'en restent pas moins d'une qualité anachronique pour l'époque (Monin, Morin, Griggo 2007). En s'appuyant sur les résultats des fouilles de la grotte Colomb qui avait livré plusieurs milliers de restes de marmotte, Müller présenta une étude archéozoologique visionnaire, basée sur un décompte par éléments anatomiques, et reconstitua, alors, une véritable chaîne opératoire d'exploitation de la marmotte (Müller 1914; Monin, Morin, Griggo 2007).

La principale conclusion de son étude, toujours en vigueur actuellement, était une exportation des fourrures hors des sites du Vercors. Selon lui, après avoir séjourné l'été en montagne à chasser la marmotte et consommer sa viande, les chasseurs paléolithiques d'origine méridionale, principalement aziliens, regagnaient leurs habitats de basse altitude, chargés de fourrures, dès les premières neiges.

D'autres campagnes de fouilles ont été réalisées postérieurement à Müller: la grotte des Freydières fouillée en 1965 


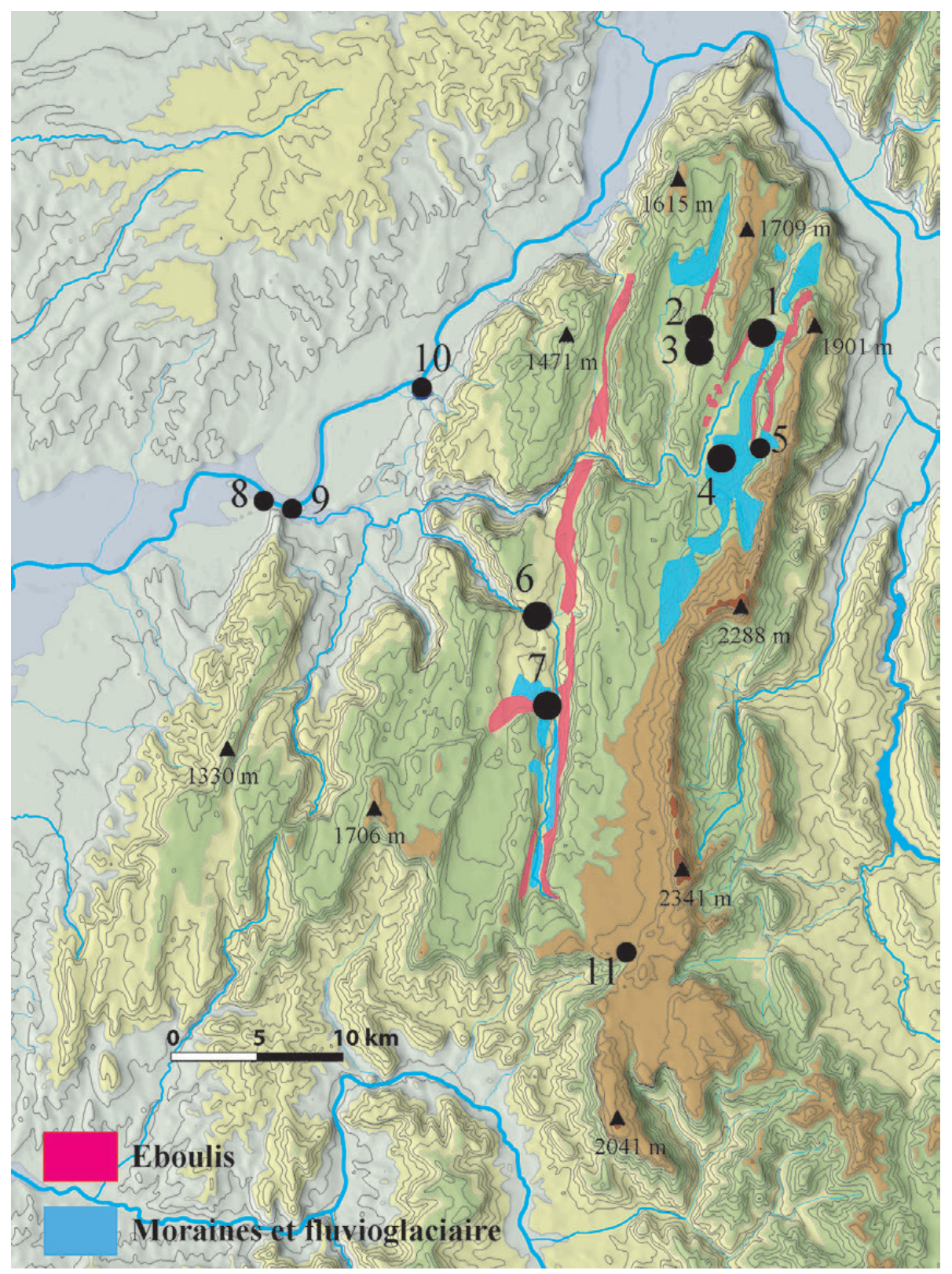

Fig. 1. Carte du relief du Vercors, avec les principales formations superficielles d'altitude. Équidistance des courbes de niveau : $100 \mathrm{~m}$. Localisation des sites tardiglaciaires mentionnés dans le texte. $\mathbf{1}$ : abri de l'Olette (950 m, Lansen-Vercors, Isère). 2, $\mathbf{3}$ : grottes Colomb et Passagère (1050 m, Méaudre, Isère). 4: abri des Pierres (1040 m, Villardde-Lans, Isère). $\mathbf{5}$ : station de plein air du Clos-de-Lans (1 500 m, Lans-enVercors, Isère). 6: abri de Bobache (700 m, La Chapelle-en-Vercors, Drôme). 7 : grotte des Freydières (820 m, Saint-Agnan-en-Vercors, Drôme). 8: abri Campalou (180 m, Saint-Nazaire-en-Royans, Drôme). 9: grottes du Taï (180 m, Saint-Nazaireen-Royans, Drôme). 10: abri du Calvaire (250 m, Saint-Romans, Isère). 11: station mésolithique de Pré-Peyret (1600 m, Grese-en-Vercors, Isère).

(Bocquet, Lequatre 1973), et une reprise des fouilles de la Passagère par Pierre Bintz, en 1973 et 1974. La découverte la plus récente est l'abri des Pierres, exploré sur une surface restreinte d'1 m² en 1999 (Monin, Griggo, Tomé 2006).

\subsection{Des mélanges culturels}

Outre l'homogénéité du contexte géographique, l'absence de résolution des séquences stratigraphiques tardiglaciaires est une autre caractéristique commune de ces sites. Alors que les gisements de basse altitude de cette période présentent généralement des séquences stratigraphiques composées de plusieurs horizons, il apparaît pour les sites de notre corpus qu'un déficit d'apports sédimentaires en altitude (interprétation actuelle en l'absence de données géoarchéologiques plus précises) a entraîné la mise en contact de dépôts archéologiques diachroniques magdaléniens et épipaléolithiques, au sein du même horizon sédimentaire tardiglaciaire. Il est même possible de constater pour certains gisements des apports holocènes (Monin 2000; Monin, Griggo, Tomé 2006).

Ce constat résulte d'une approche technologique des industries lithiques, qui consiste à identifier les techniques (Pelegrin 2000) et les schémas opératoires de production des supports et de l'outillage, tout en les confrontant avec les industries issues de sites «de référence» à forte 
résolution stratigraphique. À partir d'une première étude portant sur les séries lithiques de Colomb et la Passagère, qui avait mis en évidence au moins deux périodes d'occupation tardiglaciaires, la première au Magdalénien et la seconde au Laborien, culture épipaléolithique du Dryas récent (Monin 1997; 2000), il est apparu que la plupart des séries lithiques sont issues de mélanges de dépôts magdaléniens et épipaléolithiques (Monin, Griggo, Tomé 2006). Lors du sondage de l'abri des Pierres, nous avons pu observer in situ le contact entre les dépôts magdaléniens et aziliens anciens, dans l'unique horizon stratigraphique en place (Picavet, Monin, Griggo 1999; Monin, Picavet 2000). Seuls deux sites se démarquent de ce constat: l'abri de Bobache qui avait livré à Müller une stratigraphie composée de 4 horizons (2 magdaléniens et 2 aziliens?), et l'abri de l'Olette dont l'industrie de l'horizon unique paraît homogène et épipaléolithique.

\section{Datation de la marmotte}

\subsection{Principes}

Ce problème de mélanges culturels tardiglaciaires ne permet de déterminer, ni l'identité des chasseurs de marmottes, ni quelle a été l'extension chronologique de cette activité spécialisée, sur des critères stratigraphiques ou archéologiques.

L'intervalle chronologique, dans lequel s'insère un potentiel de forte densité de marmottes dans les vallées d'altitude du Vercors, est tributaire du climat et de la dynamique végétale tardiglaciaire. À notre échelle d'observation paléoenvironnementale, le facteur déterminant est l'évolution de la limite supérieure de la forêt (correspondant environ à l'isotherme annuel $2^{\circ} \mathrm{C}$ ). Au-dessus de cette limite s'étendent les landes supra-forestières et les derniers arbres isolés de l'étage subalpin supérieur (ou « zone de combat ») puis l'étage alpin dont les pelouses constituent, davantage que le précédent, le principal domaine vital de la marmotte.

À partir des études sur l'évolution de la limite supérieure de la forêt (David 1993), nous avions émis l'hypothèse d'une continuité de la chasse spécialisée à la marmotte au cours du Tardiglaciaire (Monin, Griggo, Tomé 2006).

Pour répondre à cette problématique chrono-environnementale et culturelle, nous avons daté par ${ }^{14} \mathrm{C} \mathrm{AMS}$, 16 restes de marmottes portant des stries de découpe provenant de 4 sites. La figure 2 présente l'ensemble des dates ${ }^{14} \mathrm{C}$ disponibles pour les sites à marmottes du Vercors. Elles ont été mises en relation avec la chronologie isotopique ${ }^{16} \mathrm{O} /{ }^{18} \mathrm{O}$ du sondage GRIP (Björck et al. 1998) et la zonation pollinique. La conformité de cette démarche est assurée par la mise en évidence du synchronisme de la dynamique de la végétation avec les fluctuations et microfluctuations climatiques globales dans plusieurs sites naturels régionaux, pouvant associer analyses polliniques à haute résolution et analyses isotopiques ${ }^{16} \mathrm{O} /{ }^{18} \mathrm{O}$ : Chirens (460 m, Isère ; Eicher, Siegenthaler, Wegmüller 1981), La Thuile (884 m, Savoie; Bégeot et al. 2006; Argant et al. 2009), Le Chevelu (320 m, Savoie ; Argant et al. 2009), Moras (315 m, Isère ; Argant et al. 2009), Les Etelles (700 m, Isère; David 2001).

\subsection{Discussion de l'ensemble des dates ${ }^{14} \mathrm{C}$ des sites à marmottes}

Le corpus des dates radiocarbones des sites à marmottes du Vercors est composé de deux ensembles en fonction du mode d'échantillonnage et de la méthode de mesure utilisée (fig. 2): les dates réalisées sur plusieurs restes (« dates moyennes ») par la méthode conventionnelle, et celles réalisées par AMS sur un seul reste déterminé spécifiquement: le renne (Rangifer tarandus) et la marmotte alpine (Marmota marmota).

Trois dates moyennes (Ly 430, sur marmottes, à Colomb; Ly 1189, « sur ossements de cervidés » (Bintz, Desbrosse 1979, p. 244), à la Passagère ; Ly 451 sur esquilles osseuses, dont la marmotte, aux Freydières) s'écartent sensiblement des intervalles chronologiques définis par les datations AMS. Elles sont donc à rejeter. La quatrième date moyenne par comptage, Ly-3647: $10080 \pm 150 \mathrm{BP}$, sur esquilles de grands mammifères, à la Passagère, est à conserver. Elle s'intègre formellement dans l'intervalle chronologique définit par la datation AMS de la marmotte pour ce site et la grotte Colomb voisine.

Les dates AMS sur renne des deux sites de Méaudre s'intègrent dans l'intervalle chronologique défini par la datation directe de cette espèce dans les Alpes du Nord et le Jura méridional. Ainsi le renne n'est plus présent dans la région à partir de l'Alleröd (Oberlin, Pion 2009; Bridault et al. 2000). Pour les deux sites, elles confirment également les problèmes de mélanges diachroniques, et valident la présence magdalénienne mise en évidence par l'analyse technologique de l'industrie lithique (Monin, 1997; 2000).

\subsection{Résultats paléoenvironnementaux}

\subsubsection{Exploitation de la marmotte et évolution du milieu}

Une exploitation préférentielle de la marmotte, au détriment de la grande faune, à partir des sites des fonds de vallées du Vercors, est tributaire de son abondance et de la présence de biotopes pouvant l'accueillir. Or, par ses exigences écologiques (pelouses alpines et formations géomorphologiques superficielles, $c f$. supra), la marmotte apparaît comme un très bon marqueur environnemental. 
La capacité de confronter les résultats de la datation directe de la marmotte avec les données paléobotaniques sur la dynamique végétale et l'évolution de la limite supérieure de la forêt (David 1993) permet d'appréhender l'évolution du milieu dans les Alpes du Nord au Tardiglaciaire.

Par précaution, et sans recherche d'un quelconque actualisme, nous tenons également à prendre en compte le rôle du gradient de continentalité ouest-est qui entraîne une élévation de la limite des étages, et entraîne une répartition actuelle de la végétation alpine en trois zones, conséquence du gradient des précipitations et des températures (Ozenda 1985).

Le caractère largement diachronique et la continuité relative de l'exploitation préférentielle de la marmotte sont pertinents, par l'observation de la succession des pics de probabilités des dates calibrées (fig. 2). D'après les résultats actuels, cette activité est répartie entre la fin du Dryas I et le tout début du Préboréal. Elle se scinde en deux épisodes, strictement distribués de part et d'autre de l'Alleröd. Le premier épisode, observé à la grotte des Freydières grâce à 5 dates correspondant à un NMI de combinaison de 5 individus (NMIc déduit à partir des éléments datés et des dates calibrées), semble continu sur un millénaire calibré (13100-12000 av. J.-C.). Cet intervalle chronologique intègre trois zones polliniques: la fin de l'épisode froid du Dryas I, le Bölling, conséquence du brusque réchauffement de 14700 cal BP GRIP (Björck et al. 1998), et le Dryas II, court épisode de péjoration climatique.

L'environnement de la fin du Dryas I correspond à une «steppe-toundra» à herbacées héliophiles (Artemisia, Chenopodiaceae) associée à une végétation pionnière buissonnante d'arbustes ou d'arbrisseaux formant un paysage en mosaïque: bouleau nain (Betula nana) aux abords des zones humides, genévrier (Juniperus) préférentiellement sur sols secs et rocheux. En tenant compte de l'étagement du milieu en montagne, ces groupements pionniers ne devaient pas atteindre, ou être peu représentés, dans la vallée de la Vernaison où est située la grotte des Freydières (820 m).

Le Bölling débute avec le réchauffement brutal de 14700 cal BP GRIP (Björck et al. 1998) et se manifeste par une hausse importante des précipitations (Bintz 1994 ; 1999). Il correspond à la phase d'expansion du bouleau (Betula), et à la mise en place d'un premier couvert arboré qui reste relativement ouvert (Drucker, Bocherens, Billiou 2009). En altitude, des espèces arboréennes de bouleau ont été identifiées localement par des fruits dans deux sites: $B$. pubescens et/ou $B$. pendula, à la Thuile $(884 \mathrm{~m})$, actuellement dans la zone de végétation des Alpes externes (Bégeot et al. 2006, Argant et al. 2009); et B. pubescens ainsi que B. verrucosa/pendula aux Etelles (700 m), actuellement dans la zone de végétation des Alpes intermédiaires (David 2001).
Néanmoins, la poussée forestière du Bölling ne paraît pas avoir eu d'incidence sur l'exploitation de la marmotte aux Freydières, impliquant un environnement encore largement ouvert, et riche en pelouses, dans le secteur du synclinal de la Vernaison jusqu'au Dryas moyen.

Aucune date sur marmotte ne se situe dans l'Alleröd, phase d'extension maximale de la forêt en altitude qui se traduit dans tous les diagrammes polliniques par un taux maximal de taxons arboréens et minimal de taxons herbacés. Le pin (Pinus) est alors le taxon ligneux dominant dans les diagrammes, suivi par le bouleau (Betula). En altitude, les pinèdes semblent atteindre $1000 \mathrm{~m}$. Le genre Betula, quant à lui, est attesté jusqu'à 1700 m par la découverte de bois et de fruits au Col du Pré dans le Beaufortain, dans la zone de végétation des Alpes intermédiaires (David 1993).

Avec la montée de la forêt en altitude à l'Alleröd, nous envisageons que le couvert arboré a dû suffisamment s'étendre sur les formations superficielles des vallées du Vercors, pour entraîner un recul sensible des populations de marmotte. La faible démographie de ce petit gibier, ne justifiait sans doute plus la mise en places de campagnes de chasse spécialisée par les Aziliens au cours de cette période.

Le second épisode d'exploitation de la marmotte est défini à partir des 10 dates de la Passagère et Colomb. Il couvre l'intervalle chronologique du Dryas III, et se prolongerait jusqu'au tout début du Préboréal à l'Olette. À Colomb et la Passagère, la principale accumulation des restes de marmotte s'inscrit dans la seconde moitié de cet épisode (9 mesures entre 10310 et 10110 BP).

Le Dryas III se traduit par une forte péjoration climatique entraînant une ouverture du milieu, particulièrement marquée en altitude. Dans la zone de végétation des Alpes externes, à la Thuile (884 m), l'absence d'aiguille de pin et la rareté des fruits de bouleau dans les sédiments, laisse supposer un important recul des peuplements arborés par rapport à la phase précédente (Bégeot et al. 2006; Argant et al. 2009). Dans le domaine de végétation des Alpes intermédiaires, la forêt se maintiendrait aux alentours de 1000 m (David 1993).

Cette ouverture du milieu en altitude et l'abaissement marqué de la limite supérieure de la forêt au Dryas III, par rapport à la période précédente, ont entraîné une nouvelle extension des pelouses alpines et un regain démographique de la marmotte. On assiste consécutivement à la reprise de son exploitation préférentielle à partir du Val d'Autrans Méaudre (Colomb et la Passagère, alt. 1050 m) et du Valde-Lans jusqu'au début du Préboréal (l'Olette, alt. 950 m).

\subsubsection{Perspectives sur l'exploitation de la montagne}

La confrontation des résultats de la datation directe de la marmotte avec les données paléobotaniques montre que cette chasse spécialisée s'inscrit dans une perspective diachronique en relation avec la dynamique végétale 


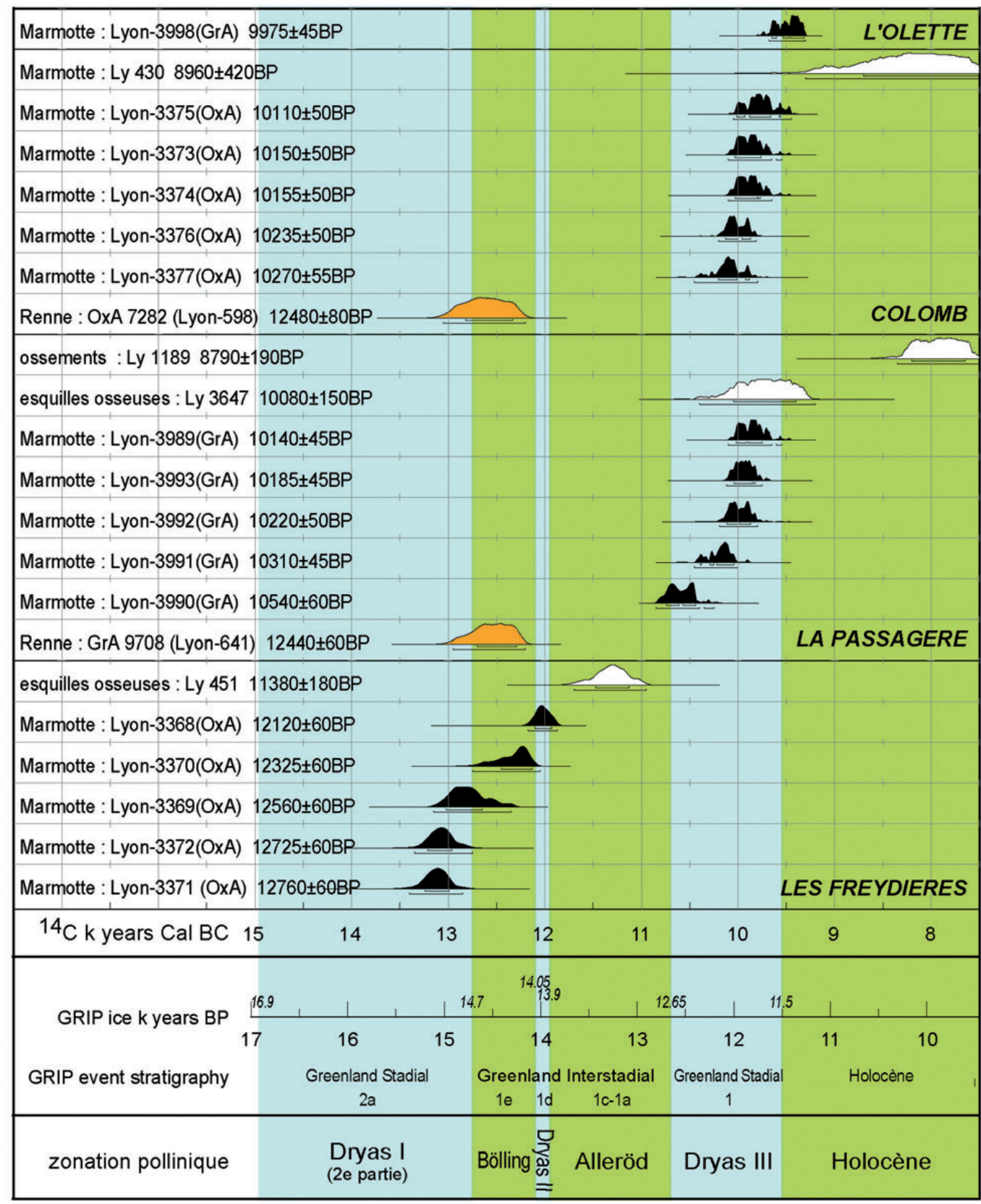

Atmospheric data from Reimer et al (2004);OxCal v3.10 Bronk Ramsey (2005); cub r:5 sd:12 prob usp[chron]

Fig. 2. Ensemble des dates ${ }^{14} \mathrm{C}$ calibrées pour les sites à marmottes du Vercors, mises en relations avec la chronologie isotopique du sondage GRIP et la zonation pollinique. En blanc, dates moyennes par comptage sur échantillons composés de plusieurs restes. En noir, dates AMS sur un reste de marmotte (Marmota marmota). En orange, dates AMS sur un reste de renne (Rangifer tarandus).

tardiglaciaire. Présente sur l'intervalle chronologique, fin du Dryas I - Bölling - Dryas II, puis au Dryas III jusqu'au début du Préboréal, cette activité n'est pas attestée d'après les résultats actuels durant l'Alleröd, qui correspond à la phase d'extension maximale de la forêt en altitude.

La cohérence du scénario associant l'étage alpin aux formations superficielles des vallées synclinales du Vercors justifie alors la rareté des découvertes du Paléolithique supérieur récent dans les secteurs d'altitude supérieure. Ainsi, dans la partie sud-orientale du massif, les Hauts Plateaux du Vercors, qui s'étendent au delà de 1400 m et jusqu'à 2000 m, riches en sites mésolithiques (Bintz 1999), ont dû être durant la plus grande partie du Tardiglaciaire, une zone stérile, battue par les vents, correspondant aux 


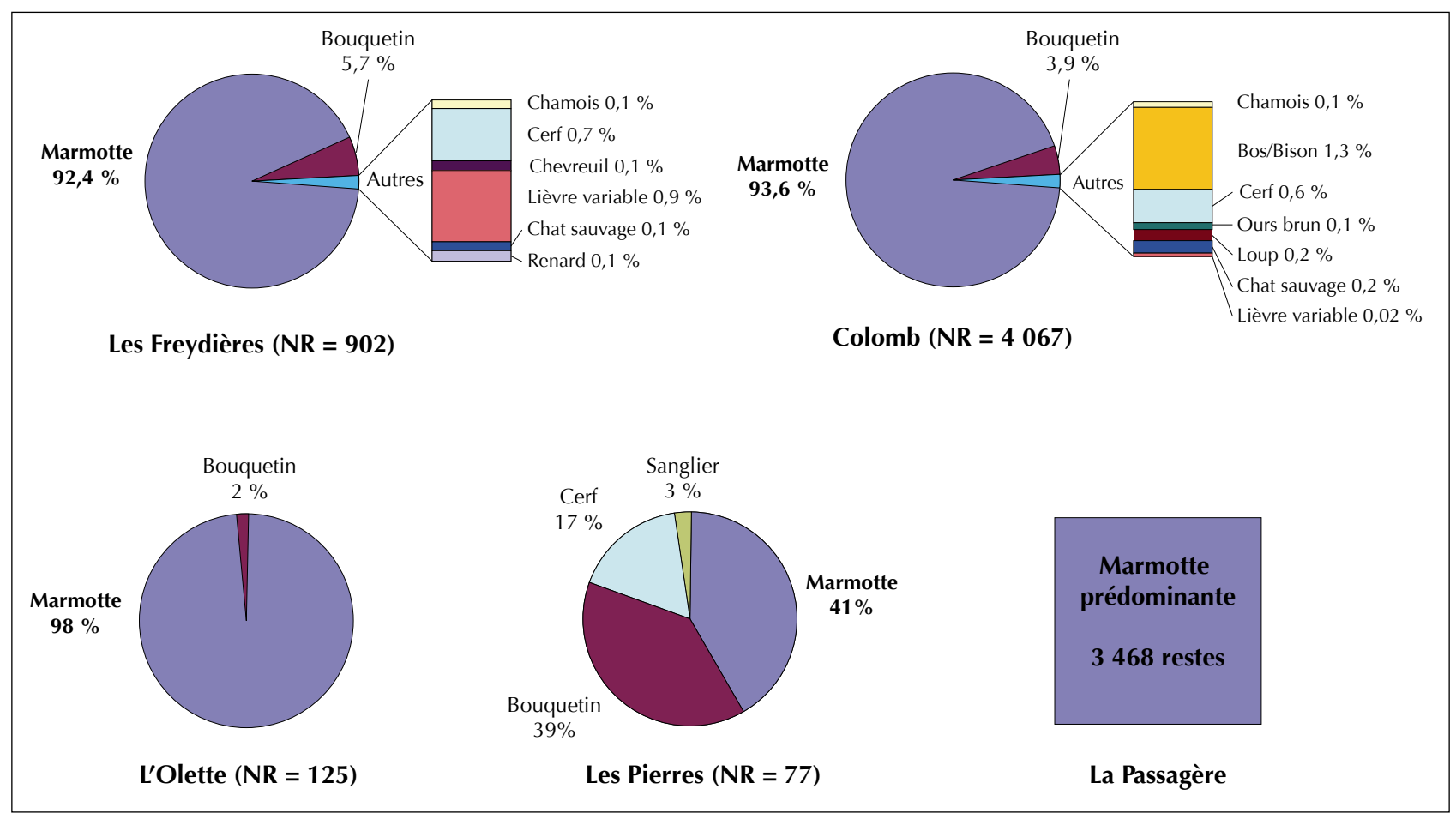

Fig. 3. Distribution de la faune en pourcentage du nombre de restes déterminés pour 4 sites à marmottes du Vercors.

barren grounds et/ou à l'étage nival. Une telle perpective environnementale est en accord avec l'hypothèse de cirques encore englacés au Tardiglaciaire dans le secteur des crêtes orientales du massif (Marnezy 1980), et d'une récurrence glaciaire dans les Alpes du nord au Dryas III (Couteaux 1983).

Dans ce contexte les rares découvertes épipaléolithiques présentant les plus hautes altitudes, la petite série du Closde-Lans à $1500 \mathrm{~m}$ (Picavet 1995), et la lame débitée à la pierre tendre de Pré Peyret à $1600 \mathrm{~m}$ (Picavet et al. 2008) pourraient se rattacher à l'Alleröd (fig. 1).

Cette approche environnementale montre que, dès le Tardiglaciaire, tous les étages ayant un potentiel économique ont été exploités. Elle permet de relativiser le discours de certains auteurs voyant une conquête de la montagne à partir du Mésolithique. Si celle-ci est bien réelle en terme de valeur absolue altitudinale, elle ne l'est pas davantage en terme d'environnement et de milieu, et ne résulte que des conditions climatiques holocènes ayant permis un développement de la végétation en altitude bien supérieur au Tardiglaciaire.

\subsection{Données chronoculturelles}

L'ensemble des dates AMS sur des sites du Vercors confirment, l'hypothèse d'une formation diachronique des assemblages archéologiques. En confrontant ces éléments chronologiques avec les résultats de l'analyse technologique des industries lithiques, et les données chronoculturelles des sites tardiglaciaires régionaux à forte résolution stratigraphique, il apparaît que la chasse spécialisée à la marmotte a été pratiquée de la fin du Magdalénien au début de l'Azilien ancien sur un intervalle compris entre la fin du Dryas I et le Dryas II, pour reprendre à partir du Dryas III jusqu'au début du Préboréal avec le Laborien.

\subsubsection{La tradition magdalénienne}

Cette tradition technique est la plus fréquente dans les sites tardiglaciaires du Vercors. Elle a été identifiée aux Freydières, Colomb, la Passagère, ainsi qu'à Bobache et aux Pierres. Pour l'industrie lithique, elle se caractérise par un schéma conceptuel opératoire de production laminaire identique à celui identifié dans le Magdalénien supérieur du Bassin parisien et régionalement (Monin 1997; 2000).

Les nucléus présentent une mise en forme élaborée par l'intermédiaire d'une à plusieurs crêtes. La production laminaire (s.l.) est obtenue en percussion directe tendre unipolaire. Sur les plus grandes lames l'aménagement de talons en éperon est fréquent. Ces supports laminaires obtenus en percussion tendre unipolaire sont dominants parmi les burins des différents gisements du corpus. Bien que présentes, les lamelles à bord abattu sont peu nombreuses dans les gisements.

Parmi l'industrie osseuse attribuable à cette phase d'occupation magdalénienne, on remarque un harpon à deux 
rangs de barbelures aux Freydières, et une petite sagaie à biseau simple en bois de renne à la Passagère.

Chronologiquement, les trois dates sur marmotte les plus anciennes obtenues aux Freydières $(12760 \pm 60 \mathrm{BP}$, $12725 \pm 60 \mathrm{BP} ; 12560 \pm 60 \mathrm{BP})$ sont synchrones avec le Magdalénien supérieur de la couche 4a de La Fru, en Chartreuse, positionné dans la fin du Dryas I par 4 mesures ${ }^{14} \mathrm{C}$ AMS sur cheval $(12810 \pm 110 \mathrm{BP} ; 12770 \pm 110 \mathrm{BP}$; $12740 \pm 110 \mathrm{BP} ; 12600 \pm 120 \mathrm{BP}$; Pion 2004).

En piémont du Vercors, la couche CII de la grotte de Taï (Brochier, Brochier 1973) est l'horizon magdalénien ayant fourni la date la plus récente pour le massif: $12580 \pm 90 \mathrm{BP}$, ${ }^{14} \mathrm{C}$ AMS sur renne située en fin du Dryas I (Oberlin, Pion 2009; Bridault et al. 2000).

Régionalement, les dates magdaléniennes les plus récentes au sein d'ensembles stratigraphiques à forte résolution ont été récemment obtenues à la grotte Jean-Pierre 1 de SaintThibaud-de-Couz pour la couche 9B (Lyon-3847 (SacA6929): $12520 \pm 60 \mathrm{BP},{ }^{14} \mathrm{C}$ AMS sur os) et la couche 9A (Lyon-3957 (SacA-6543): $12460 \pm 60 \mathrm{BP},{ }^{14} \mathrm{C}$ AMS sur élan). La couche 3 de la grotte voisine Jean-Pierre 2 a été datée $12455 \pm 54 \mathrm{BP}$ (Lyon-3920 (OxA), ${ }^{14} \mathrm{C}$ AMS sur bouquetin) et $12445 \pm 51 \mathrm{BP}$ (Lyon-3920 (OxA), ${ }^{14} \mathrm{C}$ AMS sur renne). La distribution des probabilités place les dates de Saint-Thibaud-de-Couz à la toute fin du Dryas ancien et dans la première moitié du Bölling. Les dates sur renne de Colomb et la Passagère se placent sur ce même intervalle chronologique, qui définit régionalement la fin du Magdalénien.

\subsubsection{La tradition de l'Azilien ancien}

Cette phase d'occupation a été reconnue aux Freydières ainsi qu'à Bobache et aux Pierres. L'industrie lithique de l'Azilien ancien se caractérise par un débitage laminaire unipolaire en percussion directe à la pierre tendre sans mise en forme des nucléus. Sur le plan typologique les principaux éléments sont les grattoirs, les lames à retouches écailleuses, et des pointes à bord abattu de plusieurs types : segments, fusiformes, et dos rectiligne.

À La Fru en Chartreuse, cet horizon azilien ancien (couche 3), est daté par 4 mesures ${ }^{14} \mathrm{C}$ AMS sur cerf (12200 \pm $50 \mathrm{BP}, 12110 \pm 110 \mathrm{BP}, 11950 \pm 60 \mathrm{BP}, 11840 \pm 60 \mathrm{BP})$ (Mevel, Bressy 2009).

À l'abri Campalou au pied du Vercors l'horizon équivalent (couche 2) caractérisé par des grattoirs, des lames à retouche écailleuse et des pointes à bord abattu à dos rectiligne ou fusiforme (Brochier, Livache 1997) est daté 12300

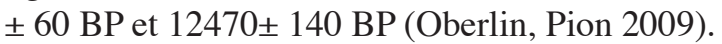

Ces dates qui situent l'émergence de l'Azilien dans les Alpes du Nord durant la seconde moitié du Bölling coïncident avec les dates sur marmotte les plus récentes des Freydières (12325 $\pm 60 \mathrm{BP}, 12120 \pm 60 \mathrm{BP})$.

\subsubsection{La tradition laborienne}

Dominant les assemblages lithiques de Colomb et la Passagère, cette tradition se caractérise par un débitage laminaire bipolaire en percussion directe à la pierre tendre, suivant un schéma opératoire spécifique. Dans ces gisements l'outillage retouché se distingue par une présence marquée des éléments tronqués et des couteaux à dos, de nombreux grattoirs, et de rares pointes à dos rectiligne et base tronquée (pointes de Malaurie).

Nous avions rapproché cette tradition de la date moyenne sur esquilles osseuses de la Passagère (10080 \pm 150 BP), en la rattachant au Laborien, culture à pointes de Malaurie du Dryas III et du début du Préboréal (Monin 1997; 2000). Sur le plan chrono-culturel, les résultats de la datation de la marmotte nous permettent d'affirmer la présence d'un ensemble culturel d'affinité laborienne dans plusieurs sites des Alpes françaises du Nord.

À l'Olette, l'industrie lithique épipaléolithique comporte peu d'outils retouchés, et n'est pas diagnostique sur le plan typologique (Monin, Griggo, Tomé 2006). En revanche, nous avons observé des lames régulières obtenues par percussion bipolaire à la pierre tendre suivant des modalités identiques à Méaudre. La date obtenue sur marmotte (9975 \pm 45 BP), située au début du Préboréal, s’inscrit dans les marges chronologiques de la culture laborienne.

À l'abri du Petit Laup (Sahune, Drôme), dans la partie inférieure de la couche $2 \mathrm{~B}$ présentant un remplissage archéologique hétérogène, nous avons identifié dans l'industrie lithique une composante épipaléolithique identique à celle de Colomb et la Passagère : exploitation laminaire bipolaire à la pierre tendre des nucléus sur toute la longueur des surfaces de débitage, présence d'éléments tronqués, et d'une pointe de Malaurie (Laudet et al. 2008). La date AMS sur os de ce niveau, $10090 \pm 60 \mathrm{BP}$, est en adéquation avec celles de Colomb, la Passagère et l'Olette.

Un rapprochement essentiel dans une perspective socioéconomique s'effectue avec la nécropole de l'Aven des Iboussières (Malataverne, Drôme), dont la seule date $10210 \pm 80 \mathrm{BP}(\mathrm{OxA} 5682)$ s'intègre pleinement dans l'intervalle chronologique définit à Colomb et la Passagère. Son industrie lithique, peu abondante, se compose de lames obtenues par un débitage bipolaire à la pierre tendre, auxquelles s'ajoute d'un couteau à dos. Elle est rapprochée des industries de la fin du Tardiglaciaire, Belloisien et Laborien (Gély et al. 2000). Un point de convergence supplémentaire avec les « chasseurs de marmottes », est la présence de cette espèce au sein du mobilier sépulcral, qui comprend une abondance d'éléments de parure réalisés sur des supports d'une grande variété (coquillages, os, minéraux ; d'Errico, Vanharen 2000 ; Gély et al. 2000). La composante mammalienne du dépôt, est issue d'une faune très diversifiée. La marmotte y est notamment représentée par 52 astragales recouvertes d'ocre $(\mathrm{NMI}=26)$, interprétées 
en tant que parures, car leur morphologie permet aisément de les attacher (Chaix 2006). Aux Iboussières, la marmotte occupe le troisième rang des espèces de mammifères ayant contribué au mobilier funéraire, derrière le cerf (203 craches) et les bovinés s.l. (184 restes).

\subsection{Perspectives fonctionnelles et économiques}

Le fait que la principale phase d'accumulation de marmottes à Colomb et la Passagère soit le produit des groupes du Dryas récent, permet de mieux comprendre les caractères typologiques de l'industrie lithique de cette tradition. Ainsi les lames tronquées et des couteaux à dos, éléments caractéristiques de l'assemblage, sont à associer au traitement des carcasses en tant qu'outils de boucherie. L'abondance de grattoirs est en adéquation avec l'activité de peausserie. Le déficit en armatures, que l'on constate également dans les composantes magdaléniennes de tous les sites, quant à lui, accrédite notre hypothèse d'une capture des marmottes par des procédés n'employant pas de projectiles armés de silex; le piégeage ayant notre faveur par sa simplicité d'emploi, la possibilité d'une vaste maîtrise territoriale, et sa fréquence dans les sources ethnographiques (Monin, Griggo, Tomé 2006). En conséquence, les traits originaux de l'industrie lithique épipaléolithique de Colomb et la Passagère traduisent un faciès d'activité propre à l'exploitation de la marmotte.

Ce faciès d'activité conforte l'hypothèse, pour les occupations du Vercors, d'un statut de sites de chasse spécialisée, principalement dévolus à l'exploitation de la marmotte sur des périodes de courte durée.

\section{4. contexte économique}

\subsection{Présentation des séries fauniques à marmottes}

La marmotte représente fréquemment plus de $90 \%$ des restes déterminés dans les spectres fauniques des gisements du massif (fig. 3). Le bouquetin arrive dans tous les sites au second rang de la faune chassée, ce qui s'explique logiquement par l'abondance des milieux rocheux dans ce contexte montagnard. Enfin, on constate que certaines espèces emblématiques du Paléolithique sont peu représentées. Ainsi le renne est rare. Ce taxon est notamment absent aux Freydières qui a donné les dates magdaléniennes les plus anciennes. Le cheval présent dans les niveaux magdaléniens de la base vallée de l'Isère, notamment à Campalou (Brochier, Brochier 1973) et à l'abri du Calvaire (Müller 1924) (fig. 1), est absent. Cette espèce n'a sans doute pas franchi les forts dénivelés permettant d'accéder aux vallées du massif au Tardiglaciaire.

\subsection{Résultats archéozoologiques}

Les études taphonomique et archéozoologique comparées des restes de marmottes ont mis en évidence une importante homogénéité de traitement des carcasses intersites (Monin, Griggo, Tomé 2006).

Le déficit marqué dans les gisements des os des pieds et des mains qui restent traditionnellement fixées aux peaux lors de leur récupération sur les carcasses, traduit une exportation des fourrures hors du massif, dans les occupations de basse altitude. Ce comportement a été mis précocement en évidence par Müller (1914).

Les ossements portent trois types de stries laissées par les outils en silex (fig. 4). Les stries de dépouillement situées au niveau du crâne proviennent de la récupération de la peau. Le second groupe indique une désarticulation complète et systématique du squelette des marmottes. Celle-ci facilite une dernière étape, déduite de l'abondance des stries de décharnement, correspondant à la récupération de la viande crue sur tous les os du squelette. Une viande cuite se détache facilement des os, surtout sur un petit gibier, et ne nécessite pas l'intervention d'outils tranchants. Cette intense activité de boucherie, traduisant un désossement complet des carcasses, trouve sa cohérence dans une perspective de d'accumulation et de conservation de la viande par séchage ou fumage. Le prolongement logique de cette étape de conservation de la viande, est une consommation différée hors de la zone d'altitude. Notons qu'à Colomb (Tomé 1998 ; 2005) comme à la Passagère (Monin, Griggo, Tomé 2006), le déficit marqué des humerus et des fémurs traduit une exportation de certains quartiers (épaule et cuisse) sans désossement préalable.

La graisse, pour sa valeur alimentaire ou technique, a certainement été un produit recherché par les préhistoriques.

\subsection{Saisonnalité de la chasse à la marmotte}

L'étude archéozoologique privilégie l'hypothèse d'une exportation des ressources alimentaires (viande, graisse) et techniques (fourrure, graisse) issues de la marmotte, plutôt qu'une consommation de subsistance durant l'occupation des sites. De plus, pour les gisements de Méaudre, le faciès d'activité mis en évidence traduit une activité spécialisée de courte durée. A contrario, une diversification des activités techniques ou de subsistance, liée à une présence de longue durée, entraînerait une nécessaire diversification de l'outillage. La rentabilité d'une activité cynégétique focalisée sur un petit gibier au détriment de la grande faune se conçoit dans une perspective de forte accumulation sur une courte période.

Pour la marmotte alpine, l'optimum de rentabilité d'une activité de prédation en terme de ressources exploitables intervient à la fin de période d'activité de l'animal, en 


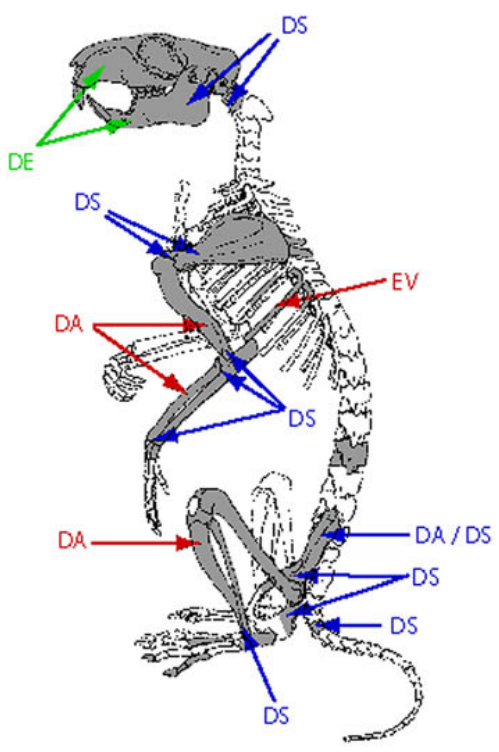

Colomb

(Tomé 1998)

$\mathrm{NR}=3809$

- Traces de découpe $=28 \%$ des éléments

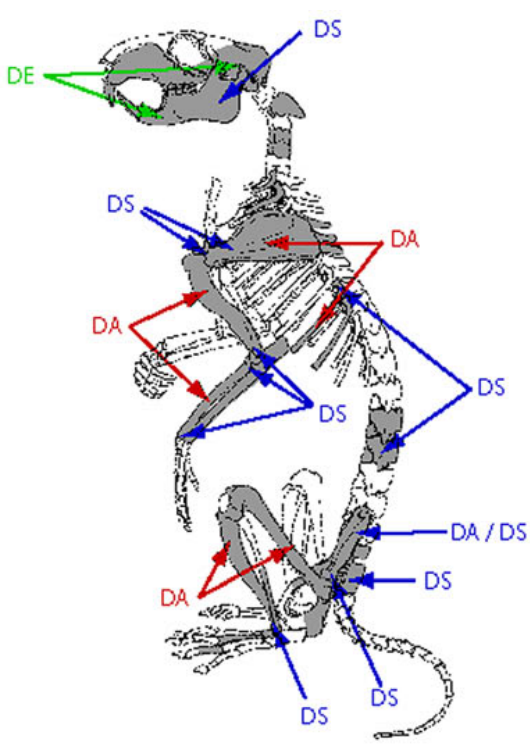

Les Freydières

(série Griggo 2006)

$$
\mathrm{NR}=407
$$

Traces de découpe $=28,2 \%$ des éléments

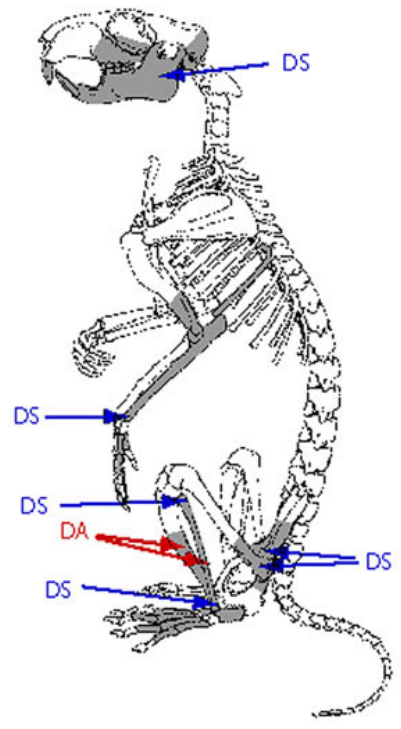

L'Olette

$\mathrm{NR}=123$

Traces de découpe $=26,8 \%$ des éléments

$$
\begin{array}{ll}
\begin{array}{l}
\text { éléments anatomiques } \\
\text { présents dans les sites }
\end{array} & \begin{array}{l}
\text { DE : stries de dépouillement } \\
\text { DE : stries de désarticulation } \\
\text { DE : stries de décharnement }
\end{array} \\
\hline
\end{array}
$$

Fig. 4. Eléments présents dans les séries, et répartition des différentes stries de découpe sur le squelette de la marmotte (d'après Monin, Griggo, Tomé 2006).

septembre voire début octobre, juste avant son entrée en hibernation. À cette époque de l'année, la marmotte a atteint sa masse maximale, sa viande est la plus grasse et sa fourrure la plus fournie en prévision de l'hibernation. En outre, elle possède une importante couche de graisse sous-cutanée.

Afin de tester cette hypothèse de saisonnalité, l'une d'entre nous a constitué un référentiel à baser sur l'attrition et l'usure dentaire de marmottes actuelles (Fournier 2005). Ce référentiel se révèle pertinent pour les deux premières périodes d'activité de la marmotte, soit de la naissance à la seconde hibernation.

L'application de ce référentiel aux séries des différents gisements de notre corpus révèle un tableau très homogène (fig. 5). Ainsi, pour tous les sites, la principale période de capture, avec environ $70 \%$ des prises, intervient au cours de la période de fin d'activité de la marmotte. Ces résultats confirment l'hypothèse d'une chasse saisonnière conditionnée par l'optimum de rentabilité des ressources en terme de quantité et de qualité.

Proportionnellement minimes, les prises intervenant entre le printemps et l'été indiquent une fréquentation des zones d'altitude durant toute la bonne saison, dès la fonte des neiges. Cette fréquentation est interprétée comme des déplacements ponctuels en altitude à vocation économique moins spécialisée ou bien tournés vers d'autres objectifs économiques, comme l'acquisition de ressources lithiques, les affleurements siliceux de bonne qualité étant très rependus dans le massif (Bressy 2003).

Les pratiques des chasseurs tardiglaciaires du Vercors concorde avec les comportements des Amérindiens de l'Alaska, des Montagnes rocheuses et de la Chaîne côtière, qui pratiquaient la chasse à la marmotte principalement en septembre (Nagorsen, Keddie, Luszcz 1996). Chez les Tathltans de Colombie britannique, l'ensemble du groupe gagnait les plateaux d'altitude à partir de la fin août jusqu'à l'hibernation des marmottes fin septembre. La viande de marmotte accumulée était séchée ou fumée puis consommée, après le retour à basse altitude, au cours de la mauvaise saison (Emmons 1911).

\section{Conclusions}

L'exploitation préférentielle de la marmotte alpine en Vercors au Tardiglaciaire est un phénomène diachronique et transculturel. Cette stratégie d'exploitation de l'étage alpin est conditionnée par le potentiel économique lié à la 
Fin Dryas - Bölling - Dryas II

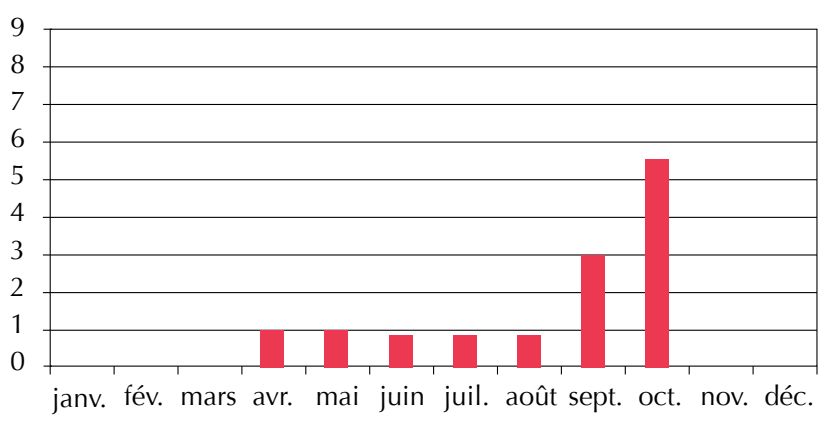

Les Freydières $(\mathrm{NMI}=13)$

\section{Dryas III}

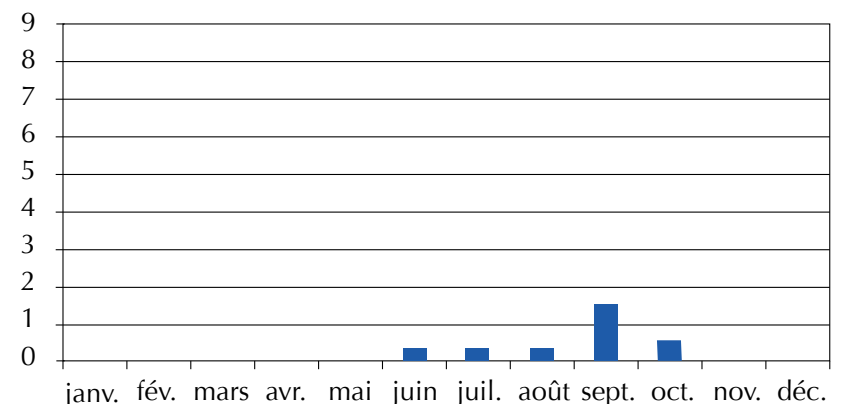

L'Olette (NMI $=3)$

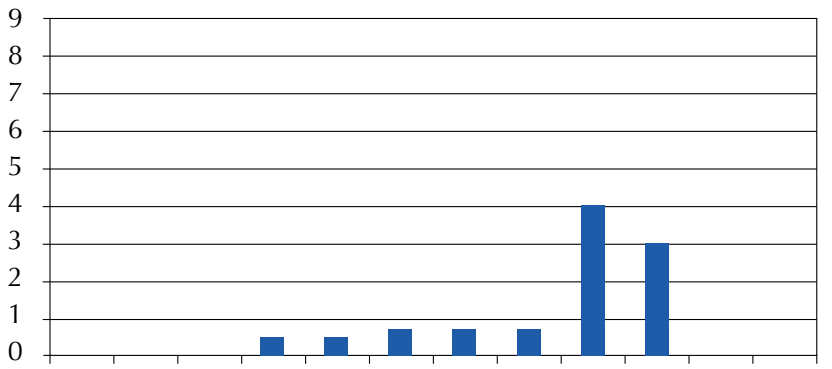

janv. fév. mars avr. mai juin juil. août sept. oct. nov. déc.

La Passagère $(\mathrm{NMI}=10)$

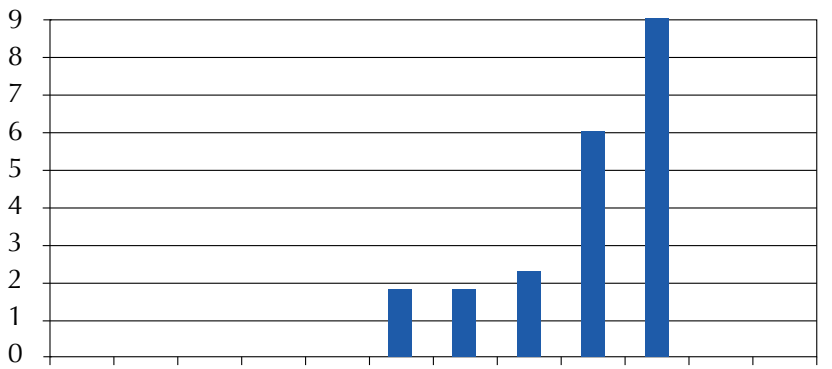

janv. fév. mars avr. mai juin juil. août sept. oct. nov. déc.

Colomb (NMI = 21)

Fig. 5. Distribution de la saisonnalité des captures en individus par mois, en fonction du nombre minimal d'individus de 0 à 2 ans (naissance à la seconde hibernation). présence de biotopes favorisant l'implantation de vastes colonies de marmottes dans les vallées synclinales du massif. D'après les données actuelles, cette chasse spécialisée est attestée entre la fin du Dryas ancien et le début du Préboréal, néanmoins elle s'interrompt à l'Alleröd, phase d'extension maximale de la forêt en altitude.

Les « chasseurs marmottes » ont été successivement des magdaléniens, des aziliens anciens, et des laboriens. Leur comportement économique est analogue à celui des chasseurs-cueilleurs amérindiens subactuels. Cette stratégie intervient préférentiellement juste avant l'hibernation (septembre), alors que la marmotte possède le plus fort potentiel quantitatif et qualitatif en terme de ressources à la fois alimentaires (viande, graisse) et techniques (fourrures, graisse). L'acquisition de ces produits n'est pas destinée à une consommation de subsistance immédiate dans les sites, mais à une consommation différée à basse altitude. Dans cette perspective, la viande et la graisse de marmotte n'avaient qu'un rôle de complément vis-à-vis des denrées alimentaires fournies par la grande faune. Cette chasse saisonnière spécialisée de courte durée à un petit gibier de montagne, est associée à une pratique d'accumulation et de stockage de ressources alimentaires et techniques. Elle traduit un système logistique d'exploitation optimale des différentes niches écologiques des Alpes françaises du Nord au Tardiglaciaire.

\section{Bibliographie}

Argant, Bégeot, Marrochi 2009: ARGANT (J), BÉGEOT (C.), MARROCHI (Y.) - L'environnement végétal au tardiglaciaire à partir de l'étude de trois lac: La Thuile, Saint-Jean-deChevelus et Moras. In: PION (G.) dir., La fin du Paléolithique supérieur dans les Alpes du Nord françaises et le Jura méridional. Approches culturelles et environnementales, Paris, Société Préhistorique Française (mémoire L), 2009, p. 23-40.

Bégeot et al. 2006: BÉGEOT (C.), PION (G.), MARROCHI (Y.), ARGANT (J.), BIRRINGER (P.), BOCHERENS (H.), BRIDAULT (A.), CHAIX (L.), THIEBAULT (S.) Environnement végétal et climatique des sociétés magdaléniennes et épipaléolithiques dans les Alpes du Nord françaises et le Jura méridional. In: MIRAS Y., SURMELY F. (dir.), Environnement et peuplement de la moyenne montagne $d u$ Tardiglaciaire à nos jours. Actes de la table ronde internationale de Pierrefort (Cantal) du 19 au 20 juin 2003, Besançon, Presses Universitaires Franc-Comtoises (Annales Littéraires, 799; Série «Environnement, sociétés et Archéologie », 9), 2006, p. 19-27.

Bintz 1994: BINTZ (P.) dir. - Les grottes Jean-Pierre 1 et JeanPierre 2 à Saint-Thibaud-de-Couz (Savoie). Première partie: Paléoenvironnement et cultures du Tardiglaciaire à 1'Holocène dans les Alpes françaises du Nord. Gallia Préhistoire, t. 36, 1994, p. 145-266. 
Bintz 1999: BINTZ(P.) - Peuplements et milieux du Paléolithique final au Mésolithique dans les Alpes du Nord fançaises: dynamique et occupations territoriales. In: DELLA CASA (P.) ed., Prehistoric alpine environment, society, and economy, Papers of the international colloquium PAESE'97 in Zurich. Bonn, Universitätsforschungen zur prähistorichen Archäologie, Band, 55, 1999, p. 11-24.

Bintz, Desbrosse 1979: BINTZ (P.), DESBROSSE (R.) - La fin des temps glaciaires dans les Alpes du Nord et le Jura méridional. Données actuelles sur la chronologie, l'environnement et les industries. In: La fin des temps glaciaires en Europe, colloque international $n^{\circ} 271 d u$ CNRS, Talence, Paris, Ed. du CNRS, 1979, p. 239-255.

Björck et al. 1998: BJÖRCK (S.), WALKER (M.J.C.), CWYNAR (L.C.), JOHENSEN (S.), KNUDSEN (K.-L.), LOWE (J. J.), WOHLFARTH (B.), and Intimate Members An event stratigraphy for the Last Termination in the North Atlantic region based on the Greenland ice-core record: a proposal by the INTIMATE group. J. Quaternary Sci., vol. 13 (4), 1998, p. 283-292.

Bocquet, Lequatre 1973 : BOCQUET (A.), LEQUATRE (P.) La grotte des Freydières à Saint-Agnan-en-Vercors (Drôme). Gisement du Magdalénien final. Bulletin de la Société Préhistorique Française, 70, 1973, p. 324-329.

Bressy 2003: BRESSY (C.) - Caractérisation et gestion du silex des sites mésolithiques et néolithiques $d u$ Nord-Ouest de l'arc alpin. Une approche pétrographique et géochimique, Oxford, BAR Internationnal Series, 1114, 2003, 295 p.

Bridault et al. 2000 : BRIDAULT (A.), CHAIX (L.), PION (G.), OBERLIN (C.), THIÉBAULT (S.), ARGANT (J.) - Position chronologique de renne (Rangifer trarandus L.) à la fin du Tardiglaciaire dans les Alpes du Nord françaises et le Jura méridional. In: PION (G.) dir., Le Paléolithique Supérieur récent: nouvelles données sur le peuplement et l'environnement, Actes de la table ronde de Chambéry 12-13 mars 1999, Paris, Société Préhistorique Française, (mémoire XXVIII), 2000, p. 47-58.

Brochier, Brochier 1973: BROCHIER (J. E.), BROCHIER (J. L.) - L'art mobilier de deux nouveaux gisements magdaléniens à Saint-Nazaire-en-Royans (Drôme). Études Préhistoriques, 4, 1973, p. 1-12.

Brochier, Livache 1997: BROCHIER (J.-E.), LIVACHE (M.) - La grotte du Taï et l'abri Campalou à Saint-Nazaire-enRoyans. Elements typologiques préliminaires. In : PION (G.) dir., PCR La fin du Paléolithique supérieur dans les Alpes françaises du Nord et le Jura méridional. Rapport de synthèse 1997, SRA Rhône-Alpes, 1997, 2 p., 3 fig.

Cartonnet, Naton 2000 : CARTONNET (M.), NATON (H.G.) Le Magdalénien de la grotte de la Chênelaz à Hostias (Ain). In : PION (G.) dir., Le Paléolithique Supérieur récent : nouvelles données sur le peuplement et l'environnement, Actes de la table ronde de Chambéry 12-13 mars 1999, Paris,
Société Préhistorique Française, (mémoire XXVIII), 2000, p. 235-243.

Chaix 2006: CHAIX (L.) - Hétéroclite et éclectique: la faune épipaléolithique de l'Aven des Iboussières (Drôme, France), Munibe (Antropologia-Arkeologia), 57/1, Homaje a Jesús Altuna, (2005/2006), p. 411-420.

Couteaux 1983: COUTEAUX (M.) - Fluctuations glaciaires de la fin du Würm dans les Alpes françaises établies par les analyses polliniques. Boreas, 12, 1983, p. 35-56.

David 1993: DAVID (F.) - Altitudinal variation in the response of the vegetation to Late-glacial climatic events in the northern French Alps. New. Phytol., 125, 1993, p. 203-220.

David 2001: DAVID (F.) - Le Tardiglacaire des Etelles (Alpes françaises du Nord): instabilité climatique et dynamique de la végétation. C.R. Académie des Science Paris, Sciences de la vie / Life Science, 324, 2001, p. 373-380.

Delannoy 1986 : DELANNOY (J.-J.) - Carte géomorphologique du massif du Vercors, (Alpes, France). Université Scientifique et Médicale de Grenoble, 1986.

Drucker, Bocherens, Billiou 2009: DRUCKER (D. G.), BOCHERENS (H.), BILLIOU (D.) - Quelle valence écologique pour les rennes et autres cervidés au Tardiglaciare dans les Alpes du nord et le Jura? Résultats de l'analyse $\left({ }^{13} \mathrm{C},{ }^{15} \mathrm{~N}\right)$ du collagène. In: PION (G.) dir., La fin du Paléolithique supérieur dans les Alpes du nord françaises et le Jura méridional. Approches culturelles et environnementales, Paris, Société Préhistorique Française. (mémoire L), 2009, p. 73-86.

Eicher, Siegenthaler, Wegmüller 1981: EICHER (U)., SIEGENTHALER (U.), WEGMÜLLER (S.) - Pollen and oxygen analyses on late- and post-glacial sediments of the Tourbière de Chirens (Dauphiné, France). Quaternary Research, 15, 1981, p. 160-170.

Emmons 1911: EMMONS (G.) - The Tahltans indians. Philadelphia, Pensylvania University, University Museum (Anthropological Publications IV, 1), 1911.

d'Errico, Vanharen 2000: D'ERRICO (F.), VANHAREN (M.) - Mes morts et les morts de mes voisins. Le mobilier funéraire de l'Aven des Iboussières et l'identification de marqueurs culturels à l'Epipaléolithique, In: Les derniers chasseurs cueilleurs d'Europe occidentale, Actes du colloque international de Besançon, octobre 1998. Besançon, Presses Universitaires Franc-Comtoises (Annales Littéraires; 699; Série «Environnement, sociétés et Archéologie »; 1), 2000, p. 325-342.

Fournier 2005 : FOURNIER (J.) - Établissement d'un référentiel actualiste de saisonnalité pour la marmotte des Alpes (collection Couturier - Muséum d'Histoire Naturelle de Grenoble), mémoire de Master 2 de recherche, Université de Provence, Ecole doctorale, Espace, culture et société, 2005, 126 p.

Gély et al. 2000: GÉLY (B.), MORAND (P.) avec la collaboration de D'ERRICO (F.), DUTOUR (O.), HANTAÏ (A.), VALENTIN (B.), VILETTE (P.) - Les sépultures 
épipaléolithiques de l'aven des Iboussières à Malataverne (Drôme). In: CROTTI (P.) ed., Meso'97, Actes de la table ronde «Épipaléolithique et Mésolithique», Lausanne, 21-23 novembre 1997, Lausanne, Cahiers d'archéologie romande, 81,2000 , p. 119-128

Laudet et al. 2008 : LAUDET (R.), BINTZ (P.), BRESSY (C.), DAUMAS (J.-C.), MONIN (G.) - Les industries lithiques de l'abri du Petit Laup (Sahune, Drôme) dans le cadre de l'Epipaléolithique et du Mésolithique des Alpes du Nord. In : RICHARD (H.), GARCIA (D.) dir., Le peuplement de l'arc alpin, $131^{e}$ congrès national des sociétés historiques et scientifiques, Grenoble, 2006, publication électronique du CTHS, 2008, p. 77-93.

Marnezy 1980: MARNEZY (A.) - Le Vercors méridionnal: étude géomorphologique karstique et glaciaire. Thèse de doctorat de $3^{\text {e }}$ cycle, Université Scientifique et Médicale de Grenoble, 1980.

Mevel, Bressy 2009: MEVEL (L.), BRESSY (C.) - Comportement technique et économique des groupes humains du Paléolithique fnal dans les Alpes du nord: l'exemple de l'Azilien ancien de la Fru (Savoie) collagène. In: PION (G.) dir., La fin du Paléolithique supérieur dans les Alpes du Nord françaises et le Jura méridional. Approches culturelles et environnementales, Paris, Société Préhistorique Française, (mémoire L), 2009, p. 117-137.

Monin 1997: MONIN (G.) - Approche technologique des assemblages tardiglaciaires des grottes de La Passagère et Colomb, à Méaudre (Vercors, Isère). D.E.A. de Préhistoire, Université de Provence, Centre d'Aix, U.F.R. Civilisations et Humanité, 1997.

Monin 2000 : MONIN (G.) - Apport de la technologie lithique à l'étude des séries anciennes. Les assemblages tardiglaciaires des chasseurs de marmottes des grottes Colomb et de la Passagère à Méaudre (Vercors, Isère). In: PION (G.) dir., Le Paléolithique Supérieur récent: nouvelles données sur le peuplement et l'environnement, Actes de la table ronde de Chambéry 12-13 mars 1999, Paris, Société Préhistorique Française, (mémoire XXVIII), 2000, p. 271-287.

Monin, Picavet 2000 : MONIN (G.), PICAVET (R.) - L'abri des Pierres $(1050 \mathrm{~m})$ à Villard-de-Lans (Isère). In : PION (G.) dir., La fin du Paléolithique Supérieur dans les Alpes du Nord françaises et le Jura méridional, Rapport Intermédiaire de P.C.R., SRA Rhône-Alpes (Inédit), 6 p.

Monin, Griggo, Tomé 2006: MONIN (G.), GRIGGO (C.), TOMÉ (C.) - Stratégies d'exploitation d'un écosystème alpin au Tardiglaciaire. Les chasseurs de Marmotte du Vercors. In: MIRAS (Y.), SURMELY (F.) dir., Environnement et peuplement de la moyenne montagne du Tardiglaciaire à nos jours. Actes de la table ronde internationale de Pierrefort (Cantal) du 19 au 20 Juin 2003. Besançon, Presses Universitaires FrancComtoises (Annales Littéraires; 799; Série «Environnement, sociétés et Archéologie »; 9), 2006, p. 29-50.
Monin, Morin, Griggo 2007: MONIN (G.), MORIN (A.), GRIGGO (C.) - Hippolyte Müller, pionnier oublié de l'ethnopréhistoire. In: EVIN (J.) dir., Un siècle de construction $d u$ discours scientifique en Préhistoire, Actes du XXVI Congrès Préhistorique de France, Avignon, 21-25 septembre 2004, Congrès du Centenaire, vol. 1, Société Préhistorique Française, 2007, p. 139-156.

Müller 1912: MÜLLER (H) - Notes sur les stations aziliennes des environ de Grenoble. Congrès International d'Anthropologie et d'Archéologie Préhistorique, C.R., 14e session, Genève, 1912, p. 558-565.

Müller 1914 : MÜLLER (H) - Les stations aziliennes du Vercors. Les chasseurs de marmottes. C.R. Congrès Ass. française pour l'avancement des sciences, $43^{\mathrm{e}}$ session, Le Havre, 1914, p. 642-648.

Müller 1924 : MÜLLER (H) - Découverte d'un gisement magdalénien à Saint-Romans (Isère). Rhodania, C.R. du $6^{\mathrm{e}}$ Congrès, Avignon, 1924, p. 61-62.

Nagorsen, Keddie, Luszcz 1996: NAGORSEN (D.W.), KEDDIE (G.), LUSZCZ (T.) - Vancouver island marmot bones from subalpine caves: archeological and biological signifiance. Victoria, B.C. Park (Occasional paper n 4), 1996.

Oberlin, Pion 2009: OBERLIN (C.), PION (G.) - Le corpus des datations radiocarbone et la disparition du renne. In: PION (G.) dir., La fin du Paléolithique supérieur dans les Alpes du nord françaises et le Jura méridional. Approches culturelles et environnementales, Paris, Société Préhistorique Française (mémoire L), 2009, p. 51-57.

Ozenda 1985 : OZENDA (P.) - La végétation de la chaîne alpine dans l'espace montagnard européen, Paris, Masson, 1985, $350 \mathrm{p}$.

Pelegrin 2000: PELEGRIN (J.) - Les techniques de débitage laminaire au Tardiglaciaire: critères de diagnoses et quelques reflexions. In: VALENTIN (B.), BODU (P.), CHRISTENSEN (M.) dir., L'Europe centrale et septentrionale au Tardiglaciaire. Confrontation des modèles régionaux de peuplement, Nemours, Éditions de l'APRAIF (Mémoire du musée de Préhistoire d'Île-de-France, 7), 2000, p. 73-86.

Peresani 2008: PERESANI (M.) dir. - Marmotte e cacciatori del paleolitico a Pradis, Comune di Clauzetto, Università di Ferrara, 2008, 130 p.

Perrin 2001 : PERRIN (C.) - La Marmotte alpine, Saint-Yrieixsur-Charente, Éveil Nature, 2001.

Picavet 1995: PICAVET (R.) - Rapport d'opérations archéologiques. La station épipaléolithique du Clos-de-Lans, Lansen-Vercors, Isère, SRA Rhône-Alpes (Inédit), 1995.

Picavet et al. 2008: PICAVET (R.), PELLETIER (D.), CHESNAUX (L.), MONIN (G.) - La station Mésolithique de Prey-Peyret à Gresse-en-Vercors (Isère), rapport d'opération 2008, SRA Rhône-Alpes (Inédit). 
Picavet, Monin, Griggo 1999: PICAVET (R.), MONIN (G.), GRIGGO (C.) - Les Pierres (Villard-de-Lans, Isère). Rapport de Sondage, SRA Rhône-Alpes (Inédit), 1999.

Pion 2004: PION (G.) - Magdalénien, Épipaléolithique et mésolithique ancien dans les deux Savoie et le Jura méridional. Thèse de doctorat, Université de Franche-Comté, 2 vol., 2004.

Tomé 1998: TOMÉ (C.) - Étude de la marmotte des Alpes (Marmota marmota L.) et de son exploitation par les chasseurs du Paléolithique final de la grotte Colomb (MéaudreVercors - France), Mémoire de maîtrise, Université Pierre Mendés France, Grenoble II, 1998.
Tomé 2005: TOMÉ (C) - Les marmottes de la grotte Colomb (Vercors, France). Revue de Paléobiologie, Vol. spéc. 10, 2005, p. 11-21.

Tomé, Chaix 2003: TOMÉ (C.), CHAIX (L.) - Marmot's hunting and exploitation in the western Alps and the southern Jura from late Pleistocene to Holocene / La Chasse et l'exploitation des marmottes dans les Alpes occidentales et le Jura du sud de la fin du Pleistocène à l'Holocène. In: RAMOUSSE (R.), ALLAINÉ (D.), LE BERRE (M.) éd., Adaptative strategies and diversity in marmots / Stratégies adaptatives et diversité chez les marmottes, International Network on Marmots, 2003, p. 79-86. 


\title{
Recherches archéologiques dans les régions du Simplon et de l'Albrun (Valais et Piémont), du Mésolithique à l'époque romaine
}

\author{
Philippe CURDY*, Jérôme BULLINGER**, Pierre CROTTI**, \\ Veruchka VALSECCHI***, Willy TINNER***
}

\begin{abstract}
Résumé. Un programme de recherches archéologiques italo-suisse a impliqué les régions des cols du Simplon et de l'Albrun. Malgré des moyens modestes, les travaux de prospection de surface, entrepris de 2003 à 2005, permettent de localiser un nombre conséquent d'indices d'occupation datés principalement du Mésolithique et des âges des Métaux. Quelques sondages archéologiques permettent de compléter les premières observations. Les indices les plus anciens remontent au Mésolithique moyen (datations ${ }^{14} \mathrm{C}$ effectuées sur des foyers et artefacts en cristal de roche); ces découvertes illustrent une fréquentation remarquable des replats et plateaux d'altitude situés vers $2000 \mathrm{~m}$ d'altitude. Les témoins archéologiques d'occupations néolithiques font quasiment défaut; les données palynologiques indiquent une intensification de la présence de l'homme à l'étage alpin dès le Néolithique. Dans les analyses palynologiques, la fin du Néolithique et l'âge du Bronze sont marqués par un impact humain prononcé. Le contrôle des débouchés des cols, confirmé par l'implantation de sites fortifiés sur collines, semble jouer un rôle important dès cette époque et plus encore à l'âge du Fer. Les résultats du programme de recherches corroborent les modèles de peuplement proposés pour les régions des sources du Rhône (canton du Valais) et confirment l'importance du peuplement mésolithique en haute altitude dans les Alpes centreoccidentales.
\end{abstract}

Archaeological survey aroud the Simplon and Albrun passes (Valais, Piemont), from Mesolihic to Roman period

Abstract. An Italo-Swiss Interreg project focused on the regions around the Simplon Pass and the Albrun Pass. Despite the modest means available, the surface prospections carried out from 2003 to 2005 yielded a number of traces of settlement, mostly dating back to the Mesolithic period and the Metal ages. A few archaeological searches have yielded some complementary information. The oldest findings date back to the middle Mesolithic period; these findings reflect a remarkably high rate of frequentation of the high-altitude shoulders and plateaus around altitudes of 2000 meters. Few Neolithic archaeological findings have been made at these sites, however, although the palynological data have indicated that human settlers were probably increasingly present in the Alpine zone during the Neolithic period. Palynological data suggest rather a strong human impact during the Late Neolithic and the Bronze age. The close watch kept on the mountain passes, as suggested by the presence of fortified sites on the hills, seems to have played an important role at this time, and even more so during the Iron age. The results obtained in this research project confirm the validity of the models previously put forward to account for patterns of settlement in the region around the sources of the Rhône (in the Valais canton) and suggest that Mesolithic settlers played an important role at high altitudes in the central western Alps.

\section{Introduction}

Les travaux menés au Simplon et à l'Albrun entre 2003 et 2005 s'inscrivent dans le cadre du programme Interreg IIIA italo-suisse « Premières traces de l'homme dans les vallées alpines ». Ce projet est coordonné par la Région Piémont
(Ente Parco Alpe Veglia-Devero) et par le Canton du Valais (Musée cantonal d'archéologie), avec la collaboration du Musée cantonal d'archéologie et d'histoire (Lausanne) et l'appui scientifique de l'Université de Berne.

En 2003 et 2004, les recherches se déroulent dans les environs du col du Simplon et dans la région de l'Albrun

\footnotetext{
* Musées cantonaux du Valais, 12 rue des château, CH1950 Sion (Suisse).

** Musée cantonal d'archéologie et d'histoire, 6 place Riponne, CH1014 Lausanne (Suisse).

*** Institut für Pflanzenwissenschaften und Oeschger Zentrum für Klimaforschung, Universität Bern, Altenbergrain 21, CH3013 Bern (Suisse).
} 


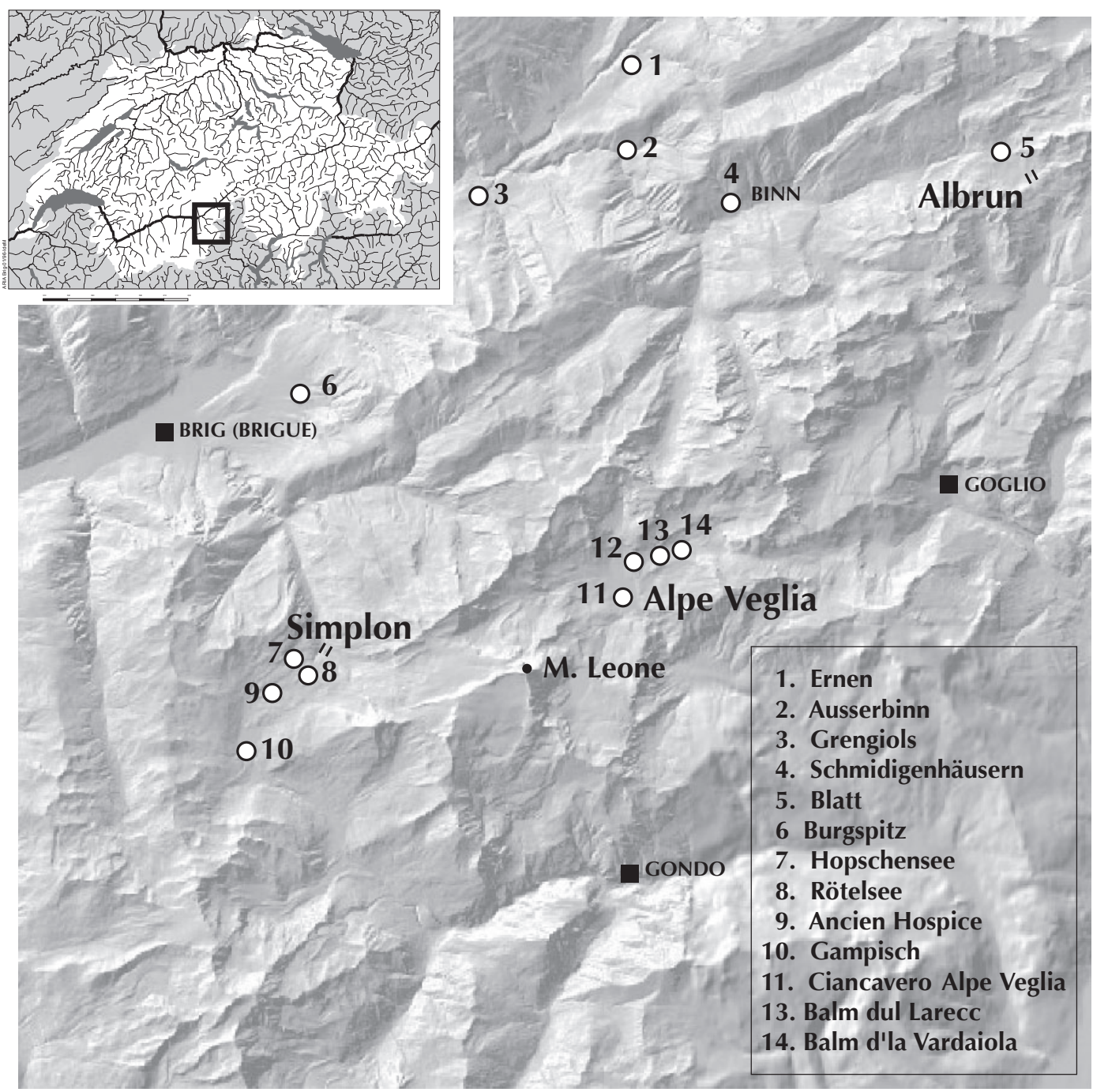

Fig. 1. Carte de la région et localisation des sites mentionnés dans le texte.

Dessin A. Benkert, Ph. Curdy et A. Guerreschi.

(fig. 1). En 2005, le versant italien du col de l'Albrun fait l'objet de recherches limitées ${ }^{1}$. Ces derniers travaux visent à compléter les données des fouilles entreprises par l'Université de Ferrare à l'Alpe Veglia (fig. 1)².

Dans la région du Simplon, les principales zones étudiées s'étagent entre le fond de la vallée de la Doveria au sud (Simplon Dorf, $1470 \mathrm{~m}$ alt.) et les environs du col, au-dessus de 2000 m d'altitude. Dans la vallée de Binn,

1. Diverses personnes ont participé à des degrés divers à ces travaux de terrain: Céline Andrey, Alain Benkert, Jérôme Bullinger, Yann Buzzi, Pierre Crotti, Nicole et Christophe Cupillard, Philippe Curdy, Vincent Dayer, Elisabeth Fierz-Dayer, Christian Gaudillère, Gabriele Giozza, Serge Hofer, Renata Huber, Tobias Imboden, Urs Leuzinger, Catherine Leuzinger-Piccand, Patricia Meyer, Patrick Moser et Gervaise Pignat. 2. Travaux dirigés sur le terrain par le professeur Antonio Guerreschi, Dipartimento di Scienze Geologiche e Paleontologiche, Université de Ferrare. Guerreschi, Pizziolo, Vullo 2002. les territoires de moyenne et haute altitude sont concernés entre la région d'Ausserbinn (1100 m alt.) et le col de l'Albrun (2600 m alt., fig. 1).

Au Simplon, les alentours du col s'inscrivent dans une ensellure de 300 ha, à l'altitude de $2000 \mathrm{~m}$ environ. Elle abrite plusieurs petits lacs dont certains aujourd'hui asséchés (fig. 2). En direction du sud, on retrouve, en contrebas du col, un second replat d'une centaine d'hectares (Ancien Hospice) à l'altitude de $1850 \mathrm{~m}$, bordé au sud par la colline de Gampisch (fig. 1, n 10). À l'Albrun, au pied du col, sur le versant suisse, un premier replat (Oxefeld) d'environ 40 ha (2200 m alt.) est marqué par la présence de nombreux blocs, dont plusieurs aménagés avec des murets de pierres sèches ${ }^{3}$. Plus bas, la zone de Blatt ( 9 ha, 2100 m

3. Dans le cadre de ce projet, aucune investigation n'a été entreprise sur ce genre de structure; leur étude et leur datation restent donc à faire. 


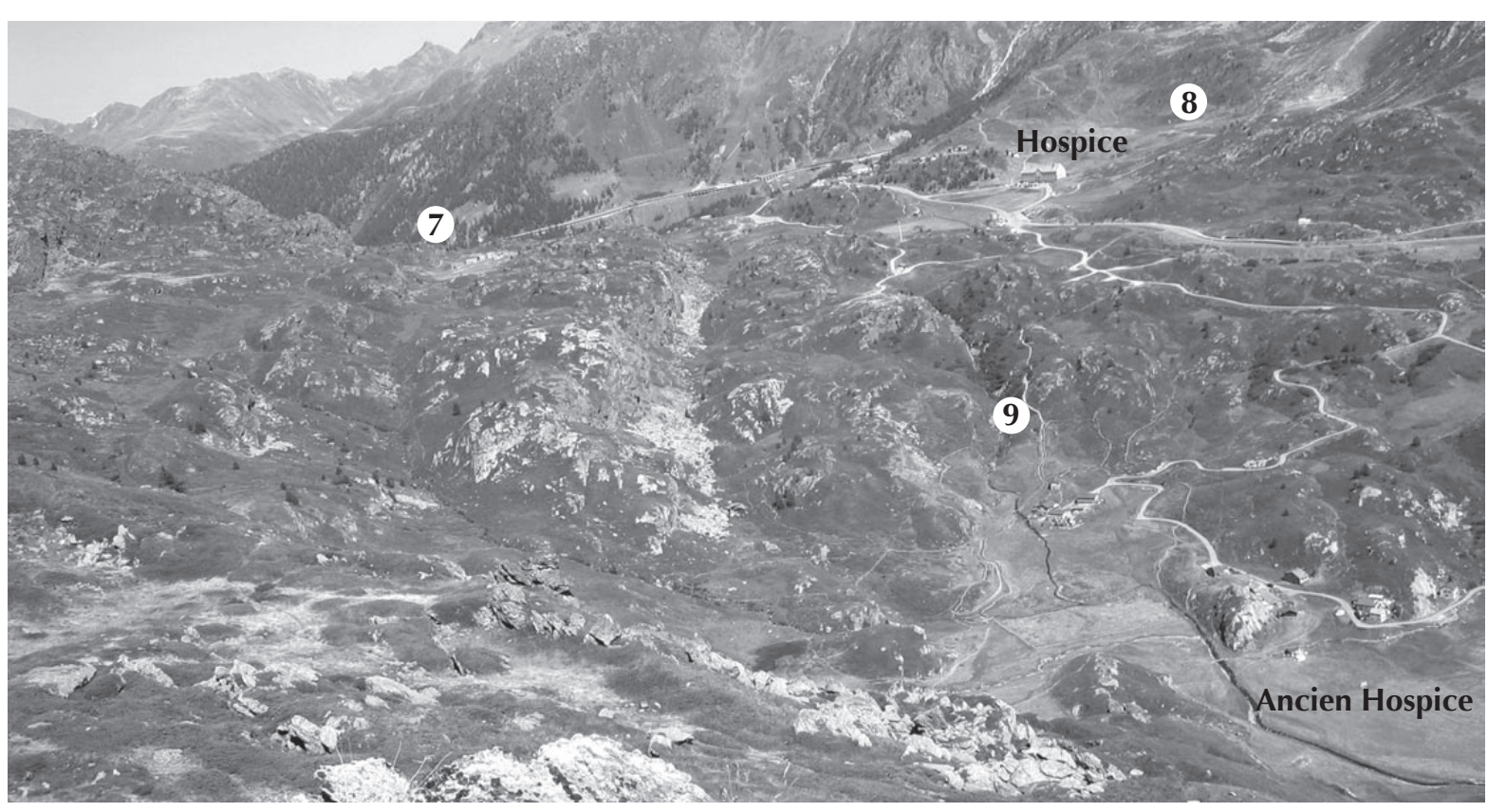

Fig. 2. Vue du Simplon depuis l'ouest. Les numéros renvoient à la fig. 1. Photo Ph. Curdy.

alt.) présente de bonnes potentialités pour des occupations saisonnières (pieds de paroi ou blocs, fig. $1, \mathrm{n}^{\circ} 5$ et fig. 4 ). Les travaux de terrain se sont limités à des observations de surface, complétées par des forages à la tarière et de petits sondages de un à deux mètres carrés. Outre les prospections archéologiques, une analyse palynologique a été entreprise au col du Simplon par l'Université de Berne (W. Tinner et V. Valsecchi) et l'un des sondages ouvert sur le site du Rötelsee a fait l'objet d'une étude sédimentologique (E. Fierz-Dayer).

\section{Mésolithique}

Avant les résultats des prospections menées au Simplon et à l'Albrun, les indices de peuplement du Valais, entre le retrait glaciaire et les premiers établissements néolithiques (fin $\mathrm{du} \mathrm{VI}$ millénaire av. J.-C.), concernaient uniquement deux sites: l'abri sous roche de Châble-Croix (ou de Vionnaz) en plaine du Rhône (388 m alt.) et l'abri de haute altitude de Alp Hermettji (2600 m alt.) au pied du Cervin ${ }^{4}$. Les recherches entreprises dans le monde alpin montrent qu'après le retrait glaciaire les chasseurs-cueilleurs investissent progressivement les secteurs d'altitude: l'étage montagnard (900-1400 m) dès l'Épipaléolithique, puis

4. Châble-Croix: traces d'occupations mésolithiques répétées entre 8500 et 7000, voire 6000 av. J.-C. (Pignat 2002; Chaix, Crotti, Pignat 2003); Alp Hermettji: campement saisonnier, 8000-7500 av. J.-C. (Curdy, Leuzinger-Piccand, Leuzinger 2003). les étages subalpin et alpin (1400-2400 m) au cours du Mésolithique. Dans les Alpes centrales, les données sur les occupations d'altitude restent encore peu étoffées (Crotti 1998; Pignat, Crotti 2002; Crotti, Bullinger 2001).

En Valais, il demeure aléatoire, voire impossible, de repérer des sites au niveau de la plaine, en raison d'un intense alluvionnement durant l'Holocène; en revanche, la prospection des zones d'altitude s'avère plus propice, grâce à une couverture sédimentaire très faible. Les travaux menés dans le cadre du programme Interreg IIIA ont rapidement mis en évidence des vestiges mésolithiques; leur localisation confirme que l'association entre cols ou zones de passage et petits lacs ou marais constitue un critère prioritaire dans le choix de l'implantation des campements. Les industries lithiques récoltées sont constituées de cristal de roche, comme sur le site tout proche de l'Alpe Veglia (IT, VB; Guerreschi, Pizziolo, Vullo 2002).

\subsection{Prospections et sondages}

Au Simplon, les témoins matériels mis au jour lors des prospections de surface sont regroupés dans trois secteurs proches du col: aux abords du vaste marais qui s'étend à l'ouest de l'Hospice et de deux petits lacs, le Rötelsee au sud-est (fig. 1, $\mathrm{n}^{\circ} 8$ ), et le Hopschensee, au nord-ouest du col (fig. 1, $n^{\circ} 7$ ). Une quinzaine de points de découverte ont pu être identifiés: il s'agit parfois de véritables concentrations d'artefacts, témoignant de l'installation de campements, comme au bord du Rötelsee, ou d'indices plus discrets, voire isolés. L'outillage lithique se rapporte 


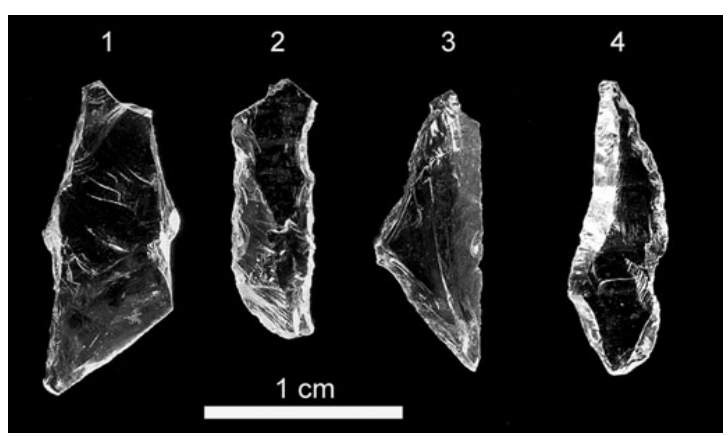

Fig.3. Col du Simplon. Microlithes en cristal de roche. Sauveterrien. 1-3. Rötelsee; 4. Marais de l'Hospice. Photo S. Ansermet.

au Mésolithique avec, en particulier, une micropointe effilée à retouche unilatérale, attribuable au Sauveterrien (fig. 3. $\left.n^{\circ} 4\right)$.

En contrebas du col du Simplon, sur le versant sud, l'exploration d'un abri sous bloc (1940 m alt.), surplombant le replat de l'Ancien Hospice, a révélé un niveau riche en charbons de bois, daté du VII millénaire av. J.-C. (fig. 1, $\mathrm{n}^{\circ}$ 9; Crotti, Curdy, Leuzinger 2004, p. 275, fig. 8) ${ }^{5}$. Un sondage d'un quart de mètre carré a mis au jour quelques artefacts en cristal de roche dont un microlithe géométrique (trapèze) qui confirme une occupation au cours du Mésolithique récent.

Dans la région de l'Albrun, sur la colline qui domine le replat de Blatt (2 $100 \mathrm{~m}$ alt.), une concentration d'éclats et d'esquilles en cristal de roche est apparue immédiatement sous la surface du sol, associée à un niveau de charbons de bois, daté du VII millénaire av. J.-C. (fig. 1, n 5, fig. 4) ${ }^{6}$. Cette découverte, malgré l'absence de pièces caractéristiques, atteste probablement d'une occupation mésolithique.

\subsection{Le Rötelsee}

Deux petits sondages ont été ouverts en 2004 en bordure du Rötelsee (fig. 5). Tout le sédiment a été tamisé à l'eau (maille: $2 \mathrm{~mm}$ ). Le sondage 2 a permis de localiser précisément une couche d'occupation mésolithique associée à une structure de combustion (fig. 6, couches d et e). L'industrie lithique du Rötelsee (654 pièces) est composée exclusivement de cristal de roche. Un premier ensemble (67 pièces), est issu des prospections de surface. Dans le sondage $1(50 \times 100 \mathrm{~cm})$, on décompte 71 artefacts, dont 20

5. Datations ${ }^{14} \mathrm{C}$ : UtC-12674, $7650 \pm 70$ et UtC-13455, 7490 $\pm 50 \mathrm{BP}$, soit 6637-6409 et 6438-6246 av. J.-C. (dates calibrées, 2 sigma, Calib 5.0.2, Stuiver et Reimer 1986-2005).

6. UtC-13456, 7990 $\pm 50 \mathrm{BP}$, soit environ 7058-6700 av. J.-C. (dates calibrées 2 sigma, Calib 5.0.2, Stuiver et Reimer 1986-2005). prélevés in situ, et dans le sondage $2(100$ x $100 \mathrm{~cm}) 516$, dont 85 in situ.

Une première analyse de l'ensemble de l'industrie lithique montre que tous les éléments de la chaîne opératoire sont présents sur le site. Les nucléus (6 pièces) et quelques gros fragments de prisme montrent que le débitage commence par des enlèvements à partir du sommet du prisme, en utilisant comme crête l'arête naturelle formée par la rencontre de deux faces. Le débitage est réalisé en percussion directe dure, à la pierre. La majorité des talons sont fortement écrasés; les bulbes présentent quelques ondes de choc bien visibles. Le débitage est orienté vers la production de petits éclats lamellaires ou de lamelles. Les cassons et les esquilles constituent une part importante de l'industrie (près de $35 \%$ ). La forte proportion de ces éléments est liée à la nature du cristal de roche, qui produit de nombreux débris lors de son débitage ou de la mise en forme des prismes. Les dimensions de l'ensemble de l'industrie sont réduites, limitées par la taille des prismes.

La série compte 14 pièces retouchées. Le groupe des armatures est composé d'un triangle isocèle et d'un triangle scalène ainsi que de cinq fragments (fig. 3, n ${ }^{\text {os }} 1-3$ ). Les outils communs comprennent un petit grattoir, 5 éclats retouchés et un éclat à enlèvements irréguliers. Cet ensemble est homogène et peut être rattaché au Sauveterrien. Deux datations radiocarbone, réalisées sur des charbons de bois, situent cette occupation entre 7000 et 6600 av. J.-C. ${ }^{7}$. Ces datations, relativement récentes, indiqueraient une phase tardive du Sauveterrien.

Par ailleurs, dans le sondage 2, un foyer situé dans la partie supérieure de la séquence témoignerait d'une occupation au Néolithique final (fig. 6, couche c), même si aucun artefact ne le confirme ${ }^{8}$.

\section{Néolithique}

Le Néolithique est plus ou moins bien représenté dans les Alpes suisses. Le Valais dévoile une densité assez conséquente d'établissements de plaine et quelques traces d'occupation sous abri en haute altitude (Curdy 2007); le territoire semble être organisé sur la base d'une agriculture concentrée aux abords de la plaine du Rhône et d'un élevage qui utiliserait déjà les prairies naturelles d'altitude pour l'estivage. Les contacts avec le Sud, bien attestés et réguliers, se font par les passages alpins dont vraisemblablement ceux de la région du Simplon-Albrun. Cependant, les données sur le Néolithique y sont totalement lacunaires et les travaux de prospection n'ont rien apporté de neuf. Seules les datations radiocarbone effectuées dans le

7. UtC-14649: $7875 \pm 41$ BP et UtC-14650: $7909 \pm 43$ BP 8. UtC-13453 : $4142 \pm 40$ BP et UtC-13454 : $4199 \pm 41$ BP 

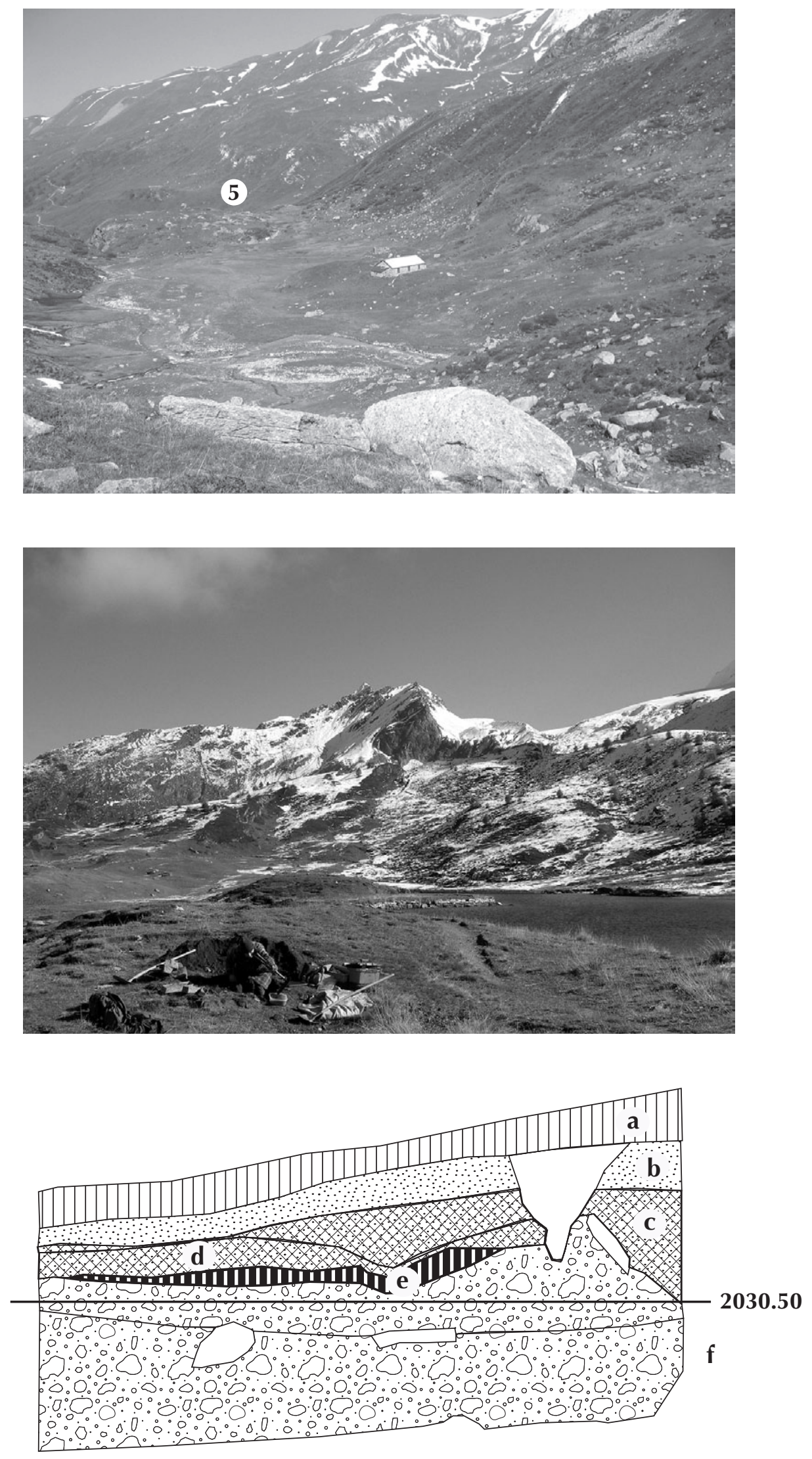

$1 \mathrm{~m}$
Fig. 4. Vue plateau de Blatt (Albrun). Photo Ph. Curdy.

Fig. 5. Rötelsee. Vue des fouilles (sondage 2). Photo Ph. Curdy.

Fig. 6. Rötelsee, sondage 2. Coupe stratigraphique sud. Dessin Ch. Gaudillère. a: humus (horizon Ah du sol actuel); b: sables moyens (colluvionnement); c: sables moyens à fin, (foyer/niveau d'incendie, période néolithique); $\mathbf{d}$ : sable limoneux (sommet d'un sol enfoui, occupation mésolithique); e: sable fin (occupation mésolithique avec foyer); f: sables avec blocs altérés (dépôt morainique). 
niveau supérieur du Rötelsee (voir plus haut) et les résultats des analyses palynologiques menées au Hopschensee ont révélé des indices de présence humaine à cette période (voir plus bas). De ces dernières, on peut faire l'hypothèse que les alentours du col ont été fréquentés tout au long du Néolithique, probablement de manière plus conséquente durant le III ${ }^{\mathrm{e}}$ millénaire av. J.-C.

\section{4. Âge du Bronze}

Cette période est l'une des mieux connues dans le massif alpin. Si l'on se restreint à la vallée du Rhône en amont du Léman, les informations - au demeurant assez denses - ont été relativement bien exploitées (David-Elbiali 2000). Dans la zone d'étude, les vestiges se concentrent au pied nord et sud des cols du Simplon et de l'Albrun, en particulier à l'étage montagnard. Par contre, la carte archéologique du Valais est presque muette pour tout ce qui concerne les hautes altitudes. La région prospectée présente des potentialités non négligeables qui permettraient de préciser certains aspects tels que les échanges par les cols, l'utilisation des pâtures d'altitude et l'exploitation minière. Dans ce cadre, le Simplon, malgré la présence de gisements aurifères sur le versant sud, ne livre que très peu d'indices métallifères ${ }^{9}$. Quant à l'Albrun, la découverte sur le versant italien du col d'une lame de poignard du Bronze moyen, fichée dans une faille de rocher (filon de quartz), soulève plus de questions qu'elle n'en résout (Morand et al. 1986, p. 302; Gambari in Di Maio 2007, p. 30-31).

Lors des travaux de prospection en altitude, les seuls résultats probants concernent des datations radiocarbone obtenues dans des structures de combustion, sans mobilier archéologique. Au sud du col du Simplon, un foyer a été daté du Bronze moyen ou final sur la colline de Gampisch (1880 m alt., fig. 1, $\left.\mathrm{n}^{\circ} 10\right)^{10}$. Un niveau de charbons daté du Bronze ancien a été observé dans un abri au pied du col de l'Albrun à $2110 \mathrm{~m}$ d'altitude (secteur de Blatt, fig. 1, $\left.n^{\circ} 5\right)^{11}$.

La découverte la plus importante faite lors des travaux de prospection en moyenne altitude est celle d'un site fortifié au pied nord du col du Simplon (fig. 1, $\mathrm{n}^{\circ} 4$; Crotti, Curdy, Leuzinger 2004, p. 276, fig. 10). Au-dessus de la ville de Brigue, un replat d'environ 4 kilomètres carrés, à environ

9. Carte des matières premières minérales de la Suisse, 1/200000, « Valais-Oberland bernois », Commission géotechnique Suisse, Zurich 1998. Voir aussi Endrizzi, Marzatico 1997, p. 59, fig. 5.

10. UtC-12709, 3179 \pm 53 BP, soit 1607-1316 av. J.-C. (dates calibrées, 2 sigma, Calib 5.0.2, Stuiver et Reimer 1986-2005).

11. UtC-13457, 3622 440 BP, soit environ 2132-1887 av. J.-C. (dates calibrées, 2 sigma, Calib 5.0.2, Stuiver et Reimer 1986-2005).
900 m d'altitude, a livré des sépultures de l'âge du Fer et de l'époque romaine.

Surplombant ce replat, la colline du Burgspitz (1 $100 \mathrm{~m}$ alt.) a fait l'objet d'un petit sondage de $3 \mathrm{~m}^{2}$ (fig. 1, $\mathrm{n}^{\circ}$ 6, fig. 7 et 8). La coupe dévoile une première couche anthropique (couche i) datée du XVII ${ }^{\mathrm{e}}-\mathrm{XVI}^{\mathrm{e}}$ s. av. J.-C. ${ }^{12}$ La date est confirmée par la présence de fragments d'une jarre à cordon et languettes de préhension (fig. 9a). Cette occupation est scellée par deux horizons datés du début du Bronze moyen ${ }^{13}$. Par la suite, on aménage un rempart matérialisé par un remblai (couche f), une berme (A8) et un parement (A7). L'abandon de la fortification (couches $n$ et $\mathrm{m}$ ) est daté de la fin du Bronze moyen/début du Bronze final ${ }^{14}$. À ce niveau correspond une jarre à cordon à rebord déversé et lèvre digitée (fig. 9b). Les niveaux qui scellent les vestiges du parement livrent du mobilier de l'âge du Fer et de l'époque romaine.

Un autre site fortifié du début du Bronze final, le Schlosshubel (commune de Grengiols, fig. 1, $\mathrm{n}^{\circ} 3$; David-Elbiali 2000, p. 442), est connu au pied nord du col de l'Albrun. Ces éléments démontrent que, pour les communautés alpines, le contrôle du débouché des cols alpins a joué un rôle de plus en plus important au cours de l'âge du Bronze.

\section{5. Âge du Fer}

Dans la zone prospectée, l'âge du Fer est représenté en basse altitude par de nombreuses sépultures, en particulier le long des vallons qui mènent au col de l'Albrun. Signalons la présence du site de Waldmatte près de Gamsen, au pied nord du Simplon, un village occupé presque sans discontinuité entre le VII ${ }^{\mathrm{e}}$ s. av. J.-C. et la fin de l'âge du Fer (Benkert, Nicoud 2008). Au tournant de notre ère, les trouvailles semblent s'intensifier dans le Binntal, avec la présence de tombes à Mülebach près de Ernen, Ausserbinn et Schmidigenhäusern (fig. 1, $\mathrm{n}^{\text {os }} 1,2$ et 4; Morand et al. 1986, p. 302-313; Paccolat 1998). Le passage par l'Albrun pourrait avoir été préféré à la voie du Simplon. Ici, les trouvailles se limitent à un fragment de bracelet en pierre (schiste) récolté dans un talus sur la rive sud du Rötelsee (fig. 1, $\mathrm{n}^{\circ} 8$; Crotti, Curdy, Leuzinger 2004, fig. 9; Curdy in Di Maio 2007, p. 48-51).

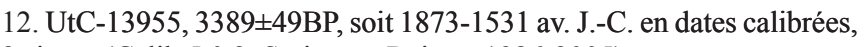
2 sigma (Calib 5.0.2, Stuiver et Reimer 1986-2005).

13. Couche h, datation sur os: UtC-13956, 3288 $\pm 44 \mathrm{BP}$, soit 1683-1457 av. J.-C. en dates calibrées, 2 sigma (Calib 5.0.2, Stuiver et Reimer 1986-2005). Couche g, charbons: UtC-13957, 3211 \pm 11 , soit 16061411 av. J.-C. en dates calibrées, 2 sigma (Calib 5.0.2, Stuiver et Reimer 1986-2005).

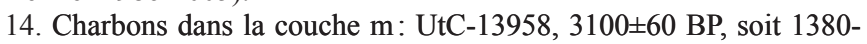
1260 av. J.-C. en dates calibrées, 2 sigma (Calib 5.0.2, Stuiver et Reimer 1986-2005). 


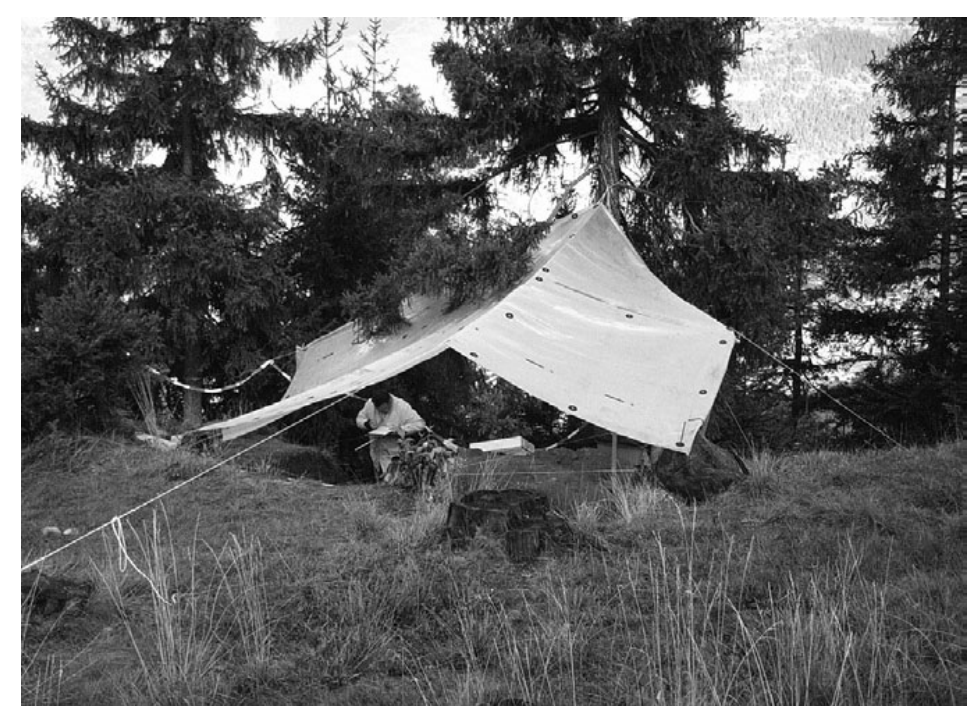

Fig. 7. Vue du sondage 1 sur la colline du Burgspitz. Photo A. Benkert.

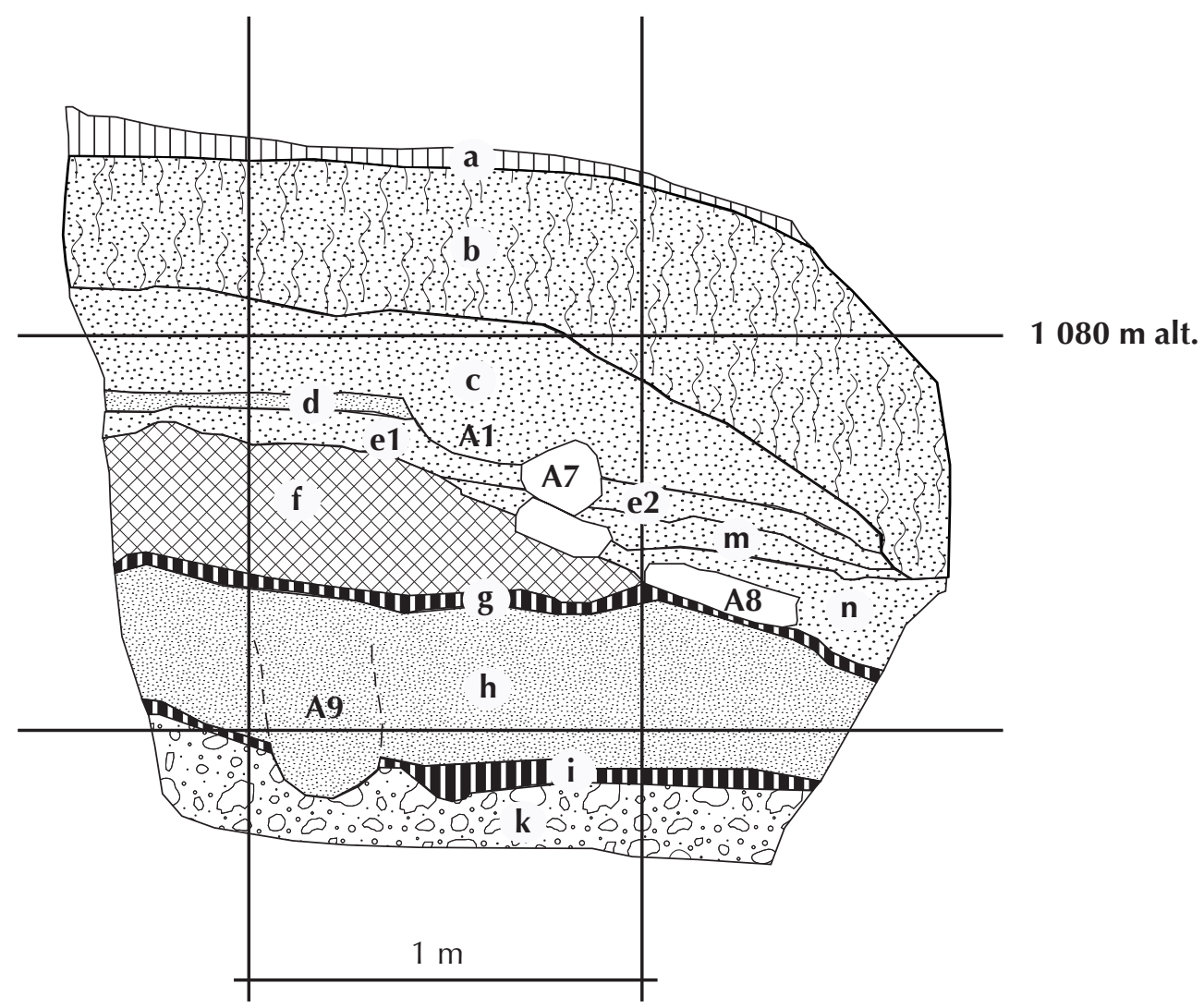

Fig. 8. Burgspitz, sondage 1. Coupe stratigraphique ouest. Dessin Ch. Gaudillère. a: humus; b: humus ancien mal dégradé; c: limon sableux, fragments de mortier et céramiques (colluvionnement); d: limon sableux avec mobilier archéologique

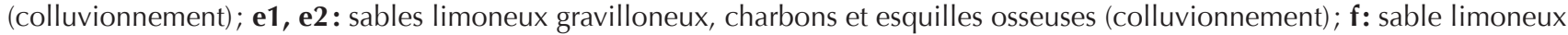
avec cailloutis, sans mobilier, (remblai artificiel); g: limon gras charbonneux (occupation du début du Bronze moyen); $\mathbf{h}$ : limon sableux avec rares charbons et esquilles osseuses, fragments de céramique (colluvionnement, début du Bronze moyen); i: limon très charbonneux (occupation du Bronze ancien); k: sable gravilloneux, quelques pierres roulées (dépôt fluvio-glaciaire); $\mathbf{m}$ et $\mathbf{n}$ : sables limoneux légèrement humifères, mobilier céramique (colluvionnement); $\mathbf{n}$ : limon sableux légèrement lité (colluvionnement). 

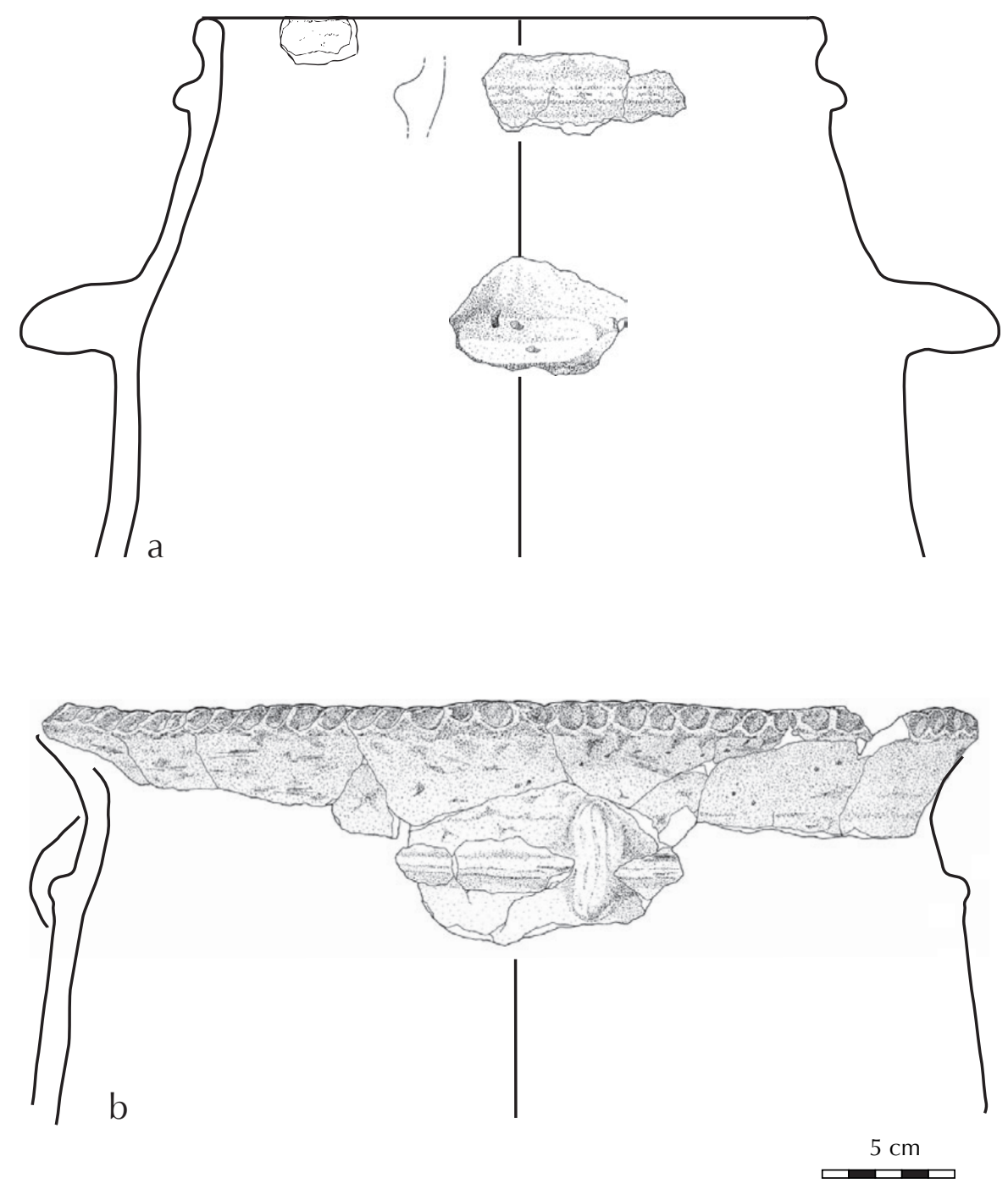

Fig. 9. Burgspitz, sondage 1. Jarres de l'âge du Bronze. Dessin Ch. Gaudillère.

\section{6. Époque romaine}

À l'époque romaine, tant le Haut-Valais que le Val d'Ossola se signalent par une assez forte densité de vestiges, principalement des tombes isolées ou des nécropoles. Sur le versant valaisan, les traces d'habitat sont assez discrètes, à l'exception remarquable de l'agglomération « indigène » de Brig-Glis/Waldmatte qui succède au site protohistorique implanté au pied du col (Paccolat 1998; 2008).

Le col du Simplon se distingue de celui de l'Albrun tout proche par la quasi-absence de trouvaille de monnaies d'époque romaine (Wiblé 1998, p. 81; Wiblé 2000) ${ }^{15}$. Les prospections menées dans le cadre du projet Interreg III

15. Pour les occupations de la vallée de Binn, voir Paccolat 1998. n'ont également rien donné. On ne constate ainsi aucun indice de l'existence d'une voie romaine par le Simplon. Le trafic devait sans doute passer presque exclusivement par le col de l'Albrun sur le versant nord duquel plusieurs trouvailles de monnaies ont été faites ${ }^{16}$.

\section{Données palynologiques provenant du Hopschensee}

En 2004, afin de compléter les données archéologiques, une colonne palynologique a été prélevée par l'Université de Berne au Hopschensee (fig. 1, $n^{\circ} 7$ ), un lac qui a fait

16. Monnaies du Bas-Empire, près de Blatt, (inédit) et plus haut en aval de la Binntalhütte (Wiblé 2000, p. 611). 


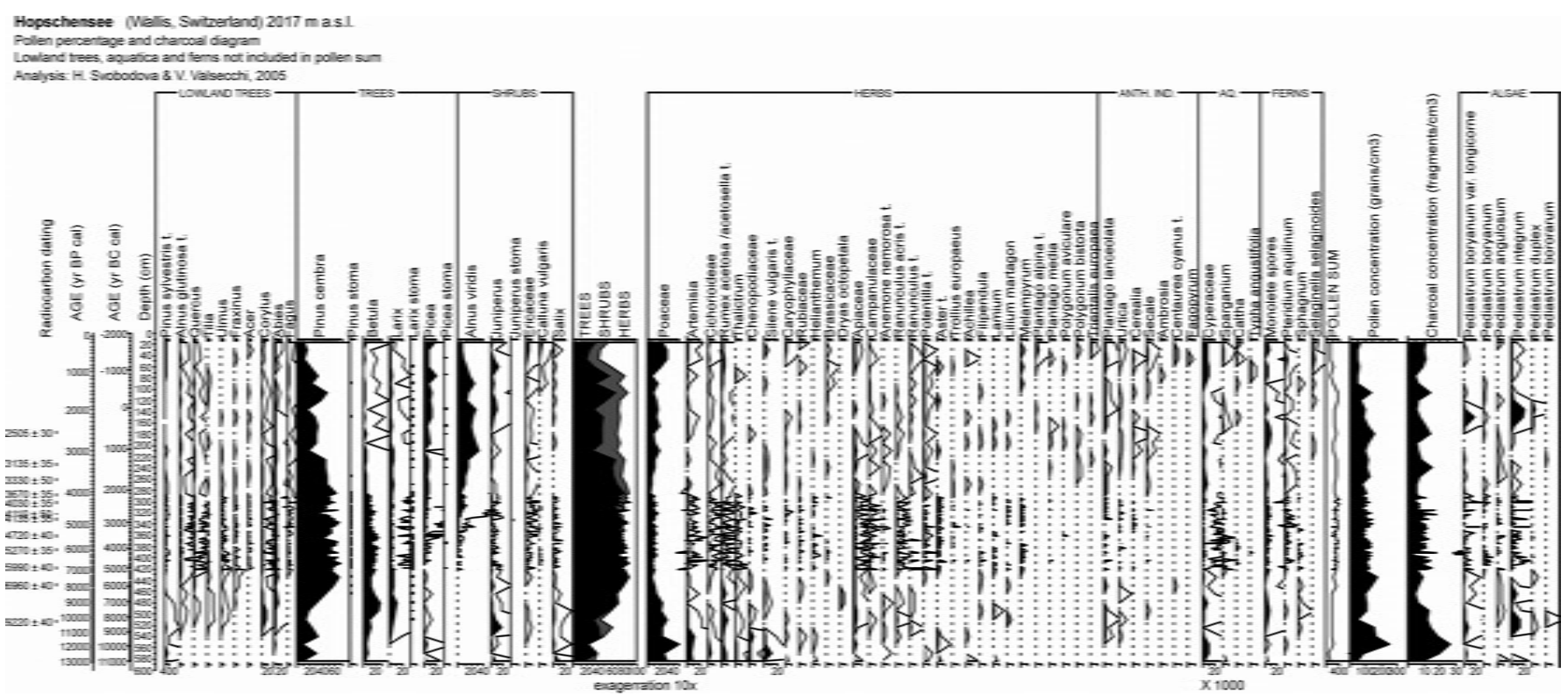

Fig. 10. Hopschensee. Diagramme palynologique général (2004).

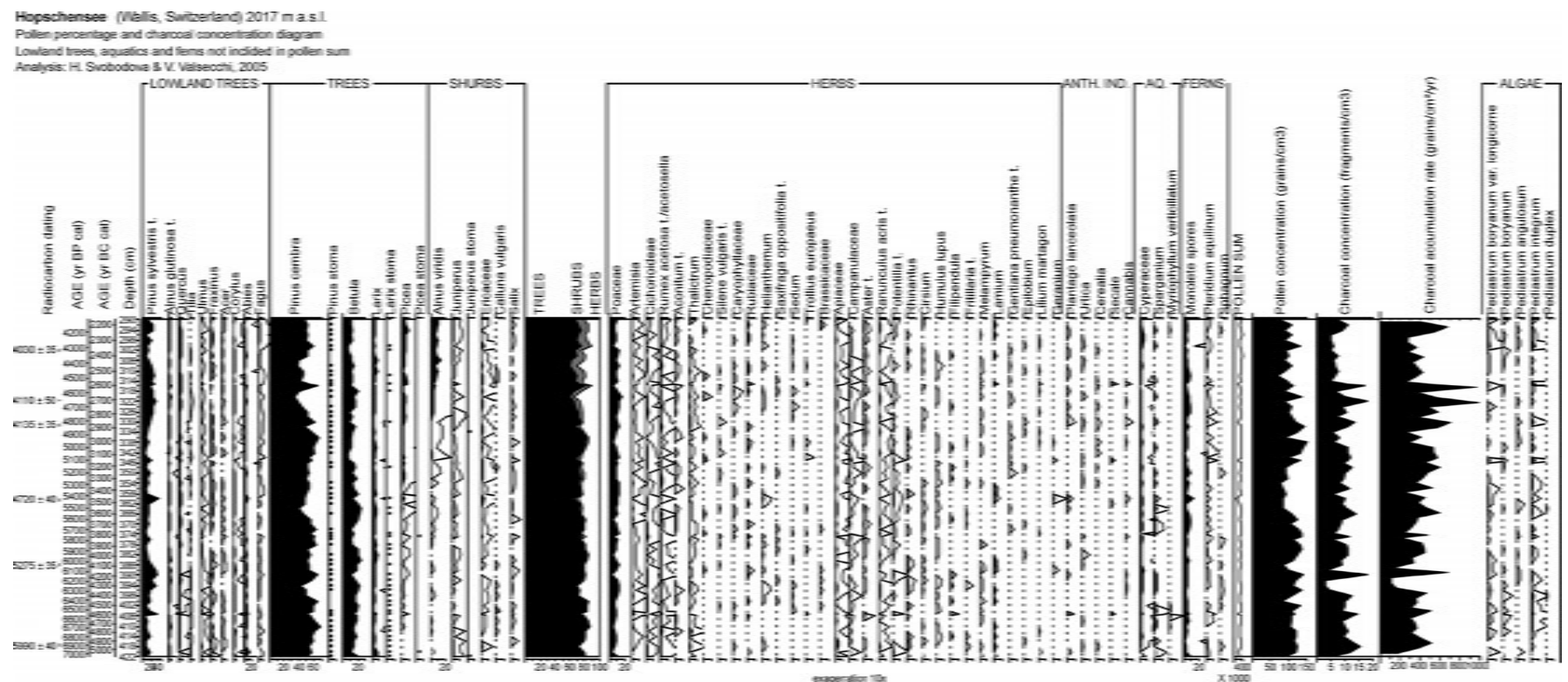

Fig. 11. Hopschensee. Diagramme palynologique (2004). Séquence 5000-2000 BC.

l'objet de plusieurs études paléobotaniques au cours du $\mathrm{XX}^{\mathrm{e}}$ s. (Welten 1982) ${ }^{17}$. Dans le carottage, d'une puissance de $585 \mathrm{~cm}, 102$ échantillons ont été prélevés et 12 datations radiocarbone effectuées en particulier dans la fourchette chronologique correspondant au Néolithique (fig. 10 et 11). Le début de la séquence sédimentaire concerne le Tardiglaciaire, vers 11000 av. J.-C. (fig. 10). À ces altitudes, on

17. Diagramme 34, Hopschusee, DA7: deux dates ${ }^{14} \mathrm{C}$, dans une fourchette située entre 4000 et 3000 av. J.-C. observe des saules/Salix, genévriers/Juniperus et bouleaux/ Betula. Dès 9500 av. J.-C., au début de l'Holocène, de nouvelles essences prennent de l'importance, en particulier le mélèze/Larix vers 9000 av. J.-C. puis, quelques siècles plus tard, l'arole/Pinus cembra. Vers 8000 av. J.-C. (Boréal), la forêt atteint son apogée.

Plus tard, dès 5000 av. J.-C., le développement de l'épicéa/ Picea abies et surtout celui de l'aulne vert/Alnus viridis, marquent une rupture; il semble que ce phénomène puisse avoir été causé par la présence de troupeaux de ruminants. 
Dans la séquence néolithique (fig. 11), l'étude des concentrations de charbons de bois témoigne d'incendies de forêt causés en partie par l'homme. Entre 5000 et 2300 av. J.-C., cinq pics d'herbacées sont visibles (5020-4900 av. J.-C., 4400-4300 av. J.-C., 3600-3340 av. J.-C., 2890-2630 av. J.-C. et 2580-2360 av. J.-C.). La deuxième et la quatrième de ces phases de «déforestation» coïncident avec des pics de densité de charbons (incendies volontaires en vue d'entretenir les clairières?).

Vers 5000 av. J.-C., les premiers indices d'agriculture en relation avec des champs présents dans les étages inférieurs font leur apparition. Mais c'est seulement entre 3600 et 3400 av. J.-C., en parallèle avec une forte diminution de la forêt, que cette présence est plus évidente.

Remarquons que, d'une manière plus générale, il n'est pas totalement exclu que ces variations soient aussi influencées par des péjorations du climat, comme par exemple, la phase froide CE-5, entre 4200 et 3700 av. J.-C. Les autres périodes de déprise ne sont pas corrélées strictement avec des phases climatiques froides et humides: CE-4 (55505150 av. J.-C.), CE-6 (3400-3000 av. J.-C.), CE-7 (18001500 av. J.-C.) ou CE-8 (800-400 av. J.-C.; Haas et al. 1998). Des résultats comparables ont été obtenus dans d'autres études paléobotaniques, aux Grisons par exemple (Gobet et al. 2004). En Valais, dès 3000-2000 av. J.-C., l'influence anthropique, plus importante que celle du climat, va entraîner un abaissement définitif de la limite supérieure de la forêt d'environ 300 m, ce qui correspond en gros à ce qui est observé de nos jours. Relevons que pour les époques plus récentes, d'autres indices encore plus nets de déboisement apparaissent à l'âge du Bronze ou au haut Moyen Âge, vers 600 apr. J.-C. (fig. 9).

\section{Conclusions}

Ces campagnes de prospection se sont révélées très riches en informations malgré la modestie des moyens engagés ${ }^{18}$. Il est bien établi que les zones du Simplon et de l'Albrun ont été fréquentées par les communautés de chasseurscueilleurs au Mésolithique. Une fois de plus, l'association étroite entre cols ou zones de passage et petits lacs ou marais, comme critère prioritaire dans le choix de l'emplacement de campements, s'est vu confirmée (Crotti, Bullinger 2001). Quant aux périodes plus récentes, le Néolithique et les âges des Métaux en particulier, les données demeurent lacunaires. Il semble que les emplacements naturellement protégés aient pu servir de gîte saisonnier à des pasteurs, mais leurs traces restent encore à découvrir. Les données

18. Les équipes de terrain se composaient de 4 à 8 collaborateurs; on décompte au total 75 jours de prospection en 2003, 66 en 2004 et environ 30 en 2005. palynologiques montrent cependant un impact humain marqué au cours du Néolithique et plus précisément au Néolithique final. La présence d'un puissant site fortifié de l'âge du Bronze au pied nord du Simplon serait peutêtre l'indice de l'importance de cette voie au cours de la Protohistoire. Pour les périodes postérieures, l'âge du Fer et l'époque romaine, l'Albrun semblerait avoir été le passage privilégié reliant Piémont et Haut Valais.

En bref, les résultats des travaux sont en parfaite conformité avec ce que livrent les autres régions alpines. Au plan des méthodes de recherche, la prospection de surface s'avère assez performante dans les zones situées au-dessus de la limite supérieure de la forêt. Par contre, les forages à la tarière à main se révèlent indispensables en cas de couverture sédimentaire plus importante, en pied de paroi ou dans des abris sous blocs. Enfin, nous sommes conscients que l'absence de fouilles sur les constructions en pierres sèches, très nombreuses, relevées dans les secteurs prospectés, constitue une lacune dans le bilan de nos recherches; ces ruines ne livrent quasiment jamais d'indices en surface et seuls des travaux de terrain d'une certaine ampleur permettraient de les dater.

\section{Bibliographie}

Baudais et al. 1990: BAUDAIS (D.), CURDY (P.), DAVIDELBIALI, (M.), MAY (O.) - La néolithisation du Valais, modèles de peuplement et premier bilan de la Prospection Archéologique du Valais (Suisse). In: BIAGI (P.) ed., The Neolithisation of the alpine region, papers delivered at the international round table held at Brescia (1988), Brescia, Museo civico di scienze naturali, 235 p. (Monografie di Natura Bresciana, 13), 1990, p. 159-174.

Benkert et al. 2003 : BENKERT (A.), EPINEY-NICOUD (C.), DAYER (V.), GENTIZON (A.), HALLER (M.), MARCHI (S.), WAGNER (C.) - La séquence chronostratigraphique de Brig-Glis/Gamsen Waldmatte (Valais, CH). In : BESSE (M.), STAHL-GRETSCH (I.), CURDY (P.) dir., ConstellaSion, Hommage à Alain Gallay, Lausanne, Cahiers d'archéologie romande, 496 p. (CAR, 95), 2003, p. 291-306.

Benkert, Nicoud 2008: BENKERT (A.), NICOUD (C.) Gamsen, une agglomération de l'âge du Fer. In: JOSPIN (J.-P.), FAVRIE (T.) dir., Premiers bergers des Alpes, de la préhistoire à l'Antiquité, catalogue de l'exposition, Grenoble, Musée dauphinois, 2008, p. 109-114.

Chaix, Crotti, Pignat 2003: CHAIX (L.), CROTTI (P.), PIGNAT (G.) - Un exemple d'économie en milieu alpin, l'abri de Châble-Croix, près de Vionnaz (Valais, Suisse). In: BESSE (M.), STAHL-GRETSCH (I.), CURDY (P.) dir., ConstellaSion, Hommage à Alain Gallay, Lausanne, Cahiers d'archéologie romande (CAR, 95), 2003, p. 59-72. 
Crotti 1998: CROTTI (P.) - Mesolithic settlement of the Central Alps and the use of the mountain sectors. Preistoria alpina, 34, 1998, p. 119-128.

Crotti, Bullinger 2001: CROTTI (P.), BULLINGER (J.) - Campements mésolithiques d'altitude sur le Jaunpass (Simmental, canton de Berne, Suisse). Annuaire de la Société suisse de préhistoire et d'archéologie, 84, 2001, p. 119-124.

Crotti, Curdy, Leuzinger 2004: CROTTI (P.), CURDY (P.), LEUZINGER (U.) - La région du Simplon, (Valais) du Mésolithique à l'époque romaine, campagne de prospection 2003, Annuaire de la Société suisse de préhistoire et d'archéologie, 87, 2004, p. 271-278.

Curdy 2007: CURDY (P.) - Prehistoric settlement in middle and high altitudes in the Upper Rhone Valley (Valais-Vaud, Switzerland), a summary of twenty years of research. Preistoria Alpina, 42, 2007, p. 129-141.

Curdy, Leuzinger-Piccand, Leuzinger 2003: CURDY (P.), LEUZINGER-PICCAND (C.), LEUZINGER (U.) Zermatt Alp Hermettji et les cols secondaires du Valais. In: BESSE (M.), STAHL-GRETSCH (I.), CURDY (P.) dir., ConstellaSion, Hommage à Alain Gallay, Lausanne, Cahiers d'archéologie romande (CAR, 95), 2003, p. 73-88.

David-Elbiali 2000 : DAVID-ELBIALI (M.) - La Suisse occidentale au II ${ }^{e}$ millénaire av. J.-C., chronologie, culture et intégration européenne. Lausanne, Cahiers d'archéologie romande, XXI (CAR, 80), 2000, 570 p.

Di Maio 2007: DI MAIO (P.) - Prime impronte dell'uomo nella regione Sempione-Arbola. Torino, Celid (I quaderni del Parco, 3), 2007, 55 p.

Endrizzi, Marzatico 1997: ENDRIZZI (L.), MARZATICO (F.) - Ori delle Alpi, Catalogo della Mostra. Trento, Museo Castello del Buonconsiglio, 1997, 591 p.

Gobet et al. 2004 : GOBET (E.), HOCHULI (P.A.), AMMANN (B.), TINNER (W.) - Vom Urwald zur Kulturlandschaft des Oberengadins, Vegetationsgeschichte der letzten 6200 Jahre, Annuaire de la Société suisse de préhistoire et d'archéologie, 87, 2004, p. 255-270.

Guerreschi, Pizziolo, Vullo 2002: GUERRESCHI (A.), PIZZIOLO (G.), VULLO (N.) - Il sito mesolitico d'altura di Alpe Veglia (Verbania), Analisi GIS per uno studio intra-site. In: PERETTO (C.) éd., Analisi informatizzata e trattamento dei dati delle struttura di abitato della preistoria e protostoria italiana, Pisa, Edizioni ETS, 2002, p. 135-145.
Haas et al. 1998: HAAS (J.-N.), RICHOZ (I.), TINNER (W.), WICK (L.) - Synchronous Holocene climatic oscillations recorded on the Swiss Plateau and at timberline in the Alps, The Holocene, 8, 1998, p. 301-309.

Morand et al. 1986: MORAND (M.C.) dir.- Le Valais avant l'Histoire, catalogue de l'exposition. Sion, Musées cantonaux du Valais, 1986, 379 p.

Paccolat 1998: PACCOLAT(O.) - L'agglomération de Waldmatte près de Brigue. In: CURDY (P.) dir., Vallis Poenina, le Valais à l'époque romaine, Catalogue de l'exposition, Sion, Musées cantonaux du Valais, 1998, p. 204-208.

Paccolat 2008 : PACCOLAT (O.) - Le pastoralisme dans l'agglomération historique de Gamsen/Waldmatte. In: JOSPIN (J.-P.), FAVRI (T.) dir., Premiers bergers des Alpes, de la préhistoire à l'Antiquité, catalogue de l'exposition, Grenoble, Musée dauphinois, 2008, p. 125-128.

Pignat 2002: PIGNAT (G.) - L'abri sous roche de ChâbleCroix, un camp de chasse et de pêche en plaine du Rhône. In: CROTTI (P.), PIGNAT (G.), RACHOUD-SCHNEIDER (A.-M.) dir., Premiers Hommes dans les Alpes de 50000 à 5000 avant Jésus-Christ, Catalogue d'exposition Musée cantonal d'archéologie Sion, Lausanne, Payot, 2002, p. 165-169.

Pignat, Crotti 2002 : PIGNAT(G.), CROTTI(P.) - Le peuplement des Alpes. In: CROTTI (P.), PIGNAT (G.), RACHOUDSCHNEIDER (A.-M.) dir., Premiers Hommes dans les Alpes de 50000 à 5000 avant Jésus-Christ, Catalogue d'exposition Musée cantonal d'archéologie Sion, Lausanne, Payot, 2002, p. 69-86.

Vallis Poenina 1998: Vallis Poenina, le Valais à l'époque romaine, Catalogue de l'exposition, Sion, Musées cantonaux du Valais, 1998, 231 p.

Welten 1982: WELTEN (M.) - Vegetationgeschichtliche Untersuchungen in den westlichen Schweizer Alpen, BernWallis. Basel, Birkhäuser, 1982, 2 vol. (Denkschriften der Schweizerischen Naturforschenden Gesellschaft, 95).

Wiblé 1998: WIBLE (F.) - Cols et communications. In: Vallis Poenina, le Valais à l'époque romaine, Catalogue de l'exposition, Sion, Musées cantonaux du Valais, 1998, p. 75-82.

Wiblé 2000: WIBLE (F.) - Binn, chemin de l'Albrun. Vallesia LV, 2000, p. 611. 


\title{
Approche archéologique et environnementale des premiers peuplements alpins autour du col du Petit-Saint-Bernard (Savoie, vallée d'Aoste) : un bilan d'étape
}

\author{
Pierre-Jérôme ReY*, Cécile BATIGNe-VALLET**, Julien COLLOMBET***, \\ Claire DeLhon***, Lucie MARTIN****, Bernard MOULIN*****, Jérôme POULENARD*****, \\ Nicolas SCOCCIMARRO******, Dominique SORDOILLET*******, Stéphanie THIÉBAULT****, \\ Jean-Michel TREFFORT********
}

\begin{abstract}
Résumé. De 2003 à 2007, une étude archéologique et sédimentaire a été réalisée sur les versants du col du Petit-Saint-Bernard (2188 m, Alpes occidentales), par de grandes séries de sondages manuels effectués dans des contextes sélectionnés. Les avantages et les inconvénients de cette méthode sont exposés et discutés. Ce travail a permis d'identifier, interstratifiés dans les remplissages holocènes, des sols bruns fersiallitiques sur les versants et des sols hydromorphes en altitude. Les répartitions chronologique et altitudinale des découvertes archéologiques sont analysées, puis comparées à une compilation des connaissances préexistantes dans les vallées alpines du Beaufortin, de la Maurienne et de la Tarentaise. Les analyses paléo-environnementales et archéologiques en cours sont présentées.
\end{abstract}

Archaeological and environmental approaches to the first alpine settlements around the Petit-Saint-Bernard pass (Savoie - Aoste valley): first results

Abstract. An archaeological and sedimentary study was realized on the hillsides of the Petit-Saint-Bernard pass (2188 m, western Alps), from 2003 to 2007. It consisted of great series of manual boreholes in selected contexts. The efficiency of this method is discussed. This work allowed identifying brown fersiallitics soils in hillsides and hyrdromorphic soils in the heights, interstratified in the Holocene fillings. The chronological and altitudinal distributions of the findings are analysed and compared to previous data from Beaufortin, Maurienne and Tarentaise. An additional project of palaeo-environmental and archaeological analyses is presented.

\section{Introduction}

Dans le cadre du programme Interreg Alpis Graia coordonné par la Surintendance des Biens Archéologiques de la vallée d'Aoste et le Service Régional de l'Archéologie
Rhône-Alpes, les versants français et italien du col du Petit-Saint-Bernard ont fait l'objet entre 2003 et 2006 de plusieurs campagnes de prospections et sondages archéologiques, prolongées en 2007 par une opération programmée sur le seul versant français. Ce travail venait compléter, par

\footnotetext{
* Environnements, Dynamiques et Territoires de la Montle agne (EDYTEM), UMR 5204 CNRS - Université de Savoie, UFR CISM, campus scientifique, Bâtiment Belledones, 73376 Le Bourget-du-Lac cedex.

** Archéométrie et Archéologie. Origine, datations et technologies des matériaux, UMR 5138 CNRS - Université Claude Bernard - Université Lumière, Maison de l'Orient et de la Méditerranée - Jean Pouilloux, 7 rue Raulin, 69365 Lyon cedex 7.

*** INRAP Rhône-Alpes-Auvergne, Centre de Recherches Archéologiques de Bron, 12 rue Louis Maggiorni, 69500 Bron.

**** Archéozoologie, Archéobotanique. Sociétés, Pratiques et Environnements, UMR 7209 CNRS - Museum National d'Histoire Naturelle, 55 rue Buffon - CP 56, 75005 Paris et Institut de Préhistoire et des Sciences de l’Archéologie (IPSA), Université de Bâle, Spalenring 145, 4055 Bâle, Suisse. ***** Centre Alpin de Recherche sur les Réseaux Trophiques des Ecosystèmes Limniques (CARRTEL), UMR A42 INRA - Université de Savoie, Station d'hydrologie lacustre, 75 avenue de Corzent - BP 511, 74203 Thonon-les-Bains cedex.

****** École Pratique des Hautes Études (EPHE), 46 rue de Lille, 75007 Paris et Sapienza, Università di Roma, Piazzale Aldo Moro, 5, I00185 Roma (Italie).

******** INRAP Grand Est sud, Centre de Recherches Archéologiques de Besançon, 9 rue Lavoisier, 25000 Besançon.

******** INRAP Rhône-Alpes-Auvergne, Centre de Recherches Archéologiques de Bron, 12 rue Louis Maggiorni, 69500 Bron et Archéologie, Terre, Histoire, Sociétés (ARTeHIS), UMR 5594 CNRS - Université de Bourgogne - Ministère de la Culture et de la Communication, 6 boulevard Gabriel, 21000 Dijon.
} 


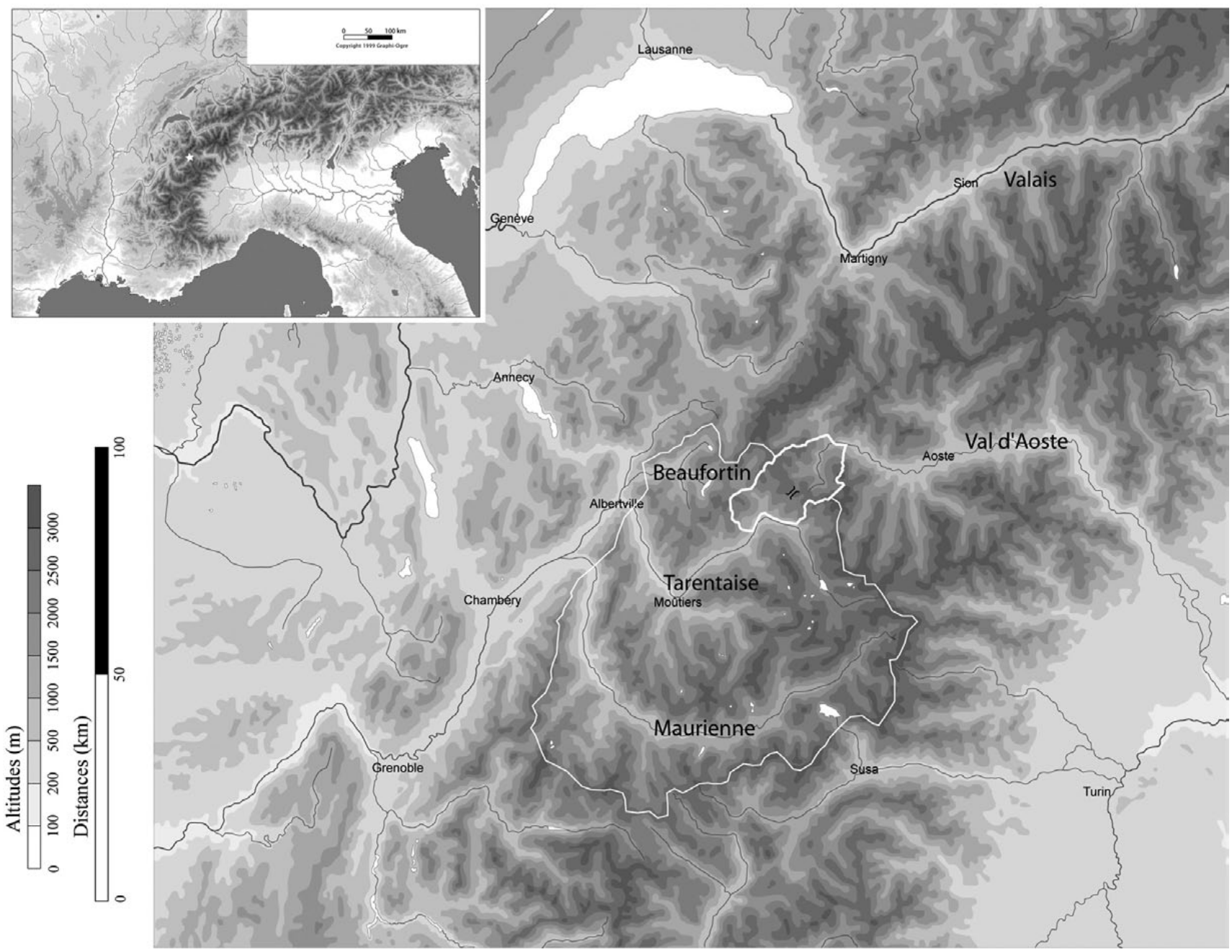

Fig. 1. Localisation du terrain étudié et de la zone de comparaison.

une vision à large échelle (fig. 1 et 2), les fouilles archéologiques et les études paléoenvironnementales entreprises sur le plateau du col par les équipes de A.-M. Cavallaro, A. Vanni Desideri, F. Mezzena, P. Leveau et J.-L. De Beaulieu (Collectif 2006). L'objectif était triple: documenter la dynamique des premières occupations humaines d'une microrégion de montagne en considérant toute la hauteur des versants, tenter d'approcher l'utilisation de ce col qui supporte l'un des grands axes historiques de franchissement du massif au sud du Mont-Blanc, et enfin préciser la dynamique pédo-sédimentaire holocène afin de mieux évaluer les conditions taphonomiques des niveaux archéologiques. Suite aux premiers comptes-rendus publiés dans les actes du colloque CTHS de Grenoble en 2006 (Rey, André, Treffort 2008) et de la table ronde du GDR Juralp en 2007 (Rey et al. 2008; Moulin, Rey 2008), cet article propose un nouveau bilan d'étape alors que les travaux de terrain sont achevés et la plupart des analyses toujours en cours. Même si nombre de datations ${ }^{14} \mathrm{C}$ ne sont pas encore disponibles, les données archéologiques font l'objet d'une nouvelle présentation synthétique et d'une première mise en perspective dans le contexte régional. Quelques séquences et sites représentatifs ont été choisis pour approfondir la compréhension de la relation société-milieu, dans une optique pluridisciplinaire centrée sur l'étude des sols holocènes enfouis, de l'évolution du couvert végétal et de l'économie des premiers peuplements.

\section{Cadre et méthode de recherche}

La zone de travail s'étend de la rive droite de l'Isère à la rive droite de la Doire Baltée, entre Bellentre et Montvalezan sur le versant français et Pré-Saint-Didier et Morgex sur le versant italien (fig. 1 et 2). Elle englobe l'intégralité des rampes d'accès au col ainsi que l'ensemble des versants voisins, de 800 à $3000 \mathrm{~m}$ d'altitude, afin de permettre une approche des systèmes agropastoraux basés sur des remues 
altitudinales. En dehors de l'établissement romain du col, les connaissances archéologiques préexistantes sont assez limitées. Il s'agit d'un poignard du Bronze ancien découvert au XIX ${ }^{\mathrm{e}}$ s. sur le chemin du col; d'un site de hauteur polyphasé occupé depuis le Néolithique au Châtelard de Bourg-Saint-Maurice, à la fois habitat et nécropole, fouillé dans les années 1970-80 mais resté mal publié; d'indices antiques à Bourg-Saint-Maurice, Seez et Pré-SaintDidier; et enfin de tombes antiques à Pont-Serrand et aux Chapelles. Ces données permettaient d'entrevoir un potentiel important, mais elles étaient insuffisantes pour orienter la conduite des recherches.

Dans des contextes très végétalisés, les prospections pédestres sont peu efficaces et documentent très imparfaitement les dépôts archéologiques, dont on ne retrouve ainsi qu'une fraction plus ou moins érodée.

Inspirée de certaines conclusions du programme PAVAC conduit en Valais dans les années 80 (Baudais et al. 1987), la méthode mise en œuvre autour du Petit-Saint-Bernard est basée sur la réalisation de grandes séries de sondages manuels, dont l'implantation a été déterminée préalablement par des repérages pédestres rapides, afin de sélectionner des contextes considérés comme favorables à l'occupation humaine et propices à la conservation des vestiges. Généralement, les sondages sont implantés en l'absence de tout vestige apparent, mais parfois sur des anomalies topographiques évoquant des terrassements ou des murs enfouis (fig. 2). Les secteurs plats ou ensellés et les points hauts ont été privilégiés, et abordés de manière quasi systématique sur les versants et le plateau du col, de manière plus extensive ailleurs en altitude. Les structures en pierre, sujet d'une opération distincte aux abords immédiats du col, ont été délibérément ignorées, à de rares exceptions près. Les grottes, abris sous roche et pieds de bloc rocheux sont rares et toujours de faible superficie. La réalisation des sondages s'est accompagnée de descriptions systématiques et normalisées des séquences sédimentaires. Ces observations permettent de développer une approche synthétique de la dynamique pédo-sédimentaire holocène. Grâce au concours d'une équipe bénévole particulièrement motivée, 688 sondages répartis dans 309 secteurs ont été réalisés de 2003 à 2007 (fig. 3). Un secteur correspond ici à un espace dépourvu d'accident topographique d'environ $200 \mathrm{~m}$ de diamètre.

\section{Approche de la dynamique pédo-sédimentaire holocène}

$\mathrm{Au}$ Petit-Saint-Bernard, les observations de terrain ont montré la fréquence des sols enfouis dans les dépôts sédimentaires, soulignant l'importance des pédogenèses pour la compréhension de la dynamique des versants durant
l'Holocène (Moulin, Rey 2008). Dans les Alpes suisses, lors des premières recherches sur les sites néolithiques et protohistoriques, la question des sols enfouis a attiré très tôt l'attention des chercheurs: dès les années 50, A. Jayet et M.-R. Sauter s'interrogent sur la nature des «terres rouges » valaisannes et proposent de les utiliser comme repère stratigraphique (Jayet, Sauter 1953). Depuis, l'étude des séquences pédo-sédimentaires est devenue véritablement à l'ordre du jour lors des travaux récents en milieu alpin et périalpin pour intégrer les sites archéologiques dans leur cadre environnemental (sites de Collombey/Barmaz, Guélat, Honegger, Rentzel 1995 ; Sierre/Creux-de-Chippis et Brig-Glis/Waldmatte en Valais, Guélat, Moulin, Rentzel 1998; Saint-Aubin/Derrière la Croix, Havlicek, Rolli, Becze-Deak 2003).

Trois séquences pédo-sédimentaires types ont été identifiées autour du Petit-Saint-Bernard. Seules les deux plus fréquentes sont ici décrites.

Sur les versants jusqu'à environ 1800 m d'altitude, des sols holocènes, de teinte brun-rouge à brun orangé (sols bruns fersiallitiques) (fig. 4 et 5 à gauche), sont tronqués et scellés par des séquences colluviales épaisses, contenant parfois des niveaux d'occupation. L'horizon d'altération de teinte brun rougeâtre se développe sur un substrat limono-sableux qui recouvre le sommet des dépôts morainiques ou fluvio-glaciaires. Cet horizon fortement coloré montre fréquemment un gradient d'intensité et de couleur sur quelques décimètres d'épaisseur. Il correspond à l'horizon d'oxydation du fer, particulièrement favorisée sur les matériaux drainant du substrat local, et de décarbonatation, lorsque ces sols se sont développés sur un substrat en partie carbonaté, ce qui est assez rarement le cas.

Ces pédogenèses de type fersiallitique n'ont pas fait l'objet, pour l'instant, de suffisamment de datations pour être bien calées chronologiquement. Toutefois les niveaux archéologiques apparaissent toujours au-dessus de l'horizon de pédogenèse. Des vestiges en place bien datés scellent ces sols dans quatre cas: le sondage Morgex Molliex 3, avec un foyer daté du Néolithique final, le site de Bellentre les Vignettes, où une fosse du Néolithique moyen s'implante sur un fin niveau de colluvions d'altérites surmontant le sol rubéfié, un empierrement daté de la fin du Bronze final 3 à Pré-Saint-Didier Pian del Bosco 6 et enfin une grande structure de combustion hallstattienne à La Thuile Grande Golette 1 .

La séquence sédimentaire antérieure à l'installation de cette pédogénèse, attribuable à la première moitié de l'Holocène, est toujours très peu épaisse. Après une troncature quasisystématique de ces sols, la dynamique sédimentaire se modifie nettement et se caractérise par des accumulations plus importantes. D'après les données disponibles, il est possible que la mise en place de ces colluvions soit à mettre en relation avec les activités humaines. 


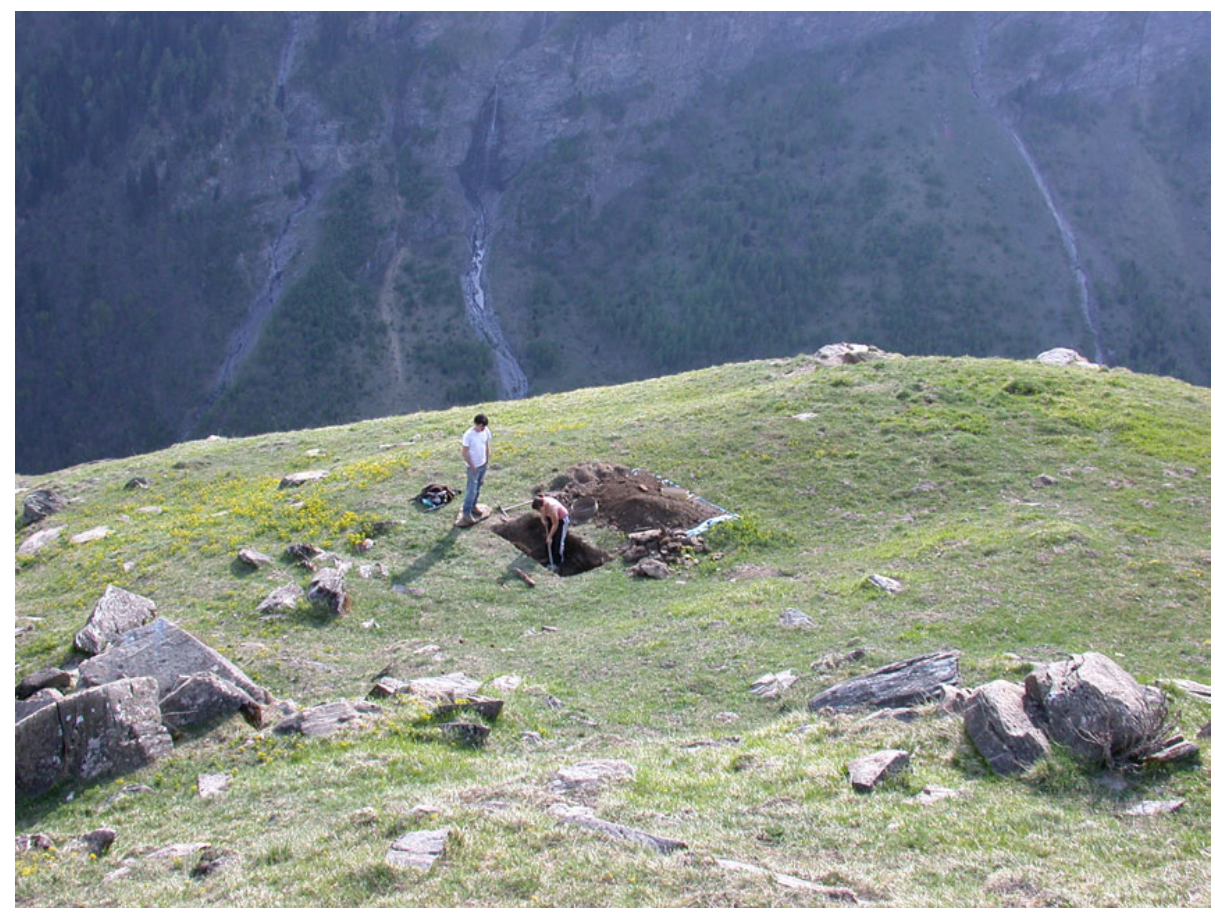

Fig. 2. Sondage sur une anomalie topographique sub-rectangulaire correspondant à une terrasse aménagée antique. Bourg-SaintMaurice, Versoye Créternas en 2006 (photo P.-J. Rey).

Au-delà de 1900 m, au-dessus de la limite actuelle des arbres, d'autres types de séquences pédo-sédimentaires sont très largement représentés (fig. 4 et 5 à droite); ce sont des séquences moins développées présentant généralement, sous l'humus actuel (horizon A0), un horizon gris clair, parfois même complètement blanchi (horizon E ou A2g - horizon albique). La présence d'un horizon d'accumulation de matière organique (horizon Bh-Bs) sous l'horizon blanchi n'est indiscutable que dans des cas assez rares (Seez les Gouillons). Les horizons inférieurs plus dilatés, de teinte rouille, passant graduellement de l'un à l'autre (horizons $\mathrm{BC}$ et $\mathrm{C}$; horizon placique), présentent d'assez fortes variations selon les profils. Ces sols sont à classer en majorité dans les sols hydromorphes, caractérisés par la réduction et la ségrégation locale du fer liées à une saturation des pores en eau, et plus particulièrement dans les sols hydromorphes de type stagnogleys ou stagnosols à horizon stagnique blanchi. Certains cas se caractérisent par une décoloration complète de 1'horizon $\mathrm{A} 2 \mathrm{~g}$ liée à une élimination complète du fer ( «albic stagnosols »), alors que les stagnogleys peu évolués plus fréquents présentent un horizon A2g généralement de teinte gris clair ou gris bleuté (fer ferreux), voire beige (coexistence du fer ferreux et du fer ferrique). Quelques cas assez rares (Seez les Gouillons), se rapprochent des podzols (podzols hydromorphes), combinant les processus de podzolisation et d'hydromorphie. Les séquences de stagnosols montrent parfois des récurrences (La Thuile Lac Verney 10, jusqu'à 5 niveaux gris superposés). Se posent alors, d'une part la question de la nature de ces récurrences (surimposition de phases de pédogenèse; interruption de la pédogenèse et une reprise d'une dynamique sédimentaire plus active liée au contexte local et/ ou climatique), d'autre part celle de l'âge de ces sols et de leur durée de formation et de fonctionnement. La position chronostratigraphique des vestiges archéologiques par rapport à ces horizons les place dans la seconde partie de l'Holocène. Les déstabilisations des versants, responsables de la mise en place de ces interstratifications, pourraient être en rapport avec le développement des activités pastorales, mais également avec la succession rapide de fluctuations glaciaires importantes et la tendance générale à l'avancée des fronts glaciaires, qui caractérisent la seconde moitié de l'Holocène dans notre zone d'étude (Orombelli 1998 ; Deline, Orombelli 2005).

\section{Les données archéologiques et leurs répartitions spatiale et chronologique}

Les résultats archéologiques sont très variés. Ils comprennent des habitats en contextes ouverts ou perchés et des structures artisanales dans les versants, ainsi que des habitats temporaires, des structures pastorales et des foyers en apparence isolés en altitude. La datation des occupations n'est cependant pas facile et repose fréquemment sur une seule date radiocarbone, car le mobilier est généralement rare et assez mal conservé. Trois séries céramiques importantes vont toutefois permettre de compléter le cadre chronoculturel pour le Bronze final au Châtelard de Bourg-Saint-Maurice, pour l'âge du Fer au Pian del Bosco 


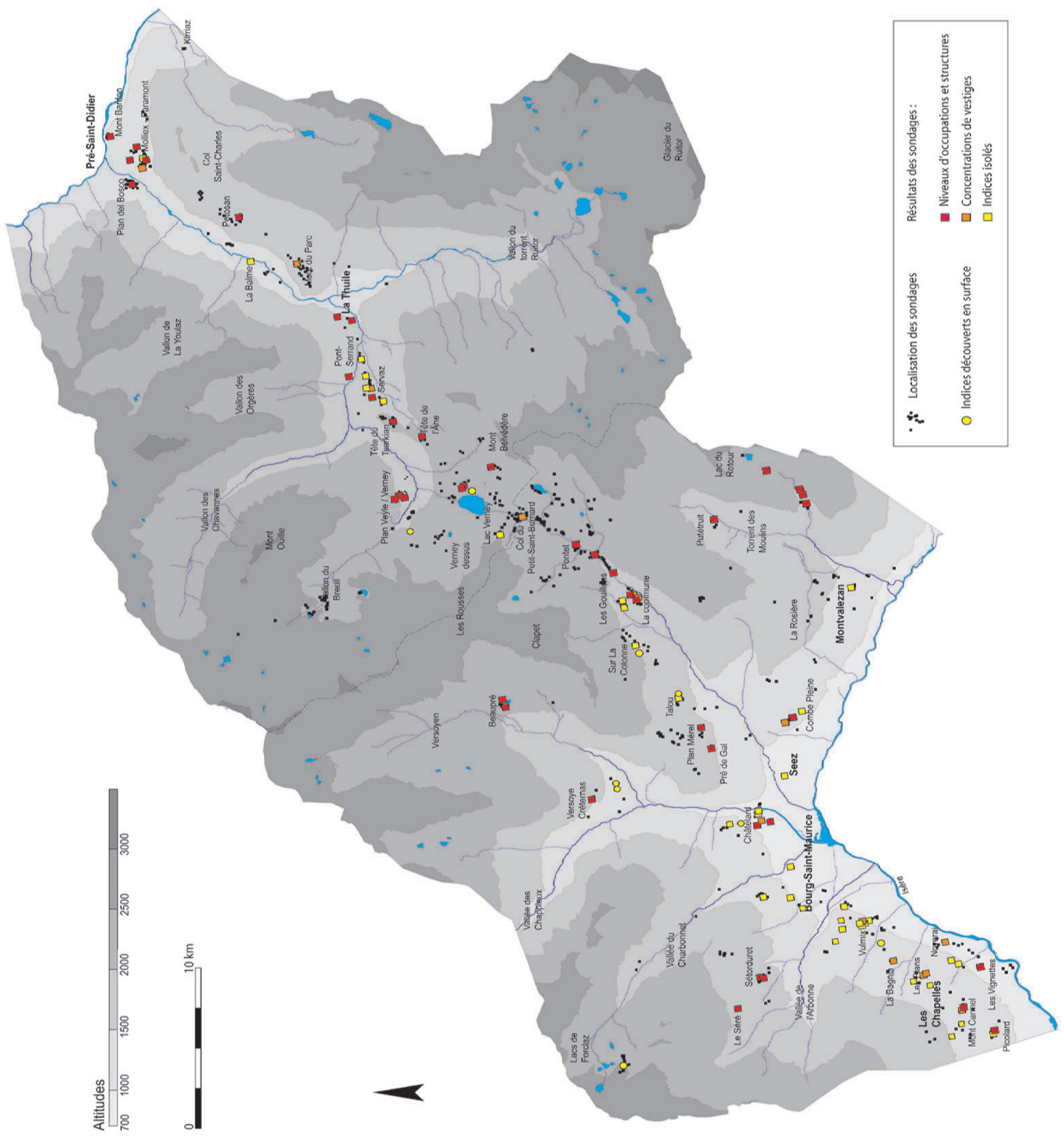

Fig. 3. Carte de la zone étudiée; implantation des sondages réalisés et principaux résultats archéologiques datés. 
(Pré-Saint-Didier) et pour l'Antiquité à Plan Veyle (La Thuile). La présentation détaillée de ces données est en cours de publication (Rey 2006; Rey, Moulin 2006; Rey et al. 2005 ; 2008 ; Rey, André, Treffort 2008; Rey, Treffort à paraître). La répartition des découvertes suit globalement celle des sondages qui se concentrent le long de l'itinéraire, dans les versants autour de Bourg-Saint-Maurice et dans quelques secteurs d'altitude (fig. 3). Seul le plateau du col et les pentes qui le dominent font exception: bien qu'intensément sondés, ils n'ont livré que quelques éléments épars liés à la proximité du site antique déjà connu. Différents contextes ont été abordés avec plus ou moins d'obstination (fig. 6). Les replats à flanc de versant sont nettement surreprésentés alors que les cônes torrentiels restent sous-documentés car ils sont souvent occupés par les constructions actuelles et restent inabordables par les moyens manuels mis en œuvre dans cette étude. Les secteurs les plus propices à la fossilisation des vestiges sont les ensellures. Parfois totalement comblées, en particulier le long des moraines latérales, leur détection impose une étude géomorphologique du paysage.

Devant la difficulté à définir précisément la notion de site archéologique, les données du Petit-Saint-Bernard ont été regroupées en trois catégories: niveaux d'occupation et structures (foyers, enclos, charbonnières...), concentrations d'indices en position secondaire témoignant d'un remaniement de faible ampleur, et éléments isolés.

De 2003 à 2007, 69 niveaux d'occupations et structures archéologiques, 20 concentrations de vestiges et 63 indices isolés ont été recensés (fig. 7). La densité des données en fonction de l'altitude présente des fluctuations marquées vraisemblablement dues à la topographie locale. Le nombre de découvertes demeure globalement élevé jusqu'à $2100 \mathrm{~m}$ d'altitude, avant de chuter brutalement. Le pourcentage de secteurs positifs (fig. 7 à gauche) baisse de manière importante au-delà de 900 m, puis se maintient remarquablement autour de $10 \%$ du total des secteurs sondés jusqu'à $2000 \mathrm{~m}$, avant de diminuer au-delà. Une petite augmentation de ce taux entre 1500 et 1600 m pourrait s'expliquer par la localisation de cette tranche d'altitude à l'interface entre les étages montagnard et subalpin, vraisemblablement dans une position cruciale pour le fonctionnement des systèmes de remues altitudinales.

Une première série de 39 datations ${ }^{14} \mathrm{C}$ par $\mathrm{AMS}$ a été réalisée pour préciser le calage chronologique de ces données. Les datations ont été réalisées essentiellement sur charbon, plus rarement sur des graines ou des os. Les restes botaniques ont été datés après détermination (S. Thiébault, L. Martin), ce qui a permis, dans la mesure du possible, de choisir les espèces à durée de vie courte et d'éviter les décalages liés l'effet de «vieux bois». Dans le cas où seules des essences à croissance lente sont disponibles, ce biais est connu et peut être pris en compte dans la discussion des séries chronologiques. Un seul résultat, incohérent avec la position stratigraphique de l'échantillon daté, a été écarté. Sur les 38 dates acceptées (fig. 8), un peu plus de la moitié (22) sont confortées par le mobilier archéologique associé ou par leur succession stratigraphique logique dans le cas des séries de plusieurs dates sur le même profil. La précision des fourchettes de datation reste cependant très variable car le mobilier archéologique, lorsqu'il est présent, n'est pas toujours très discriminant, et la courbe de calibration des dates radiocarbones est affectée de plusieurs plateaux qui nuisent à la précision des résultats durant la seconde moitié de l'Holocène. Une vingtaine d'autres dates sont en cours et une trentaine de datations supplémentaires paraissent encore nécessaires pour traiter l'ensemble des données recueillies. Les observations et les hypothèses présentées ici sont donc susceptibles d'évoluer.

Actuellement, 43 niveaux d'occupation et structures, 17 concentrations d'indices et 25 découvertes isolées sont datés de manière suffisamment précise pour pouvoir être rattachés au découpage chronologique de référence (fig. 9), qui est celui de la moyenne vallée du Rhône, fondé sur les travaux de P. Bintz, A. Beeching et J.-L. Voruz (Voruz 1995) du Tardiglaciaire au Néolithique, et de J. Vital (Vital 2002) pour les périodes protohistoriques.

Contrairement à d'autres régions des Alpes centrales, des Alpes du Sud et des massifs calcaires subalpins français, l'occupation de la région du Petit-Saint-Bernard n'est pas attestée avec certitude avant le Néolithique moyen. Par la suite, au-delà d'une tendance globale à l'accroissement, la répartition chronologique des données montre de nettes fluctuations dans le nombre de découvertes avec trois diminutions importantes au Bronze moyen, à La Tène et au BasEmpire (fig. 10).

L'examen de la répartition altitudinale des découvertes (fig. 9) apporte des informations complémentaires, même si le faible effectif des données pour chaque période considérée limite les interprétations. La dispersion verticale n'est pas aléatoire et montre plusieurs lacunes importantes. Du Néolithique moyen au Bronze moyen, les données collectées apparaissent en dessous de $1200 \mathrm{~m}$ et de 1800 à 2200 m, mais le Bronze moyen reste particulièrement mal représenté. Au Bronze final et au Hallstatt, toute la hauteur des versants paraît occupée jusque vers 2200-2300 m. Durant La Tène et le Haut-Empire, les sites ne dépassent pas 1600-1700 m. Cette grande rareté des données dans les hauteurs semble s'esquisser dès le Hallstatt et perdure vraisemblablement au Bas-Empire puisqu'un seul site a été documenté au-dessus de 1700 m (La Thuile Plan Veyle, $2001 \mathrm{~m}$, daté du $\mathrm{III}^{\mathrm{e}} \mathrm{s}$.). On remarquera qu'il s'agit d'un des rares cas d'architecture en terre et bois connus en altitude dans les Alpes françaises. Par ailleurs, la période de La Tène est particulièrement mal représentée en dessous 
de 1200 m d'altitude. Après le Bas-Empire, les données recueillies sont trop parcellaires pour être pertinentes, même si elles laissent entrevoir le maintien d'une présence entre 1600 et $1900 \mathrm{~m}$ au haut Moyen Âge.

Ces lacunes dans la dispersion chronologique et verticale des données ont déjà été discutées de manière détaillée dans une publication précédente (Rey et al. 2008), qui détaille quelques pistes d'interprétation.

\section{Confrontation au contexte archéologique régional}

En s'appuyant sur le grand nombre de sondages réalisés, le plus souvent sans indice préalable, et sur la documentation systématique des séquences observées, nous avons proposé de manière plus ou moins explicite dans des publications antérieures (Rey et al. 2008; Rey, André, Treffort 2008) de considérer ces fluctuations comme une première approche de la dynamique du peuplement. Toutefois, la représentativité du corpus de ces données est loin d'être assurée, ne serait-ce qu'à cause des disparités dans l'approche des différents contextes (fig. 8).

Afin de tester l'efficacité de la méthode employée et de discuter la signification des données recueillies, nous avons choisi de confronter les résultats archéologiques du PetitSaint-Bernard à un bilan des données préexistantes pour les trois vallées savoyardes du Beaufortin, de Maurienne et de Tarentaise, en s'intéressant à la fréquence des découvertes par grande période chronologique. Les données sont issues d'ouvrages publiés (principalement Combier 1972; Willigens 1991; Rémy, Ballet, Furber 1996; Ozanne, Vital 1999), de travaux universitaires (Collombet 2007 ; Rey 1999), et incluent quelques fouilles et découvertes récentes mentionnées dans les Bilans Scientifiques annuels du SRA Rhône-Alpes. L'inventaire a été réalisé par N. Scoccimarro pour l'Antiquité, J. Collombet pour l'âge du Fer, J.-M. Treffort pour le Bronze et P.-J. Rey pour le Néolithique. Il s'agit essentiellement de découvertes fortuites, fouillées anciennement et datées par une analyse typo-chronologique du mobilier. Les contextes stratigraphiques solides et les datations radiocarbones sont rares. Les données ont été classées en utilisant les mêmes catégories qu'au Petit-Saint-Bernard. Les découvertes de monnaies isolées n'ont pas été prises en compte car, trop souvent issues de prospections au détecteur à métaux, elles auraient faussé la comparaison avec les données des périodes pré- et protohistoriques.

En raison du faible nombre de sites pour chaque période chronologique la comparaison entre les deux séries de données ne peut se faire qu'en terme de tendance.

La question de la représentativité des autres découvertes isolées mérite d'être examinée. Au Petit-Saint-Bernard, leur prise en compte ne fait que renforcer les tendances présentées par les autres données (niveaux d'occupation, structures et concentrations d'indices), avec une petite mise en valeur du Néolithique final. Pour les vallées savoyardes le constat est globalement comparable, avec un renforcement plus net du Néolithique final ainsi qu'une meilleure visibilité à La Tène.

La confrontation par périodes chronologiques des résultats du Petit-Saint-Bernard et des données des vallées savoyardes (fig. 10) permet d'observer des tendances très comparables dans les variations du nombre de découvertes, excepté au Bronze ancien et au Hallstatt. Pour ces deux périodes le nombre de données se maintient à un niveau élevé aux abords du Petit-Saint-Bernard alors qu'il décroît nettement en Beaufortin, en Maurienne et en Tarentaise. L'interprétation de ce constat reste délicate. Deux hypothèses principales non exclusives peuvent être formulées:

- La méthode employée au Petit-Saint-Bernard permet d'obtenir un corpus d'occupations plus représentatif. La découverte d'habitats hallstattiens de versant en contexte ouvert semble aller dans ce sens. Le caractère moins accidenté de la courbe des résultats au Petit-Saint-Bernard pourrait constituer un autre argument.

- Il existe une spécificité de la région du Petit-SaintBernard durant ces deux périodes. On sait déjà qu'elles correspondent à deux phases d'occupation importante des sites perchés (Rey et al. 2008; Rey, Treffort à paraître). Cependant, les données du Bronze ancien proviennent exclusivement du versant occidental du col, alors que les données du Hallstatt se répartissent sur les deux versants. Pour le Bronze ancien, le contrôle de l'accès aux ressources minérales du versant occidental (cuivre) pourrait être plus important que la surveillance de l'itinéraire transalpin pour expliquer la répartition et la typologie des occupations. Au Hallstatt, le contrôle des circulations intervient vraisemblablement davantage, mais l'absence de données sur l'exploitation de l'importante source salée de l'Arbonne à Bourg-Saint-Maurice handicape notre raisonnement.

L'état des connaissances actuelles ne permet vraisemblablement pas de réponse tranchée, mais il sera peut-être possible de progresser en caractérisant plus finement les données disponibles selon le contexte topographique et le caractère défensif ou non des implantations. La forte proportion des sites de hauteur des âges des Métaux autour du Petit-Saint-Bernard a déjà été soulignée (Rey et al. 2008), et mériterait d'être réévaluée par rapport à la situation en Beaufortin-Maurienne-Tarentaise.

La prise en compte de la courbe des sites funéraires montre pendant La Tène une remarquable discordance avec les séries de données précédentes pendant la période de La Tène. Cette période est marquée par une opposition entre le grand nombre de nécropoles connues dans les vallées savoyardes et la rareté générale des habitats. Sur cette 


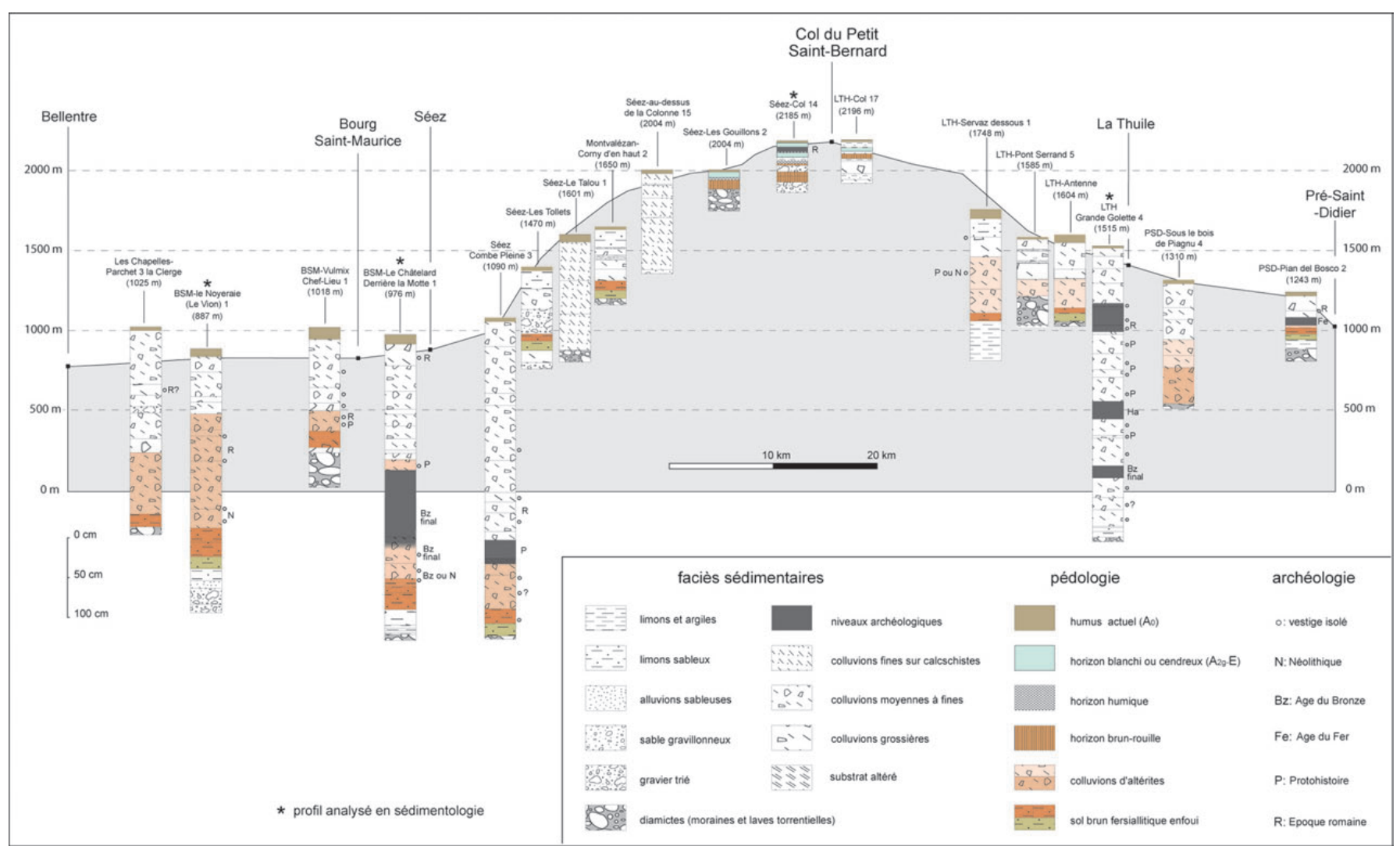

Fig. 4. Profil transversal du col du Petit-Saint-Bernard et sélection de séquences pédo-sédimentaires représentatives (DAO B. Moulin).
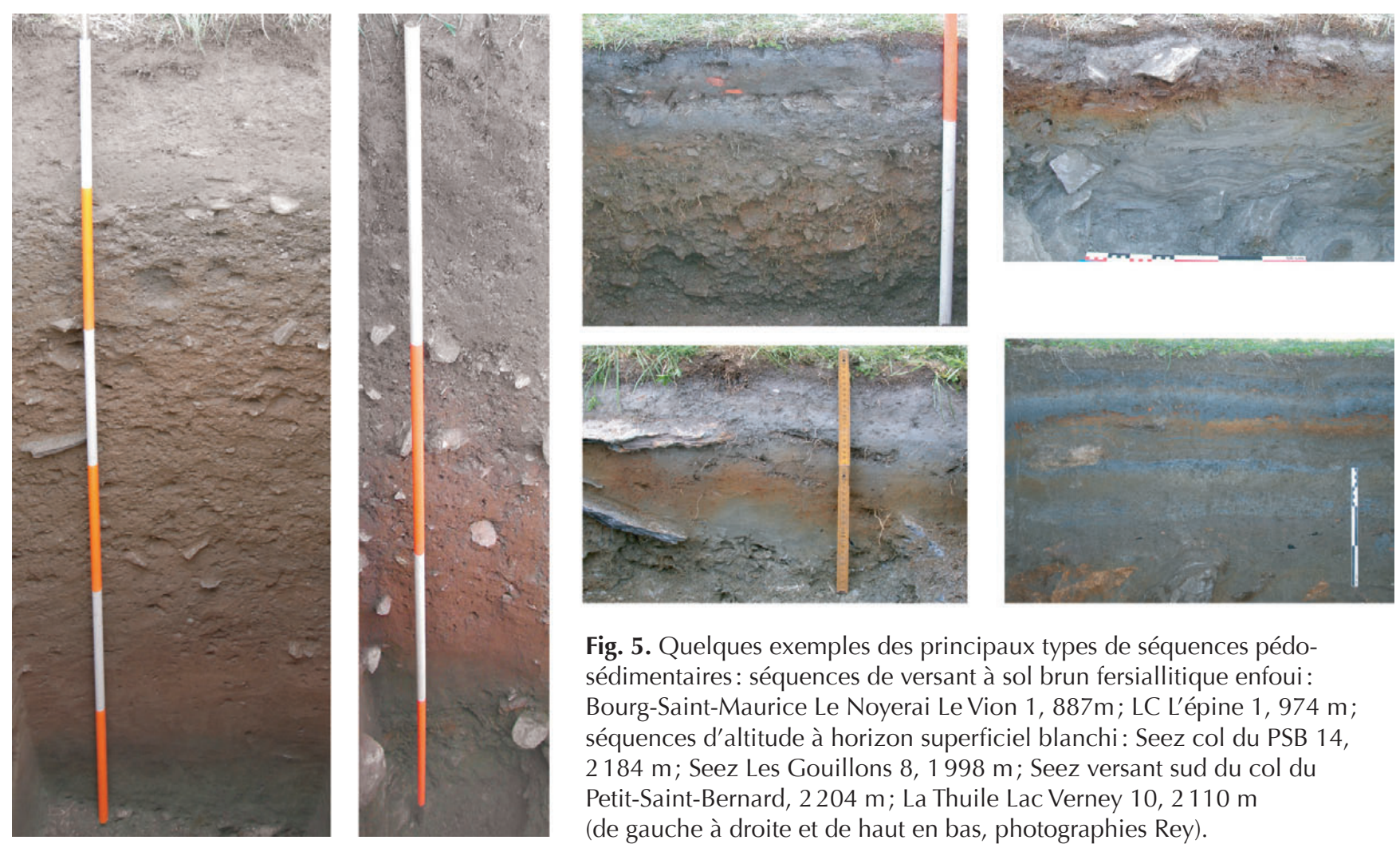

Fig. 5. Quelques exemples des principaux types de séquences pédosédimentaires: séquences de versant à sol brun fersiallitique enfoui : Bourg-Saint-Maurice Le Noyerai Le Vion 1, 887m; LC L'épine 1, 974 m; séquences d'altitude à horizon superficiel blanchi : Seez col du PSB 14, 2184 m; Seez Les Gouillons 8, 1998 m; Seez versant sud du col du Petit-Saint-Bernard, 2204 m; La Thuile Lac Verney 10, 2110 m (de gauche à droite et de haut en bas, photographies Rey). 


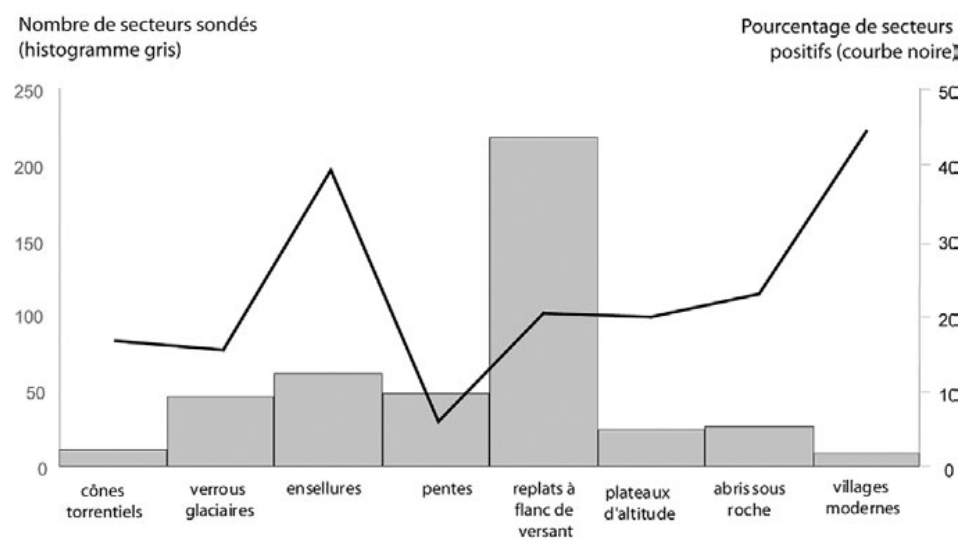

Fig. 6. Répartition des secteurs sondés selon les principaux types de contextes rencontrés; fréquence des secteurs positifs selon ces mêmes contextes.

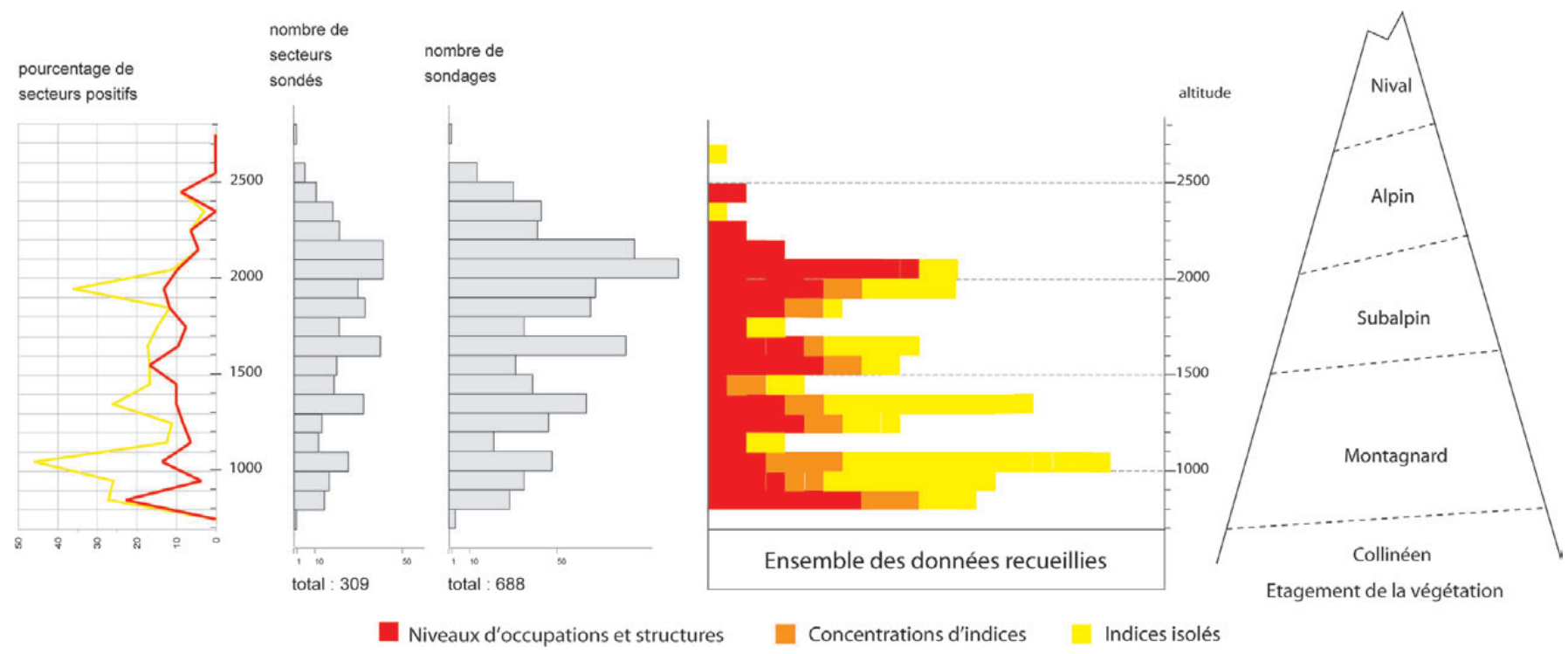

Fig. 7. Dispersion altitudinale de la totalité des résultats archéologiques confrontée à la répartition des sondages réalisés.

À gauche: fréquence des secteurs positifs en fonction de l'altitude.

question, la méthode mise en œuvre au Petit-Saint-Bernard n'aura permis aucun progrès par rapport à l'état des connaissances. Un constat identique peut être avancé pour le Bronze moyen. En revanche, la moindre abondance des données du Bas-Empire dans les vallées alpines s'explique plus facilement par la rareté des interventions archéologiques en contexte urbain et par la faible publication des séries céramiques antiques issues des fouilles anciennes.

\section{Travaux en cours et perspectives}

Les travaux de terrain ont permis de constituer une importante base documentaire archéologique et sédimentologique. Pour exploiter pleinement ce potentiel, un programme multidisciplinaire a été mis en place autour de l'analyse des sols enfouis, de l'évolution du couvert végétal et de l'économie des premiers peuplements.
Une sélection de sondages ayant fourni des paléosols a été ré-échantillonnée en vue de nouvelles datations et d'études multiproxies. Huit profils ont déjà fait l'objet d'analyses chimiques et sédimentologiques (Moulin, Rey 2008). Afin de mieux caractériser les épisodes de pédogenèses et d'en comprendre les évolutions, il est nécessaire de généraliser les analyses géochimiques poussées (J. Poulenard) et de s'intéresser à l'organisation de ces sols à l'échelle microscopique (D. Sordoillet et B. Chazerand) au moyen d'analyses micromorphologiques (Chazerand 2009). Une nouvelle série de datations est prévue sur les sols bruns fersiallitiques, qui sont les seuls qui se prêtent à des dates directes. Notre attention se porte également actuellement sur deux cas de sols «noirs» (Bourg-Saint-Maurice Le Replatet et Les Chapelles Picolard), mis au jour entre 1000 et 1300 m d'altitude, qui ne correspondent à aucun des types décrits ci-dessus, et qui pourraient s'apparenter à des sols brun-noir isohumiques. Ces formations vont faire 


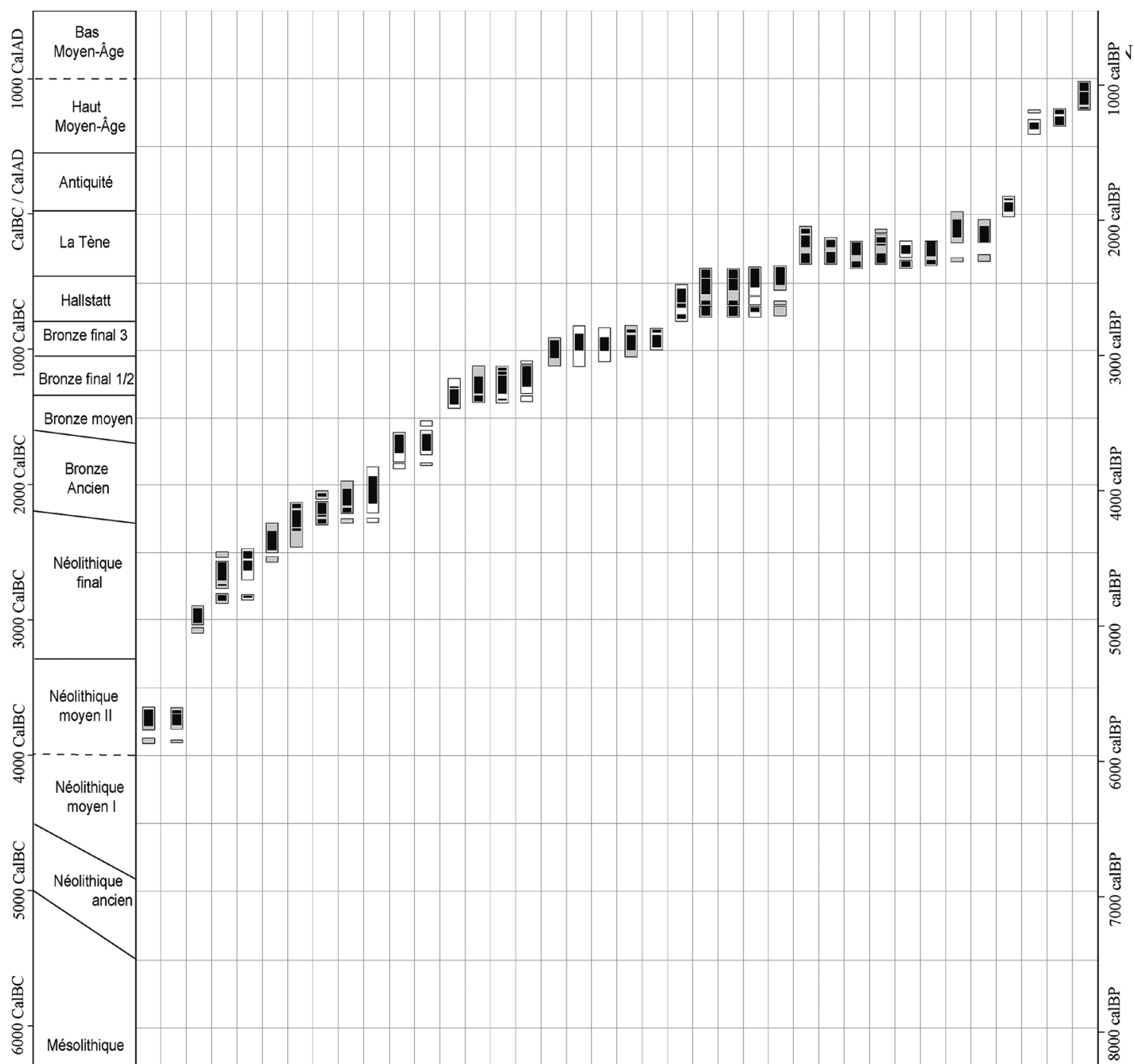

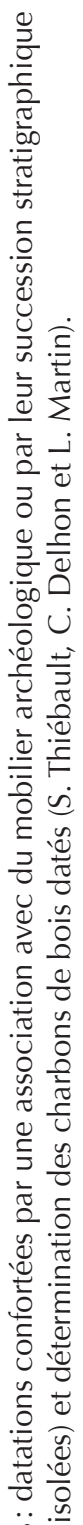

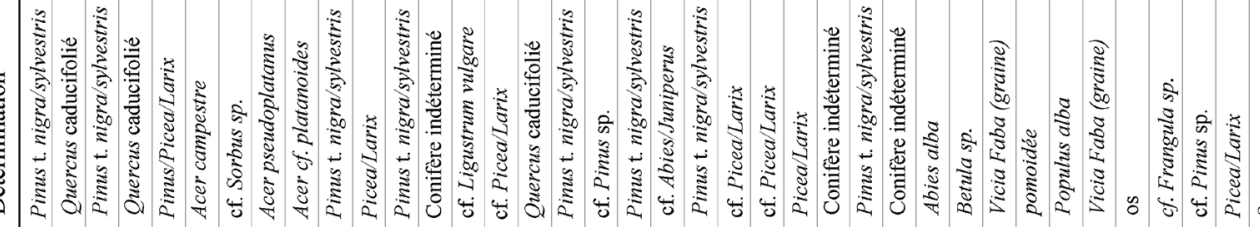

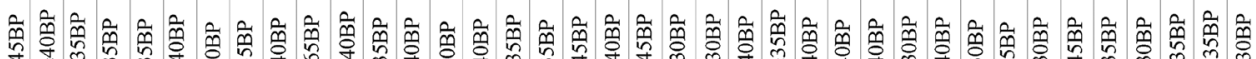

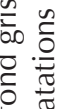

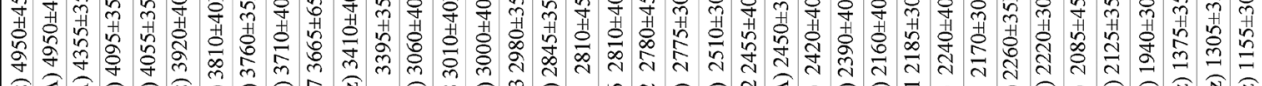

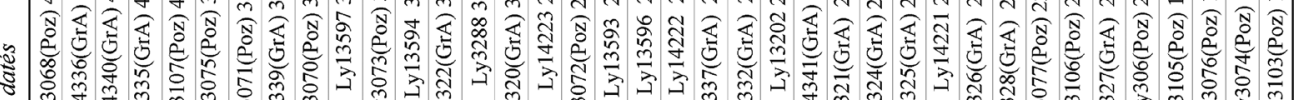

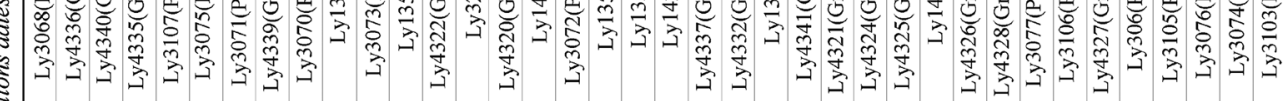

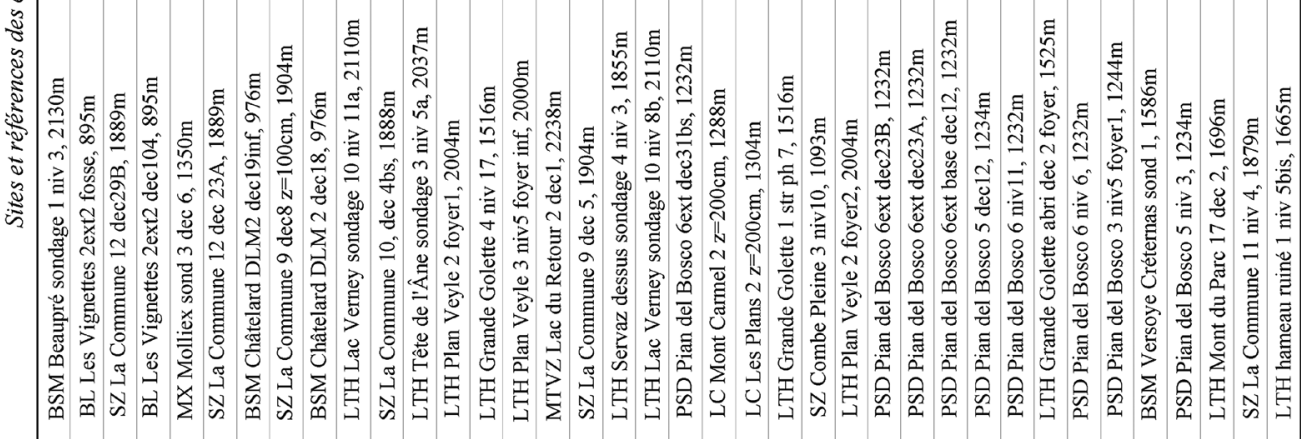

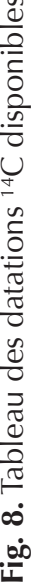


l'objet de datations et d'une batterie d'analyses pédologiques et paléobotaniques. En moyenne vallée du Rhône, ce type de sol s'étend sur de grandes superficies au cours du Néolithique moyen, dans un contexte d'exploitation agrosylvo-pastorale de la plaine alluviale (Delhon, Thiébaut, Berger 2008).

Les sols enfouis renferment en effet fréquemment des témoins de la végétation qui a contribué à leur développement. Les analyses pédo-anthracologiques permettront de documenter le paysage végétal et ses évolutions, liées aux conditions environnementales et aux activités humaines. Les spectres phytolithiques sont pour leur part les témoins privilégiés de la végétation herbacée, et l'un des paramètres documentant les conditions des pédogenèses.

Les analyses archéoenvironnementales des structures archéologiques vont également être généralisées. En l'absence de faune conservée, c'est l'environnement végétal qui est le mieux documenté. Les niveaux d'occupation et les structures de combustion ont été systématiquement prélevés (fig. 11) pour des analyses anthracologiques, carpologiques et phytolitiques offrant ainsi une large sélection d'échantillons dans des contextes topographiques, altitudinaux et chronologiques très variés. Ainsi, nous pourrons approcher l'économie du bois de feu et la gestion des ressources ligneuses, notamment à l'âge du Bronze entre 1900 et $2200 \mathrm{~m}$ d'altitude, c'est-à-dire au-dessus de la limite supérieure de la forêt. Par ailleurs les sites de l'âge du Fer du Pian del Bosco à Pré-Saint-Didier et de l'abri de Grande Golette à la Thuile ont livré de nombreux grains carbonisés de céréales et de légumineuses, ayant déjà fait l'objet d'une publication préliminaire (Martin, Thiébault 2007).

Le croisement des données « hors site » issues des séquences pédo-sédimentaires et des données intra-site permet de mieux comprendre la part des composantes naturelles (climatiques et liées à la dynamique des populations végétales) et anthropiques des forçages présidant à l'évolution du couvert végétal. Cette connaissance de l'environnement des premiers peuplements sera une donnée supplémentaire pour l'interprétation de la répartition spatiale et chronologique des occupations.

\section{Conclusion}

Après une phase de terrain lourde, les études archéologiques et paléoenvironnementales autour du Petit-SaintBernard rentrent maintenant dans une phase d'analyse. À ce stade, et alors que de nombreux résultats sont encore attendus, il était intéressant de faire un point sur la méthode employée, originale dans sa mise en œuvre plus que dans son principe, de proposer une première synthèse des données et d'en évaluer la signification par l'examen de quelques indicateurs chiffrés et par une confrontation au contexte régional. Les deux approches différentes de la dynamique du peuplement (réalisation de grandes séries de sondages manuels dans une microrégion centrée sur la ligne de crête et compilation des découvertes anciennes à l'échelle des vallées alpines nord-occidentales) montrent des évolutions souvent semblables de la fréquence des sites par période. La microrégion du Petit-Saint-Bernard, se singularise cependant par une nette surreprésentation des données pendant deux périodes: le Bronze ancien et le Hallstatt. La méthode d'acquisition des données employée apporte-t-elle un gain d'efficacité dans ces deux cas spécifiquement ? Ou avons-nous mis en évidence une spécificité de la région du Petit-Saint-Bernard, peut-être en partie liée aux circulations ? Il s'agirait alors d'un premier indice pour la compréhension de l'utilisation passée du col qui reste pour le moment assez difficile à atteindre (Rey et al. 2008). Seule une comparaison fine des contextes occupés, impliquant la datation de l'ensemble des données recueillies, sera peut-être en mesure de faire avancer ces interrogations. Concernant la dynamique pédo-sédimentaire, deux grands types de sols enfouis ont été identifiés. Nos travaux confirment l'extension alpine occidentale des sols bruns fersiallitiques et fournissent de premiers éléments de chronologie. En altitude des séquences à sols hydromorphes à horizon superficiel blanchi enregistrent des histoires complexes pour la seconde partie de l'Holocène, mais dont la chronologie nous échappe encore en grande partie, faute d'éléments de datation. Dynamiques du peuplement et dynamiques sédimentaires sont vraisemblablement intimement liées, les interactions hommes-milieux jouant un rôle clé dans la dynamique de versant et dans la troncature et l'enfouissement des sols. L'affinement de la corrélation chronologique des données archéologiques et environnementales sera une étape cruciale pour la compréhension du système.

\section{Remerciements}

Il convient de souligner que le développement du programme est largement redevable au soutien de la Maison de l'Intercommunalité de Haute-Tarentaise, de la Surintendance des Biens archéologiques de la Vallée d'Aoste, du SRA RhôneAlpes, du GDR Juralp et de nombreux acteurs locaux. Nous remercions les nombreux participants bénévoles, ainsi que Julien Boisson, Jimmy Linton et Mathilde Minotti qui ont assuré l'encadrement des campagnes de prospections pendant les deux premières années du projet.

\section{Bibliographie}

Baudais et al. 1987 : BAUDAIS (D.), CURDY (P.), DAVIDELBIALI (M.), MAY (O.) - Prospection Archéologique $\mathrm{du}$ Valais; une approche du peuplement préhistorique. Archéologie Suisse, 10, (1), 1987, p. 2-12. 

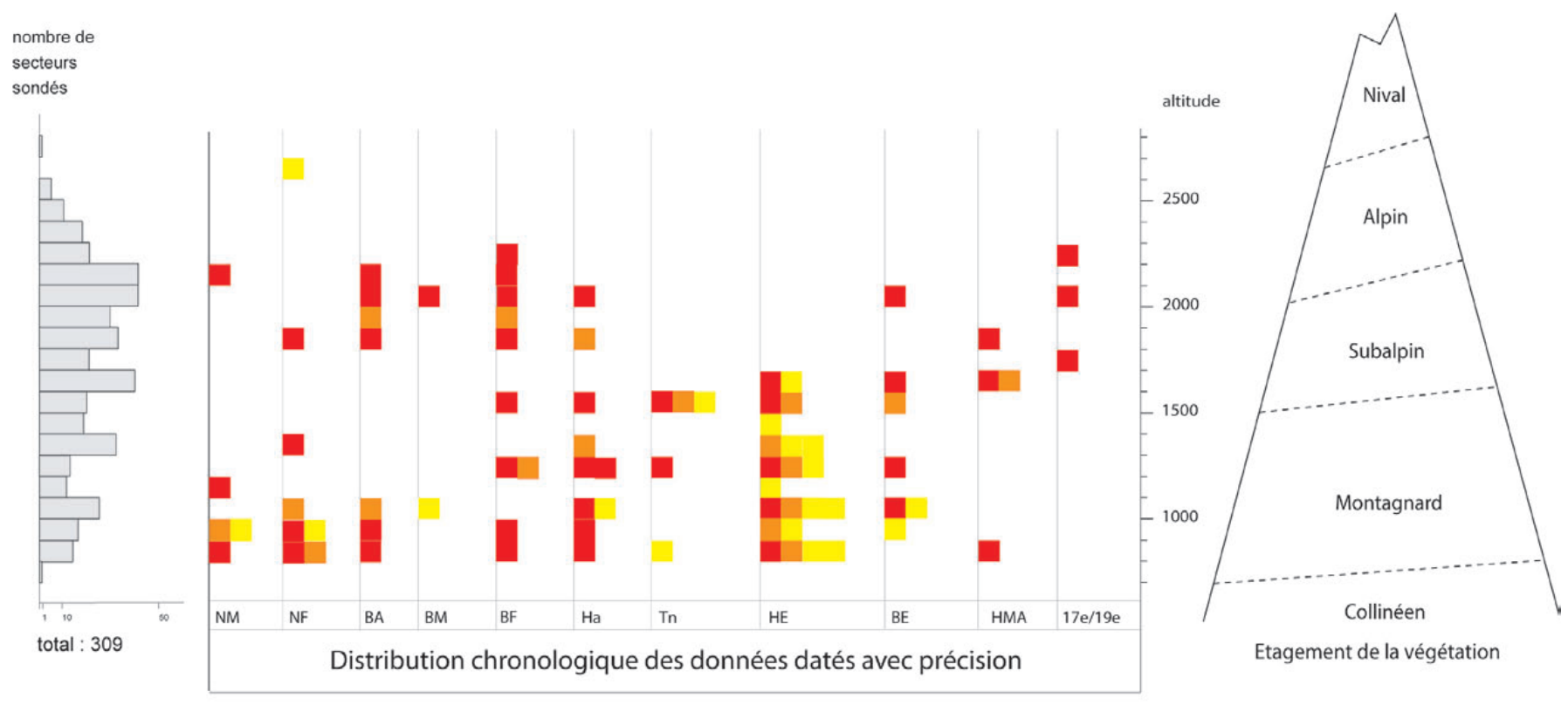

Niveaux d'occupations et structures

Concentrations d'indices

Indices isolés

Fig. 9. Répartition altitudinale et chronologique des données archéologiques datées.

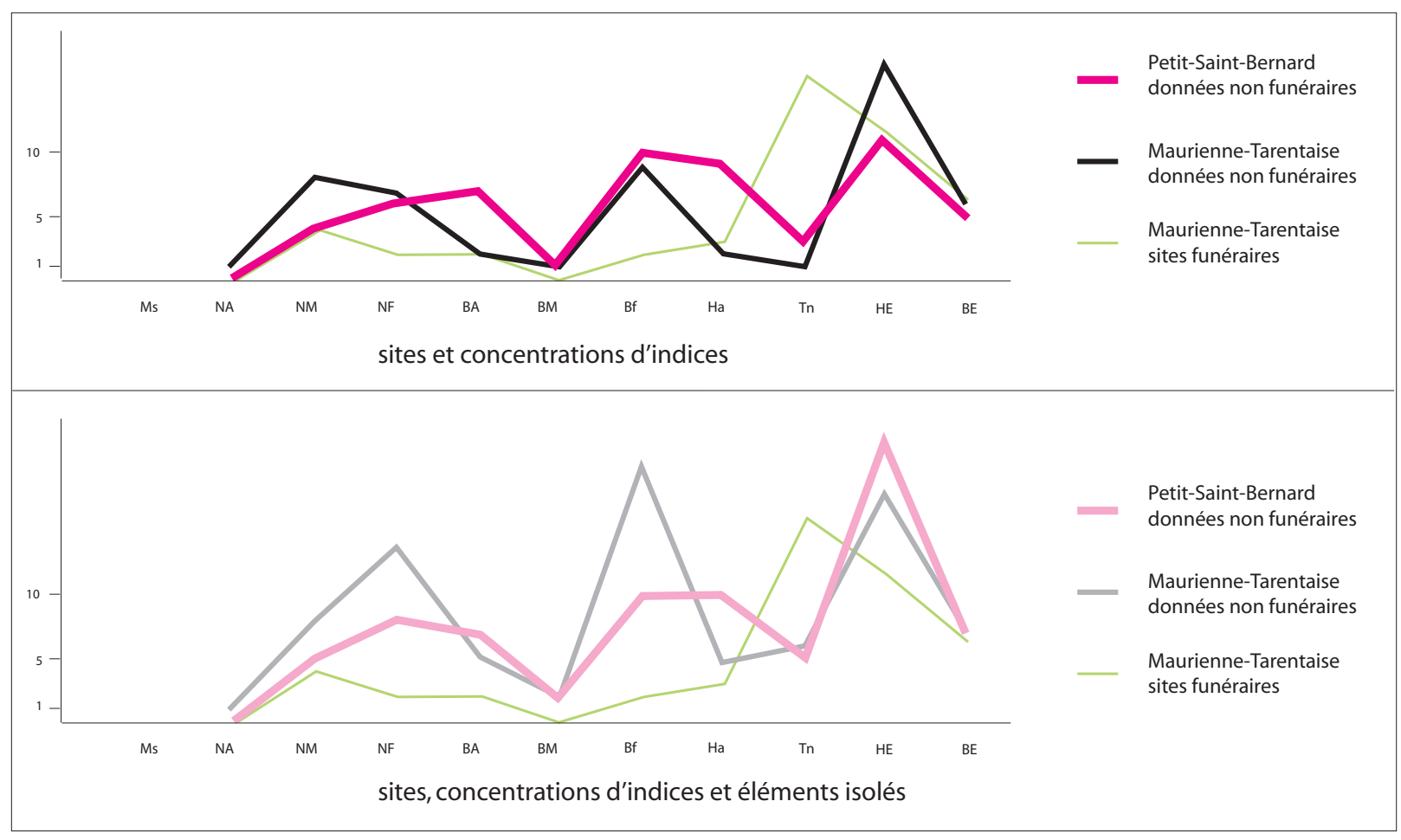

Fig. 10. Confrontation chronologique des résultats du Petit-Saint-Bernard avec la compilation des données archéologiques disponibles en Beaufortin, Maurienne et Tarentaise. 


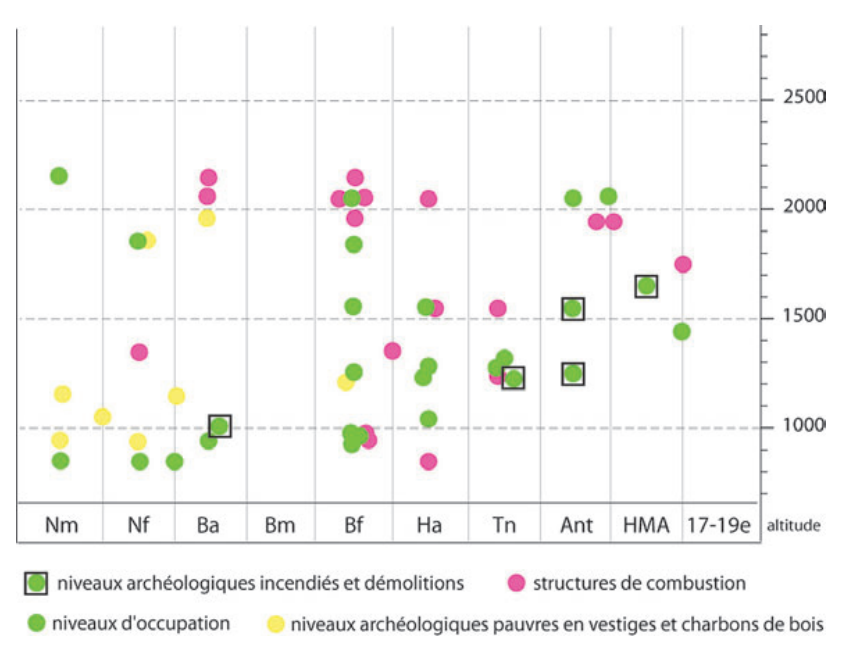

Fig. 11. Répartition altitudinale et chronologique des contextes archéologiques échantillonnés pour les analyses paléobotaniques.

Chazerand 2009: CHAZERAND (B.) - Micromorphologie d'une séquence pédo-sédimentaire en contexte archéologique. TER de Master 1 Géologie appliquée (option recherche), direction V. Bichet et D. Sordoillet. Université de FrancheComté, Besançon, 2009, 40 p. et 23 annexes.

Collectif 2006: COLLECTIF - Alpis Graia Archéologie sans frontières autour $d u$ col du Petit-Saint-Bernard, projet Interreg IIIA, seminario di chiusura Aoste 2-4 mars 2006. Aoste, Musumeci S.p.A. ed., 2006, 400 p.

Collombet 2007 : COLLOMBET (J.) - Entre Rhône et Pô, l'Âge $d u$ Fer des vallées alpines de Maurienne, de Tarentaise, du Val de Suse et du Val d'Aoste. Mémoire de Master 2 sous la direction de D. Garcia. Université de Provence - AixMarseille I, 2007, 341 p., 156 fig., 13 cartes.

Combier 1972: COMBIER (J.) - Bronze en Savoie en dehors des stations palafittiques. Albertville, publication du Centre de Documentation Régionale de Tarentaise, Académie de la Val d'Isère, Amis du Vieux Conflans, Imprimerie Gaillard à Saint-Alban-Leysse, 1972.

Delhon, Thiébault, Berger 2009: DELHON (C.), THIÉBAULT (S.), BERGER (J.-F.) - Environment and landscape management during the Middle Neolithic in Southern France: Evidence for agro-sylvo-pastoral systems in the Middle Rhone Valley. Quaternary International, Volume 200, Issues $1-2,2009$, p. $50-65$.

Deline, Orombelli 2005: DELINE (P.), OROMBELLI (G.) Glacier fluctuations in the western Alps during the Neoglacial, as indicated by the Miage morainic amphitheatre (Mont Blanc massif, Italy). Boreas, 34 (4), 2005, p. 456-467.

Guelat, Honegger, Rentzel 1995 : GUELAT (M.), HONEGGER (M.), RENTZEL (P.) - Nouvelles données sur la stratigraphie du site de Barmaz I (Collombey-Muraz VS). Analyse micromorphologique, confrontée à l'approche archéologique. Annuaire de la Société Suisse de Préhistoire et d'Archéologie, 78, 1995, p. 131-144.

Guelat, Moulin, Rentzel 1998: GUELAT (M.), MOULIN (B.), RENTZEL (P.) - Des sols enfouis dans les séquences de versant du Valais (Suisse). Caractérisation, durée des phases de pédogenèse et signification pour la chronologie régionale de l'Holocène. Actes du VIII ${ }^{\mathrm{e}}$ Colloque International sur les Alpes dans l'Antiquité, Sion, 26-28 sept. 1997. Bulletin d'Études Préhistoriques et Archéologiques Alpines, 9, 1998, p. $39-52$.

Havlicek, Rolli, Becze-Deak 2003: HAVLICEK (E.), ROLLI (M.), BECZE-DEAK (J.) - Étude paléo-environnementale. In: WÜTHRICH (S.) éd., Saint-Aubin/Derrière la Croix. Un complexe mégalithique durant le Néolithique moyen et final, Neuchâtel, Service et Musée cantonal d'Archéologie. Archéologie neuchâteloise, 29, 2003, p. 113-181.

Jayet, Sauter 1953: JAYET (A.), SAUTER (M.-R.) - Observations géologiques et archéologiques récentes sur les terres rouges. Bulletin de l'Institut national genevois, 56, 1953, p. 151-166.

Martin, Thiébault 2007: MARTIN (L.), THIÉBAULT (S.) avec coll. REY (P.-J.) - Production et consommation végétale durant la Préhistoire récente: étude archéobotanique de quelques sites des Alpes occidentales. In: BÖETSCH (G.), HUBERT (A.) éd., L'alimentation en montagne. Actes des IX Universités d'été Anthropologie des populations alpines, Vallouise 3-9 juillet 2006. Collection Anthropologie des populations alpines, 2007, p. 12-24.

Moulin, Rey 2008: MOULIN (B.), REY (P.-J.) - Les séquences pédo-sédimentaires des versants du col du Petit-SaintBernard. In : MAGNY (M.), DESMET (M.), MOCCI (F.) éd., Actes de la table ronde du GDR JURALP, Aix-en-Provence novembre 2007. Collection Edytem, $\mathrm{n}^{\circ}$ 6, Cahiers de Paléoenvironnement, 2008, p. 191-206.

Orombelli 1998: OROMBELLI (G.) - Le torbe del Ruitor: una successione significativa per la storia olocenica dei ghiacciai e del clima nelle Alpi. In: GHELARDONI (P.) ed., Studi in onore di Mario Pinna. I Il clima e la storia del clima, Roma, Società Geografica Italiana (Memorie della Società geografica italiana, LV), 1998, p. 153-165.

Ozanne, Vital 1999: OZANNE (J.-C.), VITAL (J.) - Documents pour servir à l'identification des relations transalpines occidentales dans la seconde moitié de l'Âge du Bronze. In: BEECHING (A.) dir., Circulations et identités culturelles alpines à la fin de la Préhistoire. Matériaux pour une étude. Programme CIRCALP 1997-1998. Travaux du CAP Valence $\mathrm{n}^{\circ} 2,1999$, p. 519-553.

Remy, Ballet, Ferber 1996: REMY (B.), BALLET (F.), FERBER (E.) - La Savoie 73. PROVOST (M.) dir., Carte Archéologique de la Gaule; pré-inventaire archéologique. 
Paris, Fondation Maison des Sciences de l'Homme, 1996, 248 p.

Rey 1999: REY (P.-J.) - L'occupation de la Savoie au néolithique; état des connaissances. Mémoire de maîtrise, Université de Savoie, direction F. Bertrandy et tutorat F. Ballet, 1999, 1147 p., 259 pl., 4 cartes.

Rey 2006 : REY (P.-J.) - Fortifications des accès du col et guerres modernes: présentation de quelques éléments découverts en sondage. In: DUFOUR (N.), PALUMBO (P.), VANNI DESIDERI (A.) dir., Le système de défense du col du PetitSaint-Bernard entre XVII et $X X^{e}$ s. Projet Interreg IIIA, Alpis Graia Archéologie sans frontières autour du col du PetitSaint-Bernard. Arti Grafiche Duc Imp., Saint-Christophe (AO), 2006, p. 103-119.

Rey et al. 2005 : REY (P.-J.), MOULIN (B.) avec coll. ANDRÉ (I.), BOISSON (J.), LINTON (J.), MINOTTI (M.), QUENARD (S.) - Occupations et circulations pré-romaines autour du Col du Petit-Saint-Bernard; méthode et premiers résultats d'une étude archéologique et sédimentaire de la montagne alpine. In: Échanges et voyages en Savoie. Actes du Congrès des Sociétés Savantes de Savoie, Saint-Jeande-Maurienne, septembre 2004. Bull. SHAM t. XXXVIIIXXXIX / L'histoire en Savoie, $\mathrm{n}^{\circ}$ 11, 2005, p. 17-39.

Rey et al. 2008: REY (P.-J.), TREFFORT (J.-M.), MOULIN (B.), OBERLIN (C.), ANDRÉ (I.) - Archéologie des versants du Petit-Saint-Bernard; première approche de la dynamique de l'occupation humaine autour d'un grand passage alpin, de la Préhistoire au début du Moyen Âge. In: MAGNY (M.), DESMET (M.), MOCCI (F.) éd., Actes de la table ronde du GDR JURALP, Aix-en-Provence novembre 2007. Collection Edytem, $\mathrm{n}^{\circ}$ 6, Cahiers de Paléoenvironnement, 2008, p. 209-224.

Rey, André, Treffort 2008: REY (P.-J.), ANDRÉ (I.), TREFFORT (J.-M.) - Les versants du Petit Saint-Bernard de la Préhistoire à l'Antiquité: nouvelles données sur les premières occupations de la montagne autour d'un passage transalpin. In: GARCIA (D.), RICHARD (H.) éd., Le peuplement de l'arc alpin; actes du congrès du CTHS à Grenoble 7-16 avril 2006. Paris, Éd. du CTHS, 2008, p. 149-175.

Rey, Moulin 2006: REY (P.-J.), MOULIN (B.) - Occupations et circulations pré-romaines autour du col du Petit-Saint-Bernard; méthode et premiers résultats d'une étude archéologique et sédimentaire de la montagne alpine. In: Alpis Graia Archéologie sans frontières autour du col du Petit-SaintBernard, projet Interreg IIIA, seminario di chiusura Aoste 2-4 mars 2006. Aoste, Musumeci S.p.A. ed., 2006, p. 77-118.

Rey, Treffort à paraître: REY (P.-J.), TREFFORT (J.-M.) avec coll. ANDRÉ (I.) - Il sito neolitico e protostorico del Châtelard de Bourg-Saint-Maurice (Savoia): insediamento a carattere difensivo e zona sepolcrale al piede del colle del Piccolo S. Bernardo. Atti del Convegno internazionale Il Piemonte e le Alpi occidentali all'alba della storia, Torino, Fondazione CRT, 13 e 14 aprile 2007, à paraître.

Vital 2002: VITAL (J.) - Les systèmes chronologiques ou le temps attendu. In: Âges du Bronze en Vaucluse. Notices d'archéologie vauclusienne, 5 ; Travaux du Centre d'Archéologie Préhistorique de Valence, 4. Avignon, Barthélemy éd., 2002, p. 23-36.

Voruz 1995: VORUZ (J.-L.) ed. - Chronologies néolithiques: de 6000 à 2000 dans le bassin rhodanien. Colloque d'Ambérieu-en-Bugey, 19-20 sept. 1992. Document du Département d'Anthropologie de l'Université de Genève, t. XX. Genève, Société Préhistorique Rhodanienne, 1995, 421 p.

Willigens 1991: WILLIGENS (M.-P.) - L'âge du Fer en Savoie et Haute-Savoie. In: DUVAL (A.), Les Alpes à l'âge $d u$ Fer, Actes du $\mathrm{X}^{\mathrm{e}}$ colloque sur l'âge du Fer tenu à YenneChambéry. Revue Archéologique de Narbonnaise, supplément 22. Paris, CNRS, Ministère de la Culture, Direction du Patrimoine. 1991, 437 p. 


\title{
Les Écrins, un territoire d'altitude dans le contexte des Alpes occidentales de la Préhistoire récente à l'âge du Bronze (Hautes-Alpes, France)
}

\author{
Kevin WALSH*, Florence MOCCI**, Stéfan TZORTZIS***, \\ Céline BRESSY**** et Brigitte TALON***** \\ Avec la collaboration de Suzi RICHER******, Mona COURT-PICON*****, \\ Vincent DUMAS** et Josep PALET-MARTINEZ*******
}

\begin{abstract}
Résumé. Les premiers témoignages d'une présence humaine en altitude reconnus dans les Alpes méridionales françaises, dès la Préhistoire, s'inscrivent au sein de travaux pluridisciplinaires et diachroniques menés, depuis 1998, sur le peuplement et les activités humaines en moyenne et haute montagne. Développés plus particulièrement sur les hauts massifs de l'Argentiérois/Vallouise et du Champsaur dans le Parc National des Écrins (Hautes-Alpes), ces programmes corrèlent sur le terrain données archéologiques et paléoécologiques d'altitude. Dès la seconde moitié du $\mathrm{II}^{\mathrm{e}}$ millénaire et au cours du $\mathrm{II}^{\mathrm{e}}$ millénaire BC (fin du Néolithique-âge du Bronze), se distinguent des structures bâties à vocation pastorale, entre 2067 et $2360 \mathrm{~m}$ d'altitude, en relation avec l'essor démographique observé dans les zones basses. L'occupation de la haute montagne durant cette période paraît continue et le milieu, exploité de manière durable.
\end{abstract}

The Ecrins: A high altitude territory in the context of the Southern Alps, from the later prehistoric periods to the Bronze Age (Hautes-Alpes, France)

Abstract. The earliest evidence for a prehistoric human presence identified in the Southern French Alps has been revealed by a multidisciplinary, diachronic research project that started in 1998. This research assesses the natural and social dynamics of occupation in the sub-alpine and alpine zones. This work is focussed on the high mountains of the Argentiérois/Vallouise and Champsaur areas in the Parc National des Écrins (Hautes-Alpes), and combines archaeological and palaeoenvironmental evidence. The second half of the IIIrd millennium BC and during the IInd millennium BC (the Late Neolithic and Bronze Age) is marked by the appearance of the built pastoral structures between 2067 and $2360 \mathrm{~m}$, related to the development and increase in populations at lower altitudes. This high altitude activity appears to be continuous and sustainable throughout these periods.

\section{Introduction}

Un programme de recherche sur les dynamiques naturelles et sociales du peuplement dans les Alpes méridionales françaises se développe, depuis plus de 10 ans, sur les hauts massifs de l'Argentiérois/Vallouise et du Champsaur, dans la zone orientale et méridionale du Parc National des Écrins (Hautes-Alpes) (Court-Picon 2007; Leveau, Walsh 2005; Mocci et al. 2006, 2008; Palet-Martinez, Ricou, Segard 2003 ; Py, Ancel 2007; Segard et al. 2003; Tzortzis et al.

\footnotetext{
* Department of Archaeology, King's Manor, University of York Y017EP York (Grande Bretagne) et Centre Camille Jullian (CCJ), UMR 6573 CNRS Université de Provence, Maison Méditerranéenne des Sciences de l’Homme, 5 rue du château de l'Horloge, BP 647, 13094 Aix-en-Provence cedex 2 ** Centre Camille Jullian (CCJ), UMR 6573 CNRS - Université de Provence Maison Méditerranéenne des Sciences de 1'Homme, 5 rue du château de l'Horloge, BP 647, 13094 Aix-en-Provence cedex 2.

*** Ministère de la Culture et de la Communication, DRAC de Provence-Alpes-Côte d'Azur, Service Régional de l'Archéologie, 21-23, boulevard du Roi René, 13617 Aix-en-Provence cedex 1 et Unité d'anthropologie bioculturelle, UMR 6578 CNRS - EFS - Université de la Méditerranée, faculté de Médecine, secteur Nord, bd Pierre Dramard, 13916 Marseille cedex 20.

**** Laboratoire Méditerranéen de Préhistoire Europe Afrique (LAMPEA), UMR 6636 CNRS - Université de Provence, Maison Méditerranéenne des Sciences de l'Homme, 5 rue du château de l'Horloge, BP 647, 13094 Aix-en-Provence cedex 2.

***** Institut Méditerranéen d'Écologie et de Paléoécologie (IMEP), UMR 6116 CNRS - Aix-Marseille, Université, Europôle de 1'Arbois, 13545

Aix-en-Provence.

****** Department of Archaeology, King's Manor, University of York, Y017EP York (Grande Bretagne).

******* Institut Català d'Arqueologia clàssica (ICAC), Plaça Rovellat s/n, 43003 Tarragona (Espagne).
} 


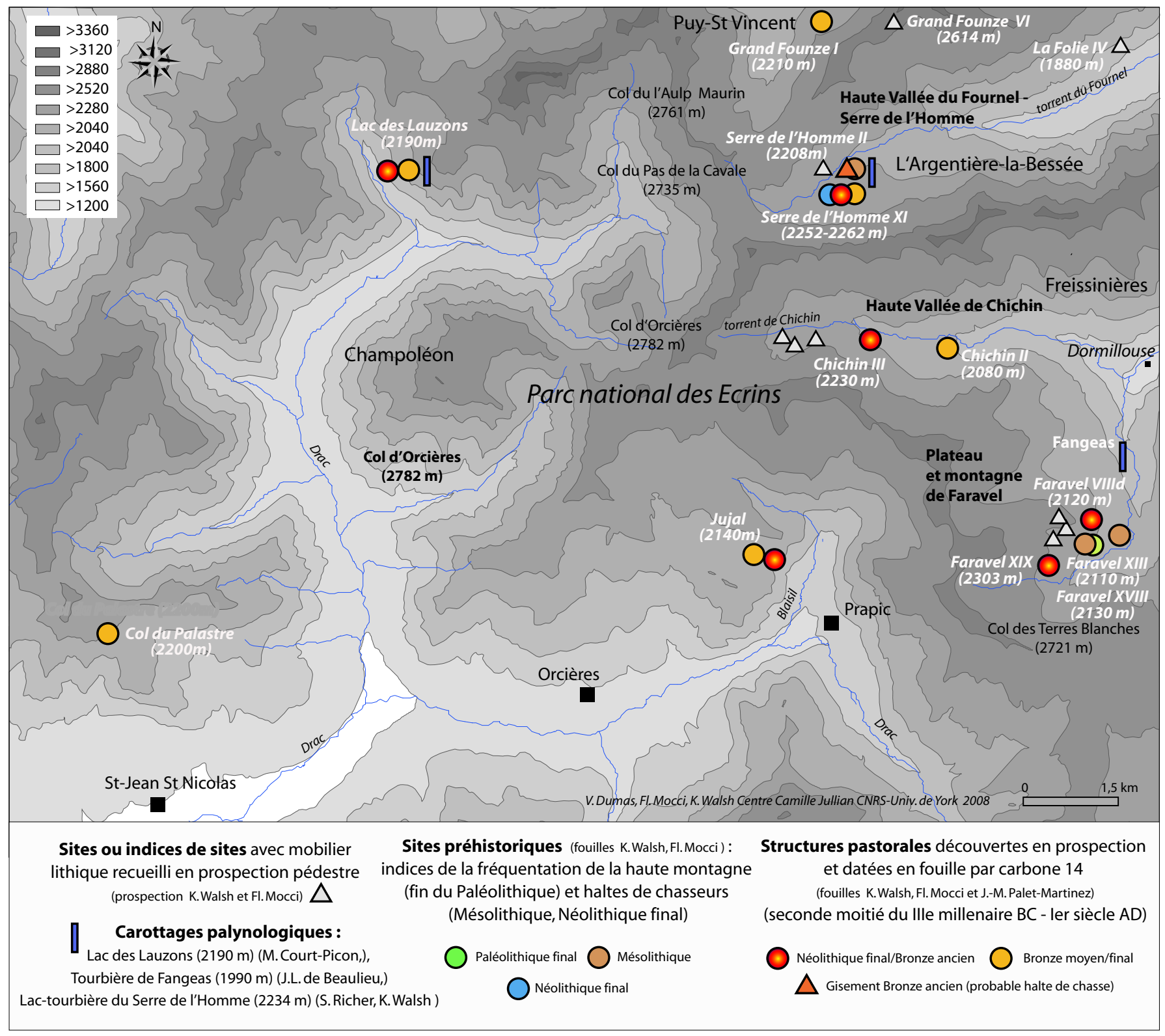

Fig. 1. Carte de localisation des sites archéologiques et des carottages palynologiques, massifs de l'Argentiérois et du Champsaur (Parc National des Écrins, Hautes-Alpes) (extrait du SIG Arc View Archéó́crins).

2008 ; Walsh 2005 ; Walsh et al. 2005 ; Walsh, Mocci 2003; Walsh, Mocci, Palet-Martinez 2007 ; Walsh, Richer 2006) ${ }^{\mathbf{1}}$.

1. Laboratoires du CNRS/Aix-Marseille Universités: Centre Camille Jullian, CCJ-UMR 6573; Institut Méditerranéen d'Écologie et de Paléoécologie, IMEP-UMR 6116; Laboratoire Méditerranéen de Préhistoire: Europe-Afrique LAMPEA-UMR 6536; Laboratoire d'Archéologie Médiévale Méditerranéenne, LAMM-UMR 6572. Intégrés depuis 2006 au sein du Groupe de Recherche du CNRS JurAlp (Dynamique holocène de l'environnement dans le Jura et les Alpes: du climat à l'homme), ces travaux bénéficient de la collaboration du Service Régional de l'Archéologie PACA, de la Communauté de Communes du
Ces travaux pluridisciplinaires et diachroniques corrèlent, sur le terrain, données historiques, archéologiques et paléoenvironnementales d'altitude ${ }^{2}$ : prospection pédestre;

Pays des Écrins et du Canton du Haut-Champsaur, du Parc National des Écrins, de la Maison du Parc de Vallouise, du Conseil Général des Hautes-Alpes, des communes de L'Argentière-la-Bessée, Freissinières, Puy-Saint-Vincent et Vallouise)... sans oublier les bénévoles, étudiants et gens du pays alpin, présents par tous les temps...

2. Dans le Parc National des Écrins, secteur Vallouise, les travaux archéologiques de terrain (prospections, sondages et fouilles programmées) sont conduits sous la direction de K. Walsh (Université 
fouilles de gisements préhistoriques, bâtis ou miniers; étude anthracologique et datation ${ }^{14} \mathrm{C}$ des charbons de bois; carottages palynologiques et analyses physico-chimiques des sédiments. Sur les 215 sites archéologiques recensés, une quinzaine a été datée par carbone 14 (absence de mobilier céramique et d'ossements alors que le matériel lithique est nettement présent). Il s'agit de gisements préhistoriques et de structures agropastorales de typologie et de période différentes, essentiellement localisés sur les communes de Freissinières (Faravel VIIId, Faravel XIX, Chichin II et III), L'Argentière-la-Bessée (Serre de l'Homme II et XI), Puy-Saint-Vincent (Grand Founze I), Champoléon (Lac des Lauzons II), Orcières (Jujal) et Saint-Jean-SaintNicolas (Col du Palastre II) (fig. 1). L'association des travaux archéologiques et paléoécologiques permet de suivre les grandes étapes de l'anthropisation de la haute montagne et renseigne sur les premiers impacts humains dans cette région. Elle révèle, entre 2000 et $2680 \mathrm{~m}$ d'altitude, les premières traces de fréquentation de la haute montagne dès le Paléolithique récent, une occupation plus marquée avec la présence de haltes de chasseurs au Mésolithique, l'apparition et le développement d'aménagements pastoraux et domestiques à partir du milieu du $\mathrm{III}^{\mathrm{e}}$ millénaire $\mathrm{BC}$, attestant d'une rupture dans la gestion de l'espace montagnard.

\section{Préambule : la Préhistoire récente dans les Alpes occidentales}

La Préhistoire récente alpine a longtemps été dominée par les approches historico-culturelles cherchant à caractériser les cultures et les économies locales et leurs liens avec celles des territoires de plaine environnants, telles les cultures méridionales de Fraischamp et de Fontbouisse pour la fin du Néolithique, ou bien les civilisations rhodaniennes durant l'âge du Bronze récent (Gallay 1990). Une autre caractéristique définissant les modèles explicatifs utilisés pour la Préhistoire alpine est la tendance à

de York), F. Mocci (CCJ) et dans le Champsaur, de 1999 à 2003, par J.-M. Palet-Martinez (Université de Barcelone). Les relevés archéologiques et le Modèle Numérique de Terrain des sites et de leur environnement sont dirigés par V. Dumas (CCJ). S. Tzortzis (SRA PACA) et S. Renault (LAMPEA) ont en charge l'analyse du mobilier lithique et C. Bressy (LAMPEA), la caractérisation des matières premières siliceuses. L'analyse microscopique des poussières visant à mettre en évidence d'éventuels indices de la présence d'animaux domestiques est réalisé par J.-L. Brochier (LAMPEA). Les carottages palynologiques ont été menés par M. Court-Picon, J.-L. De Beaulieu, F. Guiter et S. Richer (IMEP/Université de York). L'étude anthracologique est conduite par B. Talon (IMEP), A. Durand et V. Py (LAMM). Les datations ${ }^{14} \mathrm{C}$ conventionnelle et AMS ont été calibrées avec un indice de confiance de probabilité de deux sigmas par J.-F. Saliège, Laboratoire d'Océanographie Dynamique et Climatologique de Jussieu, UMR 121 (Pa..) et T. Goslar, Poznan Radiocarbon Laboratory, Foundation of the Adam Mickiewicz, Pologne (Poz...). Merci à tous ces collaborateurs ! surestimer l'effet du climat, influence fondamentale pour certains, sur l'activité humaine locale (Bocquet 1997). Ces approches ont induit des interprétations sur l'évolution des sociétés alpines fondées sur des concepts, alors dominants, de marginalité environnementale et culturelle. Le manque d'informations dans les zones de haute altitude $(2000 \mathrm{~m}$ et au-delà) soutenait alors les explications déterministes, la haute montagne étant perçue comme un milieu difficile, vierge de toute donnée relative à la présence humaine. Pour d'autres, le massif alpin était appréhendé comme une niche écologique, principalement vouée au pastoralisme (Primas 1999). Ces différentes approches ont mené à une homogénéisation des caractéristiques culturelles appliquées à l'arc alpin.

Si la présence d'un peuplement antérieur à 5000 BC est avérée dans les Alpes françaises, l'apparition d'une économie véritablement agropastorale remonte seulement au courant du Ve millénaire BC (Nicod, Picavet 2003). Cette affirmation, distinguant dans les Alpes, l'économie de production de l'économie de prédation est sans doute influencée par l'abondance et la variété des potentialités cynégétiques des écosystèmes alpins (Clark 1990). Les premières études sur le Néolithique régional ont révélé de petits groupes autonomes (jusqu'à 250 individus) parmi les cultures de Chassey, Cortaillod, Lagozza, pratiquant une agriculture de petite échelle (Phillips 1972). Certains plaident pour des origines méditerranéennes du Néolithique des HautesAlpes et considèrent que la fin de la période peut correspondre à une expansion des cultures périphériques, telle que la culture de Fraischamp (Morin 2005), bien représentée en Provence par le site de la Clairière à La Roque-surPernes, dans le Vaucluse (Sauzade, Carry, Chambert 1990). Il est également possible que les groupes humains de cette zone des Alpes soient porteurs d'un faciès culturel néolithique récent de type « rhodano-alpin » (Beeching 2003). Le matériel lithique pour le Néolithique récent est typiquement associé à la civilisation de Saône-Rhône. Quant au Chasséen, il est incontestablement représenté dans les Hautes-Alpes. Il se caractérise par des assemblages homogènes de silex (D'Anna 1991). Cependant, à la différence de quelques régions des Alpes, il n'existe aucun véritable site d'occupation bien caractérisé, tel le Petit-Chasseur à Sion dans le Valais suisse (Besse, Mottet 2003).

\section{Premières fréquentations humaines antérieures au Néolithique dans les massifs des Écrins}

Aux confins du Briançonnais et du Haut-Embrunais, sur les zones d'alpage de la commune de Freissinières (plateau et Montagne de Faravel, haute vallée de Chichin), 
de L'Argentière-la-Bessée (vallée du Haut-Fournel/Serre de l'Homme) et de Puy-Saint-Vincent (massif des Grands Fonds), les recherches entreprises à haute altitude ont révélé, plus spécifiquement, entre 2150 et $2680 \mathrm{~m}$ d'altitude, une chronologie de la présence humaine durant les temps préhistoriques relativement étendue et insoupçonnée. Ces recherches ont permis la mise en évidence d'une vingtaine de sites ou indices de sites (fig. 1). Parmi eux, cinq concernent en partie des périodes antérieures au Néolithique (Mocci et al. 2009; Tzortzis et al. 2008). Ces apports permettent de compléter les connaissances relatives au peuplement anté-néolithique de la montagne issues notamment des recherches menées en France depuis les Alpes du Nord jusqu'à la zone méridiono-occidentale du département des Hautes-Alpes (Bintz, 2004; Bintz, Bracco 2004; Bintz, Morin 2001; Muret 1991; Pion 2004) et dans la partie italienne ou valaisanne de l'arc alpin (Curdy, 2002; Fedele 1990; Broglio 1994; Fontana, Vullo, 2000). Cette documentation est presque exclusivement constituée de mobilier lithique. Les conditions de gisement, de conservation et de collecte, dans un contexte géomorphologique et environnemental très particulier, ne facilitent pas la caractérisation des ensembles d'objets lithiques constitués. Cependant, la relative homogénéité technologique de ces séries, du moins pour les plus abondantes d'entre elles, associée à la présence en leur sein de morpho-types très caractéristiques (en particulier des armatures microlithiques), nous a permis d'y déceler l'existence indéniable de plusieurs des phases chronoculturelles antérieures au Néolithique. Certaines données, certes extrêmement ténues mais néanmoins présentes, mettent en évidence un passage de groupes humains à la fin du Paléolithique supérieur (site de Faravel XIX; fig. 1, 3, 4b). Ce Paléolithique supérieur s'inscrit manifestement dans la lignée épigravettienne d'influence italique couvrant la zone méridionale et orientale de la Provence. Mais ce secteur de haute montagne livre de façon plus nette des vestiges de fréquentation attribuables au Mésolithique. On rencontre ainsi un Mésolithique ancien ou moyen de type sauveterrien (Faravel XIII et Serre de l'Homme II; fig. 1, 2, 4a) mais également le Mésolithique récent castelnovien (Faravel XVIII et XVIIIa). Les sites s'apparentent à des haltes de chasses de petits groupes parcourant de façon saisonnière la haute montagne. Le silex dont est dépourvu le secteur provient de sources d'approvisionnements lointaines, toutes situées bien plus au sud (Mocci et al. 2009). Les artefacts de Faravel XIX, dont une pointe à cran (fig. 3), sont ainsi tirés d'un silex oligocène dont les gîtes sont situés dans le bassin de Forcalquier (vallée du Largue, Alpes-de-Haute-Provence), soit à plus de 100 km en suivant le cours de la Durance. Quant aux sites mésolithiques, les assemblages lithiques sont composés très majoritairement, voire exclusivement, de deux matières premières. Il s'agit principalement du silex hauterivien dont l'origine repérée se situe dans le secteur de la montagne de Céüze près de Gap et des synclinaux perchés des pays du Buëch (Hautes-Alpes) et secondairement du silex barrémo-bédoulien dont les gîtes se trouvent dans le massif du Mont Ventoux / Montagne de Lure (Vaucluse, Alpes-deHaute-Provence) et des monts de Vaucluse.

La présence de ces sites met en lumière une problématique importante: celle d'une datation précoce et des modalités des premières pénétrations en haute montagne dans les Alpes du Sud, consécutivement à la fin des temps glaciaires (Deline, Le Roy 2009). Les données dont nous disposons sur les fluctuations, l'extension maximale et le reflux de l'englacement würmien en Haute-Durance (Jorda 1988) apparaissent en fin de compte assez compatibles avec l'idée d'une arrivée jusqu'en haute montagne de groupes humains depuis les régions méridionales (Provence, Ligurie) par le sillon durancien, dès le Tardiglaciaire. Retiré jusqu'à l'amont de l'actuelle Briançon il y a environ 15000 BC (Jorda 1991), le glacier a ainsi libéré d'importants espaces permettant la mise en place de niches écologiques spécifiques et procurant ainsi des territoires nouveaux aux dernières populations de chasseurs-cueilleurs. La végétation, telle que retranscrite par les analyses palynologiques effectuées dans les Alpes du Sud (De Beaulieu, 1977; Nakagawa, 1998) est alors une steppe froide où les armoises dominent, accompagnées de Chenopodiaceae abondantes et d'un cortège de taxons pionniers (Poaceae, Caryophyllaceae, Apiaceae, Ephedra, ...). Aux altitudes concernées par les découvertes archéologiques, le milieu reste ainsi très ouvert tout au long du Tardiglaciaire et du début de l'Holocène, et donc favorable aux incursions de groupes humains. Seuls les genévriers forment des peuplements arbustifs nains au Bølling/Allerød, sans doute accompagné d'un modeste développement du bouleau près des zones humides. Ce n'est qu'au Boréal que des boulaies claires peuvent s'installer à ces altitudes. Pour l'heure, les données culturelles relatives à ces périodes plus anciennes font défaut dans les zones basses, en particulier dans la haute vallée de la Durance, secteur où pourraient se situer les camps de base saisonniers ou du moins les formes d'occupation plus pérennes liées à ces incursions en altitude. Concernant le Paléolithique supérieur, le site le plus proche, également épigravettien, se trouve en effet loin en aval sur le cours de la Durance, dans le sud du département des Hautes-Alpes (Saint-Antoine à Vitrolles, Gagnepain, Bracco, Bertran 1999). Pour ce qui est du Mésolithique, les témoignages de présence humaine les plus proches se trouvent également à une distance importante, au sud-ouest du département des Hautes-Alpes (site du Col des Tourrettes à Montmorin, Muret, 2006; indices de site du bassin du Büech et du Dévoluy, Bintz, Morin 2001). 


\section{Peuplement, pastoralisme et échanges au Néolithique en moyenne et haute montagne}

\subsection{Dans le Parc National des Écrins}

Les recherches menées conjointement dans la Vallouise et le Haut-Champsaur ont montré que les sites et indices de site du Néolithique sont assez nombreux (Fressinières: Faravel XII, XV, XVI, XVII et sites de la vallée de Chichin; en Champsaur: col du Palastre, secteur de Faudon). Une des zones les plus intéressantes est le plateau de Faravel où cinq ensembles de concentration de matériel lithique ont été datés de façon relative par la typologie du Néolithique moyen (fig. 1). Un locus tel que Faravel XXII est typique de ce que nous rencontrons dans notre secteur d'étude. Ce gisement a livré un lot de 23 pièces de silex, comprenant notamment plusieurs lames fragmentaires, dont un fragment mésial retouché (Tzortzis et al. 2008). Une partie de ces industries lithiques a été mise en évidence en stratigraphie. On y retrouve l'association des types de matière première d'origine lointaine rencontrés dans les séries datées des périodes antérieures (principalement silex hauterivien, puis silex barémo-bédoulien et silex oligocène). En dépit du fait que cette période est témoin des premières incursions des bergers (Brochier et al. 1999; Brochier 2005), les données dans les massifs des Écrins évoquent davantage une suite des cycles courts d'activités cynégétiques, très vraisemblablement durant les saisons les plus clémentes. La confrontation des données archéologiques et palynologiques semble en effet indiquer que la chasse se poursuit aux altitudes supérieures et qu'une activité pastorale restreinte se déroule à des altitudes moins élevées (Court-Picon 2007; Mocci et al. 2009). Nous savons extrêmement peu de chose de l'occupation des fonds de vallée au Néolithique moyen et récent dans les Hautes-Alpes. Des vestiges ténus de foyers et de structures en creux ont toutefois été mis en évidence récemment à La Saulce, au sud de Gap (Bouttevin, Leal, Voyez 2007). Ce déficit de témoignages relatifs aux occupations et aux activités néolithiques dans ces secteurs bas est assurément une conséquence de processus taphonomiques extrêmes qui ont démantelé ou occulté les sites placés en fond de vallée et sur les versants. La fin du Néolithique dans les Écrins est non seulement représentée par des industries lithiques, mais également par des structures bâties dès la seconde moitié du III millénaire BC (cf. infra chap. 5).

\subsection{Dans les Alpes occidentales}

Dans la plupart des régions alpines, les archéologues ont plaidé pour une évolution régulière et progressive de l'activité pastorale et de la transhumance au cours du Néolithique. Ce sont les données palynologiques qui fournissent pour l'essentiel les arguments soutenant cette position. Il y a en effet un net décalage chronologique entre les témoins paléoenvironnementaux, plus précoces, et les témoins archéologiques (Richard 2004). Cette distinction entre les données peut éventuellement être recherchée dans le caractère fugace de la culture matérielle des premiers pasteurs du Néolithique ancien. Mais elle pourrait tout aussi bien provenir d'éléments affectant les données paléoécologiques, au vu notamment de la complexité caractérisant la dispersion des pollens dans les secteurs montagneux (pour une exception, voir Court-Picon, Buttler, De Beaulieu 2006). Dans la plupart des zones d'études, les seuls témoins archéologiques de la présence de l'Homme en haute montagne au Néolithique moyen sont des assemblages lithiques en quantité réduite. Ces pièces en silex montrent a minima que la chasse s'est perpétuée en altitude. Par conséquent, la nature de ces données ne permet d'appréhender que partiellement la réalité des activités menées sur place. Actuellement, les faits archéologiques plaident pour un pastoralisme de moyenne montagne n'incluant aucune transhumance estivale vers les pâturages de haute altitude, durant le Néolithique ancien et le Néolithique moyen (Nicod 2008). En dépit de la pénurie relative de données sur l'occupation du sol et de matériel archéologique permettant de définir des groupes et des courants culturels dans les Alpes françaises du Sud, l'occurrence de certains types de systèmes d'échange avec les régions limitrophes ou plus éloignées est tout à fait remarquable. De telles activités ont commencé pendant le Cardial. On peut citer tout particulièrement la question de l'approvisionnement des populations néolithiques en roches tenaces, pour la confection des industries lithiques polies. Jadeïte, éclogite et omphacite proviennent d'une zone bornée au nord par les Alpes suisses et au sud par les Apennins en Italie (Pétrequin et al. 2007). Ces roches, qui affleurent à des altitudes comprises entre 1800 et $2350 \mathrm{~m}$, ont motivé en partie la présence humaine dans ces secteurs. Des secteurs, tels que le massif du Viso (sur la frontière franco-italienne, à environ $50 \mathrm{~km}$ à l'est des Écrins) constituent des sources importantes de collecte de ce type de matériau. Il n'y a pour l'heure aucun élément permettant de penser que l'extraction des roches était le fait de groupes pratiquant conjointement le pastoralisme. Il semble plutôt que cette activité représentait en soi un mode spécialisé d'expédition en montagne (Pétrequin et al. 2007).

Pendant la phase de transition entre le Néolithique ancien et moyen (5000-4600 BC), les sites présents dans les Alpes occidentales françaises témoignent d'échanges transalpins, comme le montre la présence de céramique appartenant à la Culture des Vases à Bouche Carrée (Beeching 2003). Le Néolithique récent est marqué par une évolution 

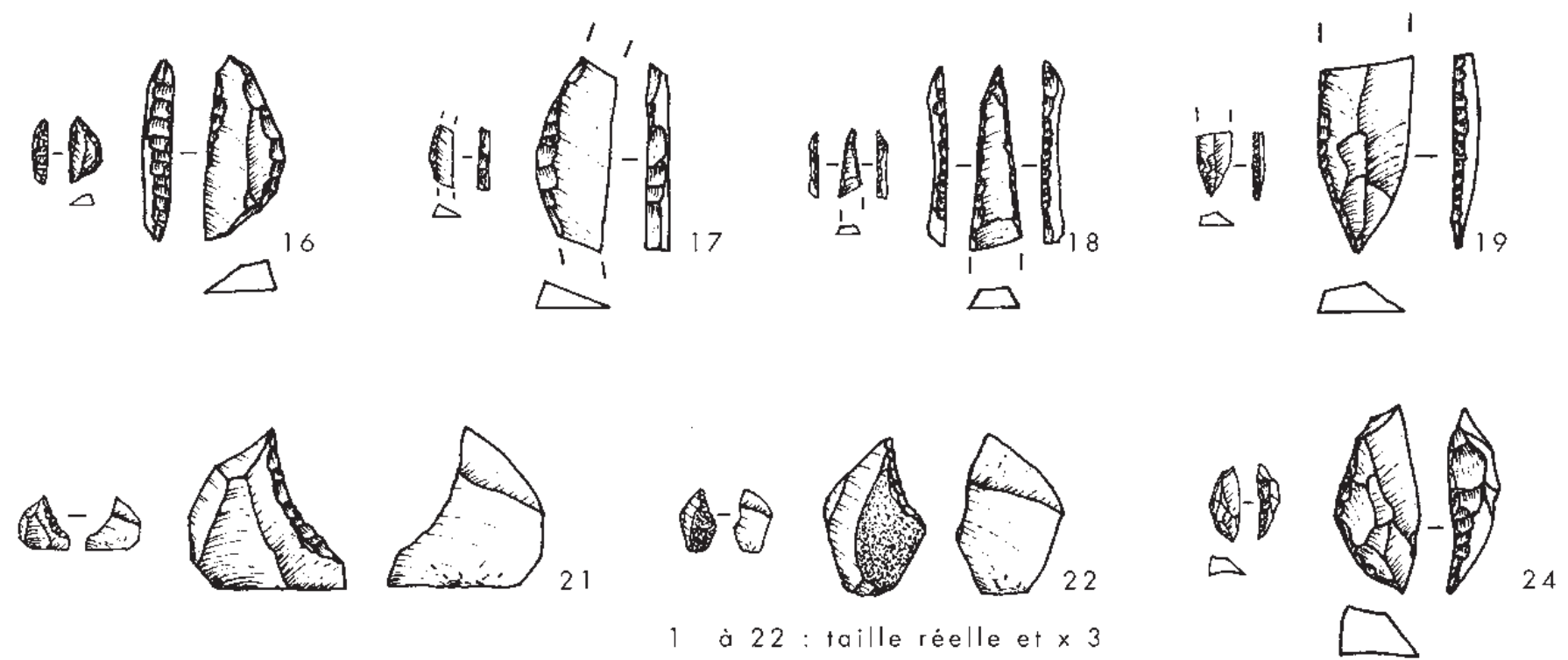

1 ò 22 : tqille réelle et $\times 3$
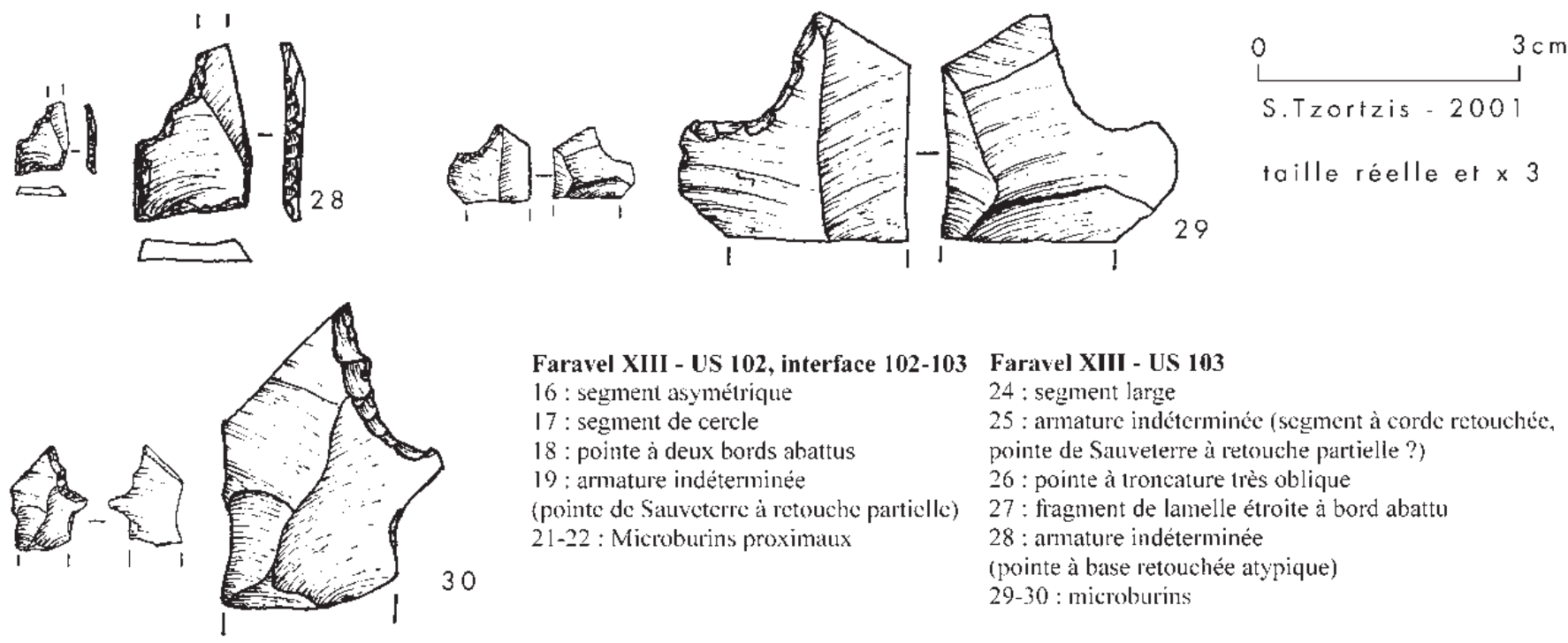

Faravel XIII - US L02, interface 102-103 Faravel XIII - US 103

16: segment asyméturique

24 : segment laprise

$17:$ segment de cercle

18 : pointe à deux bords abattus

19: armature indèterminęe

25 : amature indétermince (scement à conde retouché. pointe de Satuveterre à letouche partielle ?)

26: pointe à troncature très oblique

(pointe do Sauvetere à retouche particllo) 27 : fiament de lanelle étroite à bord abatto

21-22 : Microbutins proximaux

28 : amature indéterminée

(jointe à base retouchée atypique)

29-30: microburins

Fig. 2. Mobilier lithique recueilli en sondage sur le site de Faravel XIII, commune de Freissinières (alt. 2150 m ; août 2002).

dans les modes de diffusion des artefacts en éclogite. Comparativement aux phases antérieures, nous assistons à une réduction de la circulation lointaine, peut-être due à au développement de l'exploitation du cuivre (Thirault $2005)$; la production locale des haches en pierre se poursuit toutefois.

Ainsi, s'il est difficile d'identifier des groupes culturels au sein des écosystèmes alpins, il n'en demeure pas moins que des matériaux et des productions alpines ont fait l'objet d'échanges à longue distance. Dans ce contexte, les Alpes ne représentaient certainement pas une barrière à la circulation des matériaux. Des productions d'origine méditerranéenne sont ainsi mises en évidence au sein de sites néolithiques dans les Alpes suisses (Curdy 2002). Certaines plantes pourraient avoir été diffusées de la zone méditerranéenne vers la haute vallée du Rhône, sur le plateau suisse (Borrello 2003). La tendance à voir dans les Alpes, durant le Néolithique, un espace en marge du développement des principaux courants économiques, culturels et sociaux marquant l'Europe occidentale et la Méditerranée, n'est ainsi pas justifiée. Il est sans doute préférable de considérer à quel point cet espace ouvert aux échanges fut au contraire le cœur de flux, à la fois centripètes et centrifuges, pour autant que les groupes humains peuplant des régions lointaines aient eu conscience de l'origine alpine de certaines des productions, telles les 


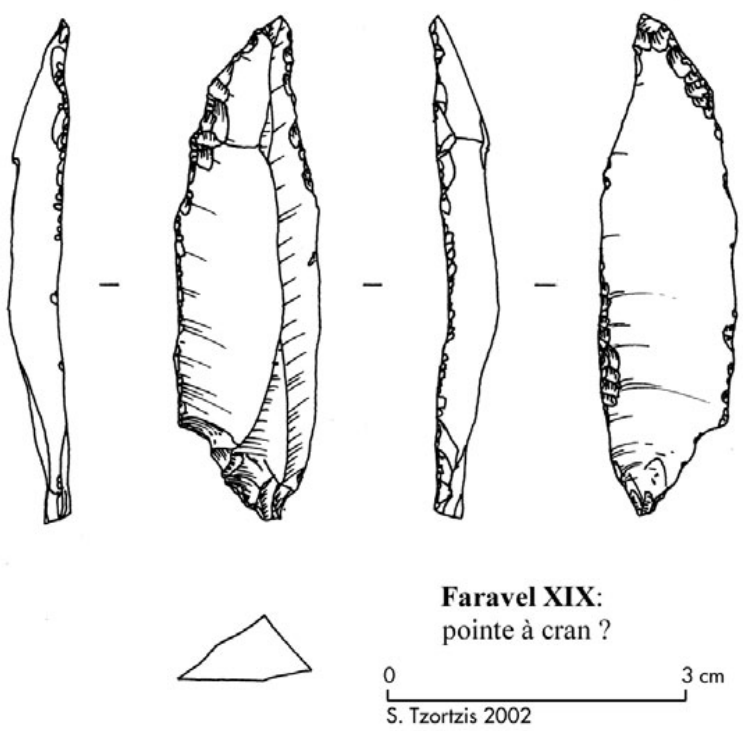

Fig. 3. Mobilier lithique recueilli en sondage sur le site de Faravel XIX, commune de Freissinières (alt. 2303 m ; août 2002).

haches en roche verte, parvenues jusqu'à eux (Pétrequin et al. 2008). A partir du $\mathrm{V}^{\mathrm{e}}$ millénaire $\mathrm{BC}$, les données archéologiques dans les Alpes françaises suggèrent l'apparition d'un système pastoral où des bergers isolés (du moins des groupes réduits) ont exercé leur activité dans les zones de moyenne montagne, détachés de leurs communautés (Brochier, Beeching 2006). Aucun témoignage factuel de communauté villageoise organisée n'a cependant été, pour l'heure, mis en évidence dans les Alpes françaises (Beeching 2003). Les témoins d'une activité néolithique récente en haute altitude (au-delà de 2000 m) dans les Alpes françaises demeurent rares mais bel et bien présents, tels ceux, dans l'Ubaye (Alpes-de-Haute-Provence), du torrent de Julien à $2700 \mathrm{~m}$ (Uvernet-Fours, Beeching 2003), du site du Lauzanier sud I à 2356 m (3270-2890 cal. BC, Pa 2366, Larche; Mocci et al. 2008, 2009) ou les découvertes ponctuelles associées au Néolithique moyen ou final (tels les sites de Roburent, $2509 \mathrm{~m}$; Pelouse IV, 2338 m dans l'Ubaye ou Grand Founze VII, 2614 m dans les Écrins ; Garcia et al. 2007). Par ailleurs, certaines zones de moindre altitude des massifs alpins français (autour de $1500 \mathrm{~m}$ ) recèlent des grottes bergeries dont l'occupation remonte au Néolithique moyen (Beeching 2003). De telles structures font pour l'instant défaut en ce qui concerne le Néolithique final.

À la transition Néolithique-âge du Bronze, de nouveaux aménagements apparaissent jusqu'aux altitudes de $1500 \mathrm{~m}$. Les seuls gisements agropastoraux connus jusqu'ici, dans les Alpes occidentales, au-dessus de $2200 \mathrm{~m}$ d'altitude, ont été mis au jour dans la zone orientale et méridionale des Écrins, dans la haute Ubaye (site du Lauzanier sud

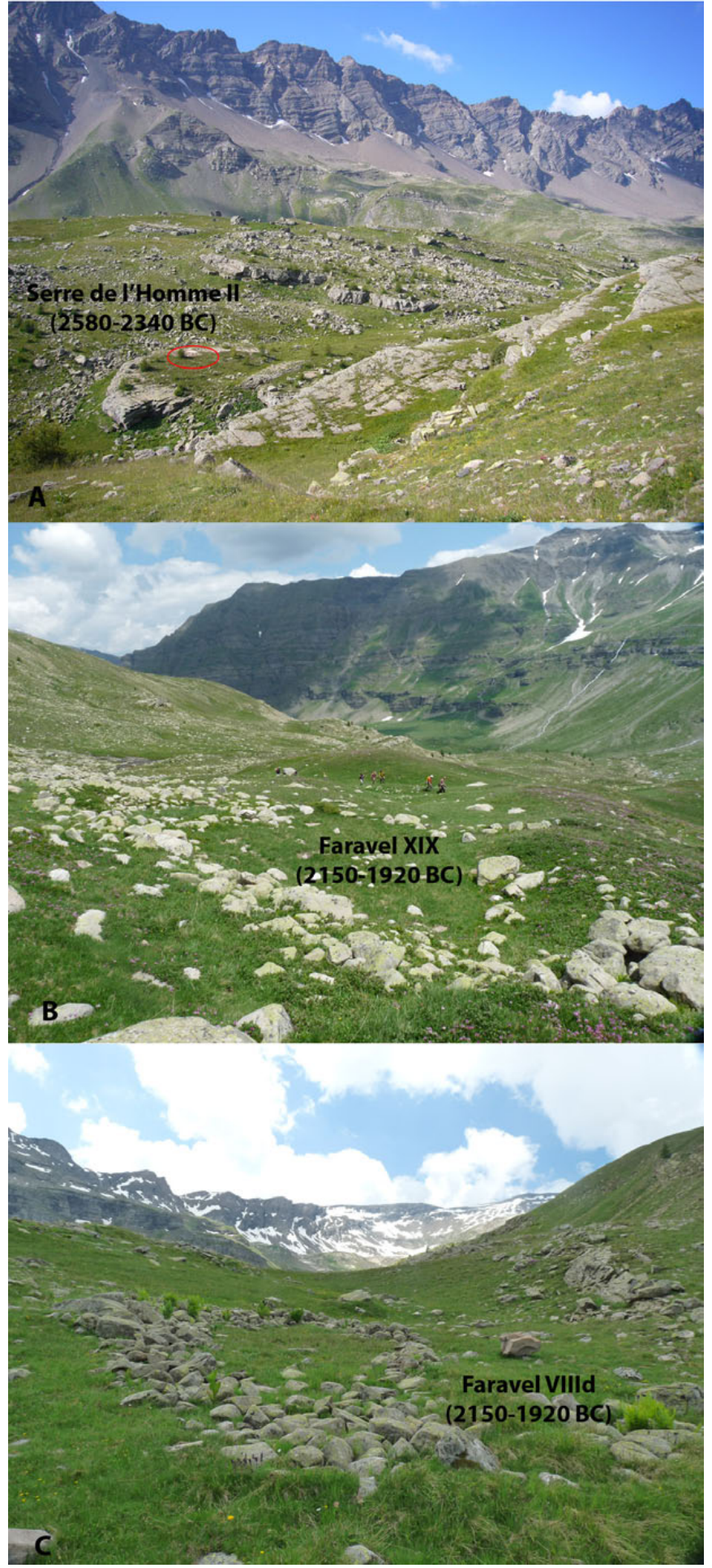

Fig. 4. Sites archéologiques de la Vallouise, dans le HautFournel (L'Argentière-la-Bessée) et sur le Plateau de Faravel (Freissinières, 05). a. Serre de l'Homme II vu depuis le nord-est (alt. 2208 m, cliché F. Mocci, 2008). b. Faravel XIX vu depuis I'ouest (alt. 2303 m, cliché K. Walsh, 2009). c. Faravel VIIId vu depuis le nord-ouest (alt. 2120 m, cliché K. Walsh, 2009). 
I, 1880-1530 cal. BC, Pa 2365) et récemment, en HauteTarentaise (Col du Petit Saint-Bernard, Rey et al. 2009).

\section{Peuplement et activités humaines de la fin du $\mathrm{III}^{\mathrm{e}}$ au $\mathrm{II}^{\mathrm{e}}$ millénaires $\mathrm{BC}$}

\section{1. Dans le Parc National des Écrins}

Dans les hautes vallées du Parc National des Écrins, sans doute en relation avec l'essor démographique observé dans les zones basses (Garcia 1995; Richard, Magny, Mordant 2007), des structures pastorales et domestiques complexes ou isolées sont bâties et se développent dès la seconde moitié du III millénaire. Ces aménagements traduisent une nouvelle gestion de l'espace montagnard: les paysages sont de plus en plus façonnés par les activités humaines et l'entretien des alpages paraît continu (Walsh et al. 2005; Court-Picon et al. 2007). La présence croissante, dans les diagrammes polliniques, de plantes liées à l'élevage et des particules carbonisées indique localement une accentuation de cette activité et l'utilisation du feu pastoral pour l'entretien des alpages. Ces signaux sont associés à une quasi-disparition de la forêt ouverte de Pinus cembra in situ, favorisant l'expansion de Larix liée à la constitution des alpages supra-forestiers locaux (Mocci et al. 2009). Hormis le site du Serre de l'Homme II dans l'Argentiérois (2208 m; fig. 1, 4a) qui ne présente pas les caractéristiques d'installations liées à une activité pastorale, une dizaine de structures pastorales complexes ou plus isolées, connaissent une, voire plusieurs occupations entre la moitié du III ${ }^{\mathrm{e}}$ et le début du $\mathrm{I}^{\mathrm{er}}$ millénaires BC (2580 à $\left.810 \mathrm{BC}\right)$ (fig. 1). Trois types de vestiges se dessinent: un ensemble de structures contemporaines les unes des autres correspondant à un enclos (Faravel XIX, fig. 4b; Chichin II et III) attenant ou à proximité d'une ou plusieurs cabanes de berger (Faravel XIX-E1-E3, Chichin II-E1, Chichin III-E2); une cabane de berger ou un enclos insérés au sein de plusieurs structures pastorales de période et de forme différentes (Jujal I, Col du Palastre II, Grand Founze I, Serre de l'Homme XI); des structures totalement isolées (enclos de Faravel VIIId, fig. 4c ; cabane du Lac des Lauzons II) (Tzortzis et al. 2008). De l'Argentiérois au Champsaur, certains éléments topographiques et architecturaux se retrouvent: implantation sur des petits plateaux ou dans des dépressions, à proximité de torrents, lacs ou tourbières; exploitation de la topographie naturelle du terrain (appui des structures sur des blocs erratiques, des éboulis ou des comblements de ravines); enclos de forme triangulaire ou ovoïde de 20 à $150 \mathrm{~m}^{2}$ environ, sans aménagements internes et cabanes de berger de forme ovoïde de faible superficie (3 à $10 \mathrm{~m}^{2}$ ) conservant des vestiges de sols de circulation et/ou de foyers, plus ou moins aménagés (Faravel XIX, Chichin II-III, Serre de l'Homme XI, Col du Palastre, Lac des Lauzons II). Les traces d'incendie internes à la structure (Faravel VIIId, Serre de l'Homme XI, Grand Founze I) ou inhérents à des déboisements en vue de la mise en valeur pastorale d'un secteur (Jujal, Serre de l'Homme XI) sont plus rares.

C'est dans la haute vallée de Freissinières et du HautFournel (L'Argentière-la-Bessée) que sont reconnus, à ce jour, les aménagements anthropiques les plus anciens. Sur le site de Chichin III (2230 m), ils correspondent à un foyer de cabane (2580-2340 cal. BC, Poz-5500) et au paléosol de l'enclos (2460-2200 cal. BC, Poz-5498); dans la haute vallée du Fournel, ce sont trois trous de poteaux (24702280 cal. BC, Pa-2363) et des structures de combustion (2580-2340 cal. BC, Poz-13919) sur le site du Serre de l'Homme II (2208 m) mais aussi dans la cabane du Serre de 1'Homme XI à 2252 m (2480-2280 cal. BC, Pa 2462). Des vestiges d'incendie antérieurs à la construction du Serre de l'Homme XI témoignent d'un déboisement antérieur à 2480-2280 $\mathrm{BC}$ (datation ${ }^{14} \mathrm{C}$ en cours). Au cours de l'âge du Bronze ancien et moyen, des sites pastoraux sont réoccupés et de nouvelles structures apparaissent. Sur la Montagne de Faravel (Freissinières), la cabane de Faravel XIX (2150-1920 cal. BC, Pa 2209) et l'enclos de Faravel VIIId (2150-1920 cal. BC, Pa 1841) connaissent une occupation contemporaine entre 2303 et $2120 \mathrm{~m}$ d'altitude (fig. 1, 4b, 4c). Dans le Haut-Fournel, le site du Serre de l'Homme XI est réoccupé et est affecté par un incendie entre 1750 et 1560 cal. BC (Pa 2463) alors que dans le HautChampsaur, un sol de circulation est attesté dans la cabane du Lac des Lauzons II à 2190 m (2050-1500 BC, Pa 1973). Dans la seconde moitié du II ${ }^{\mathrm{e}}$ millénaire BC (âge du Bronze moyen), les témoignages pastoraux sont liés aux structures d'habitats (apparition du site de Chichin II à 2080 m, 15401410 cal. BC, Poz-5603; réoccupation de la cabane du Lac des Lauzons II, 1610-1310 cal. BC, Pa 1971) mais aussi à des défrichements par le feu en vue de l'exploitation de l'espace pastoral. Trois phases d'incendie affectent ainsi le site de Jujal dans le Haut-Champsaur (2140 m), avant et après la construction de l'enclos (1690-1440 cal. BC, Pa 2140 ; 1530-1250 cal. BC, Pa 2141; 1270-1010 cal. $\mathrm{BC}, \mathrm{Pa} 2145)$. Entre le $\mathrm{II}^{\mathrm{e}}$ et le début du $\mathrm{I}^{\mathrm{er}}$ millénaires BC, seuls deux sites apportent les éléments les plus récents sur l'occupation en altitude: dans l'Argentiérois, la cabane du Grand Founze Ic à 2210 m (980-810 cal. BC, Poz-22633) et dans le Haut-Champsaur, l'enclos du Col du Palastre II à 2200 m (1220-790 cal. BC, Pa 2336).

Le statut de l'ensemble de ces sites est en grande partie induit par leur architecture et la nature des vestiges mais également par les études palynologiques menées dans le Champsaur et dans l'Argentiérois. Dans le Champsaur, les travaux de Mona Court-Picon démontrent ainsi une intensification des activités pastorales au cours des $\mathrm{III}^{\mathrm{e}}$ et 
$\mathrm{II}^{\mathrm{e}}$ millénaires (Court-Picon et al. 2007). Ces travaux sont maintenant complétés par la thèse de Suzi Richer sur le secteur du Haut-Fournel/Serre de l'Homme (Richer 2009; fig. 5): les données palynologiques corrélées spatialement et chronologiquement avec un ensemble de structures pastorales datées entre la fin du III $^{\mathrm{e}}$ millénaire et le milieu du $\mathrm{II}^{\mathrm{e}}$ millénaire $\mathrm{BC}$ corroborent les résultats acquis dans la zone méridionale des Écrins par M. Court-Picon mais aussi dans d'autres diagrammes régionaux (De Beaulieu 1977). Plus spécifiquement, la présence de Sporomiella à la base de la carotte du Serre de l'Homme permet la mise en évidence des activités pastorales dans l'environnement immédiat (fig. 5). Quelques espèces nitrophiles datées de l'âge du Bronze moyen ont par ailleurs été identifiées dans une autre carotte, celle du lac de Fangeas, dans la haute vallée de Freissinières (Walsh, Richer 2006).

L'apparition des structures bâties dans les zones de moyenne et haute altitudes au cours des $\mathrm{III}^{\mathrm{e}}$ et $\mathrm{II}^{\mathrm{e}}$ millénaires $\mathrm{BC}$ implique un changement radical des activités humaines dans ces espaces. Un nouveau réseau complexe de processus économiques, sociaux et culturels est mis en place, aboutissant sans doute à une évolution profonde de la perception humaine sur le milieu montagnard. La probable amélioration climatique (4150-3950 BP; Magny 2004) coïncidant chronologiquement avec l'apparition et le développement des structures bâties entre sans doute beaucoup moins en ligne de compte que les changements socio-économiques précédemment évoqués.

\subsection{Les $\mathrm{III}^{\mathrm{e}}$ et $\mathrm{II}^{\mathrm{e}}$ millénaires $\mathrm{BC}$ dans les Alpes occidentales}

Si les archéologues n'emploient pas toujours le terme Chalcolithique (essentiellement, les premiers siècles du III ${ }^{\mathrm{e}}$ millénaire $\mathrm{BC}$ ), ce dernier reste efficient pour définir une période où certains groupes humains des Alpes ont commencé à extraire et à travailler le cuivre. Les rapports entre ces innovations technologiques et les processus socioculturels plus larges sont complexes et divers (Carozza, Mille 2007). Parallèlement à l'émergence de cette nouvelle industrie, il apparaît que dans certaines parties de l'Europe, la période considérée a connu le développement d'un pastoralisme nomade (Lichardus et al. 1985). Cette forme de nomadisme/transhumance «complexe » est associée à un pastoralisme jusque-là cantonné à l'exploitation de pâturages locaux, insuffisants à soutenir l'économie complexe naissante qui s'affirme progressivement pendant cette période. Bien que nous ayons vu par ailleurs que nombre des discours déterministes liés à l'archéologie alpine sont critiquables (Mocci et al. 2006; Walsh 2005), il est à noter toutefois qu'une détérioration climatique et la réduction concomitante du couvert forestier ont pu réellement favoriser le développement du pastoralisme de haute altitude. Le milieu de 1'Holocène, entre 5600-5000 cal. BP (Néolithique récent), est en effet marqué par un refroidissement ayant pour conséquence l'avance des glaciers alpins, le recul de la limite forestière et une évolution de la végétation (Magny, Haas 2004; Magny, Desmet, Mocci 2009). Ces changements ont conditionné, en haute montagne, une ouverture du milieu propice aux pâturages.

À l'instar du Néolithique, l'identification de faciès culturels dans les Alpes françaises pose question pour le Chalcolithique et l'âge du Bronze ancien. L'abri sous roche des Balmes à Sollières-Sardières (Savoie), par exemple, livre un corpus de céramiques mêlant des productions connues en Italie, dans la zone méditerranéenne française et dans la vallée du Rhône (Vital 2008). Le phénomène Campaniforme dans les Alpes du Sud peut vraiment être identifié à partir de quelques structures mégalithiques, parmi lesquelles on peut citer le dolmen du Villard daté de 2030+/-120 BC (Le Lauzet-sur-Ubaye, Alpes-de-HauteProvence, Sauzade 1991) ou bien encore le dolmen de Saint-Pancrace (La Bâtie-Neuve, Hautes-Alpes, Morin 2000). Dans cet ensemble se détache un petit groupe de dolmens, dans un demi-cercle de $35 \mathrm{~km}$ à l'est de Gap dont la répartition est liée au réseau hydrographique (Durance, Ubaye et Drac). Ces gisements pourraient permettre d'associer le secteur à la culture campaniforme (Sauzade 1991). Cependant, la rareté des séries de vestiges ne permet pas d'identifier, dans cette partie des Alpes, un groupe culturel en tant que tel. La plupart des chercheurs pensent que le fin du Néolithique a vu une augmentation de la population dans la région (Morin 2000). Ph. Della Casa situe l'amorce de ce mouvement vers $3500 \mathrm{BC}$, période marquée par une péjoration climatique et correspondant à une période de déprise enregistrée sur les sites des lacs jurassiens. Ainsi, les populations contraintes par ces changements ont-elles pu être tentées par un déplacement vers les zones alpines jusque-là beaucoup moins fréquentées. Le Chalcolithique constituerait ainsi la première colonisation intensive et complète des zones alpines centrales où apparaissent les témoins des faciès culturels de Remedello, Horgen, Tamins-Carasso, Ferrières, Fontbouisse et Campaniforme (Della Casa 2003). Dans la région de Monti Lissini (au nord de l'Adige en Italie), L.H. Barfield a mis en évidence une augmentation du nombre des sites et un développement de leur répartition en altitude entre le Néolithique et l'âge du Bronze ancien (Barfield 1990). L'une des motivations principales de l'activité humaine en haute montagne dans certaines régions alpines est alors l'exploitation de minerai et de roches (Barfield 1990). Si l'extraction de minerai de cuivre (bornite) fut importante dans le massif du Queyras (en particulier le site minier des Clausis à Saint-Véran, Hautes-Alpes; Barge et al. 2003), ceci ne semble pas avoir été le cas dans le secteur voisin des Écrins. Les dates radiocarbone de Saint-Véran, toutes situées entre 2400 et 2000 


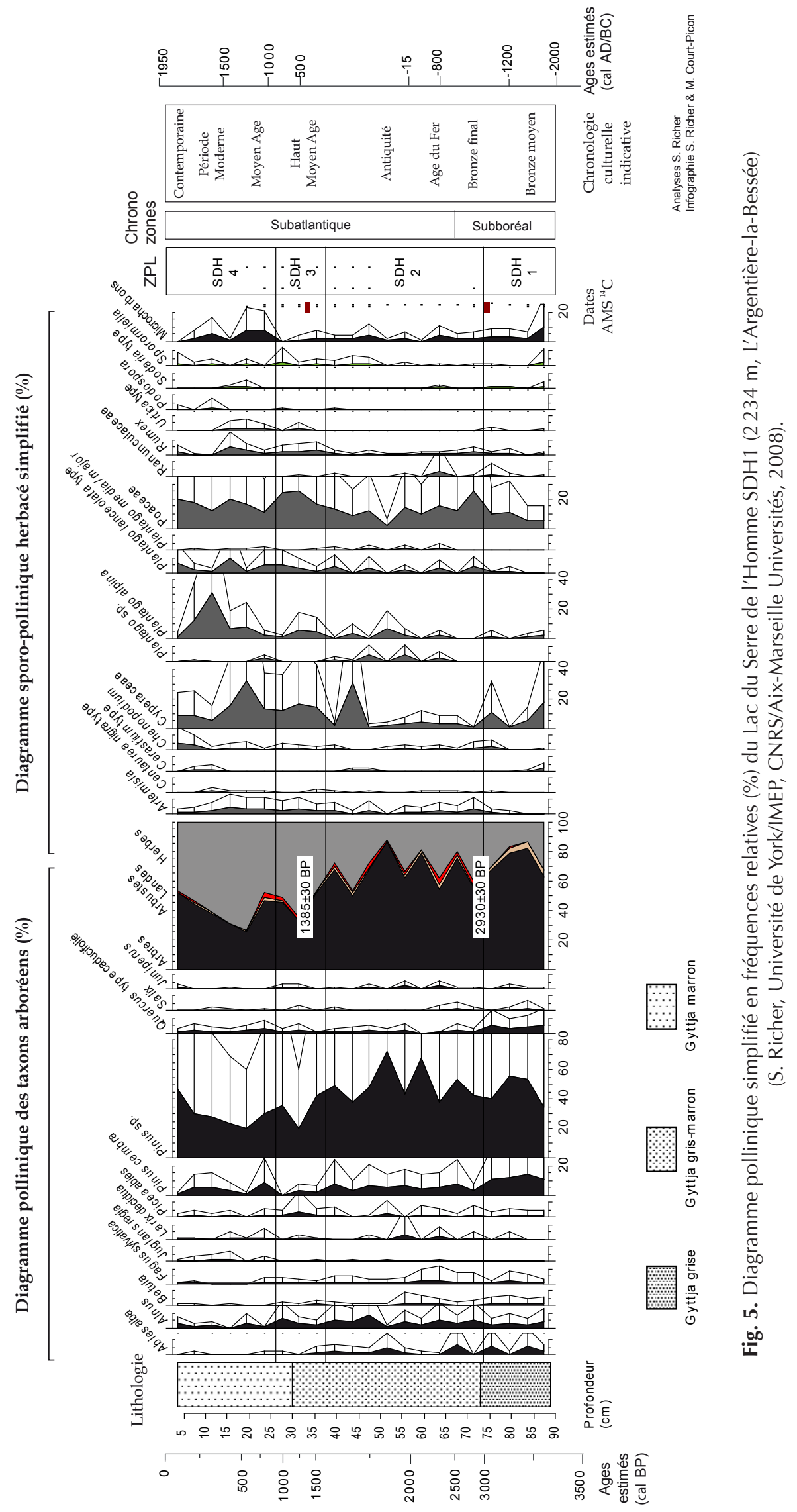


cal. BC (Carozza, Mille 2007), sont contemporaines des changements dans l'exploitation du milieu, observés dans hautes vallées du Parc National des Écrins. L'exploitation du cuivre de Saint-Véran semble être attachée à un réseau incluant la France méridionale et l'Italie septentrionale comme le suggèrent les signatures géochimiques du métal mis au jour dans les sites régionaux (Carozza, Mille 2007). D'autres faits témoignent des liens unissant les Alpes françaises et l'Italie septentrionale. La présence de gravures rupestres figurant des poignards du type Remedello dans la Drôme en est un exemple (Morin et al. 2005). Généralement, ces diverses formes d'art rupestre constituant les données les plus emblématiques de l'arc alpin (si l'on excepte la découverte d'Ötzi), sont identifiées dans deux secteurs: les Alpes-Maritimes françaises d'une part (Mont Bego; De Lumley 1995 et les zones avoisinantes y compris la partie orientale de la vallée d'Ubaye) et les Alpes italiennes centrales et septentrionales d'autre part (Valcamonica). S'il existe des représentations figurant des champs et des sites de fond de vallée (Arcà 1999; 2000; 2004), aucune ne semble correspondre aux structures pastorales découvertes dans le Parc National des Écrins. Cependant, il est intéressant de noter par ailleurs l'existence de ce que G. de Saulieu qualifie d'art discret et qui correspond à une forme d'art rupestre de haute altitude (De Saulieu 2007). Celle-ci se manifeste tout particulièrement entre 2900/2800 et 2500/2400 BC, la fin de cette période correspondant à l'apparition des premières structures de haute altitude dans notre secteur d'étude. De Saulieu considère que cette forme d'art, visible uniquement l'été, était pratiquée par ceux qui étaient sur place. Ces manifestations artistiques sont tout à fait différentes des formes apposées aux structures monumentales situées à basse altitude, visibles quant à elles toute l'année. Il faut souligner, qu'à ce jour, aucune manifestation d'art rupestre n'a été mise en évidence dans les hautes vallées des Écrins. Cette absence est peut-être la conséquence de processus taphonomiques liés notamment à la nature géologique des terrains. Mais elle pourrait refléter tout autant des comportements culturels différents par rapport aux zones d'altitude alpines situées plus à l'est ou au sud.

\section{Conclusion}

Les témoignages de peuplement et d'activité agropastorale acquis grâce à la confrontation des données archéologiques et paléoécologiques, révèlent que les espaces montagnards des hauts massifs de la Vallouise et du Champsaur possédaient un attrait certain, bien au-delà de 2000 m d'altitude et de tous les aspects contraignants inhérents à la haute montagne. Les données archéologiques indiquent une fréquentation ancienne de la haute montagne jusqu'ici insoupçonnées (Paléolithique, Mésolithique). La fin de la Préhistoire et l'âge du Bronze correspondent au début de la présence continue des communautés humaines en altitude, avec notamment l'apparition de structures bâties. Si l'influence des groupes paléolithiques et mésolithiques sur le milieu végétal semble avoir été quasi inexistante, les premiers indices polliniques d'anthropisation apparaissent néanmoins précocement dans ce secteur des Alpes du Sud (entre 6000-4500 BC) y compris dans les zones de haute altitude aujourd'hui supra-forestières. Une tendance forte se dégage pour l'âge du Bronze, malgré des situations locales variées: elle se traduit par une chute progressive des taxons arborescents dans les spectres polliniques au profit des taxons herbacés, confirmant l'abaissement de la limite supérieure des forêts et l'éclaircissement des formations boisées d'altitude (forêts mixtes de pin cembro et de mélèze). Les $\mathrm{II}^{\mathrm{e}}$ et $\mathrm{III}^{\mathrm{e}}$ millénaires $\mathrm{BC}$ connaissent des phases de déboisements/défrichements plus intenses, qui dans la plupart des cas conduisent à une installation saisonnière durable ou du moins à une pérennisation des espaces ouverts (Mocci et al. 2009). De façon presque systématique, les sites qui témoignent de telles dynamiques montrent des modifications trop importantes pour que la végétation puisse retrouver son état antérieur.

$\mathrm{Au}$ cours des $\mathrm{III}^{\mathrm{e}}$ et $\mathrm{II}^{\mathrm{e}}$ millénaires $\mathrm{BC}$, les Alpes méridionales françaises sont marquées par d'importantes innovations témoignant d'un changement radical dans la manière de vivre et d'appréhender les écosystèmes de montagne. Le développement de l'exploitation du cuivre et l'apparition de nouveaux réseaux d'échanges économiques, l'évolution des activités et en particulier celle du pastoralisme d'altitude, une nouvelle perception de la montagne, auraient ainsi constitué les éléments déterminants d'un processus de restructuration de cet espace. Les recherches menées dans le Parc National des Écrins ont ainsi démontré l'émergence d'une nouvelle forme d'activité pastorale, ou du moins, une intensification et une expansion des pratiques pastorales existantes. L'absence de vestiges osseux sur les sites, pour des raisons taphonomiques, ne permet pas d'être affirmatif sur la nature des troupeaux. Depuis le Moyen Âge, les ovins sillonnent ces massifs (Falque Vert 1997) mais rien ne permet d'exclure la présence de bovins durant les époques pré et protohistorique. L'apparition de l'art rupestre à haute altitude, dont les manifestations figurent dans certains cas les objets fabriqués à partir du minerai alpin, est également associée aux changements socio-économiques et culturels. Ces représentations d'objets issus de la paléomanufacture métallique évoquent certaines scènes agricoles (Arcà 2004) exprimant ainsi ce qui était assurément les principaux éléments structurants des paysages alpestres. Toutefois, aucune représentation qui se rapporterait aux activités pastorales n'a semble-t-il été pour l'heure identifiée (Jospin, Favrie 2008). Cela n'exclut pas 
que des pasteurs aient été les auteurs de ces représentations, choisissant délibérément de ne pas évoquer leur quotidien en montagne. Rappelons dans ce contexte que dans le cas de notre zone d'étude, l'absence à ce jour de telles manifestations artistiques ne trouve pas encore d'explication privilégiée. Il reste évidemment difficile d'associer toutes ces données à des faciès culturels particuliers voire de les définir selon une attribution chrono-culturelle fondée sur des modèles dont les racines plongent dans l'archéologie du XIX ${ }^{\mathrm{e}}$ s.... L'approche de la vie quotidienne des hommes vivant et travaillant dans ces écosystèmes importe bien davantage. Leur identité est tout autant définie par l'interaction entre le milieu et leurs activités que par que par sa conformité à telle ou telle typologie céramique (jusque-là absente sur les sites de haute altitude) ou lithique. Il n'en demeure pas moins qu'une telle approche se heurte actuellement à la grande rareté des éléments de la culture matérielle qui laisse bon nombre d'interrogations sans réponse.

\section{Bibliographie}

Arcà 1999: ARCA (A.) - Fields and settlements in topographic engravings of the Copper Age in Valcamonica and Mt. Bego rock art. In: DELLA CASA (P.) ed., Prehistoric alpine environment, society, and economy. Bonn, Rudolf Habelt $\mathrm{GmbH}$, 1999, p. 71-79.

Arcà 2000 : ARCA (A.) - Agricultural landscapes in Neolithic and Copper Age engravings of Valcamonica and Mt Bego rock art. In: NASH (G.) ed., Signifying place and space: world perspectives of rock art and landscape. Oxford, Archaeopress, 200, p. 29-40

Arcà 2004: ARCA (A.) - The topographic engravings of Alpine rock-art: fields, settlements and agricultural landscapes. In : CHIPPINDALE(C.), NASH (G.) ed., The Figured Landscapes of Rock-Art: Looking at Pictures in Place. Cambridge, CUP, 2004, p. 318-349.

Barfield 1990 : BARFIELD (L. H.) - The Lithic Factor: A Study of the Relationship between Stone Sources and Human Settlement in the Monti Lessini and Southern Alps. In: BIAGI (P.), ed. The Neolithisation of the Alpine Region. Brescia, 1990, p. 147-157.

Barge et al. 2003: BARGE (H.), TUDURI (H.), CHAUVET (J.), BARBASON (L.) - Saint-Véran, la montagne, le cuivre et l'Homme. Mine et métallurgie préhistoriques dans les Hautes-Alpes, 181, Theix, Actilia Multimédia.

Beeching 2003: BEECHING (A.) - Mobilité et société néolithiques dans les Alpes occidentales et la France méridionale. Preistoria Alpina, 39, 2003, p. 175-188.

Besse, Mottet 2003 : BESSE (M.), MOTTET (M.) - De la cabane au hameau, du hameau au village: l'habitat néolithique moyen du Petit-Chasseur à Sion (Valais, Suisse). In : BESSE (M.) et al. éd., ConstellaSion: Hommage à Alain Gallay. Lausanne, Cahiers d'Archéologie Romande, 2003, p. 185-192.

Bintz 2004: BINTZ (P.) - Mésolithique et Néolithique ancien. In: JOURDAIN-ANNEQUIN (C.) dir., Atlas culturel des alpes occidentales, De la Préhistoire à la fin du Moyen Âge. Programme ERICA, Picard, Paris, 2004, p. 38-39.

Bintz, Morin 2001 : BINTZ P., MORIN (A.) - Dévoluy. Massifs et piémonts. Bilan Scientifique, Service Rgéional de l'Archéologie de PACA. Aix-en-Provence, Ministère de la Culture et de la Communication, 2001, p. 46.

Bintz, Bracco 2004 : BINTZ (P.), BRACCO (J.-P.) - Paléolithique supérieur récent. In: JOURDAIN-ANNEQUIN (C.) dir., Atlas culturel des alpes occidentales, De la Préhistoire à la fin du Moyen Âge. Programme ERICA, Picard, Paris, 2004, p. 34-35.

Bocquet, 1997: BOQUET (A.) - Archéologie et peuplement des Alpes françaises du Nord au Néolithique et aux âges des Métaux. L'Anthropologie, 101, p. 291-393.

Borrello 2003 : BORELLO (M.-A.) - La circulation de matières premières d'origine méditerranéenne et nord-italienne dans le plateau suisse au Néolithique. Preistoria Alpina, 39, 2003, p. $189-202$.

Bouttevin, Leal, Voyez 2007 : BOUTTEVIN (C.), LEAL (E.), VOYEZ (C.) - La Saulce - ZAC de Gandière. In: Service régional de l'Archéologie de PACA, Bilan Scientifique. Aixen-Provence: Ministère de la Culture et de la Communication, p. 68-69.

Brochier 2005: BROCHIER (J.-E.) - Derniers chasseurs cueilleurs provençaux. In: DELESTRE (X.) dir., Quinze ans d'archéologie en région PACA, Edisud, 2005, pp. 26-31.

Brochier, Beeching 2006: BROCHIER (J.-L.), BEECHING (A.) - Grottes bergeries, pastoralisme et mobilité dans les Alpes au Néolithique. In: JOURDAIN-ANNEQUIN (C.), DUCLOS (J.-C.) éd., Aux origines de la transhumance: les Alpes et la vie pastorale d'hier à aujourd'hui. Paris, Picard, 2006, p. 131-157.

Brochier et al. 1999: BROCHIER (J.-L.), BEECHING (A.), SIDI-MAAMAR (H.), VITAL (J.) - Les grottes-bergeries des Préalpes et le pastoralisme alpin durant la fin de la Préhistoire. In : BEECHING (A.) éd., Circulations et identités culturelles alpines à la fin de la Préhistoire. Valence, Centre d'Archéologie Préhistorique, 1999, p. 77-114.

Broglio 1994: BROGLIO (A.) - Moutain sites in the context of North-East italian Upper Palaeolithic and Mesolithic. Preistoria Alpina, 28, 1994, p. 93-148.

Carozza, Mille 2007: CAROZZA (L.), MiLlE (B.) Chalcolithique et complexification sociale: quelle place pour le métal dans la définition du processus de mutation des sociétés de la fin du Néolithique en France ? In: GUILAINE (J.) éd., Le Chalcolithique et la construction des inégalités. T. I Le continent européen. Paris, Errance, 2007, p. 153-189. 
Clark 1990 : CLARK (R.) - The beginnings of agriculture in subalpine Italy: some theoretical considerations. In: BIAGI (P.) ed., The Neolithisation of the Alpine Region. Brescia, 1990, p. 123-137.

Court-Picon 2007: COURT-PICON (M.) - Mise en place du paysage dans un milieu de moyenne et haute montagne du Tardiglaciaire à l'époque actuelle. Analyse du signal palynologique en Champsaur (Hautes-Alpes, France) à l'interface des dynamiques naturelles et des dynamiques sociales. Thèse de Science, Université de Franche-Comté, 732 p. + annexes.

Court-Picon, Buttler, De Beaulieu 2006: COURT-PICON (M.), BUTTLER (A.), DE BEAULIEU (J.-L.) - Modern pollen/vegetation/land-use relationships in mountain environments: an example from the Champsaur valley (French Alps). Vegetation History and Archaeobotany, 15 (3), 2006, p. 151-168.

Court-Picon et al. 2007: COURT-PICON (M.), WALSH (K.), MOCCI (F.), SEGARD (M.), PALET-MARTINEZ (J.) Occupation de la montagne et transformation des milieux dans lesAlpes méridionales au cours de l'âge du Bronze: approche croisée des données palynologiques et archéologiques en Champsaur et Argentiérois (Hautes-Alpes, France). In: MORDANT (C.) et al. éd., Environnements et cultures à l'âge du Bronze en Europe occidentale. Paris, éditions du CTHS, p. 89-106.

Curdy 2002 : CURDY (P.) dir. - Premiers hommes dans les Alpes de 50000 à 5000 avant Jésus-Christ. Lausanne, Musées cantonaux du Valais, Sion, Payot, 2002, 200 p.

D’Anna 1991: D'ANNA (A.) - Les stations de plein air néolithiques dans les Hautes-Alpes. In: DUSSERRE (G.) éd., Archéologie dans les Hautes-Alpes. Gap, Musée départemental de Gap, 1991, p. 77-80.

De Beaulieu 1977: DE BEAULIEU (J.-L.) - Contribution pollenanalytique à l'histoire tardiglaciaire et holocène des Alpes méridionales françaises. Thèse de doctorat, Université d'AixMarseille III, 1977, 358 p.

De Lumley 1995: DE LUMLEY (H.) - Le Grandiose et le Sacré. Aix-en-Provence, Edisud, 1995, 450 p.

De Saulieu 2007 : DE SAULIEU (G.) - Hiérarchisation sociale et art rupestre dans les Alpes: la figure solaire dans l'art gravé du Chalcolithique et début de l'âge du Bronze. In: GUILAINE (J.) éd., Le Chalcolithique et la construction des inégalités. Paris, Errance, 2007, p. 125-150.

Della Casa 2003 : DELLA CASA (P.) - Concepts of Copper Age mobility in the Alps based on land use, raw materials and a framework of contact. Preistoria Alpina, 39, 2003, p. 203-210.

Deline, Le Roy 2009: DELINE (P.), LE ROY (M.) - Fluctuations des glaciers des Alpes occidentales depuis 5000 ans: un état des connaissances. In: MAGNY (M.), DESMET (M.), MOCCI (F.) éd., « Du Climat à l'Homme, Dynamique holocène de l'environnement », Actes du Colloque du GDR JurAlpes (Aix-en-Provence, 15-16 novembre 2007), Cahiers de Paléoenvironnement, 6-2008, Coll. Edytem, Chambéry, 2009, p. 13-28.

Falque-Vert 1997: FALQUE VERT (H.) - Les hommes et la montagne en Dauphiné au XIII ${ }^{e}$ s., Presses Universitaires de Grenoble, Grenoble, 1997, 520 p.

Fedele 1990: FEDELE (F.) - Prehistoric and ancient man at higher altitudes and latitudes. European mountains : the Alps. In: Impact of the prehistoric and medieval man on the vegetation: man at the forest limit. Strasbourg, 1990, p. 25-29.

Fontana, Vullo 2000: FONTANA (F.), VULLO (N.) Organisation et fonction d'un camp de base saisonnier au cœur des Dolomites: le gisement mésolithique de Mondeval de Sora (Belluno, Italie). In: RICHARD (A.) et al. dir., Les derniers chasseurs-cueilleurs d'Europe occidentale (130005500 av. n. ̀̀.), Actes du colloque international de Besançon (23 - 25 octobre 1998). Besançon, 2000, p. 197-208.

Gagnepain, Bracco, Bertran 1999: GAGNEPAIN (J.), BRACCO (J.-P.), BERTRAN (P.) et coll. Saint-Antoine à Vitrolles, locus 2 (Hautes-Alpes): premiers résultats des fouilles de sauvetage urgent (1995-1996) d'un gisement épigravettien. Bulletin de la Société Préhistorique Française, 96, 2, 1999, p. 191-202.

Gallay 1990: GALLAY (A.) - La place des Alpes dans la néolithisation de l'Europe. In: BIAGI (P.), ed. The Neolithisation of the Alpine Region. Brescia, 1990, p. 23-42.

Garcia et al. 2007: GARCIA (D.), MOCCI (F.), TZORTZIS (S.), WALSH (K.) avec la collaboration de DUMAS (V.) - Archéologie de la vallée de l'Ubaye (Alpes-de-hauteProvence, France): premiers résultats d'un Projet Collectif de Recherche. In: DELLA CASA (P.), WALSH (K.), Interpretation of sites and material culture from mid-high altitude mountain environments: proceedings of the 10th annual meeting of the European association of archaeologists 2004Lyon, Preistoria Alpina, 42, Trento, Museo Tridentino di scienze naturali, 2007, p. 23-48.

Jospin, Favrie 2008: JOSPIN (J.-P.), FAVRIE (T.) - Premiers Bergers des Alpes de la Préhistoire à l'Antiquité, Catalogue exposition au Musée Dauphinois, avril 2008-juin 2009, Grenoble, Infolio Edition, 159 p.

Jorda 1988: JORDA (M.) - Modalités paléoclimatiques et chronologiques de la déglaciation würmienne dans les Alpes françaises du Sud (bassin durancien et Alpes-de-HauteProvence). Bulletin de l'Association Française pour l'Étude du Quaternaire, 2/3, 1988, p. 111-122.

Jorda 1991: JORDA (M.) - Un milieu naturel montagnard et des hommes : lectures du paysage haut-alpin. In : DUSSERRE (G.), éd. Archéologie dans les Hautes-Alpes. Gap, Musée départemental de Gap, 1991, p. 33-50.

Leveau, Walsh 2005 : LEVEAU (P.), WALSH (K.) - Population sequences in a high altitude alpine environment: archaeological sites and historical and environmental time, International Journal of Anthropology, 20: 3/4, p. 155-171. 
Lichardus et al. 1985 : LICHARDUS (J.), LICHARDUS-ITTEN (M.), BAILLOUD (G.), CAUVIN (J.) - La Protohistoire de l'Europe: Le Néolithique et le Chalcolithique. Paris, Nouvelle Clio, Presses Universitaires de France, 1985, 640 p.

Magny 2004: MAGNY (M.) - Holocene climate variability as reflected by mid-european lake-level fluctuations and its probable impact on prehistoric human settlements. Quaternary International, 113, 2004, p. 65-79.

Magny et al. 2006: MAGNY (M.), LEUZINGER (U.), BORTENSCHLAGER (S.), HAAS (J. N.) - Tripartite climate reversal in Central Europe 5600-5300 years ago. Quaternary Research, 65, New York London- Academic Press, p. 3-19.

Magny, Desmet, Mocci 2009: MAGNY (M.), DESMET (M.), MOCCI (F.) ed. - « Du Climat à l'Homme, Dynamique holocène de l'environnement », Actes du Colloque du GDR JurAlpes (Aix-en-Provence, 15-16 novembre 2007), Cahiers de Paléoenvironnement, 6-2008, Coll. Edytem, Chambéry, 2009, 280 p.

Magny, Haas 2004: MAGNY (M.), HAAS (J. N.) - A major widespread climatic change around $5300 \mathrm{cal}$. BP at the time of the Alpine Iceman. Journal of Quaternary Science, 19, 2004, p. 423-430.

Mocci et al. 2006: MOCCI (F.), TZORTZIS (S.), PALETMARTINEZ (J.), SEGARD (M.), WALSH (K.) - Peuplement, pastoralisme et modes d'exploitation de la moyenne et haute montagne depuis la Préhistoire dans le Parc National des Écrins (vallées du Haut-Champsaur et de Freissinières, Hautes-Alpes). In: VERDIN (F.), BOUET (A.) éd., Territoires et paysages de l'âge du Fer au Moyen Âge, Mélanges offerts à Philippe Leveau, Collection Ausonius, Université de Bordeaux, 2006, p. 197-212.

Mocci et al. 2008: MOCCI (F.), WALSH (K.), TALON (B.), TZORTZIS (S.), COURT-PICON (M.), avec la collaboration de BRESSY (C.), DUMAS (V.), GASSEND (J.-M.), PY (V.) - Structures pastorales d'altitude et paléoenvironnment. Alpes méridionales françaises du Néolithique final à l'âge du Bronze. Premiers Bergers des Alpes de la Préhistoire à l'Antiquité, Catalogue exposition au Musée Dauphinois, avril 2008-juin 2009, Grenoble, Infolio Edition, p. 92-101

Mocci et al. 2009: MOCCI (F.), WALSH (K.), RICHER (S.), COURT-PICON (M.), TALON (B.), TZORTZIS (S.), PALET-MARTINEZ (J.), BRESSY (C.) avec la collaboration de BEAULIEU (J.-L. de), DUMAS (V.), ÉDOUARD (J.-L.), PY (V.) - Archéologie et paléoenvironnement dans les Alpes méridionales françaises. Hauts massifs de l'Argentiérois, du Champsaur et de l'Ubaye (Hautes-Alpes et Alpes de Haute Provence) (Néolithique final - début de l'Antiquité). In: MAGNY (M.), DESMET (M.), MOCCI (F.) ed., « Du Climat à l'Homme, Dynamique holocène de l'environnement ", Actes du Colloque du GDR JurAlpes (Aix-en-Provence, 15-16 novembre 2007), Cahiers de Paléoenvironnement, 6-2008, Coll. Edytem, Chambéry, 2009, p. 235-254.

Morin 2000: MORIN (A.) - État documentaire sur le Néolithique final dans la zone préalpine: massifs et piedmonts de la Chartreuse, du Vercors, et pays du Buëch. In: TILLET (T.) éd., Les paléoalpins. Hommage à Pierre Bintz. Grenoble,
Laboratoire de géodynamique des chaînes alpines - Université Joseph Fourier, 2000, p. 211-229.

Morin 2005: MORIN (A.) - Les ambiances culturelles néolithiques «haut-alpines» et leur insertion dans le contexte du bassin rhodanien. In: NICAULT (J.) éd., Vie, culture et société dans les Alpes : actes du colloque international d'Histoire et d'Archéologie sur l'Arc alpin - Gap, 28-29 septembre 2002. Gap, Louis Jean, 2005, p. 29-56.

Morin et al. 2005: MORIN (A.), PICAVET (R.), CARLES (J.), BERNARD (C.) - Étude preliminaire sur des poignards graves de type Remedello decouverts dans les Préalpes du Sud (Chastel-Arnaud, Drôme, France) et réflexions sur leur insertion dans le Néolithique final régional. Bulletin de la Société Préhistorique Francaise, 102, 2, 2005, p. 345-360.

Muret 2006: MURET (A.) dir. - Le gisement archéologique du col des Tourettes à Montmorin (Hautes-Alpes). Theix, Actilia Multimedia, 2006, $160 \mathrm{p}$.

Muret, D’Anna, Jaubert 1991: MURET (A.), D'ANNA (A.), JAUBERT (J.) JORDA (M.) - Un gisement tardiglaciaire de plein-air dans les Alpes du Sud: Saint-Antoine (Vitrolles, Hautes-Alpes). Bulletin de la Société Préhistorique Française, 88, 2, 1991, p. 49-57.

Nakagawa 1998: NAKAGAWA (T.) - Études palynologiques dans les Alpes françaises centrales et méridionales: histoire de la végétation tardiglaciaire et holocène. Thèse de doctorat, Université d'Aix-Marseille III, 211 p.

Nicod 2008: NICOD (P.-Y.) - Les premières sociétés agropastorales dans les Alpes occidentales. In : JOSPIN (J.-P.), FAVRIE (T.) éd., Premiers bergers des Alpes. Gollion, Infolio, Musée Dauphinois, 2008, p. 45-51.

Nicod, Picavet 2003: NICOD (P.-Y.), PICAVET (R.) - La stratigraphie de la Grande Rivoire (Isère, France) et la question de la néolithisation alpine. In: BESSE (M.) et al. éd., ConstellaSion: Hommage à Alain Gallay. Lausanne, Cahiers d'Archéologie Romande, 2003, p. 147-168.

Palet-Martinez, Ricou, Segard 2003: PALET-MARTINEZ (J.-M.), RICOU (F.), SEGARD (M.) - Prospections et sondages sur les sites d'altitude en Champsaur (Alpes du Sud). Archéologie du Midi Médiéval, 21, p. 199-210.

Pétrequin et al. 2007: PETREQUIN (P.), PETREQUIN (A.M.), ERRERA (M.), CASSEN (S.), CROUTSCH (C.), DUFRAISSE (A.), GAUTHIER (E.), ROSSY (M.) - In: PETREQUIN (P.) dir., La pierre en milieu alpin de la Préhistoire au Moyen Âge. Exploitation, utilisation, diffusion, XIe colloque international sur les Alpes dans l'Antiquité, La pierre en milieu alpin (Champsec / Val de Bagnes / Valais-Suisse, 15-17 septembre 2006). Bulletin d'Études Préhistoriques et Archéologiques Alpines, Société Valdôtaine de Préhistoire et d'Archéologie, numéro spécial, Aoste, 2007, p. $167-188$

Pétrequin et al. 2008: PETREQUIN (P.), SHERIDAN (A.), CASSEN (S.), ERRERA (M.), GAUTHIER (E.), KLASSEN (K.), LE MAUX (N.), PAILLER (Y.) - Neolithic alpine axeheads, from the continent to Great Britain, the Isle of Man and Ireland. In: FOKKENS (H.) et al. ed., Between Foraging 
and Farming. An extended broad spectrum of papers presentend to L. Louwe Kooijmans. Leiden., Analecta Praehistorica Leidensia, 40, p. 261-279.

Phillips 1972: PHILLIPS (P.) - Population, economy and society in the Chassey-Cortaillod-Lagozza cultures. World Archaeology, 4, 1, 1972, p. 41-56.

Pion 2004: PION (G.) - Magdalénien, Epipaléolithique et Mésolithique ancien au Tardiglaciaire dans les deux Savoie et le Jura méridional, Thèse de doctorat, Université de Besançon, 2004.

Primas 1999: PRIMAS (M.) - From fiction to facts. Current research on prehistoric human activity in the Alps. In : DELLA CASA (P.) ed., Prehistoric alpine environment, society and economy. Bonn, Rudolf Habelt GmbH, 1999, p 1-10.

Py, Ancel 2007 : PY (V.), ANCEL (B.) - Exploitation des mines métalliques de la vallée Freissinières (Hautes-Alpes, France): Contribution à l'étude de l'économie sud-alpine aux IX ${ }^{\mathrm{e}}-\mathrm{XIII}{ }^{\mathrm{e}} \mathrm{s}$., Actes du Colloque International de European Archaelogical Association (Lyon sept. 2005), Preistoria Alpina, 42, Museo Tridentino di Scienze Naturali, Trento, p. 83-98

Rey et al. 2009: REY (P.-J.), TREFFORT (J.-M.), MOULIN (B.), OBERLIN (C.), ANDRE (I.) - Archéologie des versants du Petit-Saint-Bernard: première approche de la dynamique de l'occupation humaine autour d'un grand passage alpin, de la Préhistoire au début du Moyen Âge. In: MAGNY (M.), DESMET (M.), MOCCI (F.) éd., Du Climat à l'Homme, Dynamique holocène de l'environnement, Actes du Colloque du GDR JurAlpes (Aix-en-Provence, 15-16 novembre 2007), Cahiers de Paléoenvironnement, 6-2008, Coll. Edytem, Chambéry, 2009, p. 209-224

Richard 2004: RICHARD (H.) dir. - Néolithisation précoce: premières traces d'anthropisation du couvert végétal à partir des données polliniques. Besançon, Presses Universitaires Franc-Comtoise, 2004, 219 p.

Richard, Magny, Mordant 2007: RICHARD (H.), MAGNY (M.), MORDANT (C.) dir. - Environnement et Culture à l'âge du Bronze en Europe occidentale, Éditions du CTHS, Paris, 2007.

Richer 2009: RICHER (S.) - From pollen to people: the interaction between people and their environment in the mid- to high-altitudes of the Southern French Alps. Thesis, University of York, 2009.

Sauzade 1991: SAUZADE (G.) - Le mégalithisme dans les Alpes. In : DUSSERRE (G.) éd., Archéologie dans les HautesAlpes. Gap, Musée départemental de Gap, 1991, p. 93-100.

Sauzade, Carry, Chambert 1990: SAUZADE (G.), CARRY (A.), CHAMBERT (A.) - Un nouveau faciès du Néolithique final provençal: le groupe du Fraischamp. L'habitat de la Clairière à la Roque-sur-Pernes (Vaucluse). GalliaPréhistoire, 32, 1990, p. 151-178.

Segard et al. 2003: SEGARD (M.), WALSH (K.), COURTPICON (M.) avec la collaboration de MOCCI (F.) et PALET-MARTINEZ (J.-M.) - L'occupation de la haute montagne dans les Alpes occidentales. Apport de l'archéologie et des analyses paléoenvironnementales. In: BOËTSCH (G.), DEVRIENDT (W.), PIGUEL (A.) éd., Permanence et changements dans les sociétés alpines, Actes du colloque de Gap, juillet 2002, Aix-en-Provence, Edisud, 2003, p. 17-30

Thirault 2005: THIRAULT (E.) - The politics of supply: the Neolithic axe industry in Alpine Europe. Antiquity, 79, 303, 2005, p. 34-50.

Tzortzis et al. 2008: TZORTZIS (S.), MOCCI (F.), WALSH (K.), TALON (B.), COURT-PICON (M.), DUMAS (V.), PY (V.), RICHER (S.) - Les massifs de L'Argentiérois du Mésolithique au début de l'Antiquité: au croisement des données archéologiques et paléoenvironnementales en haute montagne (Hautes-Alpes, Parc National des Écrins). In: RICHARD (H.), GARCIA (D.) dir., Le peuplement de l'arc alpin. 131 congrès annuel des Sociétés Historiques et Scientifiques, Grenoble, 2006. Paris, CD Rom, éditions du CTHS, 2008, p. 123-148.

Vital 2008: VITAL (J.) - Témoins du pastoralisme dans les Alpes nord-occidentales aux âges des Métaux. In : JOSPIN (J.-P.), FAVRIE (T.), éd. Premiers bergers des Alpes. Gollion, Infolio, Musée Dauphinois, 2008, p 84-89.

Walsh 2005: WALSH (K.) - Risk and marginality at high altitudes: new interpretations from fieldwork on the Faravel Plateau, Hautes-Alpes. Antiquity, 79, p. 289-305.

Walsh et al. 2005: WALSH (K.), MOCCI (F.), COURT-PICON (M.), PALET-MARTINEZ (J.), TZORTZIS (S.), avec la collaboration de DUMAS (V.), PY (V.), SEGARD (M.) et TALON (B.) - Dynamique du peuplement et activités agro-pastorales durant l'âge du Bronze dans les massifs du Haut-Champsaur et de la vallée de Freissinières (Hautes-Alpes, Parc National des Écrins), Documents d'Archéologie Méridionale, 28, p. $25-44$

Walsh, Mocci 2003: WALSH (K.), MOCCI (F.) avec la collaboration de DUMAS (V.), DURAND (A.), TALON (B.), TZORTZIS (S.) - Neuf mille ans d'occupation du sol en moyenne montagne: la vallée de Freissinières dans le Parc National des Écrins (Freissinières, Hautes-Alpes). Archéologie du Midi médiéval, 21, p. 185-198

Walsh, Mocci, Palet-Martinez 2007: WALSH (K.), MOCCI (F.), PALET-MARTINEZ (J.) - Nine thousand years of human/landscape dynamics in a high altitude zone in the southern French Alps (Parc National des Écrins, HautesAlpes). Preistoria Alpina, 42, 2007, p. 9-22.

Walsh, Richer 2006: WALSH (K.), RICHER (S.) - Attitudes to altitude: changing meanings and perceptions within a "marginal" Alpine landscape - the integration of palaeoecological and archaeological data in a high altitude landscape in the French Alps. World Archaeology, 38, 2006, p. 436-454. 


\title{
Structures pastorales sur les Hauts Plateaux du Vercors et les Hauts de Chartreuse
}

\author{
Alexandre MORIN*, Loïc SERRIÈRES*, Régis PICAVET* \\ avec la collaboration de Pierre-Yves CARRON***, Jean-Pascal JOSPIN****, \\ Yannick TeYSSONNEYRE*****, Christophe GRIGGO******, Fabrice MOUTHON*******
}

\begin{abstract}
Résumé. Depuis 2000, plusieurs campagnes de prospection ont été conduites sur les Hauts Plateaux du Vercors, les Hauts de Chartreuse et le massif du Dévoluy afin d'inventorier les structures en pierres sèches qui ont, pour la plupart, une fonction pastorale. En 2003 et 2005, deux campagnes de prospection, assorties de quelques micro-sondages, se sont déroulées sur les Hauts Plateaux du Vercors (Chichilianne, Isère et Treschenu-Creyers, Drôme). En 2007, un inventaire a été réalisé sur les Hauts de Chartreuse, sur les alpages de l'Alpe, du Pinet et de l'Alpette (Sainte-Marie-du-Mont et Chapareillan, Isère). Bien que les résultats de ces recherches soient encore fort modestes, ils ont néanmoins permis d'obtenir des premières données sur l'origine des activités pastorales (Hauts plateaux du Vercors) et de dresser des inventaires sur lesquels pourront s'appuyer de futures recherches.
\end{abstract}

\section{Pastoral structures in the high Vercors Plateau and the Hauts de Chartreuse}

Abstract. Several prospection campaigns have been run in the high Vercors plateaus, the Hauts de Chartreuse and the Dévoluy range since 2000 with a view to cataloguing the drystone structures, most of which were built for sheep and cow-raising purposes. Two prospection campaigns and some micro-coring procedures were carried out in the high Vercors plateaus (at Chichilianne in the Isère and Treschenu-Creyers in the Drôme) in 2003 and 2005. An inventory was drawn up in the Hauts de Chartreuse on the pastures of the Alpe, the Pinet and the Alpette (Sainte-Marie-du-Mont and Chapareillan in the department of Isère) in 2007. Although the results obtained so far are fairly modest, they provide some initial information about how pastoral activities started (in the high Vercors plateaus), and the inventories produced so far could serve as a basis for future researches.

Les travaux conduits dans la montagne pyrénéenne depuis une vingtaine d'années (Rendu 2003) et plus récemment dans les Alpes du Sud (Walsh et al. 2005; et contributions dans ce volume) ont démontré que les structures pastorales étaient un axe de recherche pertinent pour aborder, en diachronie, l'histoire de l'exploitation du milieu montagnard. Ces recherches ont permis de renouveler profondément les connaissances sur l'histoire de l'anthropisation de la montagne et sur l'économie des sociétés montagnardes, donnant toute sa place au pastoralisme. L'étude des sites de piémonts permet de restituer une image plus complète du pastoralisme en montagne, notamment pour les périodes anciennes. C'est par exemple le cas au nord du massif du Vercors, à l'entrée des gorges du Furon, où l'abri sous roche de la Grande Rivoire en cours de fouille, a fourni des formations de fumiers issues de la stabulation de troupeaux pour les horizons du Néolithique datés entre 5000 et 2500 ans av. J.-C. (Nicod et al. 2008).

C'est fort de ces acquis que plusieurs campagnes de prospection ont été conduites en Dauphiné, dans les massifs du Dévoluy dès 2000, puis sur les Hauts Plateaux du Vercors en 2003 et 2005, et enfin sur les Hauts de

\footnotetext{
* Société Paleotime, 272 rue du Lycée Polonais, 38250 Villard de Lans et UMR 6636 LAMPEA, ERPPA, Institut Dolomieu, 15 rue Maurice Gignoux, 38031 Grenoble cedex.

** Université Pierre Mendès-France, Grenoble II, BP 47, 38040 Grenoble.

*** Service du Patrimoine culturel, Conseil général de l'Isère, BP 1096, 38022 Grenoble.

**** Musée Dauphinois, 30 rue Maurice Gignoux, 38000 Grenoble.

***** Université de Provence, Centre Camille Jullian, MMSH, 5, rue du Château de l'Horloge, BP 647, 13094 Aix-en-Provence.

****** Université Joseph Fourier, UMR 6636 LAMPEA, ERPPA, Institut Dolomieu, 15 rue Maurice Gignoux, 38031 Grenoble Cedex.

******** Université de Savoie, 27 rue Marcoz, 73000 Chambéry.
} 


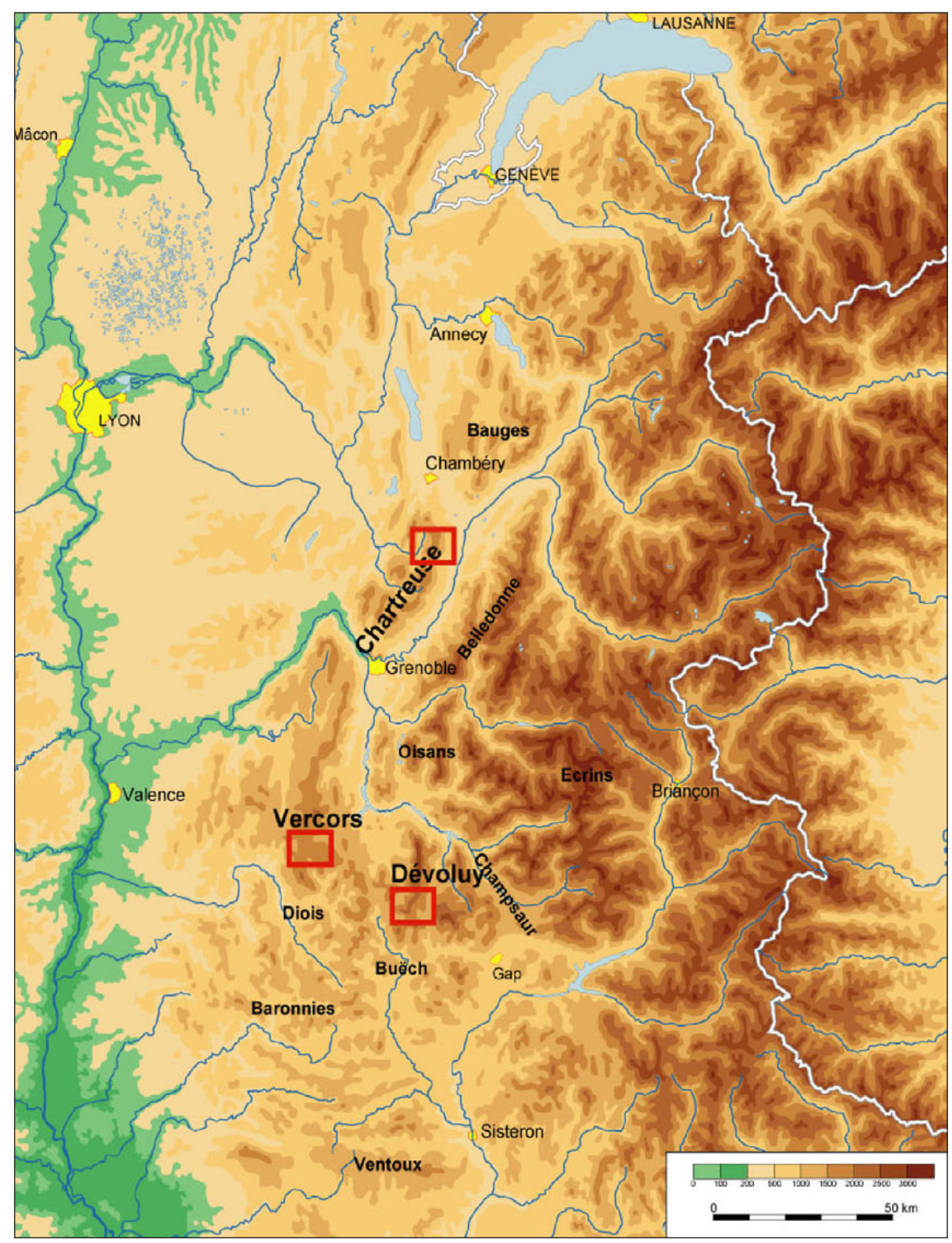

Fig. 1. Les zones prospectées de 2000 à 2007. Hauts de Chartreuse, Hauts Plateaux du Vercors et Dévoluy (fond de carte - AVDPA).

Chartreuse en 2007 (fig. 1). Les résultats des prospections en Dévoluy - où l'étude des structures pastorales était annexe - ont été commentés ailleurs (Morin et Picavet 2006) et nous nous limiterons ici aux résultats plus récents obtenus sur les Hauts Plateaux du Vercors (communes de Chichilianne, Isère, et de Treschenu-Creyers, Drôme) et sur les Hauts de Chartreuse (communes de Sainte-Mariedu-Mont et de Chapareillan en Isère). La méthodologie employée a cependant différé dans les deux cas. Dans le Vercors, les prospections furent lancées dans des zonestests et quinze micro-sondages $(50 \times 50 \mathrm{~cm})$ ont pu être réalisés afin d'apporter des éléments de datation (Morin, Picavet 2004 ; 2005 ; Picavet, Morin 2008). En Chartreuse, la collaboration entre archéologues, historiens, bergers et topographe a permis de dresser des descriptions complètes et de tenter des interprétations fonctionnelles. Une large part a été réservée aux enquêtes orales auprès des bergers actuels (Morin et al. 2007).

\section{Cabanes et enclos des Hauts Plateaux du Vercors}

Les Hauts Plateaux du Vercors sont situés dans la partie méridionale du massif. Ils constituent un immense territoire de calcaire urgonien, couvert de prairies destinées à un pâturage presque exclusivement ovin, de fôrets et de lapiaz. Les ressources en eau y sont très limitées et cela a eu 
des conséquences directes sur la fréquentation de l'homme et ses activités dès la Préhistoire. Les prospections sur les structures pastorales se sont déroulées dans un quadrilatère allant de la Bergerie de Jasneuf (1627 m) au nord, au secteur de l'Échelle (1866 m) au sud, et du Pas de l'Aiguille (1622 m) et Pas de l'Essaure (1714 m) à l'est, au Col des Bachassons (1661 m) à l'ouest.

\section{Typologie des structures}

Les 36 structures inventoriées sur les Hauts Plateaux, réunissant 53 cabanes et 26 enclos, ont été distinguées en six types:

- la cabane, apparemment isolée, souvent bien bâtie qui pourrait être l'habitat du berger ou être un lieu d'activités distinct du pastoralisme (coupe des foins, récolte de la poix);

- la cabane et son enclos: c'est la jasse, la cabane de berger et son enclos à brebis à proximité immédiate ;

- la cabane accompagnée de plusieurs enclos;

- plusieurs cabanes et plusieurs enclos;

- plusieurs cabanes apparemment isolées: dans ce cas, l'absence d'enclos pourrait indiquait un élevage bovin ou d'autres activités, à moins que les enclos n'aient pas été repérés sur le terrain;

- l'enclos seul. L'enclos peut être également associé à une ou plusieurs cabanes non repérées.

Toutes les structures ne sont pas liées au pastoralisme. Une ou deux cabanes sont liées à des activités de charbonniers et sept structures semblent avoir des fonctions diversifiées dans lesquelles le pastoralisme n'a pu être qu'une activité parmi d'autres, secondaire voire absente.

On le sait, le parcage est nécessaire pour les moutons mais peu fréquent pour les vaches. Le critère de l'absence d'enclos n'est cependant pas suffisant pour faire la distinction entre élevage bovin et ovin. Beaucoup d'enclos devaient, au moins en partie, être constitués de branchages, de «floquettes» dont il ne reste rien aujourd'hui.

Sur l'est des Hauts Plateaux, quand on quitte le secteur de Chevalière pour arriver à Chamousset et quand on quitte le vallon de Combeau pour arriver à Pré de la Font, l'estive bovine implantée dans ces secteurs en raison de la présence de sources pérennes, laisse place à l'estive ovine. Le lapiaz devient plus présent, l'eau est quasiment absente, l'ambiance plus aride. C'est le règne de la brebis, avec un véritable mitage des jasses, de la petite unité, évoquant plutôt la «remue», au grand complexe de la grande transhumance.

\section{Des structures pastorales dès l’Antiquité tardive?}

Quatre structures (structure 4 du Jas de l'Échelle 2, structures 31, 32 et 37 de l'Essaure) ont fourni des vestiges datant de l'Antiquité tardive (Morin, Picavet 2004
- déterminations J.-P. Jospin; Teyssonneyre 2005; Morin, Picavet 2008).

Implantée sur une petite butte à 1720 m d'altitude, la jasse de l'Échelle est une cabane rectangulaire d'environ $20 \mathrm{~m}^{2}$ entourée d'un vaste enclos de $85 \mathrm{~m}$ de large. Le bâti est conservé sur 1,50 m de haut pour un de large. Ce bon état de conservation indique que la jasse était utilisée encore récemment. À l'intérieur de la cabane, un micro-sondage a livré une vingtaine de tessons et quelques ossements dont certains brûlés. Un bord à lèvre rabattue de céramique commune indiquerait les $\mathrm{IV}^{\mathrm{e}}-\mathrm{VI}^{\mathrm{e}} \mathrm{s}$.

Trois jasses ont été sondées dans le secteur de l'Essaure (structures 37, 31 et 32). La première (structure 37 ) est placée sur une petite butte à $1668 \mathrm{~m}$ d'altitude. Il s'agit d'une cabane rectangulaire fortement arasée d'une vingtaine de mètres carrés. Un micro-sondage a livré des fragments d'os et de silex (pierres à feu), quelques clous, des tessons vernissés et quelques fragments de céramique commune. Des tessons à décor de stries et de triangles faits à la molette pourraient indiquer le Haut Moyen Âge. La deuxième jasse (structure 31) est mal conservée. Construite à $1676 \mathrm{~m}$ au pied d'une barre rocheuse, elle est composée d'une cabane rectangulaire d'une cinquantaine de $\mathrm{m}^{2}$, enserrée par deux vastes enclos mitoyens (fig. 2). Le micro-sondage a livré quelques tessons et des charbons. Un fragment de panse de céramique kaolinitique rappelle les pots à cuire de l'atelier de la Répara, près de Crest en Drôme, datés des IV $\mathrm{IV}^{\mathrm{e}} \mathrm{V}^{\mathrm{e}} \mathrm{s}$.

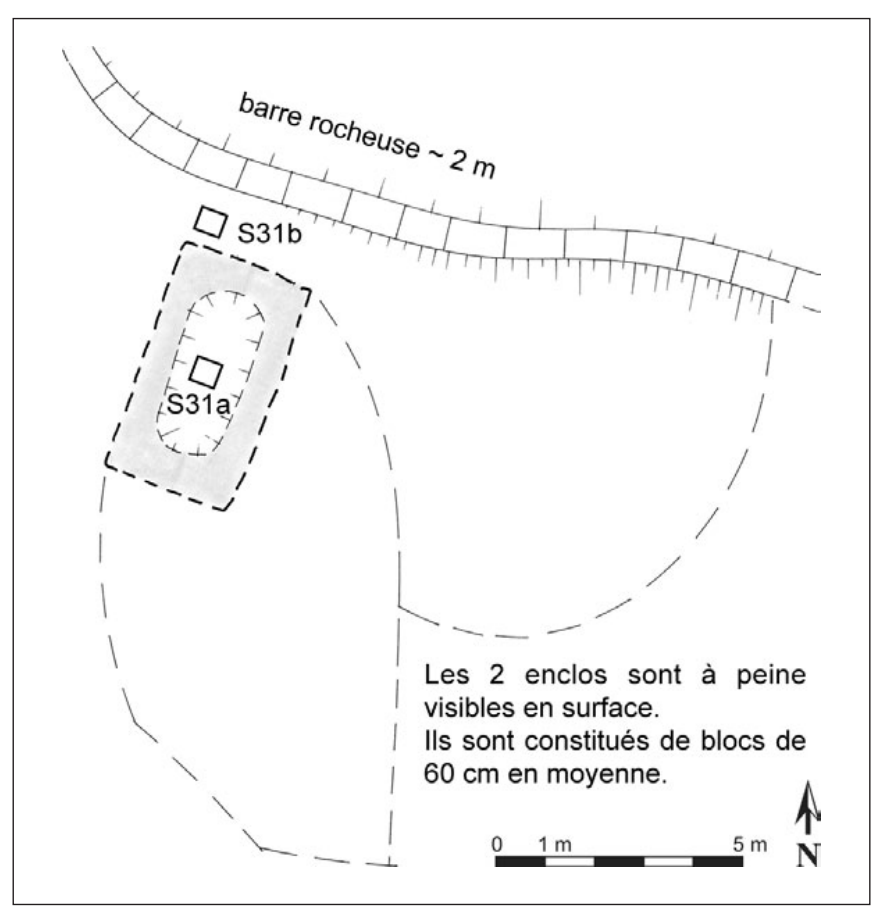

Fig. 2. La structure 31. Relevé de la cabane, des enclos et implantation des sondages (S31a et S31b). Relevé R. Picavet et A. Morin. 

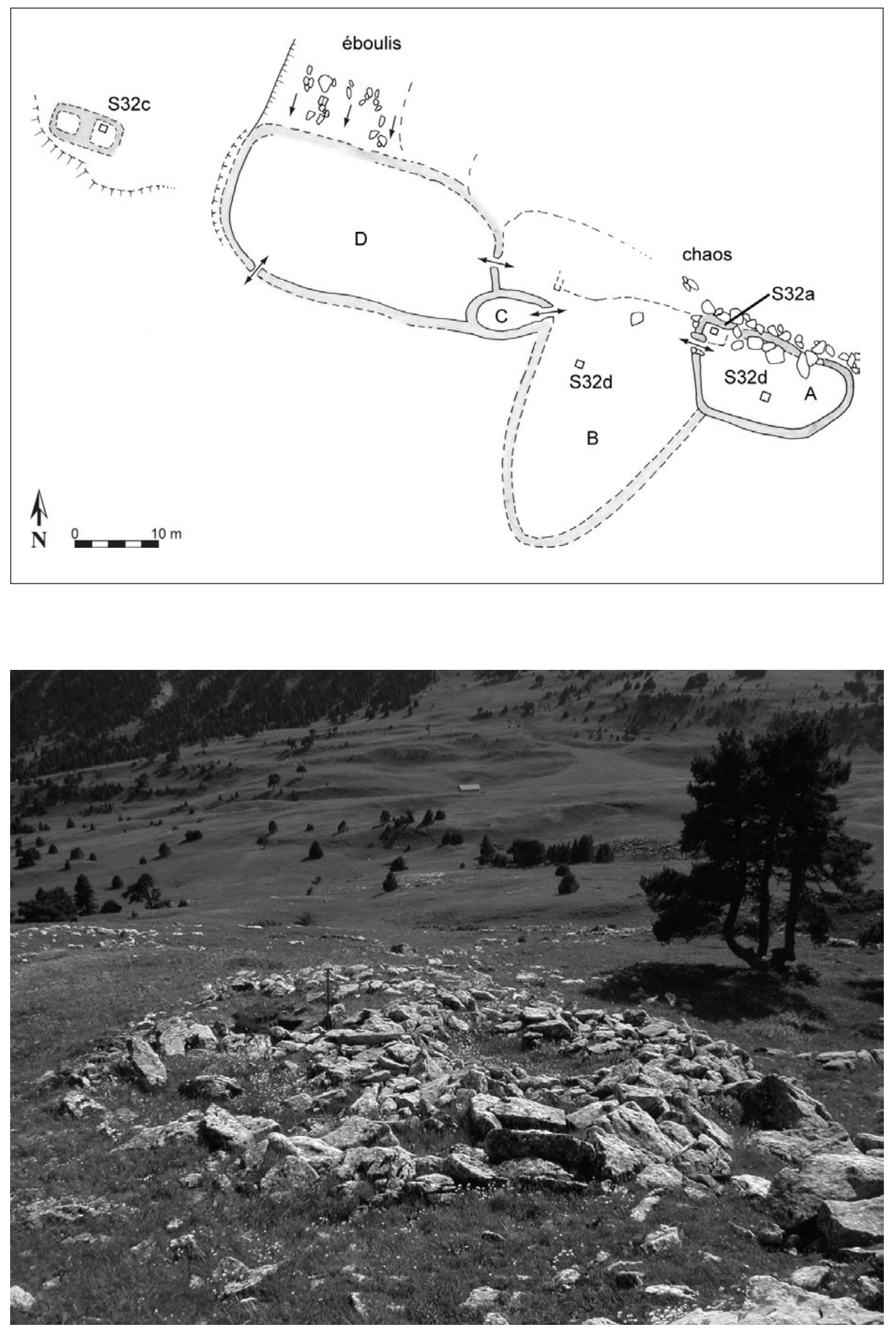

Fig. 3. La structure 32. Relevé des enclos, des cabanes et localisation des sondages (S32a à S32d). Relevé R. Picavet et A. Morin.
Fig. 4. Cabanes de la structure 32. Cliché A. Morin.
La troisième jasse (structure 32) a été construite en pied de pente, à $1684 \mathrm{~m}$ d'altitude. Elle est composée de deux cabanes rectangulaires d'environ $16 \mathrm{~m}^{2}$ et de quatre enclos attenant pour une superficie totale de $730 \mathrm{~m}^{2}$ (fig. 3 et 4). Un micro-sondage dans la cabane a livré des charbons et quelques tessons. Un bord de jatte carénée, à lèvre éversée, indiquerait les $\mathrm{V}^{\mathrm{e}}-\mathrm{VI}^{\mathrm{e}} \mathrm{s}$.

La période médiévale classique est également représentée au sein du matériel, notamment par la présence d'un clou de fer à cheval et de différents autres types de clous (cabane 
de la Jasse de l’Échelle), ainsi que de rares tessons de céramique datés des $\mathrm{XI}^{\mathrm{e}}-\mathrm{XII}{ }^{\mathrm{e}} \mathrm{s}$. (cabanes de l'Essaure).

La période est également documentée par une découverte originale. Grâce à J.-M. Roche, G. André et avec la collaboration de spéléologues, une série importante d'ossements provenant de la grotte du Biscordat, près du jasse de la Playe, a pu être étudiée par C. Griggo et T. Dokatanova. Les déterminations ont révélé la présence de 3 chiens, 11 sangliers ou porcs, un âne très âgé (traces d'arthrose sur les phalanges), 9 bœufs, 4 moutons/chèvres et un enfant de moins de dix ans. Les ossements sont en bon état et souvent complets. Seules deux pièces portent des traces de découpes. La position du puits, au fond de la salle d'entrée, laisse à penser que les animaux ont été placés là par l'homme, à l'exception des trois chèvres qui semblent mortes de faim après leur chute. Les traces de découpe sur une des phalanges du vieil âne confirment que c'est l'homme qui l'a volontairement jeté dans le puits après sa mort. Si la mort de l'enfant reste à expliquer, ces résultats font penser à un dépotoir, une «poubelle de bergers ». Des datations ${ }^{14} \mathrm{C}$ sur un humérus d'enfant, un humérus de suiné et un métatarse de boviné datent l'ensemble, qui paraît relativement synchrone, du IX ${ }^{\mathrm{e}} \mathrm{s}$. Globalement, plusieurs datations radiocarbones effectuées sur des charbons prélevés lors de micro-sondages ont fourni des dates entre le $X I^{e}$ et XIX ${ }^{e}$ s. ap. J.-C., témoignant d'une intense activité pastorale à ces périodes. Il semble que la majorité des structures conservées en élévation doive être attribuée à cette époque.

Les sondages ne peuvent prétendre dater les structures dans la mesure où aucun sondage en pied de parement interne et externe n'a été entrepris. De même, la quantité de tessons de céramique recueillis est extrêmement faible. Les structures du Pas de l'Essaure n'ont livré que 37 fragments (2 individus). Cependant, étant donné le faible nombre et la taille réduite des sondages, le potentiel des cabanes semble important. Les prospections sur les Hauts Plateaux ont également permis la mise au jour de nouvelles stations du Mésolithique moyen (env. 7000 av. J.-C.), confirmant les paramètres indispensables à leur installation (présence de l'eau et terrain plat bien exposé), mais également du Néolithique ancien (La Mare). Il s'agit là d'un complément important qui fait du secteur du Pas de l'Aiguille / Chaumailloux / La Fissolle une des plus fortes concentrations de stations préhistoriques connues à ce jour dans les Alpes françaises, au même titre que les Hauts de Chartreuse. La présence de la station du Néolithique ancien de la Mare revêt une importance toute particulière par la rareté, la qualité et l'homogénéité de la série lithique ainsi que la représentation en montagne de cette culture. Le Néolithique moyen et final (env. 4700 à 2200 av. J.-C.) est, en l'état, absent à proximité des structures sondées comme les recherches de 1997 à 1999 menées par
R. Picavet et S. Bernard-Guelle (Picavet, Bernard-Guelle, 1999) l'avaient déjà souligné.

\section{Les structures pastorales des Hauts de Chartreuse}

Les alpages de l'Alpe, du Pinet et de l'Alpette (SainteMarie-du-Mont et Chapareillan, Isère) sont situés sur la partie nord du synclinal chartreux oriental qui s'étend sur une vingtaine de kilomètres de long, de la Dent de Crolles au sud jusqu'au Granier au nord. Le point le plus haut est le sommet du Pinet à $1867 \mathrm{~m}$ et le plus bas est sur l'Alpette à 1499 m. Les accès aux alpages sont peu nombreux. À l'est, depuis le plateau des Petites Roches, le principal passage est le Col de l'Alpe (1793 m). C'est aujourd'hui un large sentier aménagé par les éleveurs qui correspond à la draille utilisée pour la montée en estive des troupeaux (bovins et ovins). À environ $700 \mathrm{~m}$ au nord du Col de l'Alpe, le Col de Belles Ombres $(1753 \mathrm{~m})$ permet un accès plus direct mais plus difficile aux alpages. Son sentier étroit et tortueux emprunte le versant raide et accidenté des rochers de Belles Ombres. Il est utilisé pour la montée en alpage des ovins-caprins. À l'extrémité du synclinal, la Porte de l'Alpette $(1530 \mathrm{~m})$ est le dernier passage possible depuis les Petites Roches. À l'est depuis les Entremonts l'accès est possible au nord depuis le hameau de la Plagne, par le Col de l'Alpette (1547 m) et au sud, depuis le cirque de SaintMême, par le vallon de Pratcel. C'est par ces deux accès que s'effectue la montée des troupeaux depuis les Entremonts, aujourd'hui essentiellement des bovins. Depuis le bas du vallon de Pratcel, le Pas de l'Échelle (1640 m) permet un accès plus direct mais plus raide sur l'alpage de l'Alpe. Une fois sur l'alpage, la circulation dans le synclinal est relativement aisée. Les dénivellations restent peu importantes et les obstacles rares. Ces derniers qui sont liés à la géologie ont créé la délimitation naturelle des alpages.

\section{Habert, halle et enclos, les structures pastorales des Hauts de Charteuse}

\section{Implantation des structures}

Quarante-six structures ont été inventoriées en 2007. trente-quatre ont été construites en plein air, sans appui sur bloc ou abri sous roche. Une s'est peut-être appuyée contre une petite barre rocheuse, deux sont placées sous des abris sous roche, une sous un abri sous bloc et une intègre une cavité. Toutes les possibilités d'implantation sont donc exploitées. Les structures pastorales ont également souvent été réutilisées et modifiées. Certaines structures inventoriées illustrent clairement des phases successives d'utilisation $(7,14$, et peut-être 11 et 17$)$. 


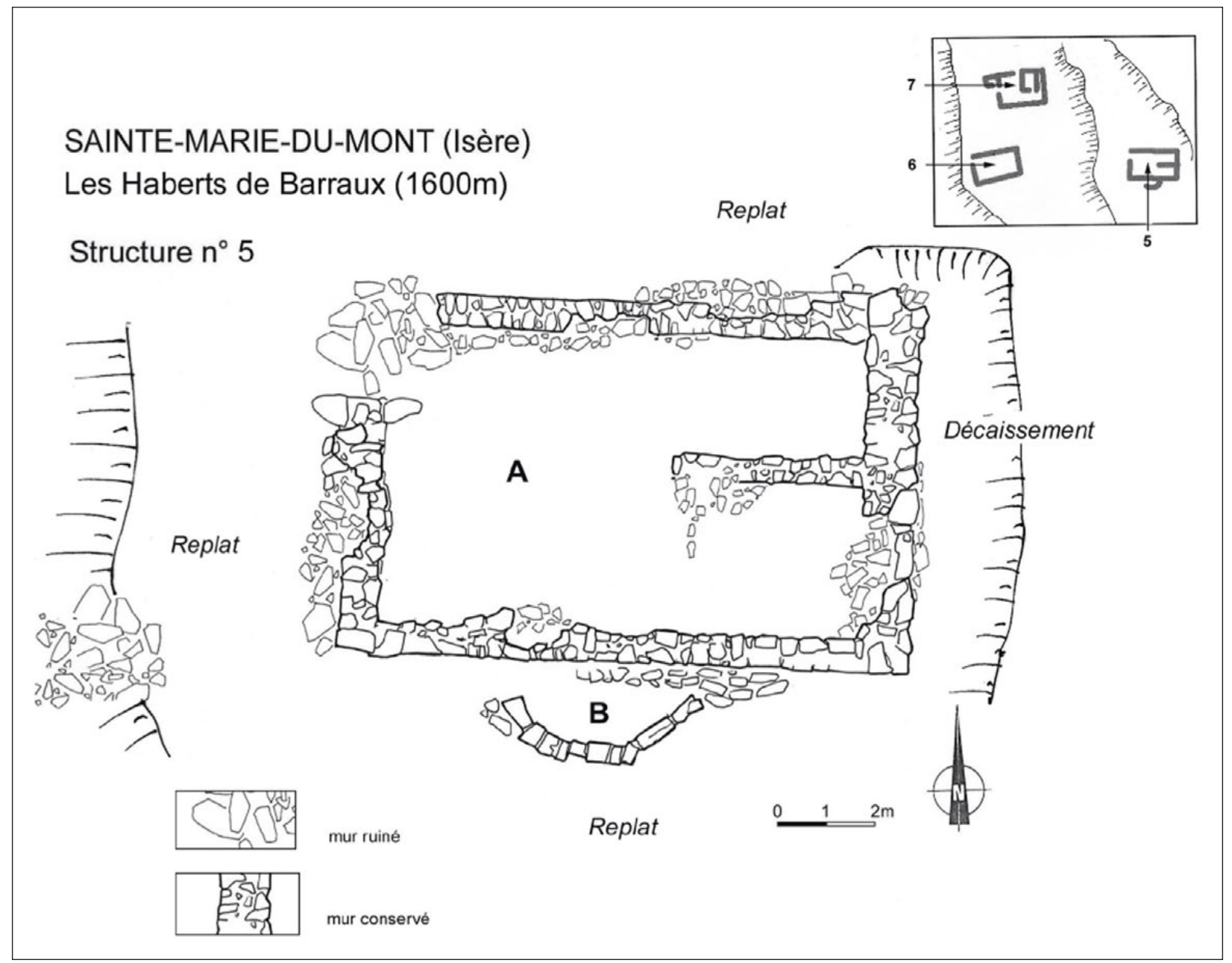

Fig. 5. La structure 5 aux Haberts de Barraux. En A, la cabane et ses deux compartiments ; en $\mathrm{B}$, une annexe à la fonction discutée. Relevé et infographie Pierre-Yves Carron.

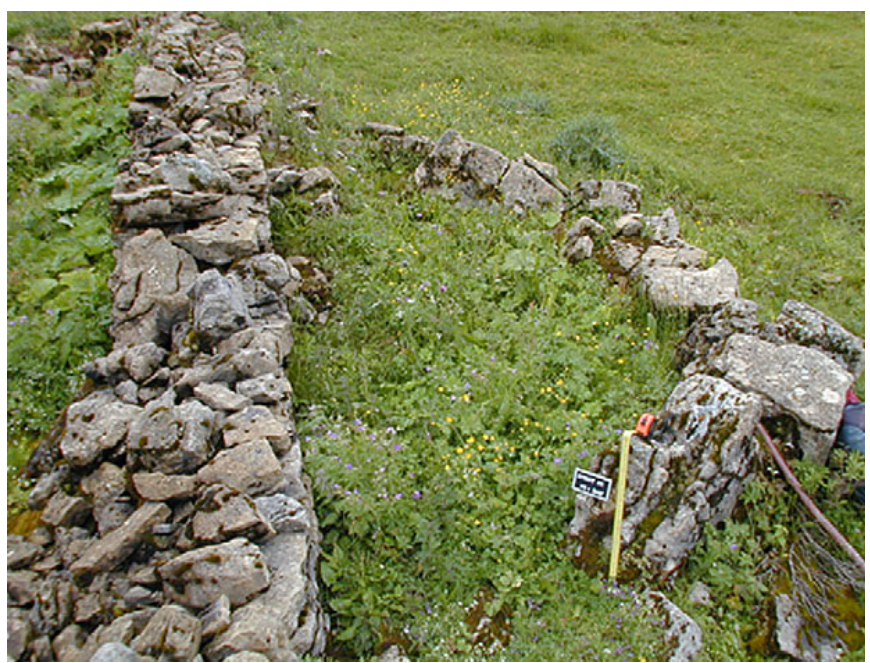

Fig. 6. Structure 5 des Haberts de Barraux, annexe (B) vue de l'ouest. Cliché Alexandre Morin.

\section{Des structures aux plans variés}

Sur les 46 structures, 42 présentent un type identifiable. 36 sont simples et 6 sont composites. Parmi les structures simples, 3 possèdent une petite annexe (structures 5,7 et 11) (fig. 5 et 6). La position des structures montre que certaines forment un ensemble de bâtiments pastoraux complémentaires. C'est le cas aux Haberts de Barraux (fig. 7) pour les structures 1 et 2,3 et 4,18 et 19 , au habert de Saint-Vincent pour les structures 30 et 31, à l'Alpette pour les structures 24 et 25. Aux Haberts de Barraux, des liens ont dû exister entre les haberts (habitats et lieux de travail du berger) et les halles (étables) qui correspondent aux structures 5, 6, 7 et 9 à 13 (fig. 7).

La forme de 36 structures a été identifiée : 28 sont rectangulaires, 4 quadrangulaires et 4 courbes ou linéaires. Pour ces 4 dernières, 3 correspondent à des enclos. La superficie intérieure totale a pu être relevée sur 40 structures. Elle 


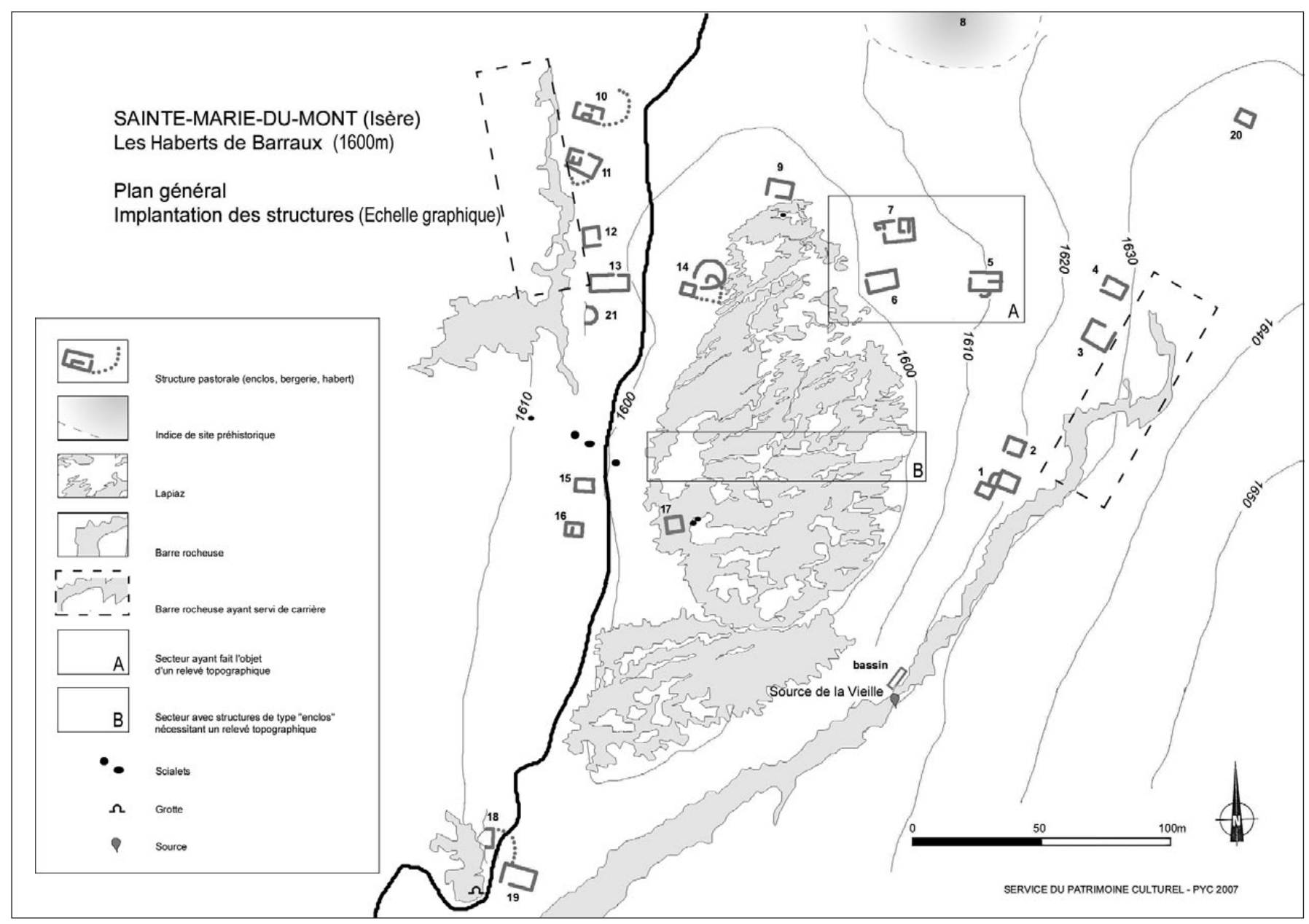

Fig. 7. Les Haberts de Barraux à Sainte-Marie-du-Mont. Topographie générale et implantation des structures. Relevé et infographie Pierre-Yves Carron.

varie considérablement, des cabanes de moins de $10 \mathrm{~m}^{2}$ à l'enclos de Belles Ombres d'environ $100 \mathrm{~m}^{2}$.

Il a été possible d'identifier les entrées de 22 structures. Seules les structures $7 \mathrm{~B}$ et 24 ont conservé une partie de leurs montants jointoyés. Aucun linteau n'est conservé, la plupart devait être de bois. Les entrées les plus étroites font autour de 0,50 m (structure 4 et 7B) et la plus large 1,30 m (structure 6).

Notre connaissance de l'aménagement de l'espace intérieur reste très limitée en raison de la disparition des matériaux périssables. Les sources ethnographiques et géographiques peuvent nous fournir certaines données pour les essais d'interprétations (Robert 1939). Des murs internes ont été reconnus dans neuf structures $(5,10,11$, $16,31,34,35,43,45)$. Mais faute d'autres éléments, la fonction des pièces ainsi délimitées reste difficile à déterminer. Plusieurs fonctions sont concurrentes : lieu de fabrication, chambre, cave à fromage, rafraîchoir, débarras? Si la structure 10 paraît toute entière consacrée au berger et à ses activités, les structures 34 et 35 semblent structurer autour d'un espace destiné au bétail, le plus vaste, et un espace destiné au berger et à ses activités (fabrication du fromage).

Trois structures $(5,7$ et 11$)$ semblent posséder une sorte d'annexe (fig. 5 et 6). Elle prend dans la structure 5 la forme d'une abside avec entrée latérale qui ne communique pas avec les autres pièces. Sa fonction n'est pas clairement identifiée. L'annexe étant plein sud, la fonction de fruitière à fromage paraît exclue. On peut penser à une petite porcherie, un petit enclos (qui pourrait abriter une bête malade par exemple), voire une remise ou un débarras.

La difficulté de lecture des structures pastorales des Hauts de Chartreuse tient à la diversité de leurs plans qui laisse place à de multiples interprétations. Une cabane ne peut se comprendre seule et s'insère dans un groupe qu'il est souvent difficile d'identifier. 


\section{Approches du pastoralisme dans les massifs du Vercors et de la Chartreuse, des travaux à poursuivre}

La comparaison entre Hauts plateaux du Vercors et Hauts de Chartreuse est difficile car les méthodologies employées ont trop divergé. Dans le Vercors, les structures paraissant les plus anciennes ont concentré l'attention. Les micro-sondages indiquent que dès l'Antiquité tardive l'emplacement des structures est déjà occupé. En Chartreuse, la problématique n'était pas de découvrir les plus anciennes traces du pastoralisme mais de dresser un inventaire diachronique. Ce sont donc, au contraire, les structures les mieux conservées qui ont fait l'objet du plus de soin. En tout cas, ont été repérées et relevées six structures très arasées qui pourraient être anciennes. Seuls des sondages pourront le confirmer. Ces sondages devront tenter, non pas un premier phasage chronologique comme dans le Vercors, mais bien de dater la construction en elle-même.

\section{Remerciements}

Réserve Naturelle des Hauts de Chartreuse, Réserve Naturelle des Hauts Plateaux du Vercors, Conseil Général de l'Isère, Musée Dauphinois, Association pour la Valorisation et la Diffusion de la Préhistoire Alpine (Grenoble), Syndicat Intercommunal de l'Alpe, Jean-Paul Locatelli, Annick Clavier, Pierre Bintz, Michel Wullschleger.

\section{Bibliographie}

Morin 2008: MORIN (A.) avec collab. CARRON (P.-Y.), MOUTHON (F.), SERRIÈRES (L.), LOCATELLI (J.-P.), EXCOFFON (S.), CLAVIER (A.), BINTZ (P.), MURAZ (S.) - Étude diachronique des structures pastorales dans la Réserve naturelle de Chartreuse: secteurs de l'Alpe, des Haberts de Barraux et de l'Alpette (Sainte-Marie-du-Mont, Chapareillan, Isère) Prospection thématique 2007. Rapport scientifique, DRAC-SRA Rhône-Alpes, 2008.

Morin, Picavet 2004 : MORIN (A.), PICAVET (R.), avec collab. JOSPIN (J.-P.), THIÉBAULT (S.), OBERLIN (C.), CUERVA (B.), FOURGOUS (B.), BIRON (P.-E.), BINTZ (P.), NICOD (P.-Y.), CHATAIN (H.) - Archéologie et pastoralisme sur les Hauts-Plateaux du Vercors. Rapport scientifique, DRACSRA Rhône-Alpes, 2004.

Morin, Picavet 2005: MORIN (A.), PICAVET (R.), avec collab. WULLSCHLEGER (M.), JOSPIN (J.-P.), TEYSSONNEYRE (Y.), CHATAIN (H.), DOKATANOVA (T.), GRIGGO (C.), ROCHE (J.-M.), ANDRÉ (G.), FOURGOUS (B.), CUERVA (B.), CAULLIREAU (G.), BIRON (P.-E.), BERNARDGUELLE (S.), BINTZ (P.), NICOD (P.-Y.), BOIS (M.) - Archéologie et pastoralisme sur les Hauts-Plateaux du Vercors. Rapport scientifique, DRAC-SRA Rhône-Alpes, 2005.
Morin, Picavet 2006 : MORIN (A.), PICAVET (R.), avec collab. JOSPIN (J.-P.), THIÉBAULT (S.), OBERLIN (C.), CUERVA (B.), FOURGOUS (B.), BIRON (P.-E.), BERNARD (C.), ARGANT (J.), BINTZ (P.), NICOD (P.-Y.), ROCHE (J.-M.), BERTOCHIO (P.) - Archéologie et pastoralisme d'altitude dans le massif du Dévoluy, la haute vallée du Buëch et les Hauts-Plateaux du Vercors (Hautes-Alpes, Drôme, Isère): premiers résultats. In JOURDAIN-ANNEQUIN (C.), DUCLOS (J.-C.) dir., Aux origines de la Transhumance, les Alpes et la vie pastorale d'hier à aujourd'hui. Paris, Picard, 2006, p. 187-203.

Nicod et al. 2008 : NICOD (P.-Y.), PICAVET (R.), ARGANT (J.), BROCHIER (J.-L.), CHAIX (L.), DELHON (C.), MARTIN (L.), MOULIN (B.), THIÉBAULT (S.) - La bergerie néolithique de la Grande Rivoire. In JOSPIN (J.-P.), FAVRIE (T.) dir., Premiers bergers des Alpes. De la Préhistoire à l'Antiquité. Grenoble, Musée Dauphinois, 2008, p. 75-80.

Picavet, Bernard-Guelle 1999: PICAVET (R.), BERNARDGUELLE (S.) - Réserve naturelle des Hauts plateaux du Vercors. Campagnes de sondages archéologiques (le Pré de la Font, Pré Peyret, Fontaine de la Baume, Gerland). Rapport scientifique, DRAC-SRA Rhône-Alpes, 1999.

Picavet, Morin 2008: PICAVET (R.), MORIN (A.) - Cabanes et enclos de bergers sur les Hauts plateaux du Vercors. In JOSPIN (J.-P.), FAVRIE (T.) dir., Premiers bergers des Alpes. De la Préhistoire à l'Antiquité. Grenoble, Musée Dauphinois, 2008, p. 132-136.

Rendu 2003: RENDU (C.) - La montagne d'Enveig. Une estive pyrénéenne dans la longue durée. Canet-en-Roussillon, Trabucaire, 2003.

Robert 1939: ROBERT (J.) - L'habitat temporaire dans les montagnes pastorales des Alpes françaises du Nord, étude de géographie humaine. Revue de Géographie Alpine, t. 27, 3, 1939, p. 483-589.

Teyssonneyre 2005: TEYSSONNEYRE (Y.) - La céramique des structures du Pas de l'Essaure. In MORIN (A.), PICAVET (R.), avec collab. WULLSCHLEGER (M.), JOSPIN (J.-P.), TEYSSONNEYRE (Y.), CHATAIN (H.), DOKATANOVA (T.), GRIGGO (C.), ROCHE (J.-M.), ANDRE (G.), FOURGOUS (B.), CUERVA (B.), CAULLIREAU (G.), BIRON (P.-E.), BERNARD-GUELLE (S.), BINTZ (P.), NICOD (P.-Y.), BOIS (M.) - Archéologie et pastoralisme sur les Hauts-Plateaux du Vercors. Rapport scientifique, DRACSRA Rhône-Alpes, 2005, p. 85-88.

Walsh et al. 2005 : WALSH (K.), MOCCI (F.), COURT-PICON (M.), TZORTZIS (S.), PALET-MARTINEZ (M.), avec collab. DUMAS (V.), PY (V.), SEGARD (M.), TALON (B.) - Dynamique du peuplement et activités agro-pastorales durant l'âge du Bronze dans les massifs du Haut Champsaur et de l'Argentièrois (Hautes-Alpes). Documents d'Archéologie méridionale, 28, 2005, p. 25-44. 


\title{
Recherches sur l'histoire de l'occupation humaine sur la planèze sud du Plomb du Cantal
}

\author{
Frédéric SURMELY*, Violaine NICOLAS**, Stéfan TZORTZIS***, Yannick MIRAS****, \\ Aurélie SAVIGNAT*****, Pascal GueneT******, Gabriel SERVERA*******, Stéphane PETIT****
}

Résumé. Le programme de recherches sur le peuplement de la planèze sud du Plomb du Cantal a débuté en 2000. Il concerne un secteur de moyenne montagne volcanique d'environ $50 \mathrm{~km}^{2}$, situé sur la partie haute des communes de Lacapelle-Barrès, Brezons, Malbo, Saint-Clément et Pailherols (cantons de Vic-sur-Cère et de Pierrefort, département du Cantal). L'altitude s'échelonne de 1000 à $1600 \mathrm{~m}$. Le projet vise à reconstituer l'histoire du peuplement et des activités humaines des origines jusqu'à la fin de l'époque moderne. À cette fin, une équipe pluridisciplinaire et diachronique a été constituée, composée de paléoenvironnementalistes et d'archéologues. Les recherchent comportent des prospections pédestres et aériennes, des sondages, des fouilles programmées, l'étude des sources écrites et un gros volet d'études paléoenvironnementales. À ce jour, plus de 700 sites et indices de sites probables ont été recensés, depuis la pièce lithique préhistorique isolée jusqu'au hameau d'époque médiévale. L'ensemble constitue un corpus qui a pu être analysé à l'aide d'un Système d'Information Géographique. La chronologie des sites va de la Préhistoire récente, notamment de la transition Mésolithique final/Néolithique ancien aux époques médiévale et moderne caractérisées par de nombreux vestiges de bâtiments semi-enterrés.

Historical survey about the human settlement on the "south Planèze" of the Plomb du Cantal

Abstract. A research project on the settlement of the southern "planèze" in Plomb du Cantal was launched in 2000. This project focuses on a medium-altitude volcanic mountain région approximately $40 \mathrm{~km}^{2}$ in area, which comprises the upper part of townships of Lacapelle-Barrès, Brezons, Malbo Saint Clément and Pailherols (in the cantons of Vic-sur-Cère and Pierrefort, department of Cantal). The altitude of the region studied ranges between 1000 and $1600 \mathrm{~m}$. The aim of this project is to trace the history of human settlement and the human activities carried out in this region from the origins to the end of the modern era. For this purpose, a multidisciplinary research group was set up, consisting of both paleoenvironmentalists and archaeologists, to carry out the prospections on the field and from the air, coring explorations, excavations, archive searches and paleoenvironmental studies. In the first stage, the emphasis was on site detection, followed by coring explorations, systematic excavations and studies on written documents, and many paleoenvironmental studies were also carried out. More than 700 sites and candidate sites have been listed to date, from isolated lithic prehistoric sites to medieval hamlets. All the information collected forms a corpus, which was analysed using a Geographic Information System. The chronology of the sites goes from recent Prehistory, especially during the period of transition from the late Mesolithic to the early Neolithic period to Middle Age and Modern Times, which are characterized by many vestiges of half-buried buildings.

\footnotetext{
* Ministère de la Culture et de la Communication, DRAC d'Auvergne, Service Régional de l'Archéologie, Hôtel de Chazerat, 4 rue Pascal, BP 378 , 63010 Clermont-Ferrand cedex 1 et GEOLAB Laboratoire de Géographie Physique et Environnementale, UMR 6042 CNRS - Université Blaise Pascal, Maison des Sciences de l'Homme, 4 rue Ledru, 63057 Clermont-Ferrand cedex 1.

** Maison de la Recherche en Sciences de l'Homme - UMS 843, Université de Caen-Basse Normandie, Esplanade de la Paix, Campus 1, 14032 Caen cedex.

*** Ministère de la Culture et de la Communication, DRAC de Provence-Alpes-Côte d'Azur, Service Régional de l'Archéologie, 21-23, boulevard du Roi René, 13617 Aix-en-Provence cedex 1 et Unité d'anthropologie bioculturelle, UMR 6578 CNRS - EFS - Université de la Méditerranée, faculté de Médecine, secteur Nord, bd Pierre Dramard, 13916 Marseille cedex 20.

**** GEOLAB Laboratoire de Géographie Physique et Environnementale, UMR 6042 CNRS - Université Blaise Pascal, Maison des Sciences de l'Homme, 4 rue Ledru, 63057 Clermont-Ferrand cedex 1.

***** Université Blaise Pascal Clermond Ferrand II, 29 bd Gergovia, 63000 Clermont-Ferrand.

****** Laboratoire de Chrono-environnement, UMR 6249 CNRS - Université de Franche Comté, La Boulaie, UFR Sciences et Techniques, 16 route de Gray, 25030 Besançon cedex.

******** Arqueobalear, Universitat de les Illes Balears, Cra. de Valldemossa, E07122 Palma (Espagne).
} 


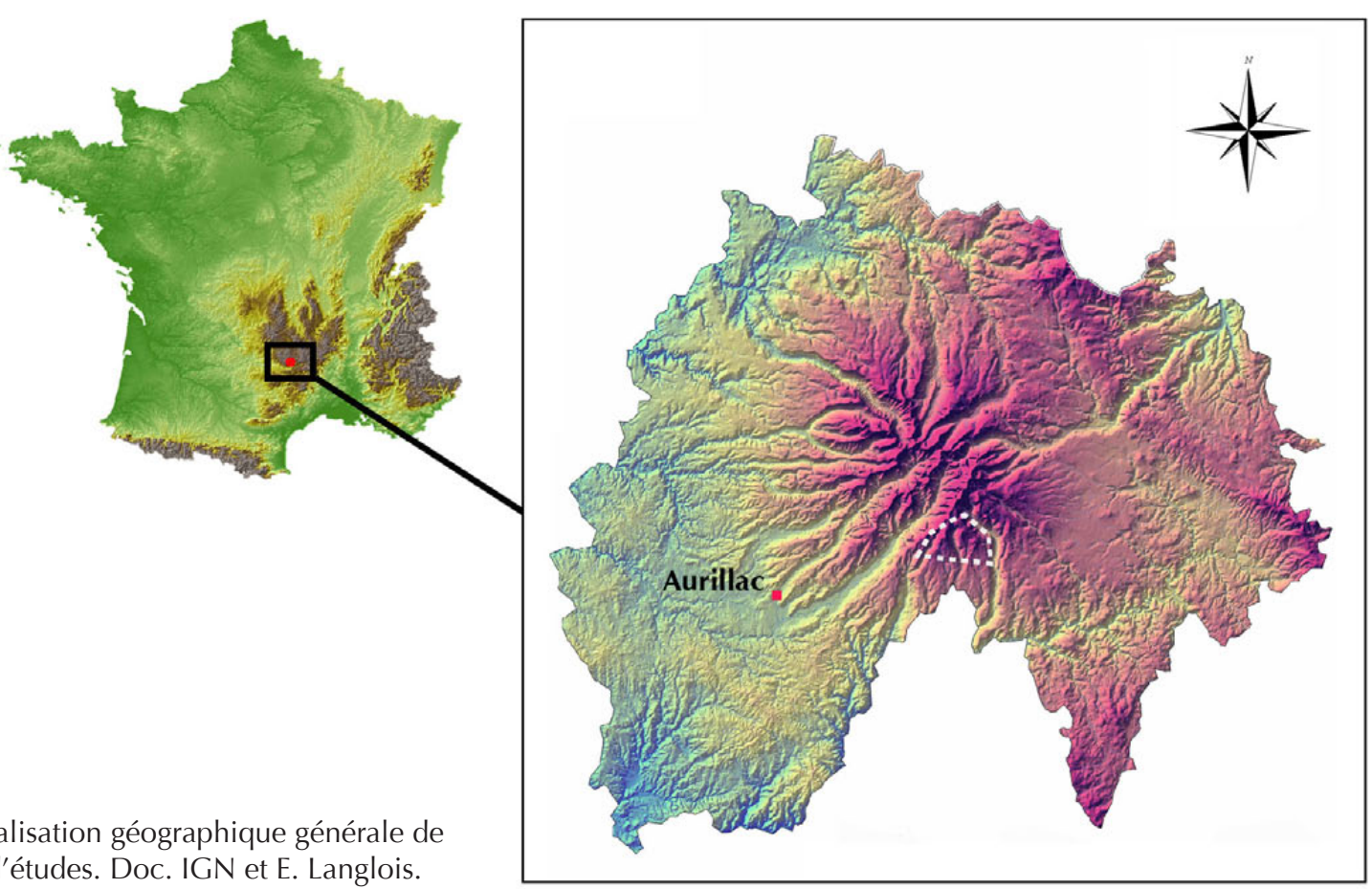

Fig. 1. Localisation géographique générale de la zone d'études. Doc. IGN et E. Langlois.

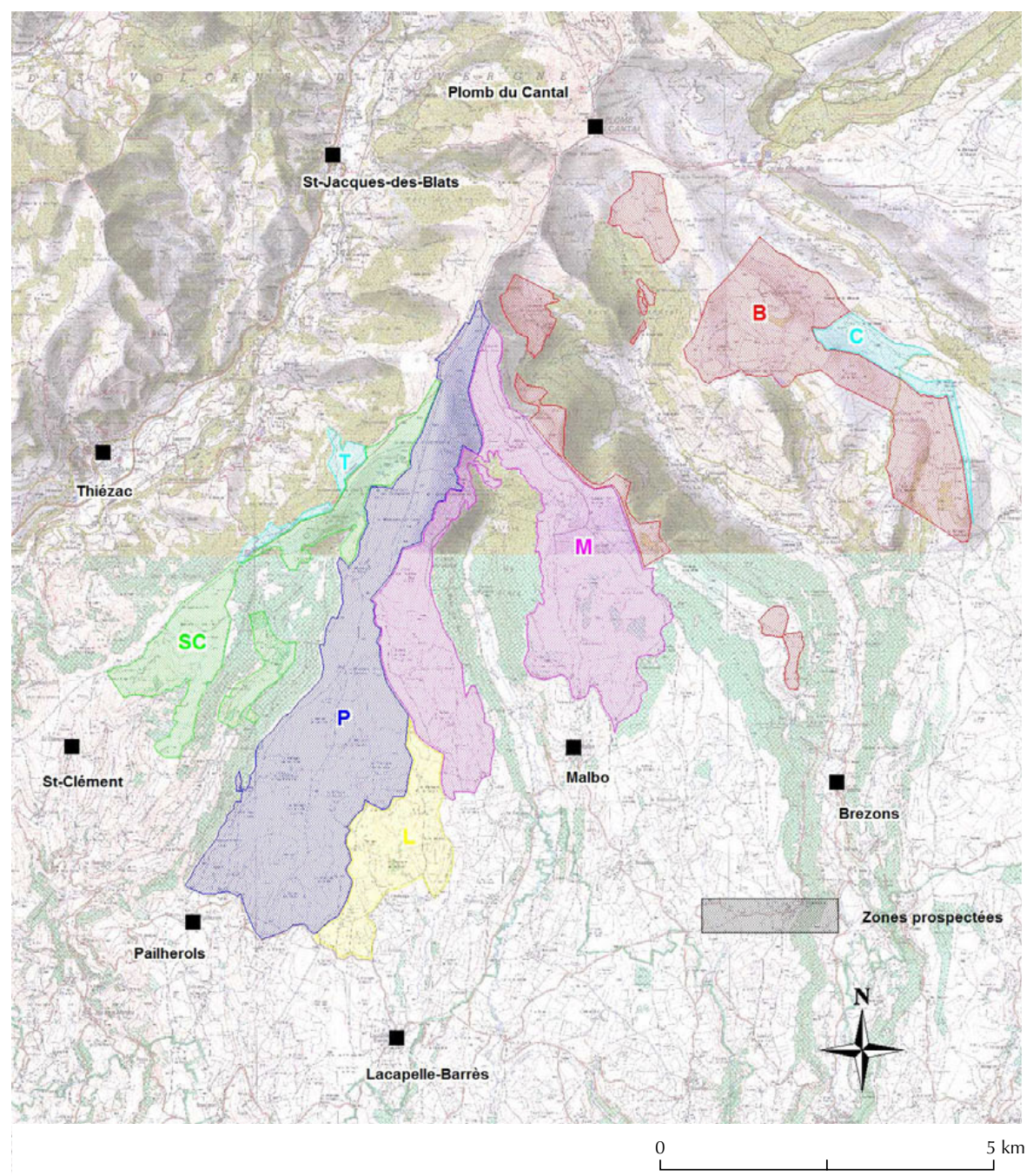

Fig. 2. Localisation précise des zones prospectées à ce jour. Doc. P. Boudon. 


\section{Introduction}

Les moyennes montagnes auvergnates furent longtemps considérées comme des espaces peu hospitaliers, peuplés de façon à la fois tardive et épisodique, en raison notamment de la rudesse climatique. Nos propres travaux (Surmely 1998), consacrés exclusivement à la période préhistorique ancienne, ont permis de reconsidérer cette idée, en mettant en évidence, à partir de travaux de terrain, l'importance et

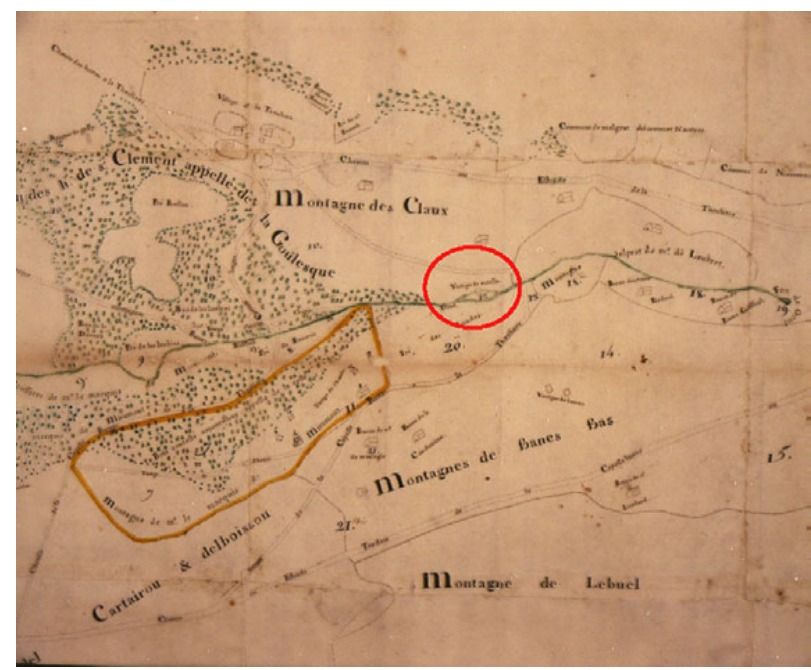

Fig. 3. Photo d'une partie du «plan géométrique» de 1776, couvrant un secteur de la montagne de Saint-Clément. Le cercle rouge indique la mention « vestiges de moulin ». Doc. Archives départementales du Cantal. l'ancienneté de la présence humaine dans ces secteurs et en soulignant aussi l'importance des facteurs taphonomiques (mauvaise conservation générale des sites).

Depuis l'année 2000, nous avons engagé un nouveau programme de recherches sur le peuplement humain de la moyenne montagne du Cantal, en lui donnant un caractère à la fois pluridisciplinaire, en intégrant l'étude du paléoenvironnement, et diachronique, sur le modèle des recherches menées dans les massifs pyrénéens et alpins. Cette orientation permet de comprendre l'évolution du peuplement sur le long terme et de mieux apprécier les interactions entre les activités humaines et l'évolution des paysages.

\section{Contexte}

La zone d'étude, d'une superficie d'environ $50 \mathrm{~km}^{2}$, correspond à la planèze sud du Plomb du Cantal, vaste plateau triangulaire né de l'épanchement volcanique lors des dernières phases d'activité du strato-volcan cantalien (Blais 1972; Moine-Vaziri 1973; Nehlig et al. 2001) (fig. 1). La surface tabulaire présente un pendage assez régulier du nord $(1600 \mathrm{~m})$ au sud $(1000 \mathrm{~m})$. Le relief initial a été remodelé par l'érosion fluviatile et l'action glaciaire. L'ensemble se présente donc sous la forme d'un plateau à la surface irrégulière, entaillé profondément par les vallées. Sur le plan administratif, le secteur correspond au territoire de cinq communes: Pailherols et Saint-Clément, Lacapelle-Barrès, Malbo et Brezons. Le climat est particulièrement rude, avec des températures assez basses et des précipitations abondantes (supérieures à $2 \mathrm{~m}$ par an). Du

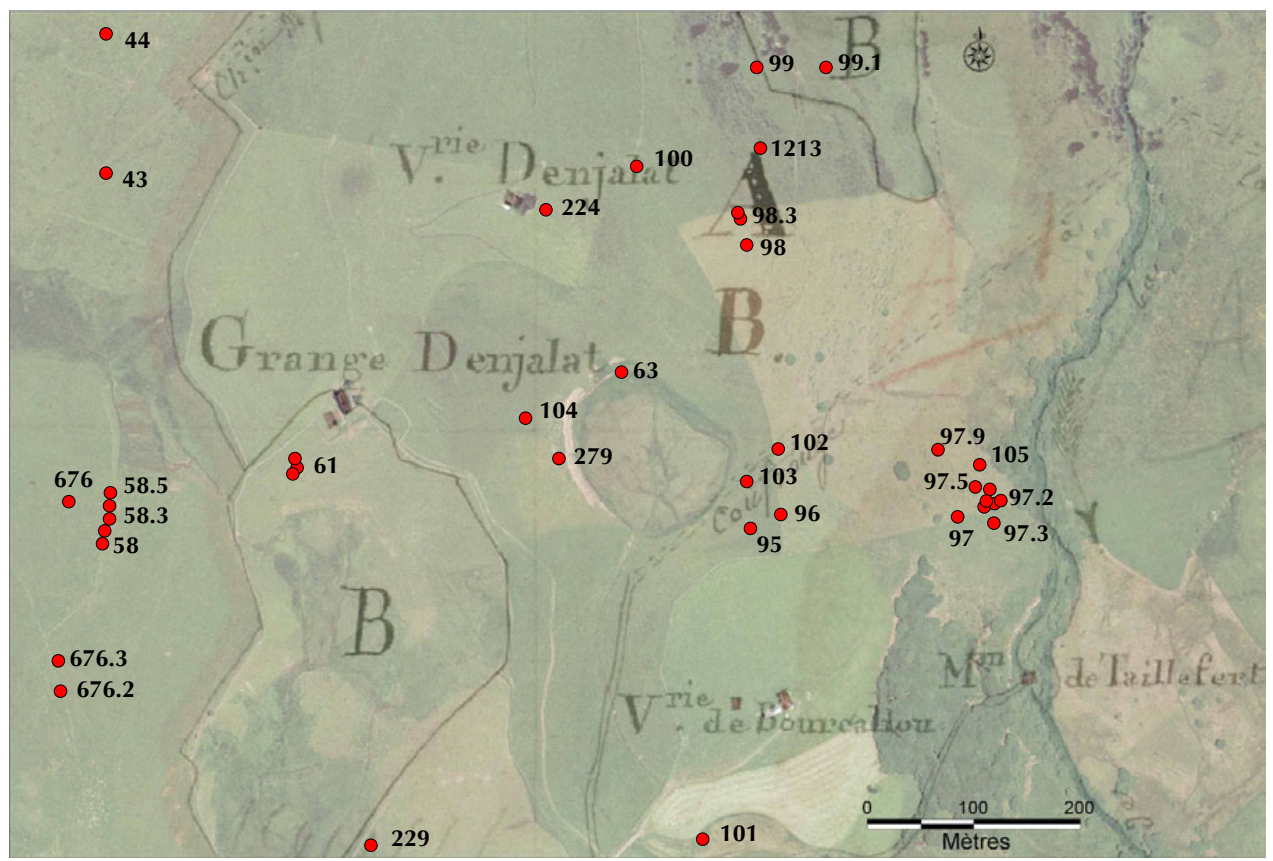

Fig. 4. Superposition, par SIG, de la localisation des sites inventoriés avec le cadastre de 1824 de la commune de Lacapelle-Barrès. 
fait de ce dernier caractère, les ressources en eau sont très abondantes, sous la forme de petites rivières, ruisseaux, et zones tourbeuses. En dehors des blocs rocheux utilisables pour la construction, la zone n'offre pas de ressource minérale exploitable. Malgré son caractère d'apparente unité, du fait des paramètres géologiques, le secteur considéré présente en fait une grande diversité des biotopes, du fait du fort gradient altitudinal et des différences d'exposition. La zone d'études n'avait jamais fait l'objet d'investigations archéologiques avant nos propres recherches.

\section{Méthodologie}

Nos travaux ont débuté en 2000 et se poursuivent actuellement. Les recherches ont commencé par une prospection pédestre approfondie (fig. 2). En parallèle, nous avons mené sur le terrain des prospections aériennes, des sondages, des fouilles programmées, ainsi que des travaux paléoenvironnementaux. Comme nous l'avons déjà dit, notre recherche se veut diachronique, avec pour objectif de retracer l'histoire du peuplement humain dans son contexte naturel, depuis les origines jusqu'à l'époque contemporaine.

En ce qui concerne la détection de sites, il faut dire que les recherches pédestres sont bien plus productives que la prospection aérienne, même pour les structures bâties. Cette dernière a surtout pour utilité de pouvoir avoir un regard d'ensemble, pour la prise de vue photographique ou la recherche d'association de structures au sein de microterroirs.

Un gros travail a été mené également sur la documentation historique. Dans ce cadre, nous avons entrepris la recherche et l'analyse de l'ensemble des documents anciens (terriers et cadastres anciens, archives notariales). Parmi les sources les plus intéressantes, figurent notamment les cadastres dits napoléoniens (plans, matrices et dossiers contentieux) du début du XIX ${ }^{\mathrm{e}} \mathrm{s}$. et des plans anciens, comme celui (inédit) dressé à l'occasion d'un procès en 1776 (fig. 3) et qui couvre une partie de la zone d'études (montagne de SaintClément). Le géoréférencement de l'ensemble des plans permet leur analyse par SIG et le croisement avec les autres données : relevé des sites, données paléoenvironnementales et géomorphologiques (fig. 4). Des enquêtes orales ont également été conduites, auprès de personnes ayant participé à l'exploitation agropastorale de la zone, avant la dernière guerre. Enfin, pour ne pas oublier le volet le plus récent de l'occupation humaine, nous avons localisé et relevé l'ensemble des constructions pastorales (appelées burons et védélats) d'époque moderne et contemporaine (Nicolas 2008).

Le programme de recherches est aussi l'occasion de tester et de mettre en œuvre des méthodologies pionnières. Dans un premier temps, nous avons réalisé des levés topographiques de façon classique, avec un théodolite laser. Cette méthode est assez laborieuse, surtout dans le cas de grandes surfaces. En 2008, a été réalisé un essai concluant de relevé topographique automatisé à l'aide d'un GPS de précision centimétrique embarqué sur un quad. Cela a permis le levé précis d'une zone de plus de 7 ha en moins d'une demi-journée, comprenant le modelé détaillé du relief et le relevé des structures archéologiques formant des anomalies topographiques (fig. 5). Mais surtout, nous avons décidé de mettre en œuvre la technologie du laser-scanner 3D pour le relevé détaillé et en trois dimensions des structures archéologiques. L'expérience, testée en 2008, est généralisée depuis 2009. Le laser-scanner 3D est un appareil de terrain véritablement innovant, capable de mesurer et d'enregistrer plusieurs millions de points en quelques minutes, à une précision de quelques millimètres et une densité pouvant atteindre plus d'un point au millimètre. Il permet de capturer la forme et la texture d'un objet en 3 dimensions, l'acquisition de la couleur étant rendue possible par la prise de 3 images à travers des filtres. L'exportation des données dans d'autres logiciels rend possible un grand nombre de démarches analytiques (calculs automatiques de surfaces, de volumes, de courbures, de densité...). Le laser-scanner offre la possibilité d'un rendu en 3 dimensions, précieux pour les études mais aussi pour les restitutions. Nous l'avons employé avec succès pour le relevé général de vastes surfaces (par exemple réseau parcellaire constitué de petits murets), le relevé volumétrique des structures à différentes étapes des investigations (avant et pendant les sondages par exemple), l'enregistrement finement détaillé des coupes stratigraphiques et le relevé en 3D d'objets de toutes tailles. Deux appareils sont employés : un laser-scanner longue portée pour les travaux à grande échelle et un laser-scanner courte portée pour les relevés détaillés et les objets. L'emploi de divers dispositifs techniques est nécessaire: bras articulé, nacelles, plateau tournant... Dans le cas des structures archéologiques, on peut associer les acquisitions réalisées au fil des investigations pour obtenir un «écorché » précis de la structure, comprenant les différentes étapes de sa fréquentation et de son abandon, ce qui constitue un document de grande valeur informative.

L'ambition d'analyser sur la longue durée les interactions socio-environnementales et les dynamiques de peuplement de ce secteur de la moyenne montagne cantalienne implique de se fonder sur une approche interdisciplinaire (Chapman, Gearey 2000). Elle repose sur la combinaison des informations issues de l'archéologie (archéologie du paysage, archéologie agraire et pastorale), de l'histoire environnementale, de la géographie physique et de la paléoécologie. Or les espaces montagnards, de part leur richesse en milieux d'études privilégiés (tourbières, lacs etc.) et leur grande sensibilité face aux changements 


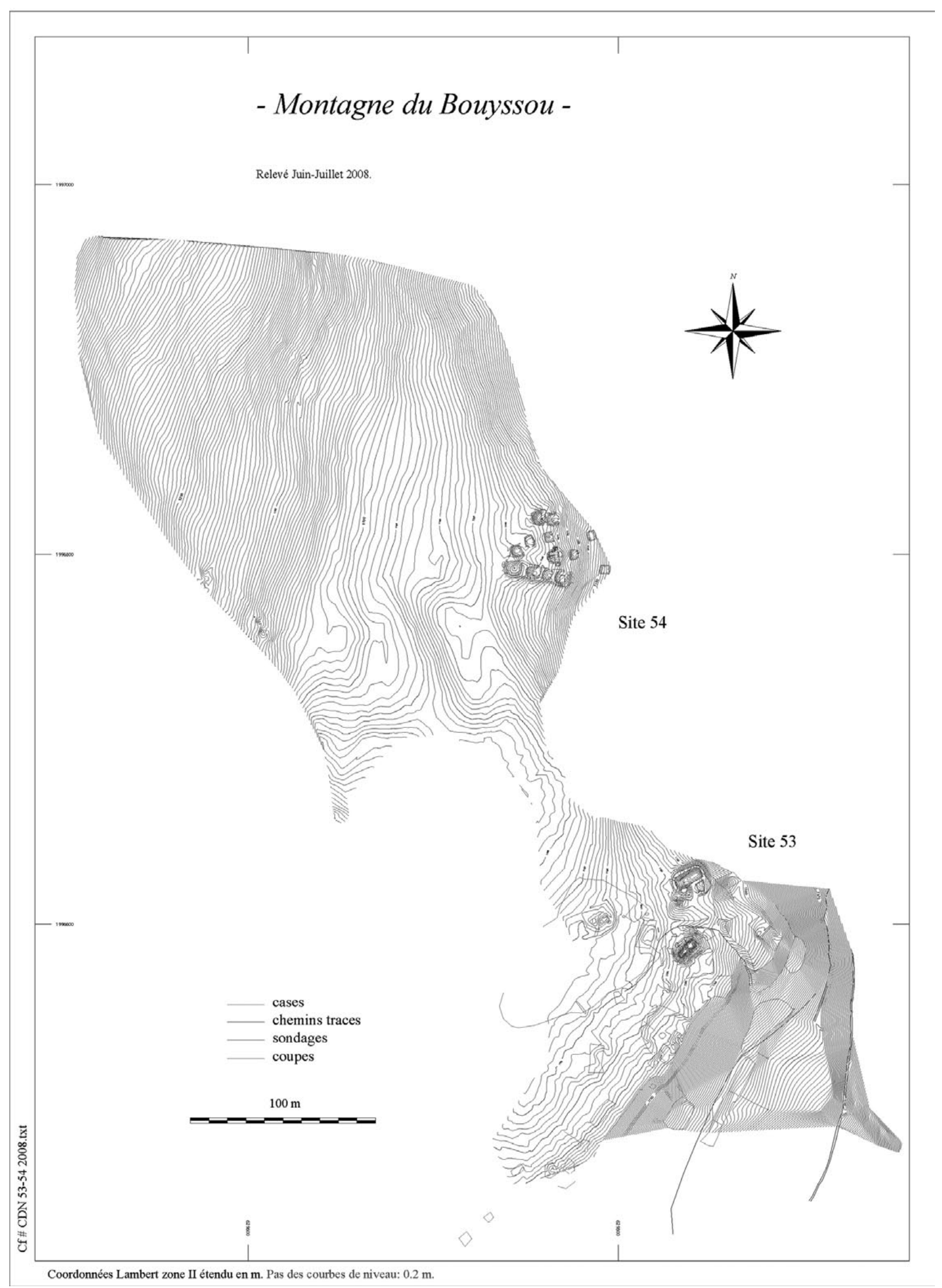

Fig. 5. Relevé microtopographique, par GPS centimétrique embarqué et théodolite, de la montagne du Bouyssou (Pailherols). Doc. P. Boudon et S. Petit. 


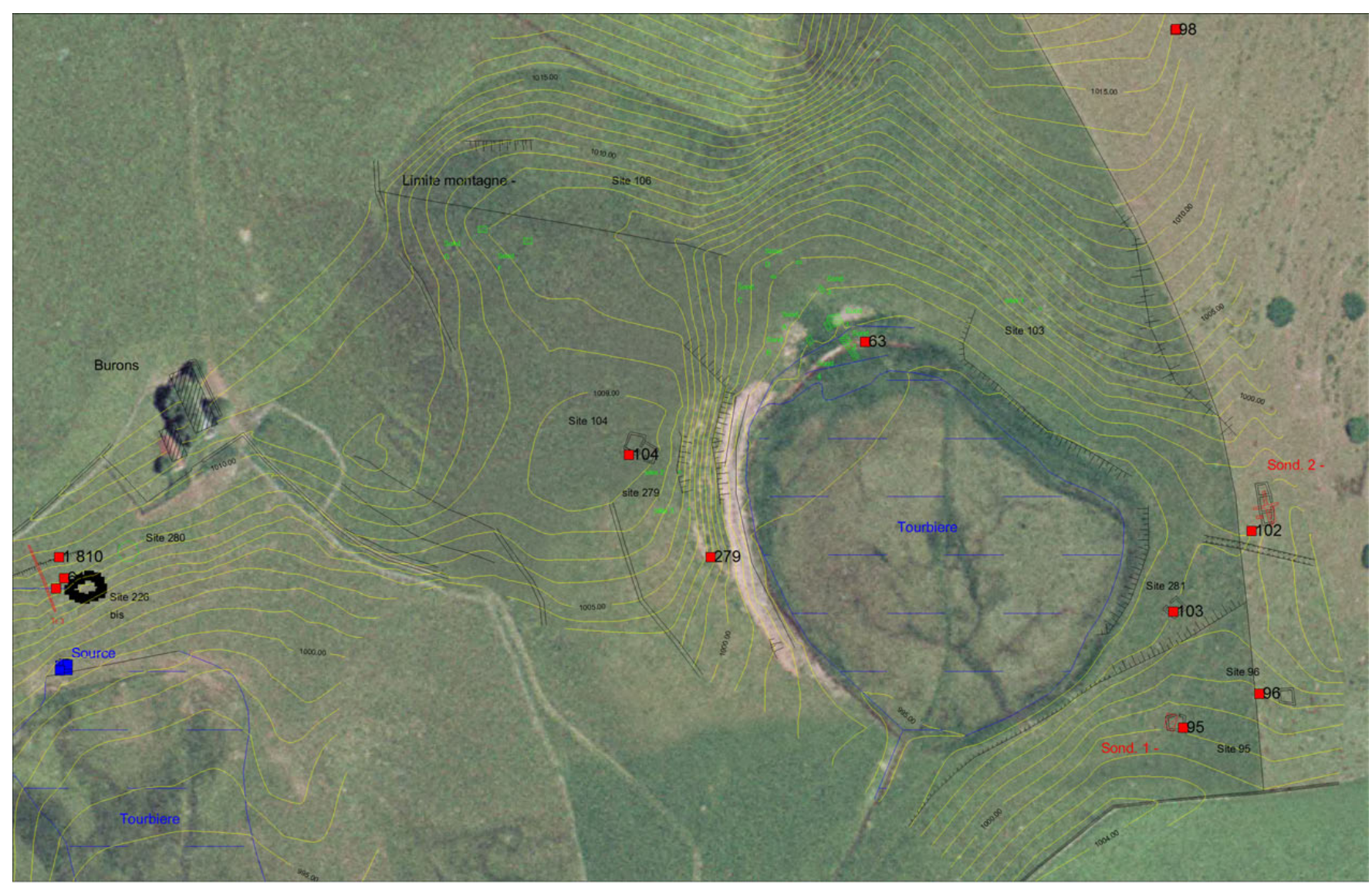

Fig. 6. Superposition par SIG de la localisation des sites inventoriés, de la photographie aérienne de l'IGN (BD Ortho) et des relevés microtopographiques sur le terroir de la Montagne de Peyre (commune de Lacapelle-Barrès). Doc. P. Boudon

environnementaux (forçages climatiques vs anthropiques), sont des aires de recherches appropriées pour atteindre ces objectifs. Dans le cadre de ce programme de recherche, l'étude paléoenvironnementale repose tout d'abord sur la confrontation de plusieurs indicateurs paléoécologiques (analyse dite «multi-proxy »): spores et grains de pollen, microfossiles non polliniques (spores d'algues et de champignons notamment coprophiles etc.), charbons et signal paléoincendie, études géochimiques. Elle est menée à faute résolution spatiale et temporelle et concerne des enregistrements sédimentaires complémentaires: séquences naturelles (tourbières, zone humide de fonds de vallon etc.) et sédiment provenant de structures archéologiques. À ce jour, 5 tourbières ou autres zones humides ont fait l'objet de carottages paléoécologiques. Distribués sur un gradient altitudinal compris entre 1000 et $1450 \mathrm{~m}$ d'altitude, ces sites tourbeux (Caillac, Peyre, Vixouze et Source du Goul; fig. 6) ont tous été choisis en fonction de leur cadre archéologique riche et varié. En outre, plusieurs carottages ont été réalisés au sein des mêmes sites tourbeux de façon à obtenir l'enregistrement sédimentaire le plus dilaté des périodes anthropisées. Les études paléoécologiques (anthracologie, carpologie et palynologie) de sédiments provenant des sites archéologiques concernent tous types de structures d'habitation et d'exploitation, pastorale notamment: cabanes, cases, enclos etc. Elles ambitionnent plus spécifiquement de traiter les questions des pratiques agropastorales (présence de bétail, fourrage, litières, intensité de la fréquentation pastorale etc.) et de déterminer la fonction de certaines structures. Les données paléoenvironnementales acquises à ce jour ont déjà fait l'objet de publications (Miras et al. 2005; Surmely et al. 2009). Aussi, la méthodologie utilisée et les résultats obtenus à ce jour ne seront pas exposés dans cet article.

Le champ chronologique considéré est vaste, allant des origines du peuplement jusqu'à la fin de l'époque moderne. L'équipe rassemble près d'une vingtaine de chercheurs, de disciplines et d'institutions variées, avec des personnels statutaires et des étudiants.

\section{Un nombre considérable de sites}

À ce jour, 608 sites et indices de sites ont été inventoriés (fig. 7). Bien évidemment, et malgré l'attention portée à la prospection, cela ne constitue qu'une partie du patrimoine 


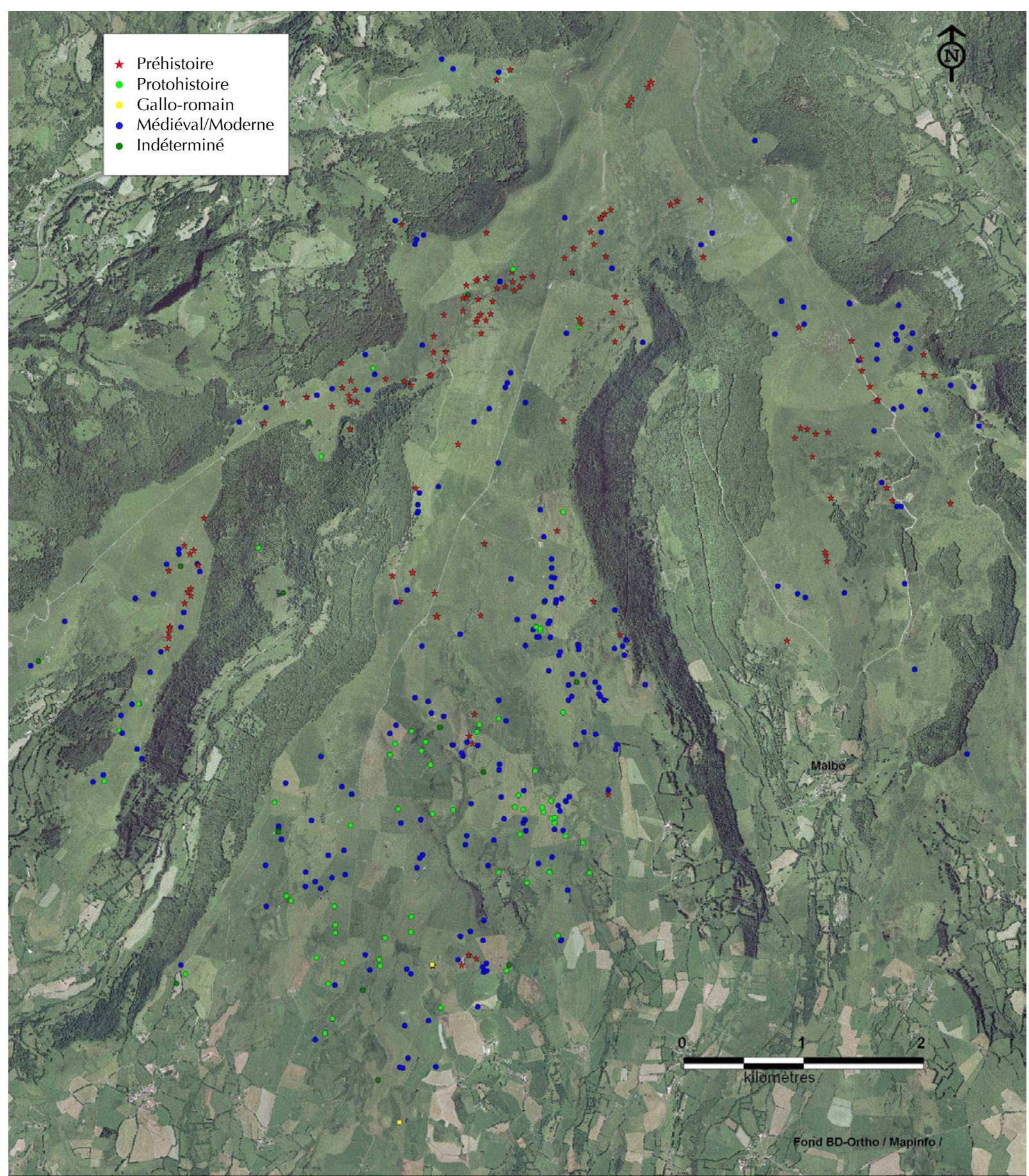

Fig. 7. Localisation spatiale de l'ensemble des sites inventoriés (état septembre 2008). Doc. F. Surmely.

archéologique du secteur. La présence d'une couverture végétale permanente (prairie) et l'absence de grands travaux d'aménagement sont en effet un frein à la découverte de sites, même si elles garantissent leur conservation. Le repérage de sites et notamment des sites anciens sans structures maçonnées, est avant tout tributaire de conditions liées à l'érosion, à la présence de cours d'eau et aux petits aménagements anthropiques postérieurs. De même, on peut penser que l'érosion, particulièrement intense à ces altitudes, a pu faire disparaître un nombre important de sites, notamment les plus anciens.

\subsection{Préhistoire}

Une grande partie des découvertes concerne la Préhistoire récente, représentée par 163 sites et indices de sites. Ces 


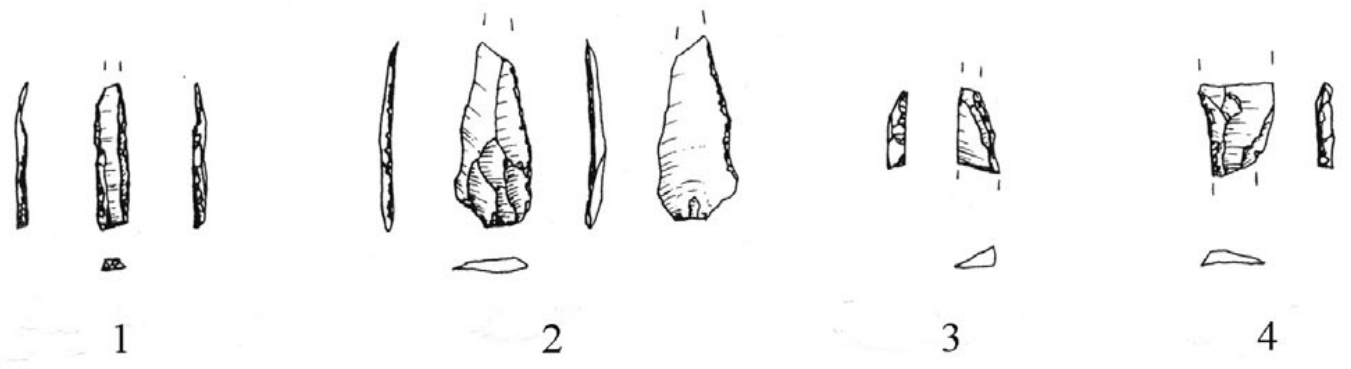

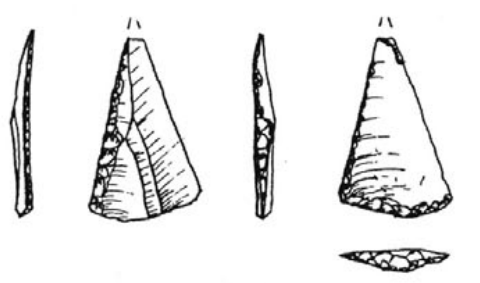

5
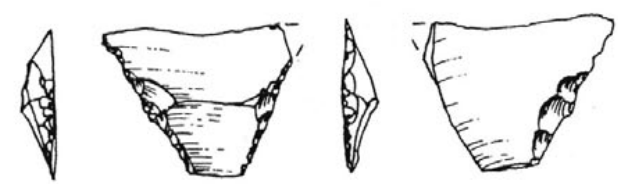

8
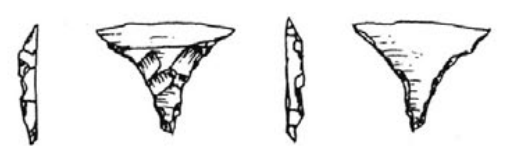

10

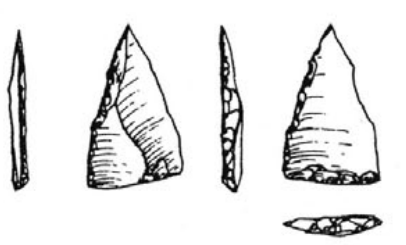

6

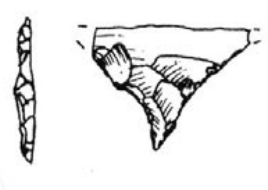

9

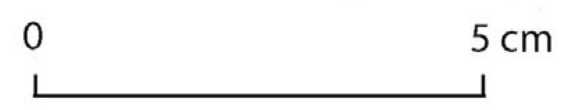

Fig. 8. Site $n^{\circ} 63$ (La Montagne de Peyre, Lacapelle-Barrès). Néolithique ancien. Armatures. Dessins S. Tzortzis. témoignages se limitent bien souvent à quelques artefacts lithiques, ce qui n'autorise qu'une caractérisation chronoculturelle très imprécise.

Le plus ancien vestige trouvé à ce jour est une armature microlithique fragmentaire: un triangle scalène allongé à trois côtés retouchés (type triangle de Montclus) qui pourrait indiquer une présence humaine lors du Mésolithique moyen. Cette découverte a été faite à une altitude de 1493 m. Plusieurs sites ( $\left.n^{\text {os }} 61,63,64,426,578,582\right)$ livrent en revanche d'abondantes séries lithiques et ont pu être datés du Mésolithique final et du Néolithique ancien (fig. 8 et 9, Surmely, Tzortzis, Miras 2008). Malheureusement, ces stations ont toutes été démantelées par l'érosion naturelle ou par des activités anthropiques postérieures. Les études paléoenvironnementales, notamment palynologiques et anthracologiques montrent un premier impact anthropique, avec défrichement et indices polliniques d'agropastoralisme, entre 5900 et 5400 cal. BC (Surmely et al. 2009) L'existence d'un vrai Néolithique ancien est ainsi confirmée. Le Néolithique final/Chalcolithique est également représenté et correspond à une amplification des marqueurs d'anthropisation sur le milieu naturel.

Du point de vue de la répartition géographique, il est également difficile d'arriver à des conclusions précises, au vu des conditions de découverte. Les pièces lithiques ont été trouvées à toutes les altitudes, y compris les plus élevées. Néanmoins, il n'y a pas de répartition uniforme qui aurait pu indiquer une remobilisation générale des pièces liée à l'érosion. Il y a des zones peu denses et, à l'inverse, des secteurs de forte concentration, qui ne sont pas des zones de bas-fonds, où auraient pu s'accumuler des pièces remaniées. Contrairement à la croyance générale, aucun lien précis ne peut être fait entre les sites et certaines caractéristiques géographiques (sources, axes naturels...).

Bien évidemment, la nature même des découvertes ne permet pas une caractérisation précise des modalités de peuplement. Il faut donc en rester à des interprétations très prudentes. Pour les chasseurs-cueilleurs du Mésolithique, il 


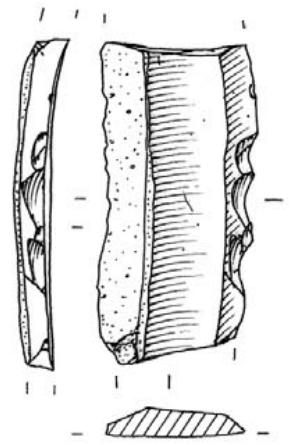

1

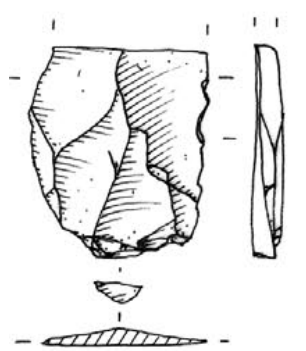

5

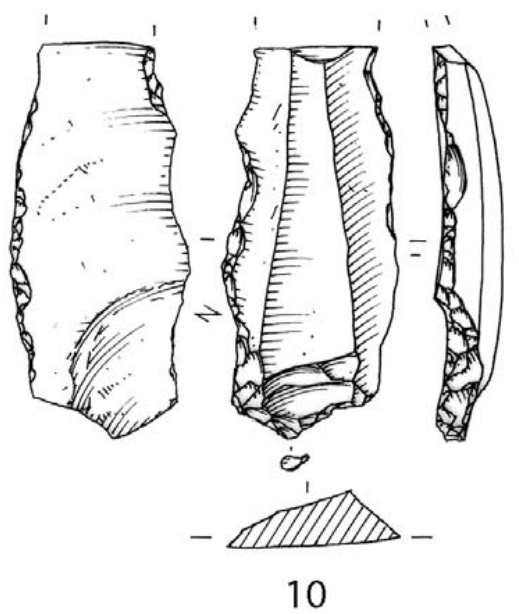

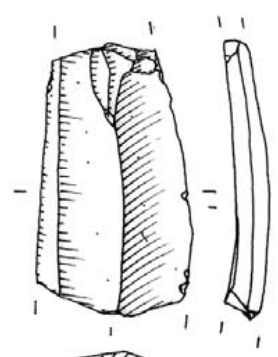

- cortrorro -

2

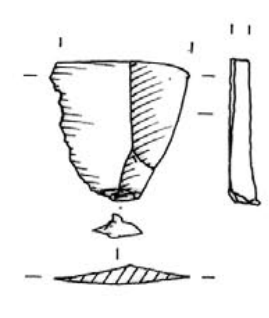

6

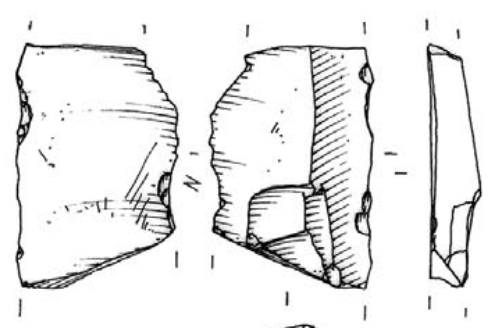

- collontro -

3

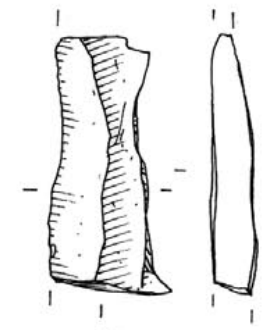

- Allos -

4

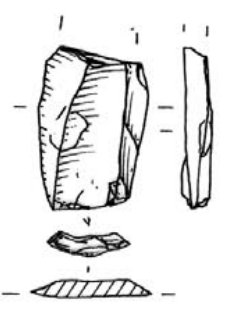

7

8

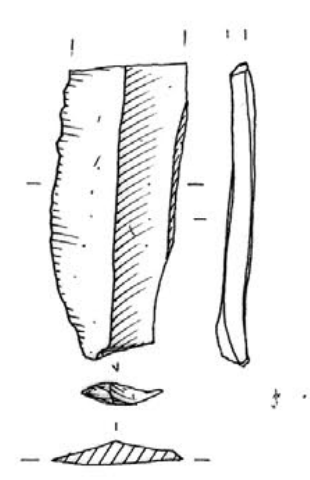

12

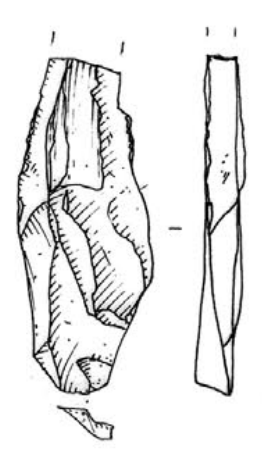

13
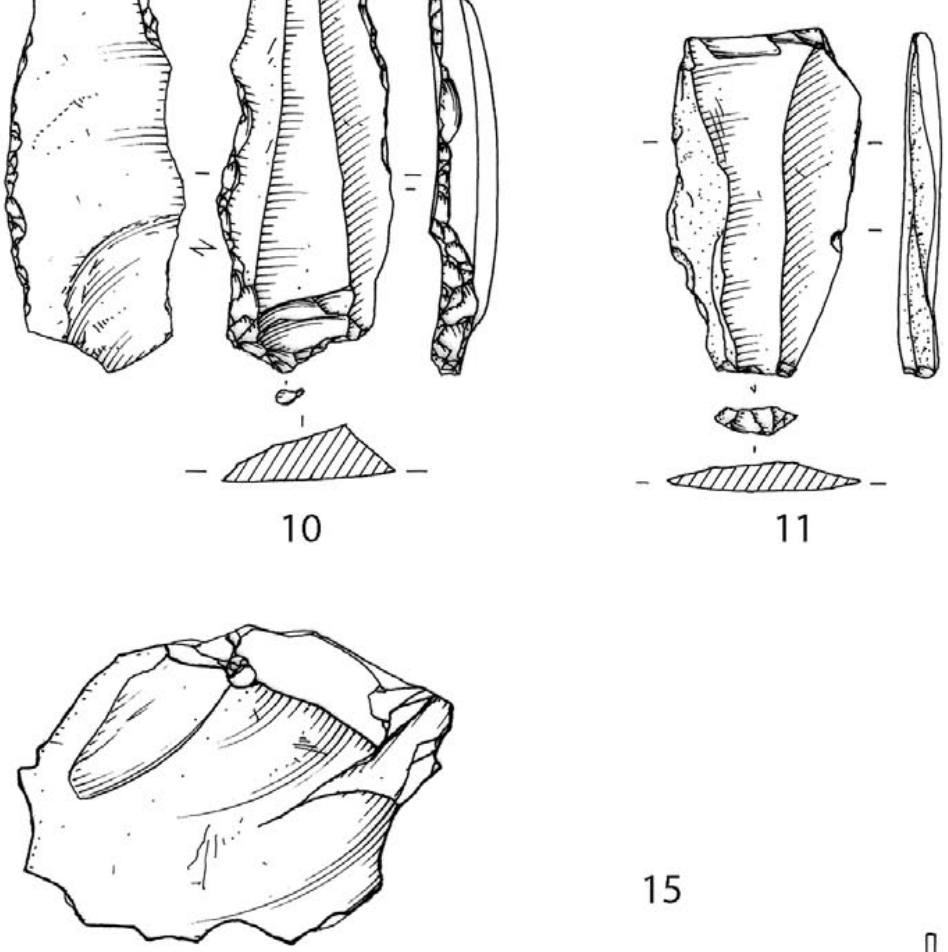

15
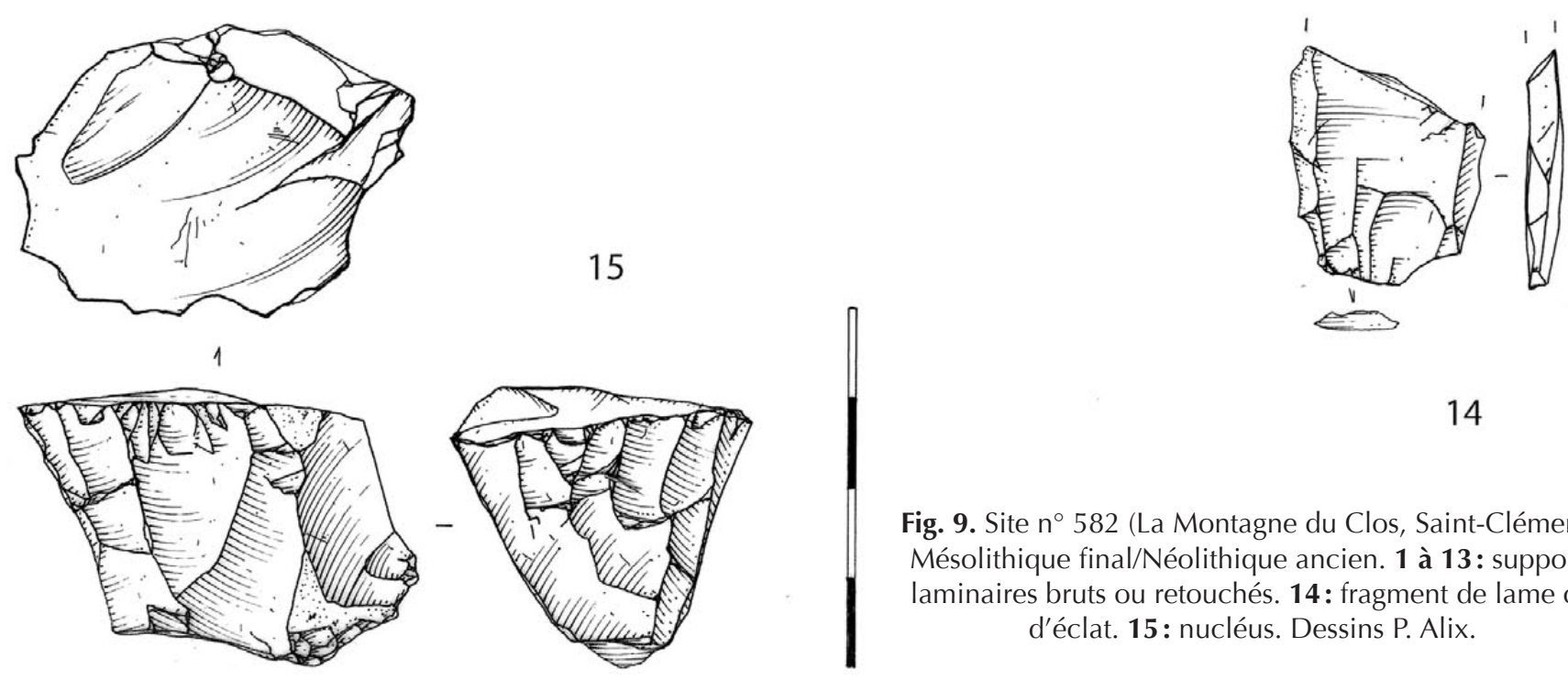

14

Fig. 9. Site $\mathrm{n}^{\circ} 582$ (La Montagne du Clos, Saint-Clément). Mésolithique final/Néolithique ancien. 1 à 13 : supports laminaires bruts ou retouchés. 14 : fragment de lame ou d'éclat. 15 : nucléus. Dessins P. Alix. 
est probable que cette zone d'altitude, offrant des biotopes diversifiés (tourbières...) devait être attractive à de nombreux égards (Surmely et al. 2003). Le fait que les artefacts lithiques découverts correspondent à tous les stades de la chaîne opératoire montre qu'il y a bien eu des opérations de taille sur place. Cela indique indiscutablement l'existence de véritables campements et non un simple passage des hommes au cours de ponctuelles et brèves expéditions. L'absence de céramique associée aux témoins néolithiques doit cependant être signalée. Si celle-ci peut avoir une origine taphonomique, elle peut en revanche tout autant être liée à un statut des sites différent de celui des habitats pérennes des secteurs de plaine. Elle s'inscrirait alors dans un contexte d'occupations vraisemblablement saisonnières, vouées à des modes économiques particuliers.

L'absence totale de ressources siliceuses interdit de penser à des campagnes d'approvisionnement en matières premières lithiques.

À partir du Néolithique, entre ca 2700 et 2500 cal BC, les analyses polliniques montrent la pratique d'activités agricoles, au moins dans la partie basse de la zone, autour de 1100 m (Surmely et al. 2009). Les sols de décomposition volcanique devaient être particulièrement fertiles et faciles à travailler, en dépit de la rudesse du climat marqué notamment par un enneigement persistant. Pour ce qui est des gisements néolithiques situés nettement au-dessus, les conditions climatiques devaient interdire l'agriculture. On peut donc penser que d'autres formes d'exploitation du milieu ont motivé la venue des hommes: pastoralisme de moyenne montagne, cueillette spécialisée, notamment de plantes procurant des poisons pour la chasse et se trouvant préférentiellement dans ces écosytèmes (aconit napel, vérâtre; Surmely 2006), pratiques cynégétiques orientées vers des gibiers spécifiques...

La totalité des pièces constituant les séries lithiques collectées a été façonnée dans le silex tertiaire (oligocène) qui peut être trouvé à quelques kilomètres en contrebas (vallée du Goul) et au-delà dans le bassin sédimentaire d'Aurillac/ Mur-de-Barrez (Pasty et al. 1999; Surmely, Santallier 2003). Aucun silex d'importation lointaine n'a été découvert. C'est une caractéristique des sites préhistoriques (toutes époques confondues) de la façade occidentale du massif cantalien, alors qu'au contraire les silex allochtones abondent dans les sites de la façade orientale (Surmely et al. 2003; Surmely, Pasty 2003). Ceci montre bien la segmentarisation des stratégies d'approvisionnement, liée à des courants de circulation bien organisés.

\subsection{Protohistoire}

Les sites protohistoriques sont relativement peu nombreux. Il serait tentant d'y voir la conséquence d'un phénomène de conservation différentielle, la céramique étant fragile.
Toutefois la découverte de quelques ensembles céramiques montre que la céramique a pu bien se conserver, même à des altitudes élevées. Les données paléoécologiques attestent un impact anthropique assez conséquent entre $c a 1950$ et 1550 cal BC (Surmely et al. 2009).

Bien évidemment, se pose le problème des tertres. 76 ensembles (soit 166 structures) ont été découverts. La plupart correspondent à de petites structures, de moins de $7 \mathrm{~m}$ de diamètre, pour une hauteur maximale d'un mètre. Elles sont traditionnellement considérées comme des tombelles funéraires protohistoriques (Provost, Vallat, 1996). Mais les sondages effectués sur 9 structures prises au hasard (fig. 10) ont montré qu'il s'agissait simplement de tas d'épierrement, d'âge antique à moderne. D'ailleurs, les «tertres » sont tous situés en dessous de $1200 \mathrm{~m}$, limite supérieure de la mise en culture. Quelques structures plus imposantes, mais peu nombreuses, pourraient être de véritables tertres funéraires protohistoriques. Cela demande à être vérifié par des investigations archéologiques approfondies.

\subsection{Période gallo-romaine}

La période gallo-romaine est peu représentée dans la zone d'études (6 sites ou indices de sites). Un seul habitat véritable a été reconnu et sondé en 2005. S'y ajoute des pierriers et un vaste enclos quadrangulaire, dont la fonction est présumée liée au pastoralisme (fig. 11). Dans tous les cas, il s'agit de sites datables de l'Antiquité tardive. Les études paléoenvironnementales montrent l'importance de la pression des activités humaines sur les paysages, surtout après $1715 \pm 50 \mathrm{BP}$ ( ca 237-422 AD). Cette date, obtenue sur tourbe, marque en effet le début d'un recul marqué de la forêt, associé à un développement des céréales et des Poaceae qui marquent l'emprise des herbages et des cultures (Surmely et al. 2009). Le développement des landes à callune et des pelouses herbeuses témoigne également de cette importante emprise agropastorale constatée dans les environs à la fin de l'Antiquité. À partir de ce moment-là, et pour les périodes postérieures, le paysage s'ouvre considérablement. On peut penser que des structures gallo-romaines étaient localisées dans les vallées, non prospectées à ce jour.

\subsection{Périodes médiévale et moderne}

À ces périodes se rattachent les innombrables structures semi-enterrées (baptisées « cases ») découvertes dans l'ensemble de la zone d'études. 287 ensembles ont été recensés (soit 565 structures), depuis la structure isolée, jusqu'au groupement de 15 bâtiments. D'après la morphologie, quatre grands groupes peuvent être individualisés.

Il y a d'abord des groupements de bâtiments de forme rectangulaire, à bases de murs en pierre, parfois cloisonnés, 

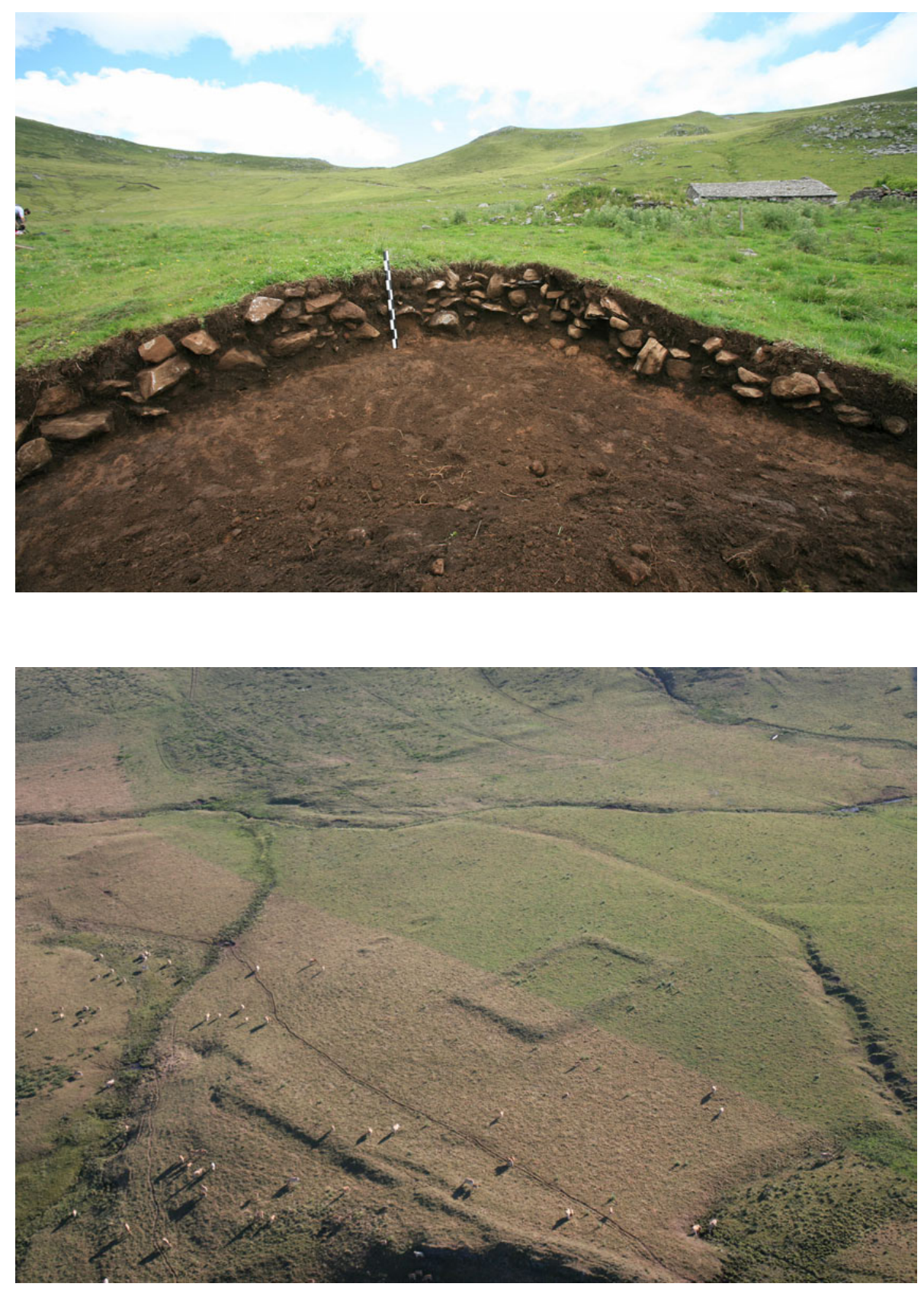

Fig. 10. Coupe du tertre (pierrier) n 1721 (La Montagne de Graval, Brezons). Photo F. Surmely.
Fig. 11. Vue aérienne de l'enclos quadrangulaire (site $n^{\circ} 12$ ) galloromain (La Montagne de la Vèze,

Pailherols). Photo F. Surmely. entourés d'aménagements divers: chemins, rigoles d'amenée d'eau, enclos...). Cinq sites de ce type ont été recensés, tous situés en dessous de $1200 \mathrm{~m}$. Un sondage pratiqué dans un des bâtiments du site 53 (Montagne du Bouyssou, Pailherols) a montré une datation autour des $\mathrm{XI}^{\mathrm{e}}-\mathrm{XII}{ }^{\mathrm{e}} \mathrm{s}$. (cal. 1040-1220 AD; VERA-3750). Il est possible de les identifier comme des hameaux désertés d'âge médiéval, liés à une occupation permanente, dans le cadre d'une économie agropastorale, en tous points comparables à ceux recensés sur la commune de Collandres, au nord du massif (Coste 1995 ; Lapeyre 2004), mais aussi en Aubrac, au sud-ouest de notre région d'étude (Hamon 1995 ; Fau 2006).
La seconde catégorie morphologique principale est celle des structures rectangulaires isolées ou groupées par deux au maximum. Elles ont la plupart des bases de murs en pierre. Les dimensions (intérieures) sont très diverses, avec des longueurs allant de 6,8 à $21 \mathrm{~m}$ et des largeurs s'échelonnant entre 2,8 et $5,7 \mathrm{~m}$. Un cloisonnement interne est fréquent, avec un mur de refend délimitant deux pièces de superficie inégale. La répartition géographique est beaucoup plus large, mais se limite à la zone située en dessous de $1400 \mathrm{~m}$ d'altitude. Le plus souvent, ces bâtiments se situent à proximité des burons voûtés modernes. De l'ensemble de ces caractéristiques, il semble possible de dire 
que beaucoup de ces « cases » correspondent probablement à des édifices liés à l'économie pastorale vraisemblablement saisonnière, du moins pour les structures situées le plus haut en altitude. La diversité des formes et des dimensions recouvre très vraisemblablement des différences fonctionnelles et des différences chronologiques. Un sondage pratiqué sur une structure $\left(\mathrm{n}^{\circ}\right.$ 13-2) de la Montagne de la Vèze (Pailherols, 1180 m d'altitude; fig. 12) a donné une date entre 1440 et 1550 cal AD, soit le début de l'époque moderne. Cela correspond bien avec les données issues des textes (Bouyssou, 1972; 1974), qui fixent le début de l'économie pastorale intensive au $\mathrm{XV}^{\mathrm{e}} \mathrm{s}$. Une date légèrement postérieure (1510-1670 cal AD) a été obtenue sur un bâtiment en pierres ( $n^{\circ} 1337$; Les montagnes de Bâne, Pailherols, $1430 \mathrm{~m}$ ), jouxtant une autre construction, dont la fonction reste indéterminée. Mais l'étude de la structure $n^{\circ} 1277$ (Montagne de Vixouze, Pailherols, $1180 \mathrm{~m}$ ) a révélé un bâtiment soigneusement bâti en grosses pierres sèches, sans séparation interne décelable, mais doté de deux entrées, dont une précédée d'un couloir coudé en pierres et d'un dallage constitué de grandes plaques rocheuses régulières. Il a livré un abondant mobilier céramique et a été daté de 1020-1210 AD, ce qui correspond à l'âge obtenu sur la maison du hameau $n^{\circ} 53$, dont il est distant de moins d'un kilomètre. Le soin apporté à la construction et la quantité de mobilier recueillie plaident en faveur d'une structure occupée toute l'année.

Il y a aussi des groupements de cases de forme carrée, rassemblant de 5 à 11 structures. Ils sont très nombreux dans toute la zone (31 recensés), et leur répartition topographique est variée, de 1120 à 1411 m d'altitude. Les dimensions des structures sont remarquablement constantes, entre 4 et $5 \mathrm{~m}$ de côté. La plupart ne présentent pas de traces de murs en pierre. Les structures sont parfois rassemblées en lignes, de façon accolée, sur le modèle des « burons en peigne » bien connus dans le Cézallier et les Monts Dore (Fournier, 1983), mais en nombre bien plus réduit. Mais le modèle largement dominant est celui d'une organisation en « grappe », avec des structures distantes de quelques mètres ou dizaines de mètres seulement (fig. 13). Quelques ensembles voient se côtoyer des modèles mixtes. Le choix du site géographique est presque toujours le même: sur le versant est d'une petite éminence, offrant à la fois une vue étendue sur les environs et une protection aux vents dominants. L'ouverture est tournée vers l'est ou le sud. Dans certains terroirs, des groupements se côtoient à quelques centaines de mètres seulement. Parfois, ils sont voisins de groupements de cases rectangulaires, mais sans recouvrement entre eux (ce qui empêche notamment toute détermination simple de chronologie relative). L'altération des formes (et notamment des bourrelets latéraux) est variable, mais ce caractère tient sûrement plus aux effets de l'érosion différentielle que de l'âge des structures.
La fouille de deux petites structures de ce type (mais isolées) sur le terroir de Peyre (Lacapelle-Barrès), en 2005 , et de trois autres sur le groupe $\mathrm{n}^{\circ} 54$ (Montagne du Bouyssou à Pailherols) en 2008, toutes situées entre 1000 et $1200 \mathrm{~m}$ d'altitude, a permis de les interpréter comme des constructions légères, à toiture et murs en matériaux périssables, édifiés au bas Moyen Âge (1300-1430 AD; VERA-3749) et réoccupés au début de l'époque moderne (cal. 1440-1640 AD; VERA-3749). Il pourrait s'agir de ces cabanes, foguals ou mazucs, décrits dans les textes des XVI-XVIII' s. (Fournier 1983; Bouyssou 1972; 1974). En 1788, le voyageur-érudit Legrand d'Aussy décrit des «cabanes en bois couvertes en mottes de gazon» dans les montagnes de Basse-Auvergne (actuel Puy-de-Dôme). Leur nombre important et leur localisation en altitude vont également dans le sens de cette hypothèse. Leur fréquent regroupement pourrait s'expliquer par le caractère collectif de la propriété foncière, dont l'importance apparaît dans les archives (« dans les montagnes indivises, les coherbassiers (éleveurs, NDLR) doivent tenir leurs parcs et burons tous ensemble au même endroit de la montagne »; cité par Bouyssou 1972; 1974). Les investigations menées sur le site $n^{\circ} 54$ ont montré des différences importantes entre les structures. Deux d'entre elles n'ont pas livré de mobilier ni d'aménagement intérieur. En revanche, la troisième a livré deux niveaux d'occupation avec d'abondants restes céramiques, et un foyer pour la couche inférieure, témoignant d'un habitat destiné à l'homme, avec réutilisation de la structure.

Reste à saisir la différence qui existe entre ces structures légères et certains bâtiments rectangulaires à murs en pierre, qui sont du même âge. Elle peut être d'ordre fonctionnel, ou liée au statut social des propriétaires. La question des « proto-burons », par référence aux constructions voûtées qui viendront plus tard, reste donc à approfondir.

Le dernier ensemble est constitué d'une multitude d'aménagements anthropiques séparés des bâtiments et difficilement datables: murs, levées de terre, chemins, amenées d'eau, enclos... On reste frappé par l'importance des aménagements qui ont littéralement modelé le relief dans la zone et surtout en dessous de $1200 \mathrm{~m}$.

En 2008, nous avons identifié un parcellaire régulier, bien conservé, qui jouxte un hameau médiéval, sur la commune de Pailherols (fig. 14). Les limites de parcelles sont constituées de petits murets de pierre sèche, aujourd'hui érodés. Ce réseau, comme nous avons pu le vérifier en superposant les deux images sur SIG, n'a rien à voir avec la délimitation parcellaire donnée par le cadastre «napoléonien » de 1811, qui correspond à une économie d'estive bovine spécialisée. Nous pensons donc qu'il s'agit d'un réseau parcellaire lié à une mise en culture céréalière, datant de la période médiévale. Le relevé finement détaillé de cet ensemble très 
intéressant et la réalisation de sondages dans les murets sont prévus pour l'été 2009.

\subsection{Les burons en pierre}

Enfin, le dernier volet de notre étude concerne les bâtiments en pierre voûtés liés à l'économie pastorale spécialisée et saisonnière, qui ont pris la place des constructions plus légères du début de l'époque moderne évoquées plus haut. Les textes fixent le début de leur construction au début du $\mathrm{XVII}{ }^{\mathrm{e}} \mathrm{s}$. Ces burons ont souvent été réaménagés et occupés jusqu'au début du $\mathrm{XX}^{\mathrm{e}} \mathrm{s}$., voire jusqu'à l'immédiat aprèsguerre pour certains. Dans le cadre de notre programme et d'un travail universitaire, tous les bâtiments ont été relevés et localisés (Nicolas 2008).

En théorie, le terme buron désigne plus particulièrement un édifice semi-enterré et voûté, divisé en deux pièces servant de fromagerie et de cave pour conserver et affiner les fourmes fabriquées quotidiennement. Ils sont très souvent accompagnés d'un bâtiment plus vaste, le védélat (abri pour les veaux) et de loges à cochons, de taille plus modeste (fig. 15). Tous ces termes apparaissent dans les matrices des cadastres dits napoléoniens datés du début du XIX $\mathrm{s}$. Sont également mentionnés quelques granges et bât. (abréviation de bâtiments). L'ensemble des édifices conservés a fait l'objet d'un relevé systématique sous forme de fiches types comportant des informations sur leur position géographique, leurs composantes architecturales et leur état de conservation. Les structures les plus anciennes comme les édifices rénovés ont été pris en compte. L'utilisation d'un SIG a ensuite permis d'obtenir de premiers éléments de datation, en mettant en relation les relevés de terrain et les cadastres anciens. Les résultats, dans l'ensemble extrêmement fiables, nous montrent que 31 édifices sur 93 sont le résultat de reconstructions et de déplacements récents (postérieurs à l'établissement des premiers cadastres). Deux tiers seulement des structures relevées par les arpenteurs $\mathrm{au}$ début $\mathrm{du} \mathrm{XIX}^{\mathrm{e}} \mathrm{s}$. ont perduré jusqu'à aujourd'hui. Les autres ont disparu ou ont seulement laissé des traces de creusement au sol, qui ressemblent aux cases des siècles précédents. Les constructions légères sont absentes des cadastres du XIX ${ }^{\mathrm{e}} \mathrm{s}$. Mais rien ne dit qu'elles aient totalement disparu, car elles ont pu être volontairement négligées par les arpenteurs, n'étant pas imposables.

Quoi qu'il en soit, aux XVII et XVIII ${ }^{\mathrm{e}}$ s., un système d'exploitation bien rôdé des montagnes s'était mis en place. La moindre zone d'herbage était occupée par des vaches laitières. Les montagnes à graisse n'avaient qu'un rôle mineur (Durand 1946). Jusqu'à $1150 \mathrm{~m}$ d'altitude, l'espace était divisé en prés de fauche. Au-delà, les pâturages étaient savamment répartis entre les fumades, parcelles entourant le buron, et les aygades, vastes terrains de parcours traversant le plateau. La distribution de l'eau était assurée par des rigoles creusées à proximité des édifices. Le plan de 1776 , montre l'importance, encore à cette époque, de la propriété seigneuriale. Les bourgeois possédaient également leur lot de montagnes et quelques parcelles étaient indivises. Sur les cadastres, ces dernières sont peu nombreuses, seulement 3 fumades et un tiers des aygades. Cette situation est la conséquence d'une réduction progressive des communaux depuis le $\mathrm{XVII}^{\mathrm{e}} \mathrm{s}$., au profit de la propriété privée.

Quant aux structures d'exploitation, elles étaient ellesmêmes largement standardisées. Les burons notamment comportaient pour la plupart une voûte en berceau, construite à partir de cintres en bois et d'un coffrage recouverts de pierres sèches. L'utilisation d'un mortier de chaux pour les joints est aussi très courante, probablement permise par l'amélioration des transports au XIX ${ }^{\mathrm{e}} \mathrm{s}$. Ceux qui n'entraient pas dans ce cas de figure étaient couverts d'une voûte en tas de charge, faite de grandes dalles empilées à l'aplomb les unes des autres et pouvant atteindre jusqu'à deux mètres de long.

Des relevés de plusieurs bâtiments au scanner 3D longue portée devraient permettre prochainement d'apporter des éléments de compréhension sur les méthodes et les moyens mis en œuvre pour ces constructions. L'approfondissement des recherches archivistiques (registres paroissiaux, baux de location, archives judiciaires...) et le recueil de nouveaux témoignages permettront de faire évoluer nos connaissances au sujet du fonctionnement du système d'estive, depuis sa mise en place au $\mathrm{XV}^{\mathrm{e}} \mathrm{s}$. jusqu'à son déclin, à partir du XIX $\mathrm{e}$.

\section{Conclusion}

Le projet de recherches a mis en évidence la richesse archéologique, inattendue, de cette zone de moyenne montagne. Parcourue vraisemblablement dès le Mésolithique, elle a été le siège d'activités agropastorales très précoces, comme en témoignent l'importance des vestiges datables du Néolithique ancien et les données paléoenvironnementales. Cela semble lié à la fertilité de ce terroir de volcanisme ancien. Bien évidemment, il reste difficile de traduire les informations acquises en terme de densité de population, compte tenu de la mauvaise conservation des sites et de l'absence de référentiel régional.

La période protohistorique reste mal connue. La plupart des innombrables «tertres », considérés initialement comme des tombelles funéraires datant de cette époque, correspond plus vraisemblablement à de simples pierriers, édifiés au cours des périodes plus récentes. Ces derniers sont toutefois intéressants, puisqu'ils sont les témoins d'une exploitation agricole des terroirs, dans une zone aujourd'hui vouée exclusivement à la prairie d'estive. 

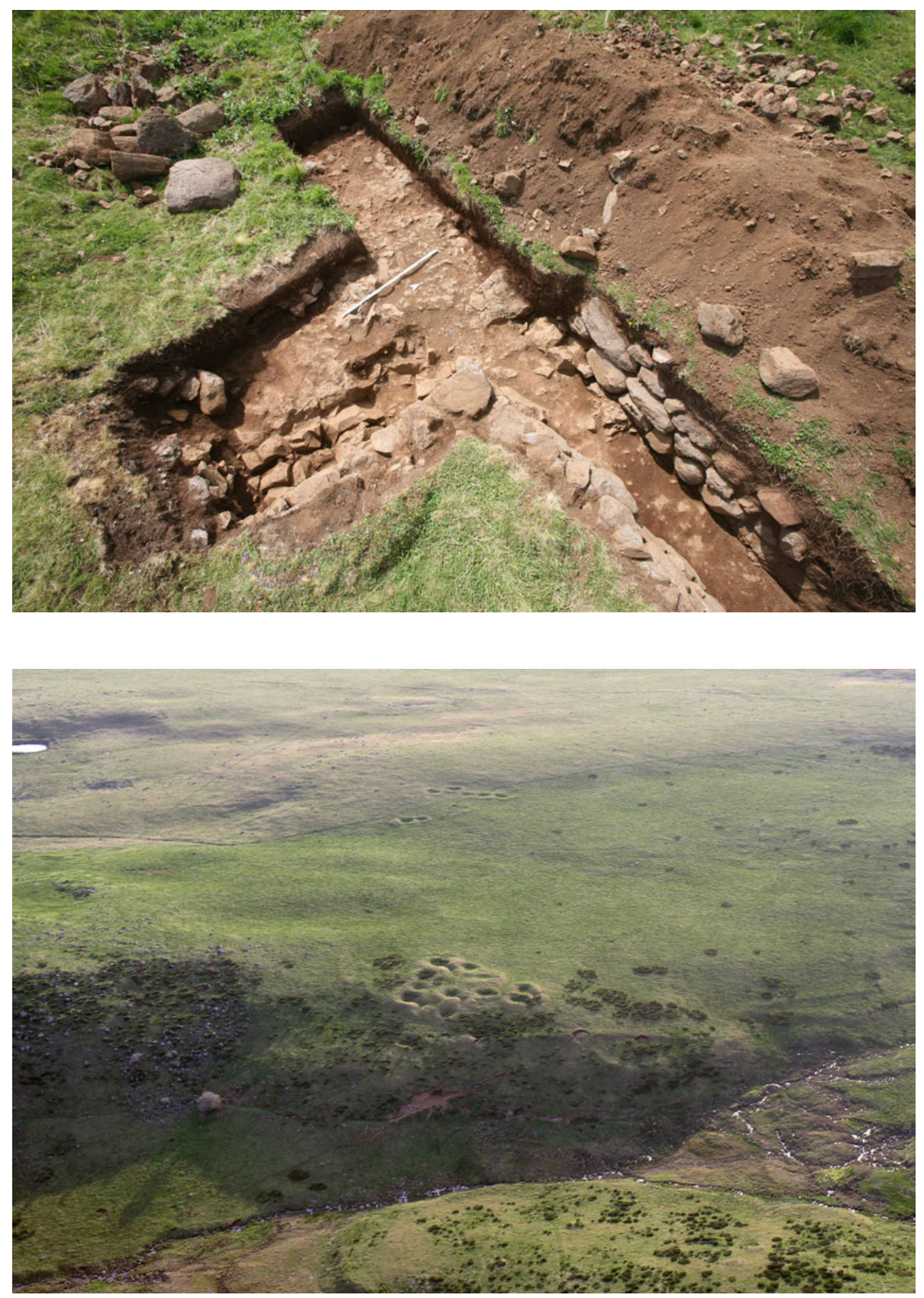

Fig. 12. Le bâtiment $n^{\circ}$ 13-2

(La Montagne de la Vèze, Pailherols) à l'achèvement des sondages de 2007. Photo F. Surmely.
Fig. 13. Vue aérienne du site 54 (La Montagne du Bouyssou, Pailherols). Photo F. Surmely.
Les études palynologiques montrent l'accentuation de la mise en valeur agricole à partir de la fin de l'Antiquité, ce qui se retrouve dans d'autres secteurs du Massif Central telle la Lozère (Reille, Pons, De Beaulieu 1992).

Le Moyen Âge voit la multiplication des bâtiments et la création de hameaux, qui sont liées à l'exploitation agricole des sols, jusqu'à 1200 m d'altitude. Le soin apporté à la construction est lié à l'occupation permanente des terroirs et à la nécessité de supporter des hivers particulièrement rudes. C'est à la fin de l'époque médiévale que se place le tournant majeur dans l'exploitation des terroirs.
L'agropastoralisme est remplacé par un système d'élevage bovin spécialisé, à caractère saisonnier, organisé par de grands propriétaires, mais aussi sans doute par des communautés villageoises. Ce nouveau cadre économique génère la construction d'abris pastoraux, bâtis en matériaux légers. Mais ces innombrables « cases » semi-enterrées, découvertes par centaines, présentent une grande variété de formes et de modes architecturaux, reflet assurément d'une évolution chronologique au cours de l'époque moderne, mais aussi fonctionnelle. Il faut dire que diverses activités humaines ont assurément coexisté, en fonction des époques 

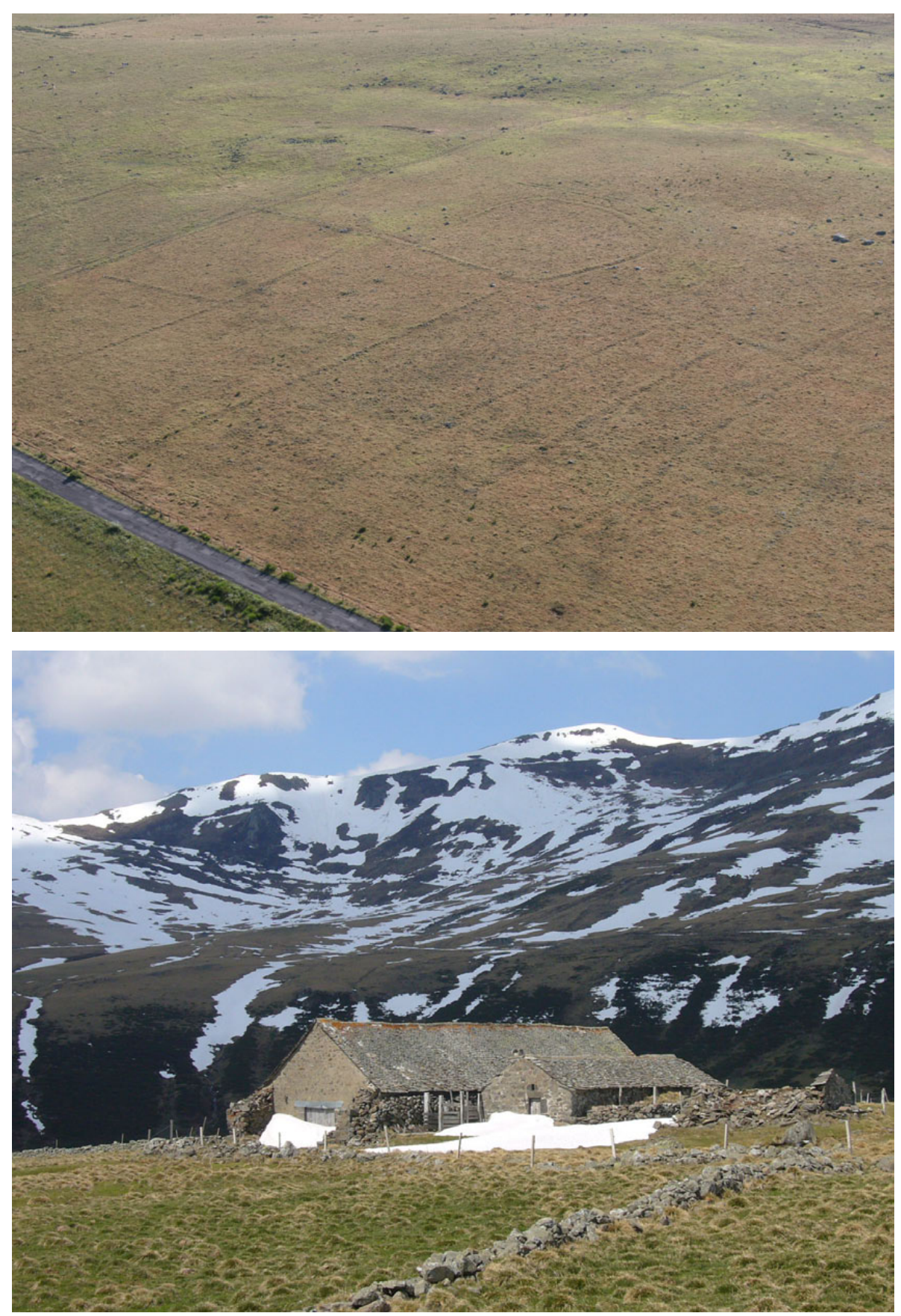

Fig. 14. Vue aérienne du parcellaire présumé médiéval de la montagne de (Pailherols). Photo F. Surmely.

Fig. 15. Un ensemble pastoral du XIXe typique, la Montagne de Granval (Brezons). De gauche à droite: védélat, buron, loges à cochon (en ruines). Photo F. Surmely. mais aussi des biotopes, avant que le système spécialisé de l'estive bovine ne se généralise sur l'ensemble de la zone, avec la construction de bâtiments en pierre (burons et védélats). Les analyses paléoenvironnementales montrent la persistance, dans les zones basses, de cultures céréalières, ce qui est confirmé par la persistance de quelques moulins à farine figurant sur les premiers cadastres du début du XIX ${ }^{\mathrm{e}} \mathrm{s}$. Les résultats sont donc importants pour la connaissance des relations hommes/milieux au travers des siècles. Plus largement, notre recherche témoigne de la nécessité de l'approche pluridisciplinaire et diachronique. Dans un contexte marqué par l'érosion des vestiges et la pauvreté des sources écrites, chaque méthode et champ disciplinaire apporte en effet des données, qui doivent être croisées et complétées par les informations issues des autres disciplines. Cette confrontation est favorisée par la multiplication des relevés topographiques et le géoréférencement de l'ensemble des données et documents (y compris des plans anciens), qui permettent l'intégration du contexte géographique et des analyses croisées, par le biais du SIG. L'analyse spatiale est fondamentale, dans un secteur marqué par des différences très importantes de biotope, du fait notamment du fort 
gradient altitudinal. Cette diversité doit être constamment gardée à l'esprit lors de l'analyse et de la comparaison des activités humaines.

Mais si les études réalisées jusqu'ici, surtout axées sur les prospections, permettent d'appréhender la richesse archéologique de la zone et la complexité de l'occupation humaine en liaison avec les activités agropastorales, elles ne suffisent pas à résoudre toutes les interrogations, notamment sur la question de la genèse de l'économie pastorale d'estive. La poursuite des travaux archéologiques, orientés vers la caractérisation chronologique et surtout fonctionnelle des sites recensés, s'avère nécessaire, par le biais de nombreux sondages et de fouilles.

Enfin, dernier aspect, notre travail présente sans conteste un intérêt conservatoire. En effet, les changements de pratiques agricoles, qui voient la multiplication des travaux d'arasement des « anomalies » du relief pour favoriser la multiplication des prairies de fauche, menacent la préservation des aménagements anciens.

\section{Bibliographie}

Blais 1972 : BLAIS (S.) - Contribution à la géologie du Cantal. Géologie du Carladès. Thèse de doctorat, Université d'Orsay, dact., 1972, $150 \mathrm{p}$.

Bouyssou 1972: BOUYSSOU (D.) - Les montagnes cantaliennes du XIII ${ }^{\mathrm{e}}$ au XVIII ${ }^{\mathrm{e}}$ s. Revue de la Haute-Auvergne, t. 43, 1972, p. 143-164.

Bouyssou 1974: BOUYSSOU (D.) - Les montagnes cantaliennes du XIII ${ }^{\mathrm{e}}$ au XVIII ${ }^{\mathrm{e}}$ s. Revue de la Haute-Auvergne, t. 44, 1974, p. 36-78.

Chapman, Gearey 2000 : CHAPMAN (G.), GEAREY (B. R.) Palaeoecology and the perception of prehistoric landscapes: some comments on visual approaches to phenomenology. Antiquity, 74 (284), 2000, p. 316-319.

Coste 1995: COSTE (M.-C.) - L'occupation médiévale de la moyenne montagne cantalienne: l'exemple de la commune de Collandres (Cantal). In: PRESSOUYRE (C.) dir., Vivre en moyenne montagne. Actes du $117^{e}$ congrès des Sociétés Historiques et Scientifiques, Clermond Ferrand 1992. Paris, éditions du CTHS, 1995, p. 203-227.

Déchelette 1912: DÉCHELETTE (J.) - Les « cases » en pierres sèches de l'Auvergne. Bulletin Archéologique du Comité des Travaux Historiques et Scientifiques, 1912, p. 2-19.

Fau 2006: FAU (L.) - Les Monts d'Aubrac au Moyen Âge. Paris, Documents d'Archéologie Française, 101 2006, 214 p.

Fournier, Fournier 1983 : FOURNIER (G.), FOURNIER (P.-F.) - La vie pastorale dans les montagnes du centre de la France. Bulletin Historique et Scientifique de l'Auvergne, 91, 676, 1983, p. 199-538.
Hamon 1995: HAMON (E.) - L'habitat temporaire sur l'Aubrac à la fin du Moyen Âge. In: PRESSOUYRE (C.) dir., Vivre en moyenne montagne. Actes du $117^{e}$ congrès des Sociétés Historiques et Scientifiques, Clermond Ferrand 1992. Paris, éditions du CTHS, 1995, p. 229-239.

Lapeyre 2004: LAPEYRE (O.) - Un village médiéval déserté: Espinasse de Collandres, Cantal. Bulletin du GRHAVS, 64, 2004, 59 p.

Miras 2004: MIRAS (Y.) - L'analyse pollinique du plateau de Millevaches (MassifCentral, France) et de sites périphériques limousins et auvergnats : approche des paléoenvironnements, des systèmes agro-pastoraux et évolution des territoires ruraux. Thèse de doctorat, Université de Franche-Comté, 2004, 299 p.

Miras et al. 2005: MIRAS (Y.), VERGNE (V.), GUENET (P.), SURMELY (F.) - Le Massif Central: premières traces d'anthropisation révélées par l'analyse pollinique des zones humides corrélées aux données archéologiques. In: RICHARD (H.) éd., Néolithisation précoce. Premières traces d'anthropisation du couvert végétal à partir des données polliniques. Besançon, Presses Universitaires de Franche-Comté, Annales littéraires, 777, série « Environnement, sociétés et archéologie », 7, 2005, p. 89-106.

Miras et al. 2006: MIRAS (Y.), SURMELY (F.), GUENET (P.), VANNIERE (B.), WALTER-SIMONNET (A.-V.), TZORTZIS (S.) - Dynamiques d'occupation et histoire de l'environnement d'un terroir de moyenne montagne: la tourbière de Peyre (Lacapelle-barrès, Cantal, Massif Central) et ses alentours. premiers résultats. In: MIRAS (Y.), SURMELY (F.) dir., Environnement et peuplement de la moyenne montagne, du Tardiglaciaire à nos jours. Actes de la table ronde de Pierrefort, juin 2003. Besançon, Presses Universitaires de Franche-Comté, Annales littéraires, 799, série « Environnement, sociétés et archéologie », 9, 2006, p. $157-182$.

Moine-Vaziri 1973: MOINE-VARIZI (H.) - Contribution à la géologie du Cantal. Géologie de Mur-de-Barrez. Thèse de de doctorat, Université d'Orsay, dact., 1973, 91 p.

Nehlig et al. 2001: NEHLIG (P.), FREOUR (G.), GOËR DE HERVE (A.), HUGUET (D.), LEYRIT (H.), MARONCLE (J.), ROGER (J.), ROIG (J.-Y.), SURMELY (F.), THIEBLEMONT (D.), VIDAL (N.) - Carte géologique de la France (1/50 000), feuille Murat, notice explicative. Orléans, BRGM, 2001, 264 p.

Nicolas 2008: NICOLAS (V.) - L'architecture pastorale des montagnes du Cantal, entre les vallées du Goul et du Siniq. Mémoire de master 2 de l'université de Clermont-Ferrand, 2008.

Pasty et al. 1999: PASTY (J.-F.), SURMELY (F.), TZORTZIS (S.) - Contribution à un inventaire des ressources en silex : le département du Cantal (Massif Central, France). Bulletin de la Société Préhistorique Française, 96, 1, 1999, p. 7-13. 
Provost, Vallat 1996: PROVOST (M.), VALLAT (P.) - Carte archéologique de la Gaule. Le Cantal. Paris, Fondation de la Maison des Sciences de l'Homme, 1996, 216 p.

Reille, Pons, De Beaulieu 1985 : REILLE (M.), PONS (A.), DE BEAULIEU (J.-L.) - Recherches pollenanalytiques sur l'histoire tardiglaciaire et holocène de la végétation du Cézallier, de la Planèze de Saint-Flour et de la Margeride (Massif Central, France). Pollens et Spores, 27, 2, 1985, p. 209-270.

Santallier, Surmely 2003 : SANTALLIER (D.), SURMELY (F.) - Le silex de la Côte-Blanche et les métadolérites du secteur d'Entraygues (Aveyron). Compte rendu de l'excursion du 22 juin 2002. In: coll. Les Matières premières lithiques en Préhistoire, actes de la table ronde internationale d'Aurillac. supplément $n^{\circ} 5$ à Préhistoire du Sud-Ouest, 2003, p. 367-372.

Simon-Coste 1988: SIMON-COSTE (M.-C.) - Les montagnes d'Auvergne avant la vie pastorale actuelle. Villages désertés et paysage fossile de la commune de Collandres (Cantal). Revue Archéologique du Centre de la France, 27, 1, 1988, p. 61-98.

Surmely 1998 : SURMELY (F.) - Le peuplement de la moyenne montagne auvergnate, des origines à la fin du mésolithique. Thèse de doctorat, Université de Bordeaux I, 1998, 2 t., 239 et $205 \mathrm{p}$.

Surmely 2006: SURMELY (F.) - Les poisons de chasse dans les sociétés préhistoriques des pays tempérés. In: MIRAS (Y.), SURMELY (F.) dir., Environnement et peuplement de la moyenne montagne, du Tardiglaciaire à nos jours. Actes de la table ronde de Pierrefort, juin 2003. Besançon, Presses Universitaires de Franche-Comté, Annales littéraires, 799, série « Environnement, sociétés et archéologie », 9, 2006, p. 51-60.

Surmely, Pasty 2003: SURMELY (F.), PASTY (J.-F.) - les importations de silex en Auvergne. In: coll. Les Matières premières lithiques en Préhistoire, actes de la table ronde internationale d'Aurillac. supplément $\mathrm{n}^{\circ} 5$ à Préhistoire $d u$ Sud-Ouest, 2003, p. 327-336.

Surmely, Tzortzis, Miras 2008: SURMELY (F.), TZORTZIS (S.), MIRAS (Y.) - Nouvelles données sur le peuplement mésolithique et néolithique du Cantal. In : RICHARD (H.), GARCIA (D.) dir., Le peuplement de l'arc alpin. 131 e congrès annuel des Sociétés Historiques et Scientifiques, Grenoble 2006. Paris, CD Rom, éditions du CTHS, 2008, p. 307-321.

Surmely et al. 2003: SURMELY (F.) dir., TZORTZIS (S.), PASTY (J.-F.), BOUBY (L.), COURTAUD (P.), COURTY (M.-A.), FONTANA (L.), HEINZ (C.), PHILIBERT (S.) - Le site mésolithique des Baraquettes (Velzic, Cantal) et le peuplement de la moyenne montagne cantalienne, des origines à la fin du Mésolithique. Paris, Société Préhistorique Française, mémoire XXXII, 2003, 282 p.

Surmely et al. 2009: SURMELY (F.), MIRAS (Y.), GUENET (P.), NICOLAS (V.), SAVIGNAT (A.), VANNIERE (B.), WALTER-SIMONNET (A.-V.), SERVERA (G.), TZORTZIS (S.) - Occupation and land-use history of a medium mountain from the Mid-Holocene: a multipluridisciplinary study performed in the South Cantal (French Central Massif). C. R. Palevol, 8, 2009, p. 737-748. 


\title{
Late Bronze Age helmets with crests on transalpine long-distance trade routes
}

\author{
Andreas LIPPERT*
}

\begin{abstract}
Résumé. The fragment of a bronze helmet with a crest was recently discovered at the northern foot of the main eastern alpine chain in southern Salzburg (Austria) at approximately 1200 metres above sea level. It was found in a sandbank of the Anlaufbach, which flows into the Nassfelder Ache and the Gasteiner Ache in the North. The latter is a tributary to the Salzach, the largest river of the Salzburg region, which flows through both the mountains and the lowlands. The object was found in a water context and may have been a votive deposit.
\end{abstract}

\section{Découvertes de casques à crête du Bronze final sur des routes commerciales transalpines}

Abstract. Une nouvelle découverte dans la région sud de Salzbourg (Autriche), porte désormais à trois le nombre de casques à crête ornés de symboles solaires, datant du Bronze final dans le secteur oriental de l'arc alpin. Ces pièces on été partiellement détruites de façon intentionnnelle, leur dépôt s'inscrivant dans le cadre de pratiques votives. Les lieux de découvertes qui se situent tous le long des routes de col avantageuses, témoignent d'un réseau de commerce lointain lequel était bel et bien destiné à l'exportation du cuivre brut et du sel. Ces échanges de matières premières à longue distance était vraisemblablement contrôlé par des aristocraties de guerriers implantées dans les Préalpes du Nord et du Sud.

$I^{n}$ a steep descent, the valley of the Anlauf leads directly to the Korntauern Pass in the main alpine chain around 2460 metres above sea level. This route was being used from an early period, and it continued to represent an important link between the northern and southern alpine regions well into modern times. The pass itself yielded a small hoard of cast copper lumps, which can only be generally assigned to the Bronze Age (Lippert 2000, 252, fig. 4/1-2). During Roman times, a wide road led across the pass, although it fell into disrepair shortly after its construction at the end of the second century AD (Lippert 1993, $30 \mathrm{ff}$.).

The bronze find from the Anlauf valley constitutes twofifths of a double-shelled late Bronze Age helmet with a crest (fig. 1). It is decorated with embossed rows of punched dots at the edges and at the ridge as well as with a concentric circular motif of punched dots around a larger boss on the sides. The reconstructed form of the helmet and its decorations closely resemble the almost entirely preserved crested helmet from Pass Lueg, which was already discovered in 1838 .

The helmet from Pass Lueg (573 metres above sea level) was discovered on a rock terrace above the present-day pass road. According to contemporary reports, numerous other bronze objects were also found on the site (fig. 1). Only a handful of these were given to the Salzburg museum and have therefore survived. The other objects are missing (Kyrle 1918, 80 ff.). It is more or less certain that votive offerings were deposited on the site either individually or in assemblages. In addition to the helmet with a crest, three old, broken socketed picks, a fragmented median winged axe and several pieces of cast copper lumps remain. The cast copper fragments and the socketed picks in particular can be directly associated with copper mining. Picks from the Bronze Age Mitterberg mining grounds in the area of Bischofshofen in the central Salzach valley are directly comparable. Calotte-shaped cast copper lumps, which are the end product obtained during copper exploitation, occur in various hoards from mining contexts; these have often remained intact. The axe from Pass Lueg can only vaguely be dated to the early or older Urnfield period.

The helmet is made up of two halves and consists of a thick bronze sheet. The cap is hemispherically shaped and drawn into a trilobate crest at the top. At the front and back sides, the two halves of the helmet are joined with rivets. In

* Institute für ur und frühgeschichte, Der universität wien, Franz Klein Gasse 1, A1190 Wien (Autriche). 


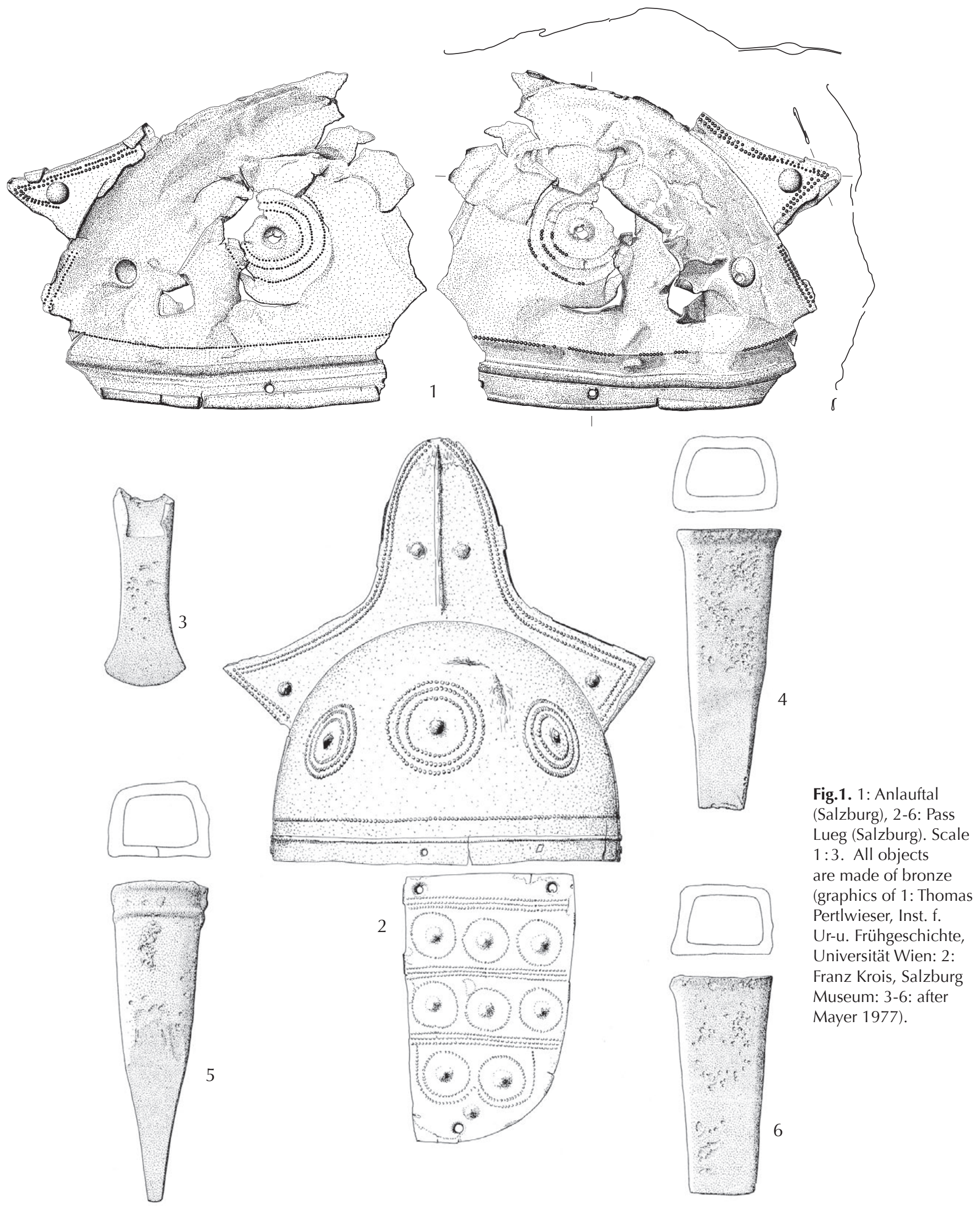



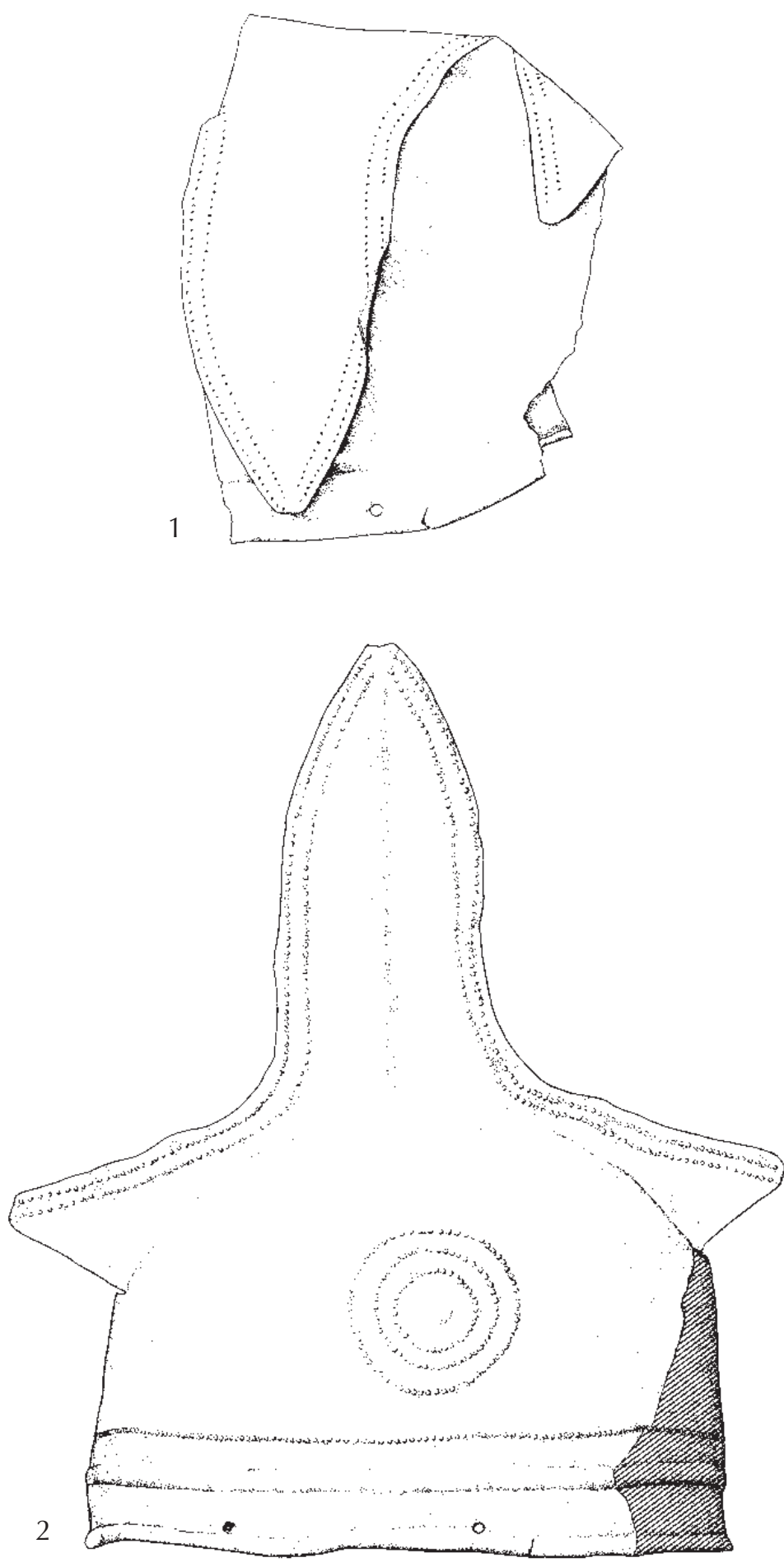

Fig. 2. Original state of finding and reconstruction of the bronzen helmet from Moosbruckschrofen (Tyrol). Scale 1:3 (after Egg, Tomedi 2002).

addition, the two parts are clasped together at the joint by use of small notches.

A horizontal strengthening ridge runs somewhat above the opening of the helmet. It is supplemented by a series of delicate, small dots that have been driven into the material from behind. An additional strengthening ridge runs along the two sides; in both cases, it traces the central axis of the top point of the crest. Two rows of small dots follow the sagittal line and the crest. In the centre of each of the two halves of the top part of the helmet there is a large circle consisting of two rows of dots; each is arranged around a larger boss. Next to this circle, there are two similar but slightly smaller circles. These circular motifs probably symbolise the sun. The helmet also has protective cheek pieces that are decorated with rows and circles of embossed dots.

In 2001, a substantial hoard was discovered in a crevice in Fliess-Moosbruckschrofen somewhat to the North of the mountain pass on the Piller Höhe in western Tyrol at approximately 1600 metres above sea level. A large clay container held numerous bronze objects, among them the intentionally deformed half of a helmet with a trilobate crest of the Pass Lueg type (fig. 2). The reconstructed helmet bears a concentric circular pattern of small embossed dots on each side that encloses a larger central boss. The top point of the crest is narrower and higher than that of either the Pass Lueg or the Anlauftal helmets. Again, it features the familiar upright strengthening ridge on both sides. We can thus discern a considerable conformity between all three helmets in terms of their shape and ornamentation.

The remainder of the hoard from Moosbruckschrofen consists of offensive weapons, such as daggers, swords and spearheads, as well as axes, sickles, razors and jewellery, such as needles, belt fittings and ornamental disks. There is no consensus regarding the period of production of these votive bronze objects. While Egg and Tomedi postulate a period between Bronze Age C 2 (end of the middle Bronze Age) until Bronze Age D (early Urnfield period) (Egg, Tomedi 2002), Schauer puts forward a period extending from Bronze Age D to Hallstatt A (early and older Urnfield period) (Schauer 2003). On the basis of these dissimilar chronological frameworks, the helmet from Moosbruckschrofen can only broadly be dated to a period between the $14^{\text {th }}$ and $12^{\text {th }}$ centuries BC. Typologically, a later date around the $11^{\text {th }}$ century BC (middle Urnfield period) is also conceivable.

The road across the pass on the Piller Höhe has remained an important transport link in the upper Inn valley well into modern times. It bypassed the gorge-like, narrow valley at Landeck and at the same time offered a considerable shortcut through the Inn valley. Towards the South, one reaches the Resia Pass (approximately 1500 metres above sea level) at the crest of the main alpine chain and, from there onwards, the Etschtal, through which the road leads on to the upper Italian lowlands.

All three crested helmets - those from Pass Lueg, the Anlauf valley and Moosbruckschrofen - were thus clearly deposited at crucial mountain passes. The helmets from 
Pass Lueg and Moosbruckschrofen belong to extensive bronze votive hoards. Though the helmet from the Anlauf valley is a single find, it should probably also be regarded as a votive deposit. ${ }^{1}$ Whereas the helmet from Pass Lueg has been preserved in its entirety, those from the Anlauf valley and Moosbruckschrofen only consist of one half of a helmet, respectively. The partial depositing of the helmet and its dismantling through folding seem to have been part of a sacrificial ritual.

Nearly all Bronze Age bronze helmets were found in the context of sacrificial hoards or as single finds. Generally speaking, they represent a rare type of object. In battle situations, they certainly offered better protection than leather or fabric caps. At the same time, however, they denoted and symbolised their elite owners' high status. This seems to have been particularly relevant in the case of helmets with crests, whose ridges held highly protruding and, perhaps, vividly coloured feathers. The deposit of helmets as votive offerings therefore signals the existence of an upper class. In addition, the precise location of such deposited helmets is informative. The fact that all three helmets of the Pass Lueg type - at present, these are the only known specimens of this kind - were found in proximity to eastern alpine passes plainly points toward the existence of a corresponding long-distance trade network.

The helmets are currently undergoing metallurgical and metallographical analyses. Interestingly, only copper from sulfidic (pyritic) ores of the Eastern Alps, probably from the Mitterberg or the neighboured ore grounds in the central Salzach valley or in eastern Tyrol was used for all three helmets.

At this point, the question arises whether the eastern alpine Urnfield period produced social elites to whom the crested helmets may be assigned. According to current research, this was not the case. Neither the mining regions in the Tyrolese Inn valley nor the Salzach valley in the Salzburg region have yielded settlement or burial evidence that may support the presence of a high-standing and ruling social class.

However, the northern and southern alpine border regions present an altogether different picture. Here we encounter elevated, frequently fortified settlements at the valley outlets. In the even more outlying lower Bavarian foothills, four richly furnished burials containing carriages were found. The graves, which date to the early and older Urnfield period, were located at a considerable distance from each other and all were positioned on important transport routes. The buried individuals probably belonged to a warrior aristocracy. It is likely that these elites controlled the copper trade (Winghart 2002, 174). Late Bronze Age

1. Cf. Wyss 1971, $140 \mathrm{ff}$. on the significance of elevated and pass finds. warrior graves with richly ornamented swords from Friuli and Trentino at the southern foot of the Eastern Alps can probably also be assigned to such an 'aristocratic' ruling class. These sites, too, are plainly located on expedient transport routes (Peroni 2004).

The tetrahedrites (Fahlerze) in the Tyrolese Inn valley and the sulfidic (pyritic) copper ores (Kupferkiese) in eastern Tyrol (the Kitzbühel region) and along the Salzach in the Salzburg region (Mitterberg ore grounds) were extracted with particular intensity during the middle and the first stage of the late Bronze Age (Goldenberg, Rieser 2004; Günther 1993). Numerous smelting sites indicate that copper was being smelted into coarse copper in these mining regions (fig. 3). An extensive production site with numerous pit ovens is located in proximity to the Mitterberg mining district. These ovens were used to refine black copper ore into coarse copper (Moosleitner 2004). However, despite the exploitation of rich copper ore deposits, a ruling class did not materialise in the mining regions. The actual miners and metalworkers were undoubtedly derived from a local, peasant background. Late Bronze and early Iron Age funerary finds in Bischofshofen in the centre of the Mitterberg mining region point to a population made up of simple farmers and miners. The grave goods and burial rites themselves imply a considerable cultural continuity; the population had thus been settled in the mining district for a long time (Lippert 2009).

Trading the copper produced in these mining districts was nonetheless an exceptionally lucrative activity that required not only security but also firm organisation and control. The prevalent political conditions relating to the extraction and trade of raw materials may perhaps be compared to those encountered in pre-colonial Central and Eastern Africa. In that region, the exchange of gold, copper and salt between points of exploitation and frequently distant marketplaces stimulated a rapid growth in economic and political authority on the part of entrepreneurs. These individuals quickly took on leading political positions, too. This warrior aristocracy resided in central locations and assumed responsibility for the protection of the mining regions against external - and sometimes internal - enemies and rivals. Its chiefs attained considerable wealth through the imposition of various dues and achieved a significant concentration of political power (Gray, Birmingham 1970, 16 f.).

Rather than occupying the mining regions themselves, a comparable leading class in Bronze Age Central Europe may well have resided in the more densely populated alpine foothills in which the copper market places were concentrated. At these "ports of trade", a regional ruler organised and supervised all trading activities. Analogous organisational systems are well-known from the early medieval period, which resembles the European Bronze and Iron Ages in some important respects; such forms of organisation even 


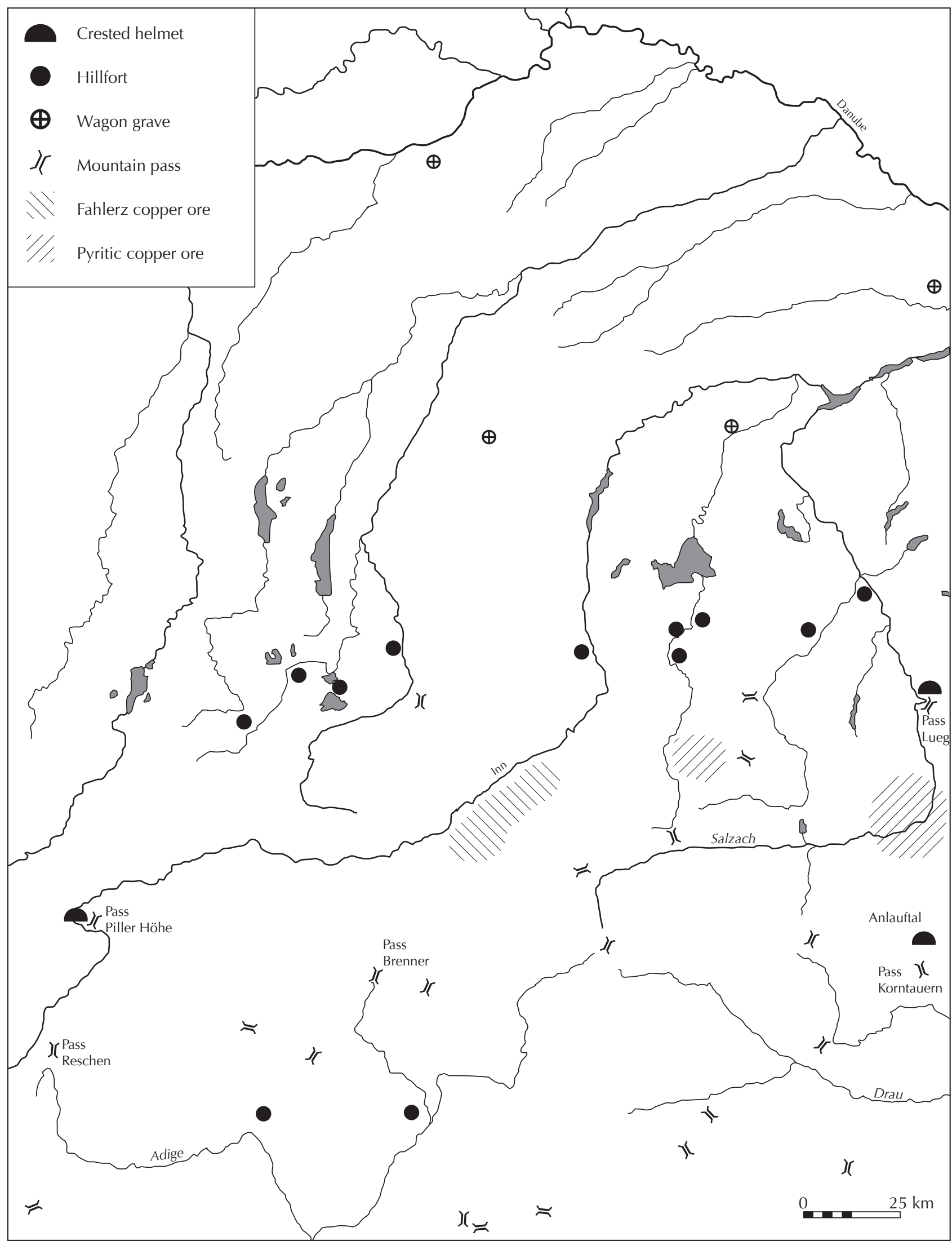

Fig. 3. Copper ore resources and important sites of the Late Bronze Age in the western part of the Eastern Alps (completed after Winghart 2002; graphic: Thomas Pertlwieser, Institut für Ur- und Frühgeschichte, Universität Wien). 
preceded the development of an independent and professional class of merchants (Steuer 1999, $559 \mathrm{f}$.).

The salt trade, too, reached its first significant apex during the later middle and late Bronze Age. In Hallstatt, located approximately 30 kilometres to the East of the Salzach valley in the Northern Limestone Alps, salt was being exploited in deep shafts as early as the later middle Bronze Age (Barth 1998, figs. 1/4). As a consequence, cured meats were traded alongside the salt itself. Lowered log structures with clay-coated interiors were already discovered in immediate proximity to the mining district at the Salzberg during the $19^{\text {th }}$ century. Recent investigations have shown that these structures or, more specifically, basins were filled with saltwater and used for the curing of large amounts of meat. Finds of animal bone demonstrate that pork was most intensively used; nonetheless, meat from sheep, goats and cattle was also cured and probably widely traded. The hitherto available radiocarbon dates point towards the $13^{\text {th }}$ and $12^{\text {th }}$ centuries BC (Kern et al. 2008, 72 ff.).

The three crested helmets discovered as votive deposits in the inner Eastern Alps can thus be linked to the copper and salt exchange without difficulty. As expressions of entreaty and gratitude for safe travel and transport, the helmets were stored in sanctuaries or, rather, deposited in the ground along long-distance trade routes connecting the mining regions with the North and South. A warrior aristocracy charged with the organisation of trading activities may have endowed these precious objects, which were likely of symbolic significance. A helmet provided safety in combat and from enemies; according to contemporary beliefs, perils of a different kind, such as storm, rain, snow, fog and falling rocks could potentially be warded off by mountains and travel deities, provided that appropriate sacrificial offerings were made.

The three helmets from Pass Lueg, the Anlauf valley and Moosbruckschrofen, though closely analogous in terms of their shape and ornamentation, were found at a considerable distance from each other. The shortest route from Pass Lueg to Moosbruckschrofen is 275 kilometres. The Anlauf valley is located some 80 kilometres from Pass Lueg and 220 kilometres from Moosbruckschrofen.

The helmets' wide distribution is probably due to the fact that their makers were settled at regional courts in the northern part of the alpine foothills, rather than in the Alps themselves. These noble households were closely connected and may well have exchanged metal workers for the production of valuable weapons. This explains why attacking and defensive weapons, such as precious helmets, were manufactured on the basis of standardised models. The helmets with crests probably reached the interior of the alpine region via long-distance transport routes that were used by copper and salt traders. It is conceivable that they were not in fact meant for export, as weapons were not necessarily passed down to new owners. However, they did take on great significance in their capacity as votive objects. At exposed sites or high-altitude mountain passes in particular, they were deposited and consecrated to the mountain and weather gods pro itu et reditu. ${ }^{2}$

\section{References}

Egg, Tomedi 2002: EGG (M.), TOMEDI (G.) - Ein Bronzehelm aus dem mittelbronzezeitlichen Depotfund vom Piller, Gemeinde Fliess, in Nordtirol. Archäologisches Korrespondenzblatt, 32, 2002, p. 543-560.

Goldenberg, Rieser 2004: GOLDENBERG (G.), RIESER (B.) - Die Fahlerzlagerstätten von Schwaz/Brixlegg (Nordtirol)Ein weiteres Zentrum urgeschichtlicher Kupferproduktion in den österreichischen Alpen. In: WEISGERBER (G.), GOLDENBERG (G.) ed., Alpenkupfer-Rame delle Alpi. In: Der Anschnitt, Beiheft 17, 2004, p. 37-52.

Gray, Birmingham 1970: GRAY (R.), BIRMINGHAM (D.) Some economic and political consequences of trade in Central and Eastern Africa in the pre-colonial period. In: GRAY (R.), BIRMINGHAM (D.) ed., Pre-Colonial African trade. Essays on trade in Central and Eastern Africa before 1900. London, Oxford University Press, 1970, p. 1-23.

Günther 1993: GÜNTHER (W.) - 5000 Jahre Kupferbergbau Mühlbach am Hochkönig - Bischofshofen. Mühlbach, 1993.

Kyrle 1918: KYRLE (G.) - Formen der Fundplätze und Kritik ihres Inhaltes. Österreichische Kunsttopographie XVII, Wien, 1918 , p. 78-121.

Lippert 1993: LIPPERT (A.) - Die Altstraßen im Raum Badgastein - Mallnitz. In: LIPPERT (A.) ed., Hochalpine Altstraßen im Raum Badgastein - Mallnitz. Wien, 1993, p. 11-108.

Lippert, Dembski 2000: LIPPERT (A.), DEMBSKI (G.) Keltische und römische Passopfer am Mallnitzer Tauern. Archäologisches Korrespondenzblatt, 30, 2000, p. 251-268.

Lippert, Stadler in press : LIPPERT (A.), STADLER (P.) - Das spätbronze-und früheisenzeitliche Gräberfeld am Pestfriedhof in Bischofshofen (Salzburg). Universitätsforschungen zur Prähistorischen Archäologie, in press.

Mayer 1977 : MAYER (E.F.) - Die Äxte und Beile in Österreich. Prähistorische Bronzefunde, IX, 9, 1977.

Moosleitner 2004: MOOSLEITNER (F.) - Bronzezeitliche Grubenöfen in St. Johann im Pongau (Salzburg). In: WEISGERBER (G.), GOLDENBERG (G.) ed., Alpenkupfer - Rame delle Alpi. In: Der Anschnitt, Beiheft 17, 2004, p. 213-221.

2. Cf. Pauli 1980, 183 on Roman period votive inscriptions to Iupiter Poeninus at the Great St. Bernard Pass. 
Peroni 2004: PERONI (R.) - Culti, comunità e gentilizie, caste guerriere e figure di eroi e principi nel secondo millennio in Italia tra Europa centrale ed Egea. In: Guerrieri, principi ed eroi. Ausstellung in Castello del Buonconsigli. Trento, 2004, p. 161-173.

Schauer 2003: SCHAUER (P.) - Zur Zeitstellung der vermeintlich ältesten Bronzekammhelme in Mitteleuropa. Archäologisches Korrespondenzblatt, 33, 2003, p. 193-203.

Steuer 1999: STEUER (H.) - Keyword „Handel“. Reallexikon der Germanischen Altertumskunde, 13, 1999, p. 497-593.
Winghart 2002: WINGHART (S.) - Die Eliten der mittleren und späten Bronzezeit. In: MENGHIN (W.), PLANCK (D.) ed., Menschen, Zeiten, Räume - Archäologie in Deutschland. Begleitband zur Ausstellung in Berlin und Bonn im Jahre 2003, p. 174-185.

Wyss 1971: WYSS (R.) - Die Eroberung der Alpen durch den Bronzezeitmenschen. Zürich, Zeitschrift für Archäologie und Kunstgeschichte, 28, 1971, p. 130-145. 


\title{
Un site métallurgique du Bronze ancien dans le vallon du Longet à Molines-en-Queyras (Hautes-Alpes) : caractérisation du contexte archéologique et des déchets liés aux activités de métallurgie extractive
}

\author{
Laurent CAROzZA*, Pierre Rostan**, David Bourgarit***, Benoît Mille***, \\ Yvan COQUINOT***, Albane BURENS****, Nicolau ESCANILLA ARTIGAS*****
}

\begin{abstract}
Résumé. L'Europe occidentale connaît durant la seconde moitié du troisième millénaire un développement important de la production métallurgique. À Saint-Véran, dans le Haut-Queyras (Hautes-Alpes), l'exploitation et la transformation des ressources cuprifères sont attestées entre 2450 et 1950 avant notre ère. La mine de la «tranchée des Anciens » a ainsi permis l'extraction de près de 2000 tonnes de minerais, la bornite. Le site de la Cabane des Clausis à Saint-Véran constituait jusqu'alors la principale zone de traitement pyrométallurgique associée. La présente communication se propose de rendre compte des sondages récents réalisés dans le vallon du Longet, à Molines-en-Queyras, qui montrent l'existence d'une petite zone métallurgique dont la datation est comprise entre le $\mathrm{XXIII}^{\mathrm{e}}$ et le $\mathrm{XX}^{\mathrm{e}} \mathrm{s}$. avant notre ère et où, pour la première fois au sein du complexe de Saint-Véran, la preuve directe de l'utilisation de fours bâtis a pu être établie. La grande similarité des scories mises au jour sur le site avec celles de la Cabane des Clausis renvoie à des procédés métallurgiques analogues, témoins d'innovations récentes accompagnant la mise en place d'une production de masse dont le complexe minier et métallurgique est alors le siège.
\end{abstract}

An Early Bronze Age metallurgic site in the longet dale (Molines-en-Queyras, Hautes-Alpes): characterization of the archaeological context and the extractive metallurgy waste

Abstract. The metallurgical production increases dramatically in Western Europe during the second half of the third millenium BC. At Saint Véran in the Haut Queyras, Hautes-Alpes, copper mining and smelting is testified between 2450 et 1950 BC, with some $2000 \mathrm{t}$ of copper ore, namely bornite, having been extracted from the main mine known to date, the "tranchée des Anciens". Until recently, the main smelting workshop associated to the mine was the site called La cabane des Clausis. The present paper aims at reporting the recent excavations carried out in the Vallon du Longet at Molines-en-Queyras, which have put into light a small metallurgical area dated between the $23^{\text {rd }}$ and the $20^{\text {th }}$ century BC. There, a vitrified rock fragment constitutes the first direct evidence of the use of smelting furnace in the district. The unearthed metallurgical slags are very similar to those known so far at Saint Véran, they reveal innovative processes promoting the set up of copper mass-production.

\section{Contexte historique, géographique et géologique}

$\mathrm{C}$ 'est dans le Haut Queyras (Hautes-Alpes), que se situe le complexe métallurgique et minier de Saint-Véran, caractérisé, à l'instar de celui de Cabrières, par l'association - dans un petit périmètre - de sites d'extraction du minerai et de zones de traitement métallurgiques (Carozza, Mille 2007). Les recherches initiées par Pierre Rostan (Rostan, Gattiglia, Rossi 2002) au cœur de ce complexe permettent aujourd'hui de disposer d'une abondante documentation sur les travaux miniers et sur l'abri sous roche de Pinilière. Les travaux de Bruno Ancel ont porté sur l'histoire du site minier et ont illustré toute sa complexité (Ancel 1999).

\footnotetext{
* Géographie de l'Environnement (GEODE), UMR 5602 CNRS - Université de Toulouse II-Le Mirail, 5 allées Antonio Machado, 31058 Toulouse cedex 9 .

** Bureau d'Études Géologiques Tethys, 05380 Châteauroux-les-Alpes.

*** Centre de Recherche et de Restauration des Musées de France (C2RMF), UMR 171 CNRS, Palais du Louvre, 14 quai François Mitterrand, 75001 Paris.

**** Archéologie des Sociétés Méditerranéennes, UMR 5140 CNRS - Université Paul Valéry Montpellier III, 390 avenue de Pérols, 34970 Lattes. ***** Departament de Prehistoria, Facultat de Filosofia i Lletres - Edifici B, Universitat Autonoma de Barcelona, Bellatera, E08193 Barcelona (Espagne).
} 


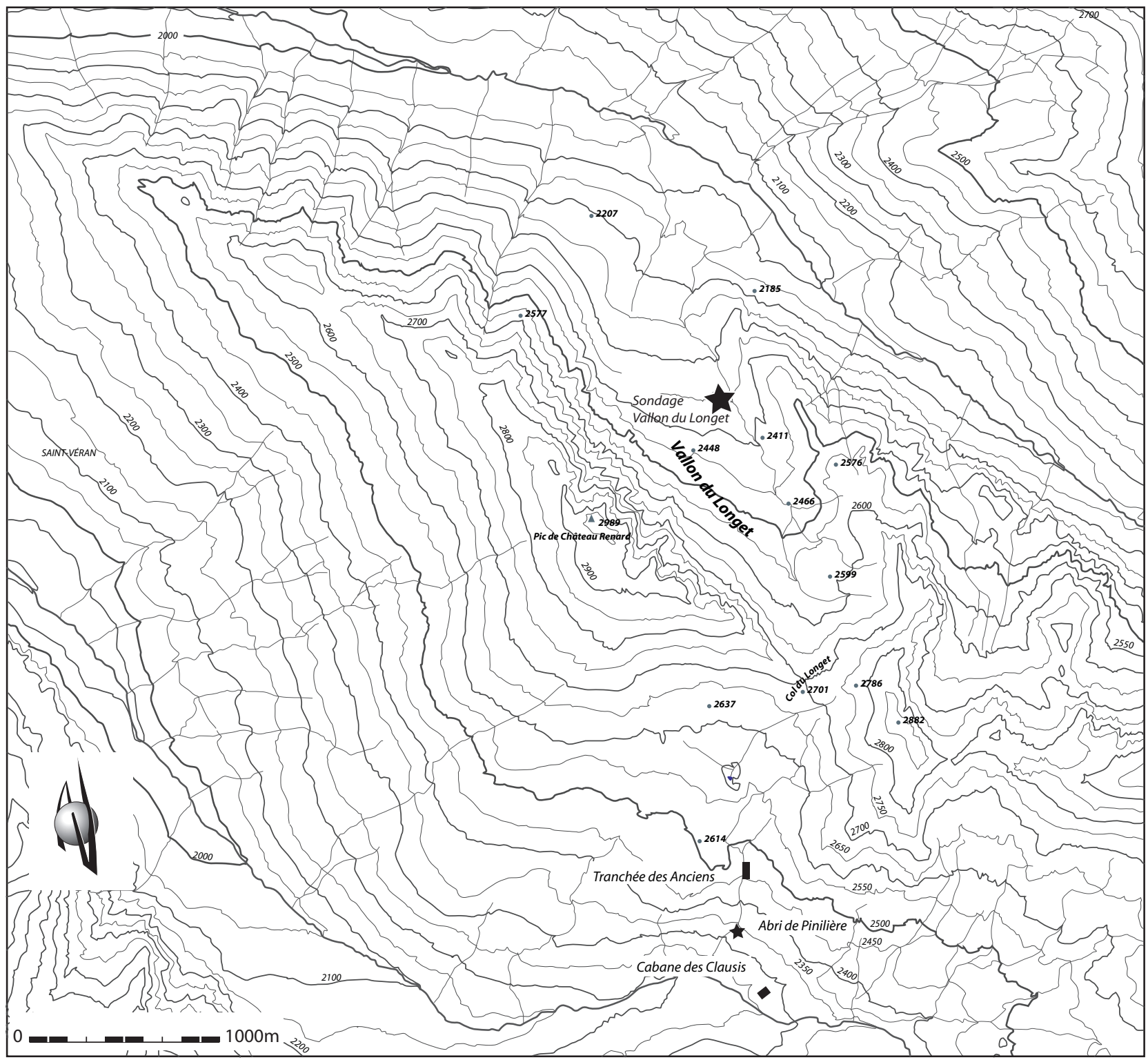

Fig. 1. Carte des principaux sites liés à l'exploitation des ressources cuprifères durant l'âge du Bronze dans la zone de Saint-Véran et de Molines-en-Queyras (Hautes-Alpes) (DAO A. Burens).

Ceux conduits par Hélène Barge sur l'atelier métallurgique de la cabane des Clausis (Barge 1999) fournissent une riche documentation qui éclaire plus largement le contexte de la production métallique protohistorique dans le sud-est de la France (Barge et al. 1998 ; pour une synthèse récente de ces travaux, se reporter à Carozza, Mille 2007).

\subsection{Circonstances de la découverte du site du vallon du Longet}

Le site de traitement métallurgique du vallon du Longet a été découvert lors de prospections autorisées antérieures à 1995, réalisées dans le cadre des travaux de recherche engagés sur le site minier des Clausis. La découverte du site a été signalée dans une publication consacrée à l'exploitation minière protohistorique (Rostan, Gattiglia, Rossi 2002). L'atelier métallurgique du vallon du Longet appartient à un ensemble de sites de traitement que nous avons mis en évidence lors de ces prospections et qui comporte l'important site de la Cabane des Clausis - fouillé par la suite par Hélène Barge - ainsi que deux sites voisins dont l'importance demeure à évaluer et qui ont ponctuellement fourni un petit nombre de scories et de tuyères.

Un des intérêts du site du vallon du Longet réside dans son éloignement relatif d'avec le site d'extraction du minerai, (fig. 1) qui est situé plus au nord du site minier au-delà du 


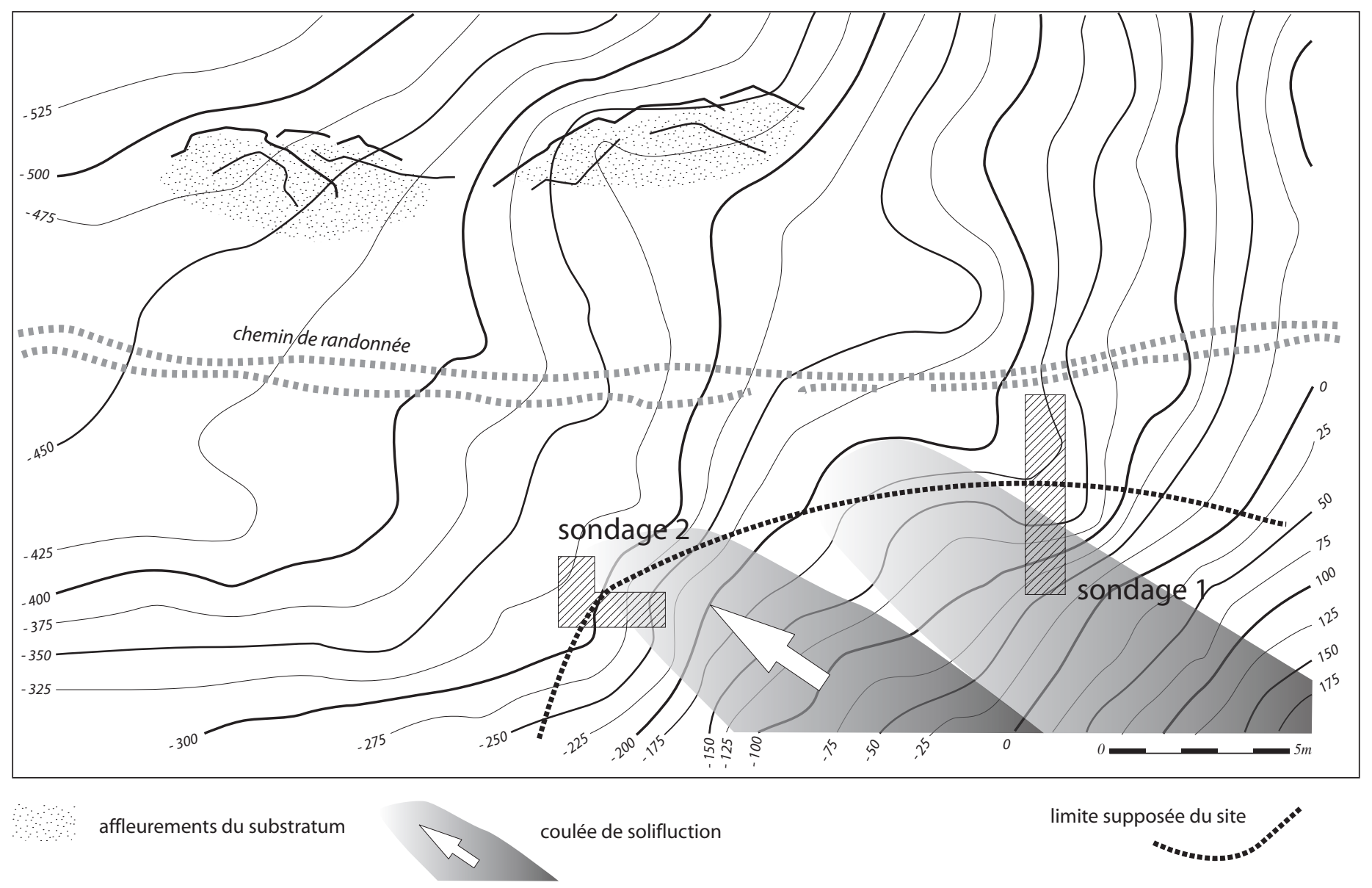

Fig. 2. Topographie et implantation des deux sondages archéologiques (DAO L. Carozza/A. Burens).

col du Longet; une des problématiques était donc de préciser si le minerai traité ici provenait d'un site d'extraction passé inaperçu jusque-là ou bien du site d'extraction des Clausis. Il se pose alors dans ce dernier cas la problématique du caractère à première vue anti-économique d'un transport lointain du minerai en particulier en raison du franchissement d'un col.

Cet aspect doit être mis en rapport avec le faible volume de minerai traité tel qu'il nous est connu actuellement sur le secteur, appréhendé par les volumes de scories accompagnant ces ateliers de traitement. En effet, ce volume de minerai traité présente un très fort déficit en regard des volumes de minerai extraits de la mine et il se pose dès lors la question du devenir du minerai extrait, dont il semble pouvoir être établi à présent qu'il n'a pas été traité au voisinage immédiat du site minier. Doit-on envisager une possible exportation plus en aval dans la vallée, ou, comme pourrait l'attester le site du vallon du Longet, dans les vallées voisines ? Se soulève alors un champ d'interrogations sur les motivations sociologiques ou techniques d'une telle exportation.

\subsection{Géologie, géomorphologie et histoire géologique récente}

Le sous-sol du secteur appartient à la zone alpine interne piémontaise occupée ici par l'unité des Schistes Lustrés, très épaisse série de schistes argileux plus ou moins détritiques affectés par un métamorphisme modéré de basse température.

Il s'agit de dépôts fins mis en place sur le fond du socle océanique de la Téthys composé de serpentines, de gabbros et de basaltes en épanchements sous-marins dans un contexte de rift.

C'est sur ce fond océanique que s'est développé un hydrothermalisme sous-marin qui a permis le dépôt de couches de sulfures métalliques principalement cuivreux dont le gisement de Saint-Véran - situé à faible distance plus au sud dans la vallée de l'Aigue Blanche - est le meilleur témoin sur le versant français des Alpes.

Le vallon du Longet est entièrement occupé par ces Schistes Lustrés mais comporte sur son flanc est ou bien en fond de vallon, différents petits massifs de «Roches Vertes » issues 

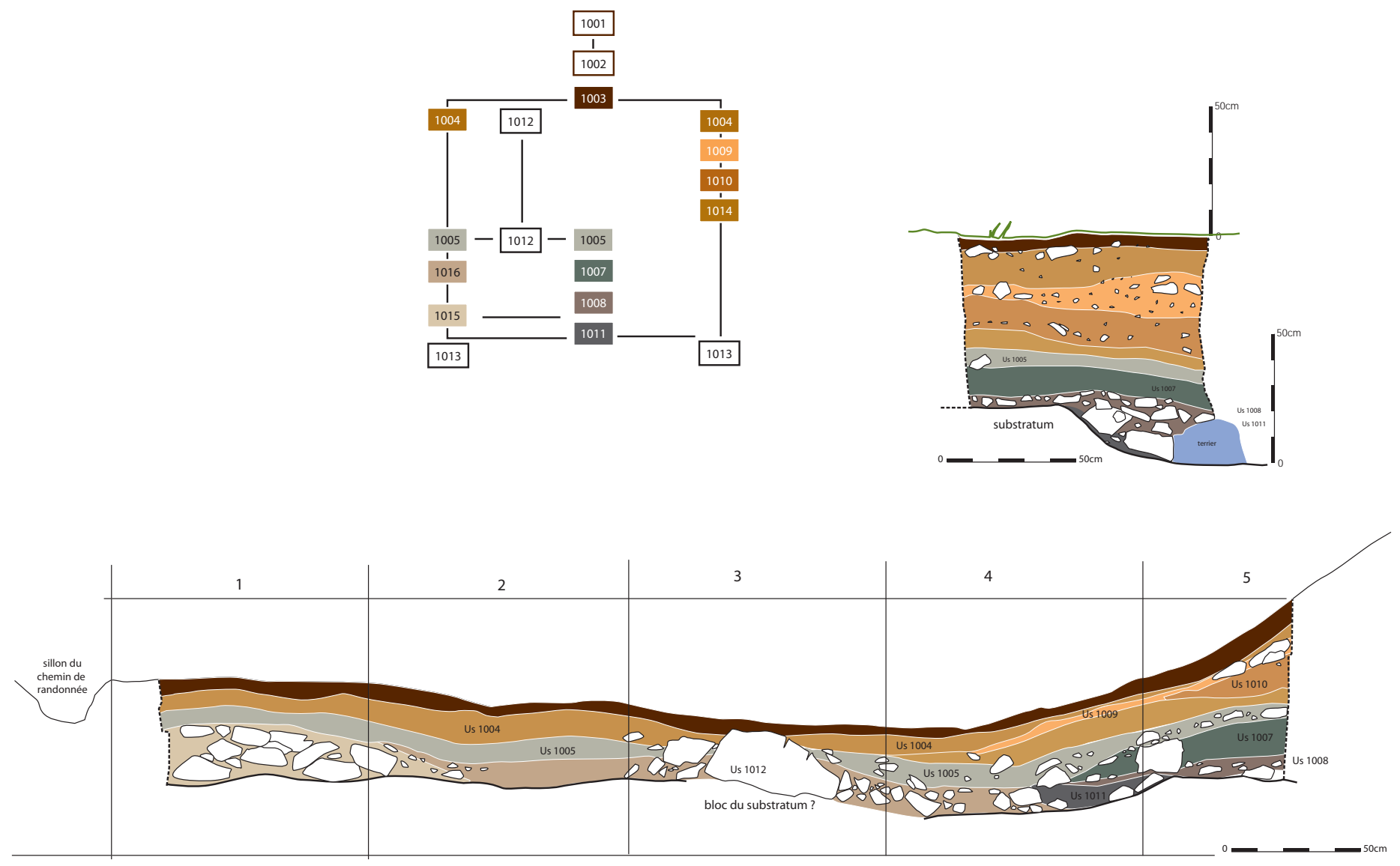

Fig. 3. Coupes longitudinale et frontale du sondage 1 et présentation du diagramme stratigraphique (DAO L. Carozza).

du socle océanique; les plus proches sont des massifs de gabbros de faibles volumes plus au sud-est en fond de vallon, ainsi qu'un affleurement de serpentinites qui occupe notamment la crête au nord-est du site et qui le sépare du vallon voisin.

D'autres massifs de roches vertes existent plus en amont, vers le col de Longet et sur la crête qui sépare le vallon du Longet de la vallée de l'Aigue Agnelle.

Au droit du site fouillé, le substratum schisteux apparaît peu profond et sub-affleurant en aval du sentier (fig. 2); il affleure sur la petite crête à une trentaine de mètres en amont du site avec une schistosité très redressée, grossièrement parallèle à l'axe de cette crête. Il est masqué partout ailleurs par la couverture morainique et colluviale manifestement peu épaisse ici. L'allure du secteur montre qu'il s'agit d'un replat topographique du substratum au droit d'un sentier, localisé en pied d'une pente raide où le substratum est peu profond et qui correspond pratiquement à une surface structurale. Il est possible ici que l'allure du toit du substratum corresponde à un repli des Schistes Lustrés, avec une schistosité peu pentée au droit du replat aval et très redressée dans la pente en amont. Le site se localiserait donc alors dans la charnière de cette structure.

L'allure topographique du site atteste de mouvements de terrains à la morphologie encore très fraîche avec une série de coulées boueuses dont la fouille montrera qu'elles se trouvent composées de limons argileux jaunâtres peu graveleux, manifestement hérités du lessivage des moraines. On y observe notamment une fraction fine au toucher onctueux, caractéristique témoignant de la présence de mica séricite directement hérité de l'altération des Schistes Lustrés. Ces coulées d'épaisseur au plus métrique apparaissent comme le décollement de la couverture colluviale (et peut-être localement morainique) du toit du substratum schisteux depuis les pentes raides en amont du site fouillé. Il s'agit de mouvements de solifluxion qui interviennent ici a priori en période de dégel rapide alors que la couche de colluvions superficielles se trouve entièrement saturée et peut passer en phase quasiment liquide. Elle vient en recouvrement direct des horizons archéologiques et ce type de mouvement de sol s'observe en différents points du secteur, en particulier plus au nord-est, sur l'autre flanc du vallon sous la crête de Cuesta Embrencha. 
Au droit du site, ces coulées se sont arrêtées sur le replat topographique du sentier où le substratum schisteux est sub-affleurant. Plus au sud-est, immédiatement au-delà de la zone fouillée, les mouvements de terrain se poursuivent jusqu'au pied de versant, à hauteur de la rive gauche du ruisseau du Longet. Toujours avec un caractère cortical, ces mouvements y présentent en ce point un caractère encore manifestement actif en relation avec de petites venues d'eau s'effectuant au toit des moraines sous-jacentes.

Ainsi, l'histoire géologique locale récente s'établit de la façon suivante : l'érosion glaciaire a mis en relief et épousé la structuration du substratum schisteux, le faisant apparaître en surface structurale. Ces éléments apparaissent lors de la décrue glaciaire. S'y ajoute une couverture morainique, ici mince, composée de moraines argilo-graveleuses jaunâtres.

L'érosion météorique de ces moraines conduit à la mise en place d'une couverture colluviale fine, curieusement peu développée sur les zones peu pentées (replat du secteur fouillé) où le substratum rocheux est très peu profond. C'est dans ce contexte qu'intervient l'installation de l'atelier de traitement métallurgique. Lors d'épisodes de fontes précoces du gel hivernal se déclenchent des coulées boueuses solifluées à caractère épidermique affectant les colluvions et sans doute des moraines. Elles viennent se caler en pied de pente en recouvrement des horizons archéologiques.

\section{Présentation des données archéologiques}

La découverte, dans un terrier de marmotte, de quelques scories et d'un fragment de tuyère, constituait un ensemble d'indices suffisamment explicites pour avérer la présence d'une aire dévolue aux activités métallurgiques (fig. 2). Si la plupart de ces indices se trouvait en position secondaire, dans les matériaux excavés par le mammifère fouisseur d'autres éléments étaient disséminés sur une plus grande zone, formant un replat d'une surface d'environ $25 \mathrm{~m}^{2}$. Dans cette zone, les collectes de surface et les premières observations montrèrent rapidement l'absence de sols archéologiques, la pelouse recouvrant seule le substratum. En amont, des coulées de solifluxions très importantes suggéraient l'hypothèse d'un recouvrement des horizons archéologiques, potentiellement préservés du processus érosif des sols ou bien au contraire un remaniement complet de l'horizon archéologique par ces coulées.

\subsection{Le contexte morphologique, sédimentaire et microtopographique}

L'implantation des sondages et la stratégie de fouille ont été dictées par la paléo-topographie du site. En effet, la

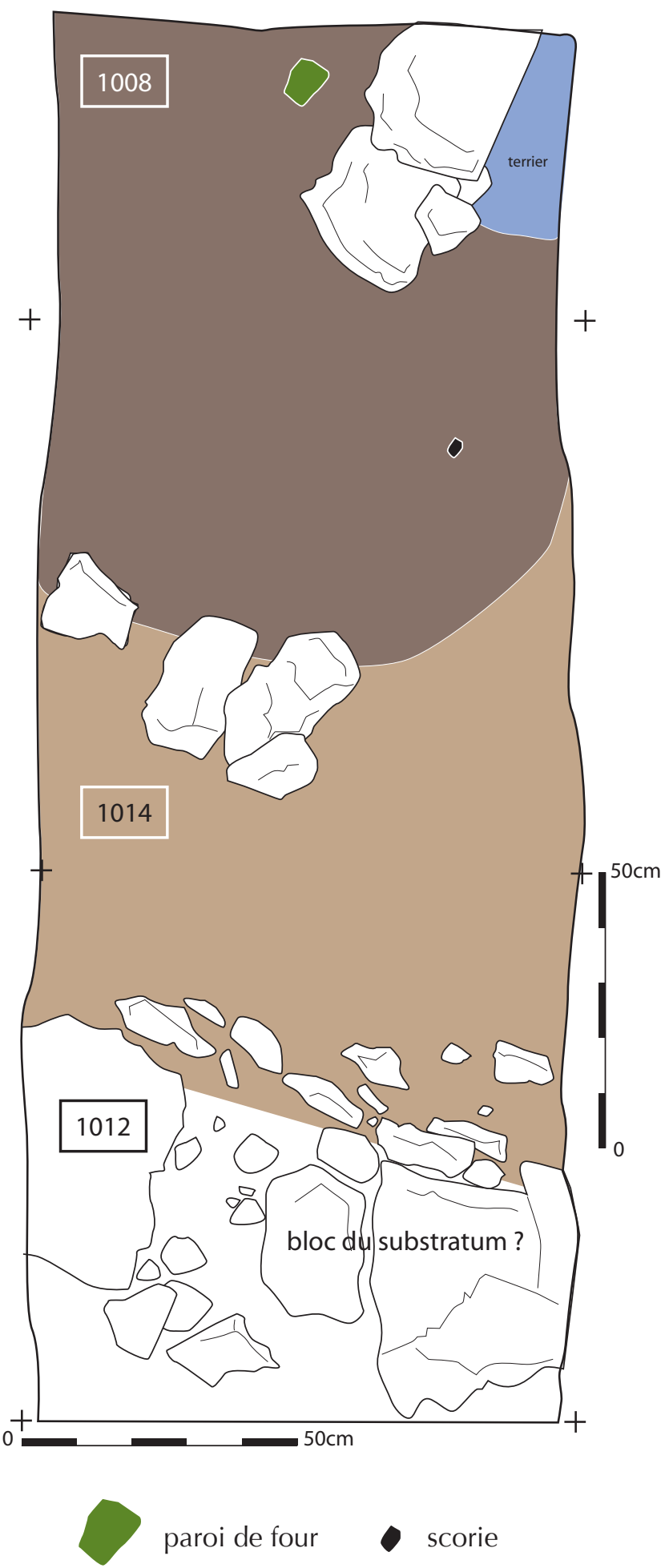

Fig. 4. Sondage, plan et vue du décapage et des unités stratigraphiques où apparaissent les principaux témoignages métallurgiques (Us 1008) (DAO L. Carozza). 
première opération a consisté en la réalisation d'un levé microtopographique de manière à circonscrire le site (fig. 2). La zone prise en compte est formée d'un replat partiellement délimité par des affleurements du substratum. Dans cette zone, la couverture sédimentaire est nulle ou se résume à la seule pelouse. Le sol brun, peu profond, repose sur des altérations du substratum ou des horizons morainiques plus graveleux. En aval de cette zone, les formations sédimentaires sont davantage liées aux écoulements souterrains des eaux. Ce secteur chaotique révèle la présence de zones humides et de petites tourbières de pente.

À l'amont, le versant se caractérise par une topographie contrastée formée par une multitude de coulées de solifluxion. Ces dernières descendent jusqu'au niveau de la zone de replat et forment des langues au profil bombé, larges d'environ $3 \mathrm{~m}$. On observe également la présence de blocs glissant par l'influence des phénomènes de gel-dégel le long de pentes, précédés d'un bourrelet de sédiments poussés lors de leur progression. L'avancée de ces blocs est facilitée par la nature du sédiment (fig. 2).

Le relevé topographique montre que la zone dont sont issues les scories découvertes en prospection se trouve à l'extrémité des coulées de solifluxion, au contact du replat, dans des zones offertes à l'érosion mécanique des sols. En revanche, les éléments mis au jour dans le terrier indiquent que les horizons archéologiques sont recouverts par les coulées.

\subsection{Description du sondage 1}

Le sondage $1 \mathrm{a}$ pris la forme d'une longue tranchée de $6 \mathrm{~m}$ de long pour une largeur de $1 \mathrm{~m}$, mais seuls $4,5 \mathrm{~m}^{2}$ ont été fouillés après dégagement de la pelouse herbeuse. Les décapages ont fait l'objet de plans pour relever les structures et les mobiliers in situ; les coupes frontales et latérales ont toutes 3 été relevées; un diagramme stratigraphique a été établi (fig. 3).

Les deux premières unités stratigraphiques sont formées par les déblais extraits du terrier par la marmotte. L'Us 1001 est formée d'un sédiment brun, fin, incluant de rares charbons de bois et un petit cailloutis; l'Us 1002 correspond à la moraine graveleuse, de teinte jaune. Ces horizons reposaient sur la pelouse (Us 1003). Leur stratification montre que le terrier a atteint en premier lieu les horizons archéologiques, puis le substratum.

Les unités stratigraphiques 1004, 1009, 1010 et 1014 constituent la partie sommitale du remplissage et ne recèlent aucun témoin archéologique en place. L'Us 1004 se développe dans la partie aval du sondage et correspond de toute évidence à un faciès détritique, formé de l'érosion de la coulée de solifluxion. Il s'agit d'un sédiment limoneux gris clair, fin, incluant des blocs pierreux épars. On observe, dans la partie médiane du sondage, l'apparition de blocs rocheux contre lesquels s'appuie l'Us 1004, et sur lesquels les unités sous-jacentes viennent se bloquer.

L'Us 1009 correspond à un épisode de l'horizon de solifluxion. Elle est de texture limoneuse et de teinte beige. On y observe la présence d'un cailloutis dense ; l'Us se singularise par une géométrie en biseau.

L'Us 1010, limoneuse de teinte beige/jaune, se singularise par la présence d'un cailloutis formant un horizon homogène à la base.

L'Us 1014, très limoneuse, s'individualise par l'absence de cailloutis et par sa texture très fine.

L'Us 1005 constitue le premier horizon archéologique. Il s'agit d'un cailloutis localement dense enrobé d'un sédiment brun fin, à dominante limoneuse. On observe la présence de petits charbons de bois qui déterminent l'origine anthropique d'une partie du sédiment. Il est probable que l'unité 1005 corresponde, pour partie, à un horizon de démantèlement.

Sous l'Us 1005, se développe l'Unité 1016. Celle-ci épouse le modelé formé par les irrégularités du substratum, ici constitué d'une moraine glaciaire sableuse, de couleur grisbeige clair, englobant un cailloutis et de petits charbons de bois. La couche 1016 se développe de part et d'autre du pointement rocheux 1012 et repose à l'aval sur une unité naturelle, en l'occurrence une moraine sablo-graveleuse beige-jaune (Us 1015). Cette dernière présente une très forte densité de blocs rocheux résultant probablement de l'altération du substratum.

Dans la partie amont du sondage, la séquence stratigraphique est davantage dilatée et la cohérence de la présentation requiert de préciser à la fois l'organisation spatiale et stratigraphique depuis la base du comblement. On observe nettement que l'Us 1016 vient épouser les irrégularités de la moraine glaciaire. Cette unité est recoupée par une petite cuvette de forme circulaire, d'un diamètre de $0,70 \mathrm{~m}$ (fig. 11). Profond de $0,15 \mathrm{~m}$, ce creusement présente un profil évasé. Son remplissage est formé de l'Us 1011 dont le sédiment limono-graveleux brun inclut de nombreux charbons de bois.

Cet horizon, qui pourrait matérialiser un niveau de sol hypothèse à confirmer par une fouille extensive - est surmonté par une couche limono-graveleuse brune, incluant un cailloutis dense (Us 1008). Cette couche repose en partie sur le substratum et comble la dépression formée par les ondulations de ce dernier (fig. 4). Elle recèle une très forte densité de charbons de bois, et a également livré un fragment de paroi de four, ainsi qu'une scorie découverte in situ. En outre, un petit fragment de tuyère en céramique et un petit tesson de céramique non tournée ont été mis au jour dans cette couche. La tuyère conique, très fine, s'apparente par sa morphologie aux objets de ce type mis au jour à Saint-Véran. Il est également probable qu'une partie des scories découvertes dans les déblais du terrier provient de 
cette unité stratigraphique. Compte tenu de la présence de nombreux blocs, de produits de combustion et de scories, l'Us 1008 pourrait correspondre à un horizon lié au fonctionnement d'installations métallurgiques (four ?).

La nature et la géométrie de l'Us 1007 viennent appuyer cette hypothèse. Cette couche, très puissante dans la partie amont du sondage, s'interrompt au contact de l'Us 1016. Elle est formée d'un sédiment limoneux brun, incluant de nombreux charbons de bois, au sein duquel émergent quelques gros blocs rocheux. Cette couche pourrait, pour partie, correspondre à des rejets anthropiques.

Pour synthétiser les données stratigraphiques et spatiales du sondage 1 nous observons que les premiers horizons archéologiques reposent sur le substratum, formé ici par une moraine argilo-graveleuse jaunâtre. La relative horizontalité des Us qui forment les niveaux archéologiques sous-tend que le site est implanté sur un replat adossé au versant. Le contenu des Us 1011, 1008 et 1007, qui comportent toutes des produits de combustion dans des densités variables, correspond à des apports anthropiques. L'Us 1008 se singularise toutefois par la présence de scories, d'une paroi de four et d'un fragment de tuyère, témoignant de manière indirecte de pratiques métallurgiques. La partie supérieure de la séquence stratigraphique correspond davantage à des horizons de nature détritique (Us 1005) ou érosifs. Nous n'observons pas d'horizons archéologiques dès lors que s'interrompt la coulée de solifluxion.

\subsection{Datation des horizons archéologiques}

La datation du site, en l'absence de tout mobilier archéologique significatif, repose sur la réalisation d'une datation par AMS sur charbons de l'Us 1008. Le résultat - Poz$223693745 \pm 35 \mathrm{BP}$ - fournit une fourchette chronologique comprise entre 2280-2030 BC, correspondant au début du Bronze ancien (fig. 5).

Si l'on prend en compte les plus fortes probabilités offertes par la calibration ( 2 sigma), nous pouvons retenir qu'à $87,9 \%$, la plage de temps comprise entre 2230 et 2030 retient toute notre attention, soit l'extrême fin du troisième millénaire avant notre ère. Par le truchement des probabilités maximales à 1 sigma (68,2 \% de probabilités), le XXII ${ }^{\mathrm{e}} \mathrm{s}$. avant notre ère pourrait être privilégié (2210-2130 bc).

Quoi qu'il en soit, cette datation nous assure que le site du vallon du Longet a été fréquenté au tout début du Bronze ancien, durant une plage de temps que l'on peut supposer post-campaniforme ou très légèrement contemporaine si l'on retient l'ensemble de la plage de probabilités. Cette question importe peu en l'état de nos réflexions mais il faut, en revanche, replacer ce résultat sur le canevas des datations des exploitations minières et métallurgiques de Saint-Véran.
L'exploitation minière de la tranchée des Anciens et la zone métallurgique de la cabane des Clausis ont fait l'objet de nombreuses datations, dont nous ne retiendrons ici que celles se rapportant directement à la période qui nous intéresse (Barge et al. 1998). D'autres éléments montrent en effet que le site a pu faire l'objet de tentatives de remise en exploitation durant la phase finale de l'âge du Bronze et au début de l'âge du Fer. La plage de temps couverte par les datations obtenues dans différents horizons du site des Clausis s'étend entre la seconde moitié du XXVI ${ }^{\mathrm{e}}$ s.avant notre ère et le XVIII ${ }^{\mathrm{e}} \mathrm{s}$. avant notre ère (fig. 5). La durée statistique représentée englobe l'extrême fin du Néolithique et l'âge du Bronze ancien. Elle recouvre l'ensemble du Campaniforme. Si l'on cumule les dates et leurs plages de probabilité par demi-siècle, la période comprise le $\mathrm{XX}^{\mathrm{e}}$ et le $\mathrm{XXIV}^{\mathrm{e}} \mathrm{s}$. avant notre ère est prépondérante. La datation obtenue pour le site du Longet s'inscrit pleinement dans cette plage moyenne, sorte d'optimum de l'exploitation minière et métallurgique à Saint-Véran (si l'on ne retient que les datations).

D'un point de vue culturel, les mobiliers mis au jour sur les différents sites ne permettent ni d'affiner cette perception, ni d'identifier de particularités culturelles. L'importance de la sphère italique a cependant été relevée par Pierre Rostan et Maurizio Rossi (Rostan, Rossi, Gattiglia 1997). La présence de pétroglyphes à proximité de Saint-Véran, représentant un personnage et deux poignards de type Remedello (à lame triangulaire à base droite et pommeau) est à souligner. L'abri des Oullas, situé dans la haute vallée de l'Ubaye (Alpes-de-Haute-Provence), à environ 6 km de la zone métallurgique de Saint-Véran, témoigne de l'importance culturelle exercée par le complexe italique. Le site minier de Saint-Véran n'est seulement distant que de $3 \mathrm{~km}$ de l'actuelle frontière franco-italienne (Rossi, Gattiglia 2005). Le col du Longet (homonyme de celui voisin du site fouillé mais localisé cette fois-ci dans la Haute-Ubaye) constitue, à une altitude de $2650 \mathrm{~m}$, une porte ouverte sur le Val Varaita (Cuneo, Piémont).

\section{Les scories, les déchets et la métallurgie extractive}

\subsection{Présentation du corpus et caractérisation macroscopique}

\section{Les scories}

Le corpus étudié est formé de onze fragments de scories liées à de la métallurgie extractive du cuivre, à ajouter aux trois fragments découverts en prospection de surface en 1995-1996 (tabl. I). Parmi les quatorze artefacts, on peut clairement en distinguer sept présentant une morphologie s'apparentant aux Plattenschlacke typiques des sites 

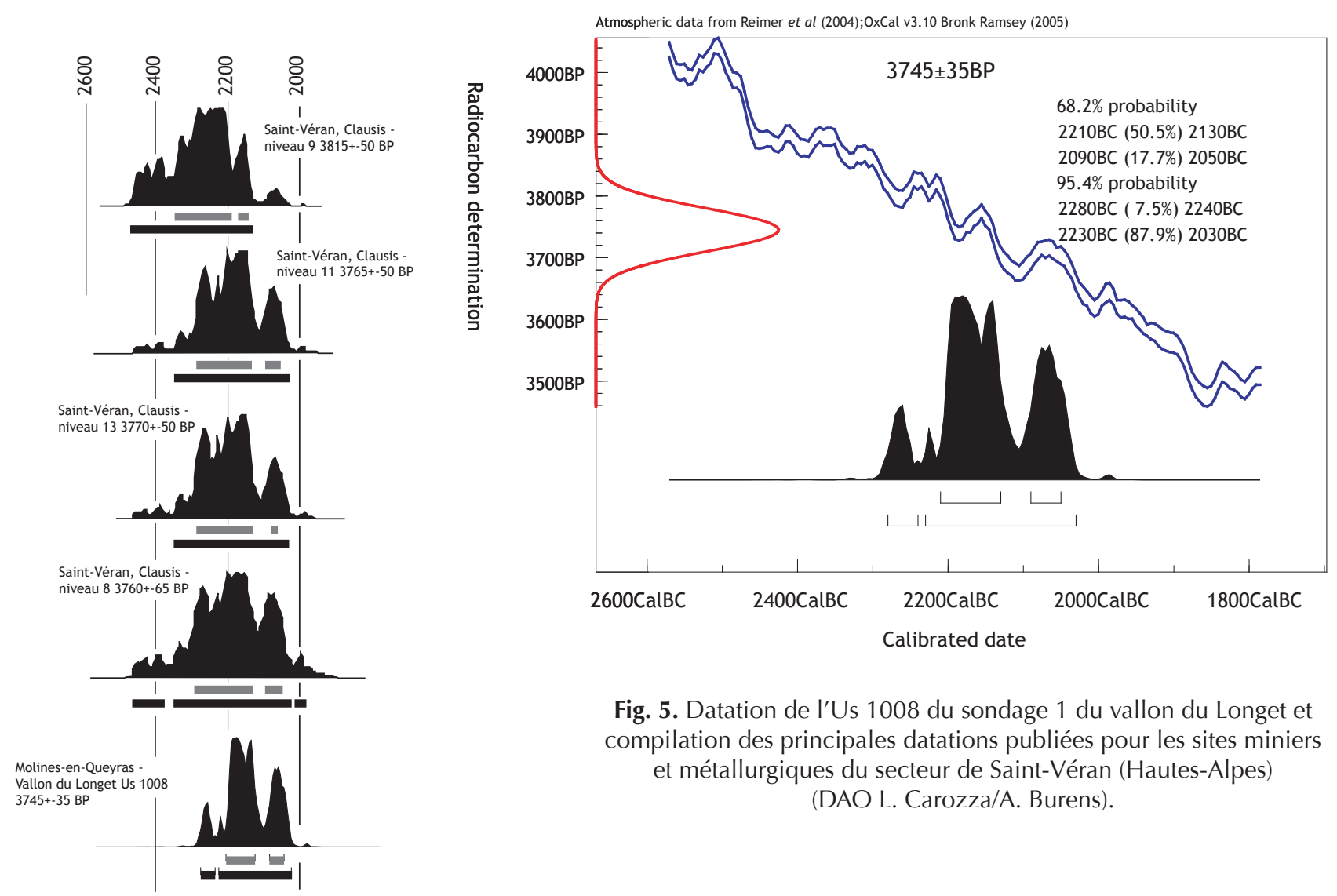

Fig. 5. Datation de I'Us 1008 du sondage 1 du vallon du Longet et compilation des principales datations publiées pour les sites miniers et métallurgiques du secteur de Saint-Véran (Hautes-Alpes)

(DAO L. Carozza/A. Burens).

métallurgiques de l'âge du Bronze moyen et final des Alpes autrichiennes et du Trentin italien (Mette 2003), à savoir des scories plates, avec une épaisseur de l'ordre du centimètre (fig. 6). D'une manière générale, les autres dimensions sont centimétriques (1 ou 2), y compris pour les scories informes.

Si la couleur dominante de toutes les scories est brunocre, sept des cinq fragments de morphologie de type Plattenschlacke présentent une surface noire d'aspect vitreux, faciès que l'on retrouve également sur deux autres scories informes. Cette surface noire est souvent marquée

de plis en «peau de lait» (fig. 6) qui marquent clairement la face supérieure de la scorie, comme cela a été observé sur les scories de la cabane des Clausis.

Contrairement aux Plattenschlacke de la cabane des Clausis, il est difficile de distinguer clairement sur les tranches des scories plates une morphologie prismatique. En revanche, la scorie 67773 apporte une grande nouveauté sur le complexe métallurgique de Saint-Véran: il s'agit de la première fois à notre connaissance qu'un bord originel de scorie est identifié. Or ce bord se trouve être droit sur toute sa longueur, soit plus de $6 \mathrm{~cm}$, ce qui pourrait laisser envisager que la structure pyrométallurgique dont la scorie est issue présente une section quadrangulaire.

Enfin, remarquons que les 14 artefacts étudiés présentent des densités comprises entre 3 et 3,7 (moyenne de $3,4)$, valeurs très semblables à celles mesurées sur les Plattenschlacke de la cabane des Clausis (moyenne de 3,3 sur 10 scories).

\section{Un fragment de roche vitrifiée}

La fouille a également permis de mettre au jour un fragment de schiste présentant une surface vitrifiée et mesurant environ $5 \times 4 \times 2 \mathrm{~cm}$ (fig. 7 et 8 ). Il correspond à un fragment de quartzophyllade (roche métamorphique formée de feuillets quartzitiques d'épaisseur millimétrique ou centimétrique, alternant avec des feuillets de schiste ou de phyllade). La 


\begin{tabular}{|c|c|c|c|c|c|c|c|c|c|c|}
\hline $\begin{array}{l}\text { date } \\
\text { fouilles }\end{array}$ & us & carré & $n^{\circ}$ C2RMF & morphologie & poids $(\mathrm{g})$ & $\begin{array}{l}\text { volume } \\
(\mathrm{cm} 3)\end{array}$ & $\begin{array}{l}\text { épaisseur } \\
\text { (cm) }\end{array}$ & $\begin{array}{l}\text { densité } \\
(\mathrm{g} / \mathrm{cm} 3)\end{array}$ & $\begin{array}{l}\text { surface } \\
\text { supérieure } \\
\text { noire }\end{array}$ & $\begin{array}{l}\text { faciès de } \\
\text { rupture } \\
\text { basaltique }\end{array}$ \\
\hline sep-08 & 1011 & & 67773 & plate & 134 & 35,6 & 1,6 & 3,8 & oui & non \\
\hline sep-07 & 1001 & & 66033-1 & plate & 3,3 & 0,9 & 1 & 3,7 & oui & oui? \\
\hline sep-07 & 1001 & & 66033-2 & plate & 2 & 0,6 & 1 & 3,3 & oui & oui? \\
\hline sep-07 & 1008 & 4 & $66034-1$ & plate & 10,2 & 2,9 & $?$ & 3,5 & non & oui? \\
\hline sep-07 & 1008 & 4 & 66034-2 & informe & 10 & 2,8 & - & 3,6 & non & non \\
\hline sep-07 & $\begin{array}{l}\text { hors strati } \\
\text { (a) }\end{array}$ & & $66035-1$ & informe & 10,3 & 3,1 & - & 3,3 & oui & non \\
\hline sep-07 & $\begin{array}{l}\text { hors strati } \\
\text { (a) }\end{array}$ & & $66035-2$ & plate & 9,9 & 3,1 & 1 & 3,2 & oui & non \\
\hline sep-07 & $\begin{array}{l}\text { hors strati } \\
\text { (a) }\end{array}$ & & $66035-3$ & plate & 12,9 & 3,9 & 1 & 3,3 & oui & non \\
\hline sep-07 & $\begin{array}{l}\text { hors strati } \\
\text { (a) }\end{array}$ & & $66035-4$ & plate & 3,3 & 1,1 & 1 & 3,0 & oui & non \\
\hline sep-07 & $\begin{array}{l}\text { hors strati } \\
\text { (a) }\end{array}$ & & $66035-5$ & informe & 2,6 & 0,8 & - & 3,3 & non & non \\
\hline sep-07 & $\begin{array}{l}\text { hors strati } \\
\text { (a) }\end{array}$ & & $66035-6$ & informe & 5,9 & 1,6 & - & 3,7 & oui & non \\
\hline 1995-96 & $\begin{array}{l}\text { hors strati } \\
\text { (b) }\end{array}$ & & $66036-1$ & plate & 19,4 & 5,9 & 1 & 3,3 & non & non \\
\hline 1995-96 & $\begin{array}{l}\text { hors strati } \\
\text { (b) }\end{array}$ & & $66036-2$ & informe & 4,6 & 1,4 & - & 3,3 & oui & non \\
\hline 1995-96 & $\begin{array}{l}\text { hors strati } \\
\text { (b) }\end{array}$ & & $66036-3$ & informe & 4,3 & 1,2 & - & 3,6 & non & non \\
\hline
\end{tabular}

Tabl. I. Inventaire des scories mises au jour autour du site du vallon du Longet.

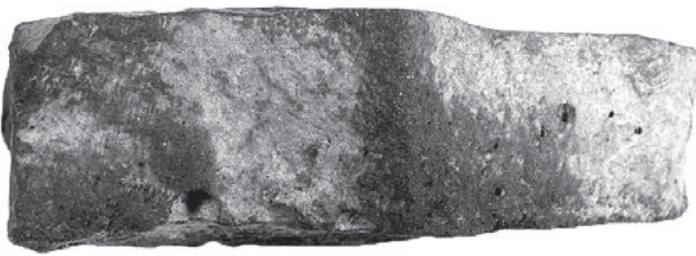

a

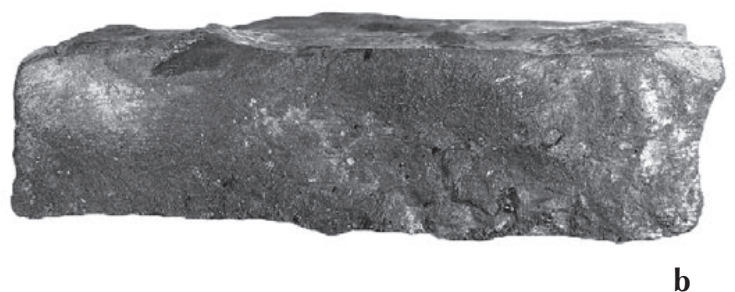

b
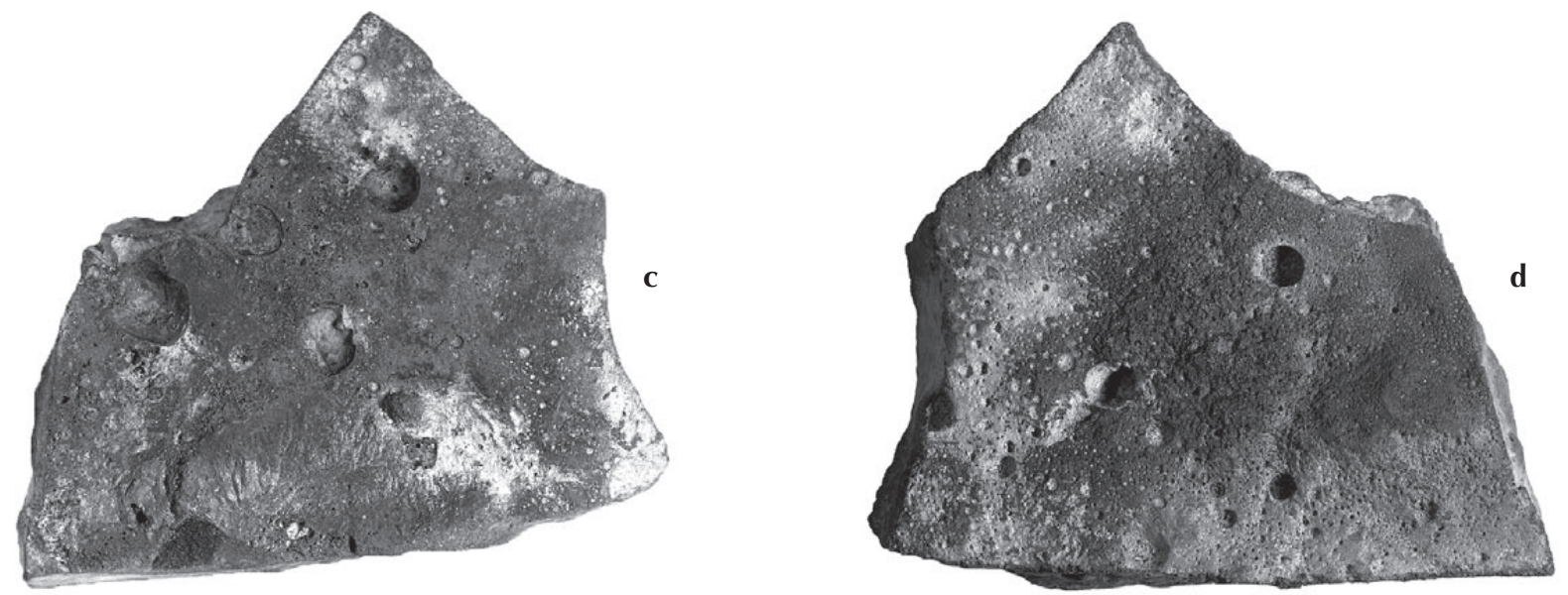

Fig. 6. Vues générales du plus gros fragment de scorie retrouvé sur le site ( $\left.n^{\circ} 67773\right)$, dont la morphologie est bien représentative du corpus de scories mises au jour: a) tranche (zone de fracture, épaisseur 1,6 cm), b) tranche (bord, env. 6,5 cm de longueur), c) surface supérieure montrant les zones vitrifiées noires, d) surface inférieure (photos C2RMF/D. Bagault). 
structure de la roche est donc marquée par l'alternance à l'échelle millimétrique de lits clairs, constitués par du quartz, et de lits vert-gris de minéraux phylliteux (fig. 9). Cette roche métamorphique présente une schistosité nette. La structure en feuillets ou lits est due à une déformation ductile qui s'est produite en même temps que le métamorphisme. La couleur dominante de l'échantillon est gris-vert, la couleur verte étant due à la présence de chlorite. Un des côtés de l'échantillon présente une surface noire d'aspect vitreux, faciès qui ressemble à celui que l'on trouve sur les scories étudiées Cette surface noire est légèrement ondulée. Ce matériau noir, dont l'épaisseur est variable mais toujours inférieure à $2 \mathrm{~mm}$, montre clairement des indices de fusion et correspond, comme nous le verrons au cours de l'étude pétrographique, à de la scorie soudée à la roche. Derrière ce matériau noir, on observe un matériau vitreux à structure vacuolaire (fig. 9). Les lits de quarztite viennent s'intercaler dans ce matériau vitreux.

\subsection{Caractérisation chimique et minéralogique: conditions expérimentales}

Les trois scories 66033-1, -2 et 67773, ainsi que le fragment de roche ont été coupés transversalement à la scie diamantée de précision. Une moitié a été incluse dans de la résine époxy et polie (papier $\mathrm{SiC}$ et diamant 3,1 et $1 / 4 \mu \mathrm{m}$ ) pour observations en microscopies optiques et en microscopie électronique à balayage (MEB). Deux types d'analyses de composition élémentaire ont été réalisés sur les surfaces polies des scories et du fragment de roche:

- des analyses globales par la méthode PIXE pour la scorie 67773 sur l'accélérateur AGLAE (faisceau de protons de $3 \mathrm{MeV}$ d'environ 0,5 $\mathrm{mm}$ de diamètre avec un balayage de la surface sur $2 \times 2 \mathrm{~mm}$, la profondeur analysée est d'environ $50 \mu \mathrm{m}$, voir Calligaro et al. 1998 et Dran, Calligaro, Salomon 2000), avec un filtre de $29 \mu \mathrm{m}$ de Co placé devant le détecteur hautes énergies,

- des analyses locales phase par phase au moyen du système de microanalyse X couplé au MEB (après dépôt de carbone en surface), et des analyses plus globales sur des aires de l'ordre de $2 \times 2 \mathrm{~mm}$ en plusieurs endroits des scories (notamment sous la surface supérieure, au milieu, audessus de la surface inférieure), pour les scories 66033-1 et 67773, ainsi que sur la coupe épaisse du fragment de roche. Le talon poli correspondant au fragment de roche a été repris ensuite pour réaliser deux lames minces polies de $30 \mu \mathrm{m}$ d'épaisseur et de dimension 60x45 mm. Les lames ont été observées en microscopie optique, en lumière polarisée non analysée (LPNA) et en lumière polarisée et analysée (LPA).

Pour les trois scories 66033-1, -2 et 67773, des mesures en diffraction X des poudres (appareil Siemens D5000) ont été réalisées. Les échantillons ont été obtenus soit en réduisant en poudre la moitié non enrobée de la scorie (scories 66033-1, -2), soit au moyen d'une microfraise diamantée sur une section proche du prélèvement pour la coupe 67773 , en prenant bien soin d'une part de dégager la couche de corrosion brune, d'autre part de prélever sur toute l'épaisseur pour une représentativité optimale de l'ensemble de la scorie. Noter que les surfaces noires des deux scories 66033-1, -2 ont également été caractérisées par diffraction $\mathrm{X}$ in situ avant les découpes.

Enfin, les lames minces correspondant au fragment de roche ont été observées en microspectrométrie Raman pour aider à l'identification de certaines phases.

\subsection{Caractérisation chimique et minéralogique: résultats}

Les trois scories étudiées présentent un faciès de corrosion sur tout leur pourtour (fig. 10): durant l'enfouissement, la surface a été corrodée sur les deux premiers millimètres, ne laissant dans cette couche que quelques îlots intacts. Sinon, la zone préservée au centre montre une grande homogénéité structurale à l'échelle macroscopique, signe que la scorie est passée par l'état liquide dans son intégralité.

Les scories apparaissent à la diffraction comme très cristallines, avec pour phase majoritaire la fayalite $\mathrm{Fe}_{2} \mathrm{SiO}_{4}$. Cette prédominance de la fayalite apparaît nettement sur les micrographies électroniques (fig. 9), qui révèlent une texture morphologique variable suivant la position dans la scorie: dans la zone supérieure, la fayalite cristallise en aiguilles et polyèdres (en gros polyèdres et en très petites aiguilles d'aspect dendritique), tandis qu'à partir d'environ $2 \mathrm{~mm}$ en dessous et sur presque l'ensemble de la scorie, la morphologie s'épaissit pour donner une texture mixte constituée de gros polyèdres et de chaînes. Les analyses locales montrent pour les scories 66033-1 et 67773 une fayalite très riche en $\mathrm{Mg}$ (plus de $4 \%$ en masse). Un zonage plus ou moins important est détecté, avec un centre du polyèdre plus riche $\mathrm{n} \mathrm{Mg}$ (entre 6 et $9 \%$ en masse) et un bord plus pauvre (autour de $3 \%$ ).

La seule autre phase cristalline détectée par diffraction $\mathrm{X}$ est la magnétite, qui montre également une texture morphologique variable suivant la position dans la scorie. Ainsi, si dans la majeure partie des deux scories étudiées au MEB elle cristallise en polyèdres plus ou moins massifs, dans la zone supérieure de la scorie 67773 la magnétite n'est présente que sous forme de fines dendrites qui semblent en certains endroits constituer des solutions de continuité avec la fayalite; en extrême surface de la scorie 66033-1, la magnétite constitue une mince couche homogène, qui apparaît également très clairement sur les diffactogrammes obtenus en diffraction rasante faite sur la surface supérieure. La magnétite massive en polyèdres montre des 
teneurs en Ti particulièrement élevées $(6 \%)$, avec également des traces de $\mathrm{Al}, \mathrm{Cr}$, et $\mathrm{V}$, voire de $\mathrm{Zn}$ (jusqu'à $2 \%$ en masse).

À fort grossissement, on parvient à distinguer dans toute la scorie une troisième phase cristalline qui s'apparente à un pyroxène type hédenbergite $\mathrm{CaFeSi}_{2} \mathrm{O}_{8}$ (fig. 11), que la diffraction parvient difficilement à déceler (limite de détection de l'ordre de $5 \%$ moléculaire). Autour de ces cristallites, l'analyse de la phase s'apparentant visuellement à un verre montre une composition identique à celle des pyroxènes. Il est cependant difficile de déterminer si cette phase est effectivement amorphe ou constituée de microcristaux de pyroxènes non visibles au MEB. Néanmoins, la diffraction n'ayant pu détecter de phase amorphe, il est probable qu'une grande partie de cette phase est cristallisée.

Enfin, la structure est émaillée de nodules de sulfures de cuivre (majoritairement de type chalcocite $\mathrm{Cu} 2 \mathrm{~S}$ ) et de cuivre métallique plus ou moins riches en fer (autour de $1 \%$ ).

À noter que la corrosion semble avoir été sélective en préservant uniquement les polyèdres de fayalite (fig. 10).

Les analyses élémentaires globales montrent une grande homogénéité de la composition au sein d'une même scorie, sans que l'on puisse notamment différencier les zones de surface (tabl. II). Il s'agit d'une composition de type fayalitique $\mathrm{Fe} 2 \mathrm{SiO} 4$ avec des teneurs importantes en $\mathrm{Mg}$, $\mathrm{Al}$ et $\mathrm{Ca}$ (de l'ordre de 3 à $5 \%$ en oxydes), et dans une moindre mesure $\mathrm{P}, \mathrm{K}$ et Ti. On remarque également les teneurs importantes en $\mathrm{CuO}$ et $\mathrm{ZnO}$ (de l'ordre de 3 à $4 \%$ ). Il est enfin intéressant de souligner la forte proportion de $\mathrm{Na}$.

\section{Un fragment de roche partiellement vitrifiée}

Comme déjà observé sur les vues macroscopiques sur coupe épaisse (fig. 9), deux types de matériau peuvent être distingués en pétrographie, de la roche partiellement vitrifiée et un matériau s'apparentant à de la scorie métallurgique. Nous verrons ci-après que les analyses des verres montrent que ces deux systèmes chimiques et minéralogiques sont « soudés », avec une zone de transition entre les deux.

La zone de roche partiellement vitrifiée évolue graduellement du point de vue structural et minéralogique depuis la scorie vers le bord opposé à la scorie (fig. 12). On peut distinguer une partie de roche partiellement fondue et vitrifiée, et une partie non vitrifiée.

Dans la partie non vitrifiée de l'échantillon, deux schistosités sont visibles en microscopie optique (fig. 13), une schistosité parallèle aux lits minéraux (S0 ?) et une schistosité de crénulation (S1) qui recoupe les lits minéraux. La roche apparaît formée de lits de quartz (quartzite) et de lits discontinus de minéraux phylliteux correspondant à une variété de mica blanc riche en fer (phengite ?) et à une variété de chlorite, également riche en fer. Les brins de mica et de chlorite sont interpénétrés. La chlorite et une apatite riche en terres rares (variété de monazite) sont présents en faible proportion dans les lits de quartz. Les lits de quartzite, constitués de grains de quartz de 50 à $300 \mu \mathrm{m}$, ne semblent pas avoir été affectés par les hautes températures. Contrairement aux minéraux phylliteux, ils sont encore visibles dans la partie fondue et notamment dans la scorie.

Quant à la partie vitrifiée, l'échantillon montre des indices de fusion sur plus de la moitié de son épaisseur (environ $1,9 \mathrm{~cm}$ ). La limite entre la scorie et la roche vitrifiée n'est pas nette. Le passage de l'une à l'autre est continu sur un ou deux millimètres. Les zones partiellement ou totalement vitrifiées de la roche correspondent aux anciens lits de minéraux phylliteux, le quartz ayant relativement bien résisté aux températures élevées atteintes. La zone de roche partiellement vitrifiée avec peu ou sans magnétite et olivine montre une structure vacuolaire (fig. 9 et fig. 12). Les vacuoles, dont les parois sont constituées par un verre relativement hétérogène en composition, ont un diamètre qui diminue de la zone à scorie vers le côté non fondu de l'échantillon. Leur diamètre est compris entre $50 \mu \mathrm{m}$ et $1 \mathrm{~mm}$. Ces vacuoles ont renfermé des gaz qui se sont échappés au cours de la vitrification.

Concernant l'autre type de matériau mis en évidence sur le fragment de roche, la «scorie», cette zone apparaît opaque en microscopie optique (fig. 9 et fig. 12). Son épaisseur varie entre $200 \mu \mathrm{m}$ et $2 \mathrm{~mm}$. En lumière convergente, il est toutefois possible de distinguer des petits cristaux opaques. Certains sont réfléchissants avec un reflet métallique cuivré. Ces cristaux sont entourés d'une phase légèrement translucide. En lumière réfléchie, deux types de cristaux opaques peuvent être distingués mais ne sont pas identifiables. Les observations et analyses en microscopie électronique (fig. 13) ont permis de caractériser plusieurs phases, qui sont présentées ci-après dans l'ordre décroissant de leur importance dans la scorie.

Une olivine en cristaux allongés et dendritiques montre une composition proche du pôle fayalite (47-49\% en masse de $\mathrm{Fe}_{2} \mathrm{O}_{3}$ et $4-8 \%$ en masse de $\mathrm{MgO}$ ). Cette olivine contient également un peu de zinc (1-3\% en masse de $\mathrm{ZnO}$ ). Elle varie légèrement entre la surface externe de la scorie et la zone interne ainsi que d'une zone à l'autre. Sa composition chimique semble varier en fonction des phases associées. Le zinc est aisément piégé dans sa structure en remplaçant le fer divalent (Chaudhuri, Newesely 1993). Elle est présente uniquement dans la phase vitreuse. Elle forme des cristaux fins en plume, en baguettes ou en dendrites. Elle présente majoritairement une texture dite «en peigne» ou spinifex, avec baguettes et cristaux harristiques. Sa structure change depuis la surface externe de la scorie (de l'échantillon) vers l'intérieur. Au niveau de la surface externe, les cristaux d'olivine sont allongés et de grande taille (100-150 $\mu \mathrm{m})$. Ils sont par ailleurs peu dendritiques. En allant vers l'intérieur de la scorie, la taille et la texture 

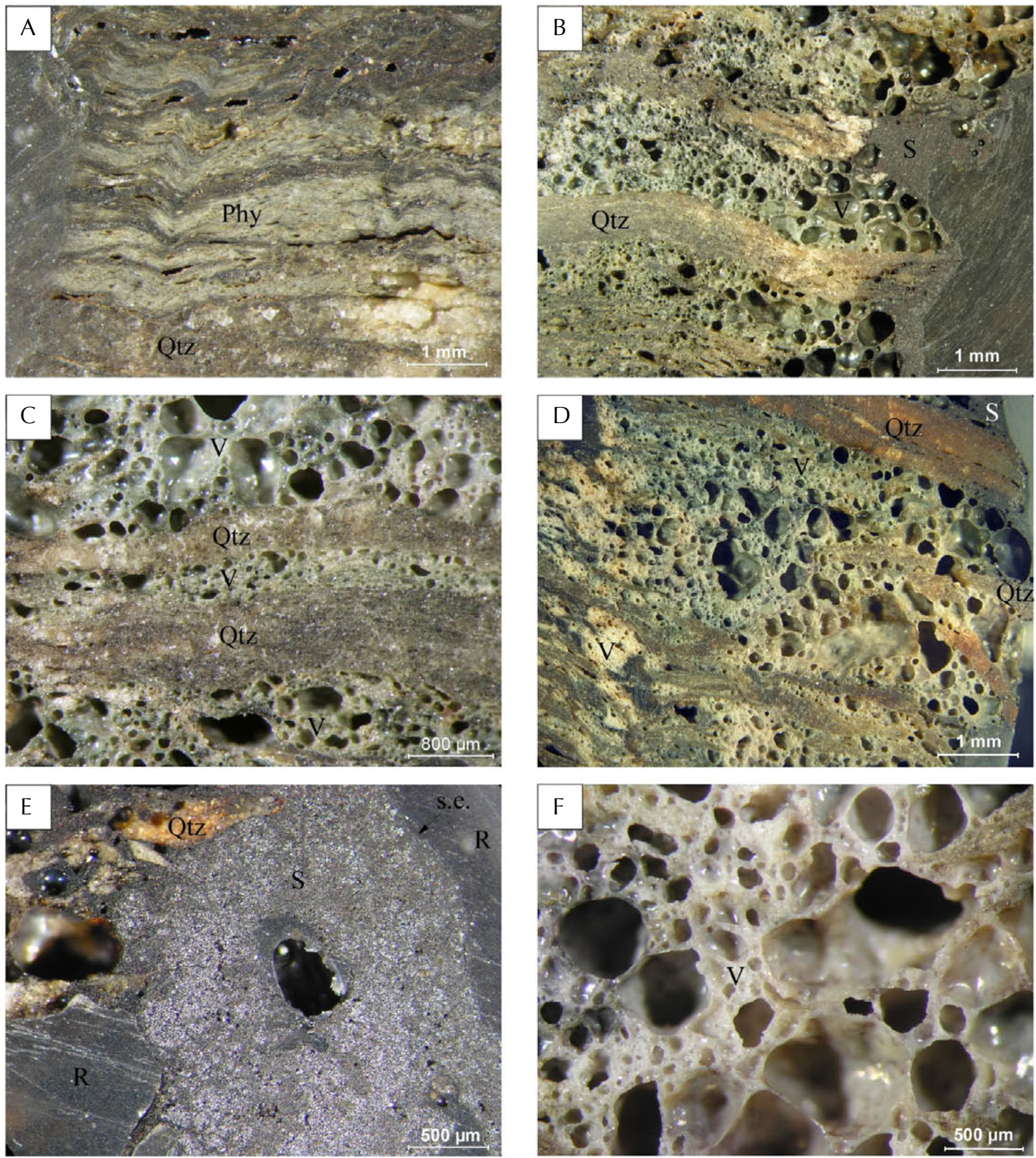

Fig. 7. Vues en coupe épaisse sous loupe binoculaire du fragment de roche: A) zone non vitrifiée de la roche montrant I'alternance de lits de quartzite et de lits de phyllosilicates; B) roche partiellement vitrifiée et scorie;

C et D) vues de la zone de roche partiellement vitrifiée; E) scorie; F) verre a structure vacuolaire

(photos C2RMF/Y. Coquinot).

des cristaux changent rapidement. Les cristaux d'olivines sont de plus en plus découpés, dendritiques et de plus en plus petits. Par endroits, leur taille est inférieure à $1 \mu \mathrm{m}$. Les cristaux de magnétite présentent majoritairement une forme polyédrique, mais apparaissent également en cristaux dendritiques. Ils montrent de petits golfes de corrosions.
Leur taille est comprise entre 2 et $50 \mu \mathrm{m}$. Cette variété de magnétite contient un peu d'aluminium (2-6\% en masse) et de magnésium $(0,5-1,5 \%)$.

Des «gouttelettes » de cuivre métallique sont localisées dans certaines zones, sans être présentes dans toute la scorie. Deux types de particules peuvent être distingués, des 

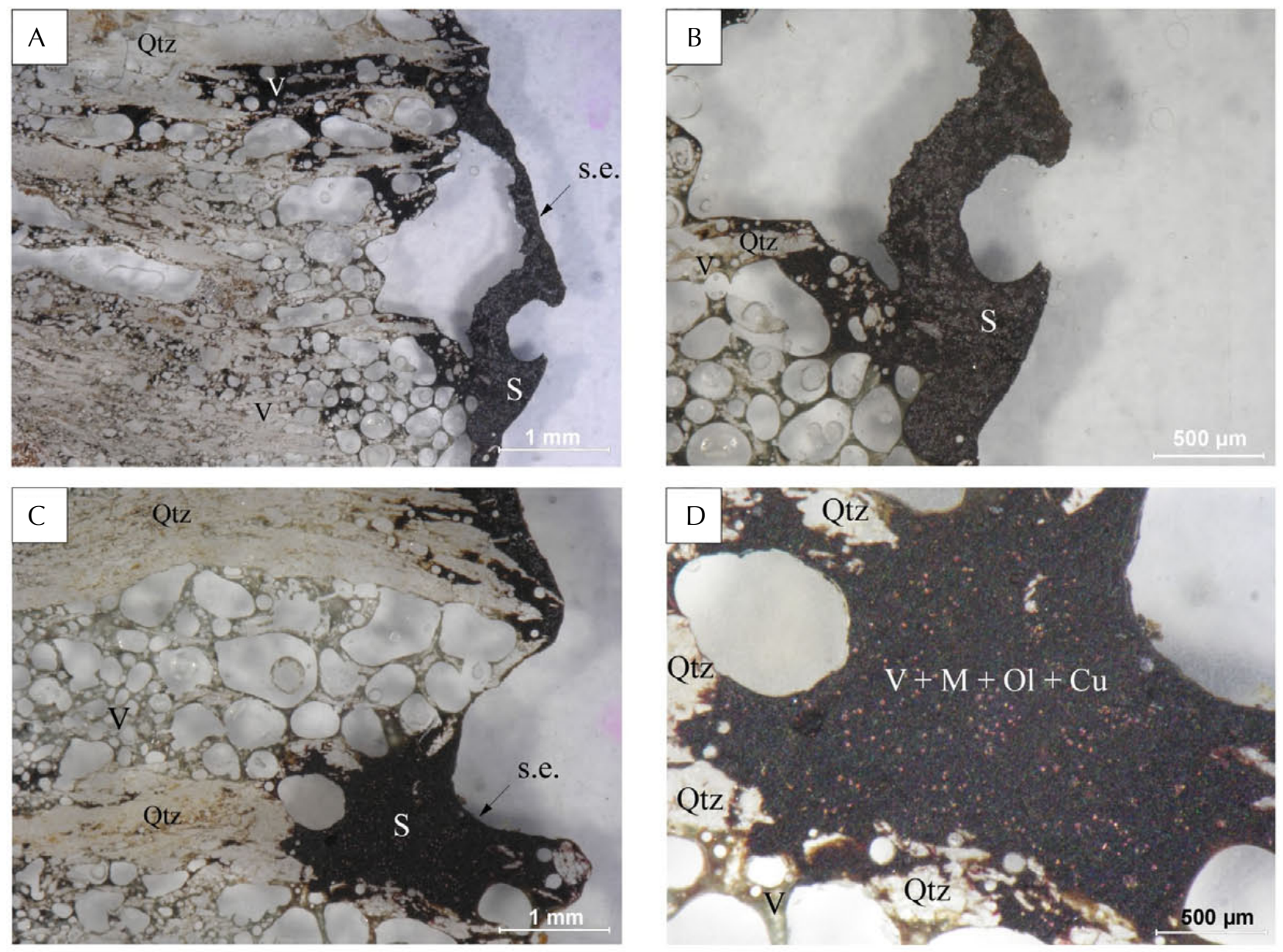

Fig. 8. Vues macroscopiques du fragment de roche mesurant environ $5 \times 4 \times 2 \mathrm{~cm}$ (photos C2RMF/D. Bagault).

particules subarrondies dont la taille est comprise entre 10 et $50 \mu \mathrm{m}$, et des particules sphériques de très petite taille $(<1 \mu \mathrm{m}$ à $2 \mu \mathrm{m})$. De plus, des sulfures de cuivre forment de petits « nodules » de quelques micromètres à quelques dizaines de micromètres de diamètre. Ils sont localisés dans des plages de la scorie riches en magnétite polyédrique. Ils contiennent un peu de fer et ont été identifiés au MEB et en microspectrométrie Raman comme étant de la chalcocite $\mathrm{Cu} 2 \mathrm{~S}$.

De très petits cristaux s'apparentent à une variété de spinelle, mais ils n'ont pas été identifiés de façon certaine en raison de leur très petite taille (planche 4 , photo $\mathrm{E}$ ). Toutefois, la composition élémentaire obtenue par analyse EDX se rapproche de celle de la ferriceylanite. Ces spinelles représentent une phase mineure dans la scorie. En général, les spinelles répondent à une composition de type ( $\left.\mathrm{Zn}, \mathrm{Mn}, \mathrm{Mg}, \mathrm{Ni}, \mathrm{Fe}^{2+}, \mathrm{Fe}^{3+}\right)\left(\mathrm{Fe}^{3+}, \mathrm{Fe}^{2+}, \mathrm{Al}, \mathrm{Cr}, \mathrm{Ti}, \mathrm{Si}\right)_{2} \mathrm{O}_{4}$ (Deer et al. 1992).

Enfin, une variété de clinopyroxène semble pouvoir être identifiée. Tous ces minéraux ne sont pas présents ensemble dans une même zone de la scorie. Plusieurs zones caractérisées par des assemblages minéralogiques différents peuvent être distinguées (fig. 13):

Assemblage 1 : olivine, magnétite, chalcocite, particules de cuivre, phase vitreuse,

Assemblage 2: olivine dans une phase vitreuse,

Assemblage 3 : olivine, particules de cuivre, phase vitreuse, Assemblage 4 : spinelle ? Olivine, phase vitreuse,

Assemblage 5 : clinopyroxène, (magnétite), phase vitreuse, Une phase vitreuse englobe tous les minéraux. Ce verre interstitiel est plus ou moins translucide selon les endroits (fig. 11 et fig. 12). Sa couleur est variable, noire à brun au niveau de la zone à scorie, beige à vert en arrière, au niveau de la roche fondue (fig. 13). Sa composition est très différente de celle de la phase interstitielle observée dans les scories métallurgiques décrite plus haut, qui affichait une composition type hédenbergite (riche en fer, calcium et silicium). Les analyses EDX montrent en effet un verre relativement pauvre en silicium (43-48\% en masse de $\left.\mathrm{SiO}_{2}\right)$ et riche en fer et en aluminium (23-30\% en masse 

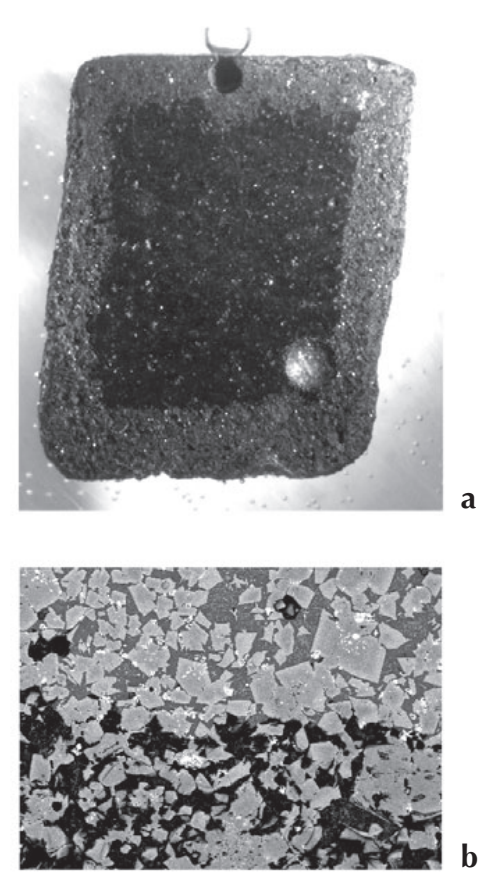

Fig. 9. a) Vue en coupe sous loupe binoculaire de la scorie 66033-2 montrant la corrosion affectant tout le pourtour de la scorie sur une profondeur pouvant atteindre $2 \mathrm{~mm}$. b) Micrographie électronique en électrons retrodiffusés montrant un détail de la couche corrodée (en bas de l'image), qui révèle que seule la fayalite (en gris) a été épargnée (photos C2RMF/D. Bourgarit).

de $\mathrm{Fe}_{2} \mathrm{O}_{3}$ et $11-17 \%$ en masse de $\mathrm{Al}_{2} \mathrm{O}_{3}$ ), contenant un peu de potassium, de sodium et de calcium. De telles teneurs en aluminium sont très surprenantes pour un verre. Des petits cristaux de spinelle mesurant moins de $2 \mu \mathrm{m}$ ont été observés dans le verre. Il pourrait s'agir de hercynite $\left(\mathrm{FeAl}_{2} \mathrm{O}_{4}\right)$. Leur présence pourrait expliquer les teneurs élevées en aluminium. Ce verre interstitiel pourrait contenir également d'autres inclusions microscopiques de silicates, des microcristallites inférieures à $1 \mu \mathrm{m}$ correspondant probablement à de l'olivine. Mais la résolution latérale du MEB n'est pas suffisante pour identifier ces microcristallites. Il pourrait également s'agir, mais avec une plus faible probabilité, d'un mélange d'une variété de mélilite et de verre. Selon Deer (Deer et al. 1986), la composition générale des mélilites peut être exprimée comme: $(\mathrm{Ca}, \mathrm{Na}, \mathrm{K})_{2}\left(\mathrm{Mg}, \mathrm{Fe}^{2+}\right.$, $\left.\mathrm{Fe}^{3+}, \mathrm{Al}, \mathrm{Si}\right)_{3} \mathrm{O}_{7}$. Tous les éléments de cette formule structurale générale sont présents dans la phase vitreuse. Quelle que soit la nature de ces microinclusions, elles peuvent significativement influencer les analyses EDX.

La phase vitreuse est partiellement ou totalement dissoute (lixiviée) dans certaines zones de la scorie ou de la roche vitrifiée. La dissolution du verre fait apparaître en relief les cristaux d'olivine qui n'ont pas subi d'altération (fig. 12).

\subsection{Interprétation des témoins métallurgiques}

Quelques grands traits peuvent être esquissés quant à l'activité anthropique dont sont issus ces témoins, en gardant à l'esprit que les observations et analyses n'ont ici porté que sur un nombre restreint d'échantillons et ne peuvent donc en aucun cas conduire à des interprétations définitives.

En premier lieu, le fragment de roche vitrifiée appartient très certainement à la paroi d'un four métallurgique ayant servi à la réduction de minerais de cuivre. En effet, la scorie soudée à la roche vitrifiée apparaît très similaire du point de vue de la microstructure et de la composition minéralogique aux scories de type Plattenschlacke découvertes sur le même site. D'ailleurs, on retrouve un faciès d'altération similaire avec lixiviation de la phase vitreuse qui n'épargne que les cristaux d'olivine. La roche a été partiellement vitrifiée au cours du fonctionnement du four. Ce sont les lits de phyllosilicates qui ont été préférentiellement vitrifiés, cela en raison de leur point de fusion relativement bas par rapport au quartz. D'après le diagramme de phase température-composition dans le système binaire FayaliteForstérite et à partir de la composition de l'olivine présente dans la scorie, il est possible d'estimer la température de cristallisation entre 1200 et $1300^{\circ} \mathrm{C}$. La température maximum a été estimée en reportant la composition du verre de la scorie dans les diagrammes d'équilibre ternaires $\mathrm{SiO}_{2}-$ $\mathrm{Al}_{2} \mathrm{O}_{3}-\mathrm{CaO}$ et $\mathrm{SiO}_{2}-\mathrm{Al}_{2} \mathrm{O}_{3}-\mathrm{FeO}$. Celle-ci est de $1400^{\circ}{ }^{2}$. Mais cette estimation est sujette à discussion car la composition du verre de la scorie est probablement dépendante de la composition de la roche qui a partiellement fondu.

Deuxièmement, les compositions élémentaires riches en fer, comportant des traces importantes de $\mathrm{Mg}, \mathrm{Ca}, \mathrm{Zn}$ sont similaires à ce qui a été vu aux Clausis. De plus, on retrouve les sulfures de cuivre plus ou moins riches en fer. Il n'est donc pas invraisemblable qu'un minerai similaire type bornite $\mathrm{Cu} 5 \mathrm{FeS} 4$ ait été exploité. Signalons également que des quantités importantes de sodium ont été relevées dans la scorie analysée par PIXE, qui pourrait laisser penser comme aux Clausis l'incorporation dans la charge d'un fondant type riébeckite.

Troisièmement, les scories retrouvées sont très similaires à celles retrouvées sur le site voisin de la Cabane des Clausis (Ploquin 1997; Bourgarit et al. 2008). D'abord au niveau typologique, on retrouve les modules centimétriques des scories et les fortes densités, avec des morphologies similaires de Plattenschlacke pour la majorité des artefacts étudiés comportant une zone supérieure en " peau de lait». On retrouve également la grande homogénéité de structure à l'échelle macroscopique, témoin d'un passage total à l'état liquide et d'une viscosité suffisamment faible pour permettre une séparation satisfaisante entre le stérile et le métal recherché. En l'occurrence, la teneur en $\mathrm{Cu}$ résiduelle (de 1 à $4 \%$ en masse d'oxyde $\mathrm{CuO}$ ) se situe dans 

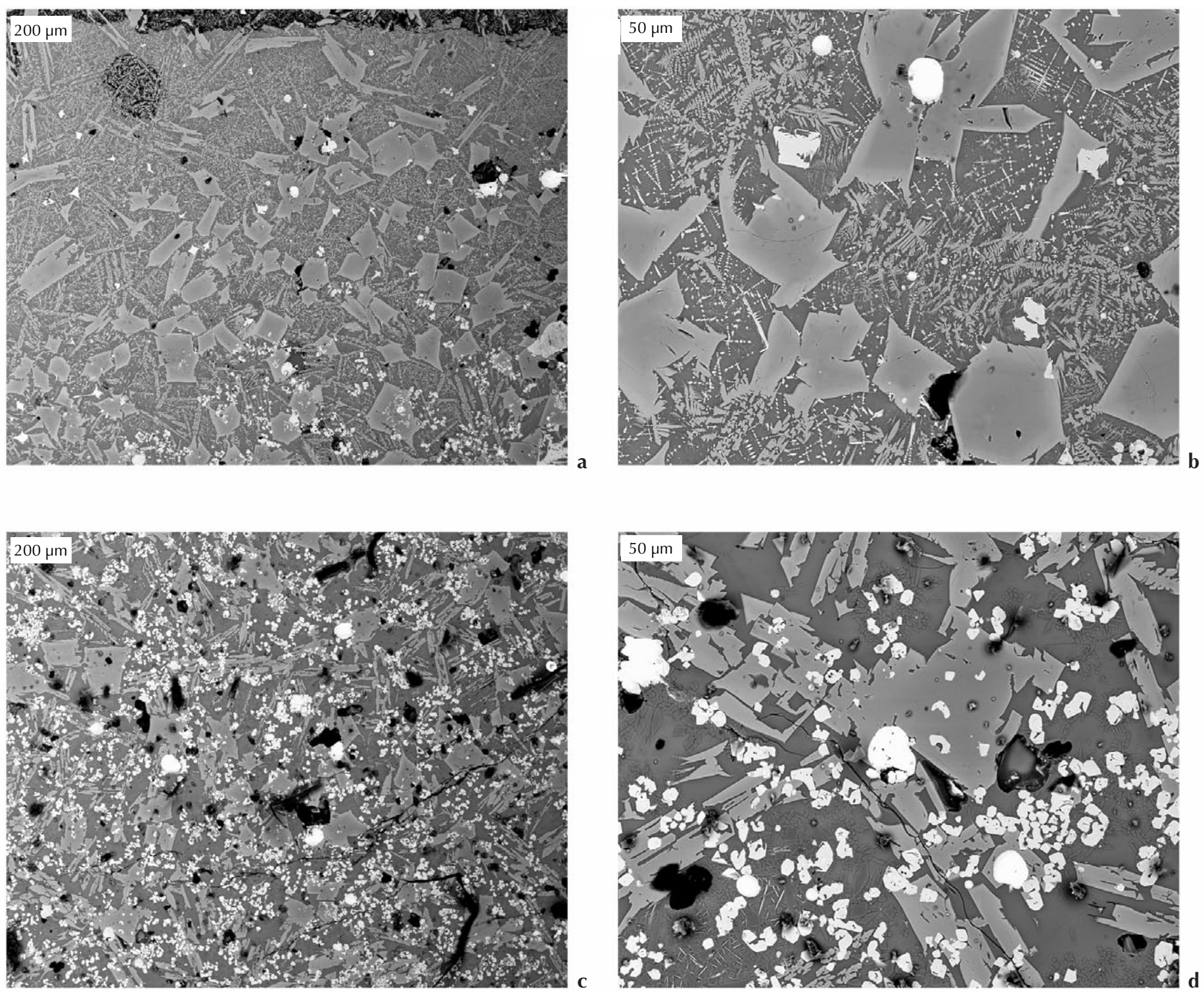

Fig. 10. Micrographies électroniques en électrons retrodiffusés montrant les trois phases cristallines principales dans les scories, à savoir la fayalite (en gris), la magnétite (en gris clair) et le cuivre métallique ou sous forme de sulfure (en blanc). Les morphologies

des deux premières phases évoluent suivant leur localisation dans la scorie: a) zone sous la surface supérieure, b) détail de

l'image précédente, c) microstructure typique dans le reste de la scorie, d) détail de l'image précédente montrant des cristaux de clinopyroxènes type hédenbergite (en gris foncé).

la moyenne des Clausis, qui constitue une nette amélioration par rapport à ce que l'on connaît des métallurgies des périodes antérieures (Bourgarit et al. 2003 ; Bourgarit 2007). De même, la nature très cristallisée et fayalitique des scories étudiées est très similaire à ce qui a été vu aux Clausis. La présence de magnétite confirme la similarité, tout comme d'ailleurs la présence-absence de pyroxène (aux Clausis certaines scories sont très riches en pyroxène, alors que d'autres en sont quasiment dépourvues). Tous ces indices renvoient à un procédé métallurgique très similaire à celui mis en évidence à la Cabane des Clausis (Bourgarit et al. 2008), témoin d'un saut technologique majeur lié notamment au besoin d'accroissement de la cadence de production.

Néanmoins, il convient de signaler un certain nombre de différences par rapport aux scories des Clausis. D'abord, on signalera la corrosion externe des scories, qui n'avait pas été observée aux Clausis, témoin d'un milieu d'enfouissement très différent. Ensuite, les faciès de fracture des fragments de scories des Clausis développent systématiquement une 

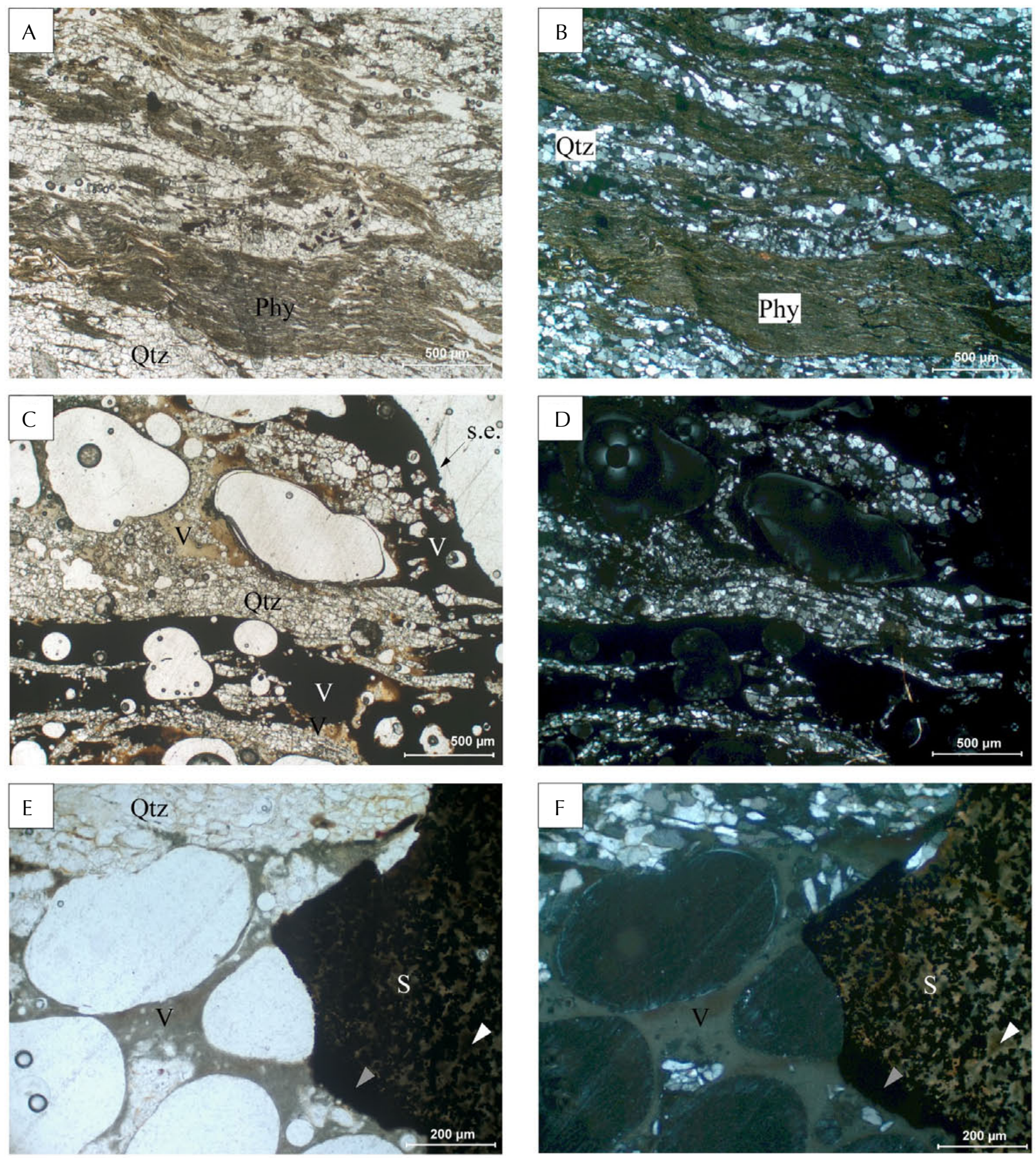

Fig. 11. Vues d'une lame mince du fragment de roche en microscopie optique. A (LPNA) et B (LPA): zone non vitrifiée de la roche montrant l'alternance de lits de quartzite et de lits de phyllosilicates; $\mathbf{C}(\mathrm{LPNA})$ et $\mathbf{D}$ (LPA): portion de la roche partiellement vitrifiée et scorie constituée principalement de verre opaque; $\mathbf{E}$ (LPNA) et F (LPA) : zoom sur la zone de soudure entre la scorie et la roche vitrifiée. Flèche blanche = verre + olivine dendritique; flèche grise: magnétite + verre (photos C2RMF/Y. Coquinot).

structure type basaltique sur les premiers millimètres à partir de la surface supérieure, provoquée par un refroidissement rapide de type trempe à l'eau. De tels faciès n'ont quasiment pas été observés au vallon du Longet, bien qu'on ne puisse pas exclure que la corrosion ait érodé ces reliefs. De plus, si aux Clausis la microstructure des scories étudiées est apparue comme homogène du haut en bas de la scorie, au Longet on observe une microstructure 


\begin{tabular}{|c|c|c|c|c|c|c|c|c|c|c|c|c|c|c|c|c|c|c|c|c|c|c|c|c|c|c|c|c|}
\hline $\begin{array}{c}\text { techni } \\
\text { que }\end{array}$ & $\begin{array}{c}n^{\circ} \\
\text { C2RMF }\end{array}$ & $\begin{array}{l}\text { locali } \\
\text { sation } \\
\end{array}$ & $\mathrm{Na} 2 \mathrm{O}$ & MgO & Al2O3 & SiO2 & P205 & SO3 & $\mathrm{K} 2 \mathrm{O}$ & $\mathrm{CaO}$ & TiO2 & $\mathrm{MnO}$ & $\mathrm{Fe} 2 \mathrm{O} 3$ & Cuo & $\mathrm{ZnO}$ & $\mathrm{PbO}$ & $\mathrm{CoO}$ & $\mathrm{NiO}$ & As205 & $\mathrm{SeO2}$ & $\mathrm{ZrO2}$ & MoO3 & Ag20 & $\mathrm{CdO}$ & $\ln 203$ & SnO2 & Sb205 & TeO2 \\
\hline PIXE & \multirow{4}{*}{67773} & \multirow{2}{*}{ milieu } & 3,6 & 3,0 & 3,8 & 29 & 1,1 & 0,5 & 0,3 & 7,0 & 1,5 & 0,2 & 43 & 3,9 & 3,3 & $<0,8$ & $<0,1$ & $<0,04$ & $<0,01$ & $<0,03$ & 0,04 & 0,0 & $<0,01$ & $<0,01$ & $<0,01$ & $<0,02$ & $<0,02$ & $<0,02$ \\
\hline \multirow{4}{*}{ MEB } & & & nd & 2,8 & 3,6 & 32 & 1,2 & 0,5 & 0,5 & 9,1 & 1,7 & nd & 43 & 2,3 & 3,7 & $<0,3$ & nd & nd & nd & nd & nd & nd & nd & nd & nd & nd & nd & nd \\
\hline & & haut & nd & 2,9 & 4,0 & 31 & 1,4 & 0,5 & 0,5 & 8,8 & 2,0 & nd & 43 & 1,9 & 3,5 & $<0,3$ & nd & nd & nd & nd & nd & nd & nd & nd & nd & nd & nd & nd \\
\hline & & bas & nd & 2,3 & 3,4 & 27 & 0,9 & 0,5 & 0,4 & 7,7 & 1,6 & nd & 47 & 4,9 & 4,4 & $<0,3$ & nd & nd & nd & nd & nd & nd & nd & nd & nd & nd & nd & nd \\
\hline & 66033-1 & poudre & nd & 0,7 & 2,7 & 27 & nd & 0,9 & 0,4 & 5,4 & 1,1 & nd & 60 & 1,1 & 2,6 & nd & nd & nd & nd & nd & nd & nd & nd & nd & nd & nd & nd & nd \\
\hline
\end{tabular}

Tabl. II. Composition élémentaire globale de deux scories du Vallon du Longet.

En gras sont indiqués les éléments majeurs (en \% pondéral d'oxydes, nd=non détecté soit environ moins de $0,5 \%$ ).

particulière dans les premiers millimètres à partir de la surface supérieure, marquée par des textures morphologiques de fayalite et de magnétite bien plus fines, voire la présence d'une couche de surface très riche en magnétite. Ceci, combiné à la possible absence de zone basaltique sur les faciès de rupture, pourrait signer des conditions de refroidissement différentes et donc des modes opératoires légèrement modifiés. L'origine de ces légères variations reste à déterminer: rendent-elles compte d'un décalage chronologique, de pratiques issues de traditions et/ou savoirs ou savoirfaire différents, d'adaptations aux contraintes particulières du milieu, etc. ?

\section{Synthèse et perspectives}

Les premiers sondages réalisés sur le site du vallon du Longet, à Molines-en-Queyras, ont permis de mettre en évidence un site daté de la fin du $\mathrm{III}^{\mathrm{e}}$ millénaire avant notre ère (2280-2030 BC). La présence de scories, découvertes lors de prospections mais également lors de la fouille, démontre que ce site est lié au complexe d'exploitation et de traitement des ressources métallurgiques de la zone de Saint-Véran. La typologie des scories mises au jour sur le site du Longet, mais également leur composition minéralogique et chimique, démontre une grande analogie avec celles mises au jour sur les sites des Clausis, de l'abri de Pinilière et en d'autres points du territoire minier et métallurgique. Ces scories attestent de la nature du procédé de métallurgie extractive mis en œuvre, qui marque un saut technologique très net par rapport à ce que l'on connaît des procédés en usage dans des contextes antérieurs de production à petite échelle (Bourgarit 2007).

La découverte, dans le sondage 1, d'un petit fragment de tuyère vient appuyer cet argumentaire et renforcer les liens chronologiques et technologiques qui unissent les sites de la zone minière et métallurgique. La découverte d'un fragment de paroi de four sous-tend grandement l'hypothèse selon laquelle des opérations de métallurgie extractive ont été pratiquées sur le gisement durant le Bronze ancien. Cet indice nous renseigne de manière indirecte sur l'existence de structures bâties dévolues aux activités pyrométallurgiques. Bien que cette hypothèse ait été présentée par Pierre Rostan dès la découverte du site de la cabane des Clausis à Saint-Véran, les fouilles successives n'ont pas permis d'en démontrer l'existence. La mise en évidence sur une des scories d'un bord droit appuie l'hypothèse de structures pyrométallurgiques quadrangulaires, qui ne seraient pas sans rappeler les fours de l'âge du Bronze connus pour les alpes autrichiennes et le Trentin italien (Goldenberg 1998; Cierny et al. 2004),

D'un point de vue archéologique, l'intérêt du site du vallon du Longet réside par son éloignement de la mine contemporaine de la tranchée des Anciens, située sur le versant opposé du massif de Château-Renard. Pour l'heure, les analyses tendent à privilégier l'hypothèse d'un transfert des minerais vers une aire de traitement éloignée, à près d'une heure de marche. Dans cette perspective, les raisons de l'implantation d'un atelier dans le vallon du Longet doivent être précisées. Au moins deux hypothèses peuvent être évoquées :

- la première se réfère à un déterminisme environnemental très souvent mis en avant lors de l'étude des sites miniers et métallurgiques, impliquant un déplacement des zones de traitement du minerai en raison de l'épuisement des ressources végétales (cycles de régénération forestière);

- la seconde implique davantage les dynamiques sociales et économiques et impliquerait que le site minier ne fasse pas l'objet d'une exploitation par un seul groupe, selon un modèle proto-industriel inscrit dans la relation mine/atelier, l'éclatement des zones de traitement du minerai sur le territoire pouvant alors être le produit de cette multiplicité d'acteurs. 

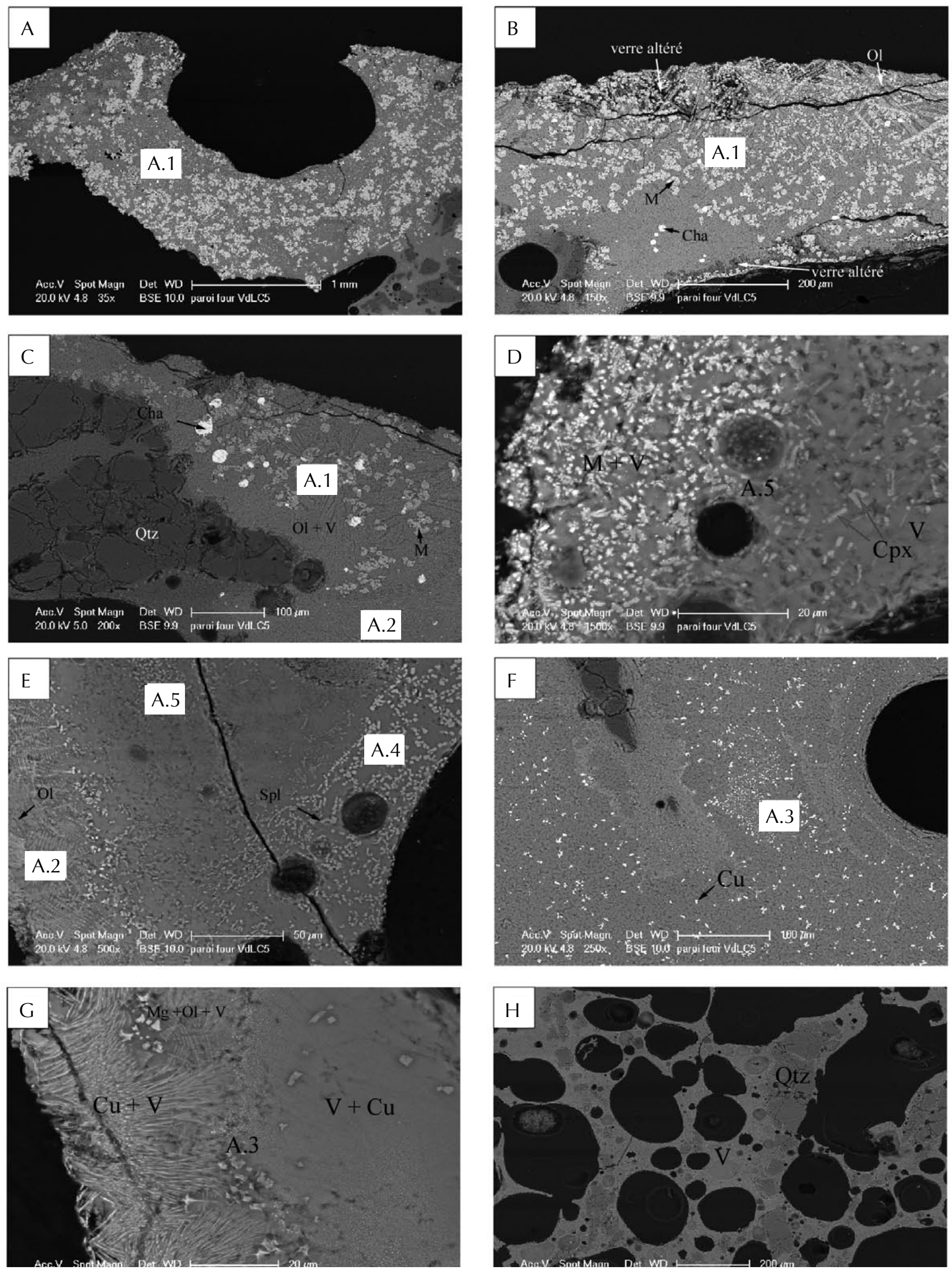

Fig. 12. Vues d'une lame mince sous loupe binoculaire du fragment de roche. A) scorie, roche partiellement vitrifiée et zone intermédiaire; $\boldsymbol{B}$ et $\mathbf{C}$ ) zoom sur la scorie et la zone de soudure avec la roche vitrifiée; D) zoom sur une zone de la scorie contenant des particules de cuivre, visibles par leur reflet métallique cuivré (photos C2RMF/Y. Coquinot). 

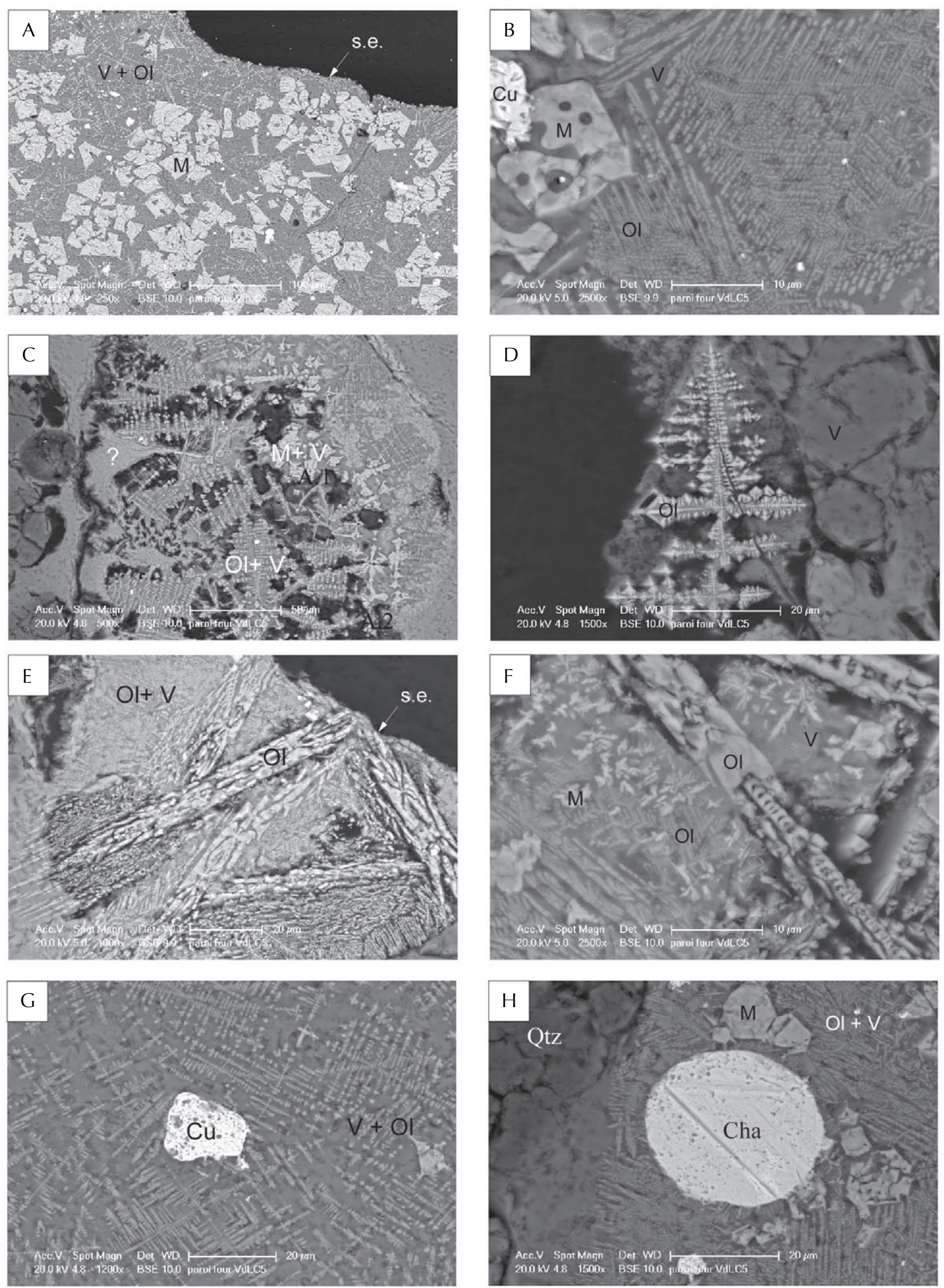

Fig. 13. Micrographies électroniques en électrons retrodiffusés du fragment de roche montrant les différents assemblages minéralogiques rencontrés dans la zone de scorie (notés A.n). Les abréviations utilisées dans les planches sont les suivantes: A.n assemblage minéralogique $\mathrm{n}$ / Cha chalcocite / Cu particule de cuivre / M magnétite / Ol olivine / Phy phyllosilicates / Qtz quartz / $\mathbf{R}$ résine / S scorie / s.e. surface externe / $\mathbf{S p l}$ spinelle / V verre. 
protohistoriques souterrains. Archéologie en Languedoc, $\mathrm{n}^{\circ} 21,1999$, p. 121-128.

Barge-mahieu 1995: BARGE-MAHIEU (H.) - Les premiers objets métalliques du Chalcolithique provençal. In: L'Homme méditerranéen. Mélanges offerts à Gabriel Camps. Aixen-Provence, Publications de l'Université de Provence, 1995, p. 359-373.

Bard 1990: BARD (J.-P.) - Microtextures des roches magmatiques et métamorphiques. Paris, Masson, 208 p.

Barge 1997 : Barge (H.) - L'installation métallurgique préhistorique de la cabane des Clausis à Saint-Véran (Hautes-Alpes), in: AMBERT (P.) dir., Actes du Colloque « Mines et métallurgie de la Préhistoire au Moyen Âge en Languedoc-Roussillon et régions périphériques », Lattes, Fédération archéologique de l'Hérault, 1997, p. 99-110 (Archéologie en Languedoc, 21).

Barge 1999: BARGE (H.) - L'installation métallurgique préhistorique de la cabane des Clausis à Saint-Véran (HautesAlpes). Archéologie en Languedoc, $\mathrm{n}^{\circ}$ 21, 1999, p. 99-110.

Barge 2003: BARGE (H.) - Saint-Véran, la montagne, le cuivre et l'homme. I, Mine et métallurgie préhistoriques dans les Hautes-Alpes; étude géologique, Johann Tuduri, Alain Chauvet et Luc Barbanson. Actilia multimédia 2003, 83 p.

Barge, Bourhis, Rostan 1998 : BARGE (H.), BOURHIS (J.-R.), ROSTAN (P.) - Métallurgie préhistorique et gîtes cuprifères dans le sud-est de la France: premiers résultats. In: D'ANNA (A.), BINDER (D.), Production et identité culturelle, actes des $2^{\mathrm{e}}$ Rencontres Méridionales de Préhistoire Récente, Arles APDCA éd., 1996, p. 65-79.

Barge, Ancel 1997: BARGE (H.), ANCEL (B.) - Exploitation d'une mine de cuivre préhistorique: Les Clausis à saintVéran, in: L'énigmatique civilisation campaniforme, Dijon, Faton, 1997, p. 46-49 (Archéologia - hors-série, 9).

Barge et al. 1998: BARGE (H.), ANCEL (B.), ROSTAN (P.), GUENDON (J.-L.) - La mine des Clausis à Saint-Véran (Hautes-Alpes): exploitation et aire de réduction du minerai de cuivre d'époque préhistorique. In: MORDANT (C.), PERNOT (M.), RYCHNER (V.), L'atelier du bronzier en Europe du XX e au VIII s. avant notre ère. Actes du colloque international Bronze'96, Neuchatel et Dijon, Paris, CTHS, 1998, p. 71-82.

Bourgarit 2007 : BOURGARIT (D.) - Chacolithic copper smelting'. In: LA NIECE (S.), HOOK (D.), CRADDOCK (P. T.) ed., Metals and mines. London: Archetype Publications Ltd, 2007, p. 3-14.

Bourgarit et al. 2003: BOURGARIT (D.,) MILLE (B.), CAROZZA (L.), BURENS (A.) - L'évolution des premières métallurgies extractives du cuivre. Techné, $\mathrm{n}^{\circ} 18$, Paris, Ministère de la Culture, RMN, 2003, p. 7-13.

Bourgarit et al. 2008: BOURGARIT (D.), ROSTAN (P.), BURGER (E.), CAROZZA (L.), ARTIOLI (G.) - The beginning of copper mass production in the western Alps: the Saint Véran mining area reconsidered. Historical Metallurgy, 42, 2008, p. 1-11.

Calligaro et al. 1998: CALLIGARO (T.), DRAN (J. C.), HAMON (H.), MOIGNARD (B.), SALOMON (J.) - An external milli-beam for archaeometric applications on the AGLAE IBA facility of the Louvre museum. Nuclear Instruments and Methods B, 1998, p. 136-138, 339-343.

Carozza, Mille 2007: CAROZZA (L.), MILLE (B.) Chalcolithique et complexification sociale: quelle place pour le métal dans la définition du processus de mutation des sociétés de la fin du Néolithique en France? In: GUILAINE (J.) dir., Publication du séminaire du Collège de France Le Chalcolithique et la construction des inégalités, t. 1-Le continent européen, Paris, Errance, 2007, p. 153-189.

Chaudhuri, Newesley 1993: CHAUDHURI (J.N.B.), NEWESELEY (H.) - Mineralogical characterization of old Harz Mountain slags. Can. Metall. Quart., 32, 1993, p. 1-12.

Cierny et al. 2004: CIERNY (J.), MARZATICO (F.), PERINI (R.), WEISGERBER (G.) - Der spätbronzezeitliche Verhüttungsplatz Acqua Fredda am Passo Redebus (Trentino). In: WEISGERBER (G.), GOLDENBERG (G.) ed., Alpenkupfer - Rame delle Alpi. Bochum, Deutsches Bergbau Museum, 2004.

Deer, Howie, Zussman 1986: DEER (W.A.), HOWIE (R.A.), ZUSSMAN (J.) - Rock forming minerals: Disilicates and Ring Silicates (2nd edition), New York, John Wiley \& Sons, 1986, 629 p.

Deer, Howie, Zussman 1992: DEER (W.A.), HOWIE (R.A.), ZUSSMAN (J.) - An introduction to the rock-forming minerals. Longmans publishing, 1992, 528 p.

Dran, Calligaro, Salomon 2000 : DRAN (J.-C.), CALLIGARO (T.), SALOMON (J). - Particle-induced X-ray emission. In: CILIBERTO (E.), SPOTO (G.) ed., Modern Analytical Methods in Art and Archaeology, Chichester, John Wile, 2000, p. 135-166.

Parneroff, Pomeroi, Tourenq 1970: PARNEROFF (A.), POMEROl (C.), TOURENQ (J.) - Les Minéraux en Grains, Méthodes d'Étude et Détermination. Paris, Masson édit., 1970, $578 \mathrm{p}$.

Goldenberg 1998: GOLDENBERG (G.) - L'exploitation du cuivre dans les Alpes Autrichiennes à l'Age du Bronze. In: MORDANT (C.), PERNOT (M.), RYCHNER (V.), L'atelier du bronzier en Europe du XXe au VIII 's. avant notre ère, Vol. 2, Du minerai au métal, du métal à l'objet, Paris, CTHS, 1998, p. 9-24.

Ploquin 1997: PLOQUIN (A.) - Scories archéologiques et reconstitution expérimentale de réduction de sulfure de cuivre (minerai de Saint-Véran, Hautes-Alpes: prémices d'une approche pétrographique), Archéologie en Languedoc, $\mathrm{n}^{\circ} 21$, 1997, p. 111-120. 
Ploquin et al. 1997: PLOQUIN (A.), HAPP (J.), BARGE (H.), BOURHIS (J.-R.) - Scories archéologiques et reconstitution expérimentale de réduction du sulfure de cuivre (minerai de Saint-Véran, Hautes-Alpes): prémices d'une approche pétrographique. In: AMBERT (P.) dir., Actes du Colloque « Mines et métallurgie de la Préhistoire au Moyen-Age en LanguedocRoussillon et régions périphériques », Lattes, Fédération archéologique de l'Hérault, 1997, p. 111-120 (Archéologie en Languedoc, 21).

Ploquin et al. 1997 : PLOQUIN (A.), HAPP (J.), BARGE (H.), GUENDON (J.-L.) - Expérimentation sur la bornite de SaintVéran (Hautes-Alpes). In: FRÈRE-SAUTOT (M.-C.) dir., Actes du Colloque "Paléométallurgie des cuivres », Bourgen-Bresse et Beaune, 17-18 octobre 1997, Monographies Instrumentum, 5, 1997, p. 37-43, 6 fig.

Rossi, Gattiglia 2005 : ROSSI (M.), GATTIGLIA (A.) - Les poignards de Remedello hors d'Italie: révision des données. In: AMBERT (P.), VAQUER (J.) dir., La première métallurgie en
France et dans les pays limitrophes, actes du colloque international de Carcassonne, septembre 2002, Mémoire de la Société Préhistorique Française, XXXVII, 2005, p. 265-271.

Rostan, Rossi, Gattiglia 1997: ROSTAN (P.), ROSSI (M.), GATTIGLIA (A.) - Richerche sulle miniere et sulla metallurgia dell'età del bronzo nel Briançonnais (Hautes-Alpes, Francia). In: La Valle d'Aosta nel quadro della preistoria et protoistoria dell'arco alpino centro-occidentale. Atti delle XXXI Riunione Scientifica IIPP, Courmayeur, Firenze, 1994, 1997, p. 499-512.

Rostan, Gattiglia, Rossi 2002: ROSTAN (P.), GATTIGLIA (A.), ROSSI (M.) - Approche économique et industrielle du complexe minier de Saint-Véran (Hautes-Alpes) dans le contexte de l'âge du Bronze des Alpes du Sud. In: Bulletin d'Études Préhistoriques et Archéologiques Alpines, actes du IX ${ }^{\mathrm{e}}$ colloque sur les Alpes dans l'Antiquité, Tende, 2000, 2002, p. 77-96. 


\title{
Évolution des écosystèmes et des pratiques agrosylvopastorale et minière pour la production de bois de feu dans le Haut-Champsaur et la Haute-Durance (France) de l'âge du Bronze ancien au $\mathrm{XVI}^{\mathrm{e}} \mathrm{S}$.
}

\author{
Vanessa PY*, Aline DURAND*
}

\begin{abstract}
Résumé. La synthèse des données anthracologiques acquises depuis une décennie dans le Haut-Champsaur et la Haute-Durance autorise une restitution de l'évolution des écosystèmes et des pratiques agropastorales et minières pour l'approvisionnement en bois de feu depuis l'âge du Bronze jusqu'à la fin du Moyen Âge-début de l'ère moderne. Elle souligne l'hétérogénéité des paysages et des terroirs sud-alpins en fonction de l'altitude, de l'exposition et du type de gestion mis en œuvre et confirme la place importante du Pin cembro au sein des formations forestières depuis l'âge du Bronze jusqu'à Moyen Âge central. Sa disparition progressive est différentielle d'une vallée à l'autre. L'ouverture du milieu au-dessus de $2200 \mathrm{~m}$ s'accentue, passé le XIII ${ }^{\mathrm{e}} \mathrm{s}$. L'évolution des écosystèmes et le démantèlement de la forêt entre 2000 et $2200 \mathrm{~m}$ d'altitude poussent les mineurs à arpenter les sommets à la recherche de boisements matures et âgés. Au contraire, les agropasteurs se rabattent au fur et à mesure sur les ligneux bas et le bois mort, glanés dans les derniers prés boisés d'altitude, avant de se tourner sur la ripisilve et les friches montagnardes.
\end{abstract}

Evolution of the ecosystems and forestry, pastoral and mining practices for the production of firewood in the upper Champsaur and upper Durance valleys (France) from the Late Bronze Age to the $16^{\text {th }}$ century AD

Abstract. The synthesis of anthracological data acquired for over a decade from the upper Champsaur and upper Durance valleys allows an overall picture to be drawn of the evolution of the ecosystems and agro-pastoral and mining practices for the supply of firewood from the Bronze Age until the late medieval and early modern era. It highlights the heterogeneity of the southern Alpine landscape according to altitude, exposure and type of land management implemented, and confirms the important place of Pinus cembra within forest formations from the Bronze Age to the central Middle Ages. Its' gradual disappearance varies from one valley to another. Opening up of the land above $2200 \mathrm{~m}$ accelerates after the thirteenth century. Ecosystem evolution and the clearing of the forest between 2000 and 2200 metres in altitude forced the miners to explore the mountains further afield in search of mature and older woodland. On the contrary, the shepherd - peasants gradually fell back on scrub timber and dead wood, gleaned from the last high wooded areas, before turning to the riverbanks and mountain wildernesses.

\section{Introduction}

$\mathrm{L}$ a présentation de V. Py réalisée lors du colloque participe à une réflexion de synthèse plus large axée sur les modes d'exploitation et de gestion des ressources ligneuses et l'évolution des écosystèmes de la haute montagne de la protohistoire aux temps modernes. Nous proposons d'en offrir ici une première synthèse fondée sur l'ensemble des données anthracologiques agrosylvopastorales et minières. En effet, depuis plus d'une décennie, des travaux pluridisciplinaires sont menés dans le Haut-Champsaur et la Haute-Durance par le Centre Camille Julian, associé aux Universités de York et de Barcelone, et plus récemment par le Laboratoire d'Archéologie Médiévale Méditerranéenne, en coopération avec le Service culturel de L'Argentière-laBessée (De Beaulieu et al. 2003; Court-Picon 2003; Leveau 2003 ; Leveau, Segard 2004; Palet-Martinez, Ricou, Segard 2003; Walsh et al. 2003; 2005; Durand 2004; Walsh, Palet-Martinez, Mocci 2007; Py, Ancel 2007; Tzortzis et al. 2008; Segard 2009). Les investigations archéologiques conjuguées aux études paléoenvironnementales ont caractérisé les principales phases et formes d'occupation de la haute montagne sud-alpine et d'exploitation de ses ressources depuis le Mésolithique. Les charbons de bois, à l'image de la céramique dans les sites archéologiques de plaine ou de fonds de vallées, sont les seuls « écofacts »

* Laboratoire d'Archéologie Médiévale Méditerranéenne (LAMM), UMR 6572 CNRS - Université de Provence, Maison Méditerranéenne des Sciences de l'Homme, 5 rue du château de l'Horloge, BP 64713094 Aix-en-Provence cedex 2. 
recueillis en fouille. Ils sont datables et abondants à toutes les époques et dans tous les types de sites: agropastoraux, artisanaux ou industriels. Ce sont les ultimes témoins des formations ligneuses - forêts, prés-bois, landes - utilisées, gérées et exploitées. Leur étude restitue avec une bonne précision l'évolution des écosystèmes et des pratiques agrosylvopastorales sur la longue durée.

\section{Méthodologie}

L'anthracologie - du grec anthrax, -akos, charbon ardent - a pour objet d'étude les charbons de bois trouvés en contexte archéologique. Elle a été envisagée conjointement à l'étude archéologique de ces sites de haute montagne (Walsh et al. 2003 ; Durand 2004; Py, Ancel 2007; Durand, Py 2008). L'interprétation des données anthracologiques, en termes d'évolution et d'économie des boisements, nécessite l'acquisition d'un corpus représentatif, qualitativement et quantitativement, de l'aire d'approvisionnement en bois de feu des agropasteurs, mineurs et artisans, impliquant en amont une méthode rigoureuse d'échantillonnage et de prélèvement adaptée au contexte de découverte des dépôts (foyers, sols, remblais etc.). Les charbons de bois provenant de contextes domestiques ont été échantillonnés prioritairement dans les couches d'épandage de foyers associées à des niveaux d'occupation. Ils ont été datés pour la plupart par le radiocarbone. Les occupations plus tardives $\left(\mathrm{XV}^{\mathrm{e}}-\mathrm{XVI}^{\mathrm{e}} \mathrm{S}\right.$.) ont livré un rare mobilier céramique ou métallique (Py 2009). Les sites miniers ont fait l'objet d'un échantillonnage complet opéré dans les couches riches en charbons caractérisées par leur granulométrie (remblais, haldes). La méthodologie de prélèvements et d'échantillonnage fait l'objet d'une réflexion approfondie (Py 2006a; Py 2009). Les couches rattachées à une étape de la dynamique opératoire, à l'abattage d'un front de taille, à l'exploitation d'une tranchée ou d'un chantier, ont été datées par la méthode radiocarbone. Les charbons de bois ont été sélectionnés et analysés au préalable de manière obtenir une datation fiable. Les résultats obtenus à Fangeas-Faravel ont déterminé avec précision le phasage chronologique de l'exploitation rythmée, entre le $\mathrm{X}^{\mathrm{e}}$ et la deuxième moitié du XIII ${ }^{\mathrm{e}}$ s., par des recherches plus ou moins concluantes et d'importants travaux d'approfondissement sur les zones enrichies (Py, Ancel 2007; Py 2009).

Cette collaboration avec les archéologues en amont de la fouille et lors de la fouille pour définir une stratégie de prélèvement pertinente est une condition sine qua non pour obtenir des résultats paléoenvironnementaux et bioarchéologiques fiables. Une partie des données acquises jusqu'à présent est présentée dans deux diagrammes anthracologiques de synthèse diachroniques (fig. 1 et 2) afin de faire apparaître les transformations de la végétation et des écosystèmes sur la longue durée. Les charbons de bois sont identifiés généralement à l'espèce ou au genre en microscopie optique à réflexion. Ces analyses ont été réalisées au laboratoire d'Archéologie Médiévale Méditerranéenne en coopération avec l'Institut Méditerranéen d'Écologie et de Paléoécologie.

\section{Résultats et interprétations}

\subsection{La montagne de Dormillouse (Cne Freissinières)}

Les données anthracologiques agropastorales de la montagne de Dormillouse située au cœur du massif des Écrins, ont été obtenues grâce aux prélèvements réalisés dans des structures pastorales et agropastorales situées entre 2000 et 2310 m d'altitude, fouillées par l'équipe de K. Walsh et F. Mocci (Faravel XIX, VIIId, XII et Fangeas VI), et par celle de V. Py (Fangeas X et Coste de Tonis I, Walsh et al. 2003; Durand 2004; Py 2005; 2006b). Elles ont été complétées par les données anthracologiques minières provenant des fouilles des mines métalliques de Fangeas et Faravel, échelonnées entre 1900 et 2200 m d'altitude, fouillées par l'équipe de V. Py et B. Ancel (Py, Ancel 2007; Py 2009). Elles reconstituent le paysage ligneux à l'échelle du vallon.

\subsubsection{Les données anthracologiques agropastorales (voir fig. 1)}

À l'âge du Bronze ancien (2200-1910 av. J.-C.), les données anthracologiques du site de Faravel XIX (Cne Freissinières), sis à $2310 \mathrm{~m}$ d'altitude, indiquent que les boisements fréquentés par les pasteurs pour alimenter leur foyer sont dominés par des formations arborescentes de type futaie où le Pin cembro est prépondérant (Tzortzis et al. 2008). Pinus type P. sylvestris (cf. Pinus uncinata) tient une place secondaire, mais non négligeable au regard des périodes plus récentes où il est toujours très discret. Les variations de fréquences des pins de type Pin sylvestre entre les deux spectres s'expliqueraient par un changement des stratégies d'approvisionnement. Le territoire fréquenté pour la coupe et le ramassage du bois de feu serait, pour la phase d'occupation la plus récente, orienté vers les versants d'adret. Les spectres ne sont pourtant pas fondamentalement différents et indiqueraient que le premier état du site (dernière occupation) est probablement peu postérieur à l'occupation de l'âge du Bronze ancien. La prépondérance des grands ligneux subalpins caractérise une forêt d'altitude peu altérée: aucun indice d'un stade de reconquête ou de transition dominé par des formations héliophiles arborescentes ou des ligneux bas n'est perceptible. Les dépôts anthracologiques plus récents ont enregistré l'émergence 
$2400 \mathrm{~m}$ d'alt.

Faravel XIX - $2310 \mathrm{~m}$ d'alt.

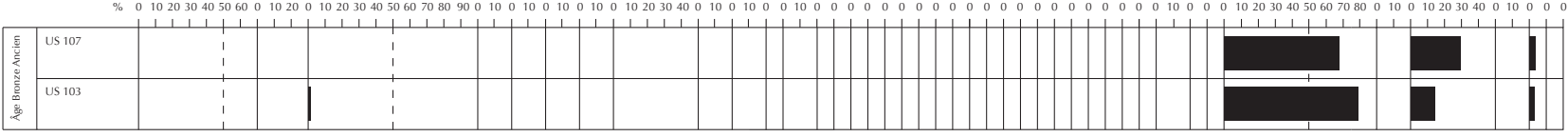

Coste de Tonis I - $2240 \mathrm{~m}$ d'alt.

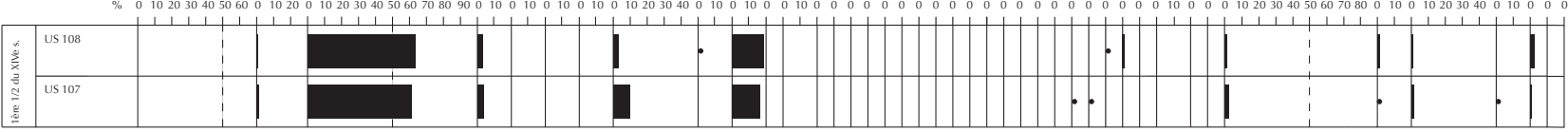

\section{$2200 \mathrm{~m}$ d'alt.}

Mines d'argent de Faravel - 2200-2100 m d'alt.

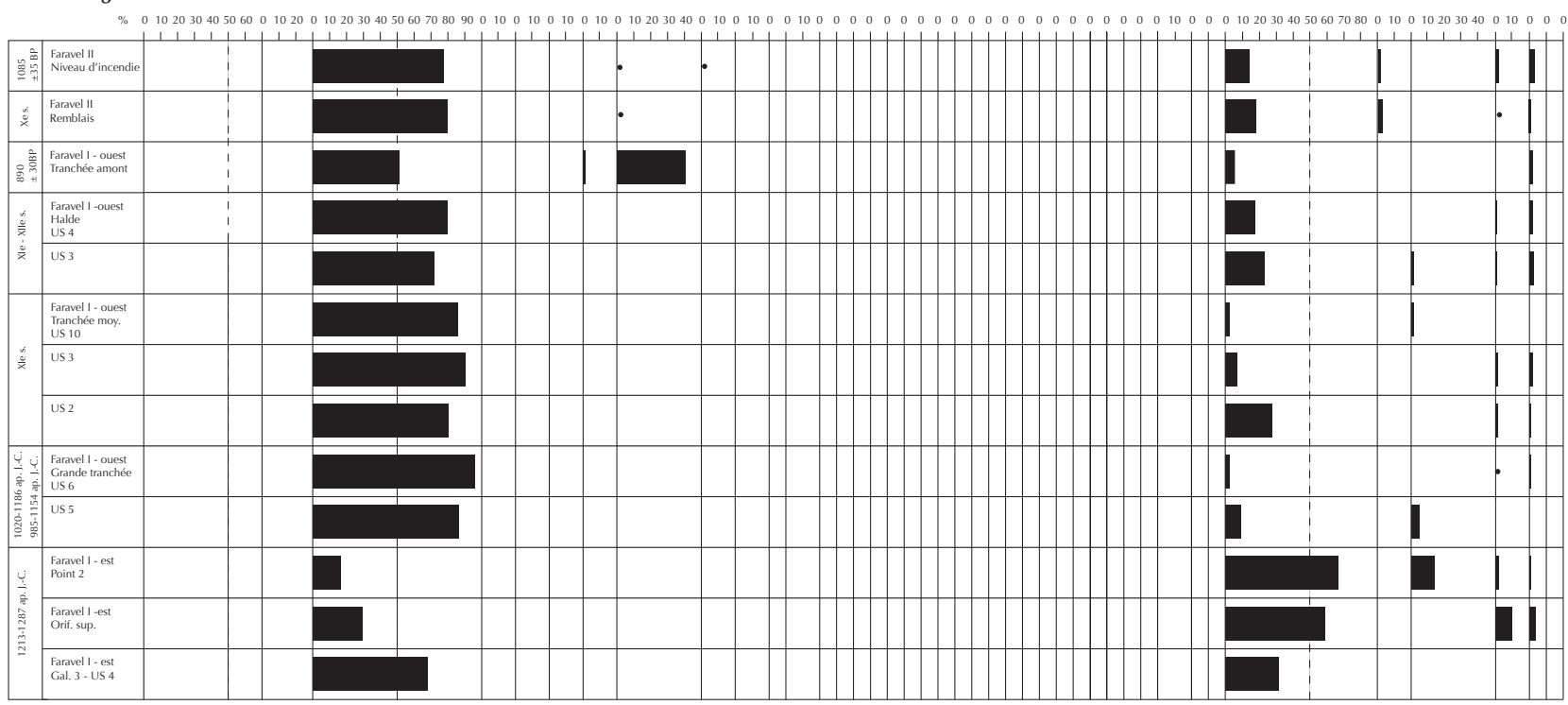

Faravel XII - 2170 m d'alt.

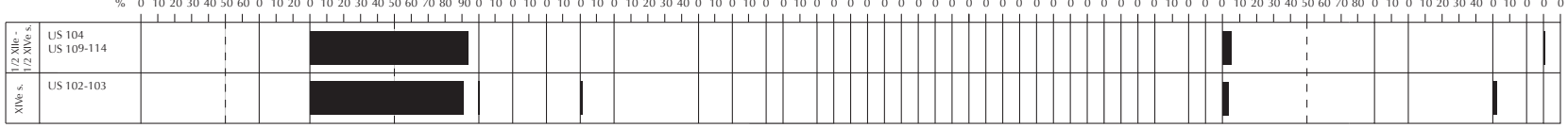

$2000 \mathrm{~m}$ d'alt.

Fangeas X - 2000 m d'alt.

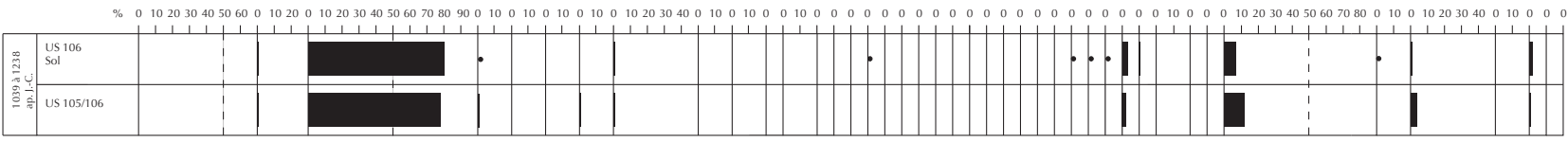

Mines métalliques de Fangeas - 2000-1900 m d'alt.

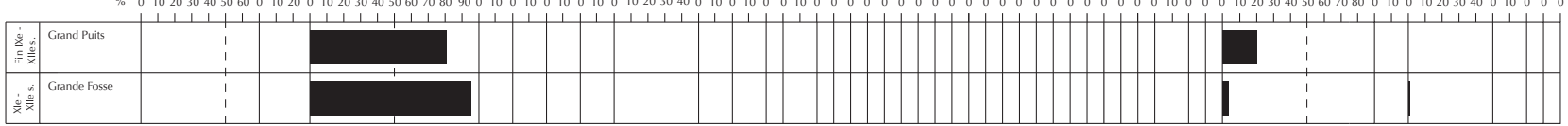

Fangeas VI - $2000 \mathrm{~m}$ d'alt.

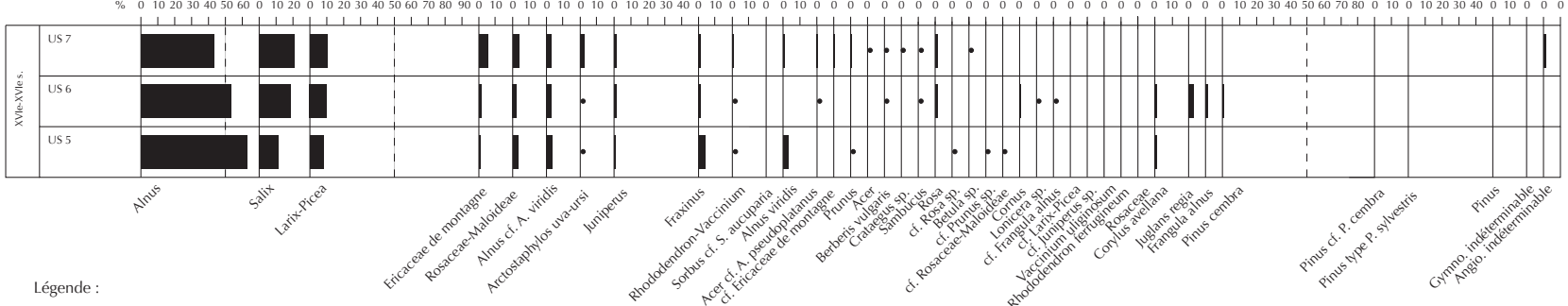

Le diagramme est exprimé en fréquences relatives $\%$ Gymno. indéterminable $=$ Gymnosperme indéterminable

Réalisation V. Py 2009

Analyses A. Durand et V. Py 2002-2009

Fig. 1. Diagramme anthracologique de synthèse de la montagne de Dormillouse (Cne Freissinières). Les spectres, classés par tranches altitudinales, et dans chaque tranche, rangés en fonction de leur chronologie relative et absolue (du plus ancien au plus récent), sont exprimés en \%. 
marginale du Mélèze et/ou Épicéa. La situation topographique du site suggère que les espaces ouverts et les zones pâturables étaient alors situés au-delà de 2200 m d'altitude et que la limite supérieure de la forêt dense se situait autour de $2300 \mathrm{~m}$ d'altitude. Il est probable que l'activité pastorale, favorisée par des conditions climatiques clémentes, ait démarré dans les pelouses alpines et dans les espaces supraforestiers.

Les résultats anthracologiques obtenus par B. Talon pour l'enclos Faravel VIIId (Cne Freissinières), implanté 145 m plus bas, daté de l'âge du Bronze ancien (2000-1970 av. J.-C.), sont basés sur de faibles effectifs biaisant ainsi légèrement les rapports de proportion. L'unité datée par le radiocarbone correspond peut-être à un épisode d'incendie de structures en bois (?). Larix-Picea (76\%) domine associé au Pin cembro (19,2\%) (Talon in Walsh 1999; Walsh et al. 2005). En raison de l'échantillonnage, il est impossible de traduire en termes quantitatifs ce résultat. Cependant il tend à confirmer la place grandissante de cette essence à $2200 \mathrm{~m}$ d'altitude durant l'âge du Bronze ancien, alors qu'elle est extrêmement discrète dans le diagramme pollinique de Fangeas (problème d'enregistrement de Larix). Ce taxon pionnier, colonisateur des espaces vides, n'était pas un obstacle au pâturage contrairement à l'Arolle (Walsh et al. 2003). De plus, ses propriétés mécaniques pouvaient déjà avoir été mises en valeur pour l'habitat (constructions exposées aux intempéries), tandis que sa meilleure tenue au feu par rapport aux pins, être appréciée pour l'alimentation du foyer. En l'état actuel, il n'est pas possible d'approfondir la réflexion. La dichotomie des résultats obtenus pour les deux sites, outre le protocole de prélèvement appliqué, peut refléter aussi l'étagement de la végétation avec une répartition quantitative et qualitative différentielle des essences sur les pentes de la montagne, liée à l'altitude ou à des bouleversements anthropiques et/ou environnementaux comme les incendies, naturels ou non. Ces données trop unicolores en raison de la nature des dépôts ou de la méthode de prélèvement ne sont pourtant pas incompatibles avec la restitution d'un milieu de pré-bois constitué d'une mosaïque d'éléments forestiers, arbustifs, sous-frutescents et herbacés, attestée par la palynologie (Walsh, Richer, De Beaulieu 2006).

Au milieu du XII ${ }^{\mathrm{e}}$-milieu XIV ${ }^{\mathrm{e}}$ s., à la même altitude que Faravel VIIId $(2170 \mathrm{~m})$, le bois utilisé comme combustible ou matériau de construction sur le site pastoral de Faravel XII (Walsh et al. 2003, p. 193-194), indique la présence de boisements de mélézins et/ou de pessières associés à des formations ouvertes de type landes, sans que l'on puisse en évaluer précisément le rapport (Durand 2004). La chute des fréquences du Pin cembro, dont l'optimum est dans l'étage subalpin, montre que cette espèce, prédominante à l'âge du Bronze ancien à plus de $2300 \mathrm{~m}$ d'altitude, n'est pas encore totalement éradiquée au Moyen
Âge central-bas Moyen Âge, même si elle apparaît nettement plus sporadique. Le Mélèze et/ou Épicéa (cf. mélézin), favorisé par le déboisement de la cembraie, était à Faravel XII l'essence de prédilection pour bâtir les cloisons mobiles ou les parties en bois de l'habitat pastoral.

L'omniprésence du mélézin et/ou pessière (cf. mélézin) et la survivance du Pin cembro à cette époque sont confirmées par l'analyse des charbons de bois domestiques dispersés dans le sol d'occupation de la structure agropastorale de Fangeas X implantée à 2000 m d'altitude (Py 2009). L'utilisation du foyer est datée du XIII' $\mathrm{s}$. grâce à une datation radiocarbone et à l'analyse du mobilier céramique et métallique. À ce moment-là, le territoire d'approvisionnement des agropasteurs est situé dans des boisements où Larix-Picea tient une place dominante. Les ligneux bas étant des indices d'ouverture du milieu, la forêt exploitée pourrait se situer dans la zone de transition entre la forêt dense - mélézin subalpin - et la zone supraforestière composée de landes et landines à Éricacées et à Genévriers, avec des individus isolés de Pin cembro et de Larix-Picea. La surreprésentation de Larix-Picea, associée aux indicateurs de la lande, est un indice indirect d'un fort recul de la forêt dense (en dessous de 2000 m d'altitude ?) et d'une extension de la zone supraforestière dominée par LarixPicea dans la strate arborescente.

La situation se renverse à la fin du Moyen Âge. Les charbons de bois prélevés dans le foyer domestique du site de Coste de Tonis I, situé à $2240 \mathrm{~m}$ d'altitude et daté de la première moitié du $\mathrm{XV}^{\mathrm{e}} \mathrm{s}$., comptent plus de 30 pour cent de ligneux bas caractéristiques de milieux ouverts (Py 2009). La strate arborée est très morcelée, voire réduite à des bouquets d'arbres disparates dominés par le Mélèze et/ ou Épicéa (cf. Mélèze), tandis que le Pin cembro subsiste à l'état de relique. Cette première observation suggère le caractère dégradé des massifs forestiers. L'extension de Larix-Picea aux dépens des pinèdes est l'écho de fortes transformations du paysage ligneux - déboisements, incendies anthropiques ou naturels - précédant un épisode de reconquête. La prolifération des Éricacées de montagne et des Genévriers, composante majeure des landes et landines de la zone supraforestière et des formations de sousbois des boisements subalpins, confirme la dégradation des forêts et le caractère très ouvert du paysage. L'utilisation massive de petits ligneux bas pourtant peu intéressants pour la bonne tenue du feu témoigne de l'éloignement de la forêt subalpine dense à une altitude inférieure à $2200 \mathrm{~m}$ (voire 2100-2000 m ?). L'aire d'approvisionnement est située en zone supraforestière. Le Frêne et le Saule peuvent indiquer une récolte ponctuelle de petits bois aux abords de zones humides, et l'Airelle des marais, qui n'a malheureusement pu être reconnue que dans un seul cas, une récolte dans les landes ou les boisements d'altitude en zone tourbeuse. 
À la fin du Moyen Âge-début de l'ère moderne ( $\mathrm{XV}^{\mathrm{e}}$ $\mathrm{XVI}^{\mathrm{e}} \mathrm{s}$.), la forêt a disparu de la montagne de Dormillouse. L'analyse des charbons de bois domestiques de la structure agropastorale de Fangeas VI (2000 m d'alt.) révèle un approvisionnement en bois de feu dans un milieu dominé par des formations arbustives. L'identification de nombreux taxons montagnards indique un ramassage de bois de feu plus bas sur les pentes et dans la vallée, plus particulièrement dans les secteurs de ripisilve, les zones de friches et en bordure des terroirs cultivés. Un approvisionnement sur la fin du parcours de l'estive dans les brousses supraforestières n'est pas à exclure, mais l'unité écologique du dépôt va dans le sens d'un approvisionnement dans une aire homogène. Les spectres de Fangeas VI révèlent en négatif la disparition de la forêt subalpine dense aux abords du plateau de Fangeas, voire jusqu'à 1800 m d'altitude. Ces données corroborent les observations archéologiques qui mettent en évidence une multiplication des sites agropastoraux au même moment (Walsh et al. 2003; Py 2009). Une partie du combustible utilisé dans les foyers domestiques provient de la récupération des branchages délaissés par le troupeau après consommation des feuilles (Py 2009). Cette hypothèse n'est pas formulée à partir de la surreprésentation d'une ou plusieurs espèces (Thiébault 2005), mais sur leur provenance extra-locale, leur calibrage et la saison d'abattage. Les feuilles prélevées avec leurs branches étaient récoltées juste avant l'automne (août, septembre). Elles étaient séchées plus stockées dans les chalets pastoraux pour être distribuées aux bestiaux durant les derniers mois de l'estive (mi-octobre au plus tard) ou consommées l'année suivante pour les bêtes en stabulation. Un autre scénario est possible. Les feuilles étaient récoltées puis distribuées vertes au troupeau qui, à cette période, a habituellement quitté les très hauts pâturages (2300-2500 m d'altitude) pour retrouver les prairies occupées au début de l'estivage entre 1900 et 2000 m. Les brindilles non consommées étaient conservées et stockées dans les chalets pour alimenter le foyer la saison suivante. Cette phase de stockage est attestée par les fortes proportions de parasites saprophages reconnus dans les tissus ligneux (Py 2009).

Les pratiques de production de bois de feu enregistrées à Fangeas VI répondent à d'importantes transformations forestières générées par deux fronts simultanés d'exploitation au Moyen Âge central: la mine et l'agropastoralisme.

\subsubsection{Les données de l'anthracologie minière (voir fig. 1)}

$\mathrm{Au} \mathrm{X}^{\mathrm{e}}$ s., les mineurs ont exploité pour la production de bois de chauffe destiné à l'abattage de la roche (Ancel, Py 2008), des boisements dominés par Larix-Picea et Pinus cembra. À lui seul, Larix-Picea compose presque 80 pour cent du combustible. La comparaison des spectres anthracologiques miniers et du spectre issu d'une couche d'incendie associée à une phase importante d'ouverture du paysage, suggère un approvisionnement local aux alentours de 2100 m d'altitude. L'absence dans les spectres de Pinus type $P$. sylvestris, composante des forêts de hauts ligneux subalpines, suggérerait un approvisionnement localisé à l'ubac où Larix-Picea tient une place dominante. Les forêts exploitées par les mineurs sont surmontées, voire morcelées, par les pelouses subalpines gagnées sur les boisements par le feu. Elles confrontent les terroirs agrosylvopastoraux sur prés bois (Durand 2004).

De l'an mil au XII s., phase qui connaît un franc développement de l'activité minière à Fangeas comme à Faravel, le territoire d'approvisionnement des mineurs est ancré dans la forêt subalpine. Larix-Picea y domine en fournissant jusqu'à 90 pour cent du bois de chauffe. Les pins de montagne et particulièrement le Pin cembro chutent sous la barre des pour cent. À en juger par ces résultats, cette espèce est en voie d'extinction dans l'étage subalpin d'ubac où les mineurs paraissent s'approvisionner exclusivement. L'omniprésence de Larix-Picea dans les résidus de foyers d'abattage peut révéler de façon indirecte la morphologie morcelée des boisements exploités. Ce postulat est confirmé par la palynologie qui enregistre aux $\mathrm{XI}^{\mathrm{e}}-\mathrm{XII}{ }^{\mathrm{e}} \mathrm{S}$. une chute vertigineuse des taux de pollens de Pins (Walsh, Richer, De Beaulieu 2006). Les prairies d'altitude morcelées et/ou délimitées de landes et de zones boisées composées presque exclusivement de Larix-Picea dominent. L'étendue du territoire d'approvisionnement est difficilement évaluable. L'absence de taxons montagnards plaide pour un approvisionnement local à extra-local, mais toujours subalpin entre 1800 et $2200 \mathrm{~m}$ d'altitude.

La période comprise entre la deuxième moitié du $\mathrm{XI}^{\mathrm{e}}$ et la première moitié $d u X^{2}{ }^{e} \mathrm{~s}$. correspond à une recrudescence du Pin cembro, notamment dans les secteurs miniers situés à $2100 \mathrm{~m}$ d'altitude. Ses fréquences atteignent 20 pour cent à Faravel I. Lors de cette campagne de travaux, les boisements exploités seraient donc plutôt situés au-delà de $2100 \mathrm{~m}$ d'altitude. L'apparition de Pinus type $P$. sylvestris et le spectre atypique à Genévriers et Raisin d'ours de la Tranchée Amont, excavée entre la deuxième moitié du $\mathrm{XI}^{\mathrm{e}} \mathrm{s}$. et la fin du XII ${ }^{\mathrm{e}} \mathrm{s}$., appuie l'hypothèse d'une extension $\mathrm{du}$ territoire d'approvisionnement vers les hauts versants d'adret fortement ouverts et dégradés. Ce changement des stratégies d'approvisionnement s'expliquerait par l'ampleur des ponctions opérées entre 1900 et 2100 m et par un abaissement de la limite supérieure de la forêt dense dominée par Larix-Picea. En effet, la courbe pollinique de ce taxon s'infléchit nettement entre les $\mathrm{XI}^{\mathrm{e}}-\mathrm{XII}^{\mathrm{e}} \mathrm{s}$. Ces résultats sont a priori en contradiction avec le diagramme pollinique où les fréquences du Pin cembro sont alors anecdotiques. Or, les travaux pédoanthracologiques de B. Talon et A. Ali dans les Alpes du Sud ont révélé la présence généralisée de 
charbons de bois de Pin cembro et de Mélèze dans les sols jusqu'à $2900 \mathrm{~m}$ d'altitude. L'interprétation des données palynologiques où la limite supérieure des grands arbres avait été sous-estimée a été révisée (Talon, Carcaillet, Thinon 1998; Ali et al. 2003a). Cette divergence doit être attribuée au décalage qui existe entre la limite altitudinale des arbres producteurs de pollens et la limite de développement potentiel des espèces ligneuses, où les individus, souvent prostrés, se reproduisent par voie végétative et plus difficilement par voie sexuée (Ali et al. 2003b; Carcaillet, Talon, Barbero 1998). La synthèse récente des données paléoenvironnementales de six sites des Alpes internes françaises met en évidence l'existence passée de cembraies denses entre 2000 et 2250 m d'altitude (Muller et al. 2006). Ces résultats corroborés par ceux de l'anthracologie minière dans le massif des Écrins précisent les modalités d'approvisionnement en bois minier. L'intense pression agropastorale et minière dans les terroirs situés entre 1900 et $2200 \mathrm{~m}$ d'altitude ont conduit les mineurs à exploiter des boisements «préservés » en zone supraforestière au-delà de $2200 \mathrm{~m}$. Le Pin cembro a survécu en altitude durant le Moyen Âge central. Ce postulat confirme les déductions d'A. Durand dans le Haut-Champsaur à des altitudes comprises entre 2100 et 2300 m. Dans certains secteurs pastoraux, le Pin cembro, mêlé à Pinus type $P$. sylvestris, est même encore très largement dominant au $\mathrm{XI}^{\mathrm{e}}$ début du XIII ${ }^{\mathrm{e}}$ S. (Durand 2004). Durant la première moitié du XIII ${ }^{\mathrm{e}} \mathrm{s}$, , période probablement à rattacher à une ultime phase de recherche minière médiévale, la quête de combustible dans les hauteurs, amorcée au XI ${ }^{\mathrm{e}}-\mathrm{XII}^{\mathrm{e}}$ s., s'accentue de façon franche. Les Pins de haute montagne, Pinus cembra et Pinus type $P$. sylvestris, composent plus de la moitié du combustible utilisé. Leurs rapports de proportions indiquent même leur sursélection par rapport à Larix-Picea. Le territoire d'approvisionnement paraît presque exclusivement tourné vers les derniers massifs boisés d'altitude (ravins, combes ?). La strate arborée de la limite supraforestière serait alors constituée de pins cembro mélangés au Mélèze et/ou Épicéa et à Pinus type P. sylvestris. Cette interprétation est encore une fois parfaitement corroborée par la palynologie qui enregistre l'extinction du mélézin entre 1900 et $2100 \mathrm{~m}$ d'altitude (Walsh, Richer, De Beaulieu 2006). Les données anthracologiques ne révèlent aucun transport de bois provenant de l'étage montagnard ou du fond de la vallée. La présence du Pin cembro, dont les fréquences sont variables en fonction des stratégies d'approvisionnement, est un indice fiable. Les mineurs, après avoir ponctionné le mélézin subalpin, ont cherché leur combustible toujours plus haut en altitude. Ils ne se rabattent que de façon très marginale sur les ligneux bas. D'abord localisé dans les massifs forestiers subalpins d'ubac, le territoire d'approvisionnement s'étire progressivement vers les derniers bouquets d'arbres de la zone supraforestière, en ubac comme en adret. On peut avancer comme hypothèse au XIII $\mathrm{s}$. un parcours et un débardage des bois pour la chauffe sur 100 à $300 \mathrm{~m}$ de dénivelé au-dessus des sites d'extraction alors qu'au X $\mathrm{X}^{\mathrm{e}}$ s., les mineurs s'approvisionnaient in situ.

\subsection{Le Haut-Champsaur (voir fig. 2)}

L'omniprésence du Pin cembro dans les boisements de la haute montagne de Dormillouse au Moyen Âge central trouve des échos dans certaines vallées du HautChampsaur à la même époque. Cette espèce figure dans le territoire d'approvisionnement en bois de feu domestique de presque tous les sites pastoraux étudiés situés au-dessus de $2000 \mathrm{~m}$ d'altitude (Cabane du Cheval de bois, Cabane du Clot Lamiande II, Cabane de Chapeau Roux, Cabane du Clos de la Valette II), fouillés par l'équipe de J. M. Palet (Palet-Martinez, Ricou, Segard 2003).

L'Arolle dominait à l'âge du Bronze ancien-moyen la strate arborée du petit plateau de Jujal dans la commune d'Orcières, situé à $2140 \mathrm{~m}$ d'altitude (Palet et al. 2003, p. 204 et suiv.; Py 2009). Une partie du corpus anthracologique issu d'une couche riche en charbons interprétée comme un niveau d'incendie (?), probablement anthropique, révèle un approvisionnement et/ou un milieu riche en feuillus (Acer, Fraxinus, Salix, cf. Rosacées-Rosoidées) typiques d'une station fraîche, humide et de demi-ombre, comme les fourrés et les lisières forestières. Les fortes fréquences de Juniperus indiquent quant à elles un apport d'une station sèche et ouverte de type clairière, probablement d'adret. L'ensemble de la flore caractérisée participe, comme à Faravel à la même époque, à la reconstitution d'un paysage de pré-bois. À l'âge du Bronze moyen-final, peut-être consécutivement à une première phase de déboisement suspectée par l'archéologie (niveau d'incendie), le Mélèze et/ou Épicéa dont les fréquences augmentent de façon très significative, infiltre la cembraie, mais l'Arolle reste toujours dominant. La présence de l'Érable (Acer), loin d'être anecdotique, qui peut paraître incongrue, ne l'est pourtant pas totalement. Ce taxon a déjà été identifié à SaintMichel-de-Maurienne à $2360 \mathrm{~m}$ d'altitude, à plus de $500 \mathrm{~m}$ au-dessus de son actuelle limite. Il peut s'agir de l'Érable sycomore, pouvant s'infiltrer à la base de l'étage subalpin (1800 m d'alt.) sous certaines conditions, notamment d'adret (Carcaillet 1996, p. 91 ; Carcaillet, Talon, Barbero 1998).

Entre la fin du VIII ${ }^{\mathrm{e}}$ s.-an mil et les XI ${ }^{\mathrm{e}}$-XII ${ }^{\mathrm{e}}$ s., à la même altitude, aux alentours du site de la cabane du Clot Lamiande II (Cne de Saint-Jean-Saint-Nicolas), les formations forestières sont dominées par un peuplement mixte à Larix-Picea et Pinus cembra. Le Mélèze et/ou Épicéa progresse lentement au détriment de l'Arolle et du Pin de type P. sylvestris dont les fréquences deviennent très réduites. Il se comporte en colonisateur, favorisé par les pratiques pastorales. 
2400 m d'alt.

Diagramme du site de la Cabane du Cheval de bois (Cne Champoléon) - 2357 m d'alt.

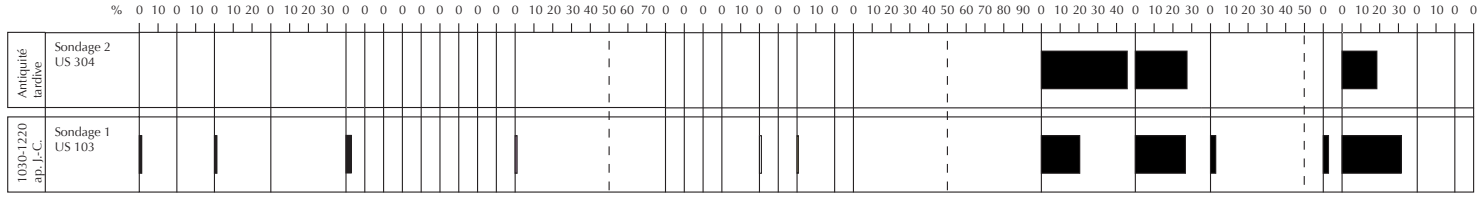

Diagramme du site de la Cabane de Chapeau Roux (Prapic, Cne Orcières) - 2340 m d'alt.

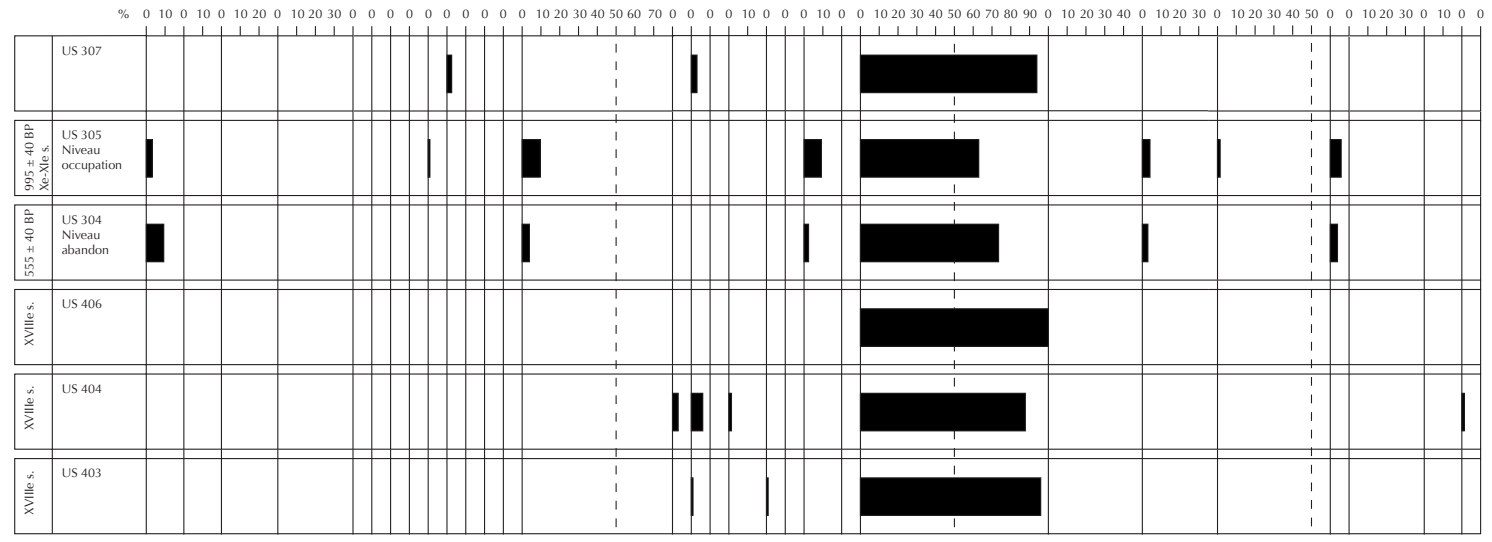

2200 m d'alt.

Diagramme du site de la Cabane de La Barre (Cne Orcières) - 2200 m d'alt.

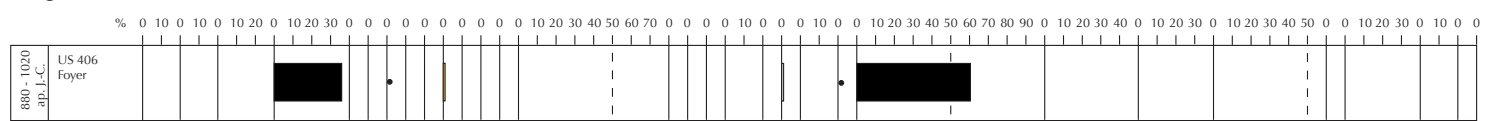

Diagramme du site de Jujal (Prapic, Cne Orcières) - 2140 m d'alt.

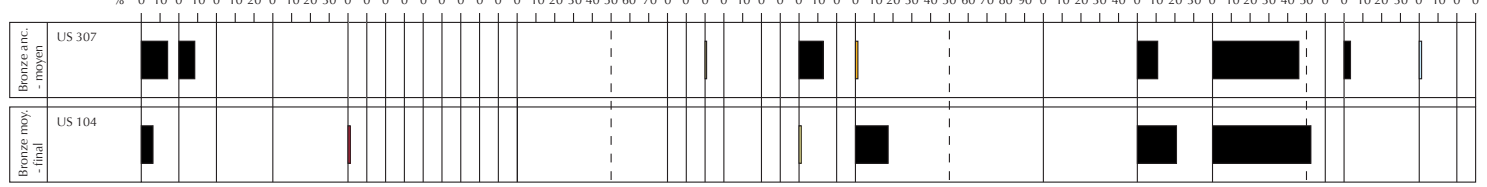

Diagramme du site du Clot Lamiande II (Cne Champoléon) - 2140 m d'alt.

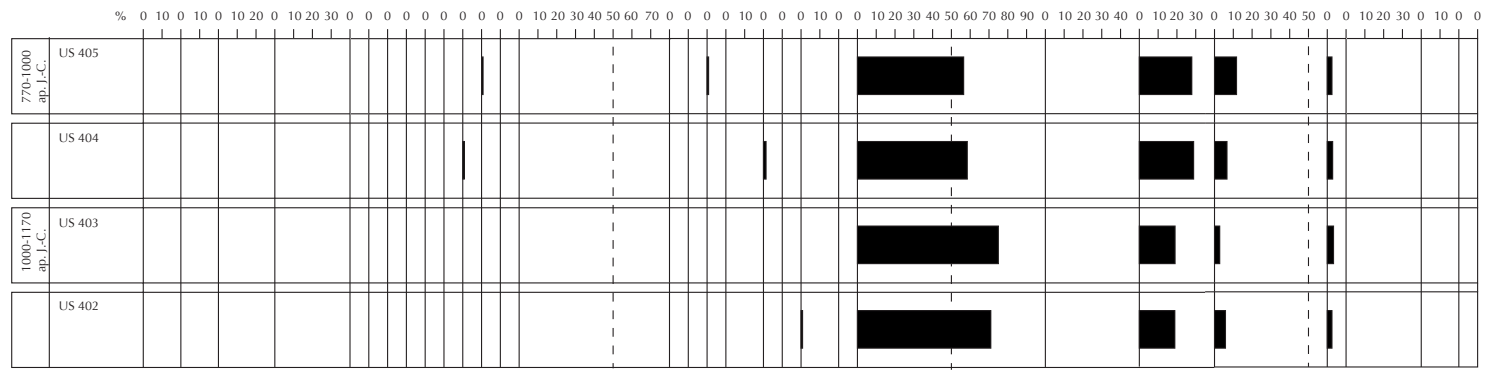

$2000 \mathrm{~m}$ d'alt

Diagramme du site du Jas des Provençaux (Cne Champoléon) - 1970 m

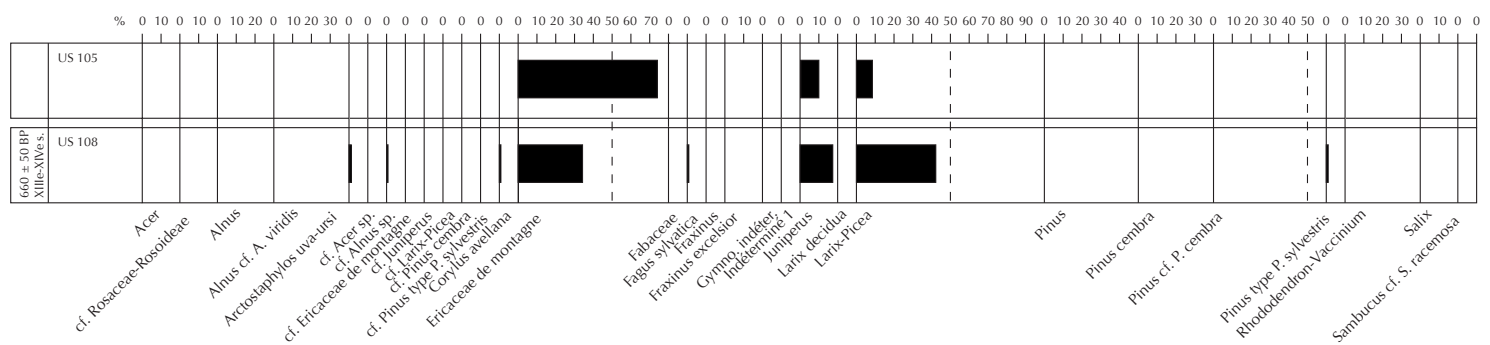

Légende:

$-<0,5 \%$

(

Gymno. indéter. = Gymnosperme indéterminable

Réalisation V. Py 2009

Analyses A. Durand et V. Py 2002-2009

Fig. 2. Diagramme anthracologique de synthèse du Haut-Champsaur. 
Plus haut en altitude, à $2357 \mathrm{~m}$, aux alentours du site pastoral du Cheval de Bois (Cne de Champoléon), sis à l'ubac, l'Arolle et le Pin de type $P$. sylvestris associés à des Éricacées de montagne composent les éléments ligneux majeurs des forêts de très haute altitude aux $\mathrm{XI}^{\mathrm{e}}-\mathrm{XIII} \mathrm{I}^{\mathrm{e}} \mathrm{s}$. Les fortes proportions d'Éricacées sont synonymes d'ouverture forestière autour de la cabane. Le territoire d'approvisionnement en bois de feu des bergers paraît à cheval sur la limite supérieure de la forêt et sur la zone de combat dominée par des landes à Rhododendrons et à Myrtilles à l'ubac et à Genévriers et Raisins d'ours à l'adret. L'absence notable du Mélèze et/ou Épicéa dans le combustible utilisé peut être interprétée comme un indice du caractère relativement préservé des derniers massifs forestiers d'altitude de cette haute vallée au Moyen Âge. Cette hypothèse est corroborée par l'absence d'enregistrement archéologique antérieur à cette date, mais on ne peut pas totalement exclure le résultat d'une politique de préservation de ces massifs d'altitude au Moyen Âge central. Quoi qu'il en soit, ces données exceptionnelles posent le problème des cycles de régénération potentielle de la cembraie sur la longue durée et mettent en évidence l'hétérogénéité de l'évolution des écosystèmes de haute montagne à l'échelle du massif.

Les investigations anthracologiques du site de Chapeau Roux (Cne d'Orcières), situé à 2340 m d'altitude au-dessus du hameau de Prapic, illustrent cette idée. Contrairement au site précédent, les formations forestières arborescentes présentes dès les $\mathrm{X}^{\mathrm{e}}-\mathrm{XI}^{\mathrm{e}}$ s. sont dominées par le spectre du mélézin et/ou pessière associé au Pin de type $P$. sylvestris et à l'Arolle dont l'importance, souvent sous-estimée, a été mise en lumière par les recherches queyrassines récentes (Ali et al. 2003a; 2003b). On note la présence de l'Érable dont l'extension inattendue, dès la protohistoire et jusqu'au Moyen Âge, plusieurs centaines de mètres au-dessus de sa limite actuelle, est maintenant confirmée en Haut-Champsaur. Le spectre du Pin cembro, très discret et les fortes fréquences des landes à Éricacées et à Genévriers attestent, contrairement au fond de la vallée de Champoléon, l'ancienneté de la pression anthropique dans cette zone d'alpage toujours fréquentée par les troupeaux. $\mathrm{Au} \mathrm{XVIII'}$ s., l'Arolle, déjà survivant au Moyen Âge, est totalement éradiqué au profit du seul mélézin et/ou pessière dont la densité, en dépit de ses fréquences relatives élevées dans le diagramme, doit être fort faible puisqu'on note la disparition des landes ouvertes et l'apport d'essences montagnardes; Frêne, Hêtre, Sureau et le ou les Fabacée(s), récoltées par les bergers sur le trajet de l'estive. Cette pratique, attestée dans la montagne de Dormillouse à la fin du Moyen Âge-début de l'époque moderne, était probablement déjà usitée par les bergers de la vallée du Tourond, dans la commune de Champoléon, qui ont occupé entre la fin du XII et le XIV ${ }^{\mathrm{e}}$ s. le site pastoral du Jas des Provençaux à 1970 m d'altitude. La flore identifiée, datée du Moyen
Âge central, est dominée par Larix-Picea et par les landes à Éricacées et à Genévriers, prépondérantes dans les dépôts datés des XIII-XIV ${ }^{\mathrm{e}}$ s. Elle est associée au Hêtre et au Noisetier, taxons typiquement montagnards, jamais identifiés dans les autres prélèvements anthracologiques champsaurins médiévaux et/ou antérieurs au XIV ${ }^{\mathrm{e}} \mathrm{s}$. Le recours à cette pratique doit être interprété comme dans la HauteDurance à un manque cruel de combustible à $2000 \mathrm{~m}$ d'altitude. Rien d'étonnant pour les hautes vallées qui ont été privilégiées pour le pastoralisme dès la protohistoire comme dans la vallée du Drac noir à Orcières. Le spectre anthracologique du site de la cabane de la Barre (Cne d'Orcières) situé à $2200 \mathrm{~m}$ d'altitude, daté de la fin du IXe-début du XI ${ }^{\mathrm{e}}$ s., est en ce sens significatif. Il est partagé entre deux taxons pionniers: Larix-Picea et Alnus viridis. Trop unicolore compte tenu de la concentration des dépôts charbonneux, il dessine néanmoins les grands traits du paysage ligneux au tournant de l'an mil, dominé en adret comme en ubac par des formations de reconquête, indicatrices de profonds bouleversements des écosystèmes dès avant cette fourchette chronologique. Les essences identifiées présentant toutes deux un attrait pastoral; l'une comme espace de pacage en sous-bois, l'autre comme complément nutritif, ont pu être entretenues et gérées par les agropasteurs.

Dans le Haut-Champsaur, comme dans la Haute-Durance, depuis la protohistoire, le Pin cembro apparaît dans son aire naturelle de répartition entre 2200-2300 et 2400 m d'altitude. Or, ses fréquences diminuent nettement au-dessous de $2200 \mathrm{~m}$ d'altitude où Larix-Picea prend le relais. Les données anthracologiques précisent le rôle important tenu par le Pin cembro encore aux $\mathrm{X}^{\mathrm{e}}-\mathrm{XI}^{\mathrm{e}} \mathrm{s}$., notamment au-dessus de $2200 \mathrm{~m}$ d'altitude. En revanche, passé le XIII ${ }^{\mathrm{e}}$ s., il se fait en général plus discret, y compris au-dessus de cette limite altitudinale. Mais, ce scénario n'est pas la règle car on note la survivance de massifs d'altitude encore fournis jusqu'au Moyen Âge central. Les charbons de bois archéologiques ont enregistré la phase ultime, médiévale, d'extension de l'essence en altitude, puis sa régression, postérieure à l'installation des terroirs d'estive autour de l'an mil. Ils confirment que le déboisement de la cembraie entre 2000 et $2200 \mathrm{~m}$ d'altitude au profit de Larix-Picea est antérieure à cette époque. Ainsi, à Chapeau Roux (2340 m), aux X $\mathrm{X}^{\mathrm{e}}$ $\mathrm{XI}^{\mathrm{e}}$ s., ou au Jas des Provençaux, à la fin du XIII ${ }^{\mathrm{e}}$ s.-début du $\mathrm{XIV}^{\mathrm{e}}$ s. (1970 m), et à Fangeas-Faravel à la fin du Moyen Âge-début de l'époque moderne (2000-2200 m), l'Arolle est absent ou très faiblement représenté. Les phases d'éclaircissement majeures de ces peuplements datent du $\mathrm{X}^{\mathrm{e}}-\mathrm{XI}^{\mathrm{e}}$ s., à la base de l'étage subalpin, puis du Moyen Âge central, dans toute l' ancienne tranche altitudinale subalpine sylvatique. Corrélativement à ce mouvement de fond, les landes à Éricacées progressent pour, lorsque l'évolution se poursuit continûment, envahir l'espace au détriment du mélézin comme au Jas des Provençaux. 


\section{Conclusion/synthèse : interactions et divergences des modalités d'approvisionnement minières et agropastorales}

Les résultats anthracologiques acquis sur la haute montagne médiévale soulignent tous l'hétérogénéité des paysages et des terroirs sud-alpins en fonction de l'altitude, de l'exposition et du type de gestion mis en œuvre (minière, agropastorale, etc.): quelques centaines de mètres, voire même moins qu'une centaine de mètres, suffisent pour que l'environnement soit différent et exploité différemment. Entre le $\mathrm{X}^{\mathrm{e}}$ et le XIII ${ }^{\mathrm{e}} \mathrm{s}$, ils confirment aussi la place importante, trop longtemps sous-estimée, du Pin cembro au sein des formations forestières et entérinent sa progressive disparition au profit soit du Mélèze et/ou Épicéa qui se comporte alors comme un véritable bouche-trou soit de landes et landines à Éricacées. Passé le XIII s., l'ouverture du milieu s'accentue, surtout au-dessus de $2200 \mathrm{~m}$. Cependant, mineurs et agro-pasteurs ne gèrent pas leur environnement de manière identique: les premiers privilégient les ligneux arborescents subalpins et supraforestiers en marginalisant les petits ligneux bas et arbustifs collectés par les seconds aux côtés des grands résineux pour alimenter leur foyer domestique, particulièrement dans les boisements de reconquête repliés sous la barre des 2000 $\mathrm{m}$. Les observations développées sur la morphologie et l'anatomie du bois vont dans le même sens : à Fangeas, aux $\mathrm{XI}^{\mathrm{e}}-\mathrm{XII}{ }^{\mathrm{e}} \mathrm{s}$., les bois (Larix-Picea) non carbonisés (quartiers courts) destinés à la chauffe des fronts de taille sont débités dans des billes âgées de 75-100 à 150-200 ans et rares sont les charbons issus de feux d'abattage présentant des cernes d'accroissement courbés synonymes de branches ou de brindilles durant toutes les phases d'exploitation ( $\mathrm{X}^{\mathrm{e}-}$ $\mathrm{XIII}^{\mathrm{e}} \mathrm{s}$.). Au contraire, la récolte de ligneux arbustifs de très faibles calibres $(0,2$ et $2,5 \mathrm{~cm}$ de diamètres) paraît favorisée pour approvisionner le foyer domestique des pasteurs alors que cette pratique est marginale en contexte minier. Ainsi les mineurs arpentent les sommets à la recherche de boisements de reconquête matures à âgés, principalement au-delà de 2200-2300 m d'altitude. Ils coupent ponctuellement les jeunes individus pour boiser et étayer les galeries, mais les préservent dans un souci de régénération et de rentabilité sur la longue durée. Ainsi les boisements où s'approvisionnent les mineurs comprennent plusieurs groupements d'âge. Les agropasteurs se contentent d'y glaner du bois mort ou des branchages et y pratiquent vraisemblablement le pacage sous forêt au-dessous de 2000-2 $100 \mathrm{~m}$. Seules les forêts cultivées pour la production de bois d'œuvre se composent d'individus proches en âge et en calibre.

\section{Bibliographie}

Ancel, Py 2008: ANCEL (B.), PY (V.) - L'abattage par le feu: une technique minière ancestrale. Archeopage, $\mathrm{n}^{\circ} 22$, « Mines et carrières », juillet 2008, p. 34-41.

Ali et al. 2003a: ALI (A.), CARCAILLET (C.), GUENDON (J.-L.), QUINIF (Y.), ROIRON (P.), TERRAL (J.-F.) - The early Holocene treeline in the southern French Alps: new evidence from travertine formations. Global Ecology \& Biogeography, 12, 2003, p. 411-419.

Ali et al. 2003b : ALI (A.), GUENDON (J.-L.), TERRAL (J.-F.), ROIRON (P.) - Les systèmes travertineux holocènes et les paléopaysages méditerranéens et subalpins (France): une analyse géobotanique séquentielle à haute résolution spatiale. Géographie physique et Quaternaire, vol. 57, n 2-3, 2003, p. 219-235.

Carcaillet 1996: CARCAILLET (C.) - Évolution de l'organisation spatiale des communautés végétales d'altitude depuis 7000 BP dans la vallée de la Maurienne (Alpes de Savoie, France): une analyse pédoanthracologique. Thèse de l'Université d'Aix-Marseille III, 2 vol., 170 p.

Carcaillet, Talon, Barbero 1998 : CARCAILLET (C.), TALON (B.), BARBERO (M.) - Pinus cembra et incendies pendant l'holocène, $300 \mathrm{~m}$ au-dessus de la limite actuelle des arbres dans le massif de la Vanoise (Alpes du nord-ouest). Écologie, t. 29,1998 , p. $277-282$

Court-Picon 2003: COURT-PICON (M.) - Approches palynologique et dendrochronologique de la mise en place du paysage dans le Champsaur (Hautes-Alpes, France) à l'interface des dynamiques naturelles et des dynamiques sociales. Thématique, méthodologie et premiers résultats. Archéologie du Midi Médiéval, 21, 2003, p. 211-224.

De Beaulieu et al. 2003 : DE BEAULIEU (J.-L.), LEVEAU (P.), MIRAMONT (C.), PALET (J. M.), WALSH (K.), COURTPICON (M.), RICOU (F.), SEGARD (M.), SIVAN (O.), ANDRIEU-PONEL (V.), BADURA (M.), BERTUCCHI (G.), BOUTTERIN (C.), DURAND (A.), ÉDOUARD (J.-L.), LAVOIE (M.), MORIN (A.), MOCCI (F.), PONEL (P.), POTHIN (A.), PY (V.), TALON (B.), TZORTZIS (S.), BONET (R.), COLUMEAU (P.), CORTOT (H.), GARCIA (D.) - Changements environnementaux postglaciaires et action de l'homme dans le basin du Buëch et en Champsaur (Hautes-Alpes, France). Premier bilan d'une etude pluridisciplinaire. In: MUXART (T.), VIVIEN (F.-D.), VILLALBA (B.), BURNOUF (J.) éd., Des milieux et des hommes : fragments d'histoires croisés, Elsevier SAS, 2003, p. 93-101.

Durand 2004: DURAND (A.) - Du paysage à la pratique des gestes à l'environnement: essai d'approches croisées sur les systèmes agraires en France méridionale et en Catalogne $\left(I X^{e}-X V^{e}\right.$ s.). Habilitation à diriger les recherches, Université d'Aix-Marseille I, 2004, I, 230 p., II, p. 233-533. 
Durand, Py 2008: DURAND (A.), PY (V.) - L'évolution des écosystèmes dans le Haut-Champsaur et la montagne de Dormillouse (Hautes-Alpes, France) au crible des charbons de bois archéologiques. In: BERNARDI (P.) dir., Forêts alpines et charpentes en Méditerranée, L'Argentière-laBessée, éditions du Fournel, 2008, p. 32-35.

Leveau 2003: LEVEAU (P.) - Les recherches sur la montagne haut alpine à la Maison méditerranéenne des Sciences de l'Homme. Archéologie du Midi médiéval, t. 21, Dossier spécial montagne, 2003, p. 183-184.

Leveau, Segard 2004 : LEVEAU (P.), SEGARD (M.) - Le pastoralisme en Gaule du Sud entre plaine et montagne: de la Crau aux Alpes du Sud. Pallas, 2004, 64, p. 99-113.

Muller et al. 2006: MULLER (S. D.), NAKAGAWA (T.), DE BEAULIEU (J.-L.), COURT-PICON (M.), FAUQUETTE (S.), GENRIES (A.) - Paléostructures de végétation à la limite supérieure des forêts dans les Alpes françaises internes. Comptes Rendus Biologies, 329, 2006, p. 502-511.

Palet-Martinez, Ricou, Segard 2003: PALET-MARTINEZ (J. M.), RICOU (F.), SEGARD (M.) - Prospections et sondages sur les sites d'altitude en Champsaur (Alpes du sud). Archéologie du Midi médiéval, t. 21, Dossier spécial montagne, 2003, p. 199-210.

Py 2005: PY (V.) - Coste de Tonis I (Freissinières). Bulletin Scientifique du SRA PACA 2004, SRA PACA, Aix-enProvence, 2005, p. 59-61.

Py 2006a: PY (V.) - Mine charcoal deposits: methods and strategies. The medieval Fournel silver mines in the Hautes-Alpes (France). In: DUFRAISSE (A.) éd., Firewood economy: analytical tools and methods. News datas for archaeology and study of societis, techniques and land uses, Papers from the Table-Ronde held in Basel, 14-15 octobre 2004, British Archaeological Reports, 2006, p. 35-46.

Py 2006b: PY (V.) - Structures agropastorales de Fangeas (Freissinières). Bulletin Scientifique du SRA PACA 2005, SRA PACA, Aix-en-Provence, 2006, p. 58.

Py 2009: PY (V.) - Mine, bois et forêt dans les Alpes du Sud au Moyen Âge. Thèse de doctorat, Université d'Aix-Marseille I, 2009.

Py, Ancel 2007 : PY (V.), ANCEL (B.) - Exploitation des mines métalliques de la vallée de Freissinières (Hautes-Alpes, France): Contribution à l'étude de l'économie sud-alpine aux $\mathrm{IX}^{\mathrm{e}-\mathrm{XIII}}{ }^{\mathrm{e}} \mathrm{s}$. In : DELLA CASA (P.), WALSH (K.) éd., Actes de la session montagne « Interpretation of sites and material culture from mid-high altitude mountain environments », colloque de l'European Association of Archaeologists, Lyon, septembre 2004, Preistoria Alpina, 42, 2007, p. 83-93.

Segard 2009: SEGARD (M.) - Les Alpes occidentales romaines. Développement urbain et exploitation des ressources des régions de montagne (Gaule Narbonnaise, Italie, provinces alpines). Aix-en-Provence, Centre Camille Jullian,
Paris, Errance, 2009, 287 p., (Bibliothèque d'archéologie méditerranéenne et africaine, 1).

Talon, Carcaillet, Thinon 1998: TALON (B.), CARCAILLET (C.), THINON (M.) - Études pédoanthracologiques des variations de la limite supérieure des arbres au cours de l'holocène dans les Alpes françaises. Géographie physique et Quaternaire, 52, 2, p. 195-208.

Thiébault 2005 : THIÉBAULT (S.) - L'apport du fourrage d'arbre dans l'élevage depuis le Néolithique. Anthropozoologica, 40 (1), 2005, p. 95-108.

Tzortzis et al. 2008: TZORTZIS (S.), MOCCI (F.), WALSH (K.), TALON (B.), COURT-PICON (M.), DUMAS (V.), PY (V.), RICHER (S.) - Les massifs de l'argentiérois du mésolithique au début de l'Antiquité: au croisement des données archéologiques et paléoenvironnementales en haute montagne (Hautes-Alpes, Parc National des Écrins). In: Le peuplement de l'arc alpin, Paris, CTHS, 2008, p. 123-148.

Walsh 1999: WALSH (K.) - Sondages archéologiques sur les structures pastorales de Faravel VIIId et XIII. Document Final de Synthèse, juillet 1999, 31 p.

Walsh et al. 2003: WALSH (K.), MOCCI (F.), avec la collaboration de DUMAS (V.), DURAND (A.), TALON (B.), TZORTZIS (S.) - 9000 ans d'occupation du sol en moyenne et haute montagne: la vallée de Freissinières dans le Parc National des Écrins (Freissinières, Hautes-Alpes). Archéologie du Midi médiéval, t. 21, Dossier spécial montagne, 2003, p. 185-198.

Walsh et al. 2005 : WALSH (K.), MOCCI (F.), COURT-PICON (M.), PALET-MARTINEZ (J.-M.), TZORTZIS (S.), DUMAS (V.), PY (V.), SEGARD (M.), TALON (B.) - Dynamique du peuplement et activités agro-pastorales durant l'Âge du Bronze dans les massifs du Haut-Champsaur et de la vallée de Freissinières (Hautes-Alpes, Parc National des Écrins). Documents d'archéologie méridionales, 28, p. 25-44.

Walsh, Mocci, Palet-Martinez 2007: WALSH (K.), MOCCI (F.), PALET-MARTINEZ (J.-M.). - Nine thousand years of human/lanscape dynamics in a high altitude zone in the southern French Alps (Parc National des Écrins, Hautes-Alpes). In : DELLA CASA (P.), WALSH (K.) éd., Actes de la session montagne «Interpretation of sites and material culture from mid-high altitude mountain environments », colloque de l'European Association of Archaeologists, Lyon, septembre 2004, Preistoria Alpina, 42, 2007, p. 9-22.

Walsh, Richer, De Beaulieu 2006: WALSH (K.), RICHER (S.), DE BEAULIEU (J.-L.) - Attitudes to altitude: changing meanings and perceptions within a « marginal » Alpine landscape - the integration of palaeoecological and archaeological data in a high-altitude landscape in the French Alps. World Archaeology, vol. 38(3), Archaeology at Altitude, Taylor \& Francis, 2006, p. 436-454. 


\title{
Les anciennes mines métalliques des Alpes du Sud : bilan diachronique
}

\author{
Bruno ANCEL*
}

\begin{abstract}
Résumé. La région montagneuse des Alpes n'est pas à proprement parler une région minière. De tout temps, beaucoup d'indices métallifères ont été prospectés, parfois en suscitant de grandes désillusions, mais peu de gisements ont fait l'objet d'une véritable exploitation. En passant en revue ces petites et grandes mines, de la côte méditerranéenne à la Savoie, depuis la Protohistoire jusqu'au XX $X^{\text {e }}$ s., par des approches croisant la géologie, l'archéologie et l'histoire, il est possible de dégager certaines spécificités propres aux activités extractives, minéralurgiques et métallurgiques dans cet espace montagnard.
\end{abstract}

Ancient metal mining activity in the southern Alps: diachronic review

Abstract. The Alpine mountain region is not, strictly speaking, a mining area. Traditionally, many traces were explored for metals, sometimes with great disillusion, but few deposits became a real mining operation. In reviewing these mines, both small and large, from the Mediterranean coast to Savoy, and from protohistory until the twentieth century, by the combining of geological, archeological and historical approaches, it is possible to identify a specificity of mining activities in the mountainous regions.

$\mathrm{L}$ 'exploitation des ressources minières a marqué les Alpes dans son histoire et ses paysages. Cette problématique a été abordée sur le terrain d'abord par les géologues qui ont dressé des inventaires de gîtes minéraux (Pierrot, Picot, Poulain 1974; Picot et al. 1974) puis par des passionnés de minéralogie et d'histoire minière qui ont donné à ces enquêtes une dimension anthropologique (Legros 1979; Mari 1979; Mari, Mari 1982; Durand 2005). L'archéologie minière a démarré en 1977 avec la fouille du site médiéval de Brandes-en-Oisans (Bailly-Maître, BrunoDupraz 1994), et au début des années 1990 dans les Alpes du Sud avec les fouilles sur le site protohistorique des Clausis à Saint-Véran (Rostan, Gattiglia, Rossi 1995) et sur le site médiéval et d'époque contemporaine du Fournel à L'Argentière-la-Bessée (Ancel 2006d), accompagnées de nombreuses prospections thématiques ${ }^{1}$.

Les données géologiques actuelles recensent plusieurs centaines de gîtes minéraux dans les Alpes, dont plus de deux cents ont fait l'objet de travaux miniers (BRGM 1984). Cependant, au regard des critères modernes, seules quelques

1. Toutes ces opérations archéologiques ont fait l'objet de notes synthétiques consultables dans les Bilans Scientifiques des Services Régionaux de l'Archéologie PACA et Rhône-Alpes. dizaines de mines ont eu une production non négligeable et seuls trois gisements sont considérés comme ayant eu une importance nationale: les mines de bauxite de Provence, les mines de zinc et de plomb des Bormettes (Var) et de La Plagne (Savoie). Même les lignites de Gardanne (Bouchesdu-Rhône) sont considérés comme secondaires. Ainsi d'un point de vue des tonnages extraits, les Alpes ne sont pas comparables en taille aux autres complexes miniers de France (Massif Central, Pyrénées, Lorraine...), encore moins à ceux de l'Europe (Erzgebirge, Harz, Cornouailles, Transylvanie...).

\section{Protohistoire}

Plusieurs dizaines de gîtes cuprifères sont connus des géologues dans les Alpes du Sud, mais la plupart sont de très faible taille. Il est toujours possible d'émettre l'hypothèse que de tels micro-gisements aient été reconnus durant la protohistoire et qu'ils aient fourni quelques kilos de cuivre (Barge 2006a). Cependant une activité extractive aussi réduite a peu de chance d'avoir laissé des traces visibles aujourd'hui. Des suspicions d'activité minière très ancienne ont été émises pour les sites de Bancairon

* Service Culturel Municipal, Hôtel de Ville, 05120 L'Argentière-la-Bessée. 
(alt. $1050 \mathrm{~m}$ ) et de Clue de Roua (alt. $900 \mathrm{~m}$ ) dans les Alpes-Maritimes, de Maraval, du Peirol, de Cap Garonne et du Vieux-Cannet dans le Var (fig. 1), mais sans fouilles approfondies les arguments restent faibles (Barge 2006a; Ancel 2006e ; Lanza-Berthet 2006; Mari 1979; Mari, Mari 1982).

Le gisement des Clausis (alt. 2700 m) à Saint-Véran (Hautes-Alpes) a été le cadre d'une importante exploitation dès le Chalcolithique et durant le Bronze ancien. Un abri sous roche et une aire de métallurgie ont été fouillés (Rostan, Gattiglia, Rossi 1995; Barge 2006b). Les chantiers d'extraction anciens ont été reconnus grâce aux travaux de la reprise moderne: ils s'étendent jusqu'à $40 \mathrm{~m}$ de profondeur sous l'affleurement et concernent environ $2000 \mathrm{~m}^{2} \mathrm{de}$ minéralisations (Ancel, Carré, Kammenthaler 2006). Par manque d'une logistique suffisante, ces extraordinaires vestiges souterrains n'ont pas encore fait l'objet d'une fouille en règle ${ }^{2}$. Plus au nord, dans le massif des Rousses (Isère), une importante exploitation protohistorique par tranchées à ciel ouvert est en cours d'investigations.

\section{Antiquité}

À en croire divers auteurs anciens et récents, il y aurait eu une vingtaine de mines romaines dans les Alpes occidentales (fig. 1). Mais tout cela repose sur des à priori qui, depuis le XIX ${ }^{\mathrm{e}} \mathrm{s}$, tendent à attribuer aux Romains des ouvrages anciens ayant un peu d'envergure. Ainsi, à L'Argentière (Hautes-Alpes), bien que la plupart des textes médiévaux avaient déjà été publiés, les préjugés de certains ingénieurs des mines lui ont attribué une origine antique qui a persisté jusqu'à nos jours (Ancel 2006a).

Actuellement nous avons des certitudes concernant une petite activité minière romaine dans le massif des Maures (Var): pour le cuivre à Collobrières, pour le fer à SaintMaxime et à l'Acate de Vaillas (Lanza-Berthet 2006). Le fer a été intensément exploité entre le $\mathrm{III}^{\mathrm{e}}$ et le $\mathrm{VI}^{\mathrm{e}} \mathrm{s}$. à Simiane (Alpes-de-Haute-Provence), à Prannes (Var) et à Tortissa (Alpes-Maritimes) d'après les datations de résidus métallurgiques (Morin, Rosenthal 2006). À Millefont (alt. 2400 m) dans la Tinée, l'activité remonterait à l'âge du Fer. L'essentiel des mines polymétalliques serait postérieur à l'Antiquité, excepté deux mines. Lors de travaux en 1828 dans la mine de plomb argentifère de Macôt-La Plagne (alt. 2000 m) en Tarentaise (Savoie) ont été recoupées de longues galeries anciennes comportant des chiffres romains gravés (Durand 2005). La mine de plomb du Pontet (alt. $900 \mathrm{~m}$ ) renferme un vieux chantier vertical, ouvert par le feu, et les datations ${ }^{14} \mathrm{C}$ indiquent une phase d'activité entre

2. Voir également la contribution de Carozza et al. dans le présent ouvrage.

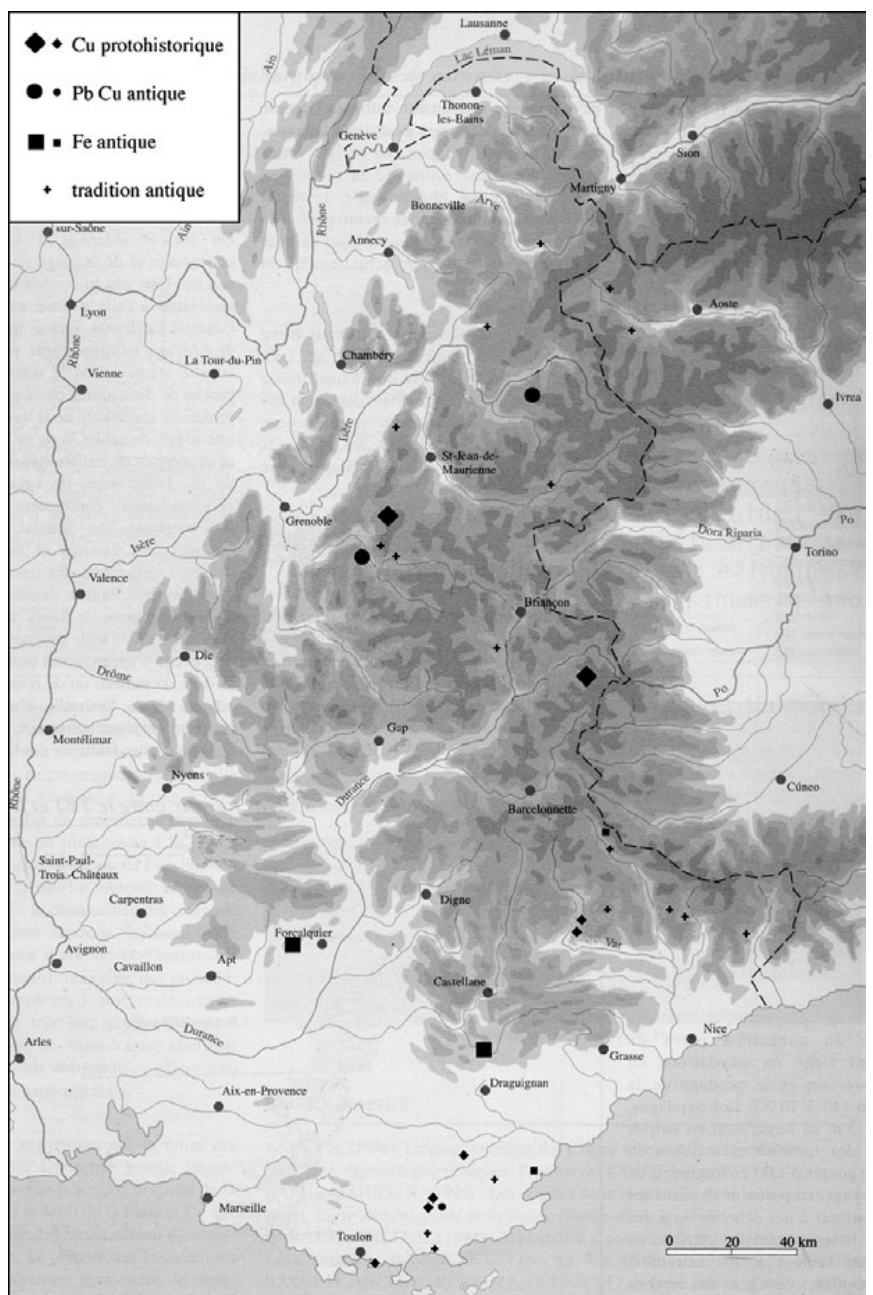

Fig. 1. Activités minières dans les Alpes durant la Protohistoire et l'Antiquité.

les $\mathrm{IV}^{\mathrm{e}}$ et $\mathrm{VII}^{\mathrm{e}} \mathrm{s}$. (Ancel, Dardignac 2008b), mais également aux $\mathrm{X}^{\mathrm{e}}$ et $\mathrm{XI}^{\mathrm{e}} \mathrm{s}$. Cela fait beaucoup pour une exploitation cantonnée à une surface de seulement $1200 \mathrm{~m}^{2}$ et l'on peut se demander si les dates les plus reculées ne sont pas faussées par des analyses réalisées sur des «vieux bois».

\section{Moyen Âge}

Les études historiques font apparaître, à partir du $\mathrm{XI}^{\mathrm{e}} \mathrm{s}$., de nombreuses mentions d'activités minières et métallurgiques (Bailly-Maître 2001; Dupraz 2004 ; Bailly-Maître, Dhénin 2004). Parfois les textes attestent d'une véritable exploitation, mais souvent il pourrait s'agir d'autorisations à prospecter une région. Pour certains cas, une confrontation sur un terrain bien lisible montre que des mynes mentionnées au Moyen Âge ne sont que des gîtes potentiels qui n'ont fait l'objet que de recherches très superficielles. Sur le terrain on reconnaît aujourd' hui une dizaine d'exploitations 
importantes et de nombreuses mines de faible envergure. Nous allons passer en revue du Sud vers le Nord les plus significatives d'entre elles (fig. 2).

Dans le massif des Maures (Var), le filon de plomb argentifère des Bormettes a été exploité depuis l'affleurement (alt. $78 \mathrm{~m}$ ) jusqu'au niveau de la mer. Des travaux anciens ont été retrouvés lors de la reprise moderne et ont été attribués, sans preuve, aux Phéniciens et aux Romains, alors que les textes mentionnent une activité minière dans cette région aux XIII ${ }^{\mathrm{e}}$ et $\mathrm{XIV}^{\mathrm{e}} \mathrm{s}$. Une galerie d'exhaure ouverte à la pointerolle et par le feu est encore accessible sur 90 m (LanzaBerthet 2006).

Dans les Alpes-Maritimes, le gîte de plomb argentifère de Vallauria (alt. $1550 \mathrm{~m}$ ) a été exploité vers les $\mathrm{XI}^{\mathrm{e}}-\mathrm{XII}^{\mathrm{e}} \mathrm{s}^{3}$ sur une étendue de 150 × $30 \mathrm{~m}$, par une succession de salles ouvertes par le feu, assistées d'un puits d'aérage central et d'une galerie d'exhaure monumentale (Ancel 1996 [1998]; Ancel 2001b). Dans la vallée de la Tinée, les petits gîtes de plomb argentifère de Tortissa (alt. 2100 à 2300 m) et de Caire Faraud (alt. 1800 m) sont exploités à l'affleurement par des tranchées ouvertes par le feu. Dans les HautesAlpes, le gisement du Fournel (alt. 1100 à 1400 m) à L'Argentière-la-Bessée a été exploité du X ${ }^{\mathrm{e}}$ au XIII ${ }^{\mathrm{e}} \mathrm{s}$. Cette vaste exploitation présente une organisation souterraine assez poussée, facilitée par l'escarpement des lieux (Ancel 1998 ; 2006a ; Ancel et al. sous presse). Les petits gîtes voisins de Faravel-Fangeas (alt. $2000 \mathrm{~m}$ ) sont exploités par des tranchées, aujourd'hui comblées et noyées, dans lesquelles les équipements en bois sont bien conservés (Py, Ancel 2007) ${ }^{4}$. Le fer a été exploité autour de la Chartreuse de Durbon et dans le Queyras (Morin, Rosenthal 2006).

En Isère, la grande exploitation du gisement de Brandes (alt. 1700 à $2600 \mathrm{~m}$ ) du XI $\mathrm{X}^{\mathrm{e}}$ au XIV ${ }^{\mathrm{e}} \mathrm{s}$. a suscité l'implantation d'un village minier, d'une église et d'une motte castrale (Bailly-Maître, Bruno-Dupraz 1994 ; Bailly-Maître 2002). La mine de plomb du Pontet (alt. $900 \mathrm{~m}$ ) est exploitée vers le $\mathrm{X}^{\mathrm{e}}-\mathrm{XI}^{\mathrm{e}} \mathrm{s}$. (Ancel, Dardignac 2008b). Vers le $\mathrm{X}^{\mathrm{e}}$ s. démarre l'activité des mines de fer de la région d'Allevard, quasi ininterrompue jusqu'au XX $X^{\mathrm{e}} \mathrm{s}$. En Savoie, l'exploitation de Saint-Georges-d'Hurtières (alt. $1400 \mathrm{~m}$ ) démarre pour le cuivre et l'argent vers le XIII ${ }^{\mathrm{e}} \mathrm{s}$. (Bailly-Maître, Dhénin 2004). L'extraction du plomb et du cuivre est pressentie aux mines de Colombière à Bramant, des Sarrazins près de Modane, de Montchabert à Argentine et du Nantuel à Montvernier.

3. Pour cette mine, comme pour beaucoup d'autres dans les Alpes, certains auteurs ont imaginé une exploitation par les Sarrasins, sans le moindre début de preuve.

4. Voir également la contribution de Py et Durand dans le présent ouvrage.

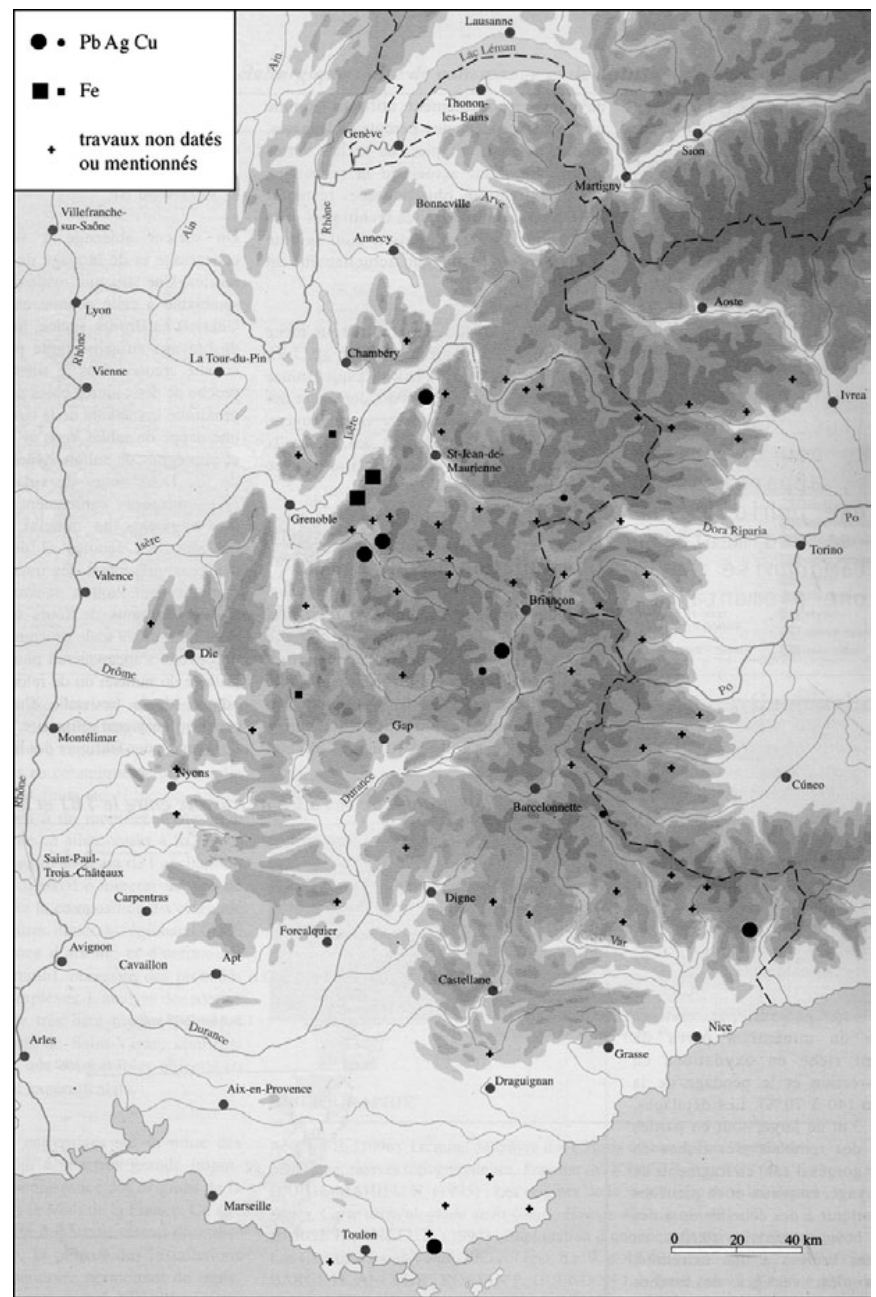

Fig. 2. Activités minières dans les Alpes durant le Moyen Âge.

La grande majorité de ces mines, excepté pour le fer, sont creusées par la méthode d'abattage par le feu ${ }^{5}$. Cependant, cette technique ne caractérise pas les exploitations médiévales: elle est induite par la dureté des roches rencontrées dans les Alpes et un outillage qui n'a pas encore atteint sa pleine efficacité (Ancel, Py 2008). Ces mines peuvent se rencontrer dans les environnements les plus extrêmes: l'altitude, l'isolement, l'escarpement des lieux et les risques naturels ne semblent pas avoir été un obstacle pour les mineurs médiévaux (Ancel 2000; 2008c).

La forte demande en argent favorise l'exploitation des gisements de plomb argentifère, au profit de multiples pouvoirs: Dauphins, comtes de Forcalquier, archevêques d'Embrun, seigneur de Lascaris, comtes de Savoie, seigneur

5. Dans ce type de travaux, il est très facile de récolter des charbons de bois et ainsi obtenir des datations radiocarbone. Pour les travaux ouverts à la pointerolle, il faut par contre engager des fouilles avec l'espoir souvent contrarié de trouver des céramiques ou des bois conservés. 


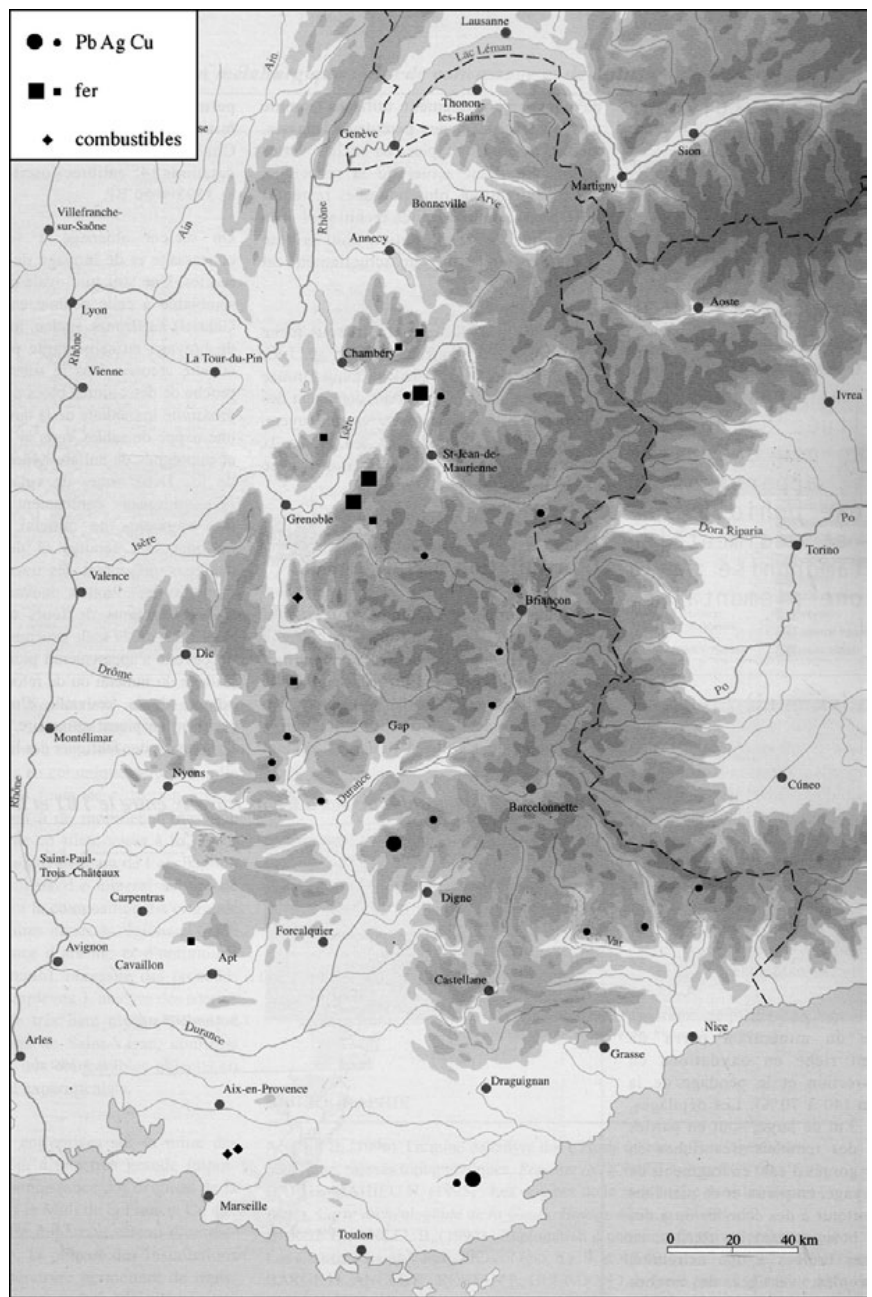

Fig. 3. Activités minières dans les Alpes durant les $X V^{e}-X V I I{ }^{e} s$.

d'Hurtières, etc. (Bailly-Maître, Dhénin 2004; Py, Ancel 2007); sept ateliers monétaires sont mentionnés dans les vallées alpines. Mais la question de la métallurgie reste en suspend: aucun site de métallurgie du plomb n'a encore été observé, y compris sur les sites majeurs de Brandes et de L'Argentière.

\section{Déprise du XVe au XVII ${ }^{e} \mathrm{~S}$.}

Après la dépression du XIV ${ }^{\mathrm{e}} \mathrm{s}$, l'activité minière est fortement ralentie. Les textes, plus abondants, attestent néanmoins de nombreuses demandes de prospections et d'exploitations. Mais souvent un défaut de technicité et de capitaux et/ou un épuisement des gîtes par les exploitations antérieures ont fait avorter ces tentatives (fig. 3).

Dans le massif des Maures, des travaux du XVe-XVI $\mathrm{s}$. pourraient exister dans la région du Luc (mines de fer de
Rascas, de plomb aux Armands et à Valpayette) et près de Toulon (mine de fer de Six-Fours). Le gisement de plomb argentifère de Saint-Daumas (alt. 150 m) renferme un important chantier ouvert à la pointerolle (Lanza-Berthet 2006). Tous ces sites mériteraient des fouilles approfondies. Dans les Alpes-de-Haute-Provence, une seule exploitation importante est à signaler, à Saint-Geniez pour le plomb (alt. $1050 \mathrm{~m}$ ), dont les ouvrages souterrains exigus et fortement remblayés ont été étudiés (Morin, Guiomar 2006).

Dans les Alpes-Maritimes, une bulle d'exorcisme de 1560 signale une reprise pour le cuivre à Salèse (alt. 1500 m). Une galerie de recherche à La Baume de Rances (alt. $1125 \mathrm{~m}$ ) présente un profil «ogival tronqué» caractéristique des ouvrages germaniques de la Renaissance. Dans les Hautes-Alpes, de nombreux gîtes de plomb et argent sont prospectés dans le Buëch aux XVI et XVII ${ }^{\mathrm{e}} \mathrm{s}$. (Ancel 2006b), mais les reprises du XIX signalent des vestiges anciens peu étendus, excepté à Sigottier et à La Piarre (alt. $1150 \mathrm{~m}$ ). Cependant, il s'avère sur le terrain que les mineurs modernes aient confondu ces travaux anciens avec du karst naturel, ouvert dans les calcaires encaissants (Ancel 2006e).

Dans les Alpes du Nord, la situation est comparable pour l'exploitation du plomb et du cuivre. L'extraction du fer est par contre en plein essor à Allevard, aux Hurtières (BaillyMaître, Ploquin, Garioud 2001); puis au XVII ${ }^{\mathrm{e}}$ s. dans les petites mines de l'Oisans (Legros, Legros 1979; BaillyMaître 2001). L'activité charbonnière démarre en Provence dès le $X^{\mathrm{e}} \mathrm{s}$. dans le bassin de lignite de Gardanne, mais de manière très artisanale (Ancel 2000a). Le gisement de houille de La Mure est également exploité avant le XVII $\mathrm{s}$.

\section{Reprise du XVIII ${ }^{\mathrm{e}}$ S.}

Le XVIII $\mathrm{s}$. est une période de réveil pour l'industrie minière des non ferreux en France, qui accuse un retard certain par rapport à l'Angleterre et aux pays germaniques. Plusieurs compagnies lancent des travaux dans les Alpes au milieu du siècle et les territoires de la Savoie et du Piémont bénéficient d'un dynamisme plus important (fig. 4). Quelques gisements connaissent alors une mise en exploitation en bonne et due forme, avec un développement souterrain conséquent, l'édification d'établissement de préparation du minerai et de logements, des aménagements hydrauliques et la construction de voie d'accès, malgré leur situation difficile dans des régions montagneuses (Ancel 2000b). C'est le cas des mines de plomb argentifère de Vallauria, près de Tende (alt. $1500 \mathrm{~m}$ ), de Pesey (alt. $1580 \mathrm{~m}$ ), de Montchabert (alt. 1000 m) en Savoie et de Vaucron (alt. $200 \mathrm{~m}$ ) dans les Maures (Mari, Mari 1982; Durand 2005; Lanza-Berthet 2006). Les mines de fer et de charbon poursuivent parallèlement un développement continu. 


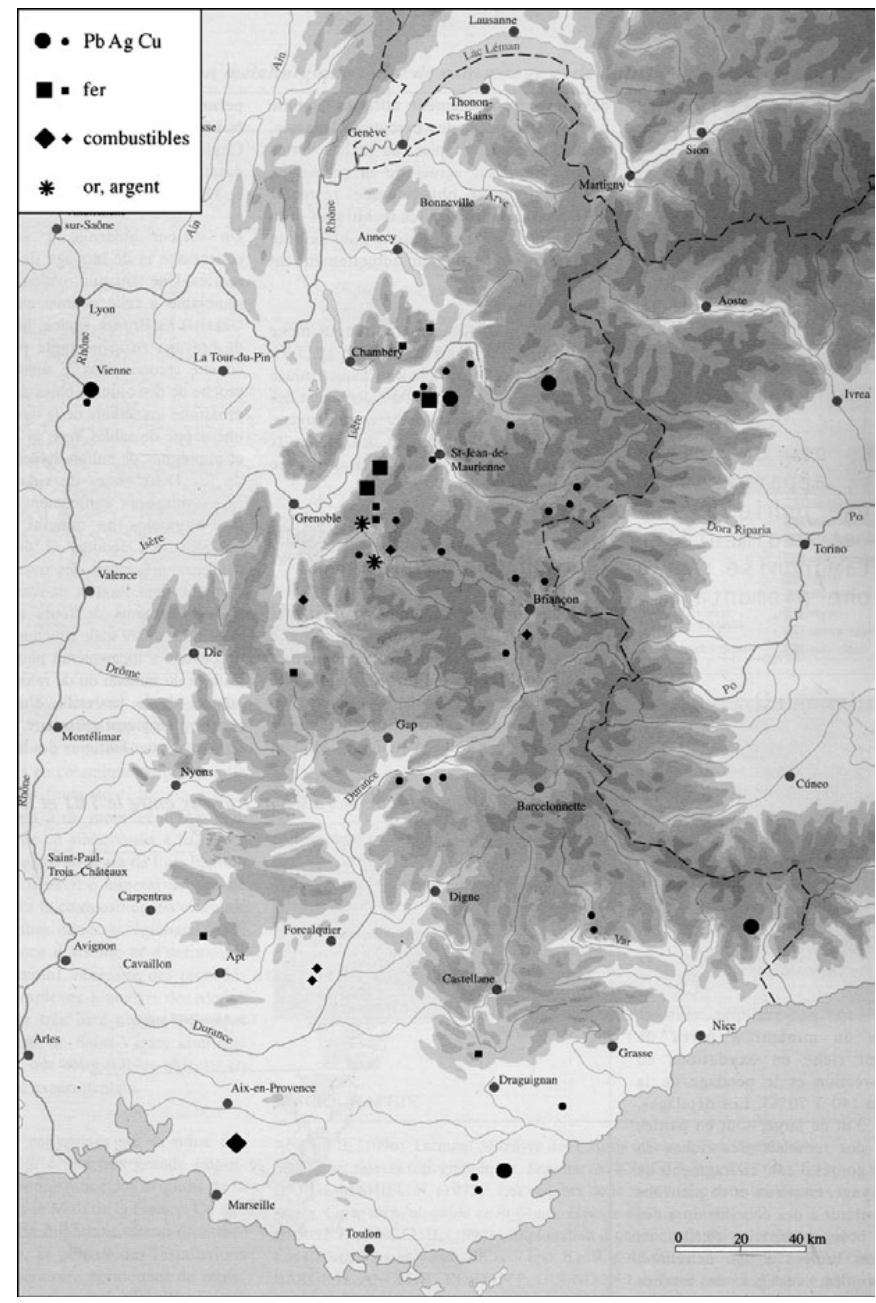

Fig. 4. Activités minières dans les Alpes durant le XVIII s.

En 1768, les mines d'argent des Challanches (alt. $2000 \mathrm{~m}$ ) en Isère sont mises en exploitation sous l'impulsion du comte de Provence, et sont rapidement accompagnées par la création d'une fonderie royale à Allemont (alt. 730 m). L'ingénieur Schreiber, d'origine saxonne, dirige cet établissement et entreprend de 1781 à 1788 l'exploration du gîte d'or de La Gardette (alt. 1250 m), célèbre pour ses cristallisations de quartz (Ancel, Dardignac 2008a). Il conclut que ce gîte n'est pas rentable, ce qui n'empêchera pas qu'il fera à nouveau l'objet de deux tentatives d'exploitation infructueuses au XIX ${ }^{\mathrm{e}} \mathrm{s}$.

En 1785, une compagnie lyonnaise entreprend une reprise des mines du Fournel à L'Argentière, construisant à grands frais un établissement au fond d'une gorge (alt. $1180 \mathrm{~m}$ ). Mais une mauvaise gestion entraîne diverses difficultés, puis les troubles de la Révolution achèvent la ruine de cette compagnie (Ancel 2006b). Au tournant du siècle, les guerres révolutionnaires puis napoléoniennes occasionnent un arrêt de presque toutes les exploitations minières dans les Alpes.

\section{Révolution industrielle}

Avec la révolution industrielle, l'activité minière connaît un développement considérable, par vagues successives, sur des territoires différents, dont le mécanisme précis reste à écrire. En effet, peu de ces exploitations modernes ont fait à ce jour l'objet d'études historiques et archéologiques approfondies (fig. 5) ${ }^{6}$.

La totalité des gîtes, vierges ou déjà reconnus par le passé, font alors l'objet de prospections et le cas échéant d'exploitations ou de tentatives d'exploitation. Le zinc (calamine), l'aluminium (bauxite) et certains métaux rares ne sont convoités qu'à la fin du XIX ${ }^{\mathrm{e}} \mathrm{s}$., lorsque leur métallurgie et leurs champs d'application sont maîtrisés. Les techniques nouvelles véhiculées par la littérature scientifique et technique sont généralement bien appliquées dans les différentes exploitations qui doivent s'adapter à un marché des ressources minérales qui sort souvent du cadre national. L'encadrement technique est fourni par un corps d'ingénieurs formés dans les écoles des Mines de Paris et de Saint-Étienne.

Malgré ce contexte théoriquement solide, les fiascos sont légions pour des causes multiples. Parfois les travaux des Anciens ont été sous-estimés et la reprise d'exploitation ne trouve pas de champ frais à extraire. Une surinterprétation des textes anciens conjuguée à une difficulté d'accès de certains secteurs montagneux entraînent des compagnies à investir dans des établissements coûteux avant même de s'être assurées de la rentabilité des gisements, comme dans le Valgodemard (Ancel 1997). Les erreurs de gestion sont fréquentes. Dans les années 1830, la Compagnie d'Allemont dilapide ses capitaux en dispersant ses forces dans un projet démesuré à cheval sur l'Oisans et le Briançonnais (Ancel 2008a). En 1847, la mine du Fournel à L'Argentière tombe dans les mains d'un personnage un peu fou, qui accumule investissements prématurés, dettes, conflits de personnes, grèves, procès, et doit s'enfuir de la mine un soir d'avril 1851 (Ancel 2008b). La fièvre de l'or s'est emparée de la mine de La Gardette (alt. $1250 \mathrm{~m}$ ): deux compagnies et de nombreux petits actionnaires en font les frais, car les $700 \mathrm{~m}$ d'ouvrages nouveaux ont rapporté à peine $3 \mathrm{~kg}$ d'or (Ancel, Dardignac 2008a). La dernière compagnie doit alors se rabattre sur le petit gisement de plomb voisin de la mine du Pontet (alt. $900 \mathrm{~m}$ ).

Avec la demande croissante de combustibles, la cherté des bois et la politique de reboisement des versants ravinés, tous les gisements de lignite et de charbon sont progressivement concédés, souvent à l'initiative des communautés montagnardes qui adoptent des modes d'exploitations très sommaires, archaïques aux yeux des ingénieurs de l'État.

6. Sur cette carte ne sont figurées que les exploitations les plus significatives. 


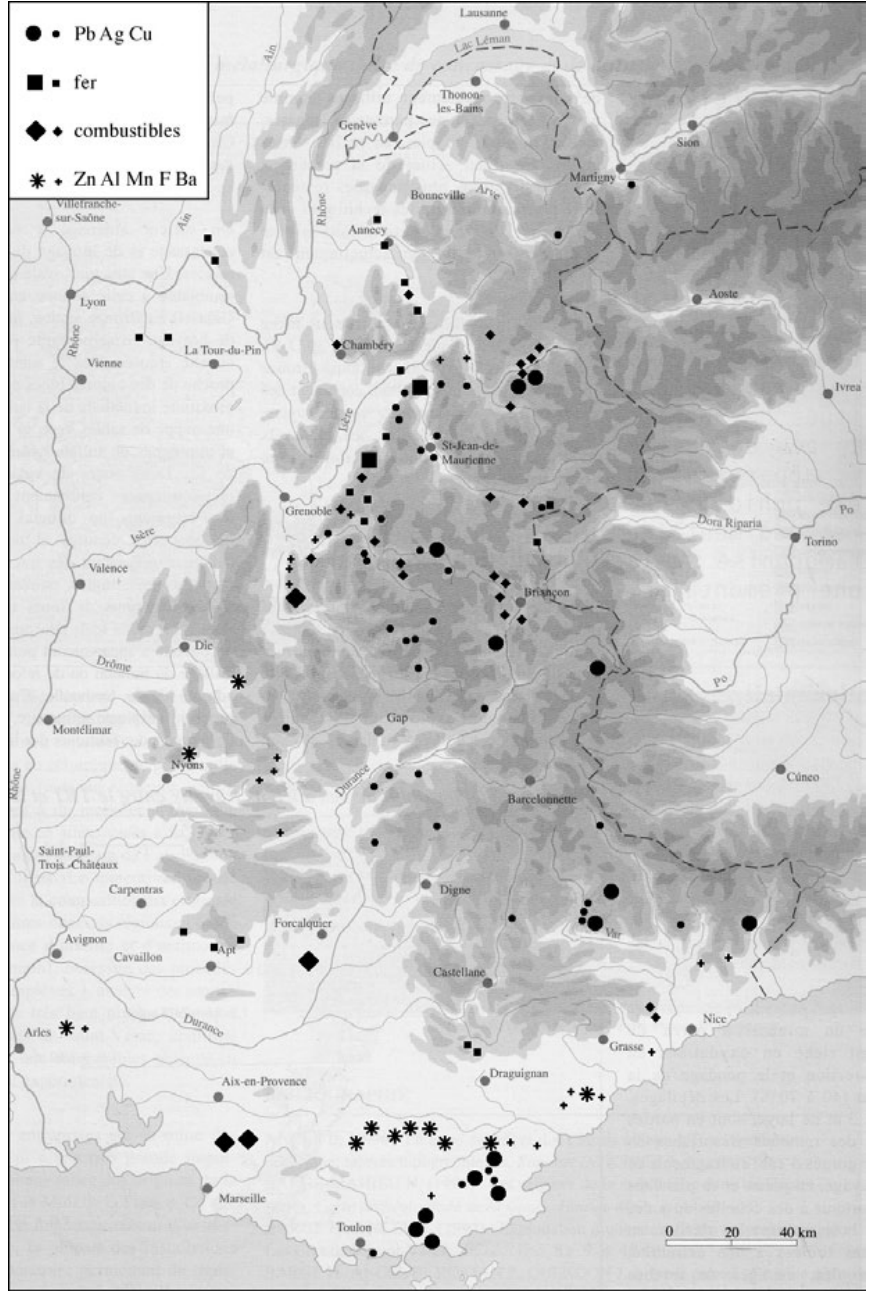

Fig. 5. Activités minières dans les Alpes durant les XIXe-XXes.

Dans le Briançonnais (alt. 1200 à 2500 m), le contexte géologique fait que les plus gros gisements tombent dans les mains de sociétés minières au début du XX $\mathrm{X}^{\mathrm{e}} \mathrm{s}$., et que les petites charbonnières artisanales perdurent jusqu'après la Seconde Guerre Mondiale (Ancel 2000a).

Les nouvelles techniques d'exploitation, développées depuis le XVIII ${ }^{\mathrm{e}}$ s., impliquent la création d'infrastructures qui doivent s'adapter à l'environnement montagnard (Ancel 2000 b ; 2008c). L'escarpement des lieux favorise l'activité souterraine qui peut s'organiser autour de niveaux de galeries de roulage et de drainage qui débouchent au jour, alors qu'en plaine il faut extraire les matériaux et les eaux par des puits d'extraction et de pompage, beaucoup plus coûteux. La difficulté réside en surface pour l'établissement des ateliers de préparation mécanique. Au Fournel, cet établissement est implanté au fond d'une gorge (alt. $1180 \mathrm{~m}$ ), éclaté en plusieurs bâtiments sur la berge du torrent, soumis aux avalanches en hiver, aux crues dévastatrices au printemps. Les machines de broyage et de lavage doivent être judicieusement disposées dans un espace restreint et l'évacuation du minerai concentré doit se faire par convois de mulets. Par contre toute l'énergie des machines est assurée par la seule force hydraulique. Une implantation aussi insolite fait que le site a été complètement abandonné à sa fermeture en 1908, et qu'une grande partie des installations de minéralurgie s'est conservée sous les ruines et a pu faire l'objet d'une archéologie industrielle (Ancel 2006d).

Dans plusieurs cas, les sites d'extraction sont nichés dans des lieux très escarpés, comme pour la mine de plomb du Grand Clot (alt. 1300 à 1600 m) à La Grave, ou très élevés en altitude, comme pour la mine de graphite du Chardonnet (alt. $2700 \mathrm{~m}$ ) près de Monêtier-les-Bains. Tous les produits d'extraction doivent alors être évacués vers le fond de la vallée au moyen de câbles aériens impressionnants. Les mineurs doivent progresser sur les versants par des sentiers taillés dans la roche et par des échelles vertigineuses, ou résider dans des baraquements hiver comme été (Ancel 1997 ; Ancel, Carré 2006).

Le problème du transport s'accentue alors que la tendance générale au XIX ${ }^{\mathrm{e}} \mathrm{s}$. est de concentrer la métallurgie près des grands centres industriels, puis des ports. L'écoulement des minerais concentrés reste difficile à travers les vallées alpines jusqu'au désenclavement par le développement d'un réseau de routes carrossables et de voies ferrées.

\section{La spécificité montagnarde}

La compétence des roches encaissantes et la vigueur du relief alpin permettent à l'élément minéral d'être très fréquemment visible en surface; les filons et les couches affleurent bien, parfois en continu. À l'exception des fonds de vallées et des grands éboulis, les formations superficielles sont minces et n'ont pas entravé le travail des prospecteurs. À chaque époque, les intéressés pouvaient observer les richesses minérales et ont exploité celles dont ils avaient le besoin dans la limite des techniques et des capitaux disponibles.

Le relief constitue un grand avantage pour les exploitations souterraines. La plupart des gîtes se situant sous des versants, leur exploitation peut se développer facilement grâce à des ouvrages étagés, d'autant plus courts que les pentes de ces versants sont raides. L'exhaure peut être assurée par gravité. L'aérage des chantiers ouvert par feu peut être facilité par l'ouverture de cheminée de faible développement. Par contre, outre de gêner les implantations de surface, le relief constitue un obstacle important pour la circulation des personnes, surtout aux périodes récentes. Ce problème a été résolu au prix d'importants aménagements. Les torrents ont des eaux abondantes toute l'année, aussi les établissements de traitement au XIX ${ }^{\mathrm{e}} \mathrm{s}$. optent pour l'énergie hydraulique, 
d'autant plus que le charbon des Alpes est très souvent mal adapté pour un bon fonctionnement des machines à vapeur. L'enclavement de certaines vallées et des accès souvent difficiles ont constitué un frein au développement de l'activité minière dans certains contextes historiques. On peut ainsi opposer les exploitations anciennes antérieures au XVII $\mathrm{s}$. à celles de la révolution technique et industrielle des XVIII ${ }^{\mathrm{e}}$ $\mathrm{XIX}^{\mathrm{e}} \mathrm{s}$.

Les exploitations les plus anciennes, non mécanisées, basées sur un savoir faire plus ou moins élaborés et un usage du bois comme matériaux de base, se sont parfaitement adaptées aux contraintes de la moyenne et haute montagne. Par contre, les exploitations récentes, exigeantes en termes d'infrastructures de traitement et de transport, ont été pénalisées par les reliefs vigoureux et les risques naturels, notamment torrentiels.

Le climat n'a pas toujours été un facteur de saisonnalité contrairement à nos a priori actuels. La disponibilité de ressources naturelles - eau, bois - a pu conditionner l'implantation des ateliers de traitement en surface, accentuant le contraste entre établissements de vallée et mines d'altitude. L'impact des grandes exploitations sur l'économie locale et l'aménagement du territoire est parfois sensible, mais pas comparable à ceux qu'ont connus les grands bassins miniers du Centre et du Nord.

\section{Bibliographie}

Ancel 1997: ANCEL (B.) - Mines et carrières dans les HautesAlpes: apports et évalutation des données de terrain. In: 12 th International Congress Speleology, La Chaux-de-Fonds, Symp. 3, 1997, p. 245-248.

Ancel 1998: ANCEL (B.) - Techniques minières et maîtrise de l'espace dans les mines d'argent médiévales. Exemples de mines de plomb argentifère des Alpes du Sud ( $\mathrm{X}^{\mathrm{e}}-\mathrm{XIV}^{\mathrm{e}} \mathrm{s}$.). In: Actes du Congrès d'Archéologie Médiévale (1996), Dijon, 1998, p. 108-110.

Ancel 2000a: ANCEL (B.) - L'exploitation charbonnière en Provence et dans les Alpes du Sud avant l'industrialisation. In: Le charbon de terre en Europe Occidentale avant l'usage industriel $d u$ coke. Actes Colloque International Histoires des Techniques, Liège (1997), De Diversis Artibus, 2000, p. 153-168.

Ancel 2000b: ANCEL (B.) - Les anciennes mines des HautesAlpes (Ecrins, Queyras) et leur adaptation à l'environnement montagnard. In: BOËTSCH (G.), RABINO-MASSA (E.) dir., Les écosystèmes alpins: approches anthropologiques, Gap, CRDP Aix-Marseille, 2000, p. 88-95.

Ancel 2006a: ANCEL (B.) - La mine d'argent du Fournel à travers les sources écrites: 1. Le souvenir de l'exploitation médiévale. Cahiers du Château Saint-Jean, nº 1, 2006, p. 89-101.

Ancel 2006b: ANCEL (B.) - La mine d'argent du Fournel à travers les sources écrites: 2. La Cie Schlagberg-MartinGuinard (1785-1805). Cahiers du Château Saint-Jean, ${ }^{\circ}$ 1, 2006, p. 25-88.

Ancel 2006c: ANCEL (B.) - Exploitations et indices de mines dans les Hautes-Alpes avant la Révolution. Cahiers $d u$ Château Saint-Jean, n 1, 2006, p. 3-24.

Ancel 2006d: ANCEL (B.) - La mine d'argent du Fournel à L'Argentière-la-Bessée (Hautes-Alpes): méthodologie et bilan 1991-2001. In: 4000 ans d'histoire des mines. Mélanges Jean-offerts à Paul Jacob. Actes du colloque Mine et métallurgie en Provence et dans les Alpes du Sud de la Préhistoire au $X X^{e}$ s.: reconversion industrielle et enjeux culturels, Châteaudouble (2001), Theix, Actilia Multimédia, 2006, p. 71-85.

Ancel 2006e: ANCEL (B.) - Archéologie minière dans les Alpes $\mathrm{du}$ Sud et la Provence. In: 4000 ans d'histoire des mines. Mélanges Jean-offerts à Paul Jacob. Actes du colloque Mine et métallurgie en Provence et dans les Alpes du Sud de la Préhistoire au $X X^{e}$ s.: reconversion industrielle et enjeux culturels, Châteaudouble (2001), Theix, Actilia Multimédia, 2006, p. 159-176.

Ancel 2008a : ANCEL (B.) - La mine d'argent du Fournel à travers les sources écrites: 3. La Société des Mines d'Allemont et des Hautes-Alpes (1833-1841). Cahiers du Château SaintJean, $\mathrm{n}^{\circ} 4$, 2008, p. 3-77.

Ancel 2008b: ANCEL (B.) - La mine d'argent du Fournel à travers les sources écrites: 4. La Société des Mines de L'Argentière, sous la direction de M. Duclos de Boussois (1847-1851). Cahiers du Château Saint-Jean, n 4, 2008, p. 79-162.

Ancel 2008c: ANCEL (B.) - Le paysage minier en zone de montagne: l'exemple des Hautes-Alpes. In: BAILLY-MAÎTRE (M.-C.), JOURDAIN-ANNEQUIN (C.), CLERMONT-JOLY (M.) dir., Archéologie et paysage des mines anciennes : de la fouille au Musée. Paris, Picard, 2008, p. 233-247.

Ancel, Carré 2006: ANCEL (B.), CARRE (R.) - La mine de graphite du col du Chardonnet. Cahiers du Château SaintJean, $\mathrm{n}^{\circ} 2$, 2006, p. 67-128.

Ancel, Dardignac 2008a: ANCEL (B.), DARDIGNAC (C.) La mine d'or de La Gardette à Bourg d'Oisans. Cahiers $d u$ Château Saint-Jean, n 5, 2008, p. 3-95.

Ancel, Dardignac 2008b : ANCEL (B.), DARDIGNAC (C.) La mine de plomb du Pontet à Bourg d'Oisans. Cahiers $d u$ Château Saint-Jean, $\mathrm{n}^{\circ}$ 5, 2008, p. 97-157.

Ancel, Py 2008: ANCEL (B.), PY (V.) - L'abattage par le feu: une technique minière ancestrale. Archéopage, ${ }^{\circ} 22$ «Mines et carrières », 2008, p. 34-41. 
Ancel, Carré, Kamenthaler 2006: ANCEL (B.), CARRE (R.), KAMENTHALER (E.) - La mine de cuivre des Clausis à Saint-Véran. Cahiers du Château Saint-Jean, n 2, 2006, p. 3-65.

Ancel et al. Sous presse : ANCEL (B.), PY (V.), MARCONNET (C.), KAMMENTHALER (E.), LELEU (V.) - Une mine de plomb argentifère dans un environnement montagnard: la mine médiévale du Fournel à L'Argentière-La Bessée (Hautes-Alpes). In: Mines et métallurgies anciennes $d u$ plomb dans leurs environnements. Actes du colloque de Florac, (2006), ArchéoSciences, sous presse.

Bailly-Maître 2001: BAILLY-MAITRE (M.-C.) - Mines et métallurgie du Moyen Âge au XIX ${ }^{\mathrm{e}} \mathrm{s}$. In: Patrimoine en Isère : le canton de l'Oisans. Musée Dauphinois / Conservation du Patrimoine de l'Isère, Grenoble, 2001, p.185-193.

Bailly-Maître 2002: BAILLY-MAÎTRE (M.-C.) - L'argent: du minerai au pouvoir dans la France médiévale. Espace Médiévaux, Paris, Picard, 2002, 211 p.

Bailly-Maître, Bruno-Dupraz 1994: BAILLY-MAÎTRE (M.C.), BRUNO-DUPRAZ (J.) - Brandes-en-Oisans, La mine d'argent des Dauphins (XII ${ }^{e}-X I V^{e}$ s.), Isère. Lyon, Documents d'Archéologie Rhône-Alpes, 9, 1994, 172 p.

Bailly-Maître, Dhénin 2004: BAILLY-MAÎTRE (M.-C.), DHENIN (M.) - Ateliers monétaires et mines d'argent dans les Alpes ( $\mathrm{X}^{\mathrm{e}}-\mathrm{XV}^{\mathrm{e}}$ s.). Archéologie Médiévale, 34, 2004, p. 43-64.

Bailly-Maître, Ploquin, Garioud 2001: BAILLY-MAÎTRE (M.-C.), PLOQUIN (A.), GARIOUD (N.) - Le fer dans les Alpes du Moyen Âge au XIXe s. Actes du colloque international de Saint-Georges-d'Hurtières (1998), Paris, éd. Monique Mergoil, 2001, 243 p.

Barge 2006a: BARGE (H.) - Les minéralisations cuprifères et leurs exploitations dans le Sud-Est de la France. In : 4000 ans d'histoire des mines. Mélanges Jean-offerst à Paul Jacob. Actes du colloque Mine et métallurgie en Provence et dans les Alpes du Sud de la Préhistoire au XX $X^{e}$ s.: reconversion industrielle et enjeux culturels, Châteaudouble (2001), Theix, Actilia Multimédia, 2006, p. 11-25.

Barge 2006b: BARGE (H.) - La mine de cuivre des Clausis à Saint-Véran (Hautes-Alpes). Méthodologie et bilan des recherches. In : 4000 ans d'histoire des mines. Mélanges Jeanofferts à Paul Jacob. Actes du colloque Mine et métallurgie en Provence et dans les Alpes du Sud de la Préhistoire au XXe s.: reconversion industrielle et enjeux culturels, Châteaudouble (2001), Theix, Actilia Multimédia, 2006, p. 27-40.

BRGM 1984: BRGM - Carte des gîtes minéraux de la France. Feuille Lyon et Marseille. Bureau de Recherches Géologiques et Minières, 1984

Dupraz 2004: DUPRAZ (J.) - Mines et métallurgie au Moyen Âge (XI ${ }^{e}-\mathrm{XV}^{\mathrm{e}} \mathrm{s}$.). In: JOURDAIN-ANNAQUIN (C.) dir., Atlas Culturel des Alpes Occidentales, de la Préhistoire à la fin du Moyen Âge. Paris, Picard, 2004, p. 334.
Durand 2005: DURAND (R.) - Anciennes mines et carrières souterraines de Savoie. BRGM 2005, 303 p.

Lanza-Berthet 2006: LANZA-BERTHET (M.-P.) - Synthèse des recherches sur les mines et la métallurgie dans le massif des Maures. In: 4000 ans d'histoire des mines. Mélanges Jean-offerts à Paul Jacob. Actes du colloque Mine et métallurgie en Provence et dans les Alpes du Sud de la Préhistoire au $X X^{e}$ s.: reconversion industrielle et enjeux culturels, Châteaudouble (2001), Theix, Actilia Multimédia, 2006, p. 149-158.

Legros, Legros 1979: LEGROS (A.), LEGROS (M.) - Histoire des anciennes mines et gîtes de l'Oisans. Toulouse, Les Presses Midi-Pyrénées, 1979, 285 p.

Morin, Guiomar 2006: MORIN (D.), GUIOMAR (M.) L'exploitation du minerai de plomb argentifère dans les Alpes-de-Haute-Provence. In : 4000 ans d'histoire des mines. Mélanges Jean-offerts à Paul Jacob. Actes du colloque Mine et métallurgie en Provence et dans les Alpes du Sud de la Préhistoire au $X X^{e}$ s.: reconversion industrielle et enjeux culturels, Châteaudouble (2001), Theix, Actilia Multimédia, 2006, p. 87-110.

Morin, Rosenthal 2006: MORIN (D.), ROSENTHAL (P.) Mines et minerais de fer de Provence et des Alpes du Sud. In : 4000 ans d'histoire des mines. Mélanges Jean-offerts à Paul Jacob. Actes du colloque Mine et métallurgie en Provence et dans les Alpes du Sud de la Préhistoire au XX $X X^{e}$ s. reconversion industrielle et enjeux culturels, Châteaudouble (2001), Theix, Actilia Multimédia, 2006, p. 113-133.

Mari 1979: MARI (G.) - Mines et minéraux de la Provence cristalline. Nice, éd. Serre, 1979, 258 p.

Mari, Mari 1982 : MARI (G.), MARI (D.) - Mines et minéraux des Alpes-Maritimes. Nice, éd. Serre, 1982, 282 p.

Pierrot, Picot, Poulain 1974: PIERROT (R.), PICOT (P.), POULAIN (P.-A.) - Inventaire minéralogique de la France: Hautes-Alpes. BRGM, 1974, 184 p.

Picot et al. 1974: PICOT (P.), FERAUD (J.), VERNET (J.), PIERROT (R.) - Inventaire minéralogique de la France: Alpes-Maritimes. BRGM, 1974, 168 p.

Py, Ancel 2007: PY (V.), ANCEL (B.) - Exploitation des mines métalliques de la vallée de Freissinières (Hautes-Alpes, France): contribution à l'étude de l'économie sud-alpine aux $\mathrm{IX}^{\mathrm{e}}$-XIII' ${ }^{\mathrm{e}}$ s. In : DELLA CASA (P.) et WALSH (K.) ed. Interpretation of sites and material culture from mid-high altitude moutain environnements. Proceedings of the $10^{\text {th }}$ annual meeting of the European Association of Archaeologists, Lyon, (2004). Trento, Preistoria Alpina, 42, 2007, p. 83-93.

Rostan, Gattiglia, Rossi 1995: ROSTAN (P.), GATTIGLIA (A.), ROSSI (M.) - Ricerche sulle miniere e sulla metallurgia dell'età del bronzo nel Briançonnais. In: De Re Metallica: Miniere e materie prime alle soglie del $3^{\circ}$ millennio. Torino, Politecnico di Torino, 1995, p. 173-181. 


\title{
Les Alpes françaises du Nord à l’âge du Fer
}

\author{
Loïc SERRIÈRES*
}

\begin{abstract}
Résumé. Malgré l'existence d'inventaires et de travaux de synthèse, l'âge du Fer des départements français actuels de la Savoie, de l'Isère et des Hautes-Alpes est peu présent dans les réflexions globales de la discipline, qu'elles concernent l'Europe de l'Ouest, une Gaule continentale ou l'espace montagnard. Pourtant, il semble que l'établissement d'une séquence chronologique des mobiliers, en particulier locaux, témoigne d'une réelle insertion des sociétés alpines dans le tissu économique de l'âge du Fer européen.
\end{abstract}

The French Northern Alps during the Iron age period (800-0)

Abstract. Despite inventories and all-encompassing studies, the Iron age of the three French departments of Savoie, Isère and Hautes-Alpes is not integrated into the largest analysis of Protohistorical populations, in the European scale, the continental Gaul scale or even in the analysis of the exploitation and settlement of the mountain environment. Nevertheless, it seems that the chronological sequence of the artifacts, especially the ones locally produced, shows that the Alpin societies are part of the European economical network.

$\mathrm{L}$ 'âge du Fer des Alpes occidentales françaises a fait l'objet de deux modèles de peuplement. Le premier, formulé par Aimé Bocquet (Bocquet 1991; 1997), repose essentiellement sur une opposition culturelle et ethnique entre les massifs et l'avant-pays. Le second, conçu par Jacques-Pierre Millotte, postule la pénétration progressive d'une population nouvelle au Hallstatt et en trouve l'origine sur le plateau suisse (Millotte 1999). Le premier jalon historiographique de la Protohistoire alpine est l'œuvre d'Ernest Chantre. Sa manière de regrouper les découvertes est à l'origine de la notion de groupes culturels alpins (Chantre 1880). La littérature livre ainsi pour le territoire d'étude trois groupes, un groupe dit «Rochefort-Oisans» ou «Drac-Romanche», «Maurienne-Tarentaise» et «Jausiers-Peyre-Haute» ou «Queyras-Ubaye» (Courtois 1976; Bocquet 1991). Chacune de ces dénominations, qui permet de placer sous une étiquette l'intégralité des découvertes alpines, mérite d'être discutée (fig. 1).

\section{Le groupe «Oisans-Rochefort»}

Dans ses études paléoethnologiques consacrées à l'âge du Fer (Chantre 1880), Ernest Chantre étudiait un «groupe de
l'Oisans et du bas Dauphiné». Il ne présentait aucun critère d'appartenance, indiquant que «Jusqu'à ce jour elles (les sépultures) n'ont donné que des bracelets du genre de ceux des nécropoles des autres groupes, mais il est probable qu'ils étaient accompagnés de quelques autres objets négligés par les auteurs des découvertes » (Chantre 1880, p. 17). Aimé Bocquet a proposé une nouvelle délimitation (Bocquet 1991, p. 122-128). Excluant la notion de «bas Dauphiné », il rebaptise le groupe «Oisans-Rochefort», marquant ainsi la prise en compte du mobilier des nécropoles est et ouest du Grand Rochefort de Varces (Bocquet 1969-1970, p. 144-152). Les bracelets à décor de «fausses torsades» (fig. 3) fourniraient alors au groupe le liant qui manquait dans le propos d'Ernest Chantre.

$\mathrm{Au}$ Hallstatt ancien, les découvertes regroupées sous l'étiquette «groupe Oisans-Rochefort» sont peu nombreuses. Doit être évoquée avec la plus grande prudence la cuirasse de Grenoble. Comparable aux cuirasses du dépôt métallique de Fillinges, daté des environs de 800 dans une mouvance Bronze final IIIb, la cuirasse de Grenoble a été attribuée à la Franche-Comté par Jacques-Pierre Millotte (Millotte 1963). En Chartreuse, les abris préhistoriques 1 et 2 de l'Aulp du Seuil sont réoccupés à la fin du Bronze final IIIb et au début du Hallstatt C (Bintz, Serrières 2008).

* Université Pierre Mendès France - CHRIPA, 1281 avenue centrale du Domaine universitaire, 38400 Saint-Martin-d'Hères. 


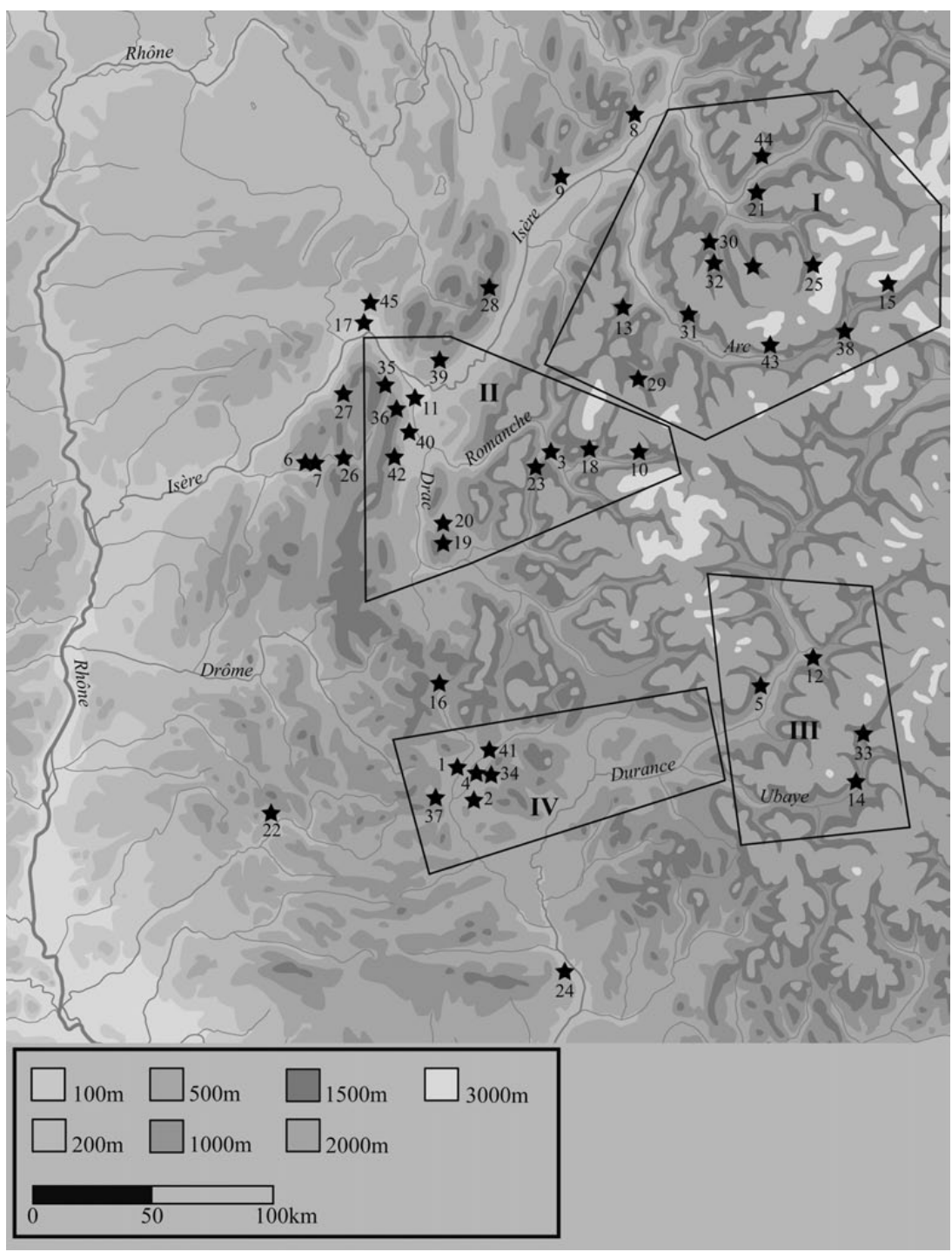

Fig. 1. Repères cartographiques. Fond de carte programme Politogenèse (UPMF).

De I à IV : groupes culturels alpins d'après

Bocquet 1991 (fig. 1, schématisée).

I. «Maurienne-Tarentaise», II. «Oisans-

Rochefort», III. "Queyras-Ubaye»,

IV. "Moyenne Durance».

De 1 à 45 : listes des communes citées dans le texte.

1. Aspremont; 2. La Bâtie-Montsaléon;

3. Le Bourg-d'Oisans; 4. Chabestan;

5. Châteauroux-les-Alpes; 6. Choranche,

Balme rousse; 7 . Choranche, Coufin II;

8. Cléry; 9. Cruet; 10. La Grave;

11. Grenoble; 12. Guillestre, Peyre-Haute;

13. Jarrier; 14. Jausiers; 15. Lanslevillard;

16. Lus-la-Croix-Haute; 17. Moirans;

18. Mont-de-Lans; 19. La Motte-d'Aveillans;

20. La Mure; 21. Notre-Dame-du-Pré;

22. Nyons; 23. Ornon; 24. Peipin;

25. Pralognan; 26. Rencurel; 27. Rovon;

28. Saint-Bernard-du-Touvet, Aulp-du-Seuil;

29. Saint-Jean-d'Arves; 30. Saint-Jean-deBelleville; 31. Saint-Julien-Montdenis;

32. Saint-Martin-de-Belleville; 33. Saint-

Paul-sur-Ubaye; 34. Le Saix; 35. Sassenage;

36. Seyssinet-Pariset; 37. Sigottier;

38. Sollières-Sardières; 39. La Tronche;

40. Varces; 41. Veynes; 42. Vif; 43. VillarodinBourget; 44 . Villette; 45 . Voiron.

Des fibules italiques, à Lus-la-Croix-Haute, au Bourgd'Oisans et à Moirans attestent une circulation des hommes d'un côté à l'autre des Alpes (Bocquet 1991). L'occupation en abri ou en grotte est le seul type d'occupation connu pour la période. Dans les environs de Grenoble, elle paraît dense même si les diagnoses chronologiques sont difficiles compte tenu de la rareté du mobilier, de sa disparition, de l'absence de contexte stratigraphique et du caractère récent de la distinction entre Bronze final et Hallstatt ancien. Une présence est en tout cas assurée à la grotte des Sarrasins de Seyssinet-Pariset. Des tessons du Golasecca, datés de 750-700, ont été signalés (Gouin 1994, p. 76). À La Grande Rivoire de Sassenage, quelques tessons renverraient peutêtre au Hallstatt C (Picavet 1991). En Matheysine, le Dictionnaire Archéologique de la Gaule mentionne des tumuli. Les relations sont imprécises et le mobilier illustré par Ernest Chantre et conservé au Musée Dauphinois, cinq pendeloques et plusieurs bracelets en bronze, pourrait être attribué à La Motte-d'Aveillans ou à La Mure (fig. 2). Selon Aimé Bocquet, les pendeloques sont originaires du Picenum et datent du VII ${ }^{\mathrm{e}}$ s. (Bocquet 1991, p. 126).

La documentation se multiplie au Hallstatt D. L'occupation des grottes est toujours importante. Elle est attestée par la céramique grise monochrome recueillie à la Grande Rivoire (Picavet 1991) mais aussi sur le site de hauteur du Grand Rochefort de Varces (Serrières 2007, p. 69-72). D'autres sites des environs de Grenoble sont à confirmer. Le défilé de Choranche, occupé dès la Préhistoire, livre des traces avec l'urne pseudo-ionienne et la petite urne non tournée de Coufin II (Vital, Bintz 1991), quelques tessons excisés de Balme Rousse (Vital, Bintz 1991), les éléments métalliques, le bracelet en lignite et la jatte à bord rentrant de la Balme Noire à Rencurel (Bocquet 1969-1970, p. 89). L'abri du Pas de l'Echelle de Rovon a livré dans une couche brassée ( $\mathrm{C}$, sous-ensemble $\mathrm{C} 2$ ) des fragments de jatte à bord droit, de coupe à profil sinueux et de coupe 


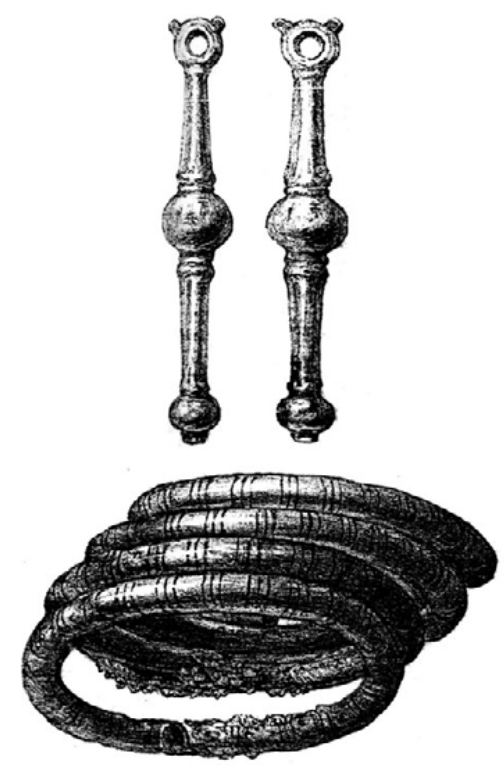

Fig. 2. Matheysine, pendeloques et bracelets creux. Dessins originaux Ernest Chantre 1880. Modifiés.

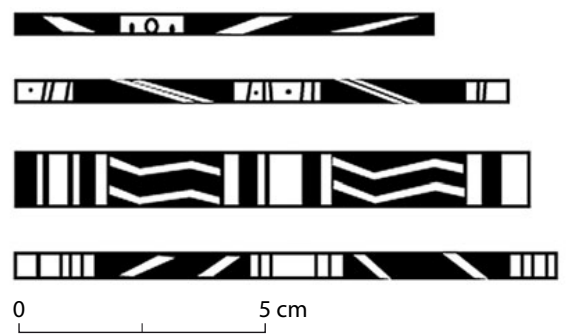

Fig. 3. Les bracelets à décor de fausses torsades ou de type Rochefort. Exemples schématisés de décors.

à bord rentrant datés du Hallstatt D (Bintz et al. 1995). La multiplication des découvertes dans le Vercors ne doit pas être vue comme le signe d'une pénétration humaine mais pourrait être imputée au hasard des découvertes. Je signalerai aussi le caractère plus récent de ces découvertes par rapport à celles d'Hippolyte Müller qu'aucun contexte stratigraphique ne permet de bien appréhender.

Ceci dit, l'âge du Fer du groupe «Rochefort-Oisans» est essentiellement documenté par l'Archéologie funéraire. Il ne nous reste essentiellement de ces tombes et cimetières que des bracelets à incisions. Les plus emblématiques sont les bracelets dits de «type Rochefort» ou à «fausses torsades» (fig. 3). La section de ces bracelets est pseudoelliptique. Le décor est composé d'incisions et de très légères bossettes alternant avec des creux. Dans le territoire d'étude, le type semble propre à la vallée du Drac. Deux bracelets de La Tronche (Isère) et de La Grave (HautesAlpes) peuvent il est vrai également correspondre au type.

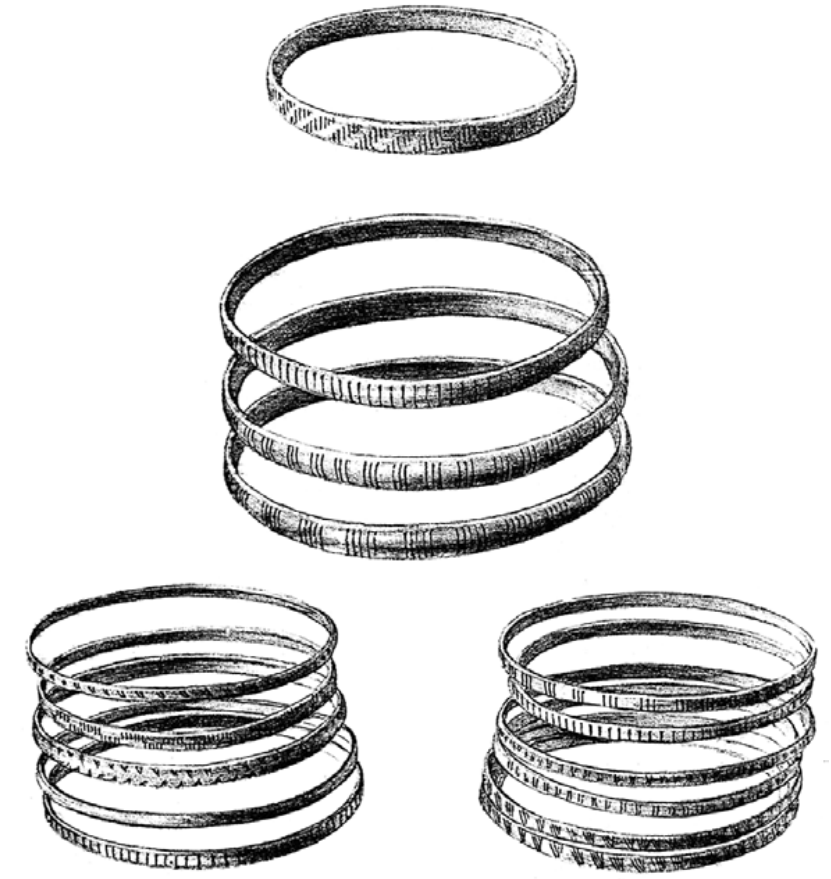

Fig. 4. Choix de bracelets à incisions de l'Oisans. Dessins originaux Ernest Chantre 1880. Modifiés.

Mais, au final, les bracelets «de Rochefort» ne sont pas si typiques. Le site de La Mouleyre à Saint-Pierre-Eynac (Haute-Loire) livre ainsi trois bracelets de bronze, sans ouverture, datés du Hallstatt D1-D2 (650-500), voire de la première moitié du VI $\mathrm{e}$ s. (Milcent 2004). La présence de bracelets en schiste de section «torique» dans la nécropole ouest de Rochefort conforte bien une datation entre 600 et 550 av. J.-C. Les sites du carrefour grenoblois livrent plus fréquemment des bracelets fins, de section rectangulaire, dont le décor est composé d'incisions simples: obliques, zigs-zags, alternance de $\mathrm{V}$ ou arêtes de poisson, sans jeu sur le relief (fig. 4). Ces bracelets sont présents à La Tronche, La Motte-d'Aveillans/La Mure, Mont-de-Lans, Ornon et quelques sites haut-Alpins (Peyre-Haute, La Grave ou Châteauroux). Le Pâtural de Clermont-Ferrand (Puyde-Dôme), le tumulus du Gué de Dun-sur-Auron (Cher) livrent des exemples assez similaires pour ne citer que des exemples empruntés aux typochronologies de Pierre-Yves Milcent (Milcent 2004). Je serais en cela tenté de dater les exemplaires isérois du $\mathrm{V}^{\mathrm{e}} \mathrm{s}$. Les bracelets creux de même décoration, comme ceux de La Motte d'Aveillans/La Mure par exemple (fig. 2), renverraient à la même période. Un dernier type reprend le même registre décoratif mais est caractérisé par une section nettement divergente. Ce sont les bracelets plats, fins mais très hauts. Ils sont plus récents. Dans le sud de la Drôme, à Nyons, ils sont associés à une fibule «discoïdale». Une datation au IV s. av. J.-C. paraît 
en cela tout indiquée. De tels exemplaires sont rares en dehors du département actuel des Hautes-Alpes de telle sorte que les quelques découvertes faites en dehors de ce territoire ont été vues comme des importations (Saint-Jeande-Belleville, Nyons).

L'artisanat du bronze a une durée de vie très courte, du $\mathrm{VI}^{\mathrm{e}} \mathrm{au} \mathrm{V}^{\mathrm{e}} \mathrm{s}$. L'arrêt de ces productions est pour beaucoup dans l'indigence de la documentation relative à la période laténienne. L'absence de fibules et de lots de campanienne témoigne également d'une forme de retrait. La mise en évidence de céramique commune grise laténienne documente la fin de la période. Les grottes des environs de Grenoble livrent quasiment toutes ce type de céramique. Les sites de hauteur de Vif et de Varces en sont également pourvus (Serrières 2007, p. 69-74), tout comme les sites de Voiron et même l'abri n' 2 de 1'Aulp-du-Seuil (Bintz et Serrières 2008). Des inscriptions du $\mathrm{I}^{\mathrm{er}}$ s. av. J.-C. y indiquent d'ailleurs l'existence d'un vaste domaine, celui des Auei (Jospin, Vendittelli 2008).

Le groupe Oisans-Rochefort tel que l'a défini Aimé Bocquet n'est en l'état pas concerné par le phénomène majeur touchant la future Allobrogie à La Tène, l'apparition de tombes de guerriers. Tout autour pourtant, à Cruet (Tène A? Tène $\mathrm{B}$ ?) et à Cléry (Tène C) à l'est et dans le Voironnais au nord (Tène $\mathrm{C}$ et $\mathrm{D}$ ), une élite joint ses armes à la tombe. En définitive, la qualification «groupe Oisans-Rochefort» ne désigne qu'un artisanat local du bronze pratiqué aux VI et $\mathrm{V}^{\mathrm{e}} \mathrm{s}$. La disparition de quasiment toute documentation dans l'espace ainsi défini à La Tène rend caduque la vision d'un groupe culturel sur un temps long.

\section{Le groupe Maurienne-Tarentaise}

Si Ernest Chantre a reproduit du matériel savoyard, c'est à Aimé Bocquet que nous devons la constitution d'un groupe «Maurienne-Tarentaise» (Bocquet 1991, p. 116-122).

$\mathrm{Au}$ Hallstatt ancien, les vallées internes savoyardes livrent peu de mobilier. Je citerai le rasoir de Pralognan, la fibule a sanguisuga et le morceau de galène du tumulus (?) de Villarodin-Bourget par exemple (Bocquet 1991). L'ensemble des rares découvertes du Hallstatt ancien trouve de bons parallèles avec les productions italiques et plus particulièrement la culture de Villanova. L'influence du Jura et du plateau suisse ne se fait pas sentir avant le Hallstatt D (bracelets en lignite et brassard-tonneau de Saint-Julien-Montdenis). Mais la période est surtout marquée par le développement des productions locales. L'ambre est porté en collier (fig. 5). Les bracelets sont marqués par un fort relief, d'abord animés par des côtes, ils prennent ensuite l'apparence d'une «roue dentée» (fig. 5). Un ornement étonnant, les crotales, sert de parure (fig. 5). Ce bijou n'est pas propre aux Alpes mais s'inscrit dans une
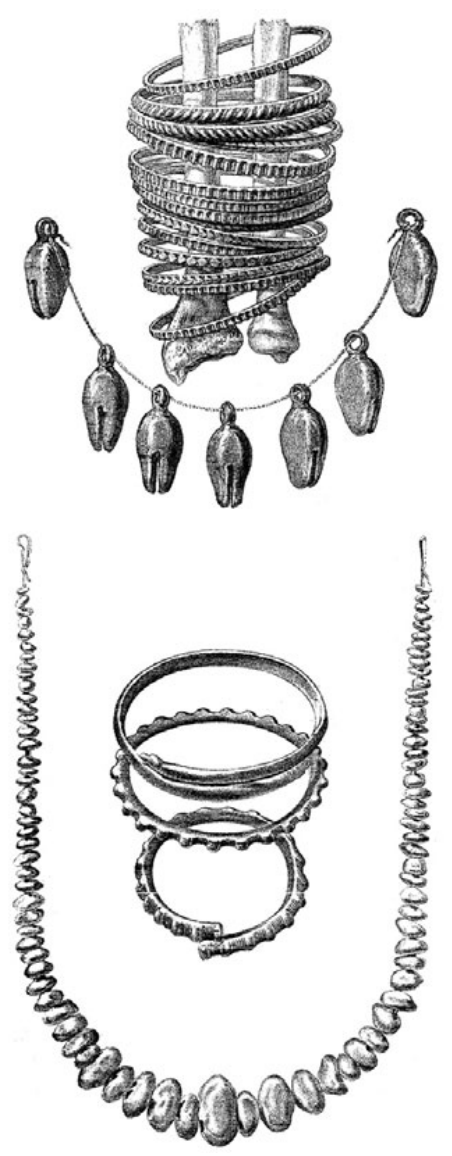

Fig. 5. bracelets à «roue dentée», crotales, collier d'ambre, bracelet à enroulement et bracelets à côtes de MaurienneTarentaise. Dessins originaux Ernest Chantre. Modifiés.

mode hallstattienne, propre à la France orientale (Millotte 1999). C'est également le cas des armilles. Leur fréquence et leur nombre les rendent plus typiques dans les Alpes et en particulier en Savoie. Les productions tarines et mauriennaises dateraient toutes des $\mathrm{VI}^{\mathrm{e}}$ et $\mathrm{V}^{\mathrm{e}} \mathrm{s}$. Leur complexité et exubérance, leur nombre et la rareté de certaines matières premières (ambre) indiquent une forme de richesse.

La période laténienne est d'une étonnante modestie. Le phénomène des tombes de guerriers ne dépasse pas la combe de Savoie (Cruet et Cléry). La céramique n'a que rarement été recueillie. À Lanslevillard (Bellon et al. 2002) et à la Balme de Sollières (Vital en préparation), deux vases dérivés des formes a trottola ont été découverts. Les objets de fabrication locale deviennent extrêmement rares: bracelets de Saint-Martin-de-Belleville (Saint-Laurent) datés de la fin du IV eu du courant du III ${ }^{\mathrm{e}} \mathrm{s}$. par Aimé Bocquet, bracelets de Villette (IV s.) (Bocquet 1991, p. 122). Sort du lot la ceinture de La Tène moyenne de Jarrier (lieu-dit Vers le Four) comparable à un exemplaire des Alpes du Sud (Guillestre). Restent les fibules de type Münsingen (dont Notre-Dame-du-Pré et Villette). Alors même que des 
nécropoles comme Saint-Jean-de-Belleville ou Saint-Jeand'Arves sont encore en fonctionnement, il n'y a plus de mobilier produit localement. Cet arrêt correspond à une baisse globale du matériel dans les tombes. Les contacts avec les cultures italiques deviennent rares: fibule type Golasecca IIIa3 au «mur des Sarrasins» à Lanslevillard (Willigens 1991, p. 171.); fibule de «type transalpinde Nauheim » à Lanslevillard-1'Adroit (Bellon et al. 2002, p. 10).

\section{Aperçu sur l'âge du Fer des Alpes méridionales}

Les productions des Alpes du Sud divergent fortement des productions des Alpes du Nord. La planche d'Ernest Chantre reproduite ci-dessus (fig. 6) est à ce titre éloquente. Les bracelets renvoient au deuxième âge du Fer à l'exception du brassard-tonnelet de Peipin qui rappelle le Hallstatt D1 suisse (650-550). Sauf erreur, il doit être l'exemplaire le plus méridional de ce type emblématique du Hallstatt D suisse et jurassien. Le troisième bracelet, à oves creux, correspond aussi très bien à certains exemplaires de La Tène B2 suisse (350-250). Les divergences avec les productions des Alpes du Nord n'empêchent donc pas l'existence de liens avec l'âge du Fer du Jura et du plateau suisse.

Dans le département actuel des Hautes-Alpes, deux groupes peuvent être opposés: l'ouest, le Gapençais et le Buëch; et l'est, l'Ubaye, l'Embrunais et le Queyras (fig. 1). À l'ouest, le Dévoluy et le Champsaur sont méconnus; à l'est, le Briançonnais est peu documenté. Le Buëch et le Gapençais sont marqués au premier âge du Fer par l'édification de nombreux tumuli (Aspremont, Chabestan...) contemporains d'inhumations plates (Le Saix, Veynes...). L'Ubaye et la haute Durance ne possèdent pas de nécropoles tumulaires. À dire vrai, la phase ancienne du premier âge du Fer est mal représentée. La documentation apparaît réellement au Hallstatt moyen, en particulier en Ubaye qui ne livrait jusque-là quasiment aucun mobilier. Ces artefacts locaux se distinguent des productions voisines: nécessaire de toilette, fibules et armement dans le groupe ouest, fibules et bracelets locaux dans les Alpes du Nord. À l'exemple des vallées internes savoyardes et iséroises, le groupe ouest livre peu d'artefacts aux IV $\mathrm{IV}^{\mathrm{e}} \mathrm{III}{ }^{\mathrm{e}} \mathrm{S}$. av. J.-C. et l'on retrouve trace d'une occupation du territoire au $\mathrm{II}^{\mathrm{e}}$ s. av. J.-C. (La Bâtie-Montsaléon, Sigottier). C'est tout l'inverse à l'est. L'âge du Fer du «groupe Queyras-Ubaye» est surtout un second âge du Fer, caractérisé par des productions très originales comme la fibule dite discoïdale, les appliques dites violonées, les bracelets plats à incisions simples et les bracelets à bossettes ou à oves (Sabatier 1985). Les deux derniers siècles avant notre ère sont méconnus.

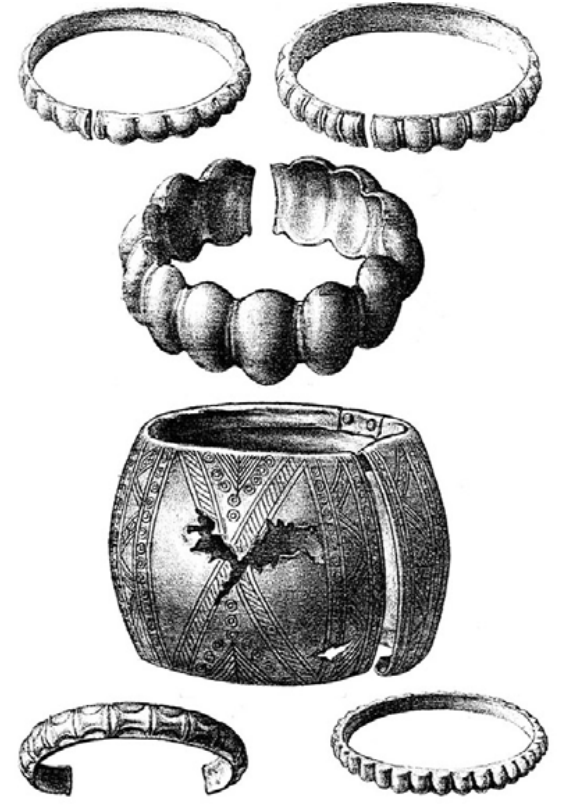

Fig. 6. Bracelets de la vallée de Barcelonnette (Chantre 1880).

\section{Les Alpes et l'«économie-monde»}

Depuis une vingtaine d'années, Patrice Brun applique la notion d' «économie-monde» à l'étude des civilisations protohistoriques (Brun 1987). Il s'agit d'une conception particulière de l'espace où l'interconnection de terroirs éloignés tient à un ensemble d'interactions économiques. Concrètement, les civilisations méditerranéennes (cités grecques, étrusques, Rome) impulsent un stimulus économique fort, auquel vont répondre les civilisations protohistoriques. Et «c'est au $\mathrm{VI}^{\mathrm{e}} \mathrm{s}$. avant notre ère que l'économie-monde méditerranéenne a atteint sa forme canonique en trois zones concentriques hiérarchisées. Les principautés celtiques correspondraient à la deuxième auréole» (Brun 1992, p. 192). Comme Patrice Brun l'a formulé, il n'y a pas de principautés celtiques au sud du Rhône (Brun 1992). Or, l'absence de ces résidences ne signifie pas que les populations alpines ne s'inscrivent pas dans «l'économie-monde». Dans cette période d'échanges internationaux, il est normal que ces populations, mâ̂tresses des passages entre péninsule italique et Europe de l'ouest, soient marquées directement par la fluctuation des échanges.

Aux VIII et VII ${ }^{\mathrm{e}}$ s. av. J.-C., les rares tombes connues dans les vallées internes livrent des éléments importés d'Italie, des fibules essentiellement. D'après Richard Adam, elles pourraient être vues comme un «passeport diplomatique» (Adam 1992). D’autres découvertes (rasoir de Pralognan, pendeloques de Matheysine) sont constitutives d'un 
mobilier privilégié. À la fin du Hallstatt C, une élite contrôle peut-être les échanges avec l'Italie. Aux VI $-\mathrm{V}^{\mathrm{e}} \mathrm{s}$., les tombes sont découvertes en plus grand nombre, certainement parce qu'elles sont plus visibles, car plus riches. À vrai dire, avec la dizaine de bracelets portés le long des bras, on ne peut pas les manquer. Cette nouvelle richesse pourrait venir du commerce. Elle entraîne le développement sans précédent d'une métallurgie locale. Cette période faste correspond au temps des princes celtes. Le parallèle est trop voyant pour ne pas être fait. Une partie du commerce étrusque passe par les Alpes du Nord. Il devait s'agir pour les habitants des vallées internes iséroises et savoyardes de convoyer du vin et du mobilier précieux dans le sens Italie/Gaule et du sel, des minerais, de la fourrure ou des esclaves dans le sens inverse. Les voies du Petit-Saint-Bernard et du Mont Cenis sont des voies du commerce international au Hallstatt D. Les Alpins ont su prendre leur part. Mais, dès la fin du V ${ }^{\mathrm{e}} \mathrm{s}$., ce système d'échanges s'effondre.

Selon Patrice Brun, le $\mathrm{V}^{\mathrm{e}} \mathrm{s}$. est marqué par un changement dans le réseau: les flux dans leur traversée de la première auréole passent plus à l'est. Cette nouvelle disposition profite à d'autres centres et, en premier lieu, à l'aire tessinoise qui ferait ensuite la redistribution (Brun 1987). Il est difficile de connaître l'origine de ces modifications et de l'écroulement des principautés celtiques. Les mouvements de population qui menacent Rome au début du IV $\mathrm{s}$. et Delphes au début du siècle suivant pourraient répondre à de graves crises internes. Une surpopulation est invoquée par Tite-Live (Ad urbe condita, V, 34, 2). De même, une péjoration climatique de 420 à 350 a été mise en évidence en Suisse occidentale (Curdy, Kaenel 2006). L'hypothèse d'une chute démographique dans les Alpes du Nord aux $\mathrm{IV}^{\mathrm{e}}-\mathrm{III}^{\mathrm{e}}$ S. av. J.-C. trouverait avec les mouvements de population un argument favorable. Cependant, gardons-nous de confondre nombre d'objets, nombre de tombes et nombre de morts.

Le modèle de Patrice Brun suffirait à expliquer l'évolution des sociétés nord-alpines. Dès la fin du V $\mathrm{V}^{\mathrm{e}} \mathrm{s}$., les productions locales et donc l'accès aux matières premières (cuivre, étain) subissent un premier coup d'arrêt. Mais l'application du modèle n'explique pas l'évolution inverse du groupe «Queyras-Ubaye» dont les productions locales semblent se développer à partir de 400 (La Tène B). Au début du IV $^{\mathrm{e}}$ s., les Celtes attaquent Rome et s'installent dans la plaine du Pô au détriment des Etrusques. Cet événement correspond au début des productions typiques du groupe Queyras-Ubaye. L'utilisation de cols méridionaux, visiblement peu usités auparavant par le commerce, marque peutêtre un évitement des passages plus septentrionaux. Des populations celtiques y entraveraient-elles le commerce, au contraire des populations du sud-ouest de l'Italie du Nord? En définitive, le lien entre artefacts métalliques d'Isère, de Savoie, du Buëch et de l'Ubaye avec ceux d'une France orientale est évident. On constate une lente disparition d'une mode septentrionale, et en particulier jurassienne, à mesure que l'on pousse vers le sud. Et c'est comme si l'éloignement des centres les plus dynamiques - ceux qui créent et diffusent les archétypes - favorisait la reprise de ses archétypes d'une manière de plus en plus originale.

\section{Bibliographie}

Adam 1992: ADAM (R.) - L'apport d'objets italiques dans le Jura: voie unique ou voies alternatives? In: KAENEL (G.), CURDY (P.) dir., L'âge du Fer dans le Jura, Actes du XVe colloque de l'AFEAF, Pontarlier/Yverdon (1991), Cahiers d'Archéologie romande, 57, 1992, p. 181-205.

Bellon et al. 2002 : BELLON (C.), BLAIZOT (F.), PERRIN (F.), RAHATSOTZ (M.) - Nouvelles sépultures à inhumation de La Tène à Lanslevillard (Savoie). Documents d'Archéologie Méridionale, 25, 2002, p. 233-244.

Bintz et al. 1995: BINTZ (P.) avec collab. ARGANT (A.), MENARD (A.), NOUACO (P.), VITAL (J.) - Pas de l'Echelle, Rovon (Isère). In: Collectif - Livret-guide excursion Préhistoire et Quaternaire en Vercors, 5e Congrès International UISPP, Grenoble, 1995, p. 80-83.

Bintz, Serrières 2008: BINTZ (P.), SERRIÈRES (L.) - L'Aulp du Seuil, Saint-Bernard-du-Touvet (Isère). In JOSPIN (J.-P.), FAVRIE (T.) dir., Premiers bergers des Alpes. De la préhistoire à l'antiquité. Grenoble, Musée Dauphinois, 2008, p. 102-104.

Bocquet 1969-1970: BOCQUET (A.) - Catalogue des collections préhistoriques et protohistoriques du Musée Dauphinois. Grenoble, Musée Dauphinois, 1969/1970.

Bocquet 1991: BOCQUET (A.) - L'archéologie de l'âge du Fer dans les Alpes occidentales françaises. In: DUVAL (A.) éd., Les Alpes à l'âge du Fer, Actes du $\mathrm{X}^{\mathrm{e}}$ colloque de l'AFEAF (1986), Yenne-Chambéry, RAN supplément 22, 1991, p. 91- 155.

Bocquet 1997: BOCQUET (A.) - Archéologie et peuplement des Alpes françaises du Nord du Néolithique aux âges des Métaux. L'Anthropologie, tome 101, n 2, 1997, p. 291-411.

Brun 1987 : BRUN (P.) - Princes et princesses de la Celtique. Le premier âge du Fer. Paris, Errance, 1987, 217 p.

Brun 1992: BRUN (P.) - La place du Jura franco-suisse dans l'économie-monde méditerranéenne au premier âge du Fer: essai de modélisation. In: KAENEL (G.), CURDY (P.) dir., L'âge du Fer dans le Jura, Actes du XVe colloque de l'AFEAF, Pontarlier/Yverdon (1991), Cahiers d'Archéologie romande, 57, 1992, p. 189-205.

Chantre 1880: CHANTRE (E.) - Études paléoethnologiques dans le bassin du Rhône au $1^{\text {er }}$ âge du Fer. Nécropoles et tumulus. Paris, Baudry, 1880, 60 p. 
Courtois 1976: COURTOIS (J.-C.) - «Les civilisations de l'Age du Fer dans les Alpes». In: GUILAINE (J.) dir., La Préhistoire française. Tome II : Les civilisations néolithiques et protohistoriques de la France, 1976. Paris, CNRS, p. 708-723.

Curdy, Kaenel 2006: CURDY (P.), KAENEL (G.) - Les Celtes de l'âge du Fer. In: GALLAY (A.) dir., Des Alpes au Léman. Images de la Préhistoire. Gollion, In folio, 2006, p. 261-325.

Dictionnaire Archéologique de la Gaule 1875: Dictionnaire Archéologique de la Gaule (époque celtique). Paris, Commission constituée au Ministère de l'Instruction publique et des Beaux-Arts, 1875.

Gouin 1995: GOUIN (T.) - Contribution à l'étude de l'âge du Fer dans les Alpes du Nord. Influences et particularismes à travers l'étude de quelques sites. Mémoire de maîtrise sous la direction de T. Tillet et A. Bocquet, Grenoble 2, 1995.

Jospin, Vendittelli 2008: JOSPIN (J.-P.), VENDITTELLI (L.) - Un domaine pastoral en Chartreuse: celui des Avei. In: JOSPIN (J.-P.), FAVRIE (T.) dir., Premiers bergers des Alpes. De la Préhistoire à l'Antiquité. Grenoble, Musée Dauphinois, 2008, p. 137-138.

Milcent 2004: MILCENT (P.-Y.) - Le premier âge du Fer en France centrale. Paris, Société Préhistorique Française, 2004, 2 vol., 718 p.

Millotte 1963: MILLOTTE (J.-P.) - Le Jura et les plaines de la Saône aux âges des Métaux. Paris, Belles Lettres, 1963, p. 162.

Millotte 1999: MILLOTTE (J.-P.) - «Le peuplement des massifs cristallins savoyards. Une interprétation ou réinterprétation possible». In : CHAUME (B.), MOHEN (J.-P.), PÉRIN (P.), Archéologie des Celtes. Mélanges à la mémoire de René Joffroy. Montagnac, Monique Mergoil, 1999, p. 243-252.

Picavet 1991: PICAVET (R.) - L'abri sous roche de la Grande Rivoire à Sassenage (Isère). Approche diachronique et culturelle. Mémoire de diplôme de l'EHESS sous la direction de J. Guilaine, Toulouse, 1991.

Sabatier 1985: SABATIER (M.) - Les vallées de la HauteDurance et de l'Ubaye à l'époque protohistorique. Mémoire de l'école du Louvre sous la direction de René Joffroy, 1985.

Serrières 2007 : SERRIÈRES (L.) - Les sites fortifiés de hauteur de l'âge du Fer dans les Alpes du Nord françaises. Départements de la Drôme, de l'Isère et de la Haute-Savoie. Rapport de prospection thématique. DRAC-SRA Rhône-Alpes, rapport dactylographié, 2007.

Vital en préparation: VITAL (J.) dir. - La grotte des Balmes à Sollières-Sardières, en préparation.

Vital, Bintz 1991: VITAL (J.), BINTZ (P.) avec la coll. de ALCAMO (J.-C.), BILLARD (M.), CAILLAT (B.), GRÜNWALD (C.), STORDEUR (D.), THIÉBAULT (S.) Les occupations protohistoriques et historiques des sites du Cirque de Choranche (Isère). Gallia Préhistoire, 33, 1991, p. 207-267.

Willigens 1991 : WILLIGENS (M.-P.) - «Inventaire des découvertes de l'âge du Fer en Savoie et Haute-Savoie». In: DUVAL (A.) éd., Les Alpes à l'âge du Fer, Actes du Xe colloque de l'AFEAF (1986), Yenne-Chambéry, RAN supplément 22, 1991, p. 157-226. 


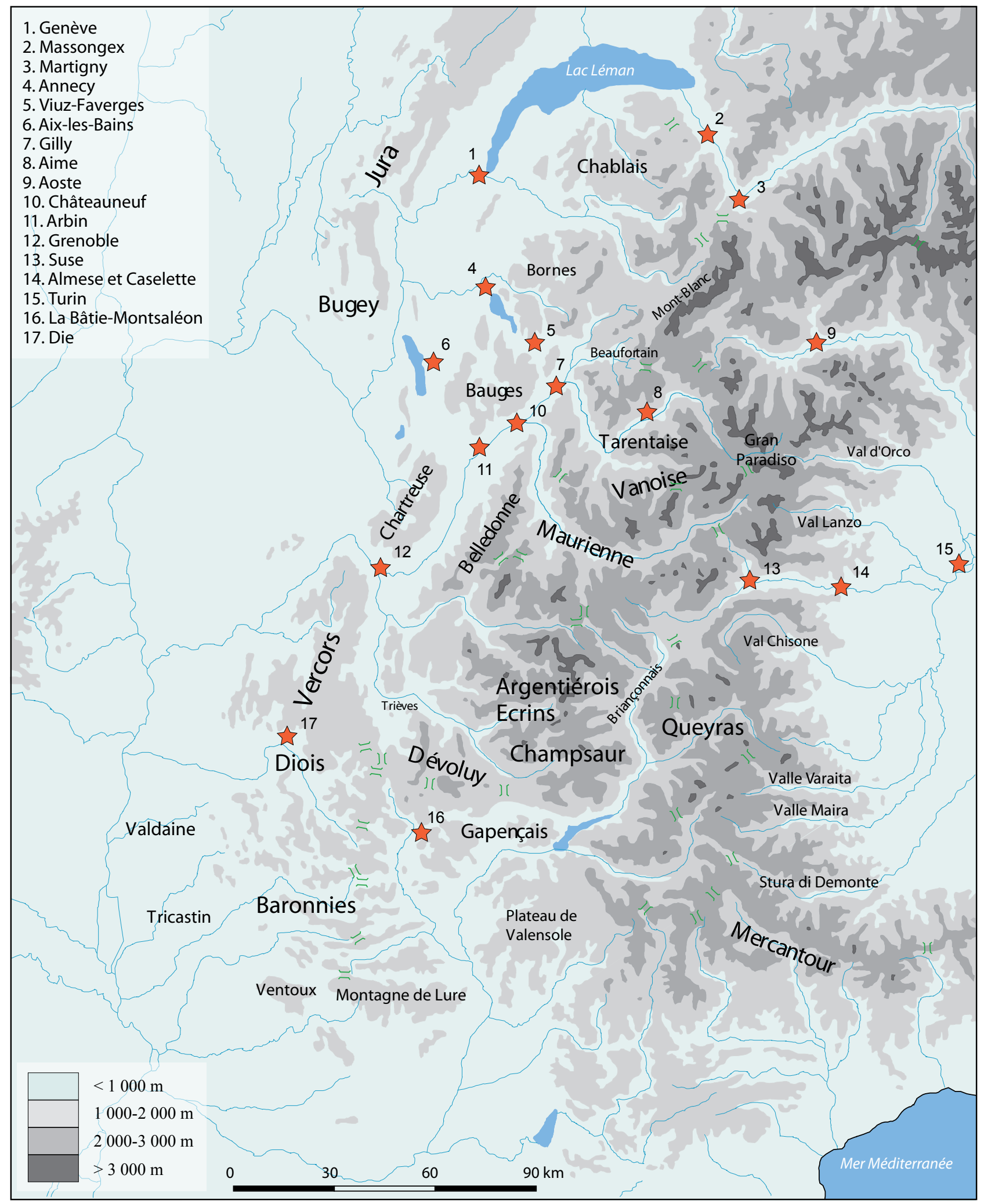

Fig. 1. Carte des principaux sites antiques dans I'arc alpin (vallées du Buëch et de la Drôme, bassins des lacs du Bourget, d’Annecy et du Léman, France ; haute vallée du Rhône, Valais, Suisse ; bordure de la plaine du Pô, Italie) (M. Segard, 2008). 


\title{
Données récentes sur l'occupation humaine dans les Alpes méridionales durant l'Antiquité
}

\author{
Florence MOCCI*, Maxence SEGARD*, Kevin WALSH** et Raphaël GOLOSETTI* \\ Avec la collaboration de Vincent DUMAS*, Carine CENZON-SALVAYRE***, \\ Brigitte TALON****
}

\begin{abstract}
Résumé. Parmi les nombreux travaux portant sur l'occupation du milieu alpin, très peu concernent la période antique. Les recherches, souvent anciennes, se sont focalisées sur des questions telles que les grandes voies transalpines, l'organisation administrative des régions alpines ou le développement urbain. L'occupation de ces régions était principalement appréhendée à travers quelques découvertes ou des fouilles anciennes, principalement dans les fonds de vallées des Alpes du Nord. Le développement de l'archéologie préventive a permis d'acquérir de nouvelles connaissances dans les zones basses mais ce sont surtout les recherches entreprises, depuis une dizaine d'années dans les Alpes méridionales, qui ont fait progresser les connaissances sur le peuplement de la montagne, en appréhendant ce milieu dans son ensemble, depuis les vallées jusqu'à la haute montagne.
\end{abstract}

\section{Recent research on human settlement in the Southern Alps during Antiquity}

Abstract. Amongst the many research projects dealing with the occupation of alpine landscapes, very few directly deal with the Roman period. Older research projects often emphasised the study of the major trans-Alpine routes, or the administrative organisation of the urban zones in the Alps. The settlement of these regions was primarily based on data from earlier excavations, mainly from the valley bottoms of the northernAlps. Rescue (or salvage) archaeology has enhanced our knowledge of lowland alpine archaeology, but it is the research undertaken during the past decade in the Southern Alps that increased our understanding of mountain populations covering all altitudes from valley bottoms to the high altitudes.

\section{Une connaissance du milieu alpin antique cantonnée aux fonds de vallée}

$\mathrm{L}$ 'intérêt croissant des historiens et des archéologues pour les territoires de montagne a conduit à des recherches autour de thématiques variées, mais peu se sont concentrés sur la période antique. Ce manque d'intérêt traduisait l'absence de problématiques propres à l'occupation de cet espace à l'époque romaine, contrairement aux préhistoriens, par exemple, abordant la conquête du milieu alpin, en termes de stratégies de chasse, de pastoralisme ou de recherche de matériaux lithiques (Beeching 1999; Della Casa 1999; Fedele 1990; Marguet et al. 2009). Pour la période romaine, les recherches, souvent anciennes, se sont focalisées sur des questions précises telles que le passage et les grandes voies transalpines, la conquête et l'organisation administrative des régions alpines voire, de façon secondaire, le développement urbain. Ces travaux, documentés par les sources littéraires ou épigraphiques, par certains vestiges urbains ou routiers importants (Aix, Aoste, Martigny, Suse, col du Grand-Saint-Bernard et vallée d'Aoste par exemple), témoignaient, avant tout, d'une

\footnotetext{
* Centre Camille Jullian (CCJ), UMR 6573 CNRS - Université de Provence, Maison Méditerranéenne des Sciences de l'Homme, 5 rue du château de l'Horloge, BP 647, 13094 Aix-en-Provence cedex 2.

** Department of Archaeology, King's Manor, University of York, Y017EP York (Grande Bretagne) et Centre Camille Jullian (CCJ), UMR 6573 CNRS - Université de Provence, Maison Méditerranéenne des Sciences de l'Homme, 5 rue du château de l'Horloge, BP 647, 13094 Aix-en-Provence cedex 2.

*** Laboratoire d'Archéologie Médiévale Méditerranéenne (LAMM), UMR 6572 CNRS - Université de Provence, Maison Méditerranéenne des Sciences de l'Homme, 5 rue du château de l'Horloge, BP 64713094 Aix-en-Provence cedex 2.

**** Institut Méditerranéen d'Écologie et de Paléoécologie (IMEP), UMR 6116 CNRS - Aix-Marseille, Université, Europôle de l'Arbois, 13545 Aixen-Provence.
} 
certaine perception des régions alpines, considérées sans intérêt économique, équipées et administrées par Rome, dans la seule perspective de les traverser (Segard 2009, 13-18, 85-89).

Dans les Alpes occidentales, les découvertes anciennes mais également la plupart des opérations archéologiques concernent avant tout les zones basses, en fond de vallée et à des altitudes souvent faibles (vallées du Buëch et de la Drôme, bassins des lacs du Bourget, d'Annecy et du Léman en France; haute vallée du Rhône, Valais suisse ; bordure de la plaine du Pô en Italie) (fig. 1). Plus précisément, quelques sites urbains majeurs (Aoste, Suse, Turin) et quelques villae (Almese, Caselette) caractérisent l'occupation antique des premiers reliefs, peu élevés, qui bordent la plaine du Pô (Armirotti 2003 ; 2004; Segard 2009, p. 36-45). Il en est de même dans le Valais, territoire cependant plus montagneux avec la vallée du Rhône et les terrasses la surplombant: Martigny, agglomération de Massongex, villa de Montheux (Segard 2009, p. 78-85). Le constat est identique dans les Alpes françaises où l'occupation était principalement appréhendée à travers des découvertes anciennes de fond de vallée (La Bâtie-Montsaléon, Arbin), mais également par quelques fouilles archéologiques réalisées dans les années 1960-80, principalement dans des grandes vallées ou les bassins densément peuplés des Alpes du nord (agglomérations d'Annecy, Gilly, Châteauneuf, Faverges, Thonon, Grenoble; villae de Faverges, d'Arbin, de Cognin ou de Fréterive) (Jourdain-Annequin 2004, p. 48-117; Segard 2009, p. 46-73).

Ce réseau dense de villes, agglomérations secondaires, sanctuaires, villae et autres établissements ruraux modestes témoignait d'une occupation des zones basses dont les modalités étaient peu différentes de celles observées dans les régions de plaine. À l'opposé, les zones de montagne demeuraient très mal connues, en dehors de découvertes isolées ou des cols traversés par les voies.

Le développement de l'archéologie préventive a certes permis de renouveler nos connaissances mais s'est peu écarté des fonds de vallées (Leveau 2002). Les hameaux de montagne du Haut-Valais (Brigue, Binn, Oberstalden, Loèche), mis au jour lors d'aménagements dans des vallées secondaires, font exception. Les travaux menés depuis la fin des années 1990 révèlent une forme d'occupation jusqu'alors méconnue pour la période romaine : hameaux construits en terrasses dont l'organisation et les modes de construction, proches des chalets actuels en pierre et en bois, évoluent peu entre l'âge du Fer et la fin de l'Antiquité (Paccolat 1998 ; 2004; Segard 2009, p. 23-29).

Dans les Alpes méridionales françaises, des travaux diachroniques entrepris depuis une dizaine d'années par des laboratoires du CNRS/Aix-Marseille Université 1 et du Département d'Archéologie de l'Université de York (Grande-Bretagne) ont fait progresser les connaissances sur le peuplement de la montagne, en appréhendant ce milieu dans son ensemble, depuis les vallées jusqu'à la haute montagne (Della Casa, Walsh 2007; Mocci et al. 2009; Richard, Garcia 2008). Cet article présente les apports de ces travaux à la connaissance des différentes formes de l'occupation de la montagne durant l'Antiquité, en insistant sur l'exemple de sites qui ont fait l'objet d'opérations archéologiques programmées récentes, dans les hauts massifs, au-delà de 2200 m d'altitude (Freissinières, Champsaur parcs nationaux des Écrins et du Mercantour), et les hautes vallées de la Durance (sites de Rama et du Clapier des Monges, Hautes-Alpes) et de l'Esteron (col d'Adon, Alpes-Maritimes) (fig. 2-3).

\section{Des vallées aux sommets : l'occupation antique dans les Alpes méridionales}

Dans les Alpes méridionales, l'occupation romaine des zones basses est relativement bien documentée grâce aux découvertes anciennes et aux opérations programmées ou préventives récentes (agglomérations de Riez, le Bourguet/ l'Escale, La Bâtie-Montsaléon, Die, Luc, Embrun, Ventavon, Monétier-Allemont, Gap...) (Segard 2009, p. 66-73). En revanche, très peu d'établissements ruraux sont bien connus malgré les données apportées par les prospections pédestres ou les découvertes fortuites (Leveau 2003; Leveau, Segard 2004).

À la fin des années 1990, des programmes de recherche pluridisciplinaires sur les dynamiques naturelles et sociales du peuplement en moyenne et haute montagne des massifs de l'Argentiérois, du Champsaur (Parc National des Écrins) et de l'Ubaye (Parc National du Mercantour) ont révélé la présence, à des altitudes supérieures à $2000 \mathrm{~m}$, d'une fréquentation humaine durant l'Antiquité (fig. 2) (Leveau, Walsh 2005; Mocci et al. 2006; 2008; Segard 2009, p. 190-200; Segard et al. 2003; Tzortzis et al. 2008; Walsh 2005; Walsh, Richer 2006) ${ }^{1}$. Cette fréquentation

1. Dans le Parc National des Écrins, les travaux archéologiques de terrain (prospections, sondages et fouilles programmées) sont conduits sous la direction de K. Walsh (Université de York), F. Mocci (CCJ) et J.-M. Palet-Martinez (Université de Barcelone). La vallée de l'Ubaye et le Parc National du Mercantour ont fait l'objet d'un PCR Histoire d'une vallée alpine. L'Ubaye des âges des Métaux aux Temps modernes (coord. D. Garcia et F. Mocci, CCJ); les opérations de terrain en haute Ubaye ont été réalisées par F. Mocci et K. Walsh (Jausiers, Larche et Saint-Paul-sur-Ubaye). Les relèves archéologiques et le Modèle Numérique de Terrain des sites et de leur environnement sont dirigés par V. Dumas (CCJ). L'analyse microscopique des poussières visant à mettre en évidence d'éventuels indices de la présence d'animaux domestiques est réalisée par J.-L. Brochier (LAMPEA). Les carottages palynologiques ont été menés par M. Court-Picon, J.-L. De Beaulieu, F. Guiter et S. Richer (IMEP/Université de York). L'étude anthracologique est conduite par B. Talon (IMEP). 
se manifeste par la présence de vestiges divers tels que la petite cabane isolée de Faravel XIV à $2450 \mathrm{~m}$ (50 BC-80 cal. AD; Freissinières), un niveau d'érosion sur le Col du Palastre II à $2200 \mathrm{~m}$ (110-260 cal. AD; Saint-Jean-SaintNicolas), l'abri du site du Lauzanier sud I à 2359 m (60180 cal. AD; Larche) (fig. 4A, B, C) ${ }^{2}$. Ces occupations, également observées dans le Vercors (Picavet, Morin 2008) ou en Tarentaise (Rey et al. 2009), sont liées à des activités saisonnières difficiles à identifier vu le caractère fugace des indices archéologiques (pastoralisme mais également agriculture de montagne - prés de fauche surtout -, sylviculture...). Cependant, la confrontation des données archéologiques et paléoenvironnementales met en évidence, pour cette période (mais aussi pour l'âge du Fer), une continuité des activités pastorales mais d'importance modeste (Court-Picon 2007; Mocci et al. 2009; Richer 2009; Segard 2009, p. 177-196)3. Les importants changements politiques, sociaux et économiques durant ces deux périodes ne semblent pas pour autant à l'origine d'évolutions majeures dans l'exploitation de ces espaces d'altitude. Nous pouvons aussi évoquer les activités minières et métallurgiques connues dans ce secteur pour les périodes médiévale et moderne (Py, Ancel 2007). L'extraction et la transformation du minerai à l'époque romaine ne sont pas documentées ici, mais reconnues dans d'autres massifs (prospections récentes dans le Mercantour notamment, Morin, Rosenthal, Fontugne 2007).

À ces travaux sur les hauts massifs argentiérois est associée la question spécifique de l'occupation romaine dans les basses vallées, avec notamment une multiplication des opérations d'archéologie préventives, à Briançon, Gap et surtout à Embrun, où un quartier de la ville romaine a été mis au jour en 2008 (Reynaud, Frangin 2009). C'est dans cette perspective, visant à définir la connaissance du peuplement et de la vie économique de la montagne à différents étages, que s'inscrivent, pour exemples, trois sites archéologiques, en cours d'étude, dans deux espaces alpins distincts, la haute vallée de la Durance (Hautes-Alpes) et la haute vallée de l'Esteron (Alpes-Martimes). Chacun de ces sites renvoie à une problématique: l'occupation des campagnes avec, à proximité, la ville romaine d'Embrun, pour le site de la Mure (alt. $800 \mathrm{~m}$ ); l'identification et la

2. Faravel XIV: $1985 \pm 50$ BP, Pa 2097; Col du Palastre II: 1915 $\pm 80, \mathrm{~Pa} 2239$; Lauzanier sud I: $1955 \pm 50, \mathrm{~Pa} 2367$. Ces datations carbone 14 conventionnelles ont été calibrées avec un indice de confiance de probabilité de deux sigma par J.-F. Saliege, Laboratoire d'Océanographie Dynamique et Climatologique de Jussieu, UMR 121, Paris.

3. Ces résultats sont très bien attestés notamment par les analyses polliniques issues des lacs des Lauzons (Champsaur), du Serre de l'Homme (Argentiérois) et du Lauzanier (Haute-Ubaye). Les datations carbone 14 des carottages des trois zones d'étude (Argentierois, Champsaur et Ubaye) ont été financées en grande partie par le GDR du CNRS « JurAlpes » (dir. M. Magny, M. Desmet et F. Mocci). caractérisation d'un site connu par les documents routiers en bordure de la Durance, pour le site de Rama (alt. 930 m); l'identification et la caractérisation d'un lieu de culte et de son environnement naturel et humain, pour le site du Col d'Adon (alt. 988 m) (fig. 3).

\subsection{Le site de la Mure (Baratier, Hautes-Alpes)}

Localisé en rive gauche de la Durance, à $2 \mathrm{~km}$ au sud d'Embrun, le site de La Mure (alt. $800 \mathrm{~m}$ ) est installé en bordure d'une terrasse qui domine d'une vingtaine de mètres le lit de la rivière (actuellement occupé par le lac de SerrePonçon). Les fouilles entreprises depuis 2005 ont permis de dégager les vestiges partiels d'un établissement antique très bien conservé (Segard 2008). Les élévations présentent une hauteur moyenne de 1,50 m et atteignent jusqu'à 2,20 m. L'état actuel des connaissances permet d'identifier plusieurs espaces sur environ $200 \mathrm{~m}^{2}$ (fig. 5-6). La pièce 1, de grandes dimensions (13 m sur une largeur inconnue), est dotée d'un épais sol en béton de tuileau. La présence de niveaux de toiture effondrée uniquement en bordure du mur 3, et de peintures murales orangées en place sur celui-ci suggère d'identifier une cour bordée d'un auvent. Elle ouvrait par une porte sur une grande pièce de $35 \mathrm{~m}^{2}$ chauffée par un hypocauste à canaux rayonnants. Le niveau de la pièce attenante est plus bas de $40 \mathrm{~cm}$, et l'ouverture était pourvue d'une marche. Le niveau estimé du sol de la pièce 4 (le côté nord-ouest; entièrement visible dans la pente, présente des élévations qui atteignent $3 \mathrm{~m}$ ) confirme l'hypothèse d'un aménagement en terrasses. Il faut donc imaginer que la porte dans le mur 5-6 était dotée de plusieurs marches ( $1 \mathrm{~m}$ de dénivelé environ).

Le soin apporté à la construction, la présence d'une pièce chauffée et de peintures murales dans toutes les pièces (et même d'un plafond peint dans la pièce 3 , attesté par les nombreux fragments d'enduit portant au revers l'empreinte d'un lattis végétal) révèlent que les espaces identifiés appartiennent à la partie résidentielle d'une habitation rurale. Quelques découvertes fortuites suggèrent que celui-ci s'étendait sur le replat au nord-est. On ne dispose malheureusement que de peu d'éléments chronologiques sur l'occupation du site. On sait cependant qu'il a connu, peu de temps après son abandon, une importante période de récupération des matériaux (moellons, tuiles, briques) identifiée par des tranchées dans le sol en béton de la salle à hypocauste. Cette phase est associée à une réoccupation (porte dans le mur 7 comblée, murs 3 et 7 reconstruits). Quelques tessons et les monnaies provenant de ces niveaux orientent vers l'Antiquité tardive (amphore lusitanienne, DSP). Par ailleurs, plusieurs dizaines de monnaies des $I^{\mathrm{e}}-\mathrm{V}^{\mathrm{e}} \mathrm{s}$. ont été découvertes aux alentours du site. Le fait que l'hypocauste à canaux rayonnants soit surtout documenté dans des aménagements de la fin de l'Antiquité (par exemple dans 


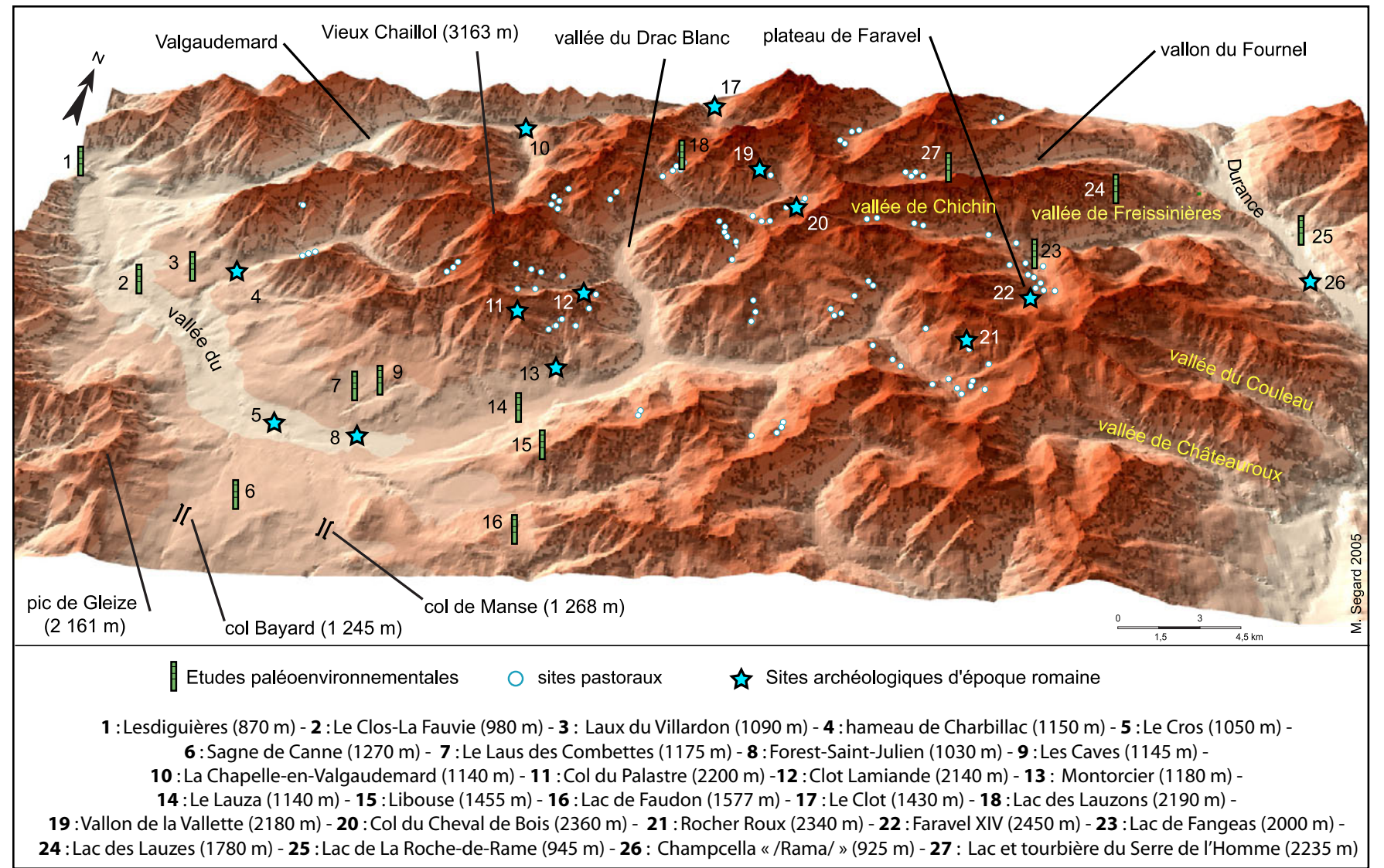

Fig. 2. Carte des découvertes archéologiques et sites étudiés par les palynologues dans les massifs du Champsaur et de l'Argentiérois (M. Segard, 2008).

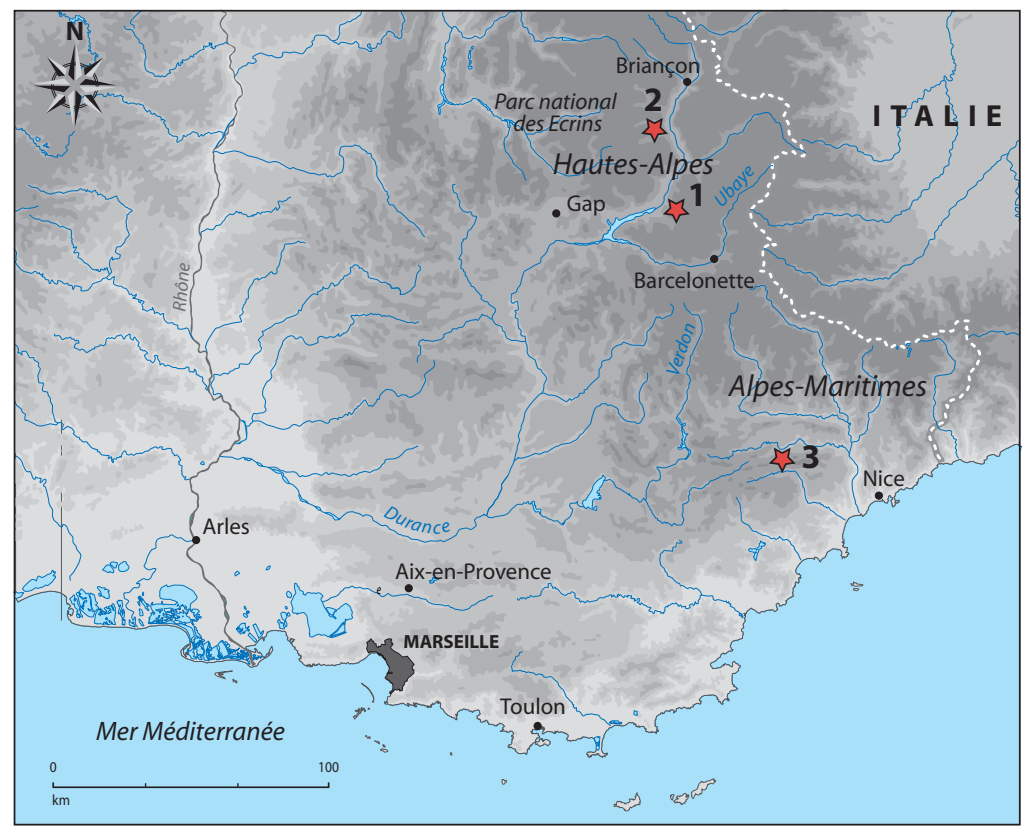

Fig. 3. Carte des sites antiques dans la haute vallée de la Durance : 1. La Mure, Baratier, alt. 800 m, 2. Rama, Champcella, alt. 928 m; et dans la haute vallée de l'Esteron : 3. Col d'Adon, Les Mujouls, Alpes-Maritimes, alt. 988 m (V. Dumas, CCJ-CNRS, 2009). 

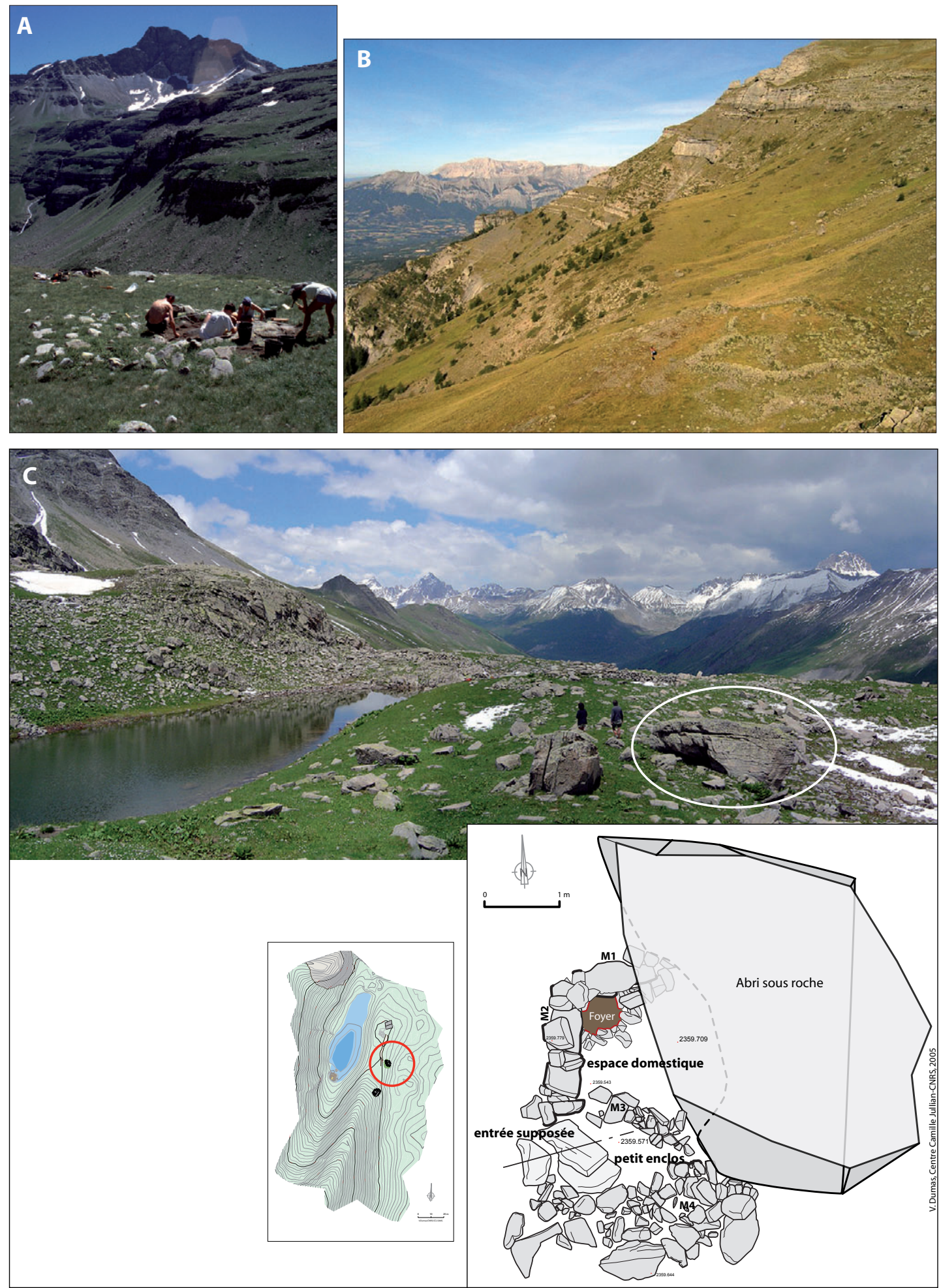

Fig. 4. A. Site de Faravel XIV à 2450 m d'altitude. Phase d'occupation : 50 BC-80 cal. AD. Freissinières, Parc National des Écrins, Hautes-Alpes. B. Structures pastorales du col du Palastre à $2200 \mathrm{~m}$ d'altitude. Phases d'occupation : 1220-790 cal BC ; 110-260 cal. AD. Vue depuis l'est (cliché K. Walsh, 2006). Saint-Jean-SaintNicolas, Haut-Champsaur, Hautes-Alpes. C. Vue panoramique sur le lac et l'abri sous roche du Lauzanier sud I à 2359 m d'altitude. Phases d'occupation: 3270-2890 cal BC; 1880-1530 cal. BC; 60-180 cal. AD. Larche, Parc National du Mercantour, Alpes-de-Haute-Provence (cliché N. Trustram-Eve, 2005). Relevé pierre à pierre et MNT (V. Dumas, CCJ-CNRS). Fouille archéologique 2005. 
plusieurs pièces de la villa des Prés Bas à Loupian au IV $\mathrm{s}$.; Bouet 2003, vol. 2, p. 143-145) conforte l'hypothèse d'une datation basse de l'aménagement des pièces à sol en béton. L'établissement de La Mure renvoie ainsi à la proximité d'Embrun/Eburodunum, bourgade connue de Strabon puis chef-lieu de la civitas Ebrodunens(ium), dans les Alpes Cottiennes dès le $\mathrm{I}^{\mathrm{er}} \mathrm{s}$. ap. J.-C., dont le développement majeur remonte au règne de Dioclétien. Nouvelle capitale des Alpes-Maritimes auxquelles ce secteur est alors intégré, Embrun devient également le siège d'un évêché (Beaujard 2006). Bien qu'on ignore l'étendue de la ville à cette époque, on peut supposer que la concentration des fonctions de l'ensemble de la province et l'importance d'Embrun ont contribué au développement des campagnes environnantes. À ce titre, on peut imaginer un personnage important qui exerçait des fonctions à Embrun et qui possédait une résidence peu éloignée, sur l'autre rive de la Durance.

\subsection{La station routière de Rama (Champcella, Hautes-Alpes)}

Le site de Rama est localisé à 928 m d'altitude, sur la terrasse alluviale d'une étroite vallée nord/sud bordant la rive droite de la Durance, à l'extrémité nord-est de la commune de Champcella. À l'ouest, la terrasse est surplombée par la falaise de la Poua et par le gouffre de Gourfouran d'où débouche le torrent de la Byaisse qui longe le site $180 \mathrm{~m}$ environ plus au nord jusqu'à sa confluence avec la Durance (fig.7A). Sur la rive gauche de la Byaisse subsistent les vestiges du site médiéval de Rame abandonné au $X V^{\mathrm{e}} \mathrm{s}$. (Manteyer 1932; Pogneaux 1997).

La mutatio de Rama, mentionnée par les itinéraires antiques entre Eburodunum et Brigantium, était implantée sur un axe majeur à l'époque romaine, la via Cottia, prolongement alpin de la via Domitia qui, par le col du Montgenèvre, permettait le passage vers la plaine du Pô. Depuis le XIX ${ }^{\mathrm{e}}$ s., un certain nombre de découvertes fortuites ont incité à localiser cette station dans le vallon dit de Rame, à proximité du site médiéval (Ganet, 1995, 99) voire en rive droite du torrent de la Byaisse (Walsh, Mocci 2003, 188). Le site fut précisément localisé en 2003 avec la présence d'anomalies dans un champ de luzerne révélant partiellement, sur une superficie de $1843 \mathrm{~m}^{2}$, un établissement organisé autour de deux grandes cours et d'un bâtiment à abside plus tardif (Congès, Leveau 2005, p. 109; Segard 2009, p. 89) ${ }^{4}$ (fig. 7B). Cette découverte a conduit, en 2005 et 2006, à la

4. Photographies prises entre juin et juillet 2003 par J.-L. Flandin, R. Chef, R. Lestournelle et A. Prorel (Société Géologique et Minière du Briançonnais). réalisation de deux opérations archéologiques 5 ; la fouille de 2006 (tranchée est/ouest de $140 \mathrm{~m}$ de long sur 1 à $3 \mathrm{~m}$ de large $)^{6}$ a confirmé la profondeur et le bon état de conservation des vestiges ainsi que leur recouvrement antérieurement à l'époque médiévale.

Plusieurs aménagements antiques et des structures géomorphologiques ont été partiellement mis au jour, entre 1,20 et 2,20 $\mathrm{m}$ de profondeur (fig. 8A-E). Les aménagements correspondent à deux espaces de circulation (E1, $\mathrm{E} 3$ ), un vaste bassin reconnu sur 3,20 $\mathrm{m}$ de long et $1 \mathrm{~m}$ de large (E2/M3-M4) et une petite structure sommaire (E6). L'espace E1, large de 4,40 m (portique ?) est bordé par deux murs parallèles (M2-M1) construits en moellons équarris et en galets, liés au mortier (fig. 8c-d); le parement externe du mur M1, associé à un sol en terre battue, a été dégagé sur 1,20 m de haut (E3) (fig. 8a-d). Ces espaces (dont le sol de circulation de l'espace E1) étaient recouverts par un important niveau de destruction (blocs, tegulae et imbrices à plat). Prenant appui sur ce niveau et sur le mur M1, une petite construction (E6/M5-M6), délimitée par des amas de blocs et de tegulae sur lesquels s'élevaient des cloisons en torchis, était bordée par un petit foyer dont le remplissage a été daté entre 250-410 cal. AD (Poz 18878) (fig. 8A-E). L'ensemble des vestiges était dissimulé par une épaisse couche charbonneuse témoignant d'un incendie (datation ${ }^{14} \mathrm{C}$ : 250-420 cal. BC) (Poz 18879) puis par des sédiments de crue d'un cours d'eau jusqu'alors insoupçonné7. Ce cours d'eau, de direction nord/sud et large d'une vingtaine de mètres, a été partiellement mis au jour en bordure ouest des vestiges antiques (E5), à une centaine de mètres à l'est de la falaise de la Poua (fig. 7C, 8B). La chronologie des périodes d'activité les plus anciennes de ce paléochenal est difficile à établir (base non atteinte). Néanmoins, l'importante phase de crue recouvrant les constructions antiques après leur abandon, semble être intervenue au cours du $\mathrm{V}^{\mathrm{e}} \mathrm{s}$. ap. J.-C. En revanche, aucune crue liée à la Durance, située 200 m environ plus à l'est, n'a été reconnue. À l'extrémité est de la tranchée, un fossé, correspondant à une

5. Ces opérations ont été menées sous la direction de Florence Mocci (CNRS-Centre Camille Jullian), et de Kevin Walsh (Université de York, Angleterre), dans le cadre d'une convention regroupant la Communauté des Communes du Pays des Écrins (maîtrise d'ouvrage et charge financière de l'opération), le Parc National des Écrins, le Département d'Archéologie de l'Université de York et le Centre Camille Jullian (CNRS), le Service Régional d'Archéologie PACA, les Communes de Champcella et de l'Argentière-la-Bessée. La prospection géophysique (Université de York) a révélé, au nord des vestiges enfouis, des indices de restes structuraux sans doute anthropiques (chemin, constructions, zones de destruction).

6. Cette tranchée a été établie en bordure nord des vestiges enfouis, localisés sur quatre parcelles comportant plus d'une vingtaine de propriétaires..

7. Ces datations carbone 14 conventionnelles ont été calibrées avec un indice de confiance de probabilité de deux sigma (Poznań Radiocarbon Laboratory, Foundation of the Adam Mickiewicz, Pologne). 


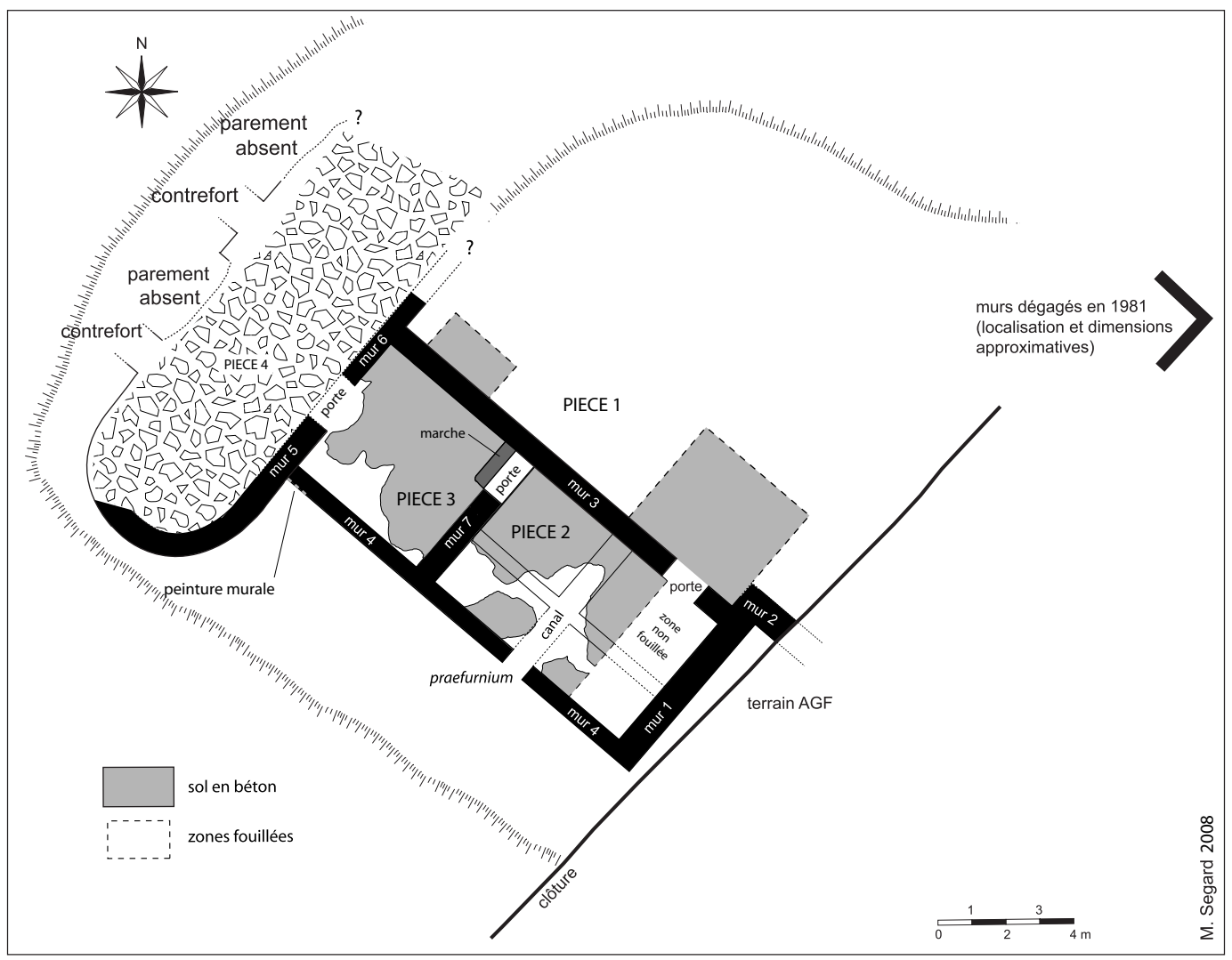

Fig. 5. Plan des vestiges du site de la Mure, Baratier, Hautes-Alpes (M. Segard, 2008).

ancienne limite parcellaire nord/sud, s'appuie sur une structure formée d'un double alignement de galets (larg. $2 \mathrm{~m}$ ), construite dans l'axe de la porte d'entrée du site médiéval. L'analyse de la faune archéologique révèle des espèces peu variées (mouton, porc et cheval) ${ }^{8}$. L'étude anthracologique du foyer, des niveaux de destruction et d'incendie apporte une très bonne image de la mosaïque paysagère, avec la présence d'arbres susceptibles de croître à proximité immédiate, comme les érables, les chênes, les saules, les bouleaux, et les rosacées. La fréquence des occurrences de pin cembro, associée aux pins sylvestres/à crochet, aux épicéas et mélèzes, témoigne de l'exploitation de tout le bassin versant dès cette époque.

Dans l'état actuel des connaissances, la découverte, dans les niveaux de crues du paléochenal, de fragments de céramiques non tournées de la fin de l'âge du Bronze-1 ${ }^{\text {er }}$ âge du Fer révèle la présence d'urnes funéraires à proximité du site antique. Pour la période antique, les vestiges et le mobilier archéologique (céramiques communes, céramiques sigillées et culinaires africaines, trois monnaies dont une de Gordien, vaisselle en verre du début du V $\mathrm{V}^{\mathrm{e}} \mathrm{s}$ )

8. L'étude de la faune a été réalisée par Philippe Columeau (CNRSCentre Camille Jullian, UMR 6573); l'analyse anthracologique par C. Cenzon-Salvayre et B. Talon. révèlent une première phase d'occupation au Haut-Empire (E1, E2, E3), une destruction partielle du site (à la fin du $\mathrm{III}^{\mathrm{e}} \mathrm{s}$. ap. J.-C) puis une réoccupation à l'Antiquité tardive (début IVe-début V ${ }^{\mathrm{e}}$ s. ap. J.-C., E6, E4).

Le site antique de Rama met en avant l'importance des vallées alpines comme voies de passage transalpines et s'inscrit au sein d'une réflexion plus générale sur le problème d'identification des établissements mentionnés sur les itinéraires routiers (Leveau 2002; 2004). La fréquente association agglomération/grande villa pose aussi la question de la diversité de formes, de statuts et de fonctions de ce type d'établissement en milieu rural et alpin (Segard 2009, p. 86-94).

\subsection{Habitat et sanctuaire gallo-romains du col d'Adon (Les Mujouls, Alpes-Maritimes)}

Implanté en périphérie par rapport à la zone qui fait l'objet de cet article, le site du col d'Adon est localisé dans la partie occidentale du département des Alpes-Maritimes, dans le Haut-Esteron et les Préalpes du Cheiron. La topographie se présente sous la forme d'un col situé à $988 \mathrm{~m}$ dans un paysage semi-ouvert entre le Mont Mal (1071 m) et la montagne de Charamel (1225 m) (fig. 9A). N'ayant jamais fait l'objet de campagne de fouille jusqu'aux recherches actuelles débutées en 2006, l'occupation gallo-romaine 


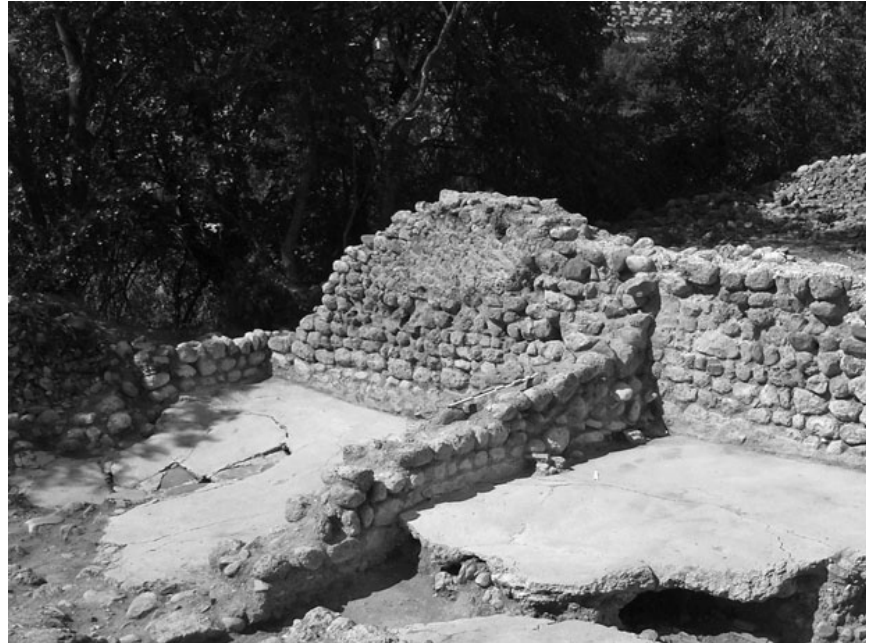

Fig. 6. Vue depuis le sud des pièces 2 et 3 du site de la Mure, Baratier, Hautes-Alpes (cliché M. Segard, 2008).
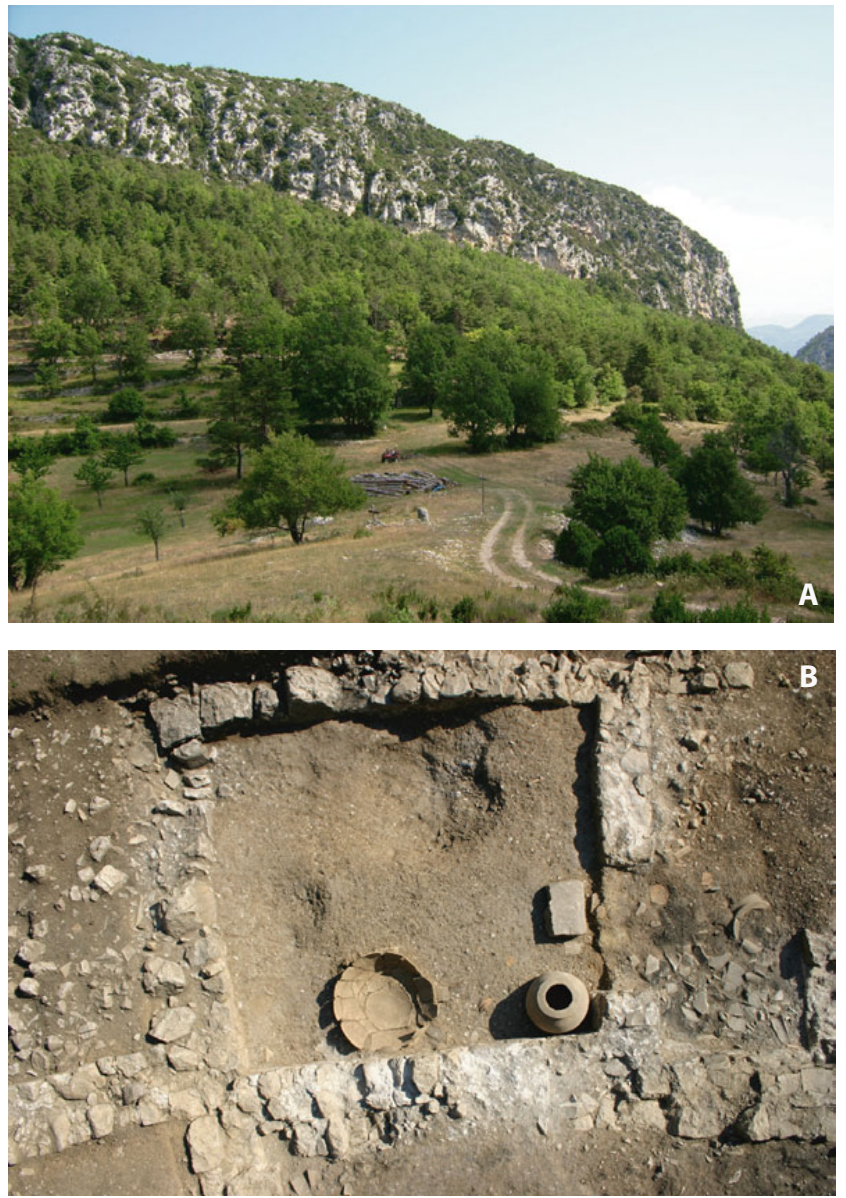
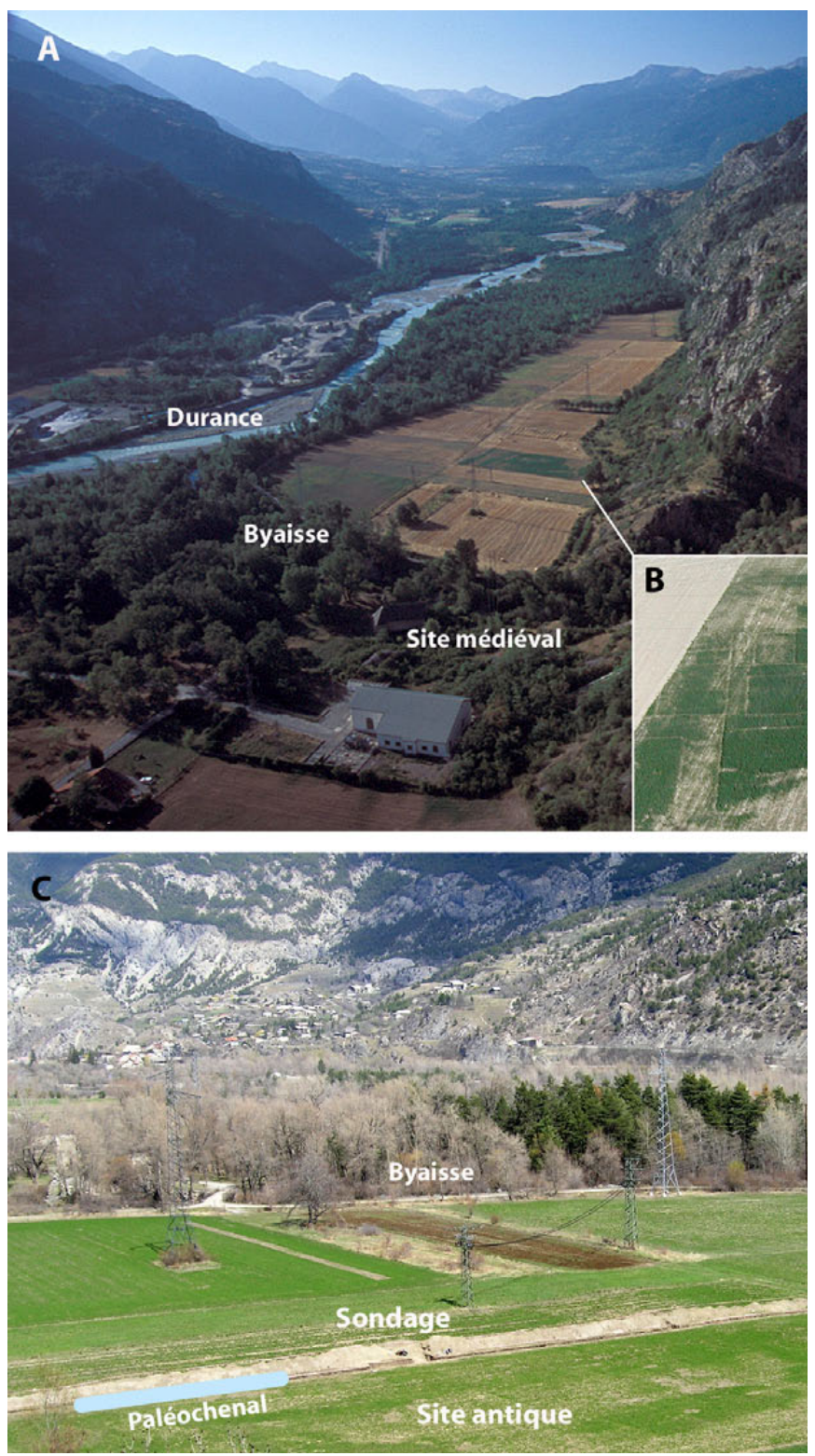

Fig. 7. A. Vue depuis le nord-ouest du vallon et des sites archéologiques de Rame (Champcella, Hautes-Alpes) (cliché

L. Damelet, CCJ-CNRS, 2003). B. Vue depuis l'ouest des anomalies phytographiques révélant le site antique de Rame (détail, cliché L. Damelet, CCJ-CNRS, 2003). C. Vue depuis le sud-ouest du sondage archéologique réalisé en 2006 en bordure des vestiges enfouis (cliché F. Mocci, CCJ-CNRS, 2006).

Fig. 9. A. Cliché du col d'Adon depuis le sud-ouest, Les Mujouls (R. Golosetti, CCJ-CNRS 2008). B. Vue zénithale de I'espace 3 (zone 4) (cliché V. Dumas, CCJ-CNRS, 2008). 


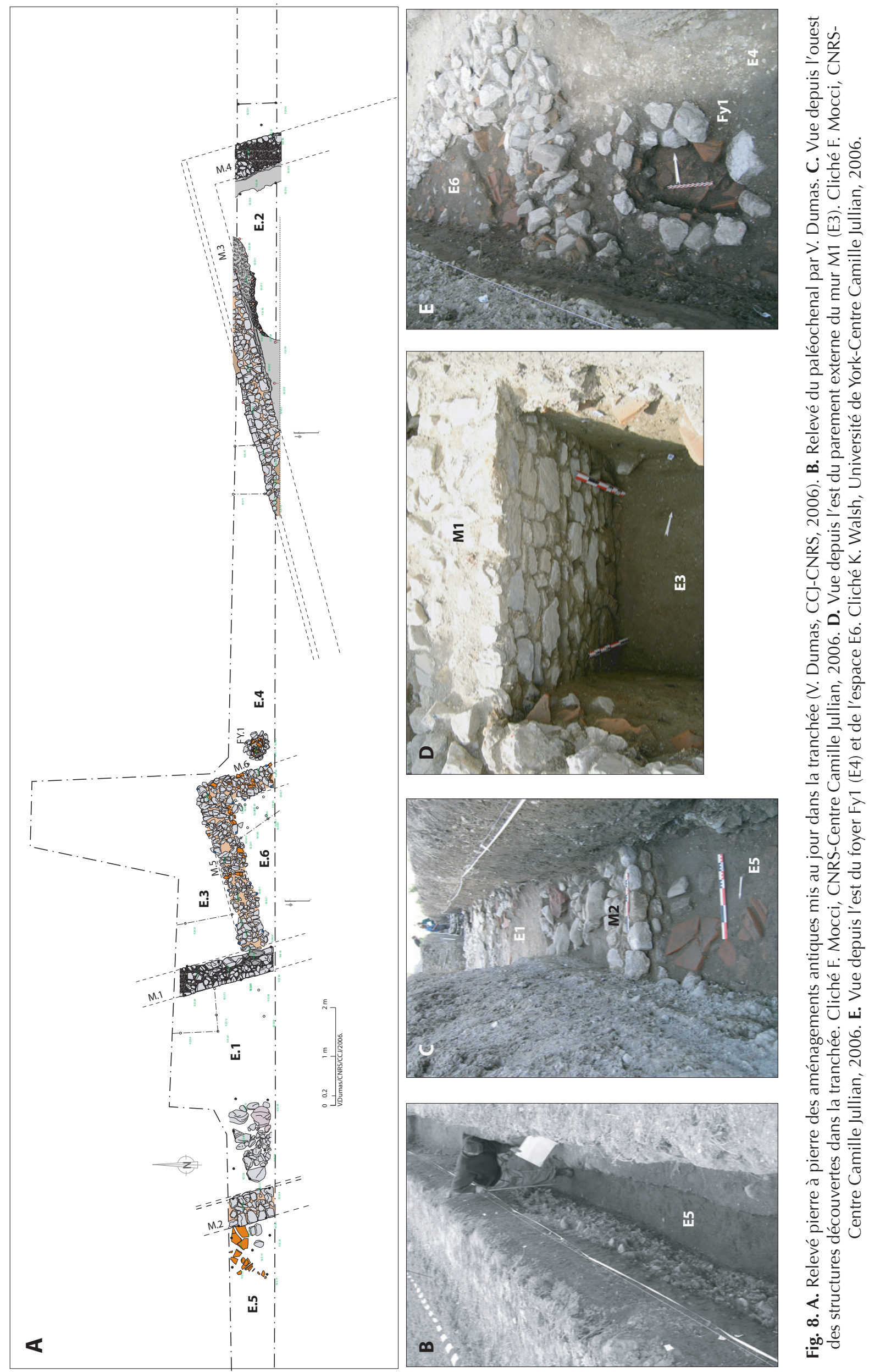


était notamment connue par la découverte, vers 1880, outre d'un matériel amphorique et monétaire, d'un autel en calcaire (A.E. 1971, $85 \mathrm{n}^{\circ}$ 241) mentionnant la réalisation d'une aedes à Deus Mars Veracinius. À ce jour, le sanctuaire n'est pas véritablement localisé9 mais les travaux récents ont largement contribué à définir l'importance et le mode d'occupation gallo-romaine du col (Golosetti 2009). Deux campagnes archéologiques ${ }^{10}$ et une campagne de prospection magnétique menée par P.-E. Mathé et J. Gattacceca (CEREGE, UMR 6635 CNRS/Université Paul Cézanne Aix-Marseille) ont livré des résultats particulièrement positifs (fig. 10). Il est apparu un établissement rural gallo-romain dont la prospection magnétique a permis de définir l'extension est-ouest à environ $23 \mathrm{~m}$ et une extension nord-sud minimale d'environ 7,5 m (fig. 2) soit environ $172,5 \mathrm{~m}^{2}$. La fouille extensive de cet établissement a permis de mettre au jour au moins sept espaces délimités par des murs maçonnés et une sablière basse (TR 4055) (fig. 11). L'espace 3 est le mieux caractérisé par la mise en évidence d'une fonction de stockage avec au moins cinq vases de stockage de dimensions variées dont deux dolia découverts in situ alors que les trois autres sont signalés par les fosses de récupération (fig. 9B) ${ }^{11}$. La présence d'un important lot matériel de céramique commune à pâte claire et kaolinitique (dont certains fonds percés en leur centre: pot horticole ?) et surtout, sur le sol de circulation, d'une palette à fard associée à la spatule ne permet pas cependant de spécifier cet espace dans l'activité de stockage alimentaire.

L'abandon du site intervient dans la seconde moitié du $\mathrm{II}^{\mathrm{e}} \mathrm{s}$. ap. J.-C., voire à la fin du $\mathrm{II}^{\mathrm{e}} \mathrm{s}$. La date d'installation est plus délicate à assurer, les premiers niveaux n'ayant pas encore été fouillés mais néanmoins la présence d'un matériel de la toute fin du $\mathrm{I}^{\mathrm{er}} \mathrm{s}$. av. J.-C.-début du $\mathrm{I}^{\mathrm{er}}$ s. ap. J.-C. dans différents niveaux indique clairement une occupation du site dès l'époque augustéenne.

Les interventions de prospection magnétique et de fouilles archéologiques témoignent de l'importance de l'occupation gallo-romaine sur le col. Des vestiges de construction, toutes contemporaines et situées dans les deux premiers siècles de notre ère, s'étendent dans le bas du versant nord du col sur une zone au minimum d'environ 90 m d'est en ouest et sur environ $40 \mathrm{~m}$ nord-sud soit sur une superficie de $3600 \mathrm{~m}^{2}$ (fig. 10). Ces premières données commencent à laisser entrevoir l'existence d'un véritable petit habitat groupé implanté sur le versant nord du col. Ce site d'habitat, pourtant dans une situation périphérique à l'extrémité

9. Seule l'identification récente d'un chaperon d'angle en calcaire vient enrichir le dossier concernant le lieu de culte proprement dit.

10. Sous la direction de R. Golosetti et avec la collaboration de V. Dumas (CNRS/CCJ), F. Mocci (CNRS/CCJ) et K. Walsh (University of York). 11. Le NMI provisoire des dolia d'après le mobilier recueilli est de huit individus. des Alpes méridionales, se révèle particulièrement stimulant pour la réflexion sur l'implantation en milieu alpin à la période gallo-romaine. Il représente ainsi un des plus hauts habitats permanents de la période romaine ayant fait l'objet de fouille. Le développement d'une problématique géoarchéologique en cours apportera des données nouvelles quant à la compréhension de l'installation de versant à la période romaine.

\section{Conclusion}

Parce qu'ils ont su s'affranchir de traditions de recherches centrées sur les zones basses, les travaux menés dans les Alpes du Sud depuis une dizaine d'années ont permis de renouveler notre connaissance de l'occupation antique des régions de montagne. L'investissement sur les zones d'altitude, le plus souvent appréhendées dans la diachronie, a montré que ces espaces étaient couramment fréquentés, pour des activités non seulement pastorales, mais également minières, voire agricoles et de prédation (chasse notamment). L'absence de mobilier dans les cabanes ou abris datés de l'époque romaine, ou le mode de construction sommaire de ceux-ci, parfois interprétés comme des indicateurs de populations isolées et à l'écart des changements de cette période, ne sont pas davantage que les caractéristiques normales d'une fréquentation saisonnière de la haute montagne. Le faible nombre des sites de haute montagne, auquel font écho les données environnementales, témoigne d'un investissement modéré de ces espaces, et sans doute pas, sauf ponctuellement, d'une accentuation de leur exploitation. À l'opposé, les vallées et autres zones basses voient leur rôle structurant confirmé. Les principales routes empruntent les grands axes naturels, où se concentrent les villes et de nombreux établissements ruraux. C'est dans ces espaces qu'on observe les changements de mode de vie, les changements sociaux et économiques à travers l'urbanisation, la diffusion de modes de construction, de mobilier ou de pratiques funéraires romains. Pour autant, les grandes vallées ne doivent pas être exclusivement considérées comme des zones de passage. Elles constituent, au même titre que les montagnes qui les entourent, un territoire disposant de ressources variées. La forte densité de villae et de fermes dans certaines vallées en témoigne. On ne doute pas davantage que les villes, petites et grandes, ne devaient pas leur existence uniquement à des enjeux stratégiques et politiques ou à leur place le long d'une voie. Elles étaient au cœur de territoires mis en valeur, auxquels elles assuraient des débouchés et aux populations desquelles elles pouvaient fournir ce qu'elles ne produisaient pas. 


\section{Bibliographie}

Armirotti 2003: ARMIROTTI (A.) - Rete viaria e insediamenti minori nel territorio valdostano in epoca romana e tardoantica. B.E.P.A.A., XIV, 2003, p. 9-220.

Armirotti 2004: ARMIROTTI (A.) - Insediamenti d'alta quota in valle d'Aosta in età romana: il caso di Vetan. B.E.P.A.A., XV, 2004, pp. 271-282 [DAUDRY (D.) dir., Actes du Xe colloque international sur les Alpes dans l'Antiquité, Cogne, Vallée d'Aoste, 12-14/09/2003].

Beaujard 2006: BEAUJARD (B.) - Les cités de la Gaule méridionale du III au VII ${ }^{\mathrm{e}}$ s. Gallia, 63, 2006, p. 11-23.

Beeching 1999: BEECHING (A.) éd. - Circulations et identités culturelles alpines à la fin de la Préhistoire. Matériaux pour une étude. Programme CIRCALP 1997-1998. Valence, agence Rhône-Alpes pour les sciences Humaines, 1999, 570 p. (Travaux du Centre d'Archéologie Préhistorique de Valence, 2).

Bouet 2003: BOUET (A.) - Les thermes privés et publics en Gaule Narbonnaise. Rome: École Française de Rome, 2003. 2 vol. (Collection de l'École Française de Rome; 320).

Congès, Leveau 2005 : CONGES (G.), LEVEAU (P.) - La campagne à l'époque romaine. In: DELESTRE (X.) éd., 15 ans d'archéologie en Provence-Alpes-Côte d'Azur, Edisud, 2005, p. 98-109.

Court-Picon 2007: COURT-PICON (M.) - Mise en place du paysage dans un milieu de moyenne et haute montagne du Tardiglaciaire à l'époque actuelle. Analyse du signal palynologique en Champsaur (Hautes-Alpes, France) à l'interface des dynamiques naturelles et des dynamiques sociales. Thèse de Science, Université de Franche-Comté, 732 p. + annexes.

Court-Picon et al. 2007: COURT-PICON (M.), WALSH (K.), MOCCI (F.), SEGARD (M.), PALET-MARTINEZ (J.) Occupation de la montagne et transformation des milieux dans les Alpes méridionales au cours de l'âge du Bronze: approche croisée des données palynologiques et archéologiques en Champsaur et Argentiérois (Hautes-Alpes, France). In: MORDANT (C.) et al. éd., Environnements et cultures à l'âge du Bronze en Europe occidentale. Paris, éditions du CTHS, p. 89-106.

Della Casa 1999: DELLA CASA (P.) ed. - Prehistoric alpine environment, society and economy. Papers of international colloquium PAESE'1997, Zürich 1997. Bonn, Verlag Rudolf Habelt, 1999, 308 p. (Universitätforschungen zür Prähistorischen archäologie, 55).

Della Casa, Walsh 2007: DELLA CASA (P.), WALSH (K.) ed. - Interpretation of sites and material culture from midhigh altitude mountain environments. Actes du Colloque International de European Archaelogical Association (Lyon sept. 2004). Preistoria Alpina, 42, Museo Tridentino di Scienze Naturali, Trento.

Fedele 1990: FEDELE (F.) - Prehistoric and ancient man at higher altitudes and latitudes. European mountains: the Alps. In: Impact of the prehistoric and medieval man on the vegetation: man at the forest limit. Strasbourg, 1990, p. 25-29.

Gallay 1990: GALLAY (A.) - La place des Alpes dans la néolithisation de l'Europe. In: BIAGI (P.) ed., The Neolithisation of the Alpine Region. Brescia, 1990, p. 23-42.

Ganet 1995: GANET (I.) - Les Hautes-Alpes. Carte archéologique de la Gaule, Paris, Inscriptions et Belles-Lettres, Ministère de la Culture, 1995.

Golosetti 2009: GOLOSETTI (R.) - Géographie du Sacré du Sud-Est de la Gaule, de la Protohistoire récente au HautEmpire. Aix-en-Provence, Thèse de doctorat sous la direction de D. Garcia, Université de Provence Aix-Marseille I, novembre 2009, 3 vol., 810 p.

Jorda 1991: JORDA (M.) - Un milieu naturel montagnard et des hommes: lectures du paysage haut-alpin. In Archéologie dans les Hautes-Alpes, Gap, Musée départemental, p. 33-50.

Jourdain-Annequin 2004 : JOURDAIN-ANNEQUIN (C.) éd. Atlas culturel des Alpes occidentales, de la Préhistoire à la fin du Moyen Âge, Picard, 2004, 439 p.

Leveau 2002: LEVEAU (P.) - L'habitat rural dans la Provence antique: villa, vicus et mansio, Étude de cas, RAN, 35, 2002, p. 59-92.

Leveau 2003: LEVEAU (P.) - La période romaine dans les Alpes occidentales. In: BÖ̈TSCH (G.), DEVRIENDT (W.) et PIGUEL (A.) dir., Permanence et changements dans les sociétés alpines. Avignon, Edisud, 2003 (actes du colloque de Gap du 4-6 juin 2002), p. 31-56.

Leveau 2004 : LEVEAU (P.) - Mansiones, « stations » et agglomérations routières. In: CAVALLARO (A.-M.), REMY (B.) éd., Les voies romaines en Méditerranée: actes du séminaire européen sur les actions et les publications, Aoste, 21 nov. 2003, Asote, 2004, p. 102-105.

Leveau, Segard 2004: LEVEAU (P.), SEGARD (M.) L'occupation de la haute montagne dans les Alpes du Sud à l'époque romaine. Premiers résultats d'une recherche dans les Hautes-Alpes (Buëch, Champsaur, Briançonnais). In: DAUDRY (D.) éd., Actes du $\mathrm{X}^{\mathrm{e}}$ Colloque International sur les Alpes dans l'Antiquité, Cogne (Vallée d'Aoste, Italie), 12-14 septembre 2003. Bulletin d'Études Préhistoriques et Archéologiques Alpines, XV, 2004, p. 229-242.

Leveau, Walsh 2005 : LEVEAU (P.), WALSH (K.) - Population sequences in a high altitude alpine environment: archaeological sites and historical and environmental time, International Journal of Anthropology, 20, 3/4, p. 155-171.

Manteyer 1932: MANTEYER (G.) - Le livre journal tenu par Fazy de Rame. Bulletin de la Société d'Études historiques, 


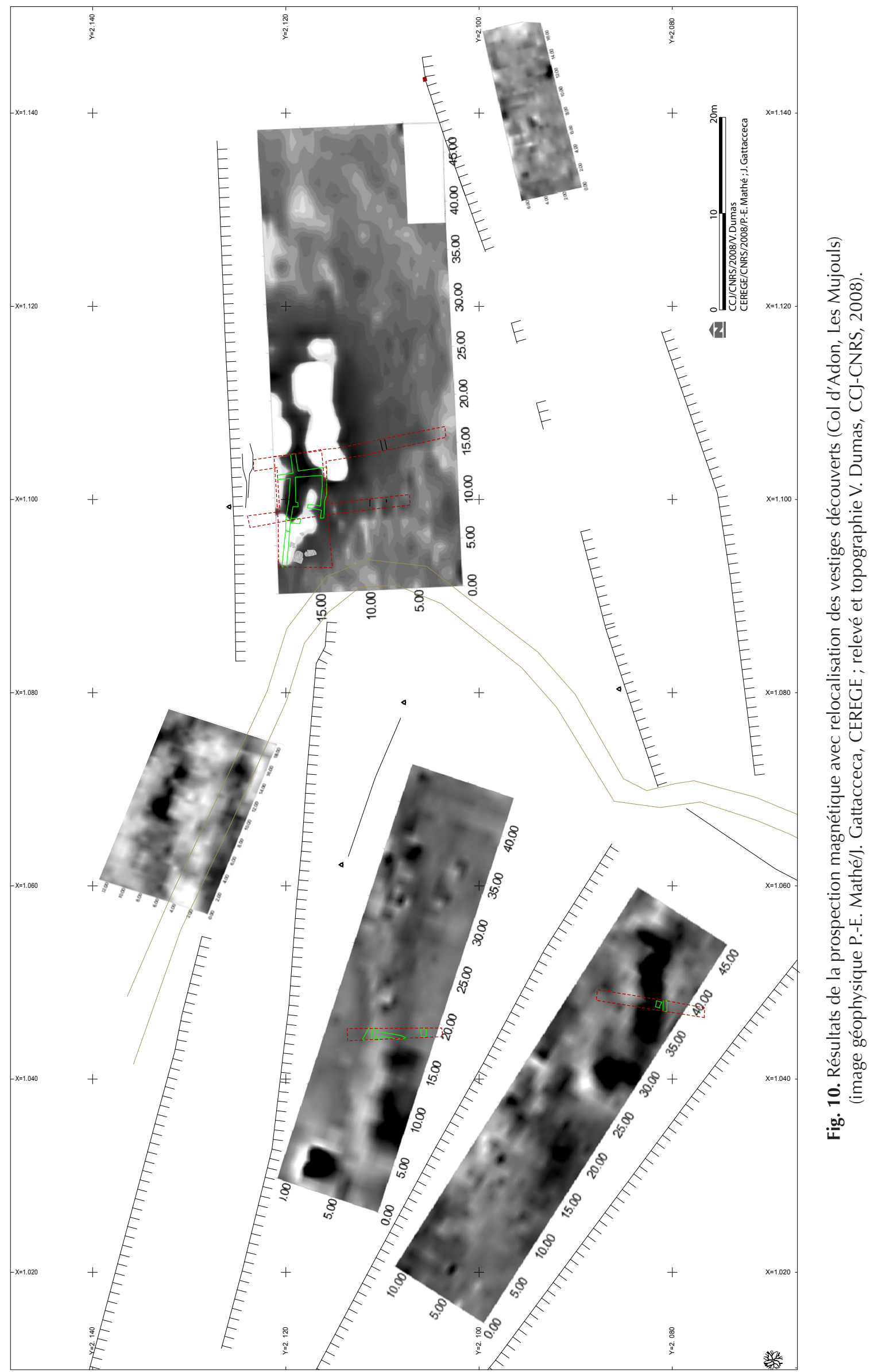


F. MOCCI et al. - DONNÉES RÉCENTES SUR L'OCCUPATION HUMAINE DANS LES ALPES MÉRIDIONALES DURANT L'ANTIQUITÉ

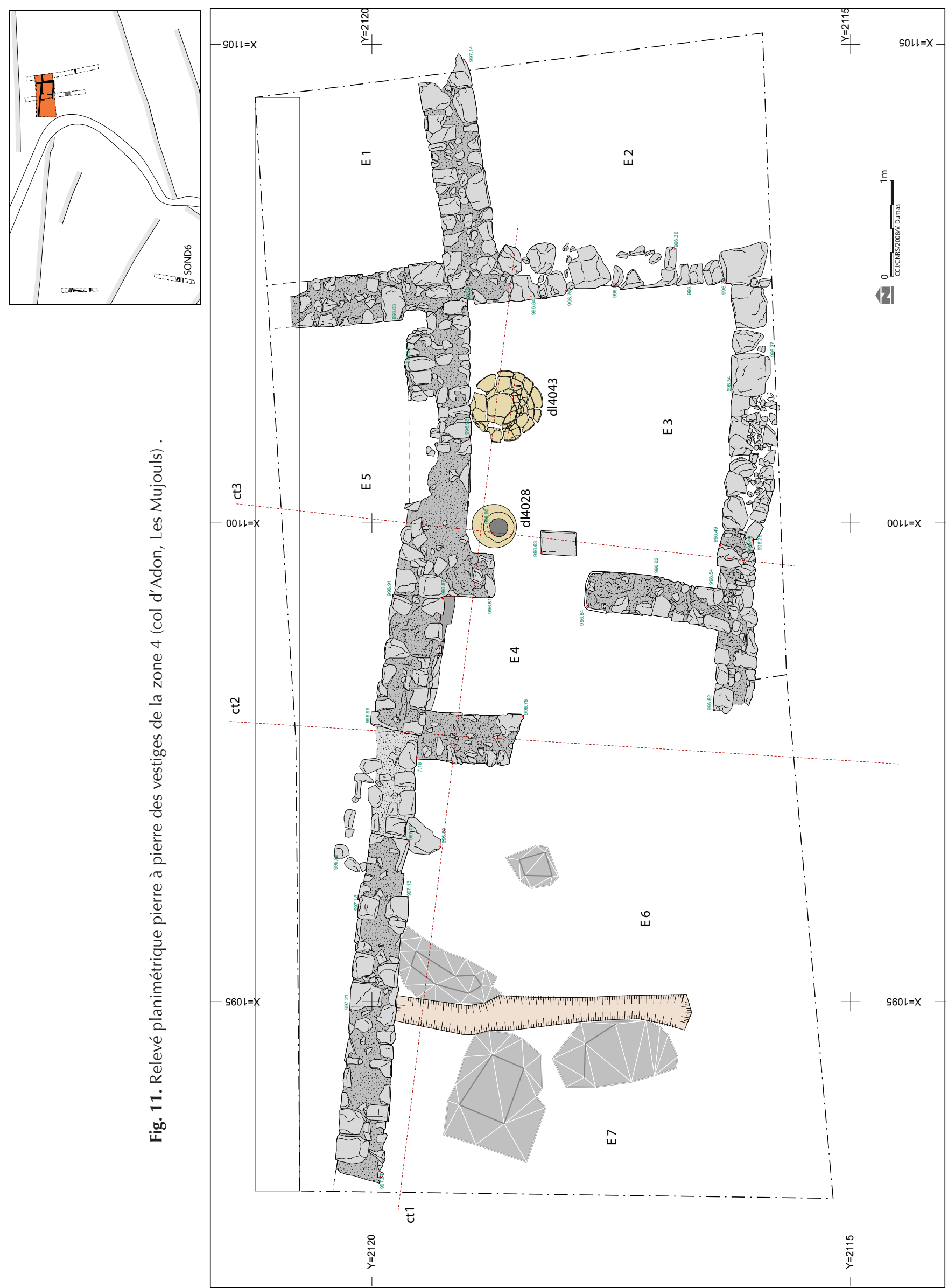


scientifiques et littéraires des Hautes-Alpes, Gap, $\mathrm{n}^{\circ}$ 1, 2, 3, 1932, 387 p.

Marguet et al. 2009: MARGUET (A.), BINTZ (P.), NICOD (P.-Y.), PICAVET (R.), REY (P.-J.), THIRAULT (E.) Éléments pour une histoire du peuplement nord-alpin français entre 10000 et 2700 ans BP. In: MAGNY (M.), DESMET (M.), MOCCI (F.) éd., Du Climat à l'Homme, Dynamique holocène de l'environnement, Actes du Colloque du GDR JurAlpes (Aix-en-Provence, 15-16 novembre 2007), Cahiers de Paléoenvironnement, 6-2008, Coll. Edytem, Chambéry, 2009, p. 225-252.

Mocci et al. 2006: MOCCI (F.), TZORTZIS (S.), PALETMARTINEZ(J.), SEGARD (M.), WALSH (K.) - Peuplement, pastoralisme et modes d'exploitation de la moyenne et haute montagne depuis la Préhistoire dans le Parc National des Écrins (vallées du Haut-Champsaur et de Freissinières, Hautes-Alpes). In : VERDIN (F.), BOUET (A.) éd., Territoires et paysages de l'âge du Fer au Moyen Âge, Mélanges offerts à Philippe Leveau, Collection Ausonius, Université de Bordeaux, 2006, p. 197-212.

Mocci et al. 2008: MOCCI (F.), WALSH (K.), TALON (B.), TZORTZIS (S.), COURT-PICON (M.), avec la coll. de BRESSY (C.), DUMAS (V.), GASSEND (J.-M.), PY (V.) - Structures pastorales d'altitude et paléoenvironnement. Alpes méridionales françaises du Néolithique final à l'âge du Bronze. Premiers Bergers des Alpes de la Préhistoire à l'Antiquité, Catalogue exposition au Musée Dauphinois, avril 2008-juin 2009, Grenoble, Infolio Édition, p. 92-101.

Mocci et al. 2009: MOCCI (F.), WALSH (K.), RICHER (S.), COURT-PICON (M.), TALON (B.), TZORTZIS (S.), PALET-MARTINEZ (J.), BRESSY (C.) avec la collaboration de BEAULIEU (J.-L. De), DUMAS (V.), ÉDOUARD (J.-L.), PY (V.) - Archéologie et paléoenvironnement dans les Alpes méridionales françaises. Hauts massifs de l'Argentiérois, du Champsaur et de l'Ubaye (Hautes-Alpes et Alpes de Haute Provence) (Néolithique final - début de l'Antiquité). In: MAGNY (M.), DESMET (M.), MOCCI (F.) éd., Du Climat à l'Homme, Dynamique holocène de l'environnement, Actes du Colloque du GDR JurAlpes (Aix-en-Provence, 15-16 novembre 2007), Cahiers de Paléoenvironnement, 6-2008, Coll. Edytem, Chambéry, 2009, p. 235-254.

Morin, Rosenthal, Fontugne 2007 : MORIN (D.), ROSENTHAL (P.), FONTUGNE (M.) - Roman-early medieval iron mining and smelting at high altitude in the Alps (ArgenteraMercantour massif - Alpes-Maritimes, France). Antiquity, 81/313, 2007.

Paccolat 1998: PACCOLAT (O.) - Chronologie relative des sites alpestres gallo-romains: quelques réflexions à partir de trois habitats valaisans. B.E.P.A.A., IX, 1998, p. 135-143 (actes du VIIe colloque international sur les Alpes dans l'antiquité, Sion, 26-28/09/1997).

Paccolat 2004 : PACCOLAT (O.) - Établissements ruraux du Valais romain: état de la question. In: DAUDRY (D.) éd., Implantations rurales et économie agro-pastorale dans les Alpes de la Préhistoire au Moyen Âge. Actes du $\mathrm{X}^{\mathrm{e}}$ Colloque International sur les Alpes dans l'Antiquité, Cogne (Vallée d'Aoste, Italie), septembre 2003. Bulletin d'Études Préhistoriques et Archéologiques Alpines, XV, 2004, p. 283-292.

Picavet, Morin 2008: PICAVET (R.), MORIN (A.) - Cabanes et enclos de bergers sur les Hauts plateaux du Vercors. Premiers Bergers des Alpes de la Préhistoire à l'Antiquité, Catalogue exposition au Musée Dauphinois, avril 2008-juin 2009, Grenoble, Infolio Édition, p. 133-136-101.

Pogneaux 1997: POGNEAUX (N.) - La dîme des cimes. Histoire de neuf villages du pays argentiérois au Moyen Âge, L'Argentière-la-Bessée, éd. Du Fournel, 1997, 135 p.

Py, Ancel 2007: PY (V.), ANCEL (B.) - Exploitation des mines métalliques de la vallée Freissinières (Hautes-Alpes, France): Contribution à l'étude de l'économie sud-alpine aux IX ${ }^{\mathrm{e}}$ XIII $\mathrm{e}$ s., Actes du Colloque International de European Archaelogical Association (Lyon sept. 2005), Preistoria Alpina, 42, Museo Tridentino di Scienze Naturali, Trento, p. 83-98.

Rey et al. 2009: REY (P.-J.), TREFFORT (J.-M.), MOULIN (B.), OBERLIN (C.), ANDRE (I.) - Archéologie des versants du Petit-Saint-Bernard: première approche de la dynamique de l'occupation humaine autour d'un grand passage alpin, de la Préhistoire au début du Moyen Âge. In: MAGNY (M.), DESMET (M.), MOCCI (F.) éd., Du Climat à l'Homme, Dynamique holocène de l'environnement, Actes du Colloque du GDR JurAlpes (Aix-en-Provence, 15-16 novembre 2007),

Cahiers de Paléoenvironnement, 6-2008, Coll. Edytem, Chambéry, 2009, p. 209-224.

Reynaud, Frangin 2009 : REYNAUD (P.), FRANGIN (E.) avec la coll. de CASTRUCCI (C.), LISFRANC (R.) - Embrun, ilôt du Thêatre II, Bilan Scientifique 2008, DRAC PACA, Aix-enProvence, p. 39-41.

Richard, Garcia 2008 : RICHARD (H.), GARCIA (D.) éd. - Le peuplement de l'arc alpin. 131 congrès annuel des Sociétés Historiques et Scientifiques, Grenoble, 2006. Paris, CD Rom, éditions du CTHS, 2008.

Richer 2009: RICHER (S.) - From pollen to people: the interaction between people and their environment in the mid- to high-altitudes of the Southern French Alps. Thesis (dir. K. Walsh et J.-L. De Beaulieu), University of York-IMEP, mai 2009, $350 \mathrm{p}$.

Segard 2008: SEGARD (M.) - Fouilles sur le site de Baratier / La Mure / Clapier des Monges», Bulletin AGER, 18, 2008, $4 \mathrm{p}$.

Segard 2009: SEGARD (M.) - Les Alpes occidentales romaines. Développement urbain et exploitation des ressources des régions de montagne (Gaule Narbonnaise, Italie, provinces alpines). Aix-en-Provence, Errance, 2009, 285 p. (Bibliothèque d'Archéologie Méditerranéenne et Africaine; 1). 
Segard etal. 2003 : SEGARD(M.), WALSH(K.), COURT-PICON (M.), avec la coll. de MOCCI (F.) et PALET-MARTINEZ (J.-M.) - L'occupation de la haute montagne dans les Alpes occidentales. Apport de l'archéologie et des analyses paléoenvironnementales. In: BOËTSCH (G.), DEVRIENDT (W.), PIGUEL (A.) éd., Permanence et changements dans les sociétés alpines, Actes du colloque de Gap, juillet 2002, Edisud, Aix-en-Provence, p. 17-30.

Tzortzis et al. 2008: TZORTZIS (S.), MOCCI (F.), WALSH (K.), TALON (B.), COURT-PICON (M.), DUMAS (V.), PY (V.), RICHER (S.) - Les massifs de L'Argentiérois du Mésolithique au début de l'Antiquité: au croisement des données archéologiques et paléoenvironnementales en haute montagne (Hautes-Alpes, Parc National des Écrins). In: RICHARD (H.), GARCIA (D.) dir., Le peuplement de l'arc alpin. $131^{e}$ congrès annuel des Sociétés Historiques et Scientifiques, Grenoble, 2006. Paris, CD Rom, éditions du CTHS, 2008, p. 123-148.
Walsh 2005: WALSH (K.) - Risk and marginality at high altitudes: new interpretations from fieldwork on the Faravel Plateau, Hautes-Alpes. Antiquity, 79, 2005, p. 289-305.

Walsh, Mocci 2003 : WALSH (K.), MOCCI (F.) avec la coll. de DUMAS (V.), DURAND (A.), TALON (B.), TZORTZIS (S.) - Neuf mille ans d'occupation du sol en moyenne montagne: la vallée de Freissinières dans le Parc National des Écrins (Freissinières, Hautes-Alpes). Archéologie du Midi médiéval, 21, p. 185-198.

Walsh, Richer 2006: WALSH (K.), RICHER (S.) - Attitudes to altitude: changing meanings and perceptions within a "marginal" Alpine landscape - the integration of palaeoecological and archaeological data in a high altitude landscape in the French Alps. World Archaeology, 38, 2006, p. 436-454. 


\title{
Longue chronologie de cernes du mélèze et occupation humaine depuis plus de mille ans dans la vallée de la Clarée (Briançonnais, Alpes françaises)
}

\author{
Jean-Louis ÉDOUARD*
}

\begin{abstract}
Résumé. L'analyse dendrochronologique de plus de 700 pièces de bois prélevées sur des constructions traditionnelles dans la vallée de la Clarée (commune de Névache, entre 1800 et 2000 m d'altitude) apporte des informations nouvelles sur l'histoire de l'habitat en haute montagne. Elle met en évidence des dates d'abattage très anciennes depuis la deuxième moitié du XII $\mathrm{s}$. La répartition de ces dates suggère une histoire de l'occupation humaine sur plus de 800 ans, jalonnée d'épisodes de constructions identifiés pendant la deuxième moitié du XII ${ }^{\mathrm{e}} \mathrm{s}$. et au début XIII $\mathrm{s}$., pendant la première moitié du XVI ${ }^{\mathrm{e}} \mathrm{s}$., au cours des XVIII ${ }^{\mathrm{e}}$ et XIX ${ }^{\mathrm{e}} \mathrm{s}$. Ces recherches fournissent une longue chronologie de cernes qui couvre la période 749 AD-2007 en associant bois de construction et arbres sur pied ou arbres morts avec un hiatus de 54 ans pendant le XIV ${ }^{\mathrm{e}}$ s. Cette chronologie constitue un référentiel pour la datation d'autres témoins de l'activité humaine passée. Les données dendrochronologiques obtenues sont aussi les bases indispensables pour la reconstruction des fluctuations climatiques historiques et l'histoire des forêts d'altitude des Alpes françaises.
\end{abstract}

The long chronology of larch trees and human settlement during more than a thousand years in the Clarée valley (Briançonnais, french Alps)

Abstract. The dendrochronologique analysis of more than 700 pieces of wood taken from traditional constructions in the valley of Clarée (Névache, Briançonnais) between 1800 and $2000 \mathrm{~m}$ a.s.l.) brings new information on the history of settlement environment in high mountain. It brings to light very ancient dates of cutting down since the second half of 12th c. The distribution of these dates suggests a history of the human occupation on more than 800 years since half of 12 th $\mathrm{c}$. marked out by episodes of building identified during the second half of 12 th c. and at the 13th beginning c., during the first half of 16th c., during 18th c. and 19th c. These searches supply a long chronology of rings which covers the period 749 AD-2007 by associating timber and trees on foot or dead trees with a hiatus of 54 years during 14th c. This chronology establishes a master chronology for the dating of the other witnesses of the past human activity. The dendrochronological data obtained are also the indispensable bases for the reconstruction of the historic climatic fluctuations and the of the high altitude forests history in the French Alps.

\section{Introduction}

$\mathrm{L}$ es études de l'habitat rural dans les Alpes françaises sont soit anciennes, souvent réalisées par des géographes dans le cadre d'études régionales consacrées aux différents massifs (Arbos 1921; Allix 1929; Blanchard 1950) ou des historiens locaux (Rostolland 1930; Sentis 1982), soit plus récentes et réalisées par des spécialistes de l'architecture et de l'histoire des sociétés humaines, notamment dans le cadre de l'inventaire du Patrimoine (Raulin 1977 ; Fray 1983; Mallé 1999). Dans les Hautes-Alpes, étant donné la permanence des modes de construction au cours des siècles, l'établissement d'une typologie de l'habitat est difficile et rend délicate la mise en place d'une chronologie relative. La question de la date de construction est donc récurrente (Pelletier 2003). Les dates disponibles actuellement reposent essentiellement sur les documents d'archives, sur les «inscriptions datantes » comme les millièmes gravés dans les linteaux en pierre ou en bois, sur les poinçons des pignons des charpentes, et fournissent une image de la dynamique démographique dans ces hautes vallées alpines (Mallé 1999). Or, les habitations sont très souvent polygéniques, construites en plusieurs étapes, modifiées ou réparées, avec un recours fréquent aux matériaux de remploi pour des raisons d'économie. Les dates recensées bien qu'assez nombreuses restent insuffisantes

\footnotetext{
* Centre Camille Jullian (CCJ), UMR 6573 CNRS - Université de Provence, Maison Méditerranéenne des Sciences de l'Homme, 5 rue du château de l'Horloge, BP 647, 13094 Aix-en-Provence cedex 2.
} 
pour rendre compte à elles seules de l'histoire de l'habitat. Le Briançonnais étant une région des Alpes où le bois entre pour une grande part dans la construction traditionnelle des chalets et granges d'alpage, il est intéressant de mettre en œuvre une recherche dendrochronologique sur ces constructions de montagne. Alors que ce type de recherche est largement pratiqué en Europe du Nord (Hoffsummer 1995), en France du Nord (Lambert 2006) et, en montagne, dans les Alpes suisses (Donati et al. 1989; Orcel, Orcel 1992; Remacle 2004; Büntgen 2008), il est encore embryonnaire dans les Alpes françaises (Bernardi et al. 2007 ; Édouard 2007 ; 2008a ; 2008b). L'objectif est de préciser, en utilisant les méthodes de la Dendrochronologie, la connaissance de l'histoire de l'habitat et la compréhension de l'architecture traditionnelle, sans pour autant faire une analyse architecturale détaillée de chaque bâtiment étudié. La longue chronologie du mélèze dans les Alpes françaises issue de ces travaux constitue un référentiel dendrochronologique, utilisable dans le domaine de l'histoire humaine, et aussi tant dans celui de la reconstruction du climat passé que celui de l'histoire de la forêt en montagne.

\section{Sites, matériel et méthode}

\subsection{Sites}

Les bâtiments étudiés sont localisés dans la haute vallée de la Clarée sur le territoire de la commune de Névache, au nord de Briançon, en amont du village, à des altitudes comprises entre 1800 et $2000 \mathrm{~m}$ (fig. 1). Ils sont répartis en cinq hameaux : en ubac, les hameaux de Buffère, celui dit «Le Serre », le chalet isolé «Les Granges » et le hameau du Queyrellin sont situés sur les deux gradins de confluence de deux vallons, affluents de la vallée principale (Buffère et Chardonnet); les chalets de La Sausse et de La Moulière leur font face, en adret, à une altitude similaire; le hameau de la Meuille est situé dans le talweg de la Clarée, un peu plus bas en altitude (tabl. I et fig. 2).

Ces constructions sont des chalets d'estive de type empilage pièce sur pièce assemblées à mi-bois, en mélèze (Larix decidua Mill.). Plus de 700 prélèvements ont été réalisés sur ces chalets en ruine, en cours de restauration ou restaurés (fig. 3).

\subsection{Méthode}

La dendrochronologie est une discipline scientifique basée sur l'analyse des cernes de croissance des arbres et de leurs variations interannuelles en fonction des facteurs écologiques environnants, en particulier le facteur climatique, qui génère un signal déterminant. L'analyse

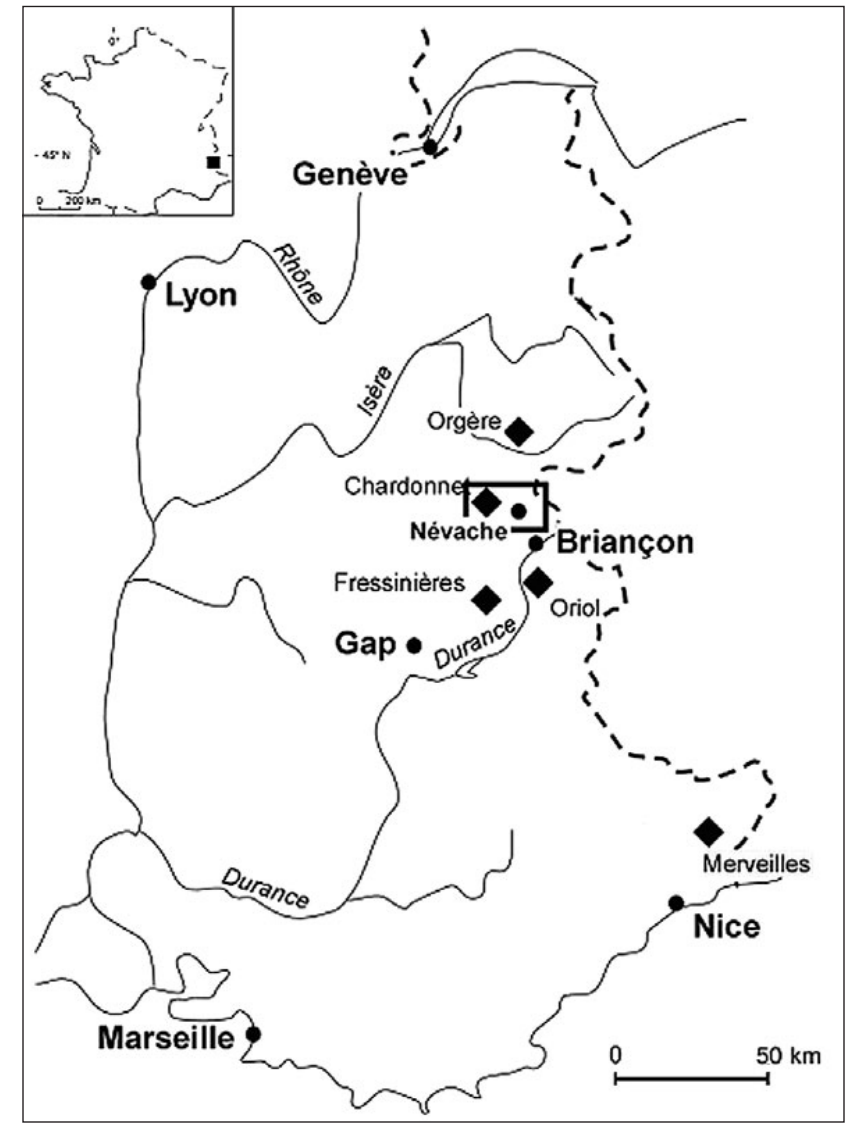

Fig. 1. Localisation des sites.

dendrochronologique permet de jalonner le temps et de dater des événements, des objets, en construisant des séries chronologiques à partir de prélèvements effectués sur des arbres vivants, sur des arbres morts, et aussi sur des bois de construction anciens (Schweingrüber 1988; Lambert 1998). La comparaison des variations de largeur de cernes non reproductibles dans le temps lorsqu'on considère des séries assez longues (> 60 ans) et la mise en évidence de variations interannuelles identiques entre des arbres de même espèce poussant dans un même contexte climatique, permet la datation absolue de bois. La datation concerne l'abattage de l'arbre. Le délai entre abattage et utilisation du bois est généralement court (quelques mois) dans la charpenterie (Hoffsummer 1995, et communication orale de charpentiers de montagne), la date d'abattage permet donc d'approcher avec précision la date de première utilisation des bois pour la construction et la construction ellemême s'il n'y a pas remploi.

\subsubsection{Prélèvements}

Les prélèvements de carottes et de sections de bois ont été effectués en priorité sur les éléments importants de la structure des bâtiments tels que poteaux, poutres sablières, 


\begin{tabular}{|l|l|l|l|l|l|l|}
\hline Référence & Auteur & Région & Latitude & Longitude & Altitude & Dates \\
\hline Orgère & Tessier (1986) & Vanoise-Maurienne & $45.219 \mathrm{~N}$ & $6.682 \mathrm{E}$ & $2100 \mathrm{~m}$ & $1353-1973$ \\
\hline Chardonnet & Édouard (non publ.) & Briançonnais & $45.029 \mathrm{~N}$ & $6.538 \mathrm{E}$ & $2150 \mathrm{~m}$ & $1492-1989$ \\
\hline Oriol & Édouard (non publ.) & Briançonnais & $44.796 \mathrm{~N}$ & $6.598 \mathrm{E}$ & $2180 \mathrm{~m}$ & $1381-1989$ \\
\hline Fressinières & Édouard (non publ.) & Briançonnais & $44.725 \mathrm{~N}$ & 6.505 & $2100 \mathrm{~m}$ & $1475-1992$ \\
\hline Merveilles & Serre-Bachet (1979) & Mercantour & $44.051 \mathrm{~N}$ & $7.449 \mathrm{E}$ & $2200 \mathrm{~m}$ & $933-1974$ \\
\hline
\end{tabular}

Tabl. I. Chronologies de référence.

poutres de plancher, et pièces de bois en empilage, constitutives des murs, appelés chapis ou chapilas localement (Mallé 1999), mais aussi sur les chevrons et bardeaux du toit ou des planches. L'état de ruines a parfois empêché l'accès à des pièces de bois intéressantes, en raison des risques (écroulement ou poutres impossibles à manipuler). Le nombre de pièces prélevées dans une ruine a aussi été limité pour des raisons de conservation ou de mauvais état du bois.

\subsubsection{Analyse dendrochronologique}

Elle a déjà été décrite dans des ouvrages et articles accessibles (Lambert 1998; Édouard 2007a; 2008). Après identification du bois (Schweingrüber 1990) et préparation des échantillons (ponçage), la mesure des largeurs des cernes est réalisée pour constituer les séries chronologiques à dater (table de mesure TSAP Rinntech). L'objectif, la datation des bois, est d'attribuer à chaque cerne l'année calendaire exacte de sa formation. Les séries chronologiques sont comparées entre elles (processus de synchronisation-interdatation ou «crossdating» en anglais) (fig. 4). Les comparaisons des séries de variation de largeur des cernes sont basées sur des tests statistiques qui proposent des positions de synchronisme avec un niveau de confiance significatifs: pourcentage de concordance des variations interannuelles, et coefficient corrélation des séries préalablement standardisées avec sa signification statistique donnée par le t de Student (Lambert 1998; 2006; Rinn 2004). Les positions significatives obtenues par ces tests sont bien sûr vérifiées par la confrontation visuelle des courbes représentant ces séries chronologiques, et, au final, validées ou non par le Dendrochronologue. La suite de la démarche consiste: 1) à regrouper les chronologies significativement corrélées et présentant visuellement des variations caractéristiques communes et à construire les chronologies moyennes représentatives de ces groupes; 2) à dater de façon absolue ces groupes sur la base de chronologies de référence existantes, construites à partir d'arbres vivants, d'arbres morts, et, aussi de pièces de bois de construction prélevées en différents sites proche des constructions étudiées. Pour cela, j'ai utilisé une chronologie locale du mélèze, Chardonnet, (Édouard, non publiée) et 4 autres chronologies de référence du mélèze des Alpes françaises du Sud: 7 longues chronologies de référence, 1 provenant du Mercantour (Serre 1978), 2 du Briançonnais (Édouard, non publiées) et une de la Maurienne (Tessier 1986; tabl. II).

Ces chronologies ont été établies à partir de vieux arbres situés en limite supérieure de la forêt subalpine, à des altitudes supérieures à $2000 \mathrm{~m}$. Le site du Chardonnet est le plus proche des bâtiments étudiés dans la vallée, à moins de $3000 \mathrm{~m}$ à vol d'oiseau. Les sites de l'Oriol (fig. 5) et de Fressinières sont un peu plus éloignés, entre 10 et $20 \mathrm{~km}$, comme le site de l'Orgère au nord, le site du Mercantour étant beaucoup plus éloigné au sud.

La présence de l'aubier et celle du dernier cerne sont deux caractéristiques essentielles pour la détermination de la date d'abattage et donc la connaissance de la date d'utilisation de l'arbre pour la construction. L'aubier, s'il est complet (conservation de l'écorce et/ou du dernier cerne formé sous l'écorce) donne la date de mort de l'arbre, donc la date d'abattage de l'arbre. Si l'aubier est présent mais érodé, c'est-à-dire si le dernier ou les derniers cernes manquent, une estimation de cette date d'abattage sera faite avec une incertitude de quelques années. Le nombre de cernes d'aubier manquants est estimé à partir de l'observation de la forme, de l'état de conservation (degré d'érosion du bois), du façonnage du tronc, et de la largeur des cernes (croissance plus ou moins forte) de l'aubier qui subsiste, sur la base de l'analyse du nombre de cernes d'aubier d'arbres d'âges variés et soumis à des conditions écologiques diverses.

\section{Résultats}

\subsection{Caractéristiques des pièces de bois}

Les pièces de bois échantillonnées sont en quasi-totalité façonnées dans des mélèzes. Quelques pièces de charpente et de mur sont en pin cembro, seulement une dizaine sur plus de 700 pièces prélevées. Les bois proviennent du mélézin local, entourant immédiatement les hameaux d'alpage. Les très fortes corrélations avec la chronologie de 


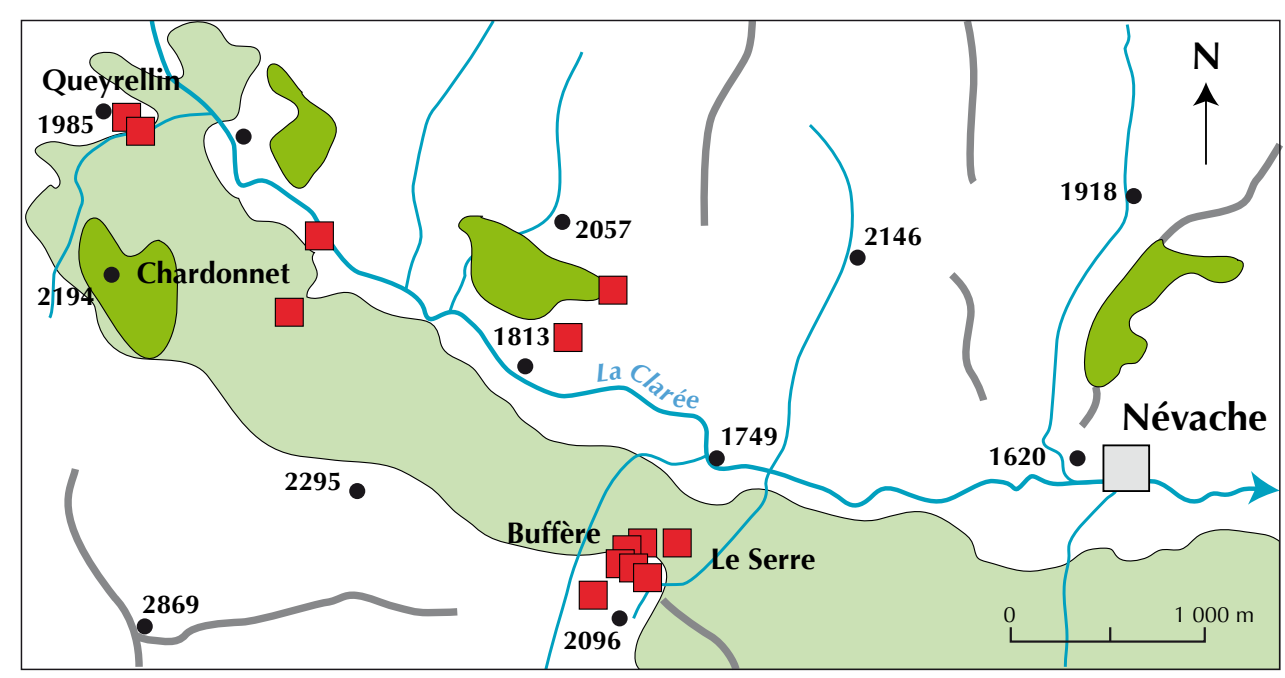

$\square$ forêt $\square$ sites de vieux mélèzes $\square$ hameaux étudiés

crêtes cotes d'altitude $\rightarrow$ cours d'eau

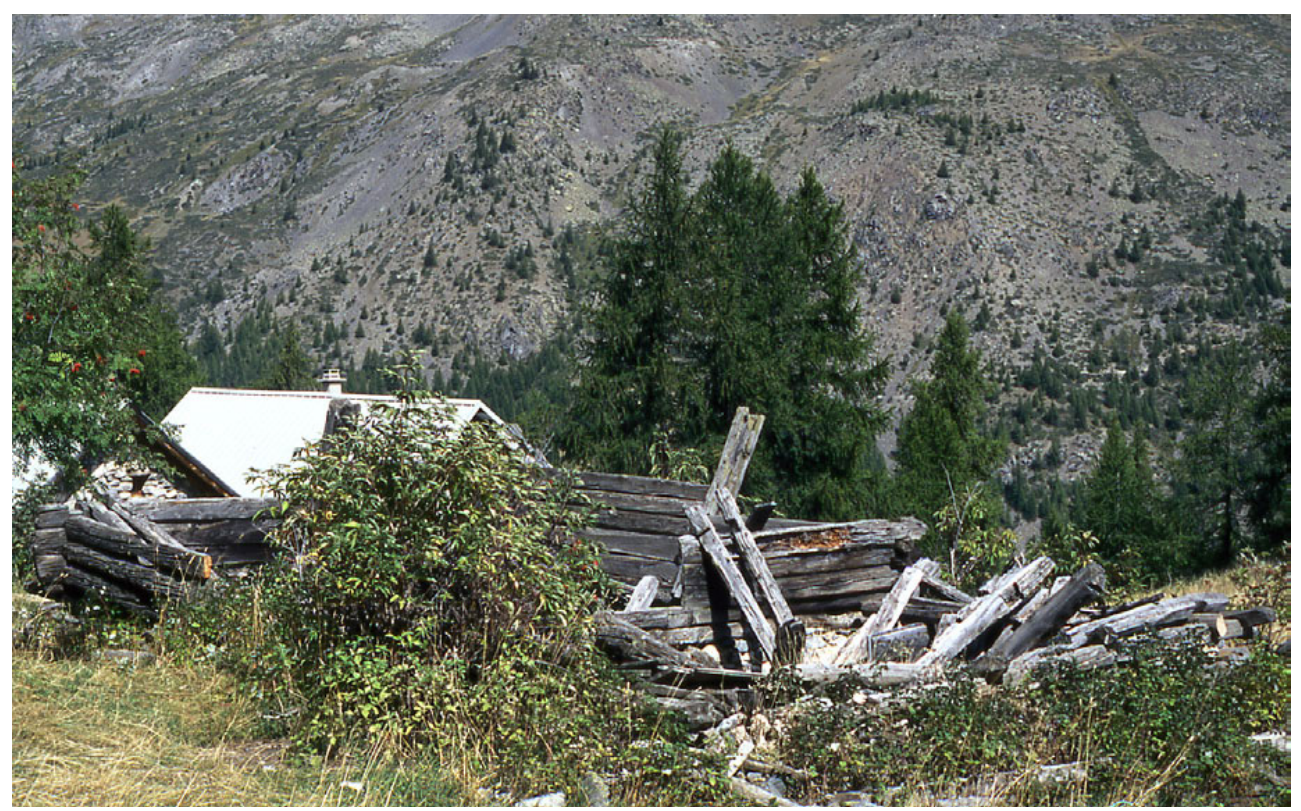

Fig. 2. Localisation des bâtiments étudiés dans la haute vallée de la Clarée (Briançonnais).

Fig. 3. Chalet-grange d'estive (Buffère 10) en ruine dans la haute vallée de la Clarée. Cliché J.-L. Édouard. référence locale (Chardonnet) pour la période moderne ne font qu'objectiver cette origine.

Les pièces de bois analysées sont représentatives des éléments qui composent les bâtiments traditionnels: poutres sablières, poutres de plancher, poteaux, poinçons, pannes, chevrons, voliges, chapilas. Il y a aussi des bardeaux (toiture) et des planches. Par exemple, les bois prélevés dans les ruines du hameau de Buffère comportent des pièces maîtresses des granges et chalets : 8 poteaux et 24 poutres, parmi lesquelles des poutres sablières (sur lesquelles reposent les empilages - murs - ou la charpente) ou des poutres de plancher ainsi que des chevrons.

Les bois prélevés dans le chalet du Queyrellin 1 en restauration sont des poutres (plancher et charpente) et des voliges. Les prélèvements sur les voliges et poutres ont souvent été doublés, ce qui explique l'effectif important de bois analysés dans ce bâtiment.

Ceux provenant de Queyrellin 2 comportent des chapis, des poutres sablières, poutre de planche et poteaux. Les bois du chalet Buffère 7 sont principalement des éléments majeurs de la structure (sablières et chapilas).

Les longueurs des chronologies des bois varient de 57 à 420 ans. Bien que les plus gros effectifs soient compris entre 60 et 140 ans, un grand nombre de séries dépassant 180 cernes a été mesuré. Les patrons de croissance et la largeur des cernes reflètent bien cette répartition des arbres entre 3 classes d'âges principales (arbres plutôt jeunes moins de 100 ans, matures, entre 100 et 250 ans et vieux 


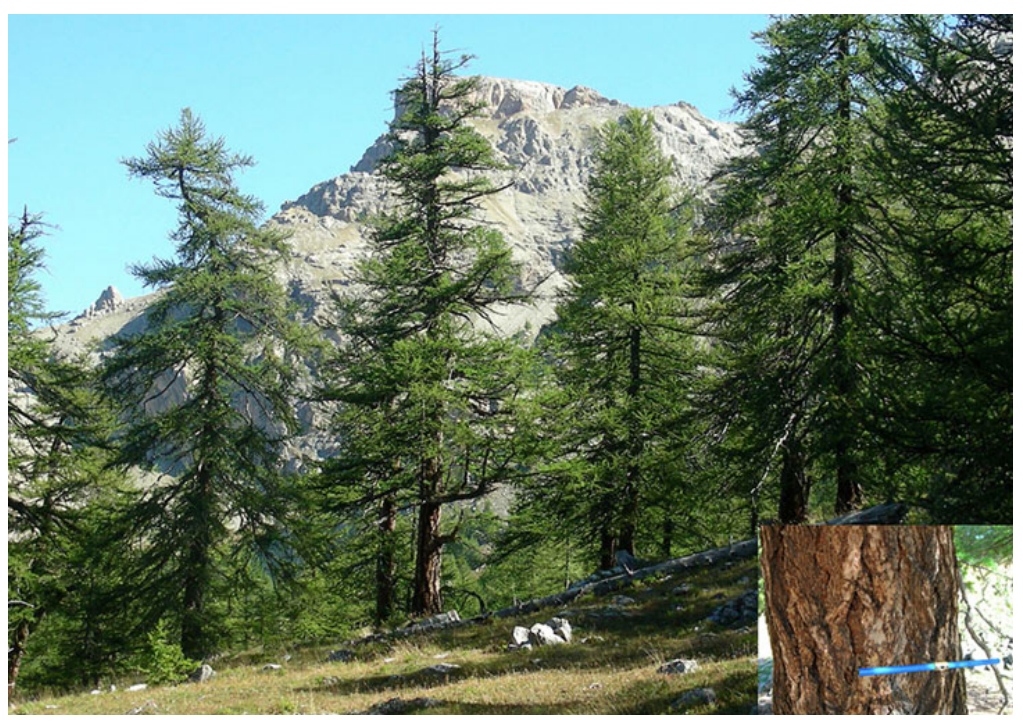

\begin{tabular}{|l|c|c|c|c|}
\hline Nom & nb pièces de bois & début & fin & longueur \\
\hline Queyrellin 1 & 117 & 1416 & 1551 & 136 \\
\hline Buffère 0 & 3 & 1559 & 1745 & 187 \\
\hline Buffère 1 & 5 & 1553 & 1757 & 205 \\
\hline Buffère 2 & 15 & 1511 & 1825 & 315 \\
\hline Buffère 3 & 3 & 1456 & 1722 & 267 \\
\hline Buffère 4 & 1 & 1823 & 1880 & 58 \\
\hline \multirow{2}{*}{ Buffère 5 } & 7 & 822 & 1185 & 364 \\
\hline Buffère 6 & 10 & 1470 & 1842 & 373 \\
\hline \multirow{2}{*}{ Buffère 7 } & 59 & 7484 & 1894 & 511 \\
\hline \multirow{2}{*}{ La Moulière } & & 1394 & 1255 & 507 \\
& & 9967 & 1860 & 396 \\
\hline La Sausse & & 1357 & 1220 & 230 \\
\hline Queyrellin 2 & 4 & 1426 & 70 \\
\hline La Meuille 1 & 12 & 805 & 1303 & 499 \\
\hline Les Granges & 9 & 1479 & 1839 & 361 \\
\hline Chapelle Saint-Hippolyte & 24 & 1485 & 1746 & 262 \\
\hline
\end{tabular}
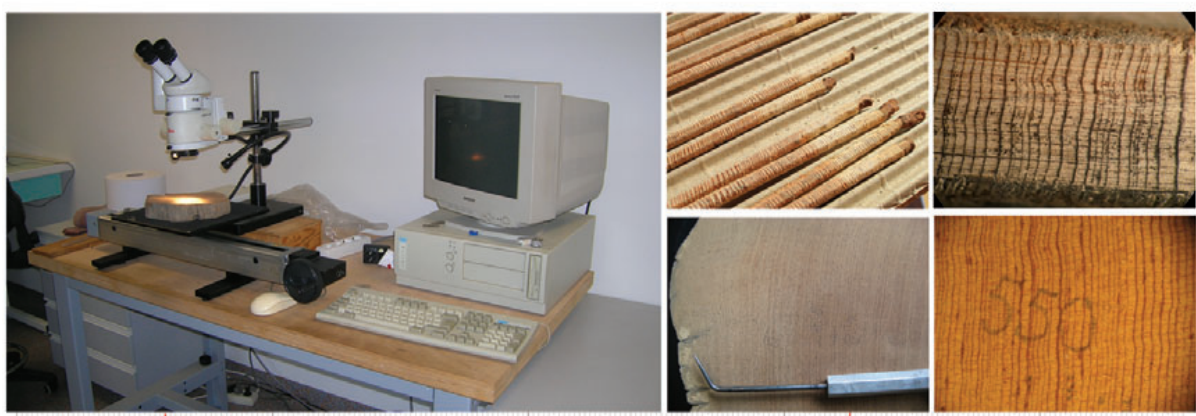

Fig. 5. Mesures des séries de cerne et interdatation (exemple de séquences de cerne et synchronisme des courbes).
Fig. 4. Peuplement de mélèzes pluricentenaires, site de I'Oriol, Briançonnais. Cliché J.-L. Édouard.

Tabl. II. Chronologies établies pour chaque bâtiment étudié.

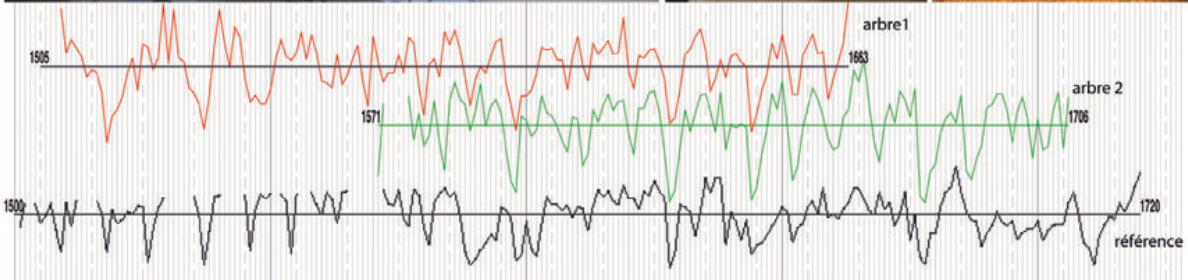


plus de 250 ans). L'observation des patrons de croissance (séquences de cernes minces) indique que les pièces de bois proviennent le plus souvent d'arbres âgés. Cela donne une information indirecte bien que partielle sur la structure de la forêt de mélèze à l'époque des abattages, riche en arbres matures et vieux.

\subsection{Deux exemples de datation dendrochronologique}

\subsubsection{Chalet Queyrellin 1}

Ce chalet est de construction traditionnelle en empilage pièce sur pièce à mi-bois, est composé d'une grange et d'une cuisine en pierre, aujourd'hui restaurée. Des chevrons, des sablières et des poutres de plancher ont pu être échantillonnés, ainsi que la toiture de bardeaux. Les poutres et les chevrons ont fourni des séries assez courtes avec un maximum de 120 cernes. Les dates de terminus (derniers cernes mesurés) sont presque toutes comprises entre 1529 et 1536 , avec deux dates d'abattage principales, 1534 et 1536 (aubier complet). Ces dates, conduisent à reconnaître une phase de construction du chalet dans les années qui suivent immédiatement l'abattage de ces arbres, en 1534 et 1536, dans la première moitié du $\mathrm{XVI}^{\mathrm{e}} \mathrm{s}$. L'analyse des empilages et d'autres pièces de la structure qui n'ont pas encore pu être échantillonnés, compléteraient évidemment cette histoire du bâtiment.

\subsubsection{Chalet Buffère 7}

Ce chalet d'estive, entièrement reconstruit au début des années 1990, était aussi un chalet traditionnel avec une grange construite selon le type empilage pièce sur pièce à mi-bois. Tous les bois non réintégrés dans le chalet actuel avaient été conservés : sablières, poteaux, chapilas, solives, chevrons et planches. 70 prélèvements sous forme de sections ont été faits. Les bois, presque exclusivement du mélèze (6 Pins cembro), ont fourni des séries dendrochronologiques souvent très longues, variant de 39 cernes à 420 cernes dont 26 de plus de 180 cernes ( $37 \%$ ), et 155 cernes en moyenne. 52 bois conservent tout ou partie de l'aubier, ce qui autorise l'obtention de dates d'abattage ou d'estimation à quelques années près pour $75 \%$ des bois étudiés. Les synchronisations sur les références du Briançonnais et des Merveilles aboutissent à la construction d'une chronologie qui couvre les périodes: $749-1255$ et $1384-1894$ (fig. 6).

Des dates d'abattage, soit établies à l'année près et soit estimées sont distribuées sur l'ensemble de ces deux périodes et révèlent ainsi l'existence d'un habitat traditionnel dès le XII ${ }^{\mathrm{e}} \mathrm{s}$. La figure 6 montre plusieurs périodes d'abattage (milieu du XII ${ }^{\mathrm{e}}$, fin du XII ${ }^{\mathrm{e}}$ et début du XIII ${ }^{\mathrm{e}}$ s., fin du XVe, milieu du XVI ${ }^{\mathrm{e}}$, début du XVIII ${ }^{\mathrm{e}}$, fin XVIII ${ }^{\mathrm{e}}$ et première moitié du XIX ${ }^{\mathrm{e}}$ s.) qui correspondent probablement à des réparations, ou des modifications du chalet.

Les arbres qui ont été utilisés ont été abattus à proximité du chalet dans le mélézin situé à la limite supérieure de la forêt. Beaucoup de ces arbres sont de vieux arbres pluricentenaires (jusqu'à plus de 400 ans). La chronologie de cernes réalisée constitue la base de la chronologie de plus de mille ans (1 250 dernières années) que je développe dans le Briançonnais.

\subsubsection{Synthèse dendrochronologique}

La chronologie moyenne locale couvre deux périodes, 751-1303 et 1357-1894, à partir des bois de construction, et jusqu'à aujourd'hui (2007) en la combinant avec celle des arbres vivants, soit 1259 ans.

Le tableau II fait la synthèse des chronologies moyennes des bâtiments de la haute vallée, étudiés ici et composant la chronologie de référence pour la vallée de la Clarée. La figure 7 représente graphiquement leur répartition chronologique et la figure 8 de la couverture globale de ces chronologies, c'est-à-dire le nombre de cernes par année.

289 bois ont été datés sur 557 bois mesurés et 180 bois provenant d'autres bâtiments sont en attente. Ces bois prélevés sur ces 15 bâtiments traditionnels racontent une histoire de l'habitat en haute montagne, longue de plus de 800 ans, encore très lacunaire, avec des phases de travaux se succédant depuis le XII ${ }^{\mathrm{e}}$ jusqu'à la fin du XIX ${ }^{\mathrm{e}} \mathrm{s}$. Ces phases témoignent aussi de l'impact des hommes sur la forêt subalpine pendant le dernier millénaire.

La chronologie de cerne est interrompue par un hiatus de 54 ans qui pose question: ce hiatus pourrait être du au nombre encore insuffisant de prélèvements et de bâtiments étudiés lié aux aléas de l'échantillonnage; il pourrait correspondre à une conjoncture économique et sociale (essor démographique avec fort prélèvements de bois et pastoralisme jusqu'à la fin du XIII ${ }^{\mathrm{e}}$ s., suivi d'un effondrement démographique consécutifs aux conflits militaires), à des épidémies, provoquant un arrêt des constructions donc des abattages de bois, une diminution de la pression pastorale et une reprise de la régénération du mélézin au milieu du $X^{\text {XIV }}$ s. (Guichonnet 1980; Falque-Vert 1997). Le facteur climatique peut aussi intervenir par le fait de son un impact sur l'écosystème forestier (mortalité, régénération). Les recherches conduites sur les reconstructions du climat passé donneront de nouveaux éléments pour préciser les rôles respectifs des facteurs naturels et anthropiques.

\subsubsection{Datations obtenues par rapport aux données de l'inventaire du patrimoine (Mallé 1999; Fray 1983)}

L'inventaire de l'habitat conservé, parallèlement à l'étude du cadastre de 1842, a mis en évidence un grand nombre de 

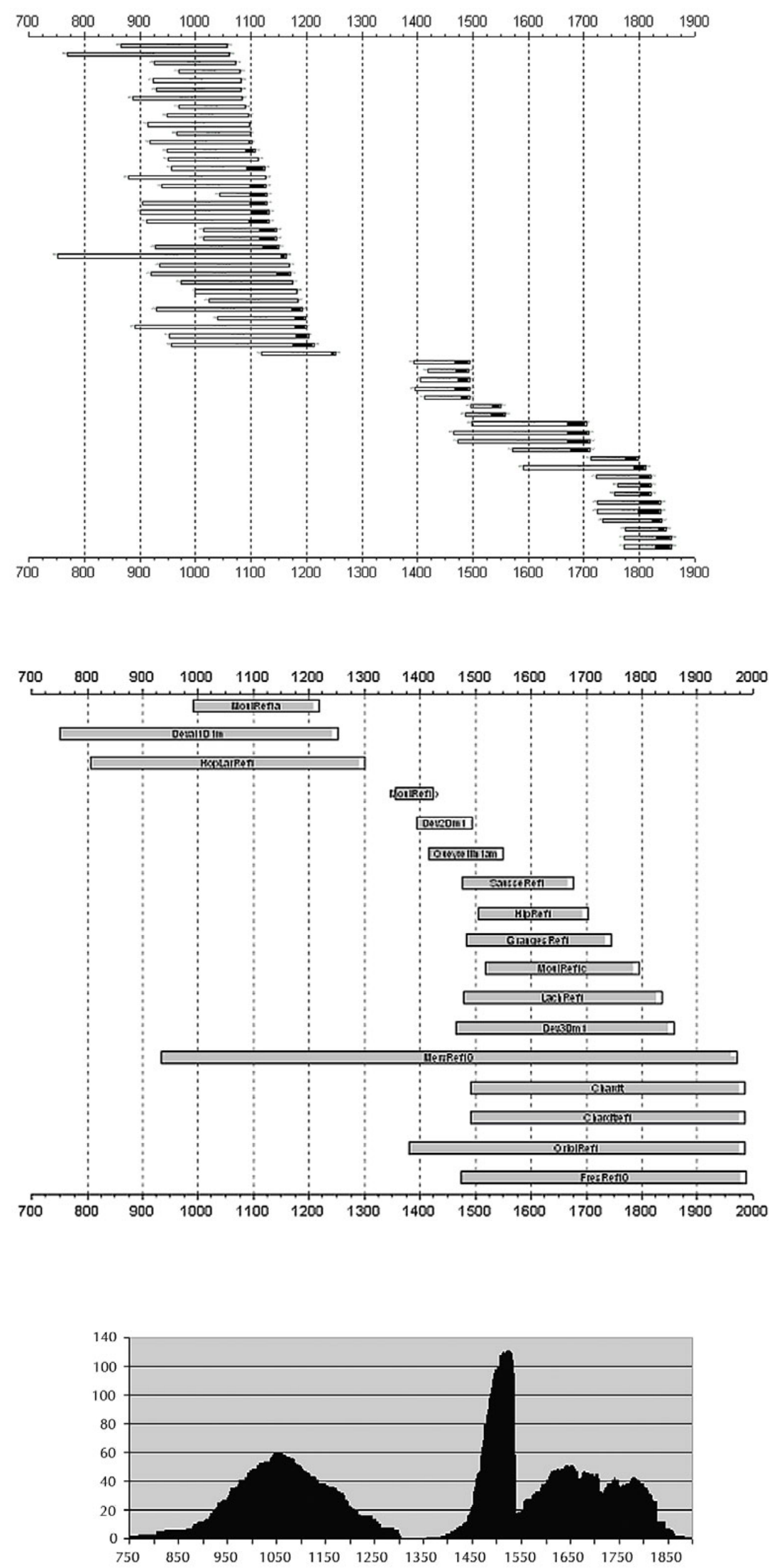

Fig. 6. Positions chronologiques des pièces de bois du chalet de Buffère 7. La longueur des bâtonnets horizontaux représentant les pièces de bois est proportionnelle au nombre de cernes.

Fig. 7. Positions chronologiques des chronologies moyennes des constructions étudiées et des chronologies issues des vieux arbres vivants du Briançonnais et du Mercantour.

Fig. 8. Couverture de la chronologie de synthèse issue des bois de constructions et des vieux arbres de la haute vallée de la Clarée (Briançonnais). Nombre de cernes par année. 
hameaux d'habitat temporaire sur la commune de Névache: 22 hameaux recensés et 64 chalets-granges encore présents. Sur ces chalets, 29 dates ont été identifiées, la plus ancienne, 1683, relevée sur un poteau de remploi (service inventaire). La distribution des dates montre que les chalets dateraient du XVIII ${ }^{e}$ et surtout du début du XIX ${ }^{\mathrm{e}} \mathrm{s}$.

Les dates obtenues par la dendrochronologie, élargissent cette répartition temporelle à la période du moyen âge. Les deux chalets présentés ici révèlent des phases importantes de construction pendant la seconde moitié du XII ${ }^{\mathrm{e}}$ s., pendant le XIII et au tout début du XIV ${ }^{\mathrm{e}}$ s., au début du XVI ${ }^{\mathrm{e}} \mathrm{s}$., et deux maximums pendant la première moitié du XVIII et la première moitié du XIX $\mathrm{s}$. La synthèse chronologique de tous les bâtiments étudiés enrichira ces premiers résultats.

\section{Conclusion}

La dendrochronologie apporte ainsi des dates précises qui positionnent dans le temps les bois de construction, d'origine ou de remploi, qui sont des informations nouvelles sur l'histoire de l'habitat et de l'occupation humaine dans ce secteur des Alpes françaises.

La chronologie de synthèse de Névache obtenue à partir des bois de construction constitue une nouvelle chronologie de référence pour les Alpes françaises. Cette chronologie de plus de 1250 ans contient un signal dendrochronologique fort, expression du signal climatique régional enregistré par les vieux arbres vivants et les arbres utilisés dans les constructions. Ce signal est utilisé dans la reconstruction du climat passé (Corona et al. 2008) dans les Alpes françaises du Sud. Cette chronologie et ses composantes contiennent d'autres signaux, qui sont les enregistrements de manifestation de perturbations naturelles affectant le mélèze, comme par exemple, la tordeuse (Zerapheira diniana Gn.) qui impacte avec un cycle 8 ans environ la croissance des mélèzes (Édouard, Thomas 2008; Büntgen et al. 2004). D'autres constructions traditionnelles en cours d'analyse dans l'ensemble des Alpes du Sud contribueront développer l'histoire de l'occupation humaine locale et la connaissance de l'environnement passé des montagnards.

\section{Remerciements}

Cette étude a été soutenue par l'IMEP, dans le cadre de programmes nationaux (Eclipse et, actuellement, ANR Escarsel). Je remercie tout particulièrement les propriétaires des bâtiments étudiés pour leur accueil et les autorisations de prélèvements.

\section{Bibliographie}

Allix 1929: ALLIX (A.) - Un pays de haute montagne: l'Oisans. Étude géographique. 1929, 819 p.

Arbos 1921: ARBOS (P.) - La vie pastorale dans les Alpes françaises. Étude de Géographie humaine. Thèse de Doctorat ès Lettres, Université de Grenoble. Paris, ed. A. Colin, 1921, $716 \mathrm{p}$.

Bernardi et al. 2007 : BERNARDI (P.), BOUTTICOURT (E.), ÉDOUARD (J.-L.), GUIBAL (F.) - Les charpentes de la collégiale de Briançon. In: BERNARDI (P.) dir., Forêts alpines et charpentes méditerranéennes, L'Argentière-la-Bessée, éd. du Fournel, 2007, p. 222-231.

Blanchard 1950 : BLANCHARD (R.) - Les grandes Alpes françaises du Sud. Les Alpes occidentales, t. 5, vol. 2, Grenoble, éd. Arthaud, 1950, p. 525-1018.

Büntgen et al. 2004: BUNGTEN (U.), ESPER (J.), SCHMIDHALTER (M.), FRANCK (D. C.), TREYDTE (K.); NEUWIRTH (B.), WINNIGER (M.), 2004. Using recent and historical larch wood to build a 1300-year Valais-chronology. Trace, 2, p. 85-92.

Büntgen et al. 2006: BUNGTEN (U.), BELLWALD (I.), KALBERMATTEN (H.), SCHMIDALTER (M.), FRANCK (D.C.), FREUND (H.), BELLWALD (W.), NEUWIRTH (B.), NUSSER (M.), ESPER (J.). 700 years of settlement and building history in the Lötschental, Swiztzerland, 2006.

Corona et al. 2008: CORONA (C.), GUIOT (J.), ÉDOUARD (J.-L.), CHALIE (F.), BUNTGEN (U.), NOLA (P.), URBINATI (C.) - Millennium-long summer temperature variations in the European Alps as reconstructed from tree rings, Climate of the past discussion, t. 4, 2008, p. 1 159-1 201.

Donati 1988: DONATI (P.) - Dendrochronologie et analyse monumentale. La villa di Dagro (Tessin) une recherche en cours d'évolution. Bulletin du Centre genevois d'Anthropologie, 1988, p. 83-105.

Édouard 2007: ÉDOUARD (J.-L.) - Les très vieux arbres vivants et les arbres morts, témoins et vestiges des forêts du passé dans les Alpes du Sud: lecture dendrochronologique d'un patrimoine naturel et humain. In : BERNARDI (P.) dir., Forêts alpines et charpentes méditerranéennes, L'Argentièrela-Bessée, éd. du Fournel, 2007, p. 9-16.

Édouard 2008: ÉDOUARD (J.-L.) - Données nouvelles sur l'histoire de la Chapelle Saint Hippolyte (Névache, HautesAlpes, France). Apport de la datation dendrochronologique. Revue de la Société d'Étude des Hautes-Alpes, 2008, p. 37-52.

Édouard 2008: ÉDOUARD (J.-L.) - Cernes d'arbres et chronologies holocènes dans les Alpes françaises. In : «Du climat à l'homme. Dynamique holocène de l'Environnement dans le Jura et les Alpes», Actes du Colloque GDR JURALP, Aixen-Provence, 15-16 novembre 2007. Collection EDYTEM, 6, 2008, p. 179-190. 
Esmenjaud 2004: ESMENJAUD (C.) - Étude dendrochronologique de l'habitat traditionnel de montagne (vallée de la Clarée, Briançonnais, Alpes françaises). DESS «Méthodes Scientifiques et Techniques en Archéologie», Centre des Sciences de la Terre, Université de Bourgogne, rapport de stage effectué à l'IMEP (Institut Méditerranéen d'Écologie et de Paléoécologie, Université Paul Cézanne, Marseille) sous la direction de J.L. Édouard (IMEP) et de G.N. Lambert (Laboratoire de ChronoEcologie, Université de FrancheComté, Besançon), 49 p. + annexes.

Falque-Vert 1997: FALQUE-VERT (H.) - Les hommes et la montagne en Dauphiné au XIII s., Grenoble, Presses Universitaires, 1997, $517 \mathrm{p}$.

Fray 1983 : FRAY (F.) - L'habitat traditionnel dans la vallée de la Clarée (Briançonnais). Le Monde Alpin et Rhodanien, 4bis, 1983, p. 121-163.

Guichonnet 1980 : GUICHONNET (P.) dir. - Histoire et civilisation des Alpes. Tome 2: destin humain, Paris, Ed. Privat/ Payot, 1980, 415 p.

Hoffsummer 1995: HOFFSUMMER (P.) - Les charpentes de toiture en Wallonie. Monuments et sites $n^{\circ} 1$, Études et Documents. Division du Patrimoine, Ministère de la Région Wallonie, Namur, 1995, 173 p.

Lambert 1998: Lambert (G.-N.) - La Dendrochronologie, mémoire de l'arbre. In: FERDIÈRE (A.) dir., La datation en laboratoire. Paris, éd. Errance, Coll. «Archéologiques», 1998, p. 13-69.

Lambert 2006: LAMBERT (G.-N.) - Dendrochronologie, Histoire et Archéologie, modélisation du temps. Le logiciel Dendron II et le projet Historic Oaks. Habilitation à diriger des recherches, Université de Franche-Comté, Besançon, 2006, 2 vol., 152 p. et 206 p.

Mallé 1999: MALLE (M.-P.) - L'habitat du nord des HautesAlpes. Patrimoine architectural et mobilier. Association pour le Patrimoine de Provence et la Société d'études des HautesAlpes, 1999, $437 \mathrm{p}$.
Orcel, Orcel 1992 : ORCEL (A.), ORCEL (C.) - La dendrochronologie: un potentiel de mise en valeur de notre patrimoine. L'Anthropologie, 96, 1992, p. 187-198.

Ozenda 1981: OZENDA (P.) - Végétation des Alpes SudOccidentales. Notice détaillée des feuilles $60 \mathrm{Gap}$ - 61 Larche - 67 Digne - 68 Nice - 75 Antibes, éd. du CNRS, Paris, Gap, 1981, $258 \mathrm{p}$.

Pelletier 2003: PELLETIER (O.) - Habiter la montagne: l'architecture rurale dans les Alpes occidentales. Bilan et perspectives de recherche. In: BOETSCH (G.), DEVRIENDT (W.), PIGUEL (A.) dir., Permanences et changements dans les sociétés alpines. État des lieux et perspectives de recherche, Aix-en-Provence, Edisud, 2003, p. 197-214.

Raulin 1977: RAULIN (H.) - Dauphiné. L'architecture rurale française. Musée national des arts et traditions populaires, Berger-Levraut, 1977, 277 p.

Rinn 1996: RINN (F.) - TSAP Reference Manual. Version 3.0.

Rostolland 1930: ROSTOLLAN (H.) - Névache et la vallée de la Haute-Clarée (Briançonnais), Gap, Louis Jean imprimeuréditeur, 1930, p. 51-61.

Schweingrüber 1988 : SCHWEINGRUBER (F.-H.) - Tree-rings - Basics and applications of dendrochronology, Dordrecht, Kluwer, 1988, 277 p.

Schweingrüber 1990: SCHWEINGRUBER (F.-H.) - Anatomy of European woods, Bern, WSL/FNP, Haupt, 1990, 800 p.

Sentis 1982: SENTIS (G.) - Névache et sa vallée, Grenoble, Impr. Guirimand, 1982, 79 p.

Serre 1979: SERRE (F.) - The dendroclimatological value of European larch (Larix Decidua Mill.) in the French Maritime Alps. Tree-Ring Bulletin, 38, 1979, p. 25-34.

Tessier 1986: TESSIER (L.) - Chronologie de mélèzes des Alpes et Petit Âge Glaciaire. Dendrochronologia, 4, 1986, p. 97-113. 
